\title{
Achieving the $30 \%$ Goal: Energy and Cost Savings Analysis of ASHRAE Standard 90.1-2010
}

\author{
BA Thornton MI Rosenberg EE Richman \\ W Wang Y Xie J Zhang \\ $\mathrm{H}$ Cho $\quad \mathrm{V}$ Mendon RA Athalye \\ B Liu, Project Manager
}

May 2011

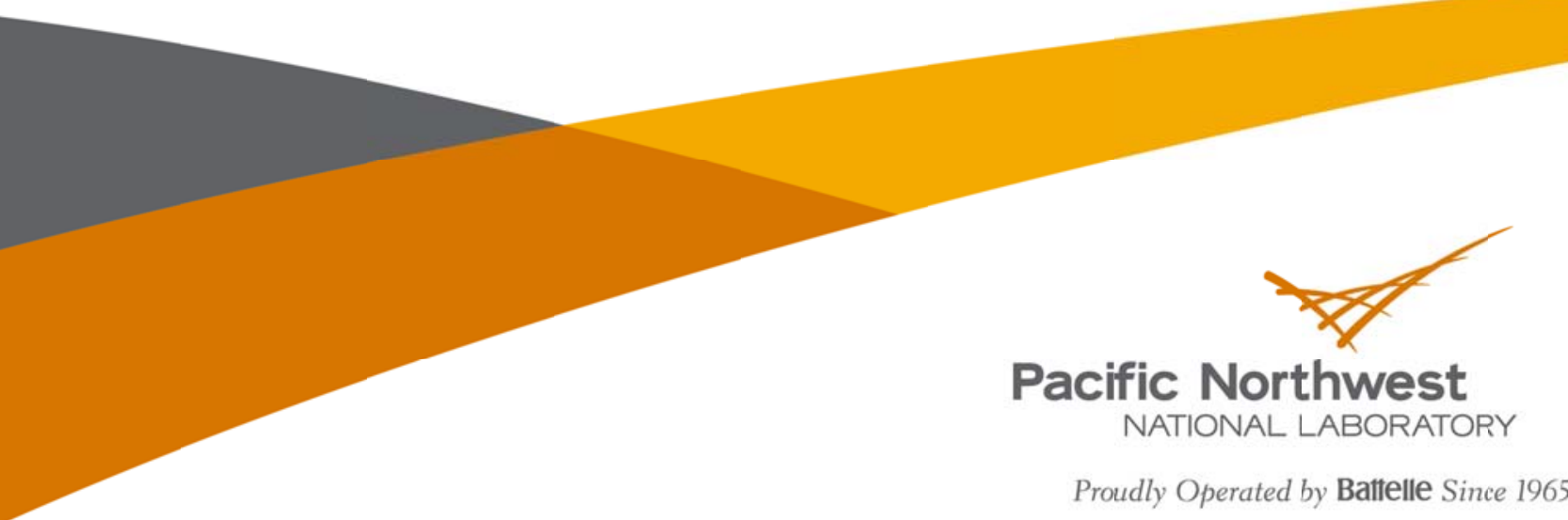




\title{
DISCLAIMER
}

This report was prepared as an account of work sponsored by an agency of the United States Government. Neither the United States Government nor any agency thereof, nor Battelle Memorial Institute, nor any of their employees, makes any warranty, express or implied, or assumes any legal liability or responsibility for the accuracy, completeness, or usefulness of any information, apparatus, product, or process disclosed, or represents that its use would not infringe privately owned rights. Reference herein to any specific commercial product, process, or service by trade name, trademark, manufacturer, or otherwise does not necessarily constitute or imply its endorsement, recommendation, or favoring by the United States Government or any agency thereof, or Battelle Memorial Institute. The views and opinions of authors expressed herein do not necessarily state or reflect those of the United States Government or any agency thereof.

\author{
PACIFIC NORTHWEST NATIONAL LABORATORY \\ operated by \\ BATTELLE \\ for the \\ UNITED STATES DEPARTMENT OF ENERGY \\ under Contract DE-AC05-76RL01830
}

Printed in the United States of America

\author{
Available to DOE and DOE contractors from the \\ Office of Scientific and Technical Information, \\ P.O. Box 62, Oak Ridge, TN 37831-0062; \\ ph: (865) 576-8401 \\ fax: (865) 576-5728 \\ email: reports@adonis.osti.gov \\ Available to the public from the National Technical Information Service, \\ U.S. Department of Commerce, 5285 Port Royal Rd., Springfield, VA 22161 \\ ph: (800) 553-6847 \\ fax: (703) 605-6900 \\ email: orders@ntis.fedworld.gov \\ online ordering: http://www.ntis.gov/ordering.htm
}

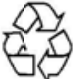

This document was printed on recycled paper

$$
\text { (9/2003) }
$$




\title{
Achieving the 30\% Goal: Energy and Cost Savings Analysis of ASHRAE Standard 90.1-2010
}

\author{
BA Thornton MI Rosenberg EE Richman \\ W Wang Y Xie J Zhang \\ H Cho VV Mendon RA Athalye \\ B Liu, Project Manager
}

May 2011

Prepared for

the U.S. Department of Energy

under Contract DE-AC05-76RL01830

Pacific Northwest National Laboratory

Richland, Washington 99352 


\section{Executive Summary}

This project was conducted by Pacific Northwest National Laboratory (PNNL) in support of the U.S. Department of Energy's (DOE's) Building Energy Codes Program (BECP). DOE's BECP supports the upgrading of the building energy codes and standards, and the states' adoption, implementation, and enforcement of those codes and standards as they are incrementally upgraded. Building energy codes and standards set minimum requirements for energy-efficient design and construction for new and renovated buildings, and impact energy use and emissions for the life of buildings. They are part of a broader set of documents which govern the design and construction of buildings for the health and life safety of occupants. Energy codes and standards set a baseline for energy efficiency in construction by establishing minimum energy-efficiency requirements. Improving these documents generates consistent and longlasting energy savings.

When the model energy codes and standards for buildings are being updated, BECP reviews the technical and economic basis of these documents. For commercial and multi-family high-rise residential buildings, which are the subject of this report, the basis for the energy codes is the ANSI/ASHRAE/IES ${ }^{1}$ Standard 90.1. The 2004, 2007, and 2010 versions of Standard 90.1 are all utilized in the analysis described in this report (ANSI/ASHRAE/IESNA 2004, 2007 and ANSI/ASHRAE/IES 2010). These standards are referred to as 90.1-2004, 90.1-2007 and 90.1-2010 respectively in this report or as Standard 90.1 when referring to multiple versions of 90.1 . For one and two family dwellings, townhouses and lowrise multi-family residential buildings, which are not the subject of this report, the relevant code is the International Energy Conservation Code (IECC).

BECP carries out the following activities:

- Recommends revisions and amendments to the model energy codes and standards during cyclical updates

- Seeks adoption of all technologically feasible and economically justified energy efficiency measures in these documents

- Participates in the processes that update and maintain these documents.

In 2007, as part of its Advanced Codes Initiative, DOE signed a memorandum of understanding (MOU) with ASHRAE to develop advanced commercial standards and included an agreement that 90.12010 would result in 30\% energy savings relative to 90.1-2004. This MOU initiated the effort by BECP and ASHRAE which culminated in the release of 90.1-2010 in October 2010. This signed MOU introduced a new element and significant challenges for developing 90.1-2010. For the first time in the history of Standard 90.1, an energy goal was established for developing the new edition, 90.1-2010. The $30 \%$ energy efficiency goal led to a dramatic increase in the level of activity and enhancement of Standard 90.1 as reflected in the quantity of changes, called addenda, proposed and approved. Prior to the development of 90.1-2010, the last three updates of Standard 90.1 to the 2001, 2004 and 2007 editions generated 34, 32 and 44 approved addenda, respectively. When 90.1-2010 was published, 109 approved addenda to 90.1-2007 were incorporated.

\footnotetext{
${ }^{1}$ ANSI - American National Standards Institute; ASHRAE - American Society of Heating, Refrigerating, and AirConditioning Engineers; IES - Illuminating Engineering Society of North America; prior to 90.1-2010, IESNA rather than IES is identified as one of the originators, IESNA is Illuminating Engineering Society of North America.
} 
PNNL was funded by DOE's BECP to provide both leadership and technical analysis support for 90.1-2010 to reach the 30\% energy savings goal. To closely measure the progress towards the goal, PNNL developed a new metric and process called the "Progress Indicator" (PI). Using the PI, PNNL periodically reported the energy and cost saving impacts for the proposed and approved changes to Standard 90.1, called addenda, to DOE and the Standing Standards Project Committee (SSPC) for 90.1 during the three-year Standard development cycle. PNNL conducted the PI with inputs from many other contributors and sources of information. In particular, guidance and direction was provided by the Simulation Working Group under the auspices of the SSPC 90.1.

This report documents the PI process and analysis that PNNL developed to evaluate the potential energy savings from the application of 90.1-2010 to building design and construction compared to the application of 90.1-2004. The report describes PNNL's EnergyPlus simulation framework, and the building prototype simulation models. The combined upgrades from 90.1-2004 to 90.1-2010 are described, and consist of a total of 153 approved addenda (44 addenda to 90.1-2007 and 109 addenda to 90.1-2010). PNNL reviewed and considered all 153 addenda for quantitative analysis in the PI process. Fifty-three of those addenda are included in the quantitative analysis. This report provides information on the categorization of all of the addenda, a summary of the content, and a more in-depth explanation of the impact and modeling of the 53 identified addenda and their quantitative savings.

The PI process was implemented using state-of-art energy simulation software-EnergyPlus - for the quantitative analysis. PNNL developed a suite of 16 prototype buildings based on DOE's Commercial Reference Building Models (Deru et al. 2011), with substantial modifications during the PI. These 16 prototype buildings represent $80 \%$ of the U.S. commercial building floor area and over $70 \%$ of the energy consumed in U.S. commercial buildings. The prototype buildings are simulated in eight climate zones that are utilized by ASHRAE for 90.1 Standard developments. The climate zones are further divided into moist and dry regions, represented by 17 climate locations, 15 of which are in the United States. Together, these provide a solid basis for reaching conclusions about the potential energy savings of applying 90.1-2010 compared to applying 90.1-2004.

The 16 prototype building models contain inputs consistent with the type of requirements in Standard 90.1. Each building prototype was first developed as a computer model in accordance with design and construction requirements found in 90.1-2004. Each building prototype was also developed as a model in accordance with the design and construction requirements of 90.1-2010. Different versions of the models were created to match the Standard 90.1 requirements that vary with climate such as wall insulation.

The set of 90.1-2004 and 90.1-2010 buildings were simulated and energy use statistics were extracted from each building model in the form of annual energy use by fuel type. The annual energy use was then converted to energy use intensity figures expressed in annual kBtu energy use per square foot of building area. Energy usage reported for the Progress Indicator was "site" energy, utility energy, electricity and natural gas, delivered and used at the site. This report also includes summary results in terms of "source" energy, energy consumed at the power plant to generate the electricity delivered to the site, and energy delivered to the site as fuel. Using weighting factors by building type and climate related geographic areas in the United States developed from five years of recent construction data, these energy use statistics were then aggregated nationally for each step in the revision of Standard 90.1 over the three year development cycle. 
Standard 90.1 regulates the elements of commercial buildings that result in most of the energy used in those buildings. Some energy usage from what are sometimes called "process loads" come from equipment that is not directly regulated by Standard 90.1, including plug-in devices such as computers and appliances, and other equipment such as gas cooking equipment. This type of equipment uses energy directly and affects HVAC energy usage indirectly by generating heat in spaces, potentially increasing cooling energy and reducing heating energy. Plug and process loads (PPL) are incorporated in the prototypes used in the modeling for the PI. Changes to Standard 90.1 do not directly affect the energy efficiency of this type of equipment. Results are presented with PPL energy usage to show the impact on total commercial building energy usage and are also presented without PPL to show the impact on just the Standard 90.1 regulated energy usage.

Table ES. 1 shows the final results of the PI. The DOE-ASHRAE goal of $30 \%$ savings for the application of 90.1-2010 compared to 90.1-2004 was achieved. The simulation results show $32.7 \%$ site energy savings and $29.5 \%$ energy cost savings, if plug and process loads are excluded in the percentage saving calculation. Including PPL in the percentage saving calculation, the site energy savings are $25.6 \%$ and energy cost savings are $23.2 \%$. National aggregated source energy savings, not shown in the table, are $23.2 \%$ with all energy uses included.

Table ES.1. Energy and Cost Savings Results for 90.1-2010 vs. 90.1-2004

\begin{tabular}{|c|c|c|}
\hline $\begin{array}{l}\text { National-weighted } \\
\text { Energy Savings }\end{array}$ & $\begin{array}{c}\text { With } \\
\text { Plug/Process Loads }\end{array}$ & $\begin{array}{c}\text { Without } \\
\text { Plug/Process Loads }\end{array}$ \\
\hline Site Energy & $25.6 \%$ & $32.7 \%$ \\
\hline Energy Cost & $23.2 \%$ & $29.5 \%$ \\
\hline
\end{tabular}

Table ES.2 and ES.3 separate the energy usage savings by prototype with and without PPL and show the percentage savings by prototype and the energy usage index in $\mathrm{kBtu} / \mathrm{ft}^{2}$ for both the $90.1-2004$ and 90.1-2010 cases. While the highest savings percentages occur in the school prototypes when PPL are not included; these percentages do not stand out as much when PPL are included. The lowest percentage savings occur in the quick-service restaurant and two apartment prototypes, particularly when PPL are included. 
Table ES.2. Energy and Energy Cost Savings with Plug and Process Loads

\begin{tabular}{|c|c|c|c|c|c|c|c|}
\hline \multirow{2}{*}{$\begin{array}{l}\text { Building } \\
\text { Type }\end{array}$} & \multirow[t]{2}{*}{ Building Prototype } & \multicolumn{2}{|c|}{$\begin{array}{l}\text { Site Energy } \\
\left(\mathbf{k B t u} / \mathbf{f t}^{2} / \mathbf{y r}\right)\end{array}$} & \multicolumn{2}{|c|}{$\begin{array}{c}\text { Energy Cost } \\
\left(\$ / \mathbf{f t}^{2}\right) \\
\end{array}$} & \multirow{2}{*}{$\begin{array}{c}\text { Site } \\
\text { Energy } \\
\text { Savings } \\
\end{array}$} & \multirow{2}{*}{$\begin{array}{c}\text { Energy } \\
\text { Cost } \\
\text { Savings } \\
\end{array}$} \\
\hline & & 90.1-2004 & 90.1-2010 & 90.1-2004 & 90.1-2010 & & \\
\hline \multirow{3}{*}{ Office } & Small office & 41.3 & 32.8 & $\$ 1.17$ & $\$ 0.93$ & $20.6 \%$ & $20.3 \%$ \\
\hline & Medium office & 51.6 & 37.3 & $\$ 1.42$ & $\$ 1.01$ & $27.7 \%$ & $29.1 \%$ \\
\hline & Large office & 46.0 & 33.4 & $\$ 1.21$ & $\$ 0.92$ & $27.5 \%$ & $24.3 \%$ \\
\hline \multirow{2}{*}{ Retail } & Stand-alone retail & 76.0 & 49.5 & $\$ 1.89$ & $\$ 1.32$ & $34.8 \%$ & $29.9 \%$ \\
\hline & Strip mall & 80.4 & 56.9 & $\$ 1.97$ & $\$ 1.42$ & $29.2 \%$ & $28.0 \%$ \\
\hline \multirow{2}{*}{ Education } & Primary school & 73.4 & 50.2 & $\$ 1.80$ & $\$ 1.33$ & $31.6 \%$ & $26.3 \%$ \\
\hline & Secondary school & 66.2 & 41.2 & $\$ 1.64$ & $\$ 1.13$ & $37.8 \%$ & $31.0 \%$ \\
\hline \multirow{2}{*}{ Health Care } & Outpatient healthcare & 163.3 & 123.6 & $\$ 4.17$ & $\$ 3.15$ & $24.3 \%$ & $24.3 \%$ \\
\hline & Hospital & 157.4 & 118.4 & $\$ 3.55$ & $\$ 2.81$ & $24.8 \%$ & $20.9 \%$ \\
\hline \multirow{2}{*}{ Lodging } & Small hotel & 78.5 & 66.6 & $\$ 1.72$ & $\$ 1.47$ & $15.2 \%$ & $14.4 \%$ \\
\hline & Large hotel & 163.9 & 125.9 & $\$ 2.99$ & $\$ 2.42$ & $23.2 \%$ & $19.0 \%$ \\
\hline Warehouse & Warehouse & 26.3 & 19.0 & $\$ 0.57$ & $\$ 0.42$ & $27.7 \%$ & $27.3 \%$ \\
\hline \multirow{2}{*}{$\begin{array}{l}\text { Food } \\
\text { Service }\end{array}$} & Quick service restaurant & 570.1 & 519.9 & $\$ 10.16$ & $\$ 9.12$ & $8.8 \%$ & $10.3 \%$ \\
\hline & Full service restaurant & 409.7 & 330.9 & $\$ 7.96$ & $\$ 6.12$ & $19.2 \%$ & $23.1 \%$ \\
\hline \multirow{2}{*}{ Apartment } & Mid-rise apartment & 47.0 & 41.2 & $\$ 1.23$ & $\$ 1.11$ & $12.3 \%$ & $9.4 \%$ \\
\hline & High-rise apartment & 48.9 & 44.0 & $\$ 1.35$ & $\$ 1.25$ & $10.1 \%$ & $7.3 \%$ \\
\hline \multicolumn{2}{|c|}{ National-weighted average } & 73.9 & 55.0 & $\$ 1.75$ & $\$ 1.35$ & $25.6 \%$ & $23.2 \%$ \\
\hline
\end{tabular}

Table ES.3. Energy and Energy Cost Savings without Plug and Process Loads

\begin{tabular}{|c|c|c|c|c|c|c|c|}
\hline \multirow{2}{*}{$\begin{array}{l}\text { Building } \\
\text { Type }\end{array}$} & \multirow{2}{*}{ Building Prototype } & \multicolumn{2}{|c|}{$\begin{array}{l}\text { Site Energy } \\
\left(\mathbf{k B t u} / \mathbf{f t}^{2} / \mathbf{y r}\right)\end{array}$} & \multicolumn{2}{|c|}{$\begin{array}{c}\text { Energy Cost } \\
\left(\$ / \mathbf{f t}^{2}\right)\end{array}$} & \multirow{2}{*}{$\begin{array}{c}\text { Site } \\
\text { Energy } \\
\text { Savings }\end{array}$} & \multirow{2}{*}{$\begin{array}{c}\text { Energy } \\
\text { Cost } \\
\text { Savings } \\
\end{array}$} \\
\hline & & 90.1-2004 & 90.1-2010 & 90.1-2004 & 90.1-2010 & & \\
\hline \multirow{3}{*}{ Office } & Small office & 32.2 & 24.4 & $\$ 0.89$ & $\$ 0.66$ & $24.4 \%$ & $26.6 \%$ \\
\hline & Medium office & 36.6 & 23.9 & $\$ 0.97$ & $\$ 0.56$ & $34.8 \%$ & $41.8 \%$ \\
\hline & Large office & 30.4 & 19.2 & $\$ 0.85$ & $\$ 0.56$ & $36.6 \%$ & $34.0 \%$ \\
\hline \multirow{2}{*}{ Retail } & Stand-alone retail & 68.5 & 42.1 & $\$ 1.66$ & $\$ 1.10$ & $38.6 \%$ & $34.0 \%$ \\
\hline & Strip mall & 75.0 & 51.5 & $\$ 1.81$ & $\$ 1.26$ & $31.3 \%$ & $30.5 \%$ \\
\hline \multirow{2}{*}{ Education } & Primary school & 52.1 & 29.3 & $\$ 1.30$ & $\$ 0.83$ & $43.8 \%$ & $35.8 \%$ \\
\hline & Secondary school & 51.8 & 27.1 & $\$ 1.28$ & $\$ 0.78$ & $47.6 \%$ & $39.2 \%$ \\
\hline \multirow{2}{*}{ Health Care } & Outpatient healthcare & 116.0 & 77.2 & $\$ 2.88$ & $\$ 1.86$ & $33.5 \%$ & $35.3 \%$ \\
\hline & Hospital & 107.9 & 69.4 & $\$ 2.69$ & $\$ 1.96$ & $35.6 \%$ & $27.2 \%$ \\
\hline \multirow{2}{*}{ Lodging } & Small hotel & 56.1 & 44.4 & $\$ 1.32$ & $\$ 1.07$ & $20.8 \%$ & $18.7 \%$ \\
\hline & Large hotel & 128.5 & 90.9 & $\$ 2.57$ & $\$ 2.01$ & $29.2 \%$ & $21.9 \%$ \\
\hline Warehouse & Warehouse & 23.7 & 16.5 & $\$ 0.49$ & $\$ 0.34$ & $30.3 \%$ & $31.5 \%$ \\
\hline \multirow{2}{*}{$\begin{array}{l}\text { Food } \\
\text { Service }\end{array}$} & $\begin{array}{l}\text { Quick service } \\
\text { restaurant }\end{array}$ & 300.6 & 250.6 & $\$ 7.50$ & $\$ 6.46$ & $16.6 \%$ & $13.9 \%$ \\
\hline & Full service restaurant & 256.3 & 178.1 & $\$ 5.78$ & $\$ 3.94$ & $30.5 \%$ & $31.8 \%$ \\
\hline \multirow{2}{*}{ Apartment } & Mid-rise apartment & 32.4 & 26.8 & $\$ 0.79$ & $\$ 0.67$ & $17.3 \%$ & $14.7 \%$ \\
\hline & High-rise apartment & 35.7 & 31.0 & $\$ 0.95$ & $\$ 0.86$ & $13.2 \%$ & $9.8 \%$ \\
\hline \multicolumn{2}{|c|}{ National-weighted average } & 56.8 & 38.2 & $\$ 1.37$ & $\$ 0.96$ & $32.7 \%$ & $29.5 \%$ \\
\hline
\end{tabular}




\section{Acknowledgments}

This document was prepared by Pacific Northwest National Laboratory (PNNL) for the U.S. Department of Energy's (DOE's) Building Energy Codes Program. The authors would like to thank Mr. Ron Majette, DOE's Project Manager of Codes and Standards under the Building Energy Codes Program, for his dedicated support and thoughtful guidance during the three-year project life.

The authors would like to thank the members of the ASHRAE Standing Standards Project Committee (SSPC) for 90.1 for their tremendous volunteer efforts and insightful inputs and reviews of our energy analysis work during the development of the prototype models and quantification analysis of over 100 addenda. We especially want to express our appreciation of the 90.1 Simulation Working Group. This working group was charged to by the SSPC 90.1 to support PNNL's simulation analysis during the development of 90.1-2010. In addition to the SSPC 90.1 full committee's and subcommittees' meetings, this working group met three times in person and hosted countless conference meetings to establish the ground rules and provided insightful key information that contributed significantly for this analysis. The members of this working group include Ron Jarnagin, Drake Erbe, Dick Lord, Susanna Hanson, Bing Liu, Merle McBride, John Hogan, and Martha VanGeem.

The authors also would like to recognize Diana Shankle, the Program Manager who oversees the BECP Program at PNNL, for her strong support of this project. The authors greatly appreciate the assistance of Todd Taylor, Dr. Yulong Xie, and Hung Ngo at PNNL. They constructed the cluster simulation structure in EnergyPlus, which allowed us to evaluate the many variations of energy efficiency technologies in a timely fashion to meet the project's compressed schedule. Mark Halverson and Dave Conover at PNNL provided very detailed reviews on this report. Krishnan Gowri and Yunzhi Huang also contributed significantly at the early stage of this project. Mike Parker at PNNL provided the editorial and document production reviews for the report.

This project was a true team effort and the authors would like to express their deep appreciation to everyone who contributed to the completion of this work.

Bing Liu, P.E.

Project Manager

Pacific Northwest National Laboratory 



\section{Acronyms and Abbreviations}

$\mathrm{ACH}$

AEDG

AFUE

AHU

AIA

ANSI

ARI

ASHRAE

ASTM

BECP

C-factor

CAV

CBECS

CDD

CFM

CHW

COP

CPU

CTI

CQA

DCV

DOAS

DOE

DX

$\mathrm{E}_{\mathrm{c}}$

EER

EIA

EIR

EPA

ERV

$\mathrm{E}_{\mathrm{t}}$

EUI

F-factor

FCU

FF

FLP air changes per hour

Advanced Energy Design Guide

annual fuel utilization efficiency

air handling unit

American Institute of Architects

American National Standards Institute

Air-conditioning and Refrigeration Institute

American Society of Heating, Refrigerating and Air-Conditioning Engineers

American Society for Testing Materials

Building Energy Codes Program

thermal conductance

constant air volume

Commercial Buildings Energy Consumption Survey

cooling degree day

cubic feet per minute

chilled water

coefficient of performance

central processing unit

Cooling Technology Institute

construction quality adjustment

demand controlled ventilation

dedicated outdoor air system

Department of Energy (United States)

direct expansion

combustion efficiency

energy efficiency ratio

Energy Information Administration

energy input ratio

Environmental Protection Agency

energy recovery ventilator

thermal efficiency

energy use intensity

heat transfer coefficient of a slab edge unit of perimeter length

fan coil units

flow fraction

full load power 


\begin{tabular}{|c|c|}
\hline FLR & floor \\
\hline FPLR & function of part load ratio \\
\hline FT & function of temperature \\
\hline GPARM & General PARaMetrics \\
\hline gtp & ground temperature profiles \\
\hline HDD & heating degree day \\
\hline HSPF & heating seasonal performance factor \\
\hline HVAC & heating, ventilation, and air conditioning \\
\hline idd & Energy Plus input data dictionary \\
\hline IECC & International Energy Conservation Code \\
\hline IEER & integrated energy efficiency ratio \\
\hline IES & Illuminating Engineering Society \\
\hline IESNA & Illuminating Engineering Society of North America \\
\hline idf & Energy Plus input file \\
\hline IPLV & integrated part load value \\
\hline kVA & kilo volt amperes \\
\hline LBNL & Lawrence Berkeley National Laboratory \\
\hline LL & load losses \\
\hline LPD & lighting power density \\
\hline $\mathrm{MHC}$ & McGraw-Hill Construction \\
\hline MOU & memorandum of understanding \\
\hline $\mathrm{mph}$ & miles per hour \\
\hline NBI & New Buildings Institute \\
\hline $\mathrm{NC}^{3}$ & National Commercial Construction Characteristics \\
\hline NFRC & National Fenestration Rating Council \\
\hline NLL & no load losses \\
\hline NREL & National Renewable Energy Laboratory \\
\hline $\mathrm{OA}$ & outdoor air \\
\hline PI & Progress Indicator \\
\hline PLF & part-load fraction \\
\hline PNNL & Pacific Northwest National Laboratory \\
\hline PPL & plug and process loads \\
\hline PSZ-AC & packaged single zone air conditioner \\
\hline PTAC & packaged terminal air conditioner \\
\hline PTHP & packaged terminal heat pump \\
\hline $\mathrm{RCR}$ & room cavity ratio \\
\hline SA & supply air \\
\hline SEER & seasonal energy efficiency ratio \\
\hline
\end{tabular}


SHGC

SSPC

SRI

SWG

TSP

U-factor

USACE

USGBC

VAV

VFD

VLT

VRF

VRP

$\mathrm{W}$

w.c.

WSHP

WWR solar heat gain coefficient

Standing Standard Project Committee

solar reflectance index

Simulation Working Group

total static pressure

thermal transmittance

United States Army Corps of Engineers

US Green Building Council

variable air volume

variable frequency drive

visible light transmittance

variable refrigerant flow

ventilation rate procedure

Watt

water column

water source heat pump

window-to-wall ratio 



\section{Contents}

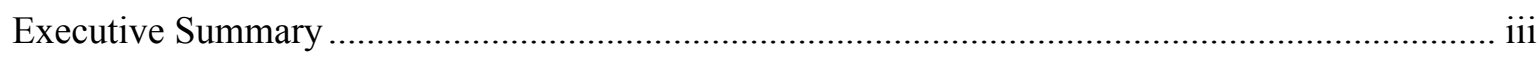

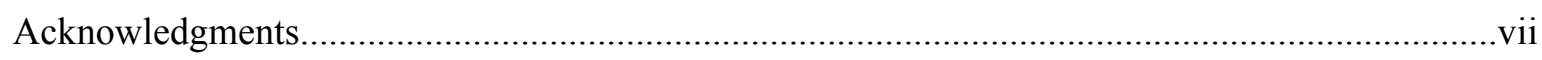

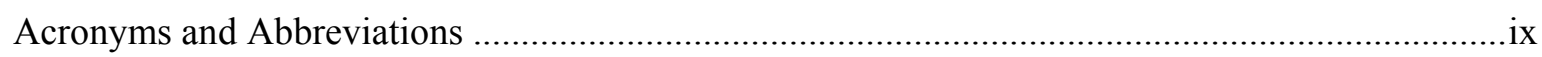

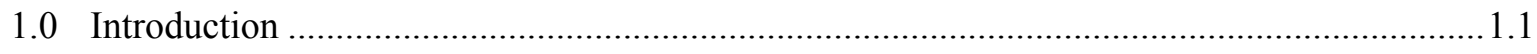

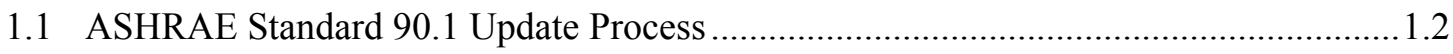

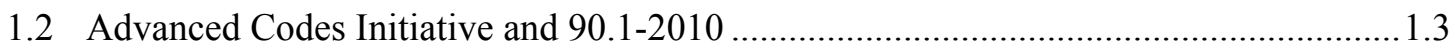

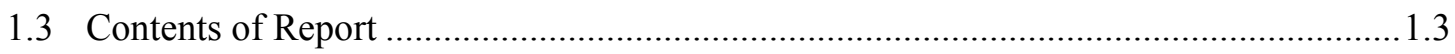

2.0 Progress Indicator Process and Methodology................................................................... 2.1

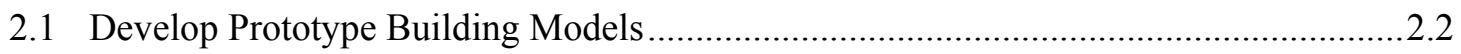

2.2 Generate Minimally Standard Compliant Models........................................................2.4

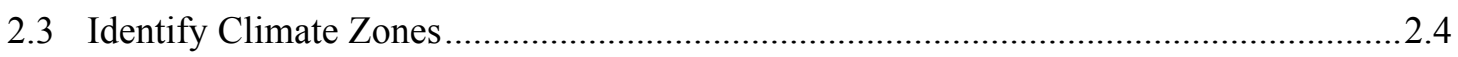

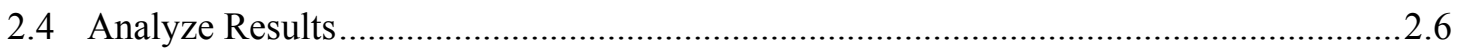

2.4.1 New Building Construction Weighting Factors …............................................2.6

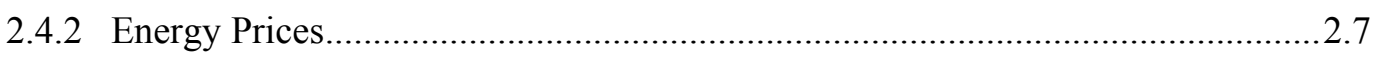

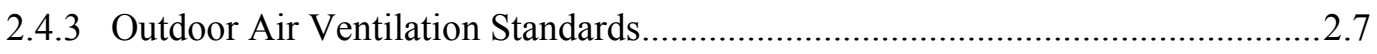

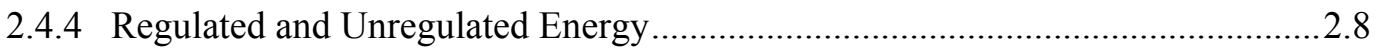

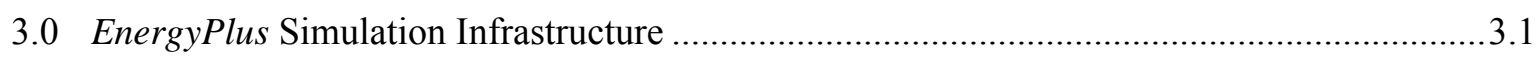

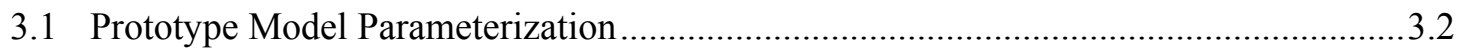

3.2 Automation of the EnergyPlus Input File Creation....................................................... 3.2

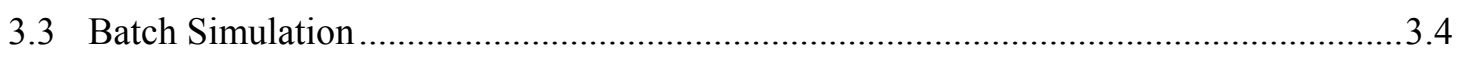

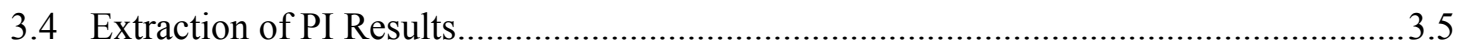

3.5 Maintenance for New Versions of EnergyPlus ............................................................. 3.5

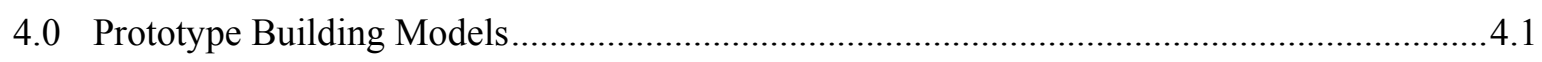

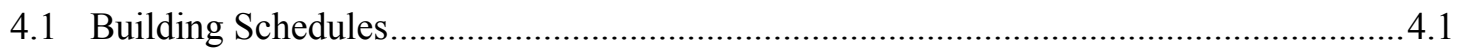

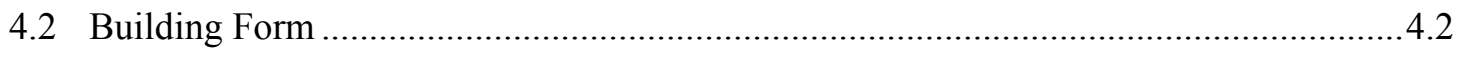

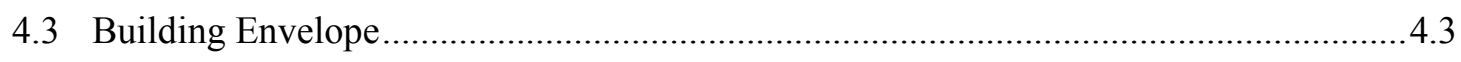

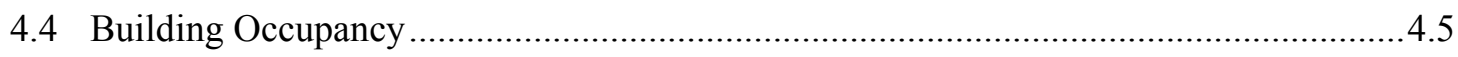

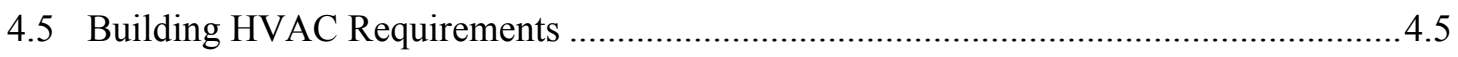

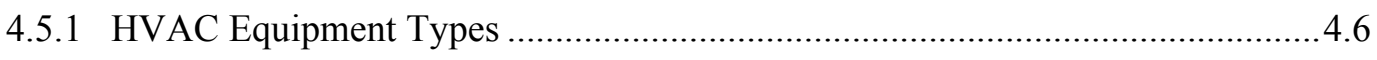

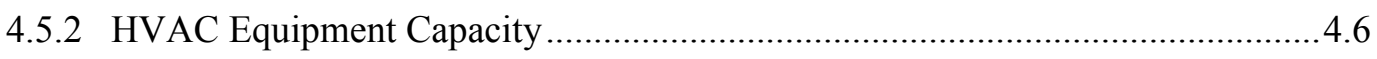

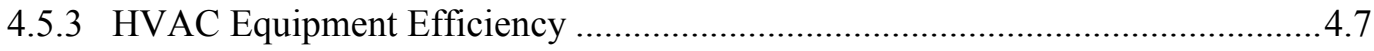

4.5.4 HVAC System Fan Power.............................................................................. 4.10

4.5.5 Outdoor Air Ventilation ........................................................................... 4.11

4.6 Service Water Heating Equipment ......................................................................13

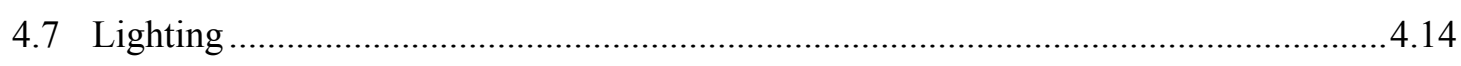

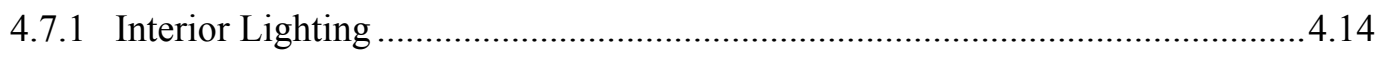




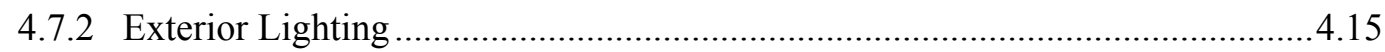

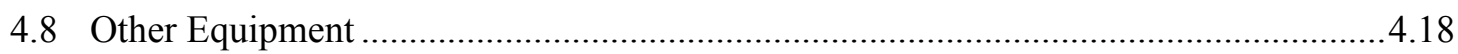

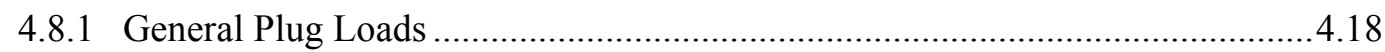

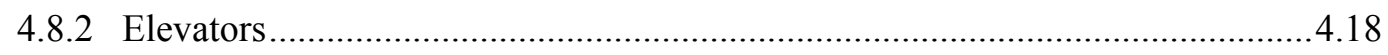

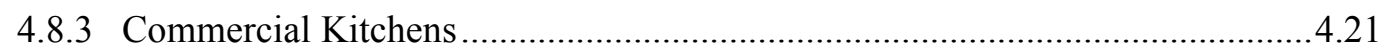

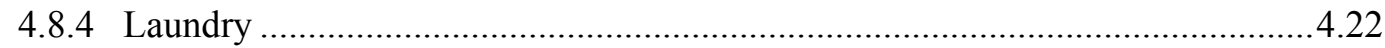

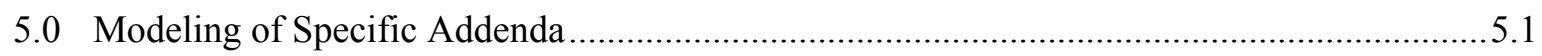

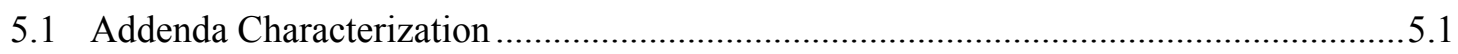

5.2 Addenda Implementation in Savings Analysis .........................................................18

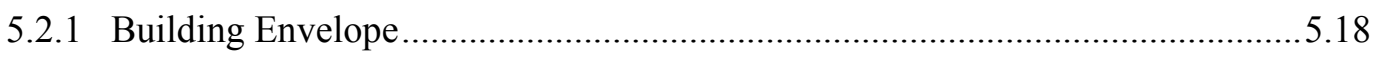

5.2.2 Heating, Ventilating and Air Conditioning ..................................................5.28

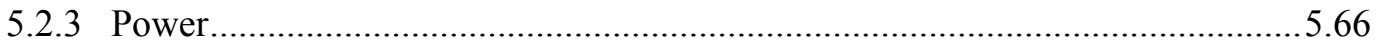

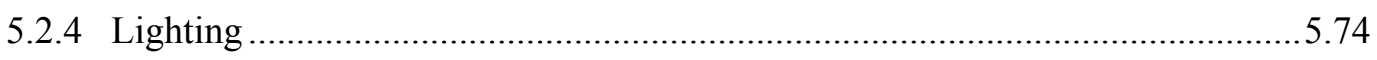

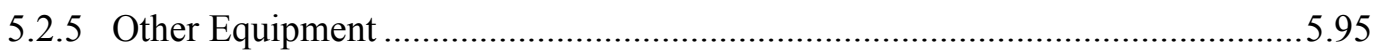

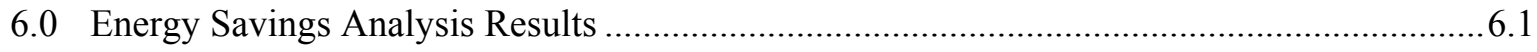

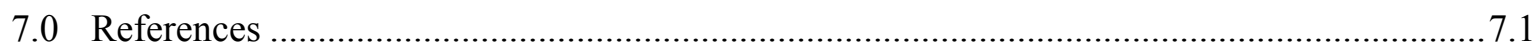

Appendix A Energy Modeling Building Descriptions ............................................................... 1

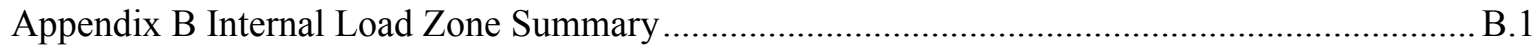

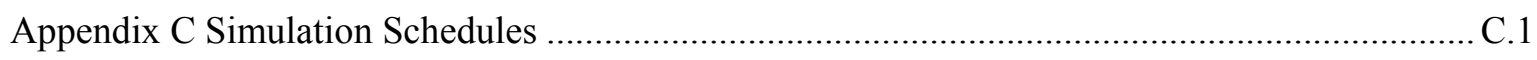

Appendix D Prototype Building HVAC System List ............................................................ D. 1

Appendix E Building Envelope Requirements ....................................................................... E.1

Appendix F 90.1-2010 Energy Savings Results by End-Uses ..................................................... 1

\section{Figures}

Figure 1.1. ANSI Consensus Standards Development Process .................................................. 1.2

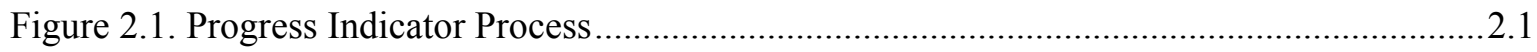

Figure 2.2. CBECS 2003 Energy Consumption by Principal Building Activity ...........................2.3

Figure 2.3. DOE-Developed Climate Zone Map .......................................................................2.5

Figure 3.1. Flow Diagram of PI Simulation Framework ........................................................... 3.3

Figure 4.1. 3D Rendering of Prototype Building Models ......................................................... 4.2

Figure 5.1. Addenda by Category and Quantity ......................................................................... 5.1

Figure 5.2. Single-maximum Terminal Box Control Sequence .................................................5.41

Figure 5.3. Dual-maximum Terminal Box Control Sequence ...................................................5.41

Figure 5.4. Baseline and Addendum 90.1-07o Transformer Efficiency Comparison....................5.68

Figure 5.5. Transformer Loss Curves as a Function of Part Load ...............................................5.71

Figure 6.1. Energy Savings with Plug and Process Loads in the Percentage Calculations..............6.2

Figure 6.2. Energy Savings without Plug and Process Loads in the Percentage Calculations ........6.3 


\section{Tables}

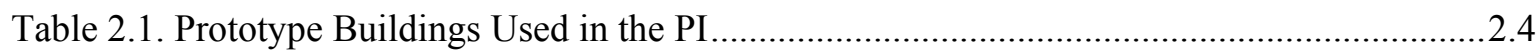

Table 2.2. MHC Data by Building Type.................................................................................2.

Table 2.3. Construction Area Weights by Building Prototype and Climate Zone.........................2.9

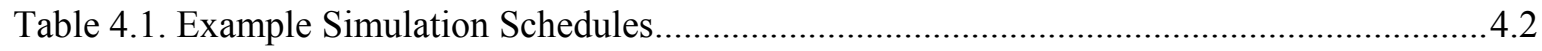

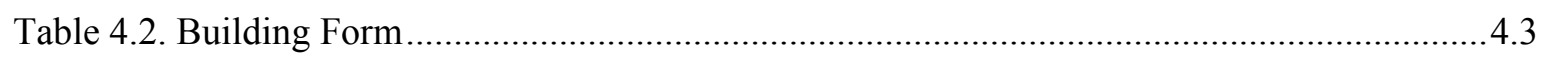

Table 4.3. Roof and Wall Construction Types..........................................................................4.4

Table 4.4. Fenestration Type Weighting Factors ...................................................................... 4.4

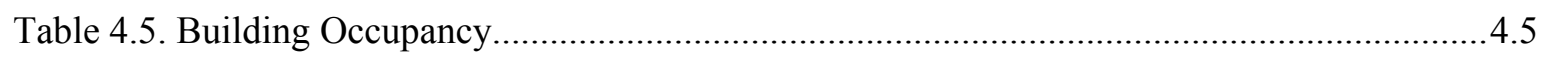

Table 4.6. HVAC Primary and Secondary Equipment .................................................................

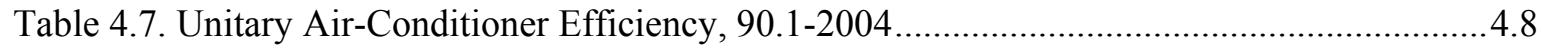

Table 4.8. Unitary Air-Cooled Heat Pump Efficiency, 90.1-2004 _..............................................4.8

Table 4.9. Water Chilling Package Efficiency, 90.1-2004 ....................................................... 4.9

Table 4.10. PTAC and Heat Pump Efficiency, 90.1-2004 .......................................................... 4.9

Table 4.11. Warm Air Furnace Efficiency, 90.1-2004 ............................................................... 4.9

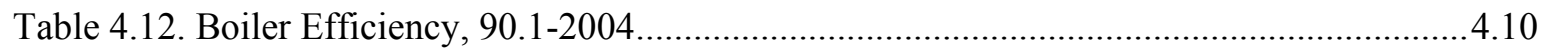

Table 4.13. Heat Rejection Equipment Performance, 90.1-2004 ............................................. 4.10

Table 4.14. Prototypes Outdoor Air Ventilation ............................................................................ 4.13

Table 4.15. Service Water Heating Equipment.........................................................................14

Table 4.16. Secondary School Example of LPD Inputs Development ........................................4.15

Table 4.17. Illuminated Parking Area ........................................................................................4.16

Table 4.18. Number of Doors by Door Type ..............................................................................16

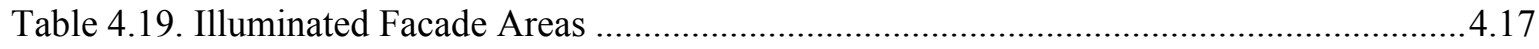

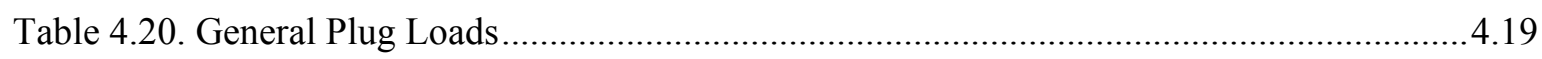

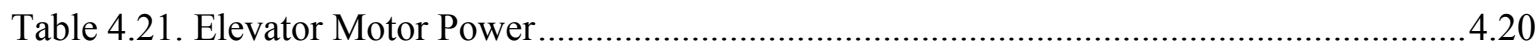

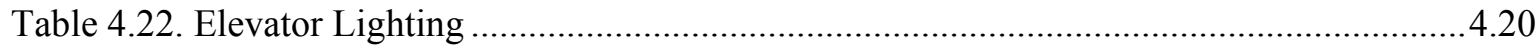

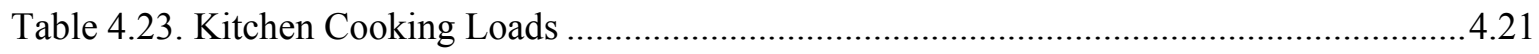

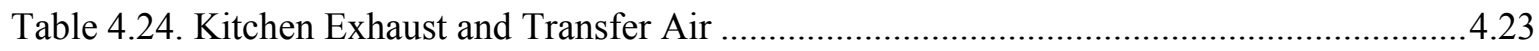

Table 4.25. Refrigeration - Walk-in Coolers and Freezers .......................................................23

Table 5.1. Addenda with Quantified Savings in PI.......................................................................5.3

Table 5.2. Addenda with Potential Energy Savings but Not Quantified in PI.............................5.13

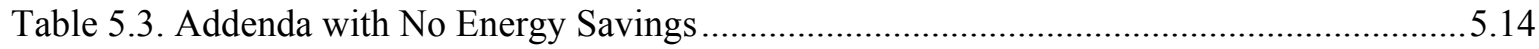

Table 5.4. 90.1-2004 Vestibule Requirements............................................................................20

Table 5.5. 90.1-2007 Vestibule Requirements (with addendum 90.1-04c) ................................5.20

Table 5.6. 90.1-2010 Vestibule Requirements (with addendum 90.1-07q) ................................5.21

Table 5.7. Envelope Component Infiltration Rates...................................................................25

Table 5.8. Unitary HVAC Equipment Efficiency $(<65,000 \mathrm{Btu} / \mathrm{h})$............................................28 


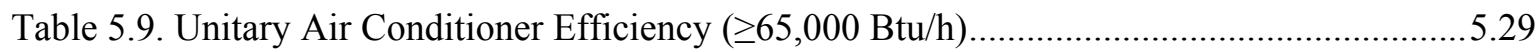

Table 5.10. Unitary Heat Pump Efficiency $(\geq 65,000$ Btu/h) .....................................................5.29

Table 5.11. Rules for Establishing Fan Power Inputs for PI Analysis........................................5.33

Table 5.12. Boiler Efficiency Used in PI Analysis ....................................................................5.34

Table 5.13. Quantity of Unit Heaters in Warehouse Prototype ..................................................5.35

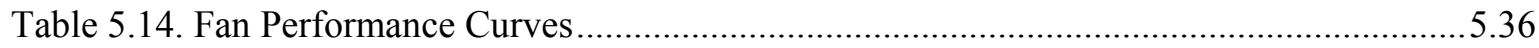

Table 5.15. Energy Recovery Requirements by Climate Zone and Outdoor Air Fraction ............5.36

Table 5.16. HVAC Systems Required to Have Energy Recovery ..............................................5.38

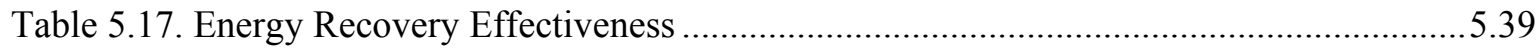

Table 5.18. 90.1-2004 and 90.1-2010 Chiller Efficiencies .........................................................42

Table 5.19. HVAC Systems Subject to Single Zone VAV Requirement ....................................5.45

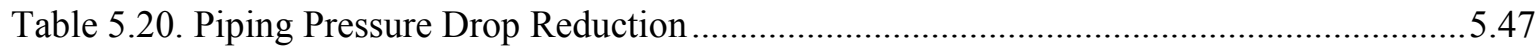

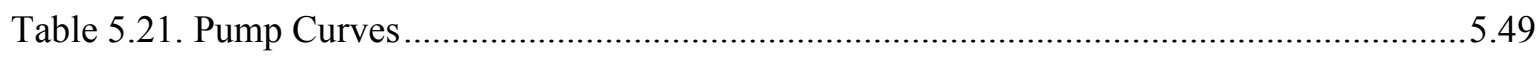

Table 5.22. Hospital Prototype Critical Space Airflow Requirements .......................................5.50

Table 5.23. Outpatient Healthcare Prototype Critical Space Airflow Requirements....................5.51

Table 5.24. Application of Addendum 90.1-07ax to Prototypes .................................................5.53

Table 5.25. PTACs and PTHPs Efficiency, 90.1-2010 …........................................................5.55

Table 5.26. Example PTAC/PTHP Fan Power Calculation........................................................5.55

Table 5.27. Applicability of Addendum 90.-07ck to Prototypes ................................................5.59

Table 5.28. Applicability of Addendum 90.1-07cy by Prototype and Climate Zone ...................5.66

Table 5.29. Low Voltage Dry-Type Transformer Efficiency Requirements ...............................5.67

Table 5.30. Reference Transformer Losses ................................................................................5.70

Table 5.31. Transformer Loss as a Function of Part Load Ratio ................................................5.70

Table 5.32. Open and Private Office Area as Percentage of Total Building Area.......................5.72

Table 5.33. Savings from Occupancy Sensors During Occupied hours .....................................5.72

Table 5.34. Plug Load Equipment Breakdown for Small Office Prototype ................................5.73

Table 5.35. Primary School Prototype Example of Receptacle Control Schedule Reduction.......5.73

Table 5.36. Skylight Fenestration Areas and Daylit Areas in Prototype Buildings......................5.76

Table 5.37. Automatic Daylighting Controls for Toplit Spaces in Standard 90.1 Prototypes .......5.76

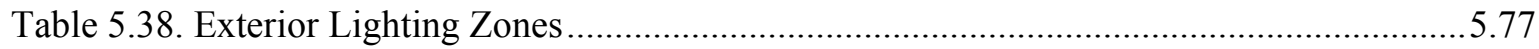

Table 5.39. Exterior Lighting Power Allowances....................................................................5.79

Table 5.40. Building Prototype Exterior Zone Assignment......................................................5.81

Table 5.41. Exterior Lighting Savings Summary for Addendum 90.1-07i.................................5.81

Table 5.42. Large Hotel Example of Percentage of Building Area by Space Type......................5.83

Table 5.43. Occupancy Sensor Control Lighting Reduction by Space Type................................5.84

Table 5.44. Summary of Addendum 90.1-07x Lighting Power Reductions by Prototype ............5.84

Table 5.45. Manual-On Occupancy Sensor Lighting Power Reduction ......................................5.85

Table 5.46. Adjusted Display Lighting Allowance for Strip Malls ...........................................5.87

Table 5.47. Lobby Lighting Reduction for Selected Zones by Prototype.....................................5.89 
Table 5.48. Large Office Example of Facade Lighting Reduction for Controls...........................5.90

Table 5.49. LPD Reduction for Stairwell Occupancy Sensor Controls ......................................5.91

Table 5.50. Sidelighting Analysis and Implementation .........................................................5.93

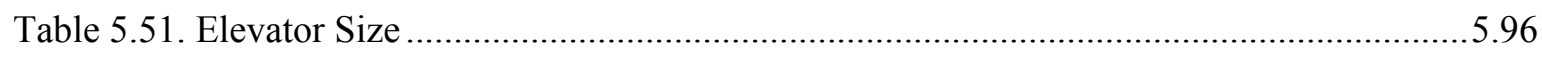

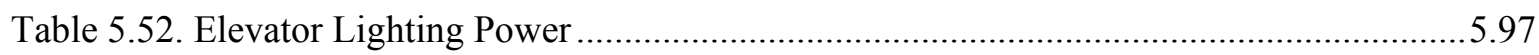

Table 5.53. Elevator Cab Ventilation Fan Power ......................................................................5.97

Table 6.1. 90.1 -2010 vs. 90.1-2004 Site Energy Savings Results .................................................. 6.1

Table 6.2. Energy and Energy Cost Savings with Plug and Process Loads...................................6.3

Table 6.3. Energy and Energy Cost Savings without Plug and Process Loads..............................6.4

Table 6.4. EUI and Energy Savings by Climate Zones................................................................ 6.4

Table 6.5. EUI by Prototype and Energy Usage Category ........................................................ 6.5 


\subsection{Introduction}

This project was conducted by Pacific Northwest National Laboratory (PNNL) in support of the U.S. Department of Energy's (DOE) Building Energy Codes Program (BECP). BECP was founded in 1993 in response to the Energy Policy Act of 1992, which mandated that DOE participate in the development process for national model codes and standards and that DOE help states adopt and implement progressive energy codes. DOE has been supporting the development and implementation of more stringent building energy codes and standards since the 1970's, but the formation of the BECP was the first time a DOE organization was assigned energy codes and standards as the focus with specific mandates.

BECP supports the incremental upgrading of the model energy codes and energy standards, and the states' adoption, implementation, and enforcement of those documents as they are upgraded. Building energy codes and energy standards set baseline minimum requirements for energy-efficient design and construction for new and renovated buildings and impact energy use and emissions for the life of the buildings. The energy codes and standards are part of the overall documents which govern the design and construction of buildings for the health and life safety of occupants. Improving these documents generates consistent and long-lasting energy savings.

When the model building energy codes and standards are being updated, BECP reviews the technical and economic basis of those documents. For commercial and multi-family high-rise residential buildings, which are the subject of this report, the basis for the energy codes is ANSI/ASHRAE/IES Standard 90.1 ${ }^{1}$. The 2004, 2007, and 2010 versions of Standard 90.1 are all utilized in the analysis described in this report (ANSI/ASHRAE/IESNA 2004, 2007 and ANSI/ASHRAE/IES 2010). These standards are referred to in this report as 90.1-2004, 90.1-2007 and 90.1-2010 respectively, or as Standard 90.1 when referring to multiple versions of 90.1. The references for the standards are implied and are not shown with each mention of Standard 90.1. For residential low-rise buildings, which are not the focus of this report, the relevant code is the International Energy Conservation Code (IECC).

BECP carries out the following activities:

- Recommends revisions amendments to the model energy codes and standards during cyclical updates

- Seeks adoption of all technologically feasible and economically justified energy efficiency measures in these documents

- Participates in the processes that update and maintain these documents.

As one of DOE's national laboratories, PNNL has played a major role in supporting DOE's BECP since its inception in 1993. PNNL is closely involved in the upgrading of the model codes and standards. Specifically, PNNL provides significant assistance to the ASHRAE Standing Standard Project Committee (SSPC) for 90.1 (SSPC 90.1). That assistance ranges from providing leadership and voting members to development committees to developing change proposals (called addenda) for standards and codes.

\footnotetext{
${ }^{1}$ ANSI - American National Standards Institute; ASHRAE - American Society of Heating, Refrigerating, and AirConditioning Engineers; IES - Illuminating Engineering Society; prior to 90.1-2010, IESNA rather than IES is identified as one of the originators, IESNA is Illuminating Engineering Society of North America.
} 
PNNL also conducts analyses and supports DOE's determinations which are published in the Federal Register. Determinations confirm whether or not each new edition of the model codes or standards will improve the energy efficiency of buildings. ${ }^{1}$

Throughout this report, each addendum to Standard 90.1 is named according to a convention that begins with 90.1, followed by a hyphen, then the last two digits of the year version of Standard 90.1 that the addendum applies to, and finally the letter name of the addendum. For example, addendum c to 90.12004 is identified as addendum 90.1-04c and addendum q to 90.1-2007 is referred to as addendum 90.1$07 \mathrm{q}$.

The rest of this chapter describes ASHRAE's process for updating Standards, in particular Standard 90.1 , and provides an overview of the contents of this report.

\subsection{ASHRAE Standard 90.1 Update Process}

In 1999, the ASHRAE Board of Directors voted to place Standard 90.1 in a continuous maintenance process. With the publication of 90.1-2001, ASHRAE began publishing new building energy standards in its entirety on a three-year cycle, with ASHRAE issuing versions of Standard 90.1 in 2004, 2007, 2010, and planning for a new version in 2013. This cycle allowed users to know when new editions would be published. Each new edition contained any errata, as well as all new addenda. The new addenda are processed through the continuous maintenance process rules approved by ANSI. Figure 1.1 illustrates ANSI consensus standards development process.

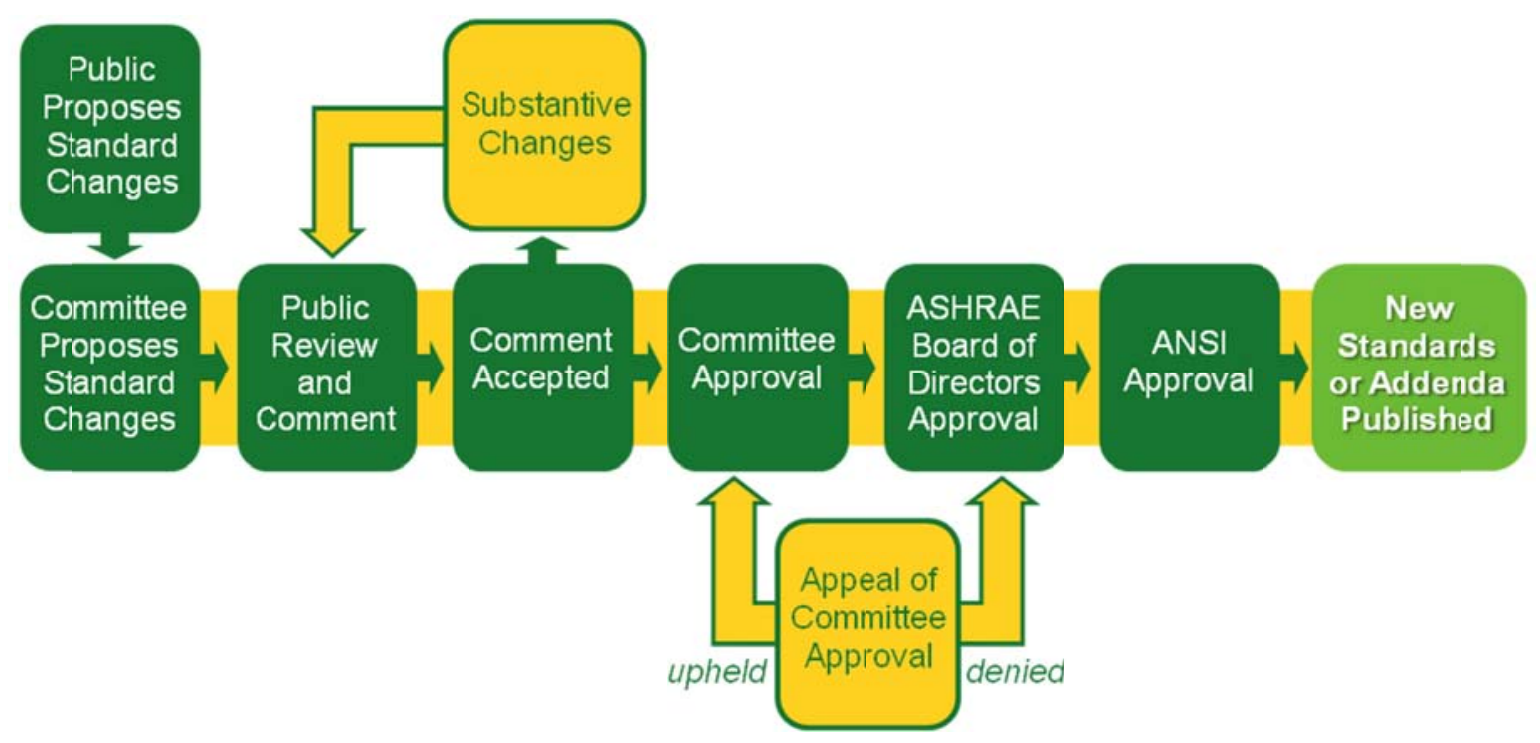

Figure 1.1. ANSI Consensus Standards Development Process

\footnotetext{
${ }^{1}$ For DOE's commercial code determination, see DOE's Energy Codes web site at http://www.energycodes.gov/status/all about determinations.stm.
} 


\subsection{Advanced Codes Initiative and 90.1-2010}

In 2007, as part of its Advanced Codes Initiative, DOE signed a memorandum of understanding (MOU) with ASHRAE to develop advanced commercial building standards and codes, with the first step being a commitment that 90.1-2010 would lead to 30\% energy savings compared to 90.1-2004. This MOU initiated the current efforts by BECP and ASHRAE, which culminated in 2010 with the release of 90.1-2010. The Advanced Codes Initiative also called for the development of advanced residential standards and codes (not addressed further in this report), with the first commitment that the 2012 IECC would be $30 \%$ better than the 2006 IECC.

This signed MOU introduced a new element and significant challenges for developing 90.1-2010. The $30 \%$ energy savings goal led to a dramatic increase in the level of activity and enhancement of Standard 90.1. For the first time in the history of Standard 90.1, an energy goal was set for developing the new edition of the standard. Prior to the development of 90.1-2010, the last three updates of Standard 90.1 to 2001, 2004 and 2007 editions generated 34, 32 and 44 approved addenda, respectively. By the time 90.12010 was published in October 2010, 109 addenda to 90.1-2007 were approved and incorporated in the new version.

PNNL was funded by DOE to provide both leadership and technical analysis support for 90.1-2010 to reach the $30 \%$ energy savings goal. To closely measure the progress towards the goal, PNNL developed a new metric and process named the "Progress Indicator" (PI). The PI is a process to measure progress toward the 30\% improvement goal by 90.1-2010 relative to the baseline 90.1-2004. Using the PI, PNNL periodically reported the energy and cost saving impacts for the approved addenda to DOE and the SSPC 90.1 during the three-year Standard development cycle. PNNL conducted this analysis with inputs from many other contributors and sources of information. In particular, guidance and direction were provided by the Simulation Working Group (SWG) under the auspices of the SSPC 90.1.

\subsection{Contents of Report}

This report documents the approach and methodologies that PNNL developed to evaluate the energy savings achievable from use of 90.1-2010. The evaluation was carried out using computer simulations of 16 prototype buildings representing $80 \%$ of U.S. commercial building floor area. These 16 prototype buildings were constructed to fit the framework of the 90.1 Standard across a range of U.S. climates. Each building prototype used in the simulation analysis was first developed as a computer model in accordance with design and construction requirements found in 90.1-2004. Building models were also developed to reflect buildings designed and constructed under the requirements of 90.1-2010. The sets of 90.1-2004 and 90.1-2010 buildings were simulated and energy use statistics were extracted from each building model in the form of annual energy use by fuel type. The annual energy use was then converted to energy use intensity (EUI) figures expressed in energy use per square foot per year $\left(\mathrm{kBtu} / \mathrm{ft}^{2}\right)$. Using weighting factors by building type and geographic area developed from five years of recent construction data, these energy use statistics were then aggregated to national results for each revision of Standard 90.1. Chapters 2, 3, and 4 in this report detail PNNL's PI process and methodology, EnergyPlus simulation framework, and prototype model descriptions, respectively.

This report covers the combined upgrades from 90.1-2004 to 90.1-2010, a total of 153 addenda. As these addenda were developed, PNNL went through a screening process. This screening focused on the 
118 addenda that affect the mandatory and prescriptive requirements in Chapters 5 through 10 of Standard 90.1. Other addenda affected only items in areas such as definitions, normative references, the Energy Cost Budget Method, and the Appendix G performance rating method. The screening of the addenda, called addenda characterization, determined if the addenda provide savings relative to the earlier standard. If so, further evaluation determined if those savings could be captured in the quantitative analysis. Some addenda are believed to contribute savings but could not be quantified in some cases because the type of building component is not included in the building prototypes modeled and in other cases because of excessive obstacles to simulation in EnergyPlus. Of the 118 addenda that affect Standard 90.1 Chapters 5 through 10, 53 are expected to result in energy savings that are quantified in the PI; 19 would likely result in energy savings but are not quantified; the remaining 46 addenda were not identified with potential energy savings. Chapter 5 in this report includes a full listing of the addenda by these categories.

The 53 addenda with quantifiable savings were evaluated through the effort outlined in Chapter 2 in this report. Energy savings were evaluated for site energy use and corresponding energy cost. Site energy refers to the utility electricity and natural gas delivered and used at the building site. Energy cost savings are based on national average energy costs applied to the site energy usage results. Finally, energy savings were separated out into energy uses regulated by Standard 90.1 excluding plug and process loads and for all energy usage including plug and process loads. Energy usage and cost were aggregated using weighting factors based on the area of new building construction of the types of buildings included in the prototypes and based on climates locations modeled in the analysis. Source energy is also reported and is the energy used in generating the electricity used at the site and energy of fuel delivered to the site, such as natural gas. The results are provided in Chapter 6 of this report.

The report has six appendixes. Appendix A includes prototype building descriptions. Appendix B lists the internal loads for each thermal zone in all prototypes. Appendix $\mathrm{C}$ includes schedules used to model time of day variation of building operations. Appendix D lists the system name and type used in EnergyPlus models for all 16 prototype buildings. Appendix E includes the building envelope prescriptive values from 90.1 -2004 and 90.1-2010. Appendix F presents energy savings results by end uses. 


\subsection{Progress Indicator Process and Methodology}

PNNL provided technical support during the development of 90.1-2010. The PI incorporated quantitative assessment of the changes between 90.1-2004 and 90.1-2010 that were identified as measurable using the simulation procedure. The process included addenda to 90.1-2004 that led to 90.12007 as well as addenda to 90.1-2007 that are now rolled into 90.1-2010.

A Simulation Working Group (SWG) was formed to guide the simulation effort conducted by PNNL. The SWG represented the SSPC 90.1 and its subcommittees, such as the Mechanical and Envelope Subcommittees. The SWG reviewed key building modeling inputs and assumptions and the energy savings results. The SWG also established the ground rules for modeling. Key guidelines developed with the SWG included the following:

- Comparison of the different versions of Standard 90.1 on a book-by-book basis, following the changes in the texts

- Prototype buildings to cover $80 \%$ of U.S. commercial building stock

- Prototype buildings to capture a reasonable level of accuracy with a reasonable level of effort

- Whole building energy usage in the models, including regulated and unregulated loads. This usage includes exterior lighting, plug loads (receptacle loads), cooking appliances, refrigeration equipment, elevators, and transformers.

PNNL updated the PI and reported to the SWG and the SSPC 90.1 at each of their quarterly meetings. PNNL also provided support to the SSPC 90.1 subcommittees such as the Envelope and Mechanical Subcommittees to evaluate new proposals being turned into addenda and provided load profile spreadsheet tools to the SSPC 90.1 Mechanical Subcommittee members. The load profile spreadsheet tools were directly used by the Mechanical Subcommittee members to evaluate the energy savings impacts of several change proposals, such as economizer and energy recovery ventilation. Figure 2.1 outlines the PI technical work done by PNNL.

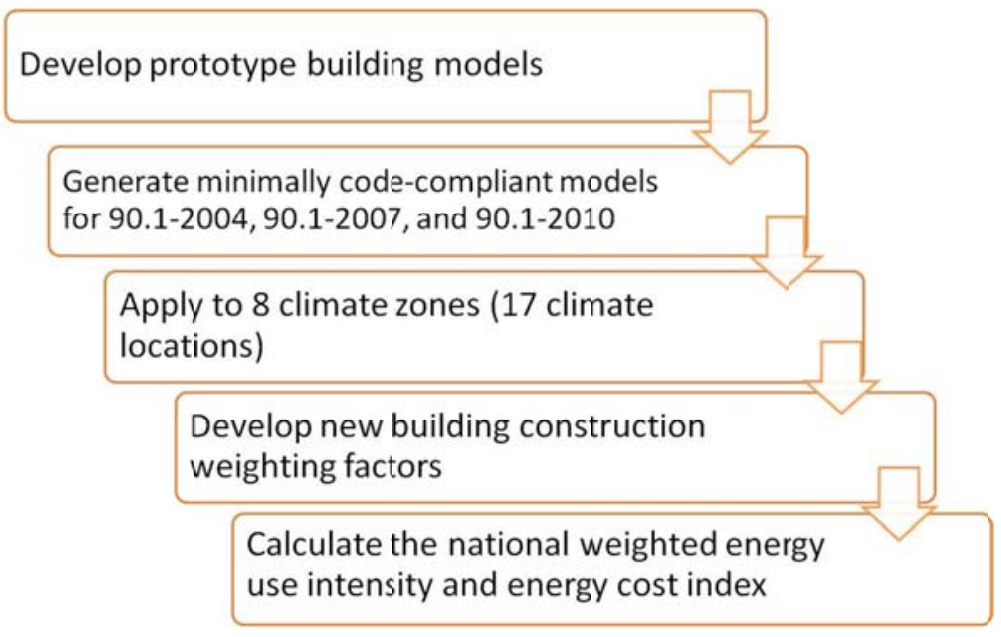

Figure 2.1. Progress Indicator Process 
The rest of this chapter describes the development of the 16 prototype buildings, the development of the models, the climate zones used in the analysis, and the approach used to analyze the results.

\subsection{Develop Prototype Building Models}

The 90.1 prototype building models used in the PI analysis are primarily based on DOE's Commercial Reference Building Models. The development of these models is described in the report, U.S. Department of Energy Commercial Reference Building Models of the National Building Stock (Deru et al. 2011). DOE's Commercial Reference Building Models (in EnergyPlus) are available at http://www1.eere.energy.gov/buildings/commercial_initiative/new_construction.html.

PNNL developed a suite of 16 prototype buildings covering the majority of the commercial building stock and mid-rise to high-rise buildings. This set of prototype buildings includes all the Reference Building types, except supermarkets, and adds a new building prototype representing high-rise apartment buildings. The high-rise apartment building was developed by PNNL based on the mid-rise apartment building and recommendations from the SSPC 90.1 Mechanical Subcommittee for the heating, ventilation, and air conditioning (HVAC) system type.

Chapter 4 in this report describes the prototypes in detail. Extensive information on the prototypes and the EnergyPlus model inputs and outputs are available for no charge at: http://www.energycodes.gov/commercial/901models/.

A number of resources were used in developing the 90.1 prototype building models to refine the prototypes used in this analysis and to quantify the savings from 90.1-2010, described in Chapter 5 of this report. Those resources included the following:

- 90.1 SWG and committee member expert recommendations and reviews

- Advanced Energy Design Guides, developed by ASHRAE, the American Institute of Architects (AIA), IESNA, the US. Green Building Council (USGBC), and DOE (http://www.ashrae.org/technology/page/938)

- The Commercial Building Energy Consumption Survey 2003 (CBECS 2003) available as downloadable reports and micro-data files from the EIA website at http://www.eia.doe.gov/emeu/cbecs/. In the 2003 CBECS survey, 4,859 buildings were surveyed, and the sampled buildings represent the entire stock of U.S. commercial buildings.

- The F.W. Dodge database (F.W. Dodge 2002) provides detailed historical and forecast databases of construction activity available for a fee at http://dodge.construction.com/. It contains extensive, comprehensive coverage of existing building space throughout the United States. Up to 20 years of historical data are combined with up to 25 years of forecast data for 15 different project types. Details include floor space, number of buildings, etc.

- National Commercial Construction Characteristics $\left(\mathrm{NC}^{3}\right)$ Database, an internal database developed by PNNL to represent nationwide commercial construction energy-related characteristics (Richman et al. 2008). This database is derived from McGraw-Hill/F.W. Dodge drawings, part of the F.W. Dodge database described above and available for a fee at http://dodge.construction.com/Plans/Electronic/ViaInternet.asp. The building plans used were developed from 1996 to 2007. The current database includes over 300 commercial buildings. 
The CBECS data are organized around 14 principal building activities. Figure 2.2 illustrates the annual energy consumption in trillions of Btus by the principal building activities, ranking from the most energy usage to the least energy usage sector. The prototype buildings cover the first seven principal building activities with the most energy consumption, representing $76 \%$ of the building energy usage of commercial buildings. In addition, the prototype buildings also include two more prototypes, mid-rise and high-rise apartment buildings, which are not included in CBECS but are regulated by Standard 90.1.

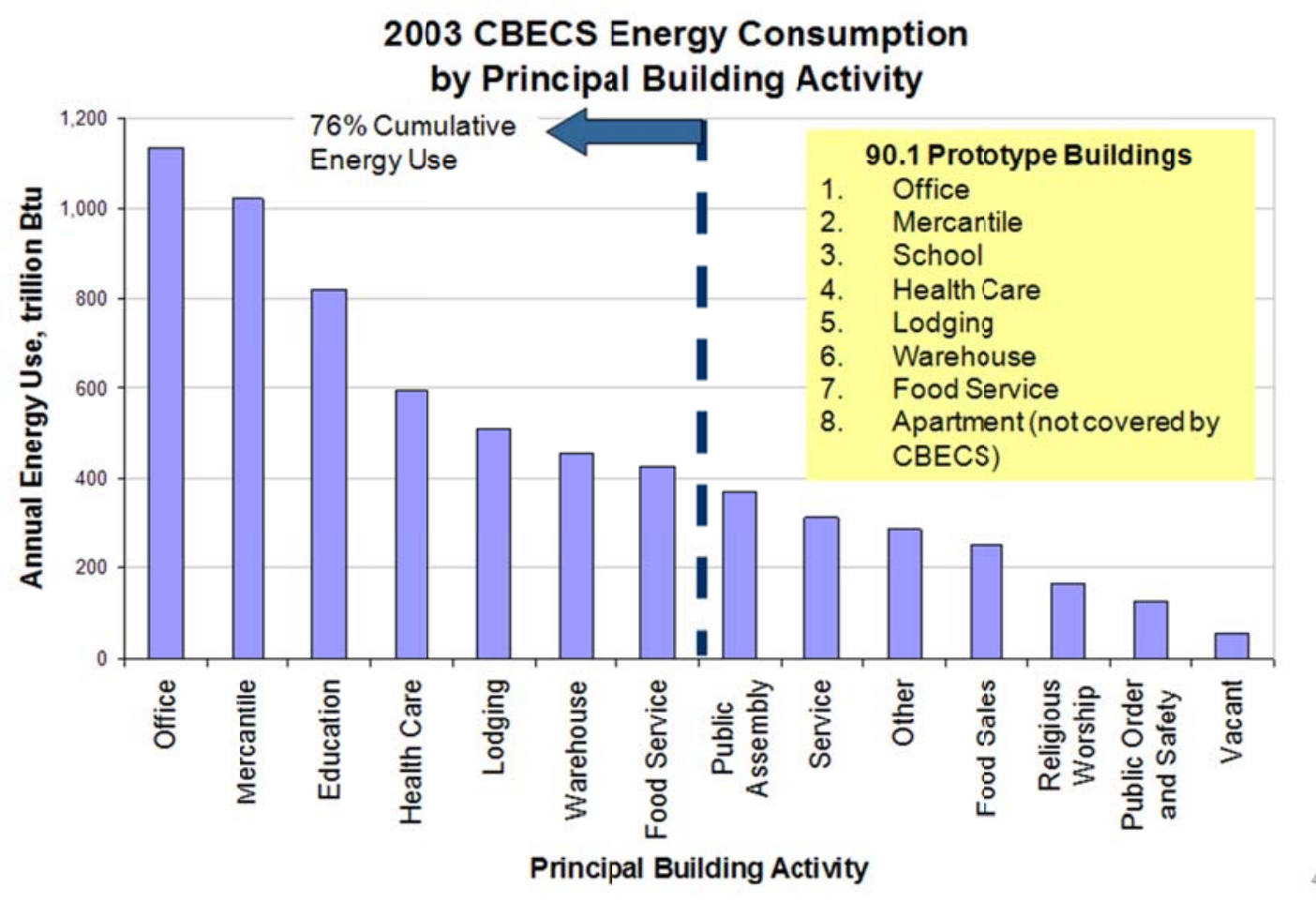

Figure 2.2. CBECS 2003 Energy Consumption by Principal Building Activity

Table 2.1 shows the 16 building prototypes, including 14 with the applicable principal building activity categories from CBECS and two added apartment building activity types. The prototypes include most of the characteristics of buildings that do not change with Standard 90.1 and climate zones.

Characteristics include building size and shape, type of building activity and occupancy, and mechanical system type. Detailed descriptions of these prototypes are provided in Chapter 4 of this report. 
Table 2.1. Prototype Buildings Used in the PI

\begin{tabular}{|c|c|}
\hline Principal Building Activity & Building Prototype \\
\hline \multirow[t]{3}{*}{ Office } & Small Office \\
\hline & Medium Office \\
\hline & Large Office \\
\hline \multirow[t]{2}{*}{ Mercantile } & Standalone Retail \\
\hline & Strip Mall \\
\hline \multirow[t]{2}{*}{ Education } & Primary School \\
\hline & Secondary School \\
\hline \multirow[t]{2}{*}{ Healthcare } & Outpatient Healthcare \\
\hline & Hospital \\
\hline \multirow[t]{2}{*}{ Lodging } & Small Hotel \\
\hline & Large Hotel \\
\hline Warehouse & Warehouse (non-refrigerated) \\
\hline \multirow[t]{2}{*}{ Food Service } & Quick-service Restaurant \\
\hline & Full-service Restaurant \\
\hline \multirow[t]{2}{*}{ Apartment } & Mid-rise Apartment \\
\hline & High-rise Apartment \\
\hline
\end{tabular}

\subsection{Generate Minimally Standard Compliant Models}

As indicated in Section 2.1 of the report, most of the building characteristics and modeling inputs do not change for the various editions of Standard 90.1. However, some building characteristics do vary with the version of Standard 90.1 that applies and by climate zones. Values from the different standards are incorporated in different versions of the models to meet the mandatory and prescriptive requirements in the standards, such as prescriptive building envelope values for roofs, walls, windows, and other components. The 90.1-2004 values were incorporated into the baseline models. The 90.1-2007 values are not reported in the PI as a comparison between 2007 and 2004 editions. However, the changes in 90.12007 are reflected in the 90.1-2010 values. The 2010 values originate from the addenda to 90.1-2004 and 2007 with quantified savings that can be incorporated in the models. The final 90.1-2010 models include all of these addenda as incorporated in 90.1-2010. Chapter 3 of the report describes the simulation process that incorporates these values and Chapter 5 describes the modeling strategies for these quantified addenda.

\subsection{Identify Climate Zones}

The prototype buildings are simulated in eight climate zones of the International Energy Conservation Code (IECC) also used by ASHRAE for residential and commercial standards. The common set of climate zones includes eight zones covering the entire United States, as shown in Figure 2.3 (Briggs et al. 2003). Climate zones are categorized from 1 to 8, with increasing heating degree days (HDDs) and decreasing cooling degree days (CDDs). These climate zones may be mapped to other climate locations for international use. The climate zones are further divided into moist, dry, and marine regions.

For this analysis, a specific climate location (city) is selected as a representative of each climate zone. A set of 17 cities is used that represents the 17 climate conditions identified in Standard 90.1. Two of 
these cities are outside the United States because the climate subzones they represent do not exist in the United States. Riyadh, Saudi Arabia, represents climate zone 1B (very hot, dry) and Vancouver B.C., Canada, represents climate zone 5C (cool, marine).

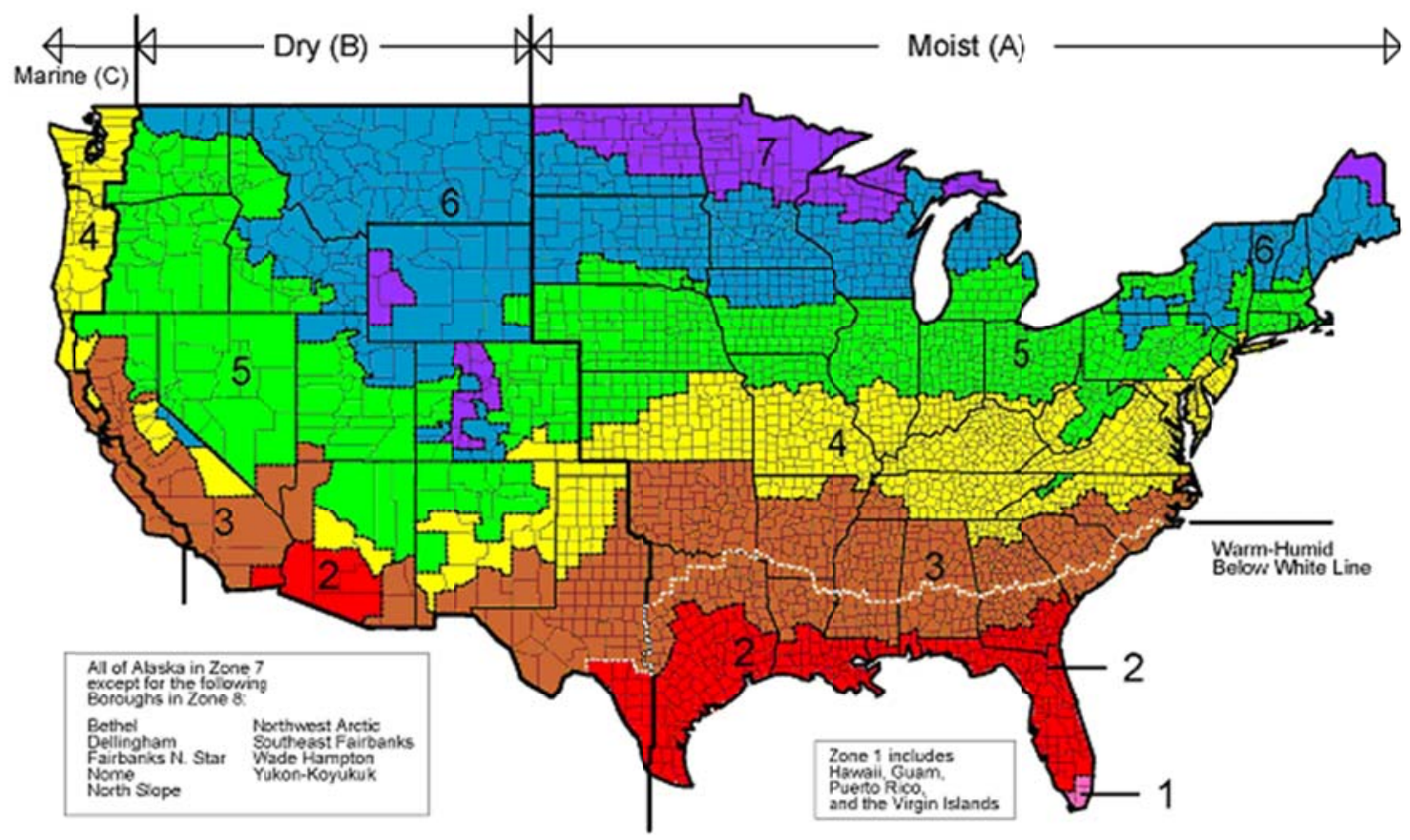

Figure 2.3. DOE-Developed Climate Zone Map

The 17 cities representing the climate zones are:

- 1A: Miami, Florida (very hot, humid)

- 1B: Riyadh, Saudi Arabia (very hot, dry)

- 2A: Houston, Texas (hot, humid)

- 2B: Phoenix, Arizona (hot, dry)

- 3A: Memphis, Tennessee (warm, humid)

- 3B: El Paso, Texas (warm, dry)

- 3C: San Francisco, California (warm, marine)

- 4A: Baltimore, Maryland (mixed, humid)

- 4B: Albuquerque, New Mexico (mixed, dry)
- 4C: Salem, Oregon (mixed, marine)

- 5A: Chicago, Illinois (cool, humid)

- 5B: Boise, Idaho (cool, dry)

- 5C: Vancouver B.C., Canada (cool, marine)

- 6A: Burlington, Vermont (cold, humid)

- 6B: Helena, Montana (cold, dry)

- 7: Duluth, Minnesota (very cold)

- 8: Fairbanks, Alaska (subarctic) 


\subsection{Analyze Results}

The primary measurement reported for the PI is the national aggregated energy and cost savings. These savings are the percentage savings for the entire set of prototypes and all of the 15 U.S. climate subzones, which excludes Riyadh and Vancouver, BC. Percentages are calculated for the change in annual energy usage and the change in annual energy cost. Annual site energy usage is reported in the PI as site energy usage intensity (EUI) values - energy use per unit floor area, $\mathrm{kBtu} / \mathrm{ft}^{2}$. This includes electricity and natural gas converted by straight unit conversion to the kBtu unit. Energy usage by utility energy type is determined during the simulation, and electricity and natural gas usage is used to calculate energy cost. Energy cost is reported per unit area, an energy cost index similar to the energy usage index described above. Energy usage that would be delivered by the utility to the building, known as "site" energy, is reported. The simulation provides a break-down of energy end uses such as lighting, cooling, heating, fan, service hot water, and plug loads.

The "source" energy is also calculated. Source energy is the energy sage at the utility generating facility needed to provide the electricity used at the site, and energy of fuel delivered to the site such as natural gas. Source energy is calculated from site energy reported from the simulations using conversion factors from the Annual Energy Outlook for 2011 (EIA 2011).

Electricity: 3.2 source Btu per site Btu (10,918 source Btu per site $\mathrm{kWh})$

Natural Gas: 1.090 source Btu per site Btu

This natural gas source energy conversion factor was calculated by dividing the sum of all natural gas usage, including usage for natural gas field production, leases, plant fuel, and pipeline (compression) supply by delivered gas energy, to the four primary energy sectors: residential, commercial, industrial, and transportation.

Energy use and cost saving results are presented in Chapter 6 of this report.

The following subsections describe the use of the weighting factors, energy prices, outdoor air ventilation standards, and regulated and unregulated energy.

\subsubsection{New Building Construction Weighting Factors}

To estimate the energy savings impact on a national scale, PNNL acquired disaggregated construction volume data from McGraw-Hill Construction (MHC) Project Starts Database. The MHC database contains the floor area of new construction in the United States for the years 2003 to 2007. PNNL analyzed this MHC database to develop detailed construction weights by climate zones, subzones, and states (Jarnagin and Bandyopadhyay 2010). These weights are used in developing a weighted national energy savings estimate for the impact of the 2010 standard.

Table 2.2 summarizes the construction floor area and percentage weights by building type. As the table shows, these 16 prototypes cover $80 \%$ of new construction floor areas. Table 2.3 lists the weighting factors assigned to each prototype in all 15 U.S. climate subzones, using 16 prototypes representing the entire commercial building stock. The two climate subzones that occur only outside the United States, Riyadh and Vancouver, are not included in the weighted average. The energy and energy cost savings are 
weighted by the percentages shown in Table 2.2 and are summed to create the national weighted-average values.

Table 2.2. MHC Data by Building Type

\begin{tabular}{lrr}
\hline \multicolumn{1}{c}{ Prototype } & $\begin{array}{c}\text { Total Floor Area } \\
\left(\mathrm{x} 1,000 \mathrm{ft}^{2}\right)\end{array}$ & $\begin{array}{c}\text { Construction } \\
\text { Weights }\end{array}$ \\
\hline Small Office & 371,009 & $4.5 \%$ \\
Medium Office & 400,091 & $4.8 \%$ \\
Large Office & 220,134 & $2.7 \%$ \\
Standalone Retail & $1,009,246$ & $12.2 \%$ \\
Strip Mall & 375,093 & $4.5 \%$ \\
Primary School & 330,418 & $4.0 \%$ \\
Secondary School & 685,508 & $8.3 \%$ \\
Outpatient Healthcare & 289,171 & $3.5 \%$ \\
Hospital & 228,131 & $2.8 \%$ \\
Small Hotel & 113,837 & $1.4 \%$ \\
Large Hotel & 327,562 & $4.0 \%$ \\
Warehouse & $1,105,951$ & $13.4 \%$ \\
Quick Service Restaurant & 38,809 & $0.5 \%$ \\
Full Service Restaurant & 43,650 & $0.5 \%$ \\
Mid-rise Apartment & 484,343 & $5.9 \%$ \\
High-rise Apartment & 593,241 & $7.2 \%$ \\
\hline Covered by Prototypes & $\mathbf{6 , 6 1 6 , 1 9 3}$ & $\mathbf{8 0 \%}$ \\
No prototype & $\mathbf{1 , 6 4 9 , 7 8 5}$ & $\mathbf{2 0 \%}$ \\
Total & $\mathbf{8 , 2 6 5 , 9 7 7}$ & $\mathbf{1 0 0 \%}$ \\
\hline
\end{tabular}

\subsubsection{Energy Prices}

PNNL calculated the energy cost savings using national average energy prices, derived from U.S. Energy Information Administration (EIA) values. The same energy prices have been approved and used by the SSPC 90.1 when evaluating the cost effectiveness of draft addenda during the development of 90.1-2010. These prices are $\$ 1.22 /$ therm for natural gas and $\$ 0.0939 / \mathrm{kWh}$ for electricity (EIA 2006). These prices are applied to the energy use savings, separated by fuel type. The same rates are used for all prototypes and in all climate zones.

\subsubsection{Outdoor Air Ventilation Standards}

Outdoor air ventilation rates can have a significant impact on the energy use of commercial buildings. Minimum outdoor air ventilation requirements are specified in ASHRAE Standard 62-1999 prior and ANSI/ASHRAE Standard 62.12004 and 2007 (ASHRAE 1999, ANSI/ASHRAE 2004 and 2007). 90.12004 lists 62-1999, and 90.1-2007 lists 62.1-2004 and 90.1-2010 lists 62.1-2007 as the corresponding normative references for outdoor air ventilation. Minimum ventilation rates determined from ASHRAE 62-1999 are generally larger than rates determined under the 62.1-2004 standard. Minimum ventilation rates determined from 62.1-2004 and 62.1-2007 are the same in nearly all cases, including for all of the prototypes in this analysis. 
Ventilation rates for both Standards 62-1999and 62.1-2004 were used when simulating the 90.1-2004 baseline for comparison of the impact of the two ventilation standards. The final simulation results used in the PI and presented in this report use the outdoor air ventilation rates corresponding to the normative references identified in the corresponding versions of Standard 90.1. The PI presents results for the 90.12004 baseline using 62-1999 outdoor air ventilation rates and for the 90.1-2010 models using the 62.12007 outdoor air ventilation rates.

\subsubsection{Regulated and Unregulated Energy}

Standard 90.1 regulates the elements of commercial buildings that result in most of the energy used in those buildings. Some energy usage from what are sometimes called "process loads" come from equipment that is not directly regulated by Standard 90.1, including plug-in devices such as computers and appliances, and other equipment such as gas cooking equipment. This type of equipment uses energy directly and affects HVAC energy usage indirectly by generating heat in spaces, potentially increasing cooling energy and reducing heating energy. Plug and process loads are incorporated in the prototypes used in the modeling for the PI. Changes to Standard 90.1 do not directly affect the energy efficiency of this type of equipment. Results are presented with plug and process load energy usage to show the impact on total commercial building energy usage and are also presented without plug and process loads to show the impact on just the Standard 90.1 regulated energy usage. 
Table 2.3. Construction Area Weights by Building Prototype and Climate Zone

\begin{tabular}{|c|c|c|c|c|c|c|c|c|c|c|c|c|c|c|c|c|}
\hline & $\begin{array}{c}1 \mathrm{~A} \\
\text { Moist }\end{array}$ & $\begin{array}{c}2 \mathrm{~A} \\
\text { Moist }\end{array}$ & $\begin{array}{l}2 B \\
\text { Dry }\end{array}$ & $\begin{array}{c}3 \mathrm{~A} \\
\text { Moist }\end{array}$ & $\begin{array}{l}3 \mathrm{~B} \\
\text { Dry }\end{array}$ & $\begin{array}{c}3 \mathrm{C} \\
\text { Marine } \\
\end{array}$ & $\begin{array}{c}4 \mathrm{~A} \\
\text { Moist } \\
\end{array}$ & $\begin{array}{l}4 \mathrm{~B} \\
\text { Dry }\end{array}$ & $\begin{array}{c}4 \mathrm{C} \\
\text { Marine } \\
\end{array}$ & $\begin{array}{c}5 \mathrm{~A} \\
\text { Moist } \\
\end{array}$ & $\begin{array}{l}5 \mathrm{~B} \\
\text { Dry }\end{array}$ & $\begin{array}{c}\text { 6A } \\
\text { Moist } \\
\end{array}$ & $\begin{array}{c}6 \mathrm{~B} \\
\text { Dry }\end{array}$ & 7 & 8 & $\begin{array}{c}\text { Weights } \\
\text { by } \\
\text { Building } \\
\text { Type } \\
\end{array}$ \\
\hline Small Office & $0.084 \%$ & $1.064 \%$ & $0.289 \%$ & $0.963 \%$ & $0.475 \%$ & $0.078 \%$ & $0.936 \%$ & $0.047 \%$ & $0.123 \%$ & $0.920 \%$ & $0.322 \%$ & $0.241 \%$ & $0.030 \%$ & $0.032 \%$ & $0.005 \%$ & $5.608 \%$ \\
\hline Medium Office & $0.129 \%$ & $0.813 \%$ & $0.292 \%$ & $0.766 \%$ & $0.715 \%$ & $0.136 \%$ & $1.190 \%$ & $0.036 \%$ & $0.196 \%$ & $1.060 \%$ & $0.342 \%$ & $0.298 \%$ & $0.035 \%$ & $0.033 \%$ & $0.007 \%$ & $6.047 \%$ \\
\hline Large Office & $0.102 \%$ & $0.326 \%$ & $0.061 \%$ & $0.445 \%$ & $0.285 \%$ & $0.117 \%$ & $1.132 \%$ & $0.000 \%$ & $0.154 \%$ & $0.442 \%$ & $0.121 \%$ & $0.133 \%$ & $0.000 \%$ & $0.011 \%$ & $0.000 \%$ & $3.327 \%$ \\
\hline Standalone Retail & $0.224 \%$ & $2.220 \%$ & $0.507 \%$ & $2.386 \%$ & $1.250 \%$ & $0.191 \%$ & $2.545 \%$ & $0.119 \%$ & $0.428 \%$ & $3.429 \%$ & $0.792 \%$ & $0.948 \%$ & $0.091 \%$ & $0.109 \%$ & $0.014 \%$ & $15.254 \%$ \\
\hline Strip Mall & $0.137 \%$ & $0.991 \%$ & $0.254 \%$ & $1.021 \%$ & $0.626 \%$ & $0.103 \%$ & $1.008 \%$ & $0.023 \%$ & $0.107 \%$ & $1.023 \%$ & $0.201 \%$ & $0.153 \%$ & $0.016 \%$ & $0.007 \%$ & $0.001 \%$ & $5.669 \%$ \\
\hline Primary School & $0.064 \%$ & $0.933 \%$ & $0.164 \%$ & $0.944 \%$ & $0.446 \%$ & $0.048 \%$ & $0.895 \%$ & $0.030 \%$ & $0.094 \%$ & $0.920 \%$ & $0.224 \%$ & $0.168 \%$ & $0.037 \%$ & $0.023 \%$ & $0.003 \%$ & $4.994 \%$ \\
\hline Secondary School & $0.160 \%$ & $1.523 \%$ & $0.230 \%$ & $1.893 \%$ & $0.819 \%$ & $0.109 \%$ & $2.013 \%$ & $0.063 \%$ & $0.243 \%$ & $2.282 \%$ & $0.438 \%$ & $0.415 \%$ & $0.086 \%$ & $0.075 \%$ & $0.012 \%$ & $10.361 \%$ \\
\hline Outpatient Healthcare & $0.037 \%$ & $0.567 \%$ & $0.134 \%$ & $0.581 \%$ & $0.275 \%$ & $0.061 \%$ & $0.818 \%$ & $0.023 \%$ & $0.181 \%$ & $1.058 \%$ & $0.218 \%$ & $0.342 \%$ & $0.033 \%$ & $0.039 \%$ & $0.002 \%$ & $4.371 \%$ \\
\hline Hospital & $0.040 \%$ & $0.479 \%$ & $0.096 \%$ & $0.468 \%$ & $0.273 \%$ & $0.039 \%$ & $0.615 \%$ & $0.022 \%$ & $0.106 \%$ & $0.812 \%$ & $0.218 \%$ & $0.221 \%$ & $0.024 \%$ & $0.034 \%$ & $0.001 \%$ & $3.448 \%$ \\
\hline Small Hotel & $0.010 \%$ & $0.288 \%$ & $0.030 \%$ & $0.268 \%$ & $0.114 \%$ & $0.022 \%$ & $0.315 \%$ & $0.020 \%$ & $0.039 \%$ & $0.365 \%$ & $0.089 \%$ & $0.107 \%$ & $0.031 \%$ & $0.020 \%$ & $0.004 \%$ & $1.721 \%$ \\
\hline Large Hotel & $0.109 \%$ & $0.621 \%$ & $0.125 \%$ & $0.635 \%$ & $0.793 \%$ & $0.106 \%$ & $0.958 \%$ & $0.037 \%$ & $0.123 \%$ & $0.919 \%$ & $0.200 \%$ & $0.227 \%$ & $0.058 \%$ & $0.038 \%$ & $0.004 \%$ & $4.951 \%$ \\
\hline Warehouse & $0.349 \%$ & $2.590 \%$ & $0.580 \%$ & $2.966 \%$ & $2.298 \%$ & $0.154 \%$ & $2.446 \%$ & $0.068 \%$ & $0.435 \%$ & $3.580 \%$ & $0.688 \%$ & $0.466 \%$ & $0.049 \%$ & $0.043 \%$ & $0.002 \%$ & $16.716 \%$ \\
\hline Quick-service Restaurant & $0.008 \%$ & $0.092 \%$ & $0.020 \%$ & $0.102 \%$ & $0.063 \%$ & $0.007 \%$ & $0.089 \%$ & $0.005 \%$ & $0.014 \%$ & $0.128 \%$ & $0.026 \%$ & $0.025 \%$ & $0.003 \%$ & $0.004 \%$ & $0.000 \%$ & $0.587 \%$ \\
\hline Full-service Restaurant & $0.009 \%$ & $0.106 \%$ & $0.025 \%$ & $0.111 \%$ & $0.047 \%$ & $0.006 \%$ & $0.127 \%$ & $0.006 \%$ & $0.010 \%$ & $0.143 \%$ & $0.031 \%$ & $0.031 \%$ & $0.004 \%$ & $0.004 \%$ & $0.000 \%$ & $0.660 \%$ \\
\hline Mid-rise Apartment & $0.257 \%$ & $1.094 \%$ & $0.093 \%$ & $0.825 \%$ & $0.862 \%$ & $0.260 \%$ & $1.694 \%$ & $0.022 \%$ & $0.371 \%$ & $1.122 \%$ & $0.318 \%$ & $0.313 \%$ & $0.056 \%$ & $0.032 \%$ & $0.000 \%$ & $7.321 \%$ \\
\hline High-rise Apartment & $1.521 \%$ & $1.512 \%$ & $0.076 \%$ & $0.652 \%$ & $0.741 \%$ & $0.173 \%$ & $2.506 \%$ & $0.000 \%$ & $0.358 \%$ & $1.163 \%$ & $0.115 \%$ & $0.125 \%$ & $0.016 \%$ & $0.008 \%$ & $0.000 \%$ & $8.967 \%$ \\
\hline Weights by Climate Zone & $3.242 \%$ & $15.217 \%$ & $2.975 \%$ & $15.025 \%$ & $10.081 \%$ & $1.609 \%$ & $19.286 \%$ & $0.522 \%$ & $2.981 \%$ & $19.366 \%$ & $4.344 \%$ & $4.214 \%$ & $0.569 \%$ & $0.513 \%$ & $0.056 \%$ & $100.000 \%$ \\
\hline
\end{tabular}




\subsection{EnergyPlus Simulation Infrastructure}

This chapter describes PNNL's EnergyPlus simulation infrastructure to support the development of 90.1-2010 through the PI. The PI primarily depends on conducting extensive building energy simulation to quantitatively evaluate the potential energy savings from the new 90.1-2010 relative to 90.1-2004. EnergyPlus (DOE 2010b) is the computer simulation software used to evaluate the energy savings impacts among various versions of Standard 90.1 and Standards 62 and 62.1. EnergyPlus is a complex building energy simulation program for modeling building heating, cooling, lighting, ventilation, and other energy uses in buildings. To run EnergyPlus simulation, the user needs to prepare a detail input file, the idf file, to specify the building characteristic as well as the requirements of different versions of Standard 90.1 and Standard 62 and 62.1. An EnergyPlus input data file (idf, which is also the file extension used in EnergyPlus) can easily have thousands of lines for numerous object blocks, which make the manual preparation both tedious and error-prone.

During development of the PI, numerous EnergyPlus simulations were involved. Each of the 16 prototype buildings has a corresponding EnergyPlus simulation model, which consists of all the values needed to run EnergyPlus simulation. Most of the objects and their values are the characteristics of the prototype buildings, which are standard-and-climate-zone-independent, but others vary with the standards and climate zone (e.g., insulation of walls and equipment efficiencies).

By assigning standard-dependent values, the model of each of the prototype building expands into three different EnergyPlus models: one for 90.1-2004, one for 90.1-2007, and one for 90.1-2010 under development. The Standard 90.1 model for each prototype is paired with the corresponding versions of the Ventilation Standard 62 or 62.1 described in Section 4.5.5 in this report. Further considering the selected 17 climate locations, the three EnergyPlus models for each prototype are expanded into 51 sets of EnergyPlus models per building type. With all the combinations of the 16 prototypes, 3 versions of the 90.1 standard, and 17 climate locations, a total of 816 EnergyPlus models $(3 \times 17 \times 16)$ are in each single batch of simulation runs.

For the PI, the results are used just for the baseline case for 90.1-2004 and 62-1999 and for the advanced case for 90.1-2010 and 62.1-2007.

PNNL further conducted sensitivity analysis to evaluate the energy savings results using ventilation standard 62.1-2004 with all three versions of Standard 90.1 considered. This additional analysis adds another set of 272 models to the batch runs, resulting in 1,088 models.

During the development of 90.1-2010, numerous batches of simulation runs were launched. For most of the addenda implemented to enhance 90.1-2010, periodic batches of simulation runs were conducted to verify the implementation and to estimate the energy savings resulting from the addenda as they were created. In addition, the PNNL simulation team provided quarterly PIs to the SSPC 90.1 to report timely progress towards the $30 \%$ improvement goal in 90.1-2010. All this translates to a large number of batches of simulations, each requiring the evaluation of over 1,000 EnergyPlus models. The massive numbers of EnergyPlus simulation runs present a challenge in preparing the idfs, conducting EnergyPlus simulations, and post-processing the output files to assemble building energy consumption information and to assess energy savings of the advanced standards against the baseline standard. 
The following sections document the infrastructure that the PNNL simulation team developed to address this challenge, including the steps below:

1. Parameterizing the prototype building models into two sets of files, i.e., templates and parms

2. Automating the EnergyPlus idf creation based on templates and parms by a PNL-developed program known as GPARM (General PARaMetrics)

3. Controlling the simulation process with make utility

4. Aggregating simulation output to assemble energy end-use results and to prepare energy savings through a series of Perl scripts.

All energy simulations were completed within a PNNL Linux energy simulation infrastructure, which manages inputs and outputs of the EnergyPlus simulations. This infrastructure includes creating EnergyPlus idfs with by GPARM, submitting input files to a computing cluster with 150 central processing units (CPUs) for batch simulation, and extracting energy end-use results. Figure 3.1 is a flow diagram of these procedures as described in the remainder of this chapter. An additional challenge discussed in this chapter is maintaining model idfs consistent with the different versions of EnergyPlus released periodically during the project.

\subsection{Prototype Model Parameterization}

Simulation for each round of PI required over 1,000 EnergyPlus models to capture the different versions of Standard 90.1 and Standards 62 and 62.1 and the different climate zones. To facilitate the automatic creation of the large number of EnergyPlus idfs, the prototype models were parameterized by splitting the prototype model into two separate but related associated file pairs called template and parm files.

The template is a modified EnergyPlus idfs where the values of the standard/climate zone dependent fields are replaced with replaceable tags (i.e., variables). The values of the variables are specified in a separate parameter file called parm file. The parm file is a simple rectangular comma delimited file. Each row of the parm file consists of the set of values that would be taken by those variables in the template file and represents one EnergyPlus idf to be generated. The combination of the template and parm pair uniquely defines all EnergyPlus models of a given prototype associated with different versions of Standard 90.1 and Standards, 62and 62.1, and climate locations.

\subsection{Automation of the EnergyPlus Input File Creation}

With the split of the prototype model into a template, which is a parameterized EnergyPlus idf, and a CSV formatted parm file, it is possible to automatically create the required EnergyPlus idfs for the combinations of the versions of Standard 90.1 and Standards 62 or 62.1 and the climate locations. The GPARM program was used for this idf creation. GPARM is a program, written in Perl, to help generate huge numbers of input files for programs like EnergyPlus. In its simplest function, GPARM is basically a generic system for doing a "mail merge." It works in a row-by-row fashion through the parm CSV file. Each time, it takes a row from the parm and uses the values specified in that row to replace the corresponding replaceable tags in the template file. After such a replacement, the template file represents a complete EnergyPlus idf, which can be saved and then used for subsequent EnergyPlus simulations. 


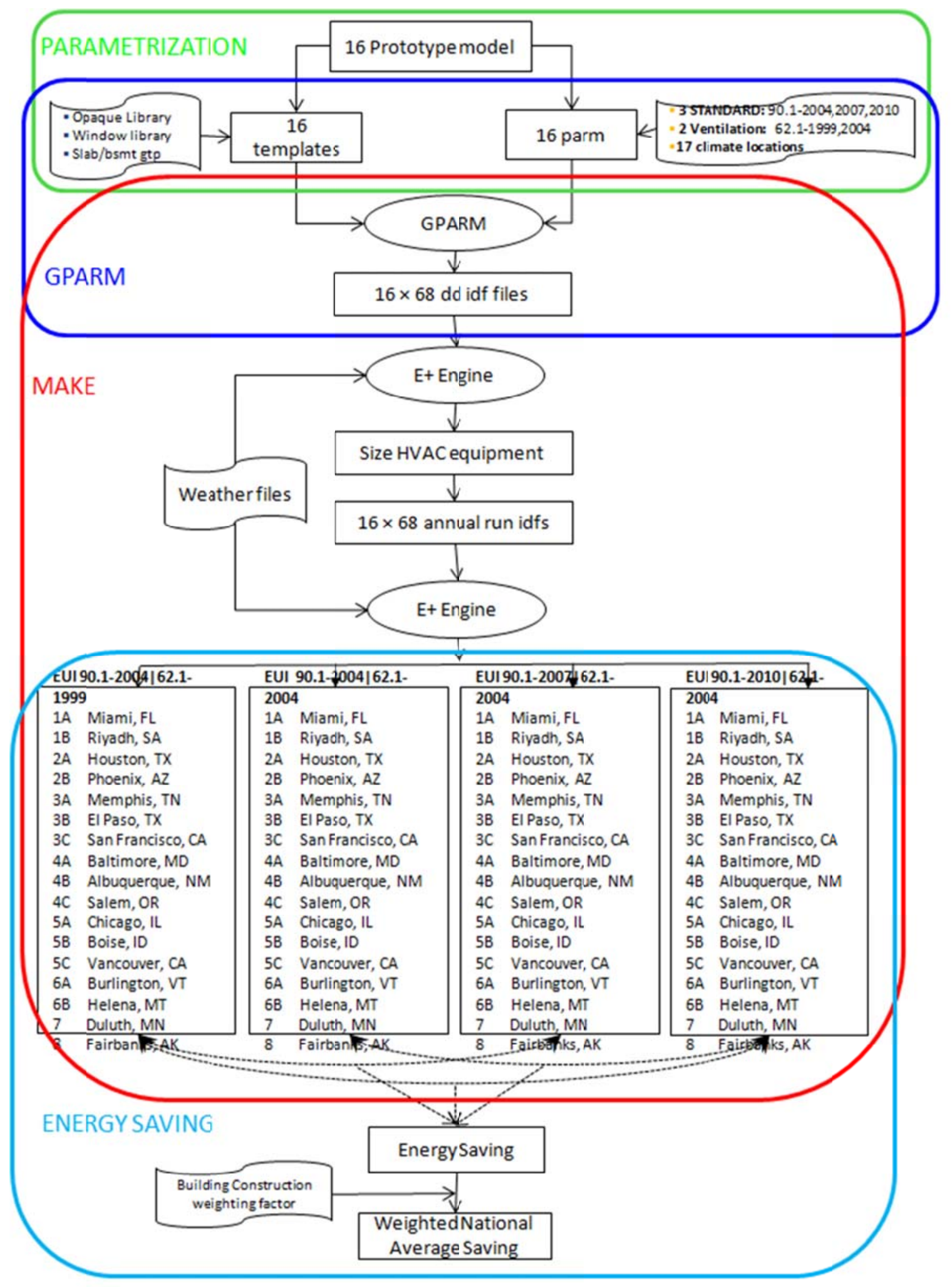

Figure 3.1. Flow Diagram of PI Simulation Framework 
During the early development of EnergyPlus simulation for 90.1-2010, PNNL created an opaque construction (walls, roofs, etc.) library, a fenestration library, and prototype building/climate zone specific slab and basement ground temperature profiles (gtp). The opaque construction and fenestration libraries are text files in EnergyPlus idf format, which consist of a large number of construction materials, such as various types of walls, floors, roofs, ceilings, and windows. The prototype-building and climate-locationspecific slab and basement gtp are sets of hundreds of files in EnergyPlus idf format. Both the construction libraries and the gtp need to be included in the EnergyPlus idfs for the simulation run.

\subsection{Batch Simulation}

One of the challenges in dealing with the required massive EnergyPlus simulations is solved by parameterizing the prototype model into template and parm, specifying Standard and climate-locationdependent values in the parm file, and using GPARM to combine the template and parm creating EnergyPlus idf. Another challenge is the time and complexity of running so many EnergyPlus simulations.

Each EnergyPlus simulation run takes time to complete. The computing time needed for the simulation of a single model ranges from minutes to over an hour, depending on the number of thermal zones in a prototype and the CPU used to run the model. A batch run with over 1,000 models needs significant time to finish. The simulation is conducted in a Linux cluster with around 150 CPUs. The Sun Grid Engine queuing system is used for scheduling and dispatching simulation jobs to the CPUs in the cluster. Simulation jobs are queued up in a single master list and sent out to the execution queues as slots become available.

As illustrated in Figure 3.1, a complete batch of simulations involves multiple steps occurring in sequence. What has been described above is the first step, which turns the prototype model into a series of EnergyPlus models distinguished by the combination of Standard 90.1, and Standards 62 and 62.1, and climate location by combining the template and parm files using the GPARM utility program.

These EnergyPlus idf files are created initially for design day simulation to size the mechanical equipment. The EnergyPlus simulation needs to run in design day mode, and the simulation outputs with the sizing information needs to be extracted and used to replace "auto-size" fields for annual simulation run. Additional information on the development of HVAC system capacity is included in Section 4.5.2 of this report. In addition, the mechanical equipment efficiencies need to be specified based on the sizing information from the design day simulation as well as the requirements of the different versions of Standard 90.1 and Standards 62 and 62.1 that are applied. Perl scripts have been written to automatically extract the sizing information from the design day simulation output files, to subsequently look up the required equipment efficiencies, and to use them to modify the design day idfs to idfs for annual simulation.

Each EnergyPlus simulation run generates dozens of miscellaneous output files. For a complete batch run of over 1,000 idfs, many thousand output files are generated. To assess the energy consumption in term of end-use categories (e.g., heating and interior lighting) and to evaluate the energy savings of the advanced case against the baseline case, the end-use energy consumption from the model runs need to be extracted from the corresponding output files in order to create energy consumption and energy savings 
tables. Another Perl script was written for aggregating all outputs into a single table. Further data extraction occurs after the batch simulation, described in Section 3.4 below.

\subsection{Extraction of PI Results}

The simulation process results in a large table of raw model output data aggregated from all of the models in a batch from the batch simulation process. The EnergyPlus annual simulation generates energy consumption in generic combined energy units (joules, millions of Btu) associated with energy end uses such as heating, cooling, and interior lighting. Visual basic macros are used to automatically load the aggregated outputs from the batch simulations and populate the numbers to separate spreadsheets with the energy consumption and energy savings tables and necessary unit conversion. The macros also automate this data loading and table-making process for all 16 prototype buildings, and create energy savings tables between pairs of 90.1 -2004 and 90.1-2007 or 90.1-2010. The spreadsheets calculate national averages of these results for each prototype and climate location using construction weights described in Chapter 2 of this report. Summary results with and without unregulated energy uses and energy costs are also extracted to overall results spreadsheets for all prototypes. Results compilation and content are described in Section 2.4 and are presented in Chapter 6 of this report.

\subsection{Maintenance for New Versions of EnergyPlus}

EnergyPlus has been under continuous development by DOE since 1996 (DOE 2010a). During the process of 90.1-2010 Standard development, the PNNL simulation team upgraded the prototype models several times from version 3.0 to version 6.0. Since the prototype models are parameterized using the pair of template and parm files and the templates carry the essence of the prototype model, the templates have to be upgraded whenever a new version of EnergyPlus was adapted as the simulation engine. Although there is a companion utility program for idf version transition associated with each newly released version of EnergyPlus, the programs cannot directly be used for the template files upgrade because of the existence of replaceable tags.

A Perl utility program developed by PNNL is used to automatically upgrade to a new version of the template files. The idea is to temporally comment out the replaceable tags in the templates and replace them with default values for those fields associated with replaceable tags based on the Input Data Dictionary (idd) files of EnergyPlus. By doing so, the template files are converted back to complete idf files that can then be upgraded to the new version by the version transition utility tool of EnergyPlus. The Perl utility program automates this process. The program automatically searches for replaceable tags in the templates files, comments them out, replaces the tags with default values from the idd file, and then saves the files to temporary idf files. It then invokes the EnergyPlus version transition tool to do the version upgrade. The program moves the commented replaceable tags in the upgraded idf files back to their original places, removes the comment characters, and then saves the files as upgraded template files. The development of this template version upgrade tool greatly facilitates the model upgrade between versions. 


\subsection{Prototype Building Models}

This chapter describes the 16 prototype buildings used in the PI that were introduced in Section 2.1 of this report.

- Office

1. Small Office

2. Medium Office

3. Large Office

- Mercantile

4. Standalone Retail

5. Strip Mall

- Education

6. Primary School

7. Secondary School

- Healthcare

8. Outpatient Healthcare

9. Hospital
- Lodging

10. Small Hotel

11. Large Hotel

- Warehouse

12. Warehouse (non-refrigerated)

- Food Service

13. Quick-service Restaurant

14. Full-service Restaurant

- Apartment

15. Mid-rise Apartment

16. High-rise Apartment

Appendix A includes prototype building descriptions. Appendix B lists the internal loads for each thermal zone in all prototypes. Appendix $\mathrm{C}$ includes schedules used to model time of day variation of building operations. The prototype "Scorecards," spreadsheets that contain the key inputs shown in Appendixes A, B, and C, as well as other information are available online (http://www.energycodes.gov/commercial/901models/). The EnergyPlus model inputs and outputs for the prototype buildings representing $90.1-2004,2007$, and 2010 are also available for free download at the same website.

For the prototype buildings, the following subsections discuss schedules, form, envelope, occupancy, HVAC requirements, service water heating equipment, lighting, other equipment, and plug and process loads.

\subsection{Building Schedules}

An important element in simulating buildings and in actual building energy usage is the time-of-day operation of the building. For simulation, this is defined by schedules that can correspond to operating hours in real-world buildings for some parameters. Schedules include values such as the fraction of lights that are on, whether HVAC systems are on or off, and thermostat temperature setpoints. Schedules contain information for each hour and may vary by day of the week and time of year. In addition to dayto-day operations, schedules are used to define values at design conditions for developing peak HVAC equipment capacities and related inputs that vary with capacity, such as motor size and efficiency. Table 4.1 shows an example schedule for interior lighting and building occupancy for the first 12 hours of the day; actual schedules continue through midnight. Values in the main body of the table are the proportion of the total lighting power that is on. Appendix $\mathrm{C}$ includes the operating schedules for all 16 prototypes. 
Table 4.1. Example Simulation Schedules

\begin{tabular}{|c|c|c|c|c|c|c|c|c|c|c|c|c|}
\hline \multirow[b]{2}{*}{$\begin{array}{l}\text { Building Lighting } \\
\text { Schedule }\end{array}$} & \multicolumn{12}{|c|}{ Hour of the day ending at hour shown (through noon shown) } \\
\hline & $1 \mathrm{am}$ & 2 am & $3 \mathrm{am}$ & $4 \mathrm{am}$ & $5 \mathrm{am}$ & $6 \mathrm{am}$ & $7 \mathrm{am}$ & $8 \mathrm{am}$ & $9 \mathrm{am}$ & $\begin{array}{l}10 \\
\mathrm{am}\end{array}$ & $\begin{array}{c}11 \\
\mathrm{am}\end{array}$ & Noon \\
\hline Weekday & 0.18 & 0.18 & 0.18 & 0.18 & 0.18 & 0.23 & 0.23 & 0.42 & 0.90 & 0.90 & 0.90 & 0.90 \\
\hline Weekend & 0.18 & 0.18 & 0.18 & 0.18 & 0.18 & 0.18 & 0.18 & 0.18 & 0.18 & 0.18 & 0.18 & 0.18 \\
\hline $\begin{array}{l}\text { Winter Design } \\
\text { Day }\end{array}$ & 0 & 0 & 0 & 0 & 0 & 0 & 0 & 0 & 0 & 0 & 0 & 0 \\
\hline $\begin{array}{l}\text { Summer Design } \\
\text { Day }\end{array}$ & 1 & 1 & 1 & 1 & 1 & 1 & 1 & 1 & 1 & 1 & 1 & 1 \\
\hline
\end{tabular}

\subsection{Building Form}

For the prototypes, building form is selected to represent typical buildings of the corresponding prototype. The model prototypes use the same building forms as DOE's Commercial Building Reference Models (Deru et al. 2011), with the exception of the high-rise apartment prototype, which is not included in the reference models. PNNL developed the high-rise apartment prototype based on the mid-rise apartment and inputs from SSPC 90.1 members. Figure 4.1 illustrates the 3D rendering of the 16 prototype building models, representing a range of building shape, size, and number of floors. Table 4.2 lists the building floor area, number of floors, window-to-wall ratio (WWR), floor-to-floor height, and floor-to-ceiling height by building type.
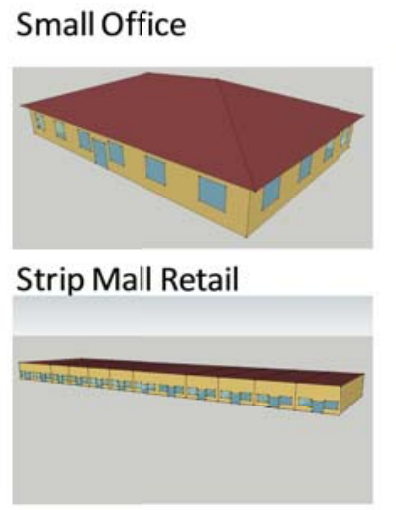

Outpatient Healthcare

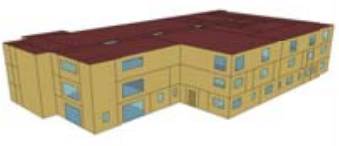

Quick-service Restaurant

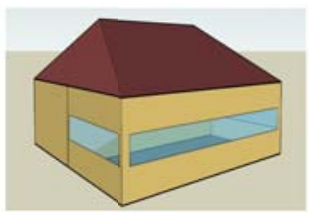

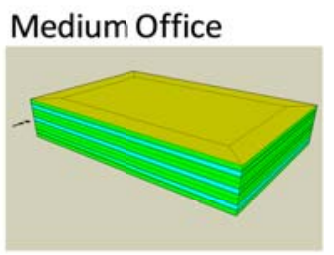

\section{Standalone Retail}

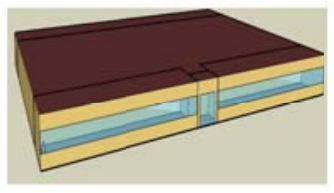

Hospital

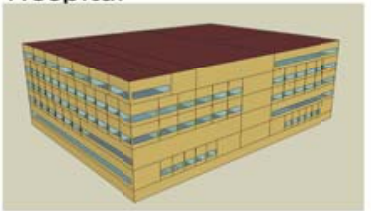

Full-service Restaurant

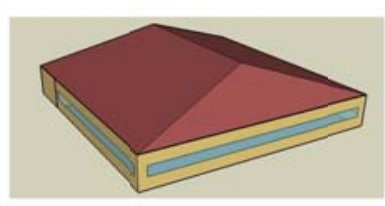

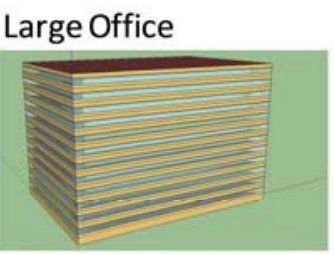

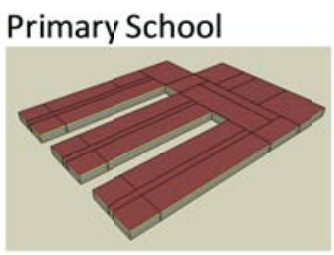

Small Hotel
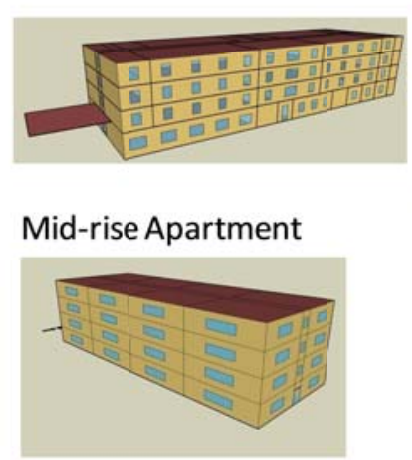
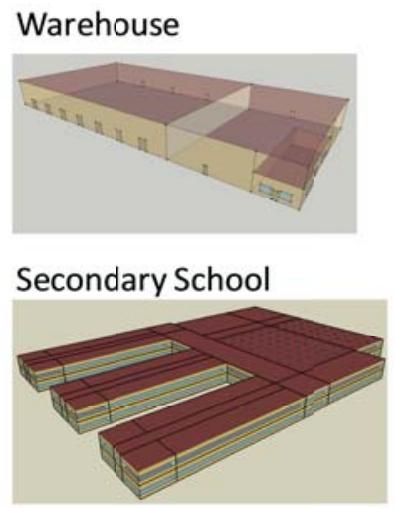

Large Hotel

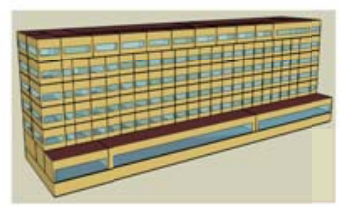

High-rise Apartment

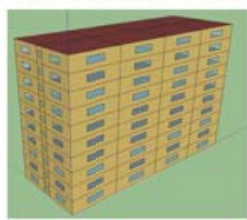

Figure 4.1. 3D Rendering of Prototype Building Models 
Table 4.2. Building Form

\begin{tabular}{lcccccc}
\hline \multicolumn{1}{c}{ Building Prototype } & $\begin{array}{c}\text { Floor area } \\
\left(\mathrm{ft}^{2}\right)\end{array}$ & $\begin{array}{c}\text { Number } \\
\text { of Floors }\end{array}$ & $\begin{array}{c}\text { Aspect } \\
\text { Ratio }\end{array}$ & $\begin{array}{c}\text { Window-to- } \\
\text { Wall Ratio } \\
(\text { WWR })\end{array}$ & $\begin{array}{c}\text { Floor-to- } \\
\text { Floor } \\
\text { Height (ft) }\end{array}$ & $\begin{array}{c}\text { Floor-to- } \\
\text { Ceiling } \\
\text { Height (ft) }\end{array}$ \\
\hline Small Office & 5,500 & 1 & 1.5 & $15 \%$ & 10 & 10 \\
Medium Office & 53,630 & 3 & 1.5 & $33 \%$ & 13 & 9 \\
Large Office & 498,640 & $12^{(\mathrm{a})}$ & 1.5 & $40 \%$ & 13 & 9 \\
Standalone Retail & 24,690 & 1 & 1.28 & $7 \%$ & 20 & 20 \\
Strip Mall & 22,500 & 1 & 4 & $11 \%$ & 17 & 17 \\
Primary School & 73,970 & 1 & NA & $35 \%$ & 13 & 13 \\
Secondary School & 210,910 & 2 & NA & $33 \%$ & 13 & 13 \\
Outpatient Healthcare & 40,950 & 3 & NA & $20 \%$ & 10 & 10 \\
Hospital & 241,410 & $5^{\text {(a) }}$ & 1.33 & $16 \%$ & 14 & 14 \\
Small Hotel & 43,210 & 4 & 3 & $11 \%$ & 9 & 9 \\
& & & & & $11^{(\mathrm{d})}$ & $11^{(\mathrm{d})}$ \\
Large Hotel & 122,120 & $6^{(\mathrm{a})}$ & 5.1 & $27 \%$ & 10 & 10 \\
& & & $3.8^{(\mathrm{b})}$ & & $13^{(\mathrm{d})}$ & $13^{(\mathrm{d})}$ \\
Warehouse & 52,050 & 1 & 2.2 & $0.71 \%{ }^{(\mathrm{c})}$ & 28 & 28 \\
Quick-service Restaurant & 2,500 & 1 & 1 & $14 \%$ & 10 & 10 \\
Full-service Restaurant & 5,500 & 1 & 1 & $18 \%$ & 10 & 10 \\
Mid-rise Apartment & 33,740 & 4 & 2.75 & $15 \%$ & 10 & 10 \\
High-rise Apartment & 84,360 & 10 & 2.75 & $15 \%$ & 10 & 10 \\
\hline
\end{tabular}

(a) These buildings also include a basement, which is not included in the number of floors.

(b) The large hotel basement aspect ratio is 3.8; all other floors have an aspect ratio of 5.1.

(c) For the warehouse, $0.71 \%$ is the overall WWR. The warehouse area has no windows; the WWR for the small office in the warehouse is $12 \%$.

(d) First floor only.

\subsection{Building Envelope}

Chapter 5 of Standard 90.1 provides prescriptive requirements for building envelope thermal performance and other characteristics. These values change with the version of Standard 90.1. Appendix $E$ in this report includes the building envelope prescriptive values from 90.1-2004 and 90.1-2010. Some fundamental characteristics of the building envelope do not change, in particular, the construction type, as shown in Table 4.3. Foundations for all prototypes are slab-on-grade except large office, hospital and hotel which have basements. These constructions are consistent with DOE's Commercial Building Reference Models (Deru et al. 2011). Originally many of these characteristics came from PNNL's analysis of CBECS 2003 information (Winiarski et al. 2007).

To determine the modeled fenestration performance values for Standard 90.1 requirements, the type of fenestration must be defined. Table 4.4 includes weighting factors for the mix of window types in each prototype used to develop the fenestration inputs. For 90.1-2004 the types are operable or fixed. For 90.12007 and 90.1-2010, the types are nonmetal, metal curtain wall/storefront, metal entrance door, and all other metal windows. 
Table 4.3. Roof and Wall Construction Types

\begin{tabular}{lll}
\hline \multicolumn{1}{c}{ Building Prototype } & \multicolumn{1}{c}{ Roof } & \multicolumn{1}{c}{ Exterior Wall } \\
\hline Small Office & Attic and Other & Wood-framed \\
Medium Office & Insulation Entirely Above Deck & Steel-framed \\
Large Office & Insulation Entirely Above Deck & Mass \\
Standalone Retail & Insulation Entirely Above Deck & Mass \\
Strip Mall & Insulation Entirely Above Deck & Steel-framed \\
Primary School & Insulation Entirely Above Deck & Steel-framed \\
Secondary School & Insulation Entirely Above Deck & Steel-framed \\
Outpatient Healthcare & Insulation Entirely Above Deck & Steel-framed \\
Hospital & Insulation Entirely Above Deck & Mass \\
Small Hotel & Insulation Entirely Above Deck & Steel-framed \\
Large Hotel & Insulation Entirely Above Deck & Mass \\
Warehouse & Metal Building Roof & Metal Building \\
Quick-service Restaurant & Attic and Other & Wood-framed \\
Full-service Restaurant & Attic and Other & Steel-framed \\
Mid-rise Apartment & Insulation Entirely Above Deck & Steel-framed \\
High-rise Apartment & Insulation Entirely Above Deck & Steel-framed \\
\hline
\end{tabular}

Table 4.4. Fenestration Type Weighting Factors

\begin{tabular}{|c|c|c|c|c|c|c|}
\hline \multirow[b]{2}{*}{$\begin{array}{l}\text { ASHRAE and Prototype } \\
\text { Building Types }\end{array}$} & \multirow[b]{2}{*}{$\begin{array}{c}\text { Ducker Building } \\
\text { Category }\end{array}$} & \multicolumn{2}{|c|}{$90.1-2004$} & \multicolumn{3}{|c|}{$90.1-2010^{(\mathrm{a})}$} \\
\hline & & Fixed & Operable $^{(a)}$ & Nonmetal & $\begin{array}{c}\text { Metal Curtain } \\
\text { Wall/Storefront }\end{array}$ & $\begin{array}{c}\text { All } \\
\text { Other }\end{array}$ \\
\hline Small Office & Office and Bank & $95 \%$ & $4.6 \%$ & $2 \%$ & $62 \%$ & $36 \%$ \\
\hline Medium Office & & $95 \%$ & $4.6 \%$ & & & \\
\hline Large Office & & $100 \%$ & $0.0 \%$ & & & \\
\hline Standalone Retail & Stores, Other & $98 \%$ & $2 \%$ & $10 \%$ & $62 \%$ & $28 \%$ \\
\hline Strip Mall & Mercantile & & & & & \\
\hline \multicolumn{7}{|l|}{ Quick-service Restaurant } \\
\hline \multicolumn{7}{|l|}{ Full-service Restaurant } \\
\hline Warehouse & $\begin{array}{l}\text { Manufacturing/ } \\
\text { Warehouse }\end{array}$ & $95 \%$ & $5 \%$ & $2 \%$ & $10 \%$ & $88 \%$ \\
\hline Primary School & Educational & $65 \%$ & $35 \%$ & $22 \%$ & $45 \%$ & $34 \%$ \\
\hline Secondary School & & & & & & \\
\hline Outpatient Healthcare & Hospital/Health Care & $88 \%$ & $12 \%$ & $9 \%$ & $60 \%$ & $31 \%$ \\
\hline Hospital & & & & & & \\
\hline Small Hotel & Hotel/Motel/Dormitory & $78 \%$ & $22 \%$ & $11 \%$ & $21 \%$ & $68 \%$ \\
\hline Hotel & & & & & & \\
\hline Mid-rise Apartment & High-rise Multifamily & $42 \%$ & $58 \%$ & $32 \%$ & $5 \%$ & $63 \%$ \\
\hline High-rise Apartment & & & & & & \\
\hline
\end{tabular}


Air leakage reduction is also part of building envelope requirements in Standard 90.1. PNNL has done considerable work in estimating infiltration and air leakage through the building envelope, as described in Infiltration Modeling Guidelines for Commercial Building Energy Analysis (Gowri et al. 2009). Model values used for the 90.1-2004 baseline are generally $0.2016 \mathrm{cfm}$ ) $/ \mathrm{ft}^{2}$ of above-grade exterior wall surface area, adjusted by wind speed.

Addendum 90.1-04c and addendum 90.1-07q (Section 5.2.1.1 of this report) modify infiltration due to changes in vestibule requirements. Addenda 90.1-07am and 90.1-07bf (Section 2.2.1.6 in this report) result in changes to infiltration through the building envelope.

\subsection{Building Occupancy}

People contribute to space loads in the building. Table 4.5 shows the total number of people in each prototype. The number of occupants is modeled with values for each zone depending on type of occupancy, and zone by zone values are included with the zone summaries in Appendix B. The number of people is consistent with DOE's Commercial Reference Buildings Models (Deru et al. 2011), derived from multiple sources, including the Advanced Energy Design Guides. Occupancy is also related to ventilation; but for some prototypes, occupancy for interior loads differs from the default occupancy used to meet the ASHRAE 62.1 ventilation requirements (Section 4.5.5 in this report).

Table 4.5. Building Occupancy

\begin{tabular}{lrcc}
\hline \multicolumn{1}{c}{ Prototype Building } & $\begin{array}{c}\text { Total Floor } \\
\text { Area }\left(\mathrm{ft}^{2}\right)\end{array}$ & $\begin{array}{c}\text { Occupancy } \\
\text { (number of people) }\end{array}$ & $\begin{array}{c}\text { Occupancy } \\
\left(\text { people/1,000 } \mathrm{ft}^{2}\right)\end{array}$ \\
\hline Small Office & 5,500 & 31 & 5.6 \\
Medium Office & 53,630 & 268 & 5.0 \\
Large Office & 498,640 & 2,493 & 5.0 \\
Standalone Retail & 24,690 & 371 & 15.0 \\
Strip Mall & 22,500 & 180 & 8.0 \\
Primary School & 73,970 & 1,477 & 20.0 \\
Secondary School & 210,910 & 6,096 & 28.9 \\
Outpatient Healthcare & 40,950 & 419 & 10.2 \\
Hospital & 241,410 & 767 & 5.0 \\
Small Hotel & 43,210 & 259 & 6.0 \\
Large Hotel & 122,120 & 1,494 & 12.2 \\
Warehouse & 52,050 & 5 & 0.1 \\
Quick-service Restaurant & 2,500 & 94 & 37.6 \\
Full-service Restaurant & 5,500 & 287 & 52.2 \\
Mid-rise Apartment & 33,740 & 79 & 2.3 \\
High-rise Apartment & 84,360 & 199 & 3.4 \\
\hline
\end{tabular}

\subsection{Building HVAC Requirements}

Chapter 6 of Standard 90.1 provides HVAC requirements. The application of these requirements depends largely on the fundamental choice of HVAC system type(s) that are chosen for a building. Once system types are defined, other elements of the 90.1 requirements follow, including system heating and 
cooling equipment efficiency, fan power, and controls. Minimum outdoor airflow is another important characteristic of HVAC systems. Outdoor air requirements vary with the version of Standard 62.1, which sets minimum outdoor air requirements as referenced in the version of Standard 90.1 considered, as described in Chapter 2 in this report. Some characteristics of the HVAC systems, such as the type of HVAC systems, remain the same in most cases for the 90.1-2004 and 2010 models. These characteristics are addressed in this section. Controls vary the most with the changes introduced by the addenda and are addressed primarily in Chapter 5 of this report.

\subsubsection{HVAC Equipment Types}

For most of the prototypes, the primary HVAC system consists of unitary packaged equipment that delivers conditioned air to the thermal zones for comfort. In some cases, central plant equipment, such as chillers and boilers, provide heating and cooling to air-delivery systems. In some buildings, separate secondary systems provide conditioning to selected zones with different operating characteristics from the zones served by the primary systems. The types of systems are generally consistent with DOE's Commercial Reference Buildings which utilize analysis of CBECS 2003 information (Winiarski et al. 2008). Table 4.6 shows these system types.

In most cases, the system types are the same in the 90.1-2004 and 90.1-2010 models. Some singlezone systems that are constant air volume (CAV) systems in the 90.1-2004 models become variable air volume (VAV) systems in the 90.1-2010 models because of the requirement of addendum 90.1-07n (Section 5.2.2.12 in this report). This change occurs depending on system capacity which varies with climate zone. In the simulations, prototypes that experience this change for at least some climate zones are shown with footnote (b) in Table 4.6. Appendix D of this report lists the system name and type used in EnergyPlus models for all 16 prototype buildings.

\subsubsection{HVAC Equipment Capacity}

HVAC equipment capacity varies with external climate conditions, internal loads, and outdoor air ventilation rate. These characteristics change for the different climate locations simulated and for differences between 90.1-2004 and 90.1-2010. The procedures for defining system capacity do not change and are incorporated in the simulation methodology described in Chapter 3 in this report.

HVAC equipment sizing refers to the method used to determine the capacity of the HVAC equipment. EnergyPlus allows users to select a "design day" simulation method for sizing equipment. With this method, two separate design day inputs are specified, one for heating and one for cooling. The program determines the design peak loads by simulating the buildings for a 24-hour period on each of the design days. The design peak loads are then used by the subprogram for sizing HVAC equipment. The analysis for the PI uses the design day sizing method primarily for two reasons: (1) it is common practice for designers to choose the design day method for sizing the HVAC equipment; and (2) using the design day method prevents equipment over-sizing to meet the extreme peak weather conditions occurring for a very short period of time during a year.

The design day data for all 16 climate locations are developed based on the weather data contained in the accompanying CD-ROM of ASHRAE's 2009 Handbook of Fundamentals (ASHRAE 2009). In this data, the heating design day condition selected is based on the $99.6 \%$ annual frequency of occurrence. 
Table 4.6. HVAC Primary and Secondary Equipment

\begin{tabular}{lllll}
\hline \multicolumn{1}{c}{ Building Prototype } & \multicolumn{1}{c}{ Heating } & \multicolumn{1}{c}{ Cooling } & \multicolumn{1}{c}{ Primary System } & Secondary System \\
\hline Small Office & Heat Pump & Unitary DX & Packaged CAV & No \\
Medium Office & Gas Furnace & Unitary DX & $\begin{array}{l}\text { Packaged VAV } \\
\text { w/Reheat }\end{array}$ & No \\
& Boiler & Chiller, Cooling Tower & VAV w/Reheat & No \\
Large Office & Gas Furnace & Unitary DX & Packaged CAV $^{(\mathrm{b})}$ & No \\
Standalone Retail & Gas Furnace & Unitary DX & Packaged CAV $^{(\mathrm{b})}$ & No \\
Strip Mall & Gas Furnace & Unitary DX & Packaged CAV & No \\
Primary School & Boiler & Air-cooled Chiller & VAV w/Reheat & Packaged CAV \\
Secondary School & Boiler & Unitary DX & Packaged VAV & No \\
Outpatient Healthcare & & & w/Reheat & \\
& Boiler & Chiller, Cooling Tower & VAV w/Reheat & Central CAV \\
Hospital & Electricity & DX & PTAC & No \\
Small Hotel & Boiler & Air-cooled chiller & Fan-coil Units & VAV w/Reheat \\
Large Hotel & Gas Furnace & Unitary DX & Unit Heater & Packaged CAV \\
Warehouse & Gas Furnace & Unitary DX & Packaged CAV & No \\
Quick-service Restaurant & Gas Furnace & Unitary DX & Packaged CAV & No \\
Full-service Restaurant & Gas & DX & Split DX system & No \\
Mid-rise Apartment & Gas & WSHP & No \\
High-rise Apartment & Boiler & Fluid Cooler & &
\end{tabular}

(a) DX - direct expansion.

(b) These systems are constant volume in the baseline, and in some cases are VAV in the 90.1-2010 models. See note in text above as well.

(c) PTAC - packaged terminal air conditioners.

The $99.6 \%$ condition means that the dry-bulb temperature occurs at or below the heating design condition for 35 hours per year in cold conditions. Similarly, annual cooling design condition is based on dry-bulb temperature corresponding to $0.4 \%$ annual frequency of occurrence in warm conditions. In EnergyPlus simulations, design day schedules can also be specified. To be consistent with the general design practice for HVAC equipment sizing, the internal loads (occupancy, lights, and plug loads) are scheduled as " 0.0 " on the heating design day, and "1.0" (maximum level) on the cooling design day.

\subsubsection{HVAC Equipment Efficiency}

Equipment efficiency is modeled using the same methodology in the 90.1-2004 and 90.1-2010 models. Efficiency values are assigned automatically according to system capacity as described in Section 3.3 of this report. However, efficiency values change with addenda for many types of equipment from 90.1-2004 to 90.1-2010, as shown in Chapter 5 of this report. Efficiency values are compared on a bookto-book basis between the published 90.1-2004 and 90.1-2010 models. Efficiency values used for the 90.1-2004 models are the values in the original effective date range when the standard began, where different effective dates are listed. For example, single package air conditioners under 65,000 Btu/h have an efficiency of 10 SEER, the value for equipment manufactured prior to January 23, 2006. Values from 90.1-2004 are shown in Tables 4.7 through 4.13. Equipment not shown in these tables is not represented in the prototypes. See 90.1-2004 for testing procedures for efficiency ratings and other notes and definitions. 
Table 4.7. Unitary Air-Conditioner Efficiency, 90.1-2004

\begin{tabular}{|c|c|c|c|c|}
\hline $\begin{array}{l}\text { Equipment } \\
\text { Type }\end{array}$ & Size Category & $\begin{array}{l}\text { Heating Section } \\
\text { Type }\end{array}$ & $\begin{array}{l}\text { Subcategory or } \\
\text { Rating Condition }\end{array}$ & Minimum Efficiency \\
\hline \multirow[t]{5}{*}{$\begin{array}{l}\text { Air } \\
\text { Conditioners, } \\
\text { Air Cooled }\end{array}$} & $<65,000 \mathrm{Btu} / \mathrm{h}$ & All & $\begin{array}{l}\text { Split System } \\
\text { Single Package }\end{array}$ & $\begin{array}{l}\text { 10.0 SEER (before } 1 / 23 / 2006 \text { ) } \\
12.0 \text { SEER (as of } 1 / 23 / 2006 \text { ) } \\
\text { 9.7 SEER (before } 1 / 23 / 2006 \text { ) } \\
\text { 12.0 SEER (as of } 1 / 23 / 2006 \text { ) }\end{array}$ \\
\hline & $\begin{array}{l}\geq 65,000 \mathrm{Btu} / \mathrm{h} \text { and } \\
<135,000 \mathrm{Btu} / \mathrm{h}\end{array}$ & $\begin{array}{l}\text { Electric Resistance } \\
\text { (or none) } \\
\text { All Other }\end{array}$ & $\begin{array}{l}\text { Split System and } \\
\text { Single Package } \\
\text { Split System and } \\
\text { Single Package }\end{array}$ & $\begin{array}{l}\text { 10.3 EER } \\
10.1 \mathrm{EER}\end{array}$ \\
\hline & $\begin{array}{l}\geq 135,000 \mathrm{Btu} / \mathrm{h} \\
\text { and }<240,000 \\
\text { Btu/h }\end{array}$ & $\begin{array}{l}\text { Electric Resistance } \\
\text { (or none) } \\
\text { All Other }\end{array}$ & $\begin{array}{l}\text { Split System and } \\
\text { Single Package } \\
\text { Split System and } \\
\text { Single Package }\end{array}$ & $\begin{array}{l}\text { 9.7 EER } \\
9.5 \mathrm{EER}\end{array}$ \\
\hline & $\begin{array}{l}\geq 240,000 \mathrm{Btu} / \mathrm{h} \\
\text { and }<760,000 \\
\text { Btu/h }\end{array}$ & $\begin{array}{l}\text { Electric Resistance } \\
\text { (or none) } \\
\text { All Other }\end{array}$ & $\begin{array}{l}\text { Split System and } \\
\text { Single Package } \\
\text { Split System and } \\
\text { Single Package }\end{array}$ & $\begin{array}{l}\text { 9.5 EER } \\
\text { 9.7 IPLV } \\
\text { 9.3 EER } \\
\text { 9.5 IPLV }\end{array}$ \\
\hline & $\geq 760,000 \mathrm{Btu} / \mathrm{h}$ & $\begin{array}{l}\text { Electric Resistance } \\
\text { (or none) } \\
\text { All Other }\end{array}$ & $\begin{array}{l}\text { Split System and } \\
\text { Single Package } \\
\text { Split System and } \\
\text { Single Package } \\
\end{array}$ & $\begin{array}{l}\text { 9.2 EER } \\
\text { 9.4 IPLV } \\
\text { 9.0 EER } \\
\text { 9.2 IPLV } \\
\end{array}$ \\
\hline $\begin{array}{l}\text { a) EER - } \\
\text { b) IPLV - }\end{array}$ & ted $n$ & & & \\
\hline
\end{tabular}

Table 4.8. Unitary Air-Cooled Heat Pump Efficiency, 90.1-2004

\begin{tabular}{|c|c|c|c|c|}
\hline Equipment Type & Size Category & $\begin{array}{l}\text { Heating Section } \\
\text { Type } \\
\end{array}$ & $\begin{array}{c}\text { Subcategory or } \\
\text { Rating Condition }\end{array}$ & Minimum Efficiency \\
\hline \multirow[t]{8}{*}{$\begin{array}{l}\text { Air Cooled } \\
\text { (cooling mode) }\end{array}$} & \multirow[t]{2}{*}{$>65,000 \mathrm{Btu} / \mathrm{h}$} & \multirow[t]{2}{*}{ All } & Split System & $\begin{array}{l}\text { 10.0 SEER (before } 1 / 23 / 2006 \text { ) } \\
\text { 12.0 SEER (as of } 1 / 23 / 2006 \text { ) }\end{array}$ \\
\hline & & & Single Package & $\begin{array}{l}\text { 9.7 SEER (before } 1 / 23 / 2006) \\
12.0 \text { SEER /(as of } 1 / 23 / 2006 \text { ) }\end{array}$ \\
\hline & \multirow[t]{2}{*}{$\begin{array}{l}\geq 65,000 \mathrm{Btu} / \mathrm{h} \text { and } \\
<135,000 \mathrm{Btu} / \mathrm{h}\end{array}$} & $\begin{array}{l}\text { Electric } \\
\text { Resistance (or } \\
\text { none) }\end{array}$ & $\begin{array}{l}\text { Split System and } \\
\text { Single Package }\end{array}$ & 10.1 EER \\
\hline & & All Other & $\begin{array}{l}\text { Split System and } \\
\text { Single Package }\end{array}$ & 9.9 EER \\
\hline & \multirow[t]{2}{*}{$\begin{array}{l}\geq 135,000 \mathrm{Btu} / \mathrm{h} \\
\text { and }<240,000 \\
\text { Btu/h }\end{array}$} & $\begin{array}{l}\text { Electric } \\
\text { Resistance (or } \\
\text { none) }\end{array}$ & $\begin{array}{l}\text { Split System and } \\
\text { Single Package }\end{array}$ & 9.3 EER \\
\hline & & All Other & $\begin{array}{l}\text { Split System and } \\
\text { Single Package }\end{array}$ & 9.1 EER \\
\hline & \multirow[t]{2}{*}{$\geq 240,000 \mathrm{Btu} / \mathrm{h}$} & $\begin{array}{l}\text { Electric } \\
\text { Resistance (or } \\
\text { none) }\end{array}$ & $\begin{array}{l}\text { Split System and } \\
\text { Single Package }\end{array}$ & $\begin{array}{l}\text { 9.0 EER } \\
\text { 9.2 IPLV }\end{array}$ \\
\hline & & All Other & $\begin{array}{l}\text { Split System and } \\
\text { Single Package }\end{array}$ & $\begin{array}{l}\text { 8.8 EER } \\
\text { 9.0 IPLV }\end{array}$ \\
\hline
\end{tabular}


Table 4.8 (cont'd)

\begin{tabular}{|c|c|c|c|c|}
\hline Equipment Type & Size Category & $\begin{array}{l}\text { Heating Section } \\
\text { Type }\end{array}$ & $\begin{array}{l}\text { Subcategory or } \\
\text { Rating Condition }\end{array}$ & Minimum Efficiency \\
\hline \multirow[t]{4}{*}{$\begin{array}{l}\text { Air Cooled } \\
\text { (heating mode) }\end{array}$} & \multirow{2}{*}{$\begin{array}{l}\geq 65,000 \mathrm{Btu} / \mathrm{h} \text { and } \\
<135,000 \mathrm{Btu} / \mathrm{h} \\
\text { (cooling capacity) }\end{array}$} & & $\begin{array}{l}47^{\circ} \mathrm{F} \mathrm{db} / 43^{\circ} \mathrm{F} \text { wb } \\
\text { outdoor air }\end{array}$ & $3.2 \mathrm{COP}$ \\
\hline & & & $\begin{array}{l}17^{\circ} \mathrm{F} \mathrm{db} / 15^{\circ} \mathrm{F} w b \\
\text { outdoor air }\end{array}$ & $2.2 \mathrm{COP}$ \\
\hline & \multirow[t]{2}{*}{$\begin{array}{l}\geq 135,000 \mathrm{Btu} / \mathrm{h} \\
\text { (cooling capacity) }\end{array}$} & & $\begin{array}{l}47^{\circ} \mathrm{F} \mathrm{db} / 43^{\circ} \mathrm{F} \mathrm{wb} \\
\text { outdoor air }\end{array}$ & $3.1 \mathrm{COP}$ \\
\hline & & & $\begin{array}{l}17^{\circ} \mathrm{F} \mathrm{db} / 15^{\circ} \mathrm{F} \text { wb } \\
\text { outdoor air }\end{array}$ & $2.0 \mathrm{COP}$ \\
\hline \multirow[t]{3}{*}{$\begin{array}{l}\text { Water-Source } \\
\text { (cooling mode) }\end{array}$} & $<17,000 \mathrm{Btu} / \mathrm{h}$ & All & $\begin{array}{l}86^{\circ} \mathrm{F} \text { Entering } \\
\text { Water }\end{array}$ & 11.2 EER \\
\hline & $\begin{array}{l}\geq 17,000 \mathrm{Btu} / \mathrm{h} \text { and } \\
<65,000 \mathrm{Btu} / \mathrm{h}\end{array}$ & All & $\begin{array}{l}86^{\circ} \mathrm{F} \text { Entering } \\
\text { Water }\end{array}$ & $12.0 \mathrm{EER}$ \\
\hline & $\begin{array}{l}\geq 35,000 \mathrm{Btu} / \mathrm{h} \text { and } \\
<135,000 \mathrm{Btu} / \mathrm{h}\end{array}$ & All & $\begin{array}{l}86^{\circ} \mathrm{F} \text { Entering } \\
\text { Water }\end{array}$ & 12.0 EER \\
\hline $\begin{array}{l}\text { Water-Source } \\
\text { (heating mode) }\end{array}$ & $<135,000 \mathrm{Btu} / \mathrm{h}$ & & $\begin{array}{l}68^{\circ} \mathrm{F} \text { Entering } \\
\text { Water }\end{array}$ & $4.2 \mathrm{COP}$ \\
\hline
\end{tabular}

Table 4.9. Water Chilling Package Efficiency, 90.1-2004

\begin{tabular}{lll}
\hline \multicolumn{1}{c}{ Equipment Type } & \multicolumn{1}{c}{ Size Category } & \multicolumn{1}{c}{ Minimum Efficiency } \\
\hline Air-Cooled with Condenser & All Capacities & 2.80 COP 3.05 IPLV \\
Air-Cooled without Condenser & All Capacities & 3.10 COP 3.45 IPLV \\
Water Cooled, Reciprocating & All Capacities & 4.20 COP 5.05 IPLV \\
Water Cooled, Rotary Screw & $<150$ tons & 4.45 COP 5.20 IPLV \\
and Scroll & $\geq 150$ tons and $<300$ tons & 4.90 COP 5.60 IPLV \\
& $\geq 300$ tons & 5.50 COP 6.15 IPLV \\
Water Cooled, Centrifugal & $<150$ tons & 5.00 COP 5.25 IPLV \\
& $\geq 150$ tons and $<300$ tons & 5.55 COP 5.90 IPLV \\
& $\geq 300$ tons & 6.10 COP 6.40 IPLV \\
\hline
\end{tabular}

Table 4.10. PTAC and Heat Pump Efficiency, 90.1-2004

\begin{tabular}{lcc}
\hline \multicolumn{1}{c}{ Equipment Type } & Size Category & \multicolumn{1}{c}{ Minimum Efficiency } \\
\hline PTAC (Cooling Mode) & All Capacities & $12.5-(0.213 \times$ capacity $/ 1000)$ EER \\
PTHP $^{(a)}$ (Cooling Mode $)$ & All Capacities & $12.3-(0.213 \times$ capacity $/ 1000)$ EER \\
PTHP (Heating Mode) & All Capacities & $3.2-(0.026 \times$ capacity $/ 1000)$ COP \\
\hline
\end{tabular}

(a) PTHP - packaged terminal heat pump

Table 4.11. Warm Air Furnace Efficiency, 90.1-2004

\begin{tabular}{cll}
\hline Equipment Types & Size Category (Input) & \multicolumn{1}{c}{ Minimum Efficiency } \\
\hline Warm Air Furnace, Gas-Fired & $<225,000 \mathrm{Btu} / \mathrm{h}$ & $78 \% \mathrm{AFUE}^{(\mathrm{a})}$ or $80 \% \mathrm{E}_{\mathrm{t}}^{(\mathrm{b})}$ \\
\hline & $\geq 225,000 \mathrm{Btu} / \mathrm{hr}$ & $80 \% \mathrm{E}_{\mathrm{t}}$
\end{tabular}

(a) AFUE - annual fuel utilization efficiency.

(b) $\mathrm{E}_{\mathrm{t}}$ - thermal efficiency. 
Table 4.12. Boiler Efficiency, 90.1-2004

\begin{tabular}{|c|c|c|c|}
\hline Equipment Types & Size Category (input) & $\begin{array}{l}\text { Subcategory or } \\
\text { Rating Condition }\end{array}$ & $\begin{array}{l}\text { Minimum } \\
\text { Efficiency }\end{array}$ \\
\hline \multirow[t]{3}{*}{ Boilers, Gas-Fired } & $<300,000 \mathrm{Btu} / \mathrm{h}$ & Hot Water & $80 \%$ AFUE \\
\hline & $\begin{array}{l}\geq 300,000 \mathrm{Btu} / \mathrm{h} \text { and } \\
\leq 2,500,000 \mathrm{Btu} / \mathrm{h}\end{array}$ & Maximum Capacity & $75 \% \mathrm{E}_{\mathrm{t}}^{(\mathrm{a})}$ \\
\hline & $\geq 2,500,000 \mathrm{Btu} / \mathrm{h}$ & Hot Water & $80 \% \mathrm{E}_{\mathrm{c}}^{(\mathrm{b})}$ \\
\hline
\end{tabular}

(a) $E_{t}-$ thermal efficiency. (b) $E_{c}-$ combustion efficiency.

Table 4.13. Heat Rejection Equipment Performance, 90.1-2004

\begin{tabular}{lcl}
\hline Equipment Type & Size Category & Performance \\
\hline Centrifugal Fan Cooling Towers & All Capacities & $\geq 20.0 \mathrm{gpm} / \mathrm{hp}^{(\mathrm{a})}$ \\
\hline (a) gpm/hp - gallons per minute/horsepower. & \\
\hline
\end{tabular}

In EnergyPlus, the efficiency of DX cooling systems is indicated by entering a COP, which is defined as the cooling power output in watts (W) divided by the electrical power input in watts determined at the same environmental conditions as the EER. However, unlike EER, the COP input in EnergyPlus does not include the rated power consumption of the supply air fan, so the EER needs to be adjusted to remove the effect of the indoor fan energy. The COP input in EnergyPlus is determined by the following equation:

$$
C O P=(E E R / 3.413+R) /(1-R)
$$

where $\mathrm{R}$ is the ratio of supply fan power to total equipment power at the rating condition.

Typical values of fan power ratio $\mathrm{R}$ for a commercial rooftop unit vary from about 0.05 to 0.17 , depending on specific product design choices. For this analysis, a ratio of 0.12 is assumed as being representative of the broad class of products (PNNL 2004).

For packaged single-zone equipment with cooling capacities under $65,000 \mathrm{Btu} / \mathrm{h}$, efficiency is rated by SEER, which represents an average efficiency throughout the year. SEER is defined as the total cooling output of an air conditioner during its normal annual usage period for cooling (in Btu) divided by the total electricity used during the same period (in Wh). For equipment rated by SEER, a conversion from SEER to EER is also required (Wassmer and Brandemuehl 2006).

$$
\mathrm{EER}=-0.0182 * \mathrm{SEER}^{2}+1.1088 * \mathrm{SEER}
$$

The EnergyPlus input for furnace efficiency is thermal efficiency $\mathrm{E}_{\mathrm{t}} \cdot 90.1-2004$ allows gas furnaces with capacity under $225,000 \mathrm{Btu} / \mathrm{h}$ to have a minimum efficiency of $80 \% \mathrm{E}_{\mathrm{t}}$ or AFUE, which, like SEER, represents average annual efficiency. Furnaces with capacity of $225,000 \mathrm{Btu} / \mathrm{h}$ or greater must meet an $80 \%$ combustion efficiency $\left(\mathrm{E}_{\mathrm{c}}\right)$ and are allowed up to $0.75 \%$ jacket losses. $\mathrm{E}_{\mathrm{t}}$ equals the combustion efficiency minus jacket losses. So, the $\mathrm{E}_{\mathrm{t}}$ for furnaces $225,000 \mathrm{Btu} / \mathrm{h}$ and larger are modeled as $79.25 \%$, which is $\mathrm{E}_{\mathrm{c}}$ of $80 \%$ minus $0.75 \%$ jacket losses.

\subsubsection{HVAC System Fan Power}

Fan power for the prototype HVAC systems is guided by the fan power limitation in Section 6.5.3.1 of Standard 90.1. These limits differ in 90.1-2004 and 90.1-2007. Section 5.2.2.5 on addendum 90.1-04ac 
in this report describes the specific development for fan power inputs under the 90.1-2004 and 90.1-2007 fan power allowances. The 90.1-2010 fan power allowance is the same as for 90.1-2007, except that single zone VAV systems are subject to the limitations for constant volume systems and except some other limited differences (addenda 90.1-07n and 90.1-07ca in Section 5.2.2.12 in this report). The general procedure for developing the fan power input is the same for the models under the different versions of Standard 90.1.

The EnergyPlus program simulates fan power by considering three inputs: the design total pressure drop, the total fan efficiency, and the motor efficiency. For modeling systems according to a version of Standard 90.1, where the maximum fan power allowance is provided, the approach is to calculate a corresponding design pressure drop for each air system using the following equation:

$$
\text { Design Pressure Drop }=(\text { brake horsepower } \times \text { fan efficiency } \times 6356) / \mathrm{cfm}
$$

where,

$$
\begin{aligned}
c \mathrm{~cm}= & \text { design supply fan airflow as determined by EnergyPlus sizing runs } \\
\text { fan efficiency }= & 65 \% \text {, based on assumptions used by the SSPC } 90.1 \text { while developing fan } \\
& \text { power requirements for the standard } \\
\text { brake horsepower = } & \text { allowed brake horsepower. }
\end{aligned}
$$

Once the brake horsepower is established for a fan system, the nameplate horsepower is calculated using a $10 \%$ over sizing factor (i.e., nameplate horsepower $=$ brake horsepower $\times 1.1$, as allowed under Standard 90.1). The nameplate motor horsepower is used in calculating the fan motor efficiency based on the requirements in 90.1 .

\subsubsection{Outdoor Air Ventilation}

Outdoor air ventilation rates are not the same for the prototypes as modeled for 90.1 -2004 and 90.12010 because the source of outdoor air minimum flow rates is ASHRAE Standard 62.1, and different versions govern the inputs for 90.1-2004 and 90.1-2010 models (ventilation in this section refers to outdoor air flow). Standard 62-1999 is the reference standard for ventilation for 90.1-2004; Standard 62.1-2004 is the reference ventilation standard for 90.1-2007; and Standard 62.1-2007 is the reference standard in 90.1-2010. Standards 62.1-2004 and 62.1-2007 have identical minimum outdoor air rates for the prototype models. Hospital ventilation, described below, follows a similar approach using information from other sources in addition to Standard 62 or 62.1, including the AIA Guidelines for Design and Construction of Hospitals and Health Care Facilities, referred to as AIA Guidelines (AIA 2001). Ventilation rates are provided per person or per square foot in intermittently occupied spaces, such as corridors, or in some cases are provided as a prescriptive $\mathrm{cfm}$ value.

To use the ventilation rates in Standard 62 or 62.1 , the modeled zones need to be identified by space type corresponding to the ventilation rates. Space types are not defined the same in all cases between the different versions of Standard 62. A consistent mapping of thermal zones to space types is needed. The space types in 62.1-2004 (and 2007) are used to identify spaces when possible. Where there is no direct equivalency in 62-1999 space types with those in 62.1-2004, assumptions are made about equivalent space types in Standard 62-1999. In some cases, ventilation rates depend on the number of occupants. To maintain consistency in occupancy numbers, the 62.1-2004 default occupancy density values are used 
when available for the 90.1-2004 models and subsequently for the 90.1-2010 models. 62-1999 default occupancy density values are used if values are not available in 62.1-2004.

Adjustments are made for particular prototypes and space types, including the following items:

- For the primary and secondary school buildings, the occupancy density from the technical support analysis for the Advanced Energy Design Guide for K-12 Schools (AEDG K-12 School) (Pless et al. 2007) is used, except the corridor and lobby areas, which are included with no occupancy.

- For the two hotel prototype buildings, an occupant density of 1.5 persons per standard guestroom (and 2 persons per suite) is used based on the technical support analysis for the Advanced Energy Design Guide for Highway Lodging (AEDG Highway Lodging) (Jiang et al. 2008).

- For hotel guestrooms, ASHRAE 62-1999 requires $30 \mathrm{cfm}$ per living room and bedroom and $35 \mathrm{cfm}$ per bath, regardless of area, for a total of $65 \mathrm{cfm}$. For bathrooms, the $35 \mathrm{cfm}$ requirement is the installed capacity for intermittent use. Based on the interpretation from ASHRAE (http://www.ashrae.org/technology/page/913), the $35 \mathrm{cfm}$ of outdoor air in bathrooms can be supplied to the hotel/motel bedroom and then exhausted through the bathroom at the same rate. Therefore, a ventilation rate of $35 \mathrm{cfm}$ is used for guestrooms rather than $65 \mathrm{cfm}$. This rate is consistent with the technical support analysis for the AEDG Highway Lodging (Jiang et al. 2008).

- For apartment prototype residence zones, both Standards 62-1999 and 62.1-2004 require 0.35 air changes per hour $(\mathrm{ACH})$ but not less than $15 \mathrm{cfm}$ per person for each room in the living area, 25 $\mathrm{cfm}$ for the kitchen, and $20 \mathrm{cfm}$ for baths (continuous). In addition, the ventilation standard also allows transfer air from living areas to compensate the exhausted air for kitchens and baths. Therefore, the outdoor air rate for a single-bedroom apartment is the maximum of $45 \mathrm{cfm}$ (kitchen and bath) and $0.35 \mathrm{ACH}$. In the apartment prototypes, each apartment unit has $950 \mathrm{ft}^{2}$ conditioned floor area and a floor-to-ceiling height of $10 \mathrm{ft}$ so $0.35 \mathrm{ACH}$ for the apartments is $55 \mathrm{cfm}$. Thus, the outdoor air rate per single-bedroom apartment unit is $55 \mathrm{cfm}$, or $27.5 \mathrm{cfm} /$ person.

- For hospitals and outpatient healthcare, ventilation rates are developed in medical critical zones using additional sources of information, including the AIA Guidelines identified above (AIA 2001).

Ventilation rates are determined for each zone based on its space type. Values shown in Table 4.14 are total ventilation airflows based on the sum of each zone's ventilation rate. For VAV systems, system ventilation rates are calculated using the multiple-zone re-circulating systems requirements in Standard 62.1-2004 (same in 62.1-2007) starting from the single-zone ventilation rates at the zone level. The multizone ventilation rate procedure results in different final outdoor ventilation air quantities for the same prototype in different climate zones and with different zones and system supply airflow. This procedure is described in this report in Section 5.2.2.21 on addendum 90.1-07ck in this report, which requires VAV systems to include ventilation reset controls. 
Table 4.14. Prototypes Outdoor Air Ventilation

\begin{tabular}{|c|c|c|c|c|c|c|}
\hline \multirow[b]{2}{*}{ Prototype Building } & \multirow{2}{*}{$\begin{array}{l}\text { Total } \\
\text { Floor } \\
\text { Area } \\
\left(\mathrm{ft}^{2}\right)\end{array}$} & \multirow{2}{*}{$\begin{array}{c}\text { Total } \\
\text { Occupants } \\
\text { (based on } \\
62.1-2004 \text { ) }\end{array}$} & \multicolumn{2}{|c|}{$\begin{array}{l}\text { Total Outdoor Air } \\
\text { Ventilation }(\mathrm{cfm})\end{array}$} & \multicolumn{2}{|c|}{$\begin{array}{l}\text { Total Outdoor Air } \\
\text { Ventilation }\left(\mathrm{cfm} / \mathrm{ft}^{2}\right)\end{array}$} \\
\hline & & & $\begin{array}{c}62-1999 \\
(90.1-2004)\end{array}$ & $\begin{array}{c}62.1-2007 \\
(90.1-2010)\end{array}$ & $\begin{array}{c}62-1999 \\
(90.1-2004)\end{array}$ & $\begin{array}{c}62.1-2007 \\
(90.1-2010)\end{array}$ \\
\hline Small Office & 5,500 & 28 & 550 & 468 & 0.100 & 0.085 \\
\hline Medium Office & 53,633 & 268 & 5,363 & 4,559 & 0.100 & 0.085 \\
\hline Large Office & 498,639 & 2,493 & 49,864 & 42,384 & 0.100 & 0.085 \\
\hline Standalone Retail & 24,695 & 370 & 6,795 & 5,281 & 0.275 & 0.214 \\
\hline Strip Mall & 22,500 & 337 & 6,750 & 5,231 & 0.300 & 0.233 \\
\hline Primary School & 73,966 & 1,433 & 30,550 & 25,041 & 0.413 & 0.339 \\
\hline Secondary School & 210,908 & 6,095 & 110,728 & 71,740 & 0.525 & 0.340 \\
\hline Outpatient Healthcare & 40,946 & 419 & 9,959 & 8,389 & 0.243 & 0.207 \\
\hline Hospital & 201,177 & 581 & 30,969 & 42,789 & 0.154 & 0.213 \\
\hline Small Hotel & 43,207 & 239 & 5,699 & 3,914 & 0.132 & 0.091 \\
\hline Large Hotel & 122,115 & 1,494 & 30,247 & 19,172 & 0.248 & 0.157 \\
\hline Warehouse & 52,050 & 13 & 2,730 & 3,187 & 0.052 & 0.061 \\
\hline Quick-service Restaurant & 2,501 & 94 & 1,841 & 1,757 & 0.736 & 0.703 \\
\hline Full-service Restaurant & 5,503 & 288 & 5,715 & 3,872 & 1.039 & 0.704 \\
\hline Mid-rise Apartment & 33,744 & 67 & 1,967 & 1,986 & 0.058 & 0.059 \\
\hline High-rise Apartment & 84,361 & 163 & 4,858 & 4,927 & 0.058 & 0.058 \\
\hline
\end{tabular}

\subsection{Service Water Heating Equipment}

Service water heating provides for general hot water usage such as lavatory sinks as well as specific loads, including commercial kitchens and laundry facilities, which are included in some of the prototypes. Peak loads are consistent with DOE's Commercial Reference Buildings (Deru et al. 2011). The simulations combine loads and storage into a single water heater for most prototype models, although loads on an hourly basis may use separate hourly schedules with the combined hourly load applied to the single water heater. Some prototypes model more than one water heater: the small hotel prototype separates the laundry and guestroom loads into two separate water heaters; the strip mall prototype includes one water heater per store; and, the apartment prototype includes one water heater per apartment. See Appendix $C$ in this report for service water heating schedules that include hourly fraction of peak usage. Service water heating efficiency remains the same for the 90.1-2004 and 90.1-2010 models and complies with minimum efficiency requirements in 90.1-2004 (see Table 4.15). 
Table 4.15. Service Water Heating Equipment

\begin{tabular}{|c|c|c|c|c|}
\hline Prototype Building & $\begin{array}{l}\text { Water Heater } \\
\text { Energy Type }\end{array}$ & $\begin{array}{c}\text { Modeled Water } \\
\text { Heaters } \\
\text { (quantity) } \\
\end{array}$ & $\begin{array}{l}\text { Storage Capacity } \\
\text { (gallons) }\end{array}$ & $\begin{array}{c}\text { Peak Load } \\
\text { (gallons/hour) }\end{array}$ \\
\hline Small Office & Natural Gas & 1 & 40 & 3 \\
\hline Medium Office & Natural Gas & 1 & 260 & 30 \\
\hline Large Office & Natural Gas & 1 & 260 & 256 \\
\hline Standalone Retail & Natural Gas & 1 & 40 & 18 \\
\hline Strip Mall & Natural Gas & 7 & 6 & 2 \\
\hline Primary School $^{(\mathrm{a})}$ & Natural Gas & 1 & 264 & 157 \\
\hline Secondary School ${ }^{(\mathrm{b})}$ & Natural Gas & 1 & 792 & 427 \\
\hline Outpatient Healthcare & Natural Gas & 1 & 793 & 30 \\
\hline Hospital $^{(\mathrm{c})}$ & Natural Gas & 1 & 800 & 265 \\
\hline Small Hotel - Laundry & Natural Gas & 1 & 100 & 202 \\
\hline Small Hotel - Guestrooms & Natural Gas & 1 & 200 & 135 \\
\hline Large Hotel ${ }^{(\mathrm{d})}$ & Natural Gas & 1 & 528 & 380 \\
\hline Warehouse & Electric & 1 & 20 & 8 \\
\hline Quick-service Restaurant & Natural Gas & 1 & 53 & 40 \\
\hline Full-service Restaurant & Natural Gas & 1 & 53 & 133 \\
\hline Mid-rise Apartment (each) & Electric & 1 & 20 & 4 \\
\hline High-rise Apartment (each) & Electric & 1 & 20 & 4 \\
\hline \multicolumn{5}{|c|}{$\begin{array}{l}\text { (a) Primary school peak load includes } 100 \text { gallons per hour (gph) for kitchen and } 56.5 \text { gph for other uses. } \\
\text { (b) Secondary school peak load includes } 133 \text { gph for kitchen, } 189.5 \text { gph for gym locker rooms, and } 104.4 \text { gph for } \\
\text { other uses. } \\
\text { (c) Hospital peak load includes } 150 \text { gph for kitchen and } 115 \text { gph for other uses. } \\
\text { (d) Large hotel peak includes } 156.6 \text { gph for laundry and } 223.8 \text { gph for guestrooms. }\end{array}$} \\
\hline
\end{tabular}

\subsection{Lighting}

\subsubsection{Interior Lighting}

Interior lighting is defined using the same methodology for the prototypes for both the 90.1-2004 and the 90.1-2010 models. For all of the models, except for the small, medium, and large office, the lighting power density (LPD) values are implemented using the space-by-space method in Standard 90.1 and zones are assigned to lighting space types with different LPD values for each space. For the offices, the general office LPD value from the building area method in Standard 90.1 is used since the zones are not broken out by 90.1 lighting space type. 90.1-2004 and 90.1-2007 have the same LPD values for interior lighting. A number of different addenda change the values going to 90.1-2010, principally addendum 90.1-07by (Section 5.2.4.7 in this report), which has an overall revision of the LPD allowance. Other addenda, such as addendum 90.1-07x (Section 5.2.4.3 in this report), which adds occupancy sensor control to more space types, also result in changes to modeled LPD. The retail strip mall values also include additional display lighting. Display lighting for the 90.1-2004 and 90.1-2010 models is described with addenda 90.1-04ai and 90.1-07bq (Section 5.2.4.6) which affect display lighting. 
In the simulation, the spaces in the model that use the space-by-space method are all assigned a Standard 90.1 space type. For each space type, the value for the LPD is assigned for the 90.1-2004 models and the adjusted values with the cumulative addenda leading to the final 90.1-2010 models. Table 4.16 shows an example for the overall LPD values for the 90.1-2004 case and the development of the 90.12010 values. See the addendum descriptions in Chapter 5 in this report for the basis of the values and reductions shown.

Table 4.16. Secondary School Example of LPD Inputs Development

\begin{tabular}{|c|c|c|c|c|c|c|c|}
\hline & Lighting Space & $90.1-2004$ & $90.1-2007$ & $\begin{array}{c}\text { New } \\
\text { Starting } \\
\text { Values from } \\
\text { Addendum } \\
\text { 90.1-07by } \\
\text { and 90.1- } \\
07 \mathrm{de}\end{array}$ & $\begin{array}{l}\text { Addendum } \\
90.1-07 x \\
\text { Reduction }\end{array}$ & $\begin{array}{l}\text { Addendum } \\
90.1-07 \mathrm{cf} \\
\text { Reduction }\end{array}$ & $90.1-2010$ \\
\hline Index & Type Parameter & \multicolumn{6}{|c|}{$\operatorname{LPD}\left(\mathrm{W} / \mathrm{ft}^{2}\right)$} \\
\hline 1 & LPD_classroom & 1.4 & 1.4 & 1.24 & 0.0966 & NA & 1.1434 \\
\hline 2 & LPD_corridor & 0.5 & 0.5 & 0.67 & 0.0966 & 0.0341 & 0.5393 \\
\hline 3 & LPD_lobby & 1.3 & 1.3 & 0.9 & 0.0966 & NA & 0.8034 \\
\hline 4 & LPD_mechanic & 1.5 & 1.5 & 0.95 & 0.0966 & NA & 0.8534 \\
\hline 5 & LPD_bath & 0.9 & 0.9 & 0.98 & 0.0966 & NA & 0.8834 \\
\hline 6 & LPD_office & 1.1 & 1.1 & 1.11 & 0.0966 & NA & 1.0134 \\
\hline 7 & LPD_gym & 1.4 & 1.4 & 0.72 & 0.0966 & NA & 0.6234 \\
\hline 8 & LPD_kitchen & 1.2 & 1.2 & 0.99 & 0.0966 & NA & 0.8934 \\
\hline 9 & LPD_cafeteria & 0.9 & 0.9 & 0.65 & 0.0966 & NA & 0.5534 \\
\hline 10 & LPD_library & 1.3 & 1.3 & 1.18 & 0.0966 & NA & 1.0834 \\
\hline 11 & LPD auditorium & 0.9 & 0.9 & 0.79 & 0.0966 & NA & 0.6934 \\
\hline
\end{tabular}

\subsubsection{Exterior Lighting}

90.1-2004 introduced exterior lighting wattage allowances for different parts of building exteriors, such as parking areas, facades, building grounds, entrances, and exits. Exterior lighting power allowances are provided based on different units such as $\mathrm{W} / \mathrm{ft}^{2}, \mathrm{~W} / \mathrm{ft}$ and $\mathrm{W} /$ door. These allowances were not changed in 90.1-2007 but were changed in addendum i to 90.1-2007 (Section 5.2.4.2 in this report). To evaluate the savings for these changes, the exterior lighting is developed in greater detail than in earlier version of the prototype models. Addendum 90.1-07i includes the exterior lighting wattage values that are included in the simulations. This section presents the exterior lighting assumptions behind the development of the exterior wattage values. PNNL and the SSPC 90.1 Lighting Subcommittee developed the parking area, number of doors (entry, rolling, and other), and lit facade areas for each prototype. Tables 4.17 through 4.19 summarize the values determined for each component. The primary data source for the parking area and the door assumptions is the $\mathrm{NC}^{3}$ database (Richman et al. 2008). The primary data for the facade lighting are from a PNNL survey of four experienced lighting design professionals on the SSPC 90.1 Lighting Subcommittee. 
Table 4.17. Illuminated Parking Area

\begin{tabular}{|c|c|c|c|}
\hline Building Prototype & $\begin{array}{c}\text { Total } \\
\text { Floor } \\
\text { Area } \\
\left(\mathrm{ft}^{2}\right)\end{array}$ & $\begin{array}{c}\text { Number of } \\
\text { Parking Spaces } \\
\text { per Unit Shown }\end{array}$ & $\begin{array}{c}\text { Total } \\
\text { Parking Area } \\
\left(\mathrm{ft}^{2}\right)\end{array}$ \\
\hline Small Office & 5,500 & 4 per $1,000 \mathrm{ft}^{2}$ & 8,910 \\
\hline Medium Office & 53,600 & 4 per $1,000 \mathrm{ft}^{2}$ & 86,832 \\
\hline Large Office & 498,600 & 1 per $620 \mathrm{ft}^{2}$ & 325,112 \\
\hline Standalone Retail & 24,695 & 3.5 per $1,000 \mathrm{ft}^{2}$ & 35,005 \\
\hline Strip Mall & 22,500 & 1 per $215 \mathrm{ft}^{2}$ & 42,373 \\
\hline Primary School & 73,960 & 1 per 17 students & 14,683 \\
\hline Secondary School & 210,900 & 1 per 8 students & 59,316 \\
\hline Outpatient Healthcare & 40,950 & 1 per $200 \mathrm{ft}^{2}$ & 82,924 \\
\hline Hospital & 241,410 & 1.2 per bed & 77,435 \\
\hline Small Hotel & 43,200 & 1 per room & 33,680 \\
\hline Large Hotel & 122,130 & 1 per room & 88,538 \\
\hline Warehouse & 49,500 & 1 per $1,000 \mathrm{ft}^{2}$ & 20,048 \\
\hline Quick-service Restaurant & 2,500 & 1 per $100 \mathrm{ft}^{2}$ & 10,125 \\
\hline Full-service Restaurant & 5,500 & 1 per $100 \mathrm{ft}^{2}$ & 22,275 \\
\hline Mid-rise Apartment & 33,700 & 2.2 per unit & 28,578 \\
\hline High-rise Apartment & 84,360 & 2.2 per unit & 71,537 \\
\hline
\end{tabular}

Table 4.18. Number of Doors by Door Type

\begin{tabular}{|c|c|c|c|c|c|c|c|}
\hline Building Prototype & $\begin{array}{c}\text { Ground } \\
\text { Floor } \\
\text { Footprint } \\
\text { Area } \\
\mathrm{ft}^{2} \\
\end{array}$ & $\begin{array}{c}\text { Rollup } \\
\text { Doors per } \\
10,000 \mathrm{ft}^{2} \\
\text { of Building } \\
\text { Footprint }\end{array}$ & $\begin{array}{c}\text { Entrance } \\
\text { Doors per } \\
10,000 \mathrm{ft}^{2} \\
\text { of Building } \\
\text { Footprint }\end{array}$ & $\begin{array}{c}\text { Other } \\
\text { Doors per } \\
10,000 \mathrm{ft}^{2} \\
\text { of Building } \\
\text { Footprint }\end{array}$ & $\begin{array}{c}\text { Total } \\
\text { Rollup } \\
\text { Doors }\end{array}$ & $\begin{array}{c}\text { Total } \\
\text { Entrance } \\
\text { Doors }^{(\mathrm{a})}\end{array}$ & $\begin{array}{c}\text { Total } \\
\text { Other } \\
\text { Doors }{ }^{(a)}\end{array}$ \\
\hline Small Office & 5,500 & 0.47 & 2.00 & 2.00 & 0.26 & 1.10 & 1.10 \\
\hline Medium Office & 17,876 & 0.13 & 1.00 & 3.00 & 0.24 & 1.79 & 5.36 \\
\hline Large Office & 38,400 & 0.00 & 1.00 & 3.00 & 0.02 & 3.84 & 11.52 \\
\hline Stand-alone Retail & 24,695 & 1.84 & 1.00 & 2.93 & 4.54 & 2.47 & 7.23 \\
\hline Strip Mall & 22,500 & 0.05 & 6.00 & 6.60 & 0.11 & 13.50 & 14.85 \\
\hline Primary School & 73,960 & 0.07 & 2.00 & 3.30 & 0.54 & 14.79 & 24.38 \\
\hline Secondary School & 128,242 & 0.10 & 2.00 & 2.45 & 1.31 & 25.65 & 31.38 \\
\hline Outpatient & 40,950 & 0.10 & 1.00 & 5.19 & 0.40 & 4.10 & 21.26 \\
\hline Hospital & 40,250 & 0.03 & 2.00 & 3.80 & 0.14 & 8.05 & 15.29 \\
\hline Small Hotel & 10,800 & 0.00 & 2.00 & 28.91 & 0.00 & 2.16 & 31.22 \\
\hline Large Hotel & 21,300 & 0.01 & 1.00 & 2.27 & 0.03 & 2.13 & 4.83 \\
\hline Warehouse & 49,500 & 3.67 & 1.00 & 2.00 & 18.15 & 4.95 & 9.88 \\
\hline $\begin{array}{l}\text { Quick-service } \\
\text { Restaurant }\end{array}$ & 2,500 & 0.00 & 2.00 & 1.00 & 0.00 & 0.50 & 0.25 \\
\hline $\begin{array}{l}\text { Full-service } \\
\text { Restaurant }\end{array}$ & 5,500 & 0.00 & 1.00 & 3.00 & 0.00 & 0.55 & 1.65 \\
\hline
\end{tabular}


Table 4.19. Illuminated Facade Areas

\begin{tabular}{|c|c|c|c|c|c|c|c|c|c|c|c|c|c|c|}
\hline \multirow[b]{2}{*}{ Building Prototype } & \multicolumn{4}{|c|}{$\begin{array}{l}\text { Average Length of } \\
\text { Lit Facade Wall (ft) }\end{array}$} & \multicolumn{4}{|c|}{ Wall Length (ft) } & \multirow{2}{*}{$\begin{array}{l}\text { Wall } \\
\text { Height } \\
\text { (ft) }\end{array}$} & \multicolumn{5}{|c|}{$\begin{array}{c}\text { Illuminated } \\
\text { Facade Area }{ }^{(\mathrm{a})}\left(\mathrm{ft}^{2}\right)\end{array}$} \\
\hline & Front & Side 1 & Side 2 & Back & Front & Side 1 & Side 2 & Back & & Front & Side 1 & Side 2 & Back & Total \\
\hline Small Office & 27.5 & 10.0 & 10.0 & 3.8 & 91 & 61 & 61 & 91 & 10 & 250 & 61 & 61 & 34 & 405 \\
\hline Medium Office & 41.3 & 15.0 & 15.0 & 3.8 & 164 & 109 & 109 & 164 & 39 & 2,638 & 638 & 638 & 240 & 4,154 \\
\hline Large Office & 76.3 & 43.8 & 43.8 & 38.8 & 240 & 160 & 160 & 240 & 156 & 28,548 & 10,920 & 10,920 & 14,508 & 64,896 \\
\hline Standalone Retail & 41.3 & 17.5 & 17.5 & 2.5 & 178 & 139 & 139 & 178 & 20 & 1,469 & 487 & 487 & 89 & 2,531 \\
\hline Strip Mall & 61.3 & 6.3 & 6.3 & 1.3 & 300 & 75 & 75 & 300 & 17 & 3,124 & 80 & 80 & 64 & 3,347 \\
\hline Primary School & 10.0 & 3.8 & 3.8 & 2.5 & 764 & 270 & 270 & 764 & 13 & 993 & 132 & 132 & 248 & 1,505 \\
\hline Secondary School & 10.0 & 3.8 & 3.8 & 2.5 & 883 & 341 & 341 & 883 & 26 & 2,296 & 332 & 332 & 574 & 3,535 \\
\hline $\begin{array}{l}\text { Outpatient } \\
\text { Healthcare }\end{array}$ & 18.8 & 3.8 & 3.8 & 3.8 & 166 & 120 & 120 & 166 & 30 & 934 & 135 & 135 & 187 & 1,391 \\
\hline Hospital & 71.3 & 15.0 & 15.0 & 10.0 & 230 & 175 & 175 & 230 & 70 & 11,471 & 1,838 & 1,838 & 1,610 & 16,756 \\
\hline Small Hotel & 30.0 & 16.3 & 16.3 & 15.0 & 180 & 60 & 60 & 180 & 38 & 2,052 & 371 & 371 & 1,026 & 3,819 \\
\hline Large Hotel & 82.5 & 75.0 & 75.0 & 47.5 & 284 & 56 & 56 & 284 & 63 & 14,761 & 2,646 & 2,646 & 8,499 & 28,552 \\
\hline Warehouse & 6.7 & 1.7 & 1.7 & 1.7 & 330 & 150 & 150 & 330 & 28 & 616 & 70 & 70 & 154 & 910 \\
\hline $\begin{array}{l}\text { Quick-service } \\
\text { Restaurant }\end{array}$ & 63.8 & 51.3 & 40.0 & 8.8 & 50 & 50 & 50 & 50 & 10 & 319 & 256 & 200 & 44 & 819 \\
\hline $\begin{array}{l}\text { Full-service } \\
\text { Restaurant }\end{array}$ & 52.5 & 41.3 & 41.3 & 3.8 & 74 & 74 & 74 & 74 & 10 & 389 & 305 & 305 & 28 & 1,027 \\
\hline $\begin{array}{l}\text { Mid-rise } \\
\text { apartment }\end{array}$ & 18.8 & 7.5 & 7.5 & 5.0 & 152 & 56 & 56 & 152 & 40 & 1,140 & 167 & 167 & 304 & 1,777 \\
\hline $\begin{array}{l}\text { High-rise } \\
\text { apartment }\end{array}$ & 42.5 & 32.5 & 32.5 & 27.5 & 152 & 56 & 56 & 152 & 100 & 6,460 & 1,804 & 1,804 & 4,180 & 14,248 \\
\hline
\end{tabular}




\subsection{Other Equipment}

Chapter 10 of Standard 90.1 applies to specified energy using equipment not covered elsewhere in Standard 90.1. Prior to 90.1-2010, the chapter only includes requirements for electric motors. These mandatory requirements are minimum efficiency for National Electric Manufacturers Association (NEMA) Type A and Type B motors. Motor efficiency values are updated by addendum 90.1-07aj. Section 5.2.5.1 in this report describes how these values are changed from the 90.1-2004 and 90.1-2007 Table 10.8 values to the 90.1-2010 Tables $10.8 \mathrm{~A}$ and $\mathrm{B}$ values.

Chapter 10 of 90.1-2010 introduces requirements for service water heating booster pumps, and elevator fans and lights. The service water heating booster pump requirements are added by addendum $90.1-07 \mathrm{cv}$. None of the prototypes include service water heating booster pumps and potential energy savings for this addendum are not quantified in the PI. Elevator fans and lights are described in Section 4.8.2 of this report and under addendum 90.1-07df (Section 5.2.5.2 in this report).

Chapter 10 of 90.1 does not currently regulate most plug and process loads, but these may be the subject of future editions of Standard 90.1. However, these loads are included in the prototypes in order to more accurately capture typical building energy usage and to include the impact of these loads on HVAC sizing and energy usage. This section of the report describes these loads including general plug loads, elevators, commercial kitchens and laundry facilities.

\subsubsection{General Plug Loads}

Equipment loads for receptacle plug-in devices such as appliances, office equipment, and specialty medical equipment vary by building type. Table 4.20 summarizes the equipment power density for these types of loads. These loads do not include elevator, kitchen, and laundry equipment loads, which are described in Sections 4.9.2 through 4.9.5 below. The values shown for each prototype are the sum of the wattage for these types of loads, divided by the total building area. The values are consistent with DOE's Commercial Reference Building Models (Deru et al. 2011). The mid-rise and high-rise apartment building plug loads are developed based on research from DOE's Building America Research Benchmark (http://www1.eere.energy.gov/buildings/building_america/index.html). PNNL's scorecards contain detailed information in the corresponding model input worksheets (http://www.energycodes.gov/commercial/901models/).

\subsubsection{Elevators}

Elevators use energy for the elevator motors that move the elevators and for lights and fans that serve the elevator cabin. The characteristics of these energy uses in the prototypes are described in this section.

\subsubsection{Elevator Motors}

The energy usage of elevator motors is modeled for the prototype buildings with multiple floors as interior or exterior electric loads, depending on the number of building stories. For buildings with fewer 
Table 4.20. General Plug Loads

\begin{tabular}{lrc}
\hline \multicolumn{1}{c}{ Prototype Building } & $\begin{array}{c}\text { Total Floor } \\
\text { Area }\left(\mathrm{ft}^{2}\right)\end{array}$ & $\begin{array}{c}\text { Plug Loads } \\
\left(\mathrm{W} / \mathrm{ft}^{2}\right)\end{array}$ \\
\hline Small Office & 5,500 & 0.63 \\
Medium Office & 53,630 & 0.75 \\
Large Office & 498,640 & 0.73 \\
Standalone Retail & 24,690 & 0.50 \\
Strip Mall & 22,500 & 0.40 \\
Primary School & 73,970 & 1.00 \\
Secondary School & 210,910 & 0.67 \\
Outpatient Healthcare & 40,950 & 1.79 \\
Hospital & 241,410 & 1.05 \\
Small Hotel & 43,210 & 0.95 \\
Large Hotel & 122,120 & 0.58 \\
Warehouse & 52,050 & 0.19 \\
Quick-service Restaurant & 2,500 & 0.00 \\
Full-service Restaurant & 5,500 & 0.00 \\
Mid-rise Apartment & 33,740 & 0.56 \\
High-rise Apartment & 84,360 & 0.56 \\
\hline
\end{tabular}

than six stories (including the basement), hydraulic motors are assumed and the electric load is added to first floor core zone. For buildings with six stories or more, traction motors are assumed and the load is modeled as exterior to the buildings. The peak power of elevator motors are estimated using the same assumptions as DOE's Commercial Reference Building Models (Deru et al. 2011) as shown in Table 4.21 below. EnergyPlus simulation does not directly model motor efficiency for elevators; wattage shown in Table 4.21 includes the effect of this motor efficiency. Because a high-rise apartment building is not included in the Commercial Reference Building Models, one elevator for every 90 units is assumed. The operation schedules of elevators are shown in Appendix $\mathrm{C}$ in this report.

\subsubsection{Elevator Lights and Fans}

The elevator lights and ventilation fans are also modeled as electric loads, which are applied to the same locations as the elevator motors. Their power is estimated based on a standard size elevator car with a length of $6.66 \mathrm{ft}$, width of $4.25 \mathrm{ft}$, and height of $8 \mathrm{ft}$. The lighting is assumed to be $70 \%$ from incandescent light source (10 lumens/W and $4 \mathrm{~W} / \mathrm{ft}^{2}$ ) and 30\% from higher efficacy light source (35 lumens $/ \mathrm{W}$ and $1.14 \mathrm{~W} / \mathrm{ft}^{2}$ ). The ventilation rate is assumed to be one air change per minute with ventilation power of $0.33 \mathrm{~W} / \mathrm{cfm}$. Based on these assumptions, the baseline lighting and ventilation fan power is calculated to be $88 \mathrm{~W}$ and $74 \mathrm{~W}$ per elevator car, respectively. Addendum 90.1-07df restricts elevator lights and fans, as shown in Section 5.2.5 of this report. Table 4.22 summarizes the baseline elevator lighting assumptions. The lights and fans are assumed to be always on. These assumptions were provided by the 90.1 Elevator Working Groups, which is also responsible for developing addendum 90.107df. 
Table 4.21. Elevator Motor Power

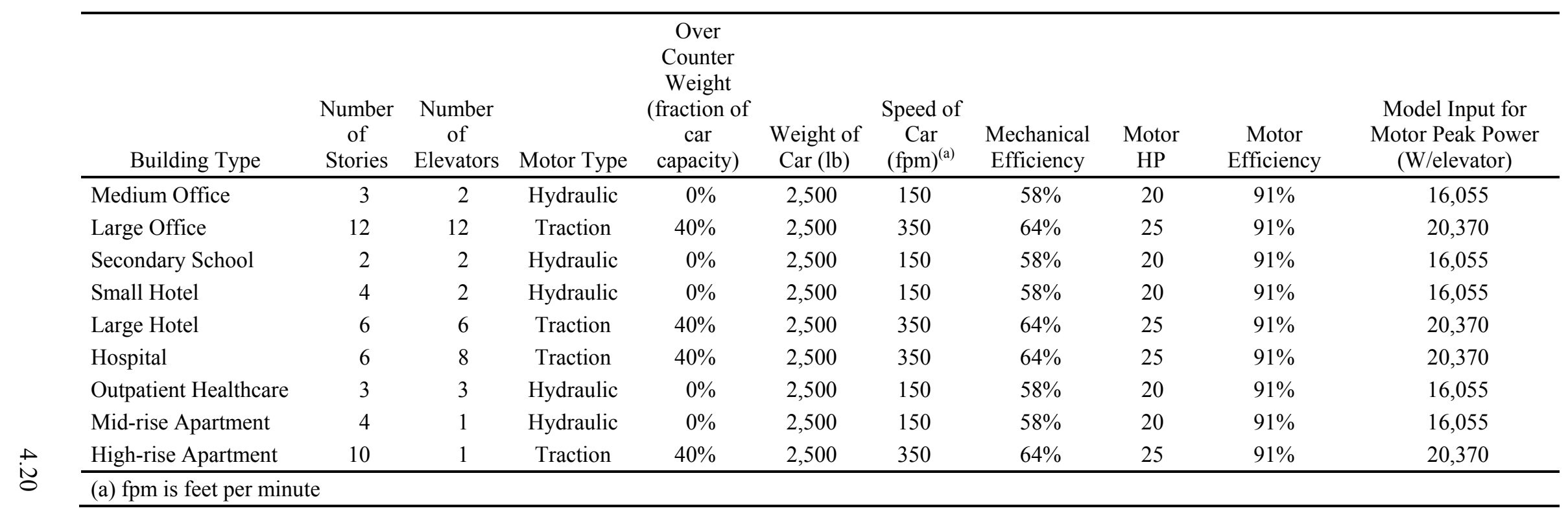

Table 4.22. Elevator Lighting

\begin{tabular}{ll}
\hline Lighting Characteristic & Value \\
\hline Design Lighting Level & 30 lumens $/ \mathrm{ft}^{2}$ \\
\hline Light Loss Factor & $75 \%$ \\
Needed Light Level & 40 lumens $/ \mathrm{ft}^{2}$ \\
Incandescent (70\%) & 10 lumens/W \\
& $4 \mathrm{~W} / \mathrm{ft}^{2}$ \\
\hline High Efficacy Source (30\%) & 35 lumens/W \\
& $1.14 \mathrm{~W} / \mathrm{ft}^{2}$ \\
\hline Average Efficacy & 17.5 lumens/W \\
Average LPD & $3.14 \mathrm{~W} / \mathrm{ft}^{2}$ \\
\hline Lighting Power & $88 \mathrm{~W} / \mathrm{elevator}$ \\
\hline
\end{tabular}




\subsubsection{Commercial Kitchens}

Six prototype buildings are modeled with commercial kitchens: primary school, secondary school, quick-service restaurant, full-service restaurant, large hotel, and hospital. The electric and gas energy consumption for food preparation is modeled as zone plug loads and include cooking appliances and reach-in refrigerators. Kitchen exhaust and use of transfer air are modeled. Walk-in coolers and freezers are modeled separately from reach-in refrigerators as described below. The gas cooking load is in kitchen zones and the electricity load is distributed in kitchen and dining zones.

Table 4.23 summarizes the peak load for cooking and other receptacle loads in the commercial kitchens for the six applicable prototypes. These loads represent the total installed capacity of the equipment. These values were derived from an earlier version of DOE's Commercial Reference Building Models. The operating schedules of the electric and gas loads are shown in Appendix $\mathrm{C}$ in this report.

Table 4.23. Kitchen Cooking Loads

\begin{tabular}{lccc}
\hline & \multicolumn{3}{c}{ Food Preparation Load } \\
\cline { 2 - 4 } & $\begin{array}{c}\text { Natural Gas in } \\
\text { Kitchen }(\mathrm{kW})\end{array}$ & $\begin{array}{c}\text { Electricity in Kitchen } \\
(\mathrm{kW})\end{array}$ & $\begin{array}{c}\text { Electricity in Dining Area } \\
(\mathrm{kW})\end{array}$ \\
\hline Primary School & 240 & 32 & 8 \\
Secondary School & 363 & 48 & 48 \\
Quick-service Restaurant & 92 & 31 & 14 \\
Full-service Restaurant & 91 & 56 & 24 \\
Large Hotel & 250 & 52 & 22 \\
Hospital & 150 & 75 & 0 \\
\hline
\end{tabular}

The selection of kitchen exhaust hoods should be specific to the cooking appliances used. Because the hypothetical kitchens of the prototype buildings do not have detailed kitchen equipment information, assumptions for total kitchen exhaust flow rate are made based on engineering judgment and a review of actual kitchen designs (see Table 4.24). A review of the F.W. Dodge Drawings for quick-service restaurants indicates that a common design practice is to transfer air from the dining zone to the kitchen as part of the replacement air for the exhaust hoods (F.W. Dodge 2002). The amount of transfer air depends on how much outdoor ventilation air is available in the dining zone. The other five buildings were assumed not to use transfer air, and the replacement air for kitchen exhaust hoods is assumed to be from zone supply air.

Refrigeration for commercial kitchens typically includes walk-in refrigerators and freezers. This type of refrigeration is included in selected prototypes as shown in Table 4.25 (Deru et al. 2011). The walk-in refrigeration equipment is modeled in EnergyPlus using the refrigeration module, not just wattage power, and schedules as are implemented with other receptacle loads. Smaller standalone refrigeration equipment is incorporated with the kitchen wattage inputs above. 


\subsubsection{Laundry}

Laundry equipment is explicitly modeled for the small and large hotel. Laundry uses natural gas for service water heating and dryers and electricity for receptacle loads for the washers and dryers. Laundry service water heating loads are included in Table 4.15 above. The large hotel laundry receptacle load is $5.7 \mathrm{~W} / \mathrm{ft}^{2}$; the dryer gas load is equivalent to $49.8 \mathrm{~W} / \mathrm{ft}^{2}$; and the laundry room is $840 \mathrm{ft}^{2}$. The small hotel laundry receptacle load is $2.0 \mathrm{~W} / \mathrm{ft}^{2}$; the dryer gas load is equivalent to $17.1 \mathrm{~W} / \mathrm{ft}^{2}$; and the laundry room is $1,053 \mathrm{ft}^{2}$. These values are derived from DOE's Commercial Reference Buildings Models (Deru et al. 2011). 
Table 4.24. Kitchen Exhaust and Transfer Air

\begin{tabular}{lcc} 
& Total Exhaust Airflow Rate $(\mathrm{cfm})$ & Use of Available Transfer Air \\
\hline Primary School & 5,000 & No \\
Secondary School & 6,000 & No \\
Quick-service Restaurant & 3,300 & Yes \\
Full-service Restaurant & 6,000 & No \\
Large Hotel & 4,000 & No \\
Hospital & 8,000 & No \\
\hline
\end{tabular}

Table 4.25. Refrigeration - Walk-in Coolers and Freezers

\begin{tabular}{|c|c|c|c|c|c|c|c|c|c|c|}
\hline Building Type & Area $\left(\mathrm{ft}^{2}\right)$ & $\begin{array}{c}\text { Length } \\
(\mathrm{ft})\end{array}$ & $\begin{array}{l}\text { Cooling } \\
\text { Capacity } \\
(\mathrm{kBtu} / \mathrm{h})\end{array}$ & $\mathrm{COP}$ & $\begin{array}{c}\text { Evaporator } \\
\text { Fan } \\
(\mathrm{W})\end{array}$ & $\begin{array}{c}\text { Condenser } \\
\text { Fan } \\
(\mathrm{W})\end{array}$ & $\begin{array}{c}\text { Lighting } \\
\left(\mathrm{W} / \mathrm{ft}^{2}\right)\end{array}$ & $\begin{array}{c}\text { Defrost } \\
(\mathrm{W})\end{array}$ & $\begin{array}{l}\text { Anti- } \\
\text { Sweat } \\
\text { (W) }\end{array}$ & $\begin{array}{c}\text { Heat } \\
\text { Rejection } \\
\text { Location } \\
\end{array}$ \\
\hline \multicolumn{11}{|c|}{ Walk-in Coolers } \\
\hline Primary School & 120 & 12 & 9.2 & 3 & 200 & 350 & 1 & 0 & 0 & Outdoors \\
\hline Secondary School & 240 & 24 & 19.1 & 3 & 400 & 750 & 1 & 0 & 0 & Outdoors \\
\hline Quick-service Restaurant & 100 & 10 & 7.7 & 3 & 200 & 330 & 1 & 0 & 0 & Outdoors \\
\hline Full-service Restaurant & 100 & 10 & 7.7 & 3 & 200 & 330 & 1 & 0 & 0 & Outdoors \\
\hline Large Hotel & 120 & 12 & 9.2 & 3 & 200 & 350 & 1 & 0 & 0 & Outdoors \\
\hline Hospital & 360 & 29 & 27 & 3 & 600 & 1,000 & 1 & 0 & 0 & Outdoors \\
\hline \multicolumn{11}{|c|}{ Walk-in Freezers } \\
\hline Primary School & 120 & 12 & 9.2 & 1.5 & 250 & 350 & 1 & 2,000 & 0 & Outdoors \\
\hline Secondary School & 240 & 24 & 18.3 & 1.5 & 500 & 750 & 1 & 3,000 & 0 & Outdoors \\
\hline Quick-service Restaurant & 80 & 8 & 5.7 & 1.5 & 180 & 329 & 1 & 2,000 & 0 & Outdoors \\
\hline Full-service Restaurant & 80 & 8 & 5.7 & 1.5 & 180 & 329 & 1 & 2,000 & 0 & Outdoors \\
\hline Large Hotel & 120 & 24 & 9.2 & 1.5 & 250 & 350 & 1 & 2,000 & 0 & Outdoors \\
\hline Hospital & 360 & 36 & 27.5 & 1.5 & 760 & 1,000 & 1 & 4,000 & 0 & Outdoors \\
\hline
\end{tabular}




\subsection{Modeling of Specific Addenda}

With the agreement of DOE and ASHRAE to achieve 30\% energy savings with the 90.1-2010 Standard, the number of addenda to 90.1-2007 approved during the three-year Standard development cycle is unprecedented compared with previous updates to the standard. 90.1-2010 incorporates 109 approved addenda to 90.1-2007. In contrast, 90.1-2007 contains 44 approved addenda to 90.1-2004. In the PI process, PNNL reviewed and considered the combined total of 153 addenda for quantitative analysis of the 2010 edition versus the 2004 edition. Of the 153 addenda, the energy savings of 53 are quantified in the final analysis. This chapter describes the categorization of all of the addenda, summarizes the content of the addenda, and provides modeling strategies and Energy Plus implementation for 53 identified addenda that can be quantified in the prototype building models.

\subsection{Addenda Characterization}

The 153 addenda reviewed in the PI can be sorted a number of different ways. There are 118 addenda that are incorporated in the mandatory and prescriptive requirements of Chapters 5 through 10 of 90.1 2010; the remaining 35 addenda only affect other chapters and appendixes. Of those that are incorporated in Chapters 5 to 10 of 90.1-2010, some are thought to result in energy savings that can be quantified in the analysis; some may result in energy savings but cannot be captured in the analysis; and some are not expected lead to energy savings. Figure 5.1 shows the number in each category and, for the addenda with quantified savings, shows the number of addenda associated with the chapters in 90.1-2010 that are affected. There are no addenda associated with Chapter 7 on service water heating.

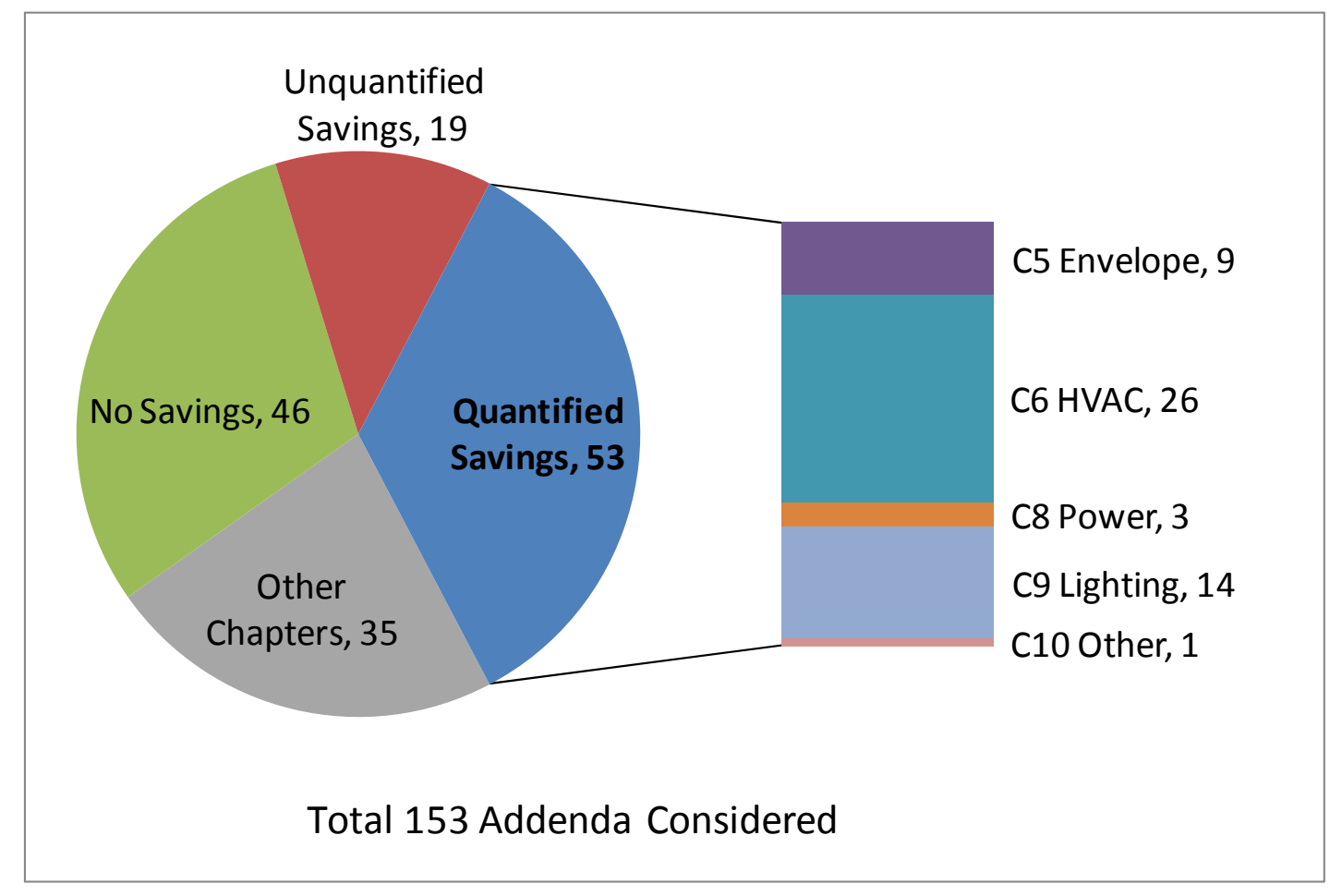

Figure 5.1. Addenda by Category and Quantity 
Tables 5.1 through 5.3 include brief descriptions and other information for the 118 addenda in Chapters 5 through 10 of Standard 90.1. Table 5.1 includes the 53 addenda with quantified savings and identifies the affected prototypes in the modeling. Table 5.2 includes 19 addenda with potential savings not quantified in the PI and explains why the savings are not quantified. Table 5.3 includes the remaining addenda that do not have identified savings; 9 of these addenda may result in increased energy use believed to be negligible relative to total energy savings.

Addenda are listed in these tables in a sorted hierarchy: (1) by the relevant 90.1 chapter, (2) with 2004 addenda first, followed by 2007 addenda, and (3) sequentially by alphabetical letter name of the addenda with two letter names following single letter names, e.g., "t" before "aa."

Addenda that affect more than one chapter in 90.1, for example, those creating changes to the building envelope and lighting controls for daylighting, are sorted into the 90.1 chapter that is primarily responsible for the energy savings. For daylighting, adding skylights can actually increase energy usage; and while necessary to bring in the daylight, the lighting controls then allow energy to be saved. Therefore, these addenda are included with Standard 90.1, Chapter 9, lighting addenda. Other affected 90.1 chapters are identified in the list as well. 
Table 5.1. Addenda with Quantified Savings in PI

\begin{tabular}{|c|c|c|c|c|c|c|c|c|c|c|c|c|c|c|c|c|c|c|}
\hline \multirow[b]{2}{*}{$\begin{array}{c}90.1 \\
\text { Addenda }\end{array}$} & \multirow[b]{2}{*}{$\begin{array}{c}90.1 \\
\text { Chapter(s) } \\
\text { Affected }\end{array}$} & \multirow[b]{2}{*}{ Description } & \multicolumn{16}{|c|}{ Prototypes Affected } \\
\hline & & & 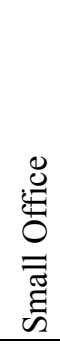 & 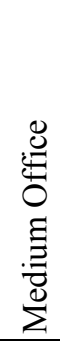 & 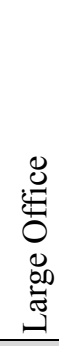 & 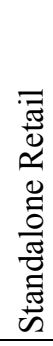 & 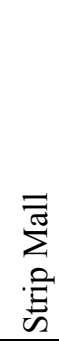 & 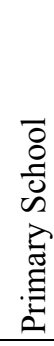 & 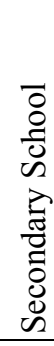 & 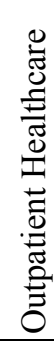 & 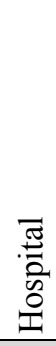 & 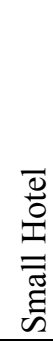 & 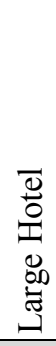 & 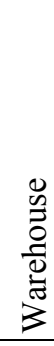 & 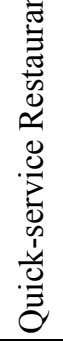 & 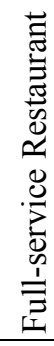 & 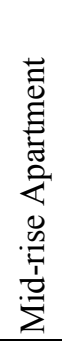 & 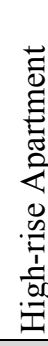 \\
\hline $90.1-04 c$ & 5. Envelope & $\begin{array}{l}\text { Revises the definition of building } \\
\text { entrance to include vestibules and } \\
\text { clarifies the requirements and } \\
\text { exceptions for vestibules. }\end{array}$ & $\mathrm{X}$ & $\mathrm{X}$ & & $\mathrm{X}$ & $\mathrm{X}$ & $\mathrm{X}$ & $X$ & $X$ & & $X$ & & $\mathrm{X}$ & $\mathrm{X}$ & $\mathrm{X}$ & $X$ & \\
\hline 90.1-04as & 5. Envelope & $\begin{array}{l}\text { Modifies the opaque assembly } \\
\text { requirements in Tables } 5.5-1 \\
\text { through } 5.5-8 \text {. }\end{array}$ & $\mathrm{X}$ & $\mathrm{X}$ & $\mathrm{X}$ & $\mathrm{X}$ & $\mathrm{X}$ & $\mathrm{X}$ & $X$ & $X$ & $\mathrm{X}$ & $X$ & $\mathrm{X}$ & $\mathrm{X}$ & $\mathrm{X}$ & $\mathrm{X}$ & $X$ & $X$ \\
\hline 90.1-04at & 5. Envelope & $\begin{array}{l}\text { Modifies the fenestration } \\
\text { requirements in Tables 5.5-1 } \\
\text { through 5.5-8. }\end{array}$ & $\mathrm{X}$ & $\mathrm{X}$ & $\mathrm{X}$ & $\mathrm{X}$ & $\mathrm{X}$ & $\mathrm{X}$ & $\mathrm{X}$ & $\mathrm{X}$ & $\mathrm{X}$ & $X$ & $\mathrm{X}$ & $\mathrm{X}$ & $\mathrm{X}$ & $\mathrm{X}$ & $X$ & $X$ \\
\hline $90.1-07 f$ & 5. Envelope & $\begin{array}{l}\text { Sets requirements for high-albedo } \\
\text { roofs. }\end{array}$ & & $\mathrm{X}$ & $\mathrm{X}$ & $\mathrm{X}$ & $\mathrm{X}$ & $\mathrm{X}$ & $\mathrm{X}$ & $\mathrm{X}$ & $\mathrm{X}$ & $X$ & $\mathrm{X}$ & & & & $\mathrm{X}$ & $\mathrm{X}$ \\
\hline $90.1-07 \mathrm{~g}$ & 5. Envelope & $\begin{array}{l}\text { Updates the building envelope } \\
\text { criteria for metal buildings. }\end{array}$ & & & & & & & & & & & & $\mathrm{X}$ & & & & \\
\hline $90.1-07 q$ & 5. Envelope & $\begin{array}{l}\text { Removes the exception to } \\
\text { vestibule requirements in Climate } \\
\text { Zone } 4 .\end{array}$ & $\mathrm{X}$ & & & & & & & & & & & & $\mathrm{X}$ & $\mathrm{X}$ & & \\
\hline $\begin{array}{l}90.1- \\
07 \mathrm{am}\end{array}$ & 5. Envelope & $\begin{array}{l}\text { Revises air leakage criteria for } \\
\text { windows and doors. }\end{array}$ & $\mathrm{X}$ & $\mathrm{X}$ & $\mathrm{X}$ & $\mathrm{X}$ & $\mathrm{X}$ & $\mathrm{X}$ & $\mathrm{X}$ & $\mathrm{X}$ & $X$ & $X$ & $X$ & $\mathrm{X}$ & $\mathrm{X}$ & $\mathrm{X}$ & $\mathrm{X}$ & $\mathrm{X}$ \\
\hline $90.1-07 b f$ & 5. Envelope & $\begin{array}{l}\text { Requires continuous air barrier } \\
\text { and performance requirements for } \\
\text { air leakage of opaque envelope } \\
\text { elements. }\end{array}$ & $\mathrm{X}$ & $\mathrm{X}$ & $\mathrm{X}$ & $\mathrm{X}$ & $\mathrm{X}$ & $\mathrm{X}$ & $\mathrm{X}$ & $\mathrm{X}$ & $X$ & $X$ & $X$ & $\mathrm{X}$ & $\mathrm{X}$ & $\mathrm{X}$ & $\mathrm{X}$ & $X$ \\
\hline
\end{tabular}


Table 5.1. (cont'd)

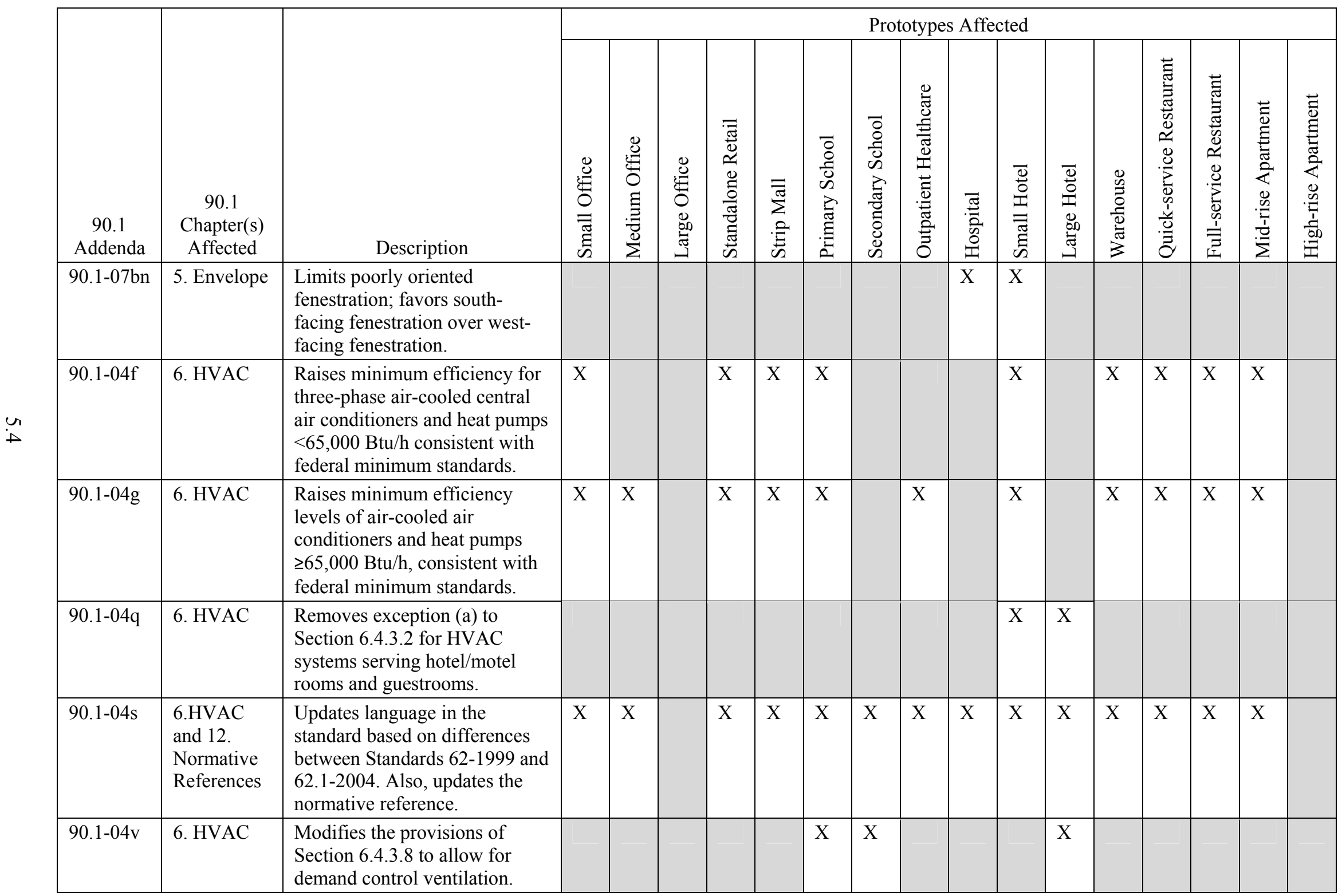


Table 5.1. (cont'd)

\begin{tabular}{|c|c|c|c|c|c|c|c|c|c|c|c|c|c|c|c|c|c|c|}
\hline \multirow[b]{2}{*}{$\begin{array}{c}90.1 \\
\text { Addenda } \\
\end{array}$} & \multirow[b]{2}{*}{$\begin{array}{c}90.1 \\
\text { Chapter(s) } \\
\text { Affected }\end{array}$} & \multirow[b]{2}{*}{ Description } & \multicolumn{16}{|c|}{ Prototypes Affected } \\
\hline & & & 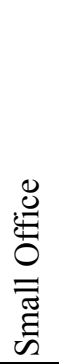 & 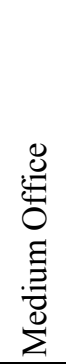 & 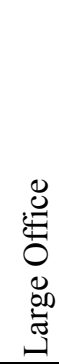 & 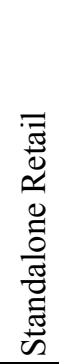 & 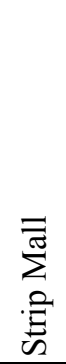 & 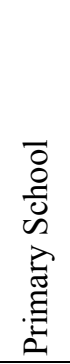 & 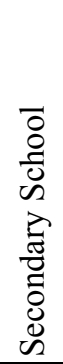 & 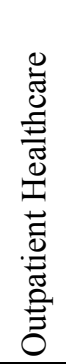 & 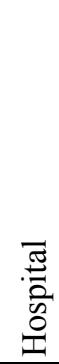 & 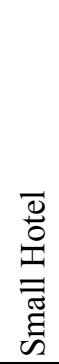 & 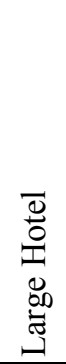 & 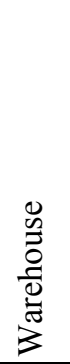 & 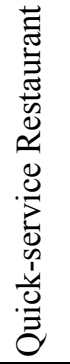 & 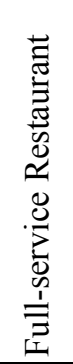 & 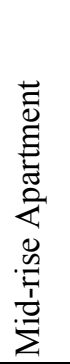 & 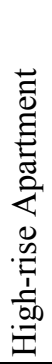 \\
\hline $90.1-04 a c$ & $\begin{array}{l}\text { 6. HVAC } \\
\text { and } 3 . \\
\text { Definitions }\end{array}$ & $\begin{array}{l}\text { Modifies the fan power } \\
\text { limitation requirements in } \\
\text { Section 6.5.3. }\end{array}$ & & $\mathrm{X}$ & $\mathrm{X}$ & $\mathrm{X}$ & $\mathrm{X}$ & $\mathrm{X}$ & $\mathrm{X}$ & $\mathrm{X}$ & $\mathrm{X}$ & $\mathrm{X}$ & $\mathrm{X}$ & & & $\mathrm{X}$ & & \\
\hline 90.1-04an & 6. HVAC & $\begin{array}{l}\text { Modifies the equipment } \\
\text { efficiency requirements for } \\
\text { commercial boilers in Table } \\
6.8 .1 \mathrm{~F} \text {. }\end{array}$ & & & $\mathrm{X}$ & & & & $\mathrm{X}$ & & $\mathrm{X}$ & & $\mathrm{X}$ & & & & & \\
\hline $90.1-04 \mathrm{ao}$ & 6. HVAC & $\begin{array}{l}\text { Adds footnote for unit heater } \\
\text { efficiency requiring intermittent } \\
\text { ignition devices, power } \\
\text { venting, or flue dampers to } \\
\text { comply with federal law. }\end{array}$ & & & & & & & & & & & & $\mathrm{X}$ & & & & \\
\hline 90.1-04ar & 6. HVAC & $\begin{array}{l}\text { Lowers the part-load fan power } \\
\text { limitation from } 15 \text { to } 10 \mathrm{hp} \text { in } \\
\text { Section } 6.5 .3 .2 .1 \text {. }\end{array}$ & & $X$ & & & & $\mathrm{X}$ & $\mathrm{X}$ & & & & & & & & & \\
\hline $90.1-07 \mathrm{e}$ & 6. HVAC & $\begin{array}{l}\text { Modifies requirements for } \\
\text { energy recovery. }\end{array}$ & & & $\mathrm{X}$ & $\mathrm{X}$ & & $\mathrm{X}$ & $\mathrm{X}$ & & $\mathrm{X}$ & & & & & & & \\
\hline $90.1-07 \mathrm{~h}$ & 6. HVAC & $\begin{array}{l}\text { Revises the airflow limits for } \\
\text { which new energy may be used } \\
\text { for reheating or re-cooling in } \\
\text { DDC systems. }\end{array}$ & & $\mathrm{X}$ & $\mathrm{X}$ & & & $\mathrm{X}$ & $\mathrm{X}$ & $\mathrm{X}$ & $\mathrm{X}$ & & $\mathrm{X}$ & & & & & \\
\hline $90.1-07 \mathrm{~m}$ & 6. HVAC & $\begin{array}{l}\text { Increases minimum chiller } \\
\text { performance and adds a second } \\
\text { Path B for alternative chiller } \\
\text { efficiency requirements. }\end{array}$ & & & $\mathrm{X}$ & & & & $\mathrm{X}$ & & $\mathrm{X}$ & & $\mathrm{X}$ & & & & & \\
\hline
\end{tabular}


Table 5.1. (cont'd)

\begin{tabular}{|c|c|c|c|c|c|c|c|c|c|c|c|c|c|c|c|c|c|c|}
\hline $\begin{array}{c}90.1 \\
\text { Addenda }\end{array}$ & $\begin{array}{c}90.1 \\
\text { Chapter(s) } \\
\text { Affected }\end{array}$ & Description & \multicolumn{16}{|c|}{ Prototypes Affected } \\
\hline $90.1-07 n$ & 6. HVAC & $\begin{array}{l}\text { Establishes requirements for } \\
\text { single zone VAV fan } \\
\text { modulation on cooling units. } \\
\text { For chilled water systems } 5 \mathrm{hp} \\
\text { and greater the requirement is } \\
\text { effective } 1 / 1 / 10 \text {. For DX } \\
\text { systems } 110,000 \text { Btuh cooling } \\
\text { capacity and greater, the } \\
\text { requirement is effective } 1 / 1 / 12 \text {. }\end{array}$ & & & & $\mathrm{X}$ & $\mathrm{X}$ & $\mathrm{X}$ & $\mathrm{X}$ & & & & & & $\mathrm{X}$ & $\mathrm{X}$ & & \\
\hline $90.1-07 u$ & 6. HVAC & $\begin{array}{l}\text { Requires open cooling towers } \\
\text { with centrifugal fan units over } \\
1,100 \text { gpm at the rating } \\
\text { conditions to meet the energy } \\
\text { efficiency requirements for } \\
\text { axial fan units. }\end{array}$ & & & $\mathrm{X}$ & & & & & & $\mathrm{X}$ & & & & & & & \\
\hline $90.1-07 \mathrm{af}$ & 6. HVAC & $\begin{array}{l}\text { Prescribes maximum flow rates } \\
\text { through chilled water and } \\
\text { condenser water piping. }\end{array}$ & & & $\mathrm{X}$ & & & & $\mathrm{X}$ & & $\mathrm{X}$ & & $\mathrm{X}$ & & & & & $\mathrm{X}$ \\
\hline
\end{tabular}


Table 5.1. (cont'd)

\begin{tabular}{|c|c|c|c|c|c|c|c|c|c|c|c|c|c|c|c|c|c|c|}
\hline $\begin{array}{c}90.1 \\
\text { Addenda }\end{array}$ & $\begin{array}{c}90.1 \\
\text { Chapter(s) } \\
\text { Affected }\end{array}$ & Description & \multicolumn{16}{|c|}{ Prototypes Affected } \\
\hline 90.1-07as & 6. HVAC & $\begin{array}{l}\text { Removes exception for VAV } \\
\text { turndown for zones with special } \\
\text { pressurization requirements. } \\
\text { Reduces laboratory threshold } \\
\text { requiring VAV or heat } \\
\text { recovery. }\end{array}$ & & & & & & & & $\mathrm{X}$ & $\mathrm{X}$ & & & & & & & \\
\hline 90.1-07ax & 6. HVAC & $\begin{array}{l}\text { Modifies the requirements for } \\
\text { kitchen hood exhaust and } \\
\text { make-up air systems. }\end{array}$ & & & & & & $\mathrm{X}$ & $\mathrm{X}$ & & $\mathrm{X}$ & & $\mathrm{X}$ & & $\mathrm{X}$ & $\mathrm{X}$ & & \\
\hline 90.1-07bh & 6. HVAC & $\begin{array}{l}\text { Requires supply air temperature } \\
\text { to be reset for multi-zone } \\
\text { HVAC systems. }\end{array}$ & & $\mathrm{X}$ & $\mathrm{X}$ & & & $\mathrm{X}$ & $\mathrm{X}$ & $\mathrm{X}$ & $\mathrm{X}$ & & $\mathrm{X}$ & & & & & \\
\hline
\end{tabular}


Table 5.1. (cont'd)

\begin{tabular}{|c|c|c|c|c|c|c|c|c|c|c|c|c|c|c|c|c|c|c|}
\hline \multirow[b]{2}{*}{$\begin{array}{c}90.1 \\
\text { Addenda }\end{array}$} & \multirow[b]{2}{*}{$\begin{array}{c}90.1 \\
\text { Chapter(s) } \\
\text { Affected }\end{array}$} & \multirow[b]{2}{*}{ Description } & \multicolumn{16}{|c|}{ Prototypes Affected } \\
\hline & & & 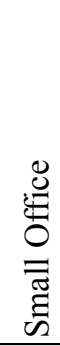 & 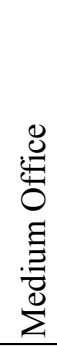 & 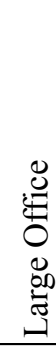 & 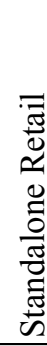 & 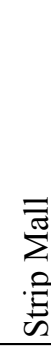 & 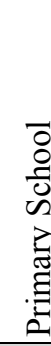 & 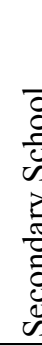 & 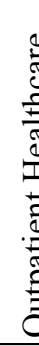 & & 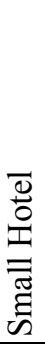 & \begin{tabular}{l}
$\overline{0}$ \\
0 \\
0 \\
0 \\
0 \\
0 \\
\multirow{J}{*}{}
\end{tabular} & 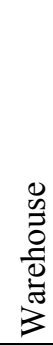 & 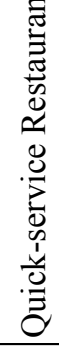 & 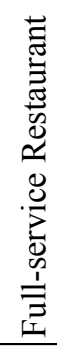 & 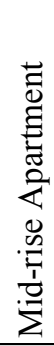 & 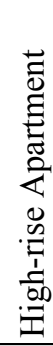 \\
\hline $\begin{array}{l}90.1- \\
07 \mathrm{bw}\end{array}$ & 6. HVAC & $\begin{array}{l}\text { Improves PTAC and PTHP } \\
\text { efficiency. }\end{array}$ & & & & & & & & & & $X$ & & & & & & \\
\hline $90.1-07 \mathrm{ca}$ & 6. HVAC & $\begin{array}{l}\text { Requires that single-zone VAV } \\
\text { systems meet the fan power } \\
\text { requirements for constant } \\
\text { volume systems. }\end{array}$ & & & & $\mathrm{X}$ & $\mathrm{X}$ & $\mathrm{X}$ & $\mathrm{X}$ & & & & & & $\mathrm{X}$ & $\mathrm{X}$ & & \\
\hline $90.1-07 \mathrm{cb}$ & 6. HVAC & $\begin{array}{l}\text { Removes the exception for } \\
\text { automatic damper requirements } \\
\text { for buildings under3 stories in } \\
\text { height. }\end{array}$ & $\mathrm{X}$ & & & $\mathrm{X}$ & $\mathrm{X}$ & $\mathrm{X}$ & $\mathrm{X}$ & & & & & $\mathrm{X}$ & $\mathrm{X}$ & $\mathrm{X}$ & & \\
\hline $90.1-07 \mathrm{cc}$ & 6. HVAC & $\begin{array}{l}\text { Modifies pipe sizing table for } \\
8 \text { " pipe. }\end{array}$ & & & $\mathrm{X}$ & & & & $\mathrm{X}$ & & $X$ & & $\mathrm{X}$ & & & & & $X$ \\
\hline $90.1-07 \mathrm{ck}$ & $\begin{array}{l}\text { 6. HVAC } \\
\text { and } 12 . \\
\text { Normative } \\
\text { References }\end{array}$ & $\begin{array}{l}\text { Requires multi-zone VAV } \\
\text { systems to have controls that } \\
\text { optimize ventilation. }\end{array}$ & & $\mathrm{X}$ & $\mathrm{X}$ & & & & & $\mathrm{X}$ & $X$ & & $\mathrm{X}$ & & & & & \\
\hline $90.1-07 \mathrm{cy}$ & 6. HVAC & $\begin{array}{l}\text { Updates economizer } \\
\text { requirements. }\end{array}$ & $\mathrm{X}$ & $\mathrm{X}$ & $\mathrm{X}$ & $\mathrm{X}$ & $\mathrm{X}$ & $\mathrm{X}$ & $\mathrm{X}$ & $\mathrm{X}$ & 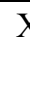 & $X$ & $\mathrm{X}$ & $\mathrm{X}$ & $\mathrm{X}$ & $\mathrm{X}$ & & \\
\hline $90.1-07 \mathrm{dj}$ & 6. HVAC & $\begin{array}{l}\text { Limits pressure drop of energy } \\
\text { recovery devices. }\end{array}$ & & & $\mathrm{X}$ & $\mathrm{X}$ & & $\mathrm{X}$ & $\mathrm{X}$ & & 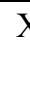 & & & & & & & \\
\hline $90.1-070$ & 8. Power & $\begin{array}{l}\text { Establishes step-down } \\
\text { transformer efficiencies. }\end{array}$ & & $\mathrm{X}$ & $\mathrm{X}$ & & & $\mathrm{X}$ & $\mathrm{X}$ & & $Y$ & & $\mathrm{X}$ & & & & & $\mathrm{X}$ \\
\hline
\end{tabular}


Table 5.1. (cont'd)

\begin{tabular}{|c|c|c|c|c|c|c|c|c|c|c|c|c|c|c|c|c|c|c|}
\hline \multirow[b]{2}{*}{$\begin{array}{c}90.1 \\
\text { Addenda }\end{array}$} & \multirow[b]{2}{*}{$\begin{array}{c}90.1 \\
\text { Chapter(s) } \\
\text { Affected }\end{array}$} & \multirow[b]{2}{*}{ Description } & \multicolumn{16}{|c|}{ Prototypes Affected } \\
\hline & & & 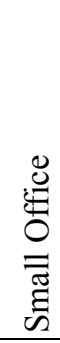 & 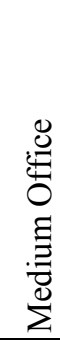 & 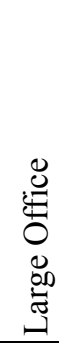 & 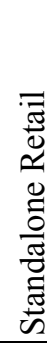 & 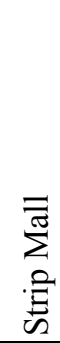 & 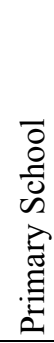 & 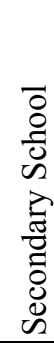 & 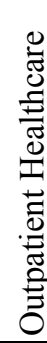 & 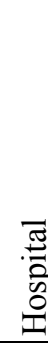 & 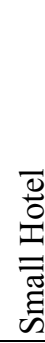 & 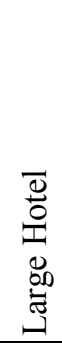 & $\begin{array}{l}0 \\
\frac{0}{0} \\
\frac{1}{0} \\
\frac{0}{\pi} \\
3\end{array}$ & 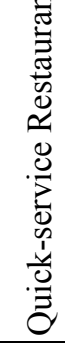 & 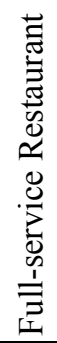 & 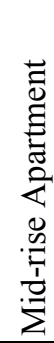 & 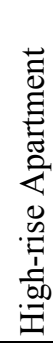 \\
\hline $90.1-07 \mathrm{bs}$ & 8. Power & $\begin{array}{l}\text { Requires noncritical receptacle } \\
\text { loads to be automatically } \\
\text { controlled (turned off) based on } \\
\text { occupancy or scheduling. }\end{array}$ & $\mathrm{X}$ & $\mathrm{X}$ & $\mathrm{X}$ & $\mathrm{X}$ & $\mathrm{X}$ & $\mathrm{X}$ & $\mathrm{X}$ & $\mathrm{X}$ & $\mathrm{X}$ & $\mathrm{X}$ & $\mathrm{X}$ & $\mathrm{X}$ & $\mathrm{X}$ & $\mathrm{X}$ & $\mathrm{X}$ & $\mathrm{X}$ \\
\hline $90.1-07 d$ & 9. Lighting & $\begin{array}{l}\text { Requires automatic daylighting } \\
\text { controls when skylights are } \\
\text { present. }\end{array}$ & & & & $\mathrm{X}$ & & $\mathrm{X}$ & $\mathrm{X}$ & & & & & $\mathrm{X}$ & & & & \\
\hline $90.1-07 \mathrm{i}$ & 9. Lighting & $\begin{array}{l}\text { Categories for external lighting } \\
\text { allowances are expanded and } \\
\text { LPDs are defined. }\end{array}$ & $\mathrm{X}$ & $\mathrm{X}$ & $\mathrm{X}$ & $\mathrm{X}$ & $\mathrm{X}$ & $\mathrm{X}$ & $\mathrm{X}$ & $\mathrm{X}$ & $\mathrm{X}$ & $\mathrm{X}$ & $\mathrm{X}$ & $\mathrm{X}$ & $\mathrm{X}$ & $\mathrm{X}$ & $\mathrm{X}$ & $\mathrm{X}$ \\
\hline $90.1-07 x$ & 9. Lighting & $\begin{array}{l}\text { Reduces the building size } \\
\text { threshold where automatic } \\
\text { lighting shutoff is required } \\
\text { from } 5,000 \mathrm{ft}^{2} \text { to any size. Adds } \\
\text { the following space types to } \\
\text { those where occupancy sensor } \\
\text { control is required: lecture } \\
\text { halls, training rooms, supply } \\
\text { and storage rooms (up to } 1,000 \\
\mathrm{ft}^{2} \text { ), office spaces (up to } 250 \\
\mathrm{ft}^{2} \text { ), restrooms, dressing rooms, } \\
\text { locker rooms, and fitting } \\
\text { rooms. }\end{array}$ & $\mathrm{X}$ & $\mathrm{X}$ & $\mathrm{X}$ & $\mathrm{X}$ & $\mathrm{X}$ & $\mathrm{X}$ & $\mathrm{X}$ & $\mathrm{X}$ & $\mathrm{X}$ & $\mathrm{X}$ & $\mathrm{X}$ & $\mathrm{X}$ & $\mathrm{X}$ & $\mathrm{X}$ & $\mathrm{X}$ & $\mathrm{X}$ \\
\hline $90.1-07$ aа & 9. Lighting & $\begin{array}{l}\text { Requires automatic shutoff } \\
\text { controls to be manual on except } \\
\text { in certain spaces. }\end{array}$ & $\mathrm{X}$ & $\mathrm{X}$ & $\mathrm{X}$ & & & & & & & & & & & & & \\
\hline
\end{tabular}


Table 5.1. (cont'd)

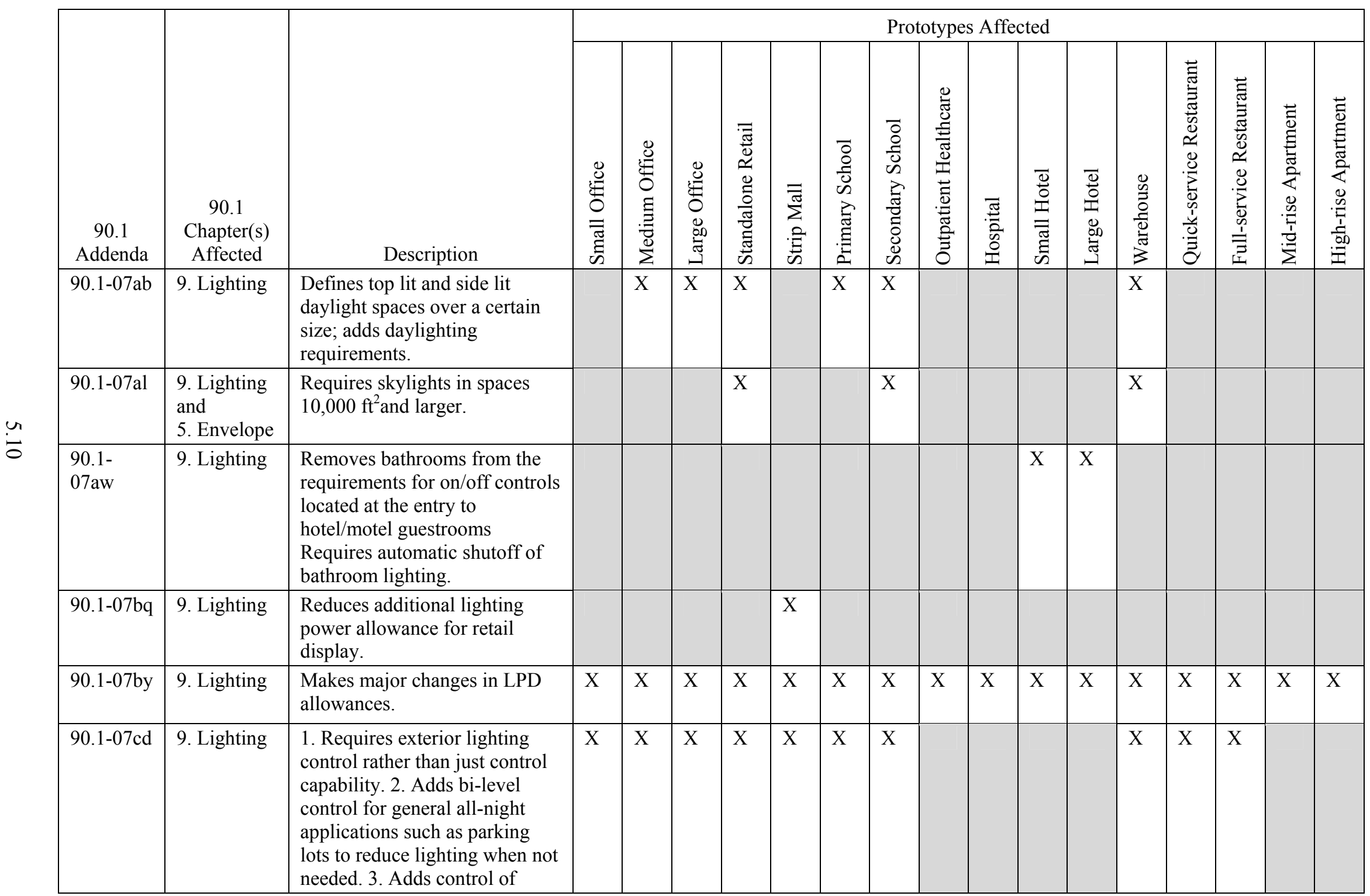


Table 5.1. (cont'd)

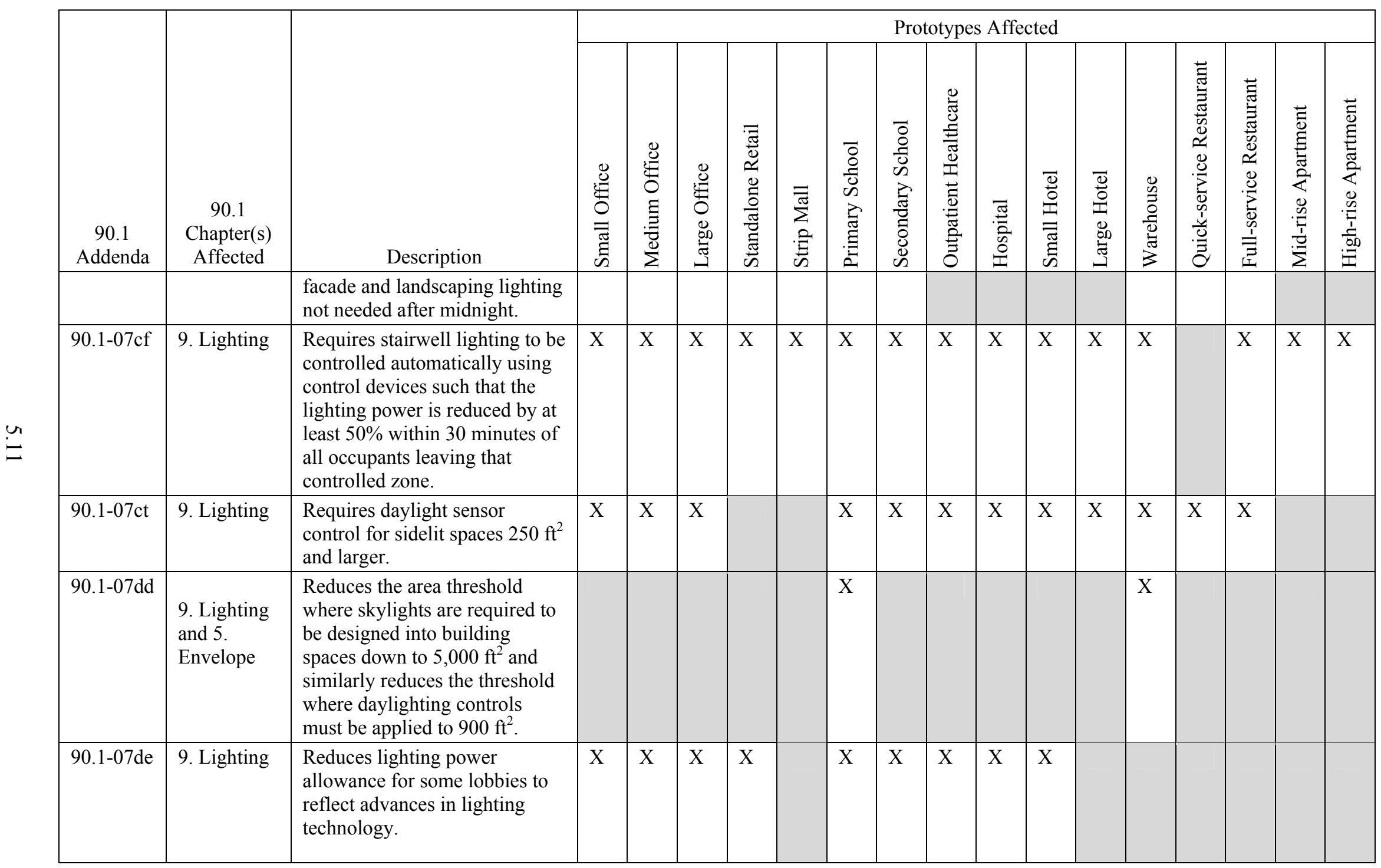


Table 5.1. (cont'd)

\begin{tabular}{|c|c|c|c|c|c|c|c|c|c|c|c|c|c|c|c|c|c|c|}
\hline \multirow[b]{2}{*}{$\begin{array}{c}90.1 \\
\text { Addenda }\end{array}$} & \multirow[b]{2}{*}{$\begin{array}{c}90.1 \\
\text { Chapter(s) } \\
\text { Affected }\end{array}$} & \multirow[b]{2}{*}{ Description } & \multicolumn{16}{|c|}{ Prototypes Affected } \\
\hline & & & 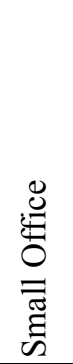 & 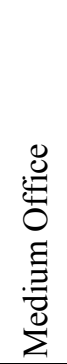 & 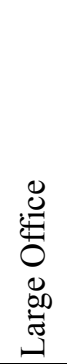 & 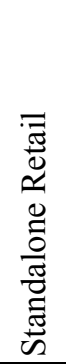 & $\begin{array}{l}\overline{\bar{\pi}} \\
\sum_{0} \\
\stackrel{0}{\Xi} \\
\text { D }\end{array}$ & $\begin{array}{l}\overline{8} \\
\overline{0} \\
\tilde{D} \\
\vec{n} \\
\vec{E} \\
\vec{\Xi} \\
\vec{\Xi}\end{array}$ & 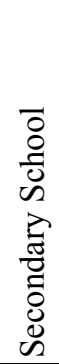 & 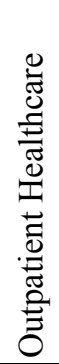 & 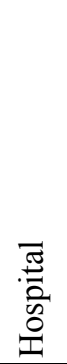 & 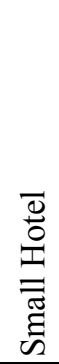 & 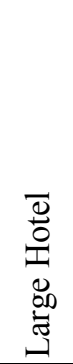 & 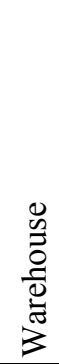 & 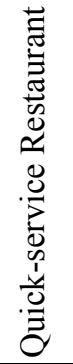 & 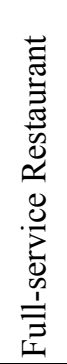 & 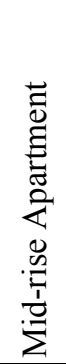 & 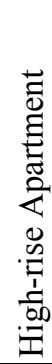 \\
\hline 90.1-07aj & $\begin{array}{l}\text { 10. Other } \\
\text { Equipment }\end{array}$ & $\begin{array}{l}\text { Updates motor efficiency } \\
\text { tables. }\end{array}$ & $\mathrm{X}$ & $\mathrm{X}$ & $\mathrm{X}$ & $\mathrm{X}$ & $\mathrm{X}$ & $\mathrm{X}$ & $\mathrm{X}$ & $\mathrm{X}$ & $\mathrm{X}$ & $\mathrm{X}$ & $\mathrm{X}$ & $X$ & $\mathrm{X}$ & $\mathrm{X}$ & $\mathrm{X}$ & $\mathrm{X}$ \\
\hline $90.1-07 \mathrm{df}$ & $\begin{array}{l}\text { 10. Other } \\
\text { Equipment }\end{array}$ & $\begin{array}{l}\text { Adds requirements for elevator } \\
\text { ventilation and lighting. }\end{array}$ & & $\mathrm{X}$ & $\mathrm{X}$ & & & & $\mathrm{X}$ & $\mathrm{X}$ & $\mathrm{X}$ & $\mathrm{X}$ & $\mathrm{X}$ & & & & $\mathrm{X}$ & $\mathrm{X}$ \\
\hline
\end{tabular}


Table 5.2. Addenda with Potential Energy Savings but Not Quantified in PI

\begin{tabular}{|c|c|c|c|}
\hline $\begin{array}{c}90.1 \\
\text { Addenda }\end{array}$ & $\begin{array}{l}\text { 90.1 Chapter } \\
\text { Affected }\end{array}$ & Description & Why Potential Savings Are Not Quantified in PI \\
\hline $90.1-07 \mathrm{ag}$ & 5. Envelope & Requires staggered joints in layered rigid insulation. & $\begin{array}{l}\text { Does not change the minimum U-factor, which is } \\
\text { what savings would be based on for the PI. This } \\
\text { addendum has a potential to reduce thermal bridging } \\
\text { and air leakage rate, but this cannot be quantified in } \\
\text { the current prototype models. }\end{array}$ \\
\hline $90.1-04 b$ & 6. HVAC & $\begin{array}{l}\text { Revises Table 6.8.1D and adds definitions for single-package vertical } \\
\text { air conditioners and single-package vertical heat pumps. }\end{array}$ & $\begin{array}{l}\text { No prototypes have single-package vertical air- } \\
\text { conditioner or single-package vertical heat pump. }\end{array}$ \\
\hline $90.1-04 \mathrm{~h}$ & 6. HVAC & $\begin{array}{l}\text { Revises the exceptions to Sections } 6.4 .3 .1 .2 \text { and } 6.4 .3 .6 \text { by removing } \\
\text { data processing centers from having specific exceptions on } \\
\text { temperature deadband and humidification deadband. }\end{array}$ & No prototypes have data centers \\
\hline $90.1-07 y$ & 6. HVAC & $\begin{array}{l}\text { Establishes AHRI 1160-2008 (AHRI 2008) as the test procedure for } \\
\text { heat pump pool heaters and requires that the minimum COP of } 4 \text { be } \\
\text { met at the low outdoor temperature of } 50^{\circ} \mathrm{F} \text { (instead of the high } \\
\text { outdoor temperature of } 80^{\circ} \mathrm{F} \text { currently required). }\end{array}$ & No prototypes have swimming pools \\
\hline $90.1-07 \mathrm{ae}$ & 6. HVAC & $\begin{array}{l}\text { Requires insulation on the thermally ineffective surface of a radiant } \\
\text { heating panel. }\end{array}$ & No prototypes have radiant panels \\
\hline 90.1-07ap & 6. HVAC & $\begin{array}{l}\text { Adds demand controlled ventilation (DCV) to simple systems, closing } \\
\text { the loophole. }\end{array}$ & $\begin{array}{l}\text { Simple system in restaurant is only prototype that } \\
\text { would be affected and savings cannot be shown since } \\
\text { transfer air to kitchen prevents DCV from being used } \\
\text { in the dining room. }\end{array}$ \\
\hline $90.1-07 \mathrm{bg}$ & 6. HVAC & Adds efficiency requirements for water-to-water heat pumps. & No prototypes have water-to-water heat pumps. \\
\hline 90.1-07bi & 6. HVAC & Provides updated requirements for pipe insulation. & $\begin{array}{l}\text { Not captured here since heat loss from piping is not } \\
\text { included in the prototypes. }\end{array}$ \\
\hline $90.1-07 \mathrm{bl}$ & 6. HVAC & Removes exemption for chillers with glycol. & No prototypes have chillers with glycol. \\
\hline $90.1-07 \mathrm{bt}$ & 6. HVAC & $\begin{array}{l}\text { Modifies centrifugal chiller adjustment factor for nonstandard } \\
\text { conditions. }\end{array}$ & $\begin{array}{l}\text { No prototypes have chillers that operate at } \\
\text { nonstandard conditions. }\end{array}$ \\
\hline $90.1-07 \mathrm{bu}$ & 6. HVAC & $\begin{array}{l}\text { Adds efficiency requirements to HVAC systems dedicated to } \\
\text { computer rooms and data centers. }\end{array}$ & No prototypes have data centers. \\
\hline $90.1-07 b x$ & 6. HVAC & $\begin{array}{l}\text { Limits reheat temperatures to } 20 \text { degrees F. above room temperature } \\
\text { for better air distribution effectiveness. }\end{array}$ & $\begin{array}{l}\text { EnergyPlus limitations make it impractical to capture } \\
\text { savings. May revisit after upgrade to EnergyPlus } \\
\text { V.6.0 }\end{array}$ \\
\hline
\end{tabular}




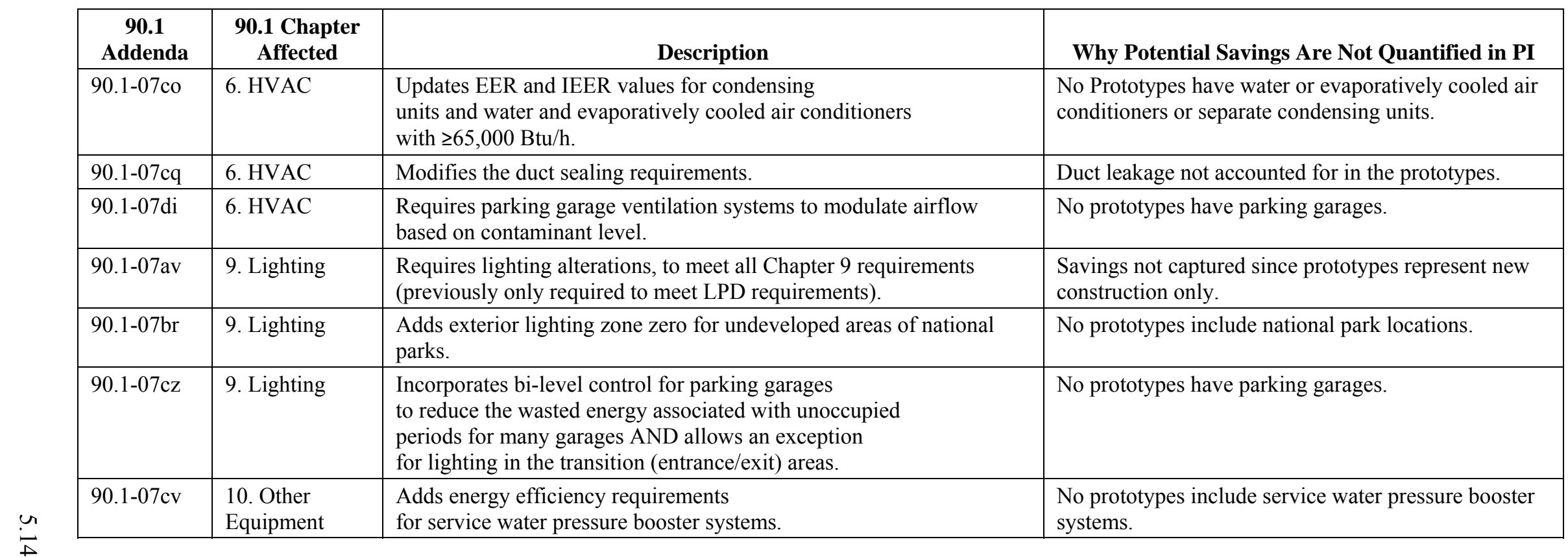

Table 5.3. Addenda with No Energy Savings

\begin{tabular}{|l|l|l|l|}
\hline $\begin{array}{c}\text { 90.1 } \\
\text { Addendum }\end{array}$ & $\begin{array}{c}\text { 90.1 Chapter } \\
\text { Affected }\end{array}$ & \multicolumn{1}{|c|}{ Description } & \multicolumn{1}{|c|}{ Why No Energy Savings Were Identified } \\
\hline $90.1-04 \mathrm{n}$ & 5. Envelope & $\begin{array}{l}\text { Revises Section 5.5.4.4.1 to provide an exception to allow a user to take } \\
\text { credit for overhangs towards compliance with the maximum solar heat } \\
\text { gain coefficient (SHGC) requirements. }\end{array}$ & Provides a tradeoff with no savings. \\
\hline $90.1-04 \mathrm{y}$ & 5. Envelope & $\begin{array}{l}\text { Adds a reference and method of testing for deriving the solar } \\
\text { reflectance index (SRI) American Society for Testing Materials } \\
\text { (ASTM) Test Method E, 1980 (ASTM 2001)) for high albedo roofs. } \\
\text { The changes are in both Section 5 and Appendix G. }\end{array}$ & Adds testing method only. \\
\hline 90.1-04ad & 5. Envelope & $\begin{array}{l}\text { Changes the exception to Section 5.3.1.1 to add a requirement that the } \\
\text { values for solar reflectance and thermal emittance be determined by a } \\
\text { laboratory accredited by a nationally recognized accreditation } \\
\text { organization, such as the Cool Roof Rating Council. }\end{array}$ & Adds testing service accreditation only. \\
\hline 90.1-04aj & 5. Envelope & Modifies the exception to Section 5.5.3.1 by adding the ASTM Test & Adds testing method only. \\
\hline
\end{tabular}




\begin{tabular}{|c|c|c|c|}
\hline $\begin{array}{c}90.1 \\
\text { Addendum }\end{array}$ & $\begin{array}{l}\text { 90.1 Chapter } \\
\text { Affected }\end{array}$ & Description & Why No Energy Savings Were Identified \\
\hline & & Method E1980 (ASTM 2001). & \\
\hline 90.1-04av & 5. Envelope & $\begin{array}{l}\text { Adds an exception to Section 5.5.4.4.1 to allow credit for overhangs } \\
\text { toward compliance with the maximum SHGC requirements. }\end{array}$ & Provides a tradeoff with no savings. \\
\hline $90.1-07 b c$ & 5. Envelope & $\begin{array}{l}\text { Clarifies that the minimum skylight areas of addendum al also apply to } \\
\text { unconditioned spaces. }\end{array}$ & Clarifies rules only. \\
\hline $90.1-07 \mathrm{cl}$ & 5. Envelope & $\begin{array}{l}\text { Clarifies how to interpret the use of dynamic glazing products that are } \\
\text { designed to be able to vary a performance property such as SHGC, } \\
\text { rather than having just a single value. }\end{array}$ & Clarifies rules only. \\
\hline $90.1-04 \mathrm{t}$ & 6. HVAC & $\begin{array}{l}\text { Changes Table } 6.8 .1 \mathrm{~F} \text { to add an additional requirement of combustion } \\
\text { efficiency to the current requirement of thermal efficiency for boilers. } \\
\text { The reference in Section } 12 \text { has also been changed to reflect the change } \\
\text { in the table. }\end{array}$ & $\begin{array}{l}\text { Doesn't change energy efficiency, just adds an } \\
\text { additional equivalent requirement. }\end{array}$ \\
\hline 90.1-04ak & 6. HVAC & $\begin{array}{l}\text { Changes Table } 6.2 .1 \mathrm{G} \text { to add requirements for cooling towers to be } \\
\text { tested to Cooling Tower Institute (CTI) test procedures and to updates } \\
\text { the corresponding references in Section 6.2.1. }\end{array}$ & Updates test procedure reference only. \\
\hline $90.1-07 a$ & 6. HVAC & $\begin{array}{l}\text { Clarifies that Table 6.8.1.G applies to open cooling towers and not } \\
\text { closed circuit cooling towers. }\end{array}$ & Clarifies rules only. \\
\hline $90.1-07 b$ & 6. HVAC & $\begin{array}{l}\text { Changes exceptions, allowing simultaneous heating and cooling up to a } \\
\text { limit set by the minimum outdoor air ventilation rate required by } \\
\text { standards other than ASHRAE } 62 \text {. }\end{array}$ & $\begin{array}{l}\text { May cause modest increased energy use for optional } \\
\text { exception. }\end{array}$ \\
\hline $90.1-07 \mathrm{c}$ & 6. HVAC & $\begin{array}{l}\text { Adds vivarium to the list of spaces where specific humidity levels are } \\
\text { required to satisfy process needs, thus allowing those spaces an } \\
\text { exemption from the simultaneous heating and cooling for } \\
\text { dehumidification prohibition. }\end{array}$ & $\begin{array}{l}\text { May cause modest increased energy use for a } \\
\text { specialized application for a space type not captured } \\
\text { in the prototypes. }\end{array}$ \\
\hline $90.1-07 \mathrm{j}$ & 6. HVAC & Updates mechanical test procedures and references. & Changes normative reference only. \\
\hline $90.1-07 \mathrm{k}$ & 6. HVAC & Clarifies warm air furnace and water heater references. & Clarifies rules only. \\
\hline $90.1-071$ & 6. HVAC & Efficiency requirements added for closed circuit cooling towers. & Only codifies standard practice. \\
\hline $90.1-07 p$ & 6. HVAC & Added pressure drop allowances for laboratory exhaust fans. & No prototypes have laboratory systems. \\
\hline $90.1-07 \mathrm{~s}$ & 6. HVAC & $\begin{array}{l}\text { Updates the COP at } 17^{\circ} \mathrm{F} \text { efficiency levels for commercial heat pumps } \\
\text { and introduces a new part-load energy efficiency descriptor for all } \\
\text { commercial unitary products above } 65,000 \mathrm{Btu} / \mathrm{h} \text { of cooling capacity }\end{array}$ & $\begin{array}{l}\text { The IEER and COP at } 17^{\circ} \mathrm{F} \text { levels in Tables } 6.8 .1 \mathrm{~A} \\
\text { and } 6.8 .1 \mathrm{~B} \text { were derived based on the already } \\
\text { expected performance of commercial unitary products } \\
\text { meeting the new full-load EER and COP at } 47^{\circ} \mathrm{F} \\
\text { requirements that took effect on January } 1,2010 \text {. }\end{array}$ \\
\hline
\end{tabular}




\begin{tabular}{|c|c|c|c|}
\hline $\begin{array}{c}90.1 \\
\text { Addendum }\end{array}$ & $\begin{array}{l}\text { 90.1 Chapter } \\
\text { Affected }\end{array}$ & Description & Why No Energy Savings Were Identified \\
\hline $90.1-07 \mathrm{t}$ & 6. HVAC & Clarifies use of "standard" and "non-standard" PTACs. & $\begin{array}{l}\text { Replacement exemption clarified to apply only to } \\
\text { nonstandard sleeve size. }\end{array}$ \\
\hline $90.1-07 \mathrm{v}$ & 6. HVAC & $\begin{array}{l}\text { Adds requirement to calculate pump head according to } \\
\text { ANSI/ASHRAE/ACCA Standard } 183 \text { (ANSI/ASHRAE/ACCA 2007). }\end{array}$ & Codifies standard calculation procedure. \\
\hline 90.1-07ad & 6. HVAC & $\begin{array}{l}\text { Adds a new testing procedure reference for liquid-to-liquid heat } \\
\text { exchangers. }\end{array}$ & Adds testing method only. \\
\hline 90.1-07ao & 6. HVAC & $\begin{array}{l}\text { Modifies Table 6.8.1E (furnaces and unit heaters) to fix known errata } \\
\text { and reorganizes table. }\end{array}$ & Fixes error and provides clarification. \\
\hline $90.1-07$ at & 6. HVAC & Clarifies and cleans up of damper section. & Clarifies rules only. \\
\hline $90.1-07 \mathrm{au}$ & 6. HVAC & Updates efficiency tradeoff table for eliminating economizers. & Provides tradeoff only, no savings. \\
\hline $90.1-07 \mathrm{ba}$ & 6. HVAC & $\begin{array}{l}\text { Allow non-metallic pipe to use a system performance option instead of } \\
\text { minimum insulation level. }\end{array}$ & $\begin{array}{l}\text { May increase energy use, but negligible impact and } \\
\text { application not in prototypes. }\end{array}$ \\
\hline $90.1-07 \mathrm{cp}$ & 6. HVAC & $\begin{array}{l}\text { Establishes, for the first time in ASHRAE90.1, efficiency requirements } \\
\text { for variable refrigerant flow air conditioners and heat pumps. }\end{array}$ & Codifies current practice. \\
\hline $90.1-07 \mathrm{bd}$ & 8. Power & $\begin{array}{l}\text { Exempts feeder conductors serving emergency circuits from voltage } \\
\text { drop requirements. }\end{array}$ & Corrects error that affects safety. \\
\hline $90.1-07 \mathrm{bk}$ & 8. Power & Clarifies motor efficiency requirements. & Clarifies rules only. \\
\hline $90.1-04 \mathrm{e}$ & 9. Lighting & $\begin{array}{l}\text { Recognizes that track and bus way type lighting systems can be limited } \\
\text { by circuit breakers and permanently installed current limiters in Section } \\
\text { 9.1.4. }\end{array}$ & May increase energy use but negligibly. \\
\hline $90.1-04 \mathrm{i}$ & 9. Lighting & $\begin{array}{l}\text { Adds language to Section 9.1.4(b) that allows additional flexibility in } \\
\text { assigning wattage to luminaires with multi-level ballasts where other } \\
\text { luminaire components would restrict lamp size. }\end{array}$ & May increase energy use but negligibly. \\
\hline $90.1-04 j$ & 9. Lighting & $\begin{array}{l}\text { In Section 9.4.1.3 allows additional flexibility in complying with the } \\
\text { controls requirements by allowing additional combinations of } \\
\text { commonly available control equipment. }\end{array}$ & $\begin{array}{l}\text { Primarily a clarification to allow commonly available } \\
\text { alternative. }\end{array}$ \\
\hline $90.1-04 m$ & 9. Lighting & $\begin{array}{l}\text { Revises the exception to Section } 9.2 .2 .3 \text { to provide an option for } \\
\text { compliance that exempts the commonly used furniture mounted track } \\
\text { lighting if it incorporates automatic shut-off. }\end{array}$ & $\begin{array}{l}\text { May increase energy use but negligibly, since these } \\
\text { are not usually part of the design documents and } \\
\text { exemption may not affect regulated lighting } \\
\text { allowance. }\end{array}$ \\
\hline $90.1-04 p$ & 9. Lighting & $\begin{array}{l}\text { Modifies Exception }(\mathrm{g}) \text { to Section 9.2.2.3 to allow for increased lighting } \\
\text { for medical- and age-related issues in addition to visual impairment. }\end{array}$ & $\begin{array}{l}\text { Addresses safety and usability; may result in modest } \\
\text { energy increase. }\end{array}$ \\
\hline
\end{tabular}




\begin{tabular}{|c|c|c|c|}
\hline $\begin{array}{c}90.1 \\
\text { Addendum }\end{array}$ & $\begin{array}{l}\text { 90.1 Chapter } \\
\text { Affected }\end{array}$ & Description & Why No Energy Savings Were Identified \\
\hline 90.1-04aa & 9. Lighting & Modifies Section 9.1 to clarify some lighting requirements. & $\begin{array}{l}\text { Changes "current regulators" to "transformers" and } \\
\text { "living units" to "dwelling units." }\end{array}$ \\
\hline 90.1-04ai & 9. Lighting & $\begin{array}{l}\text { Modifies the interior lighting power requirements for retail display } \\
\text { lighting in Section 9.6.2. }\end{array}$ & $\begin{array}{l}\text { Modifies display lighting classifications and not } \\
\text { expected to change energy usage. }\end{array}$ \\
\hline 90.1-04ap & 9. Lighting & Clarifies the intent of a "sales area" space in Table 9.6.1. & Clarifies that sales area can be in any building type. \\
\hline $90.1-07 \mathrm{ac}$ & 9. Lighting & $\begin{array}{l}\text { Adds incentives (increased LPD allowance) for lighting controls; allows } \\
\text { actual used ballast factor for calculations when adjustable bf ballasts are } \\
\text { used. }\end{array}$ & $\begin{array}{l}\text { This addendum does not require the controls but only } \\
\text { adds LPD allowance if controls are present. Therefore, } \\
\text { if controls are already present, this is a net energy } \\
\text { increase. SSPC } 90.1 \text { determined not to estimate } \\
\text { savings or penalty. }\end{array}$ \\
\hline $90.1-07 \mathrm{ar}$ & 9. Lighting & Clarifies exterior lighting power. & Clarifies rules only. \\
\hline 90.1-07ay & 9. Lighting & $\begin{array}{l}\text { Requires that lighting space types be divided by function regardless of } \\
\text { partition walls. }\end{array}$ & $\begin{array}{l}\text { May cause negligible increase in energy use not } \\
\text { captured in the prototypes. }\end{array}$ \\
\hline $90.1-07 a z$ & 9. Lighting & Requires functional testing for lighting controls. & $\begin{array}{l}\text { No savings assumed for functional testing or } \\
\text { commissioning. }\end{array}$ \\
\hline $90.1-07 \mathrm{bp}$ & 9. Lighting & $\begin{array}{l}\text { Allows auto on occupancy sensors for } 50 \% \text { of the lights instead of } \\
\text { manual on when occupancy sensors are required (no savings since only } \\
\text { option). }\end{array}$ & Provides a non-required option. \\
\hline $90.1-07 \mathrm{ce}$ & 9. Lighting & $\begin{array}{l}\text { Requires that all spaces (unless exempted) have multilevel control } \\
\text { capability (also commonly known as bi-level switching). }\end{array}$ & $\begin{array}{l}\text { Provides manual controls which are not counted for } \\
\text { savings in PI. }\end{array}$ \\
\hline $90.1-07 \mathrm{cn}$ & 9. Lighting & $\begin{array}{l}\text { Adds controls incentives for occupancy sensor control of workstation- } \\
\text { specific luminaires combined with dimming. }\end{array}$ & Provides trade-off only, no savings. \\
\hline $90.1-07 \mathrm{cs}$ & 9. Lighting & $\begin{array}{l}\text { Limits the space types where automatic receptacle control (addendum } \\
\text { bs) is required. }\end{array}$ & $\begin{array}{l}\text { Reduces application of addendum 90.1-07bs with } \\
\text { negligible savings impact. }\end{array}$ \\
\hline $90.1-07 \mathrm{dc}$ & 9. Lighting & $\begin{array}{l}\text { Eliminates the requirement for tandem wiring for fluorescent fixtures } \\
\text { with one or three lamps. }\end{array}$ & $\begin{array}{l}\text { May result in minimal increase in energy not captured } \\
\text { in prototypes. }\end{array}$ \\
\hline $90.1-07 \mathrm{do}$ & 9. Lighting & Identifies required lighting system submittals. & Changes design documentation only. \\
\hline $90.1-07 \mathrm{dr}$ & 9. Lighting & $\begin{array}{l}\text { Removes the luminaire efficacy requirement for exterior building } \\
\text { grounds lighting. }\end{array}$ & Removes now redundant requirement. \\
\hline
\end{tabular}




\subsection{Addenda Implementation in Savings Analysis}

Implementing the addenda for the PI follows the procedures outlined in Chapter 2 of this report. The procedures include developing model inputs, automatically inserting some requirements into the prototype models, running the simulations, and extracting and post-processing the results. This section focuses on explaining the addenda and their impact on energy savings, the modeling strategies and development of the simulation inputs for EnergyPlus. Each section describes one addendum or a group of related addenda that build on and adjust earlier addenda through the three-year Standard development cycle. Descriptions include identifying what is in the 2004 and/or 2007 standard and what is changed. The basis and supporting analysis used to develop model inputs are provided, as is information on the climate zones and prototypes affected. Any special issues in implementing the addenda in EnergyPlus are covered. Finally, in some cases other resources, such as published papers, are referenced for additional detail.

The PI analysis compares models of buildings that comply with 90.1-2004 with models that comply with 90.1-2010. The terminology "baseline" and "advanced" are used in some cases to describe the implementation of the addenda for the PI. The baseline is 90.1-2004. The advanced case is 90.1-2010. For addenda to 90.1-2007, the baseline is still considered 90.1-2004. In some cases, provisions are modified once from 90.1-2004 to 90.1-2007 and then are modified again from 90.1-2007 to 90.1-2010. For example, addendum q to 90.1-2007 builds on addendum c to 90.1-2004 on the topic of vestibules. In such cases, the 90.-2004 and 90.1-2007 addenda that coincide are described together in this report.

\subsubsection{Building Envelope}

The building envelope requirements change significantly between 90.1-2004 and 90.1-2007 for both opaque surfaces and fenestration, including a new classification system for types of windows. The changes also include enhancing the vestibule requirements. Addenda to 90.1-2007 include adjustments to a limited set of envelope performance values for metal buildings as well as provisions that impact infiltration, roof solar heat gain, and window area by wall orientation. Comprehensive changes to building envelope were included in addendum 90.1-07bb, which was not adopted because of controversy over some elements. An altered version of addendum bb is being considered as an amendment to 90.1-2010 for 90.1-2013.

\subsubsection{Addenda 90.1-04c and 90.1-07q: Vestibules}

Addendum 90.1-04c revises the 90.1-2004 definition of a "building entrance" and modifies Section 5.4.3.4, "Vestibules," when vestibules are required. Addendum 90.1-04c also explicitly requires that the exterior envelope of a conditioned vestibule comply with envelope requirements of a conditioned space and that the interior envelope of a vestibule comply with envelope requirements for semi-heated space.

Addendum 90.1-07q further modifies the vestibule requirements by changing the exceptions in Section 5.4.3.4 of 90.1-2007 by removing zone 4 from exception (e) and adding zone 4 to exception (f).

Under addendum 90.1-04c, the language regarding the envelope requirements for the outer wall of the vestibules and the adjoining wall between vestibule and interior building zone is more explicit than the language of 90.1-2004. However, this impact is not considered in the quantitative analysis because the 
impact is believed to be relatively minor. More significant are the treatment of the climate zones and building types for which vestibules would be required. Addendum 90.1-04c modifies Section 5.4.3.4 to require vestibules in many more building types. In particular, 90.1-2004 has an exception to vestibule requirements for buildings less than four stories in height. This exception is modified to apply only to buildings in climate zones 3 and 4 and then only to buildings smaller than 10,000 $\mathrm{ft}^{2}$. An additional exception is provided for very small buildings (smaller than $1,000 \mathrm{ft}^{2}$ ) in all climate zones.

The energy impacts of addendum 90.1-04c are modeled by first identifying which building prototypes are affected and in which climates. For this analysis, building types not affected by the vestibule requirement are given the same defined level of infiltration calculated for each building in the 90.1-2004 models. Baseline infiltration is developed using wind-driven models for exterior wall infiltration and an assumed air leakage rate of $1.8 \mathrm{cfm} / \mathrm{ft}^{2}$ of exterior wall under a pressure differential of $0.30 \mathrm{in}$. water column (w.c.) (Gowri et al. 2009). In general, buildings considered not affected by addendum 90.1-04c are tall buildings having four or more stories.

The primary energy benefit of vestibules is to reduce infiltration in buildings during door openings. The infiltration rate for an open door is calculated for each building using a simplified method that takes into account design, wind speed, door area, and building height to a neutral pressure plan (used to estimate the stack effect driven air pressure on the door) of one half the building height and a multiplication coefficient that is a function of door opening frequency.

Peak infiltration rates are first defined on a per-unit door area for each prototype based on design day wind speeds of $15 \mathrm{mph}$, building height for each affected prototype, and average annual outdoor temperature and then are defined based on study data for different building types. In addition, reductions in peak infiltration rates using vestibules are derived for buildings with vestibules and automatic doors based on an ASHRAE research project study as a function of door opening frequency (Cho et al. 2010). Door opening frequency is estimated for a "peak period" and an off-peak period for each building prototype. The hours defined by peak door opening frequency are based on the building occupancy schedule and identification of hours where occupancy (as a proxy for door use) is significantly high compared with the low or no occupancy periods for each particular building type.

Table 5.4 shows the vestibule requirements for each prototype in each climate zone for 90.1-2004. Table 5.5 shows the same information for 90.1-2007 incorporated from addendum 90.1-04c. Addendum 90.1-07q modifies vestibule requirement exceptions in Section 5.4.3.4 of 90.1-2007. This modification removes zone 4 from exception (e) and adds zone 4 to exception (f). Table 5.6 shows the vestibule requirements for each prototype in each climate zone for 90.1-2010 with addendum 90.1-07q incorporated. The exceptions are described in PNNL publication (Cho et al. 2010), which also includes details on the analysis of infiltration, impact of vestibules and the modeling strategy for incorporating the addendum vestibule requirements into the 90.1-2010 models. 
Table 5.4. 90.1-2004 Vestibule Requirements

\begin{tabular}{lcccccccc}
\hline & \multicolumn{7}{c}{ Zone } \\
\cline { 2 - 8 } \multicolumn{1}{c}{ Building Prototype } & 1 & 2 & 3 & 4 & 5 & 6 & 7 & 8 \\
\hline Small Office & No & No & No & No & No & No & No & No \\
Medium Office & No & No & No & No & No & No & No & No \\
Large Office & No & No & Yes & Yes & Yes & Yes & Yes & Yes \\
Standalone Retail & No & No & No & No & No & No & No & No \\
Strip Mall & No & No & No & No & No & No & No & No \\
Primary School & No & No & No & No & No & No & No & No \\
Secondary School & No & No & No & No & No & No & No & No \\
Outpatient Healthcare & No & No & No & No & No & No & No & No \\
Hospital & No & No & Yes & Yes & Yes & Yes & Yes & Yes \\
Small Hotel & No & No & No & No & No & No & No & No \\
Large Hotel & No & No & Yes & Yes & Yes & Yes & Yes & Yes \\
Warehouse & No & No & No & No & No & No & No & No \\
Quick-service Restaurant & No & No & No & No & No & No & No & No \\
Full-service Restaurant & No & No & No & No & No & No & No & No \\
Mid-rise Apartment & No & No & No & No & No & No & No & No \\
High-rise Apartment & No & No & No & No & No & No & No & No \\
\hline
\end{tabular}

Table 5.5. 90.1-2007 Vestibule Requirements (with addendum 90.1-04c)

\begin{tabular}{|c|c|c|c|c|c|c|c|c|}
\hline \multirow[b]{2}{*}{ Building Prototype } & \multicolumn{8}{|c|}{ Zone } \\
\hline & 1 & 2 & 3 & 4 & 5 & 6 & 7 & 8 \\
\hline Small Office & No & No & No & No & Yes & Yes & Yes & Yes \\
\hline Medium Office & No & No & Yes & Yes & Yes & Yes & Yes & Yes \\
\hline Large Office & No & No & Yes & Yes & Yes & Yes & Yes & Yes \\
\hline Standalone Retail & No & No & Yes & Yes & Yes & Yes & Yes & Yes \\
\hline Strip Mall & No & No & Yes & Yes & Yes & Yes & Yes & Yes \\
\hline Primary School & No & No & Yes & Yes & Yes & Yes & Yes & Yes \\
\hline Secondary School & No & No & Yes & Yes & Yes & Yes & Yes & Yes \\
\hline Outpatient Healthcare & No & No & Yes & Yes & Yes & Yes & Yes & Yes \\
\hline Hospital & No & No & Yes & Yes & Yes & Yes & Yes & Yes \\
\hline Small Hotel & No & No & Yes & Yes & Yes & Yes & Yes & Yes \\
\hline Large Hotel & No & No & Yes & Yes & Yes & Yes & Yes & Yes \\
\hline Warehouse & No & No & Yes & Yes & Yes & Yes & Yes & Yes \\
\hline Quick-service Restaurant & No & No & No & No & Yes & Yes & Yes & Yes \\
\hline Full-service Restaurant & No & No & No & No & Yes & Yes & Yes & Yes \\
\hline Mid-rise Apartment & No & No & Yes & Yes & Yes & Yes & Yes & Yes \\
\hline High-rise Apartment & No & No & Yes & Yes & Yes & Yes & Yes & Yes \\
\hline
\end{tabular}


Table 5.6. 90.1-2010 Vestibule Requirements (with addendum 90.1-07q)

\begin{tabular}{lccccccccc}
\hline \multicolumn{1}{c}{ Building Prototype } & \multicolumn{9}{c}{ Zone } \\
\cline { 2 - 8 } \multicolumn{1}{c}{} & \multicolumn{1}{c}{ 1 } & 2 & 3 & 4 & 5 & 6 & 7 & 8 \\
\hline Small Office & No & No & No & Yes & Yes & Yes & Yes & Yes \\
Medium Office & No & No & Yes & Yes & Yes & Yes & Yes & Yes \\
Large Office & No & No & Yes & Yes & Yes & Yes & Yes & Yes \\
Standalone Retail & No & No & Yes & Yes & Yes & Yes & Yes & Yes \\
Strip Mall & No & No & Yes & Yes & Yes & Yes & Yes & Yes \\
Primary School & No & No & Yes & Yes & Yes & Yes & Yes & Yes \\
Secondary School & No & No & Yes & Yes & Yes & Yes & Yes & Yes \\
Outpatient Healthcare & No & No & Yes & Yes & Yes & Yes & Yes & Yes \\
Hospital & No & No & Yes & Yes & Yes & Yes & Yes & Yes \\
Small Hotel & No & No & Yes & Yes & Yes & Yes & Yes & Yes \\
Large Hotel & No & No & Yes & Yes & Yes & Yes & Yes & Yes \\
Warehouse & No & No & Yes & Yes & Yes & Yes & Yes & Yes \\
Quick-service Restaurant & No & No & No & Yes & Yes & Yes & Yes & Yes \\
Full-service Restaurant & No & No & No & Yes & Yes & Yes & Yes & Yes \\
Mid-rise Apartment & No & No & Yes & Yes & Yes & Yes & Yes & Yes \\
High-rise Apartment & No & No & Yes & Yes & Yes & Yes & Yes & Yes \\
\hline
\end{tabular}

\subsubsection{Addendum 90.1-04as: Opaque Envelope Thermal Performance}

90.1-2004 has specific envelope requirements, generally expressed in terms of maximum allowed Ufactor for above ground opaque envelope components, including roofs, walls, opaque doors, and floors exposed to the ambient, maximum allowed $\mathrm{C}$-factor for exterior below grade walls, and F-factors for slabon-grade floors. These factors are defined for three distinct space type categories: nonresidential, residential, and semi-heated spaces. Addendum 90.1-04as modifies these requirements, increasing the stringency for many of them. Appendix $E$ in this report includes tables of all of the opaque envelope thermal performance requirements for both 90.1-2004 and 90.1-2010 incorporating the changes from addendum 90.1-04as.

For modeling in EnergyPlus, the U-, C-, and F-factors corresponding to construction types and components defined in the prototype buildings (e.g., metal frame wall) are modified to reflect either the minimum requirements under 90.1 -2004 or 90.1-2007, as appropriate. The 90.1-2010 values match the 90.1-2007 values except for the metal building values changed by addendum 90.1-07g (Section 5.2.1.5 in this report).

\subsubsection{Addendum 90.1-04at: Fenestration Requirements}

90.1-2004 has requirements for fenestration SHGC and U-factor, including requirements for glass doors. As with the opaque envelope, these requirements are defined for three space type categories (nonresidential, residential, and semi-heated spaces) and by climate zone. The prescriptive requirements for windows are provided as a function of percentage of wall area that is glazed (here referred to as WWR in five WWR bins, up to a maximum of 50\% WWR for vertical fenestration. WWR levels greater than $50 \%$ are not allowed in the prescriptive path; such buildings must use either the envelope tradeoff path 
found in Appendix C of Standard 90.1, or the performance path outlined in Standard 90.1, Chapter 11, "Energy Cost Budget Method," to show compliance with the standard.

U-factor requirements are provided for two types of vertical glazing, fixed and operable. In general, U-factors for a given type of vertical glazing are the same for all WWRs up to $40 \%$. U-factor requirements for the $40.1 \%$ to $50 \%$ WWR bin are more stringent compared with the $30.1 \%$ to $40 \%$ WWR bin. This reduction in U-factor for the highest WWR bin was originally developed by the SSPC 90.1 Envelope Subcommittee using an energy tradeoff approach and was designed to provide roughly equal envelope energy impact for both $30.1 \%$ to $40 \%$ and $40.1 \%$ to $50 \%$ WWR bins.

SHGC requirements in 90.1-2004 are also provided by WWR bin, in general showing a reduction in allowed SHGC for higher WWR bins for nonresidential and residential space types. SHGC requirements do not exist for semi-heated space types. In addition, 90.1-2004 provides different, generally higher SHGC allowances for north-facing fenestration.

90.1-2004 also provides maximum U-factor and minimum SHGC requirements for skylights as a function of fraction of roof area that is glazed (up to a maximum of 5\%).

Addendum 90.1-04at modifies the fenestration requirements in the following ways:

- Defines new types of vertical glazing: non-metal framing - all; metal framing - curtain wall/storefront; metal frame-entrance door; and metal framing-all other. These replace the previous operable and fixed vertical glazing categories.

- Limits the WWR ratio to $40 \%$ in the prescriptive path.

- Eliminates the variation in SHGC by WWR bin by defining requirements to be the same for vertical fenestration from $0 \%$ to $40 \%$ WWR.

- Defines U-factors for each of the four new vertical glazing types defined.

- Defines a single maximum SHGC allowance for all vertical glazing types up to $40 \% \mathrm{WWR}$ for nonresidential and residential space types.

Taken in concert, these changes significantly alter vertical fenestration requirements between 90.12004 and 90.1-2007. A tabulated comparison of these differences in SHGC and U-factor by climate zone and space type is provided in Appendix E in this report. For most climate zones, U-factors are approximately equivalent to or somewhat reduced from the U-factors allowed by 90.1-2007. Maximum SHGC allowances move up or down depending on building WWR.

As described in Section 4.3 in this report, the prototype window performance values are developed by applying weighting factors for the different window types, fixed and operable for 90.1-2004, and nonmetal framing, metal frame - curtain wall/storefront; metal framing - all other. Metal frame: entrance door is not included in the weighting.

Regardless of the version of Standard 90.1, window requirements in the standard are defined by bulk properties of U-factor and SHGC. EnergyPlus, however, requires that the thermal/optical properties be defined for the window assembly layer by layer. 
To analyze these changes, PNNL first establishes a method for selecting an actual window option, including framing that meet as closely as possible both the maximum U-factor and SHGC allowed for in 90.1-2004 or 90.1-2007. Glazing materials are selected to match the required assembly u-factor including framing. Assembly U-factor is used, and window frames are not modeled directly to reduce complexity in the EnergyPlus models and make the simulations run faster. The window performance is modeled for the entire glazed area. U-factor and SHGC values were treated as whole-assembly values. A total of 45 different combinations of U-factor, SHGC, and VLT are used from the EnergyPlus library. These combinations are developed into window constructions corresponding the 90.1-2004 or 90.1-2007 requirements and are included in a separate EnergyPlus construction library input file. The constructions are assigned in the model automatically through the parm structure described in Chapter 2 in this report. With this method, EnergyPlus window descriptions essentially meeting Standard 90.1 fenestration requirements, but reflecting windows with real window materials and glazing properties, are developed and used in the quantitative analysis.

The 90.1-2010 model values are the same as the 90.1-2007 and are incorporated in the 90.1-2010 models.

\subsubsection{Addendum 90.1-07f: Cool Roofs}

90.1-2004 and 90.1-2007 do not specify minimum reflectance or emittance requirements for roofs. Solar absorptance of 0.7 (solar reflectance of 0.3) and thermal emittance of 0.9 are used in the 90.1-2004 models representing typical roofing materials. Addendum 90.1-07f adds Section 5.5.3.1.2 to Standard 90.1 and establishes minimum requirements for solar reflectance and thermal emittance for certain types of roofs in climate zones 1 through 3.

Addendum 90.1-07f requires a minimum three-year-aged solar reflectance of 0.55 and a minimum three-year-aged thermal emittance of 0.75 for roofs in climate zones 1 through 3 . The addendum includes exceptions for roofs having any one of the following properties:

- Ballasted roofs, vegetated roofs, and shaded roofs

- Steep sloped roofs (roofs with slopes greater than 2/12)

- Low-sloped metal building roofs in climate zones 2 and 3.

- Roofs over ventilated attics and over semi-heated spaces

- Metal building roofs in climate zones 2 and 3

- Asphaltic membranes in climate zones 2 and 3.

Exceptions apply to only four prototypes. The small office, quick-service restaurant, and full-service restaurant prototypes have steep sloped roofs and qualify for exception (2). The warehouse roof is over semi-heated space and is metal building construction so meets exceptions (4) and (5).

Current prototype models do not carry information to correctly account for exceptions (1) and (6). The modeling team approached the SSPC 90.1 Envelope Subcommittee (Envelope Subcommittee) to determine if certain prototypes needed to be excluded to account for the effect of ballasted roofs and asphaltic membranes. However, the Envelope Subcommittee could not reach consensus on this issue. Therefore, none of the prototypes have been exempted based on exceptions (1) and (6). 
To implement addendum 90.1-07f into the 90.1-2010 models, the roof solar absorptance and roof emissivity of the topmost layer in the roof construction are changed. EnergyPlus uses solar absorptance as the input, which is one minus the solar reflectance value. The baseline models use an absorptance of 0.7 and emissivity of 0.9. The 90.1-2010 models use an absorptance of 0.45 (reflectance of 0.55) and an emissivity of 0.9 . The emissivity for implementing the addendum is not lowered to the minimum allowed value of 0.75 since the baseline already has a value of 0.9 . The addendum $90.1-07 \mathrm{f}$ values are applied to all prototypes only in climate zones 1 through 3 except those four prototypes that are exempt (small office, quick-service restaurant, full-service restaurant, and warehouse).

\subsubsection{Addendum 90.1-07g: Opaque Envelope Performance for Metal Buildings}

Addendum 90.1-07g updates the building envelope criteria for metal buildings in Section 5.5 and Appendix A of 90.1-2007. The updates from addendum 90.1-07g are included in the envelope tables provided in Appendix E in this report. The addendum changes at least some roof and exterior wall Ufactor and insulation values for metal buildings in nearly all climates. The baseline requirements in 90.12004, and the same values which are in 90.1-2007, are also shown in Appendix E of this report.

The warehouse prototype is the only prototype that is a metal building. The changes resulting from addendum 90.1-07g apply in all climate zones. The 90.1-2010 models are modified with reduced assembly U-factor parameters to meet the new requirements. The office and fine storage areas in the warehouse are conditioned spaces, so the nonresidential envelope requirements criteria are applied to the models. The bulk storage area is a semi-heated space, and the semi-heated envelope requirements are applied in the models.

\subsubsection{Addenda 90.1-07am and 90.1-07bf: Air Leakage}

Addenda 90.1-07am and 90.1-07bf address air leakage through the building envelope. 90.1-2004 and 90.1- 2007, Section 5.4.3.1, require buildings to have continuous air barrier design, installation, materials, and assemblies. Section 5.4.3.2 of 90.1-2004 and 2007 specify that air leakage of fenestrations and doors shall be determined according to National Fenestration Rating Council (NFRC) 400 (NFRC 2004) and shall not be exceeded at the minimum requirements, described in Table 5.7 below.

Addendum 90.1-07am modifies building envelope component air leakage rate requirements in Section 5.4.3.2 to include additional options for air leakage testing for fenestration and doors, e.g., either AAMA/WDMA/CSA 101/I.S.2/A440 (AAMA/WDMA/CSA 2004) or NFRC 400 (NFRC 2004)for air leakage testing. Addendum 90.1-07bf modifies the language of the air barrier design requirement in Section 5.4.3.1.1 to include performance requirements for air leakage of the opaque envelope and to add and change acceptable materials and assemblies in Section 5.4.3.1.3. These addenda apply to all prototypes, and implementing the PI savings analysis for these addenda requires determining the whole building air leakage rates.

For the implementation of air barrier requirement, including addenda 90.1-07am and bf, the Envelope Subcommittee initially developed recommendations for baseline (i.e., 90.1-2004) and advanced (i.e., 90.1-2010) infiltration levels for building components, as shown in Table 5.7. These recommendations were provided for each opaque element of the envelope, such as walls, windows, and roofs. For each 
prototype, the total building infiltration rate is calculated by multiplying the component infiltration rate by the component area and summing the resulting values.

Table 5.7. Envelope Component Infiltration Rates

\begin{tabular}{|c|c|c|c|c|}
\hline & $\begin{array}{c}\text { Baseline } \\
\text { Infiltration } \\
\text { at } 0.30 \text { in. w.c. } \\
\left(\mathrm{cfm} / \mathrm{ft}^{2}\right)\end{array}$ & $\begin{array}{c}\text { Advanced } \\
\text { Infiltration at } \\
0.30 \text { in. w.c. } \\
\left(\mathrm{cfm} / \mathrm{ft}^{2}\right)\end{array}$ & Area Calculation Notes & Reference \\
\hline \multicolumn{5}{|l|}{ Opaque Elements } \\
\hline Roofs & 0.12 & 0.04 & Net opaque area of roof & $\begin{array}{l}\text { Envelope } \\
\text { Subcommittee }\end{array}$ \\
\hline Above-Grade Walls & 0.12 & 0.04 & $\begin{array}{l}\text { Net opaque area of above } \\
\text { grade walls }\end{array}$ & $\begin{array}{l}\text { Envelope } \\
\text { Subcommittee }\end{array}$ \\
\hline Below-Grade Walls & 0.12 & 0.04 & $\begin{array}{l}\text { Net opaque area of below } \\
\text { grade walls }\end{array}$ & $\begin{array}{l}\text { Envelope } \\
\text { Subcommittee }\end{array}$ \\
\hline Floor & 0.12 & 0.04 & $\begin{array}{l}\text { Net opaque area of floor } \\
\text { over unconditioned space }\end{array}$ & $\begin{array}{l}\text { Envelope } \\
\text { Subcommittee }\end{array}$ \\
\hline Floor & 0.12 & 0.04 & Net opaque area of slab & $\begin{array}{l}\text { Envelope } \\
\text { Subcommittee }\end{array}$ \\
\hline Opaque Doors & 0.40 & 0.20 & Area of opaque doors & 90.1, Section 5.4.3.2 \\
\hline Loading Dock Doors & 0.40 & 0.20 & $\begin{array}{l}\text { Area of door, applicable } \\
\text { only for warehouses }\end{array}$ & 90.1, Section 5.4.3.2 \\
\hline \multicolumn{5}{|l|}{ Fenestration Elements } \\
\hline $\begin{array}{l}\text { Swinging or Revolving } \\
\text { Glass Doors }\end{array}$ & 1.00 & 1.00 & $\begin{array}{l}\text { Area of swinging or } \\
\text { revolving glass doors }\end{array}$ & 90.1, Section 5.4.3.2 \\
\hline Vestibule & 1.00 & 1.00 & Area of door & 90.1, Section 5.4.3.2 \\
\hline Sliding Glass Doors & 0.40 & 0.20 & $\begin{array}{l}\text { Area of sliding glass } \\
\text { doors }\end{array}$ & 90.1, Section 5.4.3.2 \\
\hline Windows & 0.40 & 0.20 & Area of windows & 90.1, Section 5.4.3.2 \\
\hline Skylights & 0.40 & 0.20 & Area of skylights & 90.1, Section 5.4.3.2 \\
\hline $\begin{array}{l}\text { Total Component } \\
\text { Infiltration Rate }\end{array}$ & \multicolumn{4}{|c|}{$\begin{array}{l}\text { Determined as the sum of the component infiltration rates. The individual component } \\
\text { infiltration rates equal the infiltration rate per area times the component areas. The results } \\
\text { are different for each prototype and for the baseline and advanced cases. }\end{array}$} \\
\hline
\end{tabular}

The total infiltration for a building can be partially calculated by aggregating the component infiltration rates. Although the component infiltration rates specify the infiltration rate of the materials and components, leakage through interfaces between components and workmanship need to be accounted for in calculating the total building infiltration rate. The leakage and workmanship are called the construction quality adjustment (CQA).

The Envelope Subcommittee recommended using total building baseline 90.1-2004 infiltration rate of $1.8 \mathrm{cfm} / \mathrm{ft}^{2}$ at $0.3 \mathrm{in}$. w.c. of exterior above-grade envelope surface area, based on the average air tightness levels summarized in a National Institute of Science and Technology report (Emmerich et al. 2005).

The CQA is found by subtracting the total 90.1-2004 component infiltration rates from the assumed baseline infiltration rate of $1.8 \mathrm{cfm} / \mathrm{ft}^{2}$. The CQA is different for each prototype building. 


\section{$\mathrm{CQA}=$ Baseline Total Building Infiltration Rate $-\left(\sum\right.$ baseline component infiltration rates $)$}

Furthermore, the Envelope Subcommittee also recommended that the CQA calculated based on the baseline infiltration rate for each building be used to determine the total building infiltration rate for advanced requirements from addenda 90.1-07am and bf.

Advanced Total Building Infiltration Rate $=\mathrm{CQA}+\left(\sum\right.$ advanced component infiltration rates $)$

This methodology shows that the reduction in infiltration level from addenda 90.1-07am and bf is relatively small compared with the reduction in practice when a good air barrier design is implemented. The analysis shows that the infiltration rate with the new requirements can be reduced from $1.8 \mathrm{cfm} / \mathrm{ft}^{2}$ at 0.3 in. w.c. to an average of $1.7 \mathrm{cfm} / \mathrm{ft}^{2}$ at the same pressure differential.

No definite requirement exists for the completed building envelope air leakage in 90.1-2010 and its predecessor standards. The Envelope Subcommittee recommended that a different value of $1.0 \mathrm{cfm} / \mathrm{ft}^{2}$ at 0.3 in. w.c. be used as the whole building air leakage rate for the 90.1-2010 models. This implies a significant improvement in the construction quality in addition to reduced component infiltration. The following rationale was provided by the Envelope Subcommittee:

- The original air barrier proposal (addendum 90.1-07z) included an option of $0.40 \mathrm{cfm} / \mathrm{ft}^{2}$ at $0.3 \mathrm{in}$. w.c. as the target whole building air leakage for the airtight building. This number was originally used for energy savings and scalar calculations for the air barrier proposal.

- The final version, addendum 90.1-07bf, does not have a whole building air-tightness option; therefore, the Envelope Subcommittee considered that taking the full credit for air leakage reduction (i.e., all the way to $0.40 \mathrm{cfm} / \mathrm{ft}^{2}$ at $0.3 \mathrm{in}$. w.c.) would be unrealistic and too aggressive. Consequently, a more conservative target was selected.

- Addendum 90.1-07bf includes quantitative air leakage requirements for air barrier materials and air barrier assemblies, which are new requirements compared with 90.1-2007. In addition, addendum bf contains strong language on air barrier design and air barrier installation for continuity at critical interfaces and penetrations. Based on professional judgment, the Envelope Subcommittee members considered these requirements as sufficient to contribute to a significant air leakage reduction towards the $0.40 \mathrm{cfm} / \mathrm{ft}^{2}$ target. The target of $0.4 \mathrm{cfm} / \mathrm{ft}^{2}$ is $1.3 \mathrm{cfm} / \mathrm{ft}^{2}$ below the $1.7 \mathrm{cfm} / \mathrm{ft}^{2}$ baseline. The recommended value to use for the PI of $1.0 \mathrm{cfm} / \mathrm{ft}^{2}$ at $0.3 \mathrm{in}$. w.c. is a reduction of 0.7 $\mathrm{cfm} / \mathrm{ft}^{2}$ below the $1.7 \mathrm{cfm} / \mathrm{ft}^{2}$ baseline or about $55 \%$ of the $1.3 \mathrm{cfm} / \mathrm{ft}^{2}$ total target reduction. Relative to the $1.8 \mathrm{cfm} / \mathrm{ft}^{2}$ baseline, the corresponding reduction of $0.8 \mathrm{cfm} / \mathrm{ft}^{2}$ is about a $60 \%$ reduction compared to the $1.3 \mathrm{cfm} / \mathrm{ft}^{2}$ total target reduction.

- Establishment of this intermediate air leakage reduction is supported by the significant progress that the United States Army Corps of Engineers (USACE) achieved in the last two to three years to reduce infiltration. According to general contractor testimonials, this progress was largely the result of higher attention to details, already part of addendum bf. The study of USACE buildings (Zhivov 2010) shows that air leakage rate well below USACE standards of $0.25 \mathrm{cfm} / \mathrm{ft}^{2}$ at $0.3 \mathrm{in}$. w.c. can be achieved, demonstrating that the recommended $1.0 \mathrm{cfm} / \mathrm{ft}^{2}$ at $0.3 \mathrm{in.} \mathrm{w.c.} \mathrm{is} \mathrm{a} \mathrm{conservative} \mathrm{value.}$

The changes in infiltration are implemented in EnergyPlus by changing the zone level infiltration inputs. Infiltration rates vary according to hourly schedules, which remain the same for the 90.1-2004 and 
90.-2010 models. The total building infiltration schedule fraction is 1.0 when HVAC fans shut off and 0.25 when fans are on. See Appendix C in this report for infiltration schedules for the prototypes.

\subsubsection{Addendum 90.1-07bn: Fenestration Orientation}

90.1-2004 and 90.1-2007 do not specify requirements for orienting fenestration in a particular manner. Addendum 90.10bn adds Section 5.5.4.5 and attempts to limit poorly oriented fenestration. The addendum requires the total area of fenestration facing south to be greater than or equal to each of the total areas of fenestration facing east and west, governed by the area inequalities below.

$$
\mathrm{A}_{\mathrm{s}} \geq \mathrm{A}_{\mathrm{w}} \text { and } \mathrm{A}_{\mathrm{s}} \geq \mathrm{A}_{\mathrm{e}}
$$

where,

$\mathrm{A}_{\mathrm{s}}=$ the total fenestration area facing south (oriented no more than $45^{\circ}$ of true south)

$\mathrm{A}_{\mathrm{w}}=$ the total fenestration area facing west (oriented no more than $45^{\circ}$ of true west)

$\mathrm{A}_{\mathrm{e}}=$ is the total fenestration area facing east (oriented no more than $45^{\circ}$ of true east).

Addendum 90.1-07bn provides an exception for east and west fenestration that is shaded by overhangs or fins for a certain period of the year. This exception is not implemented for two reasons: 1) the PI analysis generally does not include implementation of optional exceptions, and 2) none of the prototypes include east and west fins or overhangs.

All 16 prototypes are analyzed to determine if the conditions for the addendum were met. Only three prototypes do not satisfy the area conditions set by the addendum: warehouse, small hotel, and hospital. The application of addendum bn to these prototypes is discussed below.

Warehouse: The office is the only space in the warehouse prototype that does not meet the requirements of addendum bn. The office space area is very small compared with the total warehouse area. The impact of the addendum on the warehouse prototype is very small; therefore this space is assumed to be exempted from addendum bn. No changes are made to the warehouse prototype because of addendum bn.

Small Hotel: The small hotel prototype has its longer side along the north-south axis. The glazing cannot be reconfigured to meet the conditions of the area inequalities. The easiest way to apply addendum $\mathrm{bn}$ in this case is to rotate the building so the longer side is along the east-west axis. Accordingly, the small hotel prototype is rotated 90 degrees clockwise in the advanced case, thereby satisfying the area conditions.

Hospital: The hospital prototype does not satisfy the conditions of the area inequalities for the west facade. Similar to the small hotel prototype, the orientation of the hospital prototype is changed to comply with addendum bn. The hospital prototype is rotated 90 degrees counterclockwise in the advanced case, thereby satisfying the area conditions. Changing the building orientation for the advanced cases requires a change in the "North Axis" field of the "Building" object in EnergyPlus. 


\subsubsection{Heating, Ventilating and Air Conditioning}

\subsubsection{Addenda 90.1-04f and 90.1-04g: Unitary HVAC Equipment Efficiency}

90.1-2004 Section 6.4.1.1 and its related tables include mandatory minimum efficiency values for HVAC equipment. Table 6.8.1 A applies to unitary air conditioners and condensing units. Table 6.8.1 B applies to unitary and applied heat pumps. Minimum efficiency values are provided for equipment with different cooling capacities and different manufacturing time periods.

Addendum 90.1-04f increases the efficiency values for unitary air conditioners and heat pumps under $65,000 \mathrm{Btu} / \mathrm{h}$ cooling capacity and manufactured on or after January 23, 2006. Table 5.8 shows the 90.12004 values and the amended values from addendum 90.1-04f for this size equipment manufactured on or after January 23, 2006. Table values not shown remain the same as in 90.1-2004.

Addendum 90.1-04g increases the efficiency values for equipment with cooling capacity of 65,000 $\mathrm{Btu} / \mathrm{h}$ or larger when manufactured on or after January 1, 2010. Tables 5.9 and 5.10 show the 90.1-2004 values and the amended values from addendum 90.1-04g for unitary air conditioners and heat pumps manufactured on or after January 1, 2010. Table values not shown remain the same as in 90.1-2004.

Table 5.8. Unitary HVAC Equipment Efficiency $(<65,000 \mathrm{Btu} / \mathrm{h})$

\begin{tabular}{|c|c|c|c|c|c|}
\hline Equipment Type & Size Category & $\begin{array}{c}\text { Heating } \\
\text { Section } \\
\text { Type } \\
\end{array}$ & $\begin{array}{c}\text { Subcategory or } \\
\text { Rating } \\
\text { Condition } \\
\end{array}$ & $\begin{array}{c}90.1-2004 \\
\text { Minimum } \\
\text { Efficiency as of } \\
1 / 23 / 2006\end{array}$ & $\begin{array}{c}\text { Addendum 90.1- } \\
04 \mathrm{f} \text { Minimum } \\
\text { Efficiency } \\
\text { as of } 1 / 23 / 2006 \\
\end{array}$ \\
\hline \multirow{2}{*}{$\begin{array}{l}\text { Air Conditioners Air } \\
\text { Cooled }\end{array}$} & \multirow[t]{2}{*}{$<65,000 \mathrm{Btu} / \mathrm{h}$} & \multirow[t]{2}{*}{ All } & Split System & 12.0 SEER & 13.0 SEER \\
\hline & & & Single Package & 12.0 SEER & 13.0 SEER \\
\hline \multirow{2}{*}{$\begin{array}{l}\text { Heat Pumps, Air } \\
\text { Cooled (cooling mode) }\end{array}$} & \multirow[t]{2}{*}{$<65,000 \mathrm{Btu} / \mathrm{h}$} & \multirow[t]{2}{*}{ All } & Split System & 12.0 SEER & 13.0 SEER \\
\hline & & & Single Package & 12.0 SEER & 13.0 SEER \\
\hline \multirow{2}{*}{$\begin{array}{l}\text { Heat Pumps, Air } \\
\text { Cooled (heating mode) }\end{array}$} & \multirow{2}{*}{$\begin{array}{l}<65,000 \text { Btu/h } \\
\text { (cooling capacity) }\end{array}$} & \multirow[t]{2}{*}{ All } & Split System & 7.4 HSPF ${ }^{(a)}$ & 7.7 HSPF \\
\hline & & & Single Package & 7.4 HSPF & 7.7 HSPF \\
\hline
\end{tabular}


Table 5.9. Unitary Air Conditioner Efficiency ( $\geq 65,000 \mathrm{Btu} / \mathrm{h})$

\begin{tabular}{|c|c|c|c|c|c|}
\hline $\begin{array}{l}\text { Equipment } \\
\text { Type }\end{array}$ & Size Category & $\begin{array}{l}\text { Heating Section } \\
\text { Type }\end{array}$ & $\begin{array}{c}\text { Subcategory or } \\
\text { Rating Condition }\end{array}$ & $\begin{array}{c}90.1-2004 \\
\text { Minimum } \\
\text { Efficiency as } \\
\text { of } 1 / 1 / 2010\end{array}$ & $\begin{array}{c}\text { Addendum } \\
90.1-04 \mathrm{~g} \\
\text { Minimum } \\
\text { Efficiency } \\
\text { as of } 1 / 1 / 2010\end{array}$ \\
\hline \multirow{8}{*}{$\begin{array}{l}\text { Air } \\
\text { Conditioners, } \\
\text { Air Cooled }\end{array}$} & \multirow[t]{2}{*}{$\begin{array}{l}\geq 65,000 \mathrm{Btu} / \mathrm{h} \text { and } \\
<135,000 \mathrm{Btu} / \mathrm{h}\end{array}$} & $\begin{array}{l}\text { Electric Resistance } \\
\text { (or none) }\end{array}$ & $\begin{array}{l}\text { Split System and } \\
\text { Single Package }\end{array}$ & 10.3 EER & $11.2 \mathrm{EER}$ \\
\hline & & All other & $\begin{array}{l}\text { Split System and } \\
\text { Single Package }\end{array}$ & 10.1 EER & 11.0 EER \\
\hline & \multirow[t]{2}{*}{$\begin{array}{l}\geq 135,000 \mathrm{Btu} / \mathrm{h} \text { and } \\
<240,000 \mathrm{Btu} / \mathrm{h}\end{array}$} & $\begin{array}{l}\text { Electric Resistance } \\
\text { (or none) }\end{array}$ & $\begin{array}{l}\text { Split System and } \\
\text { Single Package }\end{array}$ & 9.7 EER & 11.0 EER \\
\hline & & All Other & $\begin{array}{l}\text { Split System and } \\
\text { Single Package }\end{array}$ & 9.5 EER & 10.8 EER \\
\hline & \multirow[t]{2}{*}{$\begin{array}{l}\geq 240,000 \mathrm{Btu} / \mathrm{h} \text { and } \\
<760,000 \mathrm{Btu} / \mathrm{h}\end{array}$} & $\begin{array}{l}\text { Electric Resistance } \\
\text { (or none) }\end{array}$ & $\begin{array}{l}\text { Split System and } \\
\text { Single Package }\end{array}$ & $\begin{array}{l}\text { 9.5 EER } \\
\text { 9.7 IPLV }\end{array}$ & $\begin{array}{l}\text { 10.0 EER } \\
\text { 9.7 IPLV }\end{array}$ \\
\hline & & All Other & $\begin{array}{l}\text { Split System and } \\
\text { Single Package }\end{array}$ & $\begin{array}{l}\text { 9.3 EER } \\
\text { 9.5 IPLV }\end{array}$ & $\begin{array}{l}\text { 9.8 EER } \\
\text { 9.7 IPLV }\end{array}$ \\
\hline & \multirow[t]{2}{*}{$\geq 760,000 \mathrm{Btu} / \mathrm{h}$} & $\begin{array}{l}\text { Electric Resistance } \\
\text { (or none) }\end{array}$ & $\begin{array}{l}\text { Split System and } \\
\text { Single Package }\end{array}$ & $\begin{array}{l}\text { 9.2 EER } \\
\text { 9.4 IPLV }\end{array}$ & $\begin{array}{l}\text { 9.7 EER } \\
\text { 9.4 IPLV }\end{array}$ \\
\hline & & All Other & $\begin{array}{l}\text { Split System and } \\
\text { Single Package }\end{array}$ & $\begin{array}{l}\text { 9.0 EER } \\
\text { 9.2 IPLV }\end{array}$ & $\begin{array}{l}\text { 9.5 EER } \\
\text { 9.2 IPLV }\end{array}$ \\
\hline
\end{tabular}

Table 5.10. Unitary Heat Pump Efficiency $(\geq 65,000 \mathrm{Btu} / \mathrm{h})$

\begin{tabular}{|c|c|c|c|c|c|}
\hline $\begin{array}{l}\text { Equipment } \\
\text { Type }\end{array}$ & Size Category & $\begin{array}{c}\text { Heating Section } \\
\text { Type }\end{array}$ & $\begin{array}{l}\text { Subcategory or } \\
\text { Rating Condition }\end{array}$ & $\begin{array}{l}90.1-2004 \\
\text { Minimum } \\
\text { Efficiency } \\
\text { as of } \\
1 / 1 / 2010\end{array}$ & $\begin{array}{c}\text { Addendum } \\
90.1-04 \mathrm{~g} \\
\text { Minimum } \\
\text { Efficiency } \\
\text { as of } 1 / 1 / 2010\end{array}$ \\
\hline \multirow[t]{4}{*}{$\begin{array}{l}\text { Air Cooled } \\
\text { (cooling } \\
\text { mode) }\end{array}$} & $\begin{array}{l}\geq 65,000 \mathrm{Btu} / \mathrm{h} \text { and } \\
<135,000 \mathrm{Btu} / \mathrm{h}\end{array}$ & $\begin{array}{l}\text { Electric Resistance } \\
\text { (or none) } \\
\text { All Other }\end{array}$ & $\begin{array}{c}\text { Split System and } \\
\text { Single Package }\end{array}$ & 10.1 EER & 11.0 EER \\
\hline & $\begin{array}{l}\geq 135,000 \mathrm{Btu} / \mathrm{h} \text { and } \\
<240,000 \mathrm{Btu} / \mathrm{h}\end{array}$ & $\begin{array}{l}\text { Electric Resistance } \\
\text { (or none) } \\
\text { All Other }\end{array}$ & $\begin{array}{c}\text { Split System and } \\
\text { Single Package }\end{array}$ & 9.3 EER & 11.0 EER \\
\hline & \multirow[t]{2}{*}{$\geq 240,000 \mathrm{Btu} / \mathrm{h}$} & $\begin{array}{l}\text { Electric Resistance } \\
\text { (or none) }\end{array}$ & \multirow{2}{*}{$\begin{array}{c}\text { Split System and } \\
\text { Single Package }\end{array}$} & $\begin{array}{l}\text { 9.0 EER } \\
\text { 9.2 IPLV }\end{array}$ & $\begin{array}{l}\text { 10.0 EER } \\
\text { 9.2 IPLV }\end{array}$ \\
\hline & & All Other & & $\begin{array}{l}\text { 8.8 EER } \\
\text { 9.0 IPLV }\end{array}$ & $\begin{array}{l}\text { 9.8 EER } \\
\text { 9.0 IPLV }\end{array}$ \\
\hline \multirow{2}{*}{$\begin{array}{l}\text { Air Cooled } \\
\text { (heating } \\
\text { mode) }\end{array}$} & \multirow{2}{*}{$\begin{array}{l}\geq 65,000 \mathrm{Btu} / \mathrm{h} \text { and } \\
<135,000 \mathrm{Btu} / \mathrm{h} \\
\text { (cooling capacity) }\end{array}$} & & $\begin{array}{c}47^{\circ} \mathrm{F} \mathrm{db} / 43^{\circ} \mathrm{F} \text { wb } \\
\text { Outdoor Air }\end{array}$ & $3.2 \mathrm{COP}$ & $3.3 \mathrm{COP}$ \\
\hline & & & $\begin{array}{c}17^{\circ} \mathrm{F} \mathrm{db} / 15^{\circ} \mathrm{F} \text { wb } \\
\text { Outdoor Air }\end{array}$ & $2.2 \mathrm{COP}$ & $2.2 \mathrm{COP}$ \\
\hline \multirow{2}{*}{$\begin{array}{l}\text { Air Cooled } \\
\text { (heating } \\
\text { mode) }\end{array}$} & \multirow[t]{2}{*}{$\begin{array}{l}\geq 135,000 \text { Btu/h } \\
\text { (cooling capacity) }\end{array}$} & & $\begin{array}{c}47^{\circ} \mathrm{F} \mathrm{db} / 43^{\circ} \mathrm{F} \text { wb } \\
\text { Outdoor Air }\end{array}$ & $3.1 \mathrm{COP}$ & $3.2 \mathrm{COP}$ \\
\hline & & & $\begin{array}{c}17^{\circ} \mathrm{F} \mathrm{db} / 15^{\circ} \mathrm{F} \text { wb } \\
\text { Outdoor Air }\end{array}$ & $2.0 \mathrm{COP}$ & $2.0 \mathrm{COP}$ \\
\hline
\end{tabular}


The changes are implemented in the analysis by modifying a script routine that extracts the equipment cooling capacity and assigns the corresponding equipment efficiency based on that capacity. Therefore, for the 90.1-2010 models, the higher efficiency values are applied for the applicable unit type and capacity. This affects the HVAC units in prototypes with unitary HVAC equipment, including the small office, medium office, standalone retail, strip mall, primary school, outpatient healthcare, small hotel, warehouse, quick-service restaurant, full-service restaurant, and mid-rise apartment.

\subsubsection{Addendum 90.1-04q: Off-Hour Controls for Hotels and Motels}

90.1-2004 has requirements for off-hour controls (e.g., thermostat setback) for most conditioned building spaces. An exception is provided for HVAC systems serving motel and hotel guestrooms. This original exception is based largely on the premise that such systems are not cost effective because hotel and motel guestrooms are under control of the occupant and a controller cannot be set up without prior knowledge of when a space would be unoccupied. Addendum 90.1-04q removes this exception, because controls specific to hotel/motel applications are now available that can be used to indicate when rooms are unoccupied (considered off-hour) and thus control certain HVAC functions, including thermostat setpoint.

To model the effect of addendum 90.1-04q on hotels and motels, the occupied guestroom heating and cooling thermostat setpoints are modified from a constant $70^{\circ} \mathrm{F}$ indoor setpoint condition to a setpoint schedule of $66^{\circ} \mathrm{F}$ for heating and $74^{\circ} \mathrm{F}$ for cooling from 9 am to $4 \mathrm{pm}$ each day. This assumption is based on a similar analysis that PNNL conducted in support of the Advanced Energy esign Guide for Highway Lodging (Jiang et al. 2008)

\subsubsection{Addendum 90.1-04s: Ventilation Outdoor Air Requirements}

Chapter 12 ("Normative References") of 90.1-2004 has a normative reference to Standard 62-1999, Ventilation for Acceptable Indoor Air Quality (Standard 62-1999). 90.1-2004 also includes in Section 6.4.3.8, on ventilation controls for high occupancy areas a general requirement that ventilation controls be in compliance with Standard 62, as well as specifically referencing the ventilation standard and including language that is consistent with controls and other requirements of that standard.

Addendum 90.1-04s updates the ventilation standard to Standard 62.1-2004. The addendum also changes the text in Section 6.4.3.8 to refer to Standard 62.1-2004. Addendum 90.1-07ck (Section 5.2.2.21 in this report) updates Chapter 12 for 90.1-2010 to Standard 62.1-2007 which has identical requirements as 62.1-2004 as applied to the prototype models. Addendum 90.1-04s affects all prototypes in all climate zones.

Minimum outdoor air ventilation rates determined from Standard 62-1999 are generally larger than rates determined under 62.1-2004. 90.1-2004 models use outdoor rates calculated from Standard 62-1999. 90.1-2010 models use outdoor air ventilation rates as required by 62.1-2007 (equivalent to 62.1-2004). Chapter 4, Table 4.14 in this report provides the ventilation rates for both versions of the ventilation standard. Outdoor air rates are modeled by changing zone level outdoor air inputs in most cases.

For multi-zone HVAC systems affected by addendum 90.1-07ck (Section 5.2.2.21 in this report), system outdoor air is calculated for the baseline and advanced models using the multi-zone system 
requirements in Standard 62-1999 and 62.1-2007 respectively which start from the zone level minimum outdoor air requirements corresponding to these Standards.

\subsubsection{Addendum 90.1-04v: Demand Control Ventilation}

90.1-2004 has specific ventilation requirements for high-occupancy areas that require a method to automatically reduce the ventilation rates when spaces are partially occupied (Section 6.4.3.8, "Ventilation Controls for High Occupancy Areas"). High-occupancy areas for which these requirements apply are spaces with design occupancy of greater than 100 persons per $1000 \mathrm{ft}^{2}$ floor area served by systems with more than $3000 \mathrm{cfm}$ of design outdoor airflow.

Addendum 90.1-04v modifies the provisions of Standard 90.1 Section 6.4.3.9 by expanding the criteria for requiring DCV. The addendum changes the minimum size threshold for the spaces so that it applies to spaces larger than $500 \mathrm{ft}^{2}$ and lowers the design occupancy density threshold from 100 persons per $1000 \mathrm{ft}^{2}$ to 40 persons per $1000 \mathrm{ft}^{2}$ of floor area.

The impact of this addendum is analyzed by first identifying buildings prototypes with spaces that would be qualified as the high-occupancy areas defined in addendum 90.1-04v. High-occupancy spaces are identified in three prototypes: primary school, secondary school, and large hotel.

For the primary and secondary schools, DCV controllers are implemented in the 90.1-2010 models for the cafeteria spaces. For the secondary school, the auditorium space already fell under the DCV requirements in 90.1-2004 and is modeled with this control in both 90.1-2004 and 90.1-2010. For the large hotel prototype, DCV controllers are implemented in the following zones: first floor cafeteria, sixth floor banquet room, and sixth floor dining room.

DCV is implemented in EnergyPlus by modifying the minimum outdoor air schedule from a fixed schedule to a controller-based schedule with the minimum outdoor air rate as required by Standard 62.1.

\subsubsection{Addendum 90.1-04ac: Fan Power Requirements}

90.1-2004 Section 6.5.3 specifies maximum fan power allowances for HVAC systems with total fan power greater than $5 \mathrm{hp}$. Addendum 90.1-04ac strengthens fan power limitations for simple systems and expands coverage for many complex systems to properly address complex exhaust fan systems associated with hospitals and laboratories, spaces that could be treated as exempt in 90.1-2004. Fans for these systems are not explicitly covered in 90.1-2004 and could be considered as exempt due to the overlap between fan system design and health and safety impacts for these types of buildings.

Addendum 90.1-04ac changes the fan power allowance structure to be based on a continuous curve for allowed horsepower as a function of design fan air volume (the 90.1-2004 requirement had a step function in the allowed motor horsepower curve based on system airflow volume). The addendum also provides two distinct compliance path options. The first path is similar to 90.1-2004 in that it defines total allowable fan system nameplate motor horsepower based on system design air volume (with different curves provided for constant volume and variable volume systems). The second path defines the allowable fan system fan brake horsepower as a function of design fan volume and specific pressure drop adjustments for key system components. The second path allows higher fan power to be provided, but only where it is actually needed due to the presence of specific system components, such as fully ducted 
return and exhaust systems, high efficiency particulate filtration, air cleaners, and heat recovery devices. Because these components are widely used in hospitals and laboratories, the second path in essence provides a path that eliminates a need to exempt these applications.

The EnergyPlus program simulates fan power by considering three inputs: the design pressure drop through the fan, total fan efficiency, and motor efficiency. For modeling systems according to where the maximum fan power has been specified (as in Standard 90.1), a corresponding design pressure drop for each air system is calculated using the following equation:

$$
\text { Design Pressure Drop }=(\text { brake horsepower } \times \text { fan efficiency } \times 6356) / \mathrm{cfm}
$$

where,

$$
\begin{aligned}
& \mathrm{cfm}= \text { supply fan airflow as determined by EnergyPlus sizing runs } \\
& \text { fan efficiency }= 65 \%, \text { based on assumptions used by the SSPC 90.1 while developing fan power } \\
& \text { requirements for Standard } 90.1 \\
& \text { brake horsepower }=\quad \text { allowed brake horsepower. }
\end{aligned}
$$

Once the brake horsepower is established for a fan system, the nameplate horsepower is calculated using a $10 \%$ oversizing factor (i.e., nameplate horsepower $=$ brake horsepower $\times 1.1$, as allowed under Standard 90.1). The nameplate motor horsepower is used in calculating the fan motor efficiency.

To implement this addendum, a rule set was established for determining fan system brake horsepower based on fan system type, system air volume, and the fan efficiency. This rule set is shown in Table 5.11 and is based on the following assumptions.

- Systems of 5.0 nameplate horsepower or smaller are not regulated by Section 6.5.3.1 which limits fan power in either 90.1-2004 or 90.1-2007.

- For the calculations, fan mechanical efficiency is set to $65 \%$.

- Total static pressure for constant volume fan systems with airflow larger than 7,437 cfm is assumed to be 2.5 in. w.c. based on the analysis done to support the Small Retail Building AEDG (Liu et al. 2006). The $7,437 \mathrm{cfm}$ at 2.5 in. w.c. total static pressure requires 4.5 brake horsepower or larger than 5 nameplate motor horsepower once motor efficiencies and safety factors have been accounted for.

- For CAV fan systems, if system air volume is larger than 7,437 cfm, then the fan power limitation is assumed to apply.

- For VAV systems, if the design air volume is larger than $4,648 \mathrm{cfm}$, the fan power limitation is assumed to apply, based on an assumption of 4 in. w.c. static pressure for small VAV systems.

- Unit heater total static pressure is equal to 0.2 in. w.c. and motor efficiency is assumed equal to $82.5 \%$, based on review of manufacturers' catalog data. This assumption is applied to all sizes of unit heater.

- The PTAC, PTHP, and fan coil units (FCU) are assumed to have total static pressure of 1.33 in. w.c. based on fan motor efficiency being set to 0.8 in. w.c. This assumption reflects total fan power for this equipment and is based on fan power assumptions used in 90.1-2007. More information can 
be found in Appendix G, "Performance Rating Method," for modeling fan systems for these types of equipment.

Table 5.11. Rules for Establishing Fan Power Inputs for PI Analysis

\begin{tabular}{llll}
\hline System & CFM Range & TSP in. w.c. & Fan Efficiency \\
\hline Fan Power Limitation Rule for & 90.1-2004 & & \\
\hline CAV & $<7,437$ & 2.50 & 0.65 \\
VAV & $<4,648$ & 4.00 & 0.65 \\
CAV & $\geq 7,437$ and $<20,000$ & 4.46 & 0.65 \\
CAV & $\geq 20,000$ & 4.09 & 0.65 \\
VAV & $\geq 4,648$ and $<20,000$ & 6.32 & 0.65 \\
VAV & $\geq 20,000$ & 5.58 & 0.65 \\
Unit Heater & All & 0.2 & 0.65 \\
PTAC, PTHP, or FCUs & All & 1.33 & 0.65 \\
\hline Fan Power Limitation Rule for Addendum 90.1-04ac & & \\
\hline CAV & $<7,437$ & 2.50 & 0.65 \\
VAV & $<4,648$ & 4.00 & 0.65 \\
CAV & $\geq 7,437$ & 4.09 & 0.65 \\
VAV & $\geq 4,648$ & 5.58 & 0.65 \\
Unit Heater & All & 0.2 & 0.65 \\
PTAC, PTHP, or FCUs & All & 1.33 & 0.65 \\
\hline
\end{tabular}

The last required input, motor efficiency, is taken directly from Table 10.8 in Standard 90.1- 2004 and reflects minimum federal efficiency standards, based on motor nameplate size and assuming enclosed motors operating at 1,800 rotations per minute (rpm).

\subsubsection{Addendum 90.1-04an: Boiler Efficiency}

Boiler efficiency minimum requirements are provided in Table 6.8.1F of 90.1-2004. This table is impacted by two addenda to that standard's addendum: 90.1-04an and 90.1-04t. Addendum 90.1-04t is described but does not affect the progress indicator result. Addendum 90.1-04an impacts savings and is implemented for the PI.

Addendum 90.1-04t modifies the baseline efficiency requirements for certain classes of boilers by adding a requirement for thermal efficiency. 90.1-2004 only includes minimum efficiency requirements for combustion efficiency. A DOE review of commercial boiler efficiency suggested that $75 \%$ thermal efficiency proposed by addenda 90.1-04t for boilers with a minimum $80 \%$ combustion efficiency would have no significant impact on products available or likely to become available in the market. No credit has been given for this addendum in the quantitative analysis (DOE 2010a).

Addendum 90.1-04an improves the thermal efficiency requirements for most classes of commercial boilers. The thermal efficiency improvements for gas boilers were effective in on March 2, 2010, within three years of the publication date of 90.1-2007, therefore the change in efficiency is included in the quantitative analysis. 
The addendum does not address boilers under 300,000 Btu/h input capacity, which are covered as residential products. For boilers under $300,000 \mathrm{Btu} / \mathrm{h}$ capacity, the efficiency requirement is actually expressed in terms of AFUE but has been approximated as thermal efficiency for the EnergyPlus simulations. Because this efficiency did not change between different versions of Standard 90.1, this was considered to be a reasonable approximation for the quantitative analysis.

For boilers larger than 2,500,000 Btu/h capacity, the requirement in Standard 90.1 is expressed in terms of combustion efficiency. Combustion efficiency is converted to a thermal efficiency by assuming a $0.007 \%$ difference between combustion and thermal efficiency for boilers in this size range.

Six prototypes use commercial gas-fired hot water boilers for space heating: large office, large hotel, hospital, outpatient healthcare, primary school, and secondary school. None of the prototypes use steam or oil-fired boilers. For each building model in each climate simulated, the buildings boilers are sized using the design day sizing analysis, and the efficiency of boilers is determined for both 90.1-2004 and addendum 90.1-04an, as listed in Table 5.12 below. The 90.1-2010 values are the same as in 90.1-2007 (i.e., addendum 90.1-04an). Where multiple boilers exist in a prototype, the total heating capacity is first calculated using the EnergyPlus design day sizing run and is divided by the number of boilers prior to establishing the thermal efficiency of each boiler.

Table 5.12. Boiler Efficiency Used in PI Analysis

\begin{tabular}{lcc}
\hline \multirow{2}{*}{$\begin{array}{c}\text { Gas Hot Water Boiler (input) } \\
\text { Capacity }\end{array}$} & \multicolumn{2}{c}{ Thermal Efficiency Used in Prototype Simulation } \\
\cline { 2 - 3 } & $90.1-2004$ & Addendum 90.1-04an \\
\hline$<300 \mathrm{kBtu} / \mathrm{h}$ & $0.80^{(\mathrm{a})}$ & $0.80^{(\mathrm{a})}$ \\
$\geq 300 \mathrm{kBtu} / \mathrm{h}$ and $<2,500 \mathrm{kBtu} / \mathrm{h}$ & 0.75 & 0.80 \\
$>2,500 \mathrm{kBtu} / \mathrm{h}$ & 0.793 & 0.813 \\
\hline
\end{tabular}

(a) Based on 0.80 AFUE requirement

\subsubsection{Addendum 90.1-04ao: Unit Heater Equipment}

90.1-2004, Table 6.8.1E, sets minimum efficiency requirements for warm air heating equipment. Addendum 90.1-04ao adds a footnote (h) to Table 6.8.1E. The footnote requires that gas-fired and oilfired warm air unit heaters include an interrupted or intermittent ignition device and have either power venting or an automatic flue damper. A vent damper is an acceptable alternative to a flue damper for unit heaters where combustion air is drawn from the conditioned space.

To analyze the energy savings impact of this addendum, the unit heaters in the 90.1-2004 baseline models are assumed to include $250-\mathrm{W}$ pilot lights $(850 \mathrm{Btu} / \mathrm{h})$. This assumption is derived from engineering specifications and catalogs of the available commercial products. Addendum 90.1-04ao is applied to the warehouse prototype building, which uses gas-fired unit heaters in the bulk storage area. The number of unit heaters is determined based on typical unit heater sizes, design practice, and heating loads at design condition. The number of unit heaters in the warehouse models is listed in Table 5.13 for all 17 climate locations. 


\subsubsection{Addendum 90.1-04ar: Part Load Fan Power Limitation}

90.1-2004, Section 6.5.3.2.1 on fan part load power limitations requires that individual VAV fan systems with motors $15 \mathrm{hp}$ or larger will either (a) be driven by a mechanical or electrical variable-speed drive, (b) be a vane axial fan with variable pitch blades, or (c) have other controls or devices so the fan motor demand be no more than $30 \%$ of design wattage at $50 \%$ of design airflow rate

Table 5.13. Quantity of Unit Heaters in Warehouse Prototype

\begin{tabular}{|c|c|c|c|c|c|}
\hline Location & $\begin{array}{c}\text { Number of } \\
\text { Heaters }\end{array}$ & Location & $\begin{array}{c}\text { Number of } \\
\text { Heaters }\end{array}$ & Location & $\begin{array}{c}\text { Number of } \\
\text { Heaters }\end{array}$ \\
\hline 1A Miami & 7 & 3C San Francisco & 8 & 5C Vancouver & 13 \\
\hline 1B Riyadh & 9 & 4A Baltimore & 20 & $6 \mathrm{~A}$ Burlington & 19 \\
\hline 2A Houston & 12 & 4B Albuquerque & 15 & 6B Helena & 26 \\
\hline 2B Phoenix & 7 & 4C Salem & 12 & 7 Duluth & 19 \\
\hline 3A Memphis & 16 & 5A Chicago & 20 & 8 Fairbanks & 21 \\
\hline 3B El Paso & 9 & 5B Boise & 19 & & \\
\hline
\end{tabular}

when the static pressure setpoint equals one third of total design static pressure, based on manufacturer's certified fan data. This requirement provides two prescriptive design options and one performance option to provide for acceptably low fan part-load fan power for VAV fan systems.

Addendum 90.1-04ar reduces the fan motor size threshold in Section 6.5.3.2.1 from $15 \mathrm{hp}$ to $10 \mathrm{hp}$, increasing the number of VAV fan systems that would have to meet one or another of the three prescribed options. This addendum is incorporated into the simulation routines by first calculating a total fan air volume for any VAV system based on design day sizing, then calculating a brake horsepower requirement for that fan system using the methodology discussed previously under addendum 90.1-04ac, and then using the required motor efficiency to calculate a motor input power in watts. Motors with input power thresholds under 7,378 W (equivalent to $9.9 \mathrm{hp}$ of electrical power input) are deemed equivalent to less than $15 \mathrm{hp}$ nameplate horsepower given nominal motor sizes available in this size range $(7.5,10,15$, and $20 \mathrm{hp}$ ). Motors with input power thresholds of less than 5,626 W (equivalent to $7.54 \mathrm{hp}$ of electrical power input) are deemed equivalent to less than $10 \mathrm{hp}$ nameplate horsepower given nominal motor sizes available. If the motor input power is less than 7,378 W in the 90.1-2004 models or less than 5,626 $\mathrm{W}$ in the addendum 90.1-04ar models, then VAV fan system part-load curve A is used in the EnergyPlus simulation, effectively representing a VAV fan controlled using outlet dampers only. For motor input power at or above these thresholds, VAV fan system part-load curve B is used in the EnergyPlus simulation, representative of a fan system curve complying with Option $\mathrm{C}$ of Section 6.5.3.2.1.

EnergyPlus uses a fourth order polynomial curve, which gives the part load fraction (PLF), the fraction of full load power of the supply fan as a function of flow fraction (FF), which is the air mass flow rate divided by the maximum air mass flow rate (design maximum). The curve is of the form:

$$
\mathrm{PLF}=\mathrm{C}_{1}+\mathrm{C}_{2} \times \mathrm{FF}+\mathrm{C}_{3} \times \mathrm{FF}^{2}+\mathrm{C}_{4} \times \mathrm{FF}^{3}+\mathrm{C}_{5} \times \mathrm{FF}^{4}
$$

Table 5.14 shows the coefficients $C_{1}$ through $C_{5}$ for both VAV fan performance curve $A$ and fan performance curve $\mathrm{B}$. 
Table 5.14. Fan Performance Curves

\begin{tabular}{llllll}
\hline \multicolumn{1}{c}{ Coefficients } & \multicolumn{1}{c}{$\mathrm{C}_{1}$} & \multicolumn{1}{c}{$\mathrm{C}_{2}$} & \multicolumn{1}{c}{$\mathrm{C}_{3}$} & $\mathrm{C}_{4}$ & $\mathrm{C}_{5}$ \\
\hline Curve A & 0.18984763 & 0.31447014 & 0.49568211 & 0 & 0 \\
Curve B & 0.0408 & 0.0880 & -0.0729 & 0.9437 & 0 \\
\hline
\end{tabular}

The implementation to capture the impact of addendum 90.1-04ar is made in the modeling scripts. Only the primary school has some VAV systems with fan power of between $10 \mathrm{hp}$ and $15 \mathrm{hp}$ in the 90.12004 models in some climate zones; therefore addendum 90.1-04ar only affects the primary school.

\subsubsection{Addendum 90.1-07e and 90.1-07dj: Exhaust Air Energy Recovery}

90.1-2004 and 90.1-2007 7 require that exhaust air energy recovery ventilator (ERV) be used if a fan system meets the following two criteria:

- The design supply air capacity is 5,000 cfm or larger

- The design minimum outdoor air supply is $70 \%$ or more of the design supply air.

Addendum 90.1-07e greatly expands the scope of requirements for energy recovery by establishing a range of values for systems, in some cases lowering the thresholds for design supply air capacity with lower ratios of outdoor air varying by climate zone. The expanded energy recovery requirements in addendum 90.1-07e depend on the design supply airflow, climate zone, and the outdoor air fraction at design supply airflow rate, as shown in Table 5.15. Addendum 90.1-07dj sets limits on the pressure drop allowed through energy recovery devices.

Based on the system sizing information from the EnergyPlus simulation, each air system of all 16 building prototypes in all 17 climate locations is checked against the values in Table 5.15 below to determine whether energy recovery is applicable. Table 5.16 shows which HVAC systems in the affected prototypes are required to included energy recovery ventilators.

Table 5.15. Energy Recovery Requirements by Climate Zone and Outdoor Air Fraction

\begin{tabular}{lcccccc}
\hline & \multicolumn{5}{c}{ Outdoor Air Fraction at Design Air Flow Rate } \\
\cline { 2 - 7 } \multicolumn{1}{c}{ Climate zone } & $30-40 \%$ & $40-50 \%$ & $50-60 \%$ & $60-70 \%$ & $70-80 \%$ & $\geq 80 \%$ \\
\cline { 2 - 7 } & \multicolumn{7}{c}{ Design Supply Fan Airflow Rate $(\mathrm{cfm})$} \\
\hline 3B, 3C, 4B, 4C, 5B & $\mathrm{NR}^{(\mathrm{a})}$ & $\mathrm{NR}$ & $\mathrm{NR}$ & $\mathrm{NR}$ & $\geq 5,000$ & $\geq 5,000$ \\
1B, 2B, 5C & $\mathrm{NR}$ & $\mathrm{NR}$ & $\geq 26,000$ & $\geq 12,000$ & $\geq 5,000$ & $\geq 4,000$ \\
6B & $\geq 11,000$ & $\geq 5,500$ & $\geq 4,500$ & $\geq 3,500$ & $\geq 2,500$ & $\geq 1,500$ \\
1A, 2A, 3A, 4A, 5A, 6A & $\geq 5,500$ & $\geq 4,500$ & $\geq 3,500$ & $\geq 2,000$ & $\geq 1,000$ & $\geq 0$ \\
7, 8 & $\geq 2,500$ & $\geq 1,000$ & $\geq 0$ & $\geq 0$ & $\geq 0$ & $\geq 0$ \\
\hline
\end{tabular}

(a) NR -not required

The modeled energy recovery effectiveness is listed in Table 5.17, as suggested by the $90.1 \mathrm{SWG}$. The implemented effectiveness values are higher than the minimum requirement of $50 \%$ recovery effectiveness in Standard 90.1, mainly because, in practice, the energy recovery wheels are the most 
commonly used technology to comply with this requirement and ERV wheels can achieve much higher effectiveness than the values in Table 5.17. Therefore, the modeled effectiveness values are reasonable to capture the savings from addendum 90.1-07e.

The fan energy associated with energy recovery is modeled as the wheel parasitic power. This is a work-around solution in EnergyPlus because fan energy for ERV is not an input of the ERV module and the ERV fan energy cannot simply be added to the system supply fan since the ERV may be bypassed when energy recovery does not save energy. Modeled as parasitic power, ERV fan energy occurs only when the ERV runs, which is the desired behavior. The ERV fan energy is calculated from the following assumptions:

- ERV pressure drop of on the outdoor air side is 0.65 in. w.c.

- ERV pressure drop on the exhaust air side is 0.65 in. w.c.

- Additional pressure drop due to filter on the outdoor air side is 0.20 in. w.c.

- Total fan efficiency (fan efficiency and motor efficiency) is 50\%

- Exhaust airflow is $90 \%$ of outdoor airflow after considering leakage and zone exhaust.

ERV running status depends on the air economizer status: ERVs turn off when the air economizer is on; ERVs turns on when air economizer is off due to economizer high-limit shutoff control or other economizer constraints, such as minimum outdoor air temperature. ERVs are bypassed for both the supply and the exhaust air whenever it is off.

Supply air bypass is the strategy used in the simulation for ERV frost control. When the outdoor air temperature is below $-10^{\circ} \mathrm{F}$, ERV control cycles off the supply airflow through the heat exchanger for a certain period of time while the exhaust air continues to flow through the exhaust side of the heat exchanger.

90.1-2004 and 90.1-2007 Section 6.5.3.1 sets the maximum system power allowed and includes pressure drop adjustments in Table 6.5.3.1.1B that can increase the standard maximum fan power limitation. In this section 90.1-2004 and 90.1-2007 allow the energy recovery device pressure drop at design conditions to be used as the adjustment and do not set any limit on the pressure drop of energy recovery devices. Addendum 90.1-07dj restricts the fan power limit pressure drop adjustment for energy recovery devices in Table 6.5.3.1.1B to the following values:

- For coil runaround loop, the pressure drop limitation is 0.6 in. w.c. for each air stream.

- For energy recovery devices other than coil runaround loop, the pressure drop limitation for each air stream is given by Equation: (2.2 x Energy Recovery Effectiveness) - 0.5 in. w.c.

Enthalpy wheels are used in all those air systems that have energy recovery devices. In the simulation work for addendum e to 90.1-2007, it is assumed that (1) the energy recovery effectiveness is 0.6 ; and (2) the pressure drop on each air stream is 0.65 in. w.c. This assumption satisfies addendum dj, which requires the maximum pressure drop for each airstream to be $2.2 * 0.6-0.5=0.82$ in. w.c. 
Table 5.16. HVAC Systems Required to Have Energy Recovery

\begin{tabular}{|c|c|c|c|c|c|c|}
\hline \multirow[b]{2}{*}{$\begin{array}{l}\text { Climate } \\
\text { Location }\end{array}$} & \multicolumn{6}{|c|}{ Building prototypes } \\
\hline & $\begin{array}{l}\text { Large } \\
\text { Office }\end{array}$ & Hospital & Primary School $^{(\mathrm{a})}$ & Secondary School ${ }^{(b)}$ & $\begin{array}{c}\text { Standalone } \\
\text { Retail }\end{array}$ & Large Hotel \\
\hline 1A Miami & CAV_base & $\begin{array}{l}\text { VAV_ICU, } \\
\text { VAV_PATRMS }\end{array}$ & $\begin{array}{l}\text { VAV_Pod_1, VAV_Pod_2, } \\
\text { VAV_Pod_3, PSZ-AC_2:7 }\end{array}$ & $\begin{array}{l}\text { VAV_Pod_1, VAV_Pod_2, VAV_Pod_3, } \\
\text { PSZ-AC_1:5, PSZ-AC_2:6, PSZ-AC:3:7, } \\
\text { PSZ-AC:5:9 }\end{array}$ & None & $\begin{array}{l}\text { VAV with Reheat, } \\
\text { FLR_3_DOAS, FLR_6_DOAS }\end{array}$ \\
\hline 1B Riyadh & CAV_base & None & None & PSZ-AC:3:7, PSZ-AC:5:9 & None & None \\
\hline 2A Houston & CAV_base & $\begin{array}{l}\text { VAV_ICU, } \\
\text { VAV_PATRMS }\end{array}$ & $\begin{array}{l}\text { VAV_Pod_1, VAV_Pod_2, } \\
\text { VAV_Pod_3, PSZ-AC_2:7 }\end{array}$ & $\begin{array}{l}\text { VAV_Pod_1, VAV_Pod_2, VAV_Pod_3, } \\
\text { PSZ-AC_1:5, PSZ-AC_2:6, PSZ-AC:3:7, } \\
\text { PSZ-AC:5:9 }\end{array}$ & PSZ-AC:2 & $\begin{array}{l}\text { VAV with Reheat, } \\
\text { FLR_3_DOAS, FLR_6_DOAS }\end{array}$ \\
\hline 2B Phoenix & None & None & None & $\begin{array}{l}\text { VAV_Pod_1, VAV_Pod_2, PSZ-AC:3:7, } \\
\text { PSZ-AC:5:9 }\end{array}$ & None & None \\
\hline 3A Memphis & CAV_base & $\begin{array}{l}\text { VAV_ICU, } \\
\text { VAV_PATRMS }\end{array}$ & $\begin{array}{l}\text { VAV_Pod_1, VAV_Pod_2, } \\
\text { VAV_Pod_3, PSZ-AC_2:7 }\end{array}$ & $\begin{array}{l}\text { VAV_Pod_1, VAV_Pod_2, VAV_Pod_3, } \\
\text { PSZ-AC_1:5, PSZ-AC_2:6, PSZ-AC:3:7, } \\
\text { PSZ-AC:5:9 }\end{array}$ & PSZ-AC:2 & $\begin{array}{l}\text { VAV with Reheat, } \\
\text { FLR_3_DOAS, FLR_6_DOAS }\end{array}$ \\
\hline $\begin{array}{l}3 \mathrm{~B} \\
\text { El Paso }\end{array}$ & None & None & None & PSZ-AC:3:7, PSZ-AC:5:9 & None & None \\
\hline $\begin{array}{l}3 \mathrm{C} \text { San } \\
\text { Francisco }\end{array}$ & None & None & None & $\begin{array}{l}\text { VAV_Pod_1, VAV_Pod_2, VAV_Pod_3, } \\
\text { PSZ-AC:3:7, PSZ-AC:5:9 }\end{array}$ & None & None \\
\hline 4A Baltimore & CAV_base & $\begin{array}{l}\text { VAV_ICU, } \\
\text { VAV_PATRMS }\end{array}$ & $\begin{array}{l}\text { VAV_Pod_1, VAV_Pod_2, } \\
\text { VAV_Pod_3, PSZ-AC_2:7 }\end{array}$ & $\begin{array}{l}\text { VAV_Pod_1, VAV_Pod_2, VAV_Pod_3, } \\
\text { PSZ-AC_1:5, PSZ-AC_2:6, PSZ-AC:3:7, } \\
\text { PSZ-AC:5:9 }\end{array}$ & PSZ-AC:2 & $\begin{array}{l}\text { VAV with Reheat, } \\
\text { FLR_3_DOAS, FLR_6_DOAS }\end{array}$ \\
\hline $\begin{array}{l}\text { 4B } \\
\text { Albuquerque }\end{array}$ & None & None & None & PSZ-AC:3:7, PSZ-AC:5:9 & None & None \\
\hline 4C Salem & None & None & None & $\begin{array}{l}\text { VAV_Pod_1, VAV_Pod_2, PSZ-AC:3:7, } \\
\text { PSZ-AC:5:9 }\end{array}$ & None & None \\
\hline 5A Chicago & CAV_base & $\begin{array}{l}\text { VAV_ICU, } \\
\text { VAV_PATRMS }\end{array}$ & $\begin{array}{l}\text { VAV_Pod_1, VAV_Pod_2, } \\
\text { VAV_Pod_3, PSZ-AC_2:7 }\end{array}$ & $\begin{array}{l}\text { VAV_Pod_1, VAV_Pod_2, VAV_Pod_3, } \\
\text { PSZ-AC_1:5, PSZ-AC_2:6, PSZ-AC:3:7, } \\
\text { PSZ-AC:5:9 }\end{array}$ & PSZ-AC:2 & $\begin{array}{l}\text { VAV with Reheat, } \\
\text { FLR_3_DOAS, FLR_6_DOAS }\end{array}$ \\
\hline 5B Boise & None & None & None & PSZ-AC:3:7, PSZ-AC:5:9 & None & None \\
\hline 5C Vancouver & None & None & None & PSZ-AC:3:7, PSZ-AC:5:9 & None & VAV with Reheat, \\
\hline 6A Burlington & CAV_base & $\begin{array}{l}\text { VAV_ICU, } \\
\text { VAV_PATRMS }\end{array}$ & $\begin{array}{l}\text { VAV_Pod_1, VAV_Pod_2, } \\
\text { VAV_Pod_3, PSZ-AC_2:7 }\end{array}$ & $\begin{array}{l}\text { VAV_Pod_1, VAV_Pod_2, VAV_Pod_3, } \\
\text { PSZ-AC_1:5, PSZ-AC_2:6, PSZ-AC:3:7, } \\
\text { PSZ-AC:5:9 }\end{array}$ & PSZ-AC:2 & $\begin{array}{l}\text { VAV with Reheat, } \\
\text { FLR_3_DOAS, FLR_6_DOAS }\end{array}$ \\
\hline 6B Helena & CAV_base & $\begin{array}{l}\text { VAV_ICU, } \\
\text { VAV_PATRMS }\end{array}$ & $\begin{array}{l}\text { VAV_Pod_1, VAV_Pod_2, } \\
\text { VAV_Pod_3, PSZ-AC_2:7 }\end{array}$ & $\begin{array}{l}\text { VAV_Pod_1, VAV_Pod_2, VAV_Pod_3, } \\
\text { PSZ-AC_1:5, PSZ-AC_2:6, PSZ-AC:3:7, } \\
\text { PSZ-AC:5:9 }\end{array}$ & PSZ-AC:3 & VAV with Reheat, \\
\hline
\end{tabular}


Table 5.16 (cont'd)

\begin{tabular}{|c|c|c|c|c|c|c|}
\hline \multirow{2}{*}{$\begin{array}{l}\text { Climate } \\
\text { Location }\end{array}$} & \multicolumn{6}{|c|}{ Building prototypes } \\
\hline & $\begin{array}{l}\text { Large } \\
\text { Office }\end{array}$ & Hospital & Primary School $^{(\mathrm{a})}$ & Secondary School ${ }^{(b)}$ & \begin{tabular}{|c|}
$\begin{array}{c}\text { Standalone } \\
\text { Retail }\end{array}$ \\
\end{tabular} & Large Hotel \\
\hline 7 Duluth & CAV_bas & $\begin{array}{l}\text { VAV_ICU, } \\
\text { VAV_PATRMS }\end{array}$ & $\begin{array}{l}\text { VAV_Pod_1, VAV_Pod_2, } \\
\text { VAV_Pod_3, PSZ-AC_2:5, } \\
\text { PSZ-AC__2:7 }\end{array}$ & $\begin{array}{l}\text { VAV_Pod_1, VAV_Pod_2, VAV_Pod_3, } \\
\text { PSZ-AC_1:5, PSZ-AC_2:6, PSZ-AC:3:7, } \\
\text { PSZ-AC:5:9 }\end{array}$ & PSZ-AC:4 & $\begin{array}{l}\text { VAV with Reheat, } \\
\text { FLR_3_DOAS, FLR_6_DOAS }\end{array}$ \\
\hline 8 Fairbanks & CAV_bas & $\begin{array}{l}\text { VAV_ICU, } \\
\text { VAV_PATRMS }\end{array}$ & $\begin{array}{l}\text { VAV_Pod_1, VAV_Pod_2, } \\
\text { VAV_Pod_3, PSZ-AC_2:5, } \\
\text { PSZ-AC_2:7 }\end{array}$ & $\begin{array}{l}\text { VAV_Pod_1, VAV_Pod_2, VAV_Pod_3, } \\
\text { PSZ-AC_1:5, PSZ-AC_2:6, PSZ-AC:3:7, } \\
\text { PSZ-AC:5:9 }\end{array}$ & PSZ-AC:5 & $\begin{array}{l}\text { VAV with Reheat, } \\
\text { FLR_3_DOAS, FLR_6_DOAS }\end{array}$ \\
\hline
\end{tabular}

Table 5.17. Energy Recovery Effectiveness

\begin{tabular}{lcc}
\hline & \multicolumn{2}{c}{ Energy Recovery Effectiveness } \\
\cline { 2 - 3 } Condition & Sensible & Latent \\
\hline Heating@ 100\% Airflow & 0.70 & 0.60 \\
Heating@ 75\% Airflow & 0.70 & 0.60 \\
Cooling@ 100\% Airflow & 0.75 & 0.60 \\
Cooling@ 75\% Airflow & 0.75 & 0.60 \\
\hline
\end{tabular}




\subsubsection{Addendum 90.1-07h: VAV Reheat Control}

90.1-2004 and 90.1-2007 require zone thermostatic controls to prevent simultaneous operation of heating and cooling systems to the same zone. The requirement limits the amount of air that involves simultaneous heating and cooling. This is specified as zones for which the volume of air that is reheated, recooled, or mixed is no greater than the larger of the following:

- The volume of outdoor air required to meet the ventilation requirements of Section 6.2 of Standard 62-1999 for 90.1-2004 or 62.1-2004 for 90.1-2007 for the zone

- $0.4 \mathrm{cfm} / \mathrm{ft}^{2}$ of the zone conditioned floor area

- $30 \%$ of the zone design peak supply rate

- $300 \mathrm{cfm}$ - this exception is for zones whose peak flow rate totals no more than $10 \%$ of the total fan system flow rate

- Any higher rate that can be demonstrated, to the satisfaction of the authority having jurisdiction, to reduce overall system annual energy usage by offsetting reheat/recool energy losses through a reduction in outdoor air intake for the system.

Addendum $\mathrm{h}$ to 90.1-2007 contains two major changes in the clause to limit simultaneous heating and cooling:

- Delete exceptions (b) and (d) above.

- Add a new exception to the reheating and recooling limitation for meeting the following three requirements:

0 The volume of air that is reheated, recooled, or mixed in deadband between heating and cooling will not exceed the larger of the following: (a) $20 \%$ of the zone design peak supply rate; (b) the volume of outdoor air required to meet the ventilation requirements of Section 6.2 of ASHRAE Standard 62.1 for the zone; (c) any higher rate that can be demonstrated, to the satisfaction of the authority having jurisdiction, to reduce overall system annual energy usage by offsetting reheat/recool energy losses through a reduction in outdoor air intake

o The volume of air that is reheated, recooled, or mixed in peak heating demand shall be less than $50 \%$ of the zone design peak supply rate.

o Airflow between deadband and full heating or full cooling shall be modulated.

Because this addendum relates to VAV terminal box control, it impacts building prototypes with an air system serving multiple zones: large office, medium office, hospital, outpatient healthcare, large hotel, primary school, and secondary school.

This addendum is analyzed through EnergyPlus simulation with different terminal box control sequences. The single-maximum control sequence is assumed in the 90.1-2004 baseline models while the dual-maximum control sequence is assumed after applying addendum 90.1-07h. The working principles can be illustrated with Figures 5.2 and 5.3, respectively. 
The single-maximum control sequence has only one maximum damper position for cooling. When the zone is in the deadband and heating modes, the damper stays at the minimum position. This minimum damper position is set as the higher value of $30 \%$ and the minimum position to meet the outdoor ventilation air requirement.

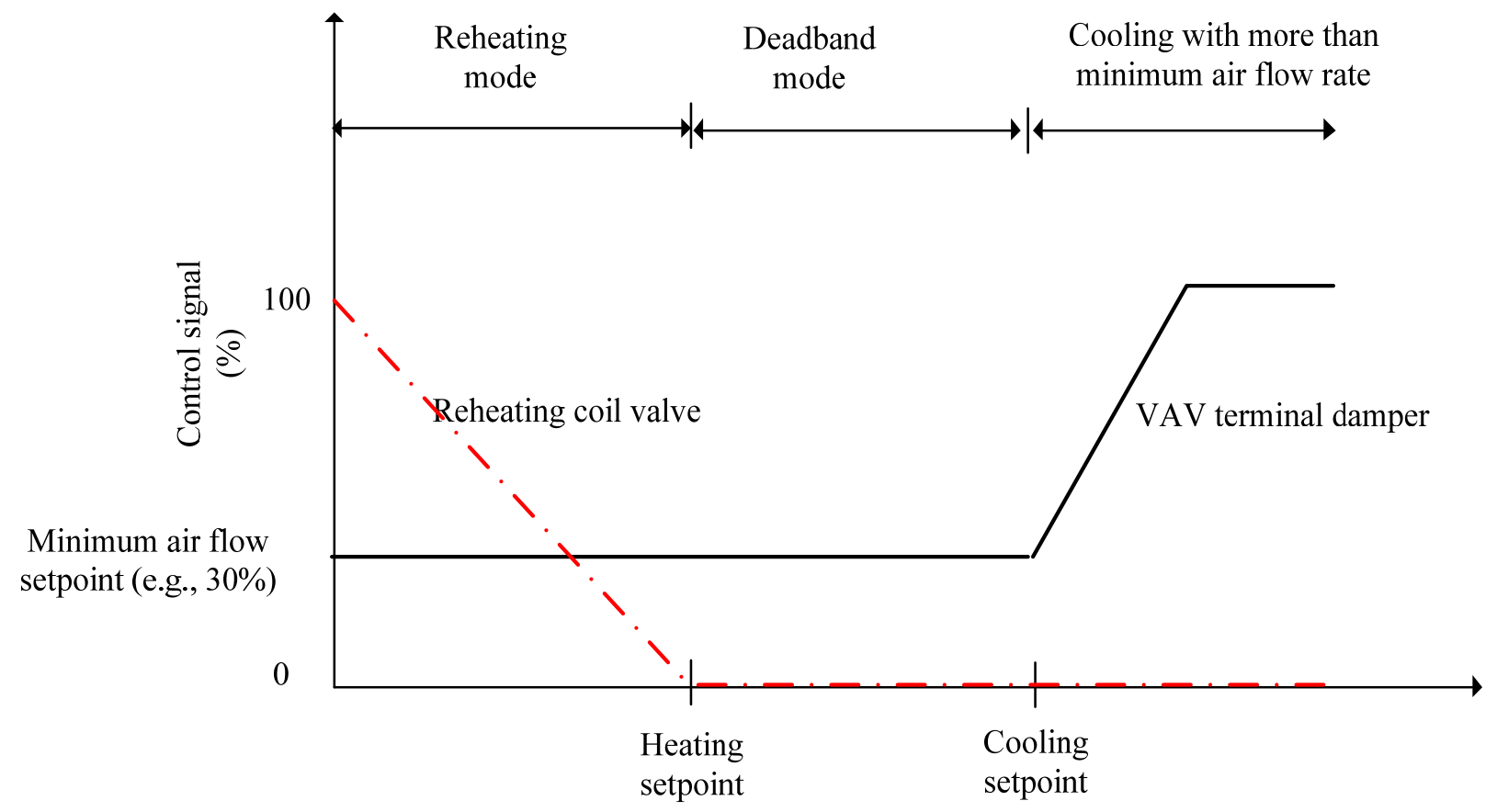

Figure 5.2. Single-maximum Terminal Box Control Sequence

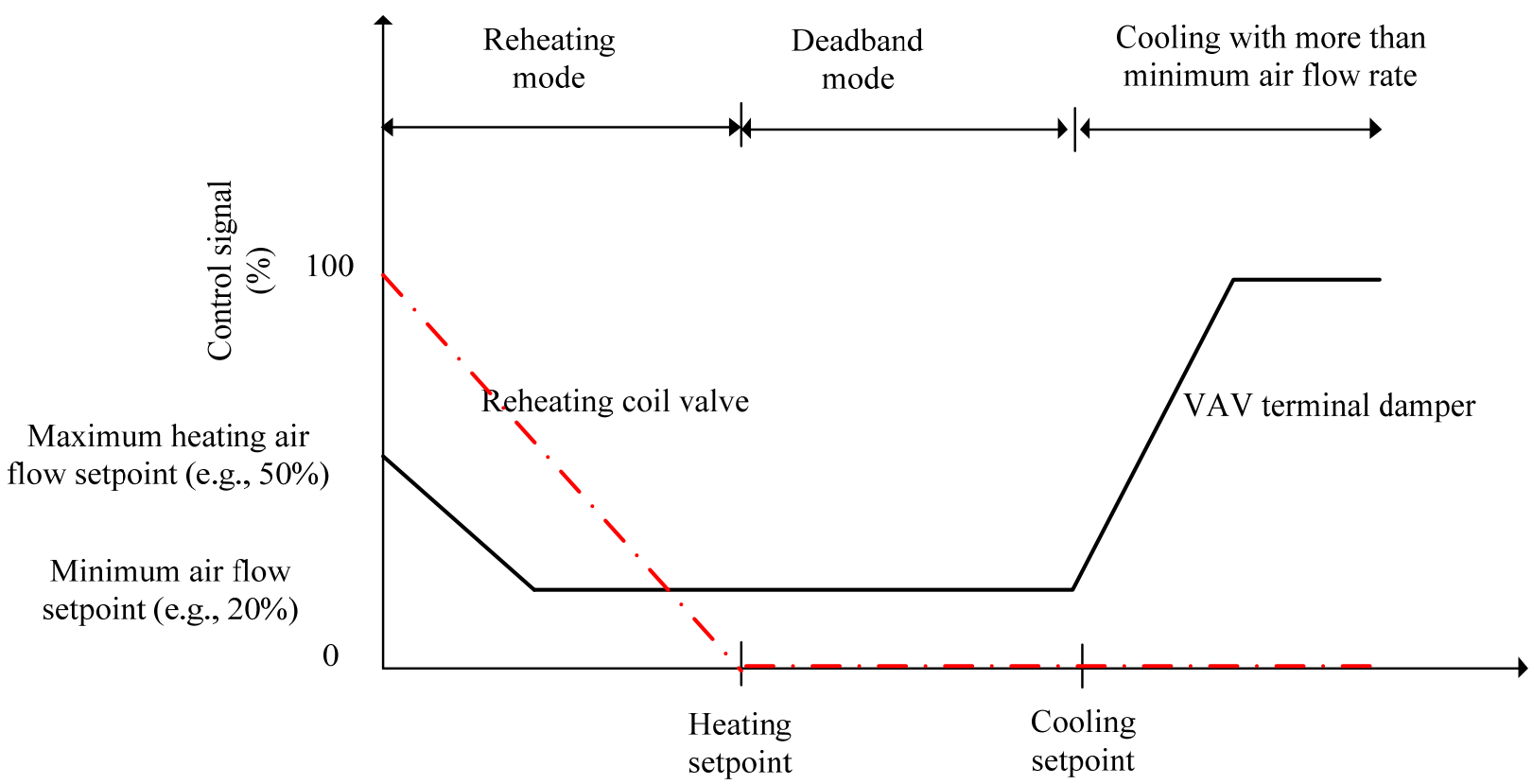

Figure 5.3. Dual-maximum Terminal Box Control Sequence

The dual-maximum control sequence has one maximum damper position for cooling and one for heating. When the zone is in the deadband mode, the damper stays at the minimum position, which is the 
higher value of $20 \%$ and the minimum position to meet the ventilation requirement. When the zone temperature falls below the heating setpoint and the zone mode changes to the heating mode, the reheating coil valve opens up increasingly while the damper position is still at the minimum position. With increasing heating load, the reheat coil valve can open up until the supply air temperature reaches the predefined maximum value. Then, the damper position increases up to the maximum heating airflow setpoint if more heat is needed for zone heating.

Addendum 90.1-07h may be affected by addendum 90.1-07ck, which may override the minimum damper position in some zones to satisfy Standard 62.1 multi-zone ventilation requirement.

\subsubsection{Addendum 90.1-07m: Chiller Efficiency Improvements}

The minimum efficiency requirements for air-cooled and water-cooled chillers are specified in 90.1 2004 and 90.1-2007 Section 6.4.1.2, Tables 6.8.1C, 6.8.1H, 6.8.1I, and 6.8.1J. While addendum 90.1-07m made several changes to these sections, only the changes that impact energy use are discussed here: the minimum efficiency requirements for all chillers, except absorption chillers, are revised; and an additional compliance path (Path B) is added for water-cooled chillers. Table 5.18 summarizes the efficiency changes for the types of chillers used in the prototypes.

Table 5.18. 90.1-2004 and 90.1-2010 Chiller Efficiencies

\begin{tabular}{|c|c|c|c|c|}
\hline $\begin{array}{l}\text { Equipment } \\
\text { Type } \\
\end{array}$ & Size Category & $\begin{array}{c}\text { 90.1-2004 Minimum } \\
\text { Efficiency }\end{array}$ & $\begin{array}{l}\text { 90.1-2010 Path A } \\
\text { Minimum Efficiency }\end{array}$ & $\begin{array}{l}\text { 90.1-2010 Path B } \\
\text { Minimum } \\
\text { Efficiency }\end{array}$ \\
\hline \multirow[t]{2}{*}{ Air Cooled } & $<150$ tons & $\begin{array}{l}\text { 9.562 EER and } \\
\text { 10.416 IPLV }\end{array}$ & $\begin{array}{l}\text { 9.562 EER } 12.500 \\
\text { IPLV }\end{array}$ & NA \\
\hline & $\geq 150$ tons & & $\begin{array}{l}\text { 9.562 EER } 12.750 \\
\text { IPLV }\end{array}$ & NA \\
\hline \multirow{4}{*}{$\begin{array}{l}\text { Water Cooled, } \\
\text { Positive } \\
\text { Displacement }\end{array}$} & $<75$ tons & $\begin{array}{l}0.790 \mathrm{~kW} / \text { ton and } \\
0.676 \mathrm{IPLV}\end{array}$ & $\begin{array}{l}0.780 \mathrm{~kW} / \text { ton and } \\
0.630 \mathrm{IPLV}\end{array}$ & $\begin{array}{l}0.800 \mathrm{~kW} / \text { ton and } \\
0.600 \mathrm{IPLV}\end{array}$ \\
\hline & $\begin{array}{l}\geq 75 \text { tons and } \\
<150 \text { tons }\end{array}$ & & $\begin{array}{l}0.775 \mathrm{~kW} / \text { ton and } \\
0.615 \mathrm{IPLV}\end{array}$ & $\begin{array}{l}0.790 \mathrm{~kW} / \text { ton and } \\
0.586 \mathrm{IPLV}\end{array}$ \\
\hline & $\begin{array}{l}\geq 150 \text { tons and } \\
<300 \text { tons }\end{array}$ & $\begin{array}{l}0.717 \mathrm{~kW} / \text { ton and } \\
0.627 \mathrm{IPLV}\end{array}$ & $\begin{array}{l}0.680 \mathrm{~kW} / \text { ton and } \\
0.580 \mathrm{IPLV}\end{array}$ & $\begin{array}{l}0.718 \mathrm{~kW} / \text { ton and } \\
0.540 \mathrm{IPLV}\end{array}$ \\
\hline & $\geq 300$ tons & $\begin{array}{l}0.639 \mathrm{~kW} / \text { ton and } \\
0.571 \mathrm{IPLV}\end{array}$ & $\begin{array}{l}0.620 \mathrm{~kW} / \text { ton and } \\
0.540 \mathrm{IPLV}\end{array}$ & $\begin{array}{l}0.639 \mathrm{~kW} / \text { ton and } \\
0.490 \mathrm{IPLV}\end{array}$ \\
\hline \multirow[t]{4}{*}{$\begin{array}{l}\text { Water Cooled, } \\
\text { Centrifugal }\end{array}$} & $<150$ tons & $\begin{array}{l}0.703 \mathrm{~kW} / \text { ton and } \\
0.669 \mathrm{IPLV}\end{array}$ & $\begin{array}{l}0.634 \mathrm{~kW} / \text { ton and } \\
0.596 \mathrm{IPLV}\end{array}$ & $\begin{array}{l}0.639 \mathrm{~kW} / \text { ton and } \\
0.450 \mathrm{IPLV}\end{array}$ \\
\hline & $\begin{array}{l}\geq 150 \text { tons and } \\
<300 \text { tons }\end{array}$ & $\begin{array}{l}0.634 \mathrm{~kW} / \text { ton and } \\
0.596 \mathrm{IPLV}\end{array}$ & & \\
\hline & $\begin{array}{l}\geq 300 \text { tons and } \\
<600 \text { tons }\end{array}$ & $\begin{array}{l}0.576 \mathrm{~kW} / \text { ton and } \\
0.549 \mathrm{IPLV}\end{array}$ & $\begin{array}{l}0.576 \mathrm{~kW} / \text { ton and } \\
0.549 \mathrm{IPLV}\end{array}$ & $\begin{array}{l}0.600 \mathrm{~kW} / \text { ton and } \\
0.400 \mathrm{IPLV}\end{array}$ \\
\hline & $\geq 600$ tons & & $\begin{array}{l}0.570 \mathrm{~kW} / \text { ton and } \\
0.539 \mathrm{IPLV}\end{array}$ & $\begin{array}{l}0.590 \mathrm{~kW} / \text { ton and } \\
0.400 \mathrm{IPLV}\end{array}$ \\
\hline
\end{tabular}

Because this addendum impacts prototypes with water chilling equipment, the large hotel, secondary school, large office, and hospital prototypes are affected. To quantify the energy savings from this addendum, credit is taken from applying only the full-load efficiency improvements as described below. 


\section{Air-Cooled Chillers:}

The large hotel and secondary school prototypes have air-cooled chillers. The chillers are modeled using an EnergyPlus chiller model based on condenser entering condition. The efficiency improvement is implemented through the energy input ratio function of temperature (EIR-FT) curve.

\section{Water-Cooled Chillers}

The large office and hospital prototypes have water-cooled chillers. The type of water-cooled chiller used in simulation depends on capacity required. Screw chillers are used for cooling capacity of equal or less than 300 tons and centrifugal chillers are used for capacity greater than 300 tons. Two compliance paths are available for water-cooled chillers: Path A is intended for applications where significant operating time is expected at full-load conditions, whereas Path B is intended for applications where significant operating time is expected at part-load conditions. Therefore, Path B allows for better part-load performance but results in a small decrease in full-load efficiency due to losses inherent in variable speed drives.

Based on input from the 90.1 SWG, the large office prototype is assumed to follow Path B and the hospital prototype is assumed to follow Path A. Large office buildings typically operate at part-load chiller operation, which is more applicable to Path B. Hospitals operate continuously and tend to be dominated by internal loads so the chillers will operate at closer to full-load much of the time making Path A the better choice. The condenser leaving condition is used to define the EnergyPlus chiller model. The efficiency improvement is implemented through the EIR-FT curve.

\subsubsection{Addendum 90.1-07n and 90.1-07ca: Single-Zone VAV}

90.1-2004 and 90.1-2007 do not require HVAC systems serving a single zone to have fan speed control; a constant speed fan is allowed in a HVAC system that serves a single zone (single zone VAV).

Addendum 90.1-07n requires VAV fan control be used for single zone units above certain size thresholds. Depending on the cooling coil type, the addendum has the following requirements:

- For air-handling units with chilled-water cooling coils, if the supply fan motor power is $5 \mathrm{hp}$ or larger, the fan is required to be controlled by a two-speed motor or a variable-speed drive. When the cooling demand is $50 \%$ or less than the unit's cooling capacity, the fan speed control must be able to reduce the airflow no greater than the larger of the following: (1) one half of the full fan speed or (2) the outdoor air volume required to meet the ventilation requirement by Standard 62.1. This requirement took effect on January 1, 2010.

- For air-handling units with DX cooling coils, if the DX cooling capacity at ARI rated conditions is $110,000 \mathrm{Btu} / \mathrm{h}$ or greater, the fan must be controlled by a two-speed motor or a variable-speed drive. When the cooling demand is $50 \%$ or less of the unit's capacity, the fan speed control should be able to reduce the airflow no greater than the larger of the following: (1) two-thirds of the full fan speed or (2) the outdoor air volume required to meet the ventilation requirement by Standard 62.1. This specification takes effect on January 1, 2012.

Addendum $n$ does not specify the applicable fan power limitation (90.1-2010, Section 6.5.3.1) for single zone VAV systems. This could lead to the use of VAV system fan power limitation by mistake 
which has a higher limit compared to constant volume fan systems. To address this issue, Addendum 90.1-07ca clarifies that single zone VAV systems must comply with the constant volume fan power limitation.

Based on the system sizing information from EnergyPlus design day runs, each cooling system serving a single zone is checked against the cooling capacity (for DX cooling) or the supply fan motor power (for chilled water cooling) to determine whether or not single zone VAV requirements are applicable. Table 5.19 summarizes which air systems use single-zone VAV according to addendum 90.107n. During the process of determining the applicability of single-zone VAV, special attention is given to systems with high outdoor air demand for ventilation, such as the system serving the auditorium in the school prototypes and the kitchens in the restaurant prototypes. The high outdoor air demand may deactivate the use of single zone VAV even if the cooling capacity is above the threshold value.

No straightforward way exists to model single-zone VAV in the versions of EnergyPlus available during the PI analysis. A work-around solution is developed to approximate the control mechanism of single zone VAV. This solution involves replacing the single zone constant volume cooling system with a single zone VAV system. Major aspects modeling single-zone VAV systems include the following:

- The HVAC unit tries to find the highest supply air setpoint temperature that will satisfy the zone cooling load at the minimum supply airflow rate. If that setpoint temperature is less than the minimum set at $55^{\circ} \mathrm{F}$, the temperature remains at the minimum, and the supply air flow rate is increased to meet the loads.

- VAV terminal units have a minimum airflow fraction set at the higher value of 0.67 and the minimum needed to meet ventilation requirements.

- The central heating coil is disabled while the terminal reheating coil is sized with sufficient capacity to meet the zone heating demand.

Addendum 90.1-07ca is also implemented. The supply fans for single zone VAV systems are sized to meet the constant volume fan power limitation.

Addendum 90.1-07n may be affected by addendum 90.1-07ax, which requires a certain amount of transfer air from adjacent spaces to a kitchen. When the space served by a single-zone VAV system provides transfer air, the transferred air volume could affect the minimum airflow turndown ratio of the single-zone VAV system.

\subsubsection{Addendum 90.1-07u: Open-Circuit Cooling Tower Performance}

90.1-2004 and 90.1-2007 Section 6.5.5 require cooling towers to meet the following performance criteria at standard rating conditions $\left(95^{\circ} \mathrm{F}\right.$ entering water, $85^{\circ} \mathrm{F}$ leaving water, and $75^{\circ} \mathrm{F}$ wb outdoor air):

- For propeller or axial fan cooling towers, the maximum flow rating of the tower divided by the fan nameplate rated motor power must be at least $38.2 \mathrm{gpm} / \mathrm{hp}$.

- For centrifugal fan cooling towers, the maximum flow rating of the tower divided by the fan nameplate rated motor power must be at least $20.0 \mathrm{gpm} / \mathrm{hp}$. 
Table 5.19. HVAC Systems Subject to Single Zone VAV Requirement

\begin{tabular}{|c|c|c|c|c|c|}
\hline \multirow[b]{2}{*}{ Climate/Location } & \multicolumn{5}{|c|}{ Building Prototype } \\
\hline & Standalone Retail & Strip Mall & Primary School & Secondary School & $\begin{array}{l}\text { Full-service } \\
\text { Restaurant }\end{array}$ \\
\hline 1A Miami & PSZ-AC:1, PSZ-AC:2 & PSZ-AC_1:1 & PSZ-AC_2:5, PSZ-AC_1:6 & PSZ-AC_1:5, PSZ-AC_2:6 & PSZ-AC_1:1 \\
\hline 1B Riyadh & PSZ-AC:1, PSZ-AC:2 & PSZ-AC_1:1 & PSZ-AC_2:5, PSZ-AC_1:6 & PSZ-AC_1:5, PSZ-AC_2:6, PSZ-AC_4:8 & PSZ-AC_1:1 \\
\hline 2A Houston & PSZ-AC:2 & None & PSZ-AC_1:6 & PSZ-AC_1:5, PSZ-AC_2:6 & PSZ-AC_1:1 \\
\hline 2B Phoenix & PSZ-AC:2 & PSZ-AC_1:1 & PSZ-AC_1:6 & PSZ-AC_1:5, PSZ-AC_2:6, PSZ-AC_4:8 & PSZ-AC_1:1 \\
\hline 3A Memphis & PSZ-AC:1, PSZ-AC:2 & PSZ-AC_1:1 & PSZ-AC_1:6 & PSZ-AC_1:5, PSZ-AC_2:6 & PSZ-AC_1:1 \\
\hline 3B El Paso & PSZ-AC:2 & None & PSZ-AC_1:6 & PSZ-AC_1:5, PSZ-AC_2:6, PSZ-AC_4:8 & PSZ-AC_1:1 \\
\hline 3C San Francisco & PSZ-AC:2 & None & PSZ-AC_1:6 & PSZ-AC_1:5, PSZ-AC_2:6, PSZ-AC_4:8 & PSZ-AC_1:1 \\
\hline 4A Baltimore & PSZ-AC:2 & None & PSZ-AC_1:6 & PSZ-AC_1:5, PSZ-AC_2:6 & PSZ-AC_1:1 \\
\hline 4B Albuquerque & PSZ-AC:2 & None & PSZ-AC_1:6 & PSZ-AC_1:5, PSZ-AC_2:6, PSZ-AC_4:8 & PSZ-AC_1:1 \\
\hline 4C Salem & PSZ-AC:2 & None & PSZ-AC_1:6 & PSZ-AC_1:5, PSZ-AC_2:6, PSZ-AC_4:8 & PSZ-AC_1:1 \\
\hline 5A Chicago & PSZ-AC:2 & None & PSZ-AC_1:6 & PSZ-AC_1:5, PSZ-AC_2:6 & PSZ-AC_1:1 \\
\hline 5B Boise & PSZ-AC:2 & None & PSZ-AC_1:6 & PSZ-AC_1:5, PSZ-AC_2:6, PSZ-AC_4:8 & PSZ-AC_1:1 \\
\hline 5C Vancouver & PSZ-AC:2 & None & PSZ-AC_1:6 & PSZ-AC_1:5, PSZ-AC_2:6, PSZ-AC_4:8 & PSZ-AC_1:1 \\
\hline 6A Burlington & PSZ-AC:2 & None & PSZ-AC_1:6 & PSZ-AC_1:5, PSZ-AC_2:6 & PSZ-AC_1:1 \\
\hline 6B Helena & PSZ-AC:2 & None & PSZ-AC_1:6 & PSZ-AC_1:5, PSZ-AC_2:6 & PSZ-AC_1:1 \\
\hline 7 Duluth & PSZ-AC:2 & None & None & PSZ-AC_1:5, PSZ-AC_2:6 & PSZ-AC_1:1 \\
\hline 8 Fairbanks & PSZ-AC:2 & None & None & PSZ-AC_1:5, PSZ-AC_2:6 & PSZ-AC_1:1 \\
\hline
\end{tabular}


Addendum 90.1-07u requires that fans in centrifugal fan open-circuit cooling towers with rated capacity of 1,100 gpm or greater meet the more stringent performance requirement of axial fan opencircuit cooling towers (at least $38.2 \mathrm{gpm} / \mathrm{hp}$ ).

Of the 16 building prototypes, large offices and hospitals use chilled water systems with cooling towers. PNNL assumed that centrifugal fan open-circuit cooling towers are used in large offices and hospitals. Therefore, these two building prototypes are affected by Addendum 90.1-07u.

This addendum was implemented through a Perl script, which automatically calculates the cooling tower fan power in the following procedure:

- Extract the design cooling tower water flow rate from an EnergyPlus design day run.

- Calculate the cooling tower fan brake horsepower. Assuming that the fan brake horsepower is $90 \%$ of the fan nameplate rated motor power, the fan brake horsepower is calculated using the following equation:

$$
\text { FanBHP }=\frac{0.9 * \text { WaterFlowRate }}{\text { FanPerformance }}
$$

where,

FanBHP = cooling tower fan brake horsepower

WaterFlow rate $=$ cooling tower design water flow rate $(\mathrm{gpm})$

FanPerformance $=$ the cooling tower design water flow rate divided by the fan nameplate rated motor power $(\mathrm{gpm} / \mathrm{hp})$. FanPerformance $=38.2 \mathrm{gpm} / \mathrm{hp}$ (WaterFlow rate larger than $1100 \mathrm{gpm})$.

- Determine the fan motor efficiency based on the fan brake horsepower. The motor efficiency is defined by the motor efficiency in Table 10.8A of Standard 90.1. In this step, the motor power is assumed to be at least $10 \%$ greater than the fan brake horsepower from the previous step.

- Calculate the fan motor power, which is equal to the fan brake horsepower divided by motor efficiency.

- Feed the fan motor power into the EnergyPlus cooling tower module.

The above implementation procedure also applies to the 90.1-2004 baseline models for large office and hospital prototypes. However, in the baseline implementation, the FanPerformance is assigned the value $20.0 \mathrm{gpm} / \mathrm{hp}$, the minimum required in $90.1-2004$.

\subsubsection{Addenda 90.1-07af and 90.1-07cc: Chilled Water and Condenser Water Pipe Sizing}

Addendum 90.1-07af introduces pipe sizing criteria in Section 6.5.4.5 of 90.1-2010, and. addendum 90.1-07cc fixes a mistake in 90.1-07af. The requirements only apply to chilled water and condenser water piping that affect the critical circuit, that is, the circuit that has the highest pressure drop required to satisfy its load. Each such piping segment is to be sized per the requirements in Table 6.5.4.5 in addenda 90.1-07af and 90.1-07cc. This table presents the maximum allowable flow per pipe section as a function of pipe size, annual hours of operation, and system flow and control. 
The SSPC 90.1 Mechanical Subcommittee estimated that the average net piping pressure drop reduction due to addendum af and addendum cc is $83 \%$ compared with standard design practice. Table 5.20 summarizes the calculation provided by the subcommittee. The estimation in Table 5.20 is based on the following assumptions:

- For chilled water systems, pipe friction accounts for $70 \%$ of total system pressure drop.

- For condenser water systems, pipe friction accounts for $50 \%$ of total system pressure drop.

- The baseline column represents standard practice, based on $4.5 \mathrm{ft}$ pressure drop/100 ft pipe and 12 feet per second.

- When standard practice without addenda 90.1-07af and cc is less than that with the addenda (21/2" to $4 "$ pipe size), designers will not increase flow based on the new requirements.

- Average velocity reduction for all pipe sizes is used for entire system reduction.

- All systems use the 2,000- to 4,400-hour-per-year category.

- Chilled water system pressure drop is $75 \mathrm{ft}$ of head with a $65 \%$ combined pump and motor efficiency, based on Standard 90.1, Appendix G (22 W/gpm).

- Condenser water system pressure drop is $60 \mathrm{ft}$ of head with a $60 \%$ combined pump and motor efficiency, based on Standard 90.1, Appendix G (19 W/gpm).

- $\operatorname{Head}_{2}=\operatorname{Head}_{1} \times\left(\text { Flow }_{2} / \text { Flow }_{1}\right)^{1.85}$ (pump affinity law adjusted due to decrease in the Fanning friction factor with increasing velocity).

Table 5.20. Piping Pressure Drop Reduction

\begin{tabular}{|c|c|c|c|c|c|}
\hline \multirow{2}{*}{ Operating Hours/Yr } & \multicolumn{2}{|c|}{$\begin{array}{c}\text { Addendum 90.1-07af and cc } \\
(90.1-2010)\end{array}$} & $\begin{array}{c}\text { Baseline } \\
(90.1-2004 / 2007) \\
\end{array}$ & \multirow{2}{*}{\multicolumn{2}{|c|}{$\%$ Reduction }} \\
\hline & $>2,000$ anc & 400 Hours/Year & All Hours/Year & & \\
\hline Nominal Pipe Size (in.) & Other & $\begin{array}{l}\text { Variable Flow/ } \\
\text { Variable Speed } \\
\end{array}$ & $\begin{array}{c}\text { Constant and } \\
\text { Variable } \\
\text { Speed/Variable Flow }\end{array}$ & $\begin{array}{l}\text { Percentage } \\
\text { of Base } \\
\text { Flow Rate }\end{array}$ & $\begin{array}{c}\text { Net } \\
\text { Reduction } \\
\end{array}$ \\
\hline $21 / 2$ & 85 & 130 & 78 & $138 \%$ & $100 \%$ \\
\hline 3 & 140 & 210 & 140 & $125 \%$ & $100 \%$ \\
\hline 4 & 260 & 400 & 290 & $114 \%$ & $100 \%$ \\
\hline 5 & 310 & 470 & 525 & $74 \%$ & $74 \%$ \\
\hline 6 & 570 & 860 & 850 & $84 \%$ & $84 \%$ \\
\hline 8 & 900 & 1,400 & 1,500 & $77 \%$ & $77 \%$ \\
\hline 10 & 1,300 & 2,000 & 2,500 & $66 \%$ & $66 \%$ \\
\hline 12 & 1,900 & 2,900 & 3,500 & $69 \%$ & $69 \%$ \\
\hline $\begin{array}{l}\text { Maximum Velocity for Pipes } \\
\text { Over } 12 \text { in. Size }\end{array}$ & 6.5 & 9.5 & 10 & $80 \%$ & $80 \%$ \\
\hline \multicolumn{5}{|c|}{ Average Net Reduction for Average System } & $83 \%$ \\
\hline
\end{tabular}

When the average piping pressure drop of $83 \%$ is applied to a chilled water system, the modeled total system pressure drop is $75 \mathrm{ft}$ for the 90.-2004 baseline models and $59.9 \mathrm{ft}$ for the 90.1-2010 models. When the $83 \%$ is applied to the condenser water system, the total system pressure drop is $60 \mathrm{ft}$ for the 
baseline model and $49.7 \mathrm{ft}$ for 90.1-2010 models. The energy savings impact is shown in five prototype buildings: large office, hospital, secondary school, large hotel, and high-rise apartment.

\subsubsection{Addendum 90.1-07ak: Hydronic Variable Flow Control}

The energy savings from addendum 90.1-07ak primarily results from three changes as below:

- Modifies Section 6.5.4.1 in 90.1-2007 by lowering the variable flow threshold for individual chilled water pumps from $50 \mathrm{hp}$ to $5 \mathrm{hp}$ and requires that variable flow be controlled through differential pressure setpoint reset.

- Adds water-cooled air conditioners to systems requiring isolation valves.

- Adds a VFD pumping requirement to hydronic heat pumps and water-cooled air conditioners having total pump system power exceeding $5 \mathrm{hp}$.

Chilled water pumping systems are used in four prototype buildings: large office, secondary school, large hotel, and hospital. The primary-secondary chilled water pump systems are modeled in these four prototypes to reflect common practices. The primary pumps are modeled as constant flow pumps, and the secondary pumps are modeled as variable flow pumps. 90.1-2004 and 90.1-2007, Section 6.5.4, include the requirement that HVAC pumping systems having a total pump system power exceeding $10 \mathrm{hp}$ to be designed with variable fluid flow. The baseline 90.1-2004 models and 90.1-2010 models for the four relevant prototypes all exceed the $10 \mathrm{hp} \mathrm{limit.}$

Section 6.5.4.1 of 90.1-2004 and 90.1-2007 require individual pumps having a pump head exceeding $100 \mathrm{ft}$ and motor exceeding $50 \mathrm{hp}$ to have controls and/or devices to achieve variable flow control (such as variable-speed drives). Addendum 90.1-07ak requires pumping systems with variable flow control to have differential pressure reset. The energy savings impact of addendum 90.1-07ak is modeled by specifying different model inputs for the secondary pump to meet the differential pressure setpoint reset requirement. This requirement is implemented for chilled water systems for all four of the prototypes identified as subject to this addendum.

Hydronic heat pumps are used in high-rise apartments only, and no water-cooled air conditioner is used in any prototype buildings. Because the total pump system power and individual pump power for the heat pump system in the high-rise apartment models in all climate locations are less than the thresholds specified by $90.1-2004,-2007$ and -2010 , a primary-only water loop system with constant speed pump is used for both baseline and 2010 models.

EnergyPlus models variable-speed pumps using a part-load performance curve. The fraction of full load power, FractionFullLoadPower, is determined by the cubic equation:

$$
\text { FractionFullLoadPower }=\mathrm{C}_{1}+\mathrm{C}_{2} \mathrm{PLR}+\mathrm{C}_{3} \mathrm{PLR}^{2}+\mathrm{C}_{4} \mathrm{PLR}^{3}
$$

As Table 5.21 shows, PNNL developed three pump curves to represent (1) a constant speed pump (pump rides on the curve), (2) a variable-speed pump without constant pressure setpoint, and (3) a variable-speed pump with pressure setpoint reset. These curves are applied to the modeled pumps. 
Table 5.21. Pump Curves

\begin{tabular}{lcccc}
\hline & $C_{1}$ & $C_{2}$ & $C_{3}$ & $C_{4}$ \\
\hline Constant Speed Pump (pump rides on the curve) & 0 & 3.2485 & -4.7443 & 2.5294 \\
Variable Speed Pump Without Pressure Setpoint & 0 & 0.5726 & -0.301 & 0.7347 \\
$\begin{array}{l}\text { Reset } \\
\text { Variable Speed Pump with Pressure Setpoint Reset }\end{array}$ & 0 & 0.0205 & 0.4101 & 0.5753 \\
\hline
\end{tabular}

\subsubsection{Addendum 90.1-07as: Laboratory Fan Systems}

90.1-2004 and 90.1-2007 include exception (b) to the simultaneous heating and cooling prohibition in Section 6.5.2.1 for "zones where special pressurization relationships, cross-contamination requirements, or code-required minimum circulation rates are such that variable air volume systems are impractical." This exception allows designers to use constant volume reheat systems in critical areas of hospitals and similar spaces needing pressure differentials with adjacent areas. 90.1-2004 and 2007 include in Section 6.5.7.2 ("Fume Hoods") a threshold of 15,000 cfm exhaust air, above which laboratory exhaust and makeup systems must include energy saving features such as VAV, heat recovery, or minimally conditioned direct makeup air.

In place of the blanket exception (b) to Section 6.5.2.1, addendum 90.1-07as added an allowance to the airflow rate that can be reheated in order to achieve reasonable energy savings in these types of spaces, while not compromising health and safety. That allowance states "the air flow rate required to comply with applicable codes or accreditation standards, such as pressure relationships or minimum air change rates." Therefore, if the peak design airflow to any of these spaces is greater than the required minimum air change rate or the minimum rate required maintaining pressure differentials, the system must use variable air volume, reducing airflow as much as possible before reheat is allowed. Also, if the minimum air change rate is only required during occupied periods (as in operating rooms), the airflow must be reduced during those unoccupied periods before reheat is allowed. Several of the zones in the hospital and outpatient healthcare prototypes include critical spaces that are affected by the change in Section 6.5.2.1 under addendum 90.1-07as.

Addendum 90.1-07as also reduces the section S.5.7.2 fume hood requirements' threshold of $15,000 \mathrm{cfm}$ of exhaust air to 5,000 $\mathrm{cfm}$. Since none of the prototypes include laboratory exhaust systems larger than 5,000 cfm, the change in Section 6.5.7.2 is not included in the savings analysis of this addendum.

The following subsections describe the implementation of addendum 90.1-07as in the hospital and outpatient healthcare prototypes for the change in Section 6.5.2.1.

\section{Hospital Modeling Strategy}

In the hospital prototype, five space types are identified as critical spaces: operating rooms, patient rooms, emergency rooms, intensive care units, and laboratories. For the baseline, the spaces are modeled with constant volume reheat by using VAV reheat terminal units with a minimum airflow fraction equal to 1.0. Each critical space type is grouped together and is served by a dedicated air-handling unit. To determine if airflow to these zones needs to be reduced during reheat to comply with addendum 90.107as, the peak design airflow from each of these air handlers is compared with the sum of the minimum 
airflow requirements for each of the critical zone types according to the most commonly used accreditation standard for hospitals, AIA Guidelines for Design and Construction of Hospital and Health Care Facilities (AIA 2001). If the peak airflow is greater than the accreditation standard airflow rate, the terminal units need to be changed to VAV with a minimum airflow ratio equal to the required accreditation standard airflow divided by the peak airflow.

To simplify the analysis, sample representative climate zones, 2A, 4A, and $6 \mathrm{~A}$ are considered. Table 5.22 shows that for the selected climates, the ratio of minimum supply air to peak does not vary significantly and the average can reasonably be used. The table shows that of the five space types, only the patient rooms had a minimum airflow rate required by the accreditation standard that is significantly less than the peak design airflow in any of the three climate zones. In fact, for the patient rooms, the minimum airflow rate required by the accreditation standard is approximately $50 \%$ of the peak design rate in each of the three climate zones. Therefore, in implementing addendum 90.1-07as, the minimum airflow fraction of terminal units serving the patient rooms is reduced from $100 \%$ to $50 \%$. Table 5.22 also shows that the laboratories are not supplying the minimum airflow rate required ( 6 air changes per hour), and that needs to be corrected in future versions of the prototypes.

As mentioned previously, in addition to savings resulting from reduced reheat when the accreditation standard minimum airflow rate is less than the peak design airflow rate, there is also potential savings when the accreditation standard minimum airflow rate is only required during occupied periods and the space is sometimes unoccupied. Of the five space types identified as critical spaces in the hospital, only the operating rooms are not occupied continuously. When unoccupied, the operating room still must be maintained under positive pressure, so the system cannot be shut down completely. Based on input from the Mechanical Subcommittee, maintaining positive pressure is assumed to be accomplished with $20 \%$ of the peak design airflow, as is required by addendum 90.1-07h (Section 5.2.2.10 above). Therefore, for the implementation of addendum 90.1-07as, the minimum airflow fraction of terminal units serving the operating rooms is reduced from $100 \%$ to $20 \%$ during unoccupied periods.

Table 5.22. Hospital Prototype Critical Space Airflow Requirements

\begin{tabular}{|c|c|c|c|c|c|c|c|c|}
\hline \multirow[b]{2}{*}{ Zone Type } & \multicolumn{3}{|c|}{ Peak Design Supply Air (cfm) } & \multirow{2}{*}{$\begin{array}{c}\text { Minimum } \\
\text { Required } \\
\mathrm{SA}^{(\mathrm{a})} \\
(\mathrm{cfm})\end{array}$} & \multicolumn{3}{|c|}{ Ratio of Min SA to Peak SA } & \multirow{2}{*}{$\begin{array}{c}\text { Average } \\
\text { Ratio of } \\
\text { Min SA to } \\
\text { Peak SA } \\
\end{array}$} \\
\hline & Houston & Baltimore & Burlington & & Houston & Baltimore & Burlington & \\
\hline Emergency & 11,758 & 11,758 & 11,758 & 11,754 & 1.00 & 1.00 & 1.00 & 1.00 \\
\hline Operating Room & 23,096 & 23,096 & 23,096 & 23,087 & 1.00 & 1.00 & 1.00 & 1.00 \\
\hline Intensive Care & 13,674 & 13,514 & 13,425 & 13,190 & 0.96 & 0.98 & 0.98 & 0.97 \\
\hline Patient Room & 29,115 & 28,684 & 28,558 & 14,273 & 0.49 & 0.50 & 0.50 & 0.50 \\
\hline Laboratory & 4,662 & 4,668 & 4,696 & 7,977 & 1.71 & 1.71 & 1.70 & 1.71 \\
\hline
\end{tabular}

(a) Minimum supply air required by AIA Guidelines (AIA 2001). Supply Air (SA)

\section{Outpatient Healthcare Implementation}

For the outpatient healthcare prototype, a similar approach to the hospital prototype is s used. Like the hospital, the critical zones are served by VAV reheat terminal units with a minimum airflow fraction equal to 1.0 , making these essentially CAV systems. However, unlike the hospital, the critical zones in 
the outpatient healthcare baseline are not served by dedicated air handlers but are instead served by air handlers that also serve true VAV nonmedical critical zones. Therefore, each zone needs to be evaluated individually instead of by each air handler serving a group of similar critical zones.

Table 5.23 identifies the critical zones, including the peak design supply airflow in each of the three representative climate zones, and the minimum airflow rate required by the accreditation standard. Of the 37 zones listed in the table, 12 (shaded in the table) have a minimum airflow rate required by the accreditation standard that is significantly less than the peak design airflow in any of the three climate zones. For those zones, the minimum airflow fraction of the terminal units is reduced to the value in the column titled "Average Ratio of Min SA to Peak SA" for the implementation of addendum 90.1-07as. Like the hospital, the outpatient healthcare prototype also includes operating rooms that can have airflow reduced to $20 \%$ during the unoccupied period to comply with addendum 90.1-07as.

Table 5.23. Outpatient Healthcare Prototype Critical Space Airflow Requirements

\begin{tabular}{|c|c|c|c|c|c|c|c|c|}
\hline \multirow{2}{*}{$\begin{array}{c}\text { Zone Name } \\
\text { (floor number first) }\end{array}$} & \multicolumn{3}{|c|}{ Peak Design Supply Air (cfm) } & \multirow{2}{*}{$\begin{array}{c}\text { Minimum } \\
\text { Required } \\
\mathrm{SA}^{(\mathrm{a})} \\
(\mathrm{cfm})\end{array}$} & \multicolumn{3}{|c|}{ Ratio of Min SA to Peak SA } & \multirow{2}{*}{$\begin{array}{c}\text { Average } \\
\text { Ratio of } \\
\text { Min SA to } \\
\text { Peak SA }\end{array}$} \\
\hline & Houston & Baltimore & Burlington & & Houston & Baltimore & Burlington & \\
\hline 1 Anesthesia & 144 & 144 & 144 & 144 & 1.00 & 1.00 & 1.00 & 1.00 \\
\hline 1 Clean & 84 & 85 & 84 & 84 & 1.00 & 0.99 & 1.00 & 1.00 \\
\hline 1 Clean Work & 110 & 110 & 110 & 110 & 1.00 & 1.00 & 1.00 & 1.00 \\
\hline 1 Lobby Toilet & 90 & 90 & 90 & 90 & 1.00 & 1.00 & 1.00 & 1.00 \\
\hline 1 MRI Toilet & 90 & 90 & 90 & 90 & 1.00 & 1.00 & 1.00 & 1.00 \\
\hline 1 Nurse Toilet & 90 & 90 & 90 & 90 & 1.00 & 1.00 & 1.00 & 1.00 \\
\hline 1 Operating Room. 1 & 1,797 & 1,834 & 1,738 & 1,534 & 0.85 & 0.84 & 0.88 & 0.86 \\
\hline 1 Operating Room. 2 & 1,794 & 1,824 & 1,741 & 1,600 & 0.89 & 0.88 & 0.92 & 0.90 \\
\hline 1 Operating Room. 3 & 1,587 & 1,587 & 1,587 & 1,587 & 1.00 & 1.00 & 1.00 & 1.00 \\
\hline $1 \mathrm{PACU}$ & 108 & 108 & 108 & 108 & 1.00 & 1.00 & 1.00 & 1.00 \\
\hline 1 Pre-Op Room 1 & 189 & 189 & 189 & 189 & 1.00 & 1.00 & 1.00 & 1.00 \\
\hline 1 Pre-Op Room 2 & 338 & 338 & 338 & 338 & 1.00 & 1.00 & 1.00 & 1.00 \\
\hline 1 Pre-Op Toilet & 90 & 90 & 90 & 90 & 1.00 & 1.00 & 1.00 & 1.00 \\
\hline 1 Procedure Room & 712 & 712 & 712 & 713 & 1.00 & 1.00 & 1.00 & 1.00 \\
\hline 1 Recovery Room & 592 & 658 & 616 & 540 & 0.91 & 0.82 & 0.88 & 0.87 \\
\hline 1 Soil & 210 & 210 & 210 & 210 & 1.00 & 1.00 & 1.00 & 1.00 \\
\hline 1 Soil Hold & 93 & 93 & 93 & 93 & 1.00 & 1.00 & 1.00 & 1.00 \\
\hline 1 Soil Work & 300 & 300 & 300 & 300 & 1.00 & 1.00 & 1.00 & 1.00 \\
\hline 1 Step Down & 440 & 455 & 409 & 300 & 0.68 & 0.66 & 0.73 & 0.69 \\
\hline 2 Conf. Toilet & 107 & 107 & 107 & 107 & 1.00 & 1.00 & 1.00 & 1.00 \\
\hline 2 Exam 1 & 755 & 725 & 656 & 360 & 0.48 & 0.50 & 0.55 & 0.51 \\
\hline 2 Exam 2 & 540 & 540 & 540 & 540 & 1.00 & 1.00 & 1.00 & 1.00 \\
\hline 2 Exam 3 & 720 & 720 & 720 & 720 & 1.00 & 1.00 & 1.00 & 1.00 \\
\hline 2 Exam 4 & 128 & 135 & 132 & 84 & 0.66 & 0.62 & 0.64 & 0.64 \\
\hline 2 Exam 5 & 548 & 523 & 464 & 350 & 0.64 & 0.67 & 0.75 & 0.69 \\
\hline 2 Exam 6 & 258 & 240 & 225 & 225 & 0.87 & 0.94 & 1.00 & 0.94 \\
\hline
\end{tabular}


Table 5.23 (cont'd)

\begin{tabular}{|c|c|c|c|c|c|c|c|c|}
\hline \multirow[b]{2}{*}{$\begin{array}{c}\text { Zone Name } \\
\text { (floor number first }\end{array}$} & \multicolumn{3}{|c|}{ Peak Design Supply Air (cfm) } & \multirow{2}{*}{$\begin{array}{l}\text { Minimum } \\
\text { Accredita- } \\
\text { tion } \\
\text { Standard }^{\text {(a) }} \\
\text { Required SA } \\
\quad \text { (cfm) }\end{array}$} & \multicolumn{3}{|c|}{ Ratio of Min SA to Peak SA } & \multirow[b]{2}{*}{$\begin{array}{l}\text { Average } \\
\text { Ratio of } \\
\text { Min SA to } \\
\text { Peak SA }\end{array}$} \\
\hline & Houston & Baltimore & Burlington & & Houston & Baltimore & Burlington & \\
\hline 2 Exam 7 & 792 & 792 & 792 & 792 & 1.00 & 1.00 & 1.00 & 1.00 \\
\hline 2 Exam 8 & 316 & 291 & 270 & 270 & 0.86 & 0.93 & 1.00 & 0.93 \\
\hline 2 Exam 9 & 396 & 396 & 396 & 396 & 1.00 & 1.00 & 1.00 & 1.00 \\
\hline 2 Reception Toilet & 210 & 210 & 210 & 210 & 1.00 & 1.00 & 1.00 & 1.00 \\
\hline 2 Work Toilet & 90 & 90 & 90 & 90 & 1.00 & 1.00 & 1.00 & 1.00 \\
\hline 3 Lounge Toilet & 320 & 320 & 320 & 320 & 1.00 & 1.00 & 1.00 & 1.00 \\
\hline 3 Office Toilet & 90 & 90 & 90 & 90 & 1.00 & 1.00 & 1.00 & 1.00 \\
\hline 3 Phys. Therapy 1 & 1,842 & 1,905 & 1,897 & 1,300 & 0.71 & 0.68 & 0.69 & 0.69 \\
\hline 3 Phys. Therapy 2 & 745 & 726 & 675 & 592 & 0.79 & 0.82 & 0.88 & 0.83 \\
\hline $\begin{array}{l}3 \text { Physical Therapy } \\
\text { Toilet }\end{array}$ & 140 & 140 & 140 & 140 & 1.00 & 1.00 & 1.00 & 1.00 \\
\hline 3 Treatment & 616 & 600 & 560 & 476 & 0.77 & 0.79 & 0.85 & 0.81 \\
\hline
\end{tabular}

(a) Minimum supply air required by AIA Guidelines (AIA 2001). Supply Air (SA)

\subsubsection{Addendum 90.1-07ax: Kitchen Exhaust Hoods}

Section 6.5.7.1 in 90.1 -2004 and 90.1-2007 has requirements for individual kitchen exhaust hoods with exhaust airflow greater than 5,000 cfm. Based on engineering judgment and inputs from ASHRAE Technical Committee TC5.10 (Kitchen Ventilation), none of the individual exhaust hoods in the prototype buildings are over 5,000 cfm. Therefore, the requirements in the Section 6.5.7.1 of 90.1-2004 and 90.1-2007 do not apply to the baseline buildings.

Addendum 90.1-07ax adds new requirements for all kitchen hood exhaust systems, listed as new subsections Sections 6.5.7.1.1 through 6.5.7.1.5. This addendum also adds and modifies requirements for kitchen hoods that exceed 5,000 cfm of exhaust. The new requirements are as follows:

- Section 6.5.7.1.1 requires all kitchen hoods not to be "short-circuit" hoods that directly introduce replacement air in the kitchen hood cavity for more than $10 \%$ of the hood exhaust airflow rate.

- Section 6.5.7.1.2 requires all available transfer air from adjacent spaces to be used before any other makeup air is introduced to the kitchen for any size hood.

- Section 6.5.7.1.3 requires using hoods that meet the Table 6.5.7.1.3 requirements if the total kitchen exhaust airflow rate in the kitchen/dining facility is greater than $5,000 \mathrm{cfm}$.

- Section 6.5.7.1.4 requires kitchen/dining facilities with total kitchen hood exhaust airflow rate larger than 5,000 cfm to meet one of the three options: (a) at least 50\% of replacement air from transfer air; (b) cooking-load-based demand control ventilation; (c) energy recovery devices on exhaust airflow.

- Section 6.5.7.1.5 requires performance testing on design airflow rates and on capture and containment performance of the exhaust system for all kitchen hoods. 


\section{Modeling Strategy}

The modeling strategy for these requirements includes the following:

- Section 6.5.7.1.1: Because no statistical data shows short-circuit hoods are a common design practice, the energy savings impact of this provision is not simulated.

- Section 6.5.7.1.2: To comply with this requirement, the 90.1-2010 models are modified using all available transfer air in spaces close to the kitchen (on the same floor as kitchen) before bringing any makeup air in through the kitchen air conditioning system. When the available transfer air varies with time (e.g., under a demand control ventilation system), the minimum available transfer air is used. For the quick-service restaurant, transfer air is also used in the baseline because this is common practice.

- Section 6.5.7.1.3: The exhaust airflow flow rates in Table 6.5.7.1.3 are 30\% below the minimum airflow rates in ASHRAE Standard 154-2003 (ANSI/ASHRAE 20-03). Some hoods in baseline buildings are assumed to already meet Table 6.5.7.1.3 and others just meet the minimum requirements in ASHRAE Standard 154-2003. On average the 90.1-2010 compliant hoods have $10 \%$ flow reduction comparing to the baseline hoods. $10 \%$ exhaust airflow rate reduction is assumed when listed and/or tested hoods are compared to hoods in the baseline models. The $10 \%$ number is an assumption, under which some baseline buildings are considered to have already been designed with listed and/or tested hoods.

- Section 6.5.7.1.4: Transfer air, option (a) under this section, is considered as the first choice because it is required by Section 6.5.7.2. When the requirement in option (a) is not met, options (b) and (c) are considered for the models run under 90.1-2010.

- Section 6.5.7.1.5: No savings are estimated for the testing requirement.

Six of the 16 prototype buildings contain commercial kitchens: quick-service restaurant, full-service restaurant, hospital, large hotel, primary school, and secondary school. Because the applicability of addendum 90.1-07ax requirements to the six buildings varies, the differences between the baseline and 2010 models are summarized in Table 5.24.

Table 5.24. Application of Addendum 90.1-07ax to Prototypes

\begin{tabular}{|c|c|c|c|c|c|c|}
\hline \multirow[b]{2}{*}{ Prototype } & \multicolumn{2}{|c|}{$\begin{array}{c}\text { Section 6.5.7.1.2 } \\
\text { Use of Available Transfer Air }\end{array}$} & \multicolumn{2}{|c|}{$\begin{array}{c}\text { Section 6.5.7.1.3 Total } \\
\text { Exhaust Airflow Rate } \\
\text { (cfm) }\end{array}$} & \multicolumn{2}{|c|}{$\begin{array}{c}\text { Section 6.5.7.1.4 Selected } \\
\text { Option Under Section } \\
6.5 .7 .1 .4\end{array}$} \\
\hline & 2004 Model & 2010 Model & $\begin{array}{l}2004 \\
\text { Model }\end{array}$ & 2010 Model & 2004 Model & 2010 Model \\
\hline Quick-service Restaurant & yes & yes & 3,300 & 3,300 & $\mathrm{a}$ & $\mathrm{a}$ \\
\hline Full-service Restaurant & yes & yes & 6,000 & 5,400 & a & a \\
\hline Hospital & no & yes & 8,000 & 7,200 & $\mathrm{~N} / \mathrm{A}$ & $\mathrm{a}$ \\
\hline Large Hotel & no & yes & 4,000 & 4,000 & N/A & $\mathrm{a}$ \\
\hline Primary School & no & yes & 5,000 & 4,500 & N/A & $\mathrm{a}$ \\
\hline Secondary School & no & yes & 6,000 & 5,400 & N/A & $a$ or $a+b$ \\
\hline
\end{tabular}


The quick-service and full-service restaurants use transfer air in the baseline model because it is common design practice. The options applied for secondary school vary with climate.

\subsubsection{Addendum 90.1-07bh: Supply Air Temperature Reset}

90.1-2004 and 90.12007 do not require multi-zone HVAC systems to include supply air temperature reset. As a result, following the prescriptive path of 90.1-2004 or 2007, a multi-zone system can maintain a constant cooling supply air temperature selected to satisfy the peak cooling load. However, in most applications, cooling loads are usually below the peak design condition for most periods of system operation. In such cases, a warmer supply air temperature can satisfy the cooling load. Elevating the supply air temperature will decrease both cooling and reheat energy. It will also increase the benefit of air economizers because the economizers can be used at higher ambient temperatures.

Addendum 90.1-07bh requires that multi-zone HVAC systems reset supply air temperature based on either of two alternative strategies: (1) reset based on the representative building loads or (2) reset based on outdoor air temperature. The first control strategy means that the supply air temperature is reset to meet the cooling requirement of the warmest zone. For both control strategy options, this addendum requires that the supply air temperature be reset higher to at least $25 \%$ of the difference between the design supply air temperature and the design room air temperature.

Addendum 90.1-07bh has three exceptions:

- Climate zones 1a, 2a, and 3a (intended to avoid the humidity issue due to increased supply air temperature)

- Systems that prevent reheating, recooling, or mixing of heated and cooled supply air

- Systems in which at least $75 \%$ of the energy for reheating (on an annual basis) is from siterecovered or site solar energy sources.

As required by this addendum, supply air temperature reset is applied to the VAV systems in seven building prototypes with VAV system: large office, medium office, hospital, outpatient healthcare, large hotel, and primary and secondary schools.

The supply air temperature reset is implemented in all climate zones except 1a, 2a, and 3a. To simplify the modeling analysis and reflect the most common practice, PNNL uses the reset control strategy based on outdoor air temperature. EnergyPlus has the capability to reset supply air temperature based on outdoor air temperature. Therefore, the implementation is straightforward. The reset rule is presented below:

- The supply air setpoint temperature is $55^{\circ} \mathrm{F}$ if the outdoor high temperature is at or above $70^{\circ} \mathrm{F}$.

- The supply air setpoint temperature is $60^{\circ} \mathrm{F}$ if the outdoor high temperature is at or below $50^{\circ} \mathrm{F}$.

- The supply air setpoint temperature is linearly interpolated in the simulation between $55^{\circ} \mathrm{F}$ and $60^{\circ} \mathrm{F}$ if the outdoor high temperature is between $70^{\circ} \mathrm{F}$ and $50^{\circ} \mathrm{F}$. 


\subsubsection{Addendum 90.1-07bw: PTAC and PTHP Equipment Efficiency}

Table 6.8.1 D in 90.1-2004 and 90.1-2007 requires minimum efficiency levels for PTACs and PTHPs. In 2008, DOE issued a Final Rule, which amends the existing energy efficiency levels for PTACs and PTHPs, as published in 90.1-2007. This amended federal energy conservation rule applies for both standard size and nonstandard size PTACs and PTHPs.

Addendum 90.1-07bw adopts this newly issued federal mandatory efficiency standard into its tabulated efficiency requirement as Table 6.8.1D in 90.1-2010, with the same effective date as provided by the federal standard. Table 5.25 lists the new efficiency levels introduced by addendum bw for standard size equipment only Table 4.10 in Chapter 4 of this report provides the baseline efficiency levels.

Table 5.25. PTACs and PTHPs Efficiency, 90.1-2010

\begin{tabular}{ccc}
\hline Equipment Type & Size Category & $\begin{array}{c}\text { Minimum Efficiency } \\
\text { (effective as of } 10 / 08 / 2012)\end{array}$ \\
\hline PTAC (cooling mode) & All Capacities & $13.8-(0.3 \times$ capacity $/ 1,000)$ EER \\
PTHP (cooling mode) & All Capacities & $14.0-(0.3 \times$ capacity $/ 1,000)$ EER \\
PTHP (heating mode) & All Capacities & $3.7-(0.052 \times$ capacity/1,000 $)$ COP \\
\hline
\end{tabular}

This addendum applies to the small hotel prototype, where PTAC units provide cooling and heating to the guestrooms. This addendum is implemented in EnergyPlus with two steps: (1) separating the fan power from the EER rating, as shown in Table 5.26 and (2) converting the EER to the required modeling inputs as $\mathrm{COP}_{\text {cooling }}$ in EnergyPlus. The calculations are described below.

Table 5.26. Example PTAC/PTHP Fan Power Calculation

\begin{tabular}{ccccc}
\hline & \multicolumn{2}{c}{ Cooling Capacity } & \multicolumn{3}{c}{ Fan Motor } \\
\cline { 2 - 5 } Product & $(\mathrm{Btu} / \mathrm{h})$ & W/cfm & Supply Airflow & W \\
\hline PTAC/PTHP & 9,000 & 0.30 & $275 \mathrm{cfm}$ & 82.5 \\
\hline
\end{tabular}

The addendum $90.1 \mathrm{bw}$ efficiency calculations are as follows:

$$
\begin{aligned}
\text { EER } & =13.8-(0.3 \times \text { Capacity } / 1,000) \\
& =13.8-(0.3 \times 9,000 \mathrm{Btu} / \mathrm{h} / 1,000) \\
& =11.1
\end{aligned}
$$

Energy Input Ratio $($ EIR $)=($ Capacity $/$ EER - FanPower $) /($ Capacity $/ 3.413+$ FanPower $)$

$$
\begin{aligned}
& =\left(\frac{9,000}{11.1}-82.5\right) /\left(\frac{9,000}{3.413}+82.5\right) \\
& =0.267813
\end{aligned}
$$

COPcooling $=\frac{1}{\text { EIR }}=3.734$ 


\subsubsection{Addendum 90.1-07cb: Outdoor Air Damper Requirements}

Addendum 90.1-07cb includes a number of changes to outdoor air damper requirements:

- Requires simple systems to meet prescriptive outdoor air damper requirements. HVAC systems using the simplified approach (Section 6.3 in 90.1-2004 and 90.1-2007) are not required to meet the outdoor air damper requirements as systems using the mandatory and prescriptive requirements (Sections 6.4 and 6.5 respectively in 90.1-2004 and 90.1-2007). Addendum 90.1-07cb adds a new section in the simplified approach, which requires simplified systems to meet the outdoor air damper requirements.

- Allows backdraft dampers only for exhaust and relief dampers in buildings less than three stories in height. Section 6.4.3.4.3 of 90.1-2004 and 90.1-2007 has an exception that allows gravity (nonmotorized) dampers in buildings less than 3 stories in height and for buildings of any height in climate zones 1 through 3 . The addendum distinguishes outdoor air ventilation backdraft dampers from exhaust and relief dampers and rewords the exception to exclude the exception for ventilation intake dampers in climate zones 4 through 8.

- Requires backdraft dampers on outdoor air intakes to be protected from wind-limiting, wind-blown infiltration through the damper.

- Moves climate zone 5a to the category of climates that require low leakage dampers. Section 6.4.3.4.4 in 90.1-2004 and 90.1-2007 include low leakage damper requirements. These requirements are more stringent for climate zones $1,2,6,7$, and 8, and nonmotorized dampers are not allowed in these climates. This addendum adds climate zone 5 to the climate zones that are not allowed to use non-motorized dampers of the time regulated by Section 6.4.3.4.3.

The energy saving impacts from the first two changes above are considered significant and are accounted for in the PI analysis. The savings result because the gravity backdraft outdoor air intake dampers are open whenever the fan is running. The damper will bring in minimum levels of outdoor ventilation air, which must be conditioned even when the HVAC system cycles on to meet the temperature setpoints during unoccupied periods or when the fan system comes on during a preoccupancy warm-up/cool-down period. When automatically controlled motorized outdoor air intake dampers are used, the dampers can be closed when outdoor air is not required. This change leads to savings in climate zones 4 through 8 for the eight prototypes that are less than three stories: small office, standalone retail, strip mall, quick-service restaurant, full-service restaurant, primary and secondary schools, and warehouse.

In the simulation, this addendum is implemented by varying the outdoor air schedules in the outdoor air control in EnergyPlus. In the baseline case, the eight prototypes less than three stories in climate zones 4 through 8 are assigned a minimum outdoor air schedule with a value of " 1 " at all times. The value of " 1 " means that whenever the fan is running, the outdoor air damper is open, bringing in minimum levels of ventilation. For the 2010 PI, those same prototypes are assigned a minimum outdoor air schedule with a value of " 1 " from the beginning to the end of the occupied period in the spaces served by each system and a value of " 0 " when the space is unoccupied. The value of " 0 " causes the damper to remain closed even if the fan is running, unless the air economizer is on.

An added complication when accounting for savings from this addendum is that systems with an economizer will always have an automatic damper. Many of the eight prototypes less than three stories in 
climate zones 4 through 8 are required to have economizers in the baseline, based on the climate zone as well as the size of the HVAC system. It is assumed that, if the system is required to have an economizer in the baseline, it must already have an automatic damper even if not required specifically in 90.1-2004 or 90.1-2007. Therefore, those systems are assigned an outdoor air schedule that applies a motorized damper in the baseline and the 90.1-2010 models and do not show savings from addendum 90.1-07cb.

\subsubsection{Addendum 90.1-07ck: Outdoor Air Ventilation Optimization Control}

90.1-2004 and 90.1-2007, Section 6.5.3, requires that each HVAC system having a total fan system motor nameplate power larger than $5 \mathrm{hp}$ meet Sections 6.5.3.1 and 6.5.3.2, which govern fan maximum allowed horsepower and VAV fan control. 90.1-2007, Section 12, includes Standard 62.1-2004 as the reference standard for ventilation.

Addendum 90.1-07ck adds a new section, Section 6.5.3.3, "Multiple-zone VAV System Ventilation Optimization Control". The addendum also updates the reference standard from 62.1-2004 to 62.1-2007 in Section 12. However, note that all of the elements of Standard 62.1-2007 relevant to this addendum are identical in Standard 62.1-2004.

Addendum ck adds the requirement that multiple-zone VAV systems with DDC control of terminal units include means to automatically reduce outdoor air intake flow below the design rate in response to changes in system ventilation efficiency, as defined by Standard 62.1-2007, Appendix A. This new section includes three exceptions: (a) three types of VAV systems, including those with zonal transfer fans for recirculation, dual-duct dual fan VAV systems, and VAV systems with fan-powered boxes, (b) systems required to have energy recovery under 90.1-2010, Section 6.5.6.1, and (c) systems with total design exhaust airflow more than $70 \%$ of total design outdoor air intake.

Ventilation Standard 62.1-2007, Table 6.1, provides prescriptive zone outdoor air requirements based on number of occupants and zone floor area. For a multiple-zone VAV system, the sum of the prescriptive zone outdoor air requirements is the minimum system outdoor air intake. Standard 62.12007, Section 6.2.5, for multiple-zone recirculating systems, governs the system design outdoor air intake modified to account for system ventilation efficiency. Standard 62.1-2007, Section 6.2.7, for dynamic reset, allows outdoor air intake flow to be reset as operating conditions change, including the changes to system ventilation efficiency as outdoor air is distributed to the zones under different ventilation airflows and temperatures. The ventilation optimization required by addendum ck is equivalent to this dynamic reset. An ASHRAE journal article, Dynamic Reset for Multiple Zone Systems (Stanke 2010) provides an overview of the calculation steps required in Standard 62.1, as well as a discussion of the benefits of dynamic reset.

Outdoor air ventilation requirements are discussed in Chapter 4, Section 4.5.5 of this report. Table 4.14 presents the minimum outdoor air rate calculated as the sum of the prescriptive single zone values based on number of occupants and zone area, without incorporating the multiple-zone rules in Standard 62.1-2007. In implementing addendum ck, system level outdoor air intake flow is adjusted to meet the multi-zone ventilation requirements. Development of these multi-zone system outdoor air intake rates is discussed at the end of this section. Some parameters of this calculation require explanation here to understand how the ventilation optimization results in energy savings. 
One parameter in the Standard 62.1-2007 multiple-zone ventilation calculation is the system ventilation efficiency. System ventilation efficiency is a measure of how much the system outdoor air intake must be increased beyond the sum of the minimum zone prescriptive requirements that provide the minimum outdoor air to the zones. The system ventilation efficiency depends on the ventilation requirements of the zone or zones, which have the highest ratios of zone ventilation requirement to zone design airflow at minimum damper position. These zones are known as critical zones. Typically, in practice, design calculation of the system ventilation efficiency is made at the cooling design condition (or heating if heating load is dominant). Other conditions may occur with lower system ventilation effectiveness, which can be revealed by hourly load analysis, but this is not generally applied.

To satisfy Standard 62.1, a VAV system without ventilation optimization must maintain outdoor air intake airflow at the design value, even as supply air varies with space load. This requires airflow sensing and adjustment of the outdoor air damper. Real systems do not always work this way, but this is a way to fully meet Standard 62.1. Ventilation optimization allows the system outdoor air intake to be adjusted in response to changing airflow at the system and at the zone with changing loading conditions. The Standard 62.1 multiple-zone calculations are carried out automatically in the control equipment using airflow and damper position data.

Implementing addendum ck for the PI requires two main steps: (1) identifying the prototypes and VAV systems required to provide the ventilation optimization control and (2) adding the control in the EnergyPlus simulation.

As Table 5.27 shows, there are 21 VAV systems in 7 of the prototypes. Some systems in some climate zones meet the new Section 6.5.3.3 exception (b) for systems requiring energy recovery. Exceptions (a) and (c) do not apply. Also, two hospital and one outpatient healthcare systems include substantial proportion of zones with ventilation dominated by AIA guideline ventilation requirements (AIA 2001) and are not subject to the multiple-zone ventilation requirements in ASHRAE 62.1 or addendum ck. Table 5.27 summarizes the systems that are and are not required to meet the ventilation optimization control rules in the prototypes with VAV systems.

Ventilation optimization is implemented in the PI using a control algorithm that is available in EnergyPlus. For systems and climate zones with ventilation optimization, the Controller:MechanicalVentilation object is used with System Outdoor Air field set to ventilation rate procedure (VRP), the option for meeting ventilation requirements in Standard 62.1, which includes the multiple-zone calculations. When using the VRP option, EnergyPlus implements the Standard 62.1 multiple-zone calculation at each time step and calculates system efficiency and system outdoor air intake.

The VRP option in EnergyPlus is capable of implementing DCV as well as the ventilation optimization required by addendum ck. However, DCV is not part of the ventilation optimization control requirement in addendum ck. The EnergyPlus mechanical ventilation controller input fields include single-zone minimum outdoor air requirement per area and per occupant as determined by Standard 62.1, Table 6.1. The VRP option would adjust the per-occupant ventilation at each time step based on the scheduled occupancy, DCV, if allowed to. To avoid DCV where not required in Standard 90.1, the total zone outdoor air is combined, including both the floor area based and occupant based values, and is entered in the zone outdoor air per unit area field in the mechanical ventilation control object. This allows automatic calculation of the ventilation optimization without DCV. For cases with required DCV, the 
outdoor air is input, with area- and occupant-based values separated; and the VRP option performs ventilation optimization with $\mathrm{DCV}$.

Table 5.27. Applicability of Addendum 90.-07ck to Prototypes

\begin{tabular}{|c|c|c|}
\hline Prototype & HVAC System & Systems and Climates Affected by Addendum 90.1-07ck \\
\hline \multirow[t]{3}{*}{ Medium Office } & PACU_VAV_BOT & All Systems, All Climate Zones \\
\hline & PACU_VAV_MID & \\
\hline & PACU_VAV_TOP & \\
\hline \multirow[t]{3}{*}{ Large Office } & VAV_BOT & All Systems, All Climate Zones \\
\hline & VAV_MID & \\
\hline & VAV_TOP & \\
\hline \multirow[t]{4}{*}{ Primary School } & VAV_POD_1 & All Climate Zones Except 1A, 2A, 3A, 4A, 5A, 6A,7, and 8, which \\
\hline & VAV_POD_2 & have ERV \\
\hline & VAV_POD_3 & \\
\hline & VAV_OTHER & All Climate Zones \\
\hline Large Hotel & VAV WITH REHEAT & $\begin{array}{l}\text { All Climate Zones Except 1A, 2A, 3A, 4A, 5A, 6A, 7, 8, which have } \\
\text { ERV }\end{array}$ \\
\hline \multirow{2}{*}{$\begin{array}{l}\text { Outpatient } \\
\text { Healthcare }\end{array}$} & AHU-1 ${ }^{(a)}$ & Excluded, AIA Ventilation Requirements \\
\hline & AHU-2 & All Climate Zones \\
\hline \multirow[t]{4}{*}{ Hospital } & VAV_1 & All Climate Zones \\
\hline & VAV_2 & \\
\hline & VAV_OR & Excluded, AIA Ventilation Requirements \\
\hline & VAV_PATRMS & \\
\hline \multirow[t]{4}{*}{ Secondary School } & VAV_POD_1 & All Climate Zones Except 1A, 2A, 3A, 4A, 5A, 6A, 7, and 8, which \\
\hline & VAV_POD_2 & have ERV \\
\hline & VAV_POD_3 & \\
\hline & VAV_OTHER & All Climate Zones \\
\hline
\end{tabular}

\section{Calculating Standard 62.1 Multiple-zone System Outdoor Air Flow}

Minimum outdoor air ventilation rates at the zone level are described in Section 4.5.5 in this report for all prototypes. To implement addendum ck, the design outdoor air intake flow rates are developed to meet the multiple-zone system ventilation requirements in Standard 62.1. These ventilation rates are calculated for the VAV systems that are identified in Table 5.27 and that are subject to addendum ck. Rates are calculated for the 90.1-2004 baseline models as well as for the 90.1-2010 models. The multiplezone calculation procedures don't change among different ventilation standards (62-1999 62.12004 and 62.1-2007), except that the 62-1999 does not include zone ventilation effectiveness. Item 1, Zone Outdoor Airflow, in the calculation steps below explains how this one difference is addressed.

Standard 62.1-2007, Section 6.2.5, on multiple-zone recirculating systems, governs the design outdoor air intake flow at the system level for VAV systems. The major elements of the calculations involved and some of the simplifying assumptions used to allow these calculations to be performed are described in that section. These assumptions are consistent with input provided by members of the 
Mechanical Subcommittee. Calculations are done at the system cooling design condition after verifying that higher system airflows do not occur at the heating design condition. Another option that some designers use includes hourly loads analysis to determine if any other condition results in higher outdoor air with these calculations. PNNL used the approach based on peak cooling load conditions in order to keep the modeling manageable; this method is often used in industry.

The multi-zone calculations include the following steps:

- Zone outdoor airflow $\left(\mathrm{V}_{\mathrm{oz}}\right)$ is found for each zone from the sum of the outdoor airflow per person and the outdoor airflow per area required in Standard 62.1. This value is divided by zone air distribution effectiveness from Table 6-2 in Standard 62.1. For this analysis, a value of 1.0 for zone ventilation effectiveness is used in all cases. This allows consistency when applying ventilation Standard 62-1999 for the 90.1-2004 baseline models. Standard 62-1999 has effectively the same method for determining multiple-zone system ventilation but does not include the range of zone air distribution effectiveness as in Standards 62.1-2004 and 62.1-2007. Also, addendum 90.1-07 bx sets the reheat delta-T low enough that heating zone ventilation effectiveness of 1.0 is achieved. Because of limitations in the EnergyPlus simulation, addendum bx was not implemented and savings were not included in the PI.

- Zone discharge outdoor air fraction $\left(\mathrm{Z}_{\mathrm{dz}}\right)$ is the ratio of the zone outdoor airflow divided by zone discharge airflow $\left(\mathrm{V}_{\mathrm{pz}}\right)$ (the airflow to meet the thermal comfort conditions for the zone). A range of values may be used for the zone discharge air (Stanke 2010). One option is to use the discharge airflow at the zone based on the minimum damper position. This is a worst case that may not occur at design conditions but is often used by designers. These values can result in higher values for $Z_{\mathrm{dz}}$ than actually occur, but determining the actual maximum discharge airflow that occurs was not practical for this analysis, and there was no other recognized simple assumption to use.

- Uncorrected Outdoor Intake $\left(\mathrm{V}_{\text {ou }}\right)$ is the sum of the zone outdoor air requirements for airflow per occupant and airflow per area, adjusted for diversity of the zone population. For this analysis, diversity is assumed to be 1 , a simplification since actual diversity values are not known. This is the same value as listed in Table 4.14 of this report for all prototypes.

- Average Outdoor Air Fraction $\left(\mathrm{X}_{\mathrm{s}}\right)$ is the fraction of uncorrected outdoor air intake divided by the system primary airflow, $\mathrm{V}_{\mathrm{ou}} / \mathrm{V}_{\mathrm{ps}}$. $\mathrm{V}_{\mathrm{ps}}$ is the system primary airflow, the system airflow at design conditions. In the simulation this initially is the sum of the coincident zone airflows that occur at the design conditions.

- Zone Ventilation Efficiency $\left(\mathrm{E}_{\mathrm{vz}}\right)$ Zone ventilation efficiency, $\mathrm{E}_{\mathrm{vz}}$, is determined for each zone and is equal to the sum of 1 and the average outdoor air fraction minus the zone discharge outdoor air fraction, $1+\mathrm{X}_{\mathrm{s}}-\mathrm{Z}_{\mathrm{dz}}$.

- System Ventilation Efficiency $\left(\mathrm{E}_{\mathrm{v}}\right)$ System ventilation effectiveness, $\mathrm{E}_{\mathrm{v}}$, is the lowest $\mathrm{E}_{\mathrm{vz}}$ value for the zone that is considered the critical zone.

- Outdoor Air Intake Flow $\left(\mathrm{V}_{\mathrm{ot}}\right.$ ) for the system is the uncorrected outdoor air intake divided by the system ventilation effectiveness, $\mathrm{V}_{\mathrm{ot}}=\mathrm{V}_{\mathrm{ou}} / \mathrm{E}_{\mathrm{v}}$.

For many design projects, this outdoor air intake flow in bullet 7 would be the stopping point. System ventilation efficiency may be near or at 1.0 and the outdoor air intake flow will be reasonably close to the uncorrected outdoor air intake. However, often in reality, and for many of the prototype models, the 
system ventilation efficiency calculated with the initially determined minimum damper positions is significantly less than 1.0. This low calculated ventilation efficiency can lead to a design with excessively high levels of ventilation air, which would require significant energy to condition.

Standard 62.1 allows an option for designers to increase the zone supply airflow over the minimum required for space conditioning to reduce the ratio of outdoor air to supply air that leads to low system efficiency values. One way to achieve this is to increase the minimum damper position of these zones. Section 6.5.2.1 in 90.1-2007 places restrictions on the highest value that the minimum damper position for VAV systems can have when using reheating or recooling. However, the section allows the rate to be higher than the prescriptive minimum values if energy usage can be demonstrated to be lower than would occur from restricting the minimum airflow to the allowed values. Net energy savings can be realized by increasing the minimum airflow at selected zones. This may increase reheating/recooling but will also increase system ventilation effectiveness and reduce system outdoor air intake, potentially resulting in a net reduction in energy needed to temper outdoor air. In practice, designers may make these types of adjustments to minimum damper position to improve system ventilation effectiveness without proving the energy usage is reduced based on experience and agreement with local code review. A rule of thumb approach may be followed, such as restricting the increase to $70 \%$ or some other value. The increase only needs to be made at critical zones that drive down the system ventilation effectiveness.

Implementing the Multi-zone Outdoor Air Requirements for the PI

For the PI analysis, a calculation is made to increase minimum damper positions of critical zones if needed so that the system ventilation efficiency is no less than 0.6. If the calculated system efficiency is more than this value, minimum damper positions are left at the value needed to meet Standard 90.1. The value of 0.60 was chosen based on trial analysis with the medium office building, which resulted in adjusting the critical zone minimum damper position to 0.6 to 0.7 , a value that is tolerable in actual design practice. For most of the zones in the prototypes and for the medium and large office prototypes, this approach is implemented and results in appropriate outdoor air intakes.

To develop the new ventilation rates, a partially automated procedure was developed. These procedures are incorporated in Perl scripts. The scripts extract output information from intermediate model runs (prior to adding multi-zone outdoor air rates) to use in the calculations. These values are passed to another script, which runs the multi-zone calculations and exports to a spreadsheet intermediate multi-zone calculation values, and data for model inputs populate the model input file. The intermediate multi-zone calculation values are examined manually to identify and process any special case inputs. The procedure includes the following steps:

- An initial pre-run of the baseline and progress indicator models is made with starting values for minimum damper position.

- Data relevant to determining the system ventilation efficiency are extracted from the model output files, including the variables identified in the multiple-zone calculation outline above.

- A spreadsheet calculates the system ventilation efficiency. If the result is less than 0.6, a minimum damper position is determined for the critical zone or zone that allows system ventilation efficiency to reach at least 0.6 . Some special cases were found that initially result in system ventilation efficiency of less than 1.0 , or very small values driving outdoor air intake to very high values. How these cases were addressed is described below. 
- A system outdoor air intake value is determined by dividing the sum of the single zone required ventilation by the system ventilation efficiency.

- Minimum damper positions and system outdoor air intake values are added to the adjusted models.

For the prototypes, adjustments are made to address special case zones. These prototypes still apply system ventilation efficiency no less than 0.6. Medium and large offices prototypes do not include any special case zones requiring adjustments.

Hospital: For the hospital prototype, hard-coded zone supply airflow rate for the ICU nurse station zone on the second floor are set to equal the zone outdoor air flow divided by 0.7 . This method is a rough approximation to adding a fan-powered box for this one zone, or breaking it out as a separate small system, options that are described below.

Large Hotel: For the large hotel kitchen, the minimum damper position calculated exceeds 1.0. The minimum damper is reset to 1.0 for these cases. In reality, the kitchen would probably be served by a separate makeup air system. For the basement zone, the heating design airflow is used because it is larger than for cooling. This allows implementation to go forward with other zones becoming the critical zones.

Outpatient Healthcare: The target system efficiency was set at 0.7 instead of 0.6 . This allows minimum damper positions for all zones to be less than 1 .

Primary School: The initial minimum damper position for the VAV zones is 0.3 or 0.2 . Using these values as the starting point for calculating the initial system efficiency leads to negative values for system ventilation efficiency in many zones. The initial values for the minimum damper position are adjusted to 0.7 for the calculation. This adjustment allows the calculation of system efficiency to result in positive values and then allows the calculation of minimum damper positions for critical zones to result in a system ventilation effectiveness of 0.6 .

Secondary School: Calculations for many zones result in negative or very low values for system ventilation effectiveness. A reasonable method for addressing this is not included in the multi-zone outdoor airflows at this time and the minimum zone level outdoor air requirements are used. In reality, this prototype would likely more closely determine the worst case conditions for determining the critical zone, use fan-powered terminal units, or use other methods to address the multi-zone outdoor air requirements, as described below.

Another way to address critical zones is to provide fan-powered boxes, which increase the supply airflow at the terminal unit. This approach has pros and cons as well. Additional energy usage is required to run the terminal unit fans, and additional expense occurs for the fan powered terminal units. The added energy usage for the zone fans can be offset by increasing ventilation effectiveness and reducing system outdoor air intake. This method was not applied for the PI because of issues with implementing this in the model in an automated fashion. The approach may be appropriate for the schools in particular, where zone outdoor air requirements are close or even in excess of the space load requirement. Systems with fan powered boxes are exempt from the addendum 90.1-07ck ventilation optimization control required by addendum ck.

Finally, another approach would be to break out critical zones as separate systems. This approach is potentially an option for zones such as the kitchen in the large hotel prototype. 
Further refinement of implementing the Standard 62.1 multiple-zone outdoor intake airflows will be considered for future work to address some of these special issues.

\subsubsection{Addendum 90.1-07cy: Economizers}

90.1-2004 and 90.1-2007 include all requirements for economizers in Section 6.5.1. Addendum 90.107 cy changes several provisions of Section 6.5.1. The changes from addendum cy that result in significant savings include increasing the number of climate zones in which systems are required to have air economizers, lowering the cooling capacity size limit above which an economizer is required, and eliminating the exceptions for nonintegrated economizers. All of the changes to economizer requirements that are now in 90.1-2010, including those that do not impact savings, are outlined here.

- Section 6.5.1 exceptions (c), (d), and (i) are changed.

Exception (c) is modified for hospitals and ambulatory surgery centers when humidity control is required. The modification changes the percentage of supply air of a system serving spaces to be humidified from a minimum of $25 \%$ to a minimum of $75 \%$ to trigger the exception.

Exception (d) wording is clarified for economizers with systems subject to Section 6.5.6.2 heat recovery for service water heating.

Exception (i) is changed to clarify that only economizers that provide comfort cooling are eligible to use the alternative compliance path in Section 6.3.2 based on improved system cooling efficiency.

- Table 6.5.1, which sets climate and cooling capacity criteria for when economizers are required, is split into two parts. Part A applies to comfort cooling applications and part B applies to computer room applications. Part B uses the same categorization that Table 6.5.1 did for all economizers before the addendum. Part A includes the following changes:

Economizer requirements are added for climate zones $2 \mathrm{a}, 3 \mathrm{a}$, and $4 \mathrm{a}$, which were formerly exempt. Climate zones $1 \mathrm{a}$ and $1 \mathrm{~b}$ remain exempt.

The cooling capacity above which an economizer is required is reduced to $54,000 \mathrm{Btu} / \mathrm{h}$ for all climate zones except $1 \mathrm{a}$ and $1 \mathrm{~b}$. This change reduces the threshold down from 135,000 Btu/h for climate zones 2b, 5a, 6a, 7 and 8 and down from $65,000 \mathrm{Btu} / \mathrm{h}$ for climate zones $3 \mathrm{~b}, 3 \mathrm{c}, 4 \mathrm{~b}, 4 \mathrm{c}$, $5 \mathrm{~b}, 5 \mathrm{c}$, and $6 \mathrm{~b}$.

- Section 6.5.1.3 exceptions to requirements for integrated economizers are removed:

(a) DX systems that reduce outdoor air volume for frost control with the lowest step of compressor unloading provided that is no more than $25 \%$ of total system cooling capacity.

(b) DX units with capacity less than $65,000 \mathrm{Btu} / \mathrm{h}$

(c) Systems in climate zones 1, 2, 3a, 4a, 5a, 5b, 6a, 6, 7, and 8 .

- Tables 6.5.1.1.3A and B for economizer controls are modified so that fixed dry bulb control is no longer allowed for climate zones 1a, 2a, 3a, and 4a. Note that economizers previously were not required in these four climate zones.

- Section 6.3.2, exception (c), is changed to eliminate redundancy in the language that systems meet the economizer requirements. 
- Table 6.3.2 is replaced by a new Table 6.3.2, adopted with addendum 90.1-07au, which provides exceptions for economizer requirements for systems that meet cooling efficiency thresholds above the mandatory cooling efficiency requirements in Standard 90.1 Chapter 6.

Only some of these changes are incorporated in the modeling for the PI analysis. These changes include the new Table 6.5.1A capacity thresholds and climate zone applicability, and the Section 6.5.1.3 removal of exceptions for integrated economizer control. These changes also include the modification of Tables 6.5.1.1.3A and B, which do not allow differential dry bulb control for humid climates. This modification is implemented by applying differential enthalpy control for economizers in climate zones 1a, 2a, 3a, and 4a, as now required under Table 6.5.1A.

Other addendum cy changes are not implemented to capture savings for several reasons:

- Section 6.5.1 exceptions(c), (d), and (i).

Exception (c) regarding hospitals and ambulatory surgery centers with humidity control does not change the models since in the hospital and outpatient healthcare prototypes' economizers are excluded for all systems with humidification, and these generally exceed both the $25 \%$ and the $75 \%$ threshold.

Exception (d) regarding Section 6.5.6.2 heat recovery for service water heating does not apply because no prototypes include this type of heat recovery.

Exception (i) refers to the alternative compliance path using improved cooling efficiency and is not applied in the progress indicator process.

- Section 6.5.1.3, exception (b), which removes exception for integrated economizers with systems with cooling capacity under $65,000 \mathrm{Btu} / \mathrm{h}$, does not apply because systems below this capacity are not required to have economizers in the baseline.

- The change to Section 6.3.2 language does not impact savings.

- The replacement of Table 6.3.2 does not apply. The alternative compliance path is not considered.

Addendum cy implementation results in model changes that alter energy usage in all prototypes except small office, warehouse, and high-rise and mid-rise apartments. The HVAC systems in these prototypes do not reach the capacity thresholds that trigger the inclusion of air economizers. Guestroom HVAC systems in small and large hotels also are not impacted. Savings are added to all climate zones except climate zone $1 \mathrm{a}$ and $1 \mathrm{~b}$, which continue to have no economizer requirements. Table 5.28 shows the impact for each prototype, HVAC system, and climate zone that are subject to the addendum changes. The values in the tables refer to the following addendum changes.

- Change 1: Economizers are added for climate zones 1a, 2a, 3a, 4a, as shown in 90.1-2010, Table 6.5.1A.

- Change 2: Economizers have integrated controls because of the removal of Section 6.5.1.3, exception (a), for VAV DX systems.

- Change 3 Economizers have integrated controls because of the removal of Section 6.5.1.3, exception (c), for climate zones $2 \mathrm{~b}, 5 \mathrm{a}, 5 \mathrm{~b}, 6 \mathrm{a}, 6 \mathrm{~b}, 7$, and 8 . Note that this is shown for all systems other than those shown as VAV DX. It also applies to VAV DX systems, but those are already covered under Item 2. 
- Change 4: Economizers are added in some cases for the climate zone and system types where the new cooling capacity thresholds shifted under Table 6.5.1A in 90.1-2010. For example, a system that has a capacity of $60,000 \mathrm{Btu} / \mathrm{h}$ in climate $3 \mathrm{~b}$ has an economizer required under the addendum but not under the thresholds in 90.1-2007. This was observed in some intermediate stages in the modeling and is expected for some of these climate zones in the final progress indicator models.

There are some systems identified in the column headings as VAV DX that include footnote (b). These are systems that for some climate zones are constant volume DX in the baseline models, but are variable air volume DX in the advanced models. This change of system type was triggered by the addendum 90.1-07n single-zone VAV requirement. The VAV DX systems are subject to the same economizer requirements as are other VAV DX systems.

Prototype systems in climate zones that are shaded in Table 5.28 meet economizer requirements in 90.1-2004 and are not affected by this addendum.

Model changes are made by an automated process using a Perl script that identifies the cooling capacity of systems in sizing runs for each climate zone and then includes economizers and the correct economizer controls as required by this addendum. 
Table 5.28. Applicability of Addendum 90.1-07cy by Prototype and Climate Zone

\begin{tabular}{|c|c|c|c|c|c|c|c|c|c|c|c|c|}
\hline \multirow{2}{*}{\multicolumn{2}{|c|}{$\begin{array}{c}\text { Prototype } \\
\text { System Type } \\
\end{array}$}} & \multirow{2}{*}{$\begin{array}{c}\begin{array}{c}\text { Medium } \\
\text { Office }\end{array} \\
\text { VAV DX }\end{array}$} & \multirow{2}{*}{$\begin{array}{l}\text { Large } \\
\text { Office }\end{array}$} & \multicolumn{2}{|c|}{ Standalone Retail } & \multicolumn{2}{|c|}{ Strip Mall } & \multicolumn{3}{|c|}{ Primary School } & \multicolumn{2}{|c|}{ Outpatient Healthcare } \\
\hline & & & & $\begin{array}{l}\text { VAV } \\
\text { DX }^{(a)}\end{array}$ & $\begin{array}{l}\text { CAV } \\
\text { DX }\end{array}$ & $\begin{array}{l}\text { VAV } \\
\text { DX }^{(a)}\end{array}$ & $\begin{array}{l}\text { CAV } \\
\text { DX }\end{array}$ & $\begin{array}{l}\text { VAV } \\
\text { DX }\end{array}$ & $\begin{array}{l}\text { VAV } \\
\text { DX }^{(a)}\end{array}$ & $\begin{array}{l}\text { CAV } \\
\text { DX }\end{array}$ & $\begin{array}{l}\text { VAV DX } \\
\text { (without } \\
\text { humid.) }\end{array}$ & $\begin{array}{l}\text { VAV DX } \\
\text { (with } \\
\text { humid.) }\end{array}$ \\
\hline \multicolumn{13}{|c|}{ Climate Zone } \\
\hline $2 \mathrm{~A}$ & Houston & 1 & 1 & 1 & 1 & 1 & 1 & 1 & 1 & 1 & 1 & \\
\hline $2 \mathrm{~B}$ & Phoenix & 2 & 3 & 2 & 3 & 2 & 3 & 2 & 2 & 3 & 2 & \\
\hline $3 \mathrm{~A}$ & Memphis & 1 & 1 & 1 & 1 & 1 & 1 & 1 & 1 & 1 & 1 & \\
\hline $3 \mathrm{~B}$ & El Paso & 2 & & 2 & 4 & 2 & 4 & 2 & 2 & & 2 & \\
\hline $3 \mathrm{C}$ & San Francisco & 2 & & 2 & 4 & 2 & 4 & 2 & 2 & & 2 & \\
\hline $4 \mathrm{~A}$ & Baltimore & 1 & 1 & 1 & 1 & 1 & 1 & 1 & 1 & 1 & 1 & \\
\hline $4 \mathrm{~B}$ & Albuquerque & 2 & & 2 & 4 & 2 & 4 & 2 & 2 & & 2 & \\
\hline $4 \mathrm{C}$ & Salem & 2 & & 2 & 4 & 2 & 4 & 2 & 2 & & 2 & \\
\hline $5 \mathrm{~A}$ & Chicago & 2 & 3 & 2 & 3 & 2 & 3 & 2 & 2 & 3 & 2 & \\
\hline $5 \mathrm{~B}$ & Boise & 2 & 3 & 2 & 3 & 2 & 3 & 2 & 2 & 3 & 2 & \\
\hline $5 \mathrm{C}$ & Vancouver & 2 & & 2 & 4 & 2 & 4 & 2 & 2 & & 2 & \\
\hline $6 \mathrm{~A}$ & Burlington & 2 & 3 & 2 & 3 & 2 & 3 & 2 & 2 & 3 & 2 & \\
\hline $6 \mathrm{~B}$ & Helena & 2 & 3 & 2 & 3 & 2 & 3 & 2 & 2 & 3 & 2 & \\
\hline 7 & Duluth & 2 & 3 & 2 & 3 & 2 & 3 & 2 & 2 & 3 & 2 & \\
\hline 8 & Fairbanks & 2 & 3 & 2 & 3 & 2 & 3 & 2 & 2 & 3 & 2 & \\
\hline & Prototype & \multicolumn{3}{|c|}{ Secondary School } & \multicolumn{2}{|c|}{ Hospital } & $\begin{array}{l}\text { Small } \\
\text { Hotel }\end{array}$ & $\begin{array}{l}\text { Large } \\
\text { Hotel }\end{array}$ & \multicolumn{2}{|c|}{$\begin{array}{c}\text { Quick-service } \\
\text { Restaurant }\end{array}$} & \multicolumn{2}{|c|}{ Full-service Restaurant } \\
\hline & System Type & $\begin{array}{l}\text { VAV } \\
\text { DX }\end{array}$ & $\begin{array}{l}\text { CAV } \\
\text { DX }\end{array}$ & $\begin{array}{l}\text { VAV } \\
\text { CHW }\end{array}$ & $\begin{array}{l}\text { VAV DX } \\
\text { (without } \\
\text { humid.) }\end{array}$ & $\begin{array}{c}\text { VAV } \\
\text { DX } \\
\text { (with } \\
\text { humid.) }\end{array}$ & $\begin{array}{l}\text { CAV } \\
\text { DX }\end{array}$ & $\begin{array}{l}\text { VAV, } \\
\text { CAV } \\
\text { CHW }\end{array}$ & & V DX & $\begin{array}{l}\text { VAV } \\
\text { DX }^{(a)}\end{array}$ & $\begin{array}{l}\text { CAV } \\
\text { DX }\end{array}$ \\
\hline \multicolumn{13}{|c|}{ Climate Zone } \\
\hline $2 \mathrm{~A}$ & Houston & 1 & 1 & 1 & 1 & & 1 & 1 & & 1 & 1 & 1 \\
\hline $2 \mathrm{~B}$ & Phoenix & 2 & 3 & 3 & 3 & & 3 & 3 & & 3 & 2 & 3 \\
\hline $3 \mathrm{~A}$ & Memphis & 1 & 1 & 1 & 1 & & 1 & 1 & & 1 & 1 & 1 \\
\hline $3 \mathrm{~B}$ & El Paso & 2 & 4 & & & & 4 & & & & 2 & \\
\hline $3 \mathrm{C}$ & San Francisco & 2 & 4 & & & & 4 & & & & 2 & \\
\hline $4 \mathrm{~A}$ & Baltimore & 1 & 1 & 1 & 1 & & 1 & 1 & & 1 & 1 & 1 \\
\hline $4 \mathrm{~B}$ & Albuquerque & 2 & 4 & & & & 4 & & & & 2 & \\
\hline $4 \mathrm{C}$ & Salem & 2 & 4 & & & & 4 & & & & 2 & \\
\hline $5 \mathrm{~A}$ & Chicago & 2 & 3 & 3 & 3 & & 3 & 3 & & 3 & 2 & 3 \\
\hline $5 \mathrm{~B}$ & Boise & 2 & 3 & 3 & 3 & & 3 & 3 & & 3 & 2 & 3 \\
\hline $5 \mathrm{C}$ & Vancouver & 2 & 4 & & & & 4 & & & & 2 & \\
\hline $6 \mathrm{~A}$ & Burlington & 2 & 3 & 3 & 3 & & 3 & 3 & & 3 & 2 & 3 \\
\hline $6 \mathrm{~B}$ & Helena & 2 & 3 & 3 & 3 & & 3 & 3 & & 3 & 2 & 3 \\
\hline 7 & Duluth & 2 & 3 & 3 & 3 & & 3 & 3 & & 3 & 2 & 3 \\
\hline 8 & Fairbanks & 2 & 3 & 3 & 3 & & 3 & 3 & & 3 & 2 & 3 \\
\hline
\end{tabular}

\subsubsection{Power}

Standard 90.1, Section 8, Power, applies to all building power distribution systems. Two addenda are added that expand the coverage of this section beyond the limited mandatory design voltage drop requirements for feeder and branch circuits in earlier versions of Standard 90.1. These addenda extend the 
regulation of power equipment and controls to address step-down voltage transformers in buildings and to begin the regulation of receptacle loads by adding automatic controls for receptacles. Regulation of plug loads will likely grow in future versions of Standard 90.1 .

\subsubsection{Addendum 90.1-07o: Transformers}

Low voltage dry-type transformers are used in many commercial buildings to lower the primary voltage of the electrical service provided by the utility company from 277 volts (single phase) or 480 volts ( 3 phase) to 120 volts (single phase) or 208 volts ( 3 phase). Loads commonly served by such transformers include wall plugs, lights, fans, and equipment such as computers, printers, and small industrial machinery (Cadmus Group 1999). The Energy Policy Act of 2005 created new federal minimum efficiency standards for low-voltage dry-type transformers. Addendum 90.1-07o adopts the federal mandatory requirements by adding them to 90.1-2010. Prior to this addendum, this class of equipment had no efficiency requirements. Table 5.29 includes the new efficiency requirements from addendum $\mathrm{o}$. This addendum defines the term kilo volt amperes (kVA) and efficiency and defines the regulated type of transformer: "a low voltage distribution transformer is a transformer that is air-cooled, does not use oil as a coolant, has an input voltage of 600 Volts or smaller, and is rated for operation at a frequency of $60 \mathrm{~Hz} . "$

Table 5.29. Low Voltage Dry-Type Transformer Efficiency Requirements

\begin{tabular}{cccc}
\hline \multicolumn{2}{c}{ Single-Phase Transformers } & \multicolumn{2}{c}{ Three-Phase Transformers } \\
\hline $\mathrm{kVa}$ & Efficiency (\%) & $\mathrm{kVA}$ & Efficiency (\%) \\
15 & 97.7 & 15 & 97.0 \\
25 & 98.0 & 30 & 97.5 \\
37.5 & 98.2 & 45 & 97.7 \\
50 & 98.3 & 75 & 98.0 \\
75 & 98.5 & 112.5 & 98.2 \\
100 & 98.6 & 150 & 98.3 \\
167 & 98.7 & 225 & 98.5 \\
250 & 98.8 & 300 & 98.6 \\
333 & 98.9 & 500 & 98.7 \\
NA & NA & 750 & 98.8 \\
NA & NA & 1,000 & 98.9 \\
\hline
\end{tabular}

To quantify savings from this addendum, a number of assumptions are made after consulting members of the SSPC 90.1 Lighting Subcommittee:

- All prototypes with floor areas greater than 50,000 $\mathrm{ft}^{2}$ are assumed to include step-down transformers (Cadmus Group 1999). Included in this group are large office, medium office, primary school, secondary school, hospital, large hotel, and high-rise apartment prototypes.

- All miscellaneous plug loads and incandescent lighting in the above buildings will be fed through $120-\mathrm{V}$ circuits served by step-down transformers.

- Based on lighting models used by the Lighting Subcommittee to create lighting power densities allowances, the following percentages of lighting in each of the affected prototypes are assumed to be incandescent. 
Prototype $\%$ of Incandescent Lighting

Large Office $2.81 \%$

Medium Office

$2.81 \%$

Primary School

$1.19 \%$

Secondary School

$1.94 \%$

Hospital

$2.20 \%$

Large Hotel

$3.52 \%$

High-rise Apartment

$0.15 \%{ }^{1}$

- A key input for estimating distribution transformer energy use is transformer loading (DOE 2004). To develop part-load performance characteristics, a peak load factor is required. The peak load on a transformer typically ranges from $60 \%$ to $90 \%$ if electrical engineers accurately size dry-type transformers conservatively with a $10 \%$ safety margin relative to the nameplate capacity (DOE 2004). The value of $75 \%$ was chosen for this analysis. This value enables each building to be modeled with a single transformer with average oversizing.

- DOE created 10 product classes and 13 design lines of distribution transformers for developing efficiency standards (DOE 2004). For this analysis, Product Class 4, Design Line 7, which covers low-voltage, three-phase distribution transformers from $15 \mathrm{kVA}$ to $150 \mathrm{kVA}$, was chosen as typical of the transformers covered by addendum 90.1-07o as recommended by the Lighting Subcommittee. Within the Product Class 4, Design Line 7, DOE selected the 75-kVA transformer as the representative unit for developing the requirements. Research done for the DOE rulemaking process setting the transformer efficiency standards identified baseline and target levels of efficiency for each transformer line. Figure 5.4 shows how these efficiency values vary as a function of part load for the reference transformer.

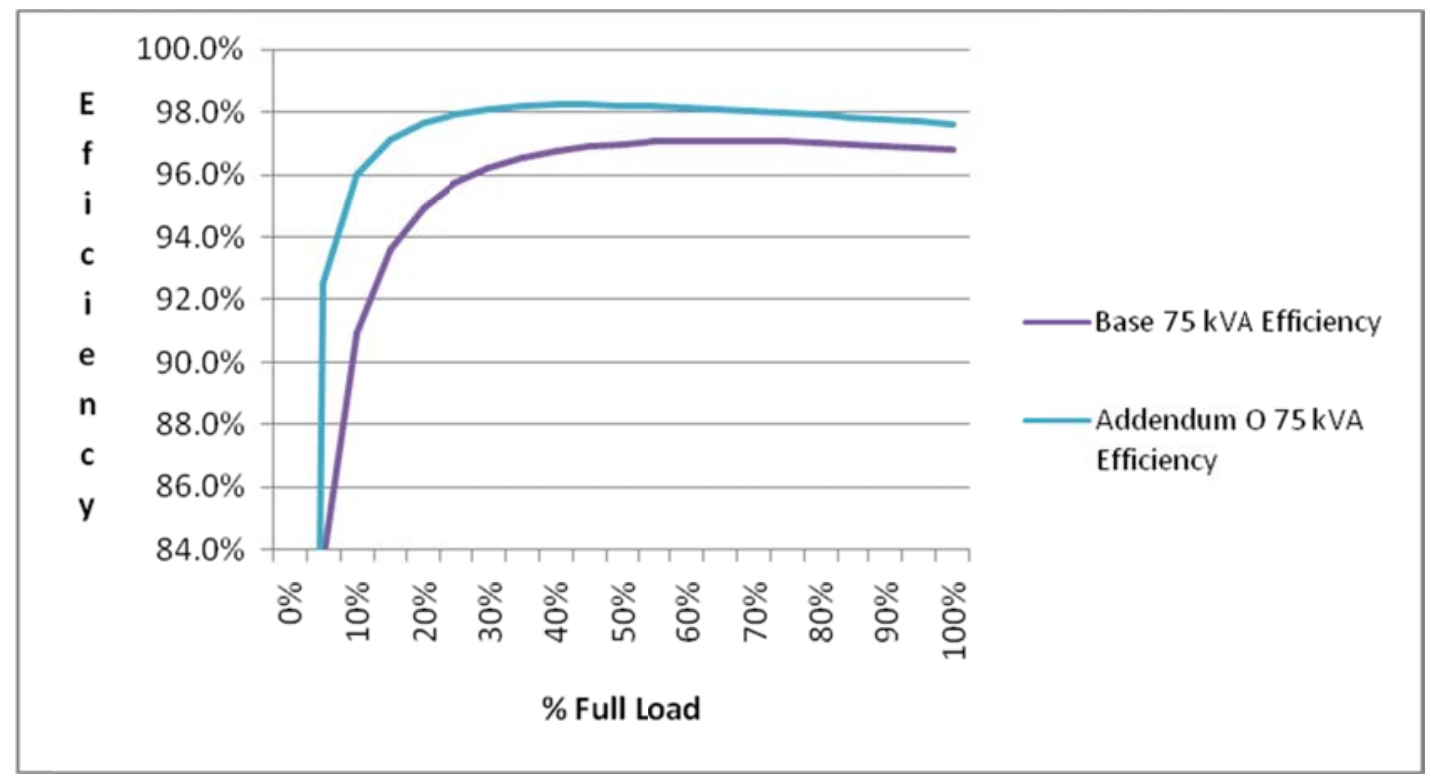

Figure 5.4. Baseline and Addendum 90.1-07o Transformer Efficiency Comparison

\footnotetext{
${ }^{1}$ Plug-in lighting within residences is not considered here because it is included as a plug load.
} 


\section{Modeling Strategy}

Quantifying the losses due to the inefficiencies of transformers pre- and post-addendum 90.1-07o requires the mathematical descriptions of those losses because the load on the transformer varies. The efficiency of transformers depends on two types of losses. No load losses (NLL) are due to switching of magnetic fields in the core material and remain roughly constant as long as the transformer is energized. Load losses (LL) are due to electric resistance losses in the windings and vary approximately with the square of the load plus a small temperature correction. Knowing the NLL and LL at peak capacity for a particular transformer allows for calculation of the energy used by the transformer at any given time (DOE 2004):

$$
E_{D T}(t)=E_{N L}+E_{L L} \times\left[\operatorname{Load}(t) /\left(L_{\text {rated }} \times P F\right)\right]^{2}
$$

where,

$$
\begin{aligned}
E_{D T}(t)= & \text { the energy used by the distribution transformer at time } t \\
E_{N L}= & \text { the no-load losses at rated load } \\
E_{L L}= & \text { the load losses at rated load } \\
\operatorname{Load}(t)= & \text { the load served by the transformer at time } t \\
L_{r a t e d}= & \text { the rated load of the transformer } \\
P F= & \text { the power factor of the load served by the transformer (assumed to be } 1.0 \text { for this } \\
& \text { analysis). }
\end{aligned}
$$

NLL- and LL-developed transformer losses through the DOE rulemaking process for the reference 75-kVA baseline and target transformers are shown in Table 5.30 (DOE 2004). To apply the same efficiency as the reference transformer to the prototype transformer, a relationship between transformer losses and percent loading was developed. Based on the results of the following equations, transformer loss as a function of part-load ratio (Trans-Loss-FPLR) was calculated as shown in Table 5.31. The polynomial curve fit is shown in Figure 5.5.

$$
\text { Trans-Loss-FPLR }=E_{D T}(t) /(L F F L) * L_{\text {rated }}
$$

where,

$$
L F F L=\text { Loss Fraction at Full Load }=\text { Loss at full load } / L_{\text {rated }}
$$

The transformer loss curves are applied to the affected prototypes by post-processing hourly results using the following procedure. Note that because savings for this addendum are calculated via postprocessing of hourly results, EnergyPlus input and output files do not include this addendum.

- For each hour, the total energy use of miscellaneous electric equipment and the fraction of lighting assumed to be incandescent (see assumptions above) are summed to represent the hourly load on the transformer $(\operatorname{Load}(t))$.

- The transformer size is calculated by determining the peak annual hourly load, assuming a peak load-to-rated capacity ratio of $0.75\left(L_{\text {rated }}\right)$.

- For each hour, the transformer loss $\left(E_{D T}(t)\right)$ is calculated according to the equation:

$$
E_{D T}(t)=L_{\text {rated }} * L F F L * \text { Trans-Loss-FPLR }
$$


- The sum of the hourly losses is added to the total annual energy use for each prototype.

Table 5.30. Reference Transformer Losses

\begin{tabular}{|l|c|c|c|c|}
\hline & $\begin{array}{c}\text { No Load } \\
\text { Loss (W) }\end{array}$ & $\begin{array}{c}\text { Load Loss, } \\
100 \%(\mathrm{~W})\end{array}$ & $\begin{array}{c}\text { Loss Fraction } \\
\text { at Full Load }\end{array}$ & $\begin{array}{c}\text { Efficiency at } \\
35 \% \text { Load }\end{array}$ \\
\hline Baseline Transformer Losses & 730.3 & $1,733.9$ & 0.03286 & $96.6 \%$ \\
\hline $\begin{array}{l}\text { Addendum 90.1-07o Transformer } \\
\text { Losses }\end{array}$ & 298.4 & $1,535.5$ & 0.02445 & $98.2 \%$ \\
\hline
\end{tabular}

Table 5.31. Transformer Loss as a Function of Part Load Ratio

\begin{tabular}{cccccc}
\hline & & \multicolumn{2}{c}{ Baseline Transformer } & \multicolumn{2}{c}{ Addendum 90.1-07o } \\
\cline { 3 - 6 } $\begin{array}{c}\text { Part Load } \\
\text { Ratio }\end{array}$ & Load (W) & Tosses (W) & Transformer & Losses (W) & Transformer \\
(PLR) & (Load(t) $)$ & (EDT(t) $)$ & Loss (FPLR) & (EDT(t)) & Loss (FPLR) \\
\hline $0 \%$ & & 730 & $29.6 \%$ & 298 & $16.3 \%$ \\
$5 \%$ & 3,750 & 735 & $29.8 \%$ & 302 & $16.5 \%$ \\
$10 \%$ & 7,500 & 748 & $30.3 \%$ & 314 & $17.1 \%$ \\
$15 \%$ & 11,250 & 769 & $31.2 \%$ & 333 & $18.2 \%$ \\
$20 \%$ & 15,000 & 800 & $32.5 \%$ & 360 & $19.6 \%$ \\
$25 \%$ & 18,750 & 839 & $34.0 \%$ & 394 & $21.5 \%$ \\
$30 \%$ & 22,500 & 886 & $36.0 \%$ & 437 & $23.8 \%$ \\
$35 \%$ & 26,250 & 943 & $38.3 \%$ & 487 & $26.5 \%$ \\
$40 \%$ & 30,000 & 1,008 & $40.9 \%$ & 544 & $29.7 \%$ \\
$45 \%$ & 33,750 & 1,081 & $43.9 \%$ & 609 & $33.2 \%$ \\
$50 \%$ & 37,500 & 1,164 & $47.2 \%$ & 682 & $37.2 \%$ \\
$55 \%$ & 41,250 & 1,255 & $50.9 \%$ & 762 & $41.6 \%$ \\
$60 \%$ & 45,000 & 1,355 & $55.0 \%$ & 851 & $46.4 \%$ \\
$65 \%$ & 48,750 & 1,463 & $59.4 \%$ & 947 & $51.6 \%$ \\
$70 \%$ & 52,500 & 1,580 & $64.1 \%$ & 1,051 & $57.3 \%$ \\
$75 \%$ & 56,250 & 1,706 & $69.2 \%$ & 1,162 & $63.4 \%$ \\
$80 \%$ & 60,000 & 1,840 & $74.7 \%$ & 1,281 & $69.9 \%$ \\
$85 \%$ & 63,750 & 1,983 & $80.5 \%$ & 1,408 & $76.8 \%$ \\
$90 \%$ & 67,500 & 2,135 & $86.6 \%$ & 1,542 & $84.1 \%$ \\
$95 \%$ & 71,250 & 2,295 & $93.1 \%$ & 1,684 & $91.8 \%$ \\
$100 \%$ & 75,000 & 2,464 & $100.0 \%$ & 1,834 & $100.0 \%$ \\
\hline
\end{tabular}




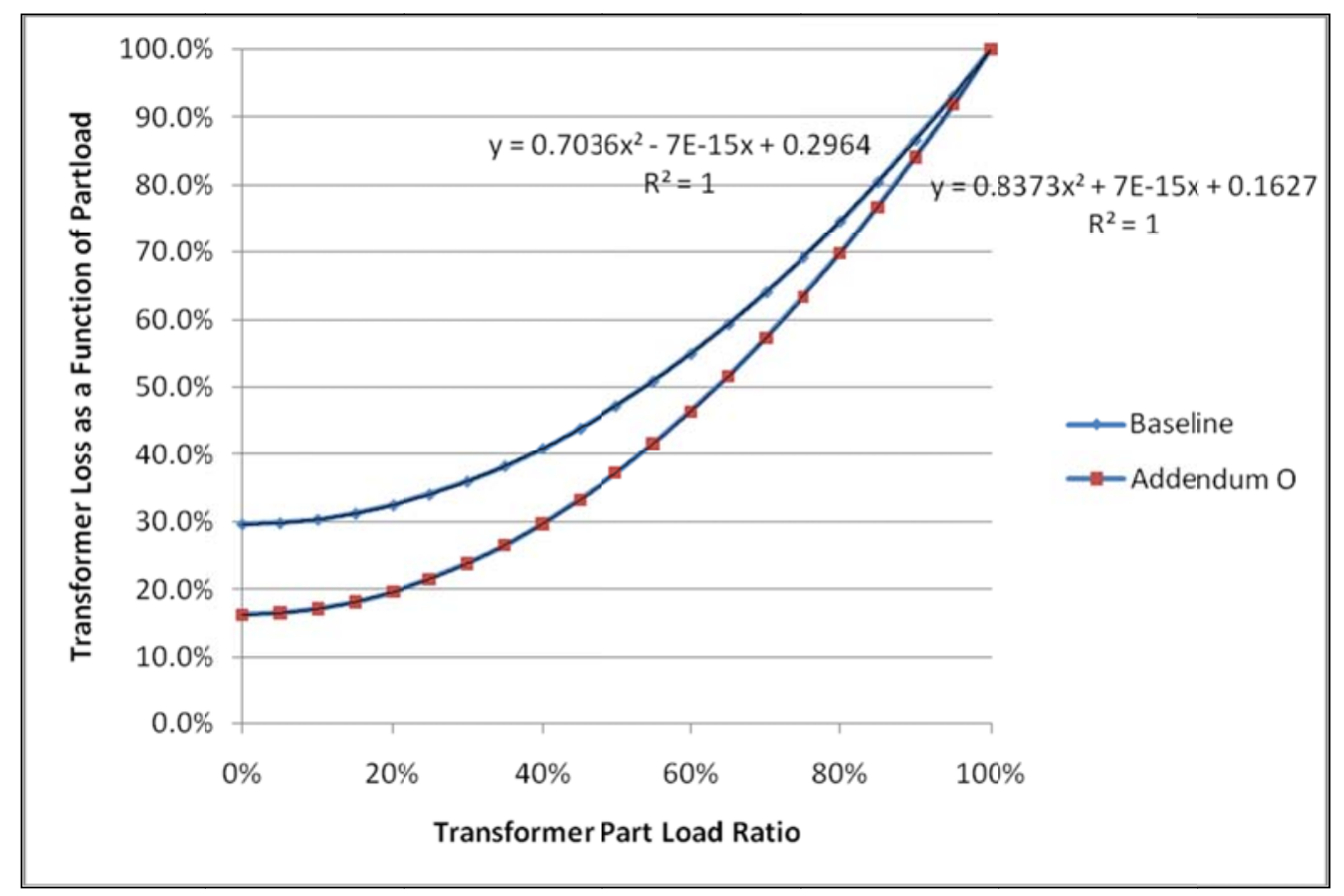

Figure 5.5. Transformer Loss Curves as a Function of Part Load

\subsubsection{Addendum 90.1-07bs: Plug Receptacle Control}

Chapter 8 in 90.1-2004 and 2007 regulates power equipment and only includes mandatory requirements for voltage drops in wiring. Addendum 90.1-07bs adds a requirement (Section 8.4.2) for automatic receptacle control. The addendum requires at least $50 \%$ of the 120 - to $125-\mathrm{V}$ receptacles in an enclosed space be controlled using a schedule or a signal from a control system based on occupancy and requires these receptacles to be switched off during unoccupied periods. Addendum $90.1-07 \mathrm{bs}$ is further modified by addendum $90.1-07 \mathrm{cs}$, which limits the application of this addendum to private offices, open offices, and computer classrooms. Addendum $90.1-07 \mathrm{cs}$ is included in Table 5.3 in this report with the addenda that do not add to savings.

The $\mathrm{NC}^{3}$ database (Richman et al. 2008) is used for the preliminary assessment of the amount of open office, private office, and computer classroom areas for each prototype building. As shown in Table 5.32, the $\mathrm{NC}^{3}$ database shows that each prototype building type has some percentage of open or private offices or both. For prototype models without separate private and open office zones and separate office/classroom equipment schedules defined in the model, area fractions determined from the $\mathrm{NC}^{3}$ data are used. The mid-rise and high-rise apartment and small hotel prototypes are not shown in the table because office equipment usage is separated out with its own office zone and plug equipment operating schedule. The $\mathrm{NC}^{3}$ data also does not include classroom area for these three building types. Computer classroom area for the primary and secondary schools are not specifically separated out in the $\mathrm{NC}^{3}$ data from other classrooms. The area fraction for computer classrooms is determined by using the area of the computer classroom zones in the prototype models. 
Table 5.32. Open and Private Office Area as Percentage of Total Building Area

\begin{tabular}{lcc}
\hline \multirow{2}{*}{\multicolumn{1}{c}{ Prototype }} & Open Office & Private Office \\
\cline { 2 - 3 } & Percentage of Total Building Area \\
\hline Small Office & $18.5 \%$ & $19.8 \%$ \\
Medium Office & $42.3 \%$ & $18.6 \%$ \\
Large Office & $72.9 \%$ & $2.5 \%$ \\
Standalone Retail & $0.6 \%$ & $1.7 \%$ \\
Strip Mall & $0.6 \%$ & $1.7 \%$ \\
Primary School & $0.5 \%$ & $3.0 \%$ \\
Secondary School & $1.2 \%$ & $5.3 \%$ \\
Outpatient Healthcare & $7.3 \%$ & $13.0 \%$ \\
Hospital & $0.9 \%$ & $5.3 \%$ \\
Large Hotel & $0.7 \%$ & $1.1 \%$ \\
Warehouse & $1.3 \%$ & $0.8 \%$ \\
Quick-service Restaurant & $0.6 \%$ & $1.3 \%$ \\
Full-service Restaurant & $0.1 \%$ & $1.1 \%$ \\
\hline
\end{tabular}

This addendum is implemented by modifying the building plug load equipment schedules based on area weighting fractions for each of the three applicable space types to estimate savings from this addendum. A conservative estimate of potential savings from using occupancy sensors during occupied hours for the three space types is selected from the lower quadrant of various industry estimates summarized in IES paper 43 (VonNeida et al. 2000). These estimates are for occupancy sensor control of lighting believed to be a reasonable proxy for plug load control savings potential since the savings are based on amount of time the spaces are unoccupied. Table 5.33 shows these fractions for each applicable space type.

Table 5.33. Savings from Occupancy Sensors During Occupied hours

\begin{tabular}{lc}
\hline \multicolumn{1}{c}{ Area } & $\begin{array}{c}\text { Savings During } \\
\text { Occupied Hours }\end{array}$ \\
\hline Private Offices & $22 \%$ \\
Open Offices & $21 \%$ \\
Computer Classrooms & $32 \%$ \\
\hline
\end{tabular}

Not all loads in an office can be unplugged when not in use. Therefore, a load fraction for the proportion of the load that can be unplugged is estimated from the plug load equipment inventory reported in two PNNL reports on approaches to achieve 50\% energy savings in small and medium offices (Thornton et al. 2009, 2010). The PI analysis makes assumptions about which items in the inventory can be assumed to be controlled by the occupancy-based control system. For the small office prototype, Table 5.34 shows the plug load equipment inventory and identifies which loads can be controlled and the total fraction of the plug load power that can be controlled, i.e., $45 \%$. 
Table 5.34. Plug Load Equipment Breakdown for Small Office Prototype

\begin{tabular}{|c|c|c|c|c|}
\hline Plug Load Equipment Inventory & $\begin{array}{c}\text { Can Be } \\
\text { Controlled }\end{array}$ & Qty. & $\begin{array}{l}\text { Plug Load Per } \\
\text { Unit (W/unit) }\end{array}$ & $\begin{array}{l}\text { Plug } \\
\text { Load } \\
\text { (W) }\end{array}$ \\
\hline Computers - servers & No & 2 & 65 & 130 \\
\hline Computers - desktop & No & 44 & 65 & 2,860 \\
\hline Computers - laptop & No & 44 & 19 & 836 \\
\hline Monitors - server - liquid crystal display & Yes & 2 & 35 & 70 \\
\hline Monitors - desktop - liquid crystal display & Yes & 88 & 35 & 3,080 \\
\hline Laser Printer - network & Yes & 2 & 215 & 430 \\
\hline Copy Machine & Yes & 2 & 1,100 & 2,200 \\
\hline Fax Machine & Yes & 2 & 35 & 70 \\
\hline Water Cooler & No & 2 & 350 & 700 \\
\hline Refrigerator, $18 \mathrm{ft}^{3}$ side mount freezer, through-door ice & No & 2 & 76 & 152 \\
\hline Vending machine, $18 \mathrm{ft}^{3}$ & No & 2 & 770 & 1,540 \\
\hline Coffee Maker & No & 2 & 1,050 & 2,100 \\
\hline Portable HVAC (heaters, fans) & Yes & 18 & 30 & 540 \\
\hline Other Small Appliances, Chargers, Network Components & Yes & 88 & 4 & 352 \\
\hline Total Plug Load (W) & & & & 15,060 \\
\hline Plug Load That Can Be Controlled (W) & & & & 6,742 \\
\hline Percentage that can be controlled & & & & $45 \%$ \\
\hline
\end{tabular}

The building equipment operating schedules are then modified to approximate savings from reduced equipment "on" hours from this addendum. The fraction in the schedule that plug equipment is on during occupied hours is reduced by the sum of the savings percentage for each space type identified as having savings (open office, private office, and classroom) multiplied by the proportion of building area that is associated with the corresponding space type. For zones defined as $100 \%$ a particular space type, for example, open office, the savings reduction is just the savings estimate percentage for that space type. For unoccupied hours, the space type area percentage is still used if applicable and the savings percentage is assumed to be $100 \%$. Table 5.35 provides an example of the development of these calculated schedule fraction reductions for the primary school. For example, if the occupied equipment schedule fraction is 0.95 during occupied hours in the baseline, the schedule fraction in the 90.1-2010 model is 0.936 .

Table 5.35. Primary School Prototype Example of Receptacle Control Schedule Reduction

\begin{tabular}{|c|c|c|c|c|c|c|c|}
\hline & \multirow{2}{*}{$\begin{array}{c}\text { Open } \\
\text { Office } \\
\text { Area } \\
\text { Fraction }\end{array}$} & \multirow{2}{*}{$\begin{array}{l}\text { Private } \\
\text { Office } \\
\text { Area } \\
\text { Fraction } \\
\end{array}$} & \multirow{2}{*}{$\begin{array}{c}\text { Computer } \\
\text { Classroom } \\
\text { Area Fraction }\end{array}$} & \multicolumn{3}{|c|}{ Occupancy Sensor Savings Estimate } & \multirow{2}{*}{$\begin{array}{c}\text { Reduction } \\
\text { to Plug } \\
\text { Loads } \\
\text { Schedule }\end{array}$} \\
\hline & & & & $\begin{array}{l}\text { Open } \\
\text { Office }\end{array}$ & $\begin{array}{l}\text { Private } \\
\text { Office }\end{array}$ & Classroom & \\
\hline$\overline{\text { Occupied Hours }}$ & $0.50 \%$ & $3.00 \%$ & $2.36 \%$ & $21 \%$ & $22 \%$ & $32 \%$ & $1.5 \%$ \\
\hline Unoccupied Hours & $0.50 \%$ & $3.00 \%$ & $2.36 \%$ & $100 \%$ & $100 \%$ & $100 \%$ & $5.9 \%$ \\
\hline
\end{tabular}




\subsubsection{Lighting}

90.1-2010 incorporates major changes that reduce lighting energy usage. For the first time, addenda introduce rules that require access to daylight and daylighting controls. Changes also include extensive updates to both interior and exterior basic lighting power allowances. Finally, significant controls requirements are added or changed for both interior and exterior lighting.

\subsubsection{Addenda 90.1-07d, ab, al, and dd: Daylighting and Skylights}

90.1-2004 and 90.1-2007, Chapter 9, "Lighting," and Chapter 5, "Building Envelope," do not specify requirements related to the minimum skylight fenestration area, minimum daylight area, or automatic dimming control of light fixtures in daylit areas. Addenda d, ab, al, and dd represent a series of revisions to 90.1-2007 that establish minimum requirements for skylight fenestration area, daylight area, and automatic dimming control. In 90.1-2007, Sections 5.5.4.2.2, 5.5.4.2.3, 9.4.1.3, and 9.4.1.4 were added and revised by these addenda. In this report these addenda are addressed with lighting because the energy savings for these addenda come from the lighting controls that are applied. Adding skylights without lighting controls will generally increase energy usage. The addition or revision made by each addendum is explained below, along with the final implementation of these addenda into the 16 prototype buildings.

The first addendum to add a requirement for daylighting in Standard 90.1 is addendum 90.1-07d. This addendum adds Section 9.4.1.4, which requires automatic dimming control in spaces where the combined daylit area under skylights exceeds 5,000 $\mathrm{ft}^{2}$. Addendum 90.1-07ab, which was drafted after addendum 90.1-07d, modifies Section 9.4.1.4 by reducing the minimum required combined daylit area under skylights to 4,000 $\mathrm{ft}^{2}$ from 5,000 $\mathrm{ft}^{2}$. Addendum ab also introduces automatic dimming controls for sidelit spaces, where the combined primary sidelit area exceeds $1,000 \mathrm{ft}^{2}$. This sidelighting requirement under addendum ab is described in Section 5.2.4.10 (addendum 90.1-07ct) of this report.

Addendum 90.1-07al, drafted after addenda 90.1-07d and 90.1-07ab, introduces a requirement for spaces greater than $10,000 \mathrm{ft}^{2}$ to provide a minimum daylit area equal to half the total floor area. Addendum al requirements are added under Sections 5.5.4.2.2 and 5.5.4.2.3 of 90.1-2007. Thus, daylighting control requirements are added by addenda 90.1-07d and ab, whereas skylight and daylight area requirements are added by addendum al.

Addendum 90.1-07dd modifies the requirements of both addenda 90.1-07ab and 90.1-07al. The minimum daylit area threshold, established by addendum ab through Section 9.4.1.4, is reduced from $4,000 \mathrm{ft}^{2}$ to $900 \mathrm{ft}^{2}$. Therefore, automatic dimming controls are now required in daylit areas greater than $900 \mathrm{ft}^{2}$. The minimum enclosed area threshold, established by addendum al through Sections 5.5.4.2.2 and 5.5.4.2.3, is reduced from $10,000 \mathrm{ft}^{2}$ to $5,000 \mathrm{ft}^{2}$. Therefore, spaces greater than $5,000 \mathrm{ft}^{2}$ are now required to have skylights.

The final requirements related to minimum skylight fenestration area and automatic dimming controls can be summarized as follows:

- Maximum Skylight Fenestration Area (Section 5.5.4.2.2): The total skylight area must not exceed $5 \%$ of the gross roof area.

- Minimum Skylight Fenestration Area (Section 5.5.4.2.3): In any enclosed space directly under a roof with a ceiling height greater than 15 feet, the total daylight area under skylights must be a 
minimum of half the floor area. Additionally, the minimum skylight area to daylight area ratio must be greater than $3 \%$ with a skylight visible light transmittance of at least 0.4 . Buildings in climate zones 6 through 8 are exempted from these requirements. Spaces with general lighting power densities less than $0.5 \mathrm{~W} / \mathrm{ft}^{2}$ are also exempted. See $90.1-2010$ for other exceptions that are not applicable to the prototype buildings.

- Automatic Daylighting Controls for Toplighting (Section 9.4.1.4): Lamps for general lighting over the daylit area must be separately controlled by multi-level photocontrol devices when the total daylit area under skylights exceeds $900 \mathrm{ft}^{2}$. Additionally, the multi-level photocontrol must be capable of lowering the design lighting power to at least $35 \%$, with one intermediate step between $50 \%$ and $70 \%$. Buildings in climate zone 8 with daylight areas less than $1,500 \mathrm{ft}^{2}$ are exempted. See Standard 90.1-2010 for other exceptions that are not applicable to the prototype buildings.

\section{Implementation of Skylight Fenestration Area and Daylight Area}

90.1-2010 Section 5.5.4.2.3 is used to identify spaces in the prototype buildings that are required to have daylit areas from skylights. Table 5.36 shows implementation of skylights into Standard 90.1 prototypes meeting the requirements of Section 5.5.4.2.3 for addendum dd. Details of skylight and daylight areas and their applicability in different climate zones are also shown in Table 5.36.

In the two school prototypes, existing baseline modeled skylights in gymnasiums and multipurpose rooms are providing daylighting to the entire space areas. Therefore, skylights are not added to the 90.12010 cases for the primary and secondary school prototypes.

A study of buildings from the $\mathrm{NC}^{3}$ and CBECS datasets revealed that the warehouse prototype's bulk storage space and the standalone retail prototype's core retail space are likely to have skylights. Therefore, skylights were added to the baseline of these two buildings with the skylight area determined from $\mathrm{NC}^{3}$ data and from the requirements of Section 5.5.4.2.3. The $\mathrm{NC}^{3}$ database showed that fine storage spaces in warehouses are not typically daylit. Therefore, the warehouse baseline does not have skylights in the fine storage space.

Skylight U-factors and SHGC values are consistent with those from Tables 5.5.1 through Table 5.5.8 of Chapter 5 in Standard 90.1. Skylights are considered to have curbs and to be made of glass. In some climate zones, the allowed assembly U-factor is above $1 \mathrm{Btu} / \mathrm{hr}-\mathrm{ft}^{2}-\mathrm{F}$ which is due to the high $\mathrm{u}$-factor of the curbs. Since curbs are not modeled in the prototype skylights, frames are added instead as an approximation with width and U-factor sufficient to raise the overall skylight assembly u-factor are combined the glazing U-factor to the required value.

\section{Implementation of Daylighting Control}

Addendum 90.1-07dd, Section 9.4.1.4, is modeled by adding automatic, stepped dimming controls to the 90.1-2010 models in spaces with daylight areas larger than $900 \mathrm{ft}^{2}$. Two sensors are assigned to each daylight area in a space, each controlling half the daylight area. Sensors are placed such that savings from the control of lighting in the daylit area captures representative areas of expected illuminance levels. 
Table 5.36. Skylight Fenestration Areas and Daylit Areas in Prototype Buildings

\begin{tabular}{|c|c|c|c|c|c|c|c|c|}
\hline Prototype/Space & $\begin{array}{c}\text { Area } \\
\left(\mathrm{ft}^{2}\right)\end{array}$ & $\begin{array}{l}\text { Ceiling } \\
\text { Height } \\
\text { (ft) }\end{array}$ & $\begin{array}{c}\text { Minimum } \\
\text { Required } \\
\text { Daylit } \\
\text { Area } \\
\left(\mathrm{ft}^{2}\right)\end{array}$ & $\begin{array}{c}\text { Actual } \\
\text { Daylit } \\
\text { Area } \\
\left(\mathrm{ft}^{2}\right)\end{array}$ & $\begin{array}{c}\text { Baseline } \\
\text { Skylight } \\
\text { Area } \\
\left(\mathrm{ft}^{2}\right)\end{array}$ & $\begin{array}{c}\text { PI } \\
\text { Skylight } \\
\text { Area } \\
\left(\mathrm{ft}^{2}\right)\end{array}$ & $\begin{array}{c}\text { PI Skylight } \\
\text { Area to } \\
\text { Daylight } \\
\text { Area Ratio }\end{array}$ & $\begin{array}{l}\text { Applied } \\
\text { to } \\
\text { Climate } \\
\text { Zones } \\
\end{array}$ \\
\hline \multicolumn{9}{|l|}{ Primary School } \\
\hline $\begin{array}{l}\text { Multipurpose } \\
\text { Room }\end{array}$ & 3,843 & 13 & - & 3,843 & 144 & 144 & $4 \%$ & $1-8$ \\
\hline \multicolumn{9}{|l|}{ Secondary School } \\
\hline Gymnasium & 21,269 & 26 & 10,635 & 21,269 & 864 & 864 & $4 \%$ & $1-8$ \\
\hline $\begin{array}{l}\text { Auxiliary } \\
\text { Gymnasium }\end{array}$ & 13,433 & 26 & 6,717 & 13,433 & 576 & 576 & $4 \%$ & $1-8$ \\
\hline \multicolumn{9}{|l|}{ Warehouse } \\
\hline Bulk Storage & 34,497 & 28 & 17,248 & 17,248 & 160 & 512 & $3 \%$ & $1-5$ \\
\hline Fine Storage & 15,000 & 28 & 7,500 & 7,500 & 0 & 220 & $3 \%$ & $1-5$ \\
\hline \multicolumn{9}{|l|}{ Standalone Retail } \\
\hline Core Retail & 17,227 & 20 & 8,614 & 8,614 & 72 & 256 & $3 \%$ & $1-5$ \\
\hline
\end{tabular}

Table 5.37 shows details of the daylighting dimming controls implemented in Standard 90.1 prototypes. The fraction of zone controlled depends on the ratio of daylight area to floor area. The target illuminance levels are based on common and recommended indoor light levels from IESA. The dimming controls can lower the peak lighting power in two steps of $33 \%$ each $(66 \%, 33 \%)$ in response to daylight illuminance levels.

Table 5.37. Automatic Daylighting Controls for Toplit Spaces in Standard 90.1 Prototypes

\begin{tabular}{|c|c|c|c|c|c|c|c|c|}
\hline Prototype/Space & $\begin{array}{c}\text { Area } \\
\left(\mathrm{ft}^{2}\right)\end{array}$ & $\begin{array}{c}\text { Actual } \\
\text { Daylit } \\
\text { Area } \\
\left(\mathrm{ft}^{2}\right)\end{array}$ & $\begin{array}{l}\text { Daylit } \\
\text { Area to } \\
\text { Zone } \\
\text { Area } \\
\text { Ratio }\end{array}$ & $\begin{array}{l}\text { Fraction of } \\
\text { Zone Area } \\
\text { Controlled by } \\
\text { Automatic } \\
\text { Dimming } \\
\text { Devices }\end{array}$ & $\begin{array}{c}\text { Sensors } \\
\text { (no.) }\end{array}$ & $\begin{array}{l}\text { Target } \\
\text { Illumi- } \\
\text { nance } \\
\text { (lux) }\end{array}$ & $\begin{array}{c}\text { Control } \\
\text { Type }\end{array}$ & $\begin{array}{l}\text { Applied to } \\
\text { Climate } \\
\text { Zones }\end{array}$ \\
\hline \multicolumn{9}{|l|}{ Primary School } \\
\hline $\begin{array}{l}\text { Multipurpose } \\
\text { Room }\end{array}$ & 3,843 & 3,843 & $100 \%$ & $100 \%$ & 2 & 500 & 3-step & $1-8$ \\
\hline \multicolumn{9}{|l|}{ Secondary School } \\
\hline Gymnasium & 21,269 & 21,269 & $100 \%$ & $100 \%$ & 2 & 500 & 3-step & $1-8$ \\
\hline $\begin{array}{l}\text { Auxiliary } \\
\text { Gymnasium }\end{array}$ & 13,433 & 13,433 & $100 \%$ & $100 \%$ & 2 & 500 & 3-step & $1-8$ \\
\hline \multicolumn{9}{|l|}{ Warehouse } \\
\hline Bulk Storage & 34,497 & 17,248 & $50 \%$ & $50 \%$ & 2 & 200 & 3-step & $1-5$ \\
\hline Fine Storage & 15,000 & 7,500 & $50 \%$ & $50 \%$ & 2 & 300 & 3-step & $1-5$ \\
\hline \multicolumn{9}{|l|}{ Standalone Retail } \\
\hline Core Retail & 17,227 & 8,614 & $50 \%$ & $50 \%$ & 2 & 200 & 3-step & $1-5$ \\
\hline
\end{tabular}




\subsubsection{Addenda 90.1-07i: Exterior Lighting}

Both 90.1-2004 and 90.1-2007 include the same lighting power limits for various exterior applications. These limits were developed based on the amount of light needed to illuminate the various applications in typical conditions. Since these limits were developed, additional lighting industry work has been done on the amount of illumination needed in various exterior environments. This work is based on the realization that contrast with the lighted surroundings is a critical lighted environment criterion and areas with less ambient light such as rural areas require less produced light. Similarly, areas with higher ambient light levels, such as city centers, require more illumination for contrast and eye adaptation.

Addendum 90.1-07i applies four exterior lighting zones to buildings with exterior lighting as shown in Table 5.38 (reproduced from 90.1-2010, Table 9.4.3A). The addendum provides exterior lighting power requirements that vary for the four exterior lighting zone types. This approach recognizes the varying lighting needs and design differences associated with different building locations. Lighting power limits are highest in downtown city centers and then are reduced in mixed commercial/high-rise residential districts, then in residential areas, and finally in rural areas. Several organizations, including the IESNA, have been working to develop a zonal approach to exterior lighting recommended practice. This change in the standard will follow that guidance. Most building sites fall into lighting zones 2, 3, or 4 , and the sites that remain in lighting zone 1 will generally be relatively small.

Table 5.38. Exterior Lighting Zones

\begin{tabular}{|c|c|}
\hline $\begin{array}{l}\text { Lighting } \\
\text { Zone }\end{array}$ & Description \\
\hline 1 & Developed areas of national parks, state parks, forest land, and rural areas \\
\hline 2 & $\begin{array}{l}\text { Areas predominantly consisting of residential zoning, neighborhood business districts, light industrial } \\
\text { with limited nighttime use and residential mixed use areas }\end{array}$ \\
\hline 3 & All other areas \\
\hline 4 & High activity commercial districts in major metropolitan areas as designated by the local jurisdiction \\
\hline
\end{tabular}

The first change in the existing exterior building lighting power section in the 90.1-2004 is the deletion of the $5 \%$ additional power allowance, which is replaced by a base wattage allowance per site. The added "Base Site Allowance" for each zone takes into account that most sites are not rectangular or do not match the iso-diagram of typical light luminaires. The new exterior lighting power allowances, including these changes and the 90.1-2004 baseline, are shown in Table 5.39.

The analysis for this addendum is built on the analysis done for the original exterior lighting addendum to 90.1-2001 which led to 90.1-2004. That addendum initially introduced the expanded exterior lighting requirements table. This earlier analysis provides estimates of exterior lighting applications in terms of areas (i.e., parking lots) and/or counts (i.e., entrance doors) that are applied to the appropriate lighting allowance from the standard to calculate a power total for the building. This method is not complete because that area or count data are not available for some applications, so some potential savings are not counted. However, the larger applications that are expected to account for the majority of exterior lighting energy use are represented and include parking lots, facades, and doors. The result of the estimate of these exterior lighting applications is included in Section 4.7.2 and Tables 4.17 through 4.19 of this report. Other applications, such as landscaping and sales lots, are expected to account for significant exterior lighting portions in some limited building types but overall will account for a small 
percentage of the national building mix total. This approach is considered to cover the majority of applications and is therefore considered to be conservative.

Each prototype is assigned to one or a mix of exterior lighting zones from Table 5.38 based on judgment about where the prototype is commonly found. Table 5.40 shows these zone assignments. These zone assignments are then used to identify the new power limit for the various applications in the analysis. The calculation of savings is a direct comparison of the estimate of exterior lighting use under Standard 90.1-2004 (applying 2004 power limits) and the expected use under 90.1-2010 (using the zone based power limits for individual or averaged zones), as shown in Table 5.41. The exterior lighting wattage inputs are changed in the prototype models to reflect the differences. 
Table 5.39. Exterior Lighting Power Allowances

\begin{tabular}{|c|c|c|c|c|c|c|}
\hline & & \multirow{2}{*}{$\begin{array}{l}\text { 90.1-2004 } \\
\text { All Zones (zones not } \\
\text { defined in 90.1-2004) }\end{array}$} & \multicolumn{4}{|c|}{ 90.1-2010 } \\
\hline & & & Zone 1 & Zone 2 & Zone 3 & Zone 4 \\
\hline $\begin{array}{l}\text { Base Site Allowance } \\
\text { (2010 base allowance } \\
\text { may be used in } \\
\text { tradable or non- } \\
\text { tradable surfaces) }\end{array}$ & & $\begin{array}{c}5 \% \text { Additional } \\
\text { Allowance for } \\
\text { Tradable Surfaces } \\
\text { Wattage }\end{array}$ & $500 \mathrm{~W}$ & $600 \mathrm{~W}$ & $750 \mathrm{~W}$ & $1300 \mathrm{~W}$ \\
\hline \multirow{11}{*}{$\begin{array}{l}\text { Tradable Surfaces } \\
\text { (Lighting power } \\
\text { densities for } \\
\text { uncovered parking } \\
\text { areas, building } \\
\text { grounds, building } \\
\text { entrances and exits, } \\
\text { canopies and } \\
\text { overhangs and } \\
\text { outdoor sales areas } \\
\text { may be traded.) }\end{array}$} & \multicolumn{6}{|l|}{ Uncovered Parking Areas } \\
\hline & $\begin{array}{r}\text { Walkways less than } 10 \\
\text { feet wide }\end{array}$ & $1.0 \mathrm{~W} /$ linear foot & $0.7 \mathrm{~W} /$ linear foot & $0.7 \mathrm{~W} /$ linear foot & $0.8 \mathrm{~W} /$ linear foot & $1.0 \mathrm{~W} /$ linear foot \\
\hline & $\begin{array}{r}\begin{array}{r}\text { Walkways } 10 \text { feet wide or } \\
\text { greater }\end{array} \\
\end{array}$ & $02 \mathrm{w} / \mathrm{ft}^{2}$ & $014 \mathrm{~W} / \mathrm{ft}^{2}$ & $014 \mathrm{w} / \mathrm{ft}^{2}$ & $016 \mathrm{~W} / \mathrm{ft}^{2}$ & $020 \mathrm{w} / \mathrm{ft}^{2}$ \\
\hline & $\begin{array}{r}\text { Plaza areas } \\
\text { Special Feature Areas }\end{array}$ & $0.2 \mathrm{~W} / \mathrm{tt}^{-}$ & $0.14 \mathrm{~W} / \mathrm{ft}^{-2}$ & $0.14 \mathrm{~W} / \mathrm{ft}^{-2}$ & $0.16 \mathrm{~W} / \mathrm{ft}^{-2}$ & $0.20 \mathrm{~W} / \mathrm{ft}^{-2}$ \\
\hline & Stairways & $1.0 \mathrm{~W} / \mathrm{ft}^{2}$ & $0.75 \mathrm{~W} / \mathrm{ft}^{2}$ & $1.0 \mathrm{~W} / \mathrm{ft}^{2}$ & $1.0 \mathrm{~W} / \mathrm{ft}^{2}$ & $1.0 \mathrm{~W} / \mathrm{ft}^{2}$ \\
\hline & Other doors & $\begin{array}{l}20 \mathrm{~W} / \text { linear foot of } \\
\text { door width }\end{array}$ & $\begin{array}{l}20 \mathrm{~W} / \text { linear foot } \\
\text { of door width }\end{array}$ & $\begin{array}{l}20 \mathrm{~W} / \text { linear foot } \\
\text { of door width }\end{array}$ & $\begin{array}{l}20 \mathrm{~W} / \text { linear foot } \\
\text { of door width }\end{array}$ & $\begin{array}{l}20 \mathrm{~W} / \text { linear foot } \\
\text { of door width }\end{array}$ \\
\hline & Entry Canopies & $\begin{array}{c}1.25 \mathrm{~W} / \mathrm{ft}^{2} \text { (also } \\
\text { applies to overhangs } \\
\text { under Canopies and } \\
\text { Overhangs) }\end{array}$ & $0.25 \mathrm{~W} / \mathrm{ft}^{2}$ & $0.25 \mathrm{~W} / \mathrm{ft}^{2}$ & $0.40 \mathrm{~W} / \mathrm{ft}^{2}$ & $0.40 \mathrm{~W} / \mathrm{ft}^{2}$ \\
\hline & \multicolumn{6}{|l|}{ Sales Canopies } \\
\hline & free standing and attached & $\begin{array}{l}1.25 \mathrm{~W} / \mathrm{ft}^{2} \text { (not } \\
\text { explicitly listed) }\end{array}$ & $0.6 \mathrm{~W} / \mathrm{ft}^{2}$ & $0.6 \mathrm{~W} / \mathrm{ft}^{2}$ & $0.8 \mathrm{~W} / \mathrm{ft}^{2}$ & $1.0 \mathrm{~W} / \mathrm{ft}^{2}$ \\
\hline & \multicolumn{6}{|l|}{ Outdoor Sales } \\
\hline & $\begin{array}{l}\text { Open areas (including } \\
\text { vehicle sales lots) }\end{array}$ & $0.5 \mathrm{~W} / \mathrm{ft}^{2}$ & $0.25 \mathrm{~W} / \mathrm{ft}^{2}$ & $0.25 \mathrm{~W} / \mathrm{ft}^{2}$ & $0.5 \mathrm{~W} / \mathrm{ft}^{2}$ & $0.7 \mathrm{~W} / \mathrm{ft}^{2}$ \\
\hline
\end{tabular}




\begin{tabular}{|c|c|c|c|c|c|c|}
\hline & & \multirow{2}{*}{$\begin{array}{l}\text { 90.1-2004 } \\
\text { All Zones (zones not } \\
\text { defined in 90.1-2004) }\end{array}$} & \multicolumn{4}{|c|}{$90.1-2010$} \\
\hline & & & Zone 1 & Zone 2 & Zone 3 & Zone 4 \\
\hline & $\begin{array}{l}\text { Street frontage for vehicle } \\
\text { sales lots in addition to } \\
\text { "open area" allowance }\end{array}$ & $20 \mathrm{~W} /$ linear foot & No allowance & $10 \mathrm{~W} /$ linear foot & $10 \mathrm{~W} /$ linear foot & $30 \mathrm{~W} /$ linear foot \\
\hline \multirow{6}{*}{$\begin{array}{c}\text { Non-Tradable } \\
\text { Surfaces (Lighting } \\
\text { power density } \\
\text { calculations for the } \\
\text { following } \\
\text { applications can be } \\
\text { used only for the } \\
\text { specific application } \\
\text { and can-not be traded } \\
\text { between surfaces or } \\
\text { with other exterior } \\
\text { lighting. The } \\
\text { following allowances } \\
\text { are in addition to any } \\
\text { allowance otherwise } \\
\text { permitted in the } \\
\text { "tradable Surfaces" } \\
\text { section of this table.) }\end{array}$} & Building Facades & $\begin{array}{l}0.2 \mathrm{~W} / \mathrm{ft}^{2} \text { for each } \\
\text { illuminated wall or } \\
\text { surface or } 5.0 \\
\mathrm{~W} / \text { linear foot for each } \\
\text { illuminated wall or } \\
\text { surface length }\end{array}$ & No allowance & $\begin{array}{c}0.1 \mathrm{~W} / \mathrm{ft}^{2} \text { for } \\
\text { each illuminated } \\
\text { wall or surface } \\
\text { or } 2.5 \mathrm{~W} / \text { linear } \\
\text { foot for each } \\
\text { illuminated wall } \\
\text { or surface length }\end{array}$ & $\begin{array}{l}0.15 \mathrm{~W} / \mathrm{ft}^{2} \text { for } \\
\text { each illuminated } \\
\text { wall or surface } \\
\text { or } 3.75 \mathrm{~W} / \text { linear } \\
\text { foot for each } \\
\text { illuminated wall } \\
\text { or surface length }\end{array}$ & $\begin{array}{c}0.2 \mathrm{~W} / \mathrm{ft}^{2} \text { for } \\
\text { each illuminated } \\
\text { wall or surface } \\
\text { or } 5.0 \mathrm{~W} / \text { linear } \\
\text { foot for each } \\
\text { illuminated wall } \\
\text { or surface length }\end{array}$ \\
\hline & $\begin{array}{l}\text { Automated teller } \\
\text { machines and night } \\
\text { depositories }\end{array}$ & $\begin{array}{c}270 \mathrm{~W} \text { per location } \\
\text { plus } 90 \mathrm{~W} \text { per } \\
\text { additional ATM per } \\
\text { location }\end{array}$ & $\begin{array}{c}270 \mathrm{~W} \text { per } \\
\text { location plus } 90 \\
\text { W per additional } \\
\text { ATM per } \\
\text { location }\end{array}$ & $\begin{array}{c}270 \mathrm{~W} \text { per } \\
\text { location plus } 90 \\
\mathrm{~W} \text { per additional } \\
\text { ATM per } \\
\text { location }\end{array}$ & $\begin{array}{c}270 \mathrm{~W} \text { per } \\
\text { location plus } 90 \\
\text { W per additional } \\
\text { ATM per } \\
\text { location }\end{array}$ & $\begin{array}{c}270 \mathrm{~W} \text { per } \\
\text { location plus } 90 \\
\mathrm{~W} \text { per additional } \\
\text { ATM per } \\
\text { location }\end{array}$ \\
\hline & $\begin{array}{l}\text { Entrances and gatehouse } \\
\text { inspection stations at } \\
\text { guarded facilities }\end{array}$ & $\begin{array}{c}1.25 \mathrm{~W} / \mathrm{ft}^{2} \text { of } \\
\text { uncovered area } \\
\text { (covered areas } \\
\text { included with } \\
\text { Canopies and } \\
\text { Overhangs) }\end{array}$ & $\begin{array}{l}1.25 \mathrm{~W} / \mathrm{ft}^{2} \text { of } \\
\text { uncovered area } \\
\text { (covered areas } \\
\text { included with } \\
\text { Canopies and } \\
\text { Overhangs) }\end{array}$ & $\begin{array}{l}1.25 \mathrm{~W} / \mathrm{ft}^{2} \text { of } \\
\text { uncovered area } \\
\text { (covered areas } \\
\text { included with } \\
\text { Canopies and } \\
\text { Overhangs) }\end{array}$ & $\begin{array}{l}1.25 \mathrm{~W} / \mathrm{ft}^{2} \text { of } \\
\text { uncovered area } \\
\text { (covered areas } \\
\text { included with } \\
\text { Canopies and } \\
\text { Overhangs) }\end{array}$ & $\begin{array}{l}1.25 \mathrm{~W} / \mathrm{ft}^{2} \text { of } \\
\text { uncovered area } \\
\text { (covered areas } \\
\text { included with } \\
\text { Canopies and } \\
\text { Overhangs) }\end{array}$ \\
\hline & $\begin{array}{l}\text { Loading areas for law } \\
\text { enforcement, fire, } \\
\text { ambulance and other } \\
\text { emergency service } \\
\text { vehicles }\end{array}$ & $\begin{array}{c}0.5 \mathrm{~W} / \mathrm{ft}^{2} \text { of } \\
\text { uncovered areas } \\
\text { (covered areas } \\
\text { included with } \\
\text { Canopies and } \\
\text { Overhangs) }\end{array}$ & $\begin{array}{l}0.5 \mathrm{~W} / \mathrm{ft}^{2} \text { of } \\
\text { uncovered areas } \\
\text { (covered areas } \\
\text { included with } \\
\text { Canopies and } \\
\text { Overhangs) }\end{array}$ & $\begin{array}{l}0.5 \mathrm{~W} / \mathrm{ft}^{2} \text { of } \\
\text { uncovered areas } \\
\text { (covered areas } \\
\text { included with } \\
\text { Canopies and } \\
\text { Overhangs) }\end{array}$ & $\begin{array}{l}0.5 \mathrm{~W} / \mathrm{ft}^{2} \text { of } \\
\text { uncovered areas } \\
\text { (covered areas } \\
\text { included with } \\
\text { Canopies and } \\
\text { Overhangs) }\end{array}$ & $\begin{array}{l}0.5 \mathrm{~W} / \mathrm{ft}^{2} \text { of } \\
\text { uncovered areas } \\
\text { (covered areas } \\
\text { included with } \\
\text { Canopies and } \\
\text { Overhangs) }\end{array}$ \\
\hline & Drive-up windows/doors & $\begin{array}{l}400 \mathrm{~W} \text { per drive- } \\
\text { through (explicitly } \\
\text { says at fast food } \\
\text { restaurants) }\end{array}$ & $\begin{array}{l}400 \mathrm{~W} \text { per drive- } \\
\text { through }\end{array}$ & $\begin{array}{l}400 \mathrm{~W} \text { per drive- } \\
\text { through }\end{array}$ & $\begin{array}{l}400 \mathrm{~W} \text { per drive- } \\
\text { through }\end{array}$ & $\begin{array}{l}400 \mathrm{~W} \text { per drive- } \\
\text { through }\end{array}$ \\
\hline & $\begin{array}{l}\text { Parking near 24-hour } \\
\text { retail entrances }\end{array}$ & $800 \mathrm{~W}$ per main entry & $\begin{array}{c}800 \text { W per main } \\
\text { entry }\end{array}$ & $\begin{array}{c}800 \mathrm{~W} \text { per main } \\
\text { entry }\end{array}$ & $\begin{array}{c}800 \mathrm{~W} \text { per main } \\
\text { entry }\end{array}$ & $\begin{array}{c}800 \mathrm{~W} \text { per main } \\
\text { entry }\end{array}$ \\
\hline
\end{tabular}


Table 5.40. Building Prototype Exterior Zone Assignment

\begin{tabular}{llll}
\hline & $\begin{array}{l}\text { Exterior } \\
\text { Lighting Zone } \\
\text { Type (s) }\end{array}$ & Prototype & $\begin{array}{l}\text { Exterior } \\
\text { Lighting Zone } \\
\text { Type(s) }\end{array}$ \\
\hline Small Office & 2,3 & Hospital & 3,4 \\
Medium Office & 2,3 & Small Hotel & 3 \\
Large Office & 4 & Large Hotel & 3,4 \\
Standalone Retail & 2,3 & Warehouse & 2,3 \\
Strip Mall & 2,3 & Quick-service Restaurant & $2,3,4$ \\
Primary School & 2 & Full-service Restaurant & $2,3,4$ \\
Secondary School & 2,3 & Mid-rise Apartment & 2,3 \\
Outpatient Healthcare & 2,3 & High-rise Apartment & 3,4 \\
\hline
\end{tabular}

Table 5.41. Exterior Lighting Savings Summary for Addendum 90.1-07i

\begin{tabular}{|c|c|c|c|c|c|c|c|c|c|}
\hline \multirow[b]{2}{*}{ Prototype } & \multicolumn{2}{|c|}{ Parking Lot } & \multicolumn{2}{|c|}{ Doors } & \multicolumn{2}{|c|}{ Facade } & \multicolumn{3}{|c|}{ Total Exterior Lighting } \\
\hline & $\begin{array}{c}90.1 \\
2004 \\
\text { Load } \\
(\mathrm{W})\end{array}$ & $\begin{array}{c}90.1 \\
2010 \\
\text { Load } \\
(\mathrm{W}) \\
\end{array}$ & $\begin{array}{c}90.1 \\
2004 \\
\text { Load } \\
(\mathrm{W}) \\
\end{array}$ & $\begin{array}{c}90.1 \\
2010 \\
\text { Load } \\
(\mathrm{W}) \\
\end{array}$ & $\begin{array}{c}90.1 \\
2004 \\
\text { Load } \\
(\mathrm{W}) \\
\end{array}$ & $\begin{array}{c}90.1 \\
2010 \\
\text { Load } \\
(\mathrm{W}) \\
\end{array}$ & $\begin{array}{c}90.1 \\
2004 \\
\text { Load } \\
(\mathrm{W}) \\
\end{array}$ & $\begin{array}{c}90.1 \\
2010 \\
\text { Load } \\
(\mathrm{W})\end{array}$ & $\begin{array}{c}\text { Savings } \\
(\mathrm{W})\end{array}$ \\
\hline Small Office & 1,215 & 648 & 255 & 240 & 72 & 36 & 1,543 & 925 & 618 \\
\hline Medium Office & 13,122 & 6,998 & 1,442 & 1,442 & 349 & 261 & 14,913 & 8,702 & 6,211 \\
\hline Large Office & 48,904 & 42,383 & 8,449 & 8,449 & 2,864 & 2,864 & 60,216 & 53,696 & 6,520 \\
\hline Stand-alone Retail & 3,189 & 1,701 & 950 & 950 & 193 & 145 & 4,333 & 2,796 & 1,537 \\
\hline Strip Mall & 2,119 & 1,130 & 709 & 574 & 130 & 65 & 2,958 & 1,769 & 1,189 \\
\hline Primary School & 2,204 & 881 & 2,905 & 2,461 & 109 & 54 & 5,217 & 3,397 & 1,821 \\
\hline Secondary School & 8,859 & 4,725 & 7,290 & 6,030 & 183 & 92 & 16,333 & 10,847 & 5,486 \\
\hline Outpatient Healthcare & 3,038 & 1,620 & 421 & 391 & 60 & 30 & 3,519 & 2,041 & 1,478 \\
\hline Hospital & 9,623 & 7,377 & 8,294 & 8,294 & 995 & 746 & 18,911 & 16,417 & 2,494 \\
\hline Small Hotel & 4,678 & 3,119 & 7,659 & 7,659 & 310 & 233 & 12,646 & 11,010 & 1,637 \\
\hline Large Hotel & 10,874 & 8,337 & 2,286 & 2,286 & 1,771 & 1,328 & 14,931 & 11,951 & 2,980 \\
\hline Warehouse & 3,038 & 1,620 & 4,715 & 4,565 & 52 & 26 & 7,805 & 6,211 & 1,594 \\
\hline Quick-service Restaurant & 1,519 & 979 & 209 & 209 & 164 & 123 & 1,891 & 1,311 & 581 \\
\hline Full-service Restaurant & 1,519 & 979 & 382 & 382 & 206 & 154 & 2,107 & 1,515 & 591 \\
\hline Mid-rise Apartment & 4,274 & 2,279 & NA & NA & 142 & 107 & 4,416 & 2,386 & 2,030 \\
\hline High-rise Apartment & 10,685 & 8,192 & NA & NA & 783 & 587 & 11,467 & 8,779 & 2,689 \\
\hline
\end{tabular}




\subsubsection{Addendum 90.1-07x: Occupancy Sensor Control of Interior Lighting}

Addendum 90.1-07x includes several changes that affect the following sections of 90.1-2007:

- Section 9.1.2, is modified so that Section 9.4.1.2 includes the occupancy sensor control requirements in subsection (a) in addition to the previous requirement to comply with Section 9.4.1.2b, which allows manual or occupancy control in space types not covered in subsection (a).

- Section 9.4.1.1, is modified so that it applies automatic shut-off controls to buildings of any size, not just buildings larger than $5,000 \mathrm{ft}^{2}$. Exception (a) is also modified so that lighting "intended" for 24-hour operation is changed to "required."

- Section 9.4.1.2a is changed to add space types subject to required shutoff within 30 minutes.

o Lecture halls and non-shop or laboratory classrooms in preschool through $12^{\text {th }}$ grade are added to classrooms.

0 Training rooms are added to conference and meeting rooms.

o Storage and supply rooms between $50 \mathrm{ft}^{2}$ and $1,000 \mathrm{ft}^{2}$, copy and printing rooms, offices up to $250 \mathrm{ft}^{2}$, restrooms, and dressing, locker, and fitting rooms are added.

o Exceptions are also modified. The multi-scene control exception remains and a definition is added to 90.1-2007, Section 3.2. As noted above, shop and laboratory classrooms are also included, spaces where control would endanger safety or where 24-hour lighting is required.

- Section 9.4.1.2b is modified so that spaces other than those in Section 9.4.1.2 a. and that require manual or automatic controls allow occupant override of two hours rather than four hours during time-of-day shutoff periods.

Savings for these changes implemented in the PI are limited to the expansion of space types with required occupancy lighting control in Section 9.4.1.2. The prototypes are all considered new construction, so Section 9.1.2 for lighting alterations is not considered. All prototypes are larger than $5,000 \mathrm{ft}^{2}$, so the change to Section 9.4.1.1 does not apply. Occupant override is considered a limited occurrence that cannot be estimated effectively, and the difference between a maximum of two and four hours for the limited hours with override would result in modest savings.

Implementing the PI savings analysis for Section 9.4.1.2a requires identifying the appropriate building areas by space type to apply the occupancy sensor control, determining the amount of reduction in lighting energy for the control for each space type, and applying this to the building prototype lighting power inputs. An outline of the implementation steps is provided below. Note that this procedure uses and is applied to the new addendum 90.1-07by LPD values that are described in Section 5.2.4.7 in this report.

- The $\mathrm{NC}^{3}$ database (Richman 2008) provides a compilation of Standard 90.1- prototype buildings and the proportion of the building area assigned to the 90.1-2007 space type per Table 9.6.1 which provides LPDs for the space-by-space method. The data do not distinguish lecture halls, dressing or fitting rooms, or copying and printing rooms; however, some of these types of rooms are likely included in other space types such as classrooms for lecture halls. Table 5.42 shows an example of these space-types percentage areas for the large hotel prototype. Space types subject to the new occupancy sensor requirements, such as restrooms, are shown in bold in Table 5.4.2. 
- Target percentage lighting reductions are determined for adding occupancy sensors. These lighting reduction values are estimated as the average of occupied hour percentage reductions from two primary sources (Richman 1994 and VonNeida et. al. 2000). For locker rooms and dressing/fitting rooms, Standard 90.1-07's Appendix G assumption of 10\% reduction is used. Table 5.43 summarizes the resulting reduction for each space type affected.

- As a simplification (and as allowed in Appendix G of Standard 90.1-07), this percentage savings is applied as a reduction to LPD for all hours of the day. The savings percentage is reduced for spaces in proportion to the lighting that is on during the occupied hours compared to the lighting that is on for all hours. The lighting that is on during the occupied hours is the sum of the hourly schedule fractions of lighting for the occupied hours. The lighting that is on for all hours is the sum of the hourly schedule fractions for all hours. See Section 4.1 of this report for an example of the fractional hourly schedules, and Appendix $\mathrm{C}$ for a listing of all of the model schedules including lighting. For example, the medium office savings reduction is adjusted to $89 \%$ of the percentage savings determined for office spaces. The hourly model schedules already account for off-hour lighting control based on sweep control or a similar method. Counting the savings reduction for addendum 90.1-07x during unoccupied hours would double count the savings. The percentage reduction in lighting is not reduced for spaces that are occupied 24 hours per day.

Table 5.42. Large Hotel Example of Percentage of Building Area by Space Type

\begin{tabular}{|c|c|}
\hline Space Type & $\begin{array}{c}\text { Percentage of } \\
\text { Total Area }\end{array}$ \\
\hline Guestrooms & $59.3 \%$ \\
\hline Corridor/Transition & $11.4 \%$ \\
\hline Fitness Area & $5.0 \%$ \\
\hline Lobby & $3.9 \%$ \\
\hline Conference Meeting/Multipurpose & $3.2 \%$ \\
\hline Dining Area & $3.2 \%$ \\
\hline Stairway & $2.6 \%$ \\
\hline Electrical/Mechanical & $2.6 \%$ \\
\hline Active Storage $>=50$ and $<=1,000^{(a)}$ & $1.9 \%$ \\
\hline Food Preparation & $1.1 \%$ \\
\hline Office - Enclosed ${ }^{(a)}$ & $1.1 \%$ \\
\hline Locker Room $^{(a)}$ & $0.9 \%$ \\
\hline Laundry - Washing & $0.9 \%$ \\
\hline Restrooms $^{(a)}$ & $0.9 \%$ \\
\hline Office - Open Plan & $0.7 \%$ \\
\hline Lounge/Recreation & $0.5 \%$ \\
\hline Active Storage $<50$ and $>1,000$ & $0.3 \%$ \\
\hline Merchandising Sales Area & $0.2 \%$ \\
\hline Exam/Treatment & $0.1 \%$ \\
\hline Workshop & $0.1 \%$ \\
\hline Total & $100.0 \%$ \\
\hline
\end{tabular}


Table 5.43. Occupancy Sensor Control Lighting Reduction by Space Type

\begin{tabular}{lc}
\hline \multicolumn{1}{c}{ Space types } & $\begin{array}{c}\text { Reduction } \\
\text { Estimate }\end{array}$ \\
\hline Pre-K to 12 Classrooms & $32 \%$ \\
Storage and Supply $\left(50-1,000 \mathrm{ft}^{2}\right)$ & $48 \%$ \\
Offices (private up to $\left.250 \mathrm{ft}^{2}\right)$ & $22 \%$ \\
Restrooms & $34 \%$ \\
Dressing/Fitting Rooms & $10 \%$ \\
Locker Rooms & $10 \%$ \\
\hline
\end{tabular}

- Wattage savings for each space type in each prototype is calculated as the product of the following values: (1) the proportion of each space type to total prototype building area, (2) the target occupancy sensor savings percentage, (3) the ratio of occupied lighting usage to total lighting usage, (4) the space-by-space LPD, and (5) the prototype total building area.

- The LPD reduction for each prototype is determined as the sum of the wattage savings for each space type affected by the control divided by prototype total area. The sum of the wattage savings for each space type is applied to all spaces in a prototype in order to capture savings for space types that are not represented in the prototype or are represented out of proportion to the proportion of the space type in the $\mathrm{NC}^{3}$ database.

- Final LPD inputs to each 90.1-2010 model are calculated by subtracting LPD reductions from the LPDs for all zones in the prototype models. Table 5.44 shows the final adjustment applied to the LPD values.

Table 5.44. Summary of Addendum 90.1-07x Lighting Power Reductions by Prototype

\begin{tabular}{lclc}
\hline \multicolumn{1}{c}{ Prototype } & $\begin{array}{c}\text { LPD } \\
\text { Reduction } \\
\left(\mathrm{W} / \mathrm{ft}^{2}\right)\end{array}$ & \multicolumn{1}{c}{ Prototype } & $\begin{array}{c}\text { LPD } \\
\text { Reduction } \\
\left(\mathrm{W} / \mathrm{ft}^{2}\right)\end{array}$ \\
\hline Small Office & 0.0493 & Hospital & 0.0316 \\
Medium Office & 0.0562 & Small Hotel & 0.0095 \\
Large Office & 0.0522 & Large Hotel & 0.0119 \\
Standalone Retail & 0.0119 & Warehouse & 0.0021 \\
Strip Mall & 0.0063 & Quick-service Restaurant & 0.0545 \\
Primary School & 0.1269 & Full-service Restaurant & 0.0472 \\
Secondary School & 0.0966 & Mid-rise Apartment & 0.0089 \\
Outpatient Healthcare & 0.0595 & High-rise Apartment & 0.0406 \\
\hline
\end{tabular}

\subsubsection{Addendum 90.1-07aa: Lighting Occupancy Sensor Control Type}

90.1-2004 and 90.1-2007 Section heading 9.4.1 Lighting Control does not include any separate text from the sub-sections that follow it. These sub-sections under 9.4.1, 9.4.1.1, 9.4.1.2 and 9.4.1.4, include requirements for occupancy sensors and automatic controls. Addendum 90.1-07aa affects these lighting controls sections by adding language to Section 9.4.1 to explicitly apply to all of the lighting control 
subsections and by adding language regarding automatic shut-off controls as applied in Sections 9.4.1.1, 9.4.1.2 and 9.4.1.4:

- Automatic controls are required to be manual on, that is, not come on automatically.

- Exceptions are provided for public corridors and stairwells, restrooms, primary building entrances, and areas where manual on would endanger safety or security.

Addendum 90.1-07aa also results in small changes to the savings implementation presented in this report's Section 5.2.4.3 on addendum 90.1-07x.

Addendum 90.1-07bp is related to addendum 90.1-07aa and adds an option for 50\%-on occupancy sensors. This type of occupancy sensor may add a little more savings than manual-on sensor, but there is no compelling evidence for this; and throughout the progress indicator process, no credit for savings from optional provisions is taken. No implementation of addendum 90.1-07bp is included in the PI.

Implementing the PI savings analysis for addendum 90.1-07aa requires determining the added benefit of this type of occupancy sensor compared with automatic on and off occupancy sensors. A limited study supports savings estimate for perimeter daylit offices only and therefore savings is applied to small, medium, and large office prototypes only (DiLouie 2009). With such a limited basis for estimating savings, a conservative approach is taken.

A similar methodology to that taken for addendum $90.1-07 \mathrm{x}$ is applied. Savings analysis is applied to the small, medium, and large office prototypes based on the proportion of daylit perimeter enclosed office space. Enclosed office space as a proportion of total building area is determined using the $\mathrm{NC}^{3}$ database (Richman 2008). Daylit perimeter enclosed office space is assumed to be $50 \%$ of total enclosed office area. The percentage reduction for the manual control is $46 \%$ and is further reduced to $25 \%$ of this value for a reduction of $11.5 \%$. A total wattage reduction is determined and divided by total building area, resulting in a LPD reduction. For each office prototype, the corresponding LPD reduction is applied. The LPD model inputs are found by applying the savings reduction to the interior lighting LPD values calculated when applying addenda 90.1-07x and 90.1-07by.

Table 5.45. Manual-On Occupancy Sensor Lighting Power Reduction

\begin{tabular}{cc}
\hline Prototype & $\begin{array}{c}\text { LPD reduction } \\
\left(\mathrm{W} / \mathrm{ft}^{2}\right)\end{array}$ \\
\hline Small Office & 0.0217 \\
Medium Office & 0.0191 \\
Large Office & 0.0143 \\
\hline
\end{tabular}

\subsubsection{Addendum 90.1-07aw: Lodging Guestroom Bathroom Lighting Control}

90.1-2004 and 90.1-2007, Section 9.4.1.4, requires a master lighting control at the point of entry/exit for all permanently installed luminaires and switched receptacles in hotel and motel guestrooms and guest suites. Addendum 90.1-07aw modifies this requirement to allow multiple control devices that collectively control all permanently installed luminaires except those in the bathrooms. The bathrooms are required to have a separate control device capable of turning off the bathroom lighting, except night lighting not exceeding $5 \mathrm{~W}$, within 60 minutes of an occupant leaving the space. 
Addendum 90.1-07aw applies to the small and large hotel prototypes. Bathroom lights are assumed to account for $31 \%$ of all guest room lighting in hotels and motels, based on input from the Lighting Subcommittee. Occupancy sensors are assumed to reduce energy consumption by $10 \%$ according to 90.1 2007, Appendix G, Table G3.2 which provides factors for lighting reduction depending on applicability of other lighting controls that are also required. The LPD for guestrooms in hotels and motels is reduced to capture savings from this addendum as shown below:

$$
1.1 \mathrm{~W} / \mathrm{ft}^{2} * 31 \% * 10 \%=0.034 \mathrm{~W} / \mathrm{ft}^{2} \text { reduction }
$$

The 90.1-2004 guest room LPD is $1.1 \mathrm{~W} / \mathrm{ft}^{2}$ and for $90.1-2010$ is $1.067 \mathrm{~W} / \mathrm{ft}^{2}$.

\subsubsection{Addendum 90.1-07bq: Retail Display Lighting}

90.1-2004 Section 9.6.2 includes two categories of retail display lighting eligible for additional lighting power allowances, normal merchandise and valuable merchandise. Section 9.6.2 in 90.1-2007 provides additional LPD allowances for display lighting (only where used to light merchandise) in sales areas for four merchandise categories:

- Retail Area 1: general, not listed in Retail Areas 2 through 4

- Retail Area 2: vehicles, sporting goods, and small electronics

- Retail Area 3: furniture, clothing, cosmetics, and artwork

- Retail Area 4: jewelry, crystal, and china.

Addendum 90.1-04ai (i.e., 90.1-2007) is the source of this change from 90.1-2004 to 90.1-2007, and is not intended to result in savings, and therefore is not treated separately in this report. However, to consistently implement retail display lighting for the different versions of the models, the 90.1-2007 additional display lighting allowance used as the starting point for addendum $90.1-07 \mathrm{bq}$ is calculated as being somewhat lower than for 90.1-2004, as shown in Table 5.46.

Addendum 90.1-07bq reduces the display lighting LPD allowances for the four sales area categories introduced in 90.1-2007.

Only the strip mall prototype includes display lighting. Based on information provided by the Lighting Subcommittee, the standalone retail prototype does not include display lighting.

The strip mall includes eight stores, which are assigned to the different retail display allowance categories. Retail areas type 2 and 3 are assigned to portions of the strip mall prototype. Addendum 90.1$07 \mathrm{bq}$ reduces the added lighting allowance for retail area type 2 from $1.7 \mathrm{~W} / \mathrm{ft}^{2}$ to $0.6 \mathrm{~W} / \mathrm{ft}^{2}$ and for retail area type 3 from $2.6 \mathrm{~W} / \mathrm{ft}^{2}$ to $1.4 \mathrm{X} \mathrm{W} / \mathrm{ft}^{2}$.

Where display lighting is included, it is assumed to light $25 \%$ of the zone. A weighted average of the display lighting allowance is determined by multiplying the percentage of the entire strip mall area for each store by the percentage of area with display lighting by the added display lighting allowance, as shown in Table 5.46. The total display lighting allowance is added to the other retail lighting determined by the space-by-space method. 
Retail areas type 1 and 4 allowance values are not used in the modeling and are not shown in Table 5.46. For addendum $90.1-07 \mathrm{bq}$, the Retail Area 1 added lighting allowance is reduced from $1.0 \mathrm{~W} / \mathrm{ft}^{2}$ to $0.6 \mathrm{~W} / \mathrm{ft}^{2}$, and the Retail Area 4 allowance is reduced from $4.2 \mathrm{~W} / \mathrm{ft}^{2}$ to $2.5 \mathrm{~W} / \mathrm{ft}^{2}$.

Table 5.46. Adjusted Display Lighting Allowance for Strip Malls

\begin{tabular}{|c|c|c|c|c|c|c|c|c|}
\hline \multirow[b]{2}{*}{ Zones } & \multirow[b]{2}{*}{$\begin{array}{l}\text { Percentage } \\
\text { of Total } \\
\text { Building } \\
\text { Area } \\
\end{array}$} & \multirow{2}{*}{$\begin{array}{l}\text { Zone } \\
\text { Area } \\
\text { with } \\
\text { Display } \\
\text { Lighting } \\
\end{array}$} & \multicolumn{2}{|c|}{$90.1-2004$} & \multicolumn{2}{|c|}{$90.1-2007$} & \multicolumn{2}{|c|}{$90.1-2010$} \\
\hline & & & $\begin{array}{l}\text { Display } \\
\text { Type }\end{array}$ & $\begin{array}{l}\text { Added } \\
\text { Display } \\
\left(\mathrm{W} / \mathrm{ft}^{2}\right) \\
\end{array}$ & $\begin{array}{l}\text { Display } \\
\text { Type }\end{array}$ & $\begin{array}{l}\text { Added } \\
\text { Display } \\
\left(\mathrm{W} / \mathrm{ft}^{2}\right) \\
\end{array}$ & $\begin{array}{l}\text { Display } \\
\text { Type }\end{array}$ & $\begin{array}{l}\text { Added } \\
\text { Display } \\
\left(\mathrm{W} / \mathrm{ft}^{2}\right) \\
\end{array}$ \\
\hline $\begin{array}{l}\text { LGSTORE1 } \\
\text { SMSTORE1 }\end{array}$ & $25 \%$ & $25 \%$ & $\begin{array}{l}\text { valuable } \\
\text { merchandise }\end{array}$ & 3.9 & Type 2 & 2.6 & Type 2 & 0.6 \\
\hline $\begin{array}{l}\text { SMSTORE2 } \\
\text { SMSTORE3 } \\
\text { SMSTORE4 }\end{array}$ & $25 \%$ & $25 \%$ & $\begin{array}{l}\text { normal } \\
\text { merchandise }\end{array}$ & 1.6 & Type 3 & 1.7 & Type 3 & 1.4 \\
\hline $\begin{array}{l}\text { LGSTORE2 } \\
\text { SMSTORE5 } \\
\text { SMSTORE6 } \\
\text { SMSTORE7 } \\
\text { SMSTORE8 }\end{array}$ & $50 \%$ & $0 \%$ & None & 0 & none & 0 & none & 0 \\
\hline $\begin{array}{l}\text { Display } \\
\text { Lighting } \\
\text { Added to } \\
\text { Total LPD }\end{array}$ & none & none & None & 0.344 & none & 0.269 & none & 0.125 \\
\hline
\end{tabular}

\subsubsection{Addendum 90.1-07by and 90.1-07de: Interior LPD Allowance}

90.1-2007, Chapter 9, includes requirements for maximum LPD. Two prescriptive methods are allowed and tables of values are provided. The primary compliance path uses Table 9.5.1 which includes LPDs that are applied to an entire building area. An alternative path uses Table 9.6.1, which allows assignment of maximum LPDs to specific space types.

Addendum 90.1-07by is a full update of the values in both Tables 9.5.1 and 9.6.1 of the standard. The maximum allowed LPD values decrease generally with some exceptions. This addendum also introduces Section 9.6.3, "Room Geometry Adjustment," which defines a room cavity ratio (RCR) threshold. RCR is defined as the product of 2.5 , room cavity height, and room perimeter length divided by room area. Room cavity height is the luminaire mounting height minus the work plane height. The RCR threshold values are added to Table 9.6.1 for each space type. If the RCR calculated for a space is greater than the threshold, then an additional allowance of $20 \%$ can be added to the normal LPD allowance in Table 9.6.1. Corridor/transition spaces are allowed in the adjustment if they are less than eight-feet wide, regardless of the RCR. 
Tables 9.5.1 and 9.6.1 in 90.1-2004, 90.1-2007, and 90.1-2010 are not included in this report and can be viewed in those different versions of Standard 90.1.

Implementing addendum 90.1-07by is straightforward for most prototypes and zones apart from the RCR allowance. All prototypes and all climate zones are affected by addendum 90.1-07 by LPD changes because all have LPD values that are based on either the building area method for small, medium, and large offices, or the space-by-space method for other prototypes and zones. In some cases, zones include a mix of space types, and the values are a weighted average of those different space types. The LPD is recalculated using the new space-by-space allowance and the area weighting.

Completing implementation of addendum 90.1-07by requires addressing the RCR. PNNL developed a set of RCR data based on the $\mathrm{NC}^{3}$ dataset of spaces in different buildings, representing many of the space types in Standard 90.1, Table 9.6.1. Zones in the prototypes are evaluated to determine which are eligible and should apply the RCR 20\% increased LPD allowance by multiplying four values:

- The area weighted proportion of each space type with areas for spaces that meet or exceed the RCR level. This calculation results in a percentage of that space type total area that is eligible for the adjustment.

- The assumed proportion of projects that use the space-by-space method: $50 \%$.

- The assumed proportion of those projects that will calculate the RCR: $50 \%$

- The allowed percentage LPD increase if the RCR threshold is met: $20 \%$

If the result exceeds a $1 \%$ increase in LPD, an LPD adjustment is considered. Three space types are identified with the RCR adjustment applied in addendum 90.1-07by to the 90.1-2010 models:

- Hotel, Exercise: $+5.0 \%$. All four cases exceed the RCR limit.

- Hospital, Exam/Treatment: $+3.3 \%$. Four of six cases exceed the RCR limit and two other cases are close.

- Corridor/Transition: $+1.1 \%$. The adjustment applies to all building types, with 5 of the 22 spaces meeting the less than $8 \mathrm{ft}$-width criteria.

Addendum 90.1-07de further modifies Table 9.6.1 as follows:

- Changes the general lobby allowance to $0.90 \mathrm{~W} / \mathrm{ft}^{2}$ from the $0.65 \mathrm{~W} / \mathrm{ft}^{2}$ allowed in addendum 90.107by.

- Introduces an elevator lobby allowance of $0.64 \mathrm{~W} / \mathrm{ft}^{2}$.

- Eliminates the LPD allowance for audience seating in the fitness center.

Addendum 90.1-07de is implemented differently for different prototypes. Small hotels, outpatient healthcare, primary and secondary schools include zones defined with the general lobby space-type, so the LPD for these areas is increased by $0.25 \mathrm{~W} / \mathrm{ft}^{2}$. High-rise and mid-rise apartments, quick-service and full-service restaurants, strip malls, and warehouses do not have lobby zones defined in the model or in $\mathrm{NC}^{3}$ database. Therefore, this addendum is not applied to these prototypes. The large hotel prototype includes a lobby zone, but hotel lobby is a separate space type from general lobby in 90.1-2010 and has a separate LPD limit, which is not changed by addendum 90.1-2007de. Calculations described below are 
made for the remaining prototypes, including hospital, standalone retail, and small, medium and large offices.

For the hospital and standalone retail prototypes, the lobby space type is not identified for a modeled zone. For offices, the LPD is defined by the building area method. The same value is used for all zones, and separate space types are not explicitly identified in the model. For these prototypes, the $\mathrm{NC}^{3}$ database includes the lobby space-type as part of the building area (Richman et al. 2008). LPD adjustments are made to reflect the increase in LPD for general lobby space weighted by the effective lobby area in the prototype. These adjustments are similar to the methodology described in Section 5.2.4.3 for addendum 90.1-07x, using the $\mathrm{NC}^{3}$ database. For offices, the LPD adjustment is applied to all zones in proportion to the $\mathrm{NC}^{3}$ ratio of lobby area to total area. Table 5.47 shows the increase in LPD allowance by zone for these prototypes.

Table 5.47. Lobby Lighting Reduction for Selected Zones by Prototype

\begin{tabular}{llc}
\hline \multicolumn{1}{c}{ Prototype } & \multicolumn{1}{c}{ Area } & LPD Increase $\left(\mathrm{W} / \mathrm{ft}^{2}\right)$ \\
\hline Small Office & LPD_Office (all zones) & 0.0233 \\
Medium Office & LPD_Office (all zones) & 0.0090 \\
Large Office & LPD_Office (all zones) & 0.0068 \\
Standalone Retail & LPD_Entry & 0.2500 \\
Hospital & LPD3_Records & 0.2250 \\
& LPD5_NurseStn_Lobby1 & 0.1000 \\
& LPD9_NurseStn_Lobby2 & 0.1500 \\
\hline
\end{tabular}

\subsubsection{Addendum 90.1-07cd: Exterior Lighting Automatic Controls}

90.1-2007, Section 9.4.1.3, requires lighting for all exterior applications to have automatic controls capable of turning the lights off when sufficient daylight is available or when lighting is not required during night time hours. The lighting that is not designed for dusk-to-dawn operation is to be controlled by either a photosensor and time switch or an astronomical time switch. 90.1-2007, Section 9.4.5, lists the exterior lighting applications exempt from the requirements of Section 9.4.1.3. Addendum 90.1-07cd modifies these sections as follows:

- Section 9.4.1.3 is modified to expand the scope of exterior lighting control. It requires lighting for exterior application not exempt in Section 9.1 to be controlled by a device that automatically shuts off lighting when sufficient daylight is available. Exterior facade and landscape lighting is to be automatically turned off between business closing or midnight, whichever is later, and until 6 am or business opening, whichever is earlier. Exterior lighting not specified as facade or landscape lighting, including advertising signage, is to be automatically reduced to $30 \%$ of its peak power between midnight or within 1 hour of business closing, whichever is later, and until 6 am or business opening, whichever is earlier, and during any period activity is not detected for a time longer than 15 minutes.

- Section 9.4.5 exceptions are expanded to include lighting for hazardous locations, swimming pools and water features, and searchlights. 
Facilities that are open 24 hours a day, such as hospitals, outpatient healthcare, small and large hotels, and high-rise and mid-rise apartments, which do not have close of business hours, do not have to turn lights off when the night time setback control would otherwise be required by this addendum.

This addendum is implemented by separating the exterior facade lighting from the total exterior lighting and modifying the exterior lighting operating schedules. This separation includes the reduction in exterior lighting power and the allocation of exterior lighting power shown in this report's Section 5.2.4.2 for addendum 90.1-07i. Table 5.48 provides an example of this separation for the Large Office.

Table 5.48. Large Office Example of Facade Lighting Reduction for Controls

\begin{tabular}{lccc}
\hline \multicolumn{1}{c}{ Case } & All Exterior Lights (W) & Facade Exterior Lights (W) & Other Exterior Lights (W) \\
\hline Baseline & 62,787 & & \\
PI & & 12,979 & 43,305 \\
\hline
\end{tabular}

Exterior lighting operating schedules are changed to reflect the minimum required power reduction during the midnight to 6 am period. The exterior lighting schedule is separated into a facade schedule with lights off from midnight to 6 am and the rest of the exterior lighting schedule with lights reduced to $30 \%$ from midnight to $6 \mathrm{am}$. The facade exterior lights schedule is applied to the facade exterior lights wattage, and the other schedule is applied to the rest of the exterior lights wattage.

\subsubsection{Addendum 90.1-07cf: Stairwell Lighting Controls}

90.1-2007, Section 9.4.1.4, provides requirements for lighting control for specialized applications. Addendum 90.1-07cf expands this section by adding a requirement for control lighting serving interior stairways. The addendum requires stairwell lighting to be controlled automatically so that lighting power is reduced to $50 \%$ within 30 minutes of all occupants leaving the zone. Stairwell lighting under 90.1-2010 has a lighting power allowance of $0.6 \mathrm{~W} / \mathrm{ft}^{2}$.

This addendum is implemented by reducing the LPD of stairwells in the prototype models. The occupancy percentage of stairwells is assumed to be $10 \%$, based on the supporting information in the foreword to the public review of this addendum. The stairwell is therefore unoccupied $90 \%$ of the time. The control is calculated as a 50\% reduction in lighting when unoccupied as required by the addendum.

$$
\text { LPD reduction }=0.6 \mathrm{~W} / \mathrm{ft}^{2} * 0.9(\text { unoccupied fraction }) * 50 \%(\text { control })=0.27 \mathrm{~W} / \mathrm{ft}^{2}
$$

The reduction is applied to a zone or zones existing in the prototype model and adjusted so that the effect is in proportion to the area of stairs in typical buildings of the respective prototype. The stairwell area weighting fractions are calculated using area information from the $\mathrm{NC}^{3}$ database. For the small hotel, a stairwell zone is defined in the model and is used directly without an area fraction adjustment. For the quick-service restaurant prototype, the $\mathrm{NC}^{3}$ database has no stairwell area and so no reduction in interior lighting is made.

An example of how the stairwell lighting control applies is provided for the high-rise apartment. In the high-rise apartment, the reduction is applied to the lighting power input for the corridor zones because there are not separately defined stairwell zones. The corridor zones are $10 \%$ of the building area. Stairwells are $2.5 \%$ of typical high-rise apartment buildings from $\mathrm{NC}^{3}$ data. The calculation below shows 
how these factors are applied to develop the lighting reduction of $0.0675 \mathrm{~W} / \mathrm{ft}^{2}$ which is applied to the high-rise apartment corridor zones.

$$
0.27 \mathrm{~W} / \mathrm{ft}^{2} \cdot 2.5 \% / 10 \%=0.0675 \mathrm{~W} / \mathrm{ft}^{2}
$$

Table 5.49 provides the LPD reductions for all of the affected prototypes.

Table 5.49. LPD Reduction for Stairwell Occupancy Sensor Controls

\begin{tabular}{lclc}
\hline \multicolumn{1}{c}{ Prototype } & $\begin{array}{c}\text { LPD } \\
\text { Reduction } \\
\left(\mathrm{W} / \mathrm{ft}^{2}\right)\end{array}$ & \multicolumn{1}{c}{ Prototype } & $\begin{array}{c}\text { LPD } \\
\text { Reduction } \\
\left(\mathrm{W} / \mathrm{ft}^{2}\right)\end{array}$ \\
\hline Small Office & 0.0019 & Hospital & 0.0233 \\
Medium Office & 0.0097 & Small Hotel & 0.2700 \\
Large Office & 0.0046 & Large Hotel & 0.0994 \\
Standalone Retail & 0.1080 & Warehouse & 0.0055 \\
Strip Mall & 0.0011 & Full-service Restaurant & 0.0007 \\
Primary School & 0.0248 & Mid-rise Apartment & 0.1095 \\
Secondary School & 0.0341 & High-rise Apartment & 0.0675 \\
Outpatient Healthcare & 0.0288 & & \\
\hline
\end{tabular}

\subsubsection{Addendum 90.1-07ct: Sidelighting Controls}

90.1-2004 and 90.1-2007, Chapter 9, do not specify requirements for automatic daylighting controls in sidelit spaces. Addendum 90.1-07ct modifies Section 9.4.1.3 and requires lamps for general lighting to be separately controlled by automatic daylighting controls when the primary sidelit area in a space is 250 $\mathrm{ft}^{2}$ or larger. There are some detailed descriptions, figures and exceptions that are not replicated here; refer to 90.1-2010, Section 9.4.1.3. See 90.1-2010, Chapter 3, for the definitions of primary sidelit area and sidelighting effective aperture.

Retail spaces (standalone retail and strip mall prototypes) and spaces where the sidelighting effective aperture is less than 0.1 are exempted from the requirements of addendum 90.1-07ct. The mid-rise and high-rise apartment prototypes are excluded from the analyzed savings since interior lighting in dwellings is exempt from the requirements in 90.1-2010, Section 9.1.1, exception b. Other spaces in the apartment prototypes either do not have access to daylight or are relatively small compared with the total building areas and are also excluded from the savings analysis.

Addendum 90.1-07ab, drafted prior to addendum ct, introduces the requirements for primary sidelighted areas. This addendum is primarily concerned with skylights and toplighting controls and is covered in Section 5.2.4.1 of this report. The minimum primary sidelighted area threshold set by addendum $90.1-07 \mathrm{ab}$ is $1,000 \mathrm{ft}^{2}$. Addendum ct lowers the minimum primary sidelighted area threshold from $1,000 \mathrm{ft}^{2}$ to $250 \mathrm{ft}^{2}$.

In implementing addendum 90.1-07ct, the primary sidelighted area in each applicable space is calculated. Spaces with less than $250 \mathrm{ft}^{2}$ of primary sidelighted area were discarded. Next, the sidelighting effective aperture is calculated in spaces that have over $250 \mathrm{ft}^{2}$ of primary sidelighted area. Again, spaces 
with an effective aperture of less than 0.1 were discarded. Automatic daylighting controls are then placed in the remaining spaces.

Table 5.50 shows the application of the requirements of addendum ct to the Standard 90.1 prototypes. The fraction of zones controlled by automatic dimming controls is equal to the ratio of primary sidelighted area to floor area of the space. Two sensors are placed in each sidelighted area, with each sensor controlling half the total sidelighted area. The dimming control is of the stepped type, and it can lower the peak lighting power in two steps to $66 \%$ and $33 \%$ of peak power.

For the small, medium, and large office prototypes, additional calculations are required to determine the proportion of modeled exterior fenestration that is accessible for daylighting. Three space types, open offices, enclosed offices and conference rooms, are identified as most likely to have access to windows as well as floor areas of $250 \mathrm{ft}^{2}$ and larger in typical office buildings. From the $\mathrm{NC}^{3}$ database, office building data is separated out into small, medium, and large office datasets based on floor area. The primary sidelighted area in each of the three typical office building types is determined from the $\mathrm{NC}^{3}$ data. For the large office prototype, usable data in the $\mathrm{NC}^{3}$ database came from only one building. Therefore, the medium office data was used for the large office prototype.

The primary sidelit area per square foot of floor area, obtained from the $\mathrm{NC}^{3}$ database, is multiplied by the prototype building's floor area to yield the primary sidelighted area in that prototype. Using this approach, total primary sidelighted areas are calculated for each of the three office prototypes. The next step is to assign the calculated sidelighted areas to different zones in the prototype models. Because no rationale favors a particular facade when distributing sidelit areas total sidelit areas for the office prototypes are distributed equally between their four facades. 
Table 5.50. Sidelighting Analysis and Implementation

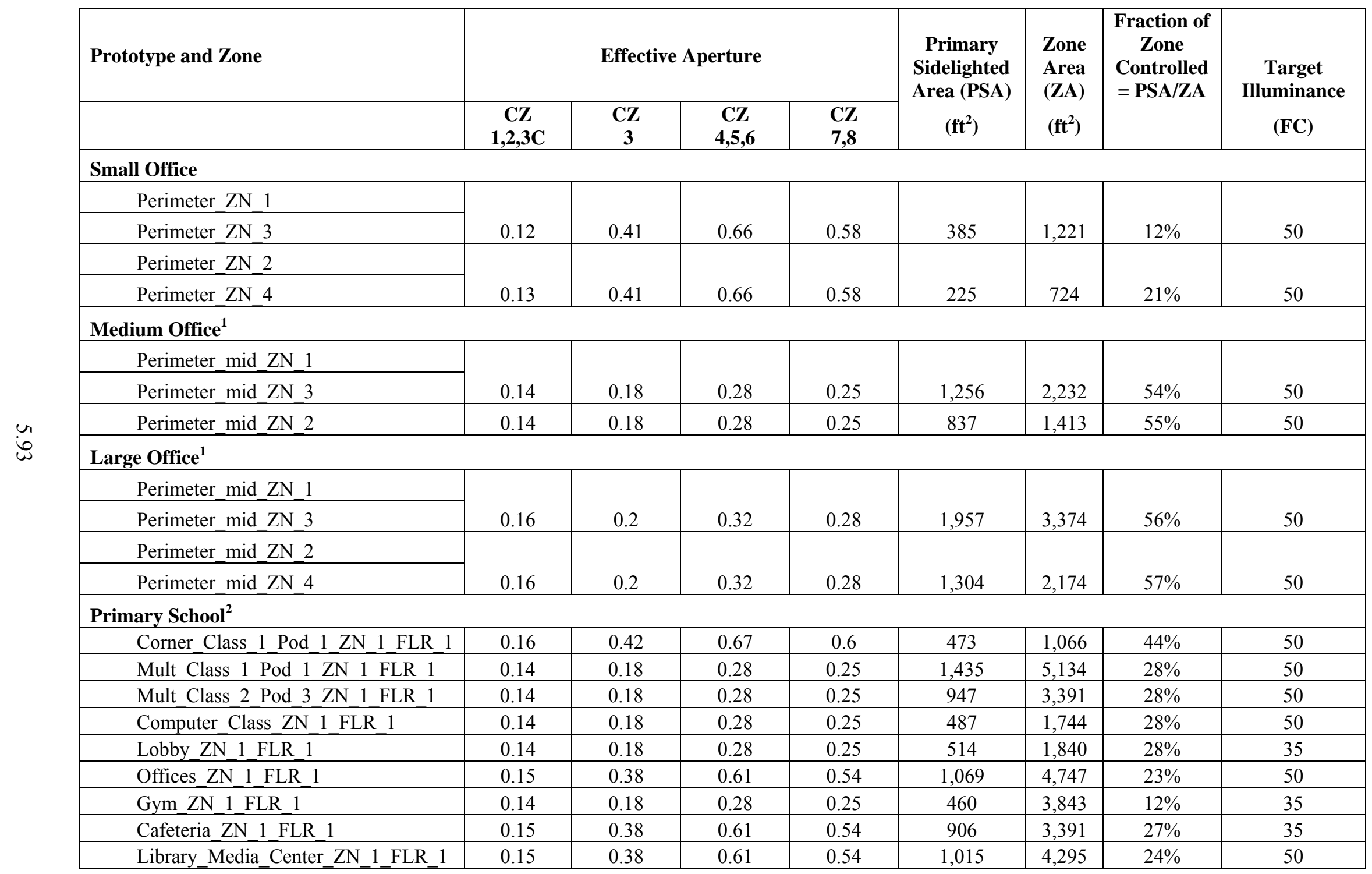


Table 5.50 (cont'd)

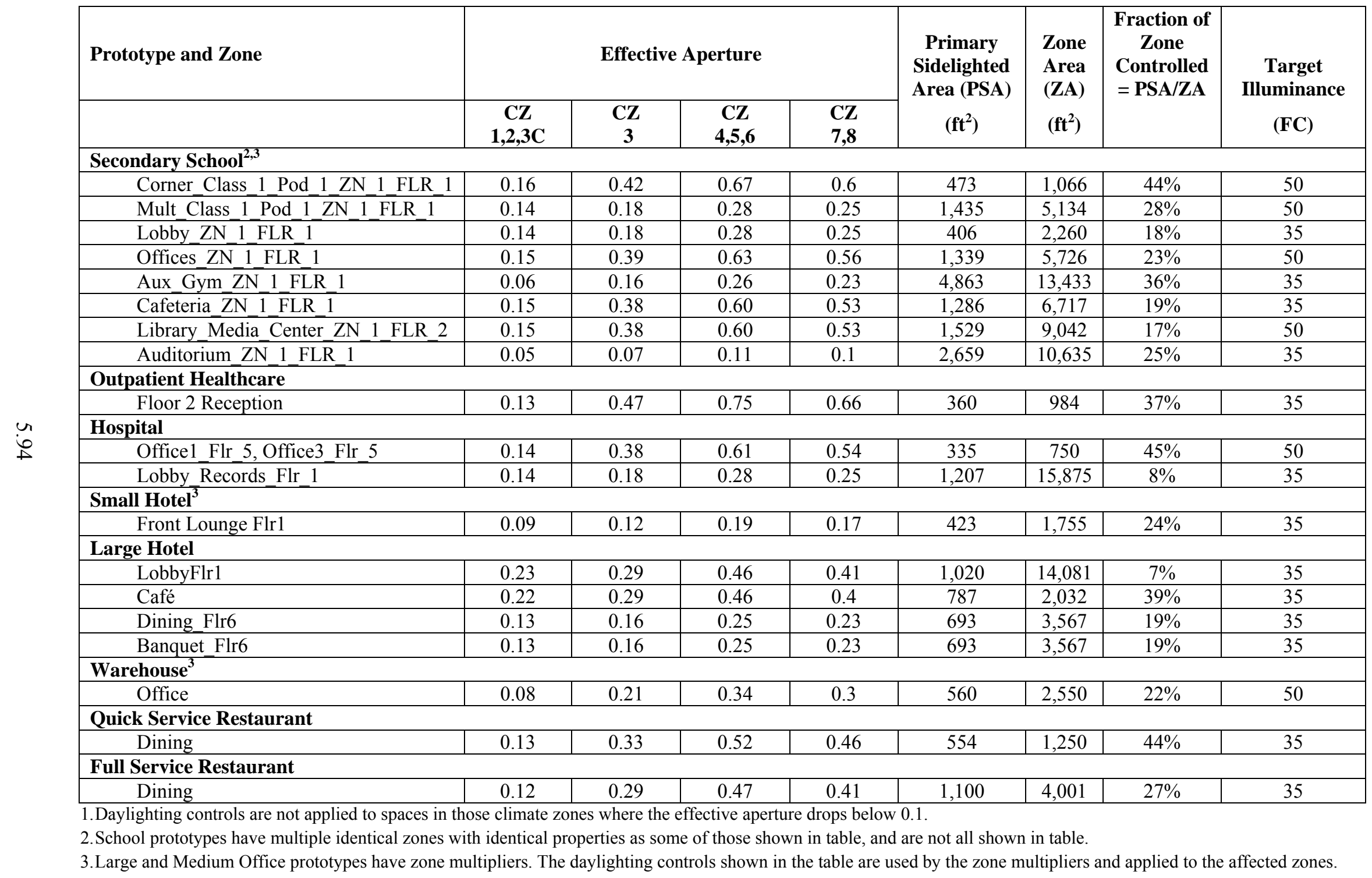




\subsubsection{Other Equipment}

Standard 90.1, Chapter 10, "Other Equipment," regulates equipment not covered in other chapters of the standard. The only other equipment covered in 90.1-2004 and 90.1-2007 are electric motors subject to the Energy Policy Act of 1992. Addendum 90.1-07aj expands the scope of motors covered by Standard 90.1 and increases the minimum motor efficiency values consisting with Federal law and federal rulemaking. Addendum 90.1-07df sets requirements on elevator lights and ventilation fans. This section discusses the modeling strategies for addenda aj and df. Addendum 90.1-07cv adds energy efficiency requirements for service water heating booster pumps, however, service water heating booster pumps are not specifically modeled in any of the prototypes, and no savings are quantified for addendum $\mathrm{cv}$.

\subsubsection{Addendum 90.1-07aj: Motor Efficiency}

90.1-2004 and 90.1-2007 provide minimum motor efficiency requirements in Chapter 10, "Other Equipment." The requirements apply to motors covered in the Energy Policy Act of 1992, identified in 90.1-2004 and 2007 Table 10.8 as general purpose design A and design B motors from 1 to 200 horsepower rated under National Electrical Manufacturers Association Standard MG 1-2006 (ANSI/NEMA 2006).

Addendum 90.1-07aj includes updated minimum efficiency values for motors manufactured as of December 19, 2010. Such motors must comply with the requirements of the Energy Independence and Security Act of 2007. Additional motor sizes larger than $200 \mathrm{hp}$ are added in $50 \mathrm{hp}$ increments from 250 to $500 \mathrm{hp}$. Addendum 90.1-07aj introduces a new motor table, Table 10.8B, for motors manufactured on or after December 19, 2010. This addendum also includes Table 10.8A, which covers motors manufactured before December 19, 2010, and is the same as Table 10.8 in 90.1-2007.

The published 90.1-2010 differs from the final version of addendum 90.1-07aj, and includes three tables instead of 2 . Tables $10.8 \mathrm{~A}$ and $10.8 \mathrm{~B}$ are as described in the preceding paragraph on addendum aj. The additional table, Table 10.8C, covers Subtype II and Design B motors and, for the motors from $1 \mathrm{hp}$ to $200 \mathrm{hp}$, includes the same efficiency requirements as in Table 10.8 in 90.1 -2004 and 90.1-2007.

Motors in the prototype buildings are understood to be the Subtype I motors covered in the Table 10.8 in the two earlier versions of Standard 90.1 and in Tables 10.8 A and B in 90.1-2010. The change in the motor efficiency requirements is applied to all prototypes and climate zones that include $1 \mathrm{hp}$ or larger standard motors. The change is implemented in the PI process through a script that uses the equipment sizing information produced in initial sizing runs and assigns motor efficiency based on nominal motor size. Nominal motor size is calculated by determining the next motor size in the table that is greater than $110 \%$ of the brake horsepower reported from the sizing runs. Motor brake horsepower results from load on the motor and other modeled inputs described in Chapter 4 in this report for the corresponding equipment such as fans and pumps.

The changes in motor efficiency requirements from the addendum add up to $3 \%$ to the earlier efficiency values, with larger increases for smaller motors. For example, the motor efficiency requirement for a $10 \mathrm{hp}$, open 4-pole, $1800 \mathrm{rpm}$ motor increases from $89.5 \%$ to $91.7 \%$. The full listing of the values for comparison is available in Table 10.8 in Standards 90.1-2004 and 90.1-2007, and in Table 10.8B in Standard 90.1-2010. 


\subsubsection{Addendum 90.1-07df: Elevator Lighting and Ventilation}

90.1 -2004 and 90.1-2007 do not specify any requirements for building elevators. Addendum 90.1$07 \mathrm{df}$ adds three provisions:

- Section 10.4.3.1, "Lighting." All cab lighting systems must have efficacy of not less than 35 lumens per watt.

- Section 10.4.3.2, "Ventilation Power Limitation." Cab ventilation fans for elevators without airconditioning must not consume over $0.33 \mathrm{~W} / \mathrm{cfm}$ at maximum speed.

- Section 10.4.3.3, "Standby Mode." When stopped and unoccupied with doors closed for over 15 minutes, cab interior lighting and ventilation must be de-energized until required for operation.

To analyze the energy savings from Section 10.4.3.1 of 90.1-2010, the elevator lighting systems in the baseline models are assumed to be composed of two lighting sources: $70 \%$ incandescent (10 lumens/W) and 30\% high efficacy (35 lumens/W) as described in Section 4.9.2 of this report. The elevator lighting in the 90.1-2010 models is assumed to use all high efficacy light sources. Table 5.51 shows the assumed elevator size. Based on the elevator floor area and LPD calculated from the required illumination levels and efficacy, the lighting power is calculated to be $88 \mathrm{~W}$ per elevator for the baseline and $32 \mathrm{~W}$ per elevator for 90.1-2010 (see Table 5.52). Table 4.21 in Chapter 4 of this report shows the number of elevators per prototype used to calculate total elevator lighting power for each prototype.

Based on engineering judgment, the ventilation power limitation specified in Section 10.4.3.2 of 90.12010 is close to common design practice. Therefore, the ventilation fan power in the baseline buildings is assumed to be the same as that in the 90.1-2010 buildings, as shown in Table 5.53.

To analyze the energy savings from Section 10.4.3.3 of the 90.1-2010, the elevator fan and lights are assumed to always be on in the baseline buildings. In the 90.1-2010 models, the schedules of the elevator fan and lights are assumed to be on the same fractional amount as the elevator motor schedules with one exception. This reflects the portion of the time the lights and fan are on, not the portion of the lighting and fan equipment that are on. The exception is that, when the elevator motor schedule fraction is $\geq 0.75$, the elevator fan and lights are scheduled completely on, a 1.0 value in the model schedule.

Table 5.51. Elevator Size

\begin{tabular}{lll}
\hline Elevator & Length & $6.66 \mathrm{ft}$. \\
Size & Width & $4.25 \mathrm{ft}$. \\
& Height & $8 \mathrm{ft}$. \\
& Floor area & $28 \mathrm{ft}^{2}$ \\
& Volume & $224 \mathrm{ft}^{3}$ \\
\hline
\end{tabular}


Table 5.52. Elevator Lighting Power

\begin{tabular}{lcl}
\hline Elevator Lighting Characteristics & Values & Units \\
\hline Design Lighting Level & 30 & lumens $/ \mathrm{ft}^{2}$ \\
Light Loss Factor & $75 \%$ & \\
Needed Light Level & 40 & lumens $/ \mathrm{ft}^{2}$ \\
& & \\
Baseline Lighting & 10 & lumens/W \\
\hline Incandescent (70\%) & 4 & $\mathrm{~W} / \mathrm{ft}^{2}$ \\
& 35 & $1 \mathrm{umens} / \mathrm{W}$ \\
High Efficacy Source (30\%) & 1.14 & $\mathrm{~W} / \mathrm{ft}^{2}$ \\
& 17.5 & $1 \mathrm{umens} / \mathrm{W}$ \\
Average Efficacy & 3.14 & $\mathrm{~W} / \mathrm{ft}^{2}$ \\
Average LPD & 88.0 & $\mathrm{~W}$ per elevator \\
Lighting Power & & \\
Addendum 90.1-07 Lighting & & \\
\hline Efficacy Required by Addendum 90.1-07df (100\%) & 35 & $1 \mathrm{umens} / \mathrm{W}$ \\
LPD & 1.14 & $\mathrm{~W} / \mathrm{ft}^{2}$ \\
Lighting Power & 32.0 & $\mathrm{~W}$ per elevator \\
\hline
\end{tabular}

Table 5.53. Elevator Cab Ventilation Fan Power

\begin{tabular}{lcl}
\hline Air Change Rate & 1 & air change per minutes \\
Ventilation Airflow Rate & 224 & cfm \\
Ventilation Power Limitation per Addendum df & 0.33 & W/cfm \\
Cab Ventilation Fan power & 73.9 & W per elevator \\
\hline
\end{tabular}




\subsection{Energy Savings Analysis Results}

This chapter provides the results of the PI quantitative savings analysis, the estimated energy and cost savings from 90.1-2010 compared with 90.1-2004. The savings include the impact of the addenda that changed 90.1-2004 to 90.1-2010. The quantitative analysis demonstrates that the DOE and ASHRAE goal of 30\% savings is realized based on PNNL's analysis. Table 6.1 presents the national aggregated results using the construction weighting factors (Table 2.2 in this report). Site energy savings are $32.7 \%$ and energy cost savings are $29.5 \%$, if plug and process loads are excluded. With plug and process loads included in the percentage saving calculations, the site energy savings are $25.6 \%$ and energy cost savings are $23.2 \%$. Site energy is utility electricity and natural gas delivered and used at the building site. Energy cost savings are based on the site energy usage results.

Source energy, the energy used (such as the energy in coal) in generating electricity, and primary energy usage at the site such as natural gas burned in a furnace is also determined. Source energy for electricity is generally much larger than site energy as it accounts for generation efficiencies and distribution losses. Conversion from site energy results from the simulation to source energy results is described in Section 2.4 in this report. Source energy savings are $23.2 \%$ with plug and process loads included.

Table 6.1. 90.1 -2010 vs. 90.1-2004 Site Energy Savings Results

\begin{tabular}{ccc}
\hline & With & Without \\
National-Weighted & Plug and Process & Plug and Process \\
Energy Savings & Loads & Loads \\
\hline Site Energy & $25.6 \%$ & $32.7 \%$ \\
Energy Cost & $23.2 \%$ & $29.5 \%$ \\
\hline
\end{tabular}

Figures 6.1 and 6.2 separate the energy usage savings by prototype with and without plug and process loads and show the percentage savings by prototype and the energy usage index in $\mathrm{kBtu} / \mathrm{ft}^{2}$ for both the 90.1 -2004 and 90.1-2010 cases. While the highest savings percentages occur in the school prototypes when plug and process loads are not included, these percentages do not stand out as much when plug and process loads are included. The lowest percentage savings occur in the quick-service restaurant and two apartment prototypes, particularly when plug and process loads are included.

In the weighting factors in Table 2.2 in this report, the schools represent a relatively large percentage of building area constructed and restaurants represent a small percentage, helping explain how the overall savings percentage is relatively high compared with lowest savings prototypes. These figures also highlight the high energy intensity of the restaurants and the healthcare prototypes. Tables 6.2 and 6.3 provide the same information in tabular form and show similar trends when energy cost is considered.

The results can be examined in other ways, such as aggregated energy savings by climate location and savings by energy end use (e.g., heating, cooling or lighting, and energy). Table 6.4 summarizes the EUI and energy savings aggregated by climate location. One trend in these results for different prototypes is that the overall percentage savings increase in the colder climates. Heating energy becomes a large proportion of total energy usage in those climates, and many changes in the addenda generate heating savings. Table 6.5 shows national aggregated energy savings from each end usage. The savings show that heating, exterior lights, and pumping have the greatest percentage change in energy usage. These energy 
usage categories are proportionally the most affected by the addenda. Out of the total national weighted annual average savings of $19 \mathrm{kBtu} / \mathrm{ft}^{2}$, heating is by far the largest energy savings category, almost half of the total savings, at $9 \mathrm{kBtu} / \mathrm{ft}^{2}$. Cooling, interior lighting, fans, and exterior lighting follow with contributions from $3.0 \mathrm{kBtu} / \mathrm{ft}^{2}$ down to $1.6 \mathrm{kBtu} / \mathrm{ft}^{2}$ respectively, with small savings for other specified usage categories. The column labeled "other" shows a small increase overall in energy, primarily due to energy usage for energy recovery ventilators added in the 90.1-2010 models, which is part of this category. Appendix $\mathrm{F}$ in this report includes energy end-use data for all 16 prototypes in each representative climate location.

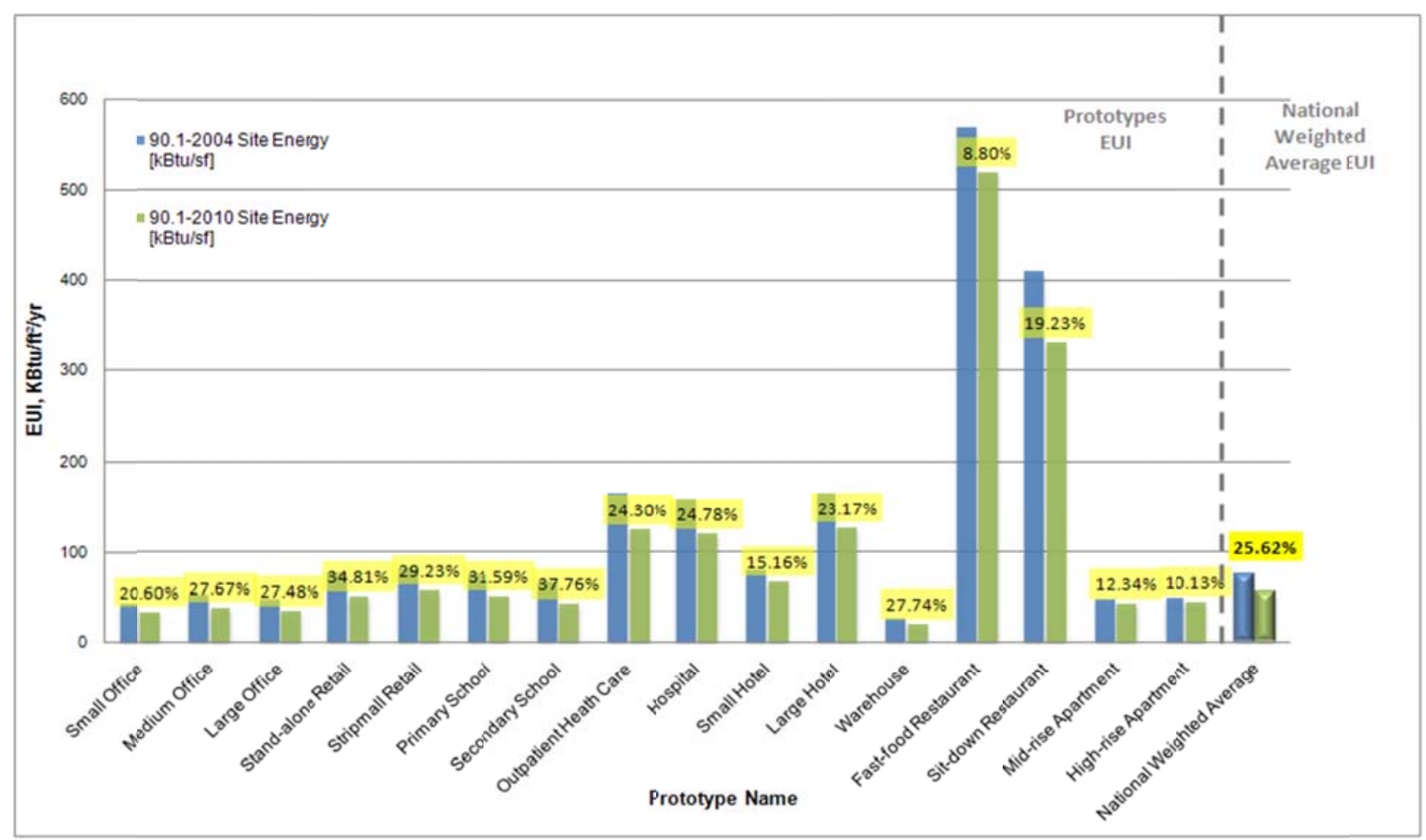

Figure 6.1. Energy Savings with Plug and Process Loads in the Percentage Calculations 


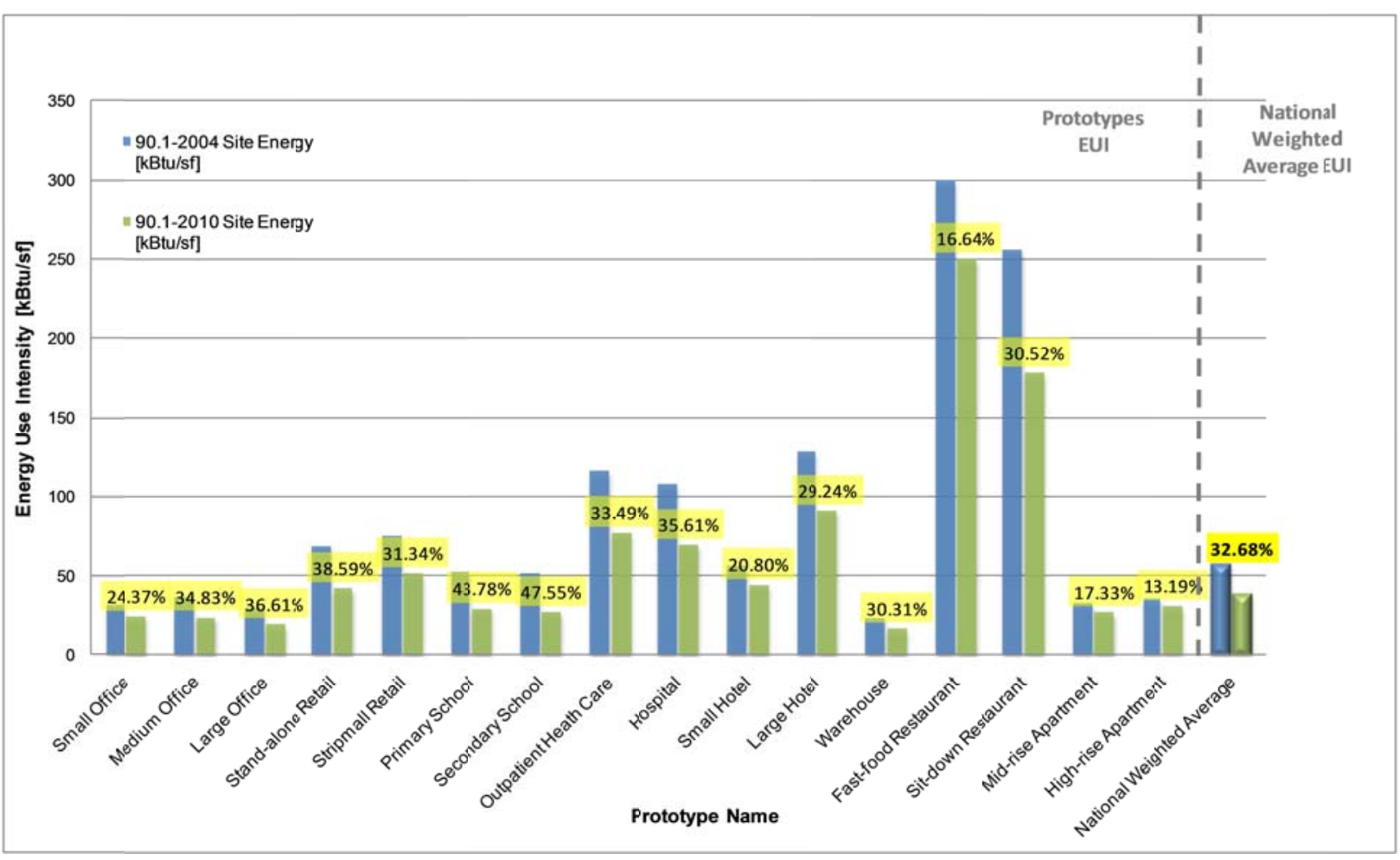

Figure 6.2. Energy Savings without Plug and Process Loads in the Percentage Calculations

Table 6.2. Energy and Energy Cost Savings with Plug and Process Loads

\begin{tabular}{|c|c|c|c|c|c|c|c|}
\hline \multirow{2}{*}{$\begin{array}{l}\text { Building } \\
\text { Type }\end{array}$} & \multirow[t]{2}{*}{ Building Prototype } & \multicolumn{2}{|c|}{$\begin{array}{l}\text { Site Energy } \\
\left(\mathbf{k B t u} / \mathbf{f t}^{2} / \mathbf{y r}\right)\end{array}$} & \multicolumn{2}{|c|}{$\begin{array}{c}\text { Energy Cost } \\
\left(\$ / \mathbf{f t}^{2}\right)\end{array}$} & \multirow{2}{*}{$\begin{array}{c}\text { Site } \\
\text { Energy } \\
\text { Savings }\end{array}$} & \multirow{2}{*}{$\begin{array}{c}\text { Energy } \\
\text { Cost } \\
\text { Savings } \\
\end{array}$} \\
\hline & & 90.1-2004 & 90.1-2010 & 90.1-2004 & 90.1-2010 & & \\
\hline \multirow{3}{*}{ Office } & Small office & 41.3 & 32.8 & $\$ 1.17$ & $\$ 0.93$ & $20.6 \%$ & $20.3 \%$ \\
\hline & Medium office & 51.6 & 37.3 & $\$ 1.42$ & $\$ 1.01$ & $27.7 \%$ & $29.1 \%$ \\
\hline & Large office & 46.0 & 33.4 & $\$ 1.21$ & $\$ 0.92$ & $27.5 \%$ & $24.3 \%$ \\
\hline \multirow{2}{*}{ Retail } & Stand-alone retail & 76.0 & 49.5 & $\$ 1.89$ & $\$ 1.32$ & $34.8 \%$ & $29.9 \%$ \\
\hline & Strip mall & 80.4 & 56.9 & $\$ 1.97$ & $\$ 1.42$ & $29.2 \%$ & $28.0 \%$ \\
\hline \multirow{2}{*}{ Education } & Primary school & 73.4 & 50.2 & $\$ 1.80$ & $\$ 1.33$ & $31.6 \%$ & $26.3 \%$ \\
\hline & Secondary school & 66.2 & 41.2 & $\$ 1.64$ & $\$ 1.13$ & $37.8 \%$ & $31.0 \%$ \\
\hline \multirow{2}{*}{ Health Care } & Outpatient healthcare & 163.3 & 123.6 & $\$ 4.17$ & $\$ 3.15$ & $24.3 \%$ & $24.3 \%$ \\
\hline & Hospital & 157.4 & 118.4 & $\$ 3.55$ & $\$ 2.81$ & $24.8 \%$ & $20.9 \%$ \\
\hline \multirow{2}{*}{ Lodging } & Small hotel & 78.5 & 66.6 & $\$ 1.72$ & $\$ 1.47$ & $15.2 \%$ & $14.4 \%$ \\
\hline & Large hotel & 163.9 & 125.9 & $\$ 2.99$ & $\$ 2.42$ & $23.2 \%$ & $19.0 \%$ \\
\hline Warehouse & Warehouse & 26.3 & 19.0 & $\$ 0.57$ & $\$ 0.42$ & $27.7 \%$ & $27.3 \%$ \\
\hline \multirow{2}{*}{$\begin{array}{l}\text { Food } \\
\text { Service }\end{array}$} & Quick service restaurant & 570.1 & 519.9 & $\$ 10.16$ & $\$ 9.12$ & $8.8 \%$ & $10.3 \%$ \\
\hline & Full service restaurant & 409.7 & 330.9 & $\$ 7.96$ & $\$ 6.12$ & $19.2 \%$ & $23.1 \%$ \\
\hline \multirow{2}{*}{ Apartment } & Mid-rise apartment & 47.0 & 41.2 & $\$ 1.23$ & $\$ 1.11$ & $12.3 \%$ & $9.4 \%$ \\
\hline & High-rise apartment & 48.9 & 44.0 & $\$ 1.35$ & $\$ 1.25$ & $10.1 \%$ & $7.3 \%$ \\
\hline \multicolumn{2}{|c|}{ National-weighted average } & 73.9 & 55.0 & $\$ 1.75$ & $\$ 1.35$ & $25.6 \%$ & $23.2 \%$ \\
\hline
\end{tabular}


Table 6.3. Energy and Energy Cost Savings without Plug and Process Loads

\begin{tabular}{|c|c|c|c|c|c|c|c|}
\hline \multirow{2}{*}{$\begin{array}{l}\text { Building } \\
\text { Type }\end{array}$} & \multirow[t]{2}{*}{ Building Prototype } & \multicolumn{2}{|c|}{$\begin{array}{l}\text { Site Energy } \\
\left(\mathbf{k B t u} / \mathbf{f t}^{2} / \mathbf{y r}\right)\end{array}$} & \multicolumn{2}{|c|}{$\begin{array}{c}\text { Energy Cost } \\
\left(\$ / \mathbf{f t}^{2}\right)\end{array}$} & \multirow{2}{*}{$\begin{array}{c}\text { Site } \\
\text { Energy } \\
\text { Savings } \\
\end{array}$} & \multirow{2}{*}{$\begin{array}{c}\text { Energy } \\
\text { Cost } \\
\text { Savings }\end{array}$} \\
\hline & & 90.1-2004 & 90.1-2010 & 90.1-2004 & 90.1-2010 & & \\
\hline \multirow{3}{*}{ Office } & Small office & 32.2 & 24.4 & $\$ 0.89$ & $\$ 0.66$ & $24.4 \%$ & $26.6 \%$ \\
\hline & Medium office & 36.6 & 23.9 & $\$ 0.97$ & $\$ 0.56$ & $34.8 \%$ & $41.8 \%$ \\
\hline & Large office & 30.4 & 19.2 & $\$ 0.85$ & $\$ 0.56$ & $36.6 \%$ & $34.0 \%$ \\
\hline \multirow{2}{*}{ Retail } & Stand-alone retail & 68.5 & 42.1 & $\$ 1.66$ & $\$ 1.10$ & $38.6 \%$ & $34.0 \%$ \\
\hline & Strip mall & 75.0 & 51.5 & $\$ 1.81$ & $\$ 1.26$ & $31.3 \%$ & $30.5 \%$ \\
\hline \multirow{2}{*}{ Education } & Primary school & 52.1 & 29.3 & $\$ 1.30$ & $\$ 0.83$ & $43.8 \%$ & $35.8 \%$ \\
\hline & Secondary school & 51.8 & 27.1 & $\$ 1.28$ & $\$ 0.78$ & $47.6 \%$ & $39.2 \%$ \\
\hline \multirow{2}{*}{ Health Care } & Outpatient healthcare & 116.0 & 77.2 & $\$ 2.88$ & $\$ 1.86$ & $33.5 \%$ & $35.3 \%$ \\
\hline & Hospital & 107.9 & 69.4 & $\$ 2.69$ & $\$ 1.96$ & $35.6 \%$ & $27.2 \%$ \\
\hline \multirow{2}{*}{ Lodging } & Small hotel & 56.1 & 44.4 & $\$ 1.32$ & $\$ 1.07$ & $20.8 \%$ & $18.7 \%$ \\
\hline & Large hotel & 128.5 & 90.9 & $\$ 2.57$ & $\$ 2.01$ & $29.2 \%$ & $21.9 \%$ \\
\hline Warehouse & Warehouse & 23.7 & 16.5 & $\$ 0.49$ & $\$ 0.34$ & $30.3 \%$ & $31.5 \%$ \\
\hline \multirow{2}{*}{$\begin{array}{l}\text { Food } \\
\text { Service }\end{array}$} & $\begin{array}{l}\text { Quick service } \\
\text { restaurant }\end{array}$ & 300.6 & 250.6 & $\$ 7.50$ & $\$ 6.46$ & $16.6 \%$ & $13.9 \%$ \\
\hline & Full service restaurant & 256.3 & 178.1 & $\$ 5.78$ & $\$ 3.94$ & $30.5 \%$ & $31.8 \%$ \\
\hline \multirow{2}{*}{ Apartment } & Mid-rise apartment & 32.4 & 26.8 & $\$ 0.79$ & $\$ 0.67$ & $17.3 \%$ & $14.7 \%$ \\
\hline & High-rise apartment & 35.7 & 31.0 & $\$ 0.95$ & $\$ 0.86$ & $13.2 \%$ & $9.8 \%$ \\
\hline \multicolumn{2}{|c|}{ National-weighted average } & 56.8 & 38.2 & $\$ 1.37$ & $\$ 0.96$ & $32.7 \%$ & $29.5 \%$ \\
\hline
\end{tabular}

Table 6.4. EUI and Energy Savings by Climate Zones

\begin{tabular}{clcccc}
\hline $\begin{array}{c}\text { Climate } \\
\text { Zone }\end{array}$ & \multicolumn{1}{c}{$\begin{array}{c}\text { Climate } \\
\text { Location }\end{array}$} & $\begin{array}{c}\text { Construction } \\
\text { Weights }\end{array}$ & $\begin{array}{c}90.1-2004 \\
\text { Site Energy } \\
\left(\mathrm{kBtu} / \mathrm{ft}^{2} / \mathrm{yr}\right)\end{array}$ & $\begin{array}{c}90.1-2010 \\
\text { Site Energy } \\
\left(\mathrm{kBtu} / \mathrm{ft}^{2} / \mathrm{yr}\right)\end{array}$ & $\begin{array}{c}\text { Site Energy } \\
\text { Savings }\end{array}$ \\
\hline 1A & Miami & $3.24 \%$ & 56.6 & 47.9 & $15.4 \%$ \\
\hline 2A & Houston & $15.22 \%$ & 69.0 & 52.4 & $24.0 \%$ \\
\hline 2B & Phoenix & $2.98 \%$ & 70.1 & 53.8 & $23.3 \%$ \\
\hline 3A & Memphis & $15.03 \%$ & 70.1 & 52.0 & $25.7 \%$ \\
\hline 3B & El Paso & $10.08 \%$ & 61.2 & 49.1 & $19.7 \%$ \\
\hline 3C & San Francisco & $1.61 \%$ & 57.0 & 45.1 & $20.8 \%$ \\
\hline 4A & Baltimore & $19.29 \%$ & 75.2 & 54.7 & $27.3 \%$ \\
\hline 4B & Albuquerque & $0.52 \%$ & 76.6 & 60.1 & $21.5 \%$ \\
\hline 4C & Salem & $2.98 \%$ & 65.7 & 51.2 & $22.1 \%$ \\
\hline 5A & Chicago & $19.37 \%$ & 85.1 & 60.8 & $28.6 \%$ \\
\hline 5B & Boise & $4.34 \%$ & 75.9 & 58.5 & $22.9 \%$ \\
\hline 6A & Burlington & $4.21 \%$ & 97.1 & 67.8 & $30.1 \%$ \\
\hline $6 \mathrm{~B}$ & Helena & $0.57 \%$ & 92.8 & 66.6 & $28.3 \%$ \\
\hline 7 & Duluth & $0.51 \%$ & 112.8 & 76.2 & $32.4 \%$ \\
\hline 8 & Fairbanks & $0.06 \%$ & 130.1 & 87.4 & $32.8 \%$ \\
\hline
\end{tabular}


Table 6.5. EUI by Prototype and Energy Usage Category

\begin{tabular}{|c|c|c|c|c|c|c|c|c|c|c|c|c|c|c|c|c|c|c|c|c|}
\hline \multirow{2}{*}{$\begin{array}{c}\begin{array}{c}\text { Units in } \\
\mathbf{k B t u} / \mathbf{f t}^{2} / \text { year }\end{array} \\
\text { Prototype }\end{array}$} & \multicolumn{2}{|c|}{ Interior Lights } & \multicolumn{2}{|c|}{$\begin{array}{c}\text { Exterior } \\
\text { Lights }\end{array}$} & \multicolumn{2}{|c|}{ Plug Loads } & \multicolumn{2}{|c|}{ Fans } & \multicolumn{2}{|c|}{ Pumps } & \multicolumn{2}{|c|}{ Cooling } & \multicolumn{2}{|c|}{ Heating } & \multicolumn{2}{|c|}{$\begin{array}{c}\text { Service Water } \\
\text { Heater }\end{array}$} & \multicolumn{2}{|c|}{ Others } & \multicolumn{2}{|c|}{ Total } \\
\hline & $\begin{array}{l}90.1- \\
2004\end{array}$ & \begin{tabular}{|l|}
$90.1-$ \\
2010
\end{tabular} & \begin{tabular}{|l|}
$90.1-$ \\
2004
\end{tabular} & $\begin{array}{l}90.1- \\
2010\end{array}$ & $\begin{array}{l}90.1- \\
2004\end{array}$ & $\begin{array}{l}90.1- \\
2010\end{array}$ & $\begin{array}{l}90.1- \\
2004\end{array}$ & $\begin{array}{l}90.1- \\
2010\end{array}$ & $\begin{array}{l}90.1- \\
2004\end{array}$ & $\begin{array}{l}90.1- \\
2010\end{array}$ & $\begin{array}{l}90.1- \\
2004\end{array}$ & $\begin{array}{l}90.1- \\
2010\end{array}$ & $\begin{array}{l}\text { 90.1- } \\
2004\end{array}$ & $\begin{array}{l}90.1- \\
2010\end{array}$ & $\begin{array}{l}\text { 90.1- } \\
2004\end{array}$ & $\begin{array}{l}\text { 90.1- } \\
2010\end{array}$ & $\begin{array}{l}90.1- \\
2004\end{array}$ & $\begin{array}{l}\text { 90.1- } \\
2010\end{array}$ & $\begin{array}{l}\text { 90.1- } \\
2004\end{array}$ & $\begin{array}{l}90.1- \\
2010\end{array}$ \\
\hline Small Office & 12.2 & 10.2 & 4.4 & 1.6 & 9.1 & 8.4 & 4.4 & 3.9 & 0.0 & 0.0 & 4.9 & 3.7 & 4.4 & 3.2 & 1.8 & 1.8 & 0.0 & 0.0 & 41.3 & 32.8 \\
\hline Medium Office & 9.8 & 6.8 & 4.0 & 1.4 & 15.0 & 13.5 & 2.1 & 1.5 & 0.0 & 0.0 & 8.4 & 5.9 & 8.8 & 4.7 & 3.5 & 3.5 & 0.0 & 0.0 & 51.6 & 37.3 \\
\hline Large Office & 9.8 & 7.2 & 1.9 & 1.0 & 15.6 & 14.1 & 2.0 & 1.6 & 1.8 & 1.1 & 6.2 & 3.9 & 8.1 & 3.8 & 0.6 & 0.6 & 0.0 & 0.0 & 46.0 & 33.4 \\
\hline $\begin{array}{l}\text { Standalone } \\
\text { Retail }\end{array}$ & 18.8 & 17.0 & 4.4 & 1.8 & 7.5 & 7.5 & 15.0 & 8.2 & 0.0 & 0.0 & 10.4 & 6.1 & 18.7 & 7.1 & 1.2 & 1.2 & 0.0 & 0.6 & 76.0 & 49.5 \\
\hline Strip Mall & 24.2 & 18.8 & 6.1 & 2.3 & 5.4 & 5.4 & 11.1 & 8.2 & 0.0 & 0.0 & 11.4 & 7.6 & 20.4 & 12.7 & 1.9 & 1.9 & 0.0 & 0.0 & 80.4 & 56.9 \\
\hline Primary School & 15.5 & 10.4 & 1.1 & 0.5 & 21.3 & 20.9 & 6.8 & 4.6 & 0.0 & 0.0 & 11.8 & 7.5 & 14.9 & 3.7 & 1.0 & 1.0 & 1.0 & 1.7 & 73.4 & 50.2 \\
\hline $\begin{array}{l}\text { Secondary } \\
\text { School }\end{array}$ & 14.8 & 9.7 & 1.0 & 0.4 & 14.4 & 14.0 & 7.4 & 4.5 & 0.6 & 0.2 & 12.1 & 8.0 & 14.6 & 2.4 & 0.5 & 0.5 & 0.7 & 1.5 & 66.2 & 41.2 \\
\hline $\begin{array}{l}\text { Outpatient } \\
\text { Healthcare }\end{array}$ & 14.2 & 12.3 & 5.3 & 3.0 & 47.3 & 46.5 & 13.7 & 9.4 & 0.5 & 0.4 & 26.4 & 18.6 & 49.8 & 29.4 & 1.1 & 1.1 & 5.1 & 2.8 & 163.3 & 123.6 \\
\hline Hospital & 16.6 & 14.2 & 1.0 & 0.8 & 49.6 & 49.0 & 17.2 & 11.4 & 5.3 & 3.4 & 18.6 & 11.7 & 47.1 & 25.6 & 1.1 & 1.1 & 0.8 & 1.2 & 157.4 & 118.4 \\
\hline Small Hotel & 10.9 & 9.0 & 2.1 & 1.4 & 22.5 & 22.2 & 8.8 & 7.9 & 0.0 & 0.0 & 9.4 & 7.3 & 13.7 & 7.5 & 11.2 & 11.2 & 0.0 & 0.0 & 78.5 & 66.6 \\
\hline Large Hotel & 11.3 & 10.6 & 2.4 & 1.8 & 35.4 & 35.0 & 6.0 & 5.1 & 2.4 & 0.7 & 23.1 & 16.4 & 34.7 & 6.1 & 48.2 & 48.2 & 0.6 & 1.9 & 163.9 & 125.9 \\
\hline Warehouse & 8.8 & 6.1 & 2.2 & 1.2 & 2.5 & 2.4 & 1.0 & 0.8 & 0.0 & 0.0 & 0.6 & 0.5 & 11.0 & 7.8 & 0.1 & 0.1 & 0.0 & 0.0 & 26.3 & 19.0 \\
\hline $\begin{array}{l}\text { Quick Service } \\
\text { Restaurant }\end{array}$ & 28.5 & 13.5 & 10.4 & 4.4 & 274.6 & 274.5 & 32.4 & 32.9 & 0.0 & 0.0 & 31.4 & 25.3 & 143.9 & 120.6 & 24.2 & 24.2 & 24.8 & 24.6 & 570.1 & 519.9 \\
\hline $\begin{array}{l}\text { Full Service } \\
\text { Restaurant }\end{array}$ & 32.0 & 13.5 & 10.0 & 4.3 & 157.6 & 157.1 & 33.5 & 16.0 & 0.0 & 0.0 & 28.1 & 18.4 & 104.0 & 77.5 & 33.3 & 33.3 & 11.1 & 10.9 & 409.7 & 330.9 \\
\hline $\begin{array}{l}\text { Mid-rise } \\
\text { Apartment }\end{array}$ & 2.8 & 2.9 & 2.0 & 1.1 & 14.5 & 14.4 & 5.7 & 5.0 & 0.0 & 0.0 & 5.1 & 4.0 & 9.3 & 6.4 & 7.4 & 7.4 & 0.0 & 0.0 & 47.0 & 41.2 \\
\hline $\begin{array}{l}\text { High-rise } \\
\text { Apartment }\end{array}$ & 2.6 & 2.7 & 2.2 & 1.7 & 13.2 & 13.0 & 5.5 & 4.9 & 0.7 & 0.5 & 9.3 & 9.0 & 7.9 & 4.8 & 7.4 & 7.4 & 0.0 & 0.0 & 48.9 & 44.0 \\
\hline $\begin{array}{l}\text { National } \\
\text { Weighted } \\
\text { Average }\end{array}$ & 12.4 & 9.8 & 3.0 & 1.4 & 17.2 & 16.8 & 7.6 & 5.2 & 0.5 & 0.3 & 9.8 & 6.8 & 17.8 & 8.8 & 5.0 & 5.0 & 0.6 & 0.8 & 73.9 & 55.0 \\
\hline $\begin{array}{l}\text { \% Savings by } \\
\text { Each End-use } \\
\text { Category }\end{array}$ & \multicolumn{2}{|c|}{$21.1 \%$} & \multicolumn{2}{|c|}{$51.7 \%$} & \multicolumn{2}{|c|}{$2.2 \%$} & \multicolumn{2}{|c|}{$31.4 \%$} & \multicolumn{2}{|c|}{$45.5 \%$} & \multicolumn{2}{|c|}{$30.5 \%$} & \multicolumn{2}{|c|}{$50.4 \%$} & \multicolumn{2}{|c|}{$0.0 \%$} & \multicolumn{2}{|c|}{$0.0 \%$} & \multicolumn{2}{|c|}{$25.6 \%$} \\
\hline
\end{tabular}




\subsection{References}

AAMA/WDMA/CSA. 2008. AAMA/WDMA/CSA 101/I.S.2/A440-08, North American Fenestration Standard/Specification for Windows, Doors, and Unit Skylights, American Architectural Manufacturers Association, Schaumburg, Illinois.

AIA. 2001. AIA Guidelines for Design and Construction of Hospital and Health Care Facilities: 2001 Edition. American Institute of Architects, Washington, D.C..

ANSI/ASHRAE. 2003. Standard 154-2003, Ventilation for Commercial Cooking Operations. American Society of Heating, Refrigerating and Air-Conditioning Engineers, Atlanta, Georgia.

ANSI/ASHRAE. 2004. ANSI/ASHRAE Standard 62.1-2004, Ventilation for Acceptable Indoor Air Quality. American Society of Heating, Refrigerating and Air-Conditioning Engineers, Atlanta, Georgia.

ANSI/ASHRAE. 2007. ANSI/ASHRAE Standard 62.1-2007, Ventilation for Acceptable Indoor Air Quality. American Society of Heating, Refrigerating and Air-Conditioning Engineers, Atlanta, Georgia.

ANSI/ASHRAE/ACCA. 2007. ANSI/ASHRAE/ACCA Standard 183-2007, Peak Cooling and Heating Load Calculations in Buildings Except Low-Rise Residential Buildings. American Society of Heating, Refrigerating and Air-Conditioning Engineers, Atlanta, Georgia.

ANSI/ASHRAE/IESNA. 2001. ANSI/ASHRAE/IESNA Standard 90.1-2001, Energy Standard for Buildings Except Low-Rise Residential Buildings. American Society of Heating, Refrigerating and AirConditioning Engineers, Atlanta, Georgia.

ANSI/ASHRAE/IESNA. 2004. ANSI/ASHRAE/IESNA 90.1-2004, Energy Standard for Buildings Except Low-Rise Residential Buildings. American Society of Heating, Refrigerating and Air-Conditioning Engineers, Atlanta, Georgia.

ANSI/ASHRAE/IESNA. 2007. ANSI/ASHRAE/IESNA 90.1-2007, Energy Standard for Buildings Except Low-Rise Residential Buildings. American Society of Heating, Refrigerating and Air-Conditioning Engineers, Atlanta, Georgia.

ANSI/ASHRAE/IES. 2010. ANSI/ASHRAE/IESNA 90.1-2010, Energy Standard for Buildings Except Low-Rise Residential Buildings. American Society of Heating, Refrigerating and Air-Conditioning Engineers, Atlanta, Georgia.

ANSI/AHRI. 2008. ANSI/AHRI 1160-2008, Performance Rating of Heat Pump Pool Heaters. AirConditioning, Heating, and Refrigeration Institute. Arlington, VA

ANSI/NEMA. 2006. ANSI/NEMA MG 1-2006, Motors and Generators. National Electrical Manufacturing Association. Rosslyn, Virginia

ASHRAE/AIA/IESNA. 2009. Advanced Energy Design Guide for Highway Lodging. American Society of Heating, Refrigerating and Air-Conditioning Engineers, Atlanta, Georgia. 
ASHRAE. 1999. ASHRAE Standard 62-1999. Ventilation for Acceptable Indoor Air Quality. American Society of Heating, Refrigerating and Air-Conditioning Engineers, Atlanta, Georgia.

ASHRAE. 2004. Advanced Energy Design Guide for Small Office Building. American Society of Heating, Refrigerating and Air-Conditioning Engineers, Atlanta, Georgia.

ASHRAE. 2009. Handbook of Fundamentals. American Society of Heating, Refrigerating and AirConditioning Engineers, Atlanta, Georgia.

ASTM. 2001. ASTM E1980 (2001), Standard Practice for Calculating Solar Reflectance Index of Horizontal and Low-Sloped Opaque Surfaces, American Society for Testing and Materials West Conshohocken, Pennsylvania.

Briggs, R.L., R.G. Lucas, and Z.T. Taylor. 2003. "Climate Classification for Building Energy Codes and Standards: Part 1—Development Process.” ASHRAE Transactions, (1):4610-4611.

Cadmus Group. 1999. Metered Load Factors for Low-Voltage, Dry-Type Transformers in Commercial, Industrial, and Public Buildings. Available through Consortium for Energy Efficiency. Last accessed in April 2011 at www.cee1.org/ind/trnsfm/neep-rpt.pdf

CBECS. 2003. Commercial Buildings Energy Consumption Survey 2003. Energy Information Administration, U.S. Department of Energy, Washington, D.C. Last accessed in July, 2009 at http://www.eia.doe.gov/emeu/cbecs/contents.html

Cho, H., K. Gowri, B. Liu, 2010, Energy Saving Impact of ASHRAE 90.1 Vestibule Requirements: Modeling of Air Infiltration through Door Openings, PNNL-20026. Pacific Northwest National Laboratory. Richland, Washington.

Deru, M., K. Field, D. Studer, K. Benne, B. Griffith, P. Torcellini, B. Liu, M. Halverson, D. Winiarski, M. Yazdazian, J. Huang, D. Crawley. 2011. U.S. Department of Energy Commercial Reference Building Models of the National Building Stock. NREL/TP-5500-46861, National Renewable Energy Laboratory, Golden, Colorado.

DiLouie, C. 2009. CLTC Study Demonstrates Major Energy Savings for Bilevel Occupancy Sensors. Lighting Controls Association, Rosslyn, Virginia. Last accessed in July, 2009 at http://www.aboutlightingcontrols.org/education/papers/2009/2009_bilevel_study.shtml

DOE. 2004. Technical Support Document: Energy Efficiency Program for Commercial and Industrial Equipment: Electrical Distribution Transformers. U.S. Department of Energy, Washington DC. Last accessed April 2011 at http://www1.eere.energy.gov/buildings/appliance_standards/commercial/dist trans_tsd_061404.html

DOE. 2010a. Energy Conservation Program for Certain Industrial Equipment: Test Procedures and Energy Conservation Standards for Commercial Heating, Air-Conditioning, and Water Heating Equipment Final Rule Technical Support Document, September 14, 2009. Washington, D.C. Available at http://wwwl.eere.energy.gov/buildings/appliance_standards/commercial/ashrae_final_rule.html 
DOE. 2010b. Energy Plus Energy Simulation Software. U.S. Department of Energy, Washington, D.C. Last accessed in April 2010 at http://apps1.eere.energy.gov/buildings/EnergyPlus/

EIA. 2006. Annual Energy Review., U.S. Energy Information Administration, Washington D.C. Accessed March 26, 2007, at http://www.eia.doe.gov/emeu/aer

EIA. 2011. Annual Energy Outlook 2011. U.S. Energy Information Administration. Last accessed May 17, 2011 at http://www.eia.doe.gov/forecasts/aeo/

Emmerich, S.J., T. McDowell, and W. Anis. 2005. Investigation of the Impact of Commercial Building Envelope Airtightness on HVAC Energy Use. June, 2005. Report No. NISTIR 7238, National Institute of Standards and Technology, Gaithersburg, Maryland.

F.W. DODGE. 2002. Dodge Plans Via The Internet. Available online at http://dodge.construction.com/Plans/Electronic/ViaInternet.asp

Gowri, K., D.W. Winiarski, and R.E. Jarnagin. 2009. Infiltration Modeling Guidelines for Commercial Building Energy Analysis. PNNL-18898, Pacific Northwest National Laboratory, Richland, Washington.

Jarnagin, R.E., and G.K. Bandyopadhyay. 2010. Weighting Factors for the Commercial Building Prototypes Used in the Development of ANSI/ASHRAE/IESNA 90.1-2010. PNNL-19116, Pacific Northwest National Laboratory, Richland, Washington.

Jiang, W., R.E. Jarnagin, K. Gowri, M.F. McBride, and L. Bing. 2008. Technical Support Document: Development of the Advanced Energy Design Guide for Highway Lodging Buildings. PNNL-17875, Pacific Northwest National Laboratory, Richland, Washington.

Liu, B., R.E. Jarnagin, D.W. Winiarski, W. Jiang, M.F. McBride, and G.C. Crall. 2006. Technical Support Document: Development of the Advanced Energy Design Guide for Small Retail Buildings. PNNL-16031, Pacific Northwest National Laboratory, Richland, Washington.

NFRC. 2004. NFRC 400-2004 Procedure for Determining Fenestration Product Air Leakage. National Fenestration Ratting Council, Silver Springs, Maryland.

Pless, S., P. Torcellini, and N. Long. 2007. Technical Support Document: Development of the Advanced Energy Design Guide for K-12 Schools-30\% Energy Savings. NREL/TP-550-42114, National Renewable Energy Laboratory, Golden, Colorado.

PNNL. 2004. Technical Support Document: Energy Efficiency Program for Commercial and Industrial Equipment: Advanced Notice of Proposed Rulemaking for Commercial Unitary Air Conditioners and Heat Pumps. U.S. Department of Energy. Washington D.C., pp. 6-1 to 6-60. Available at http://www.eere.energy.gov/buildings/appliance_standards/commercial/pdfs/cuac tsd_chp_6.pdf

Richman EE, AL Dittmer, and JM Keller. 1994. Field Analysis of Occupancy Sensor Operation: Parameters Affecting Lighting Energy Savings, PNL-10135, Pacific Northwest Laboratory. Richland, Washington. 
Richman, E.E., E. Rauch, J. Knappek, J. Phillips, K. Petty, and P. Lopez-Rangel. 2008. National Commercial Construction Characteristics and Compliance with Building Energy Codes: 1999-2007. 2008 ACEEE Summer Study on Energy Efficiency in Buildings. ACEEE Publications, Washington D.C.

Stanke, D. 2010. Dynamic Reset for Multiple-Zone Systems

ASHRAE Journal, vol. 52, no. 3, March 2010

Thornton, B.A., W. Wang, M.D. Lane, M.I. Rosenberg, and B. Liu. 2009. Technical Support Document: 50\% Energy Savings Design Technology Packages for Medium Office Buildings. PNNL-19004, Pacific Northwest National Laboratory, Richland, Washington.

Thornton B.A., W. Wang, Y Huang, M.D. Lane, and B Liu. 2010. Technical Support Document: 50\% Energy Savings for Small Office Buildings. PNNL-19341, Pacific Northwest National Laboratory, Richland, Washington.

VonNeida, B., D. Maniccia, and T. Allan. 2000. An Analysis of the Energy and Cost Savings Potential of Occupancy Sensors for Commercial Lighting Systems. Illuminating Engineering Society of North America 2000 Annual Conference: Proceedings. IESNA, New York. Last accessed in March 2010 at http://www.lrc.rpi.edu/resources/pdf/dorene1.pdf

Wassmer, M., and M. J. Brandemuehl. 2006. Effect of Data Availability on Modeling of Residential Air Conditioners and Heat Pumps for Energy Calculations. ASHRAE Transactions 111(1), pp. 214-225.

Winiarski DW, MA Halverson, and W Jiang. 2007. Analysis of Building Envelope Construction in 2003 CBECS. PNNL-20380, Pacific Northwest National Laboratory, Richland, WA.

Winiarski DW, W Jiang, and MA Halverson. 2008. Review of Pre- and Post-1980 Buildings in CBECS HVAC Equipment. Pacific Northwest National Laboratory, PNNL-20346, Richland, Washington.

Zhivov, A. 2010. "New Requirements to the United States Army Buildings Air Tightness." AIVC Workshop, Brussels, Belgium. 
Appendix A

\section{Energy Modeling Building Descriptions}




\section{A.1 Small Office Modeling Description}

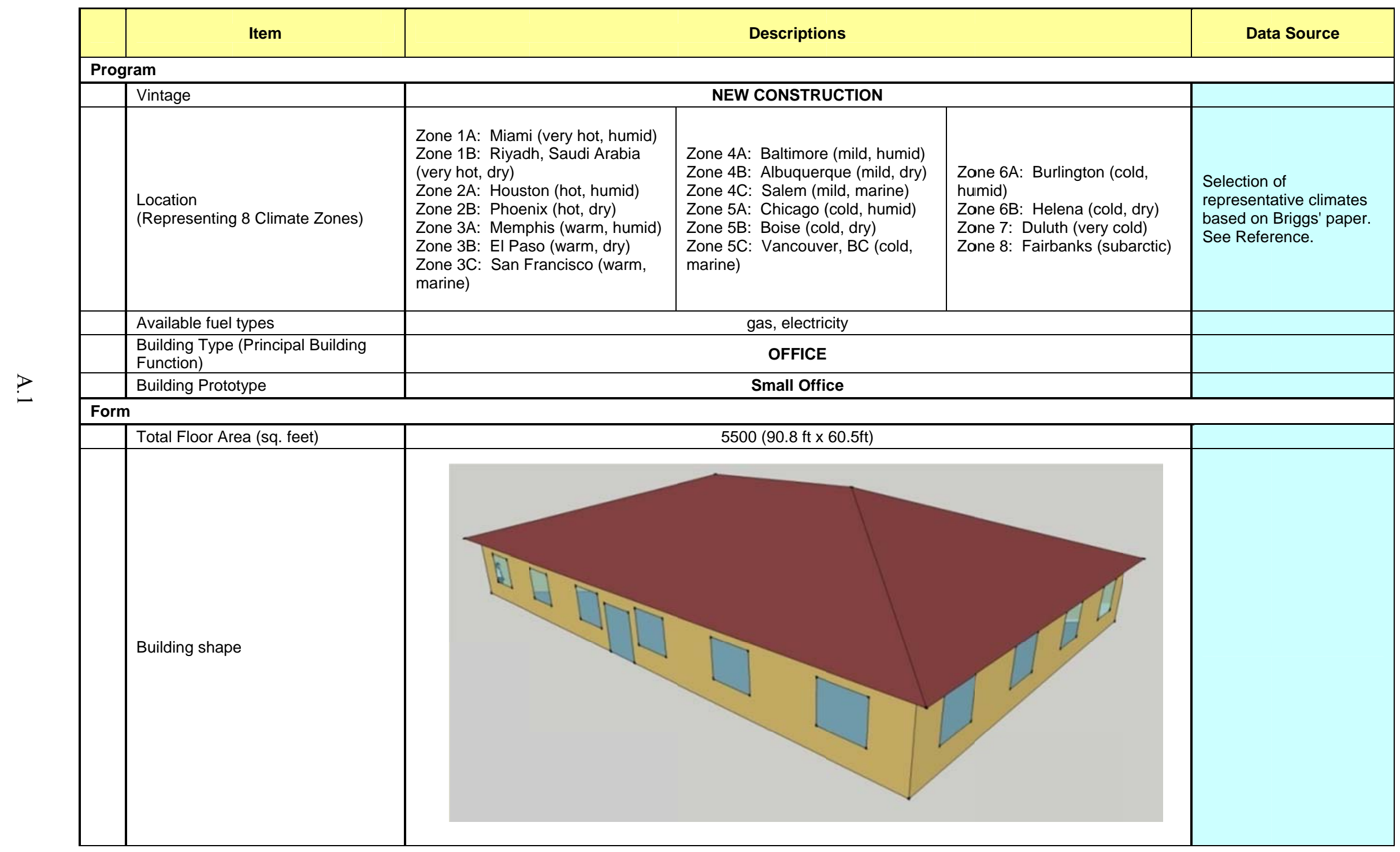




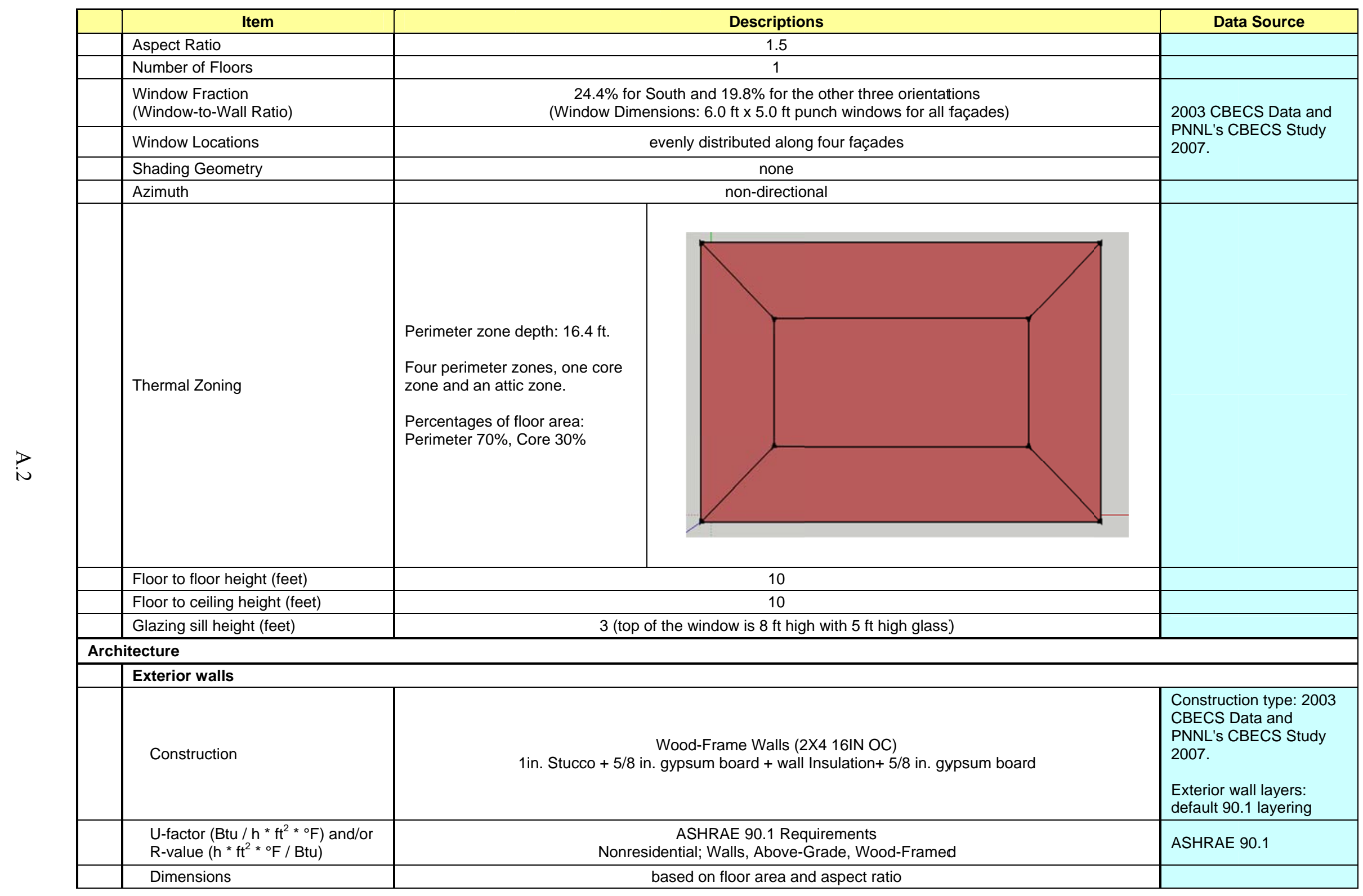




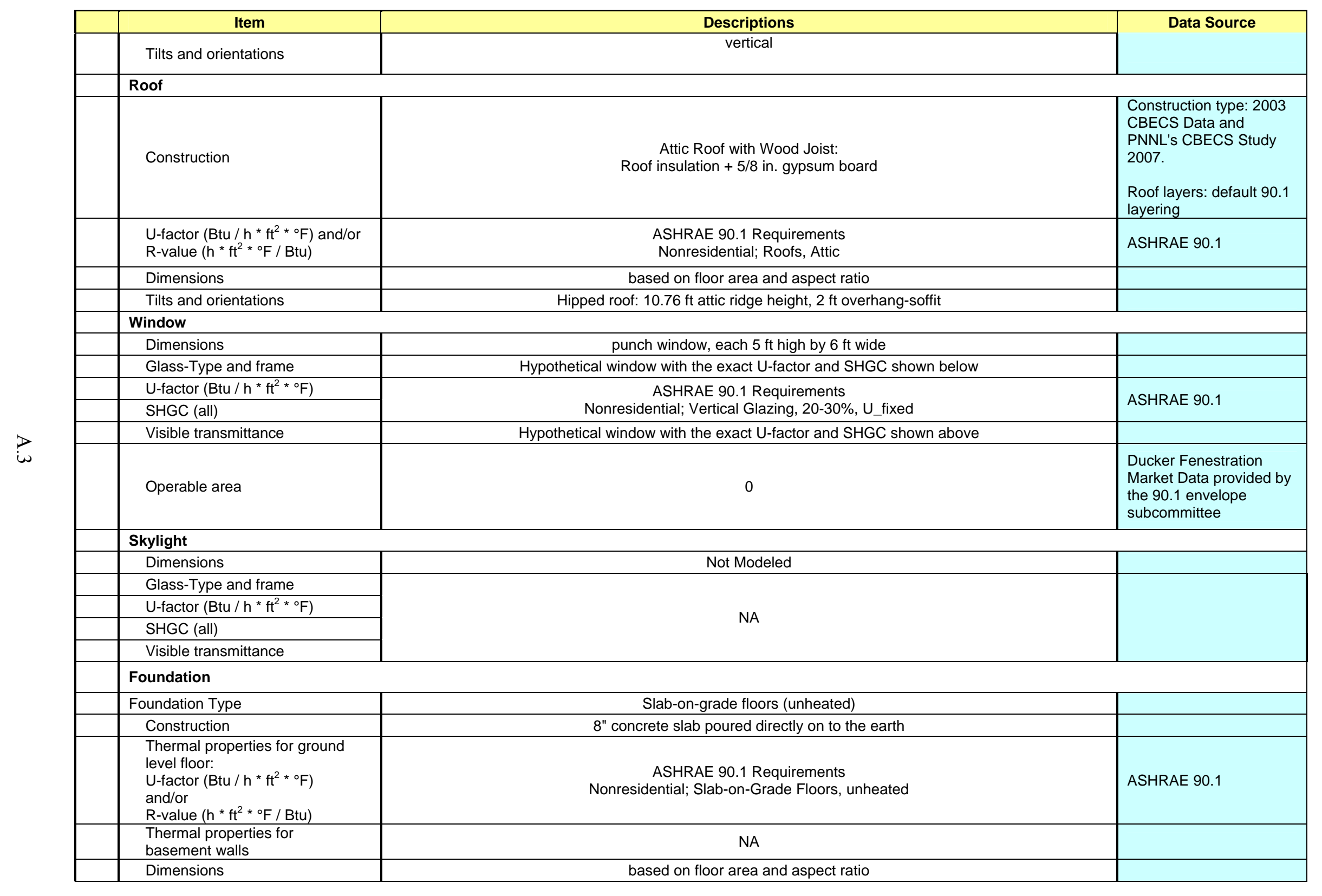




\begin{tabular}{|c|c|c|}
\hline Item & Descriptions & Data Source \\
\hline \multicolumn{3}{|l|}{ Interior Partitions } \\
\hline Construction & $2 \times 4$ uninsulated stud wall & \\
\hline Dimensions & based on floor plan and floor-to-floor height & \\
\hline Internal Mass & 6 inches standard wood $\left(16.6 \mathrm{lb} / \mathrm{ft}^{2}\right)$ & \\
\hline \multicolumn{3}{|l|}{ Air Barrier System } \\
\hline Infiltration & $\begin{array}{c}\text { Peak: } 0.2016 \mathrm{cfm} / \mathrm{sf} \text { of above grade exterior wall surface area (when fans turn off) } \\
\text { Off Peak: } 25 \% \text { of peak infiltration rate (when fans turn on) }\end{array}$ & $\begin{array}{l}\text { Reference: } \\
\text { PNNL-18898: Infiltration } \\
\text { Modeling Guidelines for } \\
\text { Commercial Building } \\
\text { Energy Analysis. }\end{array}$ \\
\hline \multicolumn{3}{|l|}{ HVAC } \\
\hline \multicolumn{3}{|l|}{ System Type } \\
\hline Heating type & Air-source heat pump with gas furnace as back up & \multirow{3}{*}{$\begin{array}{l}2003 \text { CBECS Data, } \\
\text { PNNL's CBECS Study } \\
\text { 2006, and } 90.1 \\
\text { Mechanical } \\
\text { Subcommittee input. }\end{array}$} \\
\hline Cooling type & Air-source heat pump & \\
\hline Distribution and terminal units & Single zone, constant air volume air distribution, one unit per occupied thermal zone & \\
\hline \multicolumn{3}{|l|}{ HVAC Sizing } \\
\hline Air Conditioning & autosized to design day & \\
\hline Heating & autosized to design day & \\
\hline \multicolumn{3}{|l|}{ HVAC Efficiency } \\
\hline Air Conditioning & $\begin{array}{l}\text { Various by climate location and design cooling capacity } \\
\text { ASHRAE } 90.1 \text { Requirements } \\
\text { Minimum equipment efficiency for Packaged Heat Pumps }\end{array}$ & ASHRAE 90.1 \\
\hline Heating & $\begin{array}{l}\text { Various by climate location and design heating capacity } \\
\text { ASHRAE } 90.1 \text { Requirements } \\
\text { Minimum equipment efficiency for Packaged Heat Pumps and Warm Air Furnaces }\end{array}$ & ASHRAE 90.1 \\
\hline \multicolumn{3}{|l|}{ HVAC Control } \\
\hline Thermostat Setpoint & $75^{\circ} \mathrm{F}$ Cooling $/ 70^{\circ} \mathrm{F}$ Heating & \\
\hline Thermostat Setback & $85^{\circ} \mathrm{F}$ Cooling $/ 60^{\circ} \mathrm{F}$ Heating & \\
\hline Supply air temperature & Maximum 104F, Minimum 55F & \\
\hline $\begin{array}{l}\text { Chilled water } \\
\text { supply temperatures }\end{array}$ & NA & \\
\hline Hot water supply temperatures & NA & \\
\hline Economizers & $\begin{array}{l}\text { Various by climate location and cooling capacity } \\
\text { Control type: differential dry bulb }\end{array}$ & ASHRAE 90.1 \\
\hline
\end{tabular}




\begin{tabular}{|c|c|c|}
\hline Item & Descriptions & Data Source \\
\hline Ventilation & ASHRAE Ventilation Standard 62.1 & $\begin{array}{l}\text { ASHRAE Ventilation } \\
\text { Standard } 62.1\end{array}$ \\
\hline Demand Control Ventilation & ASHRAE 90.1 Requirements & ASHRAE 90.1 \\
\hline Energy Recovery & ASHRAE 90.1 Requirements & ASHRAE 90.1 \\
\hline \multicolumn{3}{|l|}{ Supply Fan } \\
\hline Fan Hourly Operation Schedules & See Appendix C & \\
\hline Supply Fan Total Efficiency (\%) & Depending on the fan motor size & \multirow{2}{*}{$\begin{array}{l}\text { ASHRAE } 90.1 \\
\text { requirements for motor } \\
\text { efficiency and fan power } \\
\text { limitation }\end{array}$} \\
\hline Supply Fan Pressure Drop & Various depending on the fan supply air cfm & \\
\hline \multicolumn{3}{|l|}{ Pump } \\
\hline Pump Type & NA & \\
\hline Rated Pump Head & NA & \\
\hline Pump Power & autosized & \\
\hline \multicolumn{3}{|l|}{ Cooling Tower } \\
\hline Cooling Tower Type & NA & \\
\hline Cooling Tower Efficiency & NA & \\
\hline \multicolumn{3}{|l|}{ Service Water Heating } \\
\hline SWH type & Storage Tank & \\
\hline Fuel type & Natural Gas & \\
\hline Thermal efficiency (\%) & $\begin{array}{l}\text { ASHRAE } 90.1 \text { Requirements } \\
\text { Water Heating Equipment, Gas storage water heaters, }>75,000 \text { Btu/h input }\end{array}$ & ASHRAE 90.1 \\
\hline Tank Volume (gal) & 40 & \\
\hline Water temperature setpoint & $120 \mathrm{~F}$ & \\
\hline Water consumption & See Appendix C & \\
\hline \multicolumn{3}{|l|}{ Internal Loads \& Schedules } \\
\hline \multicolumn{3}{|l|}{\begin{tabular}{|l|} 
Lighting \\
\end{tabular}} \\
\hline Average power density $\left(\mathrm{W} / \mathrm{ft}^{2}\right)$ & $\begin{array}{l}\text { ASHRAE } 90.1 \\
\text { Lighting Power Densities Using the Building Area Method }\end{array}$ & ASHRAE 90.1 \\
\hline Schedule & See Appendix C & \\
\hline Daylighting Controls & ASHRAE 90.1 Requirements & \\
\hline Occupancy Sensors & ASHRAE 90.1 Requirements & \\
\hline \multicolumn{3}{|l|}{ Plug load } \\
\hline Average power density $\left(\mathrm{W} / \mathrm{ft}^{2}\right)$ & See Appendix B & $\begin{array}{l}\text { User's Manual for } \\
\text { ASHRAE Standard 90.1- } \\
2004 \text { (Appendix G) }\end{array}$ \\
\hline
\end{tabular}




\begin{tabular}{|c|c|c|}
\hline Item & Descriptions & \multirow[t]{2}{*}{ Data Source } \\
\hline Schedule & See Appendix C & \\
\hline \multicolumn{3}{|l|}{ Occupancy } \\
\hline Average people & See Appendix B & $\begin{array}{l}\text { User's Manual for } \\
\text { ASHRAE Standard 90.1- } \\
2004 \text { (Appendix G) }\end{array}$ \\
\hline Schedule & See Appendix C & \\
\hline \multicolumn{3}{|l|}{ Misc. } \\
\hline \multicolumn{3}{|l|}{ Elevator } \\
\hline Peak Power & NA & \\
\hline Schedule & NA & \\
\hline \multicolumn{3}{|l|}{ Exterior Lighting } \\
\hline Peak Power (W) & 1,634 & \multirow{2}{*}{ ASHRAE 90.1} \\
\hline Schedule & See Appendix C & \\
\hline
\end{tabular}

References

Briggs, R.S., R.G. Lucas, and Z.T. Taylor. 2003. Climate Classification for Building Energy Codes and Standards:

Part 2-Zone Definitions, Maps, and Comparisons. ASHRAE Transactions 109(2)

PNNL's CBECS Study. 2007. Analysis of Building Envelope Construction in 2003 CBECS Buildings. Dave Winiarski, Mark Halverson, and Wei Jiang. Pacific Northwest National Laboratory. March 2007.

PNNL's CBECS Study. 2006. Review of Pre- and Post-1980 Buildings in CBECS - HVAC Equipment. Dave Winiarski, Wei Jiang and Mark Halverson. Pacific Northwest National Laboratory. December 2006.

Gowri K, DW Winiarski, and RE Jarnagin. 2009. Infiltration modeling guidelines for commercial building energy analysis. PNNL-18898, Pacific Northwest National Laboratory, Richland, WA. http://www.pnl.gov/main/publications/external/technical_reports/PNNL-18898.pdf 


\section{A.1 Medium Office Modeling Description}

\begin{tabular}{|c|c|c|c|c|}
\hline Item & \multicolumn{3}{|c|}{ Descriptions } & Data Source \\
\hline \multicolumn{5}{|l|}{ Program } \\
\hline Vintage & \multicolumn{3}{|c|}{ NEW CONSTRUCTION } & \\
\hline $\begin{array}{l}\text { Location } \\
\text { (Representing } 8 \text { Climate Zones) }\end{array}$ & $\begin{array}{l}\text { Zone 1A: Miami (very hot, humid) } \\
\text { Zone 1B: Riyadh, Saudi Arabia } \\
\text { (very hot, dry) } \\
\text { Zone 2A: Houston (hot, humid) } \\
\text { Zone 2B: Phoenix (hot, dry) } \\
\text { Zone 3A: Memphis (warm, } \\
\text { humid) } \\
\text { Zone 3B: El Paso (warm, dry) } \\
\text { Zone 3C: San Francisco (warm, } \\
\text { marine) }\end{array}$ & $\begin{array}{l}\text { Zone 4A: Baltimore (mild, humid) } \\
\text { Zone 4B: Albuquerque (mild, dry) } \\
\text { Zone 4C: Salem (mild, marine) } \\
\text { Zone 5A: Chicago (cold, humid) } \\
\text { Zone 5B: Boise (cold, dry) } \\
\text { Zone 5C: Vancouver, BC (cold, } \\
\text { marine) }\end{array}$ & $\begin{array}{l}\text { Zone 6A: Burlington (cold, } \\
\text { humid) } \\
\text { Zone 6B: Helena (cold, dry) } \\
\text { Zone 7: Duluth (very cold) } \\
\text { Zone 8: Fairbanks (subarctic) }\end{array}$ & $\begin{array}{l}\text { Selection of } \\
\text { representative climates } \\
\text { based on Briggs' paper. } \\
\text { See Reference. }\end{array}$ \\
\hline Available fuel types & \multicolumn{3}{|c|}{ gas, electricity } & \\
\hline $\begin{array}{l}\text { Building Type (Principal Building } \\
\text { Function) }\end{array}$ & \multicolumn{3}{|c|}{ OFFICE } & \\
\hline Building Prototype & \multicolumn{3}{|c|}{ Medium Office } & \\
\hline \multicolumn{5}{|l|}{ Form } \\
\hline Total Floor Area (sq. feet) & \multicolumn{3}{|c|}{$53,600(163.8 \mathrm{ft} \times 109.2 \mathrm{ft})$} & \\
\hline \multicolumn{4}{|l|}{ Building shape } & \\
\hline Aspect Ratio & \multicolumn{3}{|c|}{1.5} & \\
\hline
\end{tabular}




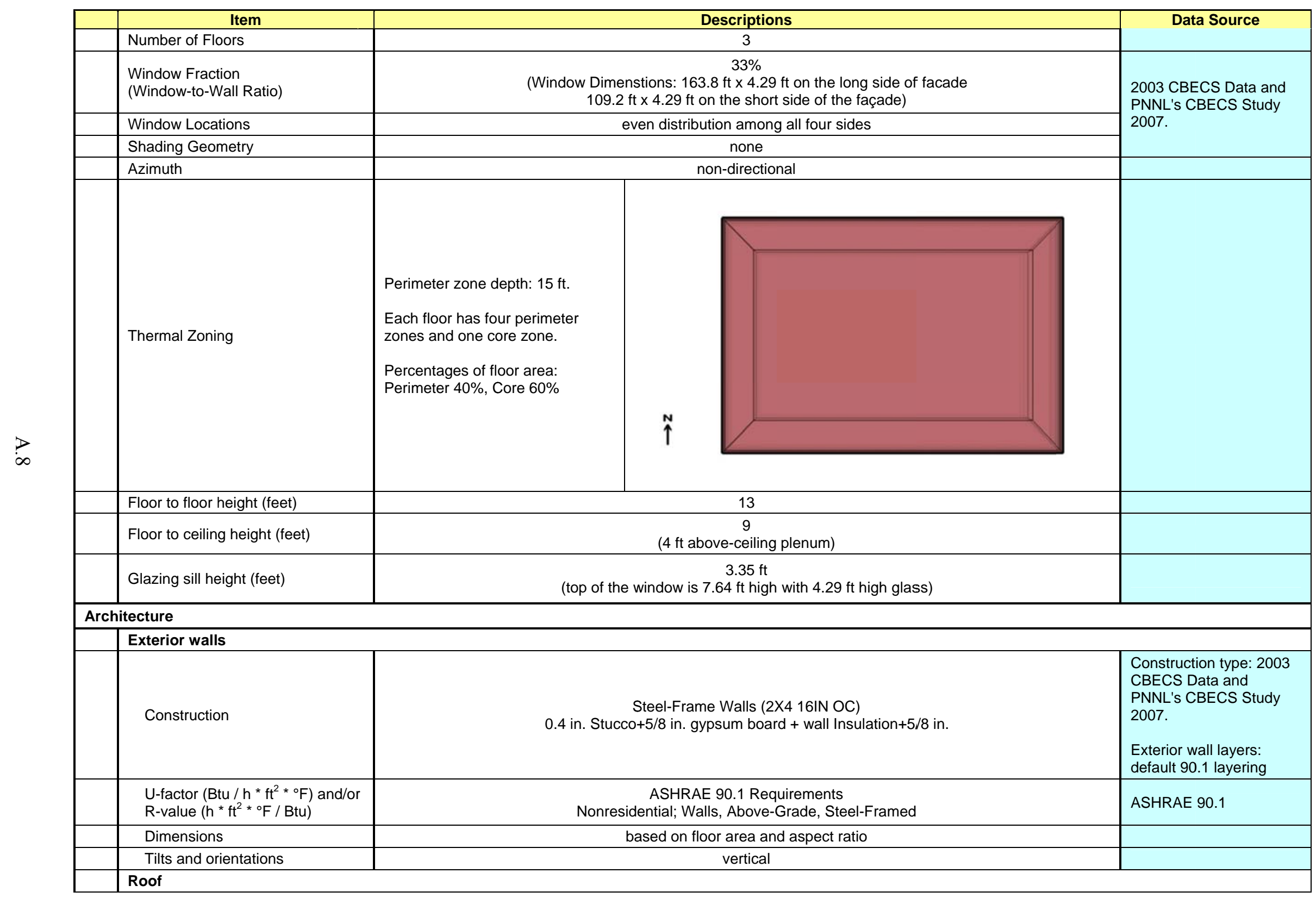




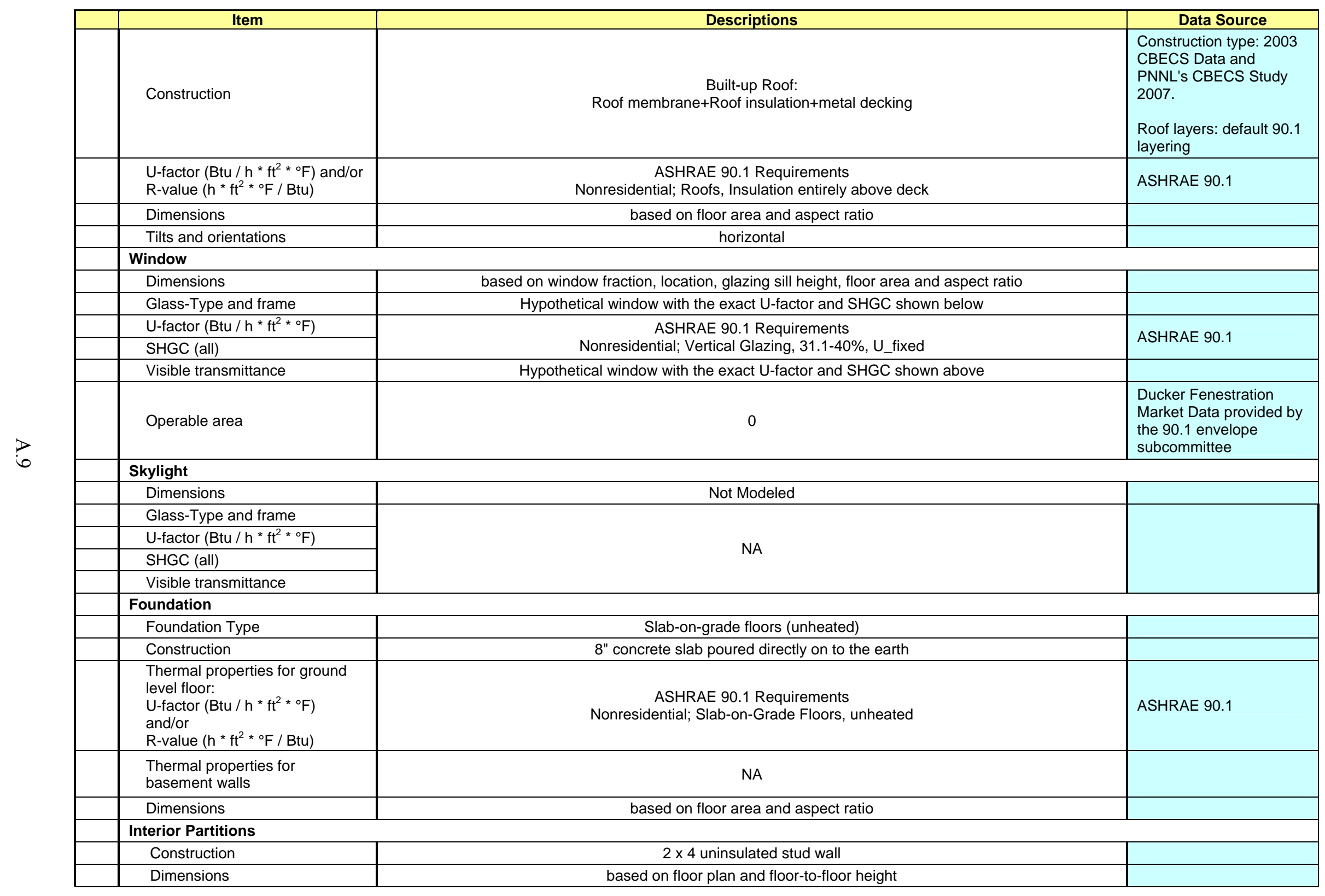




\begin{tabular}{|c|c|c|}
\hline Item & Descriptions & Data Source \\
\hline Internal Mass & 6 inches standard wood $\left(16.6 \mathrm{lb} / \mathrm{ft}^{2}\right)$ & \\
\hline \multicolumn{3}{|l|}{ Air Barrier System } \\
\hline Infiltration & $\begin{array}{l}\text { Peak: } 0.2016 \mathrm{cfm} / \mathrm{sf} \text { of above grade exterior wall surface area (when fans turn off) } \\
\text { Off Peak: } 25 \% \text { of peak infiltration rate (when fans turn on) }\end{array}$ & $\begin{array}{l}\text { Reference: } \\
\text { PNNL-18898: Infiltration } \\
\text { Modeling Guidelines for } \\
\text { Commercial Building } \\
\text { Energy Analysis. }\end{array}$ \\
\hline \multicolumn{3}{|l|}{ HVAC } \\
\hline System Type & & \\
\hline Heating type & Gas furnace inside the packaged air conditioning unit & \multirow{3}{*}{$\begin{array}{l}2003 \text { CBECS Data, } \\
\text { PNNL's CBECS Study } \\
\text { 2006, and } 90.1 \\
\text { Mechanical } \\
\text { Subcommittee input. }\end{array}$} \\
\hline Cooling type & Packaged air conditioning unit & \\
\hline Distribution and terminal units & $\begin{array}{l}\text { VAV terminal box with damper and electric reheating coil } \\
\text { Zone control type: minimum supply air at } 30 \% \text { of the zone design peak supply air. }\end{array}$ & \\
\hline \multicolumn{3}{|l|}{ HVAC Sizing } \\
\hline Air Conditioning & autosized to design day & \\
\hline Heating & autosized to design day & \\
\hline \multicolumn{3}{|l|}{ HVAC Efficiency } \\
\hline Air Conditioning & $\begin{array}{l}\text { Various by climate location and design cooling capacity } \\
\text { ASHRAE 90.1 Requirements } \\
\text { Minimum equipment efficiency for Air Conditioners and Condensing Units }\end{array}$ & ASHRAE 90.1 \\
\hline Heating & $\begin{array}{l}\text { Various by climate location and design heating capacity } \\
\text { ASHRAE } 90.1 \text { Requirements } \\
\text { Minimum equipment efficiency for Warm Air Furnaces }\end{array}$ & ASHRAE 90.1 \\
\hline \multicolumn{3}{|l|}{ HVAC Control } \\
\hline Thermostat Setpoint & $75^{\circ} \mathrm{F}$ Cooling $/ 70^{\circ} \mathrm{F}$ Heating & \\
\hline Thermostat Setback & $80^{\circ} \mathrm{F}$ Cooling $/ 60^{\circ} \mathrm{F}$ Heating & \\
\hline Supply air temperature & Maximum 104F, Minimum 55F & \\
\hline $\begin{array}{l}\text { Chilled water supply } \\
\text { temperatures }\end{array}$ & NA & \\
\hline Hot water supply temperatures & NA & \\
\hline Economizers & $\begin{array}{l}\text { Various by climate location and cooling capacity } \\
\text { Control type: differential dry bulb }\end{array}$ & ASHRAE 90.1 \\
\hline Ventilation & ASHRAE Ventilation Standard 62.1 & $\begin{array}{l}\text { ASHRAE Ventilation } \\
\text { Standard } 62.1\end{array}$ \\
\hline Demand Control Ventilation & ASHRAE 90.1 Requirements & ASHRAE 90.1 \\
\hline
\end{tabular}




\begin{tabular}{|c|c|c|}
\hline Item & Descriptions & Data Source \\
\hline Energy Recovery & ASHRAE 90.1 Requirements & ASHRAE 90.1 \\
\hline \multicolumn{3}{|l|}{ Supply Fan } \\
\hline Fan schedules & See Appendix C & \\
\hline Supply Fan Total Efficiency (\%) & $60 \%$ to $62 \%$ depending on the fan motor size & \multirow{2}{*}{$\begin{array}{l}\text { ASHRAE } 90.1 \\
\text { requirements for motor } \\
\text { efficiency and fan power } \\
\text { limitation }\end{array}$} \\
\hline Supply Fan Pressure Drop & Various depending on the fan supply air cfm & \\
\hline \multicolumn{3}{|l|}{ Pump } \\
\hline Pump Type & NA & \\
\hline Rated Pump Head & NA & \\
\hline Pump Power & autosized & \\
\hline \multicolumn{3}{|l|}{ Cooling Tower } \\
\hline Cooling Tower Type & NA & \\
\hline Cooling Tower Efficiency & NA & \\
\hline \multicolumn{3}{|l|}{ Service Water Heating } \\
\hline SWH type & Storage Tank & \\
\hline Fuel type & Natural Gas & \\
\hline Thermal efficiency (\%) & $\begin{array}{l}\text { ASHRAE } 90.1 \text { Requirements } \\
\text { Water Heating Equipment, Gas storage water heaters, }>75,000 \mathrm{Btu} / \mathrm{h} \text { input }\end{array}$ & ASHRAE 90.1 \\
\hline Tank Volume (gal) & 260 & \\
\hline Water temperature setpoint & $120 \mathrm{~F}$ & \\
\hline Water consumption & See Appendix C & \\
\hline \multicolumn{3}{|l|}{ Internal Loads \& Schedules } \\
\hline \multicolumn{3}{|l|}{ Lighting } \\
\hline Average power density $\left(\mathrm{W} / \mathrm{ft}^{2}\right)$ & $\begin{array}{l}\text { ASHRAE } 90.1 \\
\text { Lighting Power Densities Using the Building Area Method }\end{array}$ & ASHRAE 90.1 \\
\hline Schedule & See Appendix C & \\
\hline Daylighting Controls & ASHRAE 90.1 Requirements & \\
\hline Occupancy Sensors & ASHRAE 90.1 Requirements & \\
\hline \multicolumn{3}{|l|}{ Plug load } \\
\hline Average power density $\left(\mathrm{W} / \mathrm{ft}^{2}\right)$ & See Appendix B & $\begin{array}{l}\text { User's Manual for } \\
\text { ASHRAE Standard 90.1- } \\
2004 \text { (Appendix G) }\end{array}$ \\
\hline Schedule & See Appendix C & \\
\hline \multicolumn{3}{|l|}{ Occupancy } \\
\hline Average people & See Appendix B & $\begin{array}{l}\text { User's Manual for } \\
\text { ASHRAE Standard 90.1- } \\
2004 \text { (Appendix G) }\end{array}$ \\
\hline
\end{tabular}




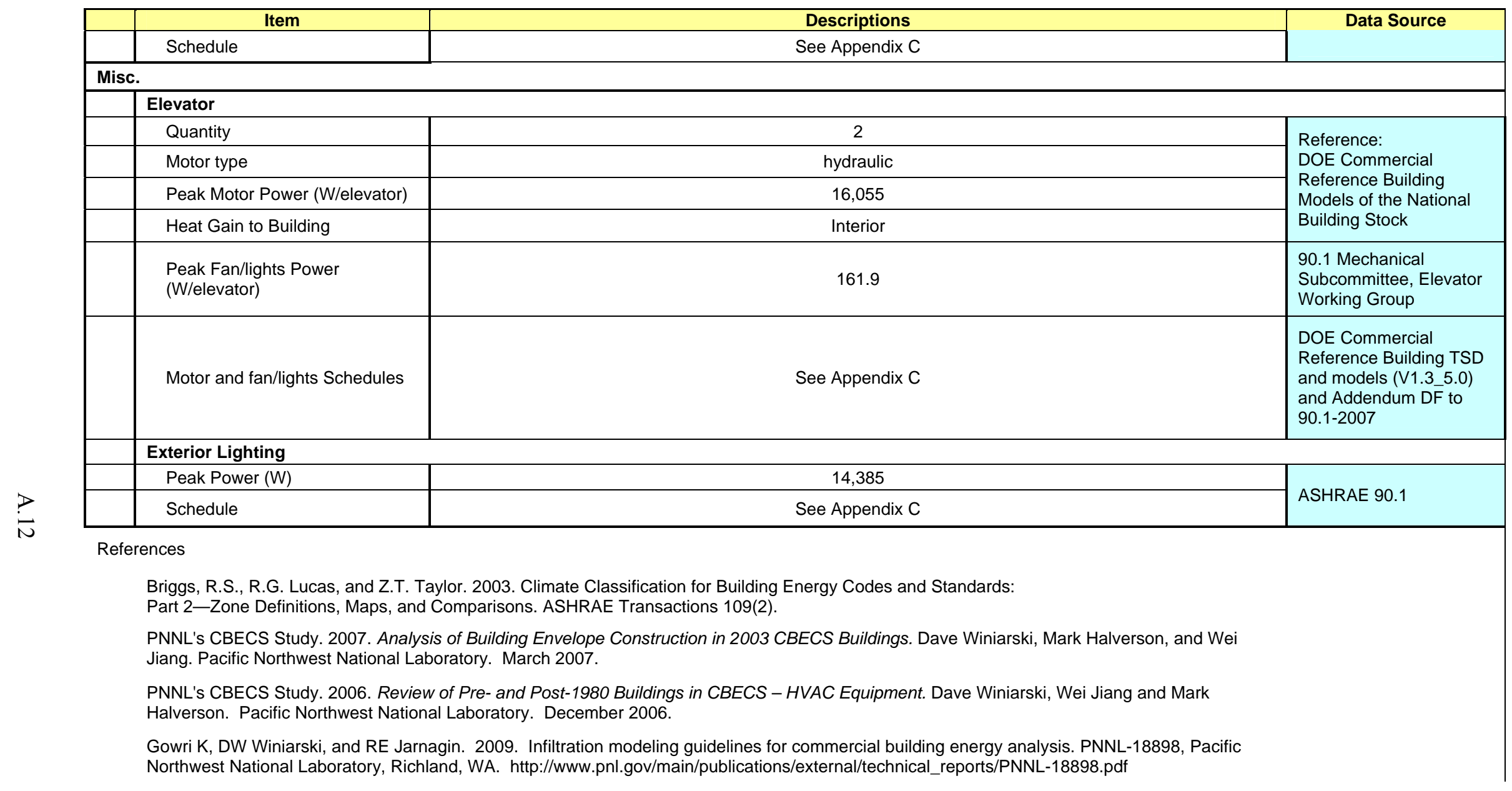




\section{A.2 Large Office Modeling Description}

\begin{tabular}{|c|c|c|c|c|}
\hline Item & \multicolumn{3}{|c|}{ Descriptions } & Data Source \\
\hline \multicolumn{5}{|c|}{ Program } \\
\hline Vintage & \multicolumn{3}{|c|}{ NEW CONSTRUCTION } & \\
\hline $\begin{array}{l}\text { Location } \\
\text { (Representing } 8 \text { Climate Zones) }\end{array}$ & $\begin{array}{l}\text { Zone 1A: Miami (very hot, humid) } \\
\text { Zone 1B: Riyadh, Saudi Arabia } \\
\text { (very hot, dry) } \\
\text { Zone 2A: Houston (hot, humid) } \\
\text { Zone 2B: Phoenix (hot, dry) } \\
\text { Zone 3A: Memphis (warm, humid) } \\
\text { Zone 3B: El Paso (warm, dry) } \\
\text { Zone 3C: San Francisco (warm, } \\
\text { marine) }\end{array}$ & $\begin{array}{l}\text { Zone 4A: Baltimore (mild, humid) } \\
\text { Zone 4B: Albuquerque (mild, dry) } \\
\text { Zone 4C: Salem (mild, marine) } \\
\text { Zone 5A: Chicago (cold, humid) } \\
\text { Zone 5B: Boise (cold, dry) } \\
\text { Zone 5C: Vancouver, BC (cold, } \\
\text { marine) }\end{array}$ & $\begin{array}{l}\text { Zone 6A: Burlington (cold, } \\
\text { humid) } \\
\text { Zone 6B: Helena (cold, dry) } \\
\text { Zone 7: Duluth (very cold) } \\
\text { Zone 8: Fairbanks (subarctic) }\end{array}$ & $\begin{array}{l}\text { Selection of } \\
\text { representative climates } \\
\text { based on Briggs' paper }\end{array}$ \\
\hline Available fuel types & \multicolumn{3}{|c|}{ gas, electricity } & \\
\hline $\begin{array}{l}\text { Building Type (Principal Building } \\
\text { Function) }\end{array}$ & \multicolumn{3}{|c|}{ OFFICE } & \\
\hline Building Prototype & \multicolumn{3}{|c|}{ LARGE OFFICE } & \\
\hline \multicolumn{5}{|c|}{ Form } \\
\hline Total Floor Area (sq. feet) & \multicolumn{3}{|c|}{$498,600(240 \mathrm{ft} \times 160 \mathrm{ft})$} & \multirow{4}{*}{$\begin{array}{l}\text { Time Saver Standards; } \\
\text { Large Office studies } \\
\text { (ConEd, EPRI, MEOS, } \\
\text { NEU1(1-4), NEU2, PNL) } \\
\text { cited in Huang et al. } \\
1991\end{array}$} \\
\hline Building shape & & & & \\
\hline Aspect Ratio & \multicolumn{3}{|c|}{1.5} & \\
\hline Number of Floors & \multicolumn{3}{|c|}{12 (plus basement) } & \\
\hline
\end{tabular}




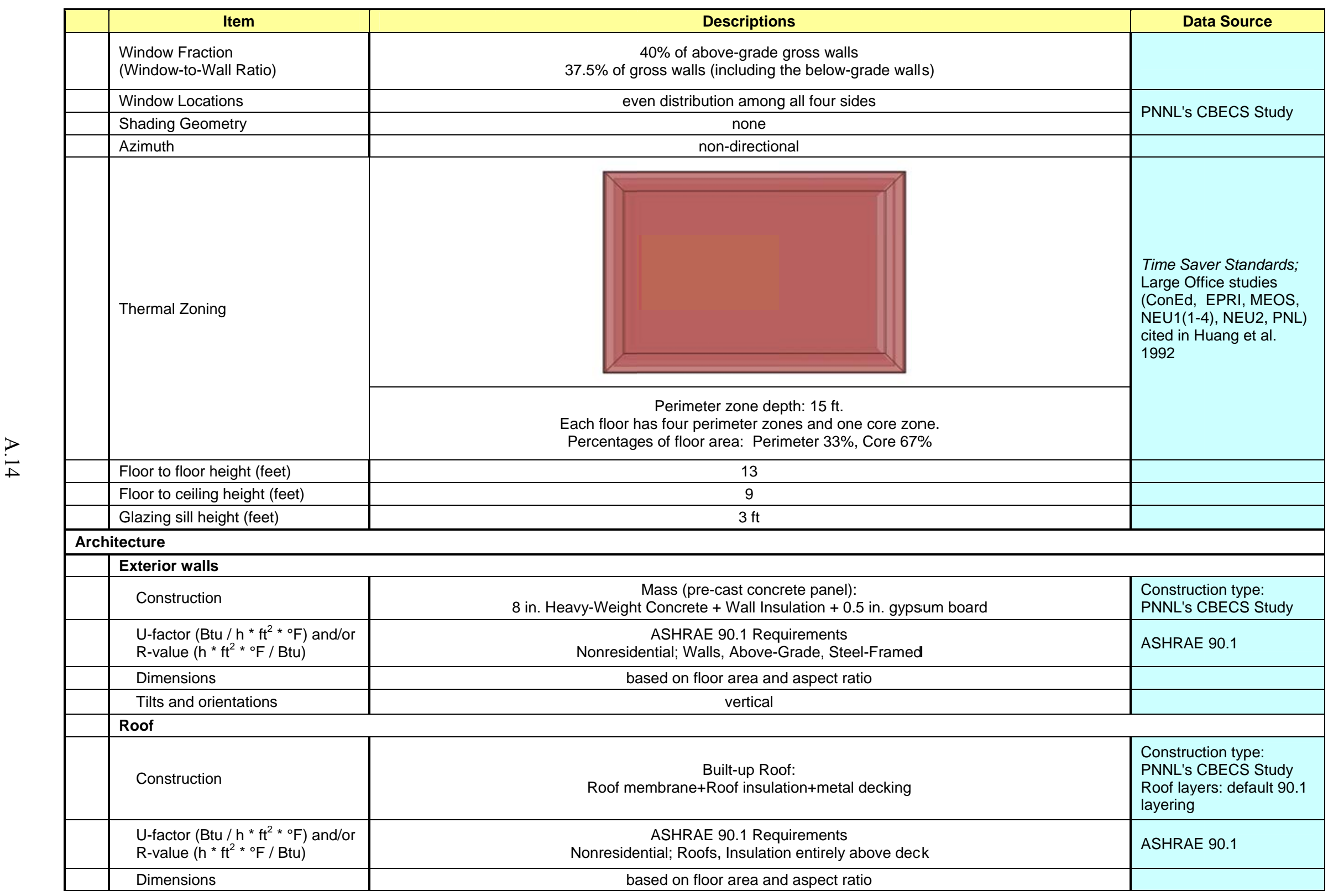




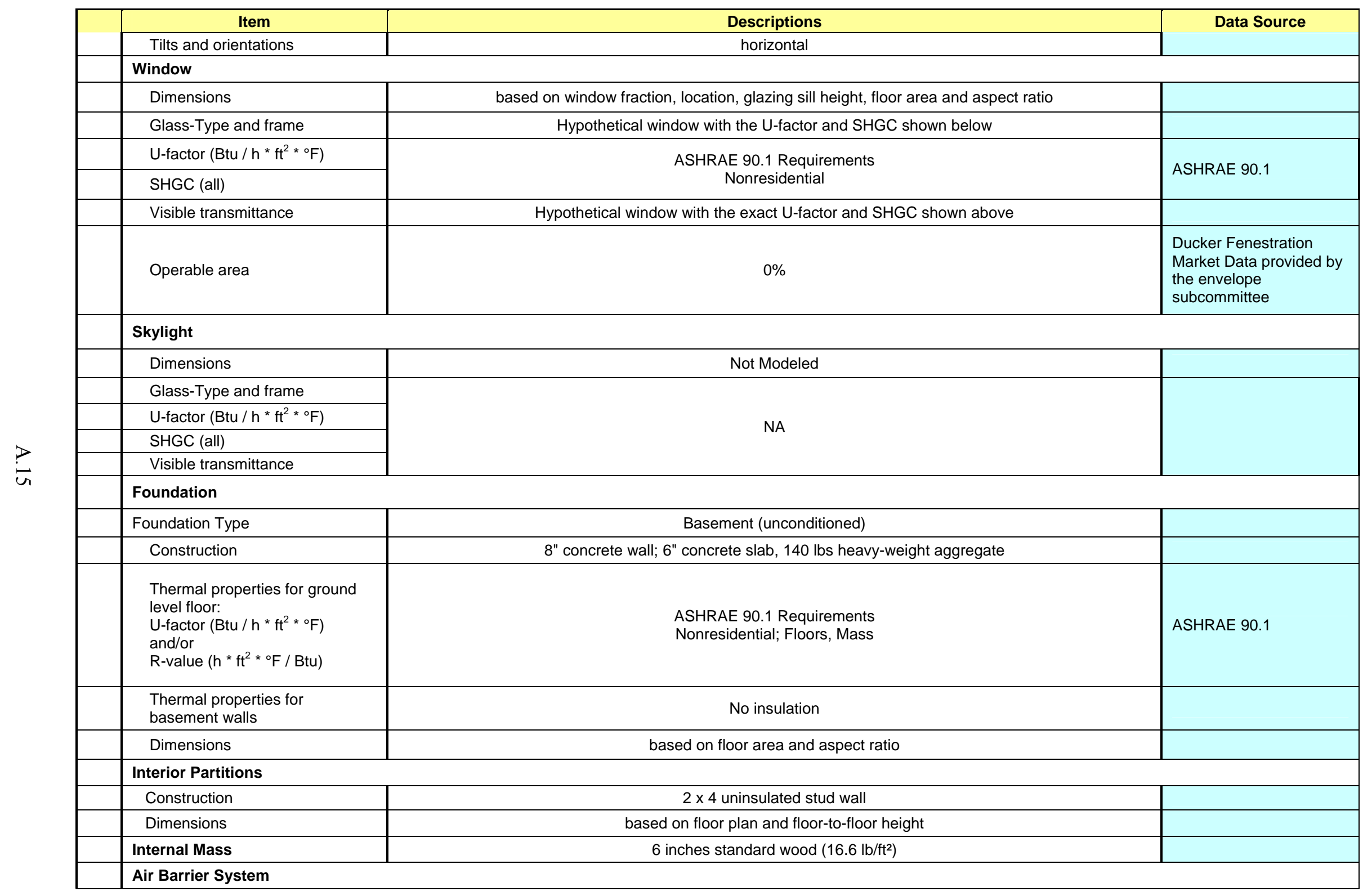




\begin{tabular}{|c|c|c|}
\hline \multirow[b]{2}{*}{ Infiltration } & Descriptions & \multirow{2}{*}{$\begin{array}{c}\text { Data Source } \\
\text { PNNL's Infiltration Study }\end{array}$} \\
\hline & $\begin{array}{l}\text { Peak: } 0.2016 \mathrm{cfm} / \mathrm{sf} \text { of above grade exterior wall surface area (when fans turn off) } \\
\text { Off Peak: } 25 \% \text { of peak infiltration rate (when fans turn on) }\end{array}$ & \\
\hline & & \\
\hline System Type & & \\
\hline Heating type & Gas boiler & \\
\hline Cooling type & Two water-cooled centrifugal chillers & PNNU 's CRFCS Studv \\
\hline Distribution and terminal units & $\begin{array}{l}\text { VAV terminal box with damper and hot-water reheating coil } \\
\text { Zone control type: minimum supply air at } 30 \% \text { of the zone design peak supply air. }\end{array}$ & TIVIVLS CDLCS GIUUy \\
\hline HVAC Sizing & & \\
\hline Air Conditioning & autosized to design day & \\
\hline Heating & autosized to design day & \\
\hline HVAC Efficiency & & \\
\hline Air Conditioning & Varies by climate locations based on cooling capacity & ASHRAE 90.1 \\
\hline Heating & Varies by climate locations based on heating capacity & ASHRAE 90.1 \\
\hline HVAC Control & & \\
\hline Thermostat Setpoint & $75^{\circ} \mathrm{F}$ Cooling $/ 70^{\circ} \mathrm{F}$ Heating & 90.1 Simulation Working \\
\hline Thermostat Setback & $85^{\circ} \mathrm{F}$ Cooling $/ 60^{\circ} \mathrm{F}$ Heating & Group \\
\hline Supply air temperature & Maximum 110F, Minimum 52F & \\
\hline $\begin{array}{l}\text { Chilled water supply } \\
\text { temperatures }\end{array}$ & $44 \mathrm{~F}$ & \\
\hline Hot water supply temperatures & $180 \mathrm{~F}$ & \\
\hline Economizers & $\begin{array}{l}\text { Air-side economizer only in all the zones except: } \\
\qquad 1 a, 1 b, 2 a, 3 a \text {, and } 4 \text { a. }\end{array}$ & ASHRAE 90.1 \\
\hline Ventilation & ASHRAE Ventilation Standard 62.1 & $\begin{array}{l}\text { ASHRAE Ventilation } \\
\text { Standard } 62.1\end{array}$ \\
\hline Demand Control Ventilation & No & ASHRAE 90.1 \\
\hline Energy Recovery & No & ASHRAE 90.1 \\
\hline Supply Fan & & \\
\hline Fan schedules & See Appendix C & \\
\hline Supply Fan Total Efficiency (\%) & $60 \%$ to $62 \%$ depending on the fan motor size & \\
\hline Supply Fan Pressure Drop & Various depending on the fan supply air cfm & ASHRAE 90.1 \\
\hline Pump & & \\
\hline Pump Type & $\begin{array}{l}\text { CHW and HW: variable speed; } \\
\text { CW: constant speed }\end{array}$ & \\
\hline Rated Pump Head & $\begin{array}{l}\text { CHW: } 56 \mathrm{ft} \\
\mathrm{HW} \text { and CW: } 60 \mathrm{ft}\end{array}$ & ASHRAE 90.1 \\
\hline
\end{tabular}




\begin{tabular}{|c|c|c|}
\hline Item & Descriptions & Data Source \\
\hline Pump Power & autosized & \\
\hline \multicolumn{3}{|l|}{\begin{tabular}{|l|} 
Cooling Tower \\
\end{tabular}} \\
\hline Cooling Tower Type & open cooling tower with two-speed fans & ASHRAE 90.1 \\
\hline Cooling Tower Power & autosized & \\
\hline \multicolumn{3}{|l|}{ Service Water Heating } \\
\hline SWH type & Storage Tank & \\
\hline Fuel type & Natural Gas & \\
\hline Thermal efficiency (\%) & $80 \%$ & \\
\hline Tank Volume (gal) & 260 & \\
\hline Water temperature setpoint & $180 \mathrm{~F}$ & \\
\hline Water consumption & See Appendix C & \\
\hline \multicolumn{3}{|l|}{ Internal Loads \& Schedules } \\
\hline \multicolumn{3}{|l|}{ Lighting } \\
\hline Average power density $\left(\mathrm{W} / \mathrm{ft}^{2}\right)$ & $\begin{array}{l}\text { ASHRAE } 90.1 \\
\text { Lighting Power Densities Using the Building-Area Method }\end{array}$ & ASHRAE 90.1 \\
\hline Schedule & See Appendix C & \\
\hline Daylighting Controls & No & \\
\hline Occupancy Sensors & No & \\
\hline \multicolumn{3}{|l|}{ Plug load } \\
\hline Average power density $\left(\mathrm{W} / \mathrm{ft}^{2}\right)$ & See Appendix B & ASHRAE 90.1 \\
\hline Schedule & See Appendix C & \\
\hline \multicolumn{3}{|l|}{ Occupancy } \\
\hline Average people & See Appendix B & $\begin{array}{l}\text { ASHRAE Ventilation } \\
\text { Standard } 62.1\end{array}$ \\
\hline Schedule & See Appendix C & \\
\hline \multicolumn{3}{|l|}{ Misc. } \\
\hline \multicolumn{3}{|l|}{ Elevator } \\
\hline Quantity & 12 & \multirow{4}{*}{$\begin{array}{l}\text { DOE Commercial } \\
\text { Reference Building TSD } \\
\text { (unpublished) and } \\
\text { models (V1.3_5.0). }\end{array}$} \\
\hline Motor type & traction & \\
\hline Peak Motor Power (W/elevator) & 20370 & \\
\hline Heat Gain to Building & Exterior & \\
\hline $\begin{array}{l}\text { Peak Fan/lights Power } \\
\text { (W/elevator) }\end{array}$ & 161.9 & $\begin{array}{l}90.1 \text { Mechnical } \\
\text { Subcommittee, Elevator } \\
\text { Working Group }\end{array}$ \\
\hline
\end{tabular}




\begin{tabular}{|c|c|c|}
\hline Item & Descriptions & Data Source \\
\hline Motor and fan/lights Schedules & See Appendix C & $\begin{array}{l}\text { DOE Commercial } \\
\text { Reference Building TSD } \\
\text { (unpublished) and } \\
\text { models (V1.3_5.0) and } \\
\text { Appendix DF 2007 }\end{array}$ \\
\hline \multicolumn{3}{|l|}{ Exterior Lighting } \\
\hline Peak Power (W) & 60,216 & $\begin{array}{l}\text { ASHRAE 90.1-2004; } \\
\text { PNNL study; } \\
\text { 90.1 Lighting } \\
\text { Subcommittee inputs }\end{array}$ \\
\hline Schedule & Astronomical Clock & ASHRAE 90.1-2004 \\
\hline
\end{tabular}

References

Briggs, R.S., R.G. Lucas, and Z.T. Taylor. 2003. Climate Classification for Building Energy Codes and Standards:

Part 2-Zone Definitions, Maps, and Comparisons. ASHRAE Transactions 109(2).

McGraw-Hill Companies, Inc. (2001). Time-Saver Standards for Building Types. New York, NY.

LBNL (1991). Huang, Joe, Akbari, H., Rainer, L. and Ritschard, R. 481 Prototypical Commercial Buildings for 20 Urban Market Areas, prepared for the Gas Research Institute, Chicago IL, also LBL-29798, Berkeley CA.

PNNL's CBECS Study. 2007. Analysis of Building Envelope Construction in 2003 CBECS Buildings. Dave Winiarski, Mark Halverson, and Wei Jiang. Pacific Northwest National Laboratory. March 2007.

PNNL's CBECS Study. 2006. Review of Pre- and Post-1980 Buildings in CBECS - HVAC Equipment. Dave Winiarski, Wei Jiang and Mark Halverson. Pacific Northwest National Laboratory. December 2006. 


\section{A.3 Stand-alone Retail Modeling Description}

\begin{tabular}{|c|c|c|c|c|}
\hline Item & \multicolumn{3}{|c|}{ Descriptions } & Data Source \\
\hline \multicolumn{5}{|l|}{ Program } \\
\hline Vintage & & NEW CONSTRUCTION & & \\
\hline $\begin{array}{l}\text { Location } \\
\text { (Representing } 8 \text { Climate Zones) }\end{array}$ & $\begin{array}{l}\text { Zone 1A: Miami (very hot, humid) } \\
\text { Zone 1B: Riyadh, Saudi Arabia } \\
\text { (very hot, dry) } \\
\text { Zone 2A: Houston (hot, humid) } \\
\text { Zone 2B: Phoenix (hot, dry) } \\
\text { Zone 3A: Memphis (warm, } \\
\text { humid) } \\
\text { Zone 3B: El Paso (warm, dry) } \\
\text { Zone 3C: San Francisco (warm, } \\
\text { marine) }\end{array}$ & $\begin{array}{l}\text { Zone 4A: Baltimore (mild, } \\
\text { humid) } \\
\text { Zone 4B: Albuquerque (mild, } \\
\text { dry) } \\
\text { Zone 4C: Salem (mild, marine) } \\
\text { Zone 5A: Chicago (cold, humid) } \\
\text { Zone 5B: Boise (cold, dry) } \\
\text { Zone 5C: Vancouver, BC (cold, } \\
\text { marine) }\end{array}$ & $\begin{array}{l}\text { Zone 6A: Burlington (cold, } \\
\text { humid) } \\
\text { Zone 6B: Helena (cold, dry) } \\
\text { Zone 7: Duluth (very cold) } \\
\text { Zone 8: Fairbanks (subarctic) }\end{array}$ & $\begin{array}{l}\text { Selection of } \\
\text { representative climates } \\
\text { based on Briggs' paper. } \\
\text { See Reference. }\end{array}$ \\
\hline Available fuel types & \multicolumn{3}{|c|}{ gas, electricity } & \\
\hline $\begin{array}{l}\text { Building Type (Principal Building } \\
\text { Function) }\end{array}$ & \multicolumn{3}{|c|}{ RETAIL } & \\
\hline Building Prototype & \multicolumn{3}{|c|}{ Standalone Retail } & \\
\hline \multicolumn{5}{|l|}{ Form } \\
\hline Total Floor Area (sq. feet) & \multicolumn{3}{|c|}{$24695(178 \mathrm{ft} \times 139 \mathrm{ft})$} & \\
\hline \multicolumn{5}{|l|}{ Building shape } \\
\hline Aspect Ratio & \multicolumn{3}{|c|}{1.28} & \\
\hline
\end{tabular}




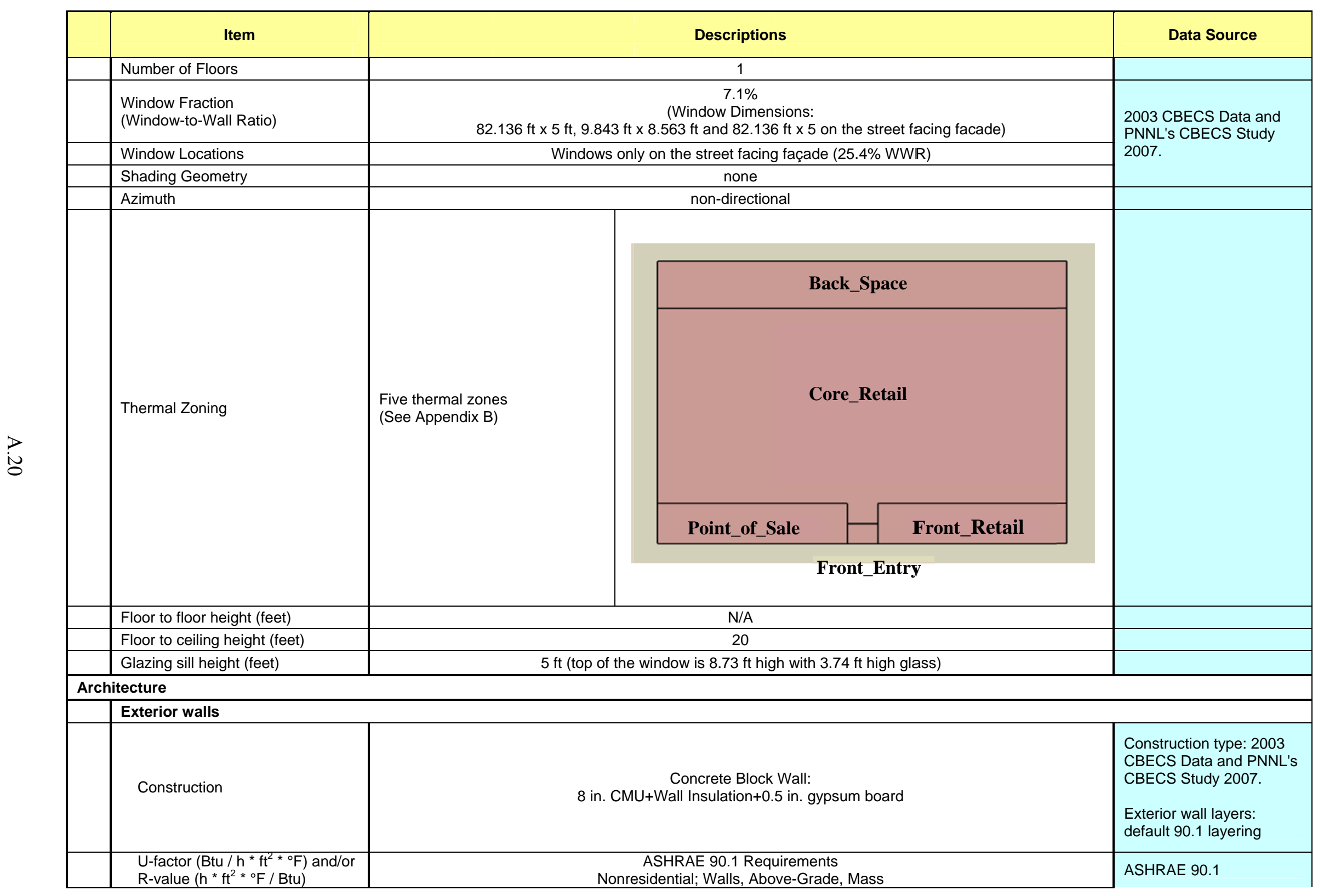




\begin{tabular}{|c|c|c|}
\hline Item & Descriptions & Data Source \\
\hline Dimensions & based on floor area and aspect ratio & \\
\hline Tilts and orientations & Vertical & \\
\hline \multicolumn{3}{|l|}{ Roof } \\
\hline Construction & $\begin{array}{l}\text { Built-up Roof: } \\
\text { Roof membrane+Roof insulation+metal decking }\end{array}$ & $\begin{array}{l}\text { Construction type: } 2003 \\
\text { CBECS Data and PNNL's } \\
\text { CBECS Study } 2007 . \\
\text { Roof layers: default } 90.1 \\
\text { layering }\end{array}$ \\
\hline $\begin{array}{l}\text { U-factor }\left(\mathrm{Btu} / \mathrm{h} * \mathrm{ft}^{2} *{ }^{\circ} \mathrm{F}\right) \text { and/or } \\
\text { R-value }\left(\mathrm{h} * \mathrm{ft}^{2} *{ }^{\circ} \mathrm{F} / \mathrm{Btu}\right)\end{array}$ & $\begin{array}{c}\text { ASHRAE 90.1 Requirements } \\
\text { Nonresidential; Roofs, Insulation entirely above deck }\end{array}$ & ASHRAE 90.1 \\
\hline Dimensions & based on floor area and aspect ratio & \\
\hline Tilts and orientations & horizontal & \\
\hline \multicolumn{3}{|l|}{ Window } \\
\hline Dimensions & based on window fraction, location, glazing sill height, floor area and aspect ratio & \\
\hline Glass-Type and frame & Hypothetical window with the exact U-factor and SHGC shown below & \\
\hline $\begin{array}{l}\left.\text { U-factor (Btu } / \mathrm{h} * \mathrm{ft}^{2}{ }^{\circ} \mathrm{F}\right) \\
\text { SHGC (all) }\end{array}$ & $\begin{array}{l}\text { ASHRAE 90.1 Requirements } \\
\text { Nonresidential; Vertical Glazing, 20.1-30.0\% }\end{array}$ & ASHRAE 90.1 \\
\hline Visible transmittance & Hypothetical window with the exact U-factor and SHGC shown above & $\begin{array}{l}\text { Ducker Fenestration } \\
\text { Market Data provided by } \\
\text { the } 90.1 \text { envelope } \\
\text { subcommittee }\end{array}$ \\
\hline Operable area & $2 \%$ & $\begin{array}{l}\text { Ducker Fenestration } \\
\text { Market Data provided by } \\
\text { the envelope } \\
\text { subcommittee }\end{array}$ \\
\hline \multicolumn{3}{|l|}{ Skylight } \\
\hline Dimensions & $\begin{array}{c}\text { Core Retail, } \\
\text { Rectangular skylight } \\
4 \mathrm{ft} \times 4 \mathrm{ft}=16 \mathrm{ft} \text { per skylight } \\
\text { Number of skylights and total skylight area vary according to ASHRAE 90.1 Requirements }\end{array}$ & ASHRAE 90.1 \\
\hline Glass-Type and frame & Hypothetical glass and frame meeting ASHRAE 90.1 Requirements below & \\
\hline U-factor $\left(\mathrm{Btu} / \mathrm{h} * \mathrm{ft}^{2} *{ }^{\circ} \mathrm{F}\right)$ & \multirow{3}{*}{$\begin{array}{l}\text { ASHRAE 90.1 Requirements } \\
\text { Nonresidential; Skylight with Curb, Glass }\end{array}$} & \multirow{3}{*}{ ASHRAE 90.1} \\
\hline SHGC (all) & & \\
\hline Visible transmittance & & \\
\hline \multicolumn{3}{|l|}{ Foundation } \\
\hline Foundation Type & Slab-on-grade floors (unheated) & \\
\hline Construction & 6" concrete slab poured directly on to the earth with carpet & \\
\hline
\end{tabular}




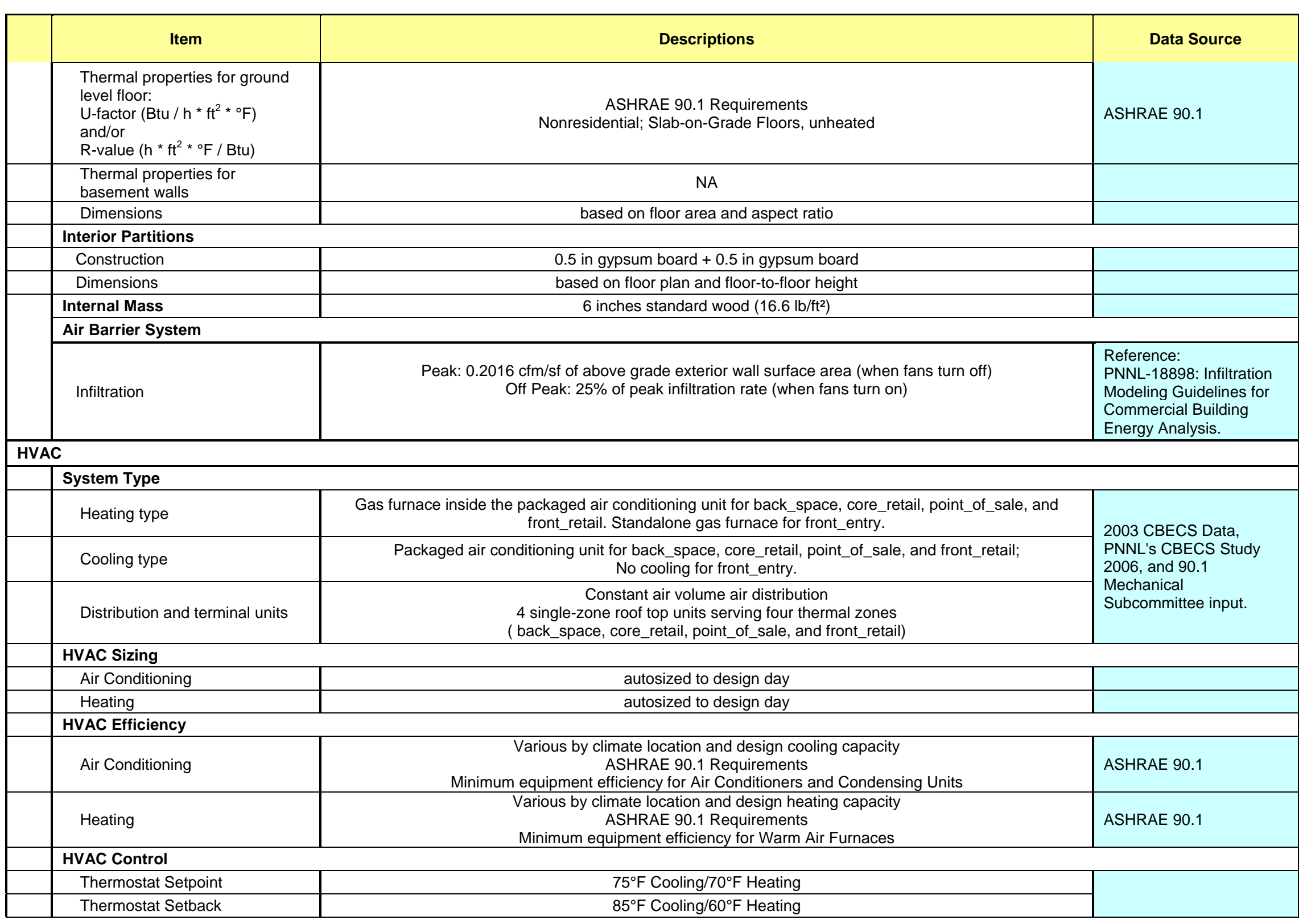




\begin{tabular}{|c|c|c|}
\hline Item & Descriptions & Data Source \\
\hline Supply air temperature & Maximum $104^{\circ} \mathrm{F}$, Minimum $55^{\circ} \mathrm{F}$ & \\
\hline $\begin{array}{l}\text { Chilled water supply } \\
\text { temperatures }\end{array}$ & NA & \\
\hline Hot water supply temperatures & NA & \\
\hline Economizers & $\begin{array}{l}\text { Various by climate location and cooling capacity } \\
\text { Control type: differential dry bulb }\end{array}$ & ASHRAE 90.1 \\
\hline Ventilation & ASHRAE Ventilation Standard 62.1 & $\begin{array}{l}\text { ASHRAE Ventilation } \\
\text { Standard } 62.1\end{array}$ \\
\hline Demand Control Ventilation & ASHRAE 90.1 Requirements & ASHRAE 90.1 \\
\hline Energy Recovery & ASHRAE 90.1 Requirements & ASHRAE 90.1 \\
\hline \multicolumn{3}{|l|}{ Supply Fan } \\
\hline Fan schedules & See Appendix C & \\
\hline $\begin{array}{l}\text { Supply Fan Mechanical } \\
\text { Efficiency (\%) }\end{array}$ & Various depending on the fan motor size & \multirow{2}{*}{$\begin{array}{l}\text { ASHRAE } 90.1 \\
\text { requirements for motor } \\
\text { efficiency and fan power } \\
\text { limitation }\end{array}$} \\
\hline Supply Fan Pressure Drop & Various depending on the fan supply air cfm & \\
\hline \multicolumn{3}{|l|}{ Pump } \\
\hline Pump Type & Service hot water & \\
\hline Rated Pump Heat & No & \\
\hline Pump Power & $100 \%$ eff. motor. Negligible power consumption & \\
\hline \multicolumn{3}{|l|}{ Cooling Tower } \\
\hline Cooling Tower Type & NA & \\
\hline Cooling Tower Efficiency & NA & \\
\hline \multicolumn{3}{|l|}{ Service Water Heating } \\
\hline SWH type & Storage Tank & \\
\hline Fuel type & Natural Gas & \\
\hline Thermal efficiency (\%) & $\begin{array}{l}\text { ASHRAE } 90.1 \text { Requirements } \\
\text { Water Heating Equipment, Gas storage water heaters, }>75,000 \text { Btu/h input }\end{array}$ & ASHRAE 90.1 \\
\hline Tank Volume (gal) & 40 & \\
\hline Water temperature setpoint & $120^{\circ} \mathrm{F}$ & \\
\hline Water consumption & $\begin{array}{l}\text { BLDG_SWH_SCH } \\
\text { See Appendix C }\end{array}$ & \\
\hline \multicolumn{3}{|l|}{ Internal Loads \& Schedules } \\
\hline \multicolumn{3}{|l|}{ Lighting } \\
\hline Average power density $\left(\mathrm{W} / \mathrm{ft}^{2}\right)$ & $\begin{array}{l}\text { ASHRAE } 90.1 \\
\text { Lighting Power Densities Using the Building Area Method }\end{array}$ & \\
\hline Schedule & See Appendix C & \\
\hline Daylighting Controls & ASHRAE 90.1 Requirements & \\
\hline
\end{tabular}




\begin{tabular}{|c|c|c|c|}
\hline & Item & Descriptions & Data Source \\
\hline & Occupancy Sensors & ASHRAE 90.1 Requirements & \\
\hline & \multicolumn{3}{|l|}{ Plug load } \\
\hline & Average power density $\left(\mathrm{W} / \mathrm{ft}^{2}\right)$ & See Appendix B & $\begin{array}{l}\text { User's Manual for } \\
\text { ASHRAE Standard 90.1- } \\
2004 \text { (Appendix G) }\end{array}$ \\
\hline & Schedule & See Appendix C & \\
\hline & \multicolumn{3}{|l|}{ Occupancy } \\
\hline & Average people & See Appendix B & \\
\hline & Schedule & See Appendix C & \\
\hline \multicolumn{4}{|c|}{ Misc. } \\
\hline & \multicolumn{3}{|l|}{ Elevator } \\
\hline & Peak Power & NA & \\
\hline & Schedule & NA & \\
\hline & \multicolumn{3}{|l|}{ Exterior Lighting } \\
\hline & Peak Power & 7,322 watts & \multirow{2}{*}{ ASHRAE 90.1} \\
\hline & Schedule & See Appendix C & \\
\hline
\end{tabular}

\section{References}

Briggs, R.S., R.G. Lucas, and Z.T. Taylor. 2003. Climate Classification for Building Energy Codes and Standards:

Part 2-Zone Definitions, Maps, and Comparisons. ASHRAE Transactions 109(2).

PNNL's CBECS Study. 2007. Analysis of Building Envelope Construction in 2003 CBECS Buildings. Dave Winiarski, Mark Halverson, and Wei Jiang. Pacific Northwest National Laboratory. March 2007.

PNNL's CBECS Study. 2006. Review of Pre- and Post-1980 Buildings in CBECS - HVAC Equipment. Dave Winiarski, Wei Jiang and Mark Halverson. Pacific Northwest National Laboratory. December 2006.

Gowri K, DW Winiarski, and RE Jarnagin. 2009. Infiltration modeling guidelines for commercial building energy analysis. PNNL-18898, Pacific Northwest National Laboratory, Richland, WA. http://www.pnl.gov/main/publications/external/technical_reports/PNNL-18898.pdf 


\section{A.4 Strip Mall Modeling Description}

\begin{tabular}{|c|c|c|c|c|}
\hline Item & \multicolumn{3}{|c|}{ Descriptions } & Data Source \\
\hline \multicolumn{5}{|l|}{ Program } \\
\hline Vintage & \multicolumn{3}{|c|}{ NEW CONSTRUCTION } & \\
\hline $\begin{array}{l}\text { Location } \\
\text { (Representing } 8 \text { Climate Zones) }\end{array}$ & $\begin{array}{l}\text { Zone 1A: Miami (very hot, humid) } \\
\text { Zone 1B: Riyadh, Saudi Arabia } \\
\text { (very hot, dry) } \\
\text { Zone 2A: Houston (hot, humid) } \\
\text { Zone 2B: Phoenix (hot, dry) } \\
\text { Zone 3A: Memphis (warm, humid) } \\
\text { Zone 3B: El Paso (warm, dry) } \\
\text { Zone 3C: San Francisco (warm, } \\
\text { marine) }\end{array}$ & $\begin{array}{l}\text { Zone 4A: Baltimore (mild, humid) } \\
\text { Zone 4B: Albuquerque (mild, dry) } \\
\text { Zone 4C: Salem (mild, marine) } \\
\text { Zone 5A: Chicago (cold, humid) } \\
\text { Zone 5B: Boise (cold, dry) } \\
\text { Zone 5C: Vancouver, BC (cold, } \\
\text { marine) }\end{array}$ & $\begin{array}{l}\text { Zone 6A: Burlington (cold, } \\
\text { humid) } \\
\text { Zone 6B: Helena (cold, dry) } \\
\text { Zone 7: Duluth (very cold) } \\
\text { Zone 8: Fairbanks (subarctic) }\end{array}$ & $\begin{array}{l}\text { Selection of } \\
\text { representative climates } \\
\text { based on Briggs' paper. } \\
\text { See Reference. }\end{array}$ \\
\hline Available fuel types & & gas, electricity & & \\
\hline $\begin{array}{l}\text { Building Type (Principal Building } \\
\text { Function) }\end{array}$ & & RETAIL & & \\
\hline Building Prototype & & Stripmall & & \\
\hline \multicolumn{5}{|l|}{ Form } \\
\hline Total Floor Area (sq feet) & & $22,500 \mathrm{ft}^{2}(300 \mathrm{ft} \times 75 \mathrm{ft})$ & & \\
\hline \multicolumn{5}{|l|}{ Building shape } \\
\hline Aspect Ratio & & $\begin{array}{c}4 \\
3 \text { for small store \& } 0.67 \text { for large sto }\end{array}$ & & \\
\hline
\end{tabular}




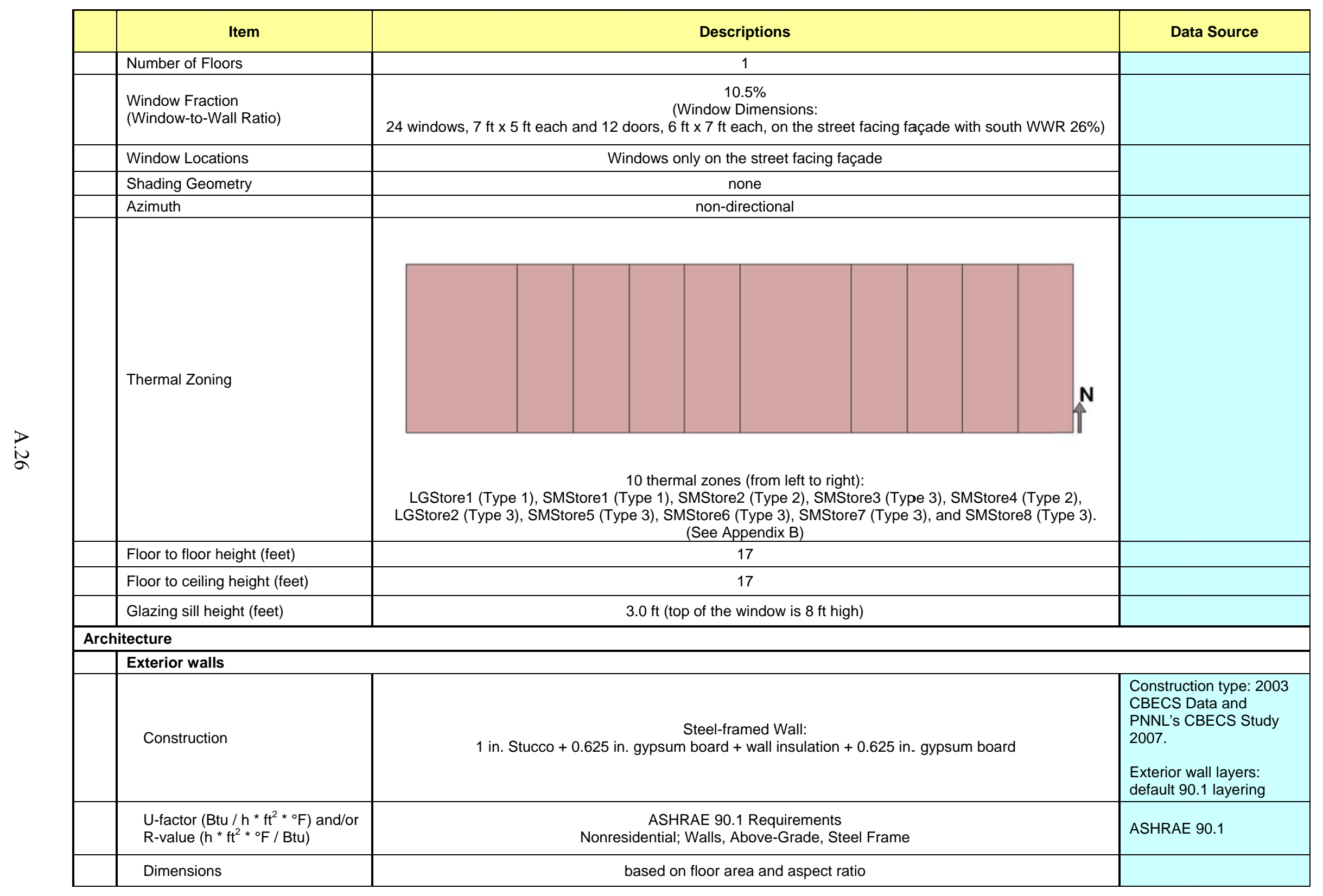




\begin{tabular}{|c|c|c|}
\hline Item & Descriptions & Data Source \\
\hline Tilts and orientations & vertical & \\
\hline \multicolumn{3}{|l|}{ Roof } \\
\hline Construction & $\begin{array}{l}\text { Built-up Roof: } \\
\text { Roof membrane+Roof insulation+metal decking }\end{array}$ & $\begin{array}{l}\text { Construction type: } 2003 \\
\text { CBECS Data and } \\
\text { PNNL's CBECS Study } \\
2007 . \\
\text { Roof layers: default } 90.1 \\
\text { layering }\end{array}$ \\
\hline $\begin{array}{l}\text { U-factor }\left(\mathrm{Btu} / \mathrm{h} \mathrm{hft}^{2} *{ }^{\circ} \mathrm{F}\right) \text { and/or } \\
\text { R-value }\left(\mathrm{h} * \mathrm{ft}^{2} *{ }^{\circ} \mathrm{F} / \mathrm{Btu}\right)\end{array}$ & $\begin{array}{c}\text { ASHRAE 90.1 Requirements } \\
\text { Nonresidential; Roofs, Insulation entirely above deck }\end{array}$ & ASHRAE 90.1 \\
\hline Dimensions & based on floor area and aspect ratio & \\
\hline Tilts and orientations & horizontal & \\
\hline \multicolumn{3}{|l|}{ Window } \\
\hline Dimensions & based on window fraction, location, glazing sill height, floor area and aspect ratio & \\
\hline Glass-Type and frame & Hypothetical window with the exact U-factor and SHGC shown below & \\
\hline $\begin{array}{l}\left.\text { U-factor (Btu } / \mathrm{h} * \mathrm{ft}^{2} *{ }^{\circ} \mathrm{F}\right) \\
\text { SHGC (all) }\end{array}$ & $\begin{array}{c}\text { ASHRAE 90.1 Requirements } \\
\text { Nonresidential; Vertical Glazing, 20.1-30.0\% }\end{array}$ & ASHRAE 90.1 \\
\hline Visible transmittance & Hypothetical window with the exact U-factor and SHGC shown above & $\begin{array}{l}\text { Ducker Fenestration } \\
\text { Market Data provided by } \\
\text { the } 90.1 \text { envelope } \\
\text { subcommittee }\end{array}$ \\
\hline Operable area & $2 \%$ & $\begin{array}{l}\text { Ducker Fenestration } \\
\text { Market Data provided by } \\
\text { the envelope } \\
\text { subcommittee }\end{array}$ \\
\hline \multicolumn{3}{|l|}{ Skylight } \\
\hline Dimensions & Not Modeled & \\
\hline Glass-Type and frame & \multirow{4}{*}{ NA } & \\
\hline U-factor $\left(\mathrm{Btu} / \mathrm{h} * \mathrm{ft}^{2} *{ }^{\circ} \mathrm{F}\right)$ & & \\
\hline SHGC (all) & & \\
\hline Visible transmittance & & \\
\hline \multicolumn{3}{|l|}{ Foundation } \\
\hline Foundation Type & Slab-on-grade floors (unheated) & \\
\hline Construction & $6 "$ concrete slab poured directly on to the earth with carpet & \\
\hline $\begin{array}{l}\text { Thermal properties for } \\
\text { ground level floor: } \\
\text { U-factor }\left(\mathrm{Btu} / \mathrm{h} * \mathrm{ft}^{2} *{ }^{\circ} \mathrm{F}\right) \\
\text { and/or } \\
\mathrm{R} \text {-value }\left(\mathrm{h} * \mathrm{ft}^{2} *{ }^{\circ} \mathrm{F} / \mathrm{Btu}\right)\end{array}$ & $\begin{array}{l}\text { ASHRAE 90.1 Requirements } \\
\text { Nonresidential; Slab-on-Grade Floors, unheated }\end{array}$ & ASHRAE 90.1 \\
\hline
\end{tabular}




\begin{tabular}{|c|c|c|}
\hline Item & Descriptions & Data Source \\
\hline $\begin{array}{l}\text { Thermal properties for } \\
\text { basement walls }\end{array}$ & NA & \\
\hline Dimensions & based on floor area and aspect ratio & \\
\hline \multicolumn{3}{|l|}{ Interior Partitions } \\
\hline Construction & 0.5 in gypsum board +0.5 in gypsum board & \\
\hline Dimensions & based on floor plan and floor-to-floor height & \\
\hline Internal Mass & 6 inches standard wood $\left(16.6 \mathrm{lb} / \mathrm{ft}^{2}\right)$ & \\
\hline \multicolumn{3}{|l|}{ Air Barrier System } \\
\hline Infiltration & $\begin{array}{l}\text { Peak: } 0.2016 \mathrm{cfm} / \mathrm{sf} \text { of above grade exterior wall surface area (when fans turn off) } \\
\text { Off Peak: } 25 \% \text { of peak infiltration rate (when fans turn on) }\end{array}$ & $\begin{array}{l}\text { Reference: } \\
\text { PNNL-18898: Infiltration } \\
\text { Modeling Guidelines for } \\
\text { Commercial Building } \\
\text { Energy Analysis. }\end{array}$ \\
\hline \multicolumn{3}{|l|}{ HVAC } \\
\hline System Type & & \\
\hline Heating type & Gas furnace inside the packaged air conditioning unit & \multirow{3}{*}{$\begin{array}{l}2003 \text { CBECS Data, } \\
\text { PNNL's CBECS Study } \\
\text { 2006, and } 90.1 \\
\text { Mechanical } \\
\text { Subcommittee input. }\end{array}$} \\
\hline Cooling type & Packaged air conditioning unit & \\
\hline Distribution and terminal units & 10 single-zone rooftop units with Constant air volume air distribution. One unit serving one store. & \\
\hline \multicolumn{3}{|l|}{ HVAC Sizing } \\
\hline Air Conditioning & autosized to design day & \\
\hline Heating & autosized to design day & \\
\hline \multicolumn{3}{|l|}{ HVAC Efficiency } \\
\hline Air Conditioning & $\begin{array}{l}\text { Various by climate location and design cooling capacity } \\
\text { ASHRAE } 90.1 \text { Requirements } \\
\text { Minimum equipment efficiency for Air Conditioners and Condensing Units }\end{array}$ & ASHRAE 90.1 \\
\hline Heating & $\begin{array}{l}\text { Various by climate location and design heating capacity } \\
\text { ASHRAE } 90.1 \text { Requirements } \\
\text { Minimum equipment efficiency for Warm Air Furnaces }\end{array}$ & ASHRAE 90.1 \\
\hline \multicolumn{3}{|l|}{ HVAC Control } \\
\hline Thermostat Setpoint & $75^{\circ} \mathrm{F}$ Cooling $/ 70^{\circ} \mathrm{F}$ Heating & \\
\hline Thermostat Setback & $85^{\circ} \mathrm{F}$ Cooling $/ 60^{\circ} \mathrm{F}$ Heating & \\
\hline Supply air temperature & Maximum $104^{\circ} \mathrm{F}$, Minimum $55^{\circ} \mathrm{F}$ & \\
\hline $\begin{array}{l}\text { Chilled water supply } \\
\text { temperatures }\end{array}$ & NA & \\
\hline Hot water supply temperatures & NA & \\
\hline
\end{tabular}




\begin{tabular}{|c|c|c|}
\hline Item & Descriptions & Data Source \\
\hline Economizers & $\begin{array}{l}\text { Various by climate location and cooling capacity } \\
\text { Control type: differential dry bulb }\end{array}$ & ASHRAE 90.1 \\
\hline OA Ventilation & ASHRAE Ventilation Standard 62.1 & $\begin{array}{l}\text { ASHRAE Ventilation } \\
\text { Standard } 62.1\end{array}$ \\
\hline Demand Control Ventilation & ASHRAE 90.1 Requirements & ASHRAE 90.1 \\
\hline Energy Recovery & ASHRAE 90.1 Requirements & ASHRAE 90.1 \\
\hline \multicolumn{3}{|l|}{ Supply Fan } \\
\hline Fan schedules & See Appendix C & \\
\hline Supply Fan Total Efficiency (\%) & $60 \%$ to $62 \%$ depending on the fan motor size & \multirow{2}{*}{$\begin{array}{l}\text { ASHRAE } 90.1 \\
\text { requirements for motor } \\
\text { efficiency and fan power } \\
\text { limitation }\end{array}$} \\
\hline Supply Fan Pressure Drop & Various depending on the fan supply air cfm & \\
\hline \multicolumn{3}{|l|}{ Pump } \\
\hline Pump Type & NA & \\
\hline Rated Pump Head & NA & \\
\hline Pump Power & NA & \\
\hline \multicolumn{3}{|l|}{ Cooling Tower } \\
\hline Cooling Tower Type & NA & \\
\hline Cooling Tower Power & NA & \\
\hline \multicolumn{3}{|l|}{ Service Water Heating } \\
\hline SWH type & Storage Tank & \\
\hline Fuel type & Natural Gas & \\
\hline Thermal efficiency (\%) & ASHRAE 90.1 & ASHRAE 90.1 \\
\hline Tank Volume (gal) & 6 & \\
\hline Water temperature setpoint & $120^{\circ} \mathrm{F}$ & \\
\hline Water consumption & $\begin{array}{l}\text { BLDG_SWH_SCH } \\
\text { See Appendix C }\end{array}$ & \\
\hline \multicolumn{3}{|l|}{ Internal Loads \& Schedules } \\
\hline \multicolumn{3}{|l|}{ Lighting } \\
\hline Average power density $\left(\mathrm{W} / \mathrm{ft}^{2}\right)$ & $\begin{array}{l}\text { ASHRAE } 90.1 \\
\text { Lighting Power Densities Using the Building Area Method }\end{array}$ & \\
\hline Schedule & See Appendix C & \\
\hline Daylighting Controls & ASHRAE 90.1 Requirements & \\
\hline Occupancy Sensors & ASHRAE 90.1 Requirements & \\
\hline \multicolumn{3}{|l|}{\begin{tabular}{|l|} 
Plug load \\
\end{tabular}} \\
\hline Average power density $\left(\mathrm{W} / \mathrm{ft}^{2}\right)$ & See Appendix B & $\begin{array}{l}\text { User's Manual for } \\
\text { ASHRAE Standard 90.1- } \\
2004 \text { (Appendix G) }\end{array}$ \\
\hline
\end{tabular}




\begin{tabular}{|c|c|c|c|}
\hline & Item & Descriptions & Data Source \\
\hline & Schedule & See Appendix C & \\
\hline & \multicolumn{3}{|l|}{ Occupancy } \\
\hline & Peak people & See Appendix B & \\
\hline & Schedule & See Appendix C & \\
\hline \multicolumn{4}{|c|}{ Misc. } \\
\hline & Elevator & NA & \\
\hline & Peak Power & NA & \\
\hline & Schedule & NA & \\
\hline & \multicolumn{3}{|l|}{ Exterior Lighting } \\
\hline & Peak Power & 9153 watts & \multirow{2}{*}{ ASHRAE 90.1} \\
\hline & Schedule & See Appendix C & \\
\hline
\end{tabular}

\section{References}

Briggs, R.S., R.G. Lucas, and Z.T. Taylor. 2003. Climate Classification for Building Energy Codes and Standards:

Part 2-Zone Definitions, Maps, and Comparisons. ASHRAE Transactions 109(2)

PNNL's CBECS Study. 2007. Analysis of Building Envelope Construction in 2003 CBECS Buildings. Dave Winiarski, Mark Halverson, and Wei Jiang. Pacific Northwest National Laboratory. March 2007.

PNNL's CBECS Study. 2006. Review of Pre- and Post-1980 Buildings in CBECS - HVAC Equipment. Dave Winiarski, Wei Jiang and Mark

Halverson. Pacific Northwest National Laboratory. December 2006.

Gowri K, DW Winiarski, and RE Jarnagin. 2009. Infiltration modeling guidelines for commercial building energy analysis. PNNL-18898, Pacific Northwest National Laboratory, Richland, WA. http://www.pnl.gov/main/publications/external/technical_reports/PNNL-18898.pdf 


\section{A.5 Primary School Modeling Description}

\begin{tabular}{|c|c|c|c|c|}
\hline Item & \multicolumn{3}{|c|}{ Descriptions } & Data Source \\
\hline \multicolumn{5}{|l|}{ Program } \\
\hline Vintage & \multicolumn{3}{|c|}{ NEW CONSTRUCTION } & \\
\hline $\begin{array}{l}\text { Location } \\
\text { (Representing } 8 \text { Climate Zones) }\end{array}$ & $\begin{array}{l}\text { Zone 1A: Miami (very hot, humid) } \\
\text { Zone 1B: Riyadh, Saudi Arabia } \\
\text { (very hot, dry) } \\
\text { Zone 2A: Houston (hot, humid) } \\
\text { Zone 2B: Phoenix (hot, dry) } \\
\text { Zone 3A: Memphis (warm, humid) } \\
\text { Zone 3B: El Paso (warm, dry) } \\
\text { Zone 3C: San Francisco (warm, } \\
\text { marine) }\end{array}$ & $\begin{array}{l}\text { Zone 4A: Baltimore (mild, humid) } \\
\text { Zone 4B: Albuquerque (mild, dry) } \\
\text { Zone 4C: Salem (mild, marine) } \\
\text { Zone 5A: Chicago (cold, humid) } \\
\text { Zone 5B: Boise (cold, dry) } \\
\text { Zone 5C: Vancouver, BC (cold, } \\
\text { marine) }\end{array}$ & $\begin{array}{l}\text { Zone 6A: Burlington (cold, humid) } \\
\text { Zone 6B: Helena (cold, dry) } \\
\text { Zone 7: Duluth (very cold) } \\
\text { Zone 8: Fairbanks (subarctic) }\end{array}$ & $\begin{array}{l}\text { Selection of representative } \\
\text { climates based on Briggs' } \\
\text { paper }\end{array}$ \\
\hline Available fuel types & & gas, electricity & & \\
\hline $\begin{array}{l}\text { Building Type (Principal Building } \\
\text { Function) }\end{array}$ & & EDUCATION & & \\
\hline Building Prototype & & Primary School & & \\
\hline \multicolumn{5}{|l|}{ Form } \\
\hline Total Floor Area (sq. feet) & & $\begin{array}{c}73,960 \\
(340 \mathrm{ft} \times 270 \mathrm{ft}) \\
\end{array}$ & & \\
\hline \multicolumn{5}{|l|}{ Building shape } \\
\hline Aspect Ratio & \multicolumn{3}{|c|}{1.3} & \\
\hline
\end{tabular}




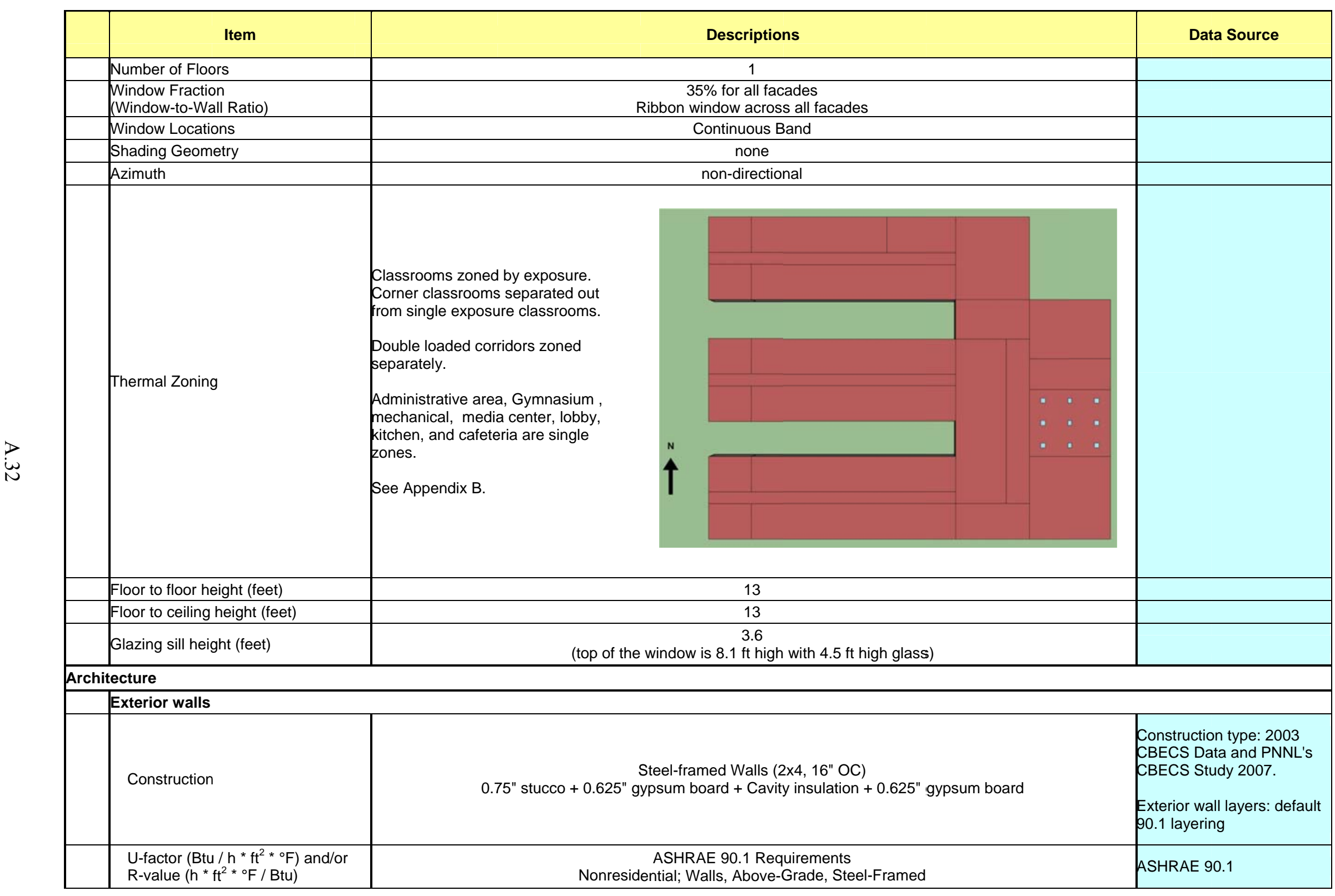




\begin{tabular}{|c|c|c|}
\hline Item & Descriptions & Data Source \\
\hline Dimensions & based on floor area and aspect ratio & \\
\hline Tilts and orientations & vertical & \\
\hline \multicolumn{3}{|l|}{ Roof } \\
\hline Construction & $\begin{array}{l}\text { Built-up Roof } \\
\text { Roof membrane + Roof insulation }+ \text { Metal decking }\end{array}$ & $\begin{array}{l}\text { Construction type: } 2003 \\
\text { CBECS Data and PNNL's } \\
\text { CBECS Study } 2007 . \\
\text { Roof layers: default } 90.1 \\
\text { layering }\end{array}$ \\
\hline $\begin{array}{l}\text { U-factor }\left(\mathrm{Btu} / \mathrm{h} * \mathrm{ft}^{2} *{ }^{\circ} \mathrm{F}\right) \text { and/or } \\
\mathrm{R} \text {-value }\left(\mathrm{h} * \mathrm{ft}^{2} *{ }^{\circ} \mathrm{F} / \mathrm{Btu}\right)\end{array}$ & $\begin{array}{l}\text { ASHRAE } 90.1 \text { Requirements } \\
\text { Nonresidential; Roofs, Insulation entirely above deck }\end{array}$ & ASHRAE 90.1 \\
\hline Area (ft2) & 73,960 & \\
\hline Tilts and orientations & horizontal & \\
\hline \multicolumn{3}{|l|}{ Window } \\
\hline Dimensions & based on window fraction, location, glazing sill height, floor area and aspect ratio & \\
\hline Glass-Type and frame & Hypothetical window with no frame and meeting ASHRAE 90.1 Requirements & \\
\hline$\frac{\left.\mathrm{U} \text {-factor (Btu } / \mathrm{h} * \mathrm{ftt}^{2}{ }^{\circ} \mathrm{F}\right)}{\mathrm{SHGC}}$ & $\begin{array}{c}\text { ASHRAE 90.1 Requirements } \\
\text { Nonresidential; Vertical Glazing, 30.1-40\% }\end{array}$ & ASHRAE 90.1 \\
\hline Visible transmittance & Hypothetical window with no frame and meeting ASHRAE 90.1 Requirements & \\
\hline Operable area & $35 \%$ & $\begin{array}{l}\text { PNNL 's Glazing Market } \\
\text { Data for ASHRAE } \\
\text { spreadsheet }\end{array}$ \\
\hline \multicolumn{3}{|l|}{ Skylight } \\
\hline Dimensions & $\begin{array}{c}\text { Gymnasium/Multipurpose Room } \\
(4 \mathrm{ft} \times 4 \mathrm{ft}) \times 9 \text { skylights }=144 \mathrm{ft}^{2} \text { total Skylight Area } \\
3.75 \% \text { of gym roof area }\end{array}$ & AEDG K-12 Guide \\
\hline Glass-Type and frame & Hypothetical glass and frame meeting ASHRAE 90.1 Requirements below & \\
\hline U-factor $\left(\mathrm{Btu} / \mathrm{h} * \mathrm{ft}^{2} *{ }^{\circ} \mathrm{F}\right)$ & \multirow{3}{*}{$\begin{array}{l}\text { ASHRAE 90.1 Requirements } \\
\text { Nonresidential; Skylight with curb, Glass, } 2.1-5 \%\end{array}$} & \multirow{3}{*}{ ASHRAE 90.1} \\
\hline SHGC & & \\
\hline Visible transmittance & & \\
\hline \multicolumn{3}{|l|}{ Foundation } \\
\hline Foundation Type & Slab-on-grade floors (unheated) & \\
\hline Construction & $6 "$ concrete slab poured directly on to the earth + carpet & \\
\hline $\begin{array}{l}\text { Thermal properties for ground } \\
\text { level floor: } \\
\text { F-factor }\left(\mathrm{Btu} / \mathrm{h} * \mathrm{ft}^{2} *{ }^{\circ} \mathrm{F}\right) \\
\text { and/or } \\
\text { R-value }\left(\mathrm{h} * \mathrm{ft}^{2} *{ }^{\circ} \mathrm{F} / \mathrm{Btu}\right)\end{array}$ & $\begin{array}{l}\text { ASHRAE 90.1 Requirements } \\
\text { Nonresidential; Slab-on-Grade Floors, unheated }\end{array}$ & ASHRAE 90.1 \\
\hline $\begin{array}{l}\text { Thermal properties for } \\
\text { basement walls: }\end{array}$ & NA & \\
\hline
\end{tabular}




\begin{tabular}{|c|c|c|}
\hline Item & Descriptions & Data Source \\
\hline Dimensions & based on floor area and aspect ratio & \\
\hline \multicolumn{3}{|l|}{ Interior Partitions } \\
\hline Construction & $2 \times 4$ uninsulated stud wall & \\
\hline Dimensions & based on floor plan and floor-to-floor height & \\
\hline Internal Mass & 6 inches standard wood $\left(16.6 \mathrm{lb} / \mathrm{ft}^{2}\right)$ & \\
\hline \multicolumn{3}{|l|}{ Air Barrier System } \\
\hline Infiltration & $\begin{array}{l}\text { Peak: } 0.2016 \mathrm{cfm} / \mathrm{ft}^{2} \text { of above grade exterior wall surface area (when fans turn off) } \\
\text { Off Peak: } 25 \% \text { of peak infiltration rate (when fans turn on) }\end{array}$ & $\begin{array}{l}\text { Reference: } \\
\text { PNNL-18898: Infiltration } \\
\text { Modeling Guidelines for } \\
\text { Commercial Building } \\
\text { Energy Analysis. }\end{array}$ \\
\hline \multicolumn{3}{|l|}{ HVAC } \\
\hline \multicolumn{3}{|l|}{ System Type } \\
\hline Heating type & $\begin{array}{l}\text { 1. Gas furnace inside packaged air conditioning unit } \\
\text { 2. Hot water from a gas boiler for heating }\end{array}$ & \multirow{3}{*}{$\begin{array}{l}\text { 2003 CBECS Data, PNNL's } \\
\text { CBECS Study 2006, and } \\
\text { 90.1 Mechanical } \\
\text { Subcommittee input. }\end{array}$} \\
\hline Cooling type & Packaged air conditioning unit & \\
\hline Distribution and terminal units & $\begin{array}{l}\text { 1. CAV systems: direct air from the packaged air conditioning unit } \\
\text { 2. VAV systems: VAV terminal box with damper and hot water reheating coil } \\
\text { Zone Control Type: minimum supply air at } 30 \% \text { of the zone design peak supply air }\end{array}$ & \\
\hline \multicolumn{3}{|l|}{ HVAC Sizing } \\
\hline Air Conditioning & autosized to design day & \\
\hline Heating & autosized to design day & \\
\hline \multicolumn{3}{|l|}{ HVAC Efficiency } \\
\hline Air Conditioning & $\begin{array}{l}\text { Varies by climate location and design cooling capacity } \\
\text { ASHRAE 90.1 Requirements } \\
\text { Minimum equipment efficiency for Air Conditioners and Condensing Units }\end{array}$ & ASHRAE 90.1 \\
\hline Heating & $\begin{array}{c}\text { Varies by climate location and design heating capacity } \\
\text { ASHRAE 90.1 Requirements } \\
\text { Minimum equipment efficiency for Warm Air Furnaces } \\
\text { Minimum equipment efficiency for Gas and Oil-fired Boilers }\end{array}$ & ASHRAE 90.1 \\
\hline \multicolumn{3}{|l|}{ HVAC Control } \\
\hline Thermostat Setpoint & $75^{\circ} \mathrm{F}$ Cooling $/ 70^{\circ} \mathrm{F}$ Heating & \\
\hline Thermostat Setback & $80^{\circ} \mathrm{F}$ Cooling $/ 60^{\circ} \mathrm{F}$ Heating & \\
\hline Supply air temperature & Minimum $50^{\circ} \mathrm{F}$ and maximum $122^{\circ} \mathrm{F}$ & \\
\hline Chilled water supply temperatures & NA & \\
\hline Hot water supply temperatures & $180^{\circ} \mathrm{F}$ & \\
\hline
\end{tabular}




\begin{tabular}{|c|c|c|}
\hline Item & Descriptions & Data Source \\
\hline Economizers & $\begin{array}{l}\text { Varies by climate location and cooling capacity } \\
\text { Control type: differential dry bulb }\end{array}$ & ASHRAE 90.1 \\
\hline Outdoor Air Ventilation & ASHRAE Ventilation Standard 62.1 & $\begin{array}{l}\text { ASHRAE Ventilation } \\
\text { Standard } 62.1\end{array}$ \\
\hline Demand Control Ventilation & ASHRAE 90.1 Requirements & ASHRAE 90.1 \\
\hline Energy Recovery & ASHRAE 90.1 Requirements & ASHRAE 90.1 \\
\hline \multicolumn{3}{|l|}{ Supply Fan } \\
\hline Fan schedules & See Appendix C & \\
\hline Supply Fan Mechanical Efficiency & Varies depending on the fan motor size and type of fan & \multirow{2}{*}{$\begin{array}{l}\text { ASHRAE } 90.1 \text { requirements } \\
\text { for motor efficiency and fan } \\
\text { power limitation }\end{array}$} \\
\hline Supply Fan Pressure Drop & Various depending on the fan supply air cfm & \\
\hline \multicolumn{3}{|l|}{ Pump } \\
\hline Pump Type & Variable speed & \\
\hline Rated Pump Head & $60 \mathrm{ft}$ & \\
\hline Pump Power & autosized & \\
\hline \multicolumn{3}{|l|}{ Cooling Tower } \\
\hline Cooling Tower Type & NA & \\
\hline Cooling Tower Power & NA & \\
\hline \multicolumn{3}{|l|}{ Service Water Heating } \\
\hline SWH type & Storage Tank & \\
\hline Fuel type & Natural Gas & \\
\hline Thermal efficiency (\%) & $\begin{array}{l}\text { ASHRAE } 90.1 \text { Requirements } \\
\text { Water Heating Equipment, Gas storage water heaters, }>75,000 \text { Btu/h input }\end{array}$ & ASHRAE 90.1 \\
\hline Tank Volume (gal) & 264 & \\
\hline Water temperature setpoint & $120 \mathrm{~F}$ & \\
\hline Water consumption (peak gpm) & See Appendix C & \\
\hline \multicolumn{3}{|l|}{ Internal Loads \& Schedules } \\
\hline \multicolumn{3}{|l|}{ Lighting } \\
\hline Lighting power density $\left(\mathrm{W} / \mathrm{ft}^{2}\right)$ & $\begin{array}{l}\text { ASHRAE 90.1 } \\
\text { Lighting Power Densities Using the Space-By-Space Method } \\
\text { See Appendix B }\end{array}$ & ASHRAE 90.1 \\
\hline Schedule & See Appendix C & \\
\hline Daylighting Controls & ASHRAE 90.1 Requirements & \\
\hline Occupancy Sensors & ASHRAE 90.1 Requirements & \\
\hline \multicolumn{3}{|l|}{ Plug load } \\
\hline Average power density $\left(\mathrm{W} / \mathrm{ft}^{2}\right)$ & See Appendix B & $\begin{array}{l}\text { User's Manual for ASHRAE } \\
\text { Standard 90.1-2004 } \\
\text { (Appendix G) }\end{array}$ \\
\hline Schedule & See Appendix C & \\
\hline
\end{tabular}




\begin{tabular}{|c|c|c|c|}
\hline & Item & Descriptions & Data Source \\
\hline & \multicolumn{3}{|l|}{ Occupancy } \\
\hline & Average people & See Appendix B & \\
\hline & Schedule & See Appendix C & \\
\hline \multicolumn{4}{|l|}{ Misc. } \\
\hline & \multicolumn{3}{|l|}{ Elevator } \\
\hline & Peak Power & NA & \\
\hline & Schedule & NA & \\
\hline \multicolumn{4}{|c|}{ Exterior Lighting } \\
\hline & Peak Power (W) & $\begin{array}{c}\text { ASHRAE 90.1 } \\
\text { Lighting Power Densities For Building Exteriors }\end{array}$ & ASHRAE 90.1 \\
\hline & Schedule & See Appendix C & \\
\hline
\end{tabular}

References

Briggs, R.S., R.G. Lucas, and Z.T. Taylor. 2003. Climate Classification for Building Energy Codes and Standards:

Part 2-Zone Definitions, Maps, and Comparisons. ASHRAE Transactions 109(2).

PNNL's CBECS Study. 2007. Analysis of Building Envelope Construction in 2003 CBECS Buildings. Dave Winiarski, Mark Halverson, and Wei Jiang. Pacific Northwest National Laboratory. March 2007.

PNNL'S CBECS Study. 2006. Review of Pre- and Post-1980 Buildings in CBECS - HVAC Equipment. Dave Winiarski, Wei Jiang and Mark Halverson. Pacific Northwest National Laboratory. December 2006.

"Study of the U.S. Market For Windows, Doors, and Skylights", American Architectural Manufacturers Association, Window \& Door Manufacturers

Association, 2006 


\section{A.6 Stand-alone Retail Modeling Description}

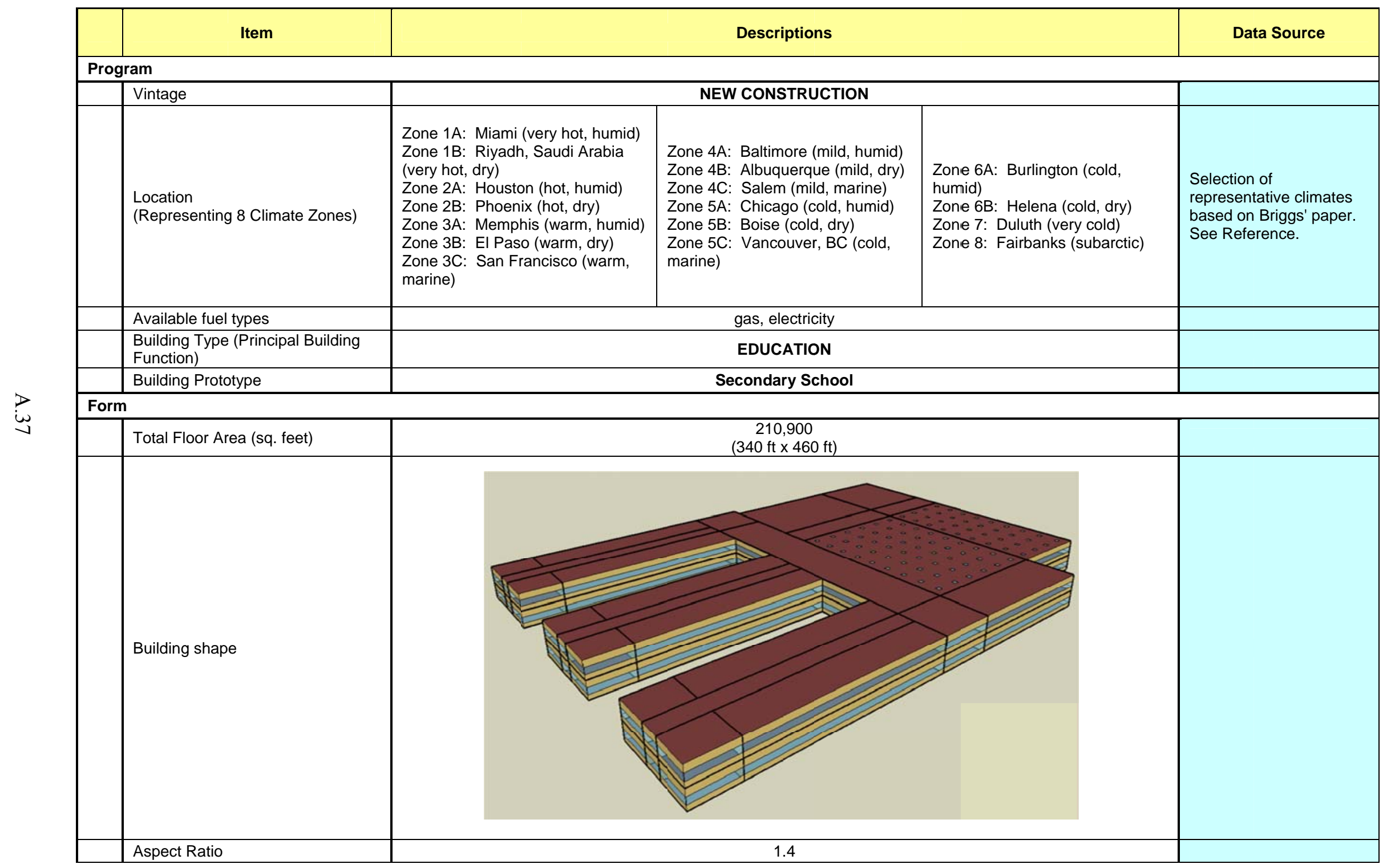




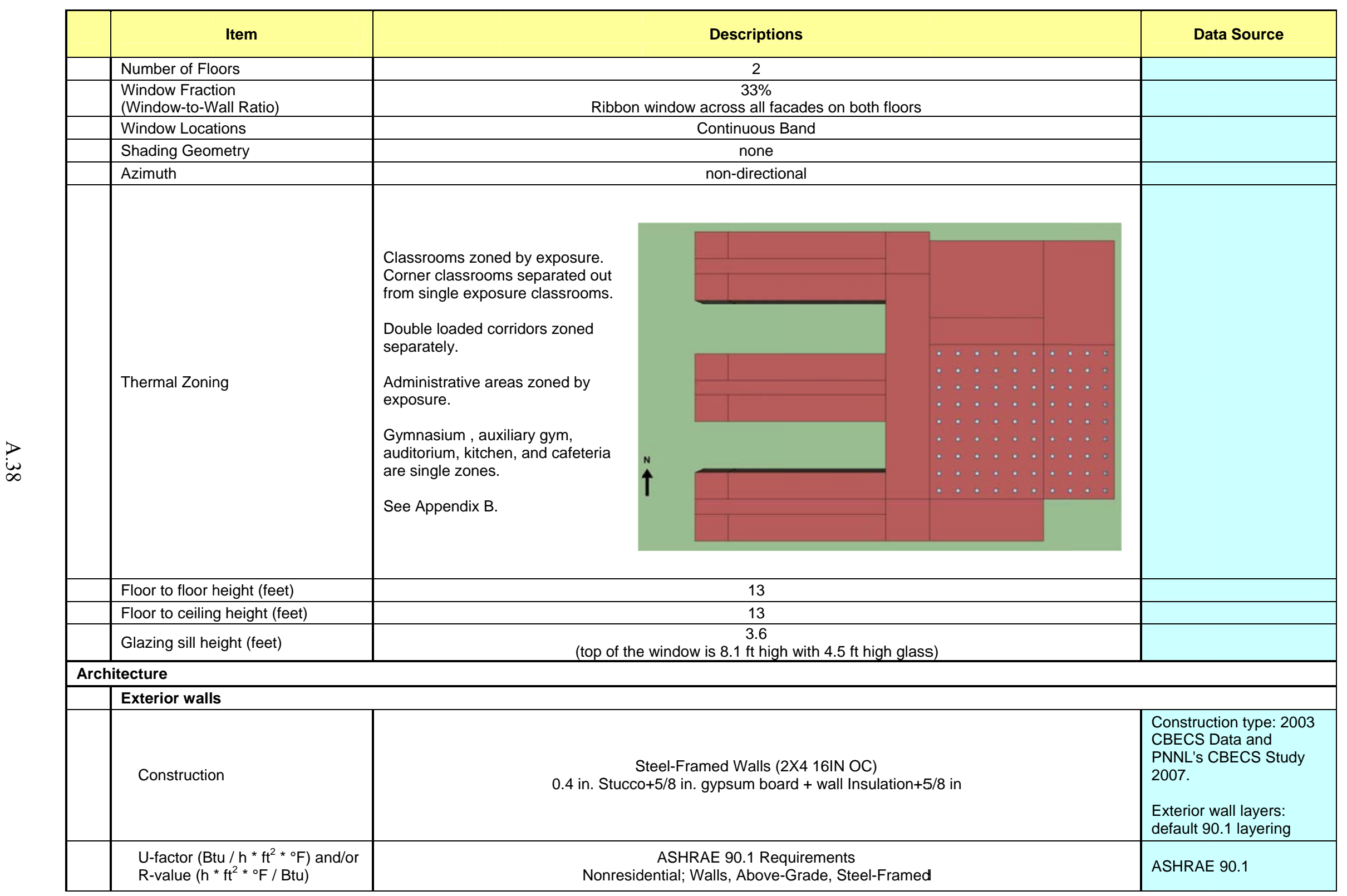




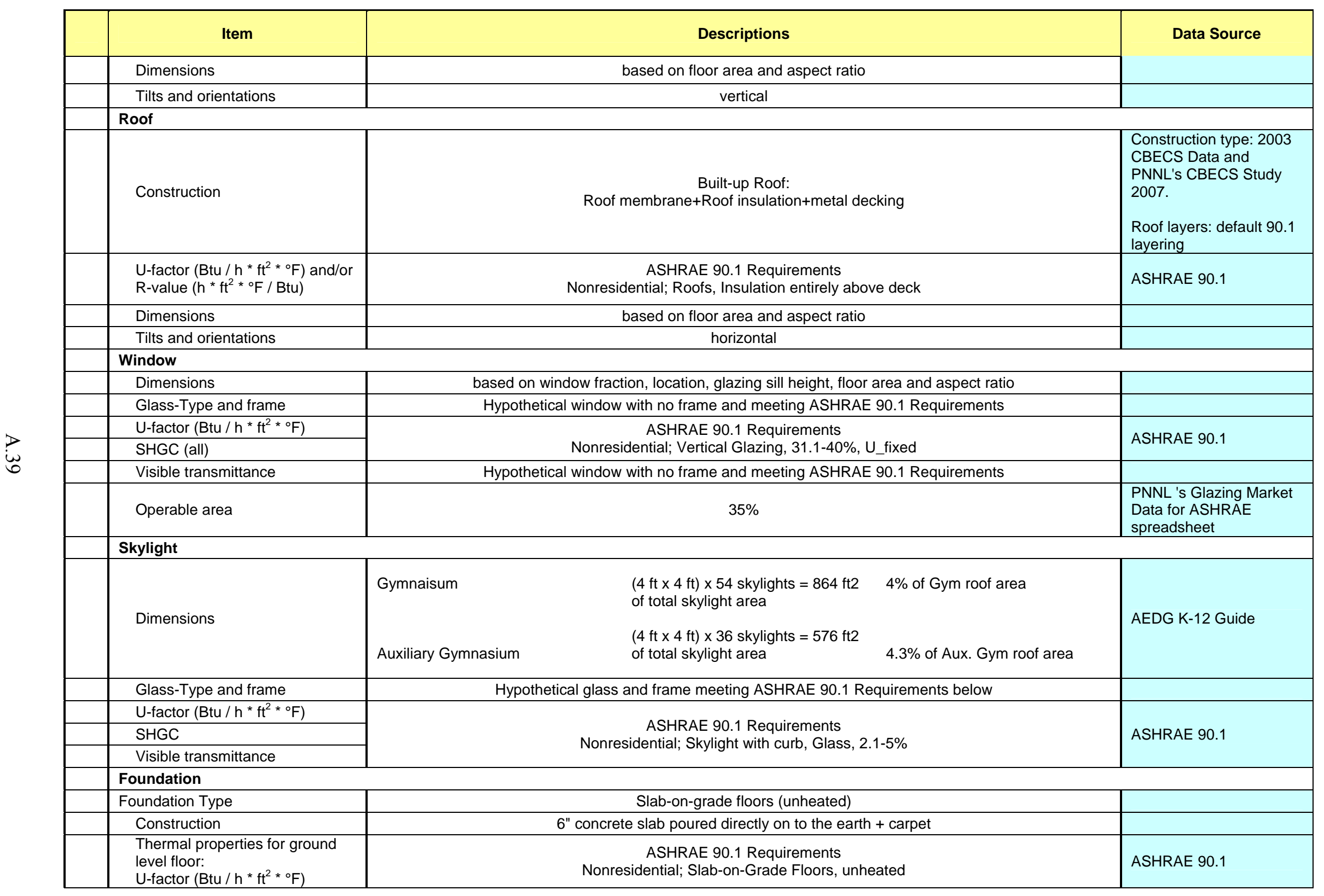




\begin{tabular}{|c|c|c|}
\hline Item & Descriptions & Data Source \\
\hline $\begin{array}{l}\text { and/or } \\
\text { R-value }\left(\mathrm{h} * \mathrm{ft}^{2} *{ }^{\circ} \mathrm{F} / \mathrm{Btu}\right)\end{array}$ & & \\
\hline $\begin{array}{l}\text { Thermal properties for } \\
\text { basement walls }\end{array}$ & NA & \\
\hline Dimensions & based on floor area and aspect ratio & \\
\hline \multicolumn{3}{|l|}{ Interior Partitions } \\
\hline Construction & $2 \times 4$ uninsulated steel stud wall & \\
\hline Dimensions & based on floor plan and floor-to-floor height & \\
\hline Internal Mass & 6 inches standard wood $\left(16.6 \mathrm{lb} / \mathrm{ft}^{2}\right)$ & \\
\hline \multicolumn{3}{|l|}{ Air Barrier System } \\
\hline Infiltration & $\begin{array}{c}\text { Peak: } 0.2016 \mathrm{cfm} / \mathrm{ft}^{2} \text { of above grade exterior wall surface area (when fans turn off) } \\
\text { Off Peak: } 25 \% \text { of peak infiltration rate (when fans turn on) }\end{array}$ & $\begin{array}{l}\text { Reference: } \\
\text { PNNL-18898: Infiltration } \\
\text { Modeling Guidelines for } \\
\text { Commercial Building } \\
\text { Energy Analysis. }\end{array}$ \\
\hline \multicolumn{3}{|l|}{ HVAC } \\
\hline \multicolumn{3}{|l|}{ System Type } \\
\hline Heating type & $\begin{array}{l}\text { 1. Gas furnaces inside packaged air conditioning units } \\
\text { 2. Gas-fired boiler } \\
\text { provide heating hot water and chilled water to these AHUs. }\end{array}$ & \multirow{3}{*}{$\begin{array}{l}2003 \text { CBECS Data, } \\
\text { PNNL's CBECS Study } \\
2006 \text {, and } 90.1 \\
\text { Mechanical } \\
\text { Subcommittee input. }\end{array}$} \\
\hline Cooling type & $\begin{array}{c}\text { 1. Packaged air conditioner } \\
\text { 2. Air-cooled Chiller }\end{array}$ & \\
\hline Distribution and terminal units & $\begin{array}{l}\text { 1. CAV system: direct air from the packaged unit } \\
\text { 2. VAV System: VAV terminal box with damper and hot water reheating coil } \\
\text { Zone Control Type: minimum supply air at } 30 \% \text { of the zone design peak supply air }\end{array}$ & \\
\hline \multicolumn{3}{|c|}{ (2 } \\
\hline Air Conditioning & autosized to design day & \\
\hline Heating & autosized to design day & \\
\hline \multicolumn{3}{|l|}{ HVAC Efficiency } \\
\hline Air Conditioning & $\begin{array}{c}\text { Various by climate location and design cooling capacity } \\
\text { ASHRAE 90.1 Requirements } \\
\text { Minimum equipment efficiency for Air Conditioners and Condensing Units } \\
\text { Minimum equipment efficiency for Air-cooled Chillers }\end{array}$ & ASHRAE 90.1 \\
\hline Heating & $\begin{array}{l}\text { Various by climate location and design heating capacity } \\
\text { ASHRAE 90.1 Requirements } \\
\text { Minimum equipment efficiency for Warm Air Furnaces } \\
\text { Minimum equipment efficiency for Gas and Oil-fired Boilers }\end{array}$ & ASHRAE 90.1 \\
\hline \multicolumn{3}{|l|}{ HVAC Control } \\
\hline Thermostat Setpoint & $75^{\circ} \mathrm{F}$ Cooling $/ 70^{\circ} \mathrm{F}$ Heating & \\
\hline Thermostat Setback & $85^{\circ} \mathrm{F}$ Cooling $/ 60^{\circ} \mathrm{F}$ Heating & \\
\hline
\end{tabular}




\begin{tabular}{|c|c|c|}
\hline Item & Descriptions & Data Source \\
\hline Supply air temperature & Minimum $50^{\circ} \mathrm{F}$, maximum $122^{\circ} \mathrm{F}$ & \\
\hline $\begin{array}{l}\text { Chilled water supply } \\
\text { temperatures }\end{array}$ & $44^{\circ} \mathrm{F}$ & \\
\hline Hot water supply temperatures & $180^{\circ} \mathrm{F}$ & \\
\hline Economizers & $\begin{array}{l}\text { Various by climate location and cooling capacity } \\
\text { Control type: differential dry bulb }\end{array}$ & ASHRAE 90.1 \\
\hline Ventilation & ASHRAE Ventilation Standard 62.1 & $\begin{array}{l}\text { ASHRAE Ventilation } \\
\text { Standard } 62.1\end{array}$ \\
\hline Demand Control Ventilation & ASHRAE 90.1 Requirements & ASHRAE 90.1 \\
\hline Energy Recovery & ASHRAE 90.1 Requirements & ASHRAE 90.1 \\
\hline \multicolumn{3}{|l|}{ Supply Fan } \\
\hline Fan schedules & See Appendix C & \\
\hline $\begin{array}{l}\text { Supply Fan Mechanical } \\
\text { Efficiency (\%) }\end{array}$ & Varies depending on fan motor size & \multirow{2}{*}{$\begin{array}{l}\text { ASHRAE } 90.1 \\
\text { requirements for motor } \\
\text { efficiency and fan power } \\
\text { limitation }\end{array}$} \\
\hline Supply Fan Pressure Drop & Various depending on the fan supply air cfm & \\
\hline \multicolumn{3}{|l|}{ Pump } \\
\hline Pump Type & Variable speed & \\
\hline Rated Pump Head & $\begin{array}{l}\text { CW: } 75 \mathrm{ft} \\
\text { HW: } 60 \mathrm{ft}\end{array}$ & \\
\hline Pump Power & autosized & \\
\hline \multicolumn{3}{|l|}{ Cooling Tower } \\
\hline Cooling Tower Type & NA & \\
\hline Cooling Tower Power & NA & \\
\hline \multicolumn{3}{|l|}{ Service Water Heating } \\
\hline SWH type & Storage Tank & \\
\hline Fuel type & Natural Gas & \\
\hline Thermal efficiency (\%) & $\begin{array}{c}\text { ASHRAE } 90.1 \text { Requirements } \\
\text { Water Heating Equipment, Gas storage water heaters, }>75,000 \mathrm{Btu} / \mathrm{h} \text { input }\end{array}$ & ASHRAE 90.1 \\
\hline Tank Volume (gal) & 792 & \\
\hline Water temperature setpoint & $120 \mathrm{~F}$ & \\
\hline Water consumption & See Appendix C & \\
\hline \multicolumn{3}{|l|}{ Internal Loads \& Schedules } \\
\hline \multicolumn{3}{|l|}{ Lighting } \\
\hline Average power density $\left(\mathrm{W} / \mathrm{ft}^{2}\right)$ & $\begin{array}{l}\text { ASHRAE 90.1 } \\
\text { Lighting Power Densities Using the Space-By-Space Method } \\
\text { See Appendix B }\end{array}$ & ASHRAE 90.1 \\
\hline Schedule & See Appendix C & \\
\hline Daylighting Controls & ASHRAE 90.1 Requirements & \\
\hline Occupancy Sensors & ASHRAE 90.1 Requirements & \\
\hline
\end{tabular}




\begin{tabular}{|c|c|c|}
\hline Item & Descriptions & Data Source \\
\hline \multicolumn{3}{|l|}{ Plug load } \\
\hline Average power density $\left(\mathrm{W} / \mathrm{ft}^{2}\right)$ & See Appendix B & \\
\hline Schedule & See Appendix C & \\
\hline \multicolumn{3}{|l|}{ Electric load (cooking) } \\
\hline Average power density $\left(\mathrm{W} / \mathrm{ft}^{2}\right)$ & $20.6 \mathrm{~W} / \mathrm{ft}^{2}-30 \%$ Radiant fraction , 25\% latent, 20\% lost & \\
\hline Schedule & See Appendix C & \\
\hline \multicolumn{3}{|l|}{ Gas Equip Cooking } \\
\hline Average power density $\left(\mathrm{W} / \mathrm{ft}^{2}\right)$ & $156 \mathrm{~W} / \mathrm{ft}^{2}-20 \%$ Radiant fraction , $10 \%$ latent, $70 \%$ lost & \\
\hline Schedule & See Appendix C & \\
\hline \multicolumn{3}{|l|}{ Occupancy } \\
\hline Average people & See Appendix B & $\begin{array}{l}\text { User's Manual for } \\
\text { ASHRAE Standard 90.1- } \\
2004 \text { (Appendix G) }\end{array}$ \\
\hline Schedule & See Appendix C & \\
\hline \multicolumn{3}{|l|}{ Misc. } \\
\hline \multicolumn{3}{|l|}{ Elevator } \\
\hline Quantity & 2 & \multirow{4}{*}{$\begin{array}{l}\text { DOE Commercial } \\
\text { Reference Building TSD } \\
\text { (unpublished) and } \\
\text { models (V1.3_5.0). }\end{array}$} \\
\hline Motor type & hydraulic & \\
\hline Peak Motor Power (W/elevator) & 16055 & \\
\hline Heat Gain to Building & Interior & \\
\hline $\begin{array}{l}\text { Peak Fan/lights Power } \\
\text { (W/elevator) }\end{array}$ & 161.9 & $\begin{array}{l}90.1 \text { Mechanical } \\
\text { Subcommittee, Elevator } \\
\text { Working Group }\end{array}$ \\
\hline Motor and fan/lights Schedules & See Appendix C & $\begin{array}{l}\text { DOE Commercial } \\
\text { Reference Building TSD } \\
\text { (unpublished) and } \\
\text { models (V1.3 5.0) and } \\
\text { Appendix DF } 2007 \\
\end{array}$ \\
\hline \multicolumn{3}{|l|}{ Exterior Lighting } \\
\hline Peak Power & $\begin{array}{c}\text { ASHRAE } 90.1 \\
\text { Lighting Power Densities For Building Exteriors }\end{array}$ & ASHRAE 90.1 \\
\hline Schedule & See Appendix C & \\
\hline
\end{tabular}

\section{References}

Briggs, R.S., R.G. Lucas, and Z.T. Taylor. 2003. Climate Classification for Building Energy Codes and Standards:

Part 2-Zone Definitions, Maps, and Comparisons. ASHRAE Transactions 109(2).

PNNL's CBECS Study. 2007. Analysis of Building Envelope Construction in 2003 CBECS Buildings. Dave Winiarski, Mark Halverson, and Wei Jiang. Pacific Northwest National Laboratory. March 2007.

PNNL's CBECS Study. 2006. Review of Pre- and Post-1980 Buildings in CBECS - HVAC Equipment. Dave Winiarski, Wei Jiang and Mark Halverson. Pacific Northwest National Laboratory. December 2006. 


\begin{tabular}{|c|c|c|}
\hline & Item & Descriptions \\
\hline & "Study of the U.S. Market For Windows, Doors, and Skylights", American Architectural Manufacturers Association, Window \& Door Manufacturers & Data
\end{tabular}

"Study of the U.S. Market For Windows, Doors, and Skylights", American Architectural Manufacturers Association, Window \& Door Manufacturers Association, 2006 


\section{A.7 Outpatient Healthcare Modeling Description}

\begin{tabular}{|c|c|c|c|c|}
\hline Item & \multicolumn{3}{|c|}{ Descriptions } & Data Source \\
\hline \multicolumn{5}{|l|}{ Program } \\
\hline Vintage & \multicolumn{3}{|c|}{ NEW CONSTRUCTION } & \\
\hline $\begin{array}{l}\text { Location } \\
\text { (Representing } 8 \text { Climate Zones) }\end{array}$ & $\begin{array}{l}\text { Zone 1A: Miami (very hot, humid) } \\
\text { Zone 1B: Riyadh, Saudi Arabia } \\
\text { (very hot, dry) } \\
\text { Zone 2A: Houston (hot, humid) } \\
\text { Zone 2B: Phoenix (hot, dry) } \\
\text { Zone 3A: Memphis (warm, humid) } \\
\text { Zone 3B: El Paso (warm, dry) } \\
\text { Zone 3C: San Francisco (warm, } \\
\text { marine) }\end{array}$ & $\begin{array}{l}\text { Zone 4A: Baltimore (mild, humid) } \\
\text { Zone 4B: Albuquerque (mild, dry) } \\
\text { Zone 4C: Salem (mild, marine) } \\
\text { Zone 5A: Chicago (cold, humid) } \\
\text { Zone 5B: Boise (cold, dry) } \\
\text { Zone 5C: Vancouver, BC (cold, } \\
\text { marine) }\end{array}$ & $\begin{array}{l}\text { Zone 6iA: Burlington (cold, humid) } \\
\text { Zone 6iB: Helena (cold, dry) } \\
\text { Zone 7: Duluth (very cold) } \\
\text { Zone 8: Fairbanks (subarctic) }\end{array}$ & $\begin{array}{l}\text { Selection of representative } \\
\text { climates based on Briggs' } \\
\text { paper. See Reference. }\end{array}$ \\
\hline Available fuel types & & gas, electricity & & \\
\hline $\begin{array}{l}\text { Building Type (Principal Building } \\
\text { Function) }\end{array}$ & & Health Care & & \\
\hline Building Prototype & & OUTPATIENT HEALTHCARE & & \\
\hline \multicolumn{5}{|l|}{ Form } \\
\hline Total Floor Area (sq. feet) & & 40,950 & & \\
\hline \multicolumn{5}{|l|}{ Building shape } \\
\hline Aspect Ratio & \multicolumn{3}{|c|}{ NA } & \\
\hline Number of Floors & \multicolumn{3}{|c|}{3} & \\
\hline $\begin{array}{l}\text { Window Fraction } \\
\text { (Window-to-Wall Ratio) }\end{array}$ & \multicolumn{3}{|c|}{$\begin{array}{c}\text { North: } 20.5 \% \text {, East: } 19.1 \% \text {, South: } 24.1 \% \text {, West: } 12.9 \% \\
\text { Average Total: } 20 \%\end{array}$} & \\
\hline
\end{tabular}




\begin{tabular}{|c|c|c|}
\hline Item & Descriptions & Data Source \\
\hline Window Locations & See pictures & \\
\hline Shading Geometry & none & \\
\hline Azimuth & non-directional & \\
\hline Thermal Zoning & See Appendix B & \\
\hline Floor to floor height (feet) & $10 \mathrm{ft}$ & \\
\hline Floor to ceiling height (feet) & $10 \mathrm{ft}$ & \\
\hline Glazing sill height (feet) & $3 \mathrm{ft}$ (4 ft high windows) & \\
\hline \multicolumn{3}{|l|}{ Architecture } \\
\hline \multicolumn{3}{|l|}{ Exterior walls } \\
\hline Construction & $\begin{array}{l}\text { Steel-Frame Walls }(2 \times 416 I N \text { OC) } \\
0.4 \text { in. Stucco+5/8 in. gypsum board + wall Insulation }+5 / 8 \text { in. }\end{array}$ & $\begin{array}{l}\text { Construction type: } 2003 \\
\text { CBECS Data and PNNL's } \\
\text { CBECS Study } 2007 . \\
\text { Exterior wall layers: default } \\
90.1 \text { layering }\end{array}$ \\
\hline $\begin{array}{l}\text { U-factor }\left(\mathrm{Btu} / \mathrm{h} * \mathrm{ft}^{2} *{ }^{\circ} \mathrm{F}\right) \text { and/or } \\
\text { R-value }\left(\mathrm{h} * \mathrm{ft}^{2} *{ }^{\circ} \mathrm{F} / \mathrm{Btu}\right)\end{array}$ & $\begin{array}{c}\text { ASHRAE 90.1 Requirements } \\
\text { Nonresidential; Walls, Above-Grade, Steel-Framed }\end{array}$ & ASHRAE 90.1 \\
\hline Dimensions & based on floor area and aspect ratio & \\
\hline Tilts and orientations & vertical & \\
\hline \multicolumn{3}{|l|}{ Roof } \\
\hline Construction & $\begin{array}{l}\text { Built-up Roof: } \\
\text { Roof membrane+Roof insulation+metal decking }\end{array}$ & $\begin{array}{l}\text { Construction type: } 2003 \\
\text { CBECS Data and PNNL's } \\
\text { CBECS Study } 2007 . \\
\text { Roof layers: default } 90.1 \\
\text { ayering }\end{array}$ \\
\hline $\begin{array}{l}\text { U-factor }\left(\mathrm{Btu} / \mathrm{h} * \mathrm{ft}^{2} *{ }^{\circ} \mathrm{F}\right) \text { and/or } \\
\text { R-value }\left(\mathrm{h} * \mathrm{ft}^{2} *{ }^{\circ} \mathrm{F} / \mathrm{Btu}\right)\end{array}$ & $\begin{array}{c}\text { ASHRAE 90.1 Requirements } \\
\text { Nonresidential; Roofs, Insulation entirely above deck }\end{array}$ & ASHRAE 90.1 \\
\hline Dimensions & based on floor area and aspect ratio & \\
\hline Tilts and orientations & horizontal & \\
\hline \multicolumn{3}{|l|}{ Window } \\
\hline Dimensions & based on window fraction, location, glazing sill height, floor area and aspect ratio & \\
\hline Glass-Type and frame & Hypothetical window with the exact U-factor and SHGC shown below & \\
\hline $\begin{array}{l}\left.\text { U-factor (Btu } / \mathrm{h} * \mathrm{ft}^{2} *{ }^{\circ} \mathrm{F}\right) \\
\text { SHGC (all) }\end{array}$ & $\begin{array}{c}\text { ASHRAE 90.1 Requirements } \\
\text { Nonresidential; Vertical Glazing, 31.1-40\%, U fixed }\end{array}$ & ASHRAE 90.1 \\
\hline Visible transmittance & Hypothetical window with the exact U-factor and SHGC shown above & \\
\hline
\end{tabular}




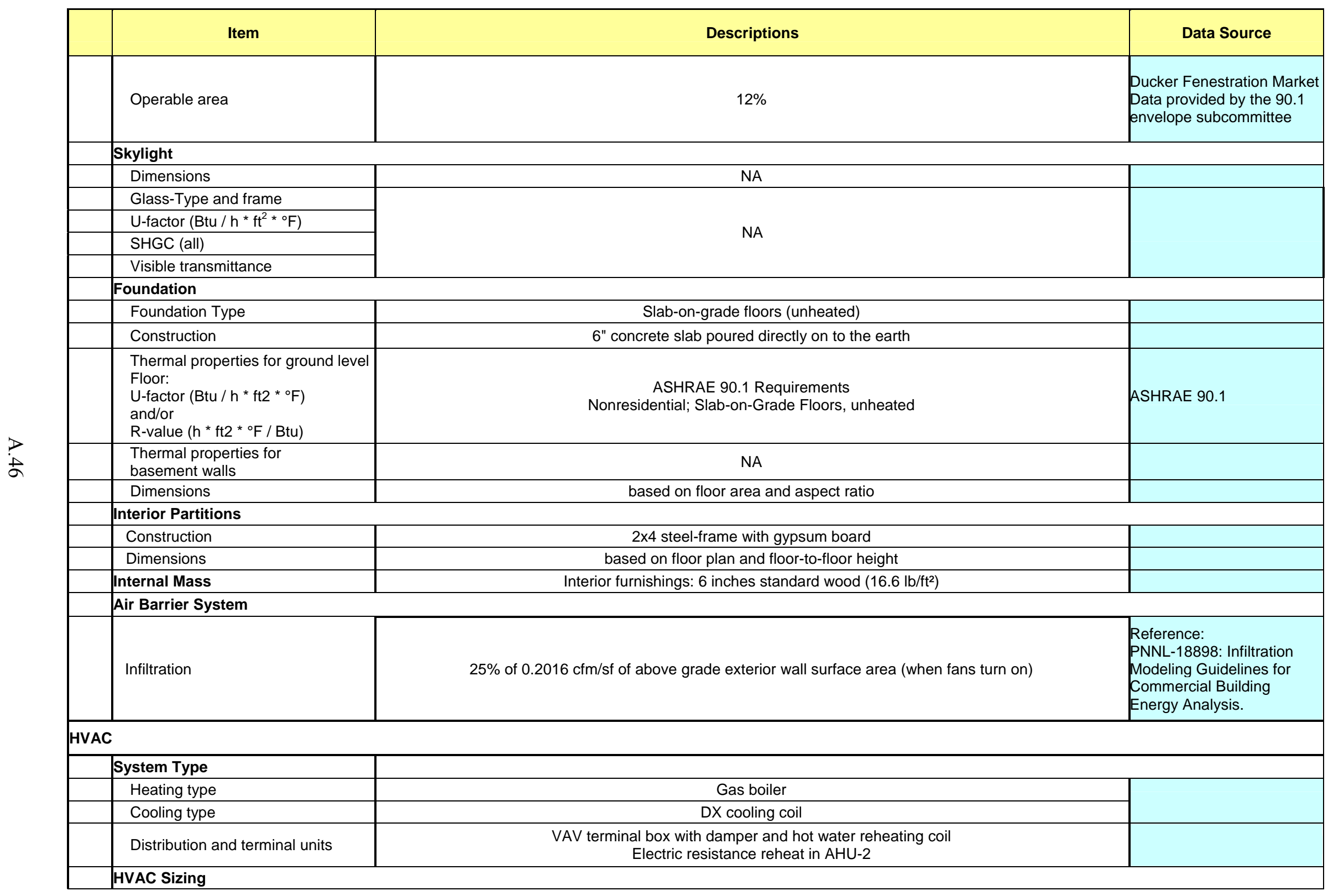




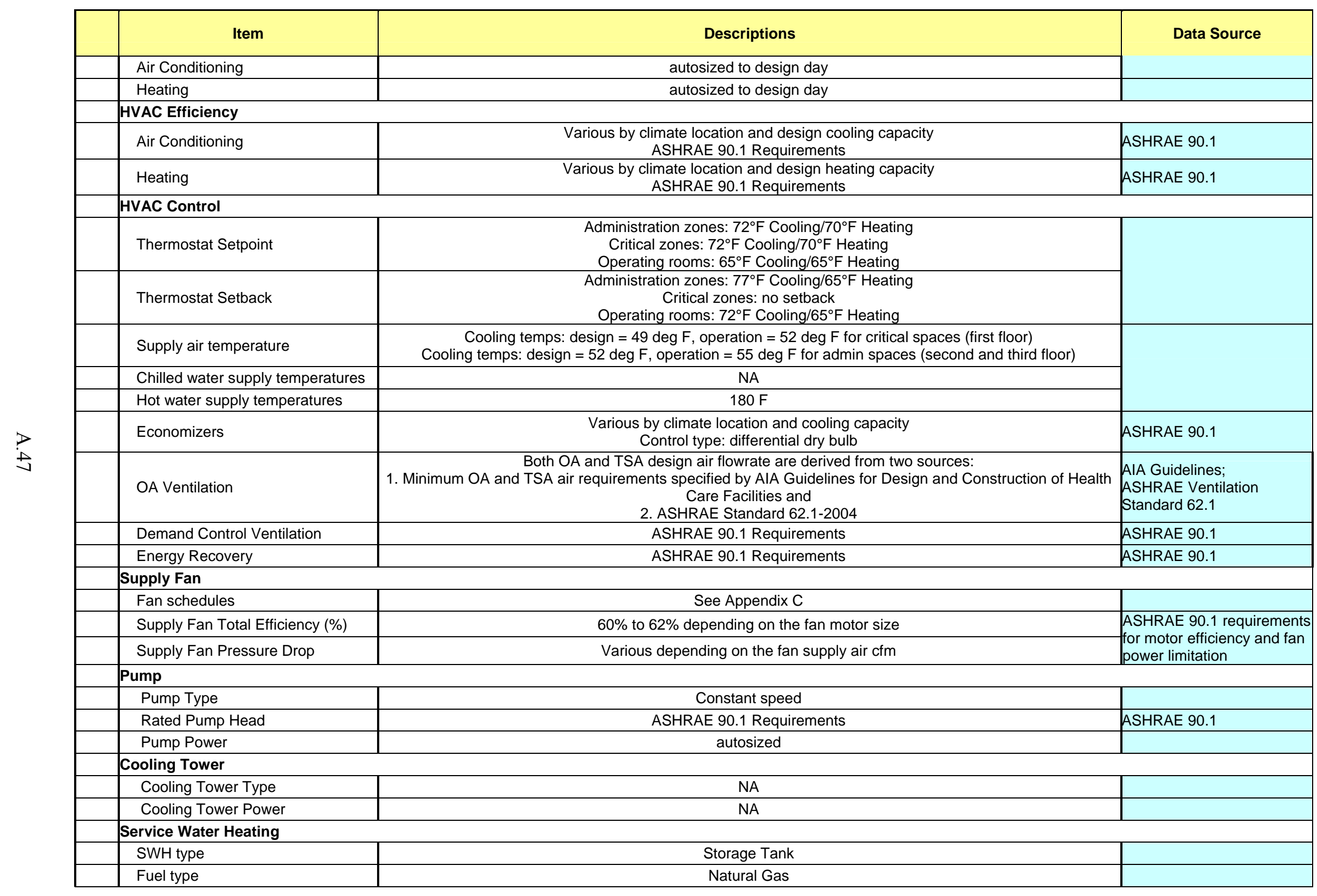




\begin{tabular}{|c|c|c|}
\hline Item & Descriptions & Data Source \\
\hline SWH Design Capacity (kBtu/h) & 2,883 & \\
\hline Thermal efficiency (\%) & $\begin{array}{c}\text { ASHRAE } 90.1 \text { Requirements } \\
\text { Water Heating Equipment, Gas storage water heaters, }>70,000 \mathrm{Btu} / \mathrm{h} \text { input }\end{array}$ & ASHRAE 90.1 \\
\hline Tank Volume (gal) & 793 & \\
\hline Water temperature setpoint & $140 \mathrm{~F}$ & \\
\hline Water consumption & See Appendix C & \\
\hline \multicolumn{3}{|l|}{ Internal Loads \& Schedules } \\
\hline \multicolumn{3}{|l|}{\begin{tabular}{l|l} 
Lighting \\
\end{tabular}} \\
\hline Average power density $\left(\mathrm{W} / \mathrm{ft}^{2}\right)$ & $\begin{array}{c}\text { ASHRAE 90.1 } \\
\text { Lighting Power Densities Using the Building Area Method }\end{array}$ & ASHRAE 90.1 \\
\hline Schedule & See Appendix C & \\
\hline Daylighting Controls & ASHRAE 90.1 Requirements & \\
\hline Occupancy Sensors & ASHRAE 90.1 Requirements & \\
\hline \multicolumn{3}{|l|}{ Plug load } \\
\hline Average power density $\left(\mathrm{W} / \mathrm{ft}^{2}\right)$ & See Appendix B & ASHRAE 90.1 \\
\hline Schedule & See Appendix C & \\
\hline \multicolumn{3}{|l|}{ Occupancy } \\
\hline Average people & See Appendix B & \\
\hline Schedule & See Appendix C & \\
\hline \multicolumn{3}{|l|}{ Misc. } \\
\hline Elevator & & \\
\hline Quantity & 3 & \multirow{4}{*}{$\begin{array}{l}\text { Reference: } \\
\text { DOE Commercial } \\
\text { Reference Building Models } \\
\text { of the National Building } \\
\text { Stock }\end{array}$} \\
\hline Motor type & hydraulic & \\
\hline Peak Motor Power (W/elevator) & 16,055 & \\
\hline Heat Gain to Building & Interior & \\
\hline $\begin{array}{l}\text { Peak Fan/lights Power } \\
\text { (W/elevator) }\end{array}$ & 161.9 & $\begin{array}{l}90.1 \text { Mechanical } \\
\text { Subcommittee, Elevator } \\
\text { Working Group }\end{array}$ \\
\hline Motor and fan/lights Schedules & See Appendix C & $\begin{array}{l}\text { DOE Commercial } \\
\text { Reference Building TSD } \\
\text { and models (V1.3 5.0) and } \\
\text { Addendum DF to 90.1-2007 }\end{array}$ \\
\hline \multicolumn{3}{|l|}{ Exterior Lighting } \\
\hline Peak Power (W) & 14,442 & \multirow{2}{*}{ ASHRAE 90.1} \\
\hline Schedule & See Appendix C & \\
\hline
\end{tabular}

References

Briggs, R.S., R.G. Lucas, and Z.T. Taylor. 2003. Climate Classification for Building Energy Codes and Standards:

Part 2-Zone Definitions, Maps, and Comparisons. ASHRAE Transactions 109(2). 


\begin{tabular}{|c|c|c|c|c|c|}
\hline & Item & \multicolumn{3}{|c|}{ Descriptions } & Data Source \\
\hline & \multicolumn{5}{|c|}{$\begin{array}{l}\text { PNNL's CBECS Study. 2007. Analysis of Building Envelope Construction in } 2003 \text { CBECS Buildings. Dave Winiarski, Mark Halverson, and Wei Jiang. } \\
\text { Pacific Northwest National Laboratory. March 2007. }\end{array}$} \\
\hline & \multicolumn{5}{|c|}{$\begin{array}{l}\text { PNNL's CBECS Study. 2006. Review of Pre- and Post-1980 Buildings in CBECS - HVAC Equipment. Dave Winiarski, Wei Jiang and Mark } \\
\text { Halverson. Pacific Northwest National Laboratory. December } 2006 .\end{array}$} \\
\hline & \multicolumn{5}{|c|}{$\begin{array}{l}\text { Gowri K, DW Winiarski, and RE Jarnagin. 2009. Infiltration modeling guidelines for commercial building energy analysis. PNNL-18898, Pacific } \\
\text { Northwest National Laboratory, Richland, WA. http://www.pnl.gov/main/publications/external/technical_reports/PNNL-18898.pdf }\end{array}$} \\
\hline A.8 & \multicolumn{5}{|c|}{ Hospital Modeling Description } \\
\hline & Item & & Descriptions & & Data Source \\
\hline \multicolumn{6}{|c|}{ Program } \\
\hline & Vintage & \multicolumn{3}{|c|}{ NEW CONSTRUCTION } & \\
\hline & $\begin{array}{l}\text { Location } \\
\text { (Representing } 8 \text { Climate Zones) }\end{array}$ & $\begin{array}{l}\text { Zone 1A: Miami (very hot, humid) } \\
\text { Zone 1B: Riyadh, Saudi Arabia } \\
\text { (very hot, dry) } \\
\text { Zone 2A: Houston (hot, humid) } \\
\text { Zone 2B: Phoenix (hot, dry) } \\
\text { Zone 3A: Memphis (warm, } \\
\text { humid) } \\
\text { Zone 3B: El Paso (warm, dry) } \\
\text { Zone 3C: San Francisco (warm, } \\
\text { marine) }\end{array}$ & $\begin{array}{l}\text { Zone 4A: Baltimore (mild, humid) } \\
\text { Zone 4B: Albuquerque (mild, dry) } \\
\text { Zone 4C: Salem (mild, marine) } \\
\text { Zone 5A: Chicago (cold, humid) } \\
\text { Zone 5B: Boise (cold, dry) } \\
\text { Zone 5C: Vancouver, BC (cold, } \\
\text { marine) }\end{array}$ & $\begin{array}{l}\text { Zone 6A: Burlington (cold, } \\
\text { humid) } \\
\text { Zone 6B: Helena (cold, dry) } \\
\text { Zone 7: Duluth (very cold) } \\
\text { Zone 8: Fairbanks (subarctic) }\end{array}$ & $\begin{array}{l}\text { Selection of } \\
\text { representative climates } \\
\text { based on Briggs' paper. } \\
\text { See Reference. }\end{array}$ \\
\hline & Available fuel types & \multicolumn{3}{|c|}{ gas, electricity } & \\
\hline & $\begin{array}{l}\text { Building Type (Principal Building } \\
\text { Function) }\end{array}$ & \multicolumn{3}{|c|}{ Health Care } & \\
\hline & Building Prototype & \multicolumn{3}{|c|}{ Hospital } & \\
\hline \multicolumn{6}{|c|}{ Form } \\
\hline & Total Floor Area (sq. feet) & \multicolumn{3}{|c|}{$\begin{array}{c}241,410 \\
\text { (including basement) }\end{array}$} & \\
\hline
\end{tabular}




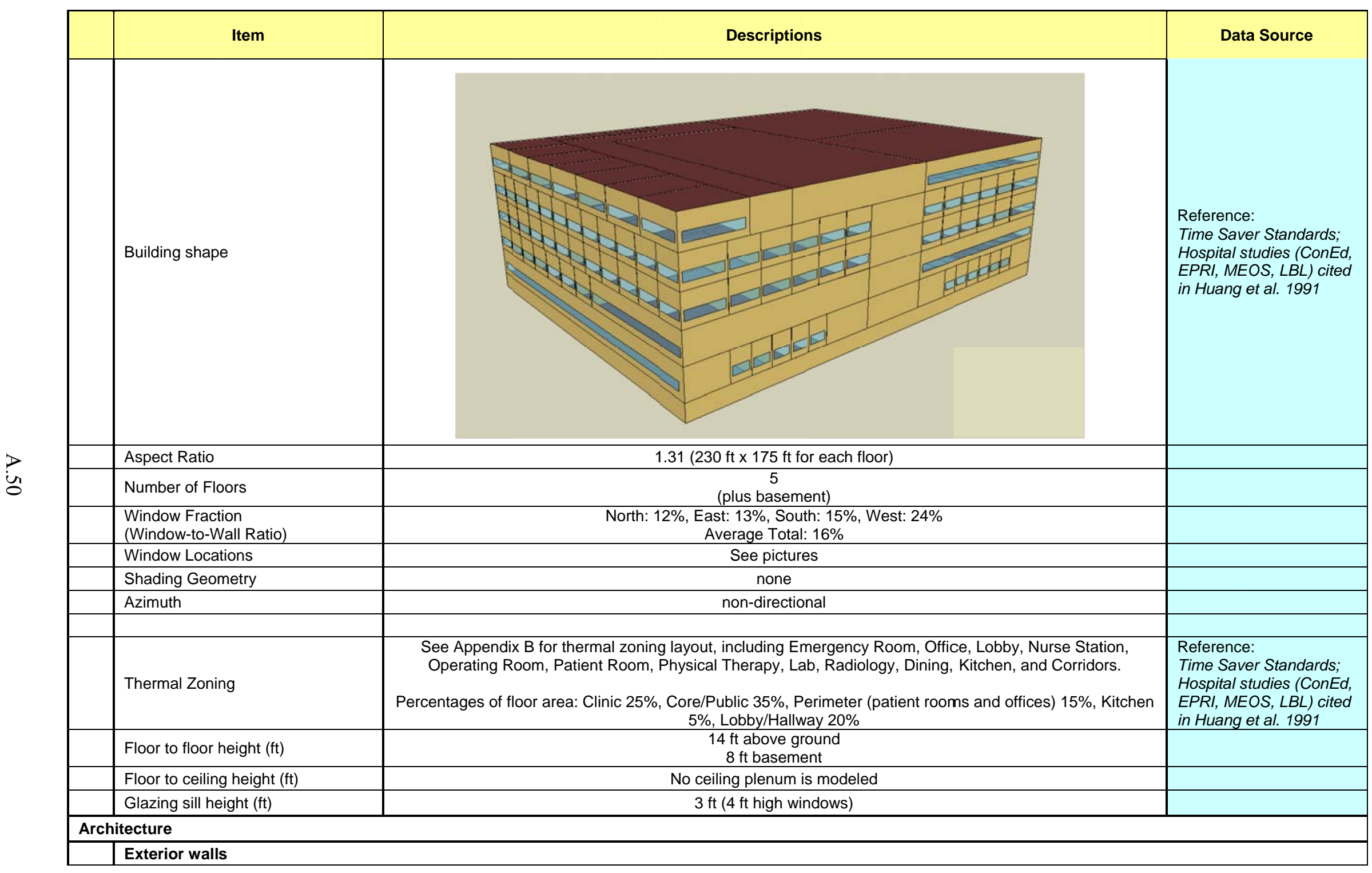




\begin{tabular}{|c|c|c|}
\hline Item & Descriptions & \multirow{2}{*}{\begin{tabular}{l}
\multicolumn{1}{|c}{ Data Source } \\
Construction type: 2003 \\
CBECS Data and \\
PNNL's CBECS Study \\
2007. \\
Exterior wall layers: \\
default 90.1 layering \\
\end{tabular}} \\
\hline Construction & $\begin{array}{l}\text { Mass (concrete blocks): } \\
8 \text { in. HW Concrete+Wall Insulation+0.5 in. Gym }\end{array}$ & \\
\hline $\begin{array}{l}\text { U-factor }\left(\mathrm{Btu} / \mathrm{h} * \mathrm{ft}^{2} *{ }^{\circ} \mathrm{F}\right) \text { and } / \text { or } \\
\text { R-value }\left(\mathrm{h} * \mathrm{ft}^{2} *{ }^{\circ} \mathrm{F} / \mathrm{Btu}\right)\end{array}$ & $\begin{array}{l}\text { 1st, 2nd and 5th floors: Use nonresidential envelop requirement } \\
\text { 3rd and 4th floors: Use residential envelope requirement since most of the spaces in the perimeter zones } \\
\text { are patient rooms, } \\
\text { which are residential spaces based on } 90.1 \text { 's definitions. }\end{array}$ & ASHRAE 90.1 \\
\hline Dimensions & based on floor area and aspect ratio & \\
\hline Tilts and orientations & vertical & \\
\hline \multicolumn{3}{|l|}{ Roof } \\
\hline Construction & $\begin{array}{l}\text { Built-up Roof: } \\
\text { Roof membrane+Roof insulation+metal decking }\end{array}$ & $\begin{array}{l}\text { Construction type: } 2003 \\
\text { CBECS Data and } \\
\text { PNNL's CBECS Study } \\
2007 \text {. } \\
\text { Roof layers: default } 90.1 \\
\text { layering }\end{array}$ \\
\hline $\begin{array}{l}\text { U-factor }\left(\mathrm{Btu} / \mathrm{h} * \mathrm{ft}^{2} *{ }^{\circ} \mathrm{F}\right) \text { and } / \text { or } \\
\text { R-value }\left(\mathrm{h} * \mathrm{ft}^{2} *{ }^{\circ} \mathrm{F} / \mathrm{Btu}\right)\end{array}$ & $\begin{array}{c}\text { ASHRAE 90.1 Requirements } \\
\text { Nonresidential; Roofs, Insulation entirely above deck }\end{array}$ & ASHRAE 90.1 \\
\hline Dimensions & based on floor area and aspect ratio & \\
\hline Tilts and orientations & horizontal & \\
\hline \multicolumn{3}{|l|}{ Window } \\
\hline Dimensions & based on window fraction, location, glazing sill height, floor area and aspect ratio & \\
\hline Glass-Type and frame & Hypothetical window with the exact U-factor and SHGC shown below & \\
\hline U-factor $\left(\mathrm{Btu} / \mathrm{h} * \mathrm{ft}^{2}{ }^{\circ} \mathrm{F}\right)$ & ASHRAE 90.1 Requirements & ASHPAE OO 1 \\
\hline SHGC (all) & Residential; Vertical Glazing, 10.1-20\% & ASHRAE Y.1 \\
\hline Visible transmittance & Hypothetical window with the exact U-factor and SHGC shown above & \\
\hline Operable area & 0 & \\
\hline \multicolumn{3}{|l|}{ Skylight } \\
\hline Dimensions & Not Modeled & \\
\hline Glass-Type and frame & \multirow{4}{*}{ NA } & \\
\hline U-factor $\left(\mathrm{Btu} / \mathrm{h} * \mathrm{ft}^{2}{ }^{\circ} \mathrm{F}\right)$ & & \\
\hline SHGC (all) & & \\
\hline Visible transmittance & & \\
\hline \multicolumn{3}{|l|}{ Foundation } \\
\hline Foundation Type & Basement (conditioned) & \\
\hline
\end{tabular}




\begin{tabular}{|c|c|c|c|}
\hline & Item & Descriptions & Data Source \\
\hline & Construction & 8" concrete wall; 8" concrete slab, 140 lbs heavy-weight aggregate & \\
\hline & $\begin{array}{l}\text { Thermal properties for ground } \\
\text { level floor } \\
\text { U-factor }\left(\mathrm{Btu} / \mathrm{h} * \mathrm{ft} 2 *{ }^{\circ} \mathrm{F}\right) \\
\text { and/or } \\
\mathrm{R} \text {-value }\left(\mathrm{h} * \mathrm{ft} 2 *{ }^{\circ} \mathrm{F} / \mathrm{Btu}\right)\end{array}$ & $\begin{array}{l}\text { ASHRAE } 90.1 \text { Requirements } \\
\text { Nonresidential; Slab-on-Grade Floors, unheated }\end{array}$ & ASHRAE 90.1 \\
\hline & $\begin{array}{l}\text { Thermal properties for } \\
\text { basement walls }\end{array}$ & No insulation & \\
\hline & Dimensions & based on floor area and aspect ratio & \\
\hline & \multicolumn{3}{|l|}{ Interior Partitions } \\
\hline & Construction & $2 \times 4$ uninsulated stud wall & \\
\hline & Dimensions & based on floor plan and floor-to-floor height & \\
\hline & Internal Mass & 6 inches standard wood $\left(16.6 \mathrm{lb} / \mathrm{ft}^{2}\right)$ & \\
\hline & \multicolumn{3}{|l|}{ Air Barrier System } \\
\hline & Infiltration $(\mathrm{ACH})$ & $25 \%$ of $0.2016 \mathrm{cfm} / \mathrm{sf}$ of above grade exterior wall surface area (when fans turn on) & $\begin{array}{l}\text { Reference: } \\
\text { PNNL-18898: Infiltration } \\
\text { Modeling Guidelines for } \\
\text { Commercial Building } \\
\text { Energy Analysis. }\end{array}$ \\
\hline \multicolumn{4}{|c|}{ HVAC } \\
\hline & System Type & & \\
\hline & Heating type & Gas boiler & \multirow{2}{*}{$\begin{array}{l}2003 \text { CBECS Data, } \\
\text { PNNL's CBECS Study } \\
\text { 2007, and } 90.1 \\
\text { Mechanical } \\
\text { Subcommittee input. }\end{array}$} \\
\hline & Cooling type & Water cooled centrifugal chiller & \\
\hline & Distribution and terminal units & $\begin{array}{l}\text { Medical critical zones: five variable air volume (VAV) systems with hot water reheating and electric stream } \\
\text { humidifiers. } \\
\text { Non-critical zones: two VAV systems for general zones and one constant air volume (CAV) system for } \\
\text { kitchen zone: VAV terminal box with damper and hot water reheating coil; minimum supply air at } 30 \% \text { of the } \\
\text { zone design peak supply air. }\end{array}$ & $\begin{array}{l}\text { AEDG for Small } \\
\text { Healthcare Facilities }\end{array}$ \\
\hline & \multicolumn{3}{|l|}{ HVAC Sizing } \\
\hline & Air Conditioning & autosized to design day & \\
\hline & Heating & autosized to design day & \\
\hline & \multicolumn{3}{|l|}{ HVAC Efficiency } \\
\hline & Cooling & $\begin{array}{l}\text { Various by climate location and design cooling capacity } \\
\text { ASHRAE 90.1 Requirements } \\
\text { Two water-cooled screw chillers, for each chiller with normal cooling capacity }\end{array}$ & ASHRAE 90.1 \\
\hline & Heating & $\begin{array}{c}\text { Various by climate location and design heating capacity } \\
\text { ASHRAE } 90.1 \text { Requirements } \\
\text { Minimum equipment efficiency for hot water boiler }\end{array}$ & ASHRAE 90.1 \\
\hline
\end{tabular}




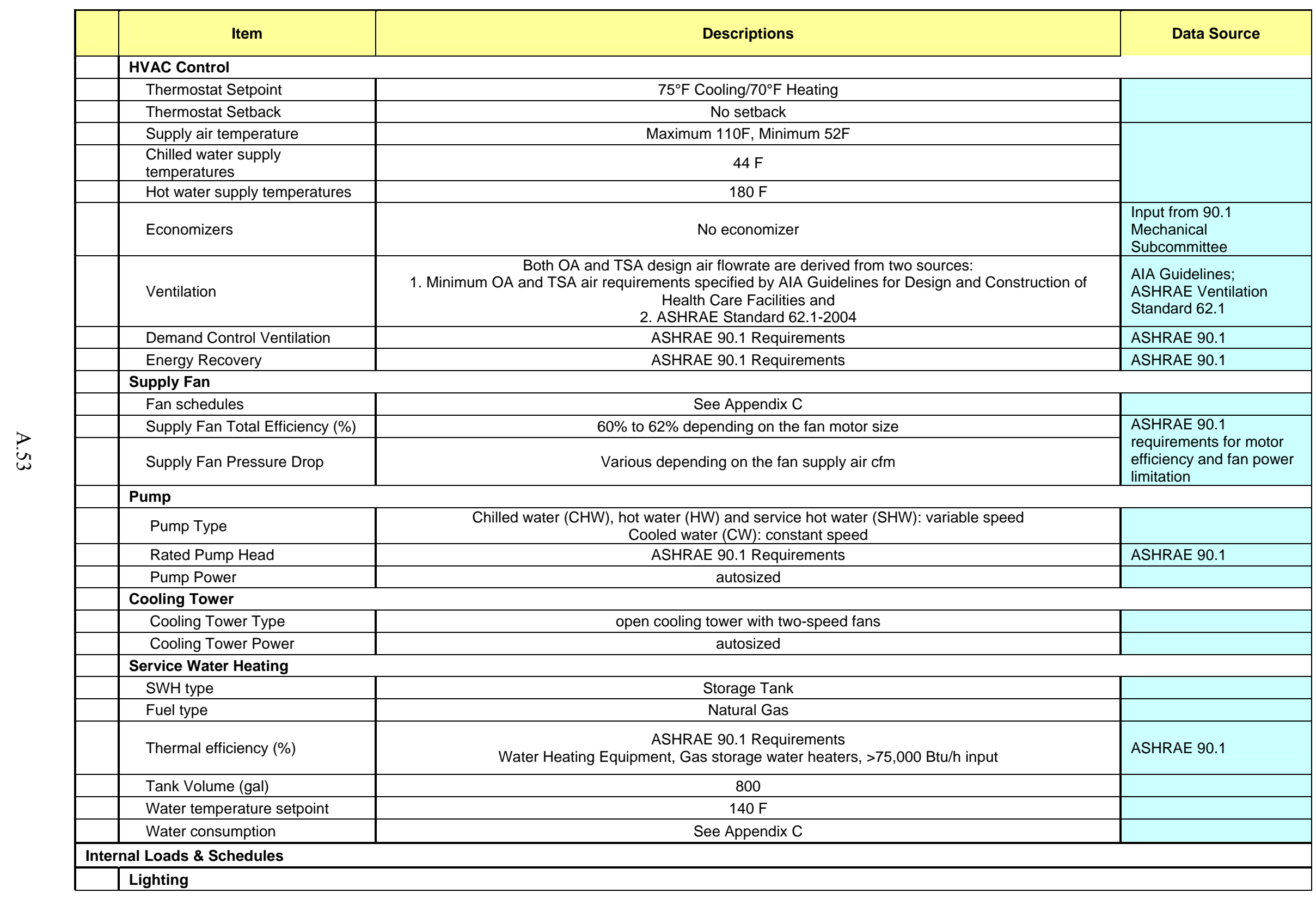




\begin{tabular}{|c|c|c|}
\hline Item & Descriptions & Data Source \\
\hline Average power density $\left(\mathrm{W} / \mathrm{ft}^{2}\right)$ & $\begin{array}{c}\text { ASHRAE 90.1 } \\
\text { Lighting Power Densities Using the Building Area Method } \\
\text { See Appendix B }\end{array}$ & ASHRAE 90.1 \\
\hline Schedule & See Appendix C & \\
\hline Daylighting Controls & ASHRAE 90.1 Requirements & \\
\hline Occupancy Sensors & ASHRAE 90.1 Requirements & \\
\hline \multicolumn{3}{|l|}{ Plug load } \\
\hline Average power density $\left(\mathrm{W} / \mathrm{ft}^{2}\right)$ & See Appendix B & \\
\hline Schedule & See Appendix C & \\
\hline \multicolumn{3}{|l|}{ Occupancy } \\
\hline Average people & See Appendix B & \\
\hline Schedule & See Appendix C & \\
\hline \multicolumn{3}{|l|}{ Misc. } \\
\hline Elevator & & \\
\hline Quantity & 8 & \multirow{4}{*}{$\begin{array}{l}\text { Reference: } \\
\text { DOE Commercial } \\
\text { Reference Building } \\
\text { Models of the National } \\
\text { Building Stock }\end{array}$} \\
\hline Motor type & Traction & \\
\hline Peak Motor Power (W/elevator) & 20,370 & \\
\hline Heat Gain to Building & Exterior & \\
\hline $\begin{array}{l}\text { Peak Fan/lights Power } \\
\text { (W/elevator) }\end{array}$ & 161.9 & $\begin{array}{l}90.1 \text { Mechanical } \\
\text { Subcommittee, Elevator } \\
\text { Working Group }\end{array}$ \\
\hline Motor and fan/lights Schedules & See Appendix C & $\begin{array}{l}\text { Reference: } \\
\text { DOE Commercial } \\
\text { Reference Building } \\
\text { Models of the National } \\
\text { Building Stock }\end{array}$ \\
\hline \multicolumn{3}{|l|}{ Exterior Lighting } \\
\hline Peak Power (W) & 16,636 & ASHRAE 90.1 \\
\hline Schedule & See Appendix C & \\
\hline
\end{tabular}

\section{References}

Briggs, R.S., R.G. Lucas, and Z.T. Taylor. 2003. Climate Classification for Building Energy Codes and Standards:

Part 2-Zone Definitions, Maps, and Comparisons. ASHRAE Transactions 109(2)

McGraw-Hill Companies, Inc. 2001. Time-Saver Standards for Building Types. New York, NY.

LBNL (1991). Huang, Joe, Akbari, H., Rainer, L. and Ritschard, R. 481 Prototypical Commercial Buildings for 20 Urban Market Areas, prepared for the Gas Research Institute, Chicago IL, also LBL-29798, Berkeley CA.

PNNL's CBECS Study. 2007. Analysis of Building Envelope Construction in 2003 CBECS Buildings. Dave Winiarski, Mark Halverson, and Wei Jiang. Pacific Northwest National Laboratory. March 2007. 


\begin{tabular}{|c|c|c|c|}
\hline & Item & Descriptions \\
\hline
\end{tabular}

Data Source

PNNL's CBECS Study. 2006. Review of Pre- and Post-1980 Buildings in CBECS - HVAC Equipment. Dave Winiarski, Wei Jiang and Mark

Halverson. Pacific Northwest National Laboratory. December 2006.

Gowri K, DW Winiarski, and RE Jarnagin. 2009. Infiltration modeling guidelines for commercial building energy analysis. PNNL-18898, Pacific Northwest National Laboratory, Richland, WA. http://www.pnl.gov/main/publications/external/technical_reports/PNNL-18898.pdf 


\section{A.9 Small Hotel Modeling Description}

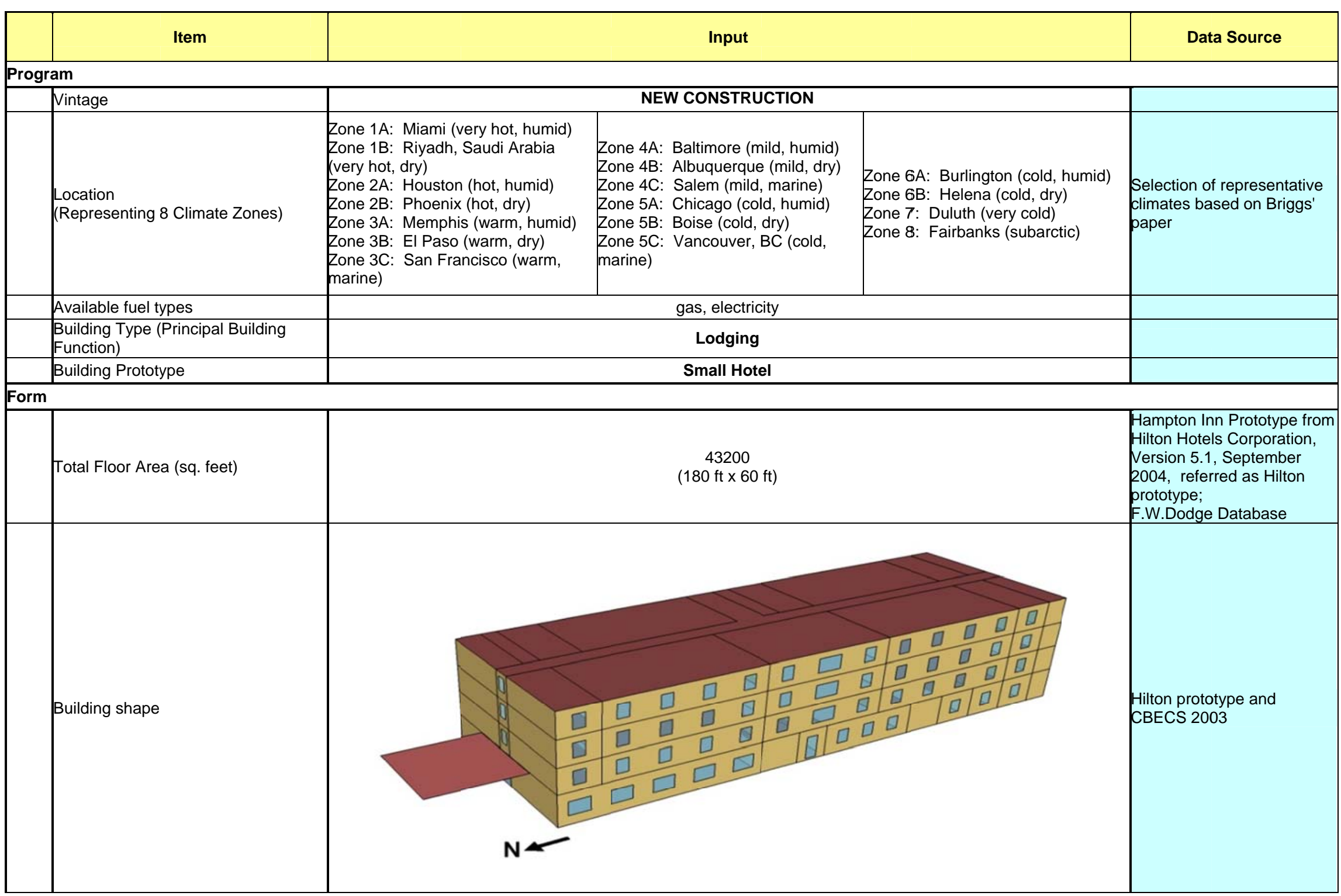




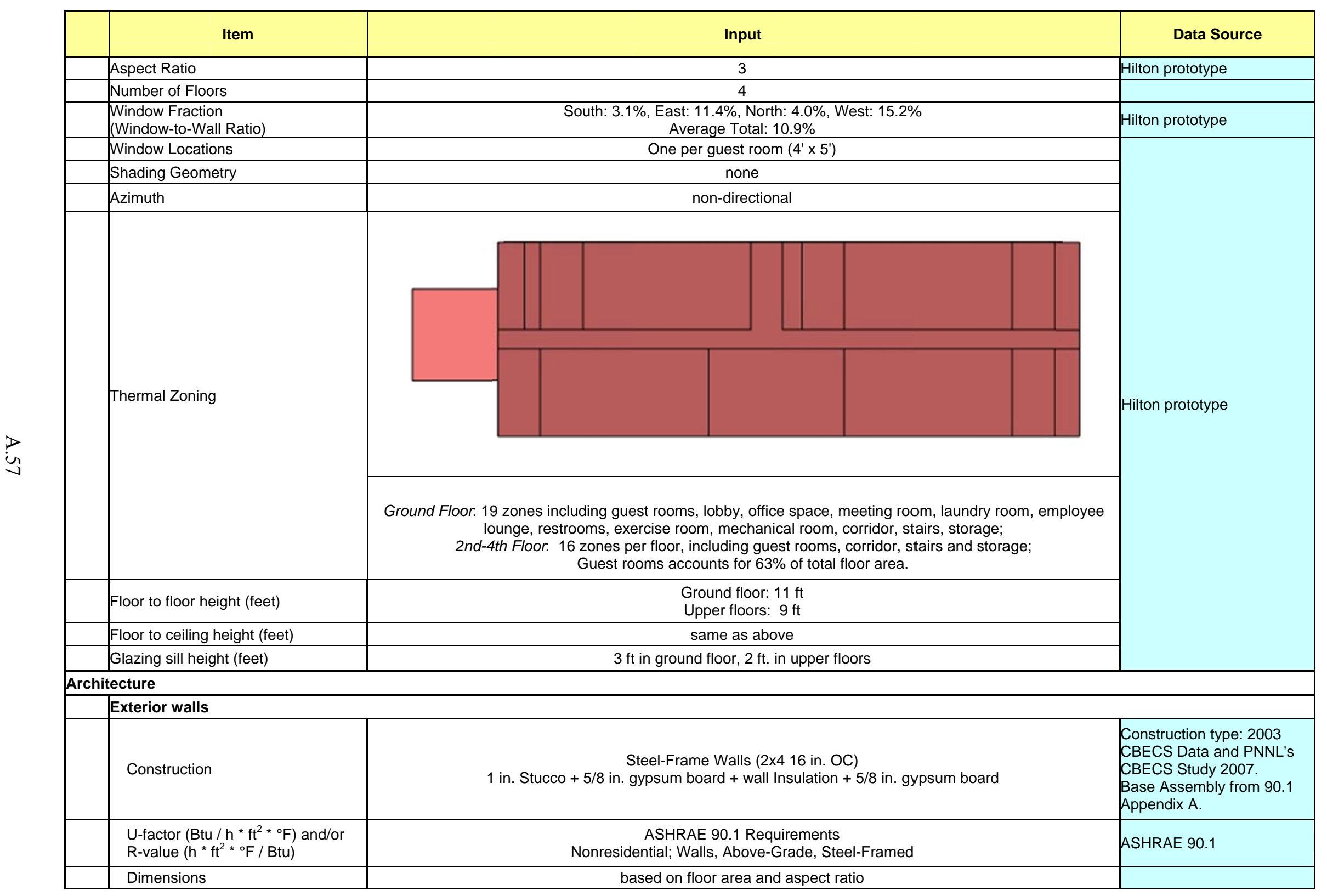




\begin{tabular}{|c|c|c|}
\hline Item & Input & \multirow[t]{2}{*}{ Data Source } \\
\hline Tilts and orientations & vertical & \\
\hline \multicolumn{3}{|l|}{ Roof } \\
\hline Construction & $\begin{array}{c}\text { Built-up Roof: } \\
\text { Roof membrane + Roof insulation + metal decking }\end{array}$ & $\begin{array}{l}\text { AEDG Highway Lodging } \\
\text { Committee } \\
\text { Recommendation }\end{array}$ \\
\hline $\begin{array}{l}\text { U-factor }\left(\mathrm{Btu} / \mathrm{h} * \mathrm{ft}^{2} *{ }^{\circ} \mathrm{F}\right) \text { and/or } \\
\text { R-value }\left(\mathrm{h} * \mathrm{ft}^{2} *{ }^{\circ} \mathrm{F} / \mathrm{Btu}\right)\end{array}$ & $\begin{array}{c}\text { ASHRAE 90.1 Requirements } \\
\text { Nonresidential; Roofs, Insulation entirely above deck }\end{array}$ & ASHRAE 90.1 \\
\hline Dimensions & based on floor area and aspect ratio & \\
\hline Tilts and orientations & horizontal & \\
\hline \multicolumn{3}{|l|}{ Window } \\
\hline Dimensions & based on window fraction, location, glazing sill height, floor area and aspect ratio & \\
\hline Glass-Type and frame & Hypothetical window with the exact U-factor and SHGC shown below & \\
\hline U-factor $\left(\mathrm{Btu} / \mathrm{h} * \mathrm{ft}^{2} *{ }^{\circ} \mathrm{F}\right)$ & ASHRAE 90.1 Requirements & ASHRAE 901 \\
\hline SHGC (all) & Nonresidential for ground floor and residential for upper floors; Vertical Glazing, $10.1 \%-20.0 \%$ & \\
\hline Visible transmittance & Hypothetical window with the exact U-factor and SHGC shown above & \\
\hline Operable area & $0.00 \%$ & \\
\hline \multicolumn{3}{|l|}{ Skylight } \\
\hline Dimensions & Not Modeled & \\
\hline Glass-Type and frame & \multirow{4}{*}{ NA } & \\
\hline U-factor $\left(\mathrm{Btu} / \mathrm{h} * \mathrm{ft}^{2}{ }^{\circ} \mathrm{F}\right)$ & & \\
\hline SHGC (all) & & \\
\hline Visible transmittance & & \\
\hline \multicolumn{3}{|l|}{ Foundation } \\
\hline Foundation Type & Slab-on-grade floors (unheated) & \\
\hline Construction & 6" concrete slab poured directly on to the earth & \\
\hline $\begin{array}{l}\text { Thermal properties for slab-on- } \\
\text { grade floor } \\
\text { F-factor }\left(\mathrm{Btu} / \mathrm{h} * \mathrm{ft} 2 *{ }^{\circ} \mathrm{F}\right) \\
\text { and/or } \\
\mathrm{R} \text {-value }\left(\mathrm{h} * \mathrm{ft} 2 *{ }^{\circ} \mathrm{F} / \mathrm{Btu}\right)\end{array}$ & ASHRAE 90.1 Requirements & ASHRAE 90.1 \\
\hline $\begin{array}{l}\text { Thermal properties for } \\
\text { basement walls }\end{array}$ & NA & \\
\hline Dimensions & based on floor area and aspect ratio & \\
\hline \multicolumn{3}{|l|}{ Interior Partitions } \\
\hline Construction & $2 \times 4$ uninsulated stud wall & \\
\hline Dimensions & based on floor plan and floor-to-floor height & \\
\hline Internal Mass & 6 inches standard wood $\left(16.6 \mathrm{lb} / \mathrm{ft}^{2}\right)$ & \\
\hline \multicolumn{3}{|l|}{ Air Barrier System } \\
\hline
\end{tabular}




\begin{tabular}{|c|c|c|}
\hline Item & Input & Data Source \\
\hline Infiltration & $\begin{array}{l}\text { Peak: } 0.2016 \mathrm{cfm} / \mathrm{sf} \text { of above grade exterior wall surface area, adjusted by wind (when fans turn off) } \\
\text { Off Peak: } 25 \% \text { of peak infiltration rate (when fans turn on) }\end{array}$ & $\begin{array}{l}\text { Reference: } \\
\text { PNNL-18898. Infiltration } \\
\text { Modeling Guidelines for } \\
\text { Commercial Building Energy } \\
\text { Analysis. }\end{array}$ \\
\hline \multicolumn{3}{|l|}{ HVAC } \\
\hline System Type & & \\
\hline Heating type & $\begin{array}{l}\text { Guest rooms: PTAC with electric resistance heating } \\
\text { Public spaces (office, laundry, lobby, and meeting room): gas furnace inside the packaged air conditioning } \\
\text { units } \\
\text { Storage and stairs: electric cabinet heaters }\end{array}$ & \multirow{3}{*}{$\begin{array}{l}2003 \text { CBECS, NC3, Ducker } \\
\text { report }\end{array}$} \\
\hline Cooling type & $\begin{array}{c}\text { Guest rooms and corridors: PTAC and make-up air unit for outdoor air ventilation } \\
\text { Public space: Split system with DX cooling } \\
\text { Storage and stairs: No cooling }\end{array}$ & \\
\hline Distribution and terminal units & Constant air volume systems & \\
\hline \multicolumn{3}{|l|}{ HVAC Sizing } \\
\hline Air Conditioning & $\begin{array}{l}\text { PTAC: } 9,000 \mathrm{Btu} / \mathrm{hr} \\
\text { Split system and packaged MAU system: autosized to design day }\end{array}$ & PTAC: Ducker report \\
\hline Heating & autosized to design day & \\
\hline \multicolumn{3}{|l|}{ HVAC Efficiency } \\
\hline Air Conditioning & $\begin{array}{c}\text { PTAC: EER }=10.58 \\
\text { Split system and packaged MAU system: varies by climate locations based on cooling capacity }\end{array}$ & ASHRAE 90.1 \\
\hline Heating & $\begin{array}{l}\text { PTAC and electric cabinet heater: } \mathrm{Et}=100 \% \\
\text { Gas furnace: varies by climate locations based on heating capacity }\end{array}$ & ASHRAE 90.1 \\
\hline \multicolumn{3}{|l|}{ HVAC Control } \\
\hline Thermostat Setpoint & $\begin{array}{c}70^{\circ} \mathrm{F} \text { Cooling/Heating for rented guest rooms } \\
74^{\circ} \mathrm{F} \text { Cooling } / 66^{\circ} \mathrm{F} \text { Heating for vacant guest rooms } \\
75^{\circ} \mathrm{F} \text { Cooling } / 70^{\circ} \mathrm{F} \text { Heating for air conditioned public spaces (lobby, meeting room etc.) } \\
45^{\circ} \mathrm{F} \text { heating for stairs and storage rooms }\end{array}$ & \multirow[t]{2}{*}{$\begin{array}{l}\text { AEDG Highway Lodging } \\
\text { Committee } \\
\text { Recommendation }\end{array}$} \\
\hline Thermostat Setback & $74^{\circ} \mathrm{F}$ Cooling $/ 66^{\circ} \mathrm{F}$ Heating for rented guest rooms & \\
\hline Supply air temperature & No seasonal supply air temperature reset. & \\
\hline Chilled water supply temperatures & $\mathrm{NA}$ & \\
\hline Hot water supply temperatures & NA & \\
\hline Economizers & no economizer & ASHRAE 90.1 \\
\hline Ventilation & ASHRAE Ventilation Standard 62.1 & $\begin{array}{l}\text { ASHRAE Ventilation } \\
\text { Standard } 62.1\end{array}$ \\
\hline Demand Control Ventilation & No & ASHRAE 90.1 \\
\hline Energy Recovery Ventilation & No & ASHRAE 90.1 \\
\hline
\end{tabular}




\begin{tabular}{|c|c|c|}
\hline Item & Input & Data Source \\
\hline \multicolumn{3}{|l|}{ Supply Fan } \\
\hline Fan schedules & See Appendix C & \\
\hline $\begin{array}{l}\text { Supply Fan Mechanical } \\
\text { Efficiency (\%) }\end{array}$ & Varies by fan motor size & $\begin{array}{l}\text { AEDG-SR Technical } \\
\text { Support Document (Liu } \\
\text { 2006) }\end{array}$ \\
\hline Supply Fan Pressure Drop & $\begin{array}{c}\text { PTAC: } 1.33 \text { in. w.c. } \\
\text { Cabinet Heater: } 0.2 \text { in w.c. } \\
\text { Split DX units and MAU: } 90.1 \text { fan power limitation (depends on design flow rate) }\end{array}$ & $\begin{array}{l}\text { PTAC Manufacture's } \\
\text { Catalogs } \\
\text { Split System: Wassmer and } \\
\text { Brandemuehl, 2006, }\end{array}$ \\
\hline \multicolumn{3}{|l|}{ Pump } \\
\hline Pump Type & Constant speed (recirculating pump for DHW) & \multirow{3}{*}{$\begin{array}{l}\text { AEDG Highway Lodging } \\
\text { Committee } \\
\text { Recommendation }\end{array}$} \\
\hline Rated Pump Head & $20 \mathrm{ft}$ & \\
\hline Pump Power & autosized & \\
\hline \multicolumn{3}{|l|}{ Cooling Tower } \\
\hline Cooling Tower Type & NA & \\
\hline Cooling Tower Power & NA & \\
\hline \multicolumn{3}{|l|}{ Service Water Heating } \\
\hline SWH type & Two Storage Tanks: one for laundry and the other for guest rooms & \\
\hline Fuel type & Natural Gas & \\
\hline Thermal efficiency (\%) & $80 \%$ & $\begin{array}{l}\text { ASHRAE 90.1-2004, } \\
\text { Table7.8, Gas storage water } \\
\text { heaters, }>=75,000 \text { Btu/h }\end{array}$ \\
\hline Tank Volume (gal) & 200 gal for guest rooms and 100 gal for laundry & $\begin{array}{l}\text { ASHRAE HandBook } \\
\text { Application 2007, Ch. } 49 \\
\text { Calculation is documented } \\
\text { at PNNL's TSD for } 30 \% \\
\text { AEDG Highway Lodging } \\
\text { (Jiang et al 2008) }\end{array}$ \\
\hline Water temperature setpoint & $120 \mathrm{~F}$ for guest rooms and $140 \mathrm{~F}$ for laundry & \\
\hline Water consumption & See Appendix C & $\begin{array}{l}\text { Guest room: ASHRAE } \\
\text { Handbook of Applications } \\
\text { 2007, Chapter 49, Table } 7 \\
\text { Laundry: AEDG Highway } \\
\text { Lodging Committee } \\
\text { Recommendation }\end{array}$ \\
\hline \multicolumn{3}{|l|}{ Internal Loads \& Schedules } \\
\hline \multicolumn{3}{|l|}{ Lighting } \\
\hline Average power density $\left(\mathrm{W} / \mathrm{ft}^{2}\right)$ & $\begin{array}{c}\text { ASHRAE } 90.1 \\
\text { Lighting Power Densities Using the Building Space-by-Space Method }\end{array}$ & ASHRAE 90.1 \\
\hline Schedule & See Appendix C & \\
\hline Daylighting Controls & No & \\
\hline Occupancy Sensors & No & \\
\hline
\end{tabular}




\begin{tabular}{|c|c|c|}
\hline Item & Input & Data Source \\
\hline \multicolumn{3}{|l|}{ Plug load } \\
\hline Average power density $\left(\mathrm{W} / \mathrm{ft}^{2}\right)$ & See Appendix B & $\begin{array}{l}\text { AEDG Highway Lodging } \\
\text { Committee } \\
\text { Recommendation }\end{array}$ \\
\hline Schedule & See Appendix C & \\
\hline \multicolumn{3}{|l|}{ Occupancy } \\
\hline Average people & See Appendix B & $\begin{array}{l}\text { Guest Room: AEDG } \\
\text { Hlighway Lodging } \\
\text { Committee } \\
\text { Recommendation } \\
\text { All other spaces: ASHRAE } \\
62.1 \text {-1999 }\end{array}$ \\
\hline Schedule & See Appendix C & \\
\hline \multicolumn{3}{|l|}{ Misc. } \\
\hline \multicolumn{3}{|l|}{ Elevator } \\
\hline Quantity & 2 & \multirow{4}{*}{$\begin{array}{l}\text { DOE Commercial Reference } \\
\text { Building TSD (unpublished) } \\
\text { and models (V1.3_5.0). }\end{array}$} \\
\hline Motor type & hydraulic & \\
\hline Peak Motor Power (W/elevator) & 16055 & \\
\hline Heat Gain to Building & Interior & \\
\hline $\begin{array}{l}\text { Peak Fan/lights Power } \\
\text { (W/elevator) }\end{array}$ & 161.9 & $\begin{array}{l}90.1 \text { Mechanical } \\
\text { Subcommittee, Elevator } \\
\text { Working Group }\end{array}$ \\
\hline Exterior Lighting & See Appendix C & $\begin{array}{l}\text { DOE Commercial Reference } \\
\text { Building TSD (unpublished) } \\
\text { and models (V1.3_5.0) and } \\
\text { Appendix DF 2007 }\end{array}$ \\
\hline Peak Power, kW & 13.03 & \multirow{2}{*}{$\begin{array}{l}\text { Derived based on ASHRAE } \\
90.1-2004 \text { and inputs from } \\
\text { 90.1 Lighting Subcommittee }\end{array}$} \\
\hline Schedule & Astronomical Clock & \\
\hline
\end{tabular}

\section{References}

Briggs, R.S., R.G. Lucas, and Z.T. Taylor. 2003. Climate Classification for Building Energy Codes and Standards:

Part 2-Zone Definitions, Maps, and Comparisons. ASHRAE Transactions 109(2).

McGraw-Hill Companies, Inc. (2001). Time-Saver Standards for Building Types. New York, NY.

LBNL (1991). Huang, Joe, Akbari, H., Rainer, L. and Ritschard, R. 481 Prototypical Commercial Buildings for 20 Urban Market Areas, prepared for the Gas Research Institute, Chicago IL, also LBL-29798, Berkeley CA.

PNNL's CBECS Study. 2007. Analysis of Building Envelope Construction in 2003 CBECS Buildings. Dave Winiarski, Mark Halverson, and Wei Jiang. Pacific Northwest National Laboratory. March 2007. 


\begin{tabular}{|c|c|c|}
\hline & Item & Input \\
\hline
\end{tabular}

\section{Data Source}

PNNL's CBECS Study. 2006. Review of Pre- and Post-1980 Buildings in CBECS - HVAC Equipment. Dave Winiarski, Wei Jiang and Mark Halverson Pacific Northwest National Laboratory. December 2006.

Ducker International Standard. 2001. 2000 U.S. Market For Residential and Specialty Air Conditioning: PTAC.

Sachs, H., 2005. Opportunities for Elevator Energy Efficiency Improvements, ACEEE.

Wassmer and Brandemuehl, 2006, Effect of Data Availability on Modeling of Residential Air Conditioners and Heat Pumps for Energy Calculations

Jiang W, RE Jarnagin, K Gowri, M McBride, and B Liu. 2008. Technical Support Document: The Development of the Advanced Energy Design Guide for Highway Lodging Buildings. PNNL-17875, Pacific Northwest National Laboratory, Richland, WA.

http://www.pnl.gov/publications/abstracts.asp?report=246912

Liu B, RE Jarnagin, DW Winiarski, W Jiang, MF McBride, and C Crall. 2006. Technical Support Document: The Development of the Advanced

Energy Design Guide for Small Retail Buildings. PNNL-16031, Pacific Northwest National Laboratory, Richland, WA.

http://www.pnl.gov/publications/abstracts.asp?report $=221540$ 


\section{A.10 Large Hotel Modeling Description}

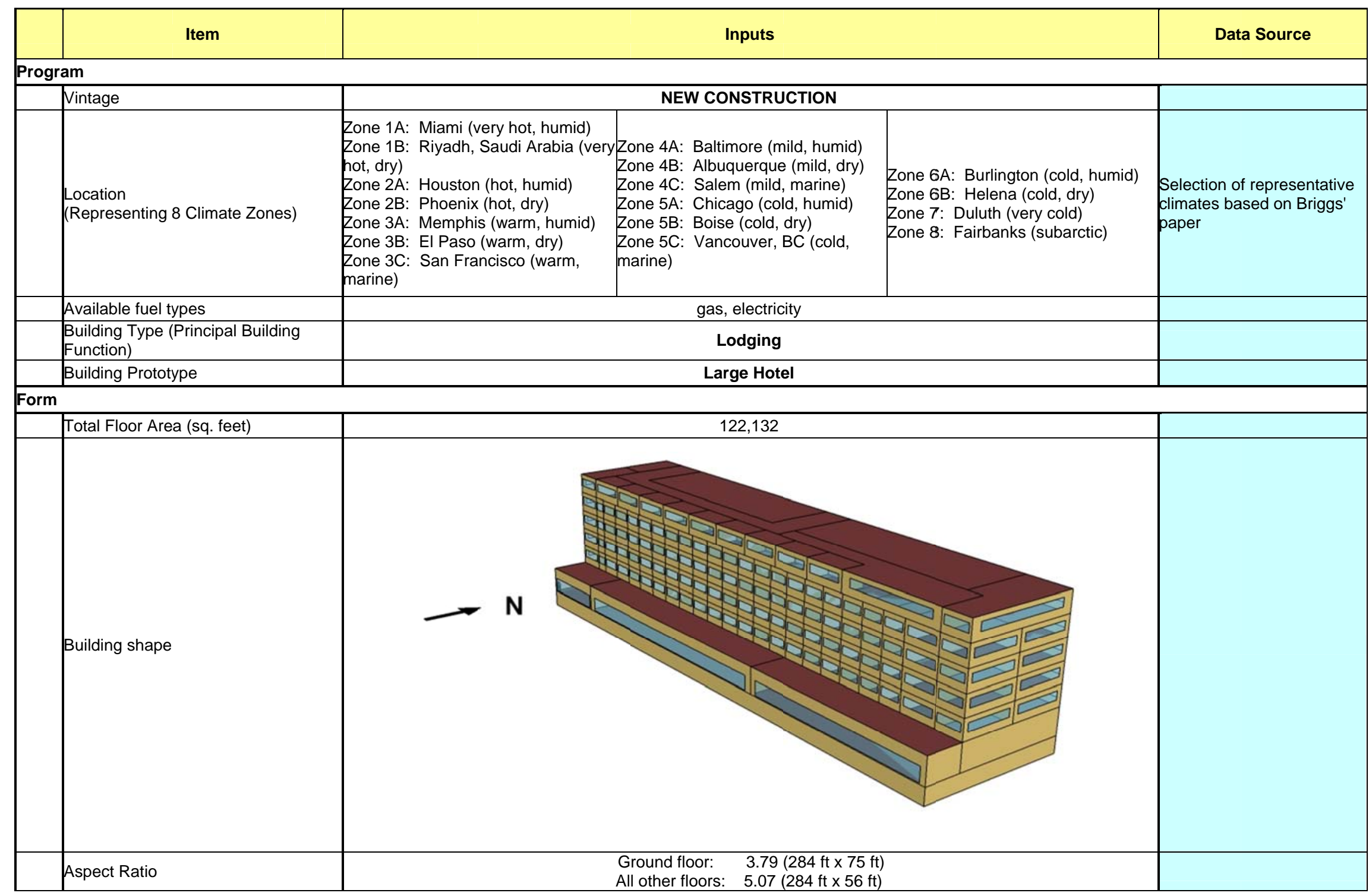




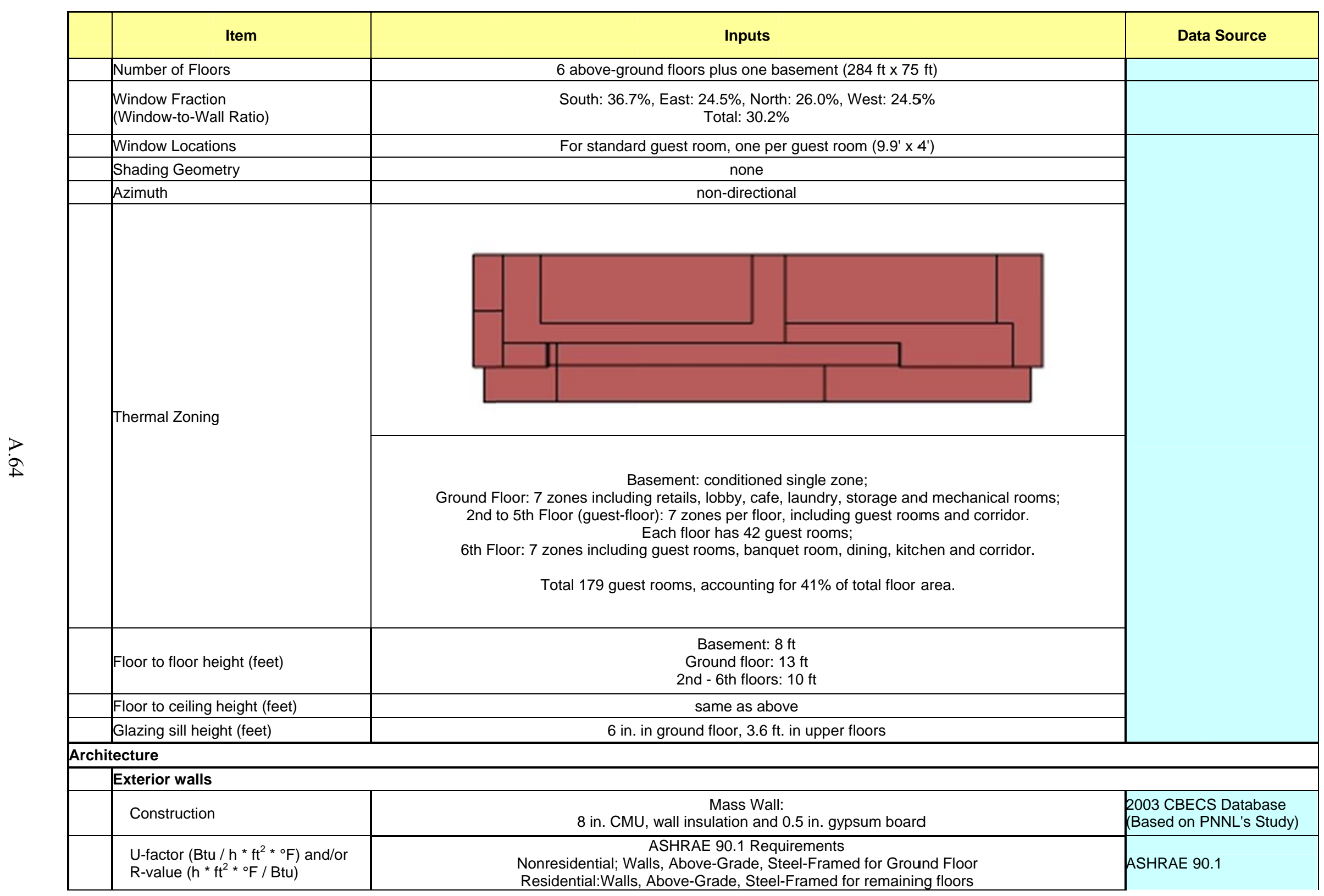




\begin{tabular}{|c|c|c|}
\hline Item & Inputs & Data Source \\
\hline Dimensions & based on floor area and aspect ratio & \\
\hline Tilts and orientations & vertical & \\
\hline \multicolumn{3}{|l|}{ Roof } \\
\hline Construction & $\begin{array}{c}\text { Insulation Entirely above Deck } \\
\text { (Single-ply roof membrane, Steel deck with rigid insulation) }\end{array}$ & $\begin{array}{l}\text { 2003 CBECS Database } \\
\text { (Based on PNNL's Study) }\end{array}$ \\
\hline $\begin{array}{l}\text { U-factor }\left(\mathrm{Btu} / \mathrm{h} * \mathrm{ft}^{2} *{ }^{\circ} \mathrm{F}\right) \text { and/or } \\
\mathrm{R} \text {-value }\left(\mathrm{h} * \mathrm{ft}^{2} *{ }^{\circ} \mathrm{F} / \mathrm{Btu}\right)\end{array}$ & $\begin{array}{c}\text { ASHRAE 90.1 Requirements } \\
\text { Nonresidential; Roofs, Insulation entirely above deck }\end{array}$ & ASHRAE 90.1 \\
\hline Dimensions & based on floor area and aspect ratio & \\
\hline Tilts and orientations & horizontal & \\
\hline \multicolumn{3}{|l|}{ Window } \\
\hline Dimensions & based on window fraction, location, glazing sill height, floor area and aspect ratio & \\
\hline Glass-Type and frame & Hypothetical window with the exact U-factor and SHGC shown below & \\
\hline U-factor $\left(\mathrm{Btu} / \mathrm{h} * \mathrm{ft}^{2} *{ }^{\circ} \mathrm{F}\right)$ & ASHRAE 90.1 Requirements & ASSHAF 901 \\
\hline SHGC (all) & Nonresidential for ground floor and residential for upper floors; Vertical Glazing, 10.1\%-20.0\% & НОПRАГ УO.. \\
\hline Visible transmittance & Hypothetical window with the exact U-factor and SHGC shown above & \\
\hline Operable area & $22 \%$ & $\begin{array}{l}\text { ASHRAE SSPC 90.1 } \\
\text { (Fenestration Market } \\
\text { Survey Data) }\end{array}$ \\
\hline \multicolumn{3}{|l|}{ Skylight } \\
\hline Dimensions & Not Modeled & \\
\hline Glass-Type and frame & \multirow{4}{*}{ NA } & \\
\hline U-factor $\left(B t u / h * \mathrm{ft}^{2}{ }^{\circ} \mathrm{F}\right)$ & & \\
\hline SHGC (all) & & \\
\hline Visible transmittance & & \\
\hline \multicolumn{3}{|l|}{ Foundation } \\
\hline Foundation Type & Basement (conditioned) & \\
\hline Construction & 8" heavy-weight Concrete with carpet for all walls and slabs in the model & \\
\hline $\begin{array}{l}\text { Thermal properties for slab-on- } \\
\text { grade floor } \\
\text { F-factor }\left(\mathrm{Btu} / \mathrm{h} * \mathrm{ft} 2 *{ }^{\circ} \mathrm{F}\right) \\
\text { and/or } \\
\mathrm{R} \text {-value }\left(\mathrm{h} * \mathrm{ft} 2 *{ }^{\circ} \mathrm{F} / \mathrm{Btu}\right)\end{array}$ & $\begin{array}{l}\text { ASHRAE 90.1 Requirements } \\
\text { Nonresidential; Floors, Mass }\end{array}$ & \multirow[t]{2}{*}{ ASHRAE 90.1} \\
\hline $\begin{array}{l}\text { Thermal properties for } \\
\text { basement walls }\end{array}$ & No insulation & \\
\hline Dimensions & based on floor area and aspect ratio & \\
\hline \multicolumn{3}{|l|}{ Interior Partitions } \\
\hline Construction & 1 in. gypsum board & \\
\hline Dimensions & based on floor plan and floor-to-floor height & \\
\hline Internal Mass & 6 inches standard wood $\left(16.6 \mathrm{lb} / \mathrm{ft}^{2}\right)$ & \\
\hline \multicolumn{3}{|l|}{ Air Barrier System } \\
\hline
\end{tabular}




\begin{tabular}{|c|c|c|}
\hline Item & Inputs & Data Source \\
\hline Infiltration & $\begin{array}{l}\text { Peak: } 0.2016 \mathrm{cfm} / \mathrm{sf} \text { of above grade exterior wall surface area, adjusted by wind (when fans turn off) } \\
\text { Off Peak: } 25 \% \text { of peak infiltration rate (when fans turn on) }\end{array}$ & \\
\hline \multicolumn{3}{|l|}{ HVAC } \\
\hline System Type & & \\
\hline Heating type & One gas-fired boiler & \\
\hline Cooling type & One air-cooled chiller & ASHRAE 90.1 \\
\hline Distribution and terminal units & $\begin{array}{l}\text { Public spaces on ground floor and top floor: VAV with hot water reheating coils; } \\
\text { Guest Rooms: dedicated outdoor air system + four-pipe fan-coil units. }\end{array}$ & $\begin{array}{l}2003 \text { CBECS Database } \\
\text { (Based on PNNL's Study) }\end{array}$ \\
\hline \multicolumn{3}{|l|}{ HVAC Sizing } \\
\hline Air Conditioning & autosized to design day & \\
\hline Heating & autosized to design day & \\
\hline \multicolumn{3}{|l|}{ HVAC Efficiency } \\
\hline Air Conditioning & Various by climate locations based on cooling capacity & ASHRAE 90.1 \\
\hline Heating & Various by climate locations based on heating capacity & ASHRAE 90.1 \\
\hline \multicolumn{3}{|l|}{ HVAC Control } \\
\hline Thermostat Setpoint & $\begin{array}{l}\text { Guest Rooms: } 70^{\circ} \mathrm{F} \text { Cooling } / 70^{\circ} \mathrm{F} \text { Heating } \\
\text { Public Area: } 75^{\circ} \mathrm{F} \text { cooling } / 70^{\circ} \mathrm{F} \text { heating }\end{array}$ & \\
\hline Thermostat Setback & No setback & \\
\hline Supply air temperature & $\begin{array}{l}\text { For the VAV system, the supply air temperature is set at } 55 \mathrm{~F} \text {; } \\
\text { For the DOAS, the supply air temperature is reset according to the outdoor air temperature: } \\
\text { Tsupply }=60 \mathrm{~F} \text { when Toa }<60 \mathrm{~F} ; \text { Tsupply }=55 \mathrm{~F} \text { when Toa }>70 \mathrm{~F} ; \\
\text { Interpolation when Toa is between } 60 \text { and } 70 \mathrm{~F} \text {. }\end{array}$ & \\
\hline Chilled water supply temperatures & $44 \mathrm{~F}$ & \\
\hline Hot water supply temperatures & $140 \mathrm{~F}$ & \\
\hline Economizers & $\begin{array}{l}\text { For the VAV system, air-side economizer only in all the zones except: } \\
\qquad 1 \mathrm{a}, 1 \mathrm{~b}, 2 \mathrm{a}, 3 \mathrm{a} \text {, and } 4 \mathrm{a} \text {. }\end{array}$ & ASHRAE 90.1 \\
\hline Ventilation & ASHRAE Ventilation Standard 62.1 & $\begin{array}{l}\text { ASHRAE Ventilation } \\
\text { Standard } 62.1\end{array}$ \\
\hline Demand Control Ventilation & No & ASHRAE 90.1 \\
\hline Energy Recovery & No & ASHRAE 90.1 \\
\hline \multicolumn{3}{|l|}{ Supply Fan } \\
\hline Fan schedules & See Appendix C & \\
\hline Fan Mechanical Efficiency (\%) & $65 \%$ & \\
\hline
\end{tabular}




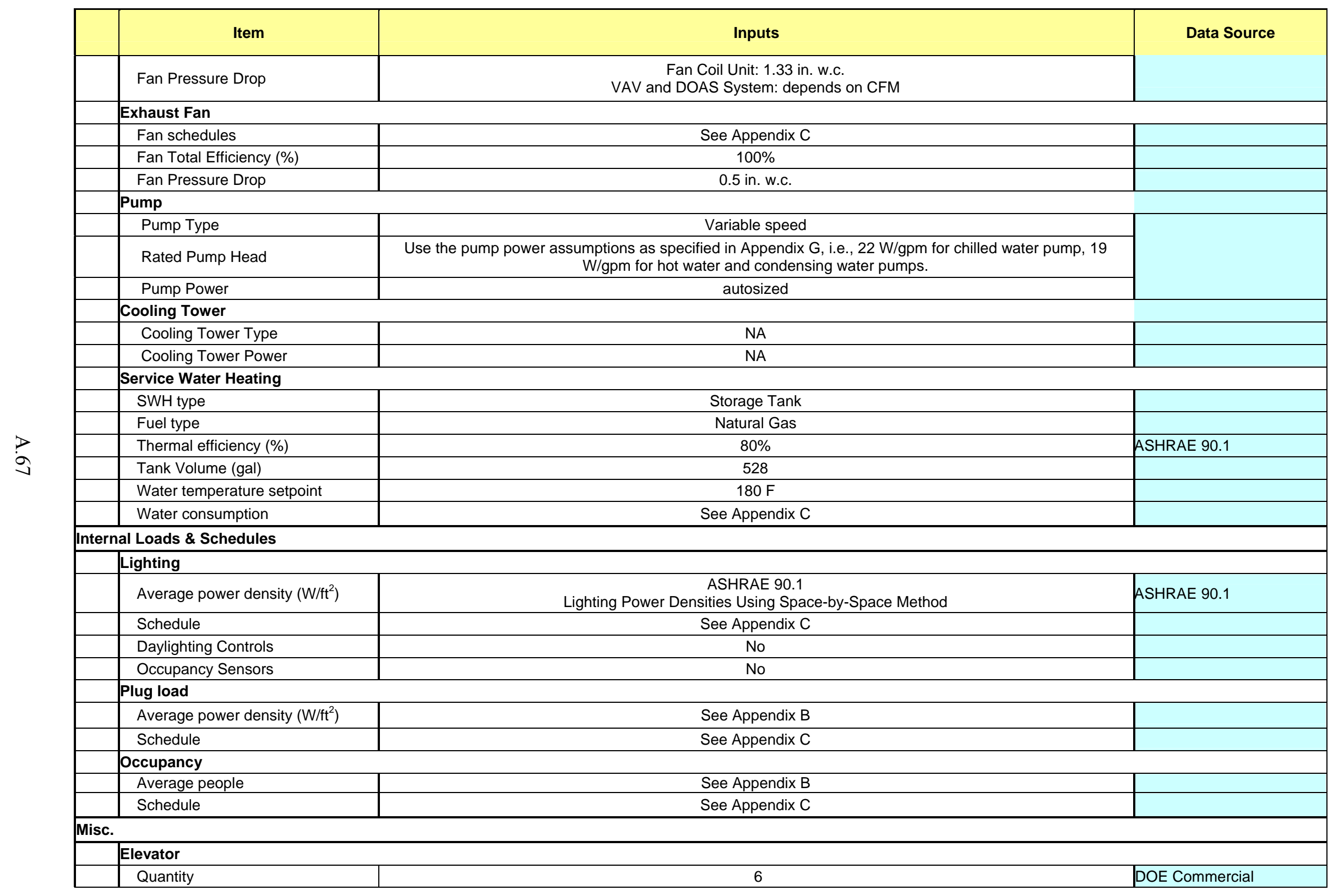




\begin{tabular}{|c|c|c|}
\hline Item & Inputs & Data Source \\
\hline Motor type & traction & \multirow{3}{*}{$\begin{array}{l}\text { Reference Building TSD } \\
\text { (unpublished) and models } \\
\text { (V1.3_5.0). }\end{array}$} \\
\hline Peak Motor Power (W/elevator) & 20370 & \\
\hline Heat Gain to Building & Exterior & \\
\hline $\begin{array}{l}\text { Peak Fan/lights Power } \\
\text { (W/elevator) }\end{array}$ & 161.9 & $\begin{array}{l}\text { 90.1 Mechanical } \\
\text { Subcommittee, Elevator } \\
\text { Working Group }\end{array}$ \\
\hline Motor and fan/lights Schedules & See Appendix C & $\begin{array}{l}\text { DOE Commercial } \\
\text { Reference Building TSD } \\
\text { and models (V1.3_5.0) and } \\
\text { Appendix DF 2007 }\end{array}$ \\
\hline \multicolumn{3}{|l|}{ Exterior Lighting } \\
\hline Peak Power $(\mathrm{W})$ & $3,589.9$ & \\
\hline Schedule & Astronomical Clock & \\
\hline
\end{tabular}

References

Briggs, R.S., R.G. Lucas, and Z.T. Taylor. 2003. Climate Classification for Building Energy Codes and Standards:

Part 2-Zone Definitions, Maps, and Comparisons. ASHRAE Transactions 109(2).

McGraw-Hill Companies, Inc. (2001). Time-Saver Standards for Building Types. New York, NY.

LBNL (1991). Huang, Joe, Akbari, H. Rainer, L and Ritschard, R. 481 Prototypical Commercial Buildings for 20 Urban Market Areas, prepared for the Gas Research Institute, Chicago IL, also LBL-29798, Berkeley CA.

PNNL's CBECS Study. 2007. Analysis of Building Envelope Construction in 2003 CBECS Buildings. Dave Winiarski, Mark Halverson, and Wei Jiang. Pacific Northwest National Laboratory. March 2007.

PNNL's CBECS Study. 2006. Review of Pre- and Post-1980 Buildings in CBECS - HVAC Equipment. Dave Winiarski, Wei Jiang and Mark Halverson. Pacific Northwest National Laboratory. December 2006.

Ducker International Standard. 2001. 2000 U.S. Market For Residential and Specialty Air Conditioning: PTAC.

Sachs, H., 2005. Opportunities for Elevator Energy Efficiency Improvements, ACEEE.

Wassmer and Brandemuehl, 2006, Effect of Data Availability on Modeling of Residential Air Conditioners and Heat Pumps for Energy Calculations 


\section{A.11 Warehouse Modeling Description}

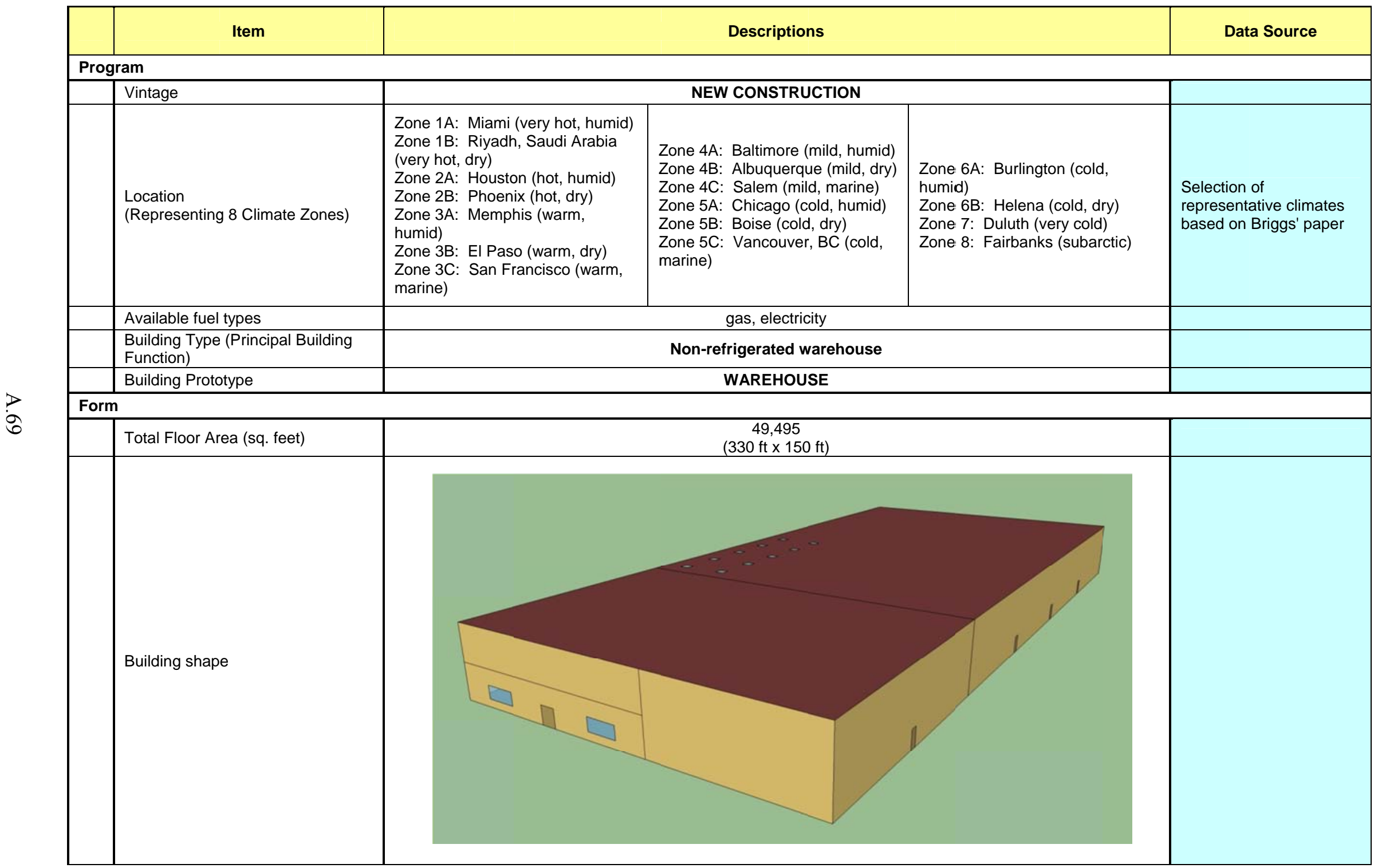




\begin{tabular}{|c|c|c|c|}
\hline Item & \multicolumn{2}{|r|}{ Descriptions } & Data Source \\
\hline Aspect Ratio & \multicolumn{2}{|r|}{2.2} & \\
\hline Number of Floors & \multicolumn{2}{|r|}{1} & \\
\hline $\begin{array}{l}\text { Window Fraction } \\
\text { (Window-to-Wall Ratio) }\end{array}$ & \multicolumn{2}{|r|}{$\begin{array}{l}0.71 \% \\
\text { Punched windows in Office Space }\end{array}$} & \\
\hline Window Locations & \multicolumn{2}{|r|}{ Only for Office Space } & \\
\hline Shading Geometry & \multicolumn{2}{|r|}{ NA } & \\
\hline Azimuth & \multicolumn{2}{|r|}{ non-directional } & \\
\hline Thermal Zoning & $\begin{array}{l}\text { Three zones: Bulk Storage, Fine } \\
\text { Storage, and Office. } \\
\text { The Office zone is enclosed on } \\
\text { two sides and at the top by the } \\
\text { Fine Storage zone. }\end{array}$ & & \\
\hline Floor to floor height (feet) & \multicolumn{2}{|r|}{28} & \\
\hline Floor to ceiling height (feet) & \multicolumn{2}{|r|}{14 (Office) } & \\
\hline Glazing sill height (feet) & \multicolumn{2}{|c|}{$\begin{array}{c}3 \\
\text { (top of the window is } 8 \mathrm{ft} \text { high with } 5 \mathrm{ft} \text { high glass) }\end{array}$} & \\
\hline \multicolumn{4}{|l|}{ Architecture } \\
\hline \multicolumn{4}{|l|}{ Exterior walls } \\
\hline Construction & \multicolumn{2}{|c|}{$\begin{array}{l}\text { Metal Building Wall } \\
\text { Metal Surface + Wall Insulation + Gypsum Board }\end{array}$} & $\begin{array}{l}\text { Construction type: } 2003 \\
\text { CBECS Data and } \\
\text { PNNL's CBECS Study } \\
2007 . \\
\\
\text { Exterior wall layers: } \\
\text { default } 90.1 \text { layering } \\
\end{array}$ \\
\hline $\begin{array}{l}\text { U-factor }\left(\mathrm{Btu} / \mathrm{h} * \mathrm{ft}^{2} *{ }^{\circ} \mathrm{F}\right) \text { and/or } \\
\mathrm{R} \text {-value }\left(\mathrm{h} * \mathrm{ft}^{2} *{ }^{\circ} \mathrm{F} / \mathrm{Btu}\right)\end{array}$ & \multicolumn{2}{|c|}{$\begin{array}{l}\text { ASHRAE 90.1 Requirements } \\
\text { Nonresidential; Walls, Above-Grade, Metal Building } \\
\text { Semiheated; Walls, Above-Grade, Metal Building }\end{array}$} & ASHRAE 90.1 \\
\hline
\end{tabular}




\begin{tabular}{|c|c|c|}
\hline Item & Descriptions & Data Source \\
\hline Dimensions & based on floor area and aspect ratio & \\
\hline Tilts and orientations & vertical & \\
\hline \multicolumn{3}{|l|}{ Roof } \\
\hline Construction & $\begin{array}{l}\text { Metal Building Roof } \\
\text { Metal Surface + Roof Insulation }\end{array}$ & $\begin{array}{l}\text { Construction type: } 2003 \\
\text { CBECS Data and } \\
\text { PNNL's CBECS Study } \\
2007 \text {. } \\
\text { Roof layers: default } 90.1 \\
\text { layering } \\
\end{array}$ \\
\hline $\begin{array}{l}\text { U-factor }\left(\mathrm{Btu} / \mathrm{h} * \mathrm{ft}^{2} *{ }^{\circ} \mathrm{F}\right) \text { and/or } \\
\text { R-value }\left(\mathrm{h} * \mathrm{ft}^{2} *{ }^{\circ} \mathrm{F} / \mathrm{Btu}\right)\end{array}$ & $\begin{array}{c}\text { ASHRAE } 90.1 \text { Requirements } \\
\text { Nonresidential; Roofs, Metal Building } \\
\text { Semiheated; Roofs, Metal Building }\end{array}$ & ASHRAE 90.1 \\
\hline Dimensions & based on floor area and aspect ratio & \\
\hline Tilts and orientations & horizontal & \\
\hline \multicolumn{3}{|l|}{ Window } \\
\hline Dimensions & based on window fraction, location, glazing sill height, floor area and aspect ratio & \\
\hline Glass-Type and frame & Hypothetical window with no frame and meeting ASHRAE 90.1 Requirements & \\
\hline U-factor (Btu $\left./ \mathrm{h} * \mathrm{ft}^{2} *{ }^{\circ} \mathrm{F}\right)$ & $\begin{array}{l}\text { ASHRAE 90.1 Requirements } \\
\text { Ponresidtial. Vertical }\end{array}$ & ASHRAE 90.1 \\
\hline SHGC (all) & Nonresidential; Vertical Glazing, 0-10\%, U_fixed & 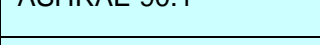 \\
\hline Visible transmittance & Hypothetical window with no frame and meeting ASHRAE 90.1 Requirements & \\
\hline Operable area & 0 & \\
\hline \multicolumn{3}{|l|}{ Skylight } \\
\hline Dimensions & $\begin{array}{c}\text { Bulk Storage, Fine Storage } \\
\text { Rectangular Skylights } \\
(4 \mathrm{ft} \times 4 \mathrm{ft})=16 \mathrm{ft} 2 \text { per skylight } \\
\text { Number of skylights and total skylight area vary according to ASHRAE 90.1 Requirements }\end{array}$ & ASHRAE 90.1 \\
\hline Glass-Type and frame & Hypothetical glass and frame meeting ASHRAE 90.1 Requirements below & \\
\hline U-factor $\left(\mathrm{Btu} / \mathrm{h} * \mathrm{ft}^{2}{ }^{\circ} \mathrm{F}\right)$ & \multirow{3}{*}{$\begin{array}{l}\text { ASHRAE 90.1 Requirements } \\
\text { Nonresidential; Skylight with Curb, Glass }\end{array}$} & \multirow{3}{*}{ ASHRAE 90.1} \\
\hline SHGC (all) & & \\
\hline Visible transmittance & & \\
\hline \multicolumn{3}{|l|}{ Foundation } \\
\hline Foundation Type & Slab-on-Grade & \\
\hline Construction & 6" concrete slab & \\
\hline $\begin{array}{l}\text { Thermal properties for ground } \\
\text { level floor } \\
\text { U-factor }\left(\mathrm{Btu} / \mathrm{h} * \mathrm{ft} 2 *{ }^{\circ} \mathrm{F}\right) \\
\text { and/or } \\
\mathrm{R} \text {-value }\left(\mathrm{h} * \mathrm{ft} 2 *{ }^{\circ} \mathrm{F} / \mathrm{Btu}\right)\end{array}$ & $\begin{array}{l}\text { ASHRAE 90.1 Requirements } \\
\text { Nonresidential; Slab-on-Grade Floors, unheated } \\
\text { Semiheated; Slab-on-Grade Floors, unheated }\end{array}$ & ASHRAE 90.1 \\
\hline Thermal properties for & NA & \\
\hline
\end{tabular}




\begin{tabular}{|c|c|c|c|}
\hline & Item & Descriptions & \multirow[t]{2}{*}{ Data Source } \\
\hline & basement walls & & \\
\hline & Dimensions & based on floor area and aspect ratio & \\
\hline & \multicolumn{3}{|l|}{ Interior Partitions } \\
\hline & Construction & $2 \times 4$ uninsulated steel stud wall & \\
\hline & Dimensions & based on floor plan and floor-to-floor height & \\
\hline & Internal Mass & $\begin{array}{l}\text { Bulk Storage Material } \\
12.5 \mathrm{lb} / \mathrm{sf}, 8 \mathrm{ft} \text { thick, area of } 64,890 \mathrm{ft} 2\end{array}$ & \\
\hline & \multicolumn{3}{|l|}{ Air Barrier System } \\
\hline & Infiltration & $\begin{array}{l}\text { office: } 0.043346 \mathrm{cfm} / \mathrm{ft} 2 \text { of exterior surface area } \\
\text { fine storage: } 0.044442 \mathrm{cfm} / \mathrm{ft} 2 \mathrm{of} \text { exterior surface area } \\
\text { bulk storage: } 3265 \mathrm{cfm} \text { (fixed) }\end{array}$ & \\
\hline & \multicolumn{3}{|c|}{ HVAC } \\
\hline & System Type & & \\
\hline & Heating type & Gas furnace inside the packaged air conditioning unit & \multirow{3}{*}{$\begin{array}{l}2003 \text { CBECS Data, } \\
\text { PNNL's CBECS Study } \\
2006, \text { and } 90.1 \\
\text { Mechanical } \\
\text { Subcommittee input. }\end{array}$} \\
\hline & Cooling type & Packaged air conditioning unit & \\
\hline & Distribution and terminal units & Direct, uncontrolled air & \\
\hline s & \multicolumn{3}{|l|}{ HVAC Sizing } \\
\hline & Air Conditioning & autosized to design day & \\
\hline & Heating & autosized to design day & \\
\hline & \multicolumn{3}{|l|}{ HVAC Efficiency } \\
\hline & Air Conditioning & $\begin{array}{l}\text { Various by climate location and design cooling capacity } \\
\text { ASHRAE 90.1 Requirements } \\
\text { Minimum equipment efficiency for Air Conditioners and Condensing Units }\end{array}$ & \multirow{2}{*}{ ASHRAE 90.1} \\
\hline & Heating & $\begin{array}{l}\text { Various by climate location and design heating capacity } \\
\text { ASHRAE 90.1 Requirements } \\
\text { Minimum equipment efficiency for Warm Air Furnaces }\end{array}$ & \\
\hline & \multicolumn{3}{|l|}{ HVAC Control } \\
\hline & Thermostat Setpoint & $\begin{array}{l}\text { Fine storage: } 80^{\circ} \mathrm{F} \text { Cooling } / 60^{\circ} \mathrm{F} \text { Heating; } \\
\text { Office Area: } 75^{\circ} \mathrm{F} \text { Cooling } 70^{\circ} \mathrm{F} \text { Heating; } \\
\text { Bulk Storage: } 50^{\circ} \mathrm{F} \text { Heating; }\end{array}$ & \\
\hline & Thermostat Setback & $85^{\circ} \mathrm{F}$ Cooling $/ 60^{\circ} \mathrm{F}$ Heating & \\
\hline & Supply air temperature & Minimum $55^{\circ} \mathrm{F}$, maximum $110^{\circ} \mathrm{F}$ & \\
\hline & $\begin{array}{l}\text { Chilled water supply } \\
\text { temperatures }\end{array}$ & NA & \\
\hline & Hot water supply temperatures & NA & \\
\hline
\end{tabular}




\begin{tabular}{|c|c|c|}
\hline Item & Descriptions & Data Source \\
\hline Economizers & $\begin{array}{l}\text { Various by climate location and cooling capacity } \\
\text { Control type: differential dry bulb }\end{array}$ & ASHRAE 90.1 \\
\hline Ventilation & ASHRAE Ventilation Standard 62.1 & $\begin{array}{l}\text { ASHRAE Ventilation } \\
\text { Standard } 62.1\end{array}$ \\
\hline Demand Control Ventilation & No & ASHRAE 90.1 \\
\hline Energy Recovery & No & ASHRAE 90.1 \\
\hline \multicolumn{3}{|l|}{ Supply Fan } \\
\hline Fan schedules & See Appendix C & \\
\hline Supply Fan Total Efficiency (\%) & Varies depending on fan motor size & \multirow{2}{*}{$\begin{array}{l}\text { ASHRAE } 90.1 \\
\text { requirements for motor } \\
\text { efficiency and fan power } \\
\text { limitation }\end{array}$} \\
\hline Supply Fan Pressure Drop & Various depending on the fan supply air cfm & \\
\hline \multicolumn{3}{|l|}{ Pump } \\
\hline Pump Type & NA & \\
\hline Rated Pump Head & NA & \\
\hline Pump Power & NA & \\
\hline Cooling Tower & & \\
\hline Cooling Tower Type & NA & \\
\hline Cooling Tower Power & NA & \\
\hline \multicolumn{3}{|l|}{ Service Water Heating } \\
\hline SWH type & Electric storage water heater & \\
\hline Fuel type & Electricity & \\
\hline Thermal efficiency (\%) & 1 & \\
\hline Tank Volume (gal) & 20 & \\
\hline Water temperature setpoint & $120 \mathrm{~F}$ & \\
\hline Water consumption & See Appendix C & \\
\hline \multicolumn{3}{|l|}{ Internal Loads \& Schedules } \\
\hline \multicolumn{3}{|l|}{ Lighting } \\
\hline Average power density $\left(\mathrm{W} / \mathrm{ft}^{2}\right)$ & $\begin{array}{l}\text { ASHRAE 90.1 } \\
\text { Lighting Power Densities Using the Space-By-Space Method } \\
\text { See Appendix B }\end{array}$ & ASHRAE 90.1 \\
\hline Schedule & See Appendix C & \\
\hline Daylighting Controls & ASHRAE 90.1 Requirements & \\
\hline Occupancy Sensors & ASHRAE 90.1 Requirements & \\
\hline \multicolumn{3}{|l|}{ Plug load } \\
\hline
\end{tabular}




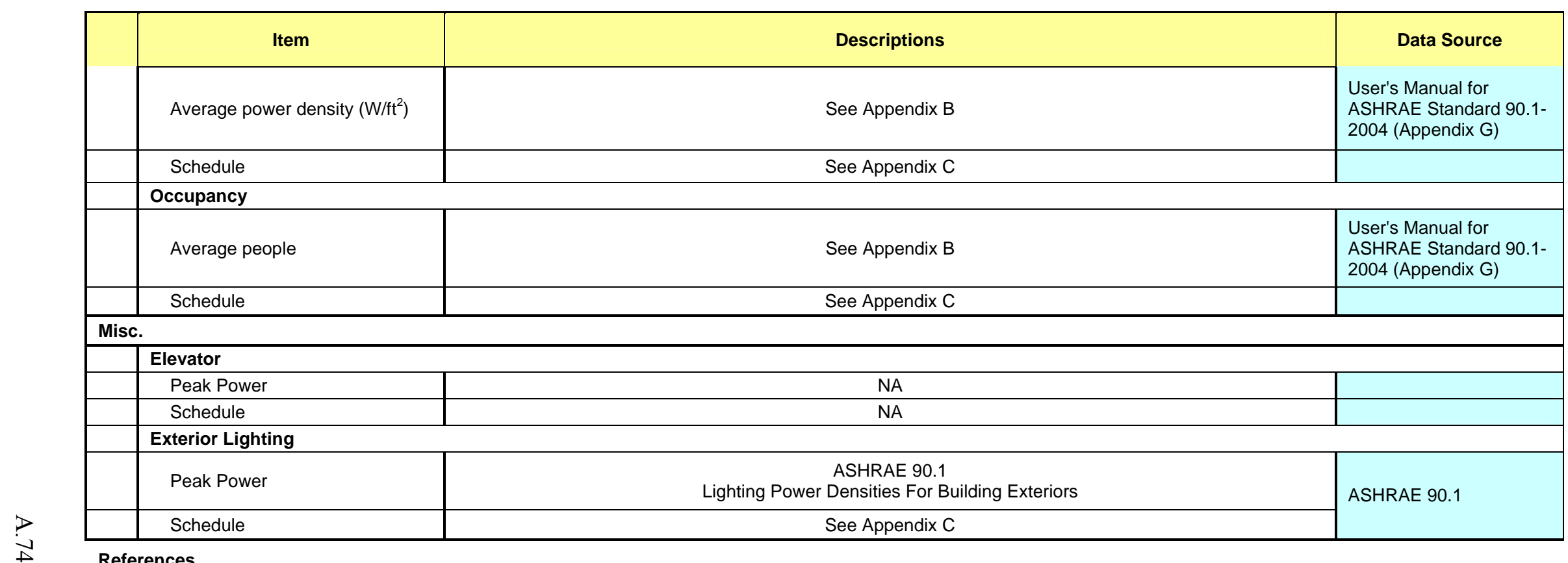

\section{References}

Briggs, R.S., R.G. Lucas, and Z.T. Taylor. 2003. Climate Classification for Building Energy Codes and Standards: Part 2-Zone Definitions, Maps, and Comparisons. ASHRAE Transactions 109(2).

McGraw-Hill Companies, Inc. (2001). Time-Saver Standards for Building Types. New York, NY.

LBNL (1991). Huang, Joe, Akbari, H., Rainer, L. and Ritschard, R. 481 Prototypical Commercial Buildings for 20 Urban Market Areas, prepared for the Gas Research Institute, Chicago IL, also LBL-29798, Berkeley CA.

PNNL's CBECS Study. 2007. Analysis of Building Envelope Construction in 2003 CBECS Buildings. Dave Winiarski, Mark Halverson, and Wei Jiang. Pacific Northwest National Laboratory. March 2007.

PNNL's CBECS Study. 2006. Review of Pre- and Post-1980 Buildings in CBECS - HVAC Equipment. Dave Winiarski, Wei Jiang and, Mark Halverson. Pacific Northwest National Laboratory. December 2006. 


\section{A.12 Quick Service Restaurant Modeling Description}

\begin{tabular}{|c|c|c|c|c|}
\hline Item & \multicolumn{3}{|c|}{ Descriptions } & Data Source \\
\hline \multicolumn{5}{|l|}{ Program } \\
\hline Vintage & & NEW CONSTRUCTION & & \\
\hline $\begin{array}{l}\text { Location } \\
\text { (Representing } 8 \text { Climate Zones) }\end{array}$ & $\begin{array}{l}\text { Zone 1A: Miami (very hot, humid) } \\
\text { Zone 1B: Riyadh, Saudi Arabia } \\
\text { (very hot, dry) } \\
\text { Zone 2A: Houston (hot, humid) } \\
\text { Zone 2B: Phoenix (hot, dry) } \\
\text { Zone 3A: Memphis (warm, humid) } \\
\text { Zone 3B: El Paso (warm, dry) } \\
\text { Zone 3C: San Francisco (warm, } \\
\text { marine) }\end{array}$ & $\begin{array}{l}\text { Zone 4A: Baltimore (mild, humid) } \\
\text { Zone 4B: Albuquerque (mild, dry) } \\
\text { Zone 4C: Salem (mild, marine) } \\
\text { Zone 5A: Chicago (cold, humid) } \\
\text { Zone 5B: Boise (cold, dry) } \\
\text { Zone 5C: Vancouver, BC (cold, } \\
\text { marine) }\end{array}$ & $\begin{array}{l}\text { Zone 6A: Burlington (cold, } \\
\text { humid) } \\
\text { Zone 6B: Helena (cold, dry) } \\
\text { Zone 7: Duluth (very cold) } \\
\text { Zone 8: Fairbanks (subarctic) }\end{array}$ & $\begin{array}{l}\text { Selection of } \\
\text { representative climates } \\
\text { based on Briggs' paper. } \\
\text { See Reference. }\end{array}$ \\
\hline Available fuel types & \multicolumn{3}{|c|}{ gas, electricity } & \\
\hline $\begin{array}{l}\text { Building Type (Principal Building } \\
\text { Function) }\end{array}$ & \multicolumn{3}{|c|}{ FOOD SERVICE } & \\
\hline Building Prototype & \multicolumn{3}{|c|}{ Quick Service Restaurant } & \\
\hline \multicolumn{5}{|l|}{ Form } \\
\hline Total Floor Area (sq. feet) & \multicolumn{3}{|c|}{$2,500(50 \mathrm{ft} \times 50 \mathrm{ft})$} & \\
\hline \multicolumn{5}{|l|}{ Building shape } \\
\hline Aspect Ratio & \multirow{2}{*}{\multicolumn{3}{|c|}{$\begin{array}{l}1 \\
1\end{array}$}} & \\
\hline Number of Floors & & & & \\
\hline
\end{tabular}




\begin{tabular}{|c|c|c|}
\hline Item & Descriptions & Data Source \\
\hline $\begin{array}{l}\text { Window Fraction } \\
\text { (Window-to-Wall Ratio) }\end{array}$ & $\begin{array}{c}\text { South: } 28 \% \\
\text { East: } 14 \% \\
\text { North: } 0 \% \\
\text { West: } 14 \% \\
\text { Total: } 14 \% \\
\end{array}$ & \\
\hline Window Locations & East $(23.3 \mathrm{ft} \times 3 \mathrm{ft})$, south $(46.7 \mathrm{ft} \times 3 \mathrm{ft})$, and west $(23.3 \mathrm{ft} \times 3 \mathrm{ft})$ sides af dining zone façade & \\
\hline Shading Geometry & none & \\
\hline Azimuth & non-directional & \\
\hline \multirow{4}{*}{ Thermal Zoning } & Kitchen & \\
\hline & & \\
\hline & Dining & \\
\hline & $\begin{array}{l}\text { Kitchen, Dining, and Unconditioned Attic (See ZoneSummary tab) } \\
\text { NA }\end{array}$ & \\
\hline Floor to floor height (feet) & NA & \\
\hline Floor to ceiling height (feet) & 10 & \\
\hline Glazing sill height (feet) & 3.5 (top of the window is $6.5 \mathrm{ft}$ high with $3 \mathrm{ft}$ high glass) & \\
\hline \multicolumn{3}{|l|}{ Architecture } \\
\hline \multicolumn{2}{|l|}{ Exterior walls } & \\
\hline Construction & Wood-framed wall: 1 in. stucco +0.625 in. gypsum board + wall insulation +0.625 in. gypsum board & $\begin{array}{l}\text { Construction type: } 2003 \\
\text { CBECS Data and } \\
\text { PNNL's CBECS Study } \\
2007 . \\
\text { Exterior wall layers: } \\
\text { default } 90.1 \text { layering } \\
\end{array}$ \\
\hline $\begin{array}{l}\text { U-factor }\left(\mathrm{Btu} / \mathrm{h} * \mathrm{ft}^{2} *{ }^{\circ} \mathrm{F}\right) \text { and/or } \\
\text { R-value }\left(\mathrm{h} * \mathrm{ft}^{2} *{ }^{\circ} \mathrm{F} / \mathrm{Btu}\right)\end{array}$ & $\begin{array}{c}\text { ASHRAE 90.1 Requirements } \\
\text { Nonresidential; Walls, Above-Grade, Wood-framed }\end{array}$ & ASHRAE 90.1 \\
\hline
\end{tabular}




\begin{tabular}{|c|c|c|}
\hline Item & Descriptions & Data Source \\
\hline Dimensions & based on floor area and aspect ratio & \\
\hline Tilts and orientations & Vertical & \\
\hline \multicolumn{3}{|l|}{ Roof } \\
\hline Construction & $\begin{array}{l}\text { Unconditioned attic roof modeled with asphalt shingles and } 0.625 \text { in. gypsum board (no insulation). Ceiling } \\
\text { between attic and conditioned zones modeled with wood-joist attic roof consisting of the following layers: } \\
\text { insulation and } 0.625 \text { in. gypsum board }\end{array}$ & $\begin{array}{l}\text { Construction type: } 2003 \\
\text { CBECS Data and } \\
\text { PNNL's CBECS Study } \\
2007 . \\
\text { Roof layers: default } 90.1 \\
\text { layering }\end{array}$ \\
\hline $\begin{array}{l}\text { U-factor }\left(\mathrm{Btu} / \mathrm{h} * \mathrm{ft}^{2} *{ }^{\circ} \mathrm{F}\right) \text { and/or } \\
\text { R-value }\left(\mathrm{h} * \mathrm{ft}^{2} *{ }^{\circ} \mathrm{F} / \mathrm{Btu}\right)\end{array}$ & $\begin{array}{l}\text { Attic Roof (all zones): } 0.071 \text { - No Insulation } \\
\text { Ceiling: ASHRAE 90.1 Requirements } \\
\text { Nonresidential; Roofs, Attic and other }\end{array}$ & ASHRAE 90.1 \\
\hline Dimensions & based on floor area and aspect ratio & \\
\hline Tilts and orientations & $\begin{array}{l}\text { Insulated Ceiling - horizontal } \\
\text { Attic Roof } \\
\text { East \& West - } 45 \text { deg. } \\
\text { North \& South - } 18.44 \text { deg. }\end{array}$ & \\
\hline \multicolumn{3}{|l|}{ Window } \\
\hline Dimensions & based on window fraction, location, glazing sill height, floor area and aspect ratio & \\
\hline Glass-Type and frame & Hypothetical window with the exact U-factor and SHGC shown below & \\
\hline $\begin{array}{l}\left.\text { U-factor (Btu } / \mathrm{h}^{*} \mathrm{ft}^{2}{ }^{\circ} \mathrm{F}\right) \\
\text { SHGC (all) }\end{array}$ & $\begin{array}{c}\text { ASHRAE 90.1 Requirements } \\
\text { Nonresidential; Vertical Glazing, 20.1-30.0\% }\end{array}$ & ASHRAE 90.1 \\
\hline Visible transmittance & Hypothetical window with the exact U-factor and SHGC shown above & $\begin{array}{l}\text { Ducker Fenestration } \\
\text { Market Data provided by } \\
\text { the } 90.1 \text { envelope } \\
\text { subcommittee }\end{array}$ \\
\hline Operable area & $2 \%$ of total WWR & $\begin{array}{l}\text { Ducker Fenestration } \\
\text { Market Data provided by } \\
\text { the envelope } \\
\text { subcommittee }\end{array}$ \\
\hline \multicolumn{3}{|l|}{ Skylight } \\
\hline Dimensions & Not Modeled & \\
\hline Glass-Type and frame & \multirow{4}{*}{ NA } & \\
\hline U-factor $\left(\mathrm{Btu} / \mathrm{h} * \mathrm{ft}^{2}{ }^{\circ} \mathrm{F}\right)$ & & \\
\hline SHGC & & \\
\hline Visible transmittance & & \\
\hline \multicolumn{3}{|l|}{ Foundation } \\
\hline Foundation Type & Slab-on-grade floors (unheated) & \\
\hline Construction & 6" concrete slab poured directly on to the earth & \\
\hline $\begin{array}{l}\text { Thermal properties for ground } \\
\text { level floor }\end{array}$ & $\begin{array}{l}\text { ASHRAE 90.1 Requirements } \\
\text { Nonresidential; Slab-on-Grade Floors, unheated }\end{array}$ & ASHRAE 90.1 \\
\hline
\end{tabular}




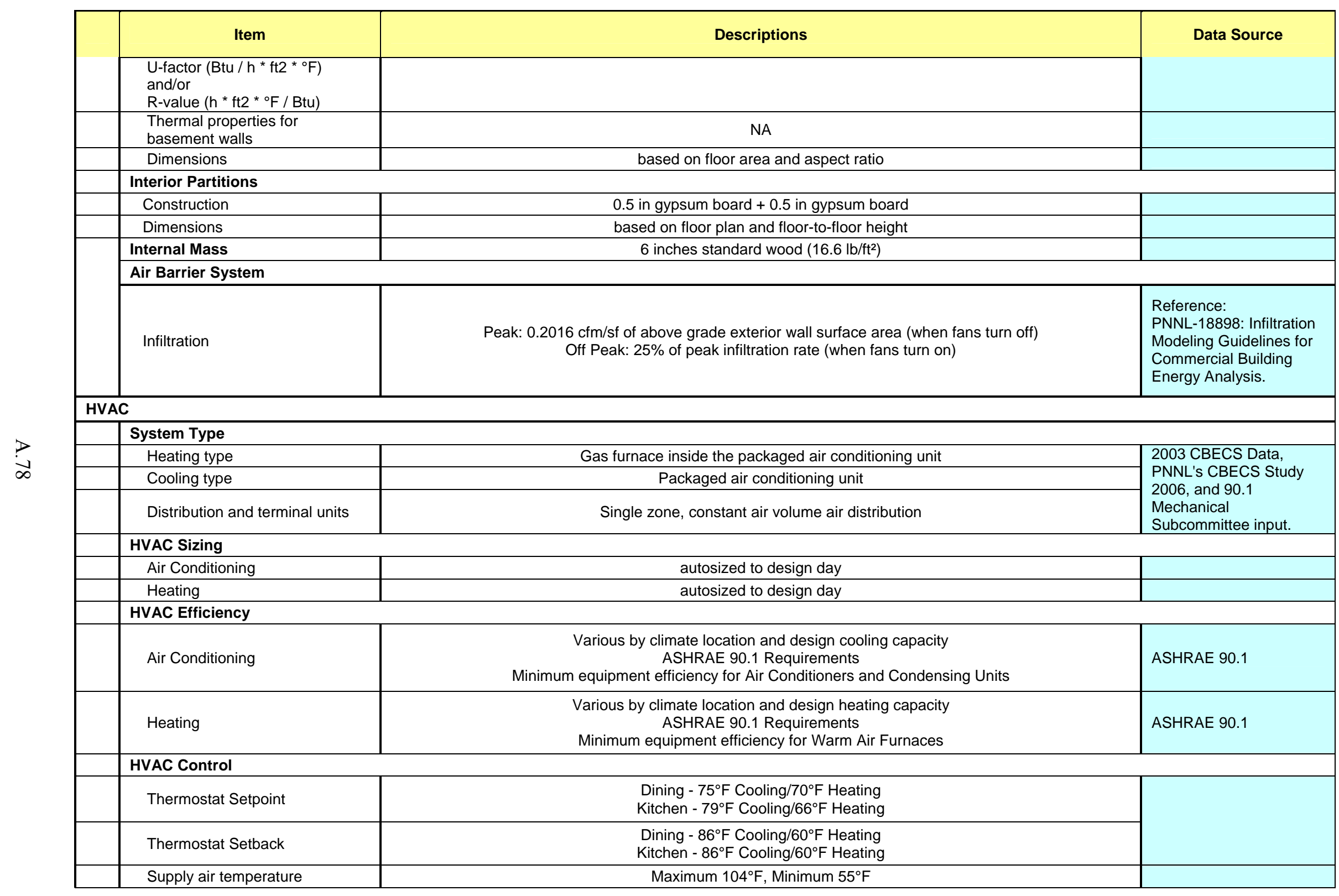




\begin{tabular}{|c|c|c|}
\hline Item & Descriptions & Data Source \\
\hline $\begin{array}{l}\text { Chilled water supply } \\
\text { temperatures }\end{array}$ & NA & \\
\hline Hot water supply temperatures & NA & \\
\hline Economizers & $\begin{array}{l}\text { Various by climate location and cooling capacity } \\
\text { Control type: differential dry bulb }\end{array}$ & ASHRAE 90.1 \\
\hline Ventilation & ASHRAE Ventilation Standard 62.1 & $\begin{array}{l}\text { ASHRAE Ventilation } \\
\text { Standard } 62.1\end{array}$ \\
\hline Demand Control Ventilation & No & ASHRAE 90.1 \\
\hline Energy Recovery & No & ASHRAE 90.1 \\
\hline \multicolumn{3}{|l|}{ Supply Fan } \\
\hline Fan schedules & See Appendix C & \\
\hline Supply Fan Total Efficiency (\%) & Various depending on the fan motor size & \multirow{2}{*}{$\begin{array}{l}\text { ASHRAE } 90.1 \\
\text { requirements for motor } \\
\text { efficiency and fan power } \\
\text { limitation }\end{array}$} \\
\hline Supply Fan Pressure Drop & Various depending on the fan supply air cfm & \\
\hline \multicolumn{3}{|l|}{ Pump } \\
\hline Pump Type & Service hot water & \\
\hline Rated Pump Head & No & \\
\hline Pump Power & $100 \%$ eff. motor. Negligible power consumption & \\
\hline \multicolumn{3}{|l|}{ Cooling Tower } \\
\hline Cooling Tower Type & NA & \\
\hline Cooling Tower Power & NA & \\
\hline \multicolumn{3}{|l|}{ Service Water Heating } \\
\hline SWH type & Storage Tank & \\
\hline Fuel type & Natural Gas & \\
\hline Thermal efficiency (\%) & $\begin{array}{l}\text { ASHRAE } 90.1 \text { Requirements } \\
\text { Water Heating Equipment, Gas storage water heaters, }>75,000 \mathrm{Btu} / \mathrm{h} \text { input }\end{array}$ & ASHRAE 90.1 \\
\hline Tank Volume (gal) & 52.8 & \\
\hline Water temperature setpoint & $140 \mathrm{~F}$ & \\
\hline Water consumption & $\begin{array}{l}\text { BLDG_SWH_SCH } \\
\text { See Appendix C }\end{array}$ & \\
\hline \multicolumn{3}{|l|}{ Internal Loads \& Schedules } \\
\hline \multicolumn{3}{|l|}{ Lighting } \\
\hline Average power density $\left(\mathrm{W} / \mathrm{ft}^{2}\right)$ & $\begin{array}{l}\text { ASHRAE } 90.1 \\
\text { Lighting Power Densities Using the Building Area Method }\end{array}$ & \\
\hline Schedule & See Appendix C & \\
\hline Daylighting Controls & ASHRAE 90.1 Requirements & \\
\hline Occupancy Sensors & ASHRAE 90.1 Requirements & \\
\hline
\end{tabular}




\begin{tabular}{|c|c|c|c|}
\hline & Item & Descriptions & Data Source \\
\hline & \multicolumn{3}{|l|}{ Plug load } \\
\hline & Average power density $\left(\mathrm{W} / \mathrm{ft}^{2}\right)$ & See Appendix B & \\
\hline & Schedule & See Appendix C & \\
\hline & \multicolumn{3}{|l|}{ Occupancy } \\
\hline & Average people & See Appendix B & \\
\hline & Schedule & See Appendix C & \\
\hline \multicolumn{4}{|c|}{ Misc. } \\
\hline & \multicolumn{3}{|l|}{ Elevator } \\
\hline & Peak Power & NA & \\
\hline & Schedule & NA & \\
\hline & \multicolumn{3}{|l|}{ Exterior Lighting } \\
\hline & Peak Power (W) & 1,743 & \multirow{2}{*}{ ASHRAE 90.1} \\
\hline & Schedule & Astronomical Clock & \\
\hline
\end{tabular}

\section{References}

Briggs, R.S., R.G. Lucas, and Z.T. Taylor. 2003. Climate Classification for Building Energy Codes and Standards:

Part 2-Zone Definitions, Maps, and Comparisons. ASHRAE Transactions 109(2).

PNNL's CBECS Study. 2007. Analysis of Building Envelope Construction in 2003 CBECS Buildings. Dave Winiarski, Mark Halverson, and Wei Jiang. Pacific Northwest National Laboratory. March 2007.

PNNL's CBECS Study. 2006. Review of Pre- and Post-1980 Buildings in CBECS - HVAC Equipment. Dave Winiarski, Wei Jiang and Mark

Halverson. Pacific Northwest National Laboratory. December 2006.

Gowri K, DW Winiarski, and RE Jarnagin. 2009. Infiltration modeling guidelines for commercial building energy analysis. PNNL-18898, Pacific Northwest National Laboratory, Richland, WA. http://www.pnl.gov/main/publications/external/technical_reports/PNNL-18898.pdf 


\section{A.13 Full Service Restaurant Modeling Description}

\begin{tabular}{|c|c|c|c|c|}
\hline Item & \multicolumn{3}{|c|}{ Descriptions } & Data Source \\
\hline \multicolumn{5}{|c|}{ Program } \\
\hline Vintage & \multicolumn{3}{|c|}{ NEW CONSTRUCTION } & \\
\hline $\begin{array}{l}\text { Location } \\
\text { (Representing } 8 \text { Climate Zones) }\end{array}$ & $\begin{array}{l}\text { Zone 1A: Miami (very hot, humid) } \\
\text { Zone 1B: Riyadh, Saudi Arabia } \\
\text { (very hot, dry) } \\
\text { Zone 2A: Houston (hot, humid) } \\
\text { Zone 2B: Phoenix (hot, dry) } \\
\text { Zone 3A: Memphis (warm, humid) } \\
\text { Zone 3B: El Paso (warm, dry) } \\
\text { Zone 3C: San Francisco (warm, } \\
\text { marine) }\end{array}$ & $\begin{array}{l}\text { Zone 4A: Baltimore (mild, humid) } \\
\text { Zone 4B: Albuquerque (mild, dry) } \\
\text { Zone 4C: Salem (mild, marine) } \\
\text { Zone 5A: Chicago (cold, humid) } \\
\text { Zone 5B: Boise (cold, dry) } \\
\text { Zone 5C: Vancouver, BC (cold, } \\
\text { marine) }\end{array}$ & $\begin{array}{l}\text { Zone 6A: Burlington (cold, humid) } \\
\text { Zone 6B: Helena (cold, dry) } \\
\text { Zone 7: Duluth (very cold) } \\
\text { Zone 8: Fairbanks (subarctic) }\end{array}$ & $\begin{array}{l}\text { Selection of representative } \\
\text { climates based on Briggs' } \\
\text { paper. See Reference. }\end{array}$ \\
\hline Available fuel types & \multicolumn{3}{|c|}{ gas, electricity } & \\
\hline $\begin{array}{l}\text { Building Type (Principal Building } \\
\text { Function) }\end{array}$ & \multicolumn{3}{|c|}{ FOOD SERVICE } & \\
\hline Building Prototype & \multicolumn{3}{|c|}{ Full Service Restaurant } & \\
\hline \multicolumn{5}{|c|}{ Form } \\
\hline Total Floor Area (sq. feet) & & $5,502(74.2 \mathrm{ft} \times 74.2 \mathrm{ft})$ & & \\
\hline \multicolumn{5}{|l|}{ Building shape } \\
\hline Aspect Ratio & \multicolumn{3}{|c|}{1} & \\
\hline Number of Floors & \multicolumn{3}{|c|}{ Single floor plus attic } & \\
\hline
\end{tabular}




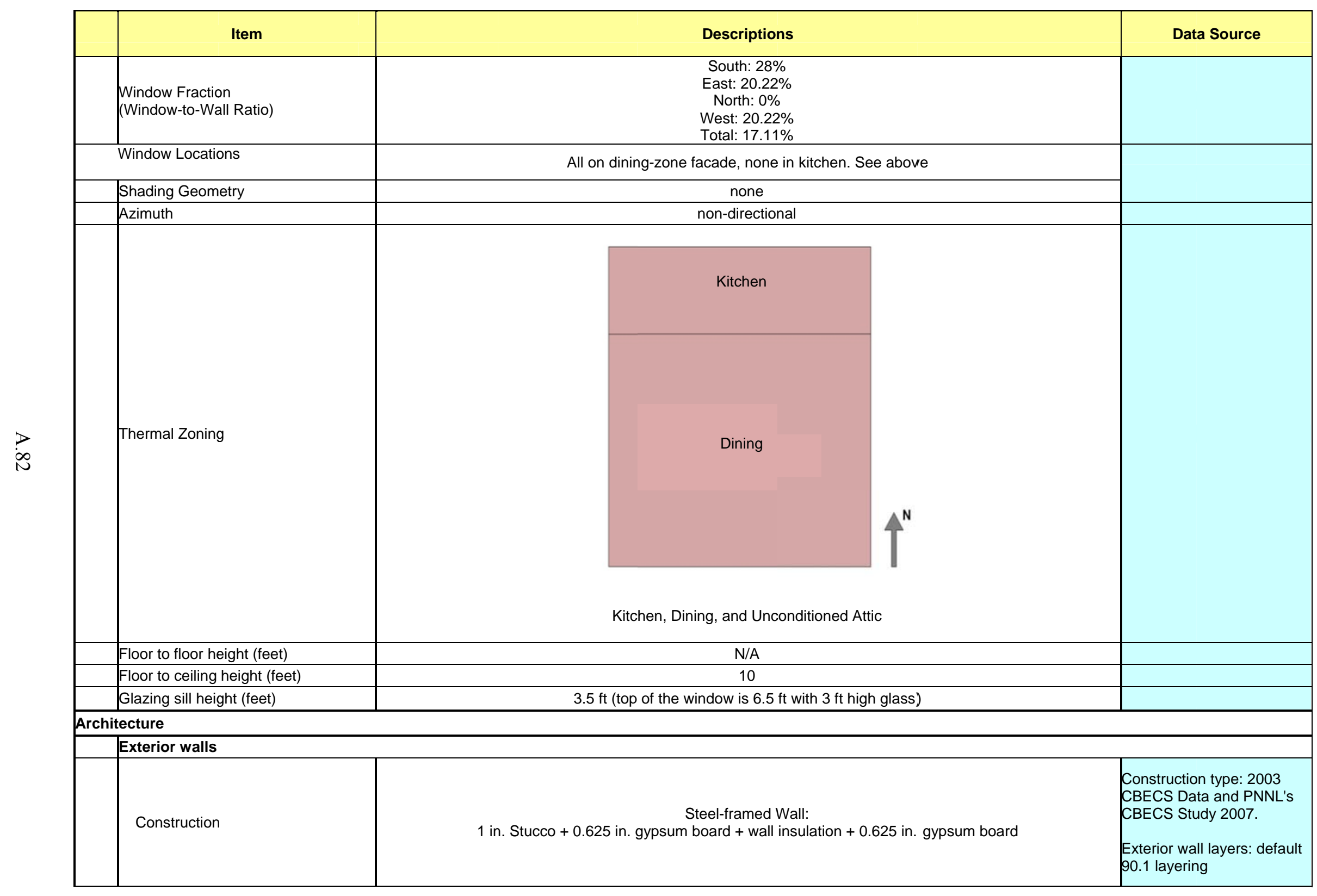




\begin{tabular}{|c|c|c|}
\hline Item & Descriptions & Data Source \\
\hline $\begin{array}{l}\text { U-factor }\left(\mathrm{Btu} / \mathrm{h} \mathrm{h}^{*} \mathrm{ft}^{2} *{ }^{\circ} \mathrm{F}\right) \text { and/or } \\
\mathrm{R} \text {-value }\left(\mathrm{h} * \mathrm{ft}^{2} *{ }^{\circ} \mathrm{F} / \mathrm{Btu}\right)\end{array}$ & $\begin{array}{c}\text { ASHRAE 90.1 Requirements } \\
\text { Nonresidential; Walls, Above-Grade, Steel-Framed }\end{array}$ & ASHRAE 90.1 \\
\hline Dimensions & based on floor area and aspect ratio & \\
\hline Tilts and orientations & vertical & \\
\hline \multicolumn{3}{|l|}{ Roof } \\
\hline Construction & $\begin{array}{l}\text { Unconditioned attic roof modeled with asphalt shingles and } 0.625 \text { in. gypsum board (no insulation). Ceiling } \\
\text { between attic and conditioned zones modeled with wood-joist attic roof consisting of the following layers: } \\
\text { insulation and } 0.625 \text { in. gypsum board }\end{array}$ & $\begin{array}{l}\text { Construction type: } 2003 \\
\text { CBECS Data and PNNL's } \\
\text { CBECS Study } 2007 . \\
\text { Roof layers: default } 90.1 \\
\text { layering }\end{array}$ \\
\hline $\begin{array}{l}\text { U-factor }\left(B t u / h * \mathrm{ft}^{2} *{ }^{\circ} \mathrm{F}\right) \text { and/or } \\
\text { R-value }\left(\mathrm{h} * \mathrm{ft}^{2} *{ }^{\circ} \mathrm{F} / \mathrm{Btu}\right)\end{array}$ & $\begin{array}{l}\text { Attic Roof (all zones): } 0.071 \text { - No Insulation } \\
\text { Ceiling: ASHRAE } 90.1 \text { Requirements } \\
\text { Nonresidential; Roofs, Attic and other }\end{array}$ & ASHRAE 90.1 \\
\hline Dimensions & based on floor area and aspect ratio & \\
\hline Tilts and orientations & $\begin{array}{l}\text { Insulated Ceiling - horizontal } \\
\text { Attic Roof } \\
\text { North \& South - } 45 \text { deg. } \\
\text { East \& West - } 18.44 \text { deg. }\end{array}$ & \\
\hline \multicolumn{3}{|l|}{ Window } \\
\hline Dimensions & based on window fraction, location, glazing sill height, floor area and aspect ratio & \\
\hline Glass-Type and frame & Hypothetical window with the exact U-factor and SHGC shown below & \\
\hline U-factor (Btu $\left./ \mathrm{h} * \mathrm{ft}^{2}{ }^{\circ}{ }^{\circ} \mathrm{F}\right)$ & ASHRAE 90.1 Requirements & ASHRAE 90.1 \\
\hline SHGC (all) & Nonresidential; Vertical Glazing, 20.1-30.0\% & \\
\hline Visible transmittance & Hypothetical window with the exact U-factor and SHGC shown above & $\begin{array}{l}\text { Ducker Fenestration Market } \\
\text { Data provided by the } 90.1 \\
\text { envelope subcommittee }\end{array}$ \\
\hline Operable area & $2 \%$ of total WWR & $\begin{array}{l}\text { Ducker Fenestration Market } \\
\text { Data provided by the } \\
\text { envelope subcommittee }\end{array}$ \\
\hline \multicolumn{3}{|l|}{ Skylight } \\
\hline Dimensions & Not Modeled & \\
\hline Glass-Type and frame & \multirow{4}{*}{ NA } & \\
\hline U-factor $\left(\mathrm{Btu} / \mathrm{h} * \mathrm{ft}^{2} *{ }^{\circ} \mathrm{F}\right)$ & & \\
\hline SHGC & & \\
\hline Visible transmittance & & \\
\hline \multicolumn{3}{|l|}{ Foundation } \\
\hline Foundation Type & Slab-on-grade floors (unheated) & \\
\hline Construction & 6" concrete slab poured directly on to the earth & \\
\hline
\end{tabular}




\begin{tabular}{|c|c|c|}
\hline Item & Descriptions & Data Source \\
\hline $\begin{array}{l}\text { Thermal properties for ground } \\
\text { level floor } \\
\mathrm{U} \text {-factor }\left(\mathrm{Btu} / \mathrm{h} * \mathrm{ft} 2 *{ }^{\circ} \mathrm{F}\right) \\
\text { and/or } \\
\text { R-value }\left(\mathrm{h} * \mathrm{ft} 2 *{ }^{\circ} \mathrm{F} / \mathrm{Btu}\right)\end{array}$ & $\begin{array}{l}\text { ASHRAE } 90.1 \text { Requirements } \\
\text { Nonresidential; Slab-on-Grade Floors, unheated }\end{array}$ & ASHRAE 90.1 \\
\hline $\begin{array}{l}\text { Thermal properties for } \\
\text { basement walls }\end{array}$ & NA & \\
\hline Dimensions & based on floor area and aspect ratio & \\
\hline \multicolumn{3}{|l|}{ Interior Partitions } \\
\hline Construction & 0.5 in gypsum board +0.5 in gypsum board & \\
\hline Dimensions & based on floor plan and floor-to-floor height & \\
\hline Internal Mass & 6 inches standard wood $\left(16.6 \mathrm{lb} / \mathrm{ft}^{2}\right)$ & \\
\hline \multicolumn{3}{|l|}{ Air Barrier System } \\
\hline Infiltration & $\begin{array}{c}\text { Peak: } 0.2016 \mathrm{cfm} / \mathrm{sf} \text { of above grade exterior wall surface area (when fans turn off) } \\
\text { Off Peak: } 25 \% \text { of peak infiltration rate (when fans turn on) }\end{array}$ & $\begin{array}{l}\text { Reference: } \\
\text { PNNL-18898: Infiltration } \\
\text { Modeling Guidelines for } \\
\text { Commercial Building } \\
\text { Energy Analysis. }\end{array}$ \\
\hline \multicolumn{3}{|l|}{ HVAC } \\
\hline \multicolumn{3}{|l|}{ System Type } \\
\hline Heating type & Gas furnace inside the packaged air conditioning unit & \multirow{3}{*}{$\begin{array}{l}2003 \text { CBECS Data, PNNL's } \\
\text { CBECS Study 2006, and } \\
90.1 \text { Mechanical } \\
\text { Subcommittee input. }\end{array}$} \\
\hline Cooling type & Packaged air conditioning unit & \\
\hline Distribution and terminal units & Single zone, constant air volume air distribution & \\
\hline \multicolumn{3}{|l|}{ HVAC Sizing } \\
\hline Air Conditioning & autosized to design day & \\
\hline Heating & autosized to design day & \\
\hline \multicolumn{3}{|l|}{ HVAC Efficiency } \\
\hline Air Conditioning & $\begin{array}{l}\text { Various by climate location and design cooling capacity } \\
\text { ASHRAE } 90.1 \text { Requirements } \\
\text { Minimum equipment efficiency for Air Conditioners and Condensing Units }\end{array}$ & ASHRAE 90.1 \\
\hline Heating & $\begin{array}{l}\text { Various by climate location and design heating capacity } \\
\text { ASHRAE } 90.1 \text { Requirements } \\
\text { Minimum equipment efficiency for Warm Air Furnaces }\end{array}$ & ASHRAE 90.1 \\
\hline \multicolumn{3}{|l|}{ HVAC Control } \\
\hline Thermostat Setpoint & $\begin{array}{l}\text { Dining }-75^{\circ} \mathrm{F} \text { Cooling } / 70^{\circ} \mathrm{F} \text { Heating } \\
\text { Kitchen }-79^{\circ} \mathrm{F} \text { Cooling } / 66^{\circ} \mathrm{F} \text { Heating }\end{array}$ & \\
\hline Thermostat Setback & $\begin{array}{l}\text { Dining }-86^{\circ} \mathrm{F} \text { Cooling } / 60^{\circ} \mathrm{F} \text { Heating } \\
\text { Kitchen }-86^{\circ} \mathrm{F} \text { Cooling } / 60^{\circ} \mathrm{F} \text { Heating }\end{array}$ & \\
\hline Supply air temperature & $55^{\circ} \mathrm{F}$ cooling $/ 104^{\circ} \mathrm{F}$ heating & \\
\hline
\end{tabular}




\begin{tabular}{|c|c|c|}
\hline Item & Descriptions & Data Source \\
\hline Chilled water supply temperatures & NA & \\
\hline Hot water supply temperatures & NA & \\
\hline Economizers & $\begin{array}{l}\text { Various by climate location and cooling capacity } \\
\text { Control type: differential dry bulb }\end{array}$ & ASHRAE 90.1 \\
\hline Ventilation & ASHRAE Ventilation Standard 62.1 & $\begin{array}{l}\text { ASHRAE Ventilation } \\
\text { Standard } 62.1\end{array}$ \\
\hline Demand Control Ventilation & No & ASHRAE 90.1 \\
\hline Energy Recovery & No & ASHRAE 90.1 \\
\hline \multicolumn{3}{|l|}{ Supply Fan } \\
\hline Fan schedules & See Appendix C & \\
\hline Supply Fan Total Efficiency (\%) & Various depending on the fan motor size & \multirow{2}{*}{$\begin{array}{l}\text { ASHRAE } 90.1 \text { requirements } \\
\text { for motor efficiency and fan } \\
\text { power limitation }\end{array}$} \\
\hline Supply Fan Pressure Drop & Various depending on the fan supply air cfm & \\
\hline \multicolumn{3}{|l|}{ Pump } \\
\hline Pump Type & Service hot water & \\
\hline Rated Pump Head & No & \\
\hline Pump Power & $100 \%$ eff. motor. Negligible power consumption & \\
\hline \multicolumn{3}{|l|}{ Cooling Tower } \\
\hline Cooling Tower Type & NA & \\
\hline Cooling Tower Power & NA & \\
\hline \multicolumn{3}{|l|}{ Service Water Heating } \\
\hline SWH type & Storage Tank & \\
\hline Fuel type & Natural Gas & \\
\hline Thermal efficiency (\%) & $\begin{array}{l}\text { ASHRAE } 90.1 \text { Requirements } \\
\text { Water Heating Equipment, Gas storage water heaters, }>75,000 \mathrm{Btu} / \mathrm{h} \text { input }\end{array}$ & ASHRAE 90.1 \\
\hline Tank Volume (gal) & 52.8 & \\
\hline Water temperature setpoint & $140 \mathrm{~F}$ & \\
\hline Water consumption & $\begin{array}{l}\text { BLDG_SWH_SCH } \\
\text { See Appendix C }\end{array}$ & \\
\hline \multicolumn{3}{|l|}{ Internal Loads \& Schedules } \\
\hline \multicolumn{3}{|l|}{ Lighting } \\
\hline Average power density $\left(\mathrm{W} / \mathrm{ft}^{2}\right)$ & $\begin{array}{c}\text { ASHRAE 90.1 } \\
\text { Lighting Power Densities Using the Building Area Method }\end{array}$ & \\
\hline Schedule & See Appendix C & \\
\hline Daylighting Controls & ASHRAE 90.1 Requirements & \\
\hline Occupancy Sensors & ASHRAE 90.1 Requirements & \\
\hline
\end{tabular}




\begin{tabular}{|c|c|c|c|}
\hline & Item & Descriptions & Data Source \\
\hline & \multicolumn{3}{|l|}{ Plug load } \\
\hline & Average power density $\left(\mathrm{W} / \mathrm{ft}^{2}\right)$ & See Appendix B & \\
\hline & Schedule & See Appendix C & \\
\hline & \multicolumn{3}{|l|}{ Occupancy } \\
\hline & Average people & See Appendix B & \\
\hline & Schedule & See Appendix C & \\
\hline \multicolumn{4}{|l|}{ Misc. } \\
\hline & \multicolumn{3}{|l|}{ Elevator } \\
\hline & Peak Power & NA & \\
\hline & Schedule & NA & \\
\hline & \multicolumn{3}{|l|}{ Exterior Lighting } \\
\hline & Peak Power (W) & 3,695 & \multirow{2}{*}{ ASHRAE 90.1} \\
\hline & Schedule & Astronomical Clock & \\
\hline
\end{tabular}

References

Briggs, R.S., R.G. Lucas, and Z.T. Taylor. 2003. Climate Classification for Building Energy Codes and Standards:

Part 2-Zone Definitions, Maps, and Comparisons. ASHRAE Transactions 109(2).

PNNL's CBECS Study. 2007. Analysis of Building Envelope Construction in 2003 CBECS Buildings. Dave Winiarski, Mark Halverson, and Wei Jiang. Pacific Northwest National Laboratory. March 2007.

PNNL's CBECS Study. 2006. Review of Pre- and Post-1980 Buildings in CBECS - HVAC Equipment. Dave Winiarski, Wei Jiang and Mark Halverson. Pacific Northwest National Laboratory. December 2006.

Gowri K, DW Winiarski, and RE Jarnagin. 2009. Infiltration modeling guidelines for commercial building energy analysis. PNNL-18898, Pacific Northwest National Laboratory, Richland, WA. http://www.pnl.gov/main/publications/external/technical_reports/PNNL-18898.pdf 


\section{A.14 Mid-Rise Apartment Modeling Description}

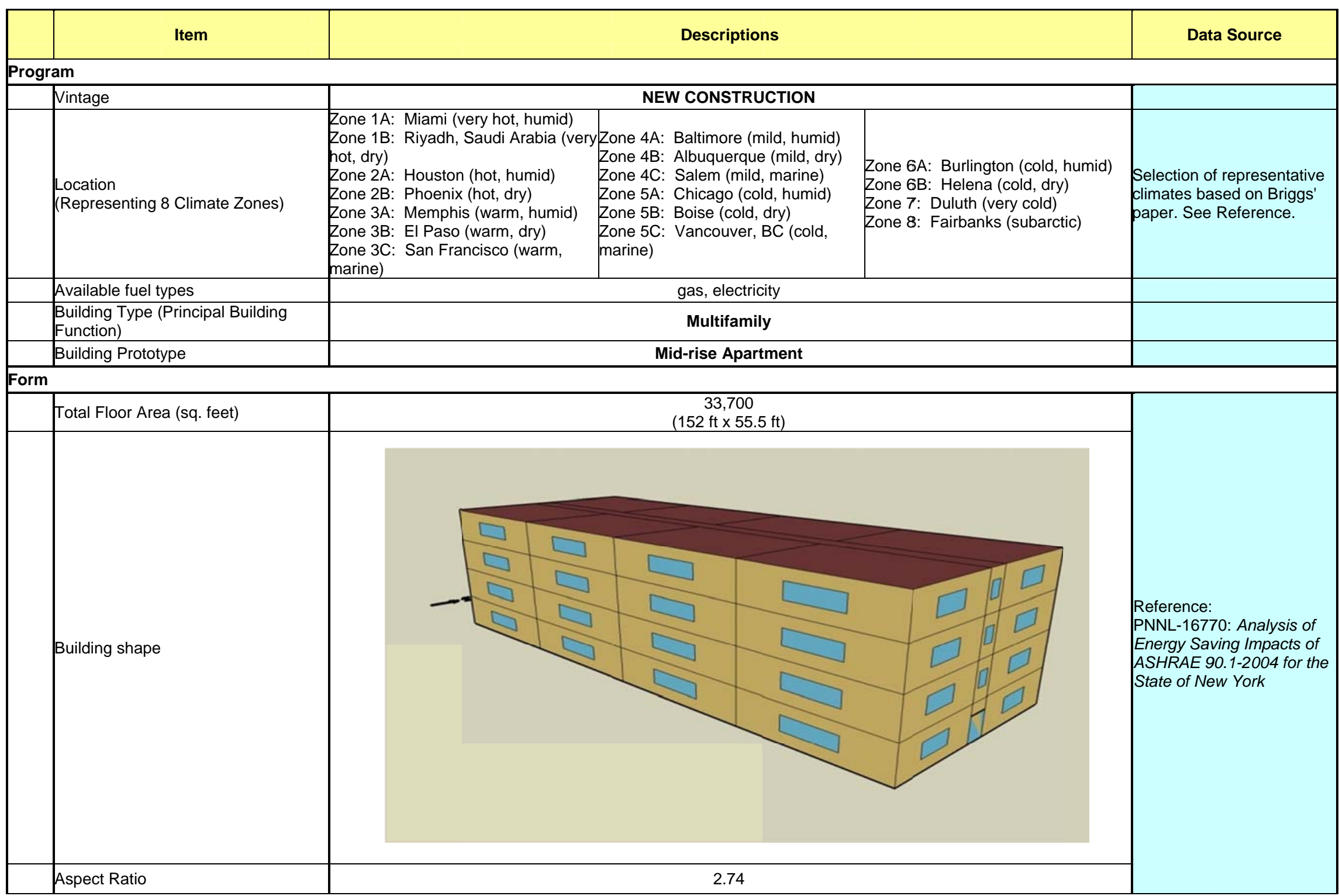




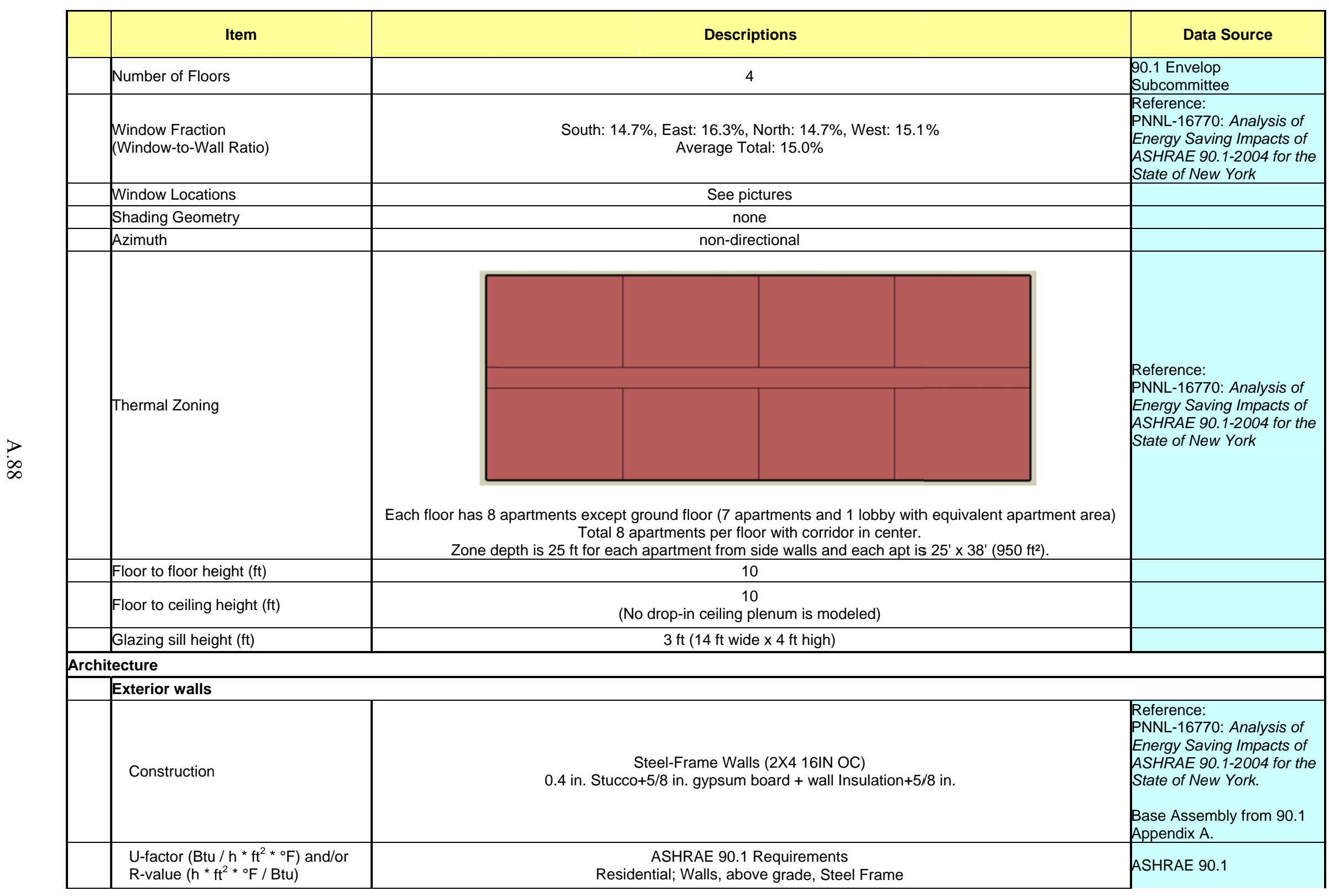




\begin{tabular}{|c|c|c|}
\hline Item & Descriptions & Data Source \\
\hline Dimensions & based on floor area and aspect ratio & \\
\hline Tilts and orientations & vertical & \\
\hline \multicolumn{3}{|l|}{ Roof } \\
\hline Construction & $\begin{array}{l}\text { Built-up Roof: } \\
\text { Roof membrane+Roof insulation+metal decking }\end{array}$ & $\begin{array}{l}\text { Reference: } \\
\text { PNNL-16770: Analysis of } \\
\text { Energy Saving Impacts of } \\
\text { ASHRAE 90.1-2004 for the } \\
\text { State of New York } \\
\text { Base Assembly from } 90.1 \\
\text { Appendix A. }\end{array}$ \\
\hline $\begin{array}{l}\text { U-factor }\left(\mathrm{Btu} / \mathrm{h} * \mathrm{ft}^{2} *{ }^{\circ} \mathrm{F}\right) \text { and/or } \\
\mathrm{R} \text {-value }\left(\mathrm{h} * \mathrm{ft}^{2} *{ }^{\circ} \mathrm{F} / \mathrm{Btu}\right)\end{array}$ & $\begin{array}{l}\text { ASHRAE 90.1 Requirements } \\
\text { Residential; Roofs, Insulation entirely above deck }\end{array}$ & ASHRAE 90.1 \\
\hline Dimensions & based on floor area and aspect ratio & \\
\hline Tilts and orientations & horizontal & \\
\hline \multicolumn{3}{|l|}{ Window } \\
\hline Dimensions & based on window fraction, location, glazing sill height, floor area and aspect ratio & \\
\hline Glass-Type and frame & Hypothetical window with the exact U-factor and SHGC shown below & \\
\hline U-factor $\left(\mathrm{Btu} / \mathrm{h} * \mathrm{ft}^{2}{ }^{\circ} \mathrm{F}\right)$ & ASHRAE 90.1 Requirements & (1) \\
\hline SHGC (all) & Residential; Vertical Glazing, 10.1-20\% & ASHRAE 90.1 \\
\hline Visible transmittance & Hypothetical window with the exact U-factor and SHGC shown above & \\
\hline Operable area & $100 \%$ & \\
\hline \multicolumn{3}{|l|}{ Skylight } \\
\hline Dimensions & Not Modeled & \\
\hline Glass-Type and frame & \multirow{4}{*}{ NA } & \\
\hline U-factor $\left(\mathrm{Btu} / \mathrm{h} * \mathrm{ft}^{2}{ }^{\circ} \mathrm{F}\right)$ & & \\
\hline SHGC (all) & & \\
\hline Visible transmittance & & \\
\hline \multicolumn{3}{|l|}{ Foundation } \\
\hline Foundation Type & Slab-on-grade floors (unheated) & \\
\hline Construction & $8 "$ concrete slab poured directly on to the earth & \\
\hline $\begin{array}{l}\text { Slab-on-grade floor insulation level } \\
\text { (F-factor) }\end{array}$ & ASHRAE 90.1 Requirements & ASHRAE 90.1 \\
\hline Dimensions & based on floor area and aspect ratio & \\
\hline \multicolumn{3}{|l|}{ Interior Partitions } \\
\hline Construction & $2 \times 4$ uninsulated stud wall & \\
\hline
\end{tabular}




\begin{tabular}{|c|c|c|}
\hline Item & Descriptions & Data Source \\
\hline Dimensions & based on floor plan and floor-to-floor height & \\
\hline Internal Mass & $8 \mathrm{lbs} / \mathrm{ft} 2$ of floor area & $\begin{array}{l}\text { Reference: } \\
\text { Building America Research } \\
\text { Benchmark }\end{array}$ \\
\hline \multicolumn{3}{|l|}{ Air Barrier System } \\
\hline Infiltration $(\mathrm{ACH})$ & $0.2016 \mathrm{cfm} / \mathrm{ft}^{2}$ of gross exterior wall area at all times (at $10 \mathrm{mph}$ wind speed) & $\begin{array}{l}\text { Reference: } \\
\text { pNNL-18898. Infiltration } \\
\text { Modeling Guidelines for } \\
\text { Commercial Building } \\
\text { Energy Analysis. }\end{array}$ \\
\hline & & \\
\hline System Type & & \\
\hline Heating type & Gas Furnace & \multirow{3}{*}{$\begin{array}{l}\text { 90.1 Mechanical } \\
\text { Subcommittee }\end{array}$} \\
\hline Cooling type & Split system DX (1 per apt) & \\
\hline Distribution and terminal units & Constant volume & \\
\hline \multicolumn{3}{|l|}{ HVAC Sizing } \\
\hline Air Conditioning & autosized to design day & \\
\hline Heating & autosized to design day & \\
\hline \multicolumn{3}{|l|}{ HVAC Efficiency } \\
\hline Air Conditioning & $\begin{array}{l}\text { ASHRAE } 90.1 \text { Requirements } \\
\text { Minimum Equipment Efficiency for Air Conditioners and Condensing Units }\end{array}$ & ASHRAE 90.1 \\
\hline Heating & $\begin{array}{l}\text { ASHRAE 90.1 Requirements } \\
\text { Minimum Equipment Efficiency for Warm Air Furnaces }\end{array}$ & ASHRAE 90.1 \\
\hline \multicolumn{3}{|l|}{ HVAC Control } \\
\hline Thermostat Setpoint & $75^{\circ} \mathrm{F}$ Cooling $/ 70^{\circ} \mathrm{F}$ Heating & \\
\hline Thermostat Setback & No setback for apartments & \\
\hline Supply air temperature & Maximum $110 \mathrm{~F}$, Minimum $52 \mathrm{~F}$ & \\
\hline Economizers & ASHRAE 90.1 Requirements & ASHRAE 90.1 \\
\hline Ventilation & ASHRAE Ventilation Standard 62.1 & $\begin{array}{l}\text { SSHRAE Ventilation } \\
\text { Standard } 62.1\end{array}$ \\
\hline Demand Control Ventilation & ASHRAE 90.1 Requirements & ASHRAE 90.1 \\
\hline Energy Recovery & ASHRAE 90.1 Requirements & ASHRAE 90.1 \\
\hline \multicolumn{3}{|l|}{ Supply Fan } \\
\hline Fan schedules & See Appendix C & \\
\hline Supply Fan Total Efficiency (\%) & Depending on the fan motor size & \multirow{2}{*}{$\begin{array}{l}\text { ASHRAE 90.1 requirements } \\
\text { for motor efficiency and fan } \\
\text { power limitation }\end{array}$} \\
\hline Supply Fan Pressure Drop & Depending on the fan supply air cfm & \\
\hline \multicolumn{3}{|l|}{ Service Water Heating } \\
\hline SWH type & Individual Residential Water Heater with Storage Tank & \\
\hline
\end{tabular}




\begin{tabular}{|c|c|c|}
\hline Item & Descriptions & \multirow{2}{*}{$\begin{array}{l}\text { Data Source } \\
\text { Reference: } \\
\text { RECS } 2005\end{array}$} \\
\hline Fuel type & Electricity & \\
\hline Thermal efficiency (\%) & ASHRAE 90.1 Requirements & ASHRAE 90.1 \\
\hline Tank Volume (gal) & 20 & \multirow{3}{*}{$\begin{array}{l}\text { Reference: } \\
\text { Building America Research } \\
\text { Benchmark }\end{array}$} \\
\hline Water temperature setpoint & $120 \mathrm{~F}$ & \\
\hline Water consumption & See Appendix C & \\
\hline \multicolumn{3}{|c|}{ Internal Loads \& Schedules } \\
\hline \multicolumn{3}{|l|}{ Lighting } \\
\hline Average power density $\left(\mathrm{W} / \mathrm{ft}^{2}\right)$ & $\begin{array}{l}\text { Apartment units: } 0.36 \text { w/ft' } \text { (daily peak for hard-wired lighting) } \\
\text { Other space types: meet maximum allowed Lighting Power Densities (LPD) by ASHRAE 90.1, } \\
\text { using Space-by-Space Method }\end{array}$ & $\begin{array}{l}\text { Apartment: Building } \\
\text { America Research } \\
\text { Benchmark } \\
\text { Corridor: ASHRAE } 90.1\end{array}$ \\
\hline Schedule & See Appendix C & $\begin{array}{l}\text { Reference: } \\
\text { Building America Research } \\
\text { Benchmark }\end{array}$ \\
\hline Daylighting Controls & ASHRAE 90.1 Requirements & ASHRAE 90.1 \\
\hline Occupancy Sensors & ASHRAE 90.1 Requirements & ASHRAE 90.1 \\
\hline \multicolumn{3}{|l|}{ Plug load } \\
\hline Average power density $\left(\mathrm{W} / \mathrm{ft}^{2}\right)$ & $0.62 \mathrm{~W} / \mathrm{ft}^{2}$ daily peak per apartment, including all the home appliances & \multirow{2}{*}{$\begin{array}{l}\text { Reference: } \\
\text { Building America Research } \\
\text { Benchmark }\end{array}$} \\
\hline Schedule & See Appendix C & \\
\hline \multicolumn{3}{|l|}{ Occupancy } \\
\hline Average people & See Appendix B & \multirow{2}{*}{$\begin{array}{l}\text { Reference: } \\
\text { Building America Research } \\
\text { Benchmark }\end{array}$} \\
\hline Schedule & See Appendix C & \\
\hline \multicolumn{3}{|c|}{ Misc. } \\
\hline \multicolumn{3}{|l|}{ Elevator } \\
\hline Quantity & 1 & \multirow{4}{*}{$\begin{array}{l}\text { Reference: } \\
\text { DOE Commercial } \\
\text { Reference Building Models } \\
\text { of the National Building } \\
\text { Stock }\end{array}$} \\
\hline Motor type & hydraulic & \\
\hline $\begin{array}{l}\text { Peak Motor Power } \\
\text { (watts/elevator) }\end{array}$ & 16,055 & \\
\hline Heat Gain to Building & Interior & \\
\hline $\begin{array}{l}\text { Peak Fan/lights Power } \\
\text { (watts/elevator) }\end{array}$ & 161.9 & $\begin{array}{l}90.1 \text { Mechanical } \\
\text { Subcommittee, Elevator } \\
\text { Working Group }\end{array}$ \\
\hline Motor and fan/lights Schedules & See Appendix C & $\begin{array}{l}\text { Reference: } \\
\text { poE Commercial } \\
\text { Reference Building Models } \\
\text { of the National Building } \\
\text { Stock }\end{array}$ \\
\hline
\end{tabular}




\begin{tabular}{|l|l|l|l|}
\multicolumn{1}{|c|}{ Item } & \multicolumn{2}{c|}{ Descriptions } \\
\hline & Exterior Lighting & & \\
\hline & Peak Power $(\mathrm{W})$ & & 4,642 \\
\hline & Schedule & See Appendix C & ASHRAE 90.1 \\
\hline
\end{tabular}

References

Briggs, R.S., R.G. Lucas, and Z.T. Taylor. 2003. Climate Classification for Building Energy Codes and Standards:

Part 2-Zone Definitions, Maps, and Comparisons. ASHRAE Transactions 109(2).

Gowri K, MA Halverson, and EE Richman. 2007. Analysis of Energy Saving Impacts of ASHRAE 90.1-2004 for New York. PNNL-16770, Pacific

Northwest National Laboratory, Richland, WA. http://www.pnl.gov/main/publications/external/technical reports/PNNL-16770.pdf

Gowri K, DW Winiarski, and RE Jarnagin. 2009. Infiltration modeling guidelines for commercial building energy analysis. PNNL-18898, Pacific

Northwest National Laboratory, Richland, WA. http://www.pnl.gov/main/publications/external/technical_reports/PNNL-18898.pdf

Building America Research Benchmark. http://www1.eere.energy.gov/buildings/building_america/index.html

DOE Commercial Reference Building Models of the National Building Stock: http://www.nrel.gov/docs/fy11osti/46861.pdf

RECS 2005. EIA's Residential Energy Consumption Survey. http://www.eia.doe.gov/emeu/recs/ 


\section{A.15 High-Rise Apartment Modeling Description}

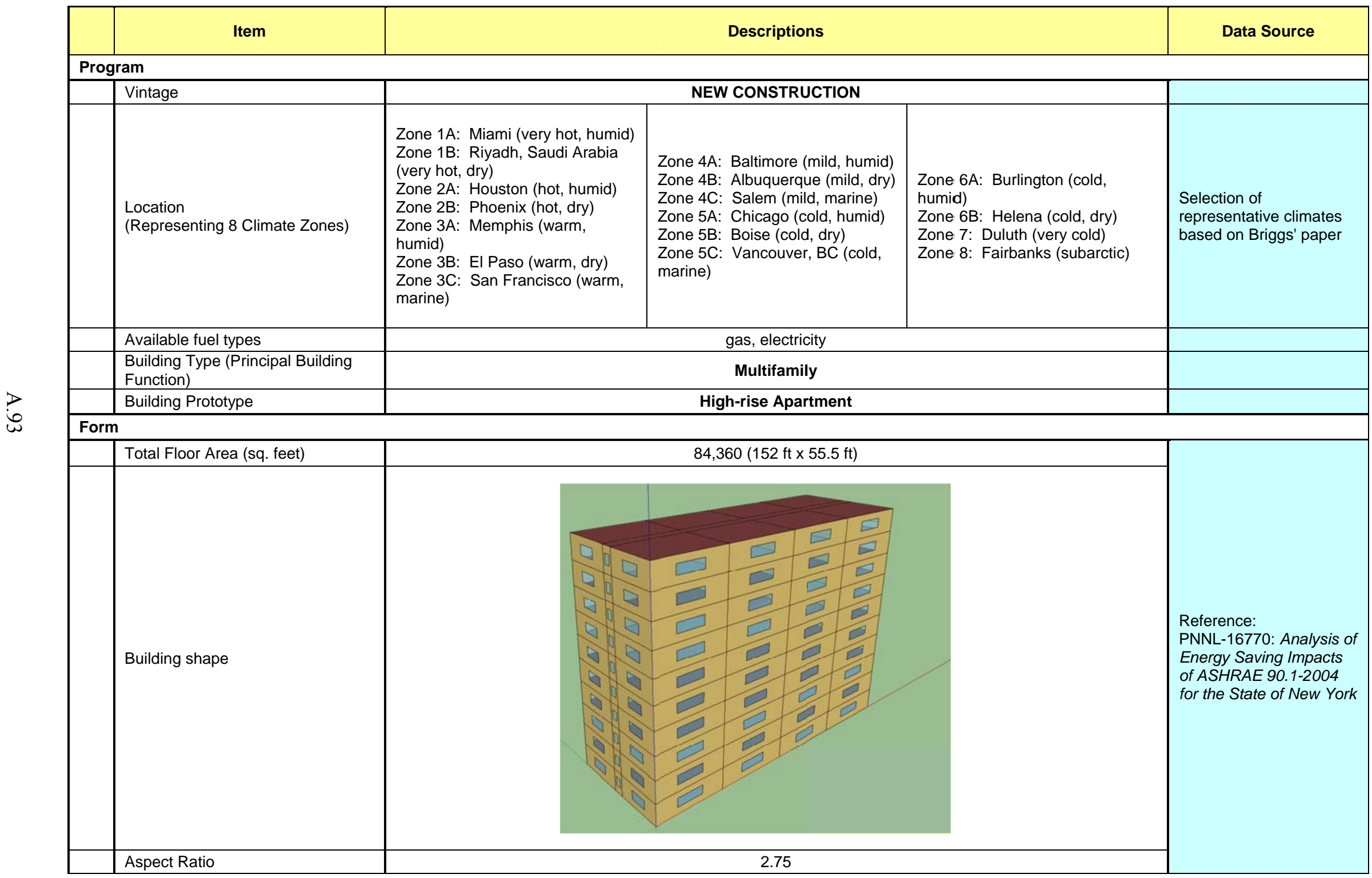




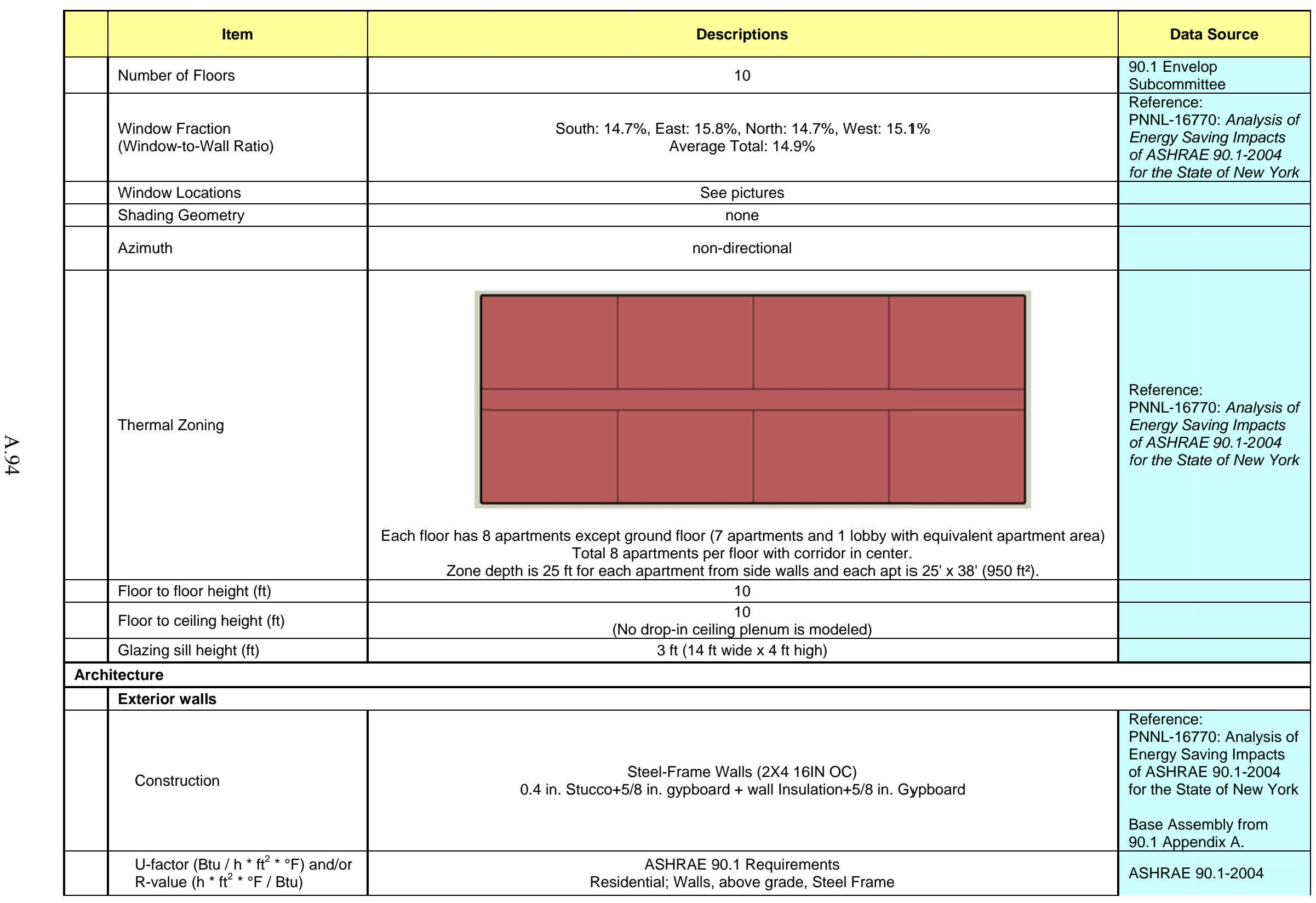




\begin{tabular}{|c|c|c|}
\hline Item & Descriptions & Data Source \\
\hline Dimensions & based on floor area and aspect ratio & \\
\hline Tilts and orientations & vertical & \\
\hline \multicolumn{3}{|l|}{ Roof } \\
\hline Construction & $\begin{array}{l}\text { Built-up Roof: } \\
\text { Roof membrane+Roof insulation+metal decking }\end{array}$ & $\begin{array}{l}\text { Reference: } \\
\text { PNNL-16770: Analysis of } \\
\text { Energy Saving Impacts } \\
\text { of ASHRAE } 90.1-2004 \\
\text { for the State of New York } \\
\text { Base Assembly from } \\
90.1 \text { Appendix A. }\end{array}$ \\
\hline $\begin{array}{l}\text { U-factor }\left(\mathrm{Btu} / \mathrm{h} * \mathrm{ft}^{2} *{ }^{\circ} \mathrm{F}\right) \text { and/or } \\
\text { R-value }\left(\mathrm{h} * \mathrm{ft}^{2} *{ }^{\circ} \mathrm{F} / \mathrm{Btu}\right)\end{array}$ & $\begin{array}{l}\text { ASHRAE 90.1 Requirements } \\
\text { Residential; Roofs, Insulation entirely above deck }\end{array}$ & ASHRAE 90.1-2004 \\
\hline Dimensions & based on floor area and aspect ratio & \\
\hline Tilts and orientations & horizontal & \\
\hline \multicolumn{3}{|l|}{ Window } \\
\hline Dimensions & based on window fraction, location, glazing sill height, floor area and aspect ratio & \\
\hline Glass-Type and frame & Hypothetical window with the exact U-factor and SHGC shown above & \\
\hline U-factor $\left(\mathrm{Btu} / \mathrm{h} * \mathrm{ft}^{2}{ }^{\circ} \mathrm{F}\right)$ & ASHRAE 90.1 Requirements & ASHRAE 90 1-2004 \\
\hline SHGC (all) & Residential; Vertical Glazing, 10.1-20\% & ASHRAE $90.1-\angle U O 4$ \\
\hline Visible transmittance & Hypothetical window with the exact U-factor and SHGC shown above & \\
\hline Operable area & $100 \%$ & \\
\hline \multicolumn{3}{|l|}{ Skylight } \\
\hline Dimensions & Not Modeled & \\
\hline Glass-Type and frame & \multirow{4}{*}{ NA } & \\
\hline U-factor $\left(\mathrm{Btu} / \mathrm{h} * \mathrm{ft}^{2} *{ }^{\circ} \mathrm{F}\right)$ & & \\
\hline SHGC (all) & & \\
\hline Visible transmittance & & \\
\hline \multicolumn{3}{|l|}{ Foundation } \\
\hline Foundation Type & Slab-on-grade floors (unheated) & \\
\hline Construction & $8 "$ concrete slab poured directly on to the earth & \\
\hline $\begin{array}{l}\text { Slab-on-grade floor insulation } \\
\text { Level (F-factor) }\end{array}$ & ASHRAE 90.1 Requirements & ASHRAE 90.1 \\
\hline Dimensions & based on floor area and aspect ratio & \\
\hline \multicolumn{3}{|l|}{ Interior Partitions } \\
\hline Construction & $2 \times 4$ uninsulated stud wall & \\
\hline
\end{tabular}




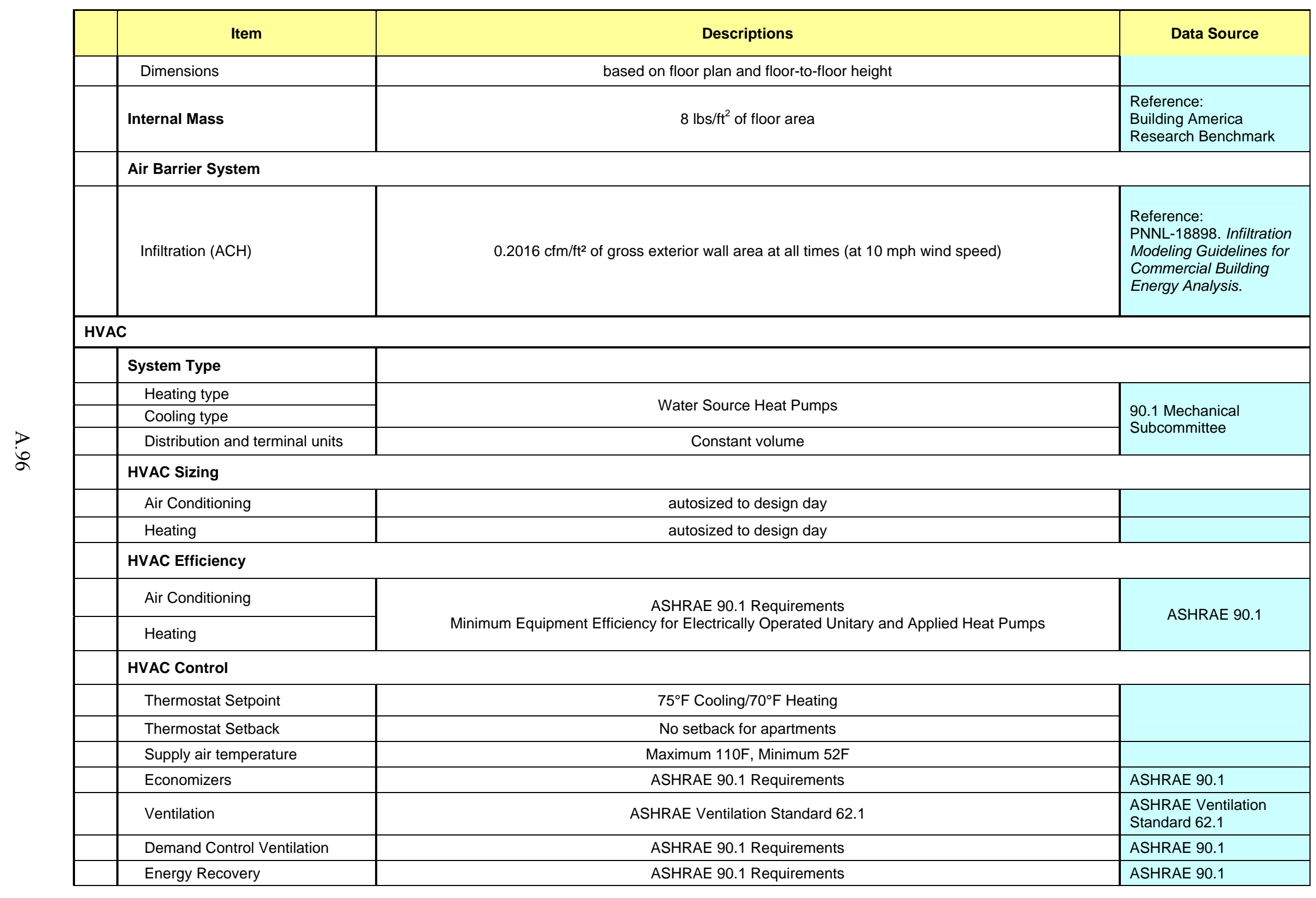




\begin{tabular}{|c|c|c|}
\hline Item & Descriptions & Data Source \\
\hline \multicolumn{3}{|l|}{ Supply Fan } \\
\hline Fan schedules & See Appendix C & \\
\hline Supply Fan Total Efficiency (\%) & Depending on the fan motor size & \multirow{2}{*}{$\begin{array}{l}\text { ASHRAE } 90.1 \\
\text { requirements for motor } \\
\text { efficiency and fan power } \\
\text { limitation }\end{array}$} \\
\hline Supply Fan Pressure Drop & Depending on the fan supply air cfm & \\
\hline \multicolumn{3}{|l|}{ Service Water Heating } \\
\hline SWH type & Individual Residential Water Heater with Storage Tank & \\
\hline Fuel type & Electricity & $\begin{array}{l}\text { Reference: } \\
\text { RECS } 2005\end{array}$ \\
\hline Thermal efficiency (\%) & ASHRAE 90.1 Requirements & ASHRAE 90.1 \\
\hline Tank Volume (gal) & 20 & \multirow{3}{*}{$\begin{array}{l}\text { Reference: } \\
\text { Building America } \\
\text { Research Benchmark }\end{array}$} \\
\hline Water temperature setpoint & $120 \mathrm{~F}$ & \\
\hline Water consumption & See Appendix C & \\
\hline \multicolumn{3}{|l|}{ Internal Loads \& Schedules } \\
\hline \multicolumn{3}{|l|}{ Lighting } \\
\hline Average power density $\left(\mathrm{W} / \mathrm{ft}^{2}\right)$ & $\begin{array}{c}\text { Apartment units: } 0.36 \text { w/ft' (daily peak for hard-wired lighting) } \\
\text { Corridor: } 0.5 \mathrm{w} / \mathrm{ft}^{2}\end{array}$ & $\begin{array}{l}\text { Apartment: Building } \\
\text { America Research } \\
\text { Benchmark } \\
\text { Corridor: 90.1-2004 }\end{array}$ \\
\hline Schedule & See Appendix C & $\begin{array}{l}\text { Reference: } \\
\text { Building America } \\
\text { Research Benchmark }\end{array}$ \\
\hline Daylighting Controls & ASHRAE 90.1 Requirements & ASHRAE 90.1 \\
\hline Occupancy Sensors & ASHRAE 90.1 Requirements & ASHRAE 90.1 \\
\hline \multicolumn{3}{|l|}{ Plug load } \\
\hline Average power density $\left(\mathrm{W} / \mathrm{ft}^{2}\right)$ & $0.62 \mathrm{~W} / \mathrm{ft}^{2}$ daily peak per apartment, including all the home appliances & \multirow{2}{*}{$\begin{array}{l}\text { Reference: } \\
\text { Building America } \\
\text { Research Benchmark }\end{array}$} \\
\hline Schedule & See Appendix C & \\
\hline \multicolumn{3}{|l|}{ Occupancy } \\
\hline Average people & See Appendix B & \multirow{2}{*}{$\begin{array}{l}\text { Reference: } \\
\text { Building America } \\
\text { Research Benchmark }\end{array}$} \\
\hline Schedule & See Appendix C & \\
\hline
\end{tabular}




\begin{tabular}{|c|c|c|}
\hline Item & Descriptions & Data Source \\
\hline \multicolumn{3}{|l|}{ Elevator } \\
\hline Quantity & 1 & \multirow{4}{*}{$\begin{array}{l}\text { Reference: } \\
\text { DOE Commercial } \\
\text { Reference Building } \\
\text { Models of the National } \\
\text { Building Stock }\end{array}$} \\
\hline Motor type & Traction & \\
\hline $\begin{array}{l}\text { Peak Motor Power } \\
\text { (watts/elevator) }\end{array}$ & 20,370 & \\
\hline Heat Gain to Building & Interior & \\
\hline $\begin{array}{l}\text { Peak Fan/lights Power } \\
\text { (watts/elevator) }\end{array}$ & 161.9 & $\begin{array}{l}90.1 \text { Mechanical } \\
\text { Subcommittee, Elevator } \\
\text { Working Group }\end{array}$ \\
\hline Motor and fan/lights Schedules & See Appendix C & $\begin{array}{l}\text { Reference: } \\
\text { DOE Commercial } \\
\text { Reference Building } \\
\text { Models of the National } \\
\text { Building Stock }\end{array}$ \\
\hline \multicolumn{3}{|l|}{ Exterior Lighting } \\
\hline Peak Power $(\mathrm{W})$ & 13,580 & ASHRAE 90.1 \\
\hline Schedule & See Appendix C & \\
\hline
\end{tabular}

\section{References}

Briggs, R.S., R.G. Lucas, and Z.T. Taylor. 2003. Climate Classification for Building Energy Codes and Standards:

Part 2-Zone Definitions, Maps, and Comparisons. ASHRAE Transactions 109(2).

Gowri K, MA Halverson, and EE Richman. 2007. Analysis of Energy Saving Impacts of ASHRAE 90.1-2004 for New York. PNNL-16770, Pacific Northwest National Laboratory, Richland, WA. http://www.pnl.gov/main/publications/external/technical_reports/PNNL-16770.pdf

Gowri K, DW Winiarski, and RE Jarnagin. 2009. Infiltration modeling guidelines for commercial building energy analysis. PNNL-18898, Pacific

Northwest National Laboratory, Richland, WA. http://www.pnl.gov/main/publications/external/technical reports/PNNL-18898.pdf

Building America Research Benchmark. http://www1.eere.energy.gov/buildings/building_america/index.html

DOE Commercial Reference Building Models of the National Building Stock: http://www.nrel.gov/docs/fy11osti/46861.pd

RECS 2005. EIA's Residential Energy Consumption Survey. http://www.eia.doe.gov/emeu/recs/ 
Appendix B

\section{Internal Load Zone Summary}




\section{B.1 Small Office Zone Summary}

\begin{tabular}{|c|c|c|c|c|c|c|c|c|c|c|}
\hline Zone & Area $\left[\mathrm{ft}^{2}\right]$ & $\begin{array}{c}\text { Conditioned } \\
{[\mathrm{Y} / \mathrm{N}]}\end{array}$ & $\begin{array}{l}\text { Volume } \\
{\left[\mathrm{ft}^{3}\right]}\end{array}$ & Multipliers & $\begin{array}{c}\text { Gross Wall } \\
\text { Area }\left[\mathrm{ft}^{2}\right]\end{array}$ & $\begin{array}{c}\text { Window } \\
\text { Glass Area } \\
{\left[\mathrm{ft}^{2}\right]}\end{array}$ & $\begin{array}{c}\text { Lighting }^{(b)} \\
{\left[\mathrm{W} / \mathrm{ft}^{2}\right]}\end{array}$ & $\begin{array}{c}\text { People } \\
{\left[\mathrm{ft}^{2} / \text { person }\right]}\end{array}$ & $\begin{array}{c}\text { Number of } \\
\text { People }\end{array}$ & $\begin{array}{c}\text { Plug and } \\
\text { Process } \\
{\left[\mathrm{W} / \mathrm{ft}^{2}\right]}\end{array}$ \\
\hline CORE_ZN & $1,611.1$ & Yes & $16,122.2$ & 1 & 0 & 0 & 1.00 & 179 & 9.0 & 0.63 \\
\hline PERIMETER_ZN_1 & $1,221.3$ & Yes & $12,221.4$ & 1 & 909.1 & 222.2 & 1.00 & 179 & 6.8 & 0.63 \\
\hline PERIMETER_ZN_2 & 724.5 & Yes & $7,249.8$ & 1 & 606.1 & 120.1 & 1.00 & 179 & 4.1 & 0.63 \\
\hline PERIMETER_ZN_3 & $1,221.3$ & Yes & $12,221.4$ & 1 & 909.1 & 180.1 & 1.00 & 179 & 6.8 & 0.63 \\
\hline PERIMETER_ZN_4 & 724.5 & Yes & $7,249.8$ & 1 & 606.1 & 120.1 & 1.00 & 179 & 4.1 & 0.63 \\
\hline ATTIC & $6,114.3$ & No & $25,437.1$ & 1 & 0 & 0 & 0 & 0 & 0 & 0 \\
\hline Total $^{(a)}$ & $5,502.6$ & & $80,501.7$ & & $3,030.3$ & 642.6 & & & 30.8 & \\
\hline Area Weighted Average & & & & & & & 1 & 179 & & 0.63 \\
\hline
\end{tabular}




\section{B.2 Medium Office Zone Summary}

\begin{tabular}{|c|c|c|c|c|c|c|c|c|c|c|}
\hline Zone & Area $\left[\mathrm{ft}^{2}\right]$ & $\begin{array}{c}\text { Conditioned } \\
{[\mathrm{Y} / \mathrm{N}]}\end{array}$ & $\begin{array}{l}\text { Volume } \\
{\left[\mathrm{ft}^{3}\right]}\end{array}$ & Multipliers & $\begin{array}{c}\text { Gross } \\
\text { Wall Area } \\
{\left[\mathrm{ft}^{2}\right]}\end{array}$ & $\begin{array}{c}\text { Window } \\
\text { Glass Area } \\
{\left[\mathrm{ft}^{2}\right]}\end{array}$ & $\begin{array}{c}\text { Lighting }^{(\mathrm{b})} \\
{\left[\mathrm{W} / \mathrm{ft}^{2}\right]}\end{array}$ & $\begin{array}{c}\text { People } \\
{\left[\mathrm{ft}^{2} / \text { person }\right]}\end{array}$ & $\begin{array}{c}\text { Number of } \\
\text { People }\end{array}$ & $\begin{array}{l}\text { Plug and } \\
\text { Process } \\
{\left[\mathrm{W} / \mathrm{ft}^{2}\right]}\end{array}$ \\
\hline CORE_BOTTOM & $10,587.8$ & Yes & $95,294.8$ & 1 & $\overline{0}$ & 0 & 1 & 200 & 53 & 0.75 \\
\hline TOPFLOOR_PLENUM & $17,877.8$ & Yes & $71,514.5$ & 1 & $2,183.6$ & 0 & 0 & 0 & 0 & 0.75 \\
\hline MIDFLOOR_PLENUM & $17,877.8$ & Yes & $71,514.5$ & 1 & $2,183.6$ & 0 & 0 & 0 & 0 & 0.75 \\
\hline FIRSTFLOOR_PLENUM & $17,877.8$ & Yes & $71,514.5$ & 1 & $2,183.6$ & 0 & 0 & 0 & 0 & 0.75 \\
\hline CORE_MID & $10,587.8$ & Yes & $95,294.8$ & 1 & 0 & 0 & 1 & 200 & 53 & 0.75 \\
\hline CORE_TOP & $10,587.8$ & Yes & $95,294.8$ & 1 & 0 & 0 & 1 & 200 & 53 & 0.75 \\
\hline PERIMETER_TOP_ZN_3 & $2,232.0$ & Yes & $20,089.0$ & 1 & $1,473.9$ & 702.7 & 1 & 200 & 11 & 0.75 \\
\hline PERIMETER_TOP_ZN_2 & $1,413.0$ & Yes & $12,718.0$ & 1 & 982.6 & 468.5 & 1 & 200 & 7 & 0.75 \\
\hline PERIMETER_TOP_ZN_1 & $2,232.0$ & Yes & $20,089.0$ & 1 & $1,473.9$ & 702.7 & 1 & 200 & 11 & 0.75 \\
\hline PERIMETER_TOP_ZN_4 & $1,412.9$ & Yes & $12,717.0$ & 1 & 982.6 & 468.5 & 1 & 200 & 7 & 0.75 \\
\hline PERIMETER_BOT_ZN_3 & $2,232.0$ & Yes & $20,089.0$ & 1 & $1,473.9$ & 702.7 & 1 & 200 & 11 & 0.75 \\
\hline PERIMETER_BOT_ZN_2 & $1,413.0$ & Yes & $12,718.0$ & 1 & 982.6 & 468.5 & 1 & 200 & 7 & 0.75 \\
\hline PERIMETER_BOT_ZN_1 & $2,232.0$ & Yes & $20,089.0$ & 1 & $1,473.9$ & 702.7 & 1 & 200 & 11 & 0.75 \\
\hline PERIMETER_BOT_ZN_4 & $1,412.9$ & Yes & $12,717.0$ & 1 & 982.6 & 468.5 & 1 & 200 & 7 & 0.75 \\
\hline PERIMETER_MID_ZN_3 & $2,232.0$ & Yes & $20,089.0$ & 1 & $1,473.9$ & 702.7 & 1 & 200 & 11 & 0.75 \\
\hline PERIMETER_MID_ZN_2 & $1,413.0$ & Yes & $12,718.0$ & 1 & 982.6 & 468.5 & 1 & 200 & 7 & 0.75 \\
\hline PERIMETER_MID_ZN_1 & $2,232.0$ & Yes & $20,089.0$ & 1 & $1,473.9$ & 702.7 & 1 & 200 & 11 & 0.75 \\
\hline PERIMETER_MID_ZN_4 & $1,412.9$ & Yes & $12,717.0$ & 1 & 982.6 & 468.5 & 1 & 200 & 7 & 0.75 \\
\hline Total $^{(a)}$ & $53,633.3$ & & $697,266.6$ & & $21,290.2$ & $7,027.4$ & & & 268.2 & \\
\hline Area Weighted Average & & & & & & & 1 & 200 & & 0.75 \\
\hline
\end{tabular}

(a) Only volume, and gross wall area include unconditioned space.

(b) 90.1-2004 baseline requirements for LPD 


\section{B.3 Large Office Zone Summary}

\begin{tabular}{|c|c|c|c|c|c|c|c|c|c|c|}
\hline Zone & Area $\left[\mathrm{ft}^{2}\right]$ & $\begin{array}{c}\text { Conditioned } \\
{[\mathrm{Y} / \mathrm{N}]}\end{array}$ & $\begin{array}{c}\text { Volume } \\
{\left[\mathrm{ft}^{3}\right]}\end{array}$ & Multipliers & $\begin{array}{c}\text { Gross Wall } \\
\text { Area }\left[\mathrm{ft}^{2}\right]\end{array}$ & $\begin{array}{c}\text { Window } \\
\text { Glass Area } \\
{\left[\mathrm{ft}^{2}\right]}\end{array}$ & $\begin{array}{l}\text { Lighting }^{(b)} \\
{\left[\mathrm{W} / \mathrm{ft}^{2}\right]}\end{array}$ & $\begin{array}{c}\text { People } \\
{\left[\mathrm{ft}^{2} / \text { person }\right]}\end{array}$ & $\begin{array}{l}\text { Number of } \\
\text { People }\end{array}$ & $\begin{array}{c}\text { Plug and } \\
\text { Process } \\
{\left[\mathrm{W} / \mathrm{ft}^{2}\right]}\end{array}$ \\
\hline BASEMENT & $38,339.1$ & Yes & $306,709.3$ & 1 & 0 & 0 & 1.0 & 199.9 & 192 & 0.45 \\
\hline CORE_BOTTOM & $27,247.8$ & Yes & $245,238.7$ & 1 & 0 & 0 & 1.0 & 199.9 & 136 & 0.75 \\
\hline CORE_MID & $27,247.8$ & Yes & $245,238.7$ & 10 & 0 & 0 & 1.0 & 199.9 & 136 & 0.75 \\
\hline CORE_TOP & $27,247.8$ & Yes & $245,238.7$ & 1 & 0 & 0 & 1.0 & 199.9 & 136 & 0.75 \\
\hline PERIMETER_BOT_ZN_3 & $3,372.3$ & Yes & $30,351.8$ & 1 & $2,158.6$ & $1,247.1$ & 1.0 & 199.9 & 17 & 0.75 \\
\hline PERIMETER_BOT_ZN_2 & $2,173.3$ & Yes & $19,560.0$ & 1 & $1,439.0$ & 831.4 & 1.0 & 199.9 & 11 & 0.75 \\
\hline PERIMETER_BOT_ZN_1 & $3,372.4$ & Yes & $30,352.5$ & 1 & $2,158.6$ & $1,247.1$ & 1.0 & 199.9 & 17 & 0.75 \\
\hline PERIMETER_BOT_ZN_4 & $2,173.3$ & Yes & $19,560.0$ & 1 & $1,439.0$ & 831.4 & 1.0 & 199.9 & 11 & 0.75 \\
\hline PERIMETER_MID_ZN_3 & $3,372.3$ & Yes & $30,351.8$ & 10 & $2,158.6$ & $1,247.1$ & 1.0 & 199.9 & 17 & 0.75 \\
\hline PERIMETER_MID_ZN_2 & $2,173.3$ & Yes & $19,560.0$ & 10 & $1,439.0$ & 831.4 & 1.0 & 199.9 & 11 & 0.75 \\
\hline PERIMETER_MID_ZN_1 & $3,372.4$ & Yes & $30,352.5$ & 10 & $2,158.6$ & $1,247.1$ & 1.0 & 199.9 & 17 & 0.75 \\
\hline PERIMETER_MID_ZN_4 & $2,173.3$ & Yes & $19,560.0$ & 10 & $1,439.0$ & 831.4 & 1.0 & 199.9 & 11 & 0.75 \\
\hline PERIMETER_TOP_ZN_3 & $3,372.3$ & Yes & $30,351.8$ & 1 & $2,158.6$ & $1,247.1$ & 1.0 & 199.9 & 17 & 0.75 \\
\hline PERIMETER_TOP_ZN_2 & $2,173.3$ & Yes & $19,560.0$ & 1 & $1,439.0$ & 831.4 & 1.0 & 199.9 & 11 & 0.75 \\
\hline PERIMETER_TOP_ZN_1 & $3,372.4$ & Yes & $30,352.5$ & 1 & $2,158.6$ & $1,247.1$ & 1.0 & 199.9 & 17 & 0.75 \\
\hline PERIMETER_TOP_ZN_4 & $2,173.3$ & Yes & $19,560.0$ & 1 & $1,439.0$ & 831.4 & 1.0 & 199.9 & 11 & 0.75 \\
\hline GROUNDFLOOR_PLENUM & $38,339.1$ & No & $153,316.9$ & 1 & $3,196.9$ & 0 & 0 & 0 & 0 & 0 \\
\hline MIDFLOOR_PLENUM & $38,339.1$ & No & $153,316.9$ & 10 & $3,196.9$ & 0 & 0 & 0 & 0 & 0 \\
\hline TOPFLOOR_PLENUM & $38,339.1$ & No & $153,316.9$ & 1 & $3,196.9$ & 0 & 0 & 0 & 0 & 0 \\
\hline Total $^{(a)}$ & $498,407.8$ & & $6,287,267.6$ & & $124,705.4$ & $49,884.2$ & & & $2,493.0$ & \\
\hline Area Weighted Average & & & & & & & 1.0 & 199.9 & & 0.727 \\
\hline
\end{tabular}

(a) Only volume, and gross wall area include unconditioned space. Total area and volume include multiplier of zone area and zone volume from Multipliers column (b) 90.1-2004 baseline requirements for LPD 


\section{B.4 Stand-alone Retail Zone Summary}

\begin{tabular}{|c|c|c|c|c|c|c|c|c|c|c|}
\hline Zone & Area $\left[\mathrm{ft}^{2}\right]$ & $\begin{array}{c}\text { Conditioned } \\
{[\mathrm{Y} / \mathrm{N}]}\end{array}$ & $\begin{array}{l}\text { Volume } \\
{\left[\mathrm{ft}^{3}\right]}\end{array}$ & Multipliers & $\begin{array}{c}\text { Gross Wall } \\
\text { Area }\left[\mathrm{ft}^{2}\right]\end{array}$ & $\begin{array}{c}\text { Window } \\
\text { Glass Area } \\
{\left[\mathrm{ft}^{2}\right]}\end{array}$ & $\begin{array}{l}\text { Lighting }^{(b)} \\
{\left[\mathrm{W} / \mathrm{ft}^{2}\right]}\end{array}$ & $\begin{array}{c}\text { People } \\
{\left[\mathrm{ft}^{2} / \text { person }\right]}\end{array}$ & $\begin{array}{l}\text { Number of } \\
\text { People }\end{array}$ & $\begin{array}{c}\text { Plug and } \\
\text { Process } \\
{\left[\mathrm{W} / \mathrm{ft}^{2}\right]}\end{array}$ \\
\hline BACK_SPACE & 4,089 & Yes & 81,836 & 1 & 4,480 & 0 & 0.8 & 66.6 & 61 & 0.7 \\
\hline CORE_RETAIL & 17,227 & Yes & 344,775 & 1 & 3,841 & 0 & 1.7 & 66.6 & 259 & 0.3 \\
\hline POINT_OF_SALE & 1,623 & Yes & 32,487 & 1 & 2,043 & 410 & 1.7 & 66.6 & 24 & 2.0 \\
\hline FRONT_RETAIL & 1,623 & Yes & 32,487 & 1 & 2,043 & 410 & 1.7 & 66.6 & 24 & 0.3 \\
\hline FRONT_ENTRY & 129 & Yes & 2,585 & 1 & 262 & 84 & 1.3 & 66.6 & 2 & 0 \\
\hline Total $^{(a)}$ & 24,692 & & 494,171 & & 12,669 & & & & 371 & \\
\hline Area Weighted Average & & & & & & & 179.5 & 66.6 & & 0.5 \\
\hline
\end{tabular}

(a) Only volume, and gross wall area include unconditioned space.

(b) 90.1-2004 baseline requirements for LPD 


\section{B.5 Strip Mall Zone Summary}

\begin{tabular}{|c|c|c|c|c|c|c|c|c|c|c|}
\hline Zone & Area $\left[\mathrm{ft}^{2}\right]$ & $\begin{array}{c}\text { Conditioned } \\
{[\mathrm{Y} / \mathrm{N}]}\end{array}$ & $\begin{array}{c}\text { Volume } \\
{\left[\mathrm{ft}^{3}\right]}\end{array}$ & Multipliers & $\begin{array}{c}\text { Gross Wall } \\
\text { Area }\left[\mathrm{ft}^{2}\right]\end{array}$ & $\begin{array}{c}\text { Window } \\
\text { Glass Area } \\
{\left[\mathrm{ft}^{2}\right]}\end{array}$ & $\begin{array}{l}\text { Lighting }^{(b)} \\
{\left[\mathrm{W} / \mathrm{ft}^{2}\right]}\end{array}$ & $\begin{array}{c}\text { People } \\
{\left[\mathrm{ft}^{2} / \text { person }\right]}\end{array}$ & $\begin{array}{c}\text { Number of } \\
\text { People }\end{array}$ & $\begin{array}{c}\text { Plug and } \\
\text { Process } \\
{\left[\mathrm{W} / \mathrm{ft}^{2}\right]}\end{array}$ \\
\hline LGSTORE1 & 3,750 & Yes & 63,750 & 1 & 2,974 & 223 & 2.28 & 125 & 30 & 0.40 \\
\hline SMSTORE1 & 1,875 & Yes & 31,875 & 1 & 850 & 112 & 2.28 & 125 & 15 & 0.40 \\
\hline SMSTORE2 & 1,875 & Yes & 31,875 & 1 & 850 & 111 & 1.70 & 125 & 15 & 0.40 \\
\hline SMSTORE3 & 1,875 & Yes & 31,875 & 1 & 850 & 111 & 1.70 & 125 & 15 & 0.40 \\
\hline SMSTORE4 & 1,875 & Yes & 31,875 & 1 & 850 & 111 & 1.70 & 125 & 15 & 0.40 \\
\hline LGSTORE2 & 3,750 & Yes & 63,750 & 1 & 1,700 & 223 & 1.30 & 125 & 30 & 0.40 \\
\hline SMSTORE5 & 1,875 & Yes & 31,875 & 1 & 850 & 111 & 1.30 & 125 & 15 & 0.40 \\
\hline SMSTORE6 & 1,875 & Yes & 31,875 & 1 & 850 & 111 & 1.30 & 125 & 15 & 0.40 \\
\hline SMSTORE7 & 1,875 & Yes & 31,875 & 1 & 850 & 111 & 1.30 & 125 & 15 & 0.40 \\
\hline SMSTORE8 & 1,875 & Yes & 31,875 & 1 & 2,124 & 111 & 1.30 & 125 & 15 & 0.40 \\
\hline Total $^{(a)}$ & 22,500 & & 382,500 & & 12,746 & 1338 & & & 180 & \\
\hline Area Weighted Average & & & & & & & 1.64 & 125 & & 0.40 \\
\hline
\end{tabular}

(a) Only volume, and gross wall area include unconditioned space.

(b) 90.1-2004 baseline requirements for LPD 


\section{B.6 Primary School Zone Summary}

\begin{tabular}{|c|c|c|c|c|c|c|c|c|c|c|}
\hline Zone Name & Area $\left[\mathrm{ft}^{2}\right]$ & $\begin{array}{c}\text { Conditioned } \\
{[\mathrm{Y} / \mathrm{N}]}\end{array}$ & $\begin{array}{c}\text { Volume } \\
{\left[\mathrm{ft}^{3}\right]}\end{array}$ & Multipliers & $\begin{array}{c}\text { Gross Wall } \\
\text { Area }\left[\mathrm{ft}^{2}\right]\end{array}$ & $\begin{array}{c}\text { Window } \\
\text { Glass Area } \\
{\left[\mathrm{ft}^{2}\right]}\end{array}$ & $\begin{array}{c}\text { Lighting }^{(b)} \\
{\left[\mathrm{W} / \mathrm{ft}^{2}\right]}\end{array}$ & $\begin{array}{c}\text { People } \\
{\left[\mathrm{ft}^{2} / \text { person }\right]}\end{array}$ & $\begin{array}{l}\text { Number } \\
\text { of People }\end{array}$ & $\begin{array}{c}\text { Plug and } \\
\text { Process } \\
{\left[\mathrm{W} / \mathrm{ft}^{2}\right]}\end{array}$ \\
\hline CORNER_CLASS_1_POD_1_ZN_1_FLR_1 & 1,066 & Yes & 13,987 & 1 & 861 & 301 & 1.40 & 40 & 27 & 1.39 \\
\hline MULT_CLASS_1_POD_1_ZN_1_FLR_1 & 5,135 & Yes & 67,390 & 1 & 2,282 & 799 & 1.40 & 40 & 128 & 1.39 \\
\hline CORRIDOR_POD_1_ZN_1_FLR_1 & 2,067 & Yes & 27,126 & 1 & 129 & 45 & 0.50 & 0 & 0 & 0.37 \\
\hline CORNER_CLASS_2_POD_1_ZN_1_FLR_1 & 1,066 & Yes & 13,987 & 1 & 861 & 301 & 1.40 & 40 & 27 & 1.39 \\
\hline MULT_CLASS_2_POD_1_ZN_1_FLR_1 & 5,135 & Yes & 67,390 & 1 & 2,282 & 799 & 1.40 & 40 & 128 & 1.39 \\
\hline CORNER_CLASS_1_POD_2_ZN_1_FLR_1 & 1,066 & Yes & 13,987 & 1 & 861 & 301 & 1.40 & 40 & 27 & 1.39 \\
\hline MULT_CLASS_1_POD_2_ZN_1_FLR_1 & 5,135 & Yes & 67,390 & 1 & 2,282 & 799 & 1.40 & 40 & 128 & 1.39 \\
\hline CORRIDOR_POD_2_ZN_1_FLR_1 & 2,067 & Yes & 27,126 & 1 & 129 & 45 & 0.50 & 0 & 0 & 0.37 \\
\hline CORNER_CLASS_2_POD_2_ZN_1_FLR_1 & 1,066 & Yes & 13,987 & 1 & 861 & 301 & 1.40 & 40 & 27 & 1.39 \\
\hline MULT_CLASS_2_POD_2_ZN_1_FLR_1 & 5,135 & Yes & 67,390 & 1 & 2,282 & 799 & 1.40 & 40 & 128 & 1.39 \\
\hline CORNER_CLASS_1_POD_3_ZN_1_FLR_1 & 1,066 & Yes & 13,987 & 1 & 861 & 301 & 1.40 & 40 & 27 & 1.39 \\
\hline MULT_CLASS_1_POD_33ZN_1_FLR_1 & 5,135 & Yes & 67,390 & 1 & 2,282 & 799 & 1.40 & 40 & 128 & 1.39 \\
\hline CORRIDOR_POD_3_ZN_1_FLR_1 & 2,067 & Yes & 27,126 & 1 & 129 & 45 & 0.50 & 0 & 0 & 0.37 \\
\hline CORNER_CLASS_2_POD_3_ZN_1_FLR_1 & 1,066 & Yes & 13,987 & 1 & 861 & 301 & 1.40 & 40 & 27 & 1.39 \\
\hline MULT_CLASS_2_POD_3_ZN_1_FLR_1 & 3,391 & Yes & 44,503 & 1 & 1,507 & 527 & 1.40 & 40 & 85 & 1.39 \\
\hline COMPUTER_CLASS_ZN_1_FLR_1 & 1,744 & Yes & 22,887 & 1 & 775 & 271 & 1.40 & 40 & 44 & 1.86 \\
\hline MAIN_CORRIDOR_ZN_1_FLR_1 & 5,878 & Yes & 77,139 & 1 & 388 & 136 & 0.50 & 0 & 0 & 0.37 \\
\hline LOBBY_ZN_1_FLR_1 & 1,841 & Yes & 24,159 & 1 & 818 & 286 & 1.30 & 0 & 0 & 0.37 \\
\hline MECH_ZN_1_FLR_1 & 2,713 & Yes & 35,602 & 1 & 0 & 0 & 1.50 & 0 & 0 & 0.93 \\
\hline BATH_ZN_1_FLR_1 & 2,045 & Yes & 26,843 & 1 & 431 & 151 & 0.90 & 0 & 0 & 0.37 \\
\hline OFFICES_ZN_1_FLR_1 & 4,747 & Yes & 62,304 & 1 & 1,809 & 633 & 1.10 & 200 & 24 & 1.00 \\
\hline GYM_ZN_1_FLR_1 & 3,843 & Yes & 50,437 & 1 & 732 & 400 & 1.40 & 33 & 115 & 0.46 \\
\hline KITCHEN_ZN_1_FLR_1 & 1,809 & Yes & 23,735 & 1 & 344 & 121 & 1.20 & 67 & 27 & 151.11 \\
\hline CAFETERIA_ZN_1_FLR_1 & 3,391 & Yes & 44,503 & 1 & 1,550 & 543 & 0.90 & 10 & 339 & 2.36 \\
\hline LIBRARY_MEDIA_CENTER_ZN_1_FLR_1 & 4,295 & Yes & 56,370 & 1 & 1,722 & 603 & 1.30 & 100 & 43 & 1.39 \\
\hline Total $^{(a)}$ & 73,966 & & 970,730 & & 27,042 & 9,609 & & & 1,477 & \\
\hline Area Weighted Average & & & & & & & 1.19 & 42.62 & & 4.80 \\
\hline
\end{tabular}

(a) Only volume, and gross wall area include unconditioned space.

(b) 90.1-2004 baseline requirements for LPD 


\section{B.7 Secondary School Zone Summary}

\begin{tabular}{|c|c|c|c|c|c|c|c|c|c|c|}
\hline Zone Name & Area $\left[\mathrm{ft}^{2}\right]$ & $\begin{array}{c}\text { Conditioned } \\
{[\mathrm{Y} / \mathrm{N}]}\end{array}$ & $\begin{array}{c}\text { Volume } \\
{\left[\mathrm{ft}^{3}\right]}\end{array}$ & Multipliers & $\begin{array}{c}\text { Gross Wall } \\
\text { Area }\left[\mathrm{ft}^{2}\right]\end{array}$ & $\begin{array}{c}\text { Window } \\
\text { Glass Area } \\
{\left[\mathrm{ft}^{2}\right]}\end{array}$ & $\begin{array}{c}\text { Lighting }^{(b)} \\
{\left[\mathrm{W} / \mathrm{ft}^{2}\right]}\end{array}$ & $\begin{array}{c}\text { People } \\
{\left[\mathrm{ft}^{2} / \text { person }\right]}\end{array}$ & $\begin{array}{l}\text { Number } \\
\text { of People }\end{array}$ & $\begin{array}{c}\text { Plug and } \\
\text { Process } \\
{\left[\mathrm{W} / \mathrm{ft}^{2}\right]}\end{array}$ \\
\hline CORNER_CLASS_1_POD_1_ZN_1_FLR_1 & 1,066 & Yes & 13,987 & 1 & 861 & 301 & 1.4 & 28.5 & 37 & 0.9 \\
\hline CORNER_CLASS_1_POD_1_ZN_1_FLR_2 & 1,066 & Yes & 13,987 & 1 & 861 & 301 & 1.4 & 28.5 & 37 & 0.9 \\
\hline MULT_CLASS_1_POD_1_ZN_1_FLR_1 & 5,135 & Yes & 67,390 & 1 & 2,282 & 799 & 1.4 & 28.5 & 180 & 0.9 \\
\hline MULT_CLASS_1_POD_1_ZN_1_FLR_2 & 5,135 & Yes & 67,390 & 1 & 2,282 & 799 & 1.4 & 28.5 & 180 & 0.9 \\
\hline CORRIDOR_POD_1_ZN_1_FLR_1 & 3,445 & Yes & 45,209 & 1 & 215 & 75 & 0.5 & 0 & 0 & 0.4 \\
\hline CORRIDOR_POD_1_ZN_1_FLR_2 & 3,445 & Yes & 45,209 & 1 & 215 & 75 & 0.5 & 0 & 0 & 0.4 \\
\hline CORNER_CLASS_2_POD_1_ZN_1_FLR_1 & 1,066 & Yes & 13,987 & 1 & 861 & 301 & 1.4 & 28.5 & 37 & 0.9 \\
\hline CORNER_CLASS_2_POD_1_ZN_1_FLR_2 & 1,066 & Yes & 13,987 & 1 & 861 & 301 & 1.4 & 28.5 & 37 & 0.9 \\
\hline MULT_CLASS_2_POD_1_ZN_1_FLR_1 & 5,135 & Yes & 67,390 & 1 & 2,282 & 799 & 1.4 & 28.5 & 180 & 0.9 \\
\hline MULT_CLASS_2_POD_1_ZN_1_FLR_2 & 5,135 & Yes & 67,390 & 1 & 2,282 & 799 & 1.4 & 28.5 & 180 & 0.9 \\
\hline CORNER_CLASS_1_POD_2_ZN_1_FLR_1 & 1,066 & Yes & 13,987 & 1 & 861 & 301 & 1.4 & 28.5 & 37 & 0.9 \\
\hline CORNER_CLASS_1_POD_2_ZN_1_FLR_2 & 1,066 & Yes & 13,987 & 1 & 861 & 301 & 1.4 & 28.5 & 37 & 0.9 \\
\hline MULT_CLASS_1_POD_2_ZN_1_FLR_1 & 5,135 & Yes & 67,390 & 1 & 2,282 & 799 & 1.4 & 28.5 & 180 & 0.9 \\
\hline MULT_CLASS_1_POD_2_ZN_1_FLR_2 & 5,135 & Yes & 67,390 & 1 & 2,282 & 799 & 1.4 & 28.5 & 180 & 0.9 \\
\hline CORRIDOR_POD_2_ZN_1_FLR_1 & 3,445 & Yes & 45,209 & 1 & 215 & 75 & 0.5 & 0 & 0 & 0.4 \\
\hline CORRIDOR_POD_2_ZN_1_FLR_2 & 3,445 & Yes & 45,209 & 1 & 215 & 75 & 0.5 & 0 & 0 & 0.4 \\
\hline CORNER_CLASS_2_POD_2_ZN_1_FLR_1 & 1,066 & Yes & 13,987 & 1 & 861 & 301 & 1.4 & 28.5 & 37 & 0.9 \\
\hline CORNER_CLASS_2_POD_2_ZN_1_FLR_2 & 1,066 & Yes & 13,987 & 1 & 861 & 301 & 1.4 & 28.5 & 37 & 0.9 \\
\hline MULT_CLASS_2_POD_2_ZN_1_FLR_1 & 5,135 & Yes & 67,390 & 1 & 2,282 & 799 & 1.4 & 28.5 & 180 & 0.9 \\
\hline MULT_CLASS_2_POD_2_ZN_1_FLR_2 & 5,135 & Yes & 67,390 & 1 & 2,282 & 799 & 1.4 & 28.5 & 180 & 0.9 \\
\hline CORNER_CLASS_1_POD_3_ZN_1_FLR_1 & 1,066 & Yes & 13,987 & 1 & 861 & 301 & 1.4 & 28.5 & 37 & 0.9 \\
\hline CORNER_CLASS_1_POD_3_ZN_1_FLR_2 & 1,066 & Yes & 13,987 & 1 & 861 & 301 & 1.4 & 28.5 & 37 & 0.9 \\
\hline MULT_CLASS_1_POD_3_ZN_1_FLR_1 & 5,135 & Yes & 67,390 & 1 & 2,282 & 799 & 1.4 & 28.5 & 180 & 0.9 \\
\hline MULT_CLASS_1_POD_3_ZN_1_FLR_2 & 5,135 & Yes & 67,390 & 1 & 2,282 & 799 & 1.4 & 28.5 & 180 & 1.9 \\
\hline CORRIDOR_POD_3_ZN_1_FLR_1 & 3,445 & Yes & 45,209 & 1 & 215 & 75 & 0.5 & 0 & 0 & 0.4 \\
\hline CORRIDOR_POD_3_ZN_1_FLR_2 & 3,445 & Yes & 45,209 & 1 & 215 & 75 & 0.5 & 0 & 0 & 0.4 \\
\hline CORNER_CLASS_2_POD_3_ZN_1_FLR_1 & 1,066 & Yes & 13,987 & 1 & 861 & 301 & 1.4 & 28.5 & 37 & 0.9 \\
\hline CORNER_CLASS_2_POD_3_ZN_1_FLR_2 & 1,066 & Yes & 13,987 & 1 & 861 & 301 & 1.4 & 28.5 & 37 & 0.9 \\
\hline MULT_CLASS_2_POD_3_ZN_1_FLR_1 & 5,135 & Yes & 67,390 & 1 & 2,282 & 799 & 1.4 & 28.5 & 180 & 0.9 \\
\hline MULT_CLASS_2_POD_3_ZN_1_FLR_2 & 5,135 & Yes & 67,390 & 1 & 2,282 & 799 & 1.4 & 28.5 & 180 & 1.9 \\
\hline MAIN_CORRIDOR_ZN_1_FLR_1 & 12,272 & Yes & 161,057 & 1 & 2,153 & 527 & 0.5 & 0 & 0 & 0.4 \\
\hline MAIN_CORRIDOR_ZN_1_FLR_2 & 12,272 & Yes & 161,057 & 1 & 2,153 & 527 & 0.5 & 0 & 0 & 0.4 \\
\hline LOBBY_ZN_1_FLR_1 & 2,261 & Yes & 29,668 & 1 & 646 & 226 & 1.3 & 0 & 0 & 0.4 \\
\hline
\end{tabular}




\begin{tabular}{|c|c|c|c|c|c|c|c|c|c|c|}
\hline Zone Name & Area $\left[\mathrm{ft}^{2}\right]$ & $\begin{array}{c}\text { Conditioned } \\
{[\mathrm{Y} / \mathrm{N}]}\end{array}$ & $\begin{array}{c}\text { Volume } \\
{\left[\mathrm{ft}^{3}\right]}\end{array}$ & Multipliers & $\begin{array}{c}\text { Gross Wall } \\
\text { Area }\left[\mathrm{ft}^{2}\right]\end{array}$ & $\begin{array}{c}\text { Window } \\
\text { Glass Area } \\
{\left[\mathrm{ft}^{2}\right]}\end{array}$ & $\begin{array}{c}\text { Lighting }^{(b)} \\
{\left[\mathrm{W} / \mathrm{ft}^{2}\right]}\end{array}$ & $\begin{array}{c}\text { People } \\
{\left[\mathrm{ft}^{2} / \text { person }\right]}\end{array}$ & $\begin{array}{c}\text { Number } \\
\text { of People }\end{array}$ & $\begin{array}{c}\text { Plug and } \\
\text { Process } \\
{\left[\mathrm{W} / \mathrm{ft}^{2}\right]}\end{array}$ \\
\hline LOBBY_ZN_1_FLR_2 & 2,261 & Yes & 29,668 & 1 & 646 & 226 & 1.3 & 0 & 0 & 0.4 \\
\hline BATHROOMS_ZN_1_FLR_1 & 2,261 & Yes & 29,668 & 1 & 1,249 & 271 & 0.9 & 0 & 0 & 0.4 \\
\hline BATHROOMS_ZN_1_FLR_2 & 2,261 & Yes & 29,668 & 1 & 1,249 & 271 & 0.9 & 0 & 0 & 0.4 \\
\hline OFFICES_ZN_1_FLR_1 & 5,727 & Yes & 75,160 & 1 & 2,239 & 784 & 1.1 & 200.0 & 29 & 1.0 \\
\hline OFFICES_ZN_1_FLR_2 & 5,727 & Yes & 75,160 & 1 & 2,239 & 784 & 1.1 & 200.0 & 29 & 1.0 \\
\hline GYM_ZN_1_FLR_1 & 21,272 & Yes & 558,330 & 1 & 0 & 864 & 1.4 & 33.4 & 637 & 0.5 \\
\hline AUX_GYM_ZN_1_FLR_1 & 13,435 & Yes & 352,630 & 1 & 6,545 & 2,867 & 1.4 & 33.4 & 403 & 0.5 \\
\hline AUDITORIUM_ZN_1_FLR_1 & 10,636 & Yes & 279,165 & 1 & 5,512 & 1,145 & 0.9 & 6.7 & 1,594 & 0.5 \\
\hline KITCHEN_ZN_1_FLR_1 & 2,325 & Yes & 30,516 & 1 & 388 & 136 & 1.2 & 66.4 & 35 & 177.0 \\
\hline LIBRARY_MEDIA_CENTER_ZN_1_FLR_2 & 9,043 & Yes & 118,673 & 1 & 2,541 & 894 & 1.3 & 100.0 & 90 & 0.9 \\
\hline CAFETERIA_ZN_1_FLR_1 & 6,717 & Yes & 88,157 & 1 & 2,153 & 754 & 0.9 & 10.0 & 671 & 7.1 \\
\hline MECH_ZN_1_FLR_1 & 3,682 & Yes & 48,317 & 1 & 0 & 0 & 1.5 & 0 & 0 & 9.2 \\
\hline MECH_ZN_1_FLR_2 & 3,682 & Yes & 48,317 & 1 & 0 & 0 & 1.5 & 0 & 0 & 0.4 \\
\hline Total $^{(a)}$ & 210,907 & & $3,362,978$ & & 68,723 & 23,931 & & & 6,096 & \\
\hline Area Weighted Average & & & & & & & 1.13 & 32.09 & & 3.01 \\
\hline
\end{tabular}

(a) Only volume, and gross wall area include unconditioned space.

(b) 90.1-2004 baseline requirements for LPD 


\section{B.8 Outpatient Healthcare Zone Summary}

\begin{tabular}{|c|c|c|c|c|c|c|c|c|c|c|}
\hline Zone & $\begin{array}{l}\text { Area } \\
{\left[\mathrm{ft}^{2}\right]}\end{array}$ & $\begin{array}{c}\text { Conditioned } \\
{[\mathrm{Y} / \mathrm{N}]}\end{array}$ & $\begin{array}{c}\text { Volume } \\
{\left[\mathrm{ft}^{3}\right]}\end{array}$ & Multipliers & $\begin{array}{c}\text { Gross Wall } \\
\text { Area }\left[\mathrm{ft}^{2}\right]\end{array}$ & $\begin{array}{c}\text { Window Glass } \\
\text { Area }\left[\mathrm{ft}^{2}\right]\end{array}$ & $\begin{array}{c}\text { Lighting }^{(\mathrm{b})} \\
{\left[\mathrm{W} / \mathrm{ft}^{2}\right]}\end{array}$ & $\begin{array}{c}\text { People }{ }^{(\mathrm{b})} \\
{\left[\mathrm{ft}^{2} / \text { person }\right]}\end{array}$ & $\begin{array}{l}\text { Number of } \\
\text { People }\end{array}$ & $\begin{array}{c}\text { Plug and } \\
\text { Process } \\
{\left[\mathrm{W} / \mathrm{ft}^{2}\right]}\end{array}$ \\
\hline Floor 1 Anesthesia & 108 & Yes & 1,080 & 1 & 90 & 24 & 1.50 & 50 & 2 & 2.0 \\
\hline Floor 1 Bio Haz & 56 & Yes & 560 & 1 & 0 & 0 & 0.90 & 0 & 0 & 0.1 \\
\hline Floor 1 Café & 420 & Yes & 4,200 & 1 & 200 & 96 & 0.90 & 10 & 42 & 1.0 \\
\hline Floor 1 Clean & 126 & Yes & 1,260 & 1 & 0 & 0 & 1.50 & 50 & 3 & 2.0 \\
\hline Floor 1 Clean Work & 165 & Yes & 1,650 & 1 & 0 & 0 & 1.50 & 50 & 3 & 2.0 \\
\hline Floor 1 Dictation & 126 & Yes & 1,260 & 1 & 0 & 0 & 1.10 & 200 & 1 & 1.1 \\
\hline Floor 1 Dressing Room & 45 & Yes & 450 & 1 & 90 & 25 & 1.10 & 200 & 0 & 1.1 \\
\hline Floor 1 Electrical Room & 98 & Yes & 980 & 1 & 70 & 0 & 1.50 & 0 & 0 & 5.0 \\
\hline Floor 1 Elevator Pump Room & 91 & Yes & 910 & 1 & 200 & 0 & 1.50 & 0 & 0 & 534.6 \\
\hline Floor 1 Humid & 54 & Yes & 540 & 1 & 0 & 0 & 1.10 & 200 & 0 & 1.1 \\
\hline Floor 1 IT Hall & 140 & Yes & 1,400 & 1 & 0 & 0 & 1.00 & 0 & 0 & 0.4 \\
\hline Floor 1 IT Room & 112 & Yes & 1,120 & 1 & 0 & 0 & 1.10 & 200 & 1 & 1.1 \\
\hline Floor 1 Lobby & 622 & Yes & 6,220 & 1 & 220 & 96 & 1.30 & 100 & 6 & 1.1 \\
\hline Floor 1 Lobby Hall & 240 & Yes & 2,400 & 1 & 0 & 0 & 1.00 & 0 & 0 & 0.4 \\
\hline Floor 1 Lobby Toilet & 54 & Yes & 540 & 1 & 60 & 0 & 0.90 & 0 & 0 & 0.4 \\
\hline Floor 1 Locker Room & 660 & Yes & 6,600 & 1 & 220 & 60 & 0.80 & 67 & 10 & 3.0 \\
\hline Floor 1 Locker Room Hall & 496 & Yes & 4,960 & 1 & 0 & 0 & 1.00 & 0 & 0 & 0.4 \\
\hline Floor 1 Lounge & 360 & Yes & 3,600 & 1 & 0 & 0 & 0.80 & 67 & 5 & 3.0 \\
\hline Floor 1 Med Gas & 56 & Yes & 560 & 1 & 150 & 0 & 0.90 & 0 & 0 & 0.1 \\
\hline Floor 1 MRI Control Room & 168 & Yes & 1,680 & 1 & 50 & 0 & 0.40 & 50 & 3 & 10.0 \\
\hline Floor 1 MRI Hall & 147 & Yes & 1,470 & 1 & 0 & 0 & 1.00 & 0 & 0 & 0.4 \\
\hline Floor 1 MRI Room & 440 & Yes & 4,400 & 1 & 0 & 0 & 0.40 & 50 & 9 & 10.0 \\
\hline Floor 1 MRI Toilet & 54 & Yes & 540 & 1 & 60 & 0 & 0.90 & 0 & 0 & 0.4 \\
\hline Floor 1 Nourishment & 182 & Yes & 1,820 & 1 & 0 & 0 & 1.00 & 50 & 4 & 2.0 \\
\hline Floor 1 Nurse Hall & 496 & Yes & 4,960 & 1 & 0 & 0 & 1.00 & 0 & 0 & 0.4 \\
\hline Floor 1 Nurse Janitor & 54 & Yes & 540 & 1 & 0 & 0 & 0.90 & 0 & 0 & 0.1 \\
\hline Floor 1 Nurse Station & 261 & Yes & 2,610 & 1 & 0 & 0 & 1.00 & 50 & 5 & 2.0 \\
\hline Floor 1 Nurse Toilet & 54 & Yes & 540 & 1 & 0 & 0 & 0.90 & 0 & 0 & 0.4 \\
\hline Floor 1 Office & 483 & Yes & 4,830 & 1 & 0 & 0 & 1.10 & 200 & 2 & 1.1 \\
\hline Floor 1 Operating Room 1 & 460 & Yes & 4,600 & 1 & 430 & 96 & 2.20 & 50 & 9 & 11.0 \\
\hline Floor 1 Operating Room 2 & 480 & Yes & 4,800 & 1 & 240 & 72 & 2.20 & 50 & 10 & 11.0 \\
\hline Floor 1 Operating Room 3 & 476 & Yes & 4,760 & 1 & 0 & 0 & 2.20 & 50 & 10 & 11.0 \\
\hline Floor 1 PACU & 108 & Yes & 1,080 & 1 & 0 & 0 & 0.80 & 50 & 2 & 3.0 \\
\hline
\end{tabular}




\begin{tabular}{|c|c|c|c|c|c|c|c|c|c|c|}
\hline Zone & $\begin{array}{l}\text { Area } \\
{\left[\mathrm{ft}^{2}\right]}\end{array}$ & $\begin{array}{c}\text { Conditioned } \\
{[\mathrm{Y} / \mathrm{N}]}\end{array}$ & $\begin{array}{c}\text { Volume } \\
{\left[\mathrm{ft}^{3}\right]}\end{array}$ & Multipliers & $\begin{array}{c}\text { Gross Wall } \\
\text { Area }\left[\mathrm{ft}^{2}\right]\end{array}$ & $\begin{array}{c}\text { Window Glass } \\
\text { Area }\left[\mathrm{ft}^{2}\right]\end{array}$ & $\begin{array}{l}\text { Lighting }^{(b)} \\
{\left[\mathrm{W} / \mathrm{ft}^{2}\right]}\end{array}$ & $\begin{array}{c}\text { People }^{(\mathrm{b})} \\
{\left[\mathrm{ft}^{2} / \text { person }\right]}\end{array}$ & $\begin{array}{c}\text { Number of } \\
\text { People }\end{array}$ & $\begin{array}{l}\text { Plug and } \\
\text { Process } \\
{\left[\mathrm{W} / \mathrm{ft}^{2}\right]}\end{array}$ \\
\hline Floor 1 Pre-Op Hall & 528 & Yes & 5,280 & 1 & 0 & 0 & 1.00 & 0 & 0 & 0.4 \\
\hline Floor 1 Pre-Op Room 1 & 189 & Yes & 1,890 & 1 & 40 & 0 & 0.70 & 100 & 2 & 2.0 \\
\hline Floor 1 Pre-Op Room 2 & 338 & Yes & 3,380 & 1 & 0 & 0 & 0.70 & 100 & 3 & 2.0 \\
\hline Floor 1 Pre-Op Toilet & 54 & Yes & 540 & 1 & 60 & 0 & 0.90 & 0 & 0 & 0.4 \\
\hline Floor 1 Procedure Room & 285 & Yes & 2,850 & 1 & 190 & 60 & 2.70 & 50 & 6 & 3.0 \\
\hline Floor 1 Reception & 509 & Yes & 5,090 & 1 & 130 & 36 & 1.30 & 33 & 15 & 1.1 \\
\hline Floor 1 Reception Hall & 128 & Yes & 1,280 & 1 & 0 & 0 & 1.00 & 0 & 0 & 0.4 \\
\hline Floor 1 Recovery Room & 540 & Yes & 5,400 & 1 & 450 & 96 & 0.80 & 50 & 11 & 3.0 \\
\hline Floor 1 Scheduling & 119 & Yes & 1,190 & 1 & 70 & 8 & 1.10 & 200 & 1 & 1.1 \\
\hline Floor 1 Scrub & 84 & Yes & 840 & 1 & 0 & 0 & 1.00 & 0 & 0 & 0.4 \\
\hline Floor 1 Soil & 126 & Yes & 1,260 & 1 & 0 & 0 & 1.50 & 50 & 3 & 2.0 \\
\hline Floor 1 Soil Hold & 56 & Yes & 560 & 1 & 0 & 0 & 1.50 & 50 & 1 & 2.0 \\
\hline Floor 1 Soil Work & 180 & Yes & 1,800 & 1 & 0 & 0 & 1.50 & 50 & 4 & 2.0 \\
\hline Floor 1 Step Down & 300 & Yes & 3,000 & 1 & 370 & 72 & 0.80 & 50 & 6 & 3.0 \\
\hline Floor 1 Sterile Hall & 616 & Yes & 6,160 & 1 & 80 & 24 & 1.00 & 0 & 0 & 0.4 \\
\hline Floor 1 Sterile Storage & 396 & Yes & 3,960 & 1 & 0 & 0 & 0.90 & 0 & 0 & 0.1 \\
\hline Floor 1 Storage & 920 & Yes & 9,200 & 1 & 630 & 90 & 0.90 & 0 & 0 & 0.1 \\
\hline Floor 1 Sub-Sterile & 196 & Yes & 1,960 & 1 & 140 & 32 & 1.00 & 0 & 0 & 0.4 \\
\hline Floor 1 Utility Hall & 256 & Yes & 2,560 & 1 & 160 & 0 & 1.00 & 0 & 0 & 0.4 \\
\hline Floor 1 Utility Janitor & 42 & Yes & 420 & 1 & 0 & 0 & 0.90 & 0 & 0 & 0.1 \\
\hline Floor 1 Utility Room & 360 & Yes & 3,600 & 1 & 180 & 24 & 0.90 & 0 & 0 & 0.1 \\
\hline Floor 1 Vestibule & 72 & Yes & 720 & 1 & 80 & 0 & 1.00 & 0 & 0 & 0.4 \\
\hline Floor 2 Conference & 336 & Yes & 3,360 & 1 & 400 & 96 & 1.30 & 20 & 17 & 1.0 \\
\hline Floor 2 Conference Toilet & 64 & Yes & 640 & 1 & 0 & 0 & 0.90 & 0 & 0 & 0.4 \\
\hline Floor 2 Dictation & 70 & Yes & 700 & 1 & 0 & 0 & 1.10 & 200 & 0 & 1.1 \\
\hline Floor 2 Exam 1 & 360 & Yes & 3,600 & 1 & 420 & 96 & 1.50 & 50 & 7 & 1.1 \\
\hline Floor 2 Exam 2 & 540 & Yes & 5,400 & 1 & 180 & 40 & 1.50 & 50 & 11 & 1.1 \\
\hline Floor 2 Exam 3 & 720 & Yes & 7,200 & 1 & 240 & 64 & 1.50 & 50 & 14 & 1.1 \\
\hline Floor 2 Exam 4 & 84 & Yes & 840 & 1 & 70 & 24 & 1.50 & 50 & 2 & 1.1 \\
\hline Floor 2 Exam 5 & 350 & Yes & 3,500 & 1 & 250 & 64 & 1.50 & 50 & 7 & 1.1 \\
\hline Floor 2 Exam 6 & 225 & Yes & 2,250 & 1 & 150 & 45 & 1.50 & 50 & 5 & 1.1 \\
\hline Floor 2 Exam 7 & 792 & Yes & 7,920 & 1 & 240 & 60 & 1.50 & 50 & 16 & 1.1 \\
\hline Floor 2 Exam 8 & 270 & Yes & 2,700 & 1 & 180 & 60 & 1.50 & 50 & 5 & 1.1 \\
\hline Floor 2 Exam 9 & 396 & Yes & 3,960 & 1 & 120 & 30 & 1.50 & 50 & 8 & 1.1 \\
\hline Floor 2 Exam Hall 1 & 180 & Yes & 1,800 & 1 & 60 & 0 & 1.00 & 0 & 0 & 0.4 \\
\hline
\end{tabular}




\begin{tabular}{|c|c|c|c|c|c|c|c|c|c|c|}
\hline Zone & $\begin{array}{l}\text { Area } \\
{\left[\mathrm{ft}^{2}\right]}\end{array}$ & $\begin{array}{c}\text { Conditioned } \\
{[\mathrm{Y} / \mathrm{N}]}\end{array}$ & $\begin{array}{l}\text { Volume } \\
{\left[\mathrm{ft}^{3}\right]}\end{array}$ & Multipliers & $\begin{array}{l}\text { Gross Wall } \\
\text { Area }\left[\mathrm{ft}^{2}\right]\end{array}$ & $\begin{array}{c}\text { Window Glass } \\
\text { Area }\left[\mathrm{ft}^{2}\right]\end{array}$ & $\begin{array}{l}\text { Lighting }^{(b)} \\
{\left[\mathrm{W} / \mathrm{ft}^{2}\right]}\end{array}$ & $\begin{array}{c}\text { People }^{(\mathrm{b})} \\
{\left[\mathrm{ft}^{2} / \text { person }\right]}\end{array}$ & $\begin{array}{l}\text { Number of } \\
\text { People }\end{array}$ & $\begin{array}{l}\text { Plug and } \\
\text { Process } \\
{\left[\mathrm{W} / \mathrm{ft}^{2}\right]}\end{array}$ \\
\hline Floor 2 Exam Hall 2 & 180 & Yes & 1,800 & 1 & 60 & 0 & 1.00 & 0 & 0 & 0.4 \\
\hline Floor 2 Exam Hall 3 & 180 & Yes & 1,800 & 1 & 60 & 0 & 1.00 & 0 & 0 & 0.4 \\
\hline Floor 2 Exam Hall 4 & 198 & Yes & 1,980 & 1 & 60 & 0 & 1.00 & 0 & 0 & 0.4 \\
\hline Floor 2 Exam Hall 5 & 198 & Yes & 1,980 & 1 & 60 & 0 & 1.00 & 0 & 0 & 0.4 \\
\hline Floor 2 Exam Hall 6 & 198 & Yes & 1,980 & 1 & 60 & 0 & 1.00 & 0 & 0 & 0.4 \\
\hline Floor 2 Janitor & 63 & Yes & 630 & 1 & 160 & 0 & 0.90 & 0 & 0 & 0.1 \\
\hline Floor 2 Lounge & 80 & Yes & 800 & 1 & 0 & 0 & 0.80 & 67 & 1 & 3.0 \\
\hline Floor 2 Nurse Station 1 & 150 & Yes & 1,500 & 1 & 0 & 0 & 1.00 & 50 & 3 & 2.0 \\
\hline Floor 2 Nurse Station 2 & 180 & Yes & 1,800 & 1 & 0 & 0 & 1.00 & 50 & 4 & 2.0 \\
\hline Floor 2 Office & 560 & Yes & 5,600 & 1 & 400 & 96 & 1.10 & 200 & 3 & 1.1 \\
\hline Floor 2 Office Hall & 444 & Yes & 4,440 & 1 & 0 & 0 & 1.00 & 0 & 0 & 0.4 \\
\hline Floor 2 Reception & 984 & Yes & 9,840 & 1 & 490 & 180 & 1.30 & 33 & 29 & 1.1 \\
\hline Floor 2 Reception Hall & 564 & Yes & 5,640 & 1 & 70 & 0 & 1.00 & 0 & 0 & 0.4 \\
\hline Floor 2 Reception Toilet & 126 & Yes & 1,260 & 1 & 0 & 0 & 0.90 & 0 & 0 & 0.4 \\
\hline Floor 2 Scheduling 1 & 324 & Yes & 3,240 & 1 & 0 & 0 & 1.10 & 200 & 2 & 1.1 \\
\hline Floor 2 Scheduling 2 & 342 & Yes & 3,420 & 1 & 0 & 0 & 1.10 & 200 & 2 & 1.1 \\
\hline Floor 2 Storage 1 & 56 & Yes & 560 & 1 & 0 & 0 & 0.90 & 0 & 0 & 0.1 \\
\hline Floor 2 Storage 2 & 120 & Yes & 1,200 & 1 & 0 & 0 & 0.90 & 0 & 0 & 0.1 \\
\hline Floor 2 Storage 3 & 144 & Yes & 1,440 & 1 & 0 & 0 & 0.90 & 0 & 0 & 0.1 \\
\hline Floor 2 Utility & 126 & Yes & 1,260 & 1 & 90 & 24 & 0.90 & 0 & 0 & 0.1 \\
\hline Floor 2 Work & 1,690 & Yes & 16,900 & 1 & 260 & 60 & 1.10 & 200 & 8 & 0.9 \\
\hline Floor 2 Work Hall & 834 & Yes & 8,340 & 1 & 60 & 0 & 1.00 & 0 & 0 & 0.4 \\
\hline Floor 2 Work Toilet & 54 & Yes & 540 & 1 & 60 & 0 & 0.90 & 0 & 0 & 0.4 \\
\hline Floor 2 X-Ray & 900 & Yes & 9,000 & 1 & 0 & 0 & 0.40 & 50 & 18 & 10.0 \\
\hline Floor 3 Dressing Room & 42 & Yes & 420 & 1 & 0 & 0 & 1.10 & 200 & 0 & 1.1 \\
\hline Floor 3 Elevator Hall & 370 & Yes & 3,700 & 1 & 40 & 0 & 1.00 & 0 & 0 & 0.4 \\
\hline Floor 3 Humid & 108 & Yes & 1,080 & 1 & 0 & 0 & 1.10 & 200 & 1 & 1.1 \\
\hline Floor 3 Janitor & 63 & Yes & 630 & 1 & 160 & 0 & 0.90 & 0 & 0 & 0.1 \\
\hline Floor 3 Locker & 120 & Yes & 1,200 & 1 & 0 & 0 & 0.80 & 67 & 2 & 3.0 \\
\hline Floor 3 Lounge & 759 & Yes & 7,590 & 1 & 230 & 60 & 0.80 & 67 & 11 & 3.0 \\
\hline Floor 3 Lounge Toilet & 192 & Yes & 1,920 & 1 & 120 & 45 & 0.90 & 0 & 0 & 0.4 \\
\hline Floor 3 Mechanical & 350 & Yes & 3,500 & 1 & 250 & 64 & 1.50 & 0 & 0 & 5.0 \\
\hline Floor 3 Mechanical Hall & 300 & Yes & 3,000 & 1 & 0 & 0 & 1.00 & 0 & 0 & 0.4 \\
\hline Floor 3 Office & 3,036 & Yes & 30,360 & 1 & 740 & 210 & 1.10 & 200 & 15 & 1.1 \\
\hline Floor 3 Office Hall & 834 & Yes & 8,340 & 1 & 60 & 0 & 1.00 & 0 & 0 & 0.4 \\
\hline
\end{tabular}




\begin{tabular}{|c|c|c|c|c|c|c|c|c|c|c|}
\hline Zone & $\begin{array}{l}\text { Area } \\
{\left[\mathrm{ft}^{2}\right]}\end{array}$ & $\begin{array}{l}\text { Conditioned } \\
{[\mathrm{Y} / \mathrm{N}]}\end{array}$ & $\begin{array}{c}\text { Volume } \\
{\left[\mathrm{ft}^{3}\right]}\end{array}$ & Multipliers & $\begin{array}{c}\text { Gross Wall } \\
\text { Area }\left[\mathrm{ft}^{2}\right]\end{array}$ & $\begin{array}{c}\text { Window Glass } \\
\text { Area }\left[\mathrm{ft}^{2}\right]\end{array}$ & $\begin{array}{l}\text { Lighting }^{(b)} \\
{\left[\mathrm{W} / \mathrm{ft}^{2}\right]}\end{array}$ & $\begin{array}{c}\text { People }{ }^{(\mathrm{b})} \\
{\left[\mathrm{ft}^{2} / \text { person }\right]}\end{array}$ & $\begin{array}{l}\text { Number of } \\
\text { People }\end{array}$ & $\begin{array}{c}\text { Plug and } \\
\text { Process } \\
{\left[\mathrm{W} / \mathrm{ft}^{2}\right]}\end{array}$ \\
\hline Floor 3 Office Toilet & 54 & Yes & 540 & 1 & 60 & 0 & 0.90 & 0 & 0 & 0.4 \\
\hline Floor 3 Physical Therapy 1 & 1,300 & Yes & 13,000 & 1 & 850 & 312 & 0.90 & 50 & 26 & 1.5 \\
\hline Floor 3 Physical Therapy 2 & 592 & Yes & 5,920 & 1 & 0 & 0 & 0.90 & 50 & 12 & 1.5 \\
\hline Floor 3 Physical Therapy Toilet & 84 & Yes & 840 & 1 & 0 & 0 & 0.90 & 0 & 0 & 0.4 \\
\hline Floor 3 Storage 1 & 108 & Yes & 1,080 & 1 & 0 & 0 & 0.90 & 0 & 0 & 0.1 \\
\hline Floor 3 Storage 2 & 84 & Yes & 840 & 1 & 0 & 0 & 0.90 & 0 & 0 & 0.1 \\
\hline Floor 3 Treatment & 476 & Yes & 4,760 & 1 & 0 & 0 & 1.50 & 50 & 10 & 1.1 \\
\hline Floor 3 Undeveloped 1 & 2,268 & Yes & 22,680 & 1 & 720 & 276 & 0.90 & 0 & 0 & 1.1 \\
\hline Floor 3 Undeveloped 2 & 1,152 & Yes & 11,520 & 1 & 560 & 144 & 0.90 & 0 & 0 & 1.1 \\
\hline Floor 3 Utility & 216 & Yes & 2,160 & 1 & 0 & 0 & 0.90 & 0 & 0 & 0.1 \\
\hline Floor 3 Work & 574 & Yes & 5,740 & 1 & 410 & 96 & 1.10 & 200 & 3 & 1.1 \\
\hline NE Stair & 168 & Yes & 5,040 & 1 & 1050 & 129 & 1.00 & 0 & 0 & 0.4 \\
\hline NW Elevator & 140 & Yes & 4,200 & 1 & 810 & 0 & 1.00 & 0 & 0 & 0.4 \\
\hline NW Stair & 192 & Yes & 5,760 & 1 & 1200 & 120 & 1.00 & 0 & 0 & 0.4 \\
\hline SW Stair & 96 & Yes & 2,880 & 1 & 600 & 12 & 1.00 & 0 & 0 & 0.4 \\
\hline Total $^{(a)}$ & 40,946 & & 421,380 & & 16,719 & 3,318 & & & 419 & \\
\hline Area Weighted Average & & & & & & & 1.09 & 59.43 & & 2.97 \\
\hline
\end{tabular}

$\sim$ (a) Only volume, and gross wall area include unconditioned space.

(b) Requirements from 90.1-2004 baseline, AEDG Small Healthcare and Green Guide for Healthcare 


\section{B.9 Hospital Zone Summary}

\begin{tabular}{|c|c|c|c|c|c|c|c|c|c|c|}
\hline Zone & Area $\left[\mathrm{ft}^{2}\right]$ & $\begin{array}{c}\text { Conditioned } \\
{[\mathrm{Y} / \mathrm{N}]}\end{array}$ & $\begin{array}{c}\text { Volume } \\
{\left[\mathrm{ft}^{3}\right]}\end{array}$ & Multipliers & $\begin{array}{c}\text { Gross } \\
\text { Wall Area } \\
{\left[\mathrm{ft}^{2}\right]}\end{array}$ & $\begin{array}{c}\text { Window } \\
\text { Glass Area } \\
{\left[\mathrm{ft}^{2}\right]}\end{array}$ & $\begin{array}{l}\text { Lighting }^{(\mathrm{b})} \\
{\left[\mathrm{W} / \mathrm{ft}^{2}\right]}\end{array}$ & $\begin{array}{c}\text { People }^{2} \\
{\left[\mathrm{ft}^{2} / \text { person] }\right.}\end{array}$ & $\begin{array}{l}\text { Number } \\
\text { of People }\end{array}$ & $\begin{array}{c}\text { Plug and } \\
\text { Process } \\
{\left[\mathrm{W} / \mathrm{ft}^{2}\right]}\end{array}$ \\
\hline BASEMENT & $40,235.4$ & No & $321,832.0$ & 1 & 0 & 0 & 1.00 & 400 & 101 & 0.75 \\
\hline ER_EXAM1_MULT4_FLR_1 & 299.9 & Yes & $4,197.8$ & 4 & 280 & 0 & 2.70 & 50 & 6 & 1.50 \\
\hline ER_TRAUMA1_FLR_1 & 299.9 & Yes & $4,197.8$ & 1 & 490 & 0 & 2.70 & 50 & 6 & 4.00 \\
\hline ER_EXAM3_MULT4_FLR_1 & 299.9 & Yes & $4,197.8$ & 4 & 210 & 0 & 2.70 & 50 & 6 & 1.50 \\
\hline ER_TRAUMA2_FLR_1 & 299.9 & Yes & $4,197.8$ & 1 & 490 & 0 & 2.70 & 50 & 6 & 4.00 \\
\hline ER_TRIAGE_MULT4_FLR_1 & 299.9 & Yes & $4,197.8$ & 4 & 280 & 0 & 2.70 & 50 & 6 & 2.00 \\
\hline OFFICE1_MULT4_FLR_1 & 150.0 & Yes & $2,099.6$ & 5 & 140 & 32 & 1.10 & 143 & 1 & 1.10 \\
\hline LOBBY_RECORDS_FLR_1 & $15,869.0$ & Yes & $222,132.3$ & 1 & 4,409 & 674 & 1.27 & 750 & 21 & 0.10 \\
\hline CORRIDOR_FLR_1 & $6,122.8$ & Yes & $85,706.1$ & 1 & 980 & 0 & 1.00 & 1,000 & 6 & 0 \\
\hline ER_NURSESTN_LOBBY_FLR_1 & $13,295.2$ & Yes & $186,104.8$ & 1 & 1190 & 327 & 1.12 & 750 & 18 & 1.36 \\
\hline OR1_FLR_2 & 599.8 & Yes & $8,395.3$ & 1 & 700 & 0 & 2.20 & 200 & 3 & 4.00 \\
\hline OR2_MULT5_FLR_2 & 599.8 & Yes & $8,395.3$ & 5 & 280 & 0 & 2.20 & 200 & 3 & 4.00 \\
\hline OR3_FLR_2 & 599.8 & Yes & $8,395.3$ & 1 & 420 & 0 & 2.20 & 200 & 3 & 4.00 \\
\hline OR4_FLR_2 & $2,399.2$ & Yes & $33,583.2$ & 1 & 0 & 0 & 2.20 & 200 & 12 & 4.00 \\
\hline IC_PATROOM1_MULT5_FLR_2 & 224.9 & Yes & $3,148.0$ & 5 & 210 & 53 & 0.80 & 200 & 1 & 3.00 \\
\hline IC_PATROOM2_FLR_2 & 299.9 & Yes & $4,197.8$ & 1 & 490 & 123 & 0.80 & 200 & 1 & 3.00 \\
\hline IC_PATROOM3_MULT6_FLR_2 & 224.9 & Yes & $3,148.0$ & 6 & 210 & 53 & 0.80 & 200 & 1 & 3.00 \\
\hline ICU_FLR_2 & $6,649.2$ & Yes & $93,075.5$ & 1 & 2,310 & 269 & 0.80 & 200 & 33 & 3.00 \\
\hline ICU_NURSESTN_LOBBY_FLR_2 & $7,196.0$ & Yes & $100,728.7$ & 1 & 0 & 0 & 1.00 & 750 & 10 & 2.00 \\
\hline CORRIDOR_FLR_2 & $6,122.8$ & Yes & $85,706.1$ & 1 & 980 & 0 & 1.00 & 1,000 & 6 & 0 \\
\hline OR_NURSESTN_LOBBY_FLR_2 & $10,896.0$ & Yes & $152,521.3$ & 1 & 1,960 & 385 & 1.18 & 750 & 15 & 1.04 \\
\hline PATROOM1_MULT10_FLR_3 & 224.9 & Yes & $3,148.0$ & 10 & 210 & 53 & 0.70 & 200 & 1 & 2.00 \\
\hline PATROOM2_FLR_3 & 374.9 & Yes & $5,247.6$ & 1 & 560 & 141 & 0.70 & 200 & 2 & 2.00 \\
\hline PATROOM3_MULT10_FLR_3 & 217.5 & Yes & $3,043.9$ & 10 & 203 & 51 & 0.70 & 200 & 1 & 2.00 \\
\hline PATROOM4_FLR_3 & 374.9 & Yes & $5,247.6$ & 1 & 560 & 141 & 0.70 & 200 & 2 & 2.00 \\
\hline PATROOM5_MULT10_FLR_3 & 224.9 & Yes & $3,148.0$ & 10 & 210 & 53 & 0.70 & 200 & 1 & 2.00 \\
\hline PHYSTHERAPY_FLR_3 & $5,248.1$ & Yes & $73,462.3$ & 1 & 0 & 0 & 0.90 & 200 & 26 & 1.50 \\
\hline PATROOM6_FLR_3 & 299.9 & Yes & $4,197.8$ & 1 & 490 & 123 & 0.70 & 200 & 1 & 2.00 \\
\hline PATROOM7_MULT10_FLR_3 & 217.5 & Yes & $3,043.9$ & 10 & 203 & 51 & 0.70 & 200 & 1 & 2.00 \\
\hline PATROOM8_FLR_3 & 299.9 & Yes & $4,197.8$ & 1 & 490 & 123 & 0.70 & 200 & 1 & 2.00 \\
\hline NURSESTN_LOBBY_FLR_3 & $9,746.4$ & Yes & $136,430.5$ & 1 & 420 & 0 & 1.18 & 750 & 13 & 1.04 \\
\hline LAB_FLR_3 & $2,848.9$ & Yes & $39,854.8$ & 1 & 0 & 0 & 1.40 & 200 & 14 & 4.00 \\
\hline CORRIDOR_SE_FLR_3 & $6,097.8$ & Yes & $85,356.4$ & 1 & 490 & 0 & 1.00 & 1,000 & 6 & 0 \\
\hline
\end{tabular}




\begin{tabular}{|c|c|c|c|c|c|c|c|c|c|c|}
\hline Zone & Area $\left[\mathrm{ft}^{2}\right]$ & $\begin{array}{c}\text { Conditioned } \\
{[\mathrm{Y} / \mathrm{N}]}\end{array}$ & $\begin{array}{c}\text { Volume } \\
{\left[\mathrm{ft}^{3}\right]}\end{array}$ & Multipliers & $\begin{array}{c}\text { Gross } \\
\text { Wall Area } \\
{\left[\mathrm{ft}^{2}\right]}\end{array}$ & $\begin{array}{c}\text { Window } \\
\text { Glass Area } \\
{\left[\mathrm{ft}^{2}\right]}\end{array}$ & $\begin{array}{c}\text { Lighting }^{(b)} \\
{\left[\mathrm{W} / \mathrm{ft}^{2}\right]}\end{array}$ & $\begin{array}{c}\text { People }^{2} \\
{\left[\mathrm{ft}^{2} / \text { person] }\right.}\end{array}$ & $\begin{array}{l}\text { Number } \\
\text { of People }\end{array}$ & $\begin{array}{c}\text { Plug and } \\
\text { Process } \\
{\left[\mathrm{W} / \mathrm{ft}^{2}\right]}\end{array}$ \\
\hline CORRIDOR_NW_FLR_3 & $6,097.8$ & Yes & $85,356.4$ & 1 & 907 & 0 & 1.00 & 1,000 & 6 & 0 \\
\hline PATROOM1_MULT10_FLR_4 & 224.9 & Yes & $3,148.0$ & 10 & 210 & 53 & 0.70 & 200 & 1 & 2.00 \\
\hline PATROOM2_FLR_4 & 374.9 & Yes & $5,247.6$ & 1 & 560 & 141 & 0.70 & 200 & 2 & 2.00 \\
\hline PATROOM3_MULT10_FLR_4 & 217.5 & Yes & $3,043.9$ & 10 & 203 & 51 & 0.70 & 200 & 1 & 2.00 \\
\hline PATROOM4_FLR_4 & 374.9 & Yes & $5,247.6$ & 1 & 560 & 141 & 0.70 & 200 & 2 & 2.00 \\
\hline PATROOM5_MULT10_FLR_4 & 224.9 & Yes & $3,148.0$ & 10 & 210 & 53 & 0.70 & 200 & 1 & 2.00 \\
\hline RADIOLOGY_FLR_4 & $5,248.1$ & Yes & $73,462.3$ & 1 & 0 & 0 & 0.40 & 200 & 26 & 10.00 \\
\hline PATROOM6_FLR_4 & 299.9 & Yes & $4,197.8$ & 1 & 490 & 123 & 0.70 & 200 & 1 & 2.00 \\
\hline PATROOM7_MULT10_FLR_4 & 217.5 & Yes & $3,043.9$ & 10 & 203 & 51 & 0.70 & 200 & 1 & 2.00 \\
\hline PATROOM8_FLR_4 & 299.9 & Yes & $4,197.8$ & 1 & 490 & 123 & 0.70 & 200 & 1 & 2.00 \\
\hline NURSESTN_LOBBY_FLR_4 & $9,746.4$ & Yes & $136,429.4$ & 1 & 420 & 0 & 1.18 & 750 & 13 & 1.04 \\
\hline LAB_FLR_4 & $2,848.9$ & Yes & $39,854.8$ & 1 & 0 & 0 & 1.40 & 200 & 14 & 4.00 \\
\hline CORRIDOR_SE_FLR_4 & $6,097.8$ & Yes & $85,356.4$ & 1 & 490 & 0 & 1.00 & 1,000 & 6 & 0 \\
\hline CORRIDOR_NW_FLR_4 & $6,097.8$ & Yes & $85,356.4$ & 1 & 907 & 0 & 1.00 & 1,000 & 6 & 0 \\
\hline DINING_FLR_5 & $7,497.2$ & Yes & $104,946.6$ & 1 & 2,450 & 385 & 0.90 & 100 & 75 & 1.00 \\
\hline NURSESTN_LOBBY_FLR_5 & $11,195.9$ & Yes & $156,720.1$ & 1 & 1,120 & 0 & 1.18 & 750 & 15 & 1.04 \\
\hline KITCHEN_FLR_5 & $9,996.4$ & Yes & $139,928.2$ & 1 & 2,800 & 0 & 1.20 & 200 & 50 & 22.63 \\
\hline OFFICE1_FLR_5 & 750.0 & Yes & $10,498.0$ & 1 & 770 & 193 & 1.10 & 143 & 5 & 1.00 \\
\hline OFFICE2_MULT5_FLR_5 & 749.8 & Yes & $10,494.9$ & 5 & 350 & 88 & 1.10 & 143 & 5 & 1.00 \\
\hline OFFICE3_FLR_5 & 749.8 & Yes & $10,494.9$ & 1 & 770 & 193 & 1.10 & 143 & 5 & 1.00 \\
\hline OFFICE4_MULT6_FLR_5 & 150.0 & Yes & $2,099.6$ & 6 & 140 & 32 & 1.10 & 143 & 1 & 1.00 \\
\hline CORRIDOR_FLR_5 & $5,398.1$ & Yes & $75,561.9$ & 1 & 840 & 0 & 1.00 & 1,000 & 5 & 0 \\
\hline Total $^{(a)}$ & $241,412.5$ & & $3,137,849.2$ & & 57,598 & 9,130 & & & 767 & \\
\hline Area Weighted Average & & & & & & & 1.09 & 542.86 & & 2.22 \\
\hline
\end{tabular}




\section{B.10 Small Hotel Zone Summary}

\begin{tabular}{|c|c|c|c|c|c|c|c|c|c|c|}
\hline Zone & Area $\left[\mathrm{ft}^{2}\right]$ & $\begin{array}{l}\text { Conditioned } \\
{[\mathrm{Y} / \mathrm{N}]}\end{array}$ & $\begin{array}{c}\text { Volume } \\
{\left[\mathrm{ft}^{3}\right]}\end{array}$ & Multipliers & $\begin{array}{c}\text { Gross Wall } \\
\text { Area }\left[\mathrm{ft}^{2}\right]\end{array}$ & $\begin{array}{c}\text { Window Glass } \\
\text { Area }\left[\mathrm{ft}^{2}\right]\end{array}$ & $\begin{array}{c}\text { Lighting }^{(b)} \\
{\left[\mathrm{W} / \mathrm{ft}^{2}\right]}\end{array}$ & $\begin{array}{c}\text { People } \\
{\left[\mathrm{ft}^{2} / \text { person }\right]}\end{array}$ & $\begin{array}{l}\text { Number of } \\
\text { People }\end{array}$ & $\begin{array}{c}\text { Plug and } \\
\text { Process }\left[\mathrm{W} / \mathrm{ft}^{2}\right]\end{array}$ \\
\hline REARSTAIRSFLR1 & 216 & Yes & 2,375 & 1 & 385 & 0 & 0.60 & 0 & 0 & 0 \\
\hline CORRIDORFLR1 & 1,620 & Yes & 17,809 & 1 & 352 & 106 & 0.50 & 0 & 0 & 0 \\
\hline REARSTORAGEFLR1 & 216 & No & 2,375 & 1 & 385 & 0 & 0.80 & 0 & 0 & 0 \\
\hline FRONTLOUNGEFLR1 & 1,755 & Yes & 19,295 & 1 & 1,012 & 160 & 1.10 & 33 & 53 & 2.42 \\
\hline RESTROOMFLR1 & 351 & Yes & 3,859 & 1 & 143 & 0 & 0.90 & 351 & 1 & 0 \\
\hline MEETINGROOMFLR1 & 864 & Yes & 9,499 & 1 & 352 & 53 & 1.30 & 20 & 43 & 0.57 \\
\hline MECHANICALROOMFLR1 & 351 & Yes & 3,859 & 1 & 143 & 0 & 1.50 & 0 & 0 & 0 \\
\hline GUESTROOM101 & 351 & Yes & 3,859 & 1 & 143 & 18 & 1.10 & 234 & 2 & 1.11 \\
\hline GUESTROOM102 & 351 & Yes & 3,859 & 1 & 143 & 18 & 1.10 & 234 & 2 & 1.11 \\
\hline GUESTROOM103 & 351 & Yes & 3,859 & 1 & 143 & 18 & 1.10 & 234 & 2 & 1.11 \\
\hline GUESTROOM104 & 351 & Yes & 3,859 & 1 & 143 & 18 & 1.10 & 234 & 2 & 1.11 \\
\hline GUESTROOM105 & 351 & Yes & 3,859 & 1 & 143 & 18 & 1.10 & 234 & 2 & 1.11 \\
\hline EMPLOYEELOUNGEFLR1 & 351 & Yes & 3,859 & 1 & 143 & 18 & 1.20 & 19 & 18 & 2.00 \\
\hline LAUNDRYROOMFLR1 & 1,053 & No & 11,576 & 1 & 429 & 53 & 0.60 & 96 & 11 & 40.67 \\
\hline ELEVATORCOREFLR1 & 162 & No & 1,781 & 1 & 66 & 0 & 0 & 0 & 0 & 200.28 \\
\hline EXERCISECENTERFLR1 & 351 & Yes & 3,859 & 1 & 143 & 18 & 0.90 & 50 & 7 & 1.73 \\
\hline FRONTOFFICEFLR1 & 1,404 & Yes & 15,435 & 1 & 572 & 71 & 1.10 & 140 & 10 & 1.28 \\
\hline FRONTSTAIRSFLR1 & 216 & Yes & 2,374 & 1 & 385 & 0 & 0.60 & 0 & 0 & 0 \\
\hline FRONTSTORAGEFLR1 & 135 & No & 1,484 & 1 & 55 & 0 & 0.80 & 0 & 0 & 0 \\
\hline REARSTAIRSFLR2 & 216 & Yes & 1,943 & 1 & 315 & 0 & 0.60 & 0 & 0 & 0 \\
\hline CORRIDORFLR2 & 1,350 & Yes & 12,142 & 1 & 198 & 28 & 0.50 & 0 & 0 & 0 \\
\hline REARSTORAGEFLR2 & 216 & No & 1,944 & 1 & 315 & 0 & 0.80 & 0 & 0 & 0 \\
\hline GUESTROOM201 & 351 & Yes & 3,157 & 1 & 360 & 18 & 1.10 & 234 & 2 & 1.11 \\
\hline GUESTROOM202_205 & 1,404 & Yes & 12,629 & 1 & 468 & 71 & 1.10 & 234 & 6 & 1.11 \\
\hline GUESTROOM206_208 & 1,134 & Yes & 10,200 & 1 & 378 & 72 & 1.10 & 252 & 5 & 1.11 \\
\hline GUESTROOM209_212 & 1,404 & Yes & 12,629 & 1 & 468 & 71 & 1.10 & 234 & 6 & 1.11 \\
\hline GUESTROOM213 & 351 & Yes & 3,157 & 1 & 117 & 18 & 1.10 & 234 & 2 & 1.11 \\
\hline GUESTROOM214 & 351 & Yes & 3,157 & 1 & 117 & 18 & 1.10 & 234 & 2 & 1.11 \\
\hline GUESTROOM215_218 & 1,404 & Yes & 12,628 & 1 & 468 & 71 & 1.10 & 234 & 6 & 1.11 \\
\hline ELEVATORCOREFLR2 & 162 & No & 1,457 & 1 & 54 & 0 & 0 & 0 & 0 & 0 \\
\hline GUESTROOM219 & 351 & Yes & 3,157 & 1 & 117 & 18 & 1.10 & 234 & 2 & 1.11 \\
\hline GUESTROOM220_223 & 1,404 & Yes & 12,628 & 1 & 468 & 71 & 1.10 & 234 & 6 & 1.11 \\
\hline GUESTROOM224 & 351 & Yes & 3,157 & 1 & 117 & 18 & 1.10 & 234 & 2 & 1.11 \\
\hline FRONTSTORAGEFLR2 & 135 & No & 1,214 & 1 & 45 & 0 & 0.80 & 0 & 0 & 0 \\
\hline FRONTSTAIRSFLR2 & 216 & Yes & 1,943 & 1 & 315 & 0 & 0.60 & 0 & 0 & 0 \\
\hline
\end{tabular}




\begin{tabular}{|c|c|c|c|c|c|c|c|c|c|c|}
\hline Zone & Area $\left[\mathrm{ft}^{2}\right]$ & $\begin{array}{c}\text { Conditioned } \\
{[\mathrm{Y} / \mathrm{N}]}\end{array}$ & $\begin{array}{l}\text { Volume } \\
{\left[\mathrm{ft}^{3}\right]}\end{array}$ & Multipliers & $\begin{array}{c}\text { Gross Wall } \\
\text { Area }\left[\mathrm{ft}^{2}\right]\end{array}$ & $\begin{array}{c}\text { Window Glass } \\
\text { Area }\left[\mathrm{ft}^{2}\right]\end{array}$ & $\begin{array}{c}\text { Lighting }{ }^{(b)} \\
{\left[\mathrm{W} / \mathrm{ft}^{2}\right]}\end{array}$ & $\begin{array}{c}\text { People } \\
{\left[\mathrm{ft}^{2} / \text { person] }\right.}\end{array}$ & $\begin{array}{c}\text { Number of } \\
\text { People }\end{array}$ & $\begin{array}{c}\text { Plug and } \\
\text { Process }\left[\mathrm{W} / \mathrm{ft}^{2}\right]\end{array}$ \\
\hline REARSTAIRSFLR3 & 216 & Yes & 1,943 & 1 & 315 & 0 & 0.60 & 0 & 0 & 0 \\
\hline CORRIDORFLR3 & 1,350 & Yes & 12,142 & 1 & 198 & 28 & 0.50 & 0 & 0 & 0 \\
\hline REARSTORAGEFLR3 & 216 & No & 1,944 & 1 & 315 & 0 & 0.80 & 0 & 0 & 0 \\
\hline GUESTROOM301 & 351 & Yes & 3,157 & 1 & 360 & 18 & 1.10 & 234 & 2 & 1.11 \\
\hline GUESTROOM302_305 & 1,404 & Yes & 12,629 & 1 & 468 & 71 & 1.10 & 234 & 6 & 1.11 \\
\hline GUESTROOM306_308 & 1,134 & Yes & 10,200 & 1 & 378 & 72 & 1.10 & 252 & 5 & 1.11 \\
\hline GUESTROOM309_312 & 1,404 & Yes & 12,629 & 1 & 468 & 71 & 1.10 & 234 & 6 & 1.11 \\
\hline GUESTROOM313 & 351 & Yes & 3,157 & 1 & 117 & 18 & 1.10 & 234 & 2 & 1.11 \\
\hline GUESTROOM314 & 351 & Yes & 3,157 & 1 & 117 & 18 & 1.10 & 234 & 2 & 1.11 \\
\hline GUESTROOM315_318 & 1,404 & Yes & 12,628 & 1 & 468 & 71 & 1.10 & 234 & 6 & 1.11 \\
\hline ELEVATORCOREFLR3 & 162 & No & 1,457 & 1 & 54 & 0 & 0 & 0 & 0 & 0 \\
\hline GUESTROOM319 & 351 & Yes & 3,157 & 1 & 117 & 18 & 1.10 & 234 & 2 & 1.11 \\
\hline GUESTROOM $320 \_323$ & 1,404 & Yes & 12,628 & 1 & 468 & 71 & 1.10 & 234 & 6 & 1.11 \\
\hline GUESTROOM324 & 351 & Yes & 3,157 & 1 & 117 & 18 & 1.10 & 234 & 2 & 1.11 \\
\hline FRONTSTORAGEFLR3 & 135 & No & 1,214 & 1 & 45 & 0 & 0.80 & 0 & 0 & 0 \\
\hline FRONTSTAIRSFLR3 & 216 & Yes & 1,943 & 1 & 315 & 0 & 0.60 & 0 & 0 & 0 \\
\hline REARSTAIRSFLR4 & 216 & Yes & 1,943 & 1 & 315 & 0 & 0.60 & 0 & 0 & 0 \\
\hline CORRIDORFLR4 & 1,350 & Yes & 12,142 & 1 & 198 & 28 & 0.50 & 0 & 0 & 0 \\
\hline REARSTORAGEFLR4 & 216 & No & 1,944 & 1 & 315 & 0 & 0.80 & 0 & 0 & 0 \\
\hline GUESTROOM401 & 351 & Yes & 3,157 & 1 & 360 & 18 & 1.10 & 234 & 2 & 1.11 \\
\hline GUESTROOM402_405 & 1,404 & Yes & 12,629 & 1 & 468 & 71 & 1.10 & 234 & 6 & 1.11 \\
\hline GUESTROOM406_408 & 1,134 & Yes & 10,200 & 1 & 378 & 72 & 1.10 & 252 & 5 & 1.11 \\
\hline GUESTROOM409_412 & 1,404 & Yes & 12,629 & 1 & 468 & 71 & 1.10 & 234 & 6 & 1.11 \\
\hline GUESTROOM413 & 351 & Yes & 3,157 & 1 & 117 & 18 & 1.10 & 234 & 2 & 1.11 \\
\hline GUESTROOM414 & 351 & Yes & 3,157 & 1 & 117 & 18 & 1.10 & 234 & 2 & 1.11 \\
\hline GUESTROOM415_418 & 1,404 & Yes & 12,628 & 1 & 468 & 71 & 1.10 & 234 & 6 & 1.11 \\
\hline ELEVATORCOREFLR4 & 162 & No & 1,457 & 1 & 54 & 0 & 0 & 0 & 0 & 0 \\
\hline GUESTROOM419 & 351 & Yes & 3,157 & 1 & 117 & 18 & 1.10 & 234 & 2 & 1.11 \\
\hline GUESTROOM420_423 & 1,404 & Yes & 12,628 & 1 & 468 & 71 & 1.10 & 234 & 6 & 1.11 \\
\hline GUESTROOM424 & 351 & Yes & 3,157 & 1 & 117 & 18 & 1.10 & 234 & 2 & 1.11 \\
\hline FRONTSTORAGEFLR4 & 135 & No & 1,214 & 1 & 45 & 0 & 0.80 & 0 & 0 & 0 \\
\hline FRONTSTAIRSFLR4 & 216 & Yes & 1,943 & 1 & 315 & 0 & 0.60 & 0 & 0 & 0 \\
\hline Total $^{(\mathrm{a})}$ & 40,101 & & 410,163 & & 18,235 & 1,983 & & & 259 & \\
\hline Area Weighted Average & & & & & & & 1.04 & 173.6 & & 2.82 \\
\hline
\end{tabular}




\section{B.11 Large Hotel Zone Summary}

\begin{tabular}{|c|c|c|c|c|c|c|c|c|c|c|}
\hline Zone & Area $\left[\mathrm{ft}^{2}\right]$ & $\begin{array}{c}\text { Conditioned } \\
{[\mathrm{Y} / \mathrm{N}]}\end{array}$ & $\begin{array}{c}\text { Volume } \\
{\left[\mathrm{ft}^{3}\right]}\end{array}$ & Multipliers & $\begin{array}{c}\text { Gross Wall } \\
\text { Area }\left[\mathrm{ft}^{2}\right]\end{array}$ & $\begin{array}{c}\text { Window Glass } \\
\text { Area }\left[\mathrm{ft}^{2}\right]\end{array}$ & $\begin{array}{c}\text { Lighting }^{(\mathrm{b})} \\
{\left[\mathrm{W} / \mathrm{ft}^{2}\right]}\end{array}$ & $\begin{array}{c}\text { People } \\
{\left[\mathrm{ft}^{2} / \text { person }\right]}\end{array}$ & $\begin{array}{l}\text { Number } \\
\text { of People }\end{array}$ & $\begin{array}{l}\text { Plug and } \\
\text { Process } \\
{\left[\mathrm{W} / \mathrm{ft}^{2}\right]}\end{array}$ \\
\hline BASEMENT & 21,300 & Yes & 170,442 & 1 & 0 & 0 & 1.00 & 400 & 106 & 0.50 \\
\hline RETAIL_1_FLR_1 & 722 & Yes & 9,385 & 1 & 741 & 251 & 1.50 & 125 & 11 & 1.00 \\
\hline RETAIL_2_FLR_1 & 836 & Yes & 10,868 & 1 & 286 & 0 & 1.50 & 125 & 13 & 1.00 \\
\hline MECH_FLR_1 & 1,768 & Yes & 22,983 & 1 & 676 & 0 & 1.50 & 0 & 0 & 0.50 \\
\hline STORAGE_FLR_1 & 1,020 & Yes & 13,259 & 1 & 390 & 0 & 0.90 & 501 & 0 & 0.25 \\
\hline LAUNDRY FLR 1 & 840 & Yes & 10,920 & 1 & 923 & 0 & 0.60 & 250 & 8 & 55.53 \\
\hline CAFE_FLR_1 & 2,033 & Yes & 26,427 & 1 & 1,638 & 706 & 1.30 & 15 & 142 & 0.50 \\
\hline LOBBY_FLR_1 & 14,081 & Yes & 183,054 & 1 & 4,680 & 918 & 1.10 & 33 & 422 & 0.75 \\
\hline ROOM_1_FLR_3 & 420 & Yes & 4,200 & 4 & 430 & 142 & 1.10 & 280 & 2 & 0.63 \\
\hline ROOM_2_FLR_3 & 420 & Yes & 4,200 & 4 & 430 & 142 & 1.10 & 280 & 2 & 0.63 \\
\hline ROOM_3_MULT19_FLR_3 & 264 & Yes & 2,640 & 76 & 120 & 40 & 1.10 & 176 & 2 & 0.98 \\
\hline ROOM_4_MULT19_FLR_3 & 264 & Yes & 2,640 & 76 & 120 & 40 & 1.10 & 176 & 2 & 0.98 \\
\hline ROOM_5_FLR_3 & 420 & Yes & 4,200 & 4 & 430 & 142 & 1.10 & 280 & 2 & 0.63 \\
\hline ROOM_6_FLR_3 & 420 & Yes & 4,200 & 4 & 430 & 142 & 1.10 & 280 & 2 & 0.63 \\
\hline CORRIDOR_FLR_3 & 4,191 & Yes & 41,915 & 4 & 520 & 172 & 0.50 & 997 & 0 & 0 \\
\hline ROOM_1_FLR_6 & 420 & Yes & 4,200 & 1 & 430 & 142 & 1.10 & 280 & 2 & 0.63 \\
\hline ROOM_2_FLR_6 & 420 & Yes & 4,200 & 1 & 430 & 142 & 1.10 & 280 & 2 & 0.63 \\
\hline ROOM_3_MULT9_FLR_6 & 264 & Yes & 2,640 & 9 & 220 & 73 & 1.10 & 176 & 2 & 0.98 \\
\hline BANQUET_FLR_6 & 3,570 & Yes & 35,699 & 1 & 1,050 & 347 & 1.30 & 15 & 250 & 6.30 \\
\hline DINING_FLR_6 & 3,570 & Yes & 35,699 & 1 & 1,050 & 347 & 1.30 & 15 & 250 & 6.30 \\
\hline KITCHEN_FLR_6 & 1,112 & Yes & 11,119 & 1 & 940 & 284 & 1.20 & 200 & 22 & 272.68 \\
\hline CORRIDOR_FLR_6 & 4,436 & Yes & 44,360 & 1 & 920 & 304 & 0.50 & 997 & 0 & 0 \\
\hline Total $^{(a)}$ & 122,115 & & $1,242,537$ & & 43,337 & 13,071 & & & 1,494 & \\
\hline Area Weighted Average & & & & & & & 1.00 & 335.69 & & 3.82 \\
\hline
\end{tabular}

(a) Only volume, and gross wall area include unconditioned space.

(b) 90.1-2004 baseline requirements for LPD 


\section{B.12 Warehouse Zone Summary}

\begin{tabular}{|c|c|c|c|c|c|c|c|c|c|c|}
\hline Zone & Area $\left[\mathrm{ft}^{2}\right]$ & $\begin{array}{c}\text { Conditioned } \\
{[\mathrm{Y} / \mathrm{N}]}\end{array}$ & $\begin{array}{l}\text { Volume } \\
{\left[\mathrm{ft}^{3}\right]}\end{array}$ & Multipliers & $\begin{array}{c}\text { Gross Wall } \\
\text { Area }\left[\mathrm{ft}^{2}\right]\end{array}$ & $\begin{array}{c}\text { Window } \\
\text { Glass Area } \\
{\left[\mathrm{ft}^{2}\right]}\end{array}$ & $\begin{array}{c}\text { Lighting }^{(b)} \\
{\left[\mathrm{W} / \mathrm{ft}^{2}\right]}\end{array}$ & $\begin{array}{c}\text { People } \\
{\left[\mathrm{ft}^{2} / \text { person }\right]}\end{array}$ & $\begin{array}{c}\text { Number of } \\
\text { People }\end{array}$ & $\begin{array}{c}\text { Plug and } \\
\text { Process } \\
{\left[\mathrm{W} / \mathrm{ft}^{2}\right]}\end{array}$ \\
\hline ZONE1 OFFICE & 2,550 & Yes & 35,700 & 1 & 1,610 & 190 & 1.0 & 510 & 5.0 & 0.75 \\
\hline ZONE2 FINE STORAGE & 15,000 & Yes & 384,300 & 1 & 8,190 & 0 & 0.8 & 0 & 0 & 0 \\
\hline ZONE3 BULK STORAGE & 34,500 & Yes & $1,245,987$ & 1 & 17,080 & 160 & 0.8 & 0 & 0 & 0.24 \\
\hline Total $^{(a)}$ & 52,050 & & $1,665,987$ & & 26,880 & 350 & & & 5 & \\
\hline Area Weighted Average & & & & & & & 0.8 & 25.0 & & 0.19 \\
\hline
\end{tabular}




\section{B.13 Quick Service Restaurant Zone Summary}

\begin{tabular}{|c|c|c|c|c|c|c|c|c|c|c|}
\hline Zone & Area $\left[\mathrm{ft}^{2}\right]$ & $\begin{array}{c}\text { Conditioned } \\
{[\mathrm{Y} / \mathrm{N}]}\end{array}$ & $\begin{array}{c}\text { Volume } \\
{\left[\mathrm{ft}^{3}\right]}\end{array}$ & Multipliers & $\begin{array}{c}\text { Gross Wall } \\
\text { Area }\left[\mathrm{ft}^{2}\right]\end{array}$ & $\begin{array}{c}\text { Window } \\
\text { Glass Area } \\
{\left[\mathrm{ft}^{2}\right]}\end{array}$ & $\begin{array}{c}\text { Lighting }^{(\mathrm{b})} \\
{\left[\mathrm{W} / \mathrm{ft}^{2}\right]}\end{array}$ & $\begin{array}{c}\text { People } \\
{\left[\mathrm{ft}^{2} / \text { person }\right]}\end{array}$ & $\begin{array}{c}\text { Number of } \\
\text { People }\end{array}$ & $\begin{array}{c}\text { Plug and } \\
\text { Process } \\
{\left[\mathrm{W} / \mathrm{ft}^{2}\right]}\end{array}$ \\
\hline DINING & 1,250 & Yes & 12,508 & 1 & 1,000 & 280 & 2.1 & 14.3 & 87 & 10.9 \\
\hline KITCHEN & 1,250 & Yes & 12,508 & 1 & 1,000 & 0 & 1.2 & 199.3 & 6 & 98.8 \\
\hline ATTIC & 2,501 & No & 9,264 & 1 & 0 & 0 & 0 & 0 & 0 & 0 \\
\hline Total $^{(a)}$ & 2,501 & & 34,280 & & 2,001 & 280 & & & 94 & $\mathbf{0}$ \\
\hline Area Weighted Average & & & & & & & 1.6 & 106.8 & & 54.8 \\
\hline
\end{tabular}

(a) Only volume, and gross wall area include unconditioned space.

(b) 90.1-2004 baseline requirements for LPD 


\section{B.14 Full Service Restaurant Zone Summary}

\begin{tabular}{|c|c|c|c|c|c|c|c|c|c|c|}
\hline Zone & Area $\left[\mathrm{ft}^{2}\right]$ & $\begin{array}{c}\text { Conditioned } \\
{[\mathrm{Y} / \mathrm{N}]}\end{array}$ & $\begin{array}{l}\text { Volume } \\
{\left[\mathrm{ft}^{3}\right]}\end{array}$ & Multipliers & $\begin{array}{c}\text { Gross Wall } \\
\text { Area }\left[\mathrm{ft}^{2}\right]\end{array}$ & $\begin{array}{c}\text { Window } \\
\text { Glass Area } \\
{\left[\mathrm{ft}^{2}\right]}\end{array}$ & $\begin{array}{c}\text { Lighting }^{(\mathrm{b})} \\
{\left[\mathrm{W} / \mathrm{ft}^{2}\right]}\end{array}$ & $\begin{array}{c}\text { People } \\
{\left[\mathrm{ft}^{2} / \text { person }\right]}\end{array}$ & $\begin{array}{c}\text { Number of } \\
\text { People }\end{array}$ & $\begin{array}{c}\text { Plug and } \\
\text { Process } \\
{\left[\mathrm{W} / \mathrm{ft}^{2}\right]}\end{array}$ \\
\hline DINING & 4,001 & Yes & 40,025 & 1 & 1,821 & 508 & 2.1 & 14.3 & 280 & 6.0 \\
\hline KITCHEN & 1,501 & Yes & 15,009 & 1 & 1,147 & 0 & 1.2 & 199.3 & 8 & 97.8 \\
\hline ATTIC & 5,502 & No & 30,239 & 1 & 0 & 0 & 0 & 0 & 0 & 0 \\
\hline Total $^{(a)}$ & 5,502 & & 85,273 & & 2,968 & 508 & & & 287 & $\mathbf{0}$ \\
\hline Area Weighted Average & & & & & & & 1.9 & 64.8 & & 31.1 \\
\hline
\end{tabular}

(a) Only volume, and gross wall area include unconditioned space.

(b) 90.1-2004 baseline requirements for LPD 


\section{B.15 Mid-Rise Apartment Zone Summary}

\begin{tabular}{|c|c|c|c|c|c|c|c|c|c|c|}
\hline Zone $^{(a)}$ & Area $\left[\mathrm{ft}^{2}\right]$ & $\begin{array}{c}\text { Conditioned } \\
{[\mathrm{Y} / \mathrm{N}]}\end{array}$ & $\begin{array}{c}\text { Volume } \\
{\left[\mathrm{ft}^{3}\right]}\end{array}$ & Multipliers & $\begin{array}{c}\text { Gross Wall } \\
\text { Area }\left[\mathrm{ft}^{2}\right]\end{array}$ & $\begin{array}{c}\text { Window Glass } \\
\text { Area }\left[\mathrm{ft}^{2}\right]\end{array}$ & $\begin{array}{l}\text { Lighting } \\
{\left[\mathrm{W} / \mathrm{ft}^{2}\right]}\end{array}$ & $\begin{array}{c}\text { People } \\
{\left[\mathrm{ft}^{2} / \text { person }\right]}\end{array}$ & $\begin{array}{c}\text { Number of } \\
\text { People }\end{array}$ & $\begin{array}{l}\text { Plug and } \\
\text { Process } \\
{\left[\mathrm{W} / \mathrm{ft}^{2}\right]}\end{array}$ \\
\hline G SW APARTMENT & 950 & Yes & 9,499 & 1.0 & 630 & 92 & 0.4 & 380 & 2.5 & 0.6 \\
\hline G NW APARTMENT & 950 & Yes & 9,499 & 1.0 & 630 & 92 & 0.4 & 380 & 2.5 & 0.6 \\
\hline OFFICE & 950 & Yes & 9,499 & 1.0 & 630 & 92 & 1.1 & 950 & 1.0 & 0.6 \\
\hline G NE APARTMENT & 950 & Yes & 9,499 & 1.0 & 630 & 92 & 0.4 & 380 & 2.5 & 0.6 \\
\hline G N1 APARTMENT & 950 & Yes & 9,499 & 1.0 & 380 & 56 & 0.4 & 380 & 2.5 & 0.6 \\
\hline G N2 APARTMENT & 950 & Yes & 9,499 & 1.0 & 380 & 56 & 0.4 & 380 & 2.5 & 0.6 \\
\hline G S1 APARTMENT & 950 & Yes & 9,499 & 1.0 & 380 & 56 & 0.4 & 380 & 2.5 & 0.6 \\
\hline G S2 APARTMENT & 950 & Yes & 9,499 & 1.0 & 380 & 56 & 0.4 & 380 & 2.5 & 0.6 \\
\hline M SW APARTMENT & 950 & Yes & 9,499 & 2.0 & 630 & 92 & 0.4 & 380 & 2.5 & 0.6 \\
\hline M NW APARTMENT & 950 & Yes & 9,499 & 2.0 & 630 & 92 & 0.4 & 380 & 2.5 & 0.6 \\
\hline M SE APARTMENT & 950 & Yes & 9,499 & 2.0 & 630 & 92 & 0.4 & 380 & 2.5 & 0.6 \\
\hline M NE APARTMENT & 950 & Yes & 9,499 & 2.0 & 630 & 92 & 0.4 & 380 & 2.5 & 0.6 \\
\hline M N1 APARTMENT & 950 & Yes & 9,499 & 2.0 & 380 & 56 & 0.4 & 380 & 2.5 & 0.6 \\
\hline M N2 APARTMENT & 950 & Yes & 9,499 & 2.0 & 380 & 56 & 0.4 & 380 & 2.5 & 0.6 \\
\hline M S1 APARTMENT & 950 & Yes & 9,499 & 2.0 & 380 & 56 & 0.4 & 380 & 2.5 & 0.6 \\
\hline M S2 APARTMENT & 950 & Yes & 9,499 & 2.0 & 380 & 56 & 0.4 & 380 & 2.5 & 0.6 \\
\hline T SW APARTMENT & 950 & Yes & 9,499 & 1.0 & 630 & 92 & 0.4 & 380 & 2.5 & 0.6 \\
\hline T NW APARTMENT & 950 & Yes & 9,499 & 1.0 & 630 & 92 & 0.4 & 380 & 2.5 & 0.6 \\
\hline T SE APARTMENT & 950 & Yes & 9,499 & 1.0 & 630 & 92 & 0.4 & 380 & 2.5 & 0.6 \\
\hline T NE APARTMENT & 950 & Yes & 9,499 & 1.0 & 630 & 92 & 0.4 & 380 & 2.5 & 0.6 \\
\hline T N1 APARTMENT & 950 & Yes & 9,499 & 1.0 & 380 & 56 & 0.4 & 380 & 2.5 & 0.6 \\
\hline T N2 APARTMENT & 950 & Yes & 9,499 & 1.0 & 380 & 56 & 0.4 & 380 & 2.5 & 0.6 \\
\hline T S1 APARTMENT & 950 & Yes & 9,499 & 1.0 & 380 & 56 & 0.4 & 380 & 2.5 & 0.6 \\
\hline T S2 APARTMENT & 950 & Yes & 9,499 & 1.0 & 380 & 56 & 0.4 & 380 & 2.5 & 0.6 \\
\hline T CORRIDOR & 836 & No & 8,359 & 1.0 & 110 & 24 & 0.6 & 0 & 0.0 & 0.0 \\
\hline G CORRIDOR $^{(b)}$ & 836 & No & 8,359 & 1.0 & 110 & 50 & 0.6 & 0 & 0.0 & 19.3 \\
\hline M CORRIDOR & 836 & No & 8,359 & 2.0 & 110 & 24 & 0.6 & 0 & 0.0 & 0.0 \\
\hline Total $^{(\mathbf{c})}$ & 33,744 & & 337,392 & & 16,598 & 2,491 & & & 78.5 & \\
\hline Area Weighted Average & & & & & & & 0.4 & 358 & & 1.0 \\
\hline \multicolumn{11}{|c|}{$\begin{array}{l}\text { (a) Each apartment zone contains one apartment with one bedroom, living room and bathroom. } \\
\text { (b) Elevator load is added in the ground floor corridor zone. } \\
\text { (c) Only volume, and gross wall area include unconditioned space. }\end{array}$} \\
\hline
\end{tabular}




\section{B.16 High-Rise Apartment Zone Summary}

\begin{tabular}{|c|c|c|c|c|c|c|c|c|c|c|}
\hline Zone $^{(a)}$ & Area $\left[\mathrm{ft}^{2}\right]$ & $\begin{array}{c}\text { Conditioned } \\
{[\mathrm{Y} / \mathrm{N}]}\end{array}$ & $\begin{array}{c}\text { Volume } \\
{\left[\mathrm{ft}^{3}\right]}\end{array}$ & Multipliers & $\begin{array}{l}\text { Gross Wall } \\
\text { Area }\left[\mathrm{ft}^{2}\right]\end{array}$ & $\begin{array}{c}\text { Window Glass } \\
\text { Area }\left[\mathrm{ft}^{2}\right]\end{array}$ & $\begin{array}{l}\text { Lighting } \\
{\left[\mathrm{W} / \mathrm{ft}^{2}\right]}\end{array}$ & $\begin{array}{c}\text { People } \\
{\left[\mathrm{ft}^{2} / \text { person] }\right.}\end{array}$ & $\begin{array}{c}\text { Number of } \\
\text { People }\end{array}$ & $\begin{array}{l}\text { Plug and } \\
\text { Process } \\
{\left[\mathrm{W} / \mathrm{ft}^{2}\right]}\end{array}$ \\
\hline G SW APARTMENT & 950 & Yes & 9,499 & 1.0 & 630 & 92 & 0.4 & 380 & 2.5 & 0.6 \\
\hline G NW APARTMENT & 950 & Yes & 9,499 & 1.0 & 630 & 92 & 0.4 & 380 & 2.5 & 0.6 \\
\hline OFFICE & 950 & Yes & 9,499 & 1.0 & 630 & 92 & 1.1 & 950 & 1.0 & 0.6 \\
\hline G NE APARTMENT & 950 & Yes & 9,499 & 1.0 & 630 & 92 & 0.4 & 380 & 2.5 & 0.6 \\
\hline G N1 APARTMENT & 950 & Yes & 9,499 & 1.0 & 380 & 56 & 0.4 & 380 & 2.5 & 0.6 \\
\hline G N2 APARTMENT & 950 & Yes & 9,499 & 1.0 & 380 & 56 & 0.4 & 380 & 2.5 & 0.6 \\
\hline G S1 APARTMENT & 950 & Yes & 9,499 & 1.0 & 380 & 56 & 0.4 & 380 & 2.5 & 0.6 \\
\hline G S2 APARTMENT & 950 & Yes & 9,499 & 1.0 & 380 & 56 & 0.4 & 380 & 2.5 & 0.6 \\
\hline M SW APARTMENT & 950 & Yes & 9,499 & 8.0 & 630 & 92 & 0.4 & 380 & 2.5 & 0.6 \\
\hline M NW APARTMENT & 950 & Yes & 9,499 & 8.0 & 630 & 92 & 0.4 & 380 & 2.5 & 0.6 \\
\hline M SE APARTMENT & 950 & Yes & 9,499 & 8.0 & 630 & 92 & 0.4 & 380 & 2.5 & 0.6 \\
\hline M NE APARTMENT & 950 & Yes & 9,499 & 8.0 & 630 & 92 & 0.4 & 380 & 2.5 & 0.6 \\
\hline M N1 APARTMENT & 950 & Yes & 9,499 & 8.0 & 380 & 56 & 0.4 & 380 & 2.5 & 0.6 \\
\hline M N2 APARTMENT & 950 & Yes & 9,499 & 8.0 & 380 & 56 & 0.4 & 380 & 2.5 & 0.6 \\
\hline M S1 APARTMENT & 950 & Yes & 9,499 & 8.0 & 380 & 56 & 0.4 & 380 & 2.5 & 0.6 \\
\hline M S2 APARTMENT & 950 & Yes & 9,499 & 8.0 & 380 & 56 & 0.4 & 380 & 2.5 & 0.6 \\
\hline T SW APARTMENT & 950 & Yes & 9,499 & 1.0 & 630 & 92 & 0.4 & 380 & 2.5 & 0.6 \\
\hline T NW APARTMENT & 950 & Yes & 9,499 & 1.0 & 630 & 92 & 0.4 & 380 & 2.5 & 0.6 \\
\hline T SE APARTMENT & 950 & Yes & 9,499 & 1.0 & 630 & 92 & 0.4 & 380 & 2.5 & 0.6 \\
\hline T NE APARTMENT & 950 & Yes & 9,499 & 1.0 & 630 & 92 & 0.4 & 380 & 2.5 & 0.6 \\
\hline T N1 APARTMENT & 950 & Yes & 9,499 & 1.0 & 380 & 56 & 0.4 & 380 & 2.5 & 0.6 \\
\hline T N2 APARTMENT & 950 & Yes & 9,499 & 1.0 & 380 & 56 & 0.4 & 380 & 2.5 & 0.6 \\
\hline T S1 APARTMENT & 950 & Yes & 9,499 & 1.0 & 380 & 56 & 0.4 & 380 & 2.5 & 0.6 \\
\hline T S2 APARTMENT & 950 & Yes & 9,499 & 1.0 & 380 & 56 & 0.4 & 380 & 2.5 & 0.6 \\
\hline T CORRIDOR & 836 & No & 8,359 & 1.0 & 110 & 24 & 0.6 & 0 & 0.0 & 24.6 \\
\hline G CORRIDOR $^{(\mathrm{b})}$ & 836 & No & 8,359 & 1.0 & 110 & 50 & 0.6 & 0 & 0.0 & 0.0 \\
\hline M CORRIDOR & 836 & No & 8,359 & 8.0 & 110 & 24 & 0.6 & 0 & 0.0 & 0.0 \\
\hline Total $^{(c)}$ & 84,360 & & 843,481 & & 41,495 & 6,187 & & & 198.5 & \\
\hline Area Weighted Average & & & & & & & 0.4 & 349 & & 0.8 \\
\hline \multicolumn{11}{|c|}{$\begin{array}{l}\text { (a) Each apartment zone contains one apartment with one bedroom, living room and bathroom. } \\
\text { (b) Elevator load is added in the ground floor corridor zone. } \\
\text { (c) Only volume, and gross wall area include unconditioned space. }\end{array}$} \\
\hline
\end{tabular}


Appendix C

Simulation Schedules 


\section{C.1 Small Office Hourly Operation Schedules}

\begin{tabular}{|c|c|c|c|c|c|c|c|c|c|c|c|c|c|c|c|c|c|c|c|c|c|c|c|c|c|}
\hline Schedule & Day of Week & 1 & 2 & 3 & 4 & 5 & 6 & 7 & 8 & 9 & 10 & 11 & 12 & 13 & 14 & 15 & 16 & 17 & 18 & 19 & 20 & 21 & 22 & 23 & 24 \\
\hline \multirow[t]{4}{*}{ BLDG_LIGHT_SCH } & WD & 0.18 & 0.18 & 0.18 & 0.18 & 0.18 & 0.23 & 0.23 & 0.42 & 0.9 & 0.9 & 0.9 & 0.9 & 0.8 & 0.9 & 0.9 & 0.9 & 0.9 & 0.61 & 0.42 & 0.42 & 0.32 & 0.32 & 0.23 & 0.18 \\
\hline & WEH & 0.18 & 0.18 & 0.18 & 0.18 & 0.18 & 0.18 & 0.18 & 0.18 & 0.18 & 0.18 & 0.18 & 0.18 & 0.18 & 0.18 & 0.18 & 0.18 & 0.18 & 0.18 & 0.18 & 0.18 & 0.18 & 0.18 & 0.18 & 0.18 \\
\hline & WinterDesign & 0 & 0 & 0 & 0 & 0 & 0 & 0 & 0 & 0 & 0 & 0 & 0 & 0 & 0 & 0 & 0 & 0 & 0 & 0 & 0 & 0 & 0 & 0 & 0 \\
\hline & SummerDesign & 1 & 1 & 1 & 1 & 1 & 1 & 1 & 1 & 1 & 1 & 1 & 1 & 1 & 1 & 1 & 1 & 1 & 1 & 1 & 1 & 1 & 1 & 1 & 1 \\
\hline \multirow[t]{4}{*}{ BLDG_EQUIP_SCH } & WD & 0.5 & 0.5 & 0.5 & 0.5 & 0.5 & 1 & 1 & 1 & 1 & 1 & 1 & 1 & 0.94 & 1 & 1 & 1 & 1 & 0.5 & 0.2 & 0.2 & 0.2 & 0.2 & 0.2 & 0.2 \\
\hline & WEH & 0.2 & 0.2 & 0.2 & 0.2 & 0.2 & 0.2 & 0.2 & 0.2 & 0.2 & 0.2 & 0.2 & 0.2 & 0.2 & 0.2 & 0.2 & 0.2 & 0.2 & 0.2 & 0.2 & 0.2 & 0.2 & 0.2 & 0.2 & 0.2 \\
\hline & WinterDesign & 0 & 0 & 0 & 0 & 0 & 0 & 0 & 0 & 0 & 0 & 0 & 0 & 0 & 0 & 0 & 0 & 0 & 0 & 0 & 0 & 0 & 0 & 0 & 0 \\
\hline & SummerDesign & 1 & 1 & 1 & 1 & 1 & 1 & 1 & 1 & 1 & 1 & 1 & 1 & 1 & 1 & 1 & 1 & 1 & 1 & 1 & 1 & 1 & 1 & 1 & 1 \\
\hline \multirow[t]{4}{*}{\begin{tabular}{|l} 
BLDG_OCC_SCH \\
\end{tabular}} & WD & 0 & 0 & 0 & 0 & 0 & 0 & 0.11 & 0.21 & 1 & 1 & 1 & 1 & 0.53 & 1 & 1 & 1 & 1 & 0.32 & 0.11 & 0.11 & 0.11 & 0.11 & 0.05 & 0 \\
\hline & WEH & 0 & 0 & 0 & 0 & 0 & 0 & 0 & 0 & 0 & 0 & 0 & 0 & 0 & 0 & 0 & 0 & 0 & 0 & 0 & 0 & 0 & 0 & 0 & 0 \\
\hline & WinterDesign & 0 & 0 & 0 & 0 & 0 & 0 & 0 & 0 & 0 & 0 & 0 & 0 & 0 & 0 & 0 & 0 & 0 & 0 & 0 & 0 & 0 & 0 & 0 & 0 \\
\hline & SummerDesign & 1 & 1 & 1 & 1 & 1 & 1 & 1 & 1 & 1 & 1 & 1 & 1 & 1 & 1 & 1 & 1 & 1 & 1 & 1 & 1 & 1 & 1 & 1 & 1 \\
\hline \begin{tabular}{|l|l|} 
BLDG_EXTERIOR_LIGHT \\
\end{tabular} & All Days & 1 & 1 & 1 & 1 & 1 & 1 & 1 & 1 & 1 & 1 & 1 & 1 & 1 & 1 & 1 & 1 & 1 & 1 & 1 & 1 & 1 & 1 & 1 & 1 \\
\hline \multirow[t]{2}{*}{ BLDG_SWH_SCH } & WD & 0 & 0 & 0 & 0 & 0 & 0 & 0 & 0.27 & 0.55 & 0.64 & 0.64 & 0.82 & 1 & 0.91 & 0.55 & 0.55 & 0.73 & 0.37 & 0.37 & 0.18 & 0.27 & 0.09 & 0 & 0 \\
\hline & WEH & 0 & 0 & 0 & 0 & 0 & 0 & 0 & 0 & 0 & 0 & 0 & 0 & 0 & 0 & 0 & 0 & 0 & 0 & 0 & 0 & 0 & 0 & 0 & 0 \\
\hline \multirow[t]{2}{*}{ INFIL_SCH_PNNL } & WD & 1 & 1 & 1 & 1 & 1 & 1 & 0.25 & 0.25 & 0.25 & 0.25 & 0.25 & 0.25 & 0.25 & 0.25 & 0.25 & 0.25 & 0.25 & 0.25 & 0.25 & 1 & 1 & 1 & 1 & 1 \\
\hline & WEH & 0 & 0 & 0 & 0 & 0 & 0 & 0 & 0 & 0 & 0 & 0 & 0 & 0 & 0 & 0 & 0 & 0 & 0 & 0 & 0 & 0 & 0 & 0 & 0 \\
\hline HVACOperationSchd & WD & 0 & 0 & 0 & 0 & 0 & 0 & 1 & 1 & 1 & 1 & 1 & 1 & 1 & 1 & 1 & 1 & 1 & 1 & 1 & 0 & 0 & 0 & 0 & 0 \\
\hline (Fan Schedule) & WEH & 0 & 0 & 0 & 0 & 0 & 0 & 0 & 0 & 0 & 0 & 0 & 0 & 0 & 0 & 0 & 0 & 0 & 0 & 0 & 0 & 0 & 0 & 0 & 0 \\
\hline \multirow[t]{3}{*}{ HTGSETP_SCH } & WD & 15.6 & 15.6 & 15.6 & 15.6 & 15.6 & 15.6 & 18.3 & 21.1 & 21.1 & 21.1 & 21.1 & 21.1 & 21.1 & 21.1 & 21.1 & 21.1 & 21.1 & 21.1 & 21.1 & 15.6 & 15.6 & 15.6 & 15.6 & 15.6 \\
\hline & WEH & 15.6 & 15.6 & 15.6 & 15.6 & 15.6 & 15.6 & 15.6 & 15.6 & 15.6 & 15.6 & 15.6 & 15.6 & 15.6 & 15.6 & 15.6 & 15.6 & 15.6 & 15.6 & 15.6 & 15.6 & 15.6 & 15.6 & 15.6 & 15.6 \\
\hline & WinterDesign & 21.1 & 21.1 & 21.1 & 21.1 & 21.1 & 21.1 & 21.1 & 21.1 & 21.1 & 21.1 & 21.1 & 21.1 & 21.1 & 21.1 & 21.1 & 21.1 & 21.1 & 21.1 & 21.1 & 21.1 & 21.1 & 21.1 & 21.1 & 21.1 \\
\hline \multirow[t]{3}{*}{ CLGSETP_SCH } & WD & 29.4 & 29.4 & 29.4 & 29.4 & 29.4 & 29.4 & 26.7 & 23.9 & 23.9 & 23.9 & 23.9 & 23.9 & 23.9 & 23.9 & 23.9 & 23.9 & 23.9 & 23.9 & 29.4 & 29.4 & 29.4 & 29.4 & 29.4 & 29.4 \\
\hline & WEH & 29.4 & 29.4 & 29.4 & 29.4 & 29.4 & 29.4 & 29.4 & 29.4 & 29.4 & 29.4 & 29.4 & 29.4 & 29.4 & 29.4 & 29.4 & 29.4 & 29.4 & 29.4 & 29.4 & 29.4 & 29.4 & 29.4 & 29.4 & 29.4 \\
\hline & SummerDesign & 23.9 & 23.9 & 23.9 & 23.9 & 23.9 & 23.9 & 23.9 & 23.9 & 23.9 & 23.9 & 23.9 & 23.9 & 23.9 & 23.9 & 23.9 & 23.9 & 23.9 & 23.9 & 23.9 & 23.9 & 23.9 & 23.9 & 23.9 & 23.9 \\
\hline \multirow[t]{3}{*}{ HTGSETP_SCH } & WD & 60 & 60 & 60 & 60 & 60 & 60 & 65 & 70 & 70 & 70 & 70 & 70 & 70 & 70 & 70 & 70 & 70 & 70 & 70 & 60 & 60 & 60 & 60 & 60 \\
\hline & WEH & 60 & 60 & 60 & 60 & 60 & 60 & 60 & 60 & 60 & 60 & 60 & 60 & 60 & 60 & 60 & 60 & 60 & 60 & 60 & 60 & 60 & 60 & 60 & 60 \\
\hline & WinterDesign & 70 & 70 & 70 & 70 & 70 & 70 & 70 & 70 & 70 & 70 & 70 & 70 & 70 & 70 & 70 & 70 & 70 & 70 & 70 & 70 & 70 & 70 & 70 & 70 \\
\hline \multirow[t]{3}{*}{ CLGSETP_SCH } & WD & 85 & 85 & 85 & 85 & 85 & 85 & 80 & 75 & 75 & 75 & 75 & 75 & 75 & 75 & 75 & 75 & 75 & 75 & 85 & 85 & 85 & 85 & 85 & 85 \\
\hline & WEH & 85 & 85 & 85 & 85 & 85 & 85 & 85 & 85 & 85 & 85 & 85 & 85 & 85 & 85 & 85 & 85 & 85 & 85 & 85 & 85 & 85 & 85 & 85 & 85 \\
\hline & SummerDesign & 75 & 75 & 75 & 75 & 75 & 75 & 75 & 75 & 75 & 75 & 75 & 75 & 75 & 75 & 75 & 75 & 75 & 75 & 75 & 75 & 75 & 75 & 75 & 75 \\
\hline \begin{tabular}{|l} 
MinOA_Sched \\
\end{tabular} & All & 1 & 1 & 1 & 1 & 1 & 1 & 1 & 1 & 1 & 1 & 1 & 1 & 1 & 1 & 1 & 1 & 1 & 1 & 1 & 1 & 1 & 1 & 1 & 1 \\
\hline
\end{tabular}




\section{C.2 Medium Office Hourly Operation Schedules}

\begin{tabular}{|c|c|c|c|c|c|c|c|c|c|c|c|c|c|c|c|c|c|c|c|c|c|c|c|c|c|}
\hline Schedule & Day of Week & 1 & 2 & 3 & 4 & 5 & 6 & 7 & 8 & 9 & 10 & 11 & 12 & 13 & 14 & 15 & 16 & 17 & 18 & 19 & 20 & 21 & 22 & 23 & 24 \\
\hline \multirow[t]{5}{*}{ BLDG_LIGHT_SCH } & WD & 0.05 & 0.05 & 0.05 & 0.05 & 0.05 & 0.1 & 0.1 & 0.3 & 0.9 & 0.9 & 0.9 & 0.9 & 0.9 & 0.9 & 0.9 & 0.9 & 0.9 & 0.5 & 0.3 & 0.3 & 0.2 & 0.2 & 0.1 & 0.05 \\
\hline & Saturday & 0.05 & 0.05 & 0.05 & 0.05 & 0.05 & 0.05 & 0.1 & 0.1 & 0.3 & 0.3 & 0.3 & 0.3 & 0.15 & 0.15 & 0.15 & 0.15 & 0.15 & 0.05 & 0.05 & 0.05 & 0.05 & 0.05 & 0.05 & 0.05 \\
\hline & Sun, Hol, Other & 0.05 & 0.05 & 0.05 & 0.05 & 0.05 & 0.05 & 0.05 & 0.05 & 0.05 & 0.05 & 0.05 & 0.05 & 0.05 & 0.05 & 0.05 & 0.05 & 0.05 & 0.05 & 0.05 & 0.05 & 0.05 & 0.05 & 0.05 & 0.05 \\
\hline & SummerDesign & 1 & 1 & 1 & 1 & 1 & 1 & 1 & 1 & 1 & 1 & 1 & 1 & 1 & 1 & 1 & 1 & 1 & 1 & 1 & 1 & 1 & 1 & 1 & 1 \\
\hline & WinterDesign & 0 & 0 & 0 & 0 & 0 & 0 & 0 & 0 & 0 & 0 & 0 & 0 & 0 & 0 & 0 & 0 & 0 & 0 & 0 & 0 & 0 & 0 & 0 & 0 \\
\hline \multirow[t]{5}{*}{ BLDG_EQUIP_SCH } & WD & 0.4 & 0.4 & 0.4 & 0.4 & 0.4 & 0.4 & 0.4 & 0.4 & 0.9 & 0.9 & 0.9 & 0.9 & 0.8 & 0.9 & 0.9 & 0.9 & 0.9 & 0.5 & 0.4 & 0.4 & 0.4 & 0.4 & 0.4 & 0.4 \\
\hline & Saturday & 0.3 & 0.3 & 0.3 & 0.3 & 0.3 & 0.3 & 0.4 & 0.4 & 0.5 & 0.5 & 0.5 & 0.5 & 0.35 & 0.35 & 0.35 & 0.35 & 0.35 & 0.3 & 0.3 & 0.3 & 0.3 & 0.3 & 0.3 & 0.3 \\
\hline & Sun, Hol, Other & 0.3 & 0.3 & 0.3 & 0.3 & 0.3 & 0.3 & 0.3 & 0.3 & 0.3 & 0.3 & 0.3 & 0.3 & 0.3 & 0.3 & 0.3 & 0.3 & 0.3 & 0.3 & 0.3 & 0.3 & 0.3 & 0.3 & 0.3 & 0.3 \\
\hline & SummerDesign & 1 & 1 & 1 & 1 & 1 & 1 & 1 & 1 & 1 & 1 & 1 & 1 & 1 & 1 & 1 & 1 & 1 & 1 & 1 & 1 & 1 & 1 & 1 & 1 \\
\hline & WinterDesign & 0 & 0 & 0 & 0 & 0 & 0 & 0 & 0 & 0 & 0 & 0 & 0 & 0 & 0 & 0 & 0 & 0 & 0 & 0 & 0 & 0 & 0 & 0 & 0 \\
\hline \multirow[t]{5}{*}{ BLDG_OCC_SCH } & WD & 0 & 0 & 0 & 0 & 0 & 0 & 0.1 & 0.2 & 0.95 & 0.95 & \begin{tabular}{ll|}
0.95 \\
\end{tabular} & 0.95 & 0.5 & \begin{tabular}{ll|}
0.95 \\
\end{tabular} & 0.95 & 0.95 & 0.95 & 0.3 & 0.1 & 0.1 & 0.1 & 0.1 & 0.05 & 0.05 \\
\hline & Saturday & 0 & 0 & 0 & 0 & 0 & 0 & 0.1 & 0.1 & 0.3 & 0.3 & 0.3 & 0.3 & 0.1 & 0.1 & 0.1 & 0.1 & 0.1 & 0.05 & 0.05 & 0 & 0 & 0 & 0 & 0 \\
\hline & Sun, Hol, Other & 0 & 0 & 0 & 0 & 0 & 0 & 0.05 & 0.05 & 0.05 & 0.05 & 0.05 & 0.05 & 0.05 & 0.05 & 0.05 & 0.05 & 0.05 & 0.05 & 0 & 0 & 0 & 0 & 0 & 0 \\
\hline & SummerDesign & 1 & 1 & 1 & 1 & 1 & 1 & 1 & 1 & 1 & 1 & 1 & 1 & 1 & 1 & 1 & 1 & 1 & 1 & 1 & 1 & 1 & 1 & 1 & 1 \\
\hline & WinterDesign & 0 & 0 & 0 & 0 & 0 & 0 & 0 & 0 & 0 & 0 & 0 & 0 & 0 & 0 & 0 & 0 & 0 & 0 & 0 & 0 & 0 & 0 & 0 & 0 \\
\hline \multirow[t]{3}{*}{ BLDG_ELEVATORS } & WD & 0 & 0 & 0 & 0 & 0 & 0 & 0 & 0.35 & 0.69 & 0.43 & $\begin{array}{ll}0.37 \\
\end{array}$ & 0.43 & 0.58 & \begin{tabular}{ll|}
0.48 \\
\end{tabular} & 0.37 & 0.37 & 0.46 & 0.62 & 0.12 & $\begin{array}{ll}0.04 \\
\end{array}$ & 0.04 & 0 & 0 & 0 \\
\hline & Saturday & 0 & 0 & 0 & 0 & 0 & 0 & 0 & 0.16 & 0.14 & 0.21 & 0.18 & 0.25 & 0.21 & 0.13 & 0.08 & 0.04 & 0.05 & 0.06 & 0 & 0 & 0 & 0 & 0 & 0 \\
\hline & Sun, Hol, Other & 0 & 0 & 0 & 0 & 0 & 0 & 0 & 0 & 0 & 0 & 0 & 0 & 0 & 0 & 0 & 0 & 0 & 0 & 0 & 0 & 0 & 0 & 0 & 0 \\
\hline BLDG_EXTERIOR_LIGHT & All Days & 1 & 1 & 1 & 1 & 1 & 1 & 1 & 1 & 1 & 1 & 1 & 1 & 1 & 1 & 1 & 1 & 1 & 1 & 1 & 1 & 1 & 1 & 1 & 1 \\
\hline \multirow[t]{3}{*}{ BLDG_SWH_SCH } & WD & 0.05 & 0.05 & 0.05 & 0.05 & 0.05 & 0.08 & 0.07 & 0.19 & 0.35 & 0.38 & 0.39 & 0.47 & 0.57 & 0.54 & 0.34 & 0.33 & 0.44 & 0.26 & 0.21 & 0.15 & 0.17 & 0.08 & 0.05 & 0.05 \\
\hline & Saturday & 0.05 & 0.05 & 0.05 & 0.05 & 0.05 & 0.08 & 0.07 & 0.11 & 0.15 & 0.21 & 0.19 & 0.23 & 0.2 & 0.19 & 0.15 & 0.13 & 0.14 & 0.07 & 0.07 & 0.07 & 0.07 & 0.09 & 0.05 & 0.05 \\
\hline & Sun, Hol, Other & 0.04 & 0.04 & 0.04 & 0.04 & 0.04 & 0.07 & 0.04 & 0.04 & 0.04 & 0.04 & 0.04 & 0.06 & 0.06 & 0.09 & 0.06 & 0.04 & 0.04 & 0.04 & 0.04 & 0.04 & 0.04 & 0.07 & 0.04 & 0.04 \\
\hline \multirow[t]{3}{*}{ INFIL_SCH_PNNL } & $\begin{array}{l}\text { WD, } \\
\text { SummerDesign }\end{array}$ & 1 & 1 & 1 & 1 & 1 & 1 & 0.25 & 0.25 & 0.25 & 0.25 & 0.25 & 0.25 & 0.25 & 0.25 & 0.25 & 0.25 & 0.25 & 0.25 & 0.25 & 0.25 & 0.25 & 0.25 & 1 & 1 \\
\hline & $\begin{array}{l}\text { Saturday, } \\
\text { WinterDesign }\end{array}$ & 1 & 1 & 1 & 1 & 1 & 1 & 0.25 & 0.25 & 0.25 & 0.25 & 0.25 & 0.25 & 0.25 & 0.25 & 0.25 & 0.25 & 0.25 & 0.25 & 1 & 1 & 1 & 1 & 1 & 1 \\
\hline & Sun, Hol, Other & 1 & 1 & 1 & 1 & 1 & 1 & 1 & 1 & 1 & 1 & 1 & 1 & 1 & 1 & 1 & 1 & 1 & 1 & 1 & 1 & 1 & 1 & 1 & 1 \\
\hline HVACOperationSchd & $\begin{array}{l}\text { WD, } \\
\text { SummerDesign }\end{array}$ & 0 & 0 & 0 & 0 & 0 & 0 & 1 & 1 & 1 & 1 & 1 & 1 & 1 & 1 & 1 & 1 & 1 & 1 & 1 & 1 & 1 & 1 & 0 & 0 \\
\hline \multirow[t]{2}{*}{ (Fan Schedule) } & \begin{tabular}{|l|} 
Saturday, \\
WinterDesign
\end{tabular} & 0 & 0 & 0 & 0 & 0 & 0 & 1 & 1 & 1 & 1 & 1 & 1 & 1 & 1 & 1 & 1 & 1 & 1 & 0 & 0 & 0 & 0 & 0 & 0 \\
\hline & Sun, Hol, Other & 0 & 0 & 0 & 0 & 0 & 0 & 0 & 0 & 0 & 0 & 0 & 0 & 0 & 0 & 0 & 0 & 0 & 0 & 0 & 0 & 0 & 0 & 0 & 0 \\
\hline \multirow[t]{4}{*}{ HTGSETP_SCH } & WD & 15.6 & 15.6 & 15.6 & 15.6 & 15.6 & 17.6 & 19.6 & 21 & 21 & 21 & 21 & 21 & 21 & 21 & 21 & 21 & 21 & 21 & 21 & 21 & 21 & 21 & 15.6 & 15.6 \\
\hline & Saturday & 15.6 & 15.6 & 15.6 & 15.6 & 15.6 & 17.6 & 19.6 & 21 & 21 & 21 & 21 & 21 & 21 & 21 & 21 & 21 & 21 & 15.6 & 15.6 & 15.6 & 15.6 & 15.6 & 15.6 & 15.6 \\
\hline & Sun, Hol, Other & 15.6 & 15.6 & 15.6 & 15.6 & 15.6 & 15.6 & 15.6 & 15.6 & 15.6 & 15.6 & 15.6 & 15.6 & 15.6 & 15.6 & 15.6 & 15.6 & 15.6 & 15.6 & 15.6 & 15.6 & 15.6 & 15.6 & 15.6 & 15.6 \\
\hline & WinterDesign & 15.6 & 15.6 & 15.6 & 15.6 & 15.6 & 17.6 & 19.6 & 21 & 21 & 21 & 21 & 21 & 21 & 21 & 21 & 21 & 21 & 21 & 21 & 21 & 21 & 21 & 15.6 & 15.6 \\
\hline \multirow[t]{4}{*}{ CLGSETP_SCH } & WD & \begin{tabular}{|l|l|}
26.7 \\
\end{tabular} & 26.7 & 26.7 & \begin{tabular}{|l|l|}
26.7 \\
\end{tabular} & 26.7 & 25.7 & 25 & 24 & 24 & 24 & 24 & 24 & 24 & 24 & 24 & 24 & 24 & 24 & 24 & 24 & 24 & 24 & \begin{tabular}{|l|l|}
26.7 \\
\end{tabular} & 26.7 \\
\hline & Saturday & \begin{tabular}{|l|l|}
26.7 \\
\end{tabular} & 26.7 & 26.7 & \begin{tabular}{|l|l|}
26.7 \\
\end{tabular} & 26.7 & 25.7 & 25 & 24 & 24 & 24 & 24 & 24 & 24 & 24 & 24 & 24 & 24 & 26.7 & 26.7 & \begin{tabular}{|l|l|}
26.7 \\
\end{tabular} & 26.7 & 26.7 & \begin{tabular}{|l|l|}
26.7 \\
\end{tabular} & 26.7 \\
\hline & Sun, Hol, Other & 26.7 & 26.7 & 26.7 & 26.7 & 26.7 & 26.7 & 26.7 & 26.7 & 26.7 & 26.7 & 26.7 & 26.7 & 26.7 & 26.7 & 26.7 & 26.7 & 26.7 & 26.7 & 26.7 & 26.7 & 26.7 & 26.7 & 26.7 & 26.7 \\
\hline & SummerDesign & 26.7 & 26.7 & 26.7 & 26.7 & 26.7 & 25.7 & 25 & 24 & 24 & 24 & 24 & 24 & 24 & 24 & 24 & 24 & 24 & 24 & 24 & 24 & 24 & 24 & 26.7 & 26.7 \\
\hline \multirow[t]{4}{*}{ HTGSETP_SCH } & WD & 60 & 60 & 60 & 60 & 60 & 64 & 67 & 70 & 70 & 70 & 70 & 70 & 70 & 70 & 70 & 70 & 70 & 70 & 70 & 70 & 70 & 70 & 60 & 60 \\
\hline & Saturday & 60 & 60 & 60 & 60 & 60 & 64 & 67 & 70 & 70 & 70 & 70 & 70 & 70 & 70 & 70 & 70 & 70 & 60 & 60 & 60 & 60 & 60 & 60 & 60 \\
\hline & Sun, Hol, Other & 60 & 60 & 60 & 60 & 60 & 60 & 60 & 60 & 60 & 60 & 60 & 60 & 60 & 60 & 60 & 60 & 60 & 60 & 60 & 60 & 60 & 60 & 60 & 60 \\
\hline & WinterDesign & 60 & 60 & 60 & 60 & 60 & 64 & 67 & 70 & 70 & 70 & 70 & 70 & 70 & 70 & 70 & 70 & 70 & 70 & 70 & 70 & 70 & 70 & 60 & 60 \\
\hline \multirow[t]{4}{*}{ CLGSETP_SCH } & WD & 80 & 80 & 80 & 80 & 80 & 78 & 77 & 75 & 75 & 75 & 75 & 75 & 75 & 75 & 75 & 75 & 75 & 75 & 75 & 75 & 75 & 75 & 80 & 80 \\
\hline & Saturday & 80 & 80 & 80 & 80 & 80 & 78 & 77 & 75 & 75 & 75 & 75 & 75 & 75 & 75 & 75 & 75 & 75 & 80 & 80 & 80 & 80 & 80 & 80 & 80 \\
\hline & Sun, Hol, Other & 80 & 80 & 80 & 80 & 80 & 80 & 80 & 80 & 80 & 80 & 80 & 80 & 80 & 80 & 80 & 80 & 80 & 80 & 80 & 80 & 80 & 80 & 80 & 80 \\
\hline & SummerDesign & 80 & 80 & 80 & 80 & 80 & 78 & 77 & 75 & 75 & 75 & 75 & 75 & 75 & 75 & 75 & 75 & 75 & 75 & 75 & 75 & 75 & 75 & 80 & 80 \\
\hline
\end{tabular}




\begin{tabular}{|c|c|c|c|c|c|c|c|c|c|c|c|c|c|c|c|c|c|c|c|c|c|c|c|c|c|}
\hline Schedule & Day of Week & 1 & 2 & 3 & 4 & 5 & 6 & 7 & 8 & 9 & 10 & 11 & 12 & 13 & 14 & 15 & 16 & 17 & 18 & 19 & 20 & 21 & 22 & 23 & 24 \\
\hline $\begin{array}{l}\text { MinOA_MotorizedDamper_Sc } \\
\text { hed }\end{array}$ & $\begin{array}{l}\text { WD, } \\
\text { SummerDesign }\end{array}$ & 0 & 0 & 0 & 0 & 0 & 0 & 0 & 1 & 1 & 1 & 1 & 1 & 1 & 1 & 1 & 1 & 1 & 1 & 1 & 1 & 1 & 1 & 0 & 0 \\
\hline & Sat, WinterDesign & 0 & 0 & 0 & 0 & 0 & 0 & 0 & 1 & 1 & 1 & 1 & 1 & 1 & 1 & 1 & 1 & 1 & 1 & 0 & 0 & 0 & 0 & 0 & 0 \\
\hline & Sun, Hol, Other & 0 & 0 & 0 & 0 & 0 & 0 & 0 & 0 & 0 & 0 & 0 & 0 & 0 & 0 & 0 & 0 & 0 & 0 & 0 & 0 & 0 & 0 & 0 & 0 \\
\hline MinOA_Sched & All & 1 & 1 & 1 & 1 & 1 & 1 & 1 & 1 & 1 & 1 & 1 & 1 & 1 & 1 & 1 & 1 & 1 & 1 & 1 & 1 & 1 & 1 & 1 & 1 \\
\hline
\end{tabular}




\section{C.3 Large Office Hourly Operation Schedules}

\begin{tabular}{|c|c|c|c|c|c|c|c|c|c|c|c|c|c|c|c|c|c|c|c|c|c|c|c|c|c|}
\hline Schedule & Day of Week & 1 & 2 & 3 & 4 & 5 & 6 & 7 & 8 & 9 & 10 & 11 & 12 & 13 & 14 & 15 & 16 & 17 & 18 & 19 & 20 & 21 & 22 & 23 & 24 \\
\hline \multirow[t]{5}{*}{ BLDG_LIGHT_SCH } & WD & 0.05 & 0.05 & 0.05 & 0.05 & 0.05 & 0.1 & 0.1 & 0.3 & 0.9 & 0.9 & 0.9 & 0.9 & 0.9 & 0.9 & 0.9 & 0.9 & 0.9 & 0.5 & 0.3 & 0.3 & 0.2 & 0.2 & 0.1 & 0.05 \\
\hline & Sat & 0.05 & 0.05 & 0.05 & 0.05 & 0.05 & 0.05 & 0.1 & 0.1 & 0.3 & 0.3 & 0.3 & 0.3 & 0.15 & 0.15 & 0.15 & 0.15 & 0.15 & 0.05 & 0.05 & 0.05 & 0.05 & 0.05 & \begin{tabular}{|l|}
0.05 \\
\end{tabular} & 0.05 \\
\hline & Sun, Hol, Other & 0.05 & 0.05 & 0.05 & 0.05 & 0.05 & 0.05 & 0.05 & \begin{tabular}{|l|}
0.05 \\
\end{tabular} & 0.05 & 0.05 & 0.05 & 0.05 & 0.05 & 0.05 & 0.05 & 0.05 & 0.05 & 0.05 & 0.05 & 0.05 & 0.05 & 0.05 & \begin{tabular}{|l|}
0.05 \\
\end{tabular} & 0.05 \\
\hline & SummerDesign & 1 & 1 & 1 & 1 & 1 & 1 & 1 & 1 & 1 & 1 & 1 & 1 & 1 & 1 & 1 & 1 & 1 & 1 & 1 & 1 & 1 & 1 & 1 & 1 \\
\hline & WinterDesign & 0 & 0 & 0 & 0 & 0 & 0 & 0 & 0 & 0 & 0 & 0 & 0 & 0 & 0 & 0 & 0 & 0 & 0 & 0 & 0 & 0 & 0 & 0 & 0 \\
\hline \multirow[t]{5}{*}{ BLDG_EQUIP_SCH } & WD & 0.4 & 0.4 & 0.4 & 0.4 & 0.4 & 0.4 & 0.4 & 0.4 & 0.9 & 0.9 & 0.9 & 0.9 & 0.8 & 0.9 & 0.9 & 0.9 & 0.9 & 0.5 & 0.4 & 0.4 & 0.4 & 0.4 & 0.4 & 0.4 \\
\hline & Sat & 0.3 & 0.3 & 0.3 & 0.3 & 0.3 & 0.3 & 0.4 & 0.4 & 0.5 & 0.5 & 0.5 & 0.5 & 0.35 & 0.35 & 0.35 & 0.35 & 0.35 & 0.3 & 0.3 & 0.3 & 0.3 & 0.3 & 0.3 & 0.3 \\
\hline & Sun, Hol, Other & 0.3 & 0.3 & 0.3 & 0.3 & 0.3 & 0.3 & 0.3 & 0.3 & 0.3 & 0.3 & 0.3 & 0.3 & 0.3 & 0.3 & 0.3 & 0.3 & 0.3 & 0.3 & 0.3 & 0.3 & 0.3 & 0.3 & 0.3 & 0.3 \\
\hline & SummerDesign & 1 & 1 & 1 & 1 & 1 & 1 & 1 & 1 & 1 & 1 & 1 & 1 & 1 & 1 & 1 & 1 & 1 & 1 & 1 & 1 & 1 & 1 & 1 & 1 \\
\hline & WinterDesign & 0 & 0 & 0 & 0 & 0 & 0 & 0 & 0 & 0 & 0 & 0 & 0 & 0 & 0 & 0 & 0 & 0 & 0 & 0 & 0 & 0 & 0 & 0 & 0 \\
\hline \multirow[t]{5}{*}{ BLDG_OCC_SCH } & WD & 0 & 0 & 0 & 0 & 0 & 0 & 0.1 & 0.2 & 0.95 & 0.95 & 0.95 & 0.95 & 0.5 & 0.95 & 0.95 & 0.95 & 0.95 & 0.3 & 0.1 & 0.1 & 0.1 & 0.1 & \begin{tabular}{|l|}
0.05 \\
\end{tabular} & 0.05 \\
\hline & Sat & 0 & 0 & 0 & 0 & 0 & 0 & 0.1 & 0.1 & 0.3 & 0.3 & 0.3 & 0.3 & 0.1 & 0.1 & 0.1 & 0.1 & 0.1 & 0.05 & 0.05 & 0 & 0 & 0 & \begin{tabular}{|c|}
0 \\
\end{tabular} & 0 \\
\hline & Sun, Hol, Other & 0 & 0 & 0 & 0 & 0 & 0 & 0.05 & \begin{tabular}{|l|}
0.05 \\
\end{tabular} & 0.05 & 0.05 & 0.05 & 0.05 & 0.05 & 0.05 & 0.05 & 0.05 & 0.05 & 0.05 & 0 & 0 & 0 & 0 & 0 & 0 \\
\hline & SummerDesign & 0 & 0 & 0 & 0 & 0 & 0 & 1 & 1 & 1 & 1 & 1 & 1 & 1 & 1 & 1 & 1 & 1 & 1 & 1 & 1 & 1 & 1 & 0.05 & 0.05 \\
\hline & WinterDesign & 0 & 0 & 0 & 0 & 0 & 0 & 0 & 0 & 0 & 0 & 0 & 0 & 0 & 0 & 0 & 0 & 0 & 0 & 0 & 0 & 0 & 0 & 0 & 0 \\
\hline \multirow[t]{5}{*}{\begin{tabular}{|l|l|} 
BLDG_ELEVATORS \\
\end{tabular}} & WD & 0.05 & 0.05 & 0.05 & 0.05 & 0.1 & 0.2 & 0.4 & 0.5 & 0.5 & 0.35 & 0.15 & 0.15 & 0.15 & 0.15 & 0.15 & 0.15 & 0.35 & 0.5 & 0.5 & 0.4 & 0.4 & 0.3 & 0.2 & 0.1 \\
\hline & Sat & 0.05 & 0.05 & 0.05 & 0.05 & 0.1 & 0.2 & 0.4 & 0.5 & 0.5 & 0.35 & 0.15 & 0.15 & 0.15 & 0.15 & 0.15 & 0.15 & 0.35 & 0.5 & 0.5 & 0.4 & 0.4 & 0.3 & 0.2 & 0.1 \\
\hline & Sun & 0.05 & 0.05 & 0.05 & 0.05 & 0.1 & 0.2 & 0.4 & 0.5 & 0.5 & 0.35 & 0.15 & 0.15 & 0.15 & 0.15 & 0.15 & 0.15 & 0.35 & 0.5 & 0.5 & 0.4 & 0.4 & 0.3 & 0.2 & 0.1 \\
\hline & SummerDesign & 0.5 & 0.5 & 0.5 & 0.5 & 0.5 & 0.5 & 0.5 & 0.5 & 0.5 & 0.5 & 0.5 & 0.5 & 0.5 & 0.5 & 0.5 & 0.5 & 0.5 & 0.5 & 0.5 & 0.5 & 0.5 & 0.5 & 0.5 & 0.5 \\
\hline & WinterDesign & 0.05 & 0.05 & 0.05 & 0.05 & \begin{tabular}{|l|}
0.05 \\
\end{tabular} & 0.05 & 0.05 & \begin{tabular}{|l|l|}
0.05 \\
\end{tabular} & 0.05 & 0.05 & 0.05 & 0.05 & 0.05 & 0.05 & 0.05 & 0.05 & 0.05 & 0.05 & 0.05 & 0.05 & 0.05 & 0.05 & \begin{tabular}{|l|}
0.05 \\
\end{tabular} & 0.05 \\
\hline \multirow[t]{5}{*}{$\begin{array}{l}\text { ELEV_LIGHT_FAN_SCH_ } \\
24 \_7\end{array}$} & WD & 1 & 1 & 1 & 1 & 1 & 1 & 1 & 1 & 1 & 1 & 1 & 1 & 1 & 1 & 1 & 1 & 1 & 1 & 1 & 1 & 1 & 1 & 1 & 1 \\
\hline & Sat & 1 & 1 & 1 & 1 & 1 & 1 & 1 & 1 & 1 & 1 & 1 & 1 & 1 & 1 & 1 & 1 & 1 & 1 & 1 & 1 & 1 & 1 & 1 & 1 \\
\hline & Sun, Hol, Other & 1 & 1 & 1 & 1 & 1 & 1 & 1 & 1 & 1 & 1 & 1 & 1 & 1 & 1 & 1 & 1 & 1 & 1 & 1 & 1 & 1 & 1 & 1 & 1 \\
\hline & SummerDesign & 1 & 1 & 1 & 1 & 1 & 1 & 1 & 1 & 1 & 1 & 1 & 1 & 1 & 1 & 1 & 1 & 1 & 1 & 1 & 1 & 1 & 1 & 1 & 1 \\
\hline & WinterDesign & 1 & 1 & 1 & 1 & 1 & 1 & 1 & 1 & 1 & 1 & 1 & 1 & 1 & 1 & 1 & 1 & 1 & 1 & 1 & 1 & 1 & 1 & 1 & 1 \\
\hline \multirow[t]{3}{*}{ BLDG_SWH_SCH } & $\begin{array}{l}\text { WD, } \\
\text { SummerDesign }\end{array}$ & 0.05 & 0.05 & 0.05 & 0.05 & 0.05 & 0.08 & 0.07 & 0.19 & 0.35 & 0.38 & 0.39 & 0.47 & 0.57 & 0.54 & 0.34 & 0.33 & 0.44 & 0.26 & 0.21 & 0.15 & 0.17 & 0.08 & 0.05 & 0.05 \\
\hline & Sat, WinterDesign & 0.05 & 0.05 & 0.05 & 0.05 & 0.05 & 0.08 & 0.07 & \begin{tabular}{|l|}
0.11 \\
\end{tabular} & 0.15 & 0.21 & 0.19 & 0.23 & 0.2 & 0.19 & 0.15 & 0.13 & 0.14 & 0.07 & 0.07 & 0.07 & 0.07 & 0.09 & \begin{tabular}{|l|}
0.05 \\
\end{tabular} & 0.05 \\
\hline & Sun, Hol, Other & 0.04 & 0.04 & 0.04 & 0.04 & \begin{tabular}{|l|l|}
0.04 \\
\end{tabular} & 0.07 & 0.04 & \begin{tabular}{|l|}
0.04 \\
\end{tabular} & 0.04 & 0.04 & 0.04 & 0.06 & 0.06 & 0.09 & 0.06 & 0.04 & 0.04 & 0.04 & 0.04 & 0.04 & 0.04 & 0.07 & \begin{tabular}{|l|}
0.04 \\
\end{tabular} & 0.04 \\
\hline \multirow[t]{3}{*}{ INFIL_SCH_PNNL } & $\begin{array}{l}\text { WD, } \\
\text { SummerDesign }\end{array}$ & 1 & 1 & 1 & 1 & 1 & 1 & 0.25 & 0.25 & 0.25 & 0.25 & 0.25 & 0.25 & 0.25 & 0.25 & 0.25 & 0.25 & 0.25 & 0.25 & 0.25 & 0.25 & 0.25 & 0.25 & 1 & 1 \\
\hline & Sat, WinterDesign & 1 & 1 & 1 & 1 & 1 & 1 & 0.25 & \begin{tabular}{|l|}
0.25 \\
\end{tabular} & 0.25 & 0.25 & 0.25 & 0.25 & 0.25 & 0.25 & 0.25 & 0.25 & 0.25 & 0.25 & 1 & 1 & 1 & 1 & 1 & 1 \\
\hline & Sun, Hol, Other & 1 & 1 & 1 & 1 & 1 & 1 & 1 & 1 & 1 & 1 & 1 & 1 & 1 & 1 & 1 & 1 & 1 & 1 & 1 & 1 & 1 & 1 & 1 & 1 \\
\hline HVACOperationSchd & \begin{tabular}{|l|} 
WD, \\
SummerDesign
\end{tabular} & 0 & 0 & 0 & 0 & 0 & 0 & 1 & 1 & 1 & 1 & 1 & 1 & 1 & 1 & 1 & 1 & 1 & 1 & 1 & 1 & 1 & 1 & 0 & 0 \\
\hline \multirow{2}{*}{\begin{tabular}{|l} 
(Fan Schedule) \\
\end{tabular}} & \begin{tabular}{|l|} 
Sat, WinterDesign \\
\end{tabular} & 0 & 0 & 0 & 0 & 0 & 0 & 1 & 1 & 1 & 1 & 1 & 1 & 1 & 1 & 1 & 1 & 1 & 1 & 0 & 0 & 0 & 0 & 0 & 0 \\
\hline & Sun, Hol, Other & 0 & 0 & 0 & 0 & 0 & 0 & 0 & 0 & 0 & 0 & 0 & 0 & 0 & 0 & 0 & 0 & 0 & 0 & 0 & 0 & 0 & 0 & 0 & 0 \\
\hline \multirow[t]{5}{*}{\begin{tabular}{|l} 
HTGSETP_SCH \\
\end{tabular}} & WD & 60 & 60 & 60 & 60 & 60 & 64 & 67 & 70 & 70 & 70 & 70 & 70 & 70 & 70 & 70 & 70 & 70 & 70 & 70 & 70 & 70 & 70 & 60 & 60 \\
\hline & SummerDesign & 60 & 60 & 60 & 60 & 60 & 60 & 60 & 60 & 60 & 60 & 60 & 60 & 60 & 60 & 60 & 60 & 60 & 60 & 60 & 60 & 60 & 60 & 60 & 60 \\
\hline & Sat & 60 & 60 & 60 & 60 & 60 & 64 & 67 & 70 & 70 & 70 & 70 & 70 & 70 & 70 & 70 & 70 & 70 & 60 & 60 & 60 & 60 & 60 & 60 & 60 \\
\hline & WinterDesign & 60 & 60 & 60 & 60 & 60 & 64 & 67 & 70 & 70 & 70 & 70 & 70 & 70 & 70 & 70 & 70 & 70 & 70 & 70 & 70 & 70 & 70 & 60 & 60 \\
\hline & Sun, $\mathrm{Hol}$, Other & 60 & 60 & 60 & 60 & 60 & 60 & 60 & 60 & 60 & 60 & 60 & 60 & 60 & 60 & 60 & 60 & 60 & 60 & 60 & 60 & 60 & 60 & 60 & 60 \\
\hline \multirow[t]{5}{*}{ CLGSETP_SCH } & WD & 80 & 80 & 80 & 80 & 80 & 78 & 77 & 75 & 75 & 75 & 75 & 75 & 75 & 75 & 75 & 75 & 75 & 75 & 75 & 75 & 75 & 75 & 80 & 80 \\
\hline & SummerDesign & 80 & 80 & 80 & 80 & 80 & 78 & 77 & 75 & 75 & 75 & 75 & 75 & 75 & 75 & 75 & 75 & 75 & 75 & 75 & 75 & 75 & 75 & 80 & 80 \\
\hline & Sat & 80 & 80 & 80 & 80 & 80 & 78 & 77 & 75 & 75 & 75 & 75 & 75 & 75 & 75 & 75 & 75 & 75 & 80 & 80 & 80 & 80 & 80 & 80 & 80 \\
\hline & WinterDesign & 80 & 80 & 80 & 80 & 80 & 80 & 80 & 80 & 80 & 80 & 80 & 80 & 80 & 80 & 80 & 80 & 80 & 80 & 80 & 80 & 80 & 80 & 80 & 80 \\
\hline & Sun, $\mathrm{Hol}$, Other & 80 & 80 & 80 & 80 & 80 & 80 & 80 & 80 & 80 & 80 & 80 & 80 & 80 & 80 & 80 & 80 & 80 & 80 & 80 & 80 & 80 & 80 & 80 & 80 \\
\hline \begin{tabular}{|l|} 
Cool-Supply-Air-Temp-Sch \\
\end{tabular} & All & 55 & 55 & 55 & 55 & 55 & 55 & 55 & 55 & 55 & 55 & 55 & 55 & 55 & 55 & 55 & 55 & 55 & 55 & 55 & 55 & 55 & 55 & 55 & 55 \\
\hline Heat-Supply-Air-Temp-Sch & All & 55 & 55 & 55 & 55 & 55 & 55 & 55 & 55 & 55 & 55 & 55 & 55 & 55 & 55 & 55 & 55 & 55 & 55 & 55 & 55 & 55 & 55 & 55 & 55 \\
\hline
\end{tabular}




\begin{tabular}{|c|c|c|c|c|c|c|c|c|c|c|c|c|c|c|c|c|c|c|c|c|c|c|c|c|c|}
\hline Schedule & Day of Week & 1 & 2 & 3 & 4 & 5 & 6 & 7 & 8 & 9 & 10 & 11 & 12 & 13 & 14 & 15 & 16 & 17 & 18 & 19 & 20 & 21 & 22 & 23 & 24 \\
\hline CW-Loop-Temp-Schedule & All & 44 & 44 & 44 & 44 & 44 & 44 & 44 & 44 & 44 & 44 & 44 & 44 & 44 & 44 & 44 & 44 & 44 & 44 & 44 & 44 & 44 & 44 & 44 & 44 \\
\hline HW-Loop-Temp-Schedule & All & 180 & 180 & 180 & 180 & 180 & 180 & 180 & 180 & 180 & 180 & 180 & 180 & 180 & 180 & 180 & 180 & 180 & 180 & 180 & 180 & 180 & 180 & 180 & 180 \\
\hline MinOA_Sched & $\begin{array}{l}\text { WD, } \\
\text { SummerDesign }\end{array}$ & 1 & 1 & 1 & 1 & 1 & 1 & 1 & 1 & 1 & 1 & 1 & 1 & 1 & 1 & 1 & 1 & 1 & 1 & 1 & 1 & 1 & 1 & 1 & 1 \\
\hline \multirow[t]{2}{*}{ (Climate Zone 1-3) } & Sat, WinterDesign & 1 & 1 & 1 & 1 & 1 & 1 & 1 & 1 & 1 & 1 & 1 & 1 & 1 & 1 & 1 & 1 & 1 & 1 & 1 & 1 & 1 & 1 & 1 & 1 \\
\hline & Sun, Hol, Other & 1 & 1 & 1 & 1 & 1 & 1 & 1 & 1 & 1 & 1 & 1 & 1 & 1 & 1 & 1 & 1 & 1 & 1 & 1 & 1 & 1 & 1 & 1 & 1 \\
\hline $\begin{array}{l}\begin{array}{l}\text { MinOA_MotorizedDamper_ } \\
\text { sched }\end{array} \\
\end{array}$ & \begin{tabular}{|l} 
WD, \\
SummerDesign
\end{tabular} & 0 & 0 & 0 & 0 & 0 & 0 & 0 & 1 & 1 & 1 & 1 & 1 & 1 & 1 & 1 & 1 & 1 & 1 & 1 & 1 & 1 & 1 & 0 & 0 \\
\hline \multirow[t]{2}{*}{ (Climate Zone 4-8) } & Sat, WinterDesign & 0 & 0 & 0 & 0 & 0 & 0 & 0 & 1 & 1 & 1 & 1 & 1 & 1 & 1 & 1 & 1 & 1 & 1 & 0 & 0 & 0 & 0 & 0 & 0 \\
\hline & Sun, Hol, Other & 0 & 0 & 0 & 0 & 0 & 0 & 0 & 0 & 0 & 0 & 0 & 0 & 0 & 0 & 0 & 0 & 0 & 0 & 0 & 0 & 0 & 0 & 0 & 0 \\
\hline
\end{tabular}




\section{C.4 Stand-alone Retail Hourly Operation Schedules}

\begin{tabular}{|c|c|c|c|c|c|c|c|c|c|c|c|c|c|c|c|c|c|c|c|c|c|c|c|c|c|}
\hline Schedule & Day of Week & 1 & 2 & 3 & 4 & 5 & 6 & 7 & 8 & 9 & 10 & 11 & 12 & 13 & 14 & 15 & 16 & 17 & 18 & 19 & 20 & 21 & 22 & 23 & 24 \\
\hline \multirow[t]{5}{*}{ BLDG_LIGHT_SCH } & WD & 0.05 & 0.05 & 0.05 & 0.05 & 0.05 & 0.05 & 0.05 & 0.2 & 0.4 & 0.9 & 0.9 & 0.9 & 0.9 & 0.9 & 0.9 & 0.9 & 0.9 & 0.9 & 0.5 & 0.5 & 0.5 & 0.2 & 0.05 & 0.05 \\
\hline & SummerDesign & 1 & 1 & 1 & 1 & 1 & 1 & 1 & 1 & 1 & 1 & 1 & 1 & 1 & 1 & 1 & 1 & 1 & 1 & 1 & 1 & 1 & 1 & 1 & 1 \\
\hline & WinterDesign & 0 & 0 & 0 & 0 & 0 & 0 & 0 & 0 & 0 & 0 & 0 & 0 & 0 & 0 & 0 & 0 & 0 & 0 & 0 & 0 & 0 & 0 & 0 & 0 \\
\hline & Sat. & 0.05 & 0.05 & 0.05 & \begin{tabular}{|l|}
0.05 \\
\end{tabular} & 0.05 & 0.05 & 0.05 & 0.1 & 0.3 & 0.6 & 0.9 & 0.9 & 0.9 & 0.9 & 0.9 & 0.9 & 0.9 & 0.9 & 0.5 & 0.3 & 0.3 & 0.1 & 0.05 & 0.05 \\
\hline & Sun, Hol, Other & 0.05 & 0.05 & 0.05 & 0.05 & 0.05 & 0.05 & 0.05 & 0.05 & 0.05 & 0.1 & 0.4 & 0.4 & 0.6 & 0.6 & 0.6 & 0.6 & 0.6 & 0.4 & 0.2 & 0.05 & 0.05 & 0.05 & 0.05 & 0.05 \\
\hline \multirow[t]{5}{*}{ BLDG_EQUIP_SCH } & WD & 0.2 & 0.2 & 0.2 & 0.2 & 0.2 & 0.2 & 0.2 & 0.4 & 0.6 & 0.9 & 0.9 & 0.9 & 0.9 & 0.9 & 0.9 & 0.9 & 0.9 & 0.9 & 0.9 & 0.7 & 0.7 & 0.2 & 0.2 & 0.2 \\
\hline & SummerDesign & 1 & 1 & 1 & 1 & 1 & 1 & 1 & 1 & 1 & 1 & 1 & 1 & 1 & 1 & 1 & 1 & 1 & 1 & 1 & 1 & 1 & 1 & 1 & 1 \\
\hline & WinterDesign & 0 & 0 & 0 & 0 & 0 & 0 & 0 & 0 & 0 & 0 & 0 & 0 & 0 & 0 & 0 & 0 & 0 & 0 & 0 & 0 & 0 & 0 & 0 & 0 \\
\hline & Sat. & 0.15 & 0.15 & 0.15 & \begin{tabular}{|l|}
0.15 \\
\end{tabular} & 0.15 & 0.15 & 0.15 & 0.3 & 0.5 & 0.8 & 0.9 & 0.9 & 0.9 & 0.9 & 0.9 & 0.9 & 0.9 & 0.9 & 0.7 & 0.5 & 0.5 & 0.3 & 0.15 & 0.15 \\
\hline & Sun, Hol, Other & 0.15 & 0.15 & 0.15 & 0.15 & 0.15 & 0.15 & 0.15 & 0.15 & 0.15 & 0.3 & 0.6 & 0.6 & 0.8 & 0.8 & 0.8 & 0.8 & 0.8 & 0.6 & 0.4 & 0.15 & 0.15 & \begin{tabular}{|l|}
0.15 \\
\end{tabular} & 0.15 & 0.15 \\
\hline \multirow[t]{5}{*}{ BLDG_OCC_SCH } & WD & 0 & 0 & 0 & 0 & 0 & 0 & 0 & 0.1 & 0.2 & 0.5 & 0.5 & 0.7 & 0.7 & 0.7 & 0.7 & 0.8 & 0.7 & 0.5 & 0.5 & 0.3 & 0.3 & 0 & 0 & 0 \\
\hline & SummerDesign & 1 & 1 & 1 & 1 & 1 & 1 & 1 & 1 & 1 & 1 & 1 & 1 & 1 & 1 & 1 & 1 & 1 & 1 & 1 & 1 & 1 & 1 & 1 & 1 \\
\hline & WinterDesign & 0 & 0 & 0 & 0 & 0 & 0 & 0 & 0 & 0 & 0 & 0 & 0 & 0 & 0 & 0 & 0 & 0 & 0 & 0 & 0 & 0 & 0 & 0 & 0 \\
\hline & Sat. & 0 & 0 & 0 & 0 & 0 & 0 & 0 & 0.1 & 0.2 & 0.5 & 0.6 & 0.8 & 0.8 & 0.8 & 0.8 & 0.8 & 0.8 & 0.6 & 0.2 & 0.2 & 0.2 & 0.1 & 0 & 0 \\
\hline & Sun, Hol, Other & 0 & 0 & 0 & 0 & 0 & 0 & 0 & 0 & 0 & 0.1 & 0.2 & 0.2 & 0.4 & 0.4 & 0.4 & 0.4 & 0.4 & 0.2 & 0.1 & 0 & 0 & 0 & 0 & 0 \\
\hline \multirow[t]{2}{*}{ BLDG_EXTERIOR_LIGHT } & $\begin{array}{l}\text { WD, } \\
\text { SummerDesign }\end{array}$ & 1 & 1 & 1 & 1 & 1 & 1 & 1 & 1 & 1 & 1 & 1 & 1 & 1 & 1 & 1 & 1 & 1 & 1 & 1 & 1 & 1 & 1 & 1 & 1 \\
\hline & Sat, WinterDesign & 1 & 1 & 1 & 1 & 1 & 1 & 1 & 1 & 1 & 1 & 1 & 1 & 1 & 1 & 1 & 1 & 1 & 1 & 1 & 1 & 1 & 1 & 1 & 1 \\
\hline \multirow[t]{3}{*}{ BLDG_SWH_SCH } & $\begin{array}{l}\text { WD, } \\
\text { SummerDesign }\end{array}$ & 0.04 & 0.04 & 0.04 & \begin{tabular}{|l|}
0.04 \\
\end{tabular} & 0.04 & 0.04 & 0.04 & 0.15 & 0.23 & 0.32 & 0.41 & 0.57 & 0.62 & 0.61 & 0.5 & 0.45 & 0.46 & 0.47 & 0.42 & 0.34 & 0.33 & 0.04 & 0.04 & 0.04 \\
\hline & Sat, WinterDesign & 0.11 & 0.1 & 0.08 & 0.06 & 0.06 & 0.06 & 0.06 & 0.2 & 0.24 & 0.27 & 0.42 & 0.54 & 0.59 & 0.6 & 0.49 & 0.48 & 0.47 & 0.46 & \begin{tabular}{|l|l|}
0.44 \\
\end{tabular} & 0.36 & 0.29 & \begin{tabular}{|l|}
0.22 \\
\end{tabular} & 0.06 & 0.06 \\
\hline & Sun, Hol, Other & 0.07 & 0.07 & \begin{tabular}{|l|l|}
0.07 \\
\end{tabular} & \begin{tabular}{|l|}
0.06 \\
\end{tabular} & 0.06 & 0.06 & 0.06 & \begin{tabular}{|l|}
0.06 \\
\end{tabular} & \begin{tabular}{|l|}
0.06 \\
\end{tabular} & 0.14 & \begin{tabular}{|l|}
0.29 \\
\end{tabular} & \begin{tabular}{|l|}
0.31 \\
\end{tabular} & 0.36 & 0.36 & 0.34 & 0.35 & 0.37 & \begin{tabular}{|l|}
0.34 \\
\end{tabular} & \begin{tabular}{|l|}
0.25 \\
\end{tabular} & 0.06 & 0.06 & \begin{tabular}{|l|}
0.06 \\
\end{tabular} & 0.06 & \begin{tabular}{|l|}
0.06 \\
\end{tabular} \\
\hline \multirow[t]{3}{*}{ INFIL_SCH_PNNL } & $\begin{array}{l}\text { WD, } \\
\text { SummerDesign }\end{array}$ & 1 & 1 & 1 & 1 & 1 & 1 & 0.25 & 0.25 & 0.25 & 0.25 & 0.25 & 0.25 & 0.25 & 0.25 & 0.25 & 0.25 & 0.25 & 0.25 & 0.25 & 0.25 & 0.25 & 1 & 1 & 1 \\
\hline & Sat, WinterDesign & 1 & 1 & 1 & 1 & 1 & 1 & 0.25 & 0.25 & 0.25 & 0.25 & 0.25 & 0.25 & 0.25 & 0.25 & 0.25 & 0.25 & 0.25 & 0.25 & \begin{tabular}{|l|}
0.25 \\
\end{tabular} & 0.25 & 0.25 & \begin{tabular}{|l|}
0.25 \\
\end{tabular} & 1 & 1 \\
\hline & Sun, Hol, Other & 1 & 1 & 1 & 1 & 1 & 1 & 1 & 1 & 0.25 & 0.25 & \begin{tabular}{|l|l|}
0.25 \\
\end{tabular} & \begin{tabular}{|l|}
0.25 \\
\end{tabular} & 0.25 & 0.25 & 0.25 & 0.25 & 0.25 & 0.25 & \begin{tabular}{|l|}
0.25 \\
\end{tabular} & 1 & 1 & 1 & 1 & 1 \\
\hline HVACOperationSchd & $\begin{array}{l}\text { WD, } \\
\text { SummerDesign }\end{array}$ & 0 & 0 & 0 & 0 & 0 & 0 & 1 & 1 & 1 & 1 & 1 & 1 & 1 & 1 & 1 & 1 & 1 & 1 & 1 & 1 & 1 & 0 & 0 & 0 \\
\hline \multirow{2}{*}{ (FAN_SCH) } & Sat, WinterDesign & 0 & 0 & 0 & 0 & 0 & 0 & 1 & 1 & 1 & 1 & 1 & 1 & 1 & 1 & 1 & 1 & 1 & 1 & 1 & 1 & 1 & 1 & 0 & 0 \\
\hline & Sun, Hol, Other & 0 & 0 & 0 & 0 & 0 & 0 & 0 & 0 & 1 & 1 & 1 & 1 & 1 & 1 & 1 & 1 & 1 & 1 & 1 & 0 & 0 & 0 & 0 & 0 \\
\hline \multirow[t]{4}{*}{ HTGSETP_SCH } & WD, WinterDesign & 15.56 & 15.56 & 15.56 & 15.56 & 15.56 & 15.56 & 18.33 & 21.11 & \begin{tabular}{|l|}
21.11 \\
\end{tabular} & 21.11 & 21.11 & 21.11 & 21.11 & 21.11 & 21.11 & 21.11 & \begin{tabular}{|l|}
21.11 \\
\end{tabular} & 21.11 & \begin{tabular}{|l|}
21.11 \\
\end{tabular} & 21.11 & 21.11 & \begin{tabular}{|l|}
15.56 \\
\end{tabular} & 15.56 & 15.56 \\
\hline & SummerDesign & 15.56 & 15.56 & 15.56 & 15.56 & 15.56 & 15.56 & 15.56 & 15.56 & 15.56 & 15.56 & 15.56 & 15.56 & 15.56 & 15.56 & 15.56 & 15.56 & 15.56 & 15.56 & \begin{tabular}{|l|}
15.56 \\
\end{tabular} & 15.56 & 15.56 & 15.56 & 15.56 & 15.56 \\
\hline & Sat & 15.56 & 15.56 & 15.56 & \begin{tabular}{|l|}
15.56 \\
\end{tabular} & 15.56 & 15.56 & 18.33 & 21.11 & 21.11 & 21.11 & 21.11 & 21.11 & \begin{tabular}{|l|}
21.11 \\
\end{tabular} & 21.11 & 21.11 & 21.11 & 21.11 & 21.11 & \begin{tabular}{|l|}
21.11 \\
\end{tabular} & 21.11 & 21.11 & \begin{tabular}{|l|}
21.11 \\
\end{tabular} & 15.56 & 15.56 \\
\hline & Sun, Hol, Other & 15.56 & 15.56 & 15.56 & 15.56 & 15.56 & 15.56 & 15.56 & 15.56 & 18.33 & 21.11 & 21.11 & 21.11 & 21.11 & 21.11 & 21.11 & 21.11 & \begin{tabular}{|l|}
21.11 \\
\end{tabular} & 21.11 & \begin{tabular}{|l|}
21.11 \\
\end{tabular} & 15.56 & 15.56 & \begin{tabular}{|l|}
15.56 \\
\end{tabular} & 15.56 & 15.56 \\
\hline \multirow[t]{4}{*}{ HTGSETP_SCH } & WD, WinterDesign & 60 & 60 & 60 & 60 & 60 & 60 & 65 & 70 & 70 & 70 & 70 & 70 & 70 & 70 & 70 & 70 & 70 & 70 & 70 & 70 & 70 & 60 & 60 & 60 \\
\hline & SummerDesign & 60 & 60 & 60 & 60 & 60 & 60 & 60 & 60 & 60 & 60 & 60 & 60 & 60 & 60 & 60 & 60 & 60 & 60 & 60 & 60 & 60 & 60 & 60 & 60 \\
\hline & Sat & 60 & 60 & 60 & 60 & 60 & 60 & 65 & 70 & 70 & 70 & 70 & 70 & 70 & 70 & 70 & 70 & 70 & 70 & 70 & 70 & 70 & 70 & 60 & 60 \\
\hline & Sun, Hol, Other & 60 & 60 & 60 & 60 & 60 & 60 & 60 & 60 & 65 & 70 & 70 & 70 & 70 & 70 & 70 & 70 & 70 & 70 & 70 & 60 & 60 & 60 & 60 & 60 \\
\hline \multirow[t]{4}{*}{ CLGSETP_SCH } & $\begin{array}{l}\text { WD, } \\
\text { SummerDesign }\end{array}$ & 29.44 & 29.44 & 29.44 & 29.44 & 29.44 & 29.44 & 26.67 & 23.89 & 23.89 & 23.89 & 23.89 & 23.89 & 23.89 & 23.89 & 23.89 & 23.89 & 23.89 & 23.89 & 23.89 & 23.89 & 23.89 & 29.44 & 29.44 & 29.44 \\
\hline & WinterDesign & 29.44 & 29.44 & 29.44 & 29.44 & 29.44 & 29.44 & 29.44 & 29.44 & 29.44 & 29.44 & 29.44 & 29.44 & \begin{tabular}{|l|l|}
29.44 \\
\end{tabular} & 29.44 & 29.44 & 29.44 & 29.44 & \begin{tabular}{|l|}
29.44 \\
\end{tabular} & \begin{tabular}{|l|}
29.44 \\
\end{tabular} & 29.44 & \begin{tabular}{|l|}
29.44 \\
\end{tabular} & \begin{tabular}{|l|}
29.44 \\
\end{tabular} & 29.44 & 29.44 \\
\hline & Sat & 29.44 & 29.44 & 29.44 & 29.44 & 29.44 & 29.44 & 26.67 & 23.89 & 23.89 & 23.89 & 23.89 & 23.89 & 23.89 & 23.89 & 23.89 & 23.89 & 23.89 & 23.89 & \begin{tabular}{|l|}
23.89 \\
\end{tabular} & 23.89 & \begin{tabular}{|l|}
23.89 \\
\end{tabular} & \begin{tabular}{|l|}
23.89 \\
\end{tabular} & \begin{tabular}{|l|}
29.44 \\
\end{tabular} & 29.44 \\
\hline & Sun, Hol, Other & 29.44 & 29.44 & 29.44 & 29.44 & 29.44 & 29.44 & 29.44 & 29.44 & \begin{tabular}{|l|}
26.67 \\
\end{tabular} & 23.89 & 23.89 & 23.89 & 23.89 & 23.89 & 23.89 & 23.89 & 23.89 & \begin{tabular}{|l|}
23.89 \\
\end{tabular} & \begin{tabular}{|l|}
23.89 \\
\end{tabular} & 29.44 & \begin{tabular}{|l|}
29.44 \\
\end{tabular} & \begin{tabular}{|l|}
29.44 \\
\end{tabular} & \begin{tabular}{|l|}
29.44 \\
\end{tabular} & 29.44 \\
\hline \multirow[t]{4}{*}{ CLGSETP_SCH } & $\begin{array}{l}\text { WD, } \\
\text { SummerDesign }\end{array}$ & 85 & 85 & 85 & 85 & 85 & 85 & 80 & 75 & 75 & 75 & 75 & 75 & 75 & 75 & 75 & 75 & 75 & 75 & 75 & 75 & 75 & 85 & 85 & 85 \\
\hline & WinterDesign & 85 & 85 & 85 & 85 & 85 & 85 & 85 & 85 & 85 & 85 & 85 & 85 & 85 & 85 & 85 & 85 & 85 & 85 & 85 & 85 & 85 & 85 & 85 & 85 \\
\hline & Sat & 85 & 85 & 85 & 85 & 85 & 85 & 80 & 75 & 75 & 75 & 75 & 75 & 75 & 75 & 75 & 75 & 75 & 75 & 75 & 75 & 75 & 75 & 85 & 85 \\
\hline & Sun, Hol, Other & 85 & 85 & 85 & 85 & 85 & 85 & 85 & 85 & 80 & 75 & 75 & 75 & 75 & 75 & 75 & 75 & 75 & 75 & 75 & 85 & 85 & 85 & 85 & 85 \\
\hline \multirow[t]{2}{*}{ OA_DAMPER_SCH } & $\begin{array}{l}\text { WD, } \\
\text { SummerDesian }\end{array}$ & 1 & 1 & 1 & 1 & 1 & 1 & 1 & 1 & 1 & 1 & 1 & 1 & 1 & 1 & 1 & 1 & 1 & 1 & 1 & 1 & 1 & 1 & 1 & 1 \\
\hline & Sat, WinterDesign & 1 & 1 & 1 & 1 & 1 & 1 & 1 & 1 & 1 & 1 & 1 & 1 & 1 & 1 & 1 & 1 & 1 & 1 & 1 & 1 & 1 & 1 & 1 & 1 \\
\hline
\end{tabular}




\begin{tabular}{|l|l|l|l|l|l|l|l|l|l|l|l|l|l|l|l|l|l|c|c|c|c|c|c|c|c|}
\hline Schedule & Day of Week & $\mathbf{1}$ & $\mathbf{2}$ & $\mathbf{3}$ & $\mathbf{4}$ & $\mathbf{5}$ & $\mathbf{6}$ & $\mathbf{7}$ & $\mathbf{8}$ & $\mathbf{9}$ & $\mathbf{1 0}$ & $\mathbf{1 1}$ & $\mathbf{1 2}$ & $\mathbf{1 3}$ & $\mathbf{1 4}$ & $\mathbf{1 5}$ & $\mathbf{1 6}$ & $\mathbf{1 7}$ & $\mathbf{1 8}$ & $\mathbf{1 9}$ & $\mathbf{2 0}$ & $\mathbf{2 1}$ & $\mathbf{2 2}$ & $\mathbf{2 3}$ & $\mathbf{2 4}$ \\
\hline & Sun, Hol, Other & $\mathbf{1}$ & $\mathbf{1}$ & $\mathbf{1}$ & $\mathbf{1}$ & $\mathbf{1}$ & $\mathbf{1}$ & $\mathbf{1}$ & $\mathbf{1}$ & $\mathbf{1}$ & $\mathbf{1}$ & 1 & 1 & 1 & 1 & 1 & 1 & 1 & 1 & 1 & 1 & 1 & 1 & 1 & 1 \\
\hline $\begin{array}{l}\text { Dual Zone Control Type } \\
\text { Sched }\end{array}$ & All & 4 & 4 & 4 & 4 & 4 & 4 & 4 & 4 & 4 & 4 & 4 & 4 & 4 & 4 & 4 & 4 & 4 & 4 & 4 & 4 & 4 & 4 & 4 & 4 \\
\hline MinOA_Sched & All & 1 & 1 & 1 & 1 & 1 & 1 & 1 & 1 & 1 & 1 & 1 & 1 & 1 & 1 & 1 & 1 & 1 & 1 & 1 & 1 & 1 & 1 & 1 & 1 \\
\hline
\end{tabular}




\section{C.5 Strip Mall Hourly Operation Schedules}

\begin{tabular}{|c|c|c|c|c|c|c|c|c|c|c|c|c|c|c|c|c|c|c|c|c|c|c|c|c|c|}
\hline \multirow{6}{*}{\begin{tabular}{|l|} 
Schedule \\
Type1_LIGHT_SCH \\
\end{tabular}} & Day of Week & 1 & 2 & 3 & 4 & 5 & 6 & 7 & 8 & 9 & 10 & 11 & 12 & 13 & 14 & 15 & 16 & 17 & 18 & 19 & 20 & 21 & 22 & 23 & 24 \\
\hline & Monday-Thursday & 0.05 & 0.05 & 0.05 & 0.05 & 0.05 & 0.05 & 0.05 & 0.05 & 0.05 & 0.5 & 0.95 & 0.95 & 0.95 & 0.95 & 0.95 & 0.95 & 0.95 & 0.95 & 0.95 & 0.95 & 0.95 & 0.95 & 0.95 & 0.5 \\
\hline & Fri-Sat & 0.5 & 0.05 & 0.05 & 0.05 & 0.05 & 0.05 & 0.05 & 0.05 & 0.05 & 0.5 & 0.95 & 0.95 & 0.95 & 0.95 & 0.95 & 0.95 & 0.95 & 0.95 & 0.95 & 0.95 & 0.95 & 0.95 & 0.95 & 0.95 \\
\hline & Sun & 0.05 & 0.05 & 0.05 & 0.05 & 0.05 & 0.05 & 0.05 & 0.05 & 0.05 & 0.5 & 0.95 & 0.95 & 0.95 & 0.95 & 0.95 & 0.95 & 0.95 & 0.95 & 0.95 & 0.95 & 0.95 & 0.95 & 0.95 & 0.5 \\
\hline & SummerDesign & 1 & 1 & 1 & 1 & 1 & 1 & 1 & 1 & 1 & 1 & 1 & 1 & 1 & 1 & 1 & 1 & 1 & 1 & 1 & 1 & 1 & 1 & 1 & 1 \\
\hline & WinterDesign & 0 & 0 & 0 & 0 & 0 & 0 & 0 & 0 & 0 & 0 & 0 & 0 & 0 & 0 & 0 & 0 & 0 & 0 & 0 & 0 & 0 & 0 & 0 & 0 \\
\hline \multirow[t]{10}{*}{ Type2_LIGHT_SCH } & WD & 0.05 & 0.05 & 0.05 & 0.05 & 0.05 & 0.05 & 0.05 & 0.05 & 0.5 & 0.95 & 0.95 & 0.95 & 0.95 & 0.95 & 0.95 & 0.95 & 0.95 & 0.95 & 0.95 & 0.95 & 0.5 & 0.05 & 0.05 & 0.05 \\
\hline & Sat & 0.05 & 0.05 & 0.05 & 0.05 & 0.05 & 0.05 & 0.05 & 0.05 & 0.5 & 0.95 & 0.95 & 0.95 & 0.95 & 0.95 & 0.95 & 0.95 & 0.95 & 0.95 & 0.5 & 0.05 & 0.05 & 0.05 & 0.05 & 0.05 \\
\hline & Sun & 0.05 & 0.05 & 0.05 & 0.05 & 0.05 & 0.05 & 0.05 & 0.05 & 0.05 & 0.5 & 0.95 & 0.95 & 0.95 & 0.95 & 0.95 & 0.95 & 0.95 & 0.5 & 0.05 & 0.05 & 0.05 & 0.05 & 0.05 & 0.05 \\
\hline & SummerDesign & 1 & 1 & 1 & 1 & 1 & 1 & 1 & 1 & 1 & 1 & 1 & 1 & 1 & 1 & 1 & 1 & 1 & 1 & 1 & 1 & 1 & 1 & 1 & 1 \\
\hline & WinterDesign & 0 & 0 & 0 & 0 & 0 & 0 & 0 & 0 & 0 & 0 & 0 & 0 & 0 & 0 & 0 & 0 & 0 & 0 & 0 & 0 & 0 & 0 & 0 & 0 \\
\hline & WD & 0.05 & 0.05 & 0.05 & 0.05 & 0.05 & 0.05 & 0.05 & 0.05 & 0.05 & 0.5 & 0.95 & 0.95 & 0.95 & 0.95 & 0.95 & 0.95 & 0.95 & 0.95 & 0.95 & 0.95 & 0.5 & 0.05 & 0.05 & 0.05 \\
\hline & Sat & 0.05 & 0.05 & 0.05 & 0.05 & 0.05 & 0.05 & 0.05 & 0.05 & 0.05 & 0.5 & 0.95 & 0.95 & 0.95 & 0.95 & 0.95 & 0.95 & 0.95 & 0.95 & 0.5 & 0.05 & 0.05 & 0.05 & 0.05 & 0.05 \\
\hline & Sun & 0.05 & 0.05 & 0.05 & 0.05 & 0.05 & 0.05 & 0.05 & 0.05 & 0.05 & 0.05 & 0.5 & 0.95 & 0.95 & 0.95 & 0.95 & 0.95 & 0.95 & 0.5 & 0.05 & 0.05 & 0.05 & 0.05 & 0.05 & 0.05 \\
\hline & SummerDesign & 1 & 1 & 1 & 1 & 1 & 1 & 1 & 1 & 1 & 1 & 1 & 1 & 1 & 1 & 1 & 1 & 1 & 1 & 1 & 1 & 1 & 1 & 1 & 1 \\
\hline & WinterDesign & 0 & 0 & 0 & 0 & 0 & 0 & 0 & 0 & 0 & 0 & 0 & 0 & 0 & 0 & 0 & 0 & 0 & 0 & 0 & 0 & 0 & 0 & 0 & 0 \\
\hline \multirow[t]{10}{*}{ Type1_OCC_SCH } & Monday-Thursday & 0.00 & 0.00 & 0.00 & 0.00 & 0.00 & 0.00 & 0.00 & 0.00 & 0.05 & 0.05 & 0.10 & 0.10 & 0.20 & 0.40 & 0.40 & 0.25 & 0.25 & 0.50 & 0.50 & 0.50 & 0.30 & 0.30 & 0.30 & 0.05 \\
\hline & Fri-Sat & 0.05 & 0.00 & 0.00 & 0.00 & 0.00 & 0.00 & 0.00 & 0.00 & 0.00 & 0.05 & 0.10 & 0.10 & 0.20 & 0.60 & 0.40 & 0.25 & 0.25 & 0.50 & 0.50 & 0.50 & 0.30 & 0.30 & 0.30 & 0.20 \\
\hline & Sun & 0.00 & 0.00 & 0.00 & 0.00 & 0.00 & 0.00 & 0.00 & 0.00 & 0.05 & 0.05 & 0.10 & 0.20 & 0.40 & 0.60 & 0.40 & 0.40 & 0.30 & 0.60 & 0.60 & 0.40 & 0.40 & 0.30 & 0.20 & 0.05 \\
\hline & SummerDesign & 1.00 & 1.00 & 1.00 & 1.00 & 1.00 & 1.00 & 1.00 & 1.00 & 1.00 & 1.00 & 1.00 & 1.00 & 1.00 & 1.00 & 1.00 & 1.00 & 1.00 & 1.00 & 1.00 & 1.00 & 1.00 & 1.00 & 1.00 & 1.00 \\
\hline & WinterDesign & 0.00 & 0.00 & 0.00 & 0.00 & 0.00 & 0.00 & 0.00 & 0.00 & 0.00 & 0.00 & 0.00 & 0.00 & 0.00 & 0.00 & 0.00 & 0.00 & 0.00 & 0.00 & 0.00 & 0.00 & 0.00 & 0.00 & 0.00 & 0.00 \\
\hline & WD & 0.00 & 0.00 & 0.00 & 0.00 & 0.00 & 0.00 & 0.00 & 0.00 & 0.05 & 0.10 & 0.10 & 0.10 & 0.20 & 0.40 & 0.30 & 0.20 & 0.20 & 0.50 & 0.50 & 0.20 & 0.05 & 0.00 & 0.00 & 0.00 \\
\hline & Sat & 0.00 & 0.00 & 0.00 & 0.00 & 0.00 & 0.00 & 0.00 & 0.00 & 0.05 & 0.10 & 0.10 & 0.20 & 0.40 & 0.60 & 0.40 & 0.30 & 0.30 & 0.30 & 0.05 & 0.00 & 0.00 & 0.00 & 0.00 & 0.00 \\
\hline & Sun & 0.00 & 0.00 & 0.00 & 0.00 & 0.00 & 0.00 & 0.00 & 0.00 & 0.00 & 0.05 & 0.10 & 0.20 & 0.40 & 0.40 & 0.30 & 0.20 & 0.10 & 0.05 & 0.00 & 0.00 & 0.00 & 0.00 & 0.00 & 0.00 \\
\hline & SummerDesign & 1.00 & 1.00 & 1.00 & 1.00 & 1.00 & 1.00 & 1.00 & 1.00 & 1.00 & 1.00 & 1.00 & 1.00 & 1.00 & 1.00 & 1.00 & 1.00 & 1.00 & 1.00 & 1.00 & 1.00 & 1.00 & 1.00 & 1.00 & 1.00 \\
\hline & WinterDesign & 0.00 & 0.00 & 0.00 & 0.00 & 0.00 & 0.00 & 0.00 & 0.00 & 0.00 & 0.00 & 0.00 & 0.00 & 0.00 & 0.00 & 0.00 & 0.00 & 0.00 & 0.00 & 0.00 & 0.00 & 0.00 & 0.00 & 0.00 & 0.00 \\
\hline \multirow[t]{5}{*}{ Type3_OCC_SCH } & WD & 0.00 & 0.00 & 0.00 & 0.00 & 0.00 & 0.00 & 0.00 & 0.00 & 0.00 & 0.11 & 0.11 & 0.43 & 0.46 & 0.71 & 0.50 & 0.69 & 0.54 & 0.71 & 0.34 & 0.26 & 0.11 & 0.00 & 0.00 & 0.00 \\
\hline & Sat & 0.00 & 0.00 & 0.00 & 0.00 & 0.00 & 0.00 & 0.00 & 0.00 & 0.00 & 0.11 & 0.11 & 0.58 & 0.71 & 0.74 & 0.77 & 0.80 & 0.74 & 0.54 & 0.11 & 0.00 & 0.00 & 0.00 & 0.00 & 0.00 \\
\hline & Sun & 0.00 & 0.00 & 0.00 & 0.00 & 0.00 & 0.00 & 0.00 & 0.00 & 0.00 & 0.00 & 0.11 & 0.11 & 0.43 & 0.46 & 0.50 & 0.69 & 0.34 & 0.11 & 0.00 & 0.00 & 0.00 & 0.00 & 0.00 & 0.00 \\
\hline & SummerDesign & 1.00 & 1.00 & 1.00 & 1.00 & 1.00 & 1.00 & 1.00 & 1.00 & 1.00 & 1.00 & 1.00 & 1.00 & 1.00 & 1.00 & 1.00 & 1.00 & 1.00 & 1.00 & 1.00 & 1.00 & 1.00 & 1.00 & 1.00 & 1.00 \\
\hline & WinterDesign & 0.00 & 0.00 & 0.00 & 0.00 & 0.00 & 0.00 & 0.00 & 0.00 & 0.00 & 0.00 & 0.00 & 0.00 & 0.00 & 0.00 & 0.00 & 0.00 & 0.00 & 0.00 & 0.00 & 0.00 & 0.00 & 0.00 & 0.00 & 0.00 \\
\hline \multirow[t]{5}{*}{ Type1_EQUIP_SCH } & Monday-Thursday & 0.05 & 0.05 & 0.05 & 0.05 & 0.05 & 0.05 & 0.05 & 0.05 & 0.05 & 0.50 & 0.90 & 0.90 & 0.90 & 0.90 & 0.90 & 0.90 & 0.90 & 0.90 & 0.90 & 0.90 & 0.90 & 0.90 & 0.90 & 0.50 \\
\hline & Fri-Sat & 0.50 & 0.05 & 0.05 & 0.05 & 0.05 & 0.05 & 0.05 & 0.05 & 0.05 & 0.50 & 0.90 & 0.90 & 0.90 & 0.90 & 0.90 & 0.90 & 0.90 & 0.90 & 0.90 & 0.90 & 0.90 & 0.90 & 0.90 & 0.90 \\
\hline & Sun & 0.05 & 0.05 & 0.05 & 0.05 & 0.05 & 0.05 & 0.05 & 0.05 & 0.05 & 0.50 & 0.90 & 0.90 & 0.90 & 0.90 & 0.90 & 0.90 & 0.90 & 0.90 & 0.90 & 0.90 & 0.90 & 0.90 & 0.90 & 0.50 \\
\hline & SummerDesign & 1.00 & 1.00 & 1.00 & 1.00 & 1.00 & 1.00 & 1.00 & 1.00 & 1.00 & 1.00 & 1.00 & 1.00 & 1.00 & 1.00 & 1.00 & 1.00 & 1.00 & 1.00 & 1.00 & 1.00 & 1.00 & 1.00 & 1.00 & 1.00 \\
\hline & WinterDesign & 0.00 & 0.00 & 0.00 & 0.00 & 0.00 & 0.00 & 0.00 & 0.00 & 0.00 & 0.00 & 0.00 & 0.00 & 0.00 & 0.00 & 0.00 & 0.00 & 0.00 & 0.00 & 0.00 & 0.00 & 0.00 & 0.00 & 0.00 & 0.00 \\
\hline \multirow[t]{5}{*}{ Type2_EQUIP_SCH } & WD & 0.05 & 0.05 & 0.05 & 0.05 & 0.05 & 0.05 & 0.05 & 0.05 & 0.50 & 0.90 & 0.90 & 0.90 & 0.90 & 0.90 & 0.90 & 0.90 & 0.90 & 0.90 & 0.90 & 0.90 & 0.50 & 0.05 & 0.05 & 0.05 \\
\hline & Sat & 0.05 & 0.05 & 0.05 & 0.05 & 0.05 & 0.05 & 0.05 & 0.05 & 0.50 & 0.90 & 0.90 & 0.90 & 0.90 & 0.90 & 0.90 & 0.90 & 0.90 & 0.90 & 0.50 & 0.05 & 0.05 & 0.05 & 0.05 & 0.05 \\
\hline & Sun & 0.05 & 0.05 & 0.05 & 0.05 & 0.05 & 0.05 & 0.05 & 0.05 & 0.05 & 0.50 & 0.90 & 0.90 & 0.90 & 0.90 & 0.90 & 0.90 & 0.90 & 0.50 & 0.05 & 0.05 & 0.05 & 0.05 & 0.05 & 0.05 \\
\hline & SummerDesign & 1.00 & 1.00 & 1.00 & 1.00 & 1.00 & 1.00 & 1.00 & 1.00 & 1.00 & 1.00 & 1.00 & 1.00 & 1.00 & 1.00 & 1.00 & 1.00 & 1.00 & 1.00 & 1.00 & 1.00 & 1.00 & 1.00 & 1.00 & 1.00 \\
\hline & WinterDesign & 0.00 & 0.00 & 0.00 & 0.00 & 0.00 & 0.00 & 0.00 & 0.00 & 0.00 & 0.00 & 0.00 & 0.00 & 0.00 & 0.00 & 0.00 & 0.00 & 0.00 & 0.00 & 0.00 & 0.00 & 0.00 & 0.00 & 0.00 & 0.00 \\
\hline \multirow[t]{5}{*}{ Type3_EQUIP_SCH } & WD & 0.05 & 0.05 & 0.05 & 0.05 & 0.05 & 0.05 & 0.05 & 0.05 & 0.05 & 0.5 & 0.9 & 0.9 & 0.9 & 0.9 & 0.9 & 0.9 & 0.9 & 0.9 & 0.9 & 0.9 & 0.5 & 0.05 & 0.05 & 0.05 \\
\hline & Sat & 0.05 & 0.05 & 0.05 & 0.05 & 0.05 & 0.05 & 0.05 & 0.05 & 0.05 & 0.5 & 0.9 & 0.9 & 0.9 & 0.9 & 0.9 & 0.9 & 0.9 & 0.9 & 0.5 & 0.05 & 0.05 & 0.05 & 0.05 & 0.05 \\
\hline & Sun & 0.05 & 0.05 & 0.05 & 0.05 & 0.05 & 0.05 & 0.05 & 0.05 & 0.05 & 0.05 & 0.5 & 0.9 & 0.9 & 0.9 & 0.9 & 0.9 & 0.9 & 0.5 & 0.05 & 0.05 & 0.05 & 0.05 & 0.05 & 0.05 \\
\hline & SummerDesign & 1 & 1 & 1 & 1 & 1 & 1 & 1 & 1 & 1 & 1 & 1 & 1 & 1 & 1 & 1 & 1 & 1 & 1 & 1 & 1 & 1 & 1 & 1 & 1 \\
\hline & WinterDesign & 0 & 0 & 0 & 0 & 0 & 0 & 0 & 0 & 0 & 0 & 0 & 0 & 0 & 0 & 0 & 0 & 0 & 0 & 0 & 0 & 0 & 0 & 0 & 0 \\
\hline ALWAYS_ON & $\begin{array}{l}\text { WD, } \\
\text { SummerDesign }\end{array}$ & 1 & 1 & 1 & 1 & 1 & 1 & 1 & 1 & 1 & 1 & 1 & 1 & 1 & 1 & 1 & 1 & 1 & 1 & 1 & 1 & 1 & 1 & 1 & 1 \\
\hline (AstronomicalClock control) & Sat, WinterDesign & 1 & 1 & 1 & 1 & 1 & 1 & 1 & 1 & 1 & 1 & 1 & 1 & 1 & 1 & 1 & 1 & 1 & 1 & 1 & 1 & 1 & 1 & 1 & 1 \\
\hline
\end{tabular}




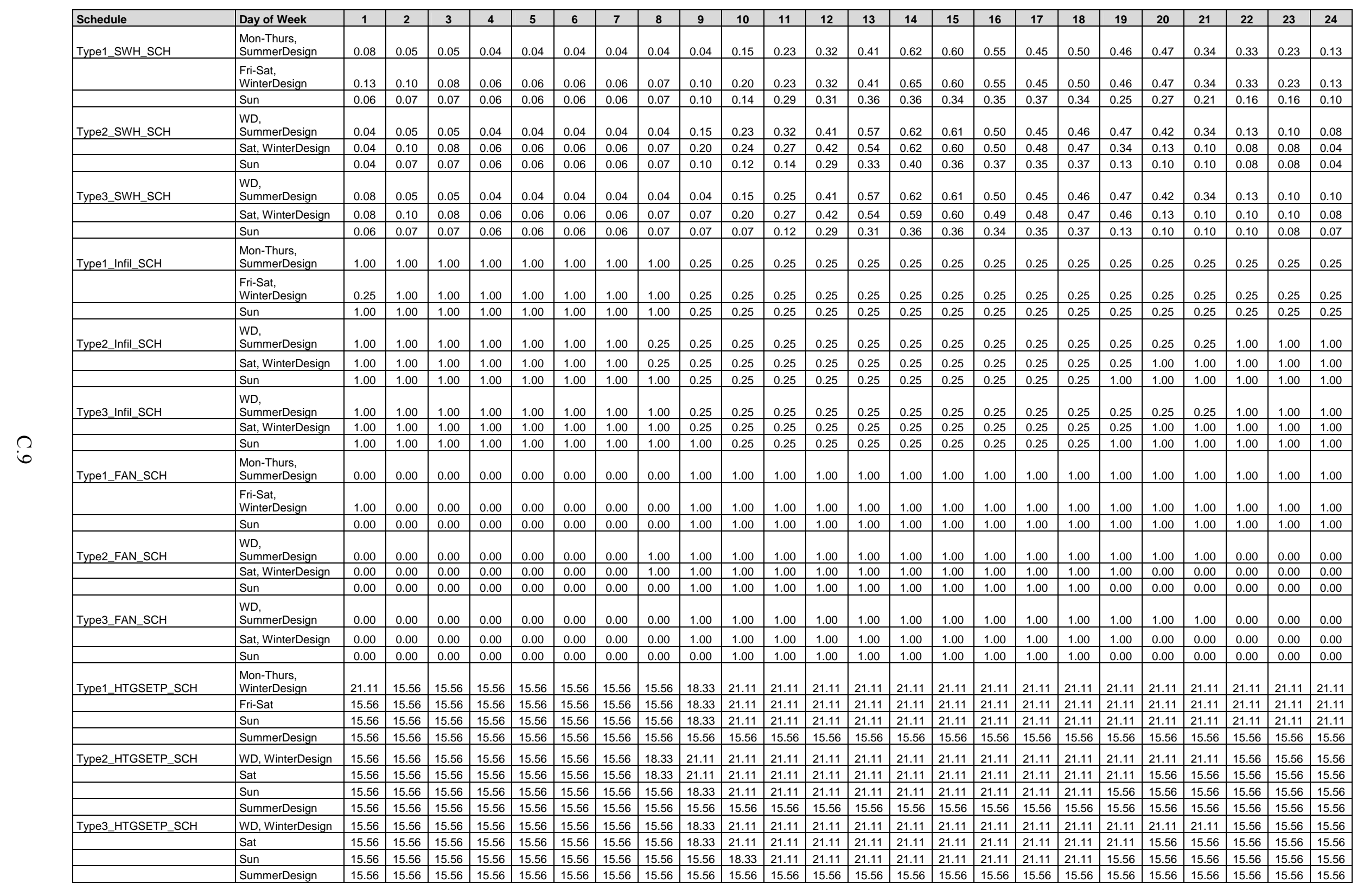




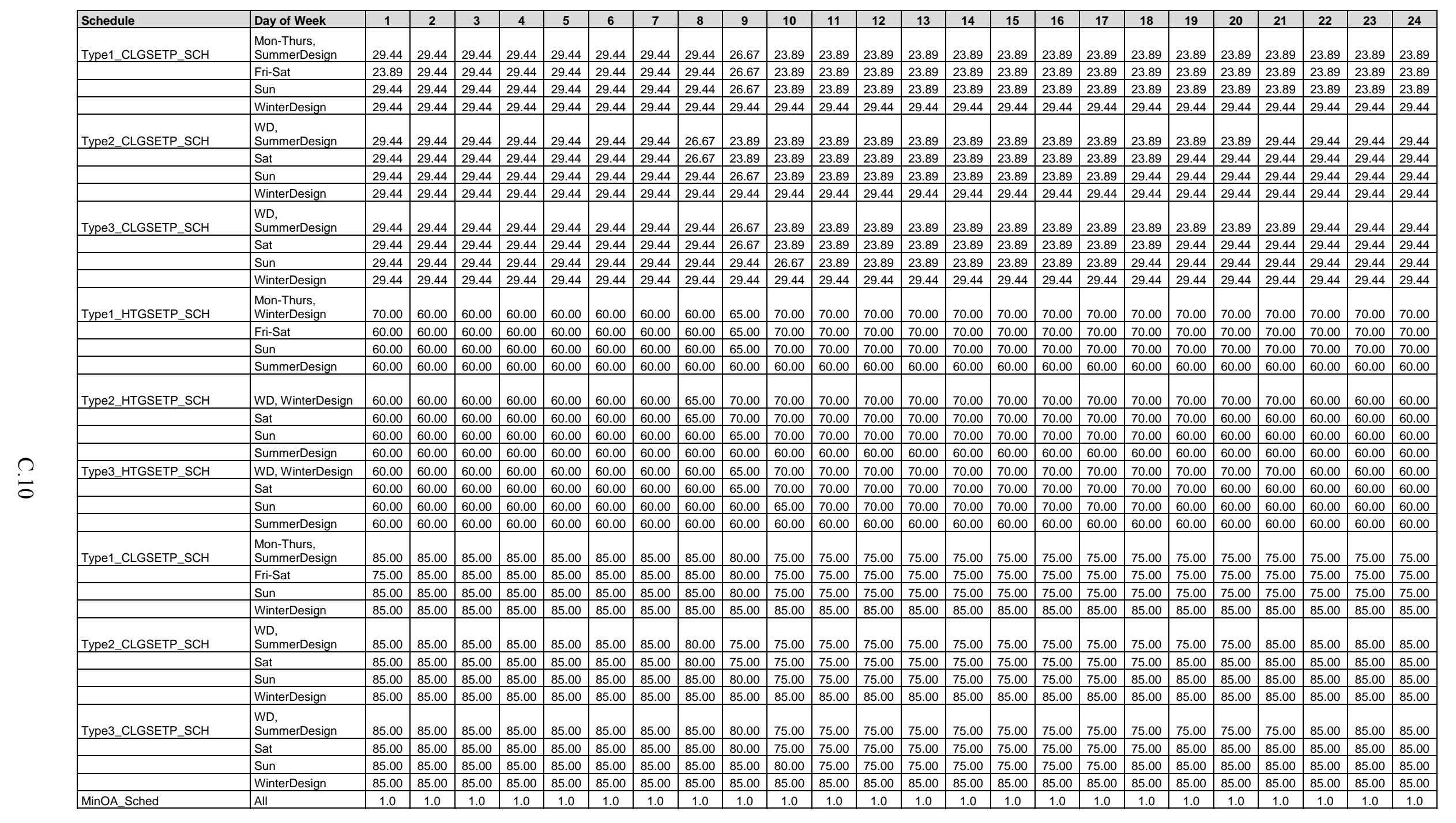




\section{C.6 Primary School Hourly Operation Schedules}

\begin{tabular}{|c|c|c|c|c|c|c|c|c|c|c|c|c|c|c|c|c|c|c|c|c|c|c|c|c|c|}
\hline Schedule & Day of Week & 1 & 2 & 3 & 4 & 5 & 6 & 7 & 8 & 9 & 10 & 11 & 12 & 13 & 14 & 15 & 16 & 17 & 18 & 19 & 20 & 21 & 22 & 23 & 24 \\
\hline BLDG_LIGHT_SCH & $\begin{array}{l}\text { WD, } \\
\text { SummerDesign }\end{array}$ & 0.18 & 0.18 & 0.18 & 0.18 & 0.18 & 0.18 & 0.18 & 0.9 & 0.9 & 0.9 & 0.9 & 0.9 & 0.9 & 0.9 & 0.9 & 0.9 & 0.9 & 0.9 & 0.9 & 0.9 & 0.9 & 0.18 & 0.18 & 0.18 \\
\hline (Study Periods) & \begin{tabular}{|l|} 
Sat, Sun, Hol, \\
WinterDesign, \\
Other \\
\end{tabular} & 0.18 & 0.18 & 0.18 & 0.18 & 0.18 & 0.18 & 0.18 & 0.18 & 0.18 & 0.18 & 0.18 & 0.18 & 0.18 & 0.18 & 0.18 & 0.18 & 0.18 & 0.18 & 0.18 & 0.18 & 0.18 & 0.18 & 0.18 & 0.18 \\
\hline BLDG_LIGHT_SCH & \begin{tabular}{l|} 
WD, \\
SummerDesign
\end{tabular} & 0.18 & 0.18 & 0.18 & 0.18 & 0.18 & 0.18 & 0.18 & 0.18 & 0.5 & 0.5 & 0.5 & 0.5 & 0.5 & 0.5 & 0.5 & 0.5 & 0.5 & 0.5 & 0.5 & 0.5 & 0.18 & 0.18 & 0.18 & 0.18 \\
\hline (Summer Holiday) & $\begin{array}{l}\text { Sat, Sun, Hol, } \\
\text { WinterDesign, } \\
\text { Other } \\
\end{array}$ & 0.18 & 0.18 & 0.18 & 0.18 & 0.18 & 0.18 & 0.18 & 0.18 & 0.18 & 0.18 & 0.18 & 0.18 & 0.18 & 0.18 & 0.18 & 0.18 & 0.18 & 0.18 & 0.18 & 0.18 & 0.18 & 0.18 & 0.18 & 0.18 \\
\hline BLDG_EQUIP_SCH & $\begin{array}{l}\text { WD, } \\
\text { SummerDesign }\end{array}$ & 0.35 & 0.35 & 0.35 & 0.35 & 0.35 & 0.35 & 0.35 & 0.35 & 0.95 & 0.95 & 0.95 & 0.95 & 0.95 & 0.95 & 0.95 & 0.95 & 0.95 & 0.35 & 0.35 & 0.35 & 0.35 & 0.35 & 0.35 & 0.35 \\
\hline (Study Periods) & \begin{tabular}{|l|} 
Sat, Sun, Hol, \\
WinterDesign, \\
Other \\
\end{tabular} & 0.35 & 0.35 & 0.35 & 0.35 & 0.35 & 0.35 & 0.35 & 0.35 & 0.35 & 0.35 & 0.35 & 0.35 & 0.35 & 0.35 & 0.35 & 0.35 & 0.35 & 0.35 & 0.35 & 0.35 & 0.35 & 0.35 & 0.35 & 0.35 \\
\hline BLDG_EQUIP_SCH & $\begin{array}{l}\text { WD, } \\
\text { SummerDesign }\end{array}$ & 0.25 & 0.25 & 0.25 & 0.25 & 0.25 & 0.25 & 0.25 & 0.25 & 0.5 & 0.5 & 0.5 & 0.5 & 0.5 & 0.5 & 0.5 & 0.5 & 0.5 & 0.25 & 0.25 & 0.25 & 0.25 & 0.25 & 0.25 & 0.25 \\
\hline (Summer Holiday) & $\begin{array}{l}\text { Sat, Sun, Hol, } \\
\text { WinterDesign, } \\
\text { Other } \\
\end{array}$ & 0.25 & 0.25 & 0.25 & 0.25 & 0.25 & 0.25 & 0.25 & 0.25 & 0.25 & 0.25 & 0.25 & 0.25 & 0.25 & 0.25 & 0.25 & 0.25 & 0.25 & 0.25 & 0.25 & 0.25 & 0.25 & 0.25 & 0.25 & 0.25 \\
\hline Kitchen_Elec_EQUIP_SCH & $\begin{array}{l}\text { WD, } \\
\text { SummerDesign }\end{array}$ & 0.1 & 0.1 & 0.1 & 0.1 & 0.1 & 0.1 & 0.1 & 0.1 & 0.15 & 0.15 & 0.25 & 0.25 & 0.25 & 0.15 & 0.15 & 0.1 & 0.1 & 0.1 & 0.1 & 0.1 & 0.1 & 0.1 & 0.1 & 0.1 \\
\hline (Study Periods) & \begin{tabular}{|l|} 
Sat, Sun, Hol, \\
WinterDesign, \\
Other \\
\end{tabular} & 0.1 & 0.1 & 0.1 & 0.1 & 0.1 & 0.1 & 0.1 & 0.1 & 0.1 & 0.1 & 0.1 & 0.1 & 0.1 & 0.1 & 0.1 & 0.1 & 0.1 & 0.1 & 0.1 & 0.1 & 0.1 & 0.1 & 0.1 & 0.1 \\
\hline Kitchen_Elec_EQUIP_SCH & \begin{tabular}{|l|} 
WD, \\
SummerDesign
\end{tabular} & 0.1 & 0.1 & 0.1 & 0.1 & 0.1 & 0.1 & 0.1 & 0.1 & 0.15 & 0.15 & 0.25 & 0.25 & 0.25 & 0.15 & 0.15 & 0.1 & 0.1 & 0.1 & 0.1 & 0.1 & 0.1 & 0.1 & 0.1 & 0.1 \\
\hline (Summer Holiday) & \begin{tabular}{|l|} 
Sat, Sun, Hol, \\
WinterDesign, \\
Other \\
\end{tabular} & 0.1 & 0.1 & 0.1 & 0.1 & 0.1 & 0.1 & 0.1 & 0.1 & 0.1 & 0.1 & 0.1 & 0.1 & 0.1 & 0.1 & 0.1 & 0.1 & 0.1 & 0.1 & 0.1 & 0.1 & 0.1 & 0.1 & 0.1 & 0.1 \\
\hline Kitchen_Gas_EQUIP_SCH & \begin{tabular}{l|} 
WD, \\
SummerDesign
\end{tabular} & 0.02 & 0.02 & 0.02 & 0.02 & 0.02 & 0.02 & 0.02 & 0.02 & 0.15 & 0.15 & 0.2 & 0.2 & 0.2 & 0.1 & 0.1 & 0.02 & 0.02 & 0.02 & 0.02 & 0.02 & 0.02 & 0.02 & 0.02 & 0.02 \\
\hline (Study Periods) & \begin{tabular}{|l|} 
Sat, Sun, Hol, \\
WinterDesign, \\
Other \\
\end{tabular} & 0.02 & 0.02 & 0.02 & 0.02 & 0.02 & 0.02 & 0.02 & 0.02 & 0.02 & 0.02 & 0.02 & 0.02 & 0.02 & 0.02 & 0.02 & 0.02 & 0.02 & 0.02 & 0.02 & 0.02 & 0.02 & 0.02 & 0.02 & 0.02 \\
\hline Kitchen_Gas_EQUIP_SCH & $\begin{array}{l}\text { WD, } \\
\text { SummerDesign }\end{array}$ & 0.02 & 0.02 & 0.02 & 0.02 & 0.02 & 0.02 & 0.02 & 0.02 & 0.15 & 0.15 & 0.2 & 0.2 & 0.2 & 0.1 & 0.1 & 0.02 & 0.02 & 0.02 & 0.02 & 0.02 & 0.02 & 0.02 & 0.02 & 0.02 \\
\hline (Summer Holiday) & \begin{tabular}{|l|} 
Sat, Sun, Hol, \\
WinterDesign, \\
Other
\end{tabular} & 0.02 & 0.02 & 0.02 & 0.02 & 0.02 & 0.02 & 0.02 & 0.02 & 0.02 & 0.02 & 0.02 & 0.02 & 0.02 & 0.02 & 0.02 & 0.02 & 0.02 & 0.02 & 0.02 & 0.02 & 0.02 & 0.02 & 0.02 & 0.02 \\
\hline BLDG_OCC_SCH & $\begin{array}{l}\text { WD, } \\
\text { SummerDesign }\end{array}$ & 0 & 0 & 0 & 0 & 0 & 0 & 0 & 0 & 0.95 & 0.95 & 0.95 & 0.95 & 0.95 & 0.95 & 0.95 & 0.95 & 0.15 & 0.15 & 0.15 & 0.15 & 0.15 & 0 & 0 & 0 \\
\hline (Study Periods) & \begin{tabular}{|l|} 
Sat, Sun, Hol, \\
WinterDesign, \\
Other
\end{tabular} & 0 & 0 & 0 & 0 & 0 & 0 & 0 & 0 & 0 & 0 & 0 & 0 & 0 & 0 & 0 & 0 & 0 & 0 & 0 & 0 & 0 & 0 & 0 & 0 \\
\hline BLDG_OCC_SCH & $\begin{array}{l}\text { WD, } \\
\text { SummerDesign }\end{array}$ & 0 & 0 & 0 & 0 & 0 & 0 & 0 & 0 & 0.15 & 0.15 & 0.15 & 0.15 & 0.15 & 0.15 & 0.15 & 0.15 & 0.15 & 0.15 & 0.15 & 0.15 & 0.15 & 0 & 0 & 0 \\
\hline (Summer Holiday) & \begin{tabular}{|l|} 
Sat, Sun, Hol, \\
WinterDesign, \\
Other \\
\end{tabular} & 0 & 0 & 0 & 0 & 0 & 0 & 0 & 0 & 0 & 0 & 0 & 0 & 0 & 0 & 0 & 0 & 0 & 0 & 0 & 0 & 0 & 0 & 0 & 0 \\
\hline BLDG_OCC_Extend & $\begin{array}{l}\text { WD, } \\
\text { SummerDesign }\end{array}$ & 0 & 0 & 0 & 0 & 0 & 0 & 0 & 0 & 0.95 & 0.95 & 0.95 & 0.95 & 0.95 & 0.95 & 0.95 & 0.95 & 0.95 & 0.95 & 0.95 & 0.95 & 0.95 & 0 & 0 & 0 \\
\hline (Study Periods) & \begin{tabular}{|l|} 
Sat, Sun, Hol, \\
WinterDesign, \\
Other \\
\end{tabular} & 0 & 0 & 0 & 0 & 0 & 0 & 0 & 0 & 0 & 0 & 0 & 0 & 0 & 0 & 0 & 0 & 0 & 0 & 0 & 0 & 0 & 0 & 0 & 0 \\
\hline BLDG_OCC_Extend & $\begin{array}{l}\text { WD, } \\
\text { SummerDesign }\end{array}$ & 0 & 0 & 0 & 0 & 0 & 0 & 0 & 0 & 0.5 & 0.5 & 0.5 & 0.5 & 0.5 & 0.5 & 0.5 & 0.5 & 0.5 & 0.5 & 0.5 & 0.5 & 0.5 & 0 & 0 & 0 \\
\hline (Summer Holiday) & $\begin{array}{l}\text { Sat, Sun, Hol, } \\
\text { WinterDesign, } \\
\text { Other } \\
\end{array}$ & 0 & 0 & 0 & 0 & 0 & 0 & 0 & 0 & 0 & 0 & 0 & 0 & 0 & 0 & 0 & 0 & 0 & 0 & 0 & 0 & 0 & 0 & 0 & 0 \\
\hline
\end{tabular}




\begin{tabular}{|c|c|c|c|c|c|c|c|c|c|c|c|c|c|c|c|c|c|c|c|c|c|c|c|c|c|}
\hline Schedule & Day of Week & 1 & 2 & 3 & 4 & 5 & 6 & 7 & 8 & 9 & 10 & 11 & 12 & 13 & 14 & 15 & 16 & 17 & 18 & 19 & 20 & 21 & 22 & 23 & 24 \\
\hline BLDG_OCC_SCH_Offices & $\begin{array}{l}\text { WD, } \\
\text { SummerDesign }\end{array}$ & 0 & 0 & 0 & 0 & 0 & 0 & 0 & 0 & 0.95 & 0.95 & 0.95 & 0.95 & 0.95 & 0.95 & 0.95 & 0.95 & 0.95 & 0.15 & 0.15 & 0.15 & 0.15 & 0 & 0 & 0 \\
\hline (Study Periods) & $\begin{array}{l}\text { Sat, Sun, Hol, } \\
\text { WinterDesign, } \\
\text { Other }\end{array}$ & 0 & 0 & 0 & 0 & 0 & 0 & 0 & 0 & 0 & 0 & 0 & 0 & 0 & 0 & 0 & 0 & 0 & 0 & 0 & 0 & 0 & 0 & 0 & 0 \\
\hline BLDG_OCC_SCH_Offices & $\begin{array}{l}\text { WD, } \\
\text { SummerDesign }\end{array}$ & 0 & 0 & 0 & 0 & 0 & 0 & 0 & 0 & 0.5 & 0.5 & 0.5 & 0.5 & 0.5 & 0.5 & 0.5 & 0.5 & 0.5 & 0.15 & 0.15 & 0.15 & 0.15 & 0 & 0 & 0 \\
\hline (Summer Holiday) & \begin{tabular}{|l} 
Sat, Sun, Hol, \\
WinterDesign, \\
Other \\
\end{tabular} & 0 & 0 & 0 & 0 & 0 & 0 & 0 & 0 & 0 & 0 & 0 & 0 & 0 & 0 & 0 & 0 & 0 & 0 & 0 & 0 & 0 & 0 & 0 & 0 \\
\hline BLDG_OCC_SCH_Gym & $\begin{array}{l}\text { WD, } \\
\text { SummerDesign }\end{array}$ & 0 & 0 & 0 & 0 & 0 & 0 & 0 & 0 & 0.35 & 0.35 & 0.35 & 0.35 & 0.35 & 0.35 & 0.35 & 0.35 & 0.95 & 0.95 & 0.95 & 0.95 & 0.95 & 0 & 0 & 0 \\
\hline (Study Periods) & $\begin{array}{l}\text { Sat, Sun, Hol, } \\
\text { WinterDesign, } \\
\text { Other }\end{array}$ & 0 & 0 & 0 & 0 & 0 & 0 & 0 & 0 & 0 & 0 & 0 & 0 & 0 & 0 & 0 & 0 & 0 & 0 & 0 & 0 & 0 & 0 & 0 & 0 \\
\hline BLDG_OCC_SCH_Gym & $\begin{array}{l}\text { WD, } \\
\text { SummerDesign }\end{array}$ & 0 & 0 & 0 & 0 & 0 & 0 & 0 & 0 & 0.35 & 0.35 & 0.35 & 0.35 & 0.35 & 0.35 & 0.35 & 0.35 & 0.35 & 0.35 & 0.35 & 0.35 & 0.35 & 0 & 0 & 0 \\
\hline (Summer Holiday) & $\begin{array}{l}\text { Sat, Sun, Hol, } \\
\text { WinterDesign, } \\
\text { Other }\end{array}$ & 0 & 0 & 0 & 0 & 0 & 0 & 0 & 0 & 0 & 0 & 0 & 0 & 0 & 0 & 0 & 0 & 0 & 0 & 0 & 0 & 0 & 0 & 0 & 0 \\
\hline BLDG_OCC_SCH_Cafeteria & $\begin{array}{l}\text { WD, } \\
\text { SummerDesign }\end{array}$ & 0 & 0 & 0 & 0 & 0 & 0 & 0 & 0 & 0 & 0.95 & 0.95 & 0.95 & 0.95 & 0.95 & 0.95 & 0.35 & 0.35 & 0.35 & 0.35 & 0.35 & 0 & 0 & 0 & 0 \\
\hline (Study Periods) & \begin{tabular}{|l} 
Sat, Sun, Hol, \\
WinterDesign, \\
Other
\end{tabular} & 0 & 0 & 0 & 0 & 0 & 0 & 0 & 0 & 0 & 0 & 0 & 0 & 0 & 0 & 0 & 0 & 0 & 0 & 0 & 0 & 0 & 0 & 0 & 0 \\
\hline BLDG_OCC_SCH_Cafeteria & $\begin{array}{l}\text { WD, } \\
\text { SummerDesign }\end{array}$ & 0 & 0 & 0 & 0 & 0 & 0 & 0 & 0 & 0 & 0.15 & 0.15 & 0.15 & 0.15 & 0.15 & 0.15 & 0.15 & 0.15 & 0.35 & 0.35 & 0 & 0 & 0 & 0 & 0 \\
\hline (Summer Holiday) & \begin{tabular}{|l|} 
Sat, Sun, Hol, \\
WinterDesign, \\
Other
\end{tabular} & 0 & 0 & 0 & 0 & 0 & 0 & 0 & 0 & 0 & 0 & 0 & 0 & 0 & 0 & 0 & 0 & 0 & 0 & 0 & 0 & 0 & 0 & 0 & 0 \\
\hline BLDG_ELEVATORS & $\begin{array}{l}\text { WD, } \\
\text { SummerDesign }\end{array}$ & 0 & 0 & 0 & 0 & 0 & 0 & 0 & 0 & 0 & 0 & 0 & 0 & 0 & 0 & 0 & 0 & 0 & 0 & 0 & 0 & 0 & 0 & 0 & 0 \\
\hline & Sat, WinterDesign & 0 & 0 & 0 & 0 & 0 & 0 & 0 & 0 & 0 & 0 & 0 & 0 & 0 & 0 & 0 & 0 & 0 & 0 & 0 & 0 & 0 & 0 & 0 & 0 \\
\hline & Sun, Hol, Other & 0 & 0 & 0 & 0 & 0 & 0 & 0 & 0 & 0 & 0 & 0 & 0 & 0 & 0 & 0 & 0 & 0 & 0 & 0 & 0 & 0 & 0 & 0 & 0 \\
\hline BLDG_SWH_SCH & \begin{tabular}{|l|} 
WD, \\
SummerDesign
\end{tabular} & 0.05 & 0.05 & 0.05 & 0.05 & 0.05 & 0.05 & 0.05 & 0.1 & 0.34 & 0.6 & 0.63 & 0.72 & 0.79 & 0.83 & 0.61 & 0.65 & 0.1 & 0.1 & 0.19 & 0.25 & 0.22 & 0.22 & 0.12 & 0.09 \\
\hline (Study Periods) & \begin{tabular}{|l} 
Sat, Sun, Hol, \\
WinterDesign, \\
Other
\end{tabular} & 0.03 & 0.03 & 0.03 & 0.03 & 0.03 & 0.03 & 0.03 & 0.03 & 0.03 & 0.05 & 0.05 & 0.05 & 0.05 & 0.03 & 0.03 & 0.03 & 0.03 & 0.03 & 0.03 & 0.03 & 0.03 & 0.03 & 0.03 & 0.03 \\
\hline BLDG_SWH_SCH & $\begin{array}{l}\text { WD, } \\
\text { SummerDesign }\end{array}$ & 0.05 & 0.05 & 0.05 & 0.05 & 0.05 & 0.05 & 0.05 & 0.1 & 0.1 & 0.1 & 0.1 & 0.1 & 0.1 & 0.1 & 0.1 & 0.1 & 0.1 & 0.1 & 0.19 & 0.25 & 0.22 & 0.22 & 0.12 & 0.09 \\
\hline (Summer Holiday) & $\begin{array}{l}\text { Sat, Sun, Hol, } \\
\text { WinterDesign, } \\
\text { Other }\end{array}$ & 0.03 & 0.03 & 0.03 & 0.03 & 0.03 & 0.03 & 0.03 & 0.03 & 0.03 & 0.05 & 0.05 & 0.05 & 0.05 & 0.03 & 0.03 & 0.03 & 0.03 & 0.03 & 0.03 & 0.03 & 0.03 & 0.03 & 0.03 & 0.03 \\
\hline INFIL_SCH_PNNL & $\begin{array}{l}\text { WD, } \\
\text { SummerDesign } \\
\end{array}$ & 1 & 1 & 1 & 1 & 1 & 1 & 1 & 0.25 & 0.25 & 0.25 & 0.25 & 0.25 & 0.25 & 0.25 & 0.25 & 0.25 & 0.25 & 0.25 & 0.25 & 0.25 & 0.25 & 1 & 1 & 1 \\
\hline & \begin{tabular}{|l|} 
Sat, Sun, Hol, \\
WinterDesign, \\
Other \\
\end{tabular} & 1 & 1 & 1 & 1 & 1 & 1 & 1 & 1 & 1 & 1 & 1 & 1 & 1 & 1 & 1 & 1 & 1 & 1 & 1 & 1 & 1 & 1 & 1 & 1 \\
\hline HVACOperationSchd & $\begin{array}{l}\text { WD, } \\
\text { SummerDesign, } \\
\text { WinterDesign }\end{array}$ & 0 & 0 & 0 & 0 & 0 & 0 & 0 & 1 & 1 & 1 & 1 & 1 & 1 & 1 & 1 & 1 & 1 & 1 & 1 & 1 & 1 & 0 & 0 & 0 \\
\hline & $\begin{array}{l}\text { Sat, Sun, Hol, } \\
\text { Other }\end{array}$ & 0 & 0 & 0 & 0 & 0 & 0 & 0 & 0 & 0 & 0 & 0 & 0 & 0 & 0 & 0 & 0 & 0 & 0 & 0 & 0 & 0 & 0 & 0 & 0 \\
\hline FAN_SCH & All & 1 & 1 & 1 & 1 & 1 & 1 & 1 & 1 & 1 & 1 & 1 & 1 & 1 & 1 & 1 & 1 & 1 & 1 & 1 & 1 & 1 & 1 & 1 & 1 \\
\hline $\begin{array}{l}\text { Dual Zone Control Type } \\
\text { Sched }\end{array}$ & All & 4 & 4 & 4 & 4 & 4 & 4 & 4 & 4 & 4 & 4 & 4 & 4 & 4 & 4 & 4 & 4 & 4 & 4 & 4 & 4 & 4 & 4 & 4 & 4 \\
\hline ReheatCoilAvailSched & All & 1 & 1 & 1 & 1 & 1 & 1 & 1 & 1 & 1 & 1 & 1 & 1 & 1 & 1 & 1 & 1 & 1 & 1 & 1 & 1 & 1 & 1 & 1 & 1 \\
\hline CoolingCoilAvailSched & All & 1 & 1 & 1 & 1 & 1 & 1 & 1 & 1 & 1 & 1 & 1 & 1 & 1 & 1 & 1 & 1 & 1 & 1 & 1 & 1 & 1 & 1 & 1 & 1 \\
\hline $\begin{array}{l}\text { MinOA_MotorizedDamper_ } \\
\text { Sched }\end{array}$ & $\begin{array}{l}\text { WD, } \\
\text { SummerDesign, } \\
\text { WinterDesign }\end{array}$ & 0 & 0 & 0 & 0 & 0 & 0 & 0 & 0 & 1 & 1 & 1 & 1 & 1 & 1 & 1 & 1 & 1 & 1 & 1 & 1 & 1 & 0 & 0 & 0 \\
\hline
\end{tabular}




\begin{tabular}{|c|c|c|c|c|c|c|c|c|c|c|c|c|c|c|c|c|c|c|c|c|c|c|c|c|c|}
\hline Schedule & Day of Week & 1 & 2 & 3 & 4 & 5 & 6 & 7 & 8 & 9 & 10 & 11 & 12 & 13 & 14 & 15 & 16 & 17 & 18 & 19 & 20 & 21 & 22 & 23 & 24 \\
\hline & $\begin{array}{l}\text { Sat, Sun, Hol, } \\
\text { Other }\end{array}$ & 0 & 0 & 0 & 0 & 0 & 0 & 0 & 0 & 0 & 0 & 0 & 0 & 0 & 0 & 0 & 0 & 0 & 0 & 0 & 0 & 0 & 0 & 0 & 0 \\
\hline MinOA_Sched & All & 1 & 1 & 1 & 1 & 1 & 1 & 1 & 1 & 1 & 1 & 1 & 1 & 1 & 1 & 1 & 1 & 1 & 1 & 1 & 1 & 1 & 1 & 1 & 1 \\
\hline HTGSETP_SCH & WD & 15.6 & 15.6 & 15.6 & 15.6 & 15.6 & 15.6 & 15.6 & 21 & 21 & 21 & 21 & 21 & 21 & 21 & 21 & 21 & 21 & 21 & 21 & 21 & 21 & 15.6 & 15.6 & 15.6 \\
\hline & \begin{tabular}{|l|} 
SummerDesign, \\
Sat, Sun, Hol, \\
Other \\
\end{tabular} & 15.6 & 15.6 & 15.6 & 15.6 & 15.6 & 15.6 & 15.6 & 15.6 & 15.6 & 15.6 & 15.6 & 15.6 & 15.6 & 15.6 & 15.6 & 15.6 & 15.6 & 15.6 & 15.6 & 15.6 & 15.6 & 15.6 & 15.6 & 15.6 \\
\hline & WinterDesign & 21 & 21 & 21 & 21 & 21 & 21 & 21 & 21 & 21 & 21 & 21 & 21 & 21 & 21 & 21 & 21 & 21 & 21 & 21 & 21 & 21 & 21 & 21 & 21 \\
\hline CLGSETP_SCH & WD & 26.7 & 26.7 & 26.7 & 26.7 & 26.7 & 26.7 & 26.7 & 24 & 24 & 24 & 24 & 24 & 24 & 24 & 24 & 24 & 24 & 24 & 24 & 24 & 24 & 26.7 & $\begin{array}{ll}26.7 \\
\end{array}$ & 26.7 \\
\hline & SummerDesign & 24 & 24 & 24 & 24 & 24 & 24 & 24 & 24 & 24 & 24 & 24 & 24 & 24 & 24 & 24 & 24 & 24 & 24 & 24 & 24 & 24 & 24 & 24 & 24 \\
\hline & $\begin{array}{l}\text { WinterDesign, Sat, } \\
\text { Sun, Hol, Other }\end{array}$ & 26.7 & 26.7 & 26.7 & 26.7 & 26.7 & 26.7 & 26.7 & 26.7 & 26.7 & 26.7 & 26.7 & 26.7 & 26.7 & 26.7 & 26.7 & 26.7 & 26.7 & 26.7 & 26.7 & 26.7 & 26.7 & 26.7 & 26.7 & 26.7 \\
\hline HTGSETP_SCH_SETBACK & WD & 15.6 & 15.6 & 15.6 & 15.6 & 15.6 & 15.6 & 15.6 & 15.6 & 15.6 & 15.6 & 15.6 & 15.6 & 15.6 & 15.6 & 15.6 & 15.6 & 15.6 & 15.6 & 15.6 & 15.6 & 15.6 & 15.6 & 15.6 & 15.6 \\
\hline $\begin{array}{l}\text { (For mechanical room and } \\
\text { bathroom) }\end{array}$ & $\begin{array}{l}\text { SummerDesign, } \\
\text { Sat, Sun, Hol, } \\
\text { Other }\end{array}$ & 15.6 & 15.6 & 15.6 & 15.6 & 15.6 & 15.6 & 15.6 & 15.6 & 15.6 & 15.6 & 15.6 & 15.6 & 15.6 & 15.6 & 15.6 & 15.6 & 15.6 & 15.6 & 15.6 & 15.6 & 15.6 & 15.6 & 15.6 & 15.6 \\
\hline & WinterDesign & 21.0 & 21.0 & 21.0 & 21.0 & 21.0 & 21.0 & 21.0 & 21.0 & 21.0 & 21.0 & 21.0 & 21.0 & 21.0 & 21.0 & 21.0 & 21.0 & 21.0 & 21.0 & 21.0 & 21.0 & 21.0 & 21.0 & 21.0 & 21.0 \\
\hline CLGSETP_SCH_SETUP & WD & 26.7 & 26.7 & 26.7 & 26.7 & 26.7 & 26.7 & 26.7 & \begin{tabular}{|l|l|}
26.7 & \\
\end{tabular} & 26.7 & $\begin{array}{ll}26.7 \\
\end{array}$ & 26.7 & 26.7 & 26.7 & 26.7 & 26.7 & 26.7 & 26.7 & 26.7 & 26.7 & 26.7 & 26.7 & 26.7 & \begin{tabular}{|l|l|}
26.7 & \\
\end{tabular} & 26.7 \\
\hline $\begin{array}{l}\text { (For mechanical room and } \\
\text { bathroom) }\end{array}$ & SummerDesign & 24.0 & 24.0 & 24.0 & 24.0 & 24.0 & 24.0 & 24.0 & 24.0 & 24.0 & 24.0 & 24.0 & 24.0 & 24.0 & 24.0 & 24.0 & 24.0 & 24.0 & 24.0 & 24.0 & 24.0 & 24.0 & 24.0 & 24.0 & 24.0 \\
\hline & $\begin{array}{l}\text { WinterDesign, Sat, } \\
\text { Sun, Hol, Other }\end{array}$ & 26.7 & 26.7 & 26.7 & 26.7 & 26.7 & 26.7 & 26.7 & 26.7 & 26.7 & 26.7 & 26.7 & 26.7 & 26.7 & 26.7 & 26.7 & 26.7 & 26.7 & 26.7 & 26.7 & 26.7 & 26.7 & 26.7 & 26.7 & 26.7 \\
\hline VAV-Supply-Air-Temp-Sch & All & 12.8 & 12.8 & 12.8 & 12.8 & 12.8 & 12.8 & 12.8 & 12.8 & 12.8 & 12.8 & 12.8 & 12.8 & 12.8 & 12.8 & 12.8 & 12.8 & $\begin{array}{ll}12.8 \\
\end{array}$ & 12.8 & 12.8 & 12.8 & 12.8 & 12.8 & 12.8 & 12.8 \\
\hline HW-Loop-Temp-Schedule & All & 82 & 82 & 82 & 82 & 82 & 82 & 82 & 82 & 82 & 82 & 82 & 82 & 82 & 82 & 82 & 82 & 82 & 82 & 82 & 82 & 82 & 82 & 82 & 82 \\
\hline Heating-Supply-Air-Temp-Sch & All & 16 & 16 & 16 & 16 & 16 & 16 & 16 & 16 & 16 & 16 & 16 & 16 & 16 & 16 & 16 & 16 & 16 & 16 & 16 & 16 & 16 & 16 & 16 & 16 \\
\hline HTGSETP_SCH & WD & 60 & 60 & 60 & 60 & 60 & 60 & 60 & 70 & 70 & 70 & 70 & 70 & 70 & 70 & 70 & 70 & 70 & 70 & 70 & 70 & 70 & 60 & 60 & 60 \\
\hline & $\begin{array}{l}\text { SummerDesign, } \\
\text { Sat, Sun, Hol, } \\
\text { Other }\end{array}$ & 60 & 60 & 60 & 60 & 60 & 60 & 60 & 60 & 60 & 60 & 60 & 60 & 60 & 60 & 60 & 60 & 60 & 60 & 60 & 60 & 60 & 60 & 60 & 60 \\
\hline & \begin{tabular}{|l|} 
WinterDesign \\
\end{tabular} & 70 & 70 & 70 & 70 & 70 & 70 & 70 & 70 & 70 & 70 & 70 & 70 & 70 & 70 & 70 & 70 & 70 & 70 & 70 & 70 & 70 & 70 & 70 & 70 \\
\hline CLGSETP_SCH & WD & 80 & 80 & 80 & 80 & 80 & 80 & 80 & 75 & 75 & 75 & 75 & 75 & 75 & 75 & 75 & 75 & 75 & 75 & 75 & 75 & 75 & 80 & 80 & 80 \\
\hline & SummerDesign & 75 & 75 & 75 & 75 & 75 & 75 & 75 & 75 & 75 & 75 & 75 & 75 & 75 & 75 & 75 & 75 & 75 & 75 & 75 & 75 & 75 & 75 & 75 & 75 \\
\hline & $\begin{array}{l}\text { WinterDesign, Sat, } \\
\text { Sun, Hol, Other }\end{array}$ & 80 & 80 & 80 & 80 & 80 & 80 & 80 & 80 & 80 & 80 & 80 & 80 & 80 & 80 & 80 & 80 & 80 & 80 & 80 & 80 & 80 & 80 & 80 & 80 \\
\hline HTGSETP_SCH_SETBACK & WD & 60 & 60 & 60 & 60 & 60 & 60 & 60 & 60 & 60 & 60 & 60 & 60 & 60 & 60 & 60 & 60 & 60 & 60 & 60 & 60 & 60 & 60 & 60 & 60 \\
\hline $\begin{array}{l}\text { (For mechanical room and } \\
\text { bathroom) }\end{array}$ & \begin{tabular}{|l|} 
SummerDesign, \\
Sat, Sun, Hol, \\
Other \\
\end{tabular} & 60 & 60 & 60 & 60 & 60 & 60 & 60 & 60 & 60 & 60 & 60 & 60 & 60 & 60 & 60 & 60 & 60 & 60 & 60 & 60 & 60 & 60 & 60 & 60 \\
\hline & WinterDesign & 70 & 70 & 70 & 70 & 70 & 70 & 70 & 70 & 70 & 70 & 70 & 70 & 70 & 70 & 70 & 70 & 70 & 70 & 70 & 70 & 70 & 70 & 70 & 70 \\
\hline CLGSETP_SCH_SETUP & WD & 80 & 80 & 80 & 80 & 80 & 80 & 80 & 80 & 80 & 80 & 80 & 80 & 80 & 80 & 80 & 80 & 80 & 80 & 80 & 80 & 80 & 80 & 80 & 80 \\
\hline $\begin{array}{l}\text { (For mechanical room and } \\
\text { bathroom) }\end{array}$ & SummerDesign & 75 & 75 & 75 & 75 & 75 & 75 & 75 & 75 & 75 & 75 & 75 & 75 & 75 & 75 & 75 & 75 & 75 & 75 & 75 & 75 & 75 & 75 & 75 & 75 \\
\hline & $\begin{array}{l}\text { WinterDesign, Sat, } \\
\text { Sun, Hol, Other }\end{array}$ & 80 & 80 & 80 & 80 & 80 & 80 & 80 & 80 & 80 & 80 & 80 & 80 & 80 & 80 & 80 & 80 & 80 & 80 & 80 & 80 & 80 & 80 & 80 & 80 \\
\hline VAV-Supply-Air-Temp-Sch & All & 55 & 55 & 55 & 55 & 55 & 55 & 55 & 55 & 55 & 55 & 55 & 55 & 55 & 55 & 55 & 55 & 55 & 55 & 55 & 55 & 55 & 55 & 55 & 55 \\
\hline N-Loop-Temp-Schedule & All & 180 & 180 & 180 & 180 & 180 & 180 & 180 & 180 & 180 & 180 & 180 & 180 & 180 & 180 & 180 & 180 & 180 & 180 & 180 & 180 & 180 & 180 & 180 & 180 \\
\hline Heat-Supply-Air-Temp-Sch & All & 61 & 61 & 61 & 61 & 61 & 61 & 61 & 61 & 61 & 61 & 61 & 61 & 61 & 61 & 61 & 61 & 61 & 61 & 61 & 61 & 61 & 61 & 61 & 61 \\
\hline
\end{tabular}




\section{C.7 Secondary School Hourly Operation Schedules}

\begin{tabular}{|c|c|c|c|c|c|c|c|c|c|c|c|c|c|c|c|c|c|c|c|c|c|c|c|c|c|}
\hline Schedule & Day of Week & 1 & 2 & 3 & 4 & 5 & 6 & 7 & 8 & 9 & 10 & 11 & 12 & 13 & 14 & 15 & 16 & 17 & 18 & 19 & 20 & 21 & 22 & 23 & 24 \\
\hline BLDG_LIGHT_SCH & $\begin{array}{l}\text { WD, } \\
\text { SummerDesign }\end{array}$ & 0.18 & 0.18 & 0.18 & 0.18 & 0.18 & 0.18 & 0.18 & 0.9 & 0.9 & 0.9 & 0.9 & 0.9 & 0.9 & 0.9 & 0.9 & 0.9 & 0.9 & 0.9 & 0.9 & 0.9 & 0.9 & 0.18 & 0.18 & 0.18 \\
\hline (Study Periods) & \begin{tabular}{|l|} 
Sat, Sun, Hol, \\
WinterDesign, \\
Other
\end{tabular} & 0.18 & 0.18 & 0.18 & 0.18 & 0.18 & 0.18 & 0.18 & 0.18 & 0.18 & 0.18 & 0.18 & 0.18 & 0.18 & 0.18 & 0.18 & 0.18 & 0.18 & 0.18 & 0.18 & 0.18 & 0.18 & 0.18 & 0.18 & 0.18 \\
\hline BLDG_LIGHT_SCH & $\begin{array}{l}\text { WD, } \\
\text { SummerDesign }\end{array}$ & 0.18 & 0.18 & 0.18 & 0.18 & 0.18 & 0.18 & 0.18 & 0.18 & 0.5 & 0.5 & 0.5 & 0.5 & 0.5 & 0.5 & 0.5 & 0.5 & 0.5 & 0.5 & 0.5 & 0.5 & 0.18 & 0.18 & 0.18 & 0.18 \\
\hline (Summer Holiday) & \begin{tabular}{|l|} 
Sat, Sun, Hol, \\
WinterDesign, \\
Other
\end{tabular} & 0.18 & 0.18 & 0.18 & 0.18 & 0.18 & 0.18 & 0.18 & 0.18 & 0.18 & 0.18 & 0.18 & 0.18 & 0.18 & 0.18 & 0.18 & 0.18 & 0.18 & 0.18 & 0.18 & 0.18 & 0.18 & 0.18 & 0.18 & 0.18 \\
\hline BLDG_EQUIP_SCH_Base & $\begin{array}{l}\text { WD, } \\
\text { SummerDesign }\end{array}$ & 0.35 & 0.35 & 0.35 & 0.35 & 0.35 & 0.35 & 0.35 & 0.35 & 0.95 & 0.95 & 0.95 & 0.95 & 0.95 & 0.95 & 0.95 & 0.95 & 0.95 & 0.35 & 0.35 & 0.35 & 0.35 & 0.35 & 0.35 & 0.35 \\
\hline (Study Periods) & \begin{tabular}{|l|} 
Sat, Sun, Hol, \\
WinterDesign, \\
Other
\end{tabular} & 0.35 & 0.35 & 0.35 & 0.35 & 0.35 & 0.35 & 0.35 & 0.35 & 0.35 & 0.35 & 0.35 & 0.35 & 0.35 & 0.35 & 0.35 & 0.35 & 0.35 & 0.35 & 0.35 & 0.35 & 0.35 & 0.35 & 0.35 & 0.35 \\
\hline BLDG_EQUIP_SCH_BASE & $\begin{array}{l}\text { WD, } \\
\text { SummerDesign }\end{array}$ & 0.25 & 0.25 & 0.25 & 0.25 & 0.25 & 0.25 & 0.25 & 0.25 & 0.5 & 0.5 & 0.5 & 0.5 & 0.5 & 0.5 & 0.5 & 0.5 & 0.5 & 0.25 & 0.25 & 0.25 & 0.25 & 0.25 & 0.25 & 0.25 \\
\hline (Summer Holiday) & $\begin{array}{l}\text { Sat, Sun, Hol, } \\
\text { WinterDesign, } \\
\text { Other } \\
\end{array}$ & 0.25 & 0.25 & 0.25 & 0.25 & 0.25 & 0.25 & 0.25 & 0.25 & 0.25 & 0.25 & 0.25 & 0.25 & 0.25 & 0.25 & 0.25 & 0.25 & 0.25 & 0.25 & 0.25 & 0.25 & 0.25 & 0.25 & 0.25 & 0.25 \\
\hline Kitchen_Elec_EQUIP_SCH & $\begin{array}{l}\text { WD, } \\
\text { SummerDesign }\end{array}$ & 0.1 & 0.1 & 0.1 & 0.1 & 0.1 & 0.1 & 0.1 & 0.1 & 0.15 & 0.15 & 0.25 & 0.25 & 0.25 & 0.15 & 0.15 & 0.1 & 0.1 & 0.1 & 0.1 & 0.1 & 0.1 & 0.1 & 0.1 & 0.1 \\
\hline (Study Periods) & \begin{tabular}{|l|} 
Sat, Sun, Hol, \\
WinterDesign, \\
Other
\end{tabular} & 0.1 & 0.1 & 0.1 & 0.1 & 0.1 & 0.1 & 0.1 & 0.1 & 0.1 & 0.1 & 0.1 & 0.1 & 0.1 & 0.1 & 0.1 & 0.1 & 0.1 & 0.1 & 0.1 & 0.1 & 0.1 & 0.1 & 0.1 & 0.1 \\
\hline Kitchen_Elec_EQUIP_SCH & $\begin{array}{l}\text { WD, } \\
\text { SummerDesign }\end{array}$ & 0.1 & 0.1 & 0.1 & 0.1 & 0.1 & 0.1 & 0.1 & 0.1 & 0.15 & 0.15 & 0.25 & 0.25 & 0.25 & 0.15 & 0.15 & 0.1 & 0.1 & 0.1 & 0.1 & 0.1 & 0.1 & 0.1 & 0.1 & 0.1 \\
\hline (Summer Holiday) & \begin{tabular}{|l|} 
Sat, Sun, Hol, \\
WinterDesign, \\
Other
\end{tabular} & 0.1 & 0.1 & 0.1 & 0.1 & 0.1 & 0.1 & 0.1 & 0.1 & 0.1 & 0.1 & 0.1 & 0.1 & 0.1 & 0.1 & 0.1 & 0.1 & 0.1 & 0.1 & 0.1 & 0.1 & 0.1 & 0.1 & 0.1 & 0.1 \\
\hline Kitchen_Gas_EQUIP_SCH & $\begin{array}{l}\text { WD, } \\
\text { SummerDesign }\end{array}$ & 0.02 & 0.02 & 0.02 & 0.02 & 0.02 & 0.02 & 0.02 & 0.02 & 0.15 & 0.15 & 0.2 & 0.2 & 0.2 & 0.1 & 0.1 & 0.02 & 0.02 & 0.02 & 0.02 & 0.02 & 0.02 & 0.02 & 0.02 & 0.02 \\
\hline (Study Periods) & \begin{tabular}{|l|} 
Sat, Sun, Hol, \\
WinterDesign, \\
Other \\
\end{tabular} & 0.02 & 0.02 & 0.02 & 0.02 & 0.02 & 0.02 & 0.02 & 0.02 & 0.02 & 0.02 & 0.02 & 0.02 & 0.02 & 0.02 & 0.02 & 0.02 & 0.02 & 0.02 & 0.02 & 0.02 & 0.02 & 0.02 & 0.02 & 0.02 \\
\hline Kitchen_Gas_EQUIP_SCH & $\begin{array}{l}\text { WD, } \\
\text { SummerDesign }\end{array}$ & 0.02 & 0.02 & 0.02 & 0.02 & 0.02 & 0.02 & 0.02 & 0.02 & 0.15 & 0.15 & 0.2 & 0.2 & 0.2 & 0.1 & 0.1 & 0.02 & 0.02 & 0.02 & 0.02 & 0.02 & 0.02 & 0.02 & 0.02 & 0.02 \\
\hline (Summer Holiday) & $\begin{array}{l}\text { Sat, Sun, Hol, } \\
\text { WinterDesign, } \\
\text { Other } \\
\end{array}$ & 0.02 & 0.02 & 0.02 & 0.02 & 0.02 & 0.02 & 0.02 & 0.02 & 0.02 & 0.02 & 0.02 & 0.02 & 0.02 & 0.02 & 0.02 & 0.02 & 0.02 & 0.02 & 0.02 & 0.02 & 0.02 & 0.02 & 0.02 & 0.02 \\
\hline BLDG_ELEVATORS & WD & 0 & 0 & 0 & 0 & 0 & 0 & 0 & 0 & 0.3 & 0.3 & 0.3 & 0.3 & 0.3 & 0.3 & 0.3 & 0.15 & 0 & 0 & 0 & 0 & 0 & 0 & 0 & 0 \\
\hline & Sat & 0 & 0 & 0 & 0 & 0 & 0 & 0 & 0 & 0 & 0 & 0 & 0 & 0 & 0 & 0 & 0 & 0 & 0 & 0 & 0 & 0 & 0 & 0 & 0 \\
\hline & Sun & 0 & 0 & 0 & 0 & 0 & 0 & 0 & 0 & 0 & 0 & 0 & 0 & 0 & 0 & 0 & 0 & 0 & 0 & 0 & 0 & 0 & 0 & 0 & 0 \\
\hline & SummerDesign & 0.3 & 0.3 & 0.3 & 0.3 & 0.3 & 0.3 & 0.3 & 0.3 & 0.3 & 0.3 & 0.3 & 0.3 & 0.3 & 0.3 & 0.3 & 0.3 & 0.3 & 0.3 & 0.3 & 0.3 & 0.3 & 0.3 & 0.3 & 0.3 \\
\hline & WinterDesign & 0 & 0 & 0 & 0 & 0 & 0 & 0 & 0 & 0 & 0 & 0 & 0 & 0 & 0 & 0 & 0 & 0 & 0 & 0 & 0 & 0 & 0 & 0 & 0 \\
\hline $\begin{array}{l}\text { ELEV_LIGHT_FAN_SCH_ } \\
24 \_7\end{array}$ & WD & 1 & 1 & 1 & 1 & 1 & 1 & 1 & 1 & 1 & 1 & 1 & 1 & 1 & 1 & 1 & 1 & 1 & 1 & 1 & 1 & 1 & 1 & 1 & 1 \\
\hline & Sat & 1 & 1 & 1 & 1 & 1 & 1 & 1 & 1 & 1 & 1 & 1 & 1 & 1 & 1 & 1 & 1 & 1 & 1 & 1 & 1 & 1 & 1 & 1 & 1 \\
\hline & Sun, Hol, Other & 1 & 1 & 1 & 1 & 1 & 1 & 1 & 1 & 1 & 1 & 1 & 1 & 1 & 1 & 1 & 1 & 1 & 1 & 1 & 1 & 1 & 1 & 1 & 1 \\
\hline & SummerDesign & 1 & 1 & 1 & 1 & 1 & 1 & 1 & 1 & 1 & 1 & 1 & 1 & 1 & 1 & 1 & 1 & 1 & 1 & 1 & 1 & 1 & 1 & 1 & 1 \\
\hline & WinterDesign & 1 & 1 & 1 & 1 & 1 & 1 & 1 & 1 & 1 & 1 & 1 & 1 & 1 & 1 & 1 & 1 & 1 & 1 & 1 & 1 & 1 & 1 & 1 & 1 \\
\hline BLDG_OCC_SCH & $\begin{array}{l}\text { WD, } \\
\text { SummerDesign } \\
\end{array}$ & 0 & 0 & 0 & 0 & 0 & 0 & 0 & 0 & 0.95 & 0.95 & 0.95 & 0.95 & 0.95 & 0.95 & 0.95 & 0.95 & 0.15 & 0.15 & 0.15 & 0.15 & 0.15 & 0 & 0 & 0 \\
\hline (Study Periods) & \begin{tabular}{|l|} 
Sat, Sun, Hol, \\
WinterDesign, \\
Other \\
\end{tabular} & 0 & 0 & 0 & 0 & 0 & 0 & 0 & 0 & 0 & 0 & 0 & 0 & 0 & 0 & 0 & 0 & 0 & 0 & 0 & 0 & 0 & 0 & 0 & 0 \\
\hline BLDG_OCC_SCH & $\begin{array}{l}\text { WD, } \\
\text { SummerDesign }\end{array}$ & 0 & 0 & 0 & 0 & 0 & 0 & 0 & 0 & 0.15 & 0.15 & 0.15 & 0.15 & 0.15 & 0.15 & 0.15 & 0.15 & 0.15 & 0.15 & 0.15 & 0.15 & 0.15 & 0 & 0 & 0 \\
\hline
\end{tabular}




\begin{tabular}{|c|c|c|c|c|c|c|c|c|c|c|c|c|c|c|c|c|c|c|c|c|c|c|c|c|c|}
\hline Schedule & Day of Week & 1 & 2 & 3 & 4 & 5 & 6 & 7 & 8 & 9 & 10 & 11 & 12 & 13 & 14 & 15 & 16 & 17 & 18 & 19 & 20 & 21 & 22 & 23 & 24 \\
\hline (Summer Holiday) & $\begin{array}{l}\text { Sat, Sun, Hol, } \\
\text { WinterDesign, } \\
\text { Other }\end{array}$ & 0 & 0 & 0 & 0 & 0 & 0 & 0 & 0 & 0 & 0 & 0 & 0 & 0 & 0 & 0 & 0 & 0 & 0 & 0 & 0 & 0 & 0 & 0 & 0 \\
\hline BLDG_OCC_Extend & $\begin{array}{l}\text { WD, } \\
\text { SummerDesign }\end{array}$ & 0 & 0 & 0 & 0 & 0 & 0 & 0 & 0 & 0.95 & 0.95 & 0.95 & 0.95 & 0.95 & 0.95 & 0.95 & 0.95 & 0.95 & 0.95 & 0.95 & 0.95 & 0.95 & 0 & 0 & 0 \\
\hline (Study Periods) & $\begin{array}{l}\text { Sat, Sun, Hol, } \\
\text { WinterDesign, } \\
\text { Other } \\
\end{array}$ & 0 & 0 & 0 & 0 & 0 & 0 & 0 & 0 & 0 & 0 & 0 & 0 & 0 & 0 & 0 & 0 & 0 & 0 & 0 & 0 & 0 & 0 & 0 & 0 \\
\hline BLDG_OCC_Extend & $\begin{array}{l}\text { WD, } \\
\text { SummerDesign }\end{array}$ & 0 & 0 & 0 & 0 & 0 & 0 & 0 & 0 & 0.5 & 0.5 & 0.5 & 0.5 & 0.5 & 0.5 & 0.5 & 0.5 & 0.5 & 0.5 & 0.5 & 0.5 & 0.5 & 0 & 0 & 0 \\
\hline (Summer Holiday) & \begin{tabular}{|l|} 
Sat, Sun, Hol, \\
WinterDesign, \\
Other \\
\end{tabular} & 0 & 0 & 0 & 0 & 0 & 0 & 0 & 0 & 0 & 0 & 0 & 0 & 0 & 0 & 0 & 0 & 0 & 0 & 0 & 0 & 0 & 0 & 0 & 0 \\
\hline BLDG_OCC_SCH_Offices & $\begin{array}{l}\text { WD, } \\
\text { SummerDesign }\end{array}$ & 0 & 0 & 0 & 0 & 0 & 0 & 0 & 0 & 0.95 & 0.95 & 0.95 & 0.95 & 0.95 & 0.95 & 0.95 & 0.95 & 0.95 & 0.15 & 0.15 & 0.15 & 0.15 & 0 & 0 & 0 \\
\hline (Study Periods) & \begin{tabular}{|l|} 
Sat, Sun, Hol, \\
WinterDesign, \\
Other
\end{tabular} & 0 & 0 & 0 & 0 & 0 & 0 & 0 & 0 & 0 & 0 & 0 & 0 & 0 & 0 & 0 & 0 & 0 & 0 & 0 & 0 & 0 & 0 & 0 & 0 \\
\hline BLDG_OCC_SCH_Offices & $\begin{array}{l}\text { WD, } \\
\text { SummerDesign }\end{array}$ & 0 & 0 & 0 & 0 & 0 & 0 & 0 & 0 & 0.5 & 0.5 & 0.5 & 0.5 & 0.5 & 0.5 & 0.5 & 0.5 & 0.5 & 0.15 & 0.15 & 0.15 & 0.15 & 0 & 0 & 0 \\
\hline (Summer Holiday) & $\begin{array}{l}\text { Sat, Sun, Hol, } \\
\text { WinterDesign, } \\
\text { Other } \\
\end{array}$ & 0 & 0 & 0 & 0 & 0 & 0 & 0 & 0 & 0 & 0 & 0 & 0 & 0 & 0 & 0 & 0 & 0 & 0 & 0 & 0 & 0 & 0 & 0 & 0 \\
\hline BLDG_OCC_SCH_Gym & $\begin{array}{l}\text { WD, } \\
\text { SummerDesign }\end{array}$ & 0 & 0 & 0 & 0 & 0 & 0 & 0 & 0 & 0.35 & 0.35 & 0.35 & 0.35 & 0.35 & 0.35 & 0.35 & 0.35 & 0.95 & 0.95 & 0.95 & 0.95 & 0.95 & 0 & 0 & 0 \\
\hline (Study Periods) & $\begin{array}{l}\text { Sat, Sun, Hol, } \\
\text { WinterDesign, } \\
\text { Other } \\
\end{array}$ & 0 & 0 & 0 & 0 & 0 & 0 & 0 & 0 & 0 & 0 & 0 & 0 & 0 & 0 & 0 & 0 & 0 & 0 & 0 & 0 & 0 & 0 & 0 & 0 \\
\hline BLDG_OCC_SCH_Gym & $\begin{array}{l}\text { WD, } \\
\text { SummerDesign }\end{array}$ & 0 & 0 & 0 & 0 & 0 & 0 & 0 & 0 & 0.35 & 0.35 & 0.35 & 0.35 & 0.35 & 0.35 & 0.35 & 0.35 & 0.35 & 0.35 & 0.35 & 0.35 & 0.35 & 0 & 0 & 0 \\
\hline (Summer Holiday) & $\begin{array}{l}\text { Sat, Sun, Hol, } \\
\text { WinterDesign, } \\
\text { Other }\end{array}$ & 0 & 0 & 0 & 0 & 0 & 0 & 0 & 0 & 0 & 0 & 0 & 0 & 0 & 0 & 0 & 0 & 0 & 0 & 0 & 0 & 0 & 0 & 0 & 0 \\
\hline BLDG_OCC_SCH_Auditorium & $\begin{array}{l}\text { WD, } \\
\text { SummerDesign }\end{array}$ & 0 & 0 & 0 & 0 & 0 & 0 & 0 & 0 & 0.25 & 0.25 & 0.25 & 0.25 & 0.25 & 0.25 & 0.25 & 0.95 & 0.95 & 0.95 & 0.95 & 0.95 & 0 & 0 & 0 & 0 \\
\hline (Study Periods) & Sat, WinterDesign & 0 & 0 & 0 & 0 & 0 & 0 & 0 & 0 & 0 & 0 & 0 & 0 & 0 & 0 & 0 & 0 & 0 & 0 & 0 & 0 & 0 & 0 & 0 & 0 \\
\hline BLDG_OCC_SCH_Auditorium & $\begin{array}{l}\text { WD, } \\
\text { SummerDesign }\end{array}$ & 0 & 0 & 0 & 0 & 0 & 0 & 0 & 0 & 0.15 & 0.15 & 0.15 & 0.15 & 0.15 & 0.15 & 0.15 & 0.15 & 0.15 & 0.35 & 0.35 & 0 & 0 & 0 & 0 & 0 \\
\hline (Summer Holiday) & Sat, WinterDesign & 0 & 0 & 0 & 0 & 0 & 0 & 0 & 0 & 0 & 0 & 0 & 0 & 0 & 0 & 0 & 0 & 0 & 0 & 0 & 0 & 0 & 0 & 0 & 0 \\
\hline BLDG_OCC_SCH_Cafeteria & $\begin{array}{l}\text { WD, } \\
\text { SummerDesign }\end{array}$ & 0 & 0 & 0 & 0 & 0 & 0 & 0 & 0 & 0 & 0.95 & 0.95 & 0.95 & 0.95 & 0.95 & 0.95 & 0.35 & 0.35 & 0.35 & 0.35 & 0.35 & 0 & 0 & 0 & 0 \\
\hline (Study Periods) & \begin{tabular}{l|} 
Sat, Sun, Hol, \\
WinterDesign, \\
Other \\
\end{tabular} & 0 & 0 & 0 & 0 & 0 & 0 & 0 & 0 & 0 & 0 & 0 & 0 & 0 & 0 & 0 & 0 & 0 & 0 & 0 & 0 & 0 & 0 & 0 & 0 \\
\hline BLDG_OCC_SCH_Cafeteria & \begin{tabular}{|l} 
WD, \\
SummerDesign \\
\end{tabular} & 0 & 0 & 0 & 0 & 0 & 0 & 0 & 0 & 0 & 0.15 & 0.15 & 0.15 & 0.15 & 0.15 & 0.15 & 0.35 & 0.35 & 0.35 & 0.35 & 0.35 & 0 & 0 & 0 & 0 \\
\hline (Summer Holiday) & \begin{tabular}{|l|} 
Sat, Sun, Hol, \\
WinterDesign, \\
Other \\
\end{tabular} & 0 & 0 & 0 & 0 & 0 & 0 & 0 & 0 & 0 & 0 & 0 & 0 & 0 & 0 & 0 & 0 & 0 & 0 & 0 & 0 & 0 & 0 & 0 & 0 \\
\hline BLDG_SWH_SCH & $\begin{array}{l}\text { WD, } \\
\text { SummerDesign }\end{array}$ & 0.05 & 0.05 & 0.05 & 0.05 & 0.05 & 0.05 & 0.05 & 0.1 & 0.34 & 0.6 & 0.63 & 0.72 & 0.79 & 0.83 & 0.61 & 0.65 & 0.1 & 0.1 & 0.19 & 0.25 & 0.22 & 0.22 & 0.12 & 0.09 \\
\hline (Study Periods) & $\begin{array}{l}\text { Sat, Sun, Hol, } \\
\text { WinterDesign, } \\
\text { Other } \\
\end{array}$ & 0.03 & 0.03 & 0.03 & 0.03 & 0.03 & 0.03 & 0.03 & 0.03 & 0.03 & 0.05 & 0.05 & 0.05 & 0.05 & 0.03 & 0.03 & 0.03 & 0.03 & 0.03 & 0.03 & 0.03 & 0.03 & 0.03 & 0.03 & 0.03 \\
\hline BLDG_SWH_SCH & $\begin{array}{l}\text { WD, } \\
\text { SummerDesign } \\
\end{array}$ & 0.05 & 0.05 & 0.05 & 0.05 & 0.05 & 0.05 & 0.05 & 0.1 & 0.1 & 0.1 & 0.1 & 0.1 & 0.1 & 0.1 & 0.1 & 0.1 & 0.1 & 0.1 & 0.19 & 0.25 & 0.22 & 0.22 & 0.12 & 0.09 \\
\hline (Summer Holiday) & \begin{tabular}{|l|} 
Sat, Sun, Hol, \\
WinterDesign, \\
Other \\
\end{tabular} & 0.03 & 0.03 & 0.03 & 0.03 & 0.03 & 0.03 & 0.03 & 0.03 & 0.03 & 0.05 & 0.05 & 0.05 & 0.05 & 0.03 & 0.03 & 0.03 & 0.03 & 0.03 & 0.03 & 0.03 & 0.03 & 0.03 & 0.03 & 0.03 \\
\hline INFIL_SCH_PNNL & $\begin{array}{l}\text { WD, } \\
\text { SummerDesign }\end{array}$ & 1 & 1 & 1 & 1 & 1 & 1 & 1 & 0.25 & 0.25 & 0.25 & 0.25 & 0.25 & 0.25 & 0.25 & 0.25 & 0.25 & 0.25 & 0.25 & 0.25 & 0.25 & 0.25 & 1 & 1 & 1 \\
\hline & Sat, WinterDesign & 1 & 1 & 1 & 1 & 1 & 1 & 1 & 0.25 & 0.25 & 0.25 & 0.25 & 0.25 & 0.25 & 0.25 & 0.25 & 0.25 & 0.25 & 0.25 & 0.25 & 0.25 & 0.25 & 1 & 1 & 1 \\
\hline & Sun, Hol, Other & 1 & 1 & 1 & 1 & 1 & 1 & 1 & 0.25 & 0.25 & 0.25 & 0.25 & 0.25 & 0.25 & 0.25 & 0.25 & 0.25 & 0.25 & 0.25 & 0.25 & 0.25 & 0.25 & 1 & 1 & 1 \\
\hline
\end{tabular}




\begin{tabular}{|c|c|c|c|c|c|c|c|c|c|c|c|c|c|c|c|c|c|c|c|c|c|c|c|c|c|}
\hline Schedule & Day of Week & 1 & 2 & 3 & 4 & 5 & 6 & 7 & 8 & 9 & 10 & 11 & 12 & 13 & 14 & 15 & 16 & 17 & 18 & 19 & 20 & 21 & 22 & 23 & 24 \\
\hline HVACOperationSchd & $\begin{array}{l}\text { WD, } \\
\text { SummerDesign, } \\
\text { WinterDesign } \\
\end{array}$ & 0 & 0 & 0 & 0 & 0 & 0 & 0 & 1 & 1 & 1 & 1 & 1 & 1 & 1 & 1 & 1 & 1 & 1 & 1 & 1 & 1 & 0 & 0 & 0 \\
\hline & $\begin{array}{l}\begin{array}{l}\text { Sat, Sun, Hol, } \\
\text { Other }\end{array} \\
\end{array}$ & 0 & 0 & 0 & 0 & 0 & 0 & 0 & 0 & 0 & 0 & 0 & 0 & 0 & 0 & 0 & 0 & 0 & 0 & 0 & 0 & 0 & 0 & 0 & 0 \\
\hline FAN_SCH & All & 1 & 1 & 1 & 1 & 1 & 1 & 1 & 1 & 1 & 1 & 1 & 1 & 1 & 1 & 1 & 1 & 1 & 1 & 1 & 1 & 1 & 1 & 1 & 1 \\
\hline $\begin{array}{l}\text { Dual Zone Control Type } \\
\text { Sched }\end{array}$ & All & 4 & 4 & 4 & 4 & 4 & 4 & 4 & 4 & 4 & 4 & 4 & 4 & 4 & 4 & 4 & 4 & 4 & 4 & 4 & 4 & 4 & 4 & 4 & 4 \\
\hline ReheatCoilAvailSched & All & 1 & 1 & 1 & 1 & 1 & 1 & 1 & 1 & 1 & 1 & 1 & 1 & 1 & 1 & 1 & 1 & 1 & 1 & 1 & 1 & 1 & 1 & 1 & 1 \\
\hline CoolingCoilAvailSched & All & 1 & 1 & 1 & 1 & 1 & 1 & 1 & 1 & 1 & 1 & 1 & 1 & 1 & 1 & 1 & 1 & 1 & 1 & 1 & 1 & 1 & 1 & 1 & 1 \\
\hline $\begin{array}{l}\text { MinOA_MotorizedDamper_ } \\
\text { Sched }\end{array}$ & $\begin{array}{l}\text { WD, } \\
\text { SummerDesign }\end{array}$ & 0.0 & 0.0 & 0.0 & 0.0 & 0.0 & 0.0 & 0.0 & 0.0 & 1.0 & 1.0 & 1.0 & 1.0 & 1.0 & 1.0 & 1.0 & 1.0 & 1.0 & 1.0 & 1.0 & 1.0 & 1.0 & 0.0 & 0.0 & 0.0 \\
\hline & $\begin{array}{l}\text { Sat, Sun, Hol, } \\
\text { WinterDesign, } \\
\text { Other }\end{array}$ & 0.0 & 0.0 & 0.0 & 0.0 & 0.0 & 0.0 & 0.0 & 0.0 & 0.0 & 0.0 & 0.0 & 0.0 & 0.0 & 0.0 & 0.0 & 0.0 & 0.0 & 0.0 & 0.0 & 0.0 & 0.0 & 0.0 & 0.0 & 0.0 \\
\hline MinOA_Sched & All & 1.0 & 1.0 & 1.0 & 1.0 & 1.0 & 1.0 & 1.0 & 1.0 & 1.0 & 1.0 & 1.0 & 1.0 & 1.0 & 1.0 & 1.0 & 1.0 & 1.0 & 1.0 & 1.0 & 1.0 & 1.0 & 1.0 & 1.0 & 1.0 \\
\hline HTGSETP_SCH & WD & 15.6 & 15.6 & 15.6 & 15.6 & 15.6 & 15.6 & 15.6 & 21.0 & 21.0 & 21.0 & 21.0 & 21.0 & 21.0 & 21.0 & 21.0 & 21.0 & 21.0 & 21.0 & 21.0 & 21.0 & 21.0 & 15.6 & 15.6 & 15.6 \\
\hline & $\begin{array}{l}\text { SummerDesign, } \\
\text { Sat, Sun, Hol, } \\
\text { Other }\end{array}$ & 15.6 & 15.6 & 15.6 & 15.6 & 15.6 & 15.6 & 15.6 & 15.6 & 15.6 & 15.6 & 15.6 & 15.6 & 15.6 & 15.6 & 15.6 & 15.6 & 15.6 & 15.6 & 15.6 & 15.6 & 15.6 & 15.6 & 15.6 & 15.6 \\
\hline & WinterDesign & 21.0 & 21.0 & 21.0 & 21.0 & 21.0 & 21.0 & 21.0 & 21.0 & 21.0 & 21.0 & 21.0 & 21.0 & 21.0 & 21.0 & 21.0 & 21.0 & 21.0 & 21.0 & 21.0 & 21.0 & 21.0 & 21.0 & 21.0 & 21.0 \\
\hline CLGSETP_SCH & WD & 29.4 & 29.4 & 29.4 & 29.4 & 29.4 & 29.4 & 29.4 & 24.0 & 24.0 & 24.0 & 24.0 & 24.0 & 24.0 & 24.0 & 24.0 & 24.0 & 24.0 & 24.0 & 24.0 & 24.0 & 24.0 & 29.4 & 29.4 & 29.4 \\
\hline & SummerDesign & 24.0 & 24.0 & 24.0 & 24.0 & 24.0 & 24.0 & 24.0 & 24.0 & 24.0 & 24.0 & 24.0 & 24.0 & 24.0 & 24.0 & 24.0 & 24.0 & 24.0 & 24.0 & 24.0 & 24.0 & 24.0 & 24.0 & 24.0 & 24.0 \\
\hline & $\begin{array}{l}\text { WinterDesign, Sat, } \\
\text { Sun, Hol, Other } \\
\end{array}$ & 29.4 & 29.4 & 29.4 & 29.4 & 29.4 & 29.4 & 29.4 & 29.4 & 29.4 & 29.4 & 29.4 & 29.4 & 29.4 & 29.4 & 29.4 & 29.4 & 29.4 & 29.4 & 29.4 & 29.4 & 29.4 & 29.4 & 29.4 & 29.4 \\
\hline HTGSETP_SCH_SETBACK & WD & 15.6 & 15.6 & 15.6 & 15.6 & 15.6 & 15.6 & 15.6 & 15.6 & 15.6 & 15.6 & 15.6 & 15.6 & 15.6 & 15.6 & 15.6 & 15.6 & 15.6 & 15.6 & 15.6 & 15.6 & 15.6 & 15.6 & 15.6 & 15.6 \\
\hline $\begin{array}{l}\text { (For mechanical room and } \\
\text { bathroom) }\end{array}$ & $\begin{array}{l}\text { SummerDesign, } \\
\text { Sat, Sun, Hol, } \\
\text { Other }\end{array}$ & 15.6 & 15.6 & 15.6 & 15.6 & 15.6 & 15.6 & 15.6 & 15.6 & 15.6 & 15.6 & 15.6 & 15.6 & 15.6 & 15.6 & 15.6 & 15.6 & 15.6 & 15.6 & 15.6 & 15.6 & 15.6 & 15.6 & 15.6 & 15.6 \\
\hline & WinterDesign & 21.0 & 21.0 & 21.0 & 21.0 & 21.0 & 21.0 & 21.0 & 21.0 & 21.0 & 21.0 & 21.0 & 21.0 & 21.0 & 21.0 & 21.0 & 21.0 & 21.0 & 21.0 & 21.0 & 21.0 & 21.0 & 21.0 & 21.0 & 21.0 \\
\hline CLGSETP_SCH_SETUP & WD & 29.4 & 29.4 & 29.4 & 29.4 & 29.4 & 29.4 & 29.4 & 29.4 & 29.4 & 29.4 & 29.4 & 29.4 & 29.4 & 29.4 & 29.4 & 29.4 & 29.4 & 29.4 & 29.4 & 29.4 & 29.4 & 29.4 & 29.4 & 29.4 \\
\hline $\begin{array}{l}\text { (For mechanical room and } \\
\text { bathroom) }\end{array}$ & SummerDesign & 24.0 & 24.0 & 24.0 & 24.0 & 24.0 & 24.0 & 24.0 & 24.0 & 24.0 & 24.0 & 24.0 & 24.0 & 24.0 & 24.0 & 24.0 & 24.0 & 24.0 & 24.0 & 24.0 & 24.0 & 24.0 & 24.0 & 24.0 & 24.0 \\
\hline & $\begin{array}{l}\text { WinterDesign, Sat, } \\
\text { Sun, Hol, Other } \\
\end{array}$ & 29.4 & 29.4 & 29.4 & 29.4 & 29.4 & 29.4 & 29.4 & 29.4 & 29.4 & 29.4 & 29.4 & 29.4 & 29.4 & 29.4 & 29.4 & 29.4 & 29.4 & 29.4 & 29.4 & 29.4 & 29.4 & 29.4 & 29.4 & 29.4 \\
\hline $\begin{array}{l}\text { Seasonal-Reset-Supply-Air- } \\
\text { Temp-Sch }\end{array}$ & All & 13.0 & 13.0 & 13.0 & 13.0 & 13.0 & 13.0 & 13.0 & 13.0 & 13.0 & 13.0 & 13.0 & 13.0 & 13.0 & 13.0 & 13.0 & 13.0 & 13.0 & 13.0 & 13.0 & 13.0 & 13.0 & 13.0 & 13.0 & 13.0 \\
\hline & All & 13.0 & 13.0 & 13.0 & 13.0 & 13.0 & 13.0 & 13.0 & 13.0 & 13.0 & 13.0 & 13.0 & 13.0 & 13.0 & 13.0 & 13.0 & 13.0 & 13.0 & 13.0 & 13.0 & 13.0 & 13.0 & 13.0 & 13.0 & 13.0 \\
\hline & All & 13.0 & 13.0 & 13.0 & 13.0 & 13.0 & 13.0 & 13.0 & 13.0 & 13.0 & 13.0 & 13.0 & 13.0 & 13.0 & 13.0 & 13.0 & 13.0 & 13.0 & 13.0 & 13.0 & 13.0 & 13.0 & 13.0 & 13.0 & 13.0 \\
\hline VAV-Supply-Air-Temp-Sch & All & 12.8 & 12.8 & 12.8 & 12.8 & 12.8 & 12.8 & 12.8 & 12.8 & 12.8 & 12.8 & 12.8 & 12.8 & 12.8 & 12.8 & 12.8 & 12.8 & 12.8 & 12.8 & 12.8 & 12.8 & 12.8 & 12.8 & 12.8 & 12.8 \\
\hline CW-Loop-Temp-Schedule & All & 6.7 & 6.7 & 67 & 67 & 67 & 67 & 6.7 & 6.7 & 6.7 & 6.7 & 6.7 & 6.7 & 6.7 & 6.7 & 6.7 & 6.7 & 6.7 & 6.7 & 6.7 & 6.7 & 6.7 & 6.7 & 6.7 & 6.7 \\
\hline HW-Loop-Temp-Schedule & All & 82.0 & 82.0 & 82.0 & 82.0 & 82.0 & 82.0 & 82.0 & 82.0 & 82.0 & 82.0 & 82.0 & 82.0 & 82.0 & 82.0 & 82.0 & 82.0 & 82.0 & 82.0 & 82.0 & 82.0 & 82.0 & 82.0 & 82.0 & 82.0 \\
\hline Heating-Supply-Air-Temp-Sch & All & 16.0 & 16.0 & 16.0 & 16.0 & 16.0 & 16.0 & 16.0 & 16.0 & 16.0 & 16.0 & 16.0 & 16.0 & 16.0 & 16.0 & 16.0 & 16.0 & 16.0 & 16.0 & 16.0 & 16.0 & 16.0 & 16.0 & 16.0 & 16.0 \\
\hline HTGSETP_SCH & WD & 60 & 60 & 60 & 60 & 60 & 60 & 60 & 70 & 70 & 70 & 70 & 70 & 70 & 70 & 70 & 70 & 70 & 70 & 70 & 70 & 70 & 60 & 60 & 60 \\
\hline & $\begin{array}{l}\text { SummerDesign, } \\
\text { Sat, Sun, Hol, } \\
\text { Other }\end{array}$ & 60 & 60 & 60 & 60 & 60 & 60 & 60 & 60 & 60 & 60 & 60 & 60 & 60 & 60 & 60 & 60 & 60 & 60 & 60 & 60 & 60 & 60 & 60 & 60 \\
\hline & WinterDesign & 70 & 70 & 70 & 70 & 70 & 70 & 70 & 70 & 70 & 70 & 70 & 70 & 70 & 70 & 70 & 70 & 70 & 70 & 70 & 70 & 70 & 70 & 70 & 70 \\
\hline CLGSETP_SCH & WD & 85 & 85 & 85 & 85 & 85 & 85 & 85 & 75 & 75 & 75 & 75 & 75 & 75 & 75 & 75 & 75 & 75 & 75 & 75 & 75 & 75 & 85 & 85 & 85 \\
\hline & Sumn & 75 & 75 & 75 & 75 & 75 & 75 & 75 & 75 & 75 & 75 & 75 & 75 & 75 & 75 & 75 & 75 & 75 & 75 & 75 & 75 & 75 & 75 & 75 & 75 \\
\hline & $\begin{array}{l}\text { WinterDesign, Sat, } \\
\text { Sun, Hol, Other }\end{array}$ & 85 & 85 & 85 & 85 & 85 & 85 & 85 & 85 & 85 & 85 & 85 & 85 & 85 & 85 & 85 & 85 & 85 & 85 & 85 & 85 & 85 & 85 & 85 & 85 \\
\hline HTGSETP_SCH_SETBACk & WD & 60 & 60 & 60 & 60 & 60 & 60 & 60 & 60 & 60 & 60 & 60 & 60 & 60 & 60 & 60 & 60 & 60 & 60 & 60 & 60 & 60 & 60 & 60 & 60 \\
\hline $\begin{array}{l}\text { (For mechanical room and } \\
\text { bathroom) }\end{array}$ & $\begin{array}{l}\text { SummerDesign, } \\
\text { Sat, Sun, Hol, } \\
\text { Other }\end{array}$ & 60 & 60 & 60 & 60 & 60 & 60 & 60 & 60 & 60 & 60 & 60 & 60 & 60 & 60 & 60 & 60 & 60 & 60 & 60 & 60 & 60 & 60 & 60 & 60 \\
\hline & WinterDesign & 70 & 70 & 70 & 70 & 70 & 70 & 70 & 70 & 70 & 70 & 70 & 70 & 70 & 70 & 70 & 70 & 70 & 70 & 70 & 70 & 70 & 70 & 70 & 70 \\
\hline CLGSETP_SCH_SETUP & WD & 85 & 85 & 85 & 85 & 85 & 85 & 85 & 85 & 85 & 85 & 85 & 85 & 85 & 85 & 85 & 85 & 85 & 85 & 85 & 85 & 85 & 85 & 85 & 85 \\
\hline
\end{tabular}




\begin{tabular}{|c|c|c|c|c|c|c|c|c|c|c|c|c|c|c|c|c|c|c|c|c|c|c|c|c|c|}
\hline Schedule & Day of Week & 1 & 2 & 3 & 4 & 5 & 6 & 7 & 8 & 9 & 10 & 11 & 12 & 13 & 14 & 15 & 16 & 17 & 18 & 19 & 20 & 21 & 22 & 23 & 24 \\
\hline \multirow{2}{*}{$\begin{array}{l}\text { (For mechanical room and } \\
\text { bathroom) }\end{array}$} & SummerDesign & 75 & 75 & 75 & 75 & 75 & 75 & 75 & 75 & 75 & 75 & 75 & 75 & 75 & 75 & 75 & 75 & 75 & 75 & 75 & 75 & 75 & 75 & 75 & 75 \\
\hline & $\begin{array}{l}\text { WinterDesign, Sat, } \\
\text { Sun, Hol, Other }\end{array}$ & 85 & 85 & 85 & 85 & 85 & 85 & 85 & 85 & 85 & 85 & 85 & 85 & 85 & 85 & 85 & 85 & 85 & 85 & 85 & 85 & 85 & 85 & 85 & 85 \\
\hline \multirow[t]{3}{*}{$\begin{array}{l}\text { Seasonal-Reset-Supply-Air- } \\
\text { Temp-Sch }\end{array}$} & All & 55 & 55 & 55 & 55 & 55 & 55 & 55 & 55 & 55 & 55 & 55 & 55 & 55 & 55 & 55 & 55 & 55 & 55 & 55 & 55 & 55 & 55 & 55 & 55 \\
\hline & All & 55 & 55 & 55 & 55 & 55 & 55 & 55 & 55 & 55 & 55 & 55 & 55 & 55 & 55 & 55 & 55 & 55 & 55 & 55 & 55 & 55 & 55 & 55 & 55 \\
\hline & All & 55 & 55 & 55 & 55 & 55 & 55 & 55 & 55 & 55 & 55 & 55 & 55 & 55 & 55 & 55 & 55 & 55 & 55 & 55 & 55 & 55 & 55 & 55 & 55 \\
\hline VAV-Supply-Air-Temp-Sch & All & 55 & 55 & 55 & 55 & 55 & 55 & 55 & 55 & 55 & 55 & 55 & 55 & 55 & 55 & 55 & 55 & 55 & 55 & 55 & 55 & 55 & 55 & 55 & 55 \\
\hline CW-Loop-Temp-Schedule & All & 44 & 44 & 44 & 44 & 44 & 44 & 44 & 44 & 44 & 44 & 44 & 44 & 44 & 44 & 44 & 44 & 44 & 44 & 44 & 44 & 44 & 44 & 44 & 44 \\
\hline HW-Loop-Temp-Schedule & All & 180 & 180 & 180 & 180 & 180 & 180 & 180 & 180 & 180 & 180 & 180 & 180 & 180 & 180 & 180 & 180 & 180 & 180 & 180 & 180 & 180 & 180 & 180 & 180 \\
\hline Heating-Supply-Air-Temp-Sch & All & 61 & 61 & 61 & 61 & 61 & 61 & 61 & 61 & 61 & 61 & 61 & 61 & 61 & 61 & 61 & 61 & 61 & 61 & 61 & 61 & 61 & 61 & 61 & 61 \\
\hline
\end{tabular}




\section{C.8 Outpatient Hourly Operation Healthcare Schedules}

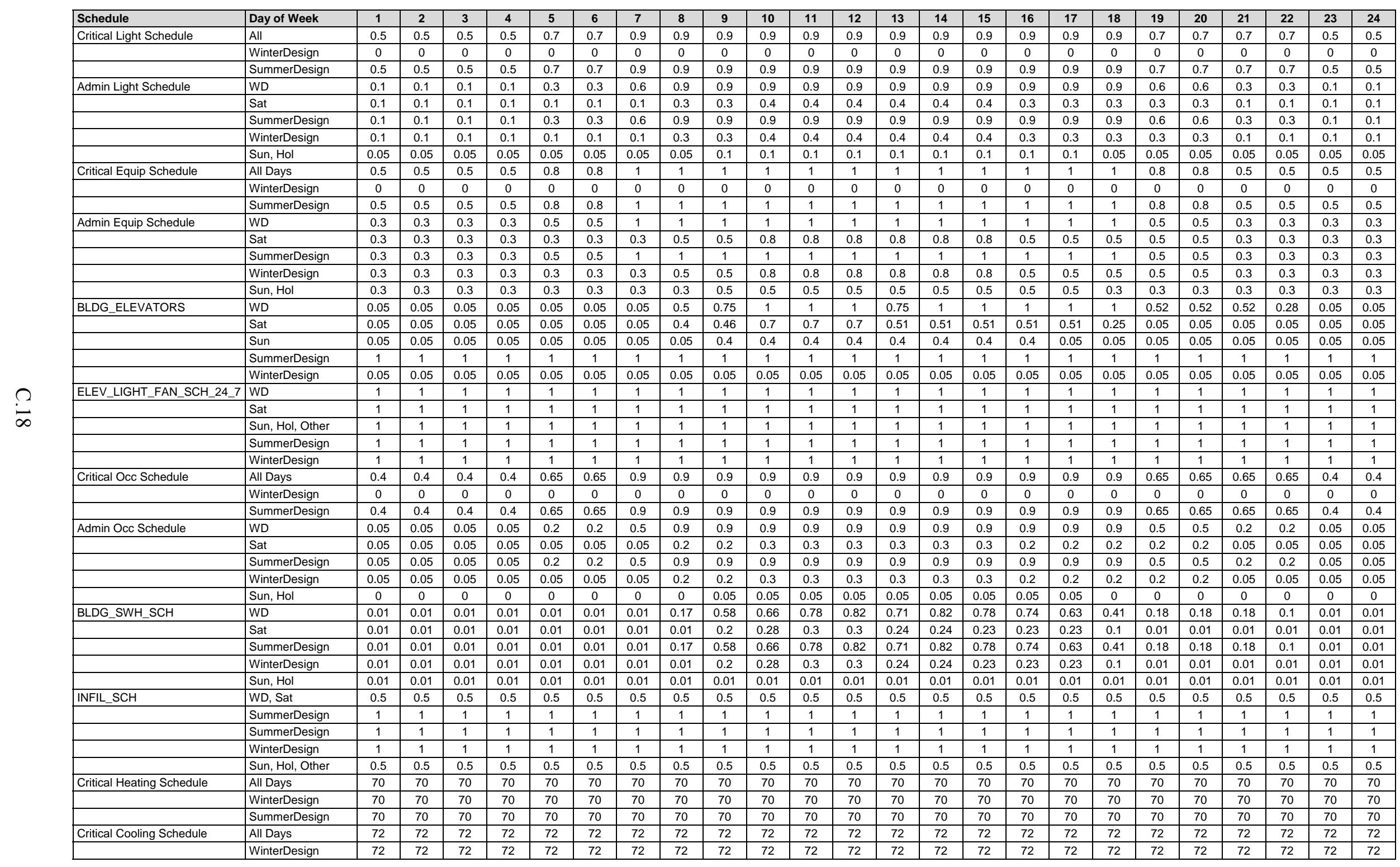




\begin{tabular}{|c|c|c|c|c|c|c|c|c|c|c|c|c|c|c|c|c|c|c|c|c|c|c|c|c|c|}
\hline Schedule & Day of Week & 1 & 2 & 3 & 4 & 5 & 6 & 7 & 8 & 9 & 10 & 11 & 12 & 13 & 14 & 15 & 16 & 17 & 18 & 19 & 20 & 21 & 22 & 23 & 24 \\
\hline & SummerDesign & 72 & 72 & 72 & 72 & 72 & 72 & 72 & 72 & 72 & 72 & 72 & 72 & 72 & 72 & 72 & 72 & 72 & 72 & 72 & 72 & 72 & 72 & 72 & 72 \\
\hline OR Heating Schedule & All Days & 65 & 65 & 65 & 65 & 65 & 65 & 65 & 65 & 65 & 65 & 65 & 65 & 65 & 65 & 65 & 65 & 65 & 65 & 65 & 65 & 65 & 65 & 65 & 65 \\
\hline & WinterDesign & 65 & 65 & 65 & 65 & 65 & 65 & 65 & 65 & 65 & 65 & 65 & 65 & 65 & 65 & 65 & 65 & 65 & 65 & 65 & 65 & 65 & 65 & 65 & 65 \\
\hline & SummerDesign & 65 & 65 & 65 & 65 & 65 & 65 & 65 & 65 & 65 & 65 & 65 & 65 & 65 & 65 & 65 & 65 & 65 & 65 & 65 & 65 & 65 & 65 & 65 & 65 \\
\hline OR Cooling Schedule & All Days & 72 & 72 & 72 & 72 & 72 & 72 & 65 & 65 & 65 & 65 & 65 & 65 & 65 & 65 & 65 & 65 & 65 & 72 & 72 & 72 & 72 & 72 & 72 & 72 \\
\hline & WinterDesign & 72 & 72 & 72 & 72 & 72 & 72 & 65 & 65 & 65 & 65 & 65 & 65 & 65 & 65 & 65 & 65 & 65 & 72 & 72 & 72 & 72 & 72 & 72 & 72 \\
\hline & SummerDesign & 72 & 72 & 72 & 72 & 72 & 72 & 65 & 65 & 65 & 65 & 65 & 65 & 65 & 65 & 65 & 65 & 65 & 72 & 72 & 72 & 72 & 72 & 72 & 72 \\
\hline Admin Heating Schedule & WD & 65 & 65 & 65 & 65 & 65 & 70 & 70 & 70 & 70 & 70 & 70 & 70 & 70 & 70 & 70 & 70 & 70 & 70 & 65 & 65 & 65 & 65 & 65 & 65 \\
\hline & Sat & 65 & 65 & 65 & 65 & 65 & 65 & 65 & 70 & 70 & 70 & 70 & 70 & 70 & 70 & 70 & 65 & 65 & 65 & 65 & 65 & 65 & 65 & 65 & 65 \\
\hline & SummerDesign & 65 & 65 & 65 & 65 & 65 & 70 & 70 & 70 & 70 & 70 & 70 & 70 & 70 & 70 & 70 & 70 & 70 & 70 & 65 & 65 & 65 & 65 & 65 & 65 \\
\hline & WinterDesign & 65 & 65 & 65 & 65 & 65 & 65 & 65 & 70 & 70 & 70 & 70 & 70 & 70 & 70 & 70 & 65 & 65 & 65 & 65 & 65 & 65 & 65 & 65 & 65 \\
\hline & Sun, Hol & 65 & 65 & 65 & 65 & 65 & 65 & 65 & 65 & 65 & 65 & 65 & 65 & 65 & 65 & 65 & 65 & 65 & 65 & 65 & 65 & 65 & 65 & 65 & 65 \\
\hline Admin Cooling Schedule & WD & 77 & 77 & 77 & 77 & 77 & 72 & 72 & 72 & 72 & 72 & 72 & 72 & 72 & 72 & 72 & 72 & 72 & 72 & 77 & 77 & 77 & 77 & 77 & 77 \\
\hline & Sat & 77 & 77 & 77 & 77 & 77 & 77 & 77 & 72 & 72 & 72 & 72 & 72 & 72 & 72 & 72 & 77 & 77 & 77 & 77 & 77 & 77 & 77 & 77 & 77 \\
\hline & SummerDesign & 77 & 77 & 77 & 77 & 77 & 72 & 72 & 72 & 72 & 72 & 72 & 72 & 72 & 72 & 72 & 72 & 72 & 72 & 77 & 77 & 77 & 77 & 77 & 77 \\
\hline & WinterDesign & 77 & 77 & 77 & 77 & 77 & 77 & 77 & 72 & 72 & 72 & 72 & 72 & 72 & 72 & 72 & 77 & 77 & 77 & 77 & 77 & 77 & 77 & 77 & 77 \\
\hline & Sun, Hol & 77 & 77 & 77 & 77 & 77 & 77 & 77 & 77 & 77 & 77 & 77 & 77 & 77 & 77 & 77 & 77 & 77 & 77 & 77 & 77 & 77 & 77 & 77 & 77 \\
\hline HVACOperationSchd & WD & 1 & 1 & 1 & 1 & 1 & 1 & 1 & 1 & 1 & 1 & 1 & 1 & 1 & 1 & 1 & 1 & 1 & 1 & 1 & 1 & 1 & 1 & 1 & 1 \\
\hline (AHU-1 Fan; AHU-2 Fan) & Sat & 1 & 1 & 1 & 1 & 1 & 1 & 1 & 1 & 1 & 1 & 1 & 1 & 1 & 1 & 1 & 1 & 1 & 1 & 1 & 1 & 1 & 1 & 1 & 1 \\
\hline & SummerDesign & 1 & 1 & 1 & 1 & 1 & 1 & 1 & 1 & 1 & 1 & 1 & 1 & 1 & 1 & 1 & 1 & 1 & 1 & 1 & 1 & 1 & 1 & 1 & 1 \\
\hline & WinterDesign & 1 & 1 & 1 & 1 & 1 & 1 & 1 & 1 & 1 & 1 & 1 & 1 & 1 & 1 & 1 & 1 & 1 & 1 & 1 & 1 & 1 & 1 & 1 & 1 \\
\hline & Sun, Hol & 1 & 1 & 1 & 1 & 1 & 1 & 1 & 1 & 1 & 1 & 1 & 1 & 1 & 1 & 1 & 1 & 1 & 1 & 1 & 1 & 1 & 1 & 1 & 1 \\
\hline Hours_of_operation & WD & 1 & 1 & 1 & 1 & 1 & 1 & 1 & 1 & 1 & 1 & 1 & 1 & 1 & 1 & 1 & 1 & 1 & 1 & 1 & 1 & 1 & 1 & 1 & 1 \\
\hline (Exhaust Fans) & Sat & 1 & 1 & 1 & 1 & 1 & 1 & 1 & 1 & 1 & 1 & 1 & 1 & 1 & 1 & 1 & 1 & 1 & 1 & 1 & 1 & 1 & 1 & 1 & 1 \\
\hline & SummerDesign & 1 & 1 & 1 & 1 & 1 & 1 & 1 & 1 & 1 & 1 & 1 & 1 & 1 & 1 & 1 & 1 & 1 & 1 & 1 & 1 & 1 & 1 & 1 & 1 \\
\hline & WinterDesign & 1 & 1 & 1 & 1 & 1 & 1 & 1 & 1 & 1 & 1 & 1 & 1 & 1 & 1 & 1 & 1 & 1 & 1 & 1 & 1 & 1 & 1 & 1 & 1 \\
\hline & Sun, Hol & 1 & 1 & 1 & 1 & 1 & 1 & 1 & 1 & 1 & 1 & 1 & 1 & 1 & 1 & 1 & 1 & 1 & 1 & 1 & 1 & 1 & 1 & 1 & 1 \\
\hline BLDG_OA_SCH & WD & 0 & 0 & 0 & 0 & 0 & 0 & 1 & 1 & 1 & 1 & 1 & 1 & 1 & 1 & 1 & 1 & 1 & 1 & 0 & 0 & 0 & 0 & 0 & 0 \\
\hline & Sat & 0 & 0 & 0 & 0 & 0 & 0 & 1 & 1 & 1 & 1 & 1 & 1 & 1 & 1 & 1 & 1 & 1 & 1 & 0 & 0 & 0 & 0 & 0 & 0 \\
\hline & SummerDesign & 0 & 0 & 0 & 0 & 0 & 0 & 1 & 1 & 1 & 1 & 1 & 1 & 1 & 1 & 1 & 1 & 1 & 1 & 0 & 0 & 0 & 0 & 0 & 0 \\
\hline & WinterDesign & 0 & 0 & 0 & 0 & 0 & 0 & 1 & 1 & 1 & 1 & 1 & 1 & 1 & 1 & 1 & 1 & 1 & 1 & 0 & 0 & 0 & 0 & 0 & 0 \\
\hline & Sun, Hol & 0 & 0 & 0 & 0 & 0 & 0 & 0 & 0 & 0 & 0 & 0 & 0 & 0 & 0 & 0 & 0 & 0 & 0 & 0 & 0 & 0 & 0 & 0 & 0 \\
\hline OR_MinSA_Sched & WD & 0.2 & 0.2 & 0.2 & 0.2 & 0.2 & 0.2 & 1 & 1 & 1 & 1 & 1 & 1 & 1 & 1 & 1 & 1 & 1 & 1 & 0.2 & 0.2 & 0.2 & 0.2 & 0.2 & 0.2 \\
\hline & Sat & 0.2 & 0.2 & 0.2 & 0.2 & 0.2 & 0.2 & 1 & 1 & 1 & 1 & 1 & 1 & 1 & 1 & 1 & 1 & 1 & 1 & 0.2 & 0.2 & 0.2 & 0.2 & 0.2 & 0.2 \\
\hline & SummerDesign & 1 & 1 & 1 & 1 & 1 & 1 & 1 & 1 & 1 & 1 & 1 & 1 & 1 & 1 & 1 & 1 & 1 & 1 & 1 & 1 & 1 & 1 & 1 & 1 \\
\hline & WinterDesign & 0.2 & 0.2 & 0.2 & 0.2 & 0.2 & 0.2 & 0.2 & 0.2 & 0.2 & 0.2 & 0.2 & 0.2 & 0.2 & 0.2 & 0.2 & 0.2 & 0.2 & 0.2 & 0.2 & 0.2 & 0.2 & 0.2 & 0.2 & 0.2 \\
\hline & Sun, Hol & 0.2 & 0.2 & 0.2 & 0.2 & 0.2 & 0.2 & 0.2 & 0.2 & 0.2 & 0.2 & 0.2 & 0.2 & 0.2 & 0.2 & 0.2 & 0.2 & 0.2 & 0.2 & 0.2 & 0.2 & 0.2 & 0.2 & 0.2 & 0.2 \\
\hline
\end{tabular}




\section{C.9 Hospital Hourly Operation Schedules}

\begin{tabular}{|c|c|c|c|c|c|c|c|c|c|c|c|c|c|c|c|c|c|c|c|c|c|c|c|c|c|}
\hline Schedule & Day of Week & 1 & 2 & 3 & 4 & 5 & 6 & 7 & 8 & 9 & 10 & 11 & 12 & 13 & 14 & 15 & 16 & 17 & 18 & 19 & 20 & 21 & 22 & 23 & 24 \\
\hline BLDG_LIGHT_SCH & $\begin{array}{l}\text { WD, } \\
\text { SummerDesign }\end{array}$ & 0.1 & 0.1 & 0.1 & 0.1 & 0.1 & 0.1 & 0.1 & 0.5 & 0.9 & 0.9 & 0.9 & 0.9 & 0.9 & 0.9 & 0.9 & 0.9 & 0.3 & 0.3 & 0.3 & 0.3 & 0.3 & 0.3 & 0.3 & 0.1 \\
\hline (Office, Lobby, Clinic, OR) & Sat, WinterDesign & 0.1 & 0.1 & 0.1 & 0.1 & 0.1 & 0.1 & 0.1 & 0.2 & 0.4 & 0.4 & 0.4 & 0.4 & 0.4 & 0.4 & 0.4 & 0.4 & 0.4 & 0.4 & 0.1 & 0.1 & 0.1 & 0.1 & 0.1 & 0.1 \\
\hline & Sun, $\mathrm{Hol}$, Other & 0.05 & 0.05 & 0.05 & 0.05 & 0.05 & 0.05 & 0.05 & 0.05 & 0.1 & 0.1 & 0.1 & 0.1 & 0.1 & 0.1 & 0.1 & 0.1 & 0.05 & 0.05 & 0.05 & 0.05 & 0.05 & 0.05 & 0.05 & 0.05 \\
\hline BLDG_LIGHT_EXTD_SCH & $\begin{array}{l}\text { WD, } \\
\text { SummerDesign }\end{array}$ & 0.5 & 0.5 & 0.5 & 0.5 & 0.5 & 0.5 & 0.5 & 0.5 & 0.9 & 0.9 & 0.9 & 0.9 & 0.9 & 0.9 & 0.9 & 0.9 & 0.5 & 0.5 & 0.5 & 0.5 & 0.5 & 0.5 & 0.5 & 0.5 \\
\hline $\begin{array}{l}\text { (ER, Patient Rm, ICU, Nurse } \\
\text { Station, Dinning, Kitchen) }\end{array}$ & Sat, WinterDesign & 0.5 & 0.5 & 0.5 & 0.5 & 0.5 & 0.5 & 0.5 & 0.5 & 0.8 & 0.8 & 0.8 & 0.8 & 0.8 & 0.8 & 0.8 & 0.8 & 0.8 & 0.8 & 0.5 & 0.5 & 0.5 & 0.5 & 0.5 & 0.5 \\
\hline & Sun, Hol, Other & 0.5 & 0.5 & 0.5 & 0.5 & 0.5 & 0.5 & 0.5 & 0.5 & 0.7 & 0.7 & 0.7 & 0.7 & 0.7 & 0.7 & 0.7 & 0.7 & 0.5 & 0.5 & 0.5 & 0.5 & 0.5 & 0.5 & 0.5 & 0.5 \\
\hline BLDG_EQUIP_SCH & $\begin{array}{l}\text { WD, } \\
\text { SummerDesign }\end{array}$ & 0.4 & 0.4 & 0.4 & 0.4 & 0.4 & 0.4 & 0.4 & 0.7 & 0.9 & 0.9 & 0.9 & 0.9 & 0.9 & 0.9 & 0.9 & 0.9 & 0.6 & 0.6 & 0.6 & 0.6 & 0.6 & 0.6 & 0.6 & 0.4 \\
\hline & Sat, WinterDesign & 0.4 & $\begin{array}{ll}0.4 \\
\end{array}$ & 0.4 & $\begin{array}{ll}0.4 \\
\end{array}$ & 0.4 & 0.4 & 0.4 & 0.5 & 0.65 & 0.65 & 0.65 & 0.65 & 0.65 & 0.65 & 0.65 & 0.65 & 0.65 & 0.65 & 0.4 & 0.4 & 0.4 & 0.4 & 0.4 & 0.4 \\
\hline & Sun, Hol, Other & 0.3 & 0.3 & 0.3 & 0.3 & 0.3 & 0.3 & 0.3 & 0.3 & 0.4 & 0.4 & 0.4 & 0.4 & 0.4 & 0.4 & 0.4 & 0.4 & 0.3 & 0.3 & 0.3 & 0.3 & 0.3 & 0.3 & 0.3 & 0.3 \\
\hline BLDG_EQUIP_EXTD_SCH & $\begin{array}{l}\text { WD, } \\
\text { SummerDesign }\end{array}$ & 0.4 & 0.4 & 0.4 & 0.4 & 0.4 & 0.4 & 0.4 & 0.7 & 0.9 & 0.9 & 0.9 & 0.9 & 0.9 & 0.9 & 0.9 & 0.9 & 0.6 & 0.6 & 0.6 & 0.6 & 0.6 & 0.6 & 0.6 & 0.4 \\
\hline & Sat & 0.4 & 0.4 & $\begin{array}{ll}0.4 \\
\end{array}$ & 0.4 & $\begin{array}{ll}0.4 \\
\end{array}$ & 0.4 & $\begin{array}{ll}0.4 \\
\end{array}$ & 0.5 & 0.65 & 0.65 & 0.65 & 0.65 & 0.65 & 0.65 & \begin{tabular}{ll|}
0.65 \\
\end{tabular} & 0.65 & 0.65 & 0.65 & 0.4 & $\begin{array}{ll}0.4 \\
\end{array}$ & 0.4 & $\begin{array}{ll}0.4 \\
\end{array}$ & 0.4 & $\begin{array}{ll}0.4 \\
\end{array}$ \\
\hline & Sun, Hol, Other & 0.4 & 0.4 & 0.4 & 0.4 & $\begin{array}{ll}0.4 \\
\end{array}$ & 0.4 & $\begin{array}{ll}0.4 \\
\end{array}$ & 0.4 & 0.6 & 0.6 & 0.6 & 0.6 & 0.6 & 0.6 & 0.6 & 0.6 & 0.4 & 0.4 & 0.4 & 0.4 & 0.4 & 0.4 & 0.4 & $\begin{array}{ll}0.4 \\
\end{array}$ \\
\hline BLDG_OCC_SCH & WD & 0 & 0 & 0 & 0 & 0 & 0 & 0 & 0.1 & 0.5 & 0.8 & 0.8 & 0.8 & 0.8 & 0.8 & 0.8 & 0.8 & 0.8 & 0.5 & 0.3 & 0.3 & 0.2 & 0.2 & 0 & 0 \\
\hline & SummerDesign & 1 & 1 & 1 & 1 & 1 & 1 & 1 & 1 & 1 & 1 & 1 & 1 & 1 & 1 & 1 & 1 & 1 & 1 & 1 & 1 & 1 & 1 & 1 & 1 \\
\hline & Sat, WinterDesign & 0 & 0 & 0 & 0 & 0 & 0 & 0 & 0.1 & 0.3 & 0.4 & 0.4 & 0.4 & 0.4 & 0.4 & 0.4 & 0.4 & 0.4 & 0.1 & 0.1 & 0 & 0 & 0 & 0 & 0 \\
\hline & Sun, Hol, Other & 0 & 0 & 0 & 0 & 0 & 0 & 0 & 0 & 0.05 & 0.05 & 0.05 & 0.05 & 0.05 & 0.05 & 0.05 & 0.05 & 0 & 0 & 0 & 0 & 0 & 0 & 0 & 0 \\
\hline BLDG_OCC_EXTD_SCH & WD & 0.4 & 0.4 & 0.4 & 0.4 & 0.4 & 0.4 & 0.4 & 0.5 & 0.6 & 0.8 & 0.8 & 0.8 & 0.8 & 0.8 & 0.8 & 0.8 & 0.8 & 0.6 & 0.5 & 0.5 & 0.4 & 0.4 & 0.4 & 0.4 \\
\hline & SummerDesign & 1 & 1 & 1 & 1 & 1 & 1 & 1 & 1 & 1 & 1 & 1 & 1 & 1 & 1 & 1 & 1 & 1 & 1 & 1 & 1 & 1 & 1 & 1 & 1 \\
\hline & Sat, WinterDesign & 0.4 & 0.4 & 0.4 & 0.4 & 0.4 & 0.4 & 0.4 & 0.5 & 0.6 & 0.6 & 0.6 & 0.6 & 0.6 & 0.6 & 0.6 & 0.6 & 0.6 & 0.5 & 0.5 & 0.4 & 0.4 & 0.4 & 0.4 & 0.4 \\
\hline & Sun, Hol, Other & 0.4 & 0.4 & 0.4 & 0.4 & 0.4 & 0.4 & 0.4 & 0.4 & 0.6 & 0.6 & 0.6 & 0.6 & 0.6 & 0.6 & 0.6 & 0.6 & 0.4 & 0.4 & 0.4 & 0.4 & 0.4 & 0.4 & 0.4 & 0.4 \\
\hline BLDG_ELEVATORS & WD & 0.2 & 0.2 & 0.2 & 0.2 & 0.2 & 0.2 & 0.2 & 0.5 & 0.75 & 1 & 1 & 1 & 0.75 & 1 & 1 & 1 & 1 & 1 & 0.52 & 0.52 & 0.52 & 0.28 & 0.2 & 0.2 \\
\hline & Sat & 0.2 & 0.2 & 0.2 & 0.2 & 0.2 & 0.2 & 0.2 & 0.4 & 0.46 & 0.7 & 0.7 & 0.7 & 0.51 & 0.51 & 0.51 & 0.51 & 0.51 & 0.25 & 0.2 & 0.2 & 0.2 & 0.2 & 0.2 & 0.2 \\
\hline & \begin{tabular}{|l|} 
Sun \\
\end{tabular} & 0.2 & 0.2 & 0.2 & 0.2 & 0.2 & 0.2 & 0.2 & 0.2 & $\begin{array}{ll}0.4 \\
\end{array}$ & 0.4 & $\begin{array}{ll}0.4 \\
\end{array}$ & 0.4 & 0.4 & 0.4 & 0.4 & 0.4 & 0.2 & 0.2 & 0.2 & 0.2 & 0.2 & 0.2 & 0.2 & 0.2 \\
\hline & SummerDesign & 1 & 1 & 1 & 1 & 1 & 1 & 1 & 1 & 1 & 1 & 1 & 1 & 1 & 1 & 1 & 1 & 1 & 1 & 1 & 1 & 1 & 1 & 1 & 1 \\
\hline & WinterDesign & 0.2 & 0.2 & 0.2 & 0.2 & 0.2 & 0.2 & 0.2 & 0.2 & 0.2 & 0.2 & 0.2 & 0.2 & 0.2 & 0.2 & 0.2 & 0.2 & 0.2 & 0.2 & 0.2 & 0.2 & 0.2 & 0.2 & 0.2 & 0.2 \\
\hline $\begin{array}{l}\text { ELEV_LIGHT_FAN_SCH_ } \\
24 \_7\end{array}$ & WD & 1 & 1 & 1 & 1 & 1 & 1 & 1 & 1 & 1 & 1 & 1 & 1 & 1 & 1 & 1 & 1 & 1 & 1 & 1 & 1 & 1 & 1 & 1 & 1 \\
\hline & Sat & 1 & 1 & 1 & 1 & 1 & 1 & 1 & 1 & 1 & 1 & 1 & 1 & 1 & 1 & 1 & 1 & 1 & 1 & 1 & 1 & 1 & 1 & 1 & 1 \\
\hline & Sun, $\mathrm{H}$ & 1 & 1 & 1 & 1 & 1 & 1 & 1 & 1 & 1 & 1 & 1 & 1 & 1 & 1 & 1 & 1 & 1 & 1 & 1 & 1 & 1 & 1 & 1 & 1 \\
\hline & SummerDesign & 1 & 1 & 1 & 1 & 1 & 1 & 1 & 1 & 1 & - & 1 & 1 & 1 & 1 & 1 & 1 & 1 & 1 & 1 & 1 & 1 & 1 & 1 & 1 \\
\hline & \begin{tabular}{|l|} 
WinterDesign \\
\end{tabular} & 1 & 1 & 1 & 1 & 1 & 1 & 1 & 1 & 1 & 1 & 1 & 1 & 1 & 1 & 1 & 1 & 1 & 1 & 1 & 1 & 1 & 1 & 1 & 1 \\
\hline BLDG_SWH_SCH & $\begin{array}{l}\text { WD, } \\
\text { SummerDesign }\end{array}$ & 0.01 & 0.01 & 0.01 & 0.01 & 0.01 & 0.01 & 0.01 & 0.17 & 0.58 & 0.66 & 0.78 & 0.82 & 0.71 & 0.82 & 0.78 & 0.74 & 0.63 & 0.41 & 0.18 & 0.18 & 0.18 & 0.1 & 0.01 & 0.01 \\
\hline & Sat, WinterDesign & 0.01 & 0.01 & 0.01 & 0.01 & 0.01 & 0.01 & 0.01 & 0.01 & 0.2 & 0.28 & 0.3 & 0.3 & 0.24 & 0.24 & 0.23 & 0.23 & 0.23 & 0.1 & 0.01 & 0.01 & 0.01 & 0.01 & 0.01 & 0.01 \\
\hline & Sun, Hol, Other & 0.01 & 0.01 & 0.01 & 0.01 & 0.01 & 0.01 & 0.01 & 0.01 & 0.01 & 0.01 & 0.01 & 0.01 & 0.01 & 0.01 & 0.01 & 0.01 & 0.01 & 0.01 & 0.01 & 0.01 & 0.01 & 0.01 & 0.01 & 0.01 \\
\hline BLDG_SWH_EXTD_SCH & $\begin{array}{l}\text { WD, } \\
\text { SummerDesign }\end{array}$ & 0.3 & 0.3 & 0.3 & 0.3 & 0.3 & 0.3 & 0.3 & 0.5 & 0.58 & 0.66 & 0.78 & 0.82 & 0.71 & 0.82 & 0.78 & 0.74 & 0.63 & 0.41 & 0.35 & 0.35 & 0.35 & 0.3 & 0.3 & 0.3 \\
\hline & Sat, WinterDesign & 0.3 & 0.3 & 0.3 & 0.3 & 0.3 & 0.3 & 0.3 & 0.3 & 0.4 & 0.5 & 0.6 & 0.6 & 0.6 & 0.6 & 0.6 & 0.6 & 0.6 & 0.5 & 0.3 & 0.3 & 0.3 & 0.3 & 0.3 & 0.3 \\
\hline & Sun, $\mathrm{Hol}$, Other & 0.3 & 0.3 & 0.3 & 0.3 & 0.3 & 0.3 & 0.3 & 0.3 & 0.4 & 0.5 & 0.6 & 0.6 & 0.6 & 0.6 & 0.6 & 0.6 & 0.6 & 0.5 & 0.3 & 0.3 & 0.3 & 0.3 & 0.3 & 0.3 \\
\hline INFIL_SCH_PNNL & $\begin{array}{l}\text { WD, } \\
\text { SummerDesign }\end{array}$ & 0.25 & 0.25 & 0.25 & 0.25 & 0.25 & 0.25 & 0.25 & 0.25 & 0.25 & 0.25 & 0.25 & 0.25 & 0.25 & 0.25 & 0.25 & 0.25 & 0.25 & 0.25 & 0.25 & 0.25 & 0.25 & 0.25 & 0.25 & 0.25 \\
\hline & Sat, WinterDesign & 0.25 & 0.25 & 0.25 & 0.25 & 0.25 & 0.25 & 0.25 & 0.25 & 0.25 & 0.25 & 0.25 & 0.25 & 0.25 & 0.25 & 0.25 & 0.25 & 0.25 & 0.25 & 0.25 & 0.25 & 0.25 & 0.25 & 0.25 & 0.25 \\
\hline & Sun, Hol, Other & 0.25 & 0.25 & 0.25 & 0.25 & 0.25 & 0.25 & 0.25 & 0.25 & 0.25 & 0.25 & 0.25 & 0.25 & 0.25 & 0.25 & 0.25 & 0.25 & 0.25 & 0.25 & 0.25 & 0.25 & 0.25 & 0.25 & 0.25 & 0.25 \\
\hline HVACOperationSchd & All & 1 & 1 & 1 & 1 & 1 & 1 & 1 & 1 & 1 & 1 & 1 & 1 & 1 & 1 & 1 & 1 & 1 & 1 & 1 & 1 & 1 & 1 & 1 & 1 \\
\hline (fan schedule) & & & & & & & & & & & & & & & & & & & & & & & & & \\
\hline HTGSETP_SCH & All & 21 & 21 & 21 & 21 & 21 & 21 & 21 & 21 & 21 & 21 & 21 & 21 & 21 & 21 & 21 & 21 & 21 & 21 & 21 & 21 & 21 & 21 & 21 & 21 \\
\hline CLGSETP_SCH & All & 24 & 24 & 24 & 24 & 24 & 24 & 24 & 24 & 24 & 24 & 24 & 24 & 24 & 24 & 24 & 24 & 24 & 24 & 24 & 24 & 24 & 24 & 24 & 24 \\
\hline
\end{tabular}




\begin{tabular}{|c|c|c|c|c|c|c|c|c|c|c|c|c|c|c|c|c|c|c|c|c|c|c|c|c|c|}
\hline Schedule & Day of Week & 1 & 2 & 3 & 4 & 5 & 6 & 7 & 8 & 9 & 10 & 11 & 12 & 13 & 14 & 15 & 16 & 17 & 18 & 19 & 20 & 21 & 22 & 23 & 24 \\
\hline $\begin{array}{l}\text { Dual Zone Control Type } \\
\text { Sched }\end{array}$ & All & 4 & 4 & 4 & 4 & 4 & 4 & 4 & 4 & 4 & 4 & 4 & 4 & 4 & 4 & 4 & 4 & 4 & 4 & 4 & 4 & 4 & 4 & 4 & 4 \\
\hline CW-Loop-Temp-Schedule & All & 6.7 & 6.7 & 6.7 & 6.7 & 6.7 & 6.7 & 6.7 & 6.7 & 6.7 & 6.7 & 6.7 & 6.7 & 6.7 & 6.7 & 6.7 & 6.7 & 6.7 & 6.7 & 6.7 & 6.7 & 6.7 & 6.7 & 6.7 & 6.7 \\
\hline HW-Loop-Temp-Schedule & All & 60 & 60 & 60 & 60 & 60 & 60 & 60 & 60 & 60 & 60 & 60 & 60 & 60 & 60 & 60 & 60 & 60 & 60 & 60 & 60 & 60 & 60 & 60 & 60 \\
\hline Heat-Supply-Air-Temp-Sch & All & 16 & 16 & 16 & 16 & 16 & 16 & 16 & 16 & 16 & 16 & 16 & 16 & 16 & 16 & 16 & 16 & 16 & 16 & 16 & 16 & 16 & 16 & 16 & 16 \\
\hline HTGSETP_SCH & All & 70 & 70 & 70 & 70 & 70 & 70 & 70 & 70 & 70 & 70 & 70 & 70 & 70 & 70 & 70 & 70 & 70 & 70 & 70 & 70 & 70 & 70 & 70 & 70 \\
\hline CLGSETP_SCH & All & 75 & 75 & 75 & 75 & 75 & 75 & 75 & 75 & 75 & 75 & 75 & 75 & 75 & 75 & 75 & 75 & 75 & 75 & 75 & 75 & 75 & 75 & 75 & 75 \\
\hline CW-Loop-Temp-Schedule & All & 44 & 44 & 44 & 44 & 44 & 44 & 44 & 44 & 44 & 44 & 44 & 44 & 44 & 44 & 44 & 44 & 44 & 44 & 44 & 44 & 44 & 44 & 44 & 44 \\
\hline HW-Loop-Temp-Schedule & All & 140 & 140 & 140 & 140 & 140 & 140 & 140 & 140 & 140 & 140 & 140 & 140 & 140 & 140 & 140 & 140 & 140 & 140 & 140 & 140 & 140 & 140 & 140 & 140 \\
\hline Heat-Supply-Air-Temp-Sch & All & 61 & 61 & 61 & 61 & 61 & 61 & 61 & 61 & 61 & 61 & 61 & 61 & 61 & 61 & 61 & 61 & 61 & 61 & 61 & 61 & 61 & 61 & 61 & 61 \\
\hline ReheatCoilAvailSched & All & 1 & 1 & 1 & 1 & 1 & 1 & 1 & 1 & 1 & 1 & 1 & 1 & 1 & 1 & 1 & 1 & 1 & 1 & 1 & 1 & 1 & 1 & 1 & 1 \\
\hline CoolingCoilAvailSched & All & 1 & 1 & 1 & 1 & 1 & 1 & 1 & 1 & 1 & 1 & 1 & 1 & 1 & 1 & 1 & 1 & 1 & 1 & 1 & 1 & 1 & 1 & 1 & 1 \\
\hline Humidity Setpoint Schedule & $\begin{array}{l}\text { WD, } \\
\text { SummerDesign }\end{array}$ & 50 & 50 & 50 & 50 & 50 & 50 & 50 & 50 & 50 & 50 & 50 & 50 & 50 & 50 & 50 & 50 & 50 & 50 & 50 & 50 & 50 & 50 & 50 & 50 \\
\hline & Sat, WinterDesign & 50 & 50 & 50 & 50 & 50 & 50 & 50 & 50 & 50 & 50 & 50 & 50 & 50 & 50 & 50 & 50 & 50 & 50 & 50 & 50 & 50 & 50 & 50 & 50 \\
\hline & Sun, Hol, Other & 50 & 50 & 50 & 50 & 50 & 50 & 50 & 50 & 50 & 50 & 50 & 50 & 50 & 50 & 50 & 50 & 50 & 50 & 50 & 50 & 50 & 50 & 50 & 50 \\
\hline MinOA_Sched & All & 1 & 1 & 1 & 1 & 1 & 1 & 1 & 1 & 1 & 1 & 1 & 1 & 1 & 1 & 1 & 1 & 1 & 1 & 1 & 1 & 1 & 1 & 1 & 1 \\
\hline $\begin{array}{l}\text { VAV_ER_OAminOA } \\
\text { FracSchedule }\end{array}$ & All & 0.33 & 0.33 & 0.33 & 0.33 & 0.33 & 0.33 & 0.33 & 0.33 & 0.33 & 0.33 & 0.33 & 0.33 & 0.33 & 0.33 & 0.33 & 0.33 & 0.33 & 0.33 & 0.33 & 0.33 & 0.33 & 0.33 & 0.33 & 0.33 \\
\hline $\begin{array}{l}\text { VAV_OR_OAminOA } \\
\text { FracSchedule }\end{array}$ & All & 0.33 & 0.33 & 0.33 & 0.33 & 0.33 & 0.33 & 0.33 & 0.33 & 0.33 & 0.33 & 0.33 & 0.33 & 0.33 & 0.33 & 0.33 & 0.33 & 0.33 & 0.33 & 0.33 & 0.33 & 0.33 & 0.33 & 0.33 & 0.33 \\
\hline $\begin{array}{l}\text { VAV_ICU_OAminOA } \\
\text { FracSchedule }\end{array}$ & All & 0.33 & 0.33 & 0.33 & 0.33 & 0.33 & 0.33 & 0.33 & 0.33 & 0.33 & 0.33 & 0.33 & 0.33 & 0.33 & 0.33 & 0.33 & 0.33 & 0.33 & 0.33 & 0.33 & 0.33 & 0.33 & 0.33 & 0.33 & 0.33 \\
\hline $\begin{array}{l}\text { VAV_PATRMS_OAminOA } \\
\text { FracSchedule_ }\end{array}$ & All & 0.33 & 0.33 & 0.33 & 0.33 & 0.33 & 0.33 & 0.33 & 0.33 & 0.33 & 0.33 & 0.33 & 0.33 & 0.33 & 0.33 & 0.33 & 0.33 & 0.33 & 0.33 & 0.33 & 0.33 & 0.33 & 0.33 & 0.33 & 0.33 \\
\hline $\begin{array}{l}\text { VAV_LABS_OAminOA } \\
\text { FracSchedule }\end{array}$ & All & 1 & 1 & 1 & 1 & 1 & 1 & 1 & 1 & 1 & 1 & 1 & 1 & 1 & 1 & 1 & 1 & 1 & 1 & 1 & 1 & 1 & 1 & 1 & 1 \\
\hline Kitchen_SAT_SCH & All & 15.6 & 15.6 & 15.6 & 15.6 & 15.6 & 15.6 & 15.6 & 15.6 & 15.6 & 15.6 & 15.6 & $\begin{array}{ll}15.6 \\
\end{array}$ & 15.6 & 15.6 & 15.6 & \begin{tabular}{|l}
15.6 \\
\end{tabular} & 15.6 & \begin{tabular}{|l|}
15.6 \\
\end{tabular} & 15.6 & 15.6 & 15.6 & 15.6 & 15.6 & $\begin{array}{l}15.6 \\
\end{array}$ \\
\hline VAV_SAT_SCH & All & 12.8 & 12.8 & 12.8 & \begin{tabular}{|l|}
12.8 \\
\end{tabular} & 12.8 & 12.8 & 12.8 & 12.8 & 12.8 & 12.8 & 12.8 & 12.8 & 12.8 & \begin{tabular}{|l|}
12.8 \\
\end{tabular} & 12.8 & \begin{tabular}{|l|l|}
12.8 & \\
\end{tabular} & 12.8 & \begin{tabular}{|l|l|}
12.8 & \\
\end{tabular} & 12.8 & 12.8 & 12.8 & 12.8 & \begin{tabular}{ll|}
12.8 \\
\end{tabular} & 12.8 \\
\hline MinRelHumSetSch & All & 40 & 40 & 40 & 40 & 40 & 40 & 40 & 40 & 40 & 40 & 40 & 40 & 40 & 40 & 40 & 40 & 40 & 40 & 40 & 40 & 40 & 40 & 40 & 40 \\
\hline MaxRelHumSetSch & All & 60 & 60 & 60 & 60 & 60 & 60 & 60 & 60 & 60 & 60 & 60 & 60 & 60 & 60 & 60 & 60 & 60 & 60 & 60 & 60 & 60 & 60 & 60 & 60 \\
\hline
\end{tabular}




\section{C.10 Small Hotel Hourly Operation Schedules}

\begin{tabular}{|c|c|c|c|c|c|c|c|c|c|c|c|c|c|c|c|c|c|c|c|c|c|c|c|c|c|}
\hline Schedule & Day of Week & 1 & 2 & 3 & 4 & 5 & 6 & 7 & 8 & 9 & 10 & 11 & 12 & 13 & 14 & 15 & 16 & 17 & 18 & 19 & 20 & 21 & 22 & 23 & 24 \\
\hline \multirow[t]{2}{*}{ GuestRoom_Ltg_Sch_Base } & WD & 0.22 & 0.17 & 0.11 & 0.11 & 0.11 & 0.22 & 0.44 & 0.56 & 0.44 & 0.44 & 0.28 & 0.28 & 0.28 & 0.28 & 0.28 & 0.28 & 0.28 & 0.28 & 0.67 & 0.89 & 1 & 0.89 & 0.67 & 0.33 \\
\hline & Sat, Sun, Hol & 0.26 & 0.26 & 0.11 & 0.11 & 0.11 & 0.11 & 0.41 & 0.41 & 0.56 & 0.56 & 0.41 & 0.33 & 0.33 & 0.33 & 0.33 & 0.33 & 0.33 & 0.33 & 0.85 & 1 & 1 & 1 & 0.85 & 0.41 \\
\hline \multirow[t]{2}{*}{ GUESTROOM_EQUIP_SCH } & WD & 0.11 & 0.11 & 0.11 & 0.11 & 0.11 & 0.11 & 0.62 & 0.9 & 0.43 & 0.43 & 0.26 & 0.26 & 0.26 & 0.26 & 0.26 & \begin{tabular}{|l|}
0.26 \\
\end{tabular} & 0.26 & 0.51 & 0.51 & 0.49 & 0.66 & 0.7 & 0.35 & 0.11 \\
\hline & Sat, Sun, Hol & 0.11 & 0.11 & 0.11 & 0.11 & 0.11 & 0.11 & 0.3 & 0.62 & 0.9 & 0.62 & 0.29 & 0.29 & 0.29 & 0.29 & 0.29 & 0.29 & 0.29 & 0.43 & 0.51 & 0.49 & 0.66 & 0.7 & 0.35 & 0.11 \\
\hline \multirow[t]{2}{*}{ GuestRoom_Occ_Sch } & WD & 1 & 1 & 1 & 1 & 1 & 1 & 0.77 & 0.43 & 0.43 & 0.2 & 0.2 & 0.2 & 0.2 & 0.2 & 0.2 & 0.31 & 0.54 & 0.54 & 0.54 & 0.77 & 0.77 & 0.89 & 1 & 1 \\
\hline & Sat, Sun, Hol & 1 & 1 & 1 & 1 & 1 & 1 & 0.77 & 0.53 & 0.53 & 0.3 & 0.3 & 0.3 & 0.3 & 0.3 & 0.3 & 0.3 & 0.3 & 0.53 & 0.54 & 0.65 & 0.65 & 0.77 & 0.77 & 0.77 \\
\hline \multirow[t]{2}{*}{ LOBBY_LIGHT_SCH } & WD & 0.5 & 0.5 & 0.5 & 0.5 & 0.5 & 0.6 & 1 & 1 & 1 & 1 & 1 & 1 & 1 & 1 & 1 & 1 & 1 & 1 & 1 & 1 & 1 & 0.6 & 0.5 & 0.5 \\
\hline & Sat, Sun, $\mathrm{Hol}$ & 0.5 & 0.5 & 0.5 & 0.5 & 0.5 & 0.6 & 1 & 1 & 1 & 1 & 1 & 1 & 1 & 1 & 1 & 1 & 1 & 1 & 1 & 1 & 1 & 0.6 & 0.5 & 0.5 \\
\hline \multirow[t]{2}{*}{ LOBBY_EQUIP_SCH } & WD & 0.21 & 0.21 & 0.21 & 0.21 & 0.21 & 0.68 & 1 & 1 & 1 & 1 & 0.32 & 0.23 & 0.23 & 0.23 & 0.23 & \begin{tabular}{|l|}
0.23 \\
\end{tabular} & 0.23 & 0.23 & 0.23 & 0.23 & 0.23 & 0.23 & 0.23 & 0.21 \\
\hline & Sat, Sun, Hol & 0.21 & 0.21 & 0.21 & 0.21 & 0.21 & 0.68 & 1 & 1 & 1 & 1 & 0.32 & 0.23 & 0.23 & 0.23 & 0.23 & 0.23 & 0.23 & 0.23 & 0.23 & 0.23 & 0.23 & 0.23 & 0.23 & 0.21 \\
\hline \multirow[t]{2}{*}{ Lobby_Occ_Sch } & WD & 0.1 & 0.1 & 0.1 & 0.1 & 0.1 & 0.3 & 0.7 & 0.7 & $\begin{array}{ll}0.7 \\
\end{array}$ & 0.7 & 0.2 & 0.2 & 0.2 & 0.2 & 0.2 & 0.2 & 0.4 & 0.4 & 0.2 & 0.2 & 0.2 & 0.2 & 0.1 & 0.1 \\
\hline & Sat, Sun, Hol & 0.1 & 0.1 & 0.1 & 0.1 & 0.1 & 0.1 & 0.3 & 0.7 & 0.7 & 0.7 & 0.2 & 0.2 & 0.2 & 0.2 & 0.2 & 0.2 & 0.2 & 0.2 & 0.2 & 0.2 & 0.2 & 0.2 & 0.1 & 0.1 \\
\hline \multirow[t]{2}{*}{ Office_Ltg_Sch_Base } & WD & 0.5 & 0.5 & 0.5 & 0.5 & 0.5 & 0.5 & 0.5 & 0.61 & 0.9 & 0.9 & 0.9 & 0.9 & 0.8 & 0.9 & 0.9 & 0.9 & 0.9 & 0.61 & 0.5 & 0.5 & 0.5 & 0.5 & 0.5 & 0.5 \\
\hline & Sat, Sun, Hol & 0.5 & 0.5 & 0.5 & 0.5 & 0.5 & 0.5 & 0.5 & 0.61 & 0.9 & $\begin{array}{ll}0.9 \\
\end{array}$ & 0.9 & 0.9 & 0.8 & 0.9 & 0.9 & 0.9 & 0.9 & 0.61 & 0.5 & 0.5 & 0.5 & 0.5 & 0.5 & 0.5 \\
\hline \multirow[t]{2}{*}{ OFFICE_EQUIP_SCH } & WD & 0.33 & 0.33 & 0.33 & 0.33 & 0.33 & 0.38 & 0.38 & 0.43 & 1.00 & 1.00 & 1.00 & 1.00 & 0.94 & 1.00 & 1.00 & 1.00 & 1.00 & 0.75 & 0.63 & 0.63 & 0.48 & 0.48 & 0.33 & 0.33 \\
\hline & Sat, Sun, $\mathrm{Hol}$ & 0.33 & 0.33 & 0.33 & 0.33 & 0.33 & 0.38 & 0.38 & 0.43 & 0.63 & 0.63 & 0.63 & 0.63 & 0.63 & 0.63 & 0.63 & \begin{tabular}{|l|}
0.63 \\
\end{tabular} & 0.63 & 0.63 & 0.48 & 0.48 & 0.48 & 0.48 & 0.33 & 0.33 \\
\hline \multirow[t]{2}{*}{ Office_Occ_Sch } & WD & 0.2 & 0.2 & 0.2 & 0.2 & 0.2 & 0.2 & 0.3 & 0.4 & 1 & 1 & 1 & 1 & 0.5 & 1 & 1 & 1 & 1 & 0.4 & 0.3 & 0.2 & 0.2 & 0.2 & 0.2 & 0.2 \\
\hline & Sat, Sun, $\mathrm{Hol}$ & 0.2 & 0.2 & 0.2 & 0.2 & 0.2 & 0.2 & 0.2 & 0.3 & 0.5 & 0.5 & 0.5 & 0.5 & 0.5 & 0.5 & 0.5 & 0.5 & 0.5 & 0.3 & 0.2 & 0.2 & 0.2 & 0.2 & 0.2 & 0.2 \\
\hline \multirow[t]{2}{*}{ MeetingRoom_Ltg_Sch_Base } & WD & 0 & 0 & 0 & 0 & 0 & 0.2 & 0.3 & 0.5 & 1 & 1 & 1 & 1 & 1 & 1 & 1 & 1 & 1 & 1 & 0.5 & 0.3 & 0.2 & 0.05 & 0 & 0 \\
\hline & Sat, Sun, Hol & 0 & 0 & 0 & 0 & 0 & 0.2 & 0.3 & 0.5 & 1 & 1 & 1 & 1 & 1 & 1 & 1 & 1 & 1 & 1 & 0.5 & 0.3 & 0.2 & 0.05 & 0 & 0 \\
\hline \multirow[t]{2}{*}{$\begin{array}{l}\text { MEETINGROOM_ } \\
\text { EQUIP_SCH }\end{array}$} & WD & 0 & 0 & 0 & 0 & 0 & 0 & 0 & 0.05 & 0.54 & 0.54 & 0.26 & 0.26 & 0.05 & 0.54 & 0.54 & 0.26 & 0.26 & 0.26 & 0.05 & 0.05 & 0 & 0 & 0 & 0 \\
\hline & Sat, Sun, Hol & 0 & 0 & 0 & 0 & 0 & 0 & 0 & 0.05 & 0.54 & 0.54 & 0.26 & 0.26 & 0.05 & 0.54 & 0.54 & 0.26 & 0.26 & 0.26 & 0.05 & 0.05 & 0 & 0 & 0 & 0 \\
\hline \multirow[t]{2}{*}{ MeetingRoom_Occ_Sch } & WD & 0 & 0 & 0 & 0 & 0 & 0 & 0 & 0.05 & 0.5 & 0.5 & 0.2 & 0.2 & 0.05 & 0.5 & 0.5 & 0.2 & 0.2 & 0.2 & 0.05 & 0.05 & 0 & 0 & 0 & 0 \\
\hline & Sat, Sun, Hol & 0 & 0 & 0 & 0 & 0 & 0 & 0 & 0.05 & 0.5 & 0.5 & 0.2 & 0.2 & 0.05 & 0.5 & 0.5 & 0.2 & 0.2 & 0.2 & 0.05 & 0.05 & 0 & 0 & 0 & 0 \\
\hline LaundryRoom_Ltg_Sch & WD & 0 & 0 & 0 & 0 & 0 & 0 & 0 & 0 & 1 & 1 & 1 & 1 & 1 & 1 & 1 & 1 & 1 & 0 & 0 & 0 & 0 & 0 & 0 & 0 \\
\hline & Sat, Sun, Hol & 0 & 0 & 0 & 0 & 0 & 0 & 0 & 0 & 1 & 1 & 1 & 1 & 1 & 1 & 1 & 1 & 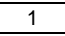 & 0 & 0 & 0 & 0 & 0 & 0 & 0 \\
\hline LAUNDRY_ELE_SCH & WD & 0 & 0 & 0 & 0 & 0 & 0 & 0 & 0 & 1 & 1 & 1 & 1 & 1 & 1 & 1 & 1 & 0 & 0 & 0 & 0 & 0 & 0 & 0 & 0 \\
\hline & Sat, Sun, Hol & 0 & 0 & 0 & 0 & 0 & 0 & 0 & 0 & 1 & 1 & 1 & $t$ & 1 & 1 & 1 & 1 & 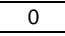 & 0 & 0 & 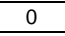 & 0 & 0 & 0 & 0 \\
\hline LAUNDRY_GAS_SCH & WD & 0 & 0 & 0 & 0 & 0 & 0 & 0 & 0 & 0 & 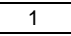 & 1 & 1 & 1 & 1 & 1 & 1 & 1 & 0 & 0 & 0 & 0 & 0 & 0 & 0 \\
\hline & Sat, Sun, Hol & 0 & 0 & 0 & 0 & 0 & 0 & 0 & 0 & 0 & 1 & 1 & 1 & 1 & 1 & 1 & 1 & 1 & 0 & 0 & 0 & 0 & 0 & 0 & 0 \\
\hline LaundryRoom_Occ_Sch & WD & 0 & 0 & 0 & 0 & 0 & 0 & 0 & 0 & 0.09 & 0.09 & 0.18 & 0.18 & 0 & 0.18 & 0.18 & \begin{tabular}{|l|l|}
0.18 \\
\end{tabular} & 0.09 & 0 & 0 & 0 & 0 & 0 & 0 & 0 \\
\hline & Sat, Sun, Hol & 0 & 0 & 0 & 0 & 0 & 0 & 0 & 0 & 0.09 & 0.09 & 0.18 & 0.18 & 0 & 0.18 & 0.18 & \begin{tabular}{|l|l|}
0.18 \\
\end{tabular} & 0.09 & 0 & 0 & 0 & 0 & 0 & 0 & 0 \\
\hline ExerciseCenter_Ltg_Sch_Base & WD & 0 & 0 & 0 & 0 & 0 & 0 & 0.5 & 1 & 1 & 1 & 1 & 1 & 1 & 1 & 1 & 1 & 1 & 1 & 1 & 1 & 1 & 1 & 0.5 & 0 \\
\hline & Sat, Sun, Hol & 0 & 0 & 0 & 0 & 0 & 0 & 0.5 & 1 & 1 & 1 & 1 & 1 & 1 & 1 & 1 & 1 & 1 & 1 & 1 & 1 & 1 & 1 & 0.5 & 0 \\
\hline ExerciseCenter_Eqp_Sch & WD & 0 & 0 & 0 & 0 & 0 & 0 & 0.5 & 1 & 1 & 0.5 & 0.5 & 0.5 & 8 & 0.5 & 0.5 & 0.5 & 1 & 0.5 & 0.5 & 1 & 1 & 0.5 & 0.5 & 0 \\
\hline & Sat, Sun, Hol & 0 & 0 & 0 & 0 & 0 & 0 & 0.5 & 1 & 1 & 0.5 & 0.5 & 0.5 & 0 & 0.5 & 0.5 & 0.5 & 1 & 0.5 & 0.5 & 1 & 1 & 0.5 & 0.5 & 0 \\
\hline ExerciseCenter_Occ_Sch & WD & 0 & 0 & 0 & 0 & 0 & 0 & 0.5 & 1 & 1 & 1 & 1 & 0.5 & 0 & 1 & 1 & 1 & 1 & 1 & 1 & 1 & 1 & 1 & 0.5 & 0 \\
\hline & Sat, Sun, Hol & 0 & 0 & 0 & 0 & 0 & 0 & 0.5 & 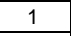 & 1 & 1 & 1 & 0.5 & 0 & 1 & $\perp$ & 1 & 1 & 1 & 1 & \pm & 1 & 1 & 0.5 & 0 \\
\hline $\begin{array}{l}\text { EMPLOYEELOUNGE_ } \\
\text { LIGHT_SCH }\end{array}$ & WD & 0.05 & 0.05 & 0.05 & 0.05 & 0.05 & 0.15 & 0.4 & 0.5 & 1 & 1 & 1 & 1 & 1 & 1 & 1 & 1 & 1 & 1 & 0.5 & 0.4 & 0.15 & 0.15 & 0.05 & 0.05 \\
\hline & Sat, Sun, Hol & 0.05 & 0.05 & 0.05 & 0.05 & 0.05 & 0.15 & 0.3 & 0.4 & 0.6 & 0.6 & 0.6 & 0.6 & 0.6 & 0.6 & 0.6 & 0.6 & 0.6 & 0.6 & 0.4 & 0.3 & 0.15 & 0.15 & 0.05 & 0.05 \\
\hline EmployeeLounge_Eqp_Sch & WD & 0.11 & 0.11 & 0.11 & 0.11 & 0.11 & 0.19 & 0.19 & 0.25 & 1 & 1 & 0.86 & 0.86 & 1 & 0.86 & 0.86 & \begin{tabular}{|l|}
0.86 \\
\end{tabular} & 0.86 & 0.86 & 0.25 & 0.19 & 0.11 & 0.11 & 0.11 & 0.11 \\
\hline & Sat, $S$ & 0.11 & 0.11 & 0.11 & 0.11 & 0.11 & 0.19 & 0.19 & 0.25 & 1 & 1 & 0.86 & 0.86 & 1 & 0.86 & 0.86 & \begin{tabular}{|l|l|}
0.86 \\
\end{tabular} & 0.86 & 0.86 & 0.25 & 0.19 & 0.11 & 0.11 & 0.11 & 0.11 \\
\hline EmployeeLounge_Occ_Sch & WD & 0 & 0 & 0 & 0 & 0 & 0.1 & 0.1 & 0.2 & 0.2 & 0.2 & 0.2 & 0.2 & 0.7 & 0.2 & 0.2 & 0.2 & 0.2 & 0.2 & 0.1 & 0.1 & 0 & 0 & 0 & 0 \\
\hline & Sat, Sun, Hol & 0 & 0 & 0 & 0 & 0 & 0.05 & 0.05 & 0.05 & 0.1 & 0.1 & 0.1 & 0.1 & 0.2 & 0.1 & 0.1 & 0.1 & 0.1 & 0.1 & 0.05 & 0.05 & 0 & 0 & 0 & 0 \\
\hline GuestRoom_SHW_Sch & WD & 0.2 & 0.15 & 0.15 & 0.15 & 0.2 & 0.35 & 0.6 & 0.8 & 0.55 & 0.4 & 0.3 & 0.2 & 0.2 & 0.2 & 0.2 & 0.2 & 0.2 & 0.3 & 0.55 & 0.4 & 0.4 & 0.6 & 0.45 & 0.25 \\
\hline & Sat, Sun, Hol & 0.2 & 0.15 & 0.15 & 0.15 & 0.2 & 0.25 & 0.35 & 0.6 & 0.8 & 0.55 & 0.4 & 0.3 & 0.2 & 0.2 & 0.2 & 0.2 & 0.2 & 0.25 & 0.3 & 0.4 & 0.4 & 0.4 & 0.6 & 0.35 \\
\hline LaundryRoo & WD & 0 & 0 & 0 & 0 & 0 & 0 & 0 & 0 & 1 & 1 & 1 & 1 & 1 & 1 & 1 & 1 & 0 & 0 & 0 & 0 & 0 & 0 & 0 & 0 \\
\hline
\end{tabular}




\begin{tabular}{|c|c|c|c|c|c|c|c|c|c|c|c|c|c|c|c|c|c|c|c|c|c|c|c|c|c|}
\hline Sched & y of Week & 1 & 2 & 3 & 4 & 5 & 6 & 7 & 8 & 9 & 10 & 11 & 12 & 13 & 14 & 15 & 16 & 17 & 18 & 19 & 20 & 21 & 22 & 23 & 24 \\
\hline & Sat, Sun, Hol & 0 & 0 & 0 & 0 & 0 & 0 & 0 & 0 & 1 & 1 & 1 & 1 & 1 & 1 & 1 & 1 & 0 & 0 & 0 & 0 & 0 & 0 & 0 & 0 \\
\hline \multirow[t]{2}{*}{ GUESTROOM_INFIL_SCH } & WD & 0.25 & 0.25 & 0.25 & 0.25 & 0.25 & 0.25 & 0.25 & 0.25 & 0.25 & 0.25 & 0.25 & 0.25 & 0.25 & 0.25 & 0.25 & 0.25 & 0.25 & 0.25 & 0.25 & 0.25 & 0.25 & 0.25 & 0.25 & 0.25 \\
\hline & Sat, Sun, Hol & 0.25 & 0.25 & 0.25 & 0.25 & 0.25 & 0.25 & 0.25 & 0.25 & 0.25 & 0.25 & 0.25 & 0.25 & 0.25 & 0.25 & 0.25 & 0.25 & 0.25 & 0.25 & 0.25 & 0.25 & 0.25 & 0.25 & 0.25 & 0.25 \\
\hline \multirow{2}{*}{ COMMONAREA_INFIL_SCH } & WD & 0.25 & 0.25 & 0.25 & 0.25 & 0.25 & 0.25 & 0.25 & 0.25 & 0.25 & 0.25 & 0.25 & 0.25 & 0.25 & 0.25 & 0.25 & 0.25 & 0.25 & 0.25 & \begin{tabular}{|c|}
0.25 \\
\end{tabular} & 0.25 & \begin{tabular}{|l|}
0.25 \\
\end{tabular} & 0.25 & 0.25 & 0.25 \\
\hline & Sat, Sun, $\mathrm{Hol}$ & 0.25 & 0.25 & 0.25 & 0.25 & 0.25 & 0.25 & 0.25 & 0.25 & 0.25 & 0.25 & 0.25 & 0.25 & 0.25 & 0.25 & 0.25 & 0.25 & 0.25 & 0.25 & \begin{tabular}{|l|}
0.25 \\
\end{tabular} & 0.25 & \begin{tabular}{|l|}
0.25 \\
\end{tabular} & 0.25 & 0.25 & 0.25 \\
\hline GUESTROOM_FAN_SCH & WD & 1.00 & 1.00 & 1.00 & 1.00 & 1.00 & 1.00 & 1.00 & 1.00 & 1.00 & 1.00 & 1.00 & 1.00 & 1.00 & 1.00 & 1.00 & 1.00 & 1.00 & 1.00 & 1.00 & 1.00 & 1.00 & 1.00 & 1.00 & 1.00 \\
\hline (HVAC Operation) & Sat, Sun, Hol & 1.00 & 1.00 & 1.00 & 1.00 & 1.00 & 1.00 & 1.00 & 1.00 & 1.00 & 1.00 & 1.00 & 1.00 & 1.00 & 1.00 & 1.00 & 1.00 & 1.00 & 1.00 & 1.00 & 1.00 & 1.00 & 1.00 & 1.00 & 1.00 \\
\hline COMMONAREA_FAN_SCH & WD & 1.00 & 1.00 & 1.00 & 1.00 & 1.00 & 1.00 & 1.00 & 1.00 & 1.00 & 1.00 & 1.00 & 1.00 & 1.00 & 1.00 & 1.00 & 1.00 & 1.00 & 1.00 & 1.00 & 1.00 & 1.00 & 1.00 & 1.00 & 1.00 \\
\hline \multirow{2}{*}{ (HVAC Operation) } & Sat, St & 1.00 & 1.00 & 1.00 & 1.00 & 1.00 & 1.00 & 1.00 & 1.00 & 1.00 & 1.00 & 1.00 & 1.00 & 1.00 & 1.00 & 1.00 & 1.00 & 1.00 & 1.00 & 1.00 & 1.00 & 1.00 & 1.00 & 1.00 & 1.00 \\
\hline & W & & & & & 00 & & & & 600 & & & & & & & & & & & & & & & \\
\hline $\begin{array}{l}\text { VacGuestl } \\
\text { (Vacant) }\end{array}$ & Sat, Sun, Hol & 66.00 & $\begin{array}{l}66.00 \\
66.00\end{array}$ & $\begin{array}{l}66.00 \\
66.00\end{array}$ & $\begin{array}{l}66.00 \\
66.00\end{array}$ & $\begin{array}{l}66.00 \\
66.00\end{array}$ & $\begin{array}{l}66.00 \\
66.00\end{array}$ & $\begin{array}{l}66.00 \\
66.00\end{array}$ & $\begin{array}{l}66.00 \\
66.00\end{array}$ & $\begin{array}{l}66.00 \\
66.00\end{array}$ & $\begin{array}{l}66.00 \\
66.00\end{array}$ & $\begin{array}{l}66.00 \\
66.00\end{array}$ & \begin{tabular}{|l}
66.00 \\
66.00
\end{tabular} & \begin{tabular}{|l}
66.00 \\
66.00
\end{tabular} & \begin{tabular}{|l|}
66.00 \\
66.00
\end{tabular} & \begin{tabular}{|l|}
66.00 \\
66.00 \\
\end{tabular} & \begin{tabular}{|l|}
66.00 \\
66.00
\end{tabular} & 66.00 & \begin{tabular}{|l|}
66.00 \\
66.00
\end{tabular} & \begin{tabular}{|l|}
66.00 \\
66.00 \\
\end{tabular} & \begin{tabular}{|l|}
66.00 \\
66.00
\end{tabular} & \begin{tabular}{|l|}
66.00 \\
66.00
\end{tabular} & \begin{tabular}{|l|}
66.00 \\
66.00 \\
\end{tabular} & \begin{tabular}{|l|}
66.00 \\
66.00 \\
\end{tabular} & 66.00 \\
\hline VacGuestRoom_ClgSP_Sch & WD & 74.00 & 74.00 & 74.00 & 74.00 & 74.00 & 74.00 & 74.00 & 74.00 & 74.00 & 74.00 & 74.00 & 74.00 & 74.00 & 74.00 & 74.00 & 74.00 & 74.00 & 74.00 & 74.00 & 74.00 & 74.00 & 74.00 & 74.00 & 74.00 \\
\hline (Vacant) & Sat, Sun, Hol & 74.00 & 74.00 & 74.00 & 74.00 & 74.00 & 74.00 & 74.00 & 74.00 & 74.00 & 74.00 & 74.00 & 74.00 & 74.00 & 74.00 & 74.00 & 74.00 & 74.00 & 74.00 & 74.00 & \begin{tabular}{|l|l|}
74.00 \\
\end{tabular} & 74.00 & 74.00 & 74.00 & 74.00 \\
\hline $\begin{array}{l}\text { Base_OccGuestRoom_HtgSP_ } \\
\text { Sch }\end{array}$ & WD & 70.00 & 70.00 & 70.00 & 70.00 & 70.00 & 70.00 & 70.00 & 70.00 & 70.00 & 70.00 & 70.00 & 70.00 & 70.00 & 70.00 & 70.00 & 70.00 & 70.00 & 70.00 & 70.00 & 70.00 & 70.00 & 70.00 & 70.00 & 70.00 \\
\hline (Rented) & Sat, Sun, $\mathrm{Hol}$ & 70.00 & 70.00 & 70.00 & 70.00 & 70.00 & 70.00 & 70.00 & 70.00 & 70.00 & 70.00 & 70.00 & 70.00 & 70.00 & 70.00 & 70.00 & 70.00 & 70.00 & 70.00 & 70.00 & 70.00 & 70.00 & 70.00 & 70.00 & 70.00 \\
\hline $\begin{array}{l}\text { Base_OccGuestRoom_ } \\
\text { Sch }\end{array}$ & WD & 70.00 & 70.00 & 70.00 & 70.00 & 70.00 & 70.00 & 70.00 & 70.00 & 70.00 & 70.00 & 70.00 & 70.00 & 70.00 & 70.00 & 70.00 & 70.00 & 70.00 & 70.00 & 70.00 & 70.00 & 70.00 & 70.00 & 70.00 & 70.00 \\
\hline (Rented) & Sat, Sun, Hol & .00 & 70.00 & 70.00 & 70.00 & 70.00 & 70.00 & 70.00 & 70.00 & 70.00 & 70.00 & 70.00 & 70.00 & 70.00 & 70.00 & 70.00 & 70.00 & 70.00 & 70.00 & 70.00 & 70.00 & 70.00 & 70.00 & 0.00 & 70.00 \\
\hline \multirow[t]{2}{*}{ CommonArea_HtgSP_Sch } & WD & 70.00 & 70.00 & 70.00 & 70.00 & 70.00 & 70.00 & 70.00 & 70.00 & 70.00 & 70.00 & 70.00 & 70.00 & 70.00 & 70.00 & 70.00 & 70.00 & 70.00 & 70.00 & 70.00 & 70.00 & 70.00 & 70.00 & 70.00 & 70.00 \\
\hline & Sat, Sun, $\mathrm{Hol}$ & 0.00 & 70.00 & 70.00 & 70.00 & 70.00 & 70.00 & 70.00 & 70.00 & 70.00 & 70.00 & 70.00 & 70.00 & 70.00 & 70.00 & 70.00 & 70.00 & 70.00 & 70.00 & 70.00 & 70.00 & 70.00 & 70.00 & 0.00 & 70.00 \\
\hline \multirow[t]{2}{*}{ CommonArea_ClgSP_Sch } & WD & 75.00 & 75.00 & 75.00 & 75.00 & 75.00 & 75.00 & 75.00 & 75.00 & 75.00 & 75.00 & 75.00 & 75.00 & 75.00 & 75.00 & 75.00 & 75.00 & 75.00 & 75.00 & 75.00 & 75.00 & 75.00 & 75.00 & 75.00 & 75.00 \\
\hline & Sat, Sun, $\mathrm{Hol}$ & 75.00 & 75.00 & 75.00 & 75.00 & 75.00 & 75.00 & 75.00 & 75.00 & 75.00 & 75.00 & 75.00 & 75.00 & 75.00 & 75.00 & 75.00 & 5.00 & 75.00 & 5.00 & 75.00 & 75.00 & 5.00 & 75.00 & 5.00 & 75.00 \\
\hline SemiHeated_HtgSP_Sch & WD & 45.00 & 45.00 & 45.00 & 45.00 & 45.00 & 45.00 & 45.00 & 45.00 & 45.00 & 45.00 & 45.00 & 45.00 & 45.00 & 45.00 & 45.00 & 45.00 & 45.00 & 45.00 & 45.00 & 45.00 & 45.00 & 45.00 & 5.00 & 45.00 \\
\hline (for storage rooms and stairs & Sat, S & 45.00 & 45.00 & 45.00 & 45.00 & 45.00 & 45.00 & 45.00 & 45.00 & 45.00 & 45.00 & 45.00 & 45.00 & 45.00 & 45.00 & 45.00 & \begin{tabular}{|l|l|}
45.00 \\
\end{tabular} & 45.00 & 45.00 & 45.00 & \begin{tabular}{|l|l|}
45.00 \\
\end{tabular} & 45.00 & 45.00 & 45.00 & 45.00 \\
\hline \multirow[t]{2}{*}{ GUESTROOM_OA_SCH } & WD & 1.00 & 1.00 & 1.00 & 1.00 & 1.00 & 1.00 & 1.00 & 1.00 & 1.00 & \begin{tabular}{|l|}
1.00 \\
\end{tabular} & 1.00 & 1.00 & 1.00 & \begin{tabular}{|l|}
1.00 \\
\end{tabular} & 1.00 & 1.00 & 1.00 & 1.00 & 1.00 & 1.00 & \begin{tabular}{|l|}
1.00 \\
\end{tabular} & 1.00 & 1.00 & 1.00 \\
\hline & Sat, $S$ & 1.00 & 1.00 & 1.00 & 1.00 & 1.00 & 1.00 & 1.00 & 1.00 & 1.00 & 1.00 & 1.00 & 1.00 & 1.00 & 1.00 & 1.00 & 1.00 & 1.00 & 1.00 & 1.00 & 1.00 & 1.00 & 1.00 & 1.00 & 1.00 \\
\hline \multirow[t]{2}{*}{ COMMONAREA_OA_SCH } & WD & 1.00 & 1.00 & 1.00 & 1.00 & 1.00 & 1.00 & 1.00 & 1.00 & 1.00 & 1.00 & 1.00 & 1.00 & 1.00 & 1.00 & 1.00 & 1.00 & 1.00 & 1.00 & 1.00 & 1.00 & 1.00 & 1.00 & 1.00 & 1.00 \\
\hline & Sat, Sun, Hol & 1.00 & 1.00 & 1.00 & 1.00 & 1.00 & 1.00 & 1.00 & 1.00 & 1.00 & 1.00 & 1.00 & 1.00 & 1.00 & 1.0 & 00 & 1.00 & 1.00 & 1.00 & 1.00 & 1.00 & 1.00 & 1.00 & 1.00 & 1.00 \\
\hline \multirow[t]{5}{*}{ BLDG_ELEVATORS } & WD & 0.05 & 0.05 & 0.05 & 0.05 & 0.1 & 0.2 & 0.4 & 0.5 & 0.5 & 0.35 & 0.15 & 0.15 & 0.15 & 0.15 & 0.15 & 0.15 & 0.35 & 0.5 & 0.5 & 0.4 & 0.4 & 0.3 & 0.2 & 0.1 \\
\hline & Sat & 0.05 & \begin{tabular}{|l|}
0.05 \\
\end{tabular} & 0.05 & 0.05 & 0.1 & 0.2 & 0.4 & 0.5 & 0.5 & \begin{tabular}{|l|}
0.35 \\
\end{tabular} & \begin{tabular}{|l|}
0.15 \\
\end{tabular} & 0.15 & 0.15 & 0.1 & 015 & 0.15 & 0.35 & 0 & 0.5 & 0.4 & 0.4 & 0.3 & 2 & 0.1 \\
\hline & Sun & 0.05 & 0.05 & 0.05 & 0.05 & 0.1 & 0.2 & 0.4 & 0.5 & 0.5 & \begin{tabular}{|l|}
0.35 \\
\end{tabular} & \begin{tabular}{|l|}
0.15 \\
\end{tabular} & 0.15 & 0.15 & 0.15 & 0.15 & 0.15 & 0.35 & 0.5 & 0.5 & 0.4 & 0.4 & 0.3 & 0.2 & 0.1 \\
\hline & SummerDesign & 0.5 & 0.5 & 0.5 & 0.5 & 0.5 & 0.5 & 0.5 & 0.5 & 0.5 & 0.5 & 0.5 & 0.5 & 0.5 & 0.5 & 0.5 & 0.5 & 0.5 & 0.5 & 0.5 & 0.5 & 0.5 & 0.5 & 0.5 & 0.5 \\
\hline & WinterDesign & 0.05 & 0.05 & 0.05 & 0.05 & 0.05 & 0.05 & $\begin{array}{ll}0.05 \\
\end{array}$ & \begin{tabular}{|l|}
0.05 \\
\end{tabular} & $\begin{array}{ll}0.05 \\
\end{array}$ & 0.05 & 0.05 & 0.05 & 0.05 & 0.05 & 0.05 & 0.05 & 0.05 & 0.05 & 0.05 & 0.05 & \begin{tabular}{|l|}
0.05 \\
\end{tabular} & 0.05 & 0.05 & 0.05 \\
\hline \multirow[t]{5}{*}{$\begin{array}{l}\text { ELEV_LIGHT_FAN_SCH_ } \\
24 \_7\end{array}$} & WD & 1 & 1 & 1 & 1 & 1 & 1 & 1 & 1 & 1 & 1 & 1 & 1 & 1 & 1 & 1 & 1 & 1 & 1 & 1 & 1 & 1 & 1 & 1 & 1 \\
\hline & Sat & 1 & 1 & 1 & 1 & 1 & 1 & 1 & 1 & 1 & 1 & 1 & 1 & 1 & 1 & 1 & 1 & 1 & 1 & 1 & 1 & 1 & 1 & 1 & 1 \\
\hline & Sun, Hol, Other & 1 & 1 & 1 & - & 1 & 1 & 1 & 1 & 1 & 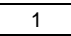 & 1 & & 1 & 1 & 1 & 1 & 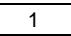 & 1 & 1 & 1 & 1 & 1 & 1 & 1 \\
\hline & Summ & 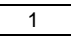 & 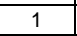 & 1 & 1 & 4 & 1 & 1 & 1 & 1 & 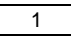 & 1 & & 1 & 1 & 1 & 1 & & 1 & & 1 & & & - & 1 \\
\hline & Winte & 1 & 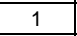 & 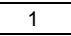 & 1 & 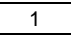 & 1 & 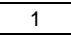 & 1 & 1 & 1 & 1 & & 1 & & & & 土 & 1 & 1 & 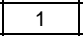 & 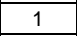 & $\perp$ & 1 & 1 \\
\hline _HtgSP_Sch & WD & 8.89 & 18.89 & 18.89 & 18.89 & 18.89 & 18.89 & 18.89 & 18.89 & 18.89 & 18.89 & 18.89 & 18.89 & \begin{tabular}{|l|}
18.89 \\
\end{tabular} & \begin{tabular}{|l|}
18.89 \\
\end{tabular} & \begin{tabular}{|l|}
18.89 \\
\end{tabular} & \begin{tabular}{|l|l|}
18.89 \\
\end{tabular} & 18.89 & \begin{tabular}{|l|l|}
18.89 \\
\end{tabular} & \begin{tabular}{|l|l|}
18.89 \\
\end{tabular} & \begin{tabular}{|l|}
18.89 \\
\end{tabular} & \begin{tabular}{|l|l|}
18.89 \\
\end{tabular} & 18.89 & \begin{tabular}{|l|}
18.89 \\
\end{tabular} & 18.89 \\
\hline (Vacant) & 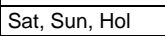 & 89 & 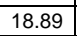 & 18.89 & 18.89 & 18.89 & 18.89 & 18.89 & \begin{tabular}{|l|}
18.89 \\
\end{tabular} & 18.89 & \begin{tabular}{|l|}
18.89 \\
\end{tabular} & \begin{tabular}{|l|}
18.89 \\
\end{tabular} & 18.89 & \begin{tabular}{|l|}
18.89 \\
\end{tabular} & \begin{tabular}{|l|}
18.89 \\
\end{tabular} & \begin{tabular}{|l|}
18.89 \\
\end{tabular} & \begin{tabular}{|l|}
18.89 \\
\end{tabular} & 18.89 & 18.89 & \begin{tabular}{|l|}
18.89 \\
\end{tabular} & \begin{tabular}{|l|}
18.89 \\
\end{tabular} & \begin{tabular}{|l|}
18.89 \\
\end{tabular} & \begin{tabular}{|l|}
18.89 \\
\end{tabular} & \begin{tabular}{|l|}
18.89 \\
\end{tabular} & 18.89 \\
\hline VacGuestRoom_ClgSP_Sch & WD & 23.33 & 23.33 & 23.33 & 23.33 & 23.33 & 23.33 & 23.33 & 23.33 & 23.33 & 23.33 & 23.33 & 23.33 & 23.33 & 23.33 & 23.33 & 23.33 & 23.33 & 23.33 & 23.33 & 23.33 & 3.33 & 23.33 & 3.33 & 23.33 \\
\hline & Sat, St & 23.33 & 23.33 & 23.33 & 23.33 & 23.33 & 23.33 & 23.33 & 23.33 & 23.33 & 23.33 & 23.33 & 23.33 & 23.33 & 23.33 & 23.33 & 23.33 & 23.33 & 23.33 & 23.33 & 23.33 & 23.33 & 23.33 & 23.33 & 23.33 \\
\hline $\begin{array}{l}\text { Base_OccGuestRoom_HtgSP_ } \\
\text { sch }\end{array}$ & WD & 21.11 & 21.11 & 21.11 & 21.11 & 21.11 & 21.11 & 21.11 & 21.11 & 21.11 & 21.11 & 21.11 & 21.11 & 21.11 & 21.11 & 21.11 & 21.11 & 21.11 & 21.11 & 21.11 & 21.11 & 21.11 & 21.11 & 21.11 & 21.11 \\
\hline (Rented) & Sat, Su & 1.11 & 21.11 & 1.11 & 21.11 & 21.11 & 21.11 & 21.11 & 21.11 & 21.11 & \begin{tabular}{|l|}
21.11 \\
\end{tabular} & 21.11 & 21.11 & 21.11 & 21.11 & 21.11 & 21.11 & 21.11 & 21.11 & 21.11 & \begin{tabular}{|l|}
21.11 \\
\end{tabular} & 21.11 & 21.11 & \begin{tabular}{|l|}
21.11 \\
\end{tabular} & 21.11 \\
\hline $\begin{array}{l}\text { Base_OccGuestRoom_ClgSP } \\
\text { Sch }\end{array}$ & WD & 21.11 & 21.11 & 21.11 & 21.11 & 21.11 & 21.11 & 21.11 & 21.11 & 21.11 & 21.11 & 21.11 & 21.11 & 21.11 & 21.11 & 21.11 & 21.11 & 21.11 & 21.11 & 21.11 & 21.11 & 21.11 & 21.11 & 21.11 & 21.11 \\
\hline (Rented) & 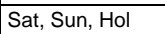 & 1.11 & 2111 & 21.11 & 211 & 211 & 21.11 & 21.11 & 21.11 & 21.11 & 1 & 21.11 & 11 & 21.11 & 21.11 & .11 & 21.11 & 1.11 & 21.11 & 1.11 & 1.11 & 1.11 & 21.11 & 1.11 & 21.11 \\
\hline \multirow[t]{2}{*}{ CommonArea_HtgSP_Sch } & WD & 21.11 & 21.11 & 21.11 & 21.11 & 21.11 & 21.11 & 21.11 & 21.11 & 21.11 & 21.11 & 21.11 & 21.11 & 21.11 & 21.11 & 21.11 & 21.11 & 21.11 & 21.11 & 21.11 & 21.11 & 21.11 & 21.11 & 1.11 & 21.11 \\
\hline & Sat, $S$ & 21.11 & 21.11 & 21.11 & 21.11 & 21.11 & 21.11 & 21.11 & 21.11 & 21.11 & 21.11 & 21.11 & 21.11 & 21.11 & 21.11 & 21.11 & 21.11 & 21.11 & 21.11 & 21.11 & 21.11 & 21.11 & 21.11 & 21.11 & 21.11 \\
\hline CommonArea_ClgSP_Sch & WD & 23.89 & 23.89 & 23.89 & 23.89 & 23.89 & 23.89 & 23.89 & 23.89 & 23.89 & 23.89 & 23.89 & 23.89 & 23.89 & 23.89 & 23.89 & 23.89 & 23.89 & 23.89 & 23.89 & 23.89 & 23.89 & 23.89 & 23.89 & 23.89 \\
\hline
\end{tabular}




\section{C.11 Large Hotel Hourly Operation Schedules}

\begin{tabular}{|c|c|c|c|c|c|c|c|c|c|c|c|c|c|c|c|c|c|c|c|c|c|c|c|c|c|}
\hline Schedule & Day of Week & 1 & 2 & 3 & 4 & 5 & 6 & 7 & 8 & 9 & 10 & 11 & 12 & 13 & 14 & 15 & 16 & 17 & 18 & 19 & 20 & 21 & 22 & 23 & 24 \\
\hline BLDG_LIGHT_SCH & WD & 0.2 & 0.15 & 0.1 & 0.1 & 0.1 & 0.2 & 0.4 & 0.5 & 0.4 & 0.4 & 0.25 & \begin{tabular}{|l|}
0.25 \\
\end{tabular} & 0.25 & \begin{tabular}{|l|}
0.25 \\
\end{tabular} & 0.25 & \begin{tabular}{|l|}
0.25 \\
\end{tabular} & 0.25 & 0.25 & 0.6 & 0.8 & 0.9 & 0.8 & 0.6 & 0.3 \\
\hline \multirow[t]{4}{*}{ (for public spaces) } & Sat & 0.2 & 0.2 & 0.1 & 0.1 & 0.1 & 0.1 & 0.3 & 0.3 & 0.4 & 0.4 & 0.3 & 0.25 & 0.25 & 0.25 & 0.25 & 0.25 & 0.25 & 0.25 & 0.6 & 0.7 & 0.7 & 0.7 & 0.6 & 0.3 \\
\hline & SummerDesign & 1 & 1 & 1 & 1 & 1 & 1 & 1 & 1 & 1 & 1 & 1 & 1 & 1 & 1 & 1 & 1 & 1 & 1 & 1 & 1 & 1 & 1 & 1 & 1 \\
\hline & WinterDesign & 0 & 0 & 0 & 0 & 0 & 0 & 0 & 0 & 0 & 0 & 0 & 0 & 0 & 0 & 0 & 0 & 0 & 0 & 0 & 0 & 0 & 0 & 0 & 0 \\
\hline & Sun, $\mathrm{Hol}$, and Other & 0.3 & 0.3 & 0.2 & 0.2 & 0.2 & 0.2 & 0.3 & 0.4 & 0.4 & 0.3 & 0.3 & 0.3 & 0.3 & 0.2 & 0.2 & 0.2 & 0.2 & 0.2 & 0.5 & 0.7 & 0.8 & 0.6 & 0.5 & 0.3 \\
\hline GuestRoom_Ltg_Sch_Base & WD & 0.22 & 0.17 & 0.11 & 0.11 & 0.11 & 0.22 & 0.44 & 0.56 & 0.44 & 0.44 & 0.28 & 0.28 & 0.28 & 0.28 & 0.28 & 0.28 & 0.28 & 0.28 & 0.67 & 0.89 & 1 & 0.89 & 0.67 & 0.33 \\
\hline \multirow[t]{3}{*}{ (for guest rooms) } & Sat, Sun, $\mathrm{Hol}$ & 0.26 & 0.26 & 0.11 & 0.11 & 0.11 & 0.11 & 0.41 & 0.41 & 0.56 & 0.56 & 0.41 & 0.33 & 0.33 & 0.33 & 0.33 & 0.33 & 0.33 & 0.33 & 0.85 & 1 & 1 & 1 & 0.85 & 0.41 \\
\hline & $\begin{array}{l}\text { SummerDesign } \\
\text { CustomDay1 } \\
\text { CustomDay2 } \\
\end{array}$ & 1 & 1 & 1 & 1 & 1 & 1 & 1 & 1 & 1 & 1 & 1 & 1 & 1 & 1 & 1 & 1 & 1 & 1 & 1 & 1 & 1 & 1 & 1 & 1 \\
\hline & WinterDesign & 0 & 0 & 0 & 0 & 0 & 0 & 0 & 0 & 0 & 0 & 0 & 0 & 0 & 0 & 0 & 0 & 0 & 0 & 0 & 0 & 0 & 0 & 0 & 0 \\
\hline BLDG_EQUIP_SCH & WD & 0.3 & 0.25 & 0.2 & 0.2 & 0.2 & 0.3 & 0.5 & 0.6 & 0.5 & 0.5 & 0.35 & 0.35 & 0.35 & 0.35 & 0.35 & \begin{tabular}{|l|}
0.35 \\
\end{tabular} & 0.35 & 0.35 & 0.7 & 0.9 & 0.95 & 0.9 & 0.7 & 0.4 \\
\hline \multirow[t]{4}{*}{$\begin{array}{l}\text { (for public spaces on the } \\
\text { ground floor) }\end{array}$} & Sat & 0.3 & 0.3 & 0.2 & 0.2 & 0.2 & 0.2 & 0.4 & 0.4 & 0.5 & 0.5 & 0.4 & 0.35 & 0.35 & 0.35 & 0.35 & 0.35 & 0.35 & 0.35 & 0.7 & 0.8 & 0.8 & 0.8 & 0.7 & 0.4 \\
\hline & SummerDesign & 1 & 1 & 1 & 1 & 1 & 1 & 1 & 1 & 1 & 1 & 1 & 1 & 1 & 1 & 1 & 1 & 1 & 1 & 1 & 1 & 1 & 1 & 1 & 1 \\
\hline & WinterDesign & 0 & 0 & 0 & 0 & 0 & 0 & 0 & 0 & 0 & 0 & 0 & 0 & 0 & 0 & 0 & 0 & 0 & 0 & 0 & 0 & 0 & 0 & 0 & 0 \\
\hline & Sun, $\mathrm{Hol}$, and Other & 0.4 & 0.4 & 0.3 & 0.3 & 0.3 & 0.3 & 0.4 & 0.5 & 0.5 & 0.4 & 0.4 & 0.4 & 0.4 & 0.3 & 0.3 & 0.3 & 0.3 & 0.3 & 0.6 & 0.8 & 0.9 & 0.7 & 0.6 & 0.4 \\
\hline GuestRoom_Eqp_Sch & WD & 0.2 & 0.2 & 0.2 & 0.2 & 0.2 & 0.2 & 0.62 & 0.9 & 0.43 & 0.43 & 0.26 & 0.26 & 0.26 & 0.26 & 0.26 & 0.26 & 0.26 & 0.51 & 0.51 & 0.49 & 0.66 & 0.7 & 0.35 & 0.2 \\
\hline \multirow[t]{3}{*}{ (for guest rooms) } & Sat, Sun, $\mathrm{Hol}$ & 0.2 & 0.2 & 0.2 & 0.2 & 0.2 & 0.2 & 0.3 & 0.62 & 0.9 & 0.62 & 0.29 & \begin{tabular}{|l|}
0.29 \\
\end{tabular} & 0.29 & \begin{tabular}{|l|}
0.29 \\
\end{tabular} & 0.29 & \begin{tabular}{|l|}
0.29 \\
\end{tabular} & 0.29 & 0.43 & 0.51 & 0.49 & 0.66 & 0.7 & 0.35 & 0.2 \\
\hline & $\begin{array}{l}\text { SummerDesign } \\
\text { CustomDay1 } \\
\text { CustomDay2 }\end{array}$ & 1 & 1 & 1 & 1 & 1 & 1 & 1 & 1 & 1 & 1 & 1 & 1 & 1 & 1 & 1 & 1 & 1 & 1 & 1 & 1 & 1 & 1 & 1 & 1 \\
\hline & WinterDesign & 0 & 0 & 0 & 0 & 0 & 0 & 0 & 0 & 0 & 0 & 0 & 0 & 0 & 0 & 0 & 0 & 0 & 0 & 0 & 0 & 0 & 0 & 0 & 0 \\
\hline Kitchen_Elec_Equip_SCH & WD & 0.1 & 0.1 & 0.1 & 0.1 & 0.1 & 0.1 & 0.25 & 0.3 & 0.3 & 0.3 & 0.3 & 0.3 & 0.3 & 0.3 & 0.3 & 0.3 & 0.3 & 0.3 & 0.3 & 0.3 & 0.3 & 0.3 & 0.3 & 0.3 \\
\hline \multirow[t]{3}{*}{$\begin{array}{l}\text { (for kitchen, dining and } \\
\text { banquet) }\end{array}$} & $\begin{array}{l}\text { Sat, Sun, Hol, } \\
\text { Others }\end{array}$ & 0.1 & 0.1 & 0.1 & 0.1 & 0.1 & 0.1 & 0.25 & 0.3 & 0.3 & 0.3 & 0.3 & 0.3 & 0.3 & 0.3 & 0.3 & 0.3 & 0.3 & 0.3 & 0.3 & 0.3 & 0.3 & 0.3 & 0.3 & 0.3 \\
\hline & SummerDesign & 0.3 & 0.3 & 0.3 & 0.3 & 0.3 & 0.3 & 0.3 & 0.3 & 0.3 & 0.3 & 0.3 & 0.3 & 0.3 & 0.3 & 0.3 & 0.3 & 0.3 & 0.3 & 0.3 & 0.3 & 0.3 & 0.3 & 0.3 & 0.3 \\
\hline & WinterDesign & 0 & 0 & 0 & 0 & 0 & 0 & 0 & 0 & 0 & 0 & 0 & 0 & 0 & 0 & 0 & 0 & 0 & 0 & 0 & 0 & 0 & 0 & 0 & 0 \\
\hline Kitchen_Gas_Equip_SCH & WD, Sat & 0.02 & 0.02 & 0.02 & 0.02 & 0.02 & 0.05 & 0.1 & 0.15 & 0.2 & 0.15 & 0.25 & 0.25 & 0.25 & 0.2 & 0.15 & 0.2 & 0.3 & 0.3 & 0.3 & 0.2 & 0.2 & 0.15 & 0.1 & 0.05 \\
\hline \multirow[t]{3}{*}{ (for kitchen) } & Sun, Hol, Others & 0.02 & 0.02 & 0.02 & 0.02 & 0.02 & 0.05 & 0.1 & 0.15 & 0.2 & 0.15 & 0.25 & 0.25 & 0.25 & 0.2 & 0.15 & 0.2 & 0.3 & 0.3 & 0.3 & 0.2 & 0.2 & 0.15 & 0.1 & 0.05 \\
\hline & SummerDesign & 0.25 & 0.25 & 0.25 & 0.25 & 0.25 & 0.25 & 0.25 & 0.25 & 0.25 & 0.25 & 0.25 & 0.25 & 0.25 & 0.25 & 0.25 & 0.25 & 0.25 & 0.25 & 0.25 & 0.25 & 0.25 & 0.25 & 0.25 & 0.25 \\
\hline & WinterDesign & 0 & 0 & 0 & 0 & 0 & 0 & 0 & 0 & 0 & 0 & 0 & 0 & 0 & 0 & 0 & 0 & 0 & 0 & 0 & 0 & 0 & 0 & 0 & 0 \\
\hline BLDG_OCC_SCH & WD & 0.9 & 0.9 & 0.9 & 0.9 & 0.9 & 0.9 & 0.7 & 0.4 & 0.4 & 0.2 & 0.2 & 0.2 & 0.2 & 0.2 & 0.2 & 0.3 & 0.5 & 0.5 & 0.5 & 0.7 & 0.7 & 0.8 & 0.9 & 0.9 \\
\hline \multirow[t]{4}{*}{ (for public spaces) } & Sat & 0.9 & 0.9 & 0.9 & 0.9 & 0.9 & 0.9 & 0.7 & 0.5 & 0.5 & 0.3 & 0.3 & 0.3 & 0.3 & 0.3 & 0.3 & 0.3 & 0.3 & 0.5 & 0.6 & 0.6 & 0.6 & 0.7 & 0.7 & 0.7 \\
\hline & SummerDesign & 1 & 1 & 1 & 1 & 1 & 1 & 1 & 1 & 1 & 1 & 1 & 1 & 1 & 1 & 1 & 1 & 1 & 1 & 1 & 1 & 1 & 1 & 1 & 1 \\
\hline & WinterDesign & 0 & 0 & 0 & 0 & 0 & 0 & 0 & 0 & 0 & 0 & 0 & 0 & 0 & 0 & 0 & 0 & 0 & 0 & 0 & 0 & 0 & 0 & 0 & 0 \\
\hline & Sun, $\mathrm{Hol}$, and Other & 0.7 & 0.7 & 0.7 & 0.7 & 0.7 & 0.7 & 0.7 & 0.7 & 0.5 & 0.5 & 0.5 & 0.3 & 0.3 & 0.2 & 0.2 & 0.2 & 0.3 & 0.4 & 0.4 & 0.6 & 0.6 & 0.8 & 0.8 & 0.8 \\
\hline GUESTROOM_OCC_SCH & WD & 0.65 & 0.65 & 0.65 & 0.65 & 0.65 & 0.65 & 0.5 & 0.28 & 0.28 & 0.13 & 0.13 & 0.13 & 0.13 & 0.13 & 0.13 & 0.2 & 0.35 & 0.35 & 0.35 & 0.5 & 0.5 & 0.58 & 0.65 & 0.65 \\
\hline \multirow[t]{3}{*}{ (for guest rooms) } & $\begin{array}{l}\text { Sat, Sun, Hol, } \\
\text { others }\end{array}$ & 0.65 & 0.65 & 0.65 & 0.65 & 0.65 & 0.65 & 0.5 & 0.34 & 0.34 & 0.2 & 0.2 & 0.2 & 0.2 & 0.2 & 0.2 & 0.2 & 0.2 & 0.34 & 0.35 & 0.65 & 0.65 & 0.5 & 0.5 & 0.5 \\
\hline & $\begin{array}{l}\text { SummerDesign } \\
\text { CustomDay1 } \\
\text { CustomDay2 } \\
\end{array}$ & 1 & 1 & 1 & 1 & 1 & 1 & 1 & 1 & 1 & 1 & 1 & 1 & 1 & 1 & 1 & 1 & 1 & 1 & 1 & 1 & 1 & 1 & 1 & 1 \\
\hline & WinterDesign & 0 & 0 & 0 & 0 & 0 & 0 & 0 & 0 & 0 & 0 & 0 & 0 & 0 & 0 & 0 & 0 & 0 & 0 & 0 & 0 & 0 & 0 & 0 & 0 \\
\hline \multirow[t]{5}{*}{ BLDG_ELEVATORS } & WD & 0.05 & 0.05 & 0.05 & 0.05 & 0.1 & 0.2 & 0.4 & 0.5 & 0.5 & 0.35 & 0.15 & \begin{tabular}{|l|}
0.15 \\
\end{tabular} & 0.15 & \begin{tabular}{|l|}
0.15 \\
\end{tabular} & 0.15 & \begin{tabular}{|l|}
0.15 \\
\end{tabular} & 0.35 & 0.5 & 0.5 & 0.4 & 0.4 & 0.3 & 0.2 & 0.1 \\
\hline & Sat & 0.05 & 0.05 & 0.05 & 0.05 & 0.1 & 0.2 & 0.4 & 0.5 & 0.5 & 0.35 & 0.15 & 0.15 & 0.15 & 0.15 & 0.15 & 0.15 & 0.35 & 0.5 & 0.5 & 0.4 & 0.4 & 0.3 & 0.2 & 0.1 \\
\hline & Sun & 0.05 & 0.05 & 0.05 & 0.05 & 0.1 & 0.2 & 0.4 & 0.5 & 0.5 & 0.35 & 0.15 & 0.15 & 0.15 & 0.15 & 0.15 & 0.15 & 0.35 & 0.5 & 0.5 & 0.4 & 0.4 & 0.3 & 0.2 & 0.1 \\
\hline & SummerDesign & 0.5 & 0.5 & 0.5 & 0.5 & 0.5 & 0.5 & 0.5 & 0.5 & 0.5 & 0.5 & 0.5 & 0.5 & 0.5 & 0.5 & 0.5 & 0.5 & 0.5 & 0.5 & 0.5 & 0.5 & 0.5 & 0.5 & 0.5 & 0.5 \\
\hline & WinterDesign & 0.05 & 0.05 & 0.05 & 0.05 & 0.05 & 0.05 & 0.05 & 0.05 & 0.05 & 0.05 & 0.05 & 0.05 & 0.05 & 0.05 & 0.05 & 0.05 & 0.05 & 0.05 & 0.05 & 0.05 & 0.05 & 0.05 & 0.05 & 0.05 \\
\hline \multirow[t]{2}{*}{ ELEV_LIGHT_FAN_SCH_24_7 } & WD & 1 & 1 & 1 & 1 & 1 & 1 & 1 & 1 & 1 & 1 & 1 & 1 & 1 & 1 & 1 & 1 & 1 & 1 & 1 & 1 & 1 & 1 & 1 & 1 \\
\hline & Sat & 1 & 1 & 1 & 1 & 1 & 1 & 1 & 1 & 1 & 1 & 1 & 1 & 1 & 1 & 1 & 1 & 1 & 1 & 1 & 1 & 1 & 1 & 1 & 1 \\
\hline
\end{tabular}




\begin{tabular}{|c|c|c|c|c|c|c|c|c|c|c|c|c|c|c|c|c|c|c|c|c|c|c|c|c|c|}
\hline Schedule & Day of Week & 1 & 2 & 3 & 4 & 5 & 6 & 7 & 8 & 9 & 10 & 11 & 12 & 13 & 14 & 15 & 16 & 17 & 18 & 19 & 20 & 21 & 22 & 23 & 24 \\
\hline & Sun, Hol, Other & 1 & 1 & 1 & 1 & 1 & 1 & 1 & 1 & 1 & 1 & 1 & 1 & 1 & 1 & 1 & 1 & 1 & 1 & 1 & 1 & 1 & 1 & 1 & 1 \\
\hline & SummerDesign & 1 & 1 & 1 & 1 & 1 & 1 & 1 & 1 & 1 & 1 & 1 & 1 & 1 & 1 & 1 & 1 & 1 & 1 & 1 & 1 & 1 & 1 & 1 & 1 \\
\hline & WinterDesign & 1 & 1 & 1 & 1 & 1 & 1 & 1 & 1 & 1 & 1 & 1 & 1 & 1 & 1 & 1 & 1 & 1 & 1 & 1 & 1 & 1 & 1 & 1 & 1 \\
\hline $\begin{array}{l}\text { Kitchen_Exhaust_SCH } \\
\text { (for plug load) }\end{array}$ & All & 0 & 0 & 0 & 0 & 0 & 0 & 0 & 1 & 1 & 1 & 1 & 1 & 1 & 1 & 1 & 1 & 1 & 1 & 1 & 1 & 1 & 1 & 1 & 1 \\
\hline BLDG_SWH_SCH & WD,SummerDesign & 0.2 & 0.15 & 0.15 & \begin{tabular}{|l|}
0.15 \\
\end{tabular} & 0.2 & \begin{tabular}{|l|}
0.25 \\
\end{tabular} & 0.5 & 0.6 & \begin{tabular}{|l|}
0.55 \\
\end{tabular} & \begin{tabular}{|l|}
0.45 \\
\end{tabular} & 0.4 & 0.45 & 0.4 & 0.35 & 0.3 & 0.3 & 0.3 & 0.4 & 0.55 & 0.6 & 0.5 & 0.55 & 0.45 & 0.25 \\
\hline \multirow[t]{2}{*}{ (for laundry) } & Sat, WinterDesign & 0.2 & 0.15 & 0.15 & \begin{tabular}{|l|l|}
0.15 \\
\end{tabular} & 0.2 & 0.25 & 0.4 & 0.5 & 0.5 & 0.5 & 0.45 & 0.5 & 0.5 & 0.45 & 0.4 & 0.4 & \begin{tabular}{|l|}
0.35 \\
\end{tabular} & 0.4 & 0.55 & 0.55 & 0.5 & 0.55 & 0.4 & 0.3 \\
\hline & Sun, $\mathrm{Hol}$, Others & 0.25 & 0.2 & 0.2 & 0.2 & 0.2 & 0.3 & 0.5 & 0.5 & 0.5 & \begin{tabular}{|l|}
0.55 \\
\end{tabular} & 0.5 & 0.5 & 0.4 & 0.4 & 0.3 & 0.3 & 0.3 & 0.4 & 0.5 & 0.5 & 0.4 & 0.5 & 0.4 & 0.2 \\
\hline \multirow[t]{2}{*}{ GuestRoom_SWH_Sch } & WD & 0.2 & 0.15 & 0.15 & \begin{tabular}{|l|l|}
0.15 \\
\end{tabular} & 0.2 & 0.35 & 0.6 & 0.8 & 0.55 & 0.4 & 0.3 & 0.2 & 0.2 & 0.2 & 0.2 & 0.2 & 0.2 & 0.3 & 0.55 & 0.4 & 0.4 & 0.6 & 0.45 & 0.25 \\
\hline & Others & 0.2 & 0.15 & 0.15 & 0.15 & 0.2 & 0.25 & 0.35 & 0.6 & 0.8 & 0.55 & 0.4 & 0.3 & 0.2 & 0.2 & 0.2 & 0.2 & 0.2 & 0.25 & 0.3 & 0.4 & 0.4 & 0.4 & 0.6 & 0.35 \\
\hline LaundryRoom_SWH_Sch & All & 0 & 0 & 0 & 0 & 0 & 0 & 0 & 0 & 1 & 1 & 1 & 1 & 1 & 1 & 1 & 1 & 0 & 0 & 0 & 0 & 0 & 0 & 0 & 0 \\
\hline INFIL_QUARTER_ON_SCH & WD & 0.25 & 0.25 & 0.25 & 0.25 & 0.25 & 0.25 & 0.25 & 0.25 & 0.25 & 0.25 & 0.25 & 0.25 & 0.25 & 0.25 & 0.25 & 0.25 & \begin{tabular}{|l|}
0.25 \\
\end{tabular} & 0.25 & 0.25 & 0.25 & 0.25 & 0.25 & 0.25 & 0.25 \\
\hline (for all zones) & Sat, Sun, Hol & 0.25 & 0.25 & 0.25 & 0.25 & 0.25 & 0.25 & 0.25 & 0.25 & 0.25 & 0.25 & 0.25 & 0.25 & 0.25 & 0.25 & 0.25 & 0.25 & \begin{tabular}{|l|}
0.25 \\
\end{tabular} & 0.25 & 0.25 & 0.25 & 0.25 & 0.25 & 0.25 & 0.25 \\
\hline GUESTROOM_FAN_SCH & All & 1.00 & 1.00 & 1.00 & 1.00 & 1.00 & 1.00 & 1.00 & 1.00 & 1.00 & 1.00 & 1.00 & 1.00 & 1.00 & 1.00 & 1.00 & 1.00 & \begin{tabular}{|c|}
1.00 \\
\end{tabular} & 1.00 & 1.00 & 1.00 & 1.00 & 1.00 & 1.00 & 1.00 \\
\hline \multicolumn{26}{|l|}{ (HVAC Operation) } \\
\hline COMMONAREA_FAN_SCH & All & 1.00 & 1.00 & 1.00 & 1.00 & 1.00 & 1.00 & 1.00 & 1.00 & 1.00 & 1.00 & 1.00 & 1.00 & 1.00 & 1.00 & 1.00 & 1.00 & \begin{tabular}{|l|}
1.00 \\
\end{tabular} & 1.00 & 1.00 & 1.00 & 1.00 & 1.00 & 1.00 & 1.00 \\
\hline \multicolumn{26}{|l|}{ (HVAC Operation) } \\
\hline HtgSetP_Sch & All & 70.00 & 70.00 & 70.00 & 70.00 & 70.00 & 70.00 & 70.00 & 70.00 & 70.00 & 70.00 & 70.00 & 70.00 & 70.00 & 70.00 & 70.00 & 70.00 & 70.00 & 70.00 & 70.00 & 70.00 & 70.00 & 70.00 & 70.00 & 70.00 \\
\hline ClgSetP_Sch & All & 70.00 & 70.00 & 70.00 & 70.00 & 70.00 & 70.00 & 70.00 & 70.00 & 70.00 & 70.00 & 70.00 & 70.00 & 70.00 & 70.00 & 70.00 & 70.00 & 70.00 & 70.00 & 70.00 & 70.00 & 70.00 & 70.00 & 70.00 & 70.00 \\
\hline $\begin{array}{l}\text { MinOA_MotorizedDamper__ } \\
\text { Sched }\end{array}$ & All & 1.00 & 1.00 & 1.00 & 1.00 & 1.00 & 1.00 & 1.00 & 1.00 & 1.00 & 1.00 & 1.00 & 1.00 & 1.00 & 1.00 & 1.00 & 1.00 & 1.00 & 1.00 & 1.00 & 1.00 & 1.00 & 1.00 & 1.00 & 1.00 \\
\hline Hours_of_operation & All & 1.00 & 1.00 & 1.00 & 1.00 & 1.00 & 1.00 & 1.00 & \begin{tabular}{|l|}
1.00 \\
\end{tabular} & 1.00 & 1.00 & 1.00 & 1.00 & 1.00 & 1.00 & 1.00 & 1.00 & \begin{tabular}{|l|}
1.00 \\
\end{tabular} & 1.00 & 1.00 & 1.00 & 1.00 & 1.00 & 1.00 & 1.00 \\
\hline
\end{tabular}




\section{C.12 Warehouse Hourly Operation Schedules}

\begin{tabular}{|c|c|c|c|c|c|c|c|c|c|c|c|c|c|c|c|c|c|c|c|c|c|c|c|c|c|}
\hline Schedule & Day of Week & 1 & 2 & 3 & 4 & 5 & 6 & 7 & 8 & 9 & 10 & 11 & 12 & 13 & 14 & 15 & 16 & 17 & 18 & 19 & 20 & 21 & 22 & 23 & 24 \\
\hline BLDG_LIGHT_SCH & $\begin{array}{l}\text { WD (Office Light WD } \\
\text { Sensor) }\end{array}$ & 0.18 & 0.18 & 0.18 & 0.18 & 0.18 & 0.18 & 0.23 & 0.42 & 0.77 & 0.77 & 0.77 & 0.77 & 0.68 & 0.77 & 0.77 & 0.77 & 0.77 & 0.61 & 0.18 & 0.18 & 0.18 & 0.18 & 0.18 & 0.18 \\
\hline & WEH (Office Light WEH) & 0.18 & 0.18 & 0.18 & 0.18 & 0.18 & 0.18 & 0.18 & 0.18 & 0.18 & 0.18 & 0.18 & 0.18 & 0.18 & 0.18 & 0.18 & 0.18 & 0.18 & 0.18 & 0.18 & 0.18 & 0.18 & 0.18 & 0.18 & 0.18 \\
\hline & WD (Storage Light WD) & 0.10 & 0.10 & 0.10 & 0.10 & 0.10 & 0.10 & 0.10 & 0.60 & 0.75 & 0.85 & 0.85 & 0.85 & 0.85 & 0.85 & 0.85 & 0.85 & 0.75 & 0.60 & 0.10 & 0.10 & 0.10 & 0.10 & 0.10 & 0.10 \\
\hline & WEH (Storage Light WEH) & 0.10 & 0.10 & 0.10 & 0.10 & 0.10 & 0.10 & 0.10 & 0.10 & 0.10 & 0.10 & 0.10 & 0.10 & 0.10 & 0.10 & 0.10 & 0.10 & 0.10 & 0.10 & 0.10 & 0.10 & 0.10 & 0.10 & 0.10 & 0.10 \\
\hline BLDG_EQUIP_SCH & \begin{tabular}{|l|} 
WD \\
(Office_Plug_WD_BASE)
\end{tabular} & 0.30 & 0.30 & 0.30 & 0.30 & 0.30 & 0.30 & 0.30 & 0.50 & 1.00 & 1.00 & 1.00 & 1.00 & 0.94 & 1.00 & 1.00 & 1.00 & 1.00 & 0.50 & 0.30 & 0.30 & 0.30 & 0.30 & 0.30 & 0.30 \\
\hline & $\begin{array}{l}\text { WEH } \\
\text { (Office_Plug_WEH_BASE) }\end{array}$ & 0.30 & 0.30 & 0.30 & 0.30 & 0.30 & 0.30 & 0.30 & 0.30 & 0.30 & 0.30 & 0.30 & 0.30 & 0.30 & 0.30 & 0.30 & 0.30 & 0.30 & 0.30 & 0.30 & 0.30 & 0.30 & 0.30 & 0.30 & 0.30 \\
\hline & $\begin{array}{l}\text { WD (Bulk Storage Plug } \\
\text { WD) }\end{array}$ & 0.25 & 0.25 & 0.25 & 0.25 & 0.25 & 0.25 & 0.25 & 0.25 & 1.00 & 1.00 & 1.00 & 1.00 & 0.25 & 1.00 & 1.00 & 1.00 & 1.00 & 0.25 & 0.25 & 0.25 & 0.25 & 0.25 & 0.25 & 0.25 \\
\hline & $\begin{array}{l}\text { WEH (Bulk Storage Plug } \\
\text { WEH) }\end{array}$ & 0.00 & 0.00 & 0.00 & 0.00 & 0.00 & 0.00 & 0.00 & 0.00 & 0.00 & 0.00 & 0.00 & 0.00 & 0.00 & 0.00 & 0.00 & 0.00 & 0.00 & 0.00 & 0.00 & 0.00 & 0.00 & 0.00 & 0.00 & 0.00 \\
\hline BLDG_OCC_SCH & WD (Office Occ WD) & 0.00 & 0.00 & 0.00 & 0.00 & 0.00 & 0.00 & 0.11 & 0.21 & 1.00 & 1.00 & 1.00 & 1.00 & 0.53 & 1.00 & 1.00 & 1.00 & 1.00 & 0.32 & 0.00 & 0.00 & 0.00 & 0.00 & 0.00 & 0.00 \\
\hline & WEH (Office Occ WEH) & 0.00 & 0.00 & 0.00 & 0.00 & 0.00 & 0.00 & 0.00 & 0.00 & 0.00 & 0.00 & 0.00 & 0.00 & 0.00 & 0.00 & \begin{tabular}{|l|}
0.00 \\
\end{tabular} & 0.00 & 0.00 & 0.00 & 0.00 & 0.00 & 0.00 & 0.00 & 0.00 & 0.00 \\
\hline BLDG_SWH_SCH & WD (Office DHW WD) & 0.05 & 0.05 & 0.05 & 0.05 & 0.05 & 0.05 & 0.05 & 0.10 & 0.40 & 0.50 & 0.50 & 0.70 & 0.90 & 0.80 & 0.70 & 0.80 & 0.30 & 0.05 & 0.05 & 0.05 & 0.05 & 0.05 & 0.05 & 0.05 \\
\hline & WEH (Office DHW WEH) & 0.02 & 0.02 & 0.02 & 0.02 & 0.02 & 0.02 & 0.02 & 0.02 & 0.02 & 0.02 & 0.02 & 0.02 & 0.02 & 0.02 & \begin{tabular}{|l|l|}
0.02 \\
\end{tabular} & 0.02 & 0.02 & 0.02 & 0.02 & 0.02 & 0.02 & 0.02 & 0.02 & 0.02 \\
\hline INFIL_SCH_PNNL & WD (Office Infiltration WD) & 1 & 1 & 1 & 1 & 1 & 1 & 1 & 1.25 & 1.25 & 0.5 & 0.5 & 0.5 & 0.5 & 0.5 & 0.5 & 0.5 & 1.25 & 1.25 & 1 & 1 & 1 & 1 & 1 & 1 \\
\hline & $\begin{array}{l}\text { WEH (Office infiltration } \\
\text { WEH) }\end{array}$ & 1 & 1 & 1 & 1 & 1 & 1 & 1 & 1 & 1 & 1 & 1 & 1 & 1 & 1 & 1 & 1 & 1 & 1 & 1 & 1 & 1 & 1 & 1 & 1 \\
\hline & $\begin{array}{l}\text { WD (Fine Storage INFIL } \\
\text { WD) }\end{array}$ & 1 & 1 & 1 & 1 & 1 & 1 & 1 & 1.25 & 1.25 & 0.5 & 0.5 & 0.5 & 0.5 & 0.5 & 0.5 & 0.5 & 1.25 & 1.25 & 1 & 1 & 1 & 1 & 1 & 1 \\
\hline & $\begin{array}{l}\text { WEH (Fine Storage INFIL } \\
\text { WEH) }\end{array}$ & 1 & 1 & 1 & 1 & 1 & 1 & 1 & 1 & 1 & 1 & 1 & 1 & 1 & 1 & 1 & 1 & 1 & 1 & 1 & 1 & 1 & 1 & 1 & 1 \\
\hline & $\begin{array}{l}\text { WD (Bulk Storage } \\
\text { INFIL_Base WD) } \\
\end{array}$ & 0.77 & 0.77 & 0.77 & 0.77 & 0.77 & 0.77 & 0.77 & 0.77 & 1 & 1 & 1 & 1 & 0.77 & 1 & 1 & 1 & 1 & 0.77 & 0.77 & 0.77 & 0.77 & 0.77 & 0.77 & 0.77 \\
\hline & $\begin{array}{l}\text { WEH_(Bulk Storage } \\
\text { INFIL_Base WEH) }\end{array}$ & 0.77 & 0.77 & 0.77 & 0.77 & 0.77 & 0.77 & 0.77 & 0.77 & 0.77 & 0.77 & 0.77 & 0.77 & 0.77 & 0.77 & 0.77 & 0.77 & 0.77 & 0.77 & 0.77 & 0.77 & 0.77 & 0.77 & 0.77 & 0.77 \\
\hline HVACOperationSchd & Compact HVAC-Always 1 & 1 & 1 & 1 & 1 & 1 & 1 & 1 & 1 & 1 & 1 & 1 & 1 & 1 & 1 & 1 & 1 & 1 & 1 & 1 & 1 & 1 & 1 & 1 & 1 \\
\hline Fan Schedule & WD (FanSched) & 0 & 0 & 0 & 0 & 0 & 0 & 0 & 1 & 1 & 1 & 1 & 1 & 1 & 1 & 1 & 1 & 1 & 1 & 0 & 0 & 0 & 0 & 0 & 0 \\
\hline & WEH (FanSched) & 0 & 0 & 0 & 0 & 0 & 0 & 0 & 0 & 0 & 0 & 0 & 0 & 0 & 0 & 0 & 0 & 0 & 0 & 0 & 0 & 0 & 0 & 0 & 0 \\
\hline & $\begin{array}{l}\begin{array}{l}\text { SummerDesignDay } \\
\text { (FanSched) }\end{array} \\
\end{array}$ & 1 & 1 & 1 & 1 & 1 & 1 & 1 & 1 & 1 & 1 & 1 & 1 & 1 & 1 & 1 & 1 & 1 & 1 & 1 & 1 & 1 & 1 & 1 & 1 \\
\hline & $\begin{array}{l}\begin{array}{l}\text { WinterDesignDay } \\
\text { (FanSched) }\end{array} \\
\end{array}$ & 1 & 1 & 1 & 1 & 1 & 1 & 1 & 1 & 1 & 1 & 1 & 1 & 1 & 1 & 1 & 1 & 1 & 1 & 1 & 1 & 1 & 1 & 1 & 1 \\
\hline MinOA_Sched & AllDays & 1 & 1 & 1 & 1 & 1 & 1 & 1 & 1 & 1 & 1 & 1 & 1 & 1 & 1 & 1 & 1 & 1 & 1 & 1 & 1 & 1 & 1 & 1 & 1 \\
\hline $\begin{array}{l}\text { MinOA_MotorizedDamper__ } \\
\text { Sched }\end{array}$ & WD, Sat & 0.0 & 0.0 & 0.0 & 0.0 & 0.0 & 0.0 & 0.0 & 0.0 & 1.0 & 1.0 & 1.0 & 1.0 & 1.0 & 1.0 & 1.0 & 1.0 & 1.0 & 1.0 & 0.0 & 0.0 & 0.0 & 0.0 & 0.0 & 0.0 \\
\hline & Sun, $\mathrm{Hol}$, Other & 0.0 & 0.0 & 0.0 & 0.0 & 0.0 & 0.0 & 0.0 & 0.0 & 0.0 & 0.0 & 0.0 & 0.0 & 0.0 & 0.0 & 0.0 & 0.0 & 0.0 & 0.0 & 0.0 & 0.0 & 0.0 & 0.0 & 0.0 & 0.0 \\
\hline & $\begin{array}{l}\text { SummerDesign, } \\
\text { WinterDesign }\end{array}$ & 1.0 & 1.0 & 1.0 & 1.0 & 1.0 & 1.0 & 1.0 & 1.0 & 1.0 & 1.0 & 1.0 & 1.0 & 1.0 & 1.0 & 1.0 & 1.0 & 1.0 & 1.0 & 1.0 & 1.0 & 1.0 & 1.0 & 1.0 & 1.0 \\
\hline HTGSETP_SCH & WD (Office Heating WD) & 15.6 & 15.6 & 15.6 & 15.6 & 15.6 & 15.6 & 18.3 & 21.1 & 21.1 & 21.1 & 21.1 & 21.1 & 21.1 & 21.1 & 21.1 & 21.1 & 21.1 & 21.1 & 15.6 & 15.6 & 15.6 & 15.6 & 15.6 & 15.6 \\
\hline & $\begin{array}{l}\text { WEH (Office Heating } \\
\text { WEH) }\end{array}$ & 15.6 & 15.6 & 15.6 & 15.6 & 15.6 & 15.6 & 15.6 & 15.6 & 15.6 & 15.6 & 15.6 & 15.6 & 15.6 & 15.6 & 15.6 & 15.6 & 15.6 & 15.6 & 15.6 & 15.6 & 15.6 & 15.6 & 15.6 & 15.6 \\
\hline CLGSETP_SCH & WD (Office Cooling WD) & 29.4 & 29.4 & 29.4 & 29.4 & 29.4 & 29.4 & 26.7 & 23.9 & 23.9 & 23.9 & 23.9 & 23.9 & 23.9 & 23.9 & 23.9 & 23.9 & 23.9 & 23.9 & 29.4 & 29.4 & 29.4 & 29.4 & 29.4 & 29.4 \\
\hline & $\begin{array}{l}\text { WEH (Office Cooling } \\
\text { WEH) }\end{array}$ & 29.4 & 29.4 & 29.4 & 29.4 & 29.4 & 29.4 & 29.4 & 29.4 & 29.4 & 29.4 & 29.4 & 29.4 & 29.4 & 29.4 & 29.4 & 29.4 & 29.4 & 29.4 & 29.4 & 29.4 & 29.4 & 29.4 & 29.4 & 29.4 \\
\hline $\begin{array}{l}\text { Bulk Storage Heating Setpoint } \\
\text { Schedule }\end{array}$ & AllDays & 10 & 10 & 10 & 10 & 10 & 10 & 10 & 10 & 10 & 10 & 10 & 10 & 10 & 10 & 10 & 10 & 10 & 10 & 10 & 10 & 10 & 10 & 10 & 10 \\
\hline $\begin{array}{l}\text { Hot Water Setpoint Temp } \\
\text { Schedule (SWH) }\end{array}$ & AllDays & 48.9 & 48.9 & 48.9 & 48.9 & 48.9 & 48.9 & 48.9 & 48.9 & 48.9 & 48.9 & 48.9 & 48.9 & 48.9 & 48.9 & 48.9 & 48.9 & 48.9 & 48.9 & 48.9 & 48.9 & 48.9 & 48.9 & 48.9 & 48.9 \\
\hline $\begin{array}{l}\text { Fine Storage Heating Setpoint } \\
\text { Schedule }\end{array}$ & AllDays & 15.6 & 15.6 & 15.6 & 15.6 & 15.6 & 15.6 & 15.6 & 15.6 & 15.6 & 15.6 & 15.6 & 15.6 & 15.6 & 15.6 & 15.6 & 15.6 & 15.6 & 15.6 & 15.6 & 15.6 & 15.6 & 15.6 & 15.6 & 15.6 \\
\hline $\begin{array}{l}\text { Fine Storage Cooling Setpoint } \\
\text { Schedule }\end{array}$ & AllDays & 26.7 & 26.7 & 26.7 & 26.7 & 26.7 & 26.7 & 26.7 & 26.7 & 26.7 & 26.7 & 26.7 & 26.7 & 26.7 & 26.7 & 26.7 & 26.7 & 26.7 & 26.7 & 26.7 & 26.7 & 26.7 & 26.7 & 26.7 & 26.7 \\
\hline HTGSETP_SCH & WD (Office Heating WD) & 60 & 60 & 60 & 60 & 60 & 60 & 65 & 70 & 70 & 70 & 70 & 70 & 70 & 70 & 70 & 70 & 70 & 70 & 60 & 60 & 60 & 60 & 60 & 60 \\
\hline
\end{tabular}




\begin{tabular}{|c|c|c|c|c|c|c|c|c|c|c|c|c|c|c|c|c|c|c|c|c|c|c|c|c|c|}
\hline Schedule & Day of Week & 1 & 2 & 3 & 4 & 5 & 6 & 7 & 8 & 9 & 10 & 11 & 12 & 13 & 14 & 15 & 16 & 17 & 18 & 19 & 20 & 21 & 22 & 23 & 24 \\
\hline & WEH (Office Heating & 60 & 60 & 60 & 60 & 60 & 60 & 60 & 60 & 60 & 60 & 60 & 60 & 60 & 60 & 60 & 60 & 60 & 60 & 60 & 60 & 60 & 60 & 60 & 60 \\
\hline \multirow[t]{2}{*}{ CLGSETP_SCH } & WD (Office Cooling WD) & 85 & 85 & 85 & 85 & 85 & 85 & 80 & 75 & 75 & 75 & 75 & 75 & 75 & 75 & 75 & 75 & 75 & 75 & 85 & 85 & 85 & 85 & 85 & 85 \\
\hline & $\begin{array}{l}\text { WEH (Office Cooling } \\
\text { WEH) }\end{array}$ & 85 & 85 & 85 & 85 & 85 & 85 & 85 & 85 & 85 & 85 & 85 & 85 & 85 & 85 & 85 & 85 & 85 & 85 & 85 & 85 & 85 & 85 & 85 & 85 \\
\hline $\begin{array}{l}\text { Bulk Storage Heating Setpoint } \\
\text { Schedule }\end{array}$ & AllDays & 50 & 50 & 50 & 50 & 50 & 50 & 50 & 50 & 50 & 50 & 50 & 50 & 50 & 50 & 50 & 50 & 50 & 50 & 50 & 50 & 50 & 50 & 50 & 50 \\
\hline $\begin{array}{l}\text { Hot Water Setpoint Temp } \\
\text { Schedule }\end{array}$ & AllDays & 120 & 120 & 120 & 120 & 120 & 120 & 120 & 120 & 120 & 120 & 120 & 120 & 120 & 120 & 120 & 120 & 120 & 120 & 120 & 120 & 120 & 120 & 120 & 120 \\
\hline $\begin{array}{l}\text { Fine Storage Heating Setpoint } \\
\text { Schedule }\end{array}$ & AllDays & 60 & 60 & 60 & 60 & 60 & 60 & 60 & 60 & 60 & 60 & 60 & 60 & 60 & 60 & 60 & 60 & 60 & 60 & 60 & 60 & 60 & 60 & 60 & 60 \\
\hline $\begin{array}{l}\text { Fine Storage Cooling Setpoint } \\
\text { Schedule }\end{array}$ & AllDays & 80 & 80 & 80 & 80 & 80 & 80 & 80 & 80 & 80 & 80 & 80 & 80 & 80 & 80 & 80 & 80 & 80 & 80 & 80 & 80 & 80 & 80 & 80 & 80 \\
\hline
\end{tabular}




\section{C.13 Quick Service Restaurant Hourly Operation Schedules}

\begin{tabular}{|c|c|c|c|c|c|c|c|c|c|c|c|c|c|c|c|c|c|c|c|c|c|c|c|c|c|}
\hline Schedule & Day of Week & 1 & 2 & 3 & 4 & 5 & 6 & 7 & 8 & 9 & 10 & 11 & 12 & 13 & 14 & 15 & 16 & 17 & 18 & 19 & 20 & 21 & 22 & 23 & 24 \\
\hline \multirow[t]{5}{*}{ BLDG_LIGHT_SCH } & WD & 0.15 & 0.15 & 0.15 & 0.15 & 0.15 & 0.2 & 0.4 & 0.4 & 0.6 & 0.6 & 0.9 & 0.9 & 0.9 & 0.9 & 0.9 & 0.9 & 0.9 & 0.9 & 0.9 & 0.9 & 0.9 & 0.9 & 0.5 & 0.3 \\
\hline & Sat & 0.2 & 0.15 & 0.15 & 0.15 & 0.15 & 0.15 & 0.3 & 0.3 & 0.6 & 0.6 & 0.8 & 0.8 & 0.8 & 0.8 & 0.8 & 0.8 & 0.8 & 0.9 & 0.9 & 0.9 & 0.9 & 0.9 & 0.5 & 0.3 \\
\hline & Sun, Hol, Other & 0.2 & 0.15 & 0.15 & 0.15 & 0.15 & 0.15 & 0.3 & 0.3 & 0.5 & 0.5 & 0.7 & 0.7 & 0.7 & 0.7 & 0.7 & 0.7 & 0.6 & 0.6 & 0.6 & 0.6 & 0.6 & 0.6 & 0.5 & 0.3 \\
\hline & SummerDesign & 1 & 1 & 1 & 1 & 1 & 1 & 1 & 1 & 1 & 1 & 1 & 1 & 1 & 1 & 1 & 1 & 1 & 1 & 1 & 1 & 1 & 1 & 1 & 1 \\
\hline & WinterDesign & 0 & 0 & 0 & 0 & 0 & 0 & 0 & 0 & 0 & 0 & 0 & 0 & 0 & 0 & 0 & 0 & 0 & 0 & 0 & 0 & 0 & 0 & 0 & 0 \\
\hline \multirow[t]{5}{*}{ BLDG_EQUIP_SCH } & WD & 0.03 & 0.02 & 0.03 & 0.02 & 0.05 & 0.12 & 0.13 & 0.15 & 0.18 & 0.21 & 0.26 & 0.29 & 0.27 & 0.25 & 0.23 & 0.23 & 0.26 & 0.26 & 0.24 & 0.22 & 0.2 & 0.18 & 0.09 & 0.03 \\
\hline & Sat & 0.03 & 0.02 & 0.03 & 0.02 & 0.05 & 0.12 & 0.13 & 0.15 & 0.18 & 0.21 & 0.26 & 0.29 & 0.27 & 0.25 & 0.23 & 0.23 & 0.26 & 0.26 & 0.24 & 0.22 & 0.2 & 0.18 & 0.09 & 0.03 \\
\hline & Sun, Hol, Other & 0.03 & 0.02 & 0.03 & 0.02 & 0.05 & 0.12 & 0.13 & 0.15 & 0.18 & 0.21 & 0.26 & 0.29 & 0.27 & 0.25 & 0.23 & 0.23 & 0.26 & 0.26 & 0.24 & 0.22 & 0.2 & 0.18 & 0.09 & 0.03 \\
\hline & SummerDesign & 0.29 & 0.29 & 0.29 & 0.29 & 0.29 & 0.29 & 0.29 & 0.29 & 0.29 & 0.29 & 0.29 & 0.29 & 0.29 & 0.29 & 0.29 & 0.29 & 0.29 & 0.29 & 0.29 & 0.29 & 0.29 & 0.29 & 0.29 & 0.29 \\
\hline & WinterDesign & 0 & 0 & 0 & 0 & 0 & 0 & 0 & 0 & 0 & 0 & 0 & 0 & 0 & 0 & 0 & 0 & 0 & 0 & 0 & 0 & 0 & 0 & 0 & 0 \\
\hline \multirow[t]{4}{*}{ FF_GAS_EQUIP_SCH } & WD, Sat & 0.03 & 0.02 & 0.03 & 0.02 & 0.05 & 0.12 & 0.13 & 0.15 & 0.18 & 0.21 & 0.26 & 0.29 & 0.27 & 0.25 & 0.23 & 0.23 & 0.26 & 0.26 & 0.24 & 0.22 & 0.2 & 0.18 & 0.09 & 0.03 \\
\hline & Sun, Hol, Other & 0.03 & 0.02 & 0.03 & 0.02 & 0.05 & 0.12 & 0.13 & 0.15 & 0.18 & 0.21 & 0.26 & 0.29 & 0.27 & 0.25 & 0.23 & 0.23 & 0.26 & 0.26 & 0.24 & 0.22 & 0.2 & 0.18 & 0.09 & 0.03 \\
\hline & SummerDesign & 0.29 & 0.29 & 0.29 & 0.29 & 0.29 & 0.29 & 0.29 & 0.29 & 0.29 & 0.29 & 0.29 & 0.29 & 0.29 & 0.29 & 0.29 & 0.29 & 0.29 & 0.29 & 0.29 & 0.29 & 0.29 & 0.29 & 0.29 & 0.29 \\
\hline & WinterDesign & 0 & 0 & 0 & 0 & 0 & 0 & 0 & 0 & 0 & 0 & 0 & 0 & 0 & 0 & 0 & 0 & 0 & 0 & 0 & 0 & 0 & 0 & 0 & 0 \\
\hline \multirow[t]{5}{*}{ BLDG_OCC_SCH } & WD & 0.05 & 0 & 0 & 0 & 0 & 0.05 & 0.1 & 0.4 & 0.4 & 0.4 & 0.2 & 0.5 & 0.8 & 0.7 & 0.4 & 0.2 & 0.25 & 0.5 & 0.8 & 0.8 & 0.8 & 0.5 & 0.35 & 0.2 \\
\hline & Sat & 0.05 & 0 & 0 & 0 & 0 & 0 & 0.05 & 0.5 & 0.5 & 0.4 & 0.2 & 0.45 & 0.5 & 0.5 & 0.35 & 0.3 & 0.3 & 0.3 & 0.7 & 0.9 & 0.7 & 0.65 & 0.55 & 0.35 \\
\hline & Sun, Hol, Other & 0.05 & 0 & 0 & 0 & 0 & 0 & 0.05 & 0.5 & 0.5 & 0.2 & 0.2 & 0.3 & 0.5 & 0.5 & 0.3 & 0.2 & 0.25 & 0.35 & 0.55 & 0.65 & 0.7 & 0.35 & 0.2 & 0.2 \\
\hline & SummerDesign & 1 & 1 & 1 & 1 & 1 & 1 & 1 & 1 & 1 & 1 & 1 & 1 & 1 & 1 & 1 & 1 & 1 & 1 & 1 & 1 & 1 & 1 & 1 & 1 \\
\hline & WinterDesign & 0 & 0 & 0 & 0 & 0 & 0 & 0 & 0 & 0 & 0 & 0 & 0 & 0 & 0 & 0 & 0 & 0 & 0 & 0 & 0 & 0 & 0 & 0 & 0 \\
\hline BLDG_EXTERIOR_LIGHT & $\begin{array}{l}\text { WD, } \\
\text { SummerDesign }\end{array}$ & 1 & 1 & 1 & 1 & 1 & 1 & 1 & 1 & 1 & 1 & 1 & 1 & 1 & 1 & 1 & 1 & 1 & 1 & 1 & 1 & 1 & 1 & 1 & 1 \\
\hline (AstronomicalClock control) & Sat, WinterDesign & 1 & 1 & 1 & 1 & 1 & 1 & 1 & 1 & 1 & 1 & 1 & 1 & 1 & 1 & 1 & 1 & 1 & 1 & 1 & 1 & 1 & 1 & 1 & 1 \\
\hline \multirow[t]{3}{*}{ BLDG_SWH_SCH } & $\begin{array}{l}\text { WD, } \\
\text { SummerDesign }\end{array}$ & 0.2 & 0 & 0 & 0 & 0 & 0 & 0.15 & 0.6 & 0.55 & 0.45 & 0.4 & 0.45 & 0.4 & 0.35 & 0.3 & 0.3 & 0.3 & 0.4 & 0.55 & 0.6 & 0.5 & 0.55 & 0.45 & 0.25 \\
\hline & Sat, WinterDesign & 0.2 & 0 & 0 & 0 & 0 & 0 & 0.15 & 0.15 & 0.15 & 0.5 & 0.45 & 0.5 & 0.5 & 0.45 & 0.4 & 0.4 & 0.35 & 0.4 & 0.55 & 0.55 & 0.5 & 0.55 & 0.4 & 0.3 \\
\hline & Sun, Hol, Other & 0.25 & 0 & 0 & 0 & 0 & 0 & 0.15 & 0.15 & 0.15 & 0.15 & 0.5 & 0.5 & 0.4 & 0.4 & 0.3 & 0.3 & 0.3 & 0.4 & 0.5 & 0.5 & 0.4 & 0.5 & 0.4 & 0.2 \\
\hline \multirow[t]{3}{*}{ INFIL_SCH_PNNL } & $\begin{array}{l}\text { WD, } \\
\text { SummerDesign }\end{array}$ & 0.25 & 1 & 1 & 1 & 1 & 0.25 & 0.25 & 0.25 & 0.25 & 0.25 & 0.25 & 0.25 & 0.25 & 0.25 & 0.25 & 0.25 & 0.25 & 0.25 & 0.25 & 0.25 & 0.25 & 0.25 & 0.25 & 0.25 \\
\hline & Sat, WinterDesign & 0.25 & 1 & 1 & 1 & 1 & 0.25 & 0.25 & 0.25 & 0.25 & 0.25 & 0.25 & 0.25 & 0.25 & 0.25 & 0.25 & 0.25 & 0.25 & 0.25 & 0.25 & 0.25 & 0.25 & 0.25 & 0.25 & 0.25 \\
\hline & Sun, Hol, Other & 0.25 & 1 & 1 & 1 & 1 & 0.25 & 0.25 & 0.25 & 0.25 & 0.25 & 0.25 & 0.25 & 0.25 & 0.25 & 0.25 & 0.25 & 0.25 & 0.25 & 0.25 & 0.25 & 0.25 & 0.25 & 0.25 & 0.25 \\
\hline HVACOperationSchd & $\begin{array}{l}\text { WD, } \\
\text { SummerDesign }\end{array}$ & 1 & 0 & 0 & 0 & 0 & 1 & 1 & 1 & 1 & 1 & 1 & 1 & 1 & 1 & 1 & 1 & 1 & 1 & 1 & 1 & 1 & 1 & 1 & 1 \\
\hline \multirow[t]{2}{*}{ (FAN_SCH) } & Sat, WinterDesign & 1 & 0 & 0 & 0 & 0 & 1 & 1 & 1 & 1 & 1 & 1 & 1 & 1 & 1 & 1 & 1 & 1 & 1 & 1 & 1 & 1 & 1 & 1 & 1 \\
\hline & Sun, Hol, Other & 1 & 0 & 0 & 0 & 0 & 1 & 1 & 1 & 1 & 1 & 1 & 1 & 1 & 1 & 1 & 1 & 1 & 1 & 1 & 1 & 1 & 1 & 1 & 1 \\
\hline \multirow[t]{5}{*}{ HTGSETP_SCH } & WD & 13 & 13 & 13 & 13 & 13 & 13 & 21 & 21 & 21 & 21 & 21 & 21 & 21 & 21 & 21 & 21 & 21 & 21 & 21 & 13 & 13 & 13 & 13 & 13 \\
\hline & SummerDesign & 13 & 13 & 13 & 13 & 13 & 13 & 13 & 13 & 13 & 13 & 13 & 13 & 13 & 13 & 13 & 13 & 13 & 13 & 13 & 13 & 13 & 13 & 13 & 13 \\
\hline & Sat & 13 & 13 & 13 & 13 & 13 & 13 & 21 & 21 & 21 & 21 & 21 & 21 & 21 & 13 & 13 & 13 & 13 & 13 & 13 & 13 & 13 & 13 & 13 & 13 \\
\hline & WinterDesign & 21 & 21 & 21 & 21 & 21 & 21 & 21 & 21 & 21 & 21 & 21 & 21 & 21 & 21 & 21 & 21 & 21 & 21 & 21 & 21 & 21 & 21 & 21 & 21 \\
\hline & Sun, Hol, Other & 13 & 13 & 13 & 13 & 13 & 13 & 13 & 13 & 13 & 13 & 13 & 13 & 13 & 13 & 13 & 13 & 13 & 13 & 13 & 13 & 13 & 13 & 13 & 13 \\
\hline \multirow[t]{5}{*}{ CLGSETP_SCH } & WD & 33 & 33 & 33 & 33 & 33 & 33 & 24 & 24 & 24 & 24 & 24 & 24 & 24 & 24 & 24 & 24 & 24 & 24 & 24 & 24 & 24 & 24 & 33 & 33 \\
\hline & SummerDesign & 24 & 24 & 24 & 24 & 24 & 24 & 24 & 24 & 24 & 24 & 24 & 24 & 24 & 24 & 24 & 24 & 24 & 24 & 24 & 24 & 24 & 24 & 24 & 24 \\
\hline & Sat & 33 & 33 & 33 & 33 & 33 & 33 & 24 & 24 & 24 & 24 & 24 & 24 & 24 & 24 & 24 & 24 & 24 & 24 & 33 & 33 & 33 & 33 & 33 & 33 \\
\hline & WinterDesign & 33 & 33 & 33 & 33 & 33 & 33 & 33 & 33 & 33 & 33 & 33 & 33 & 33 & 33 & 33 & 33 & 33 & 33 & 33 & 33 & 33 & 33 & 33 & 33 \\
\hline & Sun, Hol, Other & 33 & 33 & 33 & 33 & 33 & 33 & 33 & 33 & 33 & 33 & 33 & 33 & 33 & 33 & 33 & 33 & 33 & 33 & 33 & 33 & 33 & 33 & 33 & 33 \\
\hline $\begin{array}{l}\text { Dual Zone Control Type } \\
\text { Sched }\end{array}$ & All & 4 & 4 & 4 & 4 & 4 & 4 & 4 & 4 & 4 & 4 & 4 & 4 & 4 & 4 & 4 & 4 & 4 & 4 & 4 & 4 & 4 & 4 & 4 & 4 \\
\hline \multirow{3}{*}{$\begin{array}{l}\text { Seasonal-Reset-Supply-Air- } \\
\text { Temp-Sch }\end{array}$} & All & 16 & 16 & 16 & 16 & 16 & 16 & 16 & 16 & 16 & 16 & 16 & 16 & 16 & 16 & 16 & 16 & 16 & 16 & 16 & 16 & 16 & 16 & 16 & 16 \\
\hline & All & 13 & 13 & 13 & 13 & 13 & 13 & 13 & 13 & 13 & 13 & 13 & 13 & 13 & 13 & 13 & 13 & 13 & 13 & 13 & 13 & 13 & 13 & 13 & 13 \\
\hline & All & 16 & 16 & 16 & 16 & 16 & 16 & 16 & 16 & 16 & 16 & 16 & 16 & 16 & 16 & 16 & 16 & 16 & 16 & 16 & 16 & 16 & 16 & 16 & 16 \\
\hline CW-Loop-Temp-Schedule & All & 6.7 & 6.7 & 6.7 & 6.7 & 6.7 & 6.7 & 6.7 & 6.7 & 6.7 & 6.7 & 6.7 & 6.7 & 6.7 & 6.7 & 6.7 & 6.7 & 6.7 & 6.7 & 6.7 & 6.7 & 6.7 & 6.7 & 6.7 & 6.7 \\
\hline
\end{tabular}




\begin{tabular}{|c|c|c|c|c|c|c|c|c|c|c|c|c|c|c|c|c|c|c|c|c|c|c|c|c|c|}
\hline Schedule & Day of Week & 1 & 2 & 3 & 4 & 5 & 6 & 7 & 8 & 9 & 10 & 11 & 12 & 13 & 14 & 15 & 16 & 17 & 18 & 19 & 20 & 21 & 22 & 23 & 24 \\
\hline HW-Loop-Temp-Schedule & All & 60 & 60 & 60 & 60 & 60 & 60 & 60 & 60 & 60 & 60 & 60 & 60 & 60 & 60 & 60 & 60 & 60 & 60 & 60 & 60 & 60 & 60 & 60 & 60 \\
\hline \begin{tabular}{|l} 
Heating-Supply-Air-Temp-Sch \\
\end{tabular} & All & 16 & 16 & 16 & 16 & 16 & 16 & 16 & 16 & 16 & 16 & 16 & 16 & 16 & 16 & 16 & 16 & 16 & 16 & 16 & 16 & 16 & 16 & 16 & 16 \\
\hline HTGSETP_DINING_SCH & WD, Winter Design & 60 & 60 & 60 & 60 & 60 & 65 & 70 & 70 & 70 & 70 & 70 & 70 & 70 & 70 & 70 & 70 & 70 & 70 & 70 & 70 & 70 & 70 & 70 & 70 \\
\hline & SummerDesign & 60 & 60 & 60 & 60 & 60 & 60 & 60 & 60 & 60 & 60 & 60 & 60 & 60 & 60 & 60 & 60 & 60 & 60 & 60 & 60 & 60 & 60 & 60 & 60 \\
\hline & $\begin{array}{l}\begin{array}{l}\text { Sat, Sun, Hol, } \\
\text { Other }\end{array} \\
\end{array}$ & 60 & 60 & 60 & 60 & 60 & 65 & 70 & 70 & 70 & 70 & 70 & 70 & 70 & 70 & 70 & 70 & 70 & 70 & 70 & 70 & 70 & 70 & 70 & 70 \\
\hline HTGSETP_KITCHEN_SCH & WD, Winter Design & 60 & 60 & 60 & 60 & 60 & 63 & 66 & 66 & 66 & 66 & 66 & 66 & 66 & 66 & 66 & 66 & 66 & 66 & 66 & 66 & 66 & 66 & 66 & 66 \\
\hline & \begin{tabular}{|l} 
SummerDesign \\
\end{tabular} & 60 & 60 & 60 & 60 & 60 & 60 & 60 & 60 & 60 & 60 & 60 & 60 & 60 & 60 & 60 & 60 & 60 & 60 & 60 & 60 & 60 & 60 & 60 & 60 \\
\hline & $\begin{array}{l}\text { Sat, Sun, Hol, } \\
\text { Other }\end{array}$ & 60 & 60 & 60 & 60 & 60 & 63 & 66 & 66 & 66 & 66 & 66 & 66 & 66 & 66 & 66 & 66 & 66 & 66 & 66 & 66 & 66 & 66 & 66 & 66 \\
\hline CLGSETP_DINING_SCH & $\begin{array}{l}\text { WD, } \\
\text { SummerDesign }\end{array}$ & 86 & 86 & 86 & 86 & 86 & 80 & 75 & 75 & 75 & 75 & 75 & 75 & 75 & 75 & 75 & 75 & 75 & 75 & 75 & 75 & 75 & 75 & 75 & 75 \\
\hline & WinterDesign & 86 & 86 & 86 & 86 & 86 & 86 & 86 & 86 & 86 & 86 & 86 & 86 & 86 & 86 & 86 & 86 & 86 & 86 & 86 & 86 & 86 & 86 & 86 & 86 \\
\hline & $\begin{array}{l}\text { Sat, Sun, Hol, } \\
\text { Other }\end{array}$ & 86 & 86 & 86 & 86 & 86 & 80 & 75 & 75 & 75 & 75 & 75 & 75 & 75 & 75 & 75 & 75 & 75 & 75 & 75 & 75 & 75 & 75 & 75 & 75 \\
\hline CLGSETP_KITCHEN_SCH & $\begin{array}{l}\text { WD, } \\
\text { SummerDesign }\end{array}$ & 86 & 86 & 86 & 86 & 86 & 83 & 79 & 79 & 79 & 79 & 79 & 79 & 79 & 79 & 79 & 79 & 79 & 79 & 79 & 79 & 79 & 79 & 79 & 79 \\
\hline & WinterDesign & 86 & 86 & 86 & 86 & 86 & 86 & 86 & 86 & 86 & 86 & 86 & 86 & 86 & 86 & 86 & 86 & 86 & 86 & 86 & 86 & 86 & 86 & 86 & 86 \\
\hline & $\begin{array}{l}\text { Sat, Si } \\
\text { Other }\end{array}$ & 86 & 86 & 86 & 86 & 86 & 83 & 79 & 79 & 79 & 79 & 79 & 79 & 79 & 79 & 79 & 79 & 79 & 79 & 79 & 79 & 79 & 79 & 79 & 79 \\
\hline HTGSETP_DINING_SCH & WD, Winter Design & 15.56 & 15.56 & 15.56 & 15.56 & 15.56 & 18.33 & 21.11 & 21.11 & 21.11 & 21.11 & 21.11 & 21.11 & 21.11 & 21.11 & 21.11 & 21.11 & 21.11 & 21.11 & 21.11 & \begin{tabular}{|l|}
21.11 \\
\end{tabular} & 21.11 & 21.11 & \begin{tabular}{|l|}
21.11 \\
\end{tabular} & 21.11 \\
\hline & SummerDesign & 15.56 & 15.56 & 15.56 & 15.56 & 15.56 & 15.56 & 15.56 & 15.56 & 15.56 & 15.56 & 15.56 & 15.56 & 15.56 & 15.56 & 15.56 & 15.56 & 15.56 & 15.56 & 15.56 & 15.56 & 15.56 & 15.56 & 15.56 & 15.56 \\
\hline & $\begin{array}{l}\text { Sat, Sun, Hol, } \\
\text { Other }\end{array}$ & 15.56 & 15.56 & 15.56 & 15.56 & 15.56 & 18.33 & 21.11 & 21.11 & 21.11 & 21.11 & 21.11 & 21.11 & 21.11 & 21.11 & 21.11 & 21.11 & 21.11 & 21.11 & 21.11 & 21.11 & 21.11 & 21.11 & 21.11 & 21.11 \\
\hline HTGSETP_KITCHEN_SCH & WD, Winter Design & 15.56 & 15.56 & 15.56 & 15.56 & 15.56 & \begin{tabular}{|l|}
17.22 \\
\end{tabular} & 18.89 & 18.89 & 18.89 & 18.89 & 18.89 & 18.89 & 18.89 & 18.89 & 18.89 & 18.89 & 18.89 & 18.89 & 18.89 & 18.89 & 18.89 & \begin{tabular}{|l|}
18.89 \\
\end{tabular} & 18.89 & 18.89 \\
\hline & SummerDesign & 15.56 & 15.56 & 15.56 & 15.56 & \begin{tabular}{|l|l|}
15.56 \\
\end{tabular} & 15.56 & \begin{tabular}{|c|}
15.56 \\
\end{tabular} & 15.56 & \begin{tabular}{|c|}
15.56 \\
\end{tabular} & 15.56 & 15.56 & 15.56 & 15.56 & 15.56 & 15.56 & 15.56 & 15.56 & 15.56 & 15.56 & 15.56 & 15.56 & 15.56 & \begin{tabular}{|l|}
15.56 \\
\end{tabular} & 15.56 \\
\hline & $\begin{array}{l}\begin{array}{l}\text { Sat, Sun, Hol, } \\
\text { Other }\end{array} \\
\end{array}$ & 15.56 & 15.56 & 15.56 & 15.56 & 15.56 & 17.22 & 18.89 & 18.89 & 18.89 & 18.89 & 18.89 & 18.89 & 18.89 & 18.89 & 18.89 & 18.89 & 18.89 & 18.89 & 18.89 & 18.89 & 18.89 & 18.89 & 18.89 & 18.89 \\
\hline CLGSETP_DINING_SCH & \begin{tabular}{|l|} 
WD, \\
SummerDesign
\end{tabular} & 30.00 & 30.00 & 30.00 & 30.00 & 30.00 & 26.67 & 23.89 & 23.89 & 23.89 & 23.89 & 23.89 & 23.89 & 23.89 & 23.89 & 23.89 & 23.89 & 23.89 & 23.89 & 23.89 & 23.89 & 23.89 & 23.89 & 23.89 & 23.89 \\
\hline & WinterDesign & 30.00 & 30.00 & 30.00 & 30.00 & 30.00 & 30.00 & 30.00 & 30.00 & 30.00 & 30.00 & 30.00 & 30.00 & 30.00 & 30.00 & 30.00 & 30.00 & 30.00 & 30.00 & 30.00 & 30.00 & 30.00 & 30.00 & 30.00 & 30.00 \\
\hline & Sun, Hol, & 30.00 & 30.00 & 30.00 & 30.00 & 30.00 & 26.67 & 23.89 & 23.89 & 23.89 & 23.89 & 23.89 & 23.89 & 23.89 & 23.89 & 23.89 & 23.89 & 23.89 & 23.89 & 23.89 & 23.89 & 23.89 & 23.89 & 23.89 & 23.89 \\
\hline CLGSETP_KITCHEN_SCH & $\begin{array}{l}\text { WD, } \\
\text { SummerDesign }\end{array}$ & 30.00 & 30.00 & 30.00 & 30.00 & 30.00 & 28.33 & 26.11 & 26.11 & 26.11 & 26.11 & 26.11 & 26.11 & 26.11 & 26.11 & 26.11 & 26.11 & 26.11 & 26.11 & 26.11 & 26.11 & 26.11 & 26.11 & 26.11 & 26.11 \\
\hline & WinterDesign & 30.00 & 30.00 & 30.00 & 30.00 & 30.00 & 30.00 & 30.00 & 30.00 & \begin{tabular}{|l|}
30.00 \\
\end{tabular} & 30.00 & 30.00 & 30.00 & 30.00 & 30.00 & 30.00 & 30.00 & 30.00 & 30.00 & 30.00 & 30.00 & 30.00 & \begin{tabular}{|l|}
30.00 \\
\end{tabular} & 30.00 & 30.00 \\
\hline & Sun, Hol, & 30.00 & 30.00 & 30.00 & 30.00 & 30.00 & 28.33 & 26.11 & 26.11 & 26.11 & 26.11 & 26.11 & 26.11 & 26.11 & 26.11 & 26.11 & 26.11 & 26.11 & 26.11 & 26.11 & 26.11 & 26.11 & 26.11 & 26.11 & 26.11 \\
\hline $\begin{array}{l}\begin{array}{l}\text { MinOA_FFKitch_Sched (for } \\
\text { kichen) }\end{array} \\
\end{array}$ & $\begin{array}{l}\text { WD, } \\
\text { SummerDesign }\end{array}$ & 0 & 0 & 0 & 0 & 0 & 0 & 1 & 1 & 1 & 1 & 1 & 1 & 1 & 1 & 1 & 1 & 1 & 1 & 1 & 1 & 1 & 1 & 1 & 1 \\
\hline & Sat & 0 & 0 & 0 & 0 & 0 & 0 & 1 & 1 & 1 & 1 & 1 & 1 & 1 & 1 & 1 & 1 & 1 & 1 & 1 & 1 & 1 & 1 & 1 & 1 \\
\hline & \begin{tabular}{|l|} 
WinterDesign \\
\end{tabular} & 1 & 1 & 1 & 1 & 1 & 1 & 1 & 1 & 1 & 1 & 1 & 1 & 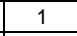 & 1 & 1 & 1 & 1 & 1 & 1 & 1 & 1 & 1 & 1 & 1 \\
\hline & Sun, & 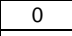 & 0 & 0 & 0 & 0 & 0 & 1 & 1 & 1 & 1 & 1 & 1 & 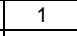 & 1 & - & 1 & 1 & 1 & 1 & \pm & 1 & 1 & 1 & 1 \\
\hline \begin{tabular}{|l} 
MinOA_Sched (for dining) \\
\end{tabular} & All & 1 & 1 & 1 & 1 & 1 & 1 & 1 & 1 & 1 & 1 & 1 & 1 & 1 & 1 & 1 & 1 & 1 & 1 & 1 & 1 & 1 & 1 & 1 & 1 \\
\hline
\end{tabular}




\section{C.14 Full Service Restaurant Hourly Operation Schedules}

\begin{tabular}{|c|c|c|c|c|c|c|c|c|c|c|c|c|c|c|c|c|c|c|c|c|c|c|c|c|c|}
\hline Schedule & Day of Week & 1 & 2 & 3 & 4 & 5 & 6 & 7 & 8 & 9 & 10 & 11 & 12 & 13 & 14 & 15 & 16 & 17 & 18 & 19 & 20 & 21 & 22 & 23 & 24 \\
\hline BLDG_LIGHT_SCH & WD & 0.15 & 0.15 & 0.15 & 0.15 & 0.15 & 0.2 & 0.4 & 0.4 & 0.6 & 0.6 & 0.9 & 0.9 & 0.9 & 0.9 & 0.9 & 0.9 & 0.9 & 0.9 & 0.9 & 0.9 & 0.9 & 0.9 & 0.5 & 0.3 \\
\hline & Sat & 0.2 & 0.15 & \begin{tabular}{|l|}
0.15 \\
\end{tabular} & 0.15 & 0.15 & 0.15 & 0.3 & 0.3 & 0.6 & 0.6 & 0.8 & 0.8 & 0.8 & 0.8 & 0.8 & 0.8 & 0.8 & 0.9 & 0.9 & 0.9 & 0.9 & 0.9 & 0.5 & 0.3 \\
\hline & Sun, Hol, Other & 0.2 & 0.15 & \begin{tabular}{|l|}
0.15 \\
\end{tabular} & 0.15 & 0.15 & 0.15 & 0.3 & 0.3 & 0.5 & 0.5 & 0.7 & 0.7 & 0.7 & 0.7 & 0.7 & 0.7 & 0.6 & 0.6 & 0.6 & 0.6 & 0.6 & 0.6 & 0.5 & 0.3 \\
\hline & SummerDesign & 1 & 1 & 1 & 1 & 1 & 1 & 1 & 1 & 1 & 1 & 1 & 1 & 1 & 1 & 1 & 1 & 1 & 1 & 1 & 1 & 1 & 1 & 1 & 1 \\
\hline & WinterDesign & 0 & 0 & 0 & 0 & 0 & 0 & 0 & 0 & 0 & 0 & 0 & 0 & 0 & 0 & 0 & 0 & 0 & 0 & 0 & 0 & 0 & 0 & 0 & 0 \\
\hline BLDG_EQUIP_SCH & WD & 0.03 & 0.02 & 0.03 & 0.02 & 0.05 & 0.12 & 0.13 & 0.15 & 0.18 & 0.21 & 0.26 & 0.29 & 0.27 & 0.25 & 0.23 & 0.23 & 0.26 & \begin{tabular}{|l|}
0.26 \\
\end{tabular} & 0.24 & 0.22 & 0.2 & 0.18 & 0.09 & 0.03 \\
\hline Used for Electric Equipment & Sat & 0.03 & 0.02 & 0.03 & 0.02 & 0.05 & 0.12 & 0.13 & 0.15 & 0.18 & 0.21 & 0.26 & 0.29 & 0.27 & 0.25 & 0.23 & 0.23 & 0.26 & 0.26 & 0.24 & 0.22 & 0.2 & 0.18 & 0.09 & 0.03 \\
\hline & Sun, Hol, Other & 0.03 & 0.02 & 0.03 & 0.02 & 0.05 & 0.12 & 0.13 & 0.15 & 0.18 & 0.21 & 0.26 & 0.29 & 0.27 & 0.25 & \begin{tabular}{|l|}
0.23 \\
\end{tabular} & 0.23 & 0.26 & 0.26 & 0.24 & 0.22 & 0.2 & 0.18 & \begin{tabular}{|l|}
0.09 \\
\end{tabular} & 0.03 \\
\hline & SummerDesign & 0.29 & 0.29 & 0.29 & 0.29 & 0.29 & 0.29 & 0.29 & 0.29 & 0.29 & 0.29 & 0.29 & 0.29 & 0.29 & 0.29 & \begin{tabular}{|l|}
0.29 \\
\end{tabular} & 0.29 & 0.29 & \begin{tabular}{|l|}
0.29 \\
\end{tabular} & 0.29 & 0.29 & 0.29 & 0.29 & \begin{tabular}{|l|}
0.29 \\
\end{tabular} & 0.29 \\
\hline & WinterDesign & 0 & 0 & 0 & 0 & 0 & 0 & 0 & 0 & 0 & 0 & 0 & 0 & 0 & 0 & 0 & 0 & 0 & 0 & 0 & 0 & 0 & 0 & 0 & 0 \\
\hline Rest_GAS_EQUIP_SCH & WD, Sat & 0.03 & 0.02 & 0.03 & 0.02 & 0.05 & 0.12 & 0.13 & 0.15 & 0.18 & 0.21 & 0.26 & 0.29 & 0.27 & 0.25 & 0.23 & 0.23 & 0.26 & \begin{tabular}{|l|}
0.26 \\
\end{tabular} & 0.24 & 0.22 & 0.2 & 0.18 & \begin{tabular}{|l|}
0.09 \\
\end{tabular} & 0.03 \\
\hline $\begin{array}{l}\text { Used for Gas Cooking } \\
\text { Equipment }\end{array}$ & Sun, Hol, Other & 0.03 & 0.02 & 0.03 & 0.02 & 0.05 & 0.12 & 0.13 & 0.15 & 0.18 & 0.21 & 0.26 & 0.29 & 0.27 & 0.25 & 0.23 & 0.23 & 0.26 & 0.26 & 0.24 & 0.22 & 0.2 & 0.18 & 0.09 & 0.03 \\
\hline & SummerDesign & 0.29 & 0.29 & 0.29 & 0.29 & 0.29 & 0.29 & 0.29 & 0.29 & \begin{tabular}{|l|}
0.29 \\
\end{tabular} & 0.29 & 0.29 & 0.29 & 0.29 & 0.29 & 0.29 & \begin{tabular}{|l|}
0.29 \\
\end{tabular} & 0.29 & \begin{tabular}{|l|}
0.29 \\
\end{tabular} & 0.29 & 0.29 & 0.29 & 0.29 & \begin{tabular}{|l|}
0.29 \\
\end{tabular} & 0.29 \\
\hline & WinterDesign & 0 & 0 & 0 & 0 & 0 & 0 & 0 & 0 & 0 & 0 & 0 & 0 & 0 & 0 & 0 & 0 & 0 & 0 & 0 & 0 & 0 & 0 & 0 & 0 \\
\hline BLDG_OCC_SCH & WD & 0.05 & 0 & 0 & 0 & 0 & 0.05 & 0.1 & 0.4 & 0.4 & 0.4 & 0.2 & 0.5 & 0.8 & 0.7 & 0.4 & 0.2 & 0.25 & 0.5 & 0.8 & 0.8 & 0.8 & 0.5 & \begin{tabular}{|l|}
0.35 \\
\end{tabular} & 0.2 \\
\hline & Sat & 0.05 & 0 & 0 & 0 & 0 & 0 & 0.05 & 0.5 & 0.5 & 0.4 & 0.2 & 0.45 & 0.5 & 0.5 & 0.35 & 0.3 & 0.3 & 0.3 & 0.7 & 0.9 & 0.7 & 0.65 & \begin{tabular}{|l|}
0.55 \\
\end{tabular} & 0.35 \\
\hline & Sun, Hol, Other & 0.05 & 0 & 0 & 0 & 0 & 0 & 0.05 & 0.5 & 0.5 & 0.2 & 0.2 & 0.3 & 0.5 & 0.5 & 0.3 & 0.2 & 0.25 & 0.35 & 0.55 & 0.65 & 0.7 & 0.35 & 0.2 & 0.2 \\
\hline & SummerDesign & 1 & 1 & 1 & 1 & 1 & 1 & 1 & 1 & 1 & 1 & 1 & 1 & 1 & 1 & 1 & 1 & 1 & 1 & 1 & 1 & 1 & 1 & 1 & 1 \\
\hline & WinterDesign & 0 & 0 & 0 & 0 & 0 & 0 & 0 & 0 & 0 & 0 & 0 & 0 & 0 & 0 & 0 & 0 & 0 & 0 & 0 & 0 & 0 & 0 & 0 & 0 \\
\hline BLDG_EXTERIOR_LIGHT & $\begin{array}{l}\text { WD, } \\
\text { SummerDesign }\end{array}$ & 1 & 1 & 1 & 1 & 1 & 1 & 1 & 1 & 1 & 1 & 1 & 1 & 1 & 1 & 1 & 1 & 1 & 1 & 1 & 1 & 1 & 1 & 1 & 1 \\
\hline (AstronomicalClock control) & Sat, WinterDesign & 1 & 1 & 1 & 1 & 1 & 1 & 1 & 1 & 1 & 1 & 1 & 1 & 1 & 1 & 1 & 1 & 1 & 1 & 1 & 1 & 1 & 1 & 1 & 1 \\
\hline BLDG_SWH_SCH & $\begin{array}{l}\text { WD, } \\
\text { SummerDesign }\end{array}$ & 0.2 & 0 & 0 & 0 & 0 & 0 & 0.15 & 0.6 & 0.55 & 0.45 & 0.4 & 0.45 & 0.4 & 0.35 & 0.3 & 0.3 & 0.3 & 0.4 & 0.55 & 0.6 & 0.5 & 0.55 & 0.45 & 0.25 \\
\hline & Sat, WinterDesign & 0.2 & 0 & 0 & 0 & 0 & 0 & 0.15 & 0.15 & 0.15 & 0.5 & 0.45 & 0.5 & 0.5 & 0.45 & 0.4 & 0.4 & 0.35 & 0.4 & 0.55 & 0.55 & 0.5 & 0.55 & 0.4 & 0.3 \\
\hline & Sun, Hol, Other & 0.25 & 0 & 0 & 0 & 0 & 0 & 0.15 & 0.15 & 0.15 & 0.15 & 0.5 & 0.5 & 0.4 & 0.4 & 0.3 & 0.3 & 0.3 & 0.4 & 0.5 & 0.5 & 0.4 & 0.5 & 0.4 & 0.2 \\
\hline INFIL_SCH_PNNL & $\begin{array}{l}\text { WD, } \\
\text { SummerDesign }\end{array}$ & 1 & 1 & 1 & 1 & 1 & 0.25 & 0.25 & 0.25 & 0.25 & 0.25 & 0.25 & 0.25 & 0.25 & 0.25 & 0.25 & 0.25 & 0.25 & 0.25 & 0.25 & 0.25 & 0.25 & 0.25 & 0.25 & 0.25 \\
\hline & Sat, WinterDesign & 1 & 1 & 1 & 1 & 1 & 0.25 & 0.25 & 0.25 & 0.25 & 0.25 & 0.25 & \begin{tabular}{|l|}
0.25 \\
\end{tabular} & \begin{tabular}{|l|}
0.25 \\
\end{tabular} & 0.25 & \begin{tabular}{|l|}
0.25 \\
\end{tabular} & \begin{tabular}{|l|}
0.25 \\
\end{tabular} & 0.25 & 0.25 & 0.25 & 0.25 & 0.25 & 0.25 & \begin{tabular}{|l|}
0.25 \\
\end{tabular} & 0.25 \\
\hline & Sun, Hol, Other & 1 & 1 & 1 & 1 & 1 & 0.25 & 0.25 & 0.25 & 0.25 & 0.25 & 0.25 & \begin{tabular}{|l|}
0.25 \\
\end{tabular} & 0.25 & \begin{tabular}{|l|}
0.25 \\
\end{tabular} & \begin{tabular}{|l|}
0.25 \\
\end{tabular} & \begin{tabular}{|l|}
0.25 \\
\end{tabular} & 0.25 & 0.25 & 0.25 & 0.25 & 0.25 & 0.25 & 0.25 & 0.25 \\
\hline HVACOperationSchd & $\begin{array}{l}\text { WD, } \\
\text { SummerDesign }\end{array}$ & 1 & 0 & 0 & 0 & 0 & 1 & 1 & 1 & 1 & 1 & 1 & 1 & 1 & 1 & 1 & 1 & 1 & 1 & 1 & 1 & 1 & 1 & 1 & 1 \\
\hline (FAN_SCH) & Sat, WinterDesign & 1 & 0 & 0 & 0 & 0 & 1 & 1 & 1 & 1 & 1 & 1 & 1 & 1 & 1 & 1 & 1 & 1 & 1 & 1 & 1 & 1 & 1 & 1 & 1 \\
\hline & Sun, Hol, Other & 1 & 0 & 0 & 0 & 0 & 1 & 1 & 1 & 1 & 1 & 1 & 1 & 1 & 1 & 1 & 1 & 1 & 1 & 1 & 1 & 1 & 1 & 1 & 1 \\
\hline HTGSETP_SCH & WD, & 16 & 16 & 16 & 16 & 16 & 18 & 21 & 21 & 21 & 21 & 21 & 21 & 21 & 21 & 21 & 21 & 21 & 21 & 21 & 21 & 21 & 21 & 21 & 21 \\
\hline (Dining) & SummerDesign & 16 & 16 & 16 & 16 & 16 & 16 & 16 & 16 & 16 & 16 & 16 & 16 & 16 & 16 & 16 & 16 & 16 & 16 & 16 & 16 & 16 & 16 & 16 & 16 \\
\hline & WinterDesign & 21 & 21 & 21 & 21 & 21 & 21 & 21 & 21 & 21 & 21 & 21 & 21 & 21 & 21 & 21 & 21 & 21 & 21 & 21 & 21 & 21 & 21 & 21 & 21 \\
\hline & Sat & 16 & 16 & 16 & 16 & 16 & 18 & 21 & 21 & 21 & 21 & 21 & 21 & 21 & 21 & 21 & 21 & 21 & 21 & 21 & 21 & 21 & 21 & 21 & 21 \\
\hline & Sun, Hol, Other & 16 & 16 & 16 & 16 & 16 & 18 & 21 & 21 & 21 & 21 & 21 & 21 & 21 & 21 & 21 & 21 & 21 & 21 & 21 & 21 & 21 & 21 & 21 & 21 \\
\hline HTGSETP_KITCHEN_SCH & WD, Winter Design & 19 & 16 & 16 & 16 & 16 & 17 & 19 & 19 & 19 & 19 & 19 & 19 & 19 & 19 & 19 & 19 & 19 & 19 & 19 & 19 & 19 & 19 & 19 & 19 \\
\hline (Kitchen) & SummerDesign & 16 & 16 & 16 & 16 & 16 & 16 & 16 & 16 & 16 & 16 & 16 & 16 & 16 & 16 & 16 & 16 & 16 & 16 & 16 & 16 & 16 & 16 & 16 & 16 \\
\hline & WinterDesign & 19 & 19 & 19 & 19 & 19 & 19 & 19 & 19 & 19 & 19 & 19 & 19 & 19 & 19 & 19 & 19 & 19 & 19 & 19 & 19 & 19 & 19 & 19 & 19 \\
\hline & Sat & 19 & 16 & 16 & 16 & 16 & 17 & 19 & 19 & 19 & 19 & 19 & 19 & 19 & 19 & 19 & 19 & 19 & 19 & 19 & 19 & 19 & 19 & 19 & 19 \\
\hline & Sun, Hol, Other & 19 & 16 & 16 & 16 & 16 & 17 & 19 & 19 & 19 & 19 & 19 & 19 & 19 & 19 & 19 & 19 & 19 & 19 & 19 & 19 & 19 & 19 & 19 & 19 \\
\hline CLGSETP_SCH & $\begin{array}{l}\text { WD, } \\
\text { SummerDesign }\end{array}$ & 30 & 30 & 30 & 30 & 30 & 26 & 24 & 24 & 24 & 24 & 24 & 24 & 24 & 24 & 24 & 24 & 24 & 24 & 24 & 24 & 24 & 24 & 24 & 24 \\
\hline (Dining) & Sat & 30 & 30 & 30 & 30 & 30 & 26 & 24 & 24 & 24 & 24 & 24 & 24 & 24 & 24 & 24 & 24 & 24 & 24 & 24 & 24 & 24 & 24 & 24 & 24 \\
\hline & WinterDesign & 30.00 & 30.00 & 30.00 & 30.00 & 30.00 & 30.00 & 30.00 & 30.00 & 30.00 & 30.00 & 30.00 & 30.00 & 30.00 & 30.00 & 30.00 & 30.00 & 30.00 & 30.00 & 30.00 & 30.00 & 30.00 & \begin{tabular}{|l|}
30.00 \\
\end{tabular} & 30.00 & 30.00 \\
\hline & Sun, Hol, Other & 30.00 & 30.00 & 30.00 & 30.00 & 30.00 & 26.11 & 23.89 & 23.89 & \begin{tabular}{|l|}
23.89 \\
\end{tabular} & 23.89 & 23.89 & 23.89 & 23.89 & 23.89 & \begin{tabular}{|l|}
23.89 \\
\end{tabular} & \begin{tabular}{|l|}
23.89 \\
\end{tabular} & 23.89 & \begin{tabular}{|l|}
23.89 \\
\end{tabular} & 23.89 & 23.89 & 23.89 & \begin{tabular}{|l|}
23.89 \\
\end{tabular} & \begin{tabular}{|l|}
23.89 \\
\end{tabular} & 23.89 \\
\hline CLGSETP_KITCHEN_SCH & WD, & 26.11 & 30.00 & 30.00 & 30.00 & 30.00 & 28.33 & 26.11 & 26.11 & 26.11 & 26.11 & 26.11 & 26.11 & 26.11 & 26.11 & 26.11 & 26.11 & 26.11 & 26.11 & 26.11 & 26.11 & 26.11 & 26.11 & 26.11 & 26.11 \\
\hline
\end{tabular}




\begin{tabular}{|c|c|c|c|c|c|c|c|c|c|c|c|c|c|c|c|c|c|c|c|c|c|c|c|c|c|}
\hline Schedule & Day of Week & 1 & 2 & 3 & 4 & 5 & 6 & 7 & 8 & 9 & 10 & 11 & 12 & 13 & 14 & 15 & 16 & 17 & 18 & 19 & 20 & 21 & 22 & 23 & 24 \\
\hline & SummerDesign & & & & & & & & & & & & & & & & & & & & & & & & \\
\hline \begin{tabular}{|l} 
(Kitchen) \\
\end{tabular} & Sat & 26.11 & 30.00 & 30.00 & 30.00 & 30.00 & 28.33 & 26.11 & 26.11 & \begin{tabular}{|l|}
26.11 \\
\end{tabular} & 26.11 & \begin{tabular}{|l|}
26.11 \\
\end{tabular} & 26.11 & \begin{tabular}{|l|}
26.11 \\
\end{tabular} & 26.11 & 26.11 & \begin{tabular}{|l|}
26.11 \\
\end{tabular} & \begin{tabular}{|l|}
26.11 \\
\end{tabular} & \begin{tabular}{|l|}
26.11 \\
\end{tabular} & 26.11 & \begin{tabular}{|l|}
26.11 \\
\end{tabular} & 26.11 & \begin{tabular}{|l|}
26.11 \\
\end{tabular} & 26.11 & 26.11 \\
\hline & WinterDesign & 30.00 & 30.00 & 30.00 & 30.00 & 30.00 & 30.00 & \begin{tabular}{|l|}
30.00 \\
\end{tabular} & 30.00 & \begin{tabular}{|l|}
30.00 \\
\end{tabular} & \begin{tabular}{|l|}
30.00 \\
\end{tabular} & 30.00 & 30.00 & 30.00 & 30.00 & 30.00 & 30.00 & 30.00 & \begin{tabular}{|l|}
30.00 \\
\end{tabular} & 30.00 & \begin{tabular}{|l|}
30.00 \\
\end{tabular} & 30.00 & \begin{tabular}{|l|}
30.00 \\
\end{tabular} & 30.00 & 30.00 \\
\hline & Sun, Hol, Other & 26.11 & 30.00 & 30.00 & 30.00 & 30.00 & 28.33 & \begin{tabular}{|l|}
26.11 \\
\end{tabular} & 26.11 & \begin{tabular}{|l|}
26.11 \\
\end{tabular} & \begin{tabular}{|l|}
26.11 \\
\end{tabular} & \begin{tabular}{|l|}
26.11 \\
\end{tabular} & 26.11 & \begin{tabular}{|l|}
26.11 \\
\end{tabular} & 26.11 & 26.11 & \begin{tabular}{|l|}
26.11 \\
\end{tabular} & \begin{tabular}{|l|}
26.11 \\
\end{tabular} & \begin{tabular}{|l|}
26.11 \\
\end{tabular} & 26.11 & \begin{tabular}{|l|}
26.11 \\
\end{tabular} & 26.11 & \begin{tabular}{|l|}
26.11 \\
\end{tabular} & 26.11 & \begin{tabular}{|l|l|}
26.11 \\
\end{tabular} \\
\hline HTGSETP_SCH & WD, & 60.00 & 60.00 & 60.00 & 60.00 & 60.00 & 65.00 & \begin{tabular}{|l|l|}
70.00 \\
\end{tabular} & 70.00 & \begin{tabular}{|l|l|}
70.00 \\
\end{tabular} & 70.00 & \begin{tabular}{|l|}
70.00 \\
\end{tabular} & 70.00 & \begin{tabular}{|l|}
70.00 \\
\end{tabular} & 70.00 & 70.00 & 70.00 & 70.00 & \begin{tabular}{|l|l|}
70.00 \\
\end{tabular} & 70.00 & \begin{tabular}{|l|l|}
70.00 \\
\end{tabular} & 70.00 & \begin{tabular}{|l|l|}
70.00 \\
\end{tabular} & 70.00 & 70.00 \\
\hline \begin{tabular}{|l|} 
(Dining) \\
\end{tabular} & SummerDesign & 60.00 & 60.00 & 60.00 & 60.00 & 60.00 & 60.00 & \begin{tabular}{|l|}
60.00 \\
\end{tabular} & 60.00 & \begin{tabular}{|l|}
60.00 \\
\end{tabular} & \begin{tabular}{|l|}
60.00 \\
\end{tabular} & \begin{tabular}{|l|}
60.00 \\
\end{tabular} & 60.00 & \begin{tabular}{|l|}
60.00 \\
\end{tabular} & 60.00 & 60.00 & \begin{tabular}{|l|l|}
60.00 \\
\end{tabular} & \begin{tabular}{|l|}
60.00 \\
\end{tabular} & \begin{tabular}{|l|}
60.00 \\
\end{tabular} & 60.00 & \begin{tabular}{|l|}
60.00 \\
\end{tabular} & 60.00 & \begin{tabular}{|l|}
60.00 \\
\end{tabular} & 60.00 & 60.00 \\
\hline & WinterDesign & 70.00 & 70.00 & 70.00 & 70.00 & 70.00 & 70.00 & \begin{tabular}{|l|l|}
70.00 \\
\end{tabular} & 70.00 & \begin{tabular}{|l|}
70.00 \\
\end{tabular} & 70.00 & \begin{tabular}{|l|}
70.00 \\
\end{tabular} & 70.00 & 70.00 & 70.00 & 70.00 & 70.00 & 70.00 & \begin{tabular}{|l|l|}
70.00 \\
\end{tabular} & 70.00 & \begin{tabular}{|l|l|}
70.00 \\
\end{tabular} & 70.00 & 70.00 & 70.00 & 70.00 \\
\hline & Sat & 60.00 & 60.00 & 60.00 & 60.00 & 60.00 & 65.00 & 70.00 & 70.00 & 70.00 & 70.00 & \begin{tabular}{|l|}
70.00 \\
\end{tabular} & 70.00 & \begin{tabular}{|l|}
70.00 \\
\end{tabular} & 70.00 & 70.00 & \begin{tabular}{|l|}
70.00 \\
\end{tabular} & 70.00 & \begin{tabular}{|l|}
70.00 \\
\end{tabular} & 70.00 & \begin{tabular}{|l|}
70.00 \\
\end{tabular} & 70.00 & \begin{tabular}{|l|}
70.00 \\
\end{tabular} & 70.00 & 70.00 \\
\hline & Sun, Hol, Other & 60.00 & 60.00 & 60.00 & 60.00 & 60.00 & 65.00 & \begin{tabular}{|l|}
70.00 \\
\end{tabular} & 70.00 & 70.00 & 70.00 & 70.00 & 70.00 & 70.00 & 70.00 & 70.00 & 70.00 & 70.00 & 70.00 & 70.00 & 70.00 & 70.00 & 70.00 & 70.00 & 70.00 \\
\hline HTGSETP_KITCHEN_SCH & WD, Winter Design & 66.00 & 60.00 & 60.00 & 60.00 & 60.00 & 63.00 & \begin{tabular}{|l|l|}
66.00 \\
\end{tabular} & 66.00 & \begin{tabular}{|l|l|}
66.00 \\
\end{tabular} & 66.00 & \begin{tabular}{|l|l|}
66.00 \\
\end{tabular} & 66.00 & 66.00 & 66.00 & 66.00 & 66.00 & 66.00 & \begin{tabular}{|l|l|}
66.00 \\
\end{tabular} & 66.00 & 66.00 & 66.00 & \begin{tabular}{|l|l|}
66.00 \\
\end{tabular} & 66.00 & 66.00 \\
\hline (Kitchen) & SummerDesign & 60 & 60 & 60 & 60 & 60 & 60 & 60 & 60 & 60 & 60 & 60 & 60 & 60 & 60 & 60 & 60 & 60 & 60 & 60 & 60 & 60 & 60 & 60 & 60 \\
\hline & WinterDesign & 66 & 66 & 66 & 66 & 66 & 66 & 66 & 66 & 66 & 66 & 66 & 66 & 66 & 66 & 66 & 66 & 66 & 66 & 66 & 66 & 66 & 66 & 66 & 66 \\
\hline & Sat & 66 & 60 & 60 & 60 & 60 & 63 & 66 & 66 & 66 & 66 & 66 & 66 & 66 & 66 & 66 & 66 & 66 & 66 & 66 & 66 & 66 & 66 & 66 & 66 \\
\hline & Sun, Hol, Other & 66 & 60 & 60 & 60 & 60 & 63 & 66 & 66 & 66 & 66 & 66 & 66 & 66 & 66 & 66 & 66 & 66 & 66 & 66 & 66 & 66 & 66 & 66 & 66 \\
\hline CLGSETP_SCH & $\begin{array}{l}\text { WD, } \\
\text { SummerDesign }\end{array}$ & 86 & 86 & 86 & 86 & 86 & 79 & 75 & 75 & 75 & 75 & 75 & 75 & 75 & 75 & 75 & 75 & 75 & 75 & 75 & 75 & 75 & 75 & 75 & 75 \\
\hline \begin{tabular}{|l} 
(Dining) \\
\end{tabular} & Sat & 86 & 86 & 86 & 86 & 86 & 79 & 75 & 75 & 75 & 75 & 75 & 75 & 75 & 75 & 75 & 75 & 75 & 75 & 75 & 75 & 75 & 75 & 75 & 75 \\
\hline & WinterDesign & 86 & 86 & 86 & 86 & 86 & 86 & 86 & 86 & 86 & 86 & 86 & 86 & 86 & 86 & 86 & 86 & 86 & 86 & 86 & 86 & 86 & 86 & 86 & 86 \\
\hline & Sun, Hol, Other & 86 & 86 & 86 & 86 & 86 & 79 & 75 & 75 & 75 & 75 & 75 & 75 & 75 & 75 & 75 & 75 & 75 & 75 & 75 & 75 & 75 & 75 & 75 & 75 \\
\hline CLGSETP_KITCHEN_SCH & $\begin{array}{l}\text { WD, } \\
\text { SummerDesign }\end{array}$ & 79 & 86 & 86 & 86 & 86 & 83 & 79 & 79 & 79 & 79 & 79 & 79 & 79 & 79 & 79 & 79 & 79 & 79 & 79 & 79 & 79 & 79 & 79 & 79 \\
\hline (Kitchen) & Sat & 79 & 86 & 86 & 86 & 86 & 83 & 79 & 79 & 79 & 79 & 79 & 79 & 79 & 79 & 79 & 79 & 79 & 79 & 79 & 79 & 79 & 79 & 79 & 79 \\
\hline & WinterDesign & 86 & 86 & 86 & 86 & 86 & 86 & 86 & 86 & 86 & 86 & 86 & 86 & 86 & 86 & 86 & 86 & 86 & 86 & 86 & 86 & 86 & 86 & 86 & 86 \\
\hline & Sun, Hol, Other & 79 & 86 & 86 & 86 & 86 & 83 & 79 & 79 & 79 & 79 & 79 & 79 & 79 & 79 & 79 & 79 & 79 & 79 & 79 & 79 & 79 & 79 & 79 & 79 \\
\hline $\begin{array}{l}\begin{array}{l}\text { MinOA_MotorizedDamper_ } \\
\text { Sched }\end{array} \\
\end{array}$ & $\begin{array}{l}\text { WD, } \\
\text { SummerDesign }\end{array}$ & 1 & 0 & 0 & 0 & 0 & 0 & 1 & 1 & 1 & 1 & 1 & 1 & 1 & 1 & 1 & 1 & 1 & 1 & 1 & 1 & 1 & 1 & 1 & 1 \\
\hline \begin{tabular}{|l|} 
(Dining) \\
\end{tabular} & Sat & 1 & 0 & 0 & 0 & 0 & 0 & 1 & 1 & 1 & 1 & 1 & 1 & 1 & 1 & 1 & 1 & 1 & 1 & 1 & 1 & 1 & 1 & 1 & 1 \\
\hline & WinterDesign & 1 & 1 & 1 & 1 & 1 & 1 & 1 & 1 & 1 & 1 & 1 & 1 & 1 & 1 & 1 & 1 & 1 & 1 & 1 & 1 & 1 & 1 & 1 & 1 \\
\hline & Sun, Hol, Other & 1 & 0 & 0 & 0 & 0 & 0 & 1 & 1 & 1 & 1 & 1 & 1 & 1 & 1 & 1 & 1 & 1 & 1 & 1 & 1 & 1 & 1 & 1 & 1 \\
\hline MinOA_SDKitch_Sched & $\begin{array}{l}\text { WD, } \\
\text { SummerDesign }\end{array}$ & 0 & 0 & 0 & 0 & 0 & 0 & 1 & 1 & 1 & 1 & 1 & 1 & 1 & 1 & 1 & 1 & 1 & 1 & 1 & 1 & 1 & 1 & 1 & 1 \\
\hline (Kitchen) & Sat & 0 & 0 & 0 & 0 & 0 & 0 & 1 & 1 & 1 & 1 & - & 1 & 1 & 1 & 1 & 1 & 1 & 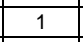 & 1 & 1 & 1 & 1 & 1 & 1 \\
\hline & WinterDesign & 1 & 1 & 1 & 1 & 1 & 1 & 1 & 1 & 1 & 1 & 1 & 1 & 1 & 1 & 1 & 1 & 1 & 1 & 1 & 1 & 1 & 1 & 1 & 1 \\
\hline & Sun, Hol, Other & 0 & 0 & 0 & 0 & 0 & 0 & 1 & 1 & 1 & 1 & 1 & 1 & 1 & 1 & 1 & 1 & 1 & 1 & 1 & 1 & 1 & 1 & 1 & 1 \\
\hline
\end{tabular}




\section{C.15 Mid-Rise Apartment Hourly Operation Schedules}

\begin{tabular}{|c|c|c|c|c|c|c|c|c|c|c|c|c|c|c|c|c|c|c|c|c|c|c|c|c|c|}
\hline Schedule & Day of Week & 1 & 2 & 3 & 4 & 5 & 6 & 7 & 8 & 9 & 10 & 11 & 12 & 13 & 14 & 15 & 16 & 17 & 18 & 19 & 20 & 21 & 22 & 23 & 24 \\
\hline OCC_APT_SCH & All & 1.00 & 1.00 & 1.00 & 1.00 & 1.00 & 1.00 & 1.00 & 0.85 & 0.39 & 0.25 & 0.25 & 0.25 & 0.25 & 0.25 & 0.25 & 0.25 & 0.30 & 0.52 & 0.87 & 0.87 & 0.87 & 1.00 & 1.00 & 1.00 \\
\hline LTG_APT_SCH & All & 0.067 & 0.067 & 0.067 & 0.067 & 0.187 & 0.394 & 0.440 & 0.393 & 0.172 & 0.119 & 0.119 & 0.119 & 0.119 & 0.119 & 0.119 & 0.206 & 0.439 & 0.616 & 0.829 & 0.986 & 1.000 & 0.692 & 0.384 & 0.160 \\
\hline EQP_APT_SCH & All & \begin{tabular}{|l|l|}
0.45 \\
\end{tabular} & \begin{tabular}{|l|}
0.41 \\
\end{tabular} & 0.39 & 0.38 & 0.38 & 0.43 & 0.54 & 0.65 & 0.66 & 0.67 & 0.69 & 0.70 & 0.69 & 0.66 & 0.65 & \begin{tabular}{|l|}
0.68 \\
\end{tabular} & \begin{tabular}{|l|}
0.80 \\
\end{tabular} & \begin{tabular}{|l|}
1.00 \\
\end{tabular} & 1.00 & 0.93 & \begin{tabular}{|l|}
0.89 \\
\end{tabular} & 0.85 & 0.71 & 0.58 \\
\hline INF_APT_SCH & All & 1.00 & 1.00 & 1.00 & 1.00 & 1.00 & 1.00 & 1.00 & 1.00 & 1.00 & 1.00 & 1.00 & 1.00 & 1.00 & 1.00 & 1.00 & 1.00 & 1.00 & 1.00 & 1.00 & 1.00 & 1.00 & 1.00 & 1.00 & 1.00 \\
\hline CLGSETP_APT_SCH & All & 75 & 75 & 75 & 75 & 75 & 75 & 75 & 75 & 75 & 75 & 75 & 75 & 75 & 75 & 75 & 75 & 75 & 75 & 75 & 75 & 75 & 75 & 75 & 75 \\
\hline HTGSETP_APT_SCH & All & 70 & 70 & 70 & 70 & 70 & 70 & 70 & 70 & 70 & 70 & 70 & 70 & 70 & 70 & 70 & 70 & 70 & 70 & 70 & 70 & 70 & 70 & 70 & 70 \\
\hline APT_DHW_SCH & All & 0.08 & 0.04 & 0.01 & 0.01 & 0.04 & 0.27 & 0.94 & 1.00 & 0.96 & 0.84 & 0.76 & 0.61 & 0.53 & 0.47 & \begin{tabular}{|l|l|}
0.41 \\
\end{tabular} & 0.47 & \begin{tabular}{|l|}
0.55 \\
\end{tabular} & \begin{tabular}{|l|}
0.73 \\
\end{tabular} & 0.86 & 0.82 & 0.75 & 0.61 & 0.53 & 0.29 \\
\hline Fan & All & 1 & 1 & 1 & 1 & 1 & 1 & 1 & 1 & 1 & 1 & 1 & 1 & 1 & 1 & 1 & 1 & 1 & 1 & 1 & 1 & 1 & 1 & 1 & 1 \\
\hline \multirow[t]{2}{*}{ OCC_OFF_SCH } & WD & 0.00 & 0.00 & 0.00 & 0.00 & 0.00 & 0.00 & 0.00 & \begin{tabular}{|l|}
0.00 \\
\end{tabular} & 1.00 & 1.00 & 1.00 & 1.00 & 0.50 & 1.00 & 1.00 & 1.00 & 1.00 & 0.00 & 0.00 & 0.00 & 0.00 & 0.00 & 0.00 & 0.00 \\
\hline & WEH & 0.00 & \begin{tabular}{|l|}
0.00 \\
\end{tabular} & 0.00 & 0.00 & 0.00 & 0.00 & 0.00 & \begin{tabular}{|l|}
0.00 \\
\end{tabular} & 0.00 & 0.00 & 0.00 & 0.00 & 0.00 & 0.00 & \begin{tabular}{|l|l|}
0.00 \\
\end{tabular} & 0.00 & \begin{tabular}{|l|}
0.00 \\
\end{tabular} & \begin{tabular}{|l|}
0.00 \\
\end{tabular} & 0.00 & 0.00 & 0.00 & 0.00 & 0.00 & 0.00 \\
\hline \multirow[t]{2}{*}{ LTG_OFF_SCH } & WD & \begin{tabular}{|l|}
0.18 \\
\end{tabular} & 0.18 & $\begin{array}{ll}0.18 \\
\end{array}$ & \begin{tabular}{|l|l|}
0.18 \\
\end{tabular} & 0.18 & \begin{tabular}{|l|}
0.18 \\
\end{tabular} & 0.18 & \begin{tabular}{|l|}
0.18 \\
\end{tabular} & 0.90 & 0.90 & 0.90 & 0.90 & 0.80 & 0.90 & \begin{tabular}{|l|}
0.90 \\
\end{tabular} & \begin{tabular}{|l|}
0.90 \\
\end{tabular} & \begin{tabular}{|l|}
0.90 \\
\end{tabular} & \begin{tabular}{|l|}
0.18 \\
\end{tabular} & \begin{tabular}{|l|}
0.18 \\
\end{tabular} & 0.18 & 0.18 & 0.18 & 0.18 & 0.18 \\
\hline & WEH & \begin{tabular}{|l|}
0.18 \\
\end{tabular} & 0.18 & 0.18 & 0.18 & 0.18 & 0.18 & 0.18 & \begin{tabular}{|l|}
0.18 \\
\end{tabular} & 0.18 & 0.18 & 0.18 & 0.18 & 0.18 & 0.18 & \begin{tabular}{|l|}
0.18 \\
\end{tabular} & \begin{tabular}{|l|}
0.18 \\
\end{tabular} & \begin{tabular}{|l|}
0.18 \\
\end{tabular} & \begin{tabular}{|l|}
0.18 \\
\end{tabular} & \begin{tabular}{|l|}
0.18 \\
\end{tabular} & 0.18 & 0.18 & 0.18 & 0.18 & 0.18 \\
\hline \multirow[t]{2}{*}{ EQP_OFF_SCH_BASE } & WD & 0.33 & \begin{tabular}{|l|}
0.33 \\
\end{tabular} & 0.33 & 0.33 & 0.33 & 0.33 & 0.33 & 0.50 & 1.00 & 1.00 & 1.00 & 1.00 & 0.94 & 1.00 & 1.00 & 1.00 & 1.00 & \begin{tabular}{|l|}
0.50 \\
\end{tabular} & 0.33 & 0.33 & 0.33 & 0.33 & 0.33 & 0.33 \\
\hline & WEH & \begin{tabular}{|l|}
0.33 \\
\end{tabular} & \begin{tabular}{|l|}
0.33 \\
\end{tabular} & 0.33 & 0.33 & 0.33 & 0.33 & 0.33 & \begin{tabular}{|l|}
0.33 \\
\end{tabular} & 0.33 & 0.33 & 0.33 & 0.33 & 0.33 & 0.33 & \begin{tabular}{|l|}
0.33 \\
\end{tabular} & 0.33 & \begin{tabular}{|l|}
0.33 \\
\end{tabular} & 0.33 & 0.33 & 0.33 & 0.33 & 0.33 & 0.33 & 0.33 \\
\hline INF_OFF_SCH & All & 1.00 & 1.00 & 1.00 & 1.00 & 1.00 & 1.00 & 1.00 & 1.00 & 1.00 & 1.00 & 1.00 & 1.00 & 1.00 & 1.00 & 1.00 & 1.00 & 1.00 & \begin{tabular}{|l|}
1.00 \\
\end{tabular} & 1.00 & 1.00 & 1.00 & 1.00 & 1.00 & 1.00 \\
\hline \multirow[t]{2}{*}{ HTGSETP_OFF_SCH } & WD & 60 & 60 & 60 & 60 & 60 & 60 & 60 & 65 & 70 & 70 & 70 & 70 & 70 & 70 & 70 & 70 & 70 & 65 & 60 & 60 & 60 & 60 & 60 & 60 \\
\hline & WEH & 60 & 60 & 60 & 60 & 60 & 60 & 60 & 60 & 60 & 60 & 60 & 60 & 60 & 60 & 60 & 60 & 60 & 60 & 60 & 60 & 60 & 60 & 60 & 60 \\
\hline \multirow[t]{2}{*}{ CLGSETP_OFF_SCH } & WD & 85 & 85 & 85 & 85 & 85 & 85 & 85 & 80 & 75 & 75 & 75 & 75 & 75 & 75 & 75 & 75 & 75 & 80 & 85 & 85 & 85 & 85 & 85 & 85 \\
\hline & WEH & 85 & 85 & 85 & 85 & 85 & 85 & 85 & 85 & 85 & 85 & 85 & 85 & 85 & 85 & 85 & 85 & 85 & 85 & 85 & 85 & 85 & 85 & 85 & 85 \\
\hline Elevator Motor & All & 0.05 & 0.05 & 0.05 & 0.05 & 0.1 & 0.2 & 0.4 & 0.5 & 0.5 & 0.35 & 0.15 & 0.15 & 0.15 & 0.15 & 0.15 & 0.15 & 0.35 & 0.5 & 0.5 & 0.4 & 0.4 & 0.3 & 0.2 & 0.1 \\
\hline ELEV_LIGHT_FAN_SCH_24_7 & All & 1 & 1 & 1 & 1 & 1 & 1 & 1 & 1 & 1 & 1 & 1 & 1 & 1 & 1 & 1 & 1 & 1 & 1 & 1 & 1 & 1 & 1 & 1 & 1 \\
\hline LTG_COR_SCH & All & 1 & 1 & 1 & 1 & 1 & 1 & 1 & 1 & 1 & 1 & 1 & 1 & 1 & 1 & 1 & 1 & 1 & 1 & 1 & 1 & 1 & 1 & 1 & 1 \\
\hline
\end{tabular}




\section{C.16 High-Rise Apartment Hourly Operation Schedules}

\begin{tabular}{|c|c|c|c|c|c|c|c|c|c|c|c|c|c|c|c|c|c|c|c|c|c|c|c|c|c|}
\hline Schedule & Day of Week & 1 & 2 & 3 & 4 & 5 & 6 & 7 & 8 & 9 & 10 & 11 & 12 & 13 & 14 & 15 & 16 & 17 & 18 & 19 & 20 & 21 & 22 & 23 & 24 \\
\hline OCC_APT_SCH & All & 1.00 & 1.00 & 1.00 & 1.00 & 1.00 & 1.00 & 1.00 & \begin{tabular}{|l|l|}
0.85 \\
\end{tabular} & \begin{tabular}{|l|}
0.39 \\
\end{tabular} & \begin{tabular}{|l|}
0.25 \\
\end{tabular} & 0.25 & 0.25 & 0.25 & 0.25 & 0.25 & 0.25 & 0.30 & 0.52 & \begin{tabular}{|l|l|}
0.87 \\
\end{tabular} & \begin{tabular}{|l|l|}
0.87 \\
\end{tabular} & \begin{tabular}{|l|l|}
0.87 \\
\end{tabular} & 1.00 & 1.00 & 1.00 \\
\hline LTG_APT_SCH & All & 0.067 & 0.067 & 0.067 & 0.067 & 0.187 & 0.394 & 0.440 & 0.393 & 0.172 & 0.119 & 0.119 & 0.119 & 0.119 & 0.119 & 0.119 & 0.206 & 0.439 & 0.616 & 0.829 & 0.986 & 1.000 & 0.692 & 0.384 & 0.160 \\
\hline EQP_APT_SCH & All & 0.45 & \begin{tabular}{|l|l|}
0.41 \\
\end{tabular} & 0.39 & 0.38 & \begin{tabular}{|l|}
0.38 \\
\end{tabular} & \begin{tabular}{|l|l|}
0.43 \\
\end{tabular} & \begin{tabular}{|l|}
0.54 \\
\end{tabular} & \begin{tabular}{|l|l|}
0.65 \\
\end{tabular} & \begin{tabular}{|l|}
0.66 \\
\end{tabular} & \begin{tabular}{|l|}
0.67 \\
\end{tabular} & \begin{tabular}{|l|}
0.69 \\
\end{tabular} & 0.70 & 0.69 & \begin{tabular}{|l|l|}
0.66 \\
\end{tabular} & 0.65 & 0.68 & 0.80 & 1.00 & 1.00 & \begin{tabular}{|l|}
0.93 \\
\end{tabular} & \begin{tabular}{|l|}
0.89 \\
\end{tabular} & \begin{tabular}{|l|}
0.85 \\
\end{tabular} & \begin{tabular}{|l|}
0.71 \\
\end{tabular} & \begin{tabular}{|l|}
0.58 \\
\end{tabular} \\
\hline INF_APT_SCH & All & 1.00 & 1.00 & 1.00 & 1.00 & 1.00 & 1.00 & 1.00 & 1.00 & 1.00 & 1.00 & 1.00 & 1.00 & 1.00 & 1.00 & 1.00 & 1.00 & 1.00 & 1.00 & 1.00 & 1.00 & 1.00 & 1.00 & 1.00 & 1.00 \\
\hline CLGSETP_APT_SCH & All & 75 & 75 & 75 & 75 & 75 & 75 & 75 & 75 & 75 & 75 & 75 & 75 & 75 & 75 & 75 & 75 & 75 & 75 & 75 & 75 & 75 & 75 & 75 & 75 \\
\hline HTGSETP_APT_SCH & All & 70 & 70 & 70 & 70 & 70 & 70 & 70 & 70 & 70 & 70 & 70 & 70 & 70 & 70 & 70 & 70 & 70 & 70 & 70 & 70 & 70 & 70 & 70 & 70 \\
\hline APT_DHW_SCH & All & 0.08 & 0.04 & 0.01 & 0.01 & \begin{tabular}{|l|l|}
0.04 \\
\end{tabular} & \begin{tabular}{|l|l|}
0.27 \\
\end{tabular} & 0.94 & 1.00 & \begin{tabular}{|l|l|}
0.96 \\
\end{tabular} & \begin{tabular}{|l|}
0.84 \\
\end{tabular} & 0.76 & 0.61 & 0.53 & 0.47 & 0.41 & 0.47 & 0.55 & 0.73 & 0.86 & \begin{tabular}{|l|}
0.82 \\
\end{tabular} & 0.75 & \begin{tabular}{|l|}
0.61 \\
\end{tabular} & \begin{tabular}{|l|}
0.53 \\
\end{tabular} & 0.29 \\
\hline Fan & All & 1 & 1 & 1 & 1 & 1 & 1 & 1 & 1 & 1 & 1 & 1 & 1 & 1 & 1 & 1 & 1 & 1 & 1 & 1 & 1 & 1 & 1 & 1 & 1 \\
\hline \multirow[t]{2}{*}{ OCC_OFF_SCH } & WD & 0.00 & 0.00 & 0.00 & 0.00 & \begin{tabular}{|l|}
0.00 \\
\end{tabular} & 0.00 & \begin{tabular}{|l|}
0.00 \\
\end{tabular} & \begin{tabular}{|l|}
0.00 \\
\end{tabular} & 1.00 & 1.00 & 1.00 & 1.00 & 0.50 & 1.00 & 1.00 & 1.00 & 1.00 & 0.00 & 0.00 & \begin{tabular}{|l|}
0.00 \\
\end{tabular} & 0.00 & 0.00 & 0.00 & 0.00 \\
\hline & WEH & 0.00 & 0.00 & 0.00 & 0.00 & \begin{tabular}{|l|l|}
0.00 \\
\end{tabular} & 0.00 & \begin{tabular}{|l|l|}
0.00 \\
\end{tabular} & \begin{tabular}{|l|}
0.00 \\
\end{tabular} & \begin{tabular}{|l|}
0.00 \\
\end{tabular} & \begin{tabular}{|l|}
0.00 \\
\end{tabular} & 0.00 & 0.00 & 0.00 & 0.00 & 0.00 & 0.00 & 0.00 & 0.00 & 0.00 & \begin{tabular}{|l|}
0.00 \\
\end{tabular} & 0.00 & \begin{tabular}{|l|}
0.00 \\
\end{tabular} & \begin{tabular}{|l|}
0.00 \\
\end{tabular} & 0.00 \\
\hline \multirow[t]{2}{*}{ LTG_OFF_SCH } & WD & 0.18 & \begin{tabular}{|l|l|}
0.18 \\
\end{tabular} & \begin{tabular}{|l|l|}
0.18 \\
\end{tabular} & 0.18 & \begin{tabular}{|l|}
0.18 \\
\end{tabular} & \begin{tabular}{|l|l|}
0.18 \\
\end{tabular} & \begin{tabular}{|l|}
0.18 \\
\end{tabular} & \begin{tabular}{|l|}
0.18 \\
\end{tabular} & \begin{tabular}{|l|}
0.90 \\
\end{tabular} & \begin{tabular}{|l|}
0.90 \\
\end{tabular} & \begin{tabular}{|l|}
0.90 \\
\end{tabular} & 0.90 & 0.80 & 0.90 & 0.90 & 0.90 & 0.90 & \begin{tabular}{|l|}
0.18 \\
\end{tabular} & 0.18 & \begin{tabular}{|l|}
0.18 \\
\end{tabular} & \begin{tabular}{|l|}
0.18 \\
\end{tabular} & \begin{tabular}{|l|}
0.18 \\
\end{tabular} & \begin{tabular}{|l|}
0.18 \\
\end{tabular} & \begin{tabular}{|l|}
0.18 \\
\end{tabular} \\
\hline & WEH & 0.18 & 0.18 & 0.18 & 0.18 & \begin{tabular}{|l|}
0.18 \\
\end{tabular} & \begin{tabular}{|l|l|}
0.18 \\
\end{tabular} & \begin{tabular}{|l|}
0.18 \\
\end{tabular} & \begin{tabular}{|l|}
0.18 \\
\end{tabular} & \begin{tabular}{|l|}
0.18 \\
\end{tabular} & \begin{tabular}{|l|}
0.18 \\
\end{tabular} & \begin{tabular}{|l|}
0.18 \\
\end{tabular} & 0.18 & 0.18 & 0.18 & 0.18 & 0.18 & 0.18 & 0.18 & 0.18 & \begin{tabular}{|l|l|}
0.18 \\
\end{tabular} & \begin{tabular}{|l|l|}
0.18 \\
\end{tabular} & \begin{tabular}{|l|}
0.18 \\
\end{tabular} & \begin{tabular}{|l|}
0.18 \\
\end{tabular} & \begin{tabular}{|l|}
0.18 \\
\end{tabular} \\
\hline \multirow[t]{2}{*}{ EQP_OFF_SCH_BASE } & WD & 0.33 & 0.33 & 0.33 & 0.33 & \begin{tabular}{|l|}
0.33 \\
\end{tabular} & \begin{tabular}{|l|}
0.33 \\
\end{tabular} & \begin{tabular}{|l|}
0.33 \\
\end{tabular} & 0.50 & 1.00 & 1.00 & 1.00 & 1.00 & 0.94 & 1.00 & 1.00 & 1.00 & 1.00 & 0.50 & 0.33 & \begin{tabular}{|l|}
0.33 \\
\end{tabular} & 0.33 & \begin{tabular}{|l|}
0.33 \\
\end{tabular} & \begin{tabular}{|l|}
0.33 \\
\end{tabular} & 0.33 \\
\hline & WEH & 0.33 & 0.33 & 0.33 & 0.33 & \begin{tabular}{|l|}
0.33 \\
\end{tabular} & \begin{tabular}{|l|}
0.33 \\
\end{tabular} & \begin{tabular}{|l|}
0.33 \\
\end{tabular} & \begin{tabular}{|l|}
0.33 \\
\end{tabular} & \begin{tabular}{|l|}
0.33 \\
\end{tabular} & \begin{tabular}{|l|}
0.33 \\
\end{tabular} & 0.33 & 0.33 & 0.33 & 0.33 & 0.33 & 0.33 & \begin{tabular}{|l|}
0.33 \\
\end{tabular} & \begin{tabular}{|l|}
0.33 \\
\end{tabular} & \begin{tabular}{|l|}
0.33 \\
\end{tabular} & \begin{tabular}{|l|}
0.33 \\
\end{tabular} & \begin{tabular}{|l|}
0.33 \\
\end{tabular} & \begin{tabular}{|l|}
0.33 \\
\end{tabular} & \begin{tabular}{|l|}
0.33 \\
\end{tabular} & \begin{tabular}{|l|}
0.33 \\
\end{tabular} \\
\hline INF_OFF_SCH & All & 1.00 & 1.00 & 1.00 & 1.00 & \begin{tabular}{|l|}
1.00 \\
\end{tabular} & 1.00 & 1.00 & \begin{tabular}{|l|}
1.00 \\
\end{tabular} & \begin{tabular}{|l|}
1.00 \\
\end{tabular} & \begin{tabular}{|l|}
1.00 \\
\end{tabular} & 1.00 & \begin{tabular}{|l|}
1.00 \\
\end{tabular} & 1.00 & 1.00 & 1.00 & 1.00 & 1.00 & 1.00 & 1.00 & 1.00 & 1.00 & \begin{tabular}{|l|}
1.00 \\
\end{tabular} & \begin{tabular}{|l|}
1.00 \\
\end{tabular} & 1.00 \\
\hline \multirow{2}{*}{ HTGSETP_OFF_SCH } & WD & 60 & 60 & 60 & 60 & 60 & 60 & 60 & 65 & 70 & 70 & 70 & 70 & 70 & 70 & 70 & 70 & 70 & 65 & 60 & 60 & 60 & 60 & 60 & 60 \\
\hline & WEH & 60 & 60 & 60 & 60 & 60 & 60 & 60 & 60 & 60 & 60 & 60 & 60 & 60 & 60 & 60 & 60 & 60 & 60 & 60 & 60 & 60 & 60 & 60 & 60 \\
\hline \multirow[t]{2}{*}{ CLGSETP_OFF_SCH } & WD & 85 & 85 & 85 & 85 & 85 & 85 & 85 & 80 & 75 & 75 & 75 & 75 & 75 & 75 & 75 & 75 & 75 & 80 & 85 & 85 & 85 & 85 & 85 & 85 \\
\hline & WEH & 85 & 85 & 85 & 85 & 85 & 85 & 85 & 85 & 85 & 85 & 85 & 85 & 85 & 85 & 85 & 85 & 85 & 85 & 85 & 85 & 85 & 85 & 85 & 85 \\
\hline Elevator Motor & All & 0.05 & 0.05 & 0.05 & 0.05 & 0.1 & 0.2 & 0.4 & 0.5 & 0.5 & 0.35 & 0.15 & 0.15 & 0.15 & 0.15 & 0.15 & 0.15 & 0.35 & 0.5 & 0.5 & 0.4 & 0.4 & 0.3 & 0.2 & 0.1 \\
\hline ELEV_LIGHT_FAN_SCH_24_7 & All & 1 & 1 & 1 & 1 & 1 & 1 & 1 & 1 & 1 & 1 & 1 & 1 & 1 & 1 & 1 & 1 & 1 & 1 & 1 & 1 & 1 & 1 & 1 & 1 \\
\hline LTG_COR_SCH & All & 1 & 1 & 1 & 1 & 1 & 1 & 1 & 1 & 1 & 1 & 1 & 1 & 1 & 1 & 1 & 1 & 1 & 1 & 1 & 1 & 1 & 1 & 1 & 1 \\
\hline
\end{tabular}


Appendix D

\section{Prototype Building HVAC System List}




\section{D.1 Small Office HVAC System List}

\begin{tabular}{ll}
\hline \multicolumn{1}{c}{ Zone } & \multicolumn{1}{c}{ HVAC System Name } \\
\hline CORE_ZN & PSZ-AC:1 \\
PERIMETER_ZN_1 & PSZ-AC:2 \\
PERIMETER_ZN_2 & PSZ-AC:3 \\
PERIMETER_ZN_3 & PSZ-AC:4 \\
PERIMETER_ZN_4 & PSZ-AC:5 \\
ATTIC & NA \\
\hline
\end{tabular}

\section{D.2 Medium Office HVAC System List}

\begin{tabular}{ll}
\hline \multicolumn{1}{c}{ Zone } & \multicolumn{1}{c}{ HVAC System Name } \\
\hline CORE_BOTTOM & PACU_VAV_bot \\
TOPFLOOR_PLENUM & NA \\
MIDFLOOR_PLENUM & NA \\
FIRSTFLOOR_PLENUM & NA \\
CORE_MID & PACU_VAV_mid \\
CORE_TOP & PACU_VAV_top \\
PERIMETER_TOP_ZN_3 & PACU_VAV_top \\
PERIMETER_TOP_ZN_2 & PACU_VAV_top \\
PERIMETER_TOP_ZN_1 & PACU_VAV_top \\
PERIMETER_TOP_ZN_4 & PACU_VAV_top \\
PERIMETER_BOT_ZN_3 & PACU_VAV_bot \\
PERIMETER_BOT_ZN_2 & PACU_VAV_bot \\
PERIMETER_BOT_ZN_1 & PACU_VAV_bot \\
PERIMETER_BOT_ZN_4 & PACU_VAV_bot \\
PERIMETER_MID_ZN_3 & PACU_VAV_mid \\
PERIMETER_MID_ZN_2 & PACU_VAV_mid \\
PERIMETER_MID_ZN_1 & PACU_VAV_mid \\
PERIMETER_MID_ZN_4 & PACU_VAV_mid \\
\hline
\end{tabular}




\section{D.3 Large Office HVAC System List}

\begin{tabular}{ll}
\hline \multicolumn{1}{c}{ Zone } & \multicolumn{1}{c}{ HVAC System Name } \\
\hline BASEMENT & CAV_bas \\
CORE_BOTTOM & VAV_bot WITH REHEAT \\
CORE_MID & VAV_mid WITH REHEAT \\
CORE_TOP & VAV_top WITH REHEAT \\
PERIMETER_BOT_ZN_3 & VAV_bot WITH REHEAT \\
PERIMETER_BOT_ZN_2 & VAV_bot WITH REHEAT \\
PERIMETER_BOT_ZN_1 & VAV_bot WITH REHEAT \\
PERIMETER_BOT_ZN_4 & VAV_bot WITH REHEAT \\
PERIMETER_MID_ZN_3 & VAV_mid WITH REHEAT \\
PERIMETER_MID_ZN_2 & VAV_mid WITH REHEAT \\
PERIMETER_MID_ZN_1 & VAV_mid WITH REHEAT \\
PERIMETER_MID_ZN_4 & VAV_mid WITH REHEAT \\
PERIMETER_TOP_ZN_3 & VAV_top WITH REHEAT \\
PERIMETER_TOP_ZN_2 & VAV_top WITH REHEAT \\
PERIMETER_TOP_ZN_1 & VAV_top WITH REHEAT \\
PERIMETER_TOP_ZN_4 & VAV_top WITH REHEAT \\
GROUNDFLOOR_PLENUM & NA \\
MIDFLOOR_PLENUM & NA \\
TOPFLOOR_PLENUM & NA \\
\hline
\end{tabular}

\section{D.4 Stand-alone Retail HVAC System List}

\begin{tabular}{ll}
\hline \multicolumn{1}{c}{ Zone } & \multicolumn{1}{c}{ HVAC System Name } \\
\hline BACK_SPACE & PSZ-AC:1 \\
CORE_RETAIL & PSZ-AC:2 \\
POINT_OF_SALE & PSZ-AC:3 \\
FRONT_RETAIL & PSZ-AC:4 \\
FRONT_ENTRY & Front_Entry Unit Heater \\
\hline
\end{tabular}

\section{D.5 Strip Mall HVAC System List}

\begin{tabular}{cl}
\hline Zone & \multicolumn{1}{c}{ HVAC System Name } \\
\hline LGSTORE1 & PSZ-AC_1:1 \\
SMSTORE1 & PSZ-AC_2:2 \\
SMSTORE2 & PSZ-AC_3:3 \\
SMSTORE3 & PSZ-AC_4:4 \\
SMSTORE4 & PSZ-AC_5:5 \\
LGSTORE2 & PSZ-AC_6:6 \\
SMSTORE5 & PSZ-AC_7:7 \\
SMSTORE6 & PSZ-AC_8:8 \\
SMSTORE7 & PSZ-AC_9:9 \\
SMSTORE8 & PSZ-AC_10:10 \\
\hline
\end{tabular}




\section{D.6 Primary School HVAC System List}

\begin{tabular}{ll}
\hline \multicolumn{1}{c}{ Zone } & HVAC System Name \\
\hline CORNER_CLASS_1_POD_1_ZN_1_FLR_1 & VAV_POD_1 \\
MULT_CLASS_1_POD_1_ZN_1_FLR_1 & VAV_POD_1 \\
CORRIDOR_POD_1_ZN_1_FLR_1 & VAV_POD_1 \\
CORNER_CLASS_2_POD_1_ZN_1_FLR_1 & VAV_POD_1 \\
MULT_CLASS_2_POD_1_ZN_1_FLR_1 & VAV_POD_1 \\
CORNER_CLASS_1_POD_2_ZN_1_FLR_1 & VAV_POD_2 \\
MULT_CLASS_1_POD_2_ZN_1_FLR_1 & VAV_POD_2 \\
CORRIDOR_POD_2_ZN_1_FLR_1 & VAV_POD_2 \\
CORNER_CLASS_2_POD_2_ZN_1_FLR_1 & VAV_POD_2 \\
MULT_CLASS_2_POD_2_ZN_1_FLR_1 & VAV_POD_2 \\
CORNER_CLASS_1_POD_3_ZN_1_FLR_1 & VAV_POD_3 \\
MULT_CLASS_1_POD_3_ZN_1_FLR_1 & VAV_POD_3 \\
CORRIDOR_POD_3_ZN_1_FLR_1 & VAV_POD_3 \\
CORNER_CLASS_2_POD_3_ZN_1_FLR_1 & VAV_POD_3 \\
MULT_CLASS_2_POD_3_ZN_1_FLR_1 & VAV_POD_3 \\
COMPUTER_CLASS_ZN_1_FLR_1 & VAV_OTHER \\
MAIN_CORRIDOR_ZN_1_FLR_1 & VAV_OTHER \\
LOBBY_ZN_1_FLR_1 & VAV_OTHER \\
MECH_ZN_1_FLR_1 & VAV_OTHER \\
BATH_ZN_1_FLR_1 & VAV_OTHER; Bath_ZN_1_FLR_1 Exhaust Fan \\
OFFICES_ZN_1_FLR_1 & VAV_OTHER \\
GYM_ZN_1_FLR_1 & PSZ-AC_2:5 \\
KITCHEN_ZN_1_FLR_1 & PSZ-AC_1:6; Kitchen_ZN_1_FLR_1 Exhaust Fan \\
CAFETERIA_ZN_1_FLR_1 & PSZ-AC_2:7 \\
LIBRARY_MEDIA_CENTER_ZN_1_FLR_1 & VAV_OTHER \\
\hline & \\
&
\end{tabular}




\section{D.7 Secondary School HVAC System List}

\begin{tabular}{|c|c|}
\hline Zone & HVAC System Name \\
\hline CORNER_CLASS_1_POD_1_ZN_1_FLR_1 & VAV_POD_1 \\
\hline CORNER_CLASS_1_POD_1_ZN_1_FLR_2 & VAV_POD_1 \\
\hline MULT_CLASS_1_POD_1_ZN_1_FLR_1 & VAV_POD_1 \\
\hline MULT_CLASS_1_POD_1_ZN_1_FLR_2 & VAV_POD_1 \\
\hline CORRIDOR_POD_1_ZN_1_FLR_1 & VAV_POD_1 \\
\hline CORRIDOR_POD_1_ZN_1_FLR_2 & VAV_POD_1 \\
\hline CORNER_CLASS_2_POD_1_ZN_1_FLR_1 & VAV_POD_1 \\
\hline CORNER_CLASS_2_POD_1_ZN_1_FLR_2 & VAV_POD_1 \\
\hline MULT_CLASS_2_POD_1_ZN_1_FLR_1 & VAV_POD_1 \\
\hline MULT_CLASS_2_POD_1_ZN_1_FLR_2 & VAV_POD_1 \\
\hline CORNER_CLASS_1_POD_2_ZN_1_FLR_1 & VAV_POD_2 \\
\hline CORNER_CLASS_1_POD_2_ZN_1_FLR_2 & VAV_POD_2 \\
\hline MULT_CLASS_1_POD_2_ZN_1_FLR_1 & VAV_POD_2 \\
\hline MULT_CLASS_1_POD_2_ZN_1_FLR_2 & VAV_POD_2 \\
\hline CORRIDOR_POD_2_ZN_1_FLR_1 & VAV_POD_2 \\
\hline CORRIDOR_POD_2_ZN_1_FLR_2 & VAV_POD_2 \\
\hline CORNER_CLASS_2_POD_2_ZN_1_FLR_1 & VAV_POD_2 \\
\hline CORNER_CLASS_2_POD_2_ZN_1_FLR_2 & VAV_POD_2 \\
\hline MULT_CLASS_2_POD_2_ZN_1_FLR_1 & VAV_POD_2 \\
\hline MULT_CLASS_2_POD_2_ZN_1_FLR_2 & VAV_POD_2 \\
\hline CORNER_CLASS_1_POD_3_ZN_1_FLR_1 & VAV_POD_3 \\
\hline CORNER_CLASS_1_POD_3_ZN_1_FLR_2 & VAV_POD_3 \\
\hline MULT_CLASS_1_POD_3_ZN_1_FLR_1 & VAV_POD_3 \\
\hline MULT_CLASS_1_POD_3_ZN_1_FLR_2 & VAV_POD_3 \\
\hline CORRIDOR_POD_3_ZN_1_FLR_1 & VAV_POD_3 \\
\hline CORRIDOR_POD_3_ZN_1_FLR_2 & VAV_POD_3 \\
\hline CORNER_CLASS_2_POD_3_ZN_1_FLR_1 & VAV_POD_3 \\
\hline CORNER_CLASS_2_POD_3_ZN_1_FLR_2 & VAV_POD_3 \\
\hline MULT_CLASS_2_POD_3_ZN_1_FLR_1 & VAV_POD_3 \\
\hline MULT_CLASS_2_POD_3_ZN_1_FLR_2 & VAV_POD_3 \\
\hline MAIN_CORRIDOR_ZN_1_FLR_1 & VAV_OTHER \\
\hline MAIN_CORRIDOR_ZN_1_FLR_2 & VAV_OTHER \\
\hline LOBBY_ZN_1_FLR_1 & VAV_OTHER \\
\hline LOBBY_ZN_1_FLR_2 & VAV_OTHER \\
\hline BATHROOMS_ZN_1_FLR_1 & VAV_OTHER; Bathrooms_ZN_1_FLR_1 Exhaust Fan \\
\hline BATHROOMS_ZN_1_FLR_2 & VAV_OTHER; Bathrooms_ZN_1_FLR_2 Exhaust Fan \\
\hline OFFICES_ZN_1_FLR_1 & VAV_OTHER \\
\hline OFFICES_ZN_1_FLR_2 & VAV_OTHER \\
\hline GYM_ZN_1_FLR_1 & PSZ-AC_1:5 \\
\hline AUX_GYM_ZN_1_FLR_1 & PSZ-AC_2:6 \\
\hline AUDITORIUM_ZN_1_FLR_1 & PSZ-AC_3:7 \\
\hline KITCHEN_ZN_1_FLR_1 & PSZ-AC_4:8 \\
\hline LIBRARY_MEDIA_CENTER_ZN_1_FLR_2 & VAV_OTHER \\
\hline CAFETERIA_ZN_1_FLR_1 & PSZ-AC_5:9 \\
\hline MECH_ZN_1_FLR_1 & VAV_OTHER \\
\hline MECH_ZN_1_FLR_2 & VAV_OTHER \\
\hline
\end{tabular}




\section{D.8 Outpatient Healthcare HVAC System List}

\begin{tabular}{|c|c|}
\hline Zone & HVAC System Name \\
\hline Floor 1 Anesthesia & AHU-1; Floor 1 Anesthesia Exhaust Fan \\
\hline Floor 1 Bio Haz & AHU-1 \\
\hline Floor 1 Café & AHU-1 \\
\hline Floor 1 Clean & AHU-1 \\
\hline Floor 1 Clean Work & AHU-1 \\
\hline Floor 1 Dictation & AHU-1 \\
\hline Floor 1 Dressing Room & AHU-1 \\
\hline Floor 1 Electrical Room & AHU-1 \\
\hline Floor 1 Elevator Pump Room & AHU-1 \\
\hline Floor 1 Humid & AHU-1 \\
\hline Floor 1 IT Hall & AHU-1 \\
\hline Floor 1 IT Room & AHU-1 \\
\hline Floor 1 Lobby & AHU-1 \\
\hline Floor 1 Lobby Hall & AHU-1 \\
\hline Floor 1 Lobby Toilet & AHU-1; Floor 1 Lobby Toilet Exhaust Fan \\
\hline Floor 1 Locker Room & AHU-1 \\
\hline Floor 1 Locker Room Hall & AHU-1 \\
\hline Floor 1 Lounge & AHU-1 \\
\hline Floor 1 Med Gas & AHU-1 \\
\hline Floor 1 MRI Control Room & AHU-1; Floor 1 MRI Control Room Exhaust Fan \\
\hline Floor 1 MRI Hall & AHU-1 \\
\hline Floor 1 MRI Room & AHU-1; Floor 1 MRI Room Exhaust Fan \\
\hline Floor 1 MRI Toilet & AHU-1; Floor 1 MRI Toilet Exhaust Fan \\
\hline Floor 1 Nourishment & AHU-1 \\
\hline Floor 1 Nurse Hall & AHU-1 \\
\hline Floor 1 Nurse Janitor & AHU-1 \\
\hline Floor 1 Nurse Station & AHU-1 \\
\hline Floor 1 Nurse Toilet & AHU-1; Floor 1 Nurse Toilet Exhaust Fan \\
\hline Floor 1 Office & AHU-1 \\
\hline Floor 1 Operating Room 1 & AHU-1 \\
\hline Floor 1 Operating Room 2 & AHU-1 \\
\hline Floor 1 Operating Room 3 & AHU-1 \\
\hline Floor $1 \mathrm{PACU}$ & AHU-1 \\
\hline Floor 1 Pre-Op Hall & AHU-1 \\
\hline Floor 1 Pre-Op Room 1 & AHU-1 \\
\hline Floor 1 Pre-Op Room 2 & AHU-1 \\
\hline Floor 1 Pre-Op Toilet & AHU-1; Floor 1 Pre-Op Toilet Exhaust Fan \\
\hline Floor 1 Procedure Room & AHU-1 \\
\hline Floor 1 Reception & AHU-1 \\
\hline Floor 1 Reception Hall & AHU-1 \\
\hline Floor 1 Recovery Room & AHU-1 \\
\hline Floor 1 Scheduling & AHU-1 \\
\hline Floor 1 Scrub & AHU-1 \\
\hline Floor 1 Soil & AHU-1; Floor 1 Soil Exhaust Fan \\
\hline Floor 1 Soil Hold & AHU-1; Floor 1 Soil Hold Exhaust Fan \\
\hline Floor 1 Soil Work & AHU-1; Floor 1 Soil Work Exhaust Fan \\
\hline Floor 1 Step Down & AHU-1 \\
\hline Floor 1 Sterile Hall & AHU-1 \\
\hline Floor 1 Sterile Storage & AHU-1 \\
\hline
\end{tabular}




\begin{tabular}{|c|c|}
\hline Zone & HVAC System Name \\
\hline Floor 1 Storage & AHU-1 \\
\hline Floor 1 Sub-Sterile & AHU-1 \\
\hline Floor 1 Utility Hall & AHU-1 \\
\hline Floor 1 Utility Janitor & AHU-1 \\
\hline Floor 1 Utility Room & AHU-1 \\
\hline Floor 1 Vestibule & AHU-1 \\
\hline Floor 2 Conference & AHU-2 \\
\hline Floor 2 Conference Toilet & AHU-2; Floor 2 Conference Toilet Exhaust Fan \\
\hline Floor 2 Dictation & AHU-2 \\
\hline Floor 2 Exam 1 & AHU-2 \\
\hline Floor 2 Exam 2 & AHU-2 \\
\hline Floor 2 Exam 3 & AHU-2 \\
\hline Floor 2 Exam 4 & AHU-2 \\
\hline Floor 2 Exam 5 & AHU-2 \\
\hline Floor 2 Exam 6 & AHU-2 \\
\hline Floor 2 Exam 7 & AHU-2 \\
\hline Floor 2 Exam 8 & AHU-2 \\
\hline Floor 2 Exam 9 & AHU-2 \\
\hline Floor 2 Exam Hall 1 & AHU-2 \\
\hline Floor 2 Exam Hall 2 & AHU-2 \\
\hline Floor 2 Exam Hall 3 & AHU-2 \\
\hline Floor 2 Exam Hall 4 & AHU-2 \\
\hline Floor 2 Exam Hall 5 & AHU-2 \\
\hline Floor 2 Exam Hall 6 & AHU-2 \\
\hline Floor 2 Janitor & AHU-2 \\
\hline Floor 2 Lounge & AHU-2 \\
\hline Floor 2 Nurse Station 1 & AHU-2 \\
\hline Floor 2 Nurse Station 2 & AHU-2 \\
\hline Floor 2 Office & AHU-2 \\
\hline Floor 2 Office Hall & AHU-2 \\
\hline Floor 2 Reception & AHU-2 \\
\hline Floor 2 Reception Hall & AHU-2 \\
\hline Floor 2 Reception Toilet & AHU-2; Floor 2 Reception Toilet Exhaust Fan \\
\hline Floor 2 Scheduling 1 & AHU-2 \\
\hline Floor 2 Scheduling 2 & AHU-2 \\
\hline Floor 2 Storage 1 & AHU-2 \\
\hline Floor 2 Storage 2 & AHU-2 \\
\hline Floor 2 Storage 3 & AHU-2 \\
\hline Floor 2 Utility & AHU-2 \\
\hline Floor 2 Work & AHU-2 \\
\hline Floor 2 Work Hall & AHU-2 \\
\hline Floor 2 Work Toilet & AHU-2; Floor 2 Work Toilet Exhaust Fan \\
\hline Floor 2 X-Ray & AHU-2; Floor 2 X-Ray Exhaust Fan \\
\hline Floor 3 Dressing Room & AHU-2 \\
\hline Floor 3 Elevator Hall & AHU-2 \\
\hline Floor 3 Humid & AHU-2 \\
\hline Floor 3 Janitor & AHU-2 \\
\hline Floor 3 Locker & AHU-2 \\
\hline Floor 3 Lounge & AHU-2 \\
\hline Floor 3 Lounge Toilet & AHU-2; Floor 3 Lounge Toilet Exhaust Fan \\
\hline Floor 3 Mechanical & AHU-2 \\
\hline Floor 3 Mechanical Hall & AHU-2 \\
\hline
\end{tabular}




\begin{tabular}{ll}
\hline \multicolumn{1}{c}{ Zone } & \multicolumn{1}{c}{ HVAC System Name } \\
\hline Floor 3 Office & AHU-2 \\
Floor 3 Office Hall & AHU-2 \\
Floor 3 Office Toilet & AHU-2; Floor 3 Office Toilet Exhaust Fan \\
Floor 3 Physical Therapy 1 & AHU-2 \\
Floor 3 Physical Therapy 2 & AHU-2 \\
Floor 3 Physical Therapy Toilet & AHU-2; Floor 3 Physical Therapy Toilet Exhaust Fan \\
Floor 3 Storage 1 & AHU-2 \\
Floor 3 Storage 2 & AHU-2 \\
Floor 3 Treatment & AHU-2 \\
Floor 3 Undeveloped 1 & AHU-2 \\
Floor 3 Undeveloped 2 & AHU-2 \\
Floor 3 Utility & AHU-2 \\
Floor 3 Work & AHU-2 \\
NE Stair & AHU-2 \\
NW Elevator & AHU-2 \\
NW Stair & AHU-2 \\
SW Stair & AHU-2 \\
\hline
\end{tabular}




\section{D.9 Hospital HVAC System List}

\begin{tabular}{ll}
\hline \multicolumn{1}{c}{ ZOne } & \multicolumn{1}{c}{ HVAC System Name } \\
\hline BASEMENT & VAV_1 \\
ER_EXAM1_MULT4_FLR_1 & VAV_ER \\
ER_TRAUMA1_FLR_1 & VAV_ER \\
ER_EXAM3_MULT4_FLR_1 & VAV_ER \\
ER_TRAUMA2_FLR_1 & VAV_ER \\
ER_TRIAGE_MULT_FLR_1 & VAV_ER \\
OFFICE1_MULT4_FLR_1 & VAV_1 \\
LOBBY_RECORDS_FLR_1 & VAV_1 \\
CORRIDOR_FLR_1 & VAV_1 \\
ER_NURSESTN_LOBBY_FLR_1 & VAV_1 \\
OR1_FLR_2 & VAV_OR \\
OR2_MULT5_FLR_2 & VAV_OR \\
OR3_FLR_2 & VAV_OR \\
OR4_FLR_22 & VAV_OR \\
IC_PATROOM1_MULT5_FLR_2 & VAV_ICU \\
IC_PATROOM2_FLR_2 & VAV_ICU \\
IC_PATROOM3_MULT6_FLR_2 & VAV_ICU \\
ICU_FLR_2 & VAV_ICU \\
ICU_NURSESTN_LOBBY_FLR_2 & VAV_1 \\
CORRIDOR_FLR_2 & VAV_1 \\
OR_NURSESTN_LOBBY_FLR_2 & VAV_1 \\
PATROOM1_MULT10_FLR_3 & VAV_PATRMS \\
PATROOM2_FLR_3 & VAV_PATRMS \\
PATROOM3_MULT10_FLR_3 & VAV_PATRMS \\
PATROOM4_FLR_3 & VAV_PATRMS \\
PATROOM5_MULT10_FLR_3 & VAV_PATRMS \\
PHYSTHERAPY_FLR_3 & VAV_2 \\
PATROOM6_FLR_3 & VAV_PATRMS \\
PATROOM7_MULT10_FLR_3 & VAV_PATRMS \\
PATROOM8_FLR_3 & VAV_PATRMS \\
NURSESTN_LOBBY_FLR_3 & VAV_2 \\
LAB_FLR_3 & VAV_LABS \\
CORRIDOR_SE_FLR_3 & VAV_2 \\
CORRIDOR_NW_FLR_3 & VAV_2 \\
PATROOM1_MULT10_FLR_4 & VAV_PATRMS \\
PATROOM2_FLR_4 & VAV_PATRMS \\
PATROOM3_MULT10_FLR_4 & VAV_PATRMS \\
PATROOM4_FLR_4 & VAV_PATRMS \\
PATROOM5_MULT10_FLR_4 & VAV_PATRMS \\
RADIOLOGY_FLR_4 & VAV_2 \\
PATROOM6_FLR_4 & VAV_PATRMS \\
PATROOM7_MULT10_FLR_4 & VAV_PATRMS \\
PATROOM8_FLR_4 & VAV_PATRMS \\
NURSESTN_LOBBY_FLR_4 & VAV_2 \\
LAB_FLR_4 & VAV_LABS \\
CORRIDOR_SE_FLR_4 & VAV_2 \\
CORRIDOR_NW_FLR_4 & VAV_2 \\
DINING_FLR_5 & VAV_2 \\
\hline
\end{tabular}




\begin{tabular}{ll}
\hline \multicolumn{1}{c}{ Zone } & \multicolumn{1}{c}{ HVAC System Name } \\
\hline KITCHEN_FLR_5 & CAV_KITCHEN; Kitchen_Flr_5 Exhaust Fan \\
OFFICE1_FLR_5 & VAV_2 \\
OFFICE2_MULT5_FLR_5 & VAV_2 \\
OFFICE3_FLR_5 & VAV_2 \\
OFFICE4_MULT6_FLR_5 & VAV_2 \\
CORRIDOR_FLR_5 & VAV_2 \\
\hline
\end{tabular}




\section{D.10 Small Hotel HVAC System List}

\begin{tabular}{|c|c|}
\hline Zone & HVAC System Name \\
\hline REARSTAIRSFLR1 & RearStairsFlr1 UnitHeater \\
\hline CORRIDORFLR1 & CorridorFlr1 PTAC; MAU \\
\hline REARSTORAGEFLR1 & NA \\
\hline FRONTLOUNGEFLR1 & SAC_FrontLounge \\
\hline RESTROOMFLR1 & SAC_Exc_EmpLge_RestRm \\
\hline MEETINGROOMFLR1 & SAC_MeetingRoom \\
\hline MECHANICALROOMFLR1 & MechRm UnitHeater \\
\hline GUESTROOM101 & 101 PTAC; MAU \\
\hline GUESTROOM102 & 102 PTAC; MAU \\
\hline GUESTROOM103 & 103 PTAC; MAU \\
\hline GUESTROOM104 & 104 PTAC; MAU \\
\hline GUESTROOM105 & 105 PTAC; MAU \\
\hline EMPLOYEELOUNGEFLR1 & SAC_Exc_EmpLge_RestRm \\
\hline LAUNDRYROOMFLR1 & NA \\
\hline ELEVATORCOREFLR1 & NA \\
\hline EXERCISECENTERFLR1 & SAC_Exc_EmpLge_RestRm \\
\hline FRONTOFFICEFLR1 & SAC_FrontOffice \\
\hline FRONTSTAIRSFLR1 & FrontStairsFlr1 UnitHeater \\
\hline FRONTSTORAGEFLR1 & NA \\
\hline REARSTAIRSFLR2 & RearStairsFlr2 UnitHeater \\
\hline CORRIDORFLR2 & CorridorFlr2 PTAC; MAU \\
\hline REARSTORAGEFLR2 & NA \\
\hline GUESTROOM201 & 201 PTAC; MAU \\
\hline GUESTROOM202_205 & 202_205 PTAC; MAU \\
\hline GUESTROOM206_208 & 206_208 PTAC; MAU \\
\hline GUESTROOM209_212 & 209_212 PTAC; MAU \\
\hline GUESTROOM213 & 213 PTAC; MAU \\
\hline GUESTROOM214 & 214 PTAC; MAU \\
\hline GUESTROOM215_218 & 215_218 PTAC; MAU \\
\hline ELEVATORCOREFLR2 & NA \\
\hline GUESTROOM219 & 219 PTAC; MAU \\
\hline GUESTROOM220_223 & 220_223 PTAC; MAU \\
\hline GUESTROOM224 & 224 PTAC; MAU \\
\hline FRONTSTORAGEFLR2 & NA \\
\hline FRONTSTAIRSFLR2 & FrontStairsFlr2 UnitHeater \\
\hline REARSTAIRSFLR3 & RearStairsFlr3 UnitHeater \\
\hline CORRIDORFLR3 & CorridorFlr3 PTAC; MAU \\
\hline REARSTORAGEFLR3 & NA \\
\hline GUESTROOM301 & 301 PTAC; MAU \\
\hline GUESTROOM302_305 & 302_305 PTAC; MAU \\
\hline GUESTROOM306_308 & 306_308 PTAC; MAU \\
\hline GUESTROOM309_312 & 309_312 PTAC; MAU \\
\hline GUESTROOM313 & 313 PTAC; MAU \\
\hline GUESTROOM314 & 314 PTAC; MAU \\
\hline GUESTROOM315_318 & 315_318 PTAC; MAU \\
\hline ELEVATORCOREFLR3 & NA \\
\hline GUESTROOM319 & 319 PTAC; MAU \\
\hline GUESTROOM320_323 & 320_323 PTAC; MAU \\
\hline GUESTROOM324 & 324 PTAC; MAU \\
\hline
\end{tabular}




\begin{tabular}{|c|c|}
\hline Zone & HVAC System Name \\
\hline FRONTSTORAGEFLR3 & NA \\
\hline FRONTSTAIRSFLR3 & FrontStairsFlr3 UnitHeater \\
\hline REARSTAIRSFLR4 & RearStairsFlr4 UnitHeater \\
\hline CORRIDORFLR4 & CorridorFlr4 PTAC; MAU \\
\hline REARSTORAGEFLR4 & NA \\
\hline GUESTROOM401 & 401 PTAC; MAU \\
\hline GUESTROOM402_405 & 402_405 PTAC; MAU \\
\hline GUESTROOM406_408 & 406_408 PTAC; MAU \\
\hline GUESTROOM409_412 & 409_412 PTAC; MAU \\
\hline GUESTROOM413 & 413 PTAC; MAU \\
\hline GUESTROOM414 & 414 PTAC; MAU \\
\hline GUESTROOM415_418 & 415_418 PTAC; MAU \\
\hline ELEVATORCOREFLR4 & NA \\
\hline GUESTROOM419 & 419 PTAC; MAU \\
\hline GUESTROOM420_423 & 420_423 PTAC; MAU \\
\hline GUESTROOM424 & 424 PTAC; MAU \\
\hline FRONTSTORAGEFLR4 & NA \\
\hline FRONTSTAIRSFLR4 & FrontStairsFlr4 UnitHeater \\
\hline
\end{tabular}

D.11 


\section{D.11 Large Hotel HVAC System List}

\begin{tabular}{ll}
\hline \multicolumn{1}{c}{ Zone } & \multicolumn{1}{c}{ HVAC System Name } \\
\hline BASEMENT & VAV WITH REHEAT \\
RETAIL_1_FLR_1 & VAV WITH REHEAT \\
RETAIL_2_FLR_1 & VAV WITH REHEAT \\
MECH_FLR_1 & VAV WITH REHEAT \\
STORAGE_FLR_1 & VAV WITH REHEAT \\
LAUNDRY_FLR_1 & VAV WITH REHEAT; Laundry_Flr_1 Exhaust Fan \\
CAFE_FLR_1 & VAV WITH REHEAT \\
LOBBY_FLR_1 & VAV WITH REHEAT \\
ROOM_1_FLR_3 & Room_1_Flr_3 fan coil; FLR_3_DOAS \\
ROOM_2_FLR_3 & Room_2_Flr_3 fan coil; FLR_3_DOAS \\
ROOM_3_MULT19_FLR_3 & Room_3_Mult19_Flr_3 fan coil; FLR_3_DOAS \\
ROOM_4_MULT19_FLR_3 & Room_4_Mult19_Flr_3 fan coil; FLR_3_DOAS \\
ROOM_5_FLR_3 & Room_5_Flr_3 fan coil; FLR_3_DOAS \\
ROOM_6_FLR_3 & Room_6_Flr_3 fan coil; FLR_3_DOAS \\
CORRIDOR_FLR_3 & VAV WITH REHEAT \\
ROOM_1_FLR_6 & Room_1_Flr_6 fan coil; FLR_6_DOAS \\
ROOM_2_FLR_6 & Room_2_Flr_6 fan coil; FLR_3_DOAS \\
ROOM_3_MULT9_FLR_6 & Room_3_Mult9_Flr_6 fan coil; FLR_3_DOAS \\
BANQUET_FLR_6 & VAV WITH REHEAT \\
DINING_FLR_6 & VAV WITH REHEAT \\
KITCHEN_FLR_6 & VAV WITH REHEAT; Kitchen_Flr_6 Exhaust Fan \\
CORRIDOR_FLR_6 & VAV WITH REHEAT \\
\hline
\end{tabular}

\section{D.12 Warehouse HVAC System List}

\begin{tabular}{ll}
\hline \multicolumn{1}{c}{ Zone } & \multicolumn{1}{c}{ HVAC System Name } \\
\hline ZONE1 OFFICE & PSZ-Office \\
ZONE2 FINE STORAGE & PSZ-Fine \\
ZONE3 BULK STORAGE & Zone3UnitHeater; Zone3HiRadiant \\
\hline
\end{tabular}

\section{D.13 Quick Service Restaurant HVAC System List}

\begin{tabular}{ll}
\hline \multicolumn{1}{c}{ Zone } & \multicolumn{1}{c}{ HVAC System Name } \\
\hline DINING & PSZ-AC_1:1; Dining Exhaust Fan \\
KITCHEN & PSZ-AC_2:2; Kitchen Exhaust Fan \\
ATTIC & NA \\
\hline
\end{tabular}

\section{D.14 Full Service Restaurant HVAC System List}

\begin{tabular}{ll}
\hline \multicolumn{1}{c}{ Zone } & \multicolumn{1}{c}{ HVAC System Name } \\
\hline DINING & PSZ-AC_1:1; Dining Exhaust Fan \\
KITCHEN & PSZ-AC_2:2; Kitchen Exhaust Fan \\
ATTIC & NA \\
\hline
\end{tabular}




\section{D.15 Mid-Rise Apartment HVAC System List}

\begin{tabular}{ll}
\hline \multicolumn{1}{c}{ Zone } & \multicolumn{1}{c}{ HVAC System Name } \\
\hline G SW APARTMENT & Split GSW Furnace with DX Cooling \\
G NW APARTMENT & Split GNW Furnace with DX Cooling \\
OFFICE & Split Office Furnace with DX Cooling \\
G NE APARTMENT & Split GNE Furnace with DX Cooling \\
G N1 APARTMENT & Split GN1 Furnace with DX Cooling \\
G N2 APARTMENT & Split GN2 Furnace with DX Cooling \\
G S1 APARTMENT & Split GS1 Furnace with DX Cooling \\
G S2 APARTMENT & Split GS2 Furnace with DX Cooling \\
M SW APARTMENT & Split MSW Furnace with DX Cooling \\
M NW APARTMENT & Split MNW Furnace with DX Cooling \\
M SE APARTMENT & Split MSE Furnace with DX Cooling \\
M NE APARTMENT & Split MNE Furnace with DX Cooling \\
M N1 APARTMENT & Split MN1 Furnace with DX Cooling \\
M N2 APARTMENT & Split MN2 Furnace with DX Cooling \\
M S1 APARTMENT & Split MS1 Furnace with DX Cooling \\
M S2 APARTMENT & Split MS2 Furnace with DX Cooling \\
T SW APARTMENT & Split TSW Furnace with DX Cooling \\
T NW APARTMENT & Split TNW Furnace with DX Cooling \\
T SE APARTMENT & Split TSE Furnace with DX Cooling \\
T NE APARTMENT & Split TNE Furnace with DX Cooling \\
T N1 APARTMENT & Split TN1 Furnace with DX Cooling \\
T N2 APARTMENT & Split TN2 Furnace with DX Cooling \\
T S1 APARTMENT & Split TS1 Furnace with DX Cooling \\
T S2 APARTMENT & Split TS2 Furnace with DX Cooling \\
T CORRIDOR & NA \\
G CORRIDOR & NA \\
M CORRIDOR & NA \\
\hline & \\
\hline
\end{tabular}




\section{D.16 High-Rise Apartment HVAC System List}

\begin{tabular}{|c|c|}
\hline Zone & HVAC System Name \\
\hline G SW APARTMENT & AirLoop G SW DXAC Heat Pump \\
\hline G NW APARTMENT & AirLoop G NW DXAC Heat Pump \\
\hline OFFICE & AirLoop Office DXAC Heat Pump \\
\hline G NE APARTMENT & AirLoop G NE DXAC Heat Pump \\
\hline G N1 APARTMENT & AirLoop G N1 DXAC Heat Pump \\
\hline G N2 APARTMENT & AirLoop G N2 DXAC Heat Pump \\
\hline G S1 APARTMENT & AirLoop G S1 DXAC Heat Pump \\
\hline G S2 APARTMENT & AirLoop G S2 DXAC Heat Pump \\
\hline M SW APARTMENT ${ }^{(\mathrm{a})}$ & AirLoop M SW DXAC Heat Pump \\
\hline M NW APARTMENT ${ }^{(a)}$ & AirLoop M NW DXAC Heat Pump \\
\hline M SE APARTMENT $^{(a)}$ & AirLoop M SE DXAC Heat Pump \\
\hline M NE APARTMENT $^{(a)}$ & AirLoop M NE DXAC Heat Pump \\
\hline M N1 APARTMENT ${ }^{(\mathrm{a})}$ & AirLoop M N1 DXAC Heat Pump \\
\hline M N2 APARTMENT $^{(\mathrm{a})}$ & AirLoop M N2 DXAC Heat Pump \\
\hline M S1 APARTMENT ${ }^{(a)}$ & AirLoop M S1 DXAC Heat Pump \\
\hline M S2 APARTMENT ${ }^{(a)}$ & AirLoop M S2 DXAC Heat Pump \\
\hline T SW APARTMENT & AirLoop T SW DXAC Heat Pump \\
\hline T NW APARTMENT & AirLoop T NW DXAC Heat Pump \\
\hline T SE APARTMENT & AirLoop T SE DXAC Heat Pump \\
\hline T NE APARTMENT & AirLoop T NE DXAC Heat Pump \\
\hline T N1 APARTMENT & AirLoop T N1 DXAC Heat Pump \\
\hline T N2 APARTMENT & AirLoop T N2 DXAC Heat Pump \\
\hline T S1 APARTMENT & AirLoop T S1 DXAC Heat Pump \\
\hline T S2 APARTMENT & AirLoop T S2 DXAC Heat Pump \\
\hline T CORRIDOR & NA \\
\hline G CORRIDOR & NA \\
\hline M CORRIDOR & NA \\
\hline \multicolumn{2}{|c|}{$\begin{array}{l}\text { (a) Note that the HVAC system names for middle floors correspond } \\
\text { to their zone names, e.g., for the south-west apaprtment unit in } \\
\text { the second floor (F2 SW Apartment), the HVAC system name is } \\
\text { AirLoop F2 SW DXAC Heat Pump }\end{array}$} \\
\hline
\end{tabular}


Appendix E

\section{Building Envelope Requirements}




\section{Appendix E}

\section{Building Envelope Requirements}

\section{E.1 Envelope Requirements - Roof}

\begin{tabular}{|c|c|c|c|c|c|c|c|c|c|c|c|c|c|}
\hline \multirow[b]{3}{*}{$\begin{array}{l}\text { Climate } \\
\text { Zone }\end{array}$} & \multirow{3}{*}{$\begin{array}{l}\text { Roofs } \\
\text { Opaque Elements }\end{array}$} & \multicolumn{6}{|c|}{$90.1-2004$} & \multicolumn{6}{|c|}{$90.1-2010$} \\
\hline & & \multicolumn{2}{|c|}{ Non-Residential } & \multicolumn{2}{|c|}{ Residential } & \multicolumn{2}{|c|}{ Semiheated } & \multicolumn{2}{|c|}{ Non-Residential } & \multicolumn{2}{|c|}{ Residential } & \multicolumn{2}{|c|}{ Semiheated } \\
\hline & & U-Value & R-Value & U-Value & R-Value & U-Value & R-Value & U-Value & R-Value & U-Value & R-Value & U-Value & R-Value \\
\hline \multirow[t]{3}{*}{1} & $\begin{array}{l}\text { Insulation Entirely } \\
\text { above Deck }\end{array}$ & U-0.063 & R-15.0 c.i. & U-0.063 & R-15.0 c.i. & U-1.282 & $\mathrm{R}-0$ & U-0.063 & R-15.0 c.i. & U-0.048 & R-20.0 c.i. & U-0.218 & R-3.8 c.i. \\
\hline & Metal Building & U-0.065 & $\mathrm{R}-19.0$ & U-0.065 & $\mathrm{R}-19.0$ & U-1.280 & $\mathrm{R}-0$ & U-0.065 & R-19.0 & U-0.065 & $\mathrm{R}-19.0$ & U-0.167 & R-6.0 \\
\hline & Attic and Other & U-0.034 & $\mathrm{R}-30.0$ & U-0.027 & $\mathrm{R}-38.0$ & U-0.614 & $\mathrm{R}-0$ & U-0.034 & $\mathrm{R}-30.0$ & U-0.027 & $\mathrm{R}-38.0$ & U-0.081 & $\mathrm{R}-13.0$ \\
\hline \multirow[t]{3}{*}{2} & $\begin{array}{l}\text { Insulation Entirely } \\
\text { above Deck }\end{array}$ & U-0.063 & R-15.0 c.i. & U-0.063 & R-15.0 c.i. & U-0.218 & R-3.8 c.i. & U-0.048 & R-20.0 c.i. & U-0.048 & R-20.0 c.i. & U-0.218 & R-3.8 c.i. \\
\hline & Metal Building & $\mathrm{U}-0.065$ & $\mathrm{R}-19.0$ & U-0.065 & $\mathrm{R}-19.0$ & U-0.167 & $\mathrm{R}-6.0$ & U-0.055 & $\begin{array}{l}\text { R-13.0+ } \\
\text { R-13.0 }\end{array}$ & U-0.055 & $\begin{array}{l}\text { R-13.0+ } \\
\text { R-13.0 }\end{array}$ & U-0.097 & $\mathrm{R}-10.0$ \\
\hline & Attic and Other & U-0.034 & $\mathrm{R}-30.0$ & U-0.027 & $\mathrm{R}-38.0$ & U-0.081 & $\mathrm{R}-13.0$ & U-0.027 & $\mathrm{R}-38.0$ & U-0.027 & $\mathrm{R}-38.0$ & U-0.081 & $\mathrm{R}-13.0$ \\
\hline \multirow[t]{3}{*}{3} & $\begin{array}{l}\text { Insulation Entirely } \\
\text { above Deck }\end{array}$ & U-0.063 & R-15.0 c.i. & U-0.063 & R-15.0 c.i. & U-0.218 & R-3.8 c.i. & U-0.048 & R-20.0 c.i. & U-0.048 & R-20.0 c.i. & U-0.173 & R-5.0 c.i. \\
\hline & Metal Building & U-0.065 & $\mathrm{R}-19.0$ & U-0.065 & $\mathrm{R}-19.0$ & U-0.097 & $\mathrm{R}-10.0$ & U-0.055 & $\begin{array}{l}\text { R-13.0+ } \\
\text { R-13.0 }\end{array}$ & U-0.055 & $\begin{array}{l}\text { R-13.0 + } \\
\text { R-13.0 }\end{array}$ & U-0.097 & $\mathrm{R}-10.0$ \\
\hline & Attic and Other & U-0.034 & $\mathrm{R}-30.0$ & U-0.027 & $\mathrm{R}-38.0$ & U-0.081 & $\mathrm{R}-13.0$ & U-0.027 & $\mathrm{R}-38.0$ & U-0.027 & $\mathrm{R}-38.0$ & U-0.053 & $\mathrm{R}-19.0$ \\
\hline \multirow[t]{3}{*}{4} & $\begin{array}{l}\text { Insulation Entirely } \\
\text { above Deck }\end{array}$ & U-0.063 & R-15.0 c.i. & U-0.063 & R-15.0 c.i. & U-0.218 & R-3.8 c.i. & U-0.048 & R-20.0 c.i. & U-0.048 & R-20.0 c.i. & U-0.173 & R-5.0 c.i. \\
\hline & Metal Building & U-0.065 & $\mathrm{R}-19.0$ & U-0.065 & $\mathrm{R}-19.0$ & U-0.097 & $\mathrm{R}-10.0$ & U-0.055 & $\begin{array}{l}\text { R-13.0 + } \\
\text { R-13.0 }\end{array}$ & U-0.055 & $\begin{array}{l}\mathrm{R}-13.0+ \\
\mathrm{R}-13.0\end{array}$ & U-0.097 & $\mathrm{R}-10.0$ \\
\hline & Attic and Other & U-0.034 & $\mathrm{R}-30.0$ & U-0.027 & $\mathrm{R}-38.0$ & U-0.081 & $\mathrm{R}-13.0$ & U-0.027 & $\mathrm{R}-38.0$ & U-0.027 & $\mathrm{R}-38.0$ & U-0.053 & $\mathrm{R}-19.0$ \\
\hline \multirow[t]{3}{*}{5} & $\begin{array}{l}\text { Insulation Entirely } \\
\text { above Deck }\end{array}$ & U-0.063 & R-15.0 c.i. & U-0.063 & R-15.0 c.i. & U-0.173 & R-5.0 c.i. & U-0.048 & R-20.0 c.i. & U-0.048 & R-20.0 c.i. & U-0.119 & R-7.6 c.i. \\
\hline & Metal Building & U-0.065 & $\mathrm{R}-19.0$ & U-0.065 & $\mathrm{R}-19.0$ & U-0.097 & $\mathrm{R}-10.0$ & U-0.055 & $\begin{array}{l}\text { R-13.0+ } \\
\text { R-13.0 }\end{array}$ & U-0.055 & $\begin{array}{l}\text { R-13.0+ } \\
\text { R-13.0 }\end{array}$ & U-0.083 & $\mathrm{R}-13.0$ \\
\hline & Attic and Other & U-0.034 & $\mathrm{R}-30.0$ & U-0.027 & $\mathrm{R}-38.0$ & U-0.053 & R-19.0 & U-0.027 & $\mathrm{R}-38.0$ & U-0.027 & $\mathrm{R}-38.0$ & U-0.053 & $\mathrm{R}-19.0$ \\
\hline
\end{tabular}




\begin{tabular}{|c|c|c|c|c|c|c|c|c|c|c|c|c|c|}
\hline & \multirow[b]{2}{*}{ Roofs } & \multicolumn{6}{|c|}{$90.1-2004$} & \multicolumn{6}{|c|}{$90.1-2010$} \\
\hline & & \multicolumn{2}{|c|}{ Non-Residential } & \multicolumn{2}{|c|}{ Residential } & \multicolumn{2}{|c|}{ Semiheated } & \multicolumn{2}{|c|}{ Non-Residential } & \multicolumn{2}{|c|}{ Residential } & \multicolumn{2}{|c|}{ Semiheated } \\
\hline 6 & $\begin{array}{l}\text { Insulation Entirely } \\
\text { above Deck }\end{array}$ & U-0.063 & R-15.0 c.i. & U-0.063 & R-15.0 c.i. & U-0.173 & R-5.0 c.i. & U-0.048 & R-20.0 c.i. & U-0.048 & R-20.0 c.i. & U-0.093 & R-10.0 c.i. \\
\hline & Metal Building & U-0.065 & $\mathrm{R}-19.0$ & U-0.065 & $\mathrm{R}-19.0$ & U-0.097 & $\mathrm{R}-10.0$ & U-0.049 & $\begin{array}{l}\text { R-13.0+ } \\
\text { R-19.0 }\end{array}$ & U-0.049 & $\begin{array}{l}\text { R-13.0+ } \\
\text { R-19.0 }\end{array}$ & U-0.072 & $\mathrm{R}-16.0$ \\
\hline & Attic and Other & U-0.027 & $\mathrm{R}-38.0$ & U-0.027 & $\mathrm{R}-38.0$ & U-0.053 & R-19.0 & U-0.027 & $\mathrm{R}-38.0$ & U-0.027 & $\mathrm{R}-38.0$ & U-0.034 & $\mathrm{R}-30.0$ \\
\hline \multirow[t]{3}{*}{7} & $\begin{array}{l}\text { Insulation Entirely } \\
\text { above Deck }\end{array}$ & U-0.063 & R-15.0 c.i. & U-0.063 & R-15.0 c.i. & U-0.173 & R-5.0 c.i. & U-0.048 & R-20.0 c.i. & U-0.048 & R-20.0 c.i. & U-0.093 & R-10.0 c.i. \\
\hline & Metal Building & U-0.065 & $\mathrm{R}-19.0$ & U-0.065 & R-19.0 & U-0.097 & $\mathrm{R}-10.0$ & U-0.049 & $\begin{array}{l}\text { R-13.0+ } \\
\text { R-19.0 }\end{array}$ & U-0.049 & $\begin{array}{l}\text { R-13.0+ } \\
\text { R-19.0 }\end{array}$ & U-0.072 & R-16.0 \\
\hline & Attic and Other & U-0.027 & $\mathrm{R}-38.0$ & U-0.027 & R-38.0 & U-0.053 & R-19.0 & U-0.027 & $\mathrm{R}-38.0$ & U-0.027 & R-38.0 & U-0.034 & $\mathrm{R}-30.0$ \\
\hline \multirow[t]{3}{*}{8} & $\begin{array}{l}\text { Insulation Entirely } \\
\text { above Deck }\end{array}$ & U-0.048 & R-20.0 c.i. & U-0.048 & R-20.0 c.i. & U-0.093 & R-10.0 c.i. & U-0.048 & R-20.0 c.i. & U-0.048 & R-20.0 c.i. & U-0.063 & R-15.0 c.i. \\
\hline & Metal Building $^{(a)}$ & U-0.049 & $\begin{array}{l}\text { R-13.0+ } \\
\text { R-19.0 }\end{array}$ & U-0.049 & $\begin{array}{l}\text { R-13.0+ } \\
\text { R-19.0 }\end{array}$ & U-0.072 & $\mathrm{R}-16.0$ & U-0.035 & $\begin{array}{l}\text { R-11.0+ } \\
\text { R-19.0Ls }\end{array}$ & U-0.035 & $\begin{array}{l}\text { R-11.0+ } \\
\text { R-19.0Ls }\end{array}$ & U-0.065 & R-19.0 \\
\hline & Attic and Other & U-0.027 & $\mathrm{R}-38.0$ & U-0.027 & R-38.0 & U-0.034 & $\mathrm{R}-30.0$ & U-0.021 & $\mathrm{R}-49.0$ & U-0.021 & $\mathrm{R}-49.0$ & U-0.034 & $\mathrm{R}-30.0$ \\
\hline
\end{tabular}




\section{E.2 Envelope Requirements - Walls Above Grade}

\begin{tabular}{|c|c|c|c|c|c|c|c|c|c|c|c|c|c|}
\hline & & \multicolumn{6}{|c|}{ 90.1-2004 } & \multicolumn{6}{|c|}{$90.1-2010$} \\
\hline \multicolumn{2}{|c|}{ Walls, Above-Grade } & \multicolumn{2}{|c|}{ Non-Residential } & \multicolumn{2}{|c|}{ Residential } & \multicolumn{2}{|c|}{ Semiheated } & \multicolumn{2}{|c|}{ Non-Residential } & \multicolumn{2}{|c|}{ Residential } & \multicolumn{2}{|c|}{ Semiheated } \\
\hline $\begin{array}{c}\text { Climate } \\
\text { Zone }\end{array}$ & Opaque Elements & U-Value & R-Value & U-Value & R-Value & U-Value & R-Value & U-Value & R-Value & U-Value & R-Value & U-Value & R-Value \\
\hline \multirow[t]{4}{*}{1} & Mass & U-0.580 & $\mathrm{R}-0$ & U-0.151 & $\mathrm{R}-5.7 \mathrm{ci}$ & U-0.580 & $\mathrm{R}-0$ & U-0.580 & R-0 & U-0.151 & R-5.7 c.i. ${ }^{a}$ & U-0.580 & $\mathrm{R}-0$ \\
\hline & Metal Building & U-0.113 & $\mathrm{R}-13.0$ & U-0.113 & $\mathrm{R}-13.0$ & U-1.180 & $\mathrm{R}-0$ & U-0.093 & $\mathrm{R}-16.0$ & U-0.093 & $\mathrm{R}-16.0$ & U-0.113 & $\mathrm{R}-13.0$ \\
\hline & Steel-Framed & U-0.124 & $\mathrm{R}-13.0$ & U-0.124 & $\mathrm{R}-13.0$ & U-0.352 & $\mathrm{R}-0$ & U-0.124 & $\mathrm{R}-13.0$ & U-0.124 & $\mathrm{R}-13.0$ & U-0.352 & $\mathrm{R}-0$ \\
\hline & $\begin{array}{l}\text { Wood-Framed and } \\
\text { Other }\end{array}$ & U-0.089 & $\mathrm{R}-13.0$ & U-0.089 & $\mathrm{R}-13.0$ & U-0.292 & $\mathrm{R}-0$ & U-0.089 & $\mathrm{R}-13.0$ & U-0.089 & $\mathrm{R}-13.0$ & U-0.292 & $\mathrm{R}-0$ \\
\hline \multirow[t]{4}{*}{2} & Mass & U-0.580 & $\mathrm{R}-0$ & U-0.151 & $\mathrm{R}-5.7 \mathrm{ci}$ & U-0.580 & $\mathrm{R}-0$ & U-0.151 & R5.7 c.i. & U-0.123 & R-7.6 c.i. & U-0.580 & $\mathrm{R}-0$ \\
\hline & Metal Building & U-0.113 & $\mathrm{R}-13.0$ & U-0.113 & $\mathrm{R}-13.0$ & U-0.184 & $\mathrm{R}-6.0$ & U-0.093 & $\mathrm{R}-16.0$ & U-0.093 & $\mathrm{R}-16.0$ & U-0.113 & $\mathrm{R}-13.0$ \\
\hline & Steel-Framed & U-0.124 & $\mathrm{R}-13.0$ & U-0.124 & $\mathrm{R}-13.0$ & U-0.352 & $\mathrm{R}-0$ & U-0.124 & $\mathrm{R}-13.0$ & U-0.064 & $\begin{array}{l}\text { R-13.0 + } \\
\text { R-7.5 c.i. }\end{array}$ & U-0.124 & $\mathrm{R}-13.0$ \\
\hline & $\begin{array}{l}\text { Wood-Framed and } \\
\text { Other }\end{array}$ & U-0.089 & $\mathrm{R}-13.0$ & U-0.089 & $\mathrm{R}-13.0$ & U-0.292 & $\mathrm{R}-0$ & U-0.089 & $\mathrm{R}-13.0$ & U-0.089 & $\mathrm{R}-13.0$ & U-0.089 & $\mathrm{R}-13.0$ \\
\hline \multirow[t]{4}{*}{3} & Mass & U-0.151 & R-5.7 ci & U-0.123 & R-7.6 ci & U-0.580 & $\mathrm{R}-0$ & U-0.123 & R-7.6 c.i. & U-0.104 & R-9.5 c.i. & U-0.580 & $\mathrm{R}-0$ \\
\hline & Metal Building & U-0.113 & $\mathrm{R}-13.0$ & U-0.113 & $\mathrm{R}-13.0$ & U-0.184 & $\mathrm{R}-6.0$ & U-0.084 & $\mathrm{R}-19.0$ & U-0.084 & $\mathrm{R}-19.0$ & U-0.113 & $\mathrm{R}-13.0$ \\
\hline & Steel-Framed & U-0.124 & $\mathrm{R}-13.0$ & U-0.084 & $\begin{array}{l}\mathrm{R}-13.0+ \\
\mathrm{R}-3.8 \mathrm{ci}\end{array}$ & U-0.352 & $\mathrm{R}-0$ & U-0.084 & $\begin{array}{l}\text { R-13.0 + } \\
\text { R-3.8 c.i. }\end{array}$ & U-0.064 & $\begin{array}{l}\text { R-13.0+ } \\
\text { R-7.5 c.i. }\end{array}$ & U-0.124 & $\mathrm{R}-13.0$ \\
\hline & $\begin{array}{l}\text { Wood-Framed and } \\
\text { Other }\end{array}$ & U-0.089 & $\mathrm{R}-13.0$ & U-0.089 & $\mathrm{R}-13.0$ & U-0.089 & $\mathrm{R}-13.0$ & U-0.089 & $\mathrm{R}-13.0$ & U-0.089 & $\mathrm{R}-13.0$ & U-0.089 & $\mathrm{R}-13.0$ \\
\hline \multirow[t]{4}{*}{4} & Mass & U-0.151 & R-5.7 ci & U-0.104 & $\mathrm{R}-9.5 \mathrm{ci}$ & U-0.580 & $\mathrm{R}-0$ & U-0.104 & R-9.5 c.i. & U-0.090 & R-11.4 c.i. & U-0.580 & $\mathrm{R}-0$ \\
\hline & Metal Building & U-0.113 & $\mathrm{R}-13.0$ & U-0.113 & $\mathrm{R}-13.0$ & U-0.134 & $\mathrm{R}-10.0$ & U-0.084 & $\mathrm{R}-19.0$ & U-0.084 & $\mathrm{R}-19.0$ & U-0.113 & $\mathrm{R}-13.0$ \\
\hline & Steel-Framed & U-0.124 & $\mathrm{R}-13.0$ & U-0.064 & $\begin{array}{l}\mathrm{R}-13.0+ \\
\mathrm{R}-7.5 \mathrm{ci}\end{array}$ & U-0.124 & $\mathrm{R}-13.0$ & U-0.064 & $\begin{array}{l}\text { R-13.0+ } \\
\text { R-7.5 c.i. }\end{array}$ & U-0.064 & $\begin{array}{l}\text { R-13.0+ } \\
\text { R-7.5 c.i. }\end{array}$ & U-0.124 & $\mathrm{R}-13.0$ \\
\hline & $\begin{array}{l}\text { Wood-Framed and } \\
\text { Other }\end{array}$ & U-0.089 & $\mathrm{R}-13.0$ & U-0.089 & $\mathrm{R}-13.0$ & U-0.089 & $\mathrm{R}-13.0$ & U-0.089 & $\mathrm{R}-13.0$ & U-0.064 & $\begin{array}{l}\text { R-13.0 + } \\
\text { R-3.8 c.i. }\end{array}$ & U-0.089 & $\mathrm{R}-13.0$ \\
\hline \multirow[t]{4}{*}{5} & Mass & U-0.123 & R-7.6 ci & U-0.090 & R-11.4 ci & U-0.580 & $\mathrm{R}-0$ & U-0.090 & R-11.4 c.i. & U-0.080 & R-13.3 c.i. & U-0.151 & R-5.7 c.i. \\
\hline & Metal Building & U-0.113 & $\mathrm{R}-13.0$ & U-0.057 & $\begin{array}{l}\mathrm{R}-13.0+ \\
\mathrm{R}-13.0\end{array}$ & U-0.123 & $\mathrm{R}-11.0$ & U-0.069 & $\begin{array}{l}\text { R-13.0+ } \\
\text { R-5.6 c.i. }\end{array}$ & U-0.069 & $\begin{array}{l}\text { R-13.0+ } \\
\text { R-5.6 c.i. }\end{array}$ & U-0.113 & $\mathrm{R}-13.0$ \\
\hline & Steel-Framed & U-0.084 & $\begin{array}{l}\mathrm{R}-13.0+ \\
\mathrm{R}-3.8 \mathrm{ci}\end{array}$ & U-0.064 & $\begin{array}{l}\text { R-13.0 + } \\
\text { R-7.5 ci }\end{array}$ & U-0.124 & $\mathrm{R}-13.0$ & U-0.064 & $\begin{array}{l}\text { R-13.0+ } \\
\text { R-7.5 c.i. }\end{array}$ & U-0.064 & $\begin{array}{l}\text { R-13.0 + } \\
\text { R-7.5 c.i. }\end{array}$ & U-0.124 & $\mathrm{R}-13.0$ \\
\hline & $\begin{array}{l}\text { Wood-Framed and } \\
\text { Other }\end{array}$ & U-0.089 & $\mathrm{R}-13.0$ & U-0.089 & $\mathrm{R}-13.0$ & U-0.089 & $\mathrm{R}-13.0$ & U-0.064 & $\begin{array}{l}\text { R-13.0 + } \\
\text { R-3.8 c.i. }\end{array}$ & U-0.051 & $\begin{array}{l}\text { R-13.0+ } \\
\text { R-7.5 c.i. }\end{array}$ & U-0.089 & $\mathrm{R}-13.0$ \\
\hline
\end{tabular}




\begin{tabular}{|c|c|c|c|c|c|c|c|c|c|c|c|c|c|}
\hline & & \multicolumn{6}{|c|}{$90.1-2004$} & \multicolumn{6}{|c|}{$90.1-2010$} \\
\hline \multicolumn{2}{|c|}{ Walls, Above-Grade } & \multicolumn{2}{|c|}{ Non-Residential } & \multicolumn{2}{|c|}{ Residential } & \multicolumn{2}{|c|}{ Semiheated } & \multicolumn{2}{|c|}{ Non-Residential } & \multicolumn{2}{|c|}{ Residential } & \multicolumn{2}{|c|}{ Semiheated } \\
\hline $\begin{array}{l}\text { Climate } \\
\text { Zone }\end{array}$ & Opaque Elements & U-Value & R-Value & U-Value & R-Value & U-Value & R-Value & U-Value & R-Value & U-Value & R-Value & U-Value & R-Value \\
\hline \multirow[t]{4}{*}{6} & Mass & U-0.104 & $\mathrm{R}-9.5 \mathrm{ci}$ & U-0.090 & R-11.4 ci & U-0.580 & R-0 & U-0.080 & R-13.3 c.i. & U-0.071 & R-15.2 c.i. & U-0.151 & R-5.7 c.i. \\
\hline & Metal Building & U-0.113 & $\mathrm{R}-13.0$ & U-0.057 & $\begin{array}{l}\mathrm{R}-13.0+ \\
\mathrm{R}-13.0\end{array}$ & U-0.113 & $\mathrm{R}-13.0$ & U-0.069 & $\begin{array}{l}\text { R-13.0+ } \\
\text { R-5.6 c.i. }\end{array}$ & U-0.069 & $\begin{array}{l}\text { R-13.0+ } \\
\text { R-5.6 c.i. }\end{array}$ & U-0.113 & $\mathrm{R}-13.0$ \\
\hline & Steel-Framed & U-0.084 & $\begin{array}{l}\text { R-13.0 + } \\
\text { R-3.8 ci }\end{array}$ & U-0.064 & $\begin{array}{l}\mathrm{R}-13.0+ \\
\mathrm{R}-7.5 \mathrm{ci}\end{array}$ & U-0.124 & $\mathrm{R}-13.0$ & U-0.064 & $\begin{array}{l}\text { R-13.0+ } \\
\text { R-7.5 c.i. }\end{array}$ & U-0.064 & $\begin{array}{l}\text { R-13.0+ } \\
\text { R-7.5 c.i. }\end{array}$ & U-0.124 & $\mathrm{R}-13.0$ \\
\hline & $\begin{array}{l}\text { Wood-Framed and } \\
\text { Other }\end{array}$ & U-0.089 & $\mathrm{R}-13.0$ & U-0.064 & $\begin{array}{l}\mathrm{R}-13.0+ \\
\mathrm{R}-3.8 \mathrm{ci}\end{array}$ & U-0.089 & $\mathrm{R}-13.0$ & U-0.051 & $\begin{array}{l}\mathrm{R}-13.0+ \\
\mathrm{R}-7.5 \text { c.i. }\end{array}$ & U-0.051 & $\begin{array}{l}\text { R-13.0+ } \\
\text { R-7.5 c.i. }\end{array}$ & U-0.089 & $\mathrm{R}-13.0$ \\
\hline \multirow[t]{4}{*}{7} & Mass & U-0.090 & R-11.4 ci & U-0.080 & $\mathrm{R}-13.3 \mathrm{ci}$ & U-0.580 & $\mathrm{R}-0$ & U-0.071 & R-15.2 c.i. & U-0.071 & R-15.2 c.i. & U-0.123 & R-7.6 c.i. \\
\hline & Metal Building & U-0.057 & $\begin{array}{l}\mathrm{R}-13.0+ \\
\mathrm{R}-13.0\end{array}$ & U-0.057 & $\begin{array}{l}\mathrm{R}-13.0+ \\
\mathrm{R}-13.0\end{array}$ & U-0.113 & $\mathrm{R}-13.0$ & U-0.057 & $\begin{array}{l}\text { R-19.0+ } \\
\text { R-5.6 c.i. }\end{array}$ & U-0.057 & $\begin{array}{l}\text { R-19.0+ } \\
\text { R-5.6 c.i. }\end{array}$ & U-0.113 & $\mathrm{R}-13.0$ \\
\hline & Steel-Framed & U-0.064 & $\begin{array}{l}\mathrm{R}-13.0+ \\
\mathrm{R}-7.5 \mathrm{ci}\end{array}$ & U-0.064 & $\begin{array}{l}\mathrm{R}-13.0+ \\
\mathrm{R}-7.5 \mathrm{ci}\end{array}$ & U-0.124 & $\mathrm{R}-13.0$ & U-0.064 & $\begin{array}{l}\text { R-13.0+ } \\
\text { R-7.5 c.i. }\end{array}$ & U-0.042 & $\begin{array}{l}\text { R-13.0 + } \\
\text { R-15.6 c.i. }\end{array}$ & U-0.124 & $\mathrm{R}-13.0$ \\
\hline & $\begin{array}{l}\text { Wood-Framed and } \\
\text { Other }\end{array}$ & U-0.089 & $\mathrm{R}-13.0$ & U-0.051 & $\begin{array}{l}\mathrm{R}-13.0+ \\
\mathrm{R}-7.5 \mathrm{ci}\end{array}$ & U-0.089 & $\mathrm{R}-13.0$ & U-0.051 & $\begin{array}{l}\text { R-13.0+ } \\
\text { R-7.5 c.i. }\end{array}$ & U-0.051 & $\begin{array}{l}\mathrm{R}-13.0+ \\
\mathrm{R}-7.5 \text { c.i. }\end{array}$ & U-0.089 & $\mathrm{R}-13.0$ \\
\hline \multirow[t]{4}{*}{8} & Mass & U-0.080 & $\mathrm{R}-13.3 \mathrm{ci}$ & U-0.071 & R-15.2 ci & U-0.151 & R-5.7 ci & U-0.071 & R-15.2 c.i. & U-0.052 & R-25.0 c.i. & U-0.104 & R-9.5 c.i. \\
\hline & Metal Building & U-0.057 & $\begin{array}{l}\mathrm{R}-13.0+ \\
\mathrm{R}-13.0\end{array}$ & U-0.057 & $\begin{array}{l}\mathrm{R}-13.0+ \\
\mathrm{R}-13.0\end{array}$ & U-0.113 & $\mathrm{R}-13.0$ & U-0.057 & $\begin{array}{l}\text { R-19.0+ } \\
\text { R-5.6 c.i. }\end{array}$ & U-0.057 & $\begin{array}{l}\text { R-19.0+ } \\
\text { R-5.6 c.i. }\end{array}$ & U-0.113 & $\mathrm{R}-13.0$ \\
\hline & Steel-Framed & U-0.064 & $\begin{array}{l}\text { R-13.0 + } \\
\text { R-7.5 ci }\end{array}$ & U-0.055 & $\begin{array}{l}\text { R-13.0+ } \\
\text { R-10.0 ci }\end{array}$ & U-0.124 & $\mathrm{R}-13.0$ & U-0.064 & $\begin{array}{l}\text { R-13.0+ } \\
\text { R-7.5 c.i. }\end{array}$ & U-0.037 & $\begin{array}{l}\text { R-13.0 + } \\
\text { R-18.8 c.i. }\end{array}$ & U-0.084 & $\begin{array}{l}\text { R-13.0 + } \\
\text { R-3.8 c.i. }\end{array}$ \\
\hline & $\begin{array}{l}\text { Wood-Framed and } \\
\text { Other }\end{array}$ & U-0.051 & $\begin{array}{l}\mathrm{R}-13.0+ \\
\mathrm{R}-7.5 \mathrm{ci}\end{array}$ & U-0.051 & $\begin{array}{l}\text { R-13.0 + } \\
\text { R-7.5 ci }\end{array}$ & U-0.089 & $\mathrm{R}-13.0$ & U-0.036 & $\begin{array}{l}\text { R-13.0 + } \\
\text { R-15.6 c.i. }\end{array}$ & U-0.036 & $\begin{array}{l}\text { R-13.0 + } \\
\text { R-15.6 c.i. }\end{array}$ & U-0.089 & $\mathrm{R}-13.0$ \\
\hline
\end{tabular}




\section{E.3 Envelope Requirements - Walls Below Grade}

\begin{tabular}{|c|c|c|c|c|c|c|c|c|c|c|c|c|c|}
\hline & & \multicolumn{6}{|c|}{$90.1-2004$} & \multicolumn{6}{|c|}{$90.1-2010$} \\
\hline \multicolumn{2}{|c|}{ Walls, Below-Grade } & \multicolumn{2}{|c|}{ Non-Residential } & \multicolumn{2}{|c|}{ Residential } & \multicolumn{2}{|c|}{ Semiheated } & \multicolumn{2}{|c|}{ Non-Residential } & \multicolumn{2}{|c|}{ Residential } & \multicolumn{2}{|c|}{ Semiheated } \\
\hline $\begin{array}{c}\text { Climate } \\
\text { Zone }\end{array}$ & Opaque Elements & U-Value & R-Value & U-Value & R-Value & U-Value & R-Value & U-Value & R-Value & U-Value & R-Value & U-Value & R-Value \\
\hline 1 & Below-Grade Walls & C-1.140 & $\mathrm{R}-0$ & C-1.140 & R-0 & C-1.140 & $\mathrm{R}-0$ & C-1.140 & $\mathrm{R}-0$ & C-1.140 & R-0 & C-1.140 & $\mathrm{R}-0$ \\
\hline 2 & Below-Grade Walls & C-1.140 & $\mathrm{R}-0$ & C-1.140 & $\mathrm{R}-0$ & C-1.140 & $\mathrm{R}-0$ & C-1.140 & $\mathrm{R}-0$ & C-1.140 & $\mathrm{R}-0$ & C-1.140 & $\mathrm{R}-0$ \\
\hline 3 & Below-Grade Walls & C-1.140 & $\mathrm{R}-0$ & C-1.140 & $\mathrm{R}-0$ & C-1.140 & $\mathrm{R}-0$ & C-1.140 & $\mathrm{R}-0$ & C-1.140 & $\mathrm{R}-0$ & C-1.140 & $\mathrm{R}-0$ \\
\hline 4 & Below-Grade Walls & C-1.140 & $\mathrm{R}-0$ & C-1.140 & $\mathrm{R}-0$ & C-1.140 & $\mathrm{R}-0$ & C-1.140 & $\mathrm{R}-0$ & C-0.119 & R-7.5 c.i. & C-1.140 & $\mathrm{R}-0$ \\
\hline 5 & Below-Grade Walls & C-1.140 & $\mathrm{R}-0$ & C-1.140 & $\mathrm{R}-0$ & C-1.140 & $\mathrm{R}-0$ & C-0.119 & R-7.5 c.i. & C-0.119 & R-7.5 c.i. & C-1.140 & $\mathrm{R}-0$ \\
\hline 6 & Below-Grade Walls & C-1.140 & $\mathrm{R}-0$ & C-0.119 & $\mathrm{R}-7.5 \mathrm{ci}$ & C-1.140 & $\mathrm{R}-0$ & C-0.119 & R-7.5 c.i. & C-0.119 & R-7.5 c.i. & C-1.140 & $\mathrm{R}-0$ \\
\hline 7 & Below-Grade Walls & C-0.119 & $\mathrm{R}-7.5 \mathrm{ci}$ & C-0.119 & $\mathrm{R}-7.5 \mathrm{ci}$ & C-1.140 & $\mathrm{R}-0$ & C-0.119 & R-7.5 c.i. & C-0.092 & R-10.0 c.i. & C-1.140 & $\mathrm{R}-0$ \\
\hline 8 & Below-Grade Walls & C-0.119 & $\mathrm{R}-7.5 \mathrm{ci}$ & C-0.119 & $\mathrm{R}-7.5 \mathrm{ci}$ & C-1.140 & $\mathrm{R}-0$ & C-0.119 & R-7.5 c.i. & C- -0.075 & R-12.5 c.i. & C-1.140 & $\mathrm{R}-0$ \\
\hline
\end{tabular}




\section{E.4 Envelope Requirements - Floors}

\begin{tabular}{|c|c|c|c|c|c|c|c|c|c|c|c|c|c|}
\hline \multirow[b]{3}{*}{$\begin{array}{l}\text { Climate } \\
\text { Zone }\end{array}$} & \multirow{3}{*}{$\begin{array}{l}\text { Floors } \\
\text { Opaque Elements }\end{array}$} & \multicolumn{6}{|c|}{$90.1-2004$} & \multicolumn{6}{|c|}{$90.1-2010$} \\
\hline & & \multicolumn{2}{|c|}{ Non-Residential } & \multicolumn{2}{|c|}{ Residential } & \multicolumn{2}{|c|}{ Semiheated } & \multicolumn{2}{|c|}{ Non-Residential } & \multicolumn{2}{|c|}{ Residential } & \multicolumn{2}{|c|}{ Semiheated } \\
\hline & & U-Value & R-Value & U-Value & R-Value & U-Value & R-Value & U-Value & R-Value & U-Value & R-Value & U-Value & R-Value \\
\hline \multirow[t]{3}{*}{1} & Mass & U-0.322 & R-0 & U-0.322 & R-0 & U-0.322 & R-0 & U-0.322 & R-0 & U-0.322 & $\mathrm{R}-0$ & U-0.322 & $\mathrm{R}-0$ \\
\hline & Steel-Joist & U-0.350 & $\mathrm{R}-0$ & $\mathrm{U}-0.350$ & $\mathrm{R}-0$ & U-0.350 & R-0 & U-0.350 & R-0 & U-0.350 & $\mathrm{R}-0$ & U-0.350 & R-0 \\
\hline & $\begin{array}{l}\text { Wood-Framed and } \\
\text { Other }\end{array}$ & U-0.282 & R-0 & U-0.282 & $\mathrm{R}-0$ & U-0.282 & R-0 & U-0.282 & $\mathrm{R}-0$ & U-0.282 & $\mathrm{R}-0$ & U-0.282 & $\mathrm{R}-0$ \\
\hline \multirow[t]{3}{*}{2} & Mass & U-0.137 & $\mathrm{R}-4.2 \mathrm{ci}$ & U-0.107 & R-6.3 ci & U-0.322 & $\mathrm{R}-0$ & U-0.107 & R-6.3 c.i. & U-0.087 & R-8.3 c.i. & U-0.322 & $\mathrm{R}-0$ \\
\hline & Steel-Joist & U-0.052 & $\mathrm{R}-19.0$ & U-0.052 & $\mathrm{R}-19.0$ & U-0.350 & $\mathrm{R}-0$ & U-0.052 & $\mathrm{R}-19.0$ & U-0.052 & $\mathrm{R}-19.0$ & U-0.069 & $\mathrm{R}-13.0$ \\
\hline & $\begin{array}{l}\text { Wood-Framed and } \\
\text { Other }\end{array}$ & U-0.051 & $\mathrm{R}-19.0$ & U-0.051 & $\mathrm{R}-19.0$ & U-0.282 & $\mathrm{R}-0$ & U-0.051 & $\mathrm{R}-19.0$ & U-0.033 & $\mathrm{R}-30.0$ & U-0.066 & $\mathrm{R}-13.0$ \\
\hline \multirow[t]{3}{*}{3} & Mass & U-0.107 & R-6.3 ci & U-0.087 & $\mathrm{R}-8.3 \mathrm{ci}$ & & $\mathrm{R}-0$ & U-0.107 & R-6.3 c.i. & U-0.087 & R-8.3 c.i. & U-0.322 & $\mathrm{R}-0$ \\
\hline & Steel-Joist & U-0.052 & $\mathrm{R}-19.0$ & U-0.052 & $\mathrm{R}-19.0$ & U-0.069 & $\mathrm{R}-13.0$ & U-0.052 & $\mathrm{R}-19.0$ & U-0.052 & $\mathrm{R}-19.0$ & U-0.069 & $\mathrm{R}-13.0$ \\
\hline & $\begin{array}{l}\text { Wood-Framed and } \\
\text { Other }\end{array}$ & U-0.051 & $\mathrm{R}-19.0$ & U-0.033 & $\mathrm{R}-30.0$ & U-0.282 & $\mathrm{R}-0$ & U-0.051 & $\mathrm{R}-19.0$ & U-0.033 & $\mathrm{R}-30.0$ & U-0.066 & $\mathrm{R}-13.0$ \\
\hline \multirow[t]{3}{*}{4} & Mass & U-0.107 & $\mathrm{R}-6.3 \mathrm{ci}$ & U-0.087 & $\mathrm{R}-8.3 \mathrm{ci}$ & U-0.322 & $\mathrm{R}-0$ & U-0.087 & R-8.3 c.i. & U-0.074 & R-10.4 c.i. & U-0.137 & R-4.2 c.i. \\
\hline & Steel-Joist & U-0.052 & $\mathrm{R}-19.0$ & U-0.038 & $\mathrm{R}-30.0$ & U-0.069 & $\mathrm{R}-13.0$ & U-0.038 & $\mathrm{R}-30.0$ & U-0.038 & $\mathrm{R}-30.0$ & U-0.069 & $\mathrm{R}-13.0$ \\
\hline & $\begin{array}{l}\text { Wood-Framed and } \\
\text { Other }\end{array}$ & U-0.051 & $\mathrm{R}-19.0$ & U-0.033 & $\mathrm{R}-30.0$ & U-0.066 & $\mathrm{R}-13.0$ & U-0.033 & $\mathrm{R}-30.0$ & U-0.033 & $\mathrm{R}-30.0$ & U-0.066 & $\mathrm{R}-13.0$ \\
\hline \multirow[t]{3}{*}{5} & Mass & U-0.087 & $\mathrm{R}-8.3 \mathrm{ci}$ & U-0.074 & $\mathrm{R}-10.4 \mathrm{ci}$ & U-0.322 & $\mathrm{R}-0$ & U-0.074 & R-10.4 c.i. & U-0.064 & R-12.5 c.i. & U-0.137 & R-4.2 c.i. \\
\hline & Steel-Joist & U-0.052 & $\mathrm{R}-19.0$ & U-0.038 & $\mathrm{R}-30.0$ & U-0.069 & $\mathrm{R}-13.0$ & U-0.038 & $\mathrm{R}-30.0$ & U-0.038 & $\mathrm{R}-30.0$ & U-0.052 & R-19.0 \\
\hline & $\begin{array}{l}\text { Wood-Framed and } \\
\text { Other }\end{array}$ & U-0.033 & $\mathrm{R}-30.0$ & U-0.033 & $\mathrm{R}-30.0$ & U-0.066 & $\mathrm{R}-13.0$ & U-0.033 & $\mathrm{R}-30.0$ & U-0.033 & $\mathrm{R}-30.0$ & U-0.051 & R-19.0 \\
\hline \multirow[t]{3}{*}{6} & Mass & U-0.087 & $\mathrm{R}-8.3 \mathrm{ci}$ & U-0.064 & $\mathrm{R}-12.5 \mathrm{ci}$ & U-0.322 & $\mathrm{R}-0$ & U-0.064 & R-12.5 c.i. & U-0.057 & R-14.6 c.i. & U-0.137 & R-4.2 c.i. \\
\hline & Steel-Joist & U-0.038 & $\mathrm{R}-30.0$ & U-0.038 & $\mathrm{R}-30.0$ & U-0.069 & $\mathrm{R}-13.0$ & U-0.038 & $\mathrm{R}-30.0$ & U-0.032 & $\mathrm{R}-38.0$ & U-0.052 & R-19.0 \\
\hline & $\begin{array}{l}\text { Wood-Framed and } \\
\text { Other }\end{array}$ & U-0.033 & $\mathrm{R}-30.0$ & U-0.033 & $\mathrm{R}-30.0$ & U-.0066 & $\mathrm{R}-13.0$ & U-0.033 & $\mathrm{R}-30.0$ & U-0.033 & $\mathrm{R}-30.0$ & U-.0051 & $\mathrm{R}-19.0$ \\
\hline \multirow[t]{3}{*}{7} & Mass & U-0.087 & $\mathrm{R}-8.3 \mathrm{ci}$ & U-0.064 & $\mathrm{R}-12.5 \mathrm{ci}$ & U-0.137 & $\mathrm{R}-4.2 \mathrm{ci}$ & U-0.064 & R-12.5 c.i. & U-0.051 & R-16.7 c.i. & U-0.107 & R-6.3 c.i. \\
\hline & Steel-Joist & U-0.038 & $\mathrm{R}-30.0$ & U-0.038 & $\mathrm{R}-30.0$ & U-0.052 & $\mathrm{R}-19.0$ & U-0.038 & $\mathrm{R}-30.0$ & U-0.032 & $\mathrm{R}-38.0$ & U-0.052 & $\mathrm{R}-19.0$ \\
\hline & $\begin{array}{l}\text { Wood-Framed and } \\
\text { Other }\end{array}$ & U-0.033 & $\mathrm{R}-30.0$ & U-0.033 & $\mathrm{R}-30.0$ & U-0.066 & $\mathrm{R}-13.0$ & U-0.033 & $\mathrm{R}-30.0$ & U-0.033 & $\mathrm{R}-30.0$ & U-0.051 & $\mathrm{R}-19.0$ \\
\hline \multirow[t]{3}{*}{8} & Mass & U-0.064 & $\mathrm{R}-12.5 \mathrm{ci}$ & U-0.057 & R-14.6 ci & U-0.137 & $\mathrm{R}-4.2 \mathrm{ci}$ & U-0.057 & R-14.6 c.i. & U-0.051 & R-16.7 c.i. & U-0.087 & R-8.3 c.i. \\
\hline & Steel-Joist & U-0.038 & $\mathrm{R}-30.0$ & U-0.032 & $\mathrm{R}-38.0$ & U-0.052 & $\mathrm{R}-19.0$ & U-0.032 & $\mathrm{R}-38.0$ & U-0.032 & $\mathrm{R}-38.0$ & U-0.052 & $\mathrm{R}-19.0$ \\
\hline & $\begin{array}{l}\text { Wood-Framed and } \\
\text { Other }\end{array}$ & U-0.033 & $\mathrm{R}-30.0$ & U-0.033 & $\mathrm{R}-30.0$ & U-0.051 & $\mathrm{R}-19.0$ & U-0.033 & $\mathrm{R}-30.0$ & U-0.033 & $\mathrm{R}-30.0$ & U-0.033 & $\mathrm{R}-30.0$ \\
\hline
\end{tabular}


E.5 Envelope Requirements - Slab-On-Grade Floors

\begin{tabular}{|c|c|c|c|c|c|c|c|c|c|c|c|c|c|}
\hline \multirow{2}{*}{\multicolumn{2}{|c|}{ Floors, Slab-On-Grade }} & \multicolumn{6}{|c|}{$90.1-2004$} & \multicolumn{6}{|c|}{$90.1-2010$} \\
\hline & & \multicolumn{2}{|c|}{ Non-Residential } & \multicolumn{2}{|c|}{ Residential } & \multicolumn{2}{|c|}{ Semiheated } & \multicolumn{2}{|c|}{ Non-Residential } & \multicolumn{2}{|c|}{ Residential } & \multicolumn{2}{|c|}{ Semiheated } \\
\hline $\begin{array}{c}\text { Climate } \\
\text { Zone }\end{array}$ & Opaque Elements & U-Value & R-Value & U-Value & R-Value & U-Value & R-Value & U-Value & R-Value & U-Value & R-Value & U-Value & R-Value \\
\hline \multirow[t]{2}{*}{1} & Unheated & F-0.730 & $\mathrm{R}-0$ & F- 0.730 & $\mathrm{R}-0$ & F-0.730 & $\mathrm{R}-0$ & F-0.730 & $\mathrm{R}-0$ & F-0.730 & $\mathrm{R}-0$ & F-0.730 & $\mathrm{R}-0$ \\
\hline & Heated & F-1.020 & $\begin{array}{l}\text { R- } 7.5 \text { for } \\
12 \text { in. }\end{array}$ & F-1.020 & $\begin{array}{l}\text { R- } 7.5 \text { for } \\
12 \text { in. }\end{array}$ & F-1.020 & $\begin{array}{l}\text { R- } 7.5 \text { for } \\
12 \text { in. }\end{array}$ & F-1.020 & $\begin{array}{l}\text { R- } 7.5 \text { for } \\
12 \text { in. }\end{array}$ & F-1.020 & $\begin{array}{l}\text { R- } 7.5 \text { for } \\
12 \text { in. }\end{array}$ & F-1.020 & $\begin{array}{l}\text { R- } 7.5 \text { for } \\
12 \text { in. }\end{array}$ \\
\hline \multirow[t]{2}{*}{2} & Unheated & F-0.730 & $\mathrm{R}-0$ & F- 0.730 & $\mathrm{R}-0$ & F-0.730 & $\mathrm{R}-0$ & F-0.730 & $\mathrm{R}-0$ & F-0.730 & $\mathrm{R}-0$ & F-0.730 & $\mathrm{R}-0$ \\
\hline & Heated & F-1.020 & $\begin{array}{l}\text { R- } 7.5 \text { for } \\
12 \text { in. }\end{array}$ & F-1.020 & $\begin{array}{l}\text { R- } 7.5 \text { for } \\
12 \text { in. }\end{array}$ & F-1.020 & $\begin{array}{l}\text { R- } 7.5 \text { for } \\
12 \text { in. }\end{array}$ & F-1.020 & $\begin{array}{l}\text { R- } 7.5 \text { for } \\
12 \text { in. }\end{array}$ & F-1.020 & $\begin{array}{l}\text { R- } 7.5 \text { for } \\
12 \text { in. }\end{array}$ & F-1.020 & $\begin{array}{l}\text { R- } 7.5 \text { for } \\
12 \text { in. }\end{array}$ \\
\hline \multirow[t]{2}{*}{3} & Unheated & $\mathrm{F}-0.730$ & $\mathrm{R}-0$ & F- 0.730 & $\mathrm{R}-0$ & F-0.730 & $\mathrm{R}-0$ & F-0.730 & $\mathrm{R}-0$ & F- 0.730 & $\mathrm{R}-0$ & F-0.730 & $\mathrm{R}-0$ \\
\hline & Heated & F-1.020 & $\begin{array}{l}\text { R- } 7.5 \text { for } \\
12 \text { in. }\end{array}$ & F-1.020 & $\begin{array}{l}\text { R- } 7.5 \text { for } \\
12 \text { in. }\end{array}$ & F-1.020 & $\begin{array}{l}\text { R- } 7.5 \text { for } \\
12 \text { in. }\end{array}$ & F-0.900 & $\begin{array}{l}\mathrm{R}-10 \text { for } \\
24 \mathrm{in.}\end{array}$ & F-0.900 & $\begin{array}{l}\mathrm{R}-10 \text { for } \\
24 \mathrm{in.}\end{array}$ & F-1.020 & $\begin{array}{l}\text { R- } 7.5 \text { for } \\
12 \text { in. }\end{array}$ \\
\hline \multirow[t]{2}{*}{4} & Unheated & F- 0.730 & $\mathrm{R}-0$ & F-0.730 & $\mathrm{R}-0$ & F- 0.730 & $\mathrm{R}-0$ & F-0.730 & $\mathrm{R}-0$ & F-0.540 & $\begin{array}{l}\text { R-10 for } \\
24 \text { in. }\end{array}$ & F- 0.730 & $\mathrm{R}-0$ \\
\hline & Heated & F-0.950 & $\begin{array}{l}\text { R- } 7.5 \text { for } \\
24 \text { in. }\end{array}$ & F- 0.840 & $\begin{array}{l}\mathrm{R}-10 \text { for } \\
36 \text { in. }\end{array}$ & F-1.020 & $\begin{array}{l}\text { R- } 7.5 \text { for } \\
12 \text { in. }\end{array}$ & F-0.860 & $\begin{array}{l}\mathrm{R}-15 \text { for } \\
24 \text { in. }\end{array}$ & F-0.860 & $\begin{array}{l}\mathrm{R}-15 \text { for } \\
24 \text { in. }\end{array}$ & F-1.020 & $\begin{array}{l}\text { R- } 7.5 \text { for } \\
12 \text { in. }\end{array}$ \\
\hline \multirow[t]{2}{*}{5} & Unheated & F- -0.730 & $\mathrm{R}-0$ & F-0.730 & $\mathrm{R}-0$ & F- 0.730 & $\mathrm{R}-0$ & F-0.730 & $\mathrm{R}-0$ & $\mathrm{~F}-0.540$ & $\begin{array}{l}\mathrm{R}-10 \text { for } \\
24 \mathrm{in.}\end{array}$ & F-0.730 & $\mathrm{R}-0$ \\
\hline & Heated & F-0.840 & $\begin{array}{l}\mathrm{R}-10 \text { for } \\
36 \text { in. }\end{array}$ & F- 0.840 & $\begin{array}{l}\text { R-10 for } \\
36 \text { in. }\end{array}$ & F-1.020 & $\begin{array}{l}\text { R- } 7.5 \text { for } \\
12 \text { in. }\end{array}$ & F- 0.860 & $\begin{array}{l}\text { R-15 for } \\
24 \text { in. }\end{array}$ & F- -0.860 & $\begin{array}{l}\mathrm{R}-15 \text { for } \\
24 \mathrm{in.}\end{array}$ & F-1.020 & $\begin{array}{l}\text { R- } 7.5 \text { for } \\
12 \text { in. }\end{array}$ \\
\hline \multirow[t]{2}{*}{6} & Unheated & F-0.730 & $\mathrm{R}-0$ & F- 0.730 & $\mathrm{R}-0$ & F-0.730 & $\mathrm{R}-0$ & F-0.540 & $\begin{array}{l}\mathrm{R}-10 \text { for } \\
24 \mathrm{in.}\end{array}$ & F- 0.520 & $\begin{array}{l}\text { R- } 15 \text { for } \\
24 \text { in. }\end{array}$ & F-0.730 & $\mathrm{R}-0$ \\
\hline & Heated & F-0.840 & $\begin{array}{l}\mathrm{R}-10 \text { for } \\
36 \text { in. }\end{array}$ & F-0.780 & $\begin{array}{l}\text { R- } 10 \text { for } \\
48 \text { in. }\end{array}$ & F-1.020 & $\begin{array}{l}\text { R- } 7.5 \text { for } \\
12 \text { in. }\end{array}$ & F-0.860 & $\begin{array}{l}\mathrm{R}-15 \text { for } \\
24 \text { in. }\end{array}$ & F-0.688 & $\begin{array}{l}\text { R- } 20 \text { for } \\
48 \text { in. }\end{array}$ & F-1.020 & $\begin{array}{l}\text { R- } 7.5 \text { for } \\
12 \text { in. }\end{array}$ \\
\hline \multirow[t]{2}{*}{7} & Unheated & F-0.730 & $\mathrm{R}-0$ & F- 0.540 & $\begin{array}{l}\mathrm{R}-10 \text { for } \\
24 \mathrm{in.}\end{array}$ & F-0.730 & $\mathrm{R}-0$ & F- 0.520 & $\begin{array}{l}\mathrm{R}-15 \text { for } \\
24 \text { in. }\end{array}$ & F- 0.520 & $\begin{array}{l}\mathrm{R}-15 \text { for } \\
24 \text { in. }\end{array}$ & F-0.730 & $\mathrm{R}-0$ \\
\hline & Heated & F- 0.840 & $\begin{array}{l}\mathrm{R}-10 \text { for } \\
36 \text { in. }\end{array}$ & F-0.780 & $\begin{array}{l}\mathrm{R}-10 \text { for } \\
48 \text { in. }\end{array}$ & F-1.020 & $\begin{array}{l}\text { R- } 7.5 \text { for } \\
12 \text { in. }\end{array}$ & F-0.843 & $\begin{array}{l}\mathrm{R}-20 \text { for } \\
24 \text { in. }\end{array}$ & F-0.688 & $\begin{array}{l}\mathrm{R}-20 \text { for } \\
48 \text { in. }\end{array}$ & F- 0.900 & $\begin{array}{l}\mathrm{R}-10 \text { for } \\
24 \text { in. }\end{array}$ \\
\hline \multirow[t]{2}{*}{8} & Unheated & F-0.540 & $\begin{array}{l}\mathrm{R}-10 \text { for } \\
24 \text { in. }\end{array}$ & F-0.520 & $\begin{array}{l}\text { R-15 for } \\
24 \text { in. }\end{array}$ & F- 0.730 & R-0 & F-0.520 & $\begin{array}{l}\mathrm{R}-15 \text { for } \\
24 \text { in. }\end{array}$ & F-0.510 & $\begin{array}{l}\mathrm{R}-20 \text { for } \\
24 \text { in. }\end{array}$ & F- 0.730 & $\mathrm{R}-0$ \\
\hline & Heated & F- 0.780 & $\begin{array}{l}\mathrm{R}-10 \text { for } \\
48 \text { in. }\end{array}$ & F- 0.780 & $\begin{array}{l}\mathrm{R}-10 \text { for } \\
48 \text { in. }\end{array}$ & F-0.950 & $\begin{array}{l}\text { R- } 7.5 \text { for } \\
24 \text { in. }\end{array}$ & F-0.688 & $\begin{array}{l}\text { R- } 20 \text { for } \\
48 \text { in. }\end{array}$ & F-0.688 & $\begin{array}{l}\mathrm{R}-20 \text { for } \\
48 \mathrm{in.}\end{array}$ & F-0.900 & $\begin{array}{l}\text { R- } 10.0 \text { for } \\
24 \text { in. }\end{array}$ \\
\hline
\end{tabular}




\section{E.6 Envelope Requirements - Doors}

\begin{tabular}{|c|c|c|c|c|c|c|c|c|c|c|c|c|c|}
\hline \multirow{2}{*}{\multicolumn{2}{|c|}{ Opaque Doors }} & \multicolumn{6}{|c|}{$90.1-2004$} & \multicolumn{6}{|c|}{ 90.1-2010 } \\
\hline & & \multicolumn{2}{|c|}{ Non-Residential } & \multicolumn{2}{|c|}{ Residential } & \multicolumn{2}{|c|}{ Semiheated } & \multicolumn{2}{|c|}{ Non-Residential } & \multicolumn{2}{|c|}{ Residential } & \multicolumn{2}{|c|}{ Semiheated } \\
\hline $\begin{array}{l}\text { Climate } \\
\text { Zone }\end{array}$ & Opaque Elements & U-Value & R-Value & U-Value & R-Value & U-Value & R-Value & U-Value & R-Value & U-Value & R-Value & U-Value & R-Value \\
\hline \multirow[t]{2}{*}{1} & Swinging & U-0.700 & R-1.429 & U-0.700 & R-1.429 & U-0.700 & R-1.429 & U-0.700 & R-1.429 & U-0.700 & R-1.429 & U-0.700 & R-1.429 \\
\hline & Non-Swinging & U-1.450 & R-0.69 & $\mathrm{U}-1.450$ & R-0.69 & U-1.450 & R-0.69 & U-1.450 & R-0.69 & U-1.450 & R-0.69 & U-1.450 & R-0.69 \\
\hline \multirow[t]{2}{*}{2} & Swinging & U-0.700 & R-1.429 & U-0.700 & R-1.429 & U-0.700 & R-1.429 & U-0.700 & R-1.429 & U-0.700 & R-1.429 & U-0.700 & R-1.429 \\
\hline & Non-Swinging & U-1.450 & R-0.69 & U-1.450 & R-0.69 & U-1.450 & R-0.69 & U-1.450 & R-0.69 & U-0.500 & $\mathrm{R}-2$ & U-1.450 & R-0.69 \\
\hline \multirow[t]{2}{*}{3} & Swinging & U-0.700 & R-1.429 & U-0.700 & R-1.429 & U-0.700 & R-1.429 & U-0.700 & R-1.429 & U-0.700 & R-1.429 & U-0.700 & $\mathrm{R}-1.429$ \\
\hline & Non-Swinging & U-1.450 & R-0.69 & U-0.500 & $\mathrm{R}-2$ & U-1.450 & R-0.69 & U-1.450 & R-0.69 & U- 0.500 & R-2 & U-1.450 & R-0.69 \\
\hline \multirow[t]{2}{*}{4} & Swinging & U-0.700 & R-1.429 & U-0.700 & R-1.429 & U-0.700 & R-1.429 & U-0.700 & R-1.429 & U-0.700 & R-1.429 & U-0.700 & R-1.429 \\
\hline & Non-Swinging & U-1.450 & R-0.69 & U-0.500 & $\mathrm{R}-2$ & U-1.450 & R-0.69 & U-1.500 & R-0.667 & U-0.500 & $\mathrm{R}-2$ & U-1.450 & R-0.69 \\
\hline \multirow[t]{2}{*}{5} & Swinging & U-0.700 & R-1.429 & U-0.700 & R-1.429 & U-0.700 & R-1.429 & U-0.700 & R-1.429 & U-0.500 & $\mathrm{R}-2$ & U-0.700 & R-1.429 \\
\hline & Non-Swinging & U-1.450 & R-0.69 & U-0.500 & $\mathrm{R}-2$ & U-1.450 & R-0.69 & U-0.500 & $\mathrm{R}-2$ & U-0.500 & $\mathrm{R}-2$ & U-1.450 & R-0.69 \\
\hline \multirow[t]{2}{*}{6} & Swinging & U-0.700 & R-1.429 & U-0.500 & $\mathrm{R}-2$ & U-0.700 & R-1.429 & U-0.700 & R-1.429 & U-0.500 & $\mathrm{R}-2$ & U-0.700 & R-1.429 \\
\hline & Non-Swinging & U-0.500 & $\mathrm{R}-2$ & U-0.500 & $\mathrm{R}-2$ & U-1.450 & R-0.69 & U-0.500 & $\mathrm{R}-2$ & U-0.500 & $\mathrm{R}-2$ & U-1.450 & R-0.69 \\
\hline \multirow[t]{2}{*}{7} & Swinging & U-0.700 & R-1.429 & U-0.500 & $\mathrm{R}-2$ & U-0.700 & R-1.429 & U-0.500 & $\mathrm{R}-2$ & U-0.500 & $\mathrm{R}-2$ & U-0.700 & R-1.429 \\
\hline & Non-Swinging & U-0.500 & $\mathrm{R}-2$ & U-0.500 & $\mathrm{R}-2$ & U-1.450 & R-0.69 & U-0.500 & $\mathrm{R}-2$ & U-0.500 & $\mathrm{R}-2$ & U-1.450 & R-0.69 \\
\hline \multirow[t]{2}{*}{8} & Swinging & U-0.500 & $\mathrm{R}-2$ & U-0.500 & $\mathrm{R}-2$ & U-0.700 & R-1.429 & U-0.500 & $\mathrm{R}-2$ & U-0.500 & $\mathrm{R}-2$ & U-0.700 & R-1.429 \\
\hline & Non-Swinging & U-0.500 & $\mathrm{R}-2$ & U-0.500 & $\mathrm{R}-2$ & U-1.450 & $\mathrm{R}-0.69$ & U-0.500 & $\mathrm{R}-2$ & U-0.500 & $\mathrm{R}-2$ & U-0.500 & $\mathrm{R}-2$ \\
\hline
\end{tabular}




\section{E.7 Envelope Requirements - 90.1-2004 Vertical Glazing ${ }^{(a)}$}

\begin{tabular}{|c|c|c|c|c|c|c|c|c|c|c|c|c|c|}
\hline \multicolumn{2}{|c|}{ Vertical Glazing } & \multicolumn{4}{|c|}{ Non-Residential } & \multicolumn{4}{|c|}{ Residential } & \multicolumn{4}{|c|}{ Semiheated } \\
\hline $\begin{array}{l}\text { ASHRAE } \\
\text { Zone }\end{array}$ & $\begin{array}{c}\text { WWR } \\
(\%)\end{array}$ & $\begin{array}{c}\text { U-Value } \\
\text { Fixed }\end{array}$ & $\begin{array}{c}\text { U-Value } \\
\text { Opererable }\end{array}$ & $\begin{array}{l}\text { SHGC } \\
\text { (all) }\end{array}$ & $\begin{array}{c}\text { SHGC } \\
\text { (North) }\end{array}$ & $\begin{array}{c}\text { U-Value } \\
\text { Fixed }\end{array}$ & $\begin{array}{c}\text { U-Value } \\
\text { Opererable }\end{array}$ & $\begin{array}{l}\text { SHGC } \\
\text { (all) }\end{array}$ & $\begin{array}{c}\text { SHGC } \\
\text { (North) }\end{array}$ & $\begin{array}{l}\text { U-Value } \\
\text { Fixed }\end{array}$ & $\begin{array}{c}\text { U-Value } \\
\text { Opererable }\end{array}$ & $\begin{array}{l}\text { SHGC } \\
\text { (all) }\end{array}$ & $\begin{array}{l}\text { SHGC } \\
\text { (North) }\end{array}$ \\
\hline \multirow[t]{5}{*}{1} & 10 & 1.22 & 1.27 & 0.25 & 0.61 & 1.22 & 1.27 & 0.25 & 0.61 & 1.22 & 1.27 & NR & NR \\
\hline & 20 & 1.22 & 1.27 & 0.25 & 0.61 & 1.22 & 1.27 & 0.25 & 0.61 & 1.22 & 1.27 & NR & NR \\
\hline & 30 & 1.22 & 1.27 & 0.25 & 0.61 & 1.22 & 1.27 & 0.25 & 0.61 & 1.22 & 1.27 & NR & NR \\
\hline & 40 & 1.22 & 1.27 & 0.25 & 0.44 & 1.22 & 1.27 & 0.25 & 0.44 & 1.22 & 1.27 & NR & NR \\
\hline & 50 & 1.22 & 1.27 & 0.19 & 0.33 & 1.22 & 1.27 & 0.19 & 0.33 & 0.98 & 1.02 & NR & NR \\
\hline \multirow[t]{5}{*}{2} & 10 & 1.22 & 1.27 & 0.25 & 0.61 & 1.22 & 1.27 & 0.39 & 0.61 & 1.22 & 1.27 & NR & NR \\
\hline & 20 & 1.22 & 1.27 & 0.25 & 0.61 & 1.22 & 1.27 & 0.25 & 0.61 & 1.22 & 1.27 & NR & NR \\
\hline & 30 & 1.22 & 1.27 & 0.25 & 0.61 & 1.22 & 1.27 & 0.25 & 0.61 & 1.22 & 1.27 & NR & NR \\
\hline & 40 & 1.22 & 1.27 & 0.25 & 0.61 & 1.22 & 1.27 & 0.25 & 0.61 & 1.22 & 1.27 & NR & NR \\
\hline & 50 & 1.22 & 1.27 & 0.17 & 0.44 & 1.22 & 1.27 & 0.17 & 0.43 & 0.98 & 1.02 & NR & NR \\
\hline \multirow[t]{5}{*}{3} & 10 & 0.57 & 0.67 & 0.39 & 0.49 & 0.57 & 0.67 & 0.39 & 0.49 & 1.22 & 1.27 & NR & NR \\
\hline & 20 & 0.57 & 0.67 & 0.25 & 0.49 & 0.57 & 0.67 & 0.39 & 0.49 & 1.22 & 1.27 & NR & NR \\
\hline & 30 & 0.57 & 0.67 & 0.25 & 0.39 & 0.57 & 0.67 & 0.25 & 0.39 & 1.22 & 1.27 & NR & NR \\
\hline & 40 & 0.57 & 0.67 & 0.25 & 0.39 & 0.57 & 0.67 & 0.25 & 0.39 & 1.22 & 1.27 & NR & NR \\
\hline & 50 & 0.46 & 0.47 & 0.19 & 0.26 & 0.46 & 0.47 & 0.19 & 0.26 & 0.98 & 1.02 & NR & NR \\
\hline \multirow[t]{5}{*}{$3 \mathrm{C}$} & 10 & 1.22 & 1.27 & 0.61 & 0.82 & 1.22 & 1.27 & 0.61 & 0.82 & 1.22 & 1.27 & NR & NR \\
\hline & 20 & 1.22 & 1.27 & 0.39 & 0.61 & 1.22 & 1.27 & 0.61 & 0.61 & 1.22 & 1.27 & NR & NR \\
\hline & 30 & 1.22 & 1.27 & 0.39 & 0.61 & 1.22 & 1.27 & 0.39 & 0.61 & 1.22 & 1.27 & NR & NR \\
\hline & 40 & 1.22 & 1.27 & 0.34 & 0.61 & 1.22 & 1.27 & 0.34 & 0.61 & 1.22 & 1.27 & NR & NR \\
\hline & 50 & 1.22 & 1.27 & 0.2 & 0.3 & 0.73 & 0.81 & 0.25 & 0.61 & 0.98 & 1.02 & NR & NR \\
\hline \multirow[t]{5}{*}{4} & 10 & 0.57 & 0.67 & 0.39 & 0.49 & 0.57 & 0.61 & 0.39 & 0.49 & 1.22 & 1.27 & NR & NR \\
\hline & 20 & 0.57 & 0.67 & 0.39 & 0.49 & 0.57 & 0.67 & 0.39 & 0.49 & 1.22 & 1.27 & NR & NR \\
\hline & 30 & 0.57 & 0.67 & 0.39 & 0.49 & 0.57 & 0.67 & 0.39 & 0.49 & 1.22 & 1.27 & NR & NR \\
\hline & 40 & 0.57 & 0.67 & 0.39 & 0.49 & 0.57 & 0.67 & 0.39 & 0.49 & 1.22 & 1.27 & NR & NR \\
\hline & 50 & 0.46 & 0.47 & 0.25 & 0.36 & 0.46 & 0.47 & 0.25 & 0.36 & 0.98 & 1.02 & NR & NR \\
\hline \multirow[t]{5}{*}{5} & 10 & 0.57 & 0.67 & 0.49 & 0.49 & 0.57 & 0.67 & 0.49 & 0.49 & 1.22 & 1.27 & NR & NR \\
\hline & 20 & 0.57 & 0.67 & 0.39 & 0.49 & 0.57 & 0.67 & 0.39 & 0.49 & 1.22 & 1.27 & NR & NR \\
\hline & 30 & 0.57 & 0.67 & 0.39 & 0.49 & 0.57 & 0.67 & 0.39 & 0.49 & 1.22 & 1.27 & NR & NR \\
\hline & 40 & 0.57 & 0.67 & 0.39 & 0.49 & 0.57 & 0.67 & 0.39 & 0.49 & 1.22 & 1.27 & NR & NR \\
\hline & 50 & 0.46 & 0.47 & 0.26 & 0.36 & 0.46 & 0.47 & 0.26 & 0.49 & 0.98 & 1.02 & NR & NR \\
\hline
\end{tabular}




\begin{tabular}{|c|c|c|c|c|c|c|c|c|c|c|c|c|c|}
\hline \multicolumn{2}{|c|}{ Vertical Glazing } & \multicolumn{4}{|c|}{ Non-Residential } & \multicolumn{4}{|c|}{ Residential } & \multicolumn{4}{|c|}{ Semiheated } \\
\hline $\begin{array}{l}\text { ASHRAE } \\
\text { Zone }\end{array}$ & $\begin{array}{l}\text { WWR } \\
(\%)\end{array}$ & $\begin{array}{l}\text { U-Value } \\
\text { Fixed }\end{array}$ & $\begin{array}{c}\text { U-Value } \\
\text { Opererable }\end{array}$ & $\begin{array}{l}\text { SHGC } \\
\text { (all) }\end{array}$ & $\begin{array}{l}\text { SHGC } \\
\text { (North) }\end{array}$ & $\begin{array}{l}\text { U-Value } \\
\text { Fixed }\end{array}$ & $\begin{array}{c}\text { U-Value } \\
\text { Opererable }\end{array}$ & $\begin{array}{l}\text { SHGC } \\
\text { (all) }\end{array}$ & $\begin{array}{l}\text { SHGC } \\
\text { (North) }\end{array}$ & $\begin{array}{l}\text { U-Value } \\
\text { Fixed }\end{array}$ & $\begin{array}{c}\text { U-Value } \\
\text { Opererable }\end{array}$ & $\begin{array}{l}\text { SHGC } \\
\text { (all) }\end{array}$ & $\begin{array}{l}\text { SHGC } \\
\text { (North) }\end{array}$ \\
\hline \multirow[t]{5}{*}{6} & 10 & 0.57 & 0.67 & 0.49 & 0.49 & 0.57 & 0.67 & 0.49 & 0.64 & 1.22 & 1.27 & NR & NR \\
\hline & 20 & 0.57 & 0.67 & 0.39 & 0.49 & 0.57 & 0.67 & 0.39 & 0.49 & 1.22 & 1.27 & NR & NR \\
\hline & 30 & 0.57 & 0.67 & 0.39 & 0.49 & 0.57 & 0.67 & 0.39 & 0.49 & 1.22 & 1.27 & NR & NR \\
\hline & 40 & 0.57 & 0.67 & 0.39 & 0.49 & 0.57 & 0.67 & 0.39 & 0.49 & 1.22 & 1.27 & NR & NR \\
\hline & 50 & 0.46 & 0.47 & 0.26 & 0.49 & 0.46 & 0.47 & 0.26 & 0.49 & 0.98 & 1.02 & NR & NR \\
\hline \multirow[t]{5}{*}{7} & 10 & 0.57 & 0.67 & 0.49 & 0.64 & 0.57 & 0.67 & 0.49 & 0.64 & 1.22 & 1.27 & NR & NR \\
\hline & 20 & 0.57 & 0.67 & 0.49 & 0.64 & 0.57 & 0.67 & 0.49 & 0.64 & 1.22 & 1.27 & NR & NR \\
\hline & 30 & 0.57 & 0.67 & 0.49 & 0.64 & 0.57 & 0.67 & 0.49 & 0.64 & 1.22 & 1.27 & NR & NR \\
\hline & 40 & 0.57 & 0.67 & 0.49 & 0.64 & 0.57 & 0.67 & 0.49 & 0.64 & 1.22 & 1.27 & NR & NR \\
\hline & 50 & 0.46 & 0.47 & 0.36 & 0.64 & 0.46 & 0.47 & 0.36 & 0.64 & 0.98 & 1.02 & NR & NR \\
\hline \multirow[t]{5}{*}{8} & 10 & 0.46 & 0.47 & NR & NR & 0.46 & 0.47 & NR & NR & 1.22 & 1.27 & NR & NR \\
\hline & 20 & 0.46 & 0.47 & NR & NR & 0.46 & 0.47 & NR & NR & 1.22 & 1.27 & NR & NR \\
\hline & 30 & 0.46 & 0.47 & NR & NR & 0.46 & 0.47 & NR & NR & 1.22 & 1.27 & NR & NR \\
\hline & 40 & 0.46 & 0.47 & NR & NR & 0.46 & 0.47 & NR & NR & 1.22 & 1.27 & NR & NR \\
\hline & 50 & 0.35 & 0.39 & NR & NR & 0.35 & 0.39 & NR & NR & 0.98 & 1.02 & NR & NR \\
\hline
\end{tabular}




\section{E.8 Envelope Requirements - 90.1-2010 Vertical Glazing ${ }^{(a)}$}

\begin{tabular}{|c|c|c|c|c|c|c|c|}
\hline \multicolumn{2}{|r|}{ Vertical Glazing } & \multicolumn{2}{|c|}{ Non-Residential } & \multicolumn{2}{|c|}{ Residential } & \multicolumn{2}{|c|}{ Semiheated } \\
\hline ASHRAE Zone & Frame Type & U-Value & SHGC (all) & U-Value & SHGC (all) & U-Value & SHGC (all) \\
\hline \multirow[t]{4}{*}{1} & Non-Metal Framing & 1.20 & 0.25 & 1.20 & 0.25 & 1.20 & NR \\
\hline & Metal Framing (Curtainwall) & 1.20 & 0.25 & 1.20 & 0.25 & 1.20 & NR \\
\hline & Metal Framing (Entrance) & 1.20 & 0.25 & 1.20 & 0.25 & 1.20 & NR \\
\hline & Metal Framing (All Other) & 1.20 & 0.25 & 1.20 & 0.25 & 1.20 & NR \\
\hline \multirow[t]{4}{*}{2} & Non-Metal Framing & 0.75 & 0.25 & 0.75 & 0.25 & 1.20 & NR \\
\hline & Metal Framing (Curtainwall) & 0.70 & 0.25 & 0.70 & 0.25 & 1.20 & NR \\
\hline & Metal Framing (Entrance) & 1.10 & 0.25 & 1.10 & 0.25 & 1.20 & NR \\
\hline & Metal Framing (All Other) & 0.75 & 0.25 & 0.75 & 0.25 & 1.20 & NR \\
\hline \multirow[t]{4}{*}{3} & Non-Metal Framing & 0.65 & 0.25 & 0.65 & 0.25 & 1.20 & NR \\
\hline & Metal Framing (Curtainwall) & 0.60 & 0.25 & 0.60 & 0.25 & 1.20 & NR \\
\hline & Metal Framing (Entrance) & 0.90 & 0.25 & 0.90 & 0.25 & 1.20 & NR \\
\hline & Metal Framing (All Other) & 0.65 & 0.25 & 0.65 & 0.25 & 1.20 & NR \\
\hline \multirow[t]{4}{*}{4} & Non-Metal Framing & 0.40 & 0.40 & 0.40 & 0.40 & 1.20 & NR \\
\hline & Metal Framing (Curtainwall) & 0.50 & 0.40 & 0.50 & 0.40 & 1.20 & NR \\
\hline & Metal Framing (Entrance) & 0.85 & 0.40 & 0.85 & 0.40 & 1.20 & NR \\
\hline & Metal Framing (All Other) & 0.55 & 0.40 & 0.55 & 0.40 & 1.20 & NR \\
\hline \multirow[t]{4}{*}{5} & Non-Metal Framing & 0.35 & 0.40 & 0.35 & 0.40 & 1.20 & NR \\
\hline & Metal Framing (Curtainwall) & 0.45 & 0.40 & 0.45 & 0.40 & 1.20 & NR \\
\hline & Metal Framing (Entrance) & 0.80 & 0.40 & 0.80 & 0.40 & 1.20 & NR \\
\hline & Metal Framing (All Other) & 0.55 & 0.40 & 0.55 & 0.40 & 1.20 & NR \\
\hline \multirow[t]{4}{*}{6} & Non-Metal Framing & 0.35 & 0.40 & 0.35 & 0.40 & 0.65 & NR \\
\hline & Metal Framing (Curtainwall) & 0.45 & 0.40 & 0.45 & 0.40 & 0.60 & NR \\
\hline & Metal Framing (Entrance) & 0.80 & 0.40 & 0.80 & 0.40 & 0.90 & NR \\
\hline & Metal Framing (All Other) & 0.55 & 0.40 & 0.55 & 0.40 & 0.65 & NR \\
\hline \multirow[t]{4}{*}{7} & Non-Metal Framing & 0.35 & 0.45 & 0.35 & NR & 0.65 & NR \\
\hline & Metal Framing (Curtainwall) & 0.40 & 0.45 & 0.40 & NR & 0.60 & NR \\
\hline & Metal Framing (Entrance) & 0.80 & 0.45 & 0.80 & NR & 0.90 & NR \\
\hline & Metal Framing (All Other) & 0.45 & 0.45 & 0.45 & NR & 0.65 & NR \\
\hline \multirow[t]{4}{*}{8} & Non-Metal Framing & 0.35 & 0.45 & 0.35 & NR & 0.65 & NR \\
\hline & Metal Framing (Curtainwall) & 0.40 & 0.45 & 0.40 & NR & 0.60 & NR \\
\hline & Metal Framing (Entrance) & 0.80 & 0.45 & 0.80 & NR & 0.90 & NR \\
\hline & Metal Framing (All Other) & 0.45 & 0.45 & 0.45 & NR & 0.65 & NR \\
\hline
\end{tabular}




\section{E.9 Envelope Requirements -Skylights}

\begin{tabular}{|c|c|c|c|c|c|c|c|c|c|c|c|c|c|}
\hline \multirow[b]{3}{*}{$\begin{array}{c}\text { Climate } \\
\text { Zone }\end{array}$} & \multirow{3}{*}{$\begin{array}{c}\text { Skylights } \\
\text { Type and } \% \text { of Roof Area }\end{array}$} & \multicolumn{6}{|c|}{$90.1-2004$} & \multicolumn{6}{|c|}{$90.1-2010$} \\
\hline & & \multicolumn{2}{|c|}{ Non-Residential } & \multicolumn{2}{|c|}{ Residental } & \multicolumn{2}{|c|}{ Semi-Heated } & \multicolumn{2}{|c|}{ Non-Residential } & \multicolumn{2}{|c|}{ Residental } & \multicolumn{2}{|c|}{ Semi-Heated } \\
\hline & & $\begin{array}{c}\text { U- } \\
\text { Value } \\
\end{array}$ & $\begin{array}{c}\text { SHGC } \\
\text { (all) }\end{array}$ & $\begin{array}{c}\text { U- } \\
\text { Value }\end{array}$ & $\begin{array}{c}\text { SHGC } \\
\text { (all) }\end{array}$ & $\begin{array}{c}\text { U- } \\
\text { Value } \\
\end{array}$ & $\begin{array}{c}\text { SHGC } \\
\text { (all) }\end{array}$ & $\begin{array}{c}\text { U- } \\
\text { Value }\end{array}$ & $\begin{array}{c}\text { SHGC } \\
\text { (all) }\end{array}$ & $\begin{array}{c}\text { U- } \\
\text { Value } \\
\end{array}$ & $\begin{array}{c}\text { SHGC } \\
\text { (all) }\end{array}$ & $\begin{array}{c}\text { U- } \\
\text { Value }\end{array}$ & $\begin{array}{c}\text { SHGC } \\
\text { (all) }\end{array}$ \\
\hline \multirow[t]{6}{*}{1} & Glass with curb $0 \%-2 \%$ & 1.98 & 0.36 & 1.98 & 0.19 & 1.98 & NR & 1.98 & 0.36 & 1.98 & 0.19 & 1.98 & NR \\
\hline & Glass with curb $2.1 \%-5 \%$ & 1.98 & 0.19 & 1.98 & 0.16 & 1.98 & NR & 1.98 & 0.19 & 1.98 & 0.16 & 1.98 & NR \\
\hline & Plastic with curb $0 \%-2 \%$ & 1.90 & 0.34 & 1.90 & 0.27 & 1.90 & NR & 1.90 & 0.34 & 1.90 & 0.27 & 1.90 & NR \\
\hline & Plastic with curb $2.1 \%-5 \%$ & 1.90 & 0.27 & 1.90 & 0.27 & 1.90 & NR & 1.90 & 0.27 & 1.90 & 0.27 & 1.90 & NR \\
\hline & All without curb $0 \%-2 \%$ & 1.36 & 0.36 & 1.36 & 0.19 & 1.36 & NR & 1.36 & 0.36 & 1.36 & 0.19 & 1.36 & NR \\
\hline & All without curb $2.1 \%-5 \%$ & 1.36 & 0.19 & 1.36 & 0.19 & 1.36 & NR & 1.36 & 0.19 & 1.36 & 0.19 & 1.36 & NR \\
\hline \multirow[t]{6}{*}{2} & Glass with curb $0 \%-2 \%$ & 1.98 & 0.36 & 1.98 & 0.19 & 1.98 & NR & 1.98 & 0.36 & 1.98 & 0.19 & 1.98 & NR \\
\hline & Glass with curb $2.1 \%-5 \%$ & 1.98 & 0.19 & 1.98 & 0.19 & 1.98 & NR & 1.98 & 0.19 & 1.98 & 0.19 & 1.98 & NR \\
\hline & Plastic with curb $0 \%-2 \%$ & 1.90 & 0.39 & 1.90 & 0.27 & 1.90 & NR & 1.90 & 0.39 & 1.90 & 0.27 & 1.90 & NR \\
\hline & Plastic with curb $2.1 \%-5 \%$ & 1.90 & 0.34 & 1.90 & 0.27 & 1.90 & NR & 1.90 & 0.34 & 1.90 & 0.27 & 1.90 & NR \\
\hline & All without curb $0 \%-2 \%$ & 1.36 & 0.36 & 1.36 & 0.19 & 1.36 & NR & 1.36 & 0.36 & 1.36 & 0.19 & 1.36 & NR \\
\hline & All without curb $2.1 \%-5 \%$ & 1.36 & 0.19 & 1.36 & 0.19 & 1.36 & NR & 1.36 & 0.19 & 1.36 & 0.19 & 1.36 & NR \\
\hline \multirow[t]{6}{*}{3} & Glass with curb $0 \%-2 \%$ & 1.17 & 0.39 & 1.17 & 0.36 & 1.98 & NR & 1.17 & 0.39 & 1.17 & 0.36 & 1.98 & NR \\
\hline & Glass with curb $2.1 \%-5 \%$ & 1.17 & 0.19 & 1.17 & 0.19 & 1.98 & NR & 1.17 & 0.19 & 1.17 & 0.19 & 1.98 & NR \\
\hline & Plastic with curb $0 \%-2 \%$ & 1.30 & 0.65 & 1.30 & 0.27 & 1.90 & NR & 1.30 & 0.65 & 1.30 & 0.27 & 1.90 & NR \\
\hline & Plastic with curb $2.1 \%-5 \%$ & 1.30 & 0.34 & 1.30 & 0.27 & 1.90 & NR & 1.30 & 0.34 & 1.30 & 0.27 & 1.90 & NR \\
\hline & All without curb $0 \%-2 \%$ & 0.69 & 0.39 & 0.69 & 0.36 & 1.36 & NR & 0.69 & 0.39 & 0.69 & 0.36 & 1.36 & NR \\
\hline & All without curb $2.1 \%-5 \%$ & 0.69 & 0.19 & 0.69 & 0.19 & 1.36 & NR & 0.69 & 0.19 & 0.69 & 0.19 & 1.36 & NR \\
\hline \multirow[t]{6}{*}{$3 \mathrm{C}$} & Glass with curb $0 \%-2 \%$ & 1.98 & 0.61 & 1.98 & 0.39 & 1.98 & NR & 1.17 & 0.39 & 1.17 & 0.36 & 1.98 & NR \\
\hline & Glass with curb $2.1 \%-5 \%$ & 1.98 & 0.39 & 1.98 & 0.19 & 1.98 & NR & 1.17 & 0.19 & 1.17 & 0.19 & 1.98 & NR \\
\hline & Plastic with curb $0 \%-2 \%$ & 1.90 & 0.65 & 1.90 & 0.65 & 1.90 & NR & 1.30 & 0.65 & 1.30 & 0.27 & 1.90 & NR \\
\hline & Plastic with curb $2.1 \%-5 \%$ & 1.90 & 0.39 & 1.90 & 0.34 & 1.90 & NR & 1.30 & 0.34 & 1.30 & 0.27 & 1.90 & NR \\
\hline & All without curb $0 \%-2 \%$ & 1.36 & 0.61 & 1.36 & 0.39 & 1.36 & NR & 0.69 & 0.39 & 0.69 & 0.36 & 1.36 & NR \\
\hline & All without curb $2.1 \%-5 \%$ & 1.36 & 0.39 & 1.36 & 0.19 & 1.36 & NR & 0.69 & 0.19 & 0.69 & 0.19 & 1.36 & NR \\
\hline \multirow[t]{6}{*}{4} & Glass with curb $0 \%-2 \%$ & 1.17 & 0.49 & 0.98 & 0.36 & 1.98 & NR & 1.17 & 0.49 & 0.98 & 0.36 & 1.98 & NR \\
\hline & Glass with curb $2.1 \%-5 \%$ & 1.17 & 0.39 & 0.98 & 0.19 & 1.98 & NR & 1.17 & 0.39 & 0.98 & 0.19 & 1.98 & NR \\
\hline & Plastic with curb $0 \%-2 \%$ & 1.30 & 0.65 & 1.30 & 0.62 & 1.90 & NR & 1.30 & 0.65 & 1.30 & 0.62 & 1.90 & NR \\
\hline & Plastic with curb $2.1 \%-5 \%$ & 1.30 & 0.34 & 1.30 & 0.27 & 1.90 & NR & 1.30 & 0.34 & 1.30 & 0.27 & 1.90 & NR \\
\hline & All without curb $0 \%-2 \%$ & 0.69 & 0.49 & 0.58 & 0.36 & 1.36 & NR & 0.69 & 0.49 & 0.58 & 0.36 & 1.36 & NR \\
\hline & All without curb $2.1 \%-5 \%$ & 0.69 & 0.39 & 0.58 & 0.19 & 1.36 & NR & 0.69 & 0.39 & 0.58 & 0.19 & 1.36 & NR \\
\hline
\end{tabular}




\begin{tabular}{|c|c|c|c|c|c|c|c|c|c|c|c|c|c|}
\hline \multirow[b]{3}{*}{$\begin{array}{l}\text { Climate } \\
\text { Zone }\end{array}$} & \multirow[b]{2}{*}{ Skylights } & \multicolumn{6}{|c|}{$90.1-2004$} & \multicolumn{6}{|c|}{$90.1-2010$} \\
\hline & & \multicolumn{2}{|c|}{ Non-Residential } & \multicolumn{2}{|c|}{ Residental } & \multicolumn{2}{|c|}{ Semi-Heated } & \multicolumn{2}{|c|}{ Non-Residential } & \multicolumn{2}{|c|}{ Residental } & \multicolumn{2}{|c|}{ Semi-Heated } \\
\hline & Type and $\%$ of Roof Area & $\begin{array}{c}\text { U- } \\
\text { Value }\end{array}$ & $\begin{array}{c}\text { SHGC } \\
\text { (all) }\end{array}$ & $\begin{array}{c}\text { U- } \\
\text { Value }\end{array}$ & $\begin{array}{l}\text { SHGC } \\
\text { (all) }\end{array}$ & $\begin{array}{c}\text { U- } \\
\text { Value }\end{array}$ & $\begin{array}{c}\text { SHGC } \\
\text { (all) }\end{array}$ & $\begin{array}{c}\text { U- } \\
\text { Value }\end{array}$ & $\begin{array}{c}\text { SHGC } \\
\text { (all) }\end{array}$ & $\begin{array}{c}\text { U- } \\
\text { Value }\end{array}$ & $\begin{array}{c}\text { SHGC } \\
\text { (all) }\end{array}$ & $\begin{array}{c}\text { U- } \\
\text { Value }\end{array}$ & $\begin{array}{c}\text { SHGC } \\
\text { (all) }\end{array}$ \\
\hline \multirow[t]{6}{*}{5} & Glass with curb $0 \%-2 \%$ & 1.17 & 0.49 & 1.17 & 0.49 & 1.98 & NR & 1.17 & 0.49 & 1.17 & 0.49 & 1.98 & NR \\
\hline & Glass with curb $2.1 \%-5 \%$ & 1.17 & 0.39 & 1.17 & 0.39 & 1.98 & NR & 1.17 & 0.39 & 1.17 & 0.39 & 1.98 & NR \\
\hline & Plastic with curb $0 \%-2 \%$ & 1.10 & 0.77 & 1.10 & 0.77 & 1.90 & NR & 1.10 & 0.77 & 1.10 & 0.77 & 1.90 & NR \\
\hline & Plastic with curb $2.1 \%-5 \%$ & 1.10 & 0.62 & 1.10 & 0.62 & 1.90 & NR & 1.10 & 0.62 & 1.10 & 0.62 & 1.90 & NR \\
\hline & All without curb $0 \%-2 \%$ & 0.69 & 0.49 & 0.69 & 0.49 & 1.36 & NR & 0.69 & 0.49 & 0.69 & 0.49 & 1.36 & NR \\
\hline & All without curb $2.1 \%-5 \%$ & 0.69 & 0.39 & 0.69 & 0.39 & 1.36 & NR & 0.69 & 0.39 & 0.69 & 0.39 & 1.36 & NR \\
\hline \multirow[t]{6}{*}{6} & Glass with curb $0 \%-2 \%$ & 1.17 & 0.49 & 0.98 & 0.46 & 1.98 & NR & 1.17 & 0.49 & 0.98 & 0.46 & 1.98 & NR \\
\hline & Glass with curb $2.1 \%-5 \%$ & 1.17 & 0.49 & 0.98 & 0.36 & 1.98 & NR & 1.17 & 0.49 & 0.98 & 0.36 & 1.98 & NR \\
\hline & Plastic with curb $0 \%-2 \%$ & 0.87 & 0.71 & 0.74 & 0.65 & 1.90 & NR & 0.87 & 0.71 & 0.74 & 0.65 & 1.90 & NR \\
\hline & Plastic with curb $2.1 \%-5 \%$ & 0.87 & 0.58 & 0.74 & 0.55 & 1.90 & NR & 0.87 & 0.58 & 0.74 & 0.55 & 1.90 & NR \\
\hline & All without curb $0 \%-2 \%$ & 0.69 & 0.49 & 0.58 & 0.49 & 1.36 & NR & 0.69 & 0.49 & 0.58 & 0.49 & 1.36 & NR \\
\hline & All without curb $2.1 \%-5 \%$ & 0.69 & 0.49 & 0.58 & 0.39 & 1.36 & NR & 0.69 & 0.49 & 0.58 & 0.39 & 1.36 & NR \\
\hline \multirow[t]{6}{*}{7} & Glass with curb $0 \%-2 \%$ & 1.17 & 0.68 & 1.17 & 0.64 & 1.98 & NR & 1.17 & 0.68 & 1.17 & 0.64 & 1.98 & NR \\
\hline & Glass with curb $2.1 \%-5 \%$ & 1.17 & 0.64 & 1.17 & 0.64 & 1.98 & NR & 1.17 & 0.64 & 1.17 & 0.64 & 1.98 & NR \\
\hline & Plastic with curb $0 \%-2 \%$ & 0.87 & 0.77 & 0.61 & 0.77 & 1.90 & NR & 0.87 & 0.77 & 0.61 & 0.77 & 1.90 & NR \\
\hline & Plastic with curb $2.1 \%-5 \%$ & 0.87 & 0.71 & 0.61 & 0.77 & 1.90 & NR & 0.87 & 0.71 & 0.61 & 0.77 & 1.90 & NR \\
\hline & All without curb $0 \%-2 \%$ & 0.69 & 0.68 & 0.69 & 0.64 & 1.36 & NR & 0.69 & 0.68 & 0.69 & 0.64 & 1.36 & NR \\
\hline & All without curb $2.1 \%-5 \%$ & 0.69 & 0.64 & 0.69 & 0.64 & 1.36 & NR & 0.69 & 0.64 & 0.69 & 0.64 & 1.36 & NR \\
\hline \multirow[t]{6}{*}{8} & Glass with curb $0 \%-2 \%$ & 0.98 & NR & 0.98 & NR & 1.30 & NR & 0.98 & NR & 0.98 & NR & 1.30 & NR \\
\hline & Glass with curb $2.1 \%-5 \%$ & 0.98 & NR & 0.98 & NR & 1.30 & NR & 0.98 & NR & 0.98 & NR & 1.30 & NR \\
\hline & Plastic with curb $0 \%-2 \%$ & 0.61 & NR & 0.61 & NR & 1.10 & NR & 0.61 & NR & 0.61 & NR & 1.10 & NR \\
\hline & Plastic with curb $2.1 \%-5 \%$ & 0.61 & NR & 0.61 & NR & 1.10 & NR & 0.61 & NR & 0.61 & NR & 1.10 & NR \\
\hline & All without curb $0 \%-2 \%$ & 0.58 & NR & 0.58 & NR & 0.81 & NR & 0.58 & NR & 0.58 & NR & 0.81 & NR \\
\hline & All without curb $2.1 \%-5 \%$ & 0.58 & NR & 0.58 & NR & 0.81 & NR & 0.58 & NR & 0.58 & NR & 0.81 & NR \\
\hline
\end{tabular}




\section{Appendix F}

\section{1-2010 Energy Savings Results by End-Uses}




\section{F.1 Small Office Energy Saving Results}

\begin{tabular}{|c|c|c|c|c|c|c|c|c|c|c|c|c|c|c|c|c|c|c|}
\hline Zone & Standard & $\begin{array}{c}\text { Heating } \\
\text { [MMBtu] }\end{array}$ & $\begin{array}{c}\text { Cooling } \\
\text { [MMBtu] }\end{array}$ & $\begin{array}{c}\text { Interior } \\
\text { Lights } \\
\text { [MMBtu] }\end{array}$ & $\begin{array}{c}\text { Exterior } \\
\text { Lights } \\
\text { [MMBtu] }\end{array}$ & $\begin{array}{c}\text { Interior } \\
\text { Equipment } \\
\text { [MMBtu] }\end{array}$ & $\begin{array}{c}\text { Exterior } \\
\text { Equipment } \\
\text { [MMBtu] }\end{array}$ & $\begin{array}{c}\text { Fans } \\
\text { [MMBtu] }\end{array}$ & $\begin{array}{c}\text { Pumps } \\
\text { [MMBtu] }\end{array}$ & $\begin{array}{c}\text { Heat } \\
\text { Rejection } \\
\text { [MMBtu] }\end{array}$ & $\begin{array}{l}\text { Humidifi- } \\
\text { cation } \\
\text { [MMBtu] }\end{array}$ & $\begin{array}{c}\text { Heat } \\
\text { Recovery } \\
\text { [MMBtu] }\end{array}$ & $\begin{array}{c}\text { Water } \\
\text { Heater } \\
{[\text { MMBtu] }}\end{array}$ & $\begin{array}{l}\text { Refrigera- } \\
\text { tion } \\
{[\mathrm{MMBtu}]}\end{array}$ & $\begin{array}{c}\text { Total } \\
\text { Energy } \\
{[\text { MMBtu] }}\end{array}$ & $\begin{array}{c}\text { EUI } \\
{[\mathrm{kBtu} / \mathrm{sf}]}\end{array}$ & $\begin{array}{c}\text { Energy } \\
\text { Savings [\%] }\end{array}$ & $\begin{array}{c}\text { Energy Savings } \\
\text { w/o } \\
\text { ] PlugLoad [\%] }\end{array}$ \\
\hline \multirow{2}{*}{$\begin{array}{c}1 \mathrm{~A} \\
\text { Miami }\end{array}$} & $90.1-2004$ & 0 & 53 & 67 & 24 & 50 & 0 & 24 & 0 & 0 & 0 & 0 & 9 & 0 & 227 & 41.2 & \multirow{2}{*}{$20 \%$} & \multirow{2}{*}{$26 \%$} \\
\hline & $90.1-2010$ & 0 & 39 & 57 & 9 & 46 & 0 & 22 & 0 & 0 & 0 & 0 & 9 & 0 & 182 & 33.0 & & \\
\hline \multirow{2}{*}{$\begin{array}{c}\text { 1B } \\
\text { Riyadh }\end{array}$} & $90.1-2004$ & 1 & 57 & 67 & 24 & 50 & 0 & 30 & 0 & 0 & 0 & 0 & 8 & 0 & 238 & 43.3 & \multirow{2}{*}{$19 \%$} & \multirow{2}{*}{$25 \%$} \\
\hline & $90.1-2010$ & 1 & 43 & 57 & 9 & 46 & 0 & 27 & 0 & 0 & 0 & 0 & 8 & 0 & 192 & 34.8 & & \\
\hline \multirow{2}{*}{$\begin{array}{c}2 \mathrm{~A} \\
\text { Houston }\end{array}$} & $90.1-2004$ & 7 & 40 & 67 & 24 & 50 & 0 & 24 & 0 & 0 & 0 & 0 & 9 & 0 & 222 & 40.4 & \multirow{2}{*}{$19 \%$} & \multirow{2}{*}{$25 \%$} \\
\hline & $90.1-2010$ & 6 & 29 & 57 & 9 & 46 & 0 & 22 & 0 & 0 & 0 & 0 & 9 & 0 & 179 & 32.5 & & \\
\hline \multirow{2}{*}{$\begin{array}{c}2 \mathrm{~B} \\
\text { Phoenix }\end{array}$} & $90.1-2004$ & 4 & 47 & 67 & 24 & 50 & 0 & 29 & 0 & 0 & 0 & 0 & 9 & 0 & 230 & 41.9 & \multirow{2}{*}{$20 \%$} & \multirow{2}{*}{$25 \%$} \\
\hline & $90.1-2010$ & 4 & 35 & 57 & 9 & 46 & 0 & 26 & 0 & 0 & 0 & 0 & 9 & 0 & 185 & 33.7 & & \\
\hline \multirow{2}{*}{$\begin{array}{c}3 \mathrm{~A} \\
\text { Memphis }\end{array}$} & $90.1-2004$ & 13 & 30 & 67 & 24 & 50 & 0 & 23 & 0 & 0 & 0 & 0 & 10 & 0 & 218 & 39.5 & \multirow{2}{*}{$19 \%$} & \multirow{2}{*}{$25 \%$} \\
\hline & $90.1-2010$ & 12 & 22 & 56 & 9 & 46 & 0 & 20 & 0 & 0 & 0 & 0 & 10 & 0 & 176 & 32.0 & & \\
\hline \multirow{2}{*}{$\begin{array}{c}3 \mathrm{~B} \\
\text { El Paso }\end{array}$} & $90.1-2004$ & 9 & 30 & 67 & 24 & 50 & 0 & 26 & 0 & 0 & 0 & 0 & 10 & 0 & 217 & 39.4 & \multirow{2}{*}{$19 \%$} & \multirow{2}{*}{$25 \%$} \\
\hline & $90.1-2010$ & 9 & 22 & 56 & 9 & 46 & 0 & 23 & 0 & 0 & 0 & 0 & 10 & 0 & 176 & 31.9 & & \\
\hline \multirow{2}{*}{$\begin{array}{c}\text { 3C San } \\
\text { Francisco }\end{array}$} & $90.1-2004$ & 8 & 12 & 67 & 24 & 50 & 0 & 21 & 0 & 0 & 0 & 0 & 10 & 0 & 194 & 35.2 & \multirow{2}{*}{$20 \%$} & \multirow{2}{*}{$27 \%$} \\
\hline & $90.1-2010$ & 7 & 8 & 56 & 9 & 46 & 0 & 17 & 0 & 0 & 0 & 0 & 10 & 0 & 155 & 28.2 & & \\
\hline \multirow{2}{*}{$\begin{array}{c}4 \mathrm{~A} \\
\text { Baltimore }\end{array}$} & $90.1-2004$ & 29 & 21 & 67 & 24 & 50 & 0 & 23 & 0 & 0 & 0 & 0 & 10 & 0 & 225 & 40.9 & 200 & $26^{\circ}$ \\
\hline & $90.1-2010$ & 21 & 16 & 56 & 9 & 46 & 0 & 20 & 0 & 0 & 0 & 0 & 10 & 0 & 179 & 32.6 & $20 \%$ & $20 \%$ \\
\hline $4 B$ & $90.1-2004$ & 19 & 23 & 67 & 24 & 50 & 0 & 27 & 0 & 0 & 0 & 0 & 10 & 0 & 221 & 40.2 & $19 \%$ & $25 \%$ \\
\hline Albuquerque & $90.1-2010$ & 16 & 18 & 56 & 9 & 46 & 0 & 24 & 0 & 0 & 0 & 0 & 10 & 0 & 179 & 32.5 & $19 \%$ & $25 \%$ \\
\hline $4 \mathrm{C}$ & $90.1-2004$ & 22 & 12 & 67 & 24 & 50 & 0 & 22 & 0 & 0 & 0 & 0 & 11 & 0 & 208 & 37.9 & 100 & 240 \\
\hline Salem & $90.1-2010$ & 19 & 9 & 56 & 9 & 46 & 0 & 20 & 0 & 0 & 0 & 0 & 11 & 0 & 170 & 30.8 & $19 \%$ & $24 \%$ \\
\hline $5 \mathrm{~A}$ & $90.1-2004$ & 50 & 18 & 67 & 24 & 50 & 0 & 24 & 0 & 0 & 0 & 0 & 11 & 0 & 244 & 44.4 & & \\
\hline Chicago & $90.1-2010$ & 32 & 13 & 56 & 9 & 46 & 0 & 20 & 0 & 0 & 0 & 0 & 11 & 0 & 187 & 34.1 & $23 \%$ & $29 \%$ \\
\hline $5 \mathrm{~B}$ & $90.1-2004$ & 32 & 15 & 67 & 24 & 50 & 0 & 26 & 0 & 0 & 0 & 0 & 11 & 0 & 226 & 41.0 & 200 & $26^{\circ}$ \\
\hline Boise & $90.1-2010$ & 24 & 12 & 56 & 9 & 46 & 0 & 22 & 0 & 0 & 0 & 0 & 11 & 0 & 180 & 32.7 & $20 \%$ & $20 \%$ \\
\hline $5 \mathrm{C}$ & $90.1-2004$ & 25 & 9 & 67 & 24 & 50 & 0 & 21 & 0 & 0 & 0 & 0 & 11 & 0 & 206 & 37.5 & $19 \%$ & $25 \%$ \\
\hline Vancouver & $90.1-2010$ & 20 & 7 & 56 & 9 & 46 & 0 & 18 & 0 & 0 & 0 & 0 & 11 & 0 & 168 & 30.5 & $19 \%$ & $25 \%$ \\
\hline & $90.1-2004$ & 69 & 13 & 67 & 24 & 50 & 0 & 23 & 0 & 0 & 0 & 0 & 11 & 0 & 258 & 47.0 & 250 & 310 \\
\hline Burlington & $90.1-2010$ & 42 & 10 & 56 & 9 & 46 & 0 & 20 & 0 & 0 & 0 & 0 & 11 & 0 & 194 & 35.2 & $25 \%$ & $31 \%$ \\
\hline $6 \mathrm{~B}$ & $90.1-2004$ & 60 & 12 & 67 & 24 & 50 & 0 & 26 & 0 & 0 & 0 & 0 & 11 & 0 & 251 & 45.6 & 230 & $29 \%$ \\
\hline Helena & $90.1-2010$ & 39 & 9 & 56 & 9 & 46 & 0 & 22 & 0 & 0 & 0 & 0 & 11 & 0 & 192 & 35.0 & $23 \%$ & $29 \%$ \\
\hline 7 & $90.1-2004$ & 109 & 10 & 67 & 24 & 50 & 0 & 27 & 0 & 0 & 0 & 0 & 12 & 0 & 299 & 54.4 & 280 & $34 \%$ \\
\hline Duluth & $90.1-2010$ & 64 & 7 & 56 & 9 & 46 & 0 & 20 & 0 & 0 & 0 & 0 & 12 & 0 & 214 & 39.0 & $28 \%$ & $34 \%$ \\
\hline 8 & $90.1-2004$ & 178 & 7 & 67 & 24 & 50 & 0 & 30 & 0 & 0 & 0 & 0 & 12 & 0 & 368 & 66.9 & $28 \%$ & 330 \\
\hline Fairbanks & $90.1-2010$ & 113 & 5 & 56 & 9 & 46 & 0 & 22 & 0 & 0 & 0 & 0 & 12 & 0 & 264 & 48.0 & $28 \%$ & $35 \%$ \\
\hline
\end{tabular}




\section{F.2 Medium Office Energy Saving Results}

\begin{tabular}{|c|c|c|c|c|c|c|c|c|c|c|c|c|c|c|c|c|c|c|}
\hline Zone & Standard & $\begin{array}{c}\text { Heating } \\
\text { [MMBtu] }\end{array}$ & $\begin{array}{c}\text { Cooling } \\
\text { [MMBtu] }\end{array}$ & $\begin{array}{c}\text { Interior } \\
\text { Lights } \\
\text { [MMBtu] } \\
\end{array}$ & $\begin{array}{c}\text { Exterior } \\
\text { Lights } \\
\text { [MMBtu] }\end{array}$ & $\begin{array}{c}\text { Interior } \\
\text { Equipment } \\
\text { [MMBtu] }\end{array}$ & $\begin{array}{c}\text { Exterior } \\
\text { Equipment } \\
\text { [MMBtu] }\end{array}$ & $\begin{array}{c}\text { Fans } \\
\text { [MMBtu] }\end{array}$ & $\begin{array}{c}\begin{array}{c}\text { Pumps } \\
\text { [MMBtu] }\end{array} \\
\end{array}$ & $\begin{array}{c}\text { Heat } \\
\text { Rejection } \\
{[\text { MMBtu }]}\end{array}$ & $\begin{array}{c}\text { Humidifi- } \\
\text { cation } \\
\text { [MMBtu] }\end{array}$ & $\begin{array}{c}\text { Heat } \\
\text { Recovery } \\
{[\text { MMBtu] }}\end{array}$ & $\begin{array}{c}\text { Water } \\
\text { Heater } \\
{[\text { MMBtu }]}\end{array}$ & $\begin{array}{c}\text { Refrigera- } \\
\text { tion } \\
\text { [MMBtu] }\end{array}$ & $\begin{array}{c}\text { Total } \\
\text { Energy } \\
\text { [MMBtu] } \\
\end{array}$ & $\begin{array}{c}\mathrm{EUI} \\
{[\mathrm{kBtu} / \mathrm{sf}]}\end{array}$ & $\begin{array}{c}\text { Energy } \\
\text { Savings [\%] }\end{array}$ & $\begin{array}{c}\text { Energy Savings } \\
\text { w/o } \\
\text { PlugLoad [\%] }\end{array}$ \\
\hline \multirow{2}{*}{$\begin{array}{c}\text { 1A } \\
\text { Miami }\end{array}$} & $90.1-2004$ & 19 & 929 & 525 & 215 & 805 & 0 & 131 & 0 & 0 & 0 & 0 & 117 & 0 & 2,740 & 51.1 & \multirow{2}{*}{$24 \%$} & \multirow{2}{*}{$34 \%$} \\
\hline & $90.1-2010$ & 8 & 691 & 368 & 77 & 723 & 0 & 96 & 0 & 0 & 0 & 0 & 117 & 0 & 2,080 & 38.8 & & \\
\hline \multirow{2}{*}{$\begin{array}{c}\text { 1B } \\
\text { Riyadh }\end{array}$} & $90.1-2004$ & 58 & 935 & 525 & 214 & 805 & 0 & 225 & 0 & 0 & 0 & 0 & 103 & 0 & 2,865 & 53.4 & \multirow{2}{*}{$24 \%$} & \multirow{2}{*}{$34 \%$} \\
\hline & $90.1-2010$ & 21 & 729 & 371 & 77 & 723 & 0 & 144 & 0 & 0 & 0 & 0 & 103 & 0 & 2,169 & 40.4 & & \\
\hline \multirow{2}{*}{$\begin{array}{c}2 \mathrm{~A} \\
\text { Houston }\end{array}$} & $90.1-2004$ & 227 & 736 & 525 & 214 & 805 & 0 & 118 & 0 & 0 & 0 & 0 & 147 & 0 & 2,772 & 51.7 & \multirow{2}{*}{$26 \%$} & \multirow{2}{*}{$37 \%$} \\
\hline & $90.1-2010$ & 114 & 527 & 372 & 77 & 723 & 0 & 83 & 0 & 0 & 0 & 0 & 147 & 0 & 2,043 & 38.1 & & \\
\hline \multirow{2}{*}{$\begin{array}{c}\text { 2B } \\
\text { Phoenix }\end{array}$} & $90.1-2004$ & 142 & 769 & 525 & 214 & 805 & 0 & 166 & 0 & 0 & 0 & 0 & 129 & 0 & 2,750 & 51.3 & \multirow{2}{*}{$25 \%$} & \multirow{2}{*}{$35 \%$} \\
\hline & $90.1-2010$ & 57 & 586 & 375 & 77 & 723 & 0 & 116 & 0 & 0 & 0 & 0 & 129 & 0 & 2,062 & 38.5 & & \\
\hline \multirow{2}{*}{$\begin{array}{c}3 \mathrm{~A} \\
\text { Memphis }\end{array}$} & $90.1-2004$ & 326 & 541 & 525 & 214 & 805 & 0 & 108 & 0 & 0 & 0 & 0 & 171 & 0 & 2,690 & 50.2 & \multirow{2}{*}{$28 \%$} & \multirow{2}{*}{$40 \%$} \\
\hline & $90.1-2010$ & 149 & 377 & 363 & 77 & 723 & 0 & 74 & 0 & 0 & 0 & 0 & 171 & 0 & 1,934 & 36.1 & & \\
\hline \multirow{2}{*}{$\begin{array}{c}3 \mathrm{~B} \\
\text { El Paso }\end{array}$} & 90.1-2004 & 139 & 472 & 525 & 215 & 805 & 0 & 131 & 0 & 0 & 0 & 0 & 163 & 0 & 2,448 & 45.7 & \multirow{2}{*}{$25 \%$} & \multirow{2}{*}{$38 \%$} \\
\hline & $90.1-2010$ & 64 & 343 & 363 & 77 & 723 & 0 & 95 & 0 & 0 & 0 & 0 & 163 & 0 & 1,828 & 34.1 & & \\
\hline \multirow{2}{*}{$\begin{array}{c}\text { 3C San } \\
\text { Francisco }\end{array}$} & $90.1-2004$ & 236 & 223 & 525 & 214 & 805 & 0 & 90 & 0 & 0 & 0 & 0 & 197 & 0 & 2,290 & 42.7 & \multirow{2}{*}{$32 \%$} & \multirow{2}{*}{$49 \%$} \\
\hline & $90.1-2010$ & 55 & 91 & 365 & 77 & 723 & 0 & 60 & 0 & 0 & 0 & 0 & 197 & 0 & 1,568 & 29.2 & & \\
\hline \multirow{2}{*}{$\begin{array}{c}4 \mathrm{~A} \\
\text { Baltimore }\end{array}$} & 90.1-2004 & 567 & 392 & 525 & 214 & 805 & 0 & 107 & 0 & 0 & 0 & 0 & 200 & 0 & 2,810 & 52.4 & $30^{\circ}$ & $42 \%$ \\
\hline & $90.1-2010$ & 283 & 262 & 358 & 77 & 723 & 0 & 74 & 0 & 0 & 0 & 0 & 200 & 0 & 1,977 & 36.9 & $30 \%$ & $42 \%$ \\
\hline & $90.1-2004$ & 282 & 354 & 525 & 214 & 805 & 0 & 132 & 0 & 0 & 0 & 0 & 195 & 0 & 2,507 & 46.7 & $27 \%$ & $40 \%$ \\
\hline Albuquerque & $90.1-2010$ & 128 & 252 & 357 & 77 & 723 & 0 & 101 & 0 & 0 & 0 & 0 & 195 & 0 & 1,833 & 34.2 & $21 \%$ & $40 \%$ \\
\hline $4 \mathrm{C}$ & $90.1-2004$ & 474 & 214 & 525 & 214 & 805 & 0 & 94 & 0 & 0 & 0 & 0 & 212 & 0 & 2,538 & 47.3 & $30 \%$ & $44 \%$ \\
\hline Salem & $90.1-2010$ & 206 & 134 & 360 & 78 & 723 & 0 & 68 & 0 & 0 & 0 & 0 & 212 & 0 & 1,780 & 33.2 & $30 \%$ & $44 \%$ \\
\hline $5 \mathrm{~A}$ & $90.1-2004$ & 826 & 296 & 525 & 214 & 805 & 0 & 104 & 0 & 0 & 0 & 0 & 220 & 0 & 2,990 & 55.8 & $28 \%$ & $38 \%$ \\
\hline Chicago & $90.1-2010$ & 482 & 220 & 359 & 78 & 723 & 0 & 72 & 0 & 0 & 0 & 0 & 220 & 0 & 2,155 & 40.2 & $28 \%$ & $38 \%$ \\
\hline $5 \mathrm{~B}$ & $90.1-2004$ & 570 & 244 & 525 & 214 & 805 & 0 & 113 & 0 & 0 & 0 & 0 & 217 & 0 & 2,687 & 50.1 & $28 \%$ & $40 \%$ \\
\hline Boise & $90.1-2010$ & 306 & 170 & 360 & 77 & 723 & 0 & 83 & 0 & 0 & 0 & 0 & 217 & 0 & 1,935 & 36.1 & $28 \%$ & $40 \%$ \\
\hline $5 \mathrm{C}$ & $90.1-2004$ & 545 & 153 & 525 & 214 & 805 & 0 & 89 & 0 & 0 & 0 & 0 & 221 & 0 & 2,551 & 47.6 & $29 \%$ & $43 \%$ \\
\hline Vancouver & $90.1-2010$ & 267 & 78 & 370 & 78 & 723 & 0 & 67 & 0 & 0 & 0 & 0 & 221 & 0 & 1,802 & 33.6 & $29 \%$ & $43 \%$ \\
\hline $6 \mathrm{~A}$ & $90.1-2004$ & 1,061 & 226 & 525 & 214 & 805 & 0 & 100 & 0 & 0 & 0 & 0 & 238 & 0 & 3,169 & 59.1 & $28 \%$ & $37 \%$ \\
\hline Burlington & $90.1-2010$ & 664 & 159 & 359 & 78 & 723 & 0 & 70 & 0 & 0 & 0 & 0 & 238 & 0 & 2,292 & 42.7 & $20 \%$ & 林 \\
\hline $6 \mathrm{~B}$ & $90.1-2004$ & 844 & 187 & 525 & 214 & 805 & 0 & 108 & 0 & 0 & 0 & 0 & 241 & 0 & 2,923 & 54.5 & $27 \%$ & $38 \%$ \\
\hline Helena & $90.1-2010$ & 520 & 121 & 360 & 77 & 723 & 0 & 79 & 0 & 0 & 0 & 0 & 241 & 0 & 2,121 & 39.6 & $21 \%$ & $38 \%$ \\
\hline 7 & $90.1-2004$ & 1,394 & 161 & 525 & 214 & 805 & 0 & 110 & 0 & 0 & 0 & 0 & 267 & 0 & 3,475 & 64.8 & $27 \%$ & $35 \%$ \\
\hline Duluth & $90.1-2010$ & 939 & 96 & 360 & 78 & 723 & 0 & 69 & 0 & 0 & 0 & 0 & 267 & 0 & 2,532 & 47.2 & 270 & DJ \\
\hline 8 & $90.1-2004$ & 2,234 & 104 & 525 & 213 & 805 & 0 & 110 & 0 & 0 & 0 & 0 & 302 & 0 & 4,292 & 80.0 & $21 \%$ & $26 \%$ \\
\hline Fairbanks & $90.1-2010$ & 1,787 & 52 & 375 & 80 & 723 & 0 & 70 & 0 & 0 & 0 & 0 & 302 & 0 & 3,389 & 63.2 & $21 \%$ & $20 \%$ \\
\hline
\end{tabular}




\section{F.3 Large Office Energy Saving Results}

\begin{tabular}{|c|c|c|c|c|c|c|c|c|c|c|c|c|c|c|c|c|c|c|}
\hline Zone & Standard & $\begin{array}{c}\text { Heating } \\
\text { [MMBtu] }\end{array}$ & $\begin{array}{c}\text { Cooling } \\
\text { [MMBtu] }\end{array}$ & $\begin{array}{c}\text { Interior } \\
\text { Lights } \\
\text { [MMBtu] } \\
\end{array}$ & $\begin{array}{c}\text { Exterior } \\
\text { Lights } \\
\text { [MMBtu] }\end{array}$ & $\begin{array}{c}\text { Interior } \\
\text { Equipment } \\
\text { [MMBtu] }\end{array}$ & $\begin{array}{c}\text { Exterior } \\
\text { Equipment } \\
\text { [MMBtu] }\end{array}$ & $\begin{array}{c}\text { Fans } \\
\text { [MMBtu] }\end{array}$ & $\begin{array}{c}\begin{array}{c}\text { Pumps } \\
\text { [MMBtu] }\end{array} \\
\end{array}$ & $\begin{array}{c}\text { Heat } \\
\text { Rejection } \\
{[\text { MMBtu }]}\end{array}$ & $\begin{array}{c}\text { Humidifi- } \\
\text { cation } \\
\text { [MMBtu] }\end{array}$ & $\begin{array}{c}\text { Heat } \\
\text { Recovery } \\
{[\text { MMBtu] }}\end{array}$ & $\begin{array}{c}\text { Water } \\
\text { Heater } \\
{[\text { MMBtu }]}\end{array}$ & $\begin{array}{c}\text { Refrigera- } \\
\text { tion } \\
\text { [MMBtu] }\end{array}$ & $\begin{array}{c}\text { Total } \\
\text { Energy } \\
\text { [MMBtu] } \\
\end{array}$ & $\begin{array}{c}\mathrm{EUI} \\
{[\mathrm{kBtu} / \mathrm{sf}]}\end{array}$ & $\begin{array}{c}\text { Energy } \\
\text { Savings [\%] }\end{array}$ & $\begin{array}{c}\text { Energy Savings } \\
\text { w/o } \\
\text { PlugLoad [\%] }\end{array}$ \\
\hline \multirow{2}{*}{$\begin{array}{c}1 \mathrm{~A} \\
\text { Miami }\end{array}$} & $90.1-2004$ & 156 & 4,916 & 4,877 & 937 & 5,931 & 1,855 & 1,145 & 1,374 & 2,928 & 0 & 0 & 199 & 0 & 24,318 & 48.8 & \multirow{2}{*}{$26 \%$} & \multirow{2}{*}{$34 \%$} \\
\hline & $90.1-2010$ & 60 & 3,495 & 3,646 & 516 & 5,223 & 1,806 & 953 & 789 & 1,356 & 0 & 19 & 199 & 0 & 18,062 & 36.2 & & \\
\hline \multirow{2}{*}{$\begin{array}{c}1 \mathrm{~B} \\
\text { Riyadh }\end{array}$} & $90.1-2004$ & 532 & 4,107 & 4,877 & 936 & 5,931 & 1,855 & 1,436 & 1,813 & 1,189 & 0 & 0 & 176 & 0 & 22,853 & 45.8 & \multirow{2}{*}{$22 \%$} & \multirow{2}{*}{$30 \%$} \\
\hline & $90.1-2010$ & 180 & 3,266 & 3,655 & 516 & 5,223 & 1,806 & 1,242 & 1,184 & 445 & 0 & 19 & 176 & 0 & 17,711 & 35.5 & & \\
\hline \multirow{2}{*}{$\begin{array}{c}2 \mathrm{~A} \\
\text { Houston }\end{array}$} & $90.1-2004$ & 2,430 & 3,779 & 4,877 & 935 & 5,931 & 1,855 & 1,032 & 1,222 & 2,145 & 0 & 0 & 251 & 0 & 24,456 & 49.1 & \multirow{2}{*}{$30 \%$} & \multirow{2}{*}{$39 \%$} \\
\hline & $90.1-2010$ & 762 & 2,558 & 3,672 & 515 & 5,223 & 1,806 & 808 & 685 & 919 & 0 & 15 & 251 & 0 & 17,215 & 34.5 & & \\
\hline \multirow{2}{*}{$\begin{array}{c}\text { 2B } \\
\text { Phoenix }\end{array}$} & $90.1-2004$ & 1,395 & 3,354 & 4,877 & 935 & 5,931 & 1,855 & 1,290 & 1,723 & 1,629 & 0 & 0 & 220 & 0 & 23,208 & 46.5 & \multirow{2}{*}{$27 \%$} & \multirow{2}{*}{$37 \%$} \\
\hline & $90.1-2010$ & 314 & 2,427 & 3,683 & 515 & 5,223 & 1,806 & 1,060 & 947 & 655 & 0 & 0 & 220 & 0 & 16,850 & 33.8 & & \\
\hline \multirow{2}{*}{$\begin{array}{c}3 \mathrm{~A} \\
\text { Memphis }\end{array}$} & $90.1-2004$ & 2,588 & 2,662 & 4,877 & 936 & 5,931 & 1,855 & 934 & 1,061 & 1,452 & 0 & 0 & 292 & 0 & 22,587 & 45.3 & \multirow{2}{*}{$27 \%$} & \multirow{2}{*}{$37 \%$} \\
\hline & $90.1-2010$ & 1,067 & 1,873 & 3,621 & 517 & 5,223 & 1,806 & 733 & 661 & 654 & 0 & 15 & 292 & 0 & 16,464 & 33.0 & & \\
\hline \multirow{2}{*}{$\begin{array}{c}3 \mathrm{~B} \\
\text { El Paso }\end{array}$} & 90.1-2004 & 972 & 1,912 & 4,877 & 936 & 5,931 & 1,855 & 1,181 & 712 & 647 & 0 & 0 & 278 & 0 & 19,301 & 38.7 & \multirow{2}{*}{$22 \%$} & \multirow{2}{*}{$31 \%$} \\
\hline & $90.1-2010$ & 394 & 1,604 & 3,615 & 516 & 5,223 & 1,806 & 998 & 417 & 278 & 0 & 0 & 278 & 0 & 15,129 & 30.3 & & \\
\hline \multirow{2}{*}{$\begin{array}{c}\text { 3C San } \\
\text { Francisco }\end{array}$} & $90.1-2004$ & 1,685 & 803 & 4,877 & 935 & 5,931 & 1,855 & 811 & 790 & 73 & 0 & 0 & 336 & 0 & 18,095 & 36.3 & \multirow{2}{*}{$26 \%$} & \multirow{2}{*}{$39 \%$} \\
\hline & $90.1-2010$ & 275 & 515 & 3,630 & 516 & 5,223 & 1,806 & 644 & 387 & 25 & 0 & 0 & 336 & 0 & 13,357 & 26.8 & & \\
\hline \multirow{2}{*}{$\begin{array}{c}4 \mathrm{~A} \\
\text { Baltimore }\end{array}$} & $90.1-2004$ & 4,636 & 1,955 & 4,877 & 935 & 5,931 & 1,855 & 945 & 983 & 904 & 0 & 0 & 342 & 0 & 23,362 & 46.9 & $29 \%$ & $38 \%$ \\
\hline & $90.1-2010$ & 2,163 & 1,297 & 3,596 & 518 & 5,223 & 1,806 & 767 & 532 & 400 & 0 & 15 & 342 & 0 & 16,658 & 33.4 & 2970 & $30 \%$ \\
\hline & $90.1-2004$ & 2,231 & 1,437 & 4,877 & 935 & 5,931 & 1,855 & 1,178 & 793 & 328 & 0 & 0 & 334 & 0 & 19,899 & 39.9 & $24 \%$ & $33 \%$ \\
\hline Albuquerque & $90.1-2010$ & 888 & 1,171 & 3,586 & 516 & 5,223 & 1,806 & 1,067 & 485 & 145 & 0 & 0 & 334 & 0 & 15,221 & 30.5 & $24 \%$ & $30 \%$ \\
\hline $4 \mathrm{C}$ & $90.1-2004$ & 3,598 & 773 & 4,877 & 935 & 5,931 & 1,855 & 857 & 448 & 228 & 0 & 0 & 363 & 0 & 19,865 & 39.8 & $26 \%$ & $37 \%$ \\
\hline Salem & $90.1-2010$ & 1,439 & 648 & 3,607 & 520 & 5,223 & 1,806 & 727 & 244 & 101 & 0 & 0 & 363 & 0 & 14,678 & 29.4 & $20 \%$ & $3 \%$ \\
\hline $5 \mathrm{~A}$ & $90.1-2004$ & 7,137 & 1,379 & 4,877 & 934 & 5,931 & 1,855 & 925 & 637 & 676 & 0 & 0 & 377 & 0 & 24,727 & 49.6 & $28 \%$ & $37 \%$ \\
\hline Chicago & $90.1-2010$ & 3,714 & 1,060 & 3,602 & 523 & 5,223 & 1,806 & 736 & 503 & 293 & 0 & 14 & 377 & 0 & 17,851 & 35.8 & $28 \%$ & $3 \%$ \\
\hline $5 \mathrm{~B}$ & $90.1-2004$ & 4,729 & 1,062 & 4,877 & 934 & 5,931 & 1,855 & 1,072 & 452 & 249 & 0 & 0 & 370 & 0 & 21,531 & 43.2 & $26 \%$ & $36 \%$ \\
\hline Boise & $90.1-2010$ & 2,206 & 820 & 3,601 & 514 & 5,223 & 1,806 & 930 & 269 & 103 & 0 & 0 & 370 & 0 & 15,842 & 31.8 & $20 \%$ & $30 \%$ \\
\hline $5 \mathrm{C}$ & $90.1-2004$ & 4,415 & 471 & 4,877 & 933 & 5,931 & 1,855 & 837 & 346 & 108 & 0 & 0 & 377 & 0 & 20,149 & 40.4 & $27 \%$ & $38 \%$ \\
\hline Vancouver & $90.1-2010$ & 1,813 & 346 & 3,666 & 523 & 5,223 & 1,806 & 724 & 187 & 44 & 0 & 0 & 377 & 0 & 14,709 & 29.5 & $27 \%$ & $38 \%$ \\
\hline $6 \mathrm{~A}$ & $90.1-2004$ & 8,981 & 1,049 & 4,877 & 934 & 5,931 & 1,855 & 908 & 507 & 429 & 0 & 0 & 408 & 0 & 25,878 & 51.9 & $27 \%$ & $35 \%$ \\
\hline Burlington & $90.1-2010$ & 5,279 & 785 & 3,603 & 525 & 5,223 & 1,806 & 729 & 417 & 182 & 0 & 14 & 408 & 0 & 18,970 & 38.0 & $21 \%$ & $35 \%$ \\
\hline $6 \mathrm{~B}$ & $90.1-2004$ & 6,827 & 844 & 4,877 & 934 & 5,931 & 1,855 & 996 & 541 & 133 & 0 & 0 & 412 & 0 & 23,350 & 46.8 & $26 \%$ & $35 \%$ \\
\hline Helena & $90.1-2010$ & 3,859 & 591 & 3,606 & 517 & 5,223 & 1,806 & 895 & 335 & 66 & 0 & 15 & 412 & 0 & 17,324 & 34.7 & $20 \%$ & $35 \%$ \\
\hline 7 & $90.1-2004$ & 12,082 & 712 & 4,877 & 934 & 5,931 & 1,855 & 986 & 402 & 239 & 0 & 0 & 457 & 0 & 28,474 & 57.1 & $27 \%$ & $34 \%$ \\
\hline Duluth & $90.1-2010$ & 7,409 & 476 & 3,605 & 521 & 5,223 & 1,806 & 743 & 374 & 92 & 0 & 15 & 457 & 0 & 20,722 & 41.6 & 270 & 3470 \\
\hline 8 & $90.1-2004$ & 18,961 & 442 & 4,877 & 928 & 5,931 & 1,855 & 998 & 310 & 72 & 0 & 0 & 517 & 0 & 34,890 & 70.0 & $22 \%$ & $26 \%$ \\
\hline Fairbanks & $90.1-2010$ & 14,129 & 240 & 3,703 & 538 & 5,223 & 1,806 & 759 & 313 & 20 & 0 & 16 & 517 & 0 & 27,265 & 54.7 & $22 \%$ & $20 \%$ \\
\hline
\end{tabular}




\section{F.4 Stand-alone Retail Energy Saving Results}

\begin{tabular}{|c|c|c|c|c|c|c|c|c|c|c|c|c|c|c|c|c|c|c|}
\hline Zone & Standard & $\begin{array}{c}\text { Heating } \\
\text { [MMBtu] }\end{array}$ & $\begin{array}{c}\text { Cooling } \\
\text { [MMBtu] }\end{array}$ & $\begin{array}{c}\text { Interior } \\
\text { Lights } \\
\text { [MMBtu] }\end{array}$ & $\begin{array}{c}\text { Exterior } \\
\text { Lights } \\
\text { [MMBtu] }\end{array}$ & $\begin{array}{c}\text { Interior } \\
\text { Equipment } \\
\text { [MMBtu] }\end{array}$ & $\begin{array}{c}\text { Exterior } \\
\text { Equipment } \\
\text { [MMBtu] }\end{array}$ & $\begin{array}{c}\text { Fans } \\
{[\mathrm{MMBtu}]}\end{array}$ & $\begin{array}{c}\text { Pumps } \\
\text { [MMBtu] }\end{array}$ & $\begin{array}{c}\text { Heat } \\
\text { Rejection } \\
\text { [MMBtu] }\end{array}$ & $\begin{array}{l}\text { Humidifi- } \\
\text { cation } \\
\text { [MMBtu] }\end{array}$ & $\begin{array}{c}\text { Heat } \\
\text { Recovery } \\
{[\text { MMBtu] }}\end{array}$ & $\begin{array}{c}\text { Water } \\
\text { Heater } \\
\text { [MMBtu] }\end{array}$ & $\begin{array}{l}\text { Refrigera- } \\
\text { tion } \\
{[\mathrm{MMBtu}]}\end{array}$ & $\begin{array}{c}\text { Total } \\
\text { Energy } \\
{[\text { MMBtu] }}\end{array}$ & $\begin{array}{c}\mathrm{EUI} \\
{[\mathrm{kBtu} / \mathrm{sf}]}\end{array}$ & $\begin{array}{c}\text { Energy } \\
\text { Savings [\%] }\end{array}$ & $\begin{array}{c}\text { Energy Savings } \\
\text { w/o } \\
\text { PlugLoad [\%] }\end{array}$ \\
\hline \multirow{2}{*}{$\begin{array}{c}\text { 1A } \\
\text { Miami }\end{array}$} & $90.1-2004$ & 8 & 597 & 465 & 109 & 185 & 0 & 336 & 0 & 0 & 0 & 0 & 22 & 0 & 1,722 & 69.7 & \multirow{2}{*}{$27 \%$} & \multirow{2}{*}{$30 \%$} \\
\hline & $90.1-2010$ & 9 & 394 & 411 & 45 & 185 & 0 & 188 & 0 & 0 & 0 & 0 & 22 & 0 & 1,254 & 50.8 & & \\
\hline \multirow{2}{*}{$\begin{array}{c}\text { 1B } \\
\text { Riyadh }\end{array}$} & $90.1-2004$ & 26 & 635 & 465 & 109 & 185 & 0 & 406 & 0 & 0 & 0 & 0 & 21 & 0 & 1,847 & 74.8 & \multirow{2}{*}{$24 \%$} & \multirow{2}{*}{$26 \%$} \\
\hline & $90.1-2010$ & 32 & 468 & 421 & 45 & 185 & 0 & 239 & 0 & 0 & 0 & 0 & 21 & 0 & 1,411 & 57.1 & & \\
\hline \multirow{2}{*}{$\begin{array}{c}2 \mathrm{~A} \\
\text { Houston }\end{array}$} & $90.1-2004$ & 195 & 454 & 465 & 109 & 185 & 0 & 359 & 0 & 0 & 0 & 0 & 25 & 0 & 1,793 & 72.6 & \multirow{2}{*}{$35 \%$} & \multirow{2}{*}{$39 \%$} \\
\hline & $90.1-2010$ & 64 & 233 & 417 & 45 & 185 & 0 & 183 & 0 & 0 & 0 & 20 & 25 & 0 & 1,171 & 47.4 & & \\
\hline \multirow{2}{*}{$\begin{array}{c}2 \mathrm{~B} \\
\text { Phoenix }\end{array}$} & $90.1-2004$ & 89 & 516 & 465 & 109 & 185 & 0 & 413 & 0 & 0 & 0 & 0 & 23 & 0 & 1,800 & 72.9 & \multirow{2}{*}{$31 \%$} & \multirow{2}{*}{$34 \%$} \\
\hline & $90.1-2010$ & 58 & 300 & 422 & 45 & 185 & 0 & 213 & 0 & 0 & 0 & 0 & 23 & 0 & 1,247 & 50.5 & & \\
\hline \multirow{2}{*}{$\begin{array}{c}3 \mathrm{~A} \\
\text { Memphis }\end{array}$} & $90.1-2004$ & 279 & 323 & 465 & 109 & 185 & 0 & 339 & 0 & 0 & 0 & 0 & 28 & 0 & 1,728 & 70.0 & \multirow{2}{*}{$34 \%$} & \multirow{2}{*}{$38 \%$} \\
\hline & $90.1-2010$ & 96 & 173 & 418 & 45 & 185 & 0 & 180 & 0 & 0 & 0 & 19 & 28 & 0 & 1,144 & 46.3 & & \\
\hline \multirow{2}{*}{$\begin{array}{c}3 \mathrm{~B} \\
\text { El Paso }\end{array}$} & $90.1-2004$ & 114 & 274 & 465 & 109 & 185 & 0 & 371 & 0 & 0 & 0 & 0 & 27 & 0 & 1,545 & 62.6 & \multirow{2}{*}{$25 \%$} & \multirow{2}{*}{$28 \%$} \\
\hline & $90.1-2010$ & 84 & 188 & 424 & 45 & 185 & 0 & 211 & 0 & 0 & 0 & 0 & 27 & 0 & 1,164 & 47.1 & & \\
\hline \multirow{2}{*}{$\begin{array}{c}\text { 3C San } \\
\text { Francisco }\end{array}$} & $90.1-2004$ & 178 & 47 & 465 & 109 & 185 & 0 & 314 & 0 & 0 & 0 & 0 & 31 & 0 & 1,328 & 53.8 & \multirow{2}{*}{$24 \%$} & \multirow{2}{*}{$28 \%$} \\
\hline & $90.1-2010$ & 123 & 33 & 423 & 45 & 185 & 0 & 170 & 0 & 0 & 0 & 0 & 31 & 0 & 1,010 & 40.9 & & \\
\hline \multirow{2}{*}{$\begin{array}{c}4 \mathrm{~A} \\
\text { Baltimore }\end{array}$} & $90.1-2004$ & 561 & 212 & 465 & 109 & 185 & 0 & 343 & 0 & 0 & 0 & 0 & 31 & 0 & 1,907 & 77.2 & $37 \%$ & $41 \%$ \\
\hline & $90.1-2010$ & 172 & 129 & 416 & 45 & 185 & 0 & 206 & 0 & 0 & 0 & 19 & 31 & 0 & 1,203 & 48.7 & $37 \%$ & $41 \%$ \\
\hline & $90.1-2004$ & 260 & 175 & 465 & 109 & 185 & 0 & 390 & 0 & 0 & 0 & 0 & 31 & 0 & 1,614 & 65.4 & $24 \%$ & $280 \%$ \\
\hline Albuquerque & $90.1-2010$ & 176 & 135 & 415 & 45 & 185 & 0 & 234 & 0 & 0 & 0 & 0 & 31 & 0 & 1,220 & 49.4 & $24 \%$ & $28 \%$ \\
\hline $4 \mathrm{C}$ & $90.1-2004$ & 440 & 81 & 465 & 109 & 185 & 0 & 332 & 0 & 0 & 0 & 0 & 33 & 0 & 1,644 & 66.6 & 250 & $28 \%$ \\
\hline Salem & $90.1-2010$ & 293 & 60 & 417 & 45 & 185 & 0 & 201 & 0 & 0 & 0 & 0 & 33 & 0 & 1,233 & 49.9 & $25 \%$ & $28 \%$ \\
\hline $5 \mathrm{~A}$ & $90.1-2004$ & 740 & 166 & 465 & 109 & 185 & 0 & 396 & 0 & 0 & 0 & 0 & 34 & 0 & 2,095 & 84.8 & & \\
\hline Chicago & $90.1-2010$ & 259 & 103 & 419 & 46 & 185 & 0 & 215 & 0 & 0 & 0 & 18 & 33 & 0 & 1,278 & 51.7 & $39 \%$ & $43 \%$ \\
\hline $5 \mathrm{~B}$ & 90.1-2004 & 488 & 130 & 465 & 109 & 185 & 0 & 411 & 0 & 0 & 0 & 0 & 33 & 0 & 1,821 & 73.7 & 250 & $28 \%$ \\
\hline Boise & $90.1-2010$ & 363 & 89 & 424 & 45 & 185 & 0 & 229 & 0 & 0 & 0 & 0 & 33 & 0 & 1,367 & 55.3 & $25 \%$ & $28 \%$ \\
\hline $5 \mathrm{C}$ & $90.1-2004$ & 531 & 33 & 465 & 109 & 185 & 0 & 323 & 0 & 0 & 0 & 0 & 34 & 0 & 1,678 & 68.0 & $24 \%$ & $27 \%$ \\
\hline Vancouver & $90.1-2010$ & 364 & 26 & 423 & 46 & 185 & 0 & 191 & 0 & 0 & 0 & 0 & 34 & 0 & 1,268 & 51.3 & $24 \%$ & $27 \%$ \\
\hline $6 \mathrm{~A}$ & 90.1-2004 & 955 & 115 & 465 & 109 & 185 & 0 & 402 & 0 & 0 & 0 & 0 & 36 & 0 & 2,266 & 91.8 & $11^{\circ}$ & 150 \\
\hline Burlington & $90.1-2010$ & 324 & 72 & 440 & 46 & 185 & 0 & 214 & 0 & 0 & 0 & 18 & 35 & 0 & 1,333 & 54.0 & $41 \%$ & $45 \%$ \\
\hline $6 \mathrm{~B}$ & $90.1-2004$ & 687 & 88 & 465 & 109 & 185 & 0 & 446 & 0 & 0 & 0 & 0 & 36 & 0 & 2,015 & 81.6 & $37 \%$ & $40 \%$ \\
\hline Helena & $90.1-2010$ & 254 & 64 & 440 & 45 & 185 & 0 & 239 & 0 & 0 & 0 & 18 & 36 & 0 & 1,279 & 51.8 & $37 \%$ & $40 \%$ \\
\hline 7 & $90.1-2004$ & 1,257 & 71 & 465 & 109 & 185 & 0 & 446 & 0 & 0 & 0 & 0 & 39 & 0 & 2,571 & 104.1 & 440 & 470 \\
\hline Duluth & $90.1-2010$ & 440 & 45 & 423 & 45 & 185 & 0 & 254 & 0 & 0 & 0 & 18 & 38 & 0 & 1,450 & 58.7 & $44 \%$ & $4 / \%$ \\
\hline 8 & $90.1-2004$ & 2,018 & 39 & 465 & 108 & 185 & 0 & 479 & 0 & 0 & 0 & 0 & 42 & 0 & 3,335 & 135.1 & $38 \%$ & $40 \%$ \\
\hline Fairbanks & $90.1-2010$ & 1,017 & 25 & 445 & 47 & 185 & 0 & 296 & 0 & 0 & 0 & 19 & 42 & 0 & 2,076 & 84.1 & $38 \%$ & $40 \%$ \\
\hline
\end{tabular}




\section{F.5 Strip Mall Energy Saving Results}

\begin{tabular}{|c|c|c|c|c|c|c|c|c|c|c|c|c|c|c|c|c|c|c|}
\hline Zone & Standard & $\begin{array}{c}\text { Heating } \\
\text { [MMBtu] }\end{array}$ & $\begin{array}{c}\text { Cooling } \\
\text { [MMBtu] }\end{array}$ & $\begin{array}{c}\text { Interior } \\
\text { Lights } \\
\text { [MMBtu] }\end{array}$ & $\begin{array}{c}\text { Exterior } \\
\text { Lights } \\
\text { [MMBtu] }\end{array}$ & $\begin{array}{c}\text { Interior } \\
\text { Equipment } \\
\text { [MMBtu] }\end{array}$ & $\begin{array}{c}\text { Exterior } \\
\text { Equipment } \\
\text { [MMBtu] }\end{array}$ & $\begin{array}{c}\text { Fans } \\
{[\mathrm{MMBtu}]}\end{array}$ & $\begin{array}{c}\text { Pumps } \\
\text { [MMBtu] }\end{array}$ & $\begin{array}{c}\text { Heat } \\
\text { Rejection } \\
\text { [MMBtu] }\end{array}$ & $\begin{array}{l}\text { Humidifi- } \\
\text { cation } \\
\text { [MMBtu] }\end{array}$ & $\begin{array}{c}\text { Heat } \\
\text { Recovery } \\
{[\text { MMBtu] }}\end{array}$ & $\begin{array}{c}\text { Water } \\
\text { Heater } \\
\text { [MMBtu] }\end{array}$ & $\begin{array}{l}\text { Refrigera- } \\
\text { tion } \\
{[\mathrm{MMBtu}]}\end{array}$ & $\begin{array}{c}\text { Total } \\
\text { Energy } \\
{[\text { MMBtu] }}\end{array}$ & $\begin{array}{c}\mathrm{EUI} \\
{[\mathrm{kBtu} / \mathrm{sf}]}\end{array}$ & $\begin{array}{c}\text { Energy } \\
\text { Savings [\%] }\end{array}$ & $\begin{array}{c}\text { Energy Savings } \\
\text { w/o } \\
\text { PlugLoad [\%] }\end{array}$ \\
\hline \multirow{2}{*}{$\begin{array}{c}1 \mathrm{~A} \\
\text { Miami }\end{array}$} & $90.1-2004$ & 5 & 517 & 544 & 137 & 122 & 0 & 221 & 0 & 0 & 0 & 0 & 36 & 0 & 1,581 & 70.3 & \multirow{2}{*}{$25 \%$} & \multirow{2}{*}{$28 \%$} \\
\hline & $90.1-2010$ & 4 & 369 & 424 & 52 & 122 & 0 & 172 & 0 & 0 & 0 & 0 & 36 & 0 & 1,180 & 52.4 & & \\
\hline \multirow{2}{*}{$\begin{array}{c}\text { 1B } \\
\text { Riyadh }\end{array}$} & $90.1-2004$ & 9 & 535 & 544 & 137 & 122 & 0 & 304 & 0 & 0 & 0 & 0 & 35 & 0 & 1,684 & 74.9 & \multirow{2}{*}{$23 \%$} & \multirow{2}{*}{$25 \%$} \\
\hline & $90.1-2010$ & 8 & 401 & 424 & 52 & 122 & 0 & 247 & 0 & 0 & 0 & 0 & 35 & 0 & 1,290 & 57.3 & & \\
\hline \multirow{2}{*}{$\begin{array}{c}2 \mathrm{~A} \\
\text { Houston }\end{array}$} & $90.1-2004$ & 147 & 405 & 544 & 136 & 122 & 0 & 244 & 0 & 0 & 0 & 0 & 39 & 0 & 1,637 & 72.7 & \multirow{2}{*}{$24 \%$} & \multirow{2}{*}{$26 \%$} \\
\hline & $90.1-2010$ & 112 & 288 & 424 & 52 & 122 & 0 & 200 & 0 & 0 & 0 & 0 & 39 & 0 & 1,237 & 55.0 & & \\
\hline \multirow{2}{*}{$\begin{array}{c}2 \mathrm{~B} \\
\text { Phoenix }\end{array}$} & $90.1-2004$ & 51 & 450 & 544 & 136 & 122 & 0 & 307 & 0 & 0 & 0 & 0 & 37 & 0 & 1,648 & 73.2 & \multirow{2}{*}{$25 \%$} & \multirow{2}{*}{$28 \%$} \\
\hline & $90.1-2010$ & 38 & 315 & 424 & 52 & 122 & 0 & 240 & 0 & 0 & 0 & 0 & 37 & 0 & 1,228 & 54.6 & & \\
\hline \multirow{2}{*}{$\begin{array}{c}3 \mathrm{~A} \\
\text { Memphis }\end{array}$} & $90.1-2004$ & 326 & 303 & 544 & 136 & 122 & 0 & 245 & 0 & 0 & 0 & 0 & 41 & 0 & 1,717 & 76.3 & \multirow{2}{*}{$31 \%$} & \multirow{2}{*}{$33 \%$} \\
\hline & $90.1-2010$ & 204 & 182 & 424 & 52 & 122 & 0 & 161 & 0 & 0 & 0 & 0 & 41 & 0 & 1,187 & 52.7 & & \\
\hline \multirow{2}{*}{$\begin{array}{c}3 \mathrm{~B} \\
\text { El Paso }\end{array}$} & $90.1-2004$ & 99 & 250 & 544 & 136 & 122 & 0 & 281 & 0 & 0 & 0 & 0 & 40 & 0 & 1,473 & 65.5 & \multirow{2}{*}{$27 \%$} & \multirow{2}{*}{$29 \%$} \\
\hline & $90.1-2010$ & 72 & 168 & 424 & 52 & 122 & 0 & 201 & 0 & 0 & 0 & 0 & 40 & 0 & 1,079 & 47.9 & & \\
\hline \multirow{2}{*}{$\begin{array}{c}\text { 3C San } \\
\text { Francisco }\end{array}$} & $90.1-2004$ & 182 & 39 & 544 & 136 & 122 & 0 & 193 & 0 & 0 & 0 & 0 & 43 & 0 & 1,259 & 56.0 & \multirow{2}{*}{$27 \%$} & \multirow{2}{*}{$30 \%$} \\
\hline & $90.1-2010$ & 117 & 22 & 424 & 52 & 122 & 0 & 140 & 0 & 0 & 0 & 0 & 43 & 0 & 921 & 40.9 & & \\
\hline \multirow{2}{*}{$\begin{array}{c}4 \mathrm{~A} \\
\text { Baltimore }\end{array}$} & $90.1-2004$ & 664 & 193 & 544 & 136 & 122 & 0 & 240 & 0 & 0 & 0 & 0 & 43 & 0 & 1,942 & 86.3 & 320 & $34 \%$ \\
\hline & $90.1-2010$ & 377 & 123 & 424 & 52 & 122 & 0 & 180 & 0 & 0 & 0 & 0 & 43 & 0 & 1,322 & 58.8 & $32 \%$ & $34 \%$ \\
\hline & $90.1-2004$ & 268 & 160 & 544 & 136 & 122 & 0 & 277 & 0 & 0 & 0 & 0 & 43 & 0 & 1,550 & 68.9 & $28 \%$ & $30 \%$ \\
\hline Albuquerque & $90.1-2010$ & 154 & 115 & 424 & 52 & 122 & 0 & 209 & 0 & 0 & 0 & 0 & 43 & 0 & 1,120 & 49.8 & $28 \%$ & $30 \%$ \\
\hline $4 \mathrm{C}$ & 90.1-2004 & 549 & 77 & 544 & 136 & 122 & 0 & 230 & 0 & 0 & 0 & 0 & 45 & 0 & 1,702 & 75.6 & $30^{\circ}$ & $320 \%$ \\
\hline Salem & $90.1-2010$ & 322 & 56 & 424 & 52 & 122 & 0 & 176 & 0 & 0 & 0 & 0 & 44 & 0 & 1,197 & 53.2 & $30 \%$ & $32 \%$ \\
\hline $5 \mathrm{~A}$ & $90.1-2004$ & 941 & 146 & 544 & 136 & 122 & 0 & 243 & 0 & 0 & 0 & 0 & 45 & 0 & 2,176 & 96.7 & & \\
\hline Chicago & $90.1-2010$ & 589 & 92 & 424 & 53 & 122 & 0 & 179 & 0 & 0 & 0 & 0 & 45 & 0 & 1,504 & 66.8 & $31 \%$ & $33 \%$ \\
\hline $5 \mathrm{~B}$ & 90.1-2004 & 607 & 115 & 544 & 136 & 122 & 0 & 263 & 0 & 0 & 0 & 0 & 45 & 0 & 1,831 & 81.4 & 280 & $30 \%$ \\
\hline Boise & $90.1-2010$ & 390 & 80 & 424 & 52 & 122 & 0 & 203 & 0 & 0 & 0 & 0 & 45 & 0 & 1,316 & 58.5 & $28 \%$ & $30 \%$ \\
\hline $5 \mathrm{C}$ & $90.1-2004$ & 701 & 29 & 544 & 136 & 122 & 0 & 171 & 0 & 0 & 0 & 0 & 45 & 0 & 1,748 & 77.7 & $29 \%$ & $31 \%$ \\
\hline Vancouver & $90.1-2010$ & 430 & 24 & 424 & 53 & 122 & 0 & 145 & 0 & 0 & 0 & 0 & 45 & 0 & 1,243 & 55.2 & $29 \%$ & $31 \%$ \\
\hline $6 \mathrm{~A}$ & 90.1-2004 & 1220 & 94 & 544 & 136 & 122 & 0 & 256 & 0 & 0 & 0 & 0 & 47 & 0 & 2,419 & 107.5 & 330 & $34 \%$ \\
\hline Burlington & $90.1-2010$ & 755 & 61 & 424 & 53 & 122 & 0 & 171 & 0 & 0 & 0 & 0 & 46 & 0 & 1,631 & 72.5 & $33 \%$ & $34 \%$ \\
\hline $6 \mathrm{~B}$ & $90.1-2004$ & 854 & 70 & 544 & 136 & 122 & 0 & 285 & 0 & 0 & 0 & 0 & 47 & 0 & 2,058 & 91.4 & $28 \%$ & $30 \%$ \\
\hline Helena & $90.1-2010$ & 578 & 54 & 424 & 52 & 122 & 0 & 197 & 0 & 0 & 0 & 0 & 46 & 0 & 1,473 & 65.5 & $28 \%$ & $30 \%$ \\
\hline 7 & $90.1-2004$ & 1,573 & 56 & 544 & 136 & 122 & 0 & 299 & 0 & 0 & 0 & 0 & 49 & 0 & 2,778 & 123.5 & 230 & $250 \%$ \\
\hline Duluth & $90.1-2010$ & 982 & 31 & 424 & 52 & 122 & 0 & 192 & 0 & 0 & 0 & 0 & 49 & 0 & 1,852 & 82.3 & $35 \%$ & $53 \%$ \\
\hline 8 & $90.1-2004$ & 2,456 & 29 & 544 & 135 & 122 & 0 & 364 & 0 & 0 & 0 & 0 & 51 & 0 & 3,701 & 164.5 & $30 \%$ & $31 \%$ \\
\hline Fairbanks & $90.1-2010$ & 1,673 & 12 & 424 & 54 & 122 & 0 & 255 & 0 & 0 & 0 & 0 & 51 & 0 & 2,591 & 115.2 & $30 \%$ & $31 \%$ \\
\hline
\end{tabular}




\section{F.6 Primary School Energy Saving Results}

\begin{tabular}{|c|c|c|c|c|c|c|c|c|c|c|c|c|c|c|c|c|c|c|}
\hline Zone & Standard & $\begin{array}{c}\text { Heating } \\
\text { [MMBtu] }\end{array}$ & $\begin{array}{c}\text { Cooling } \\
\text { [MMBtu] }\end{array}$ & $\begin{array}{c}\text { Interior } \\
\text { Lights } \\
\text { [MMBtu] }\end{array}$ & $\begin{array}{c}\text { Exterior } \\
\text { Lights } \\
\text { [MMBtu] }\end{array}$ & $\begin{array}{c}\text { Interior } \\
\text { Equipment } \\
\text { [MMBtu] }\end{array}$ & $\begin{array}{c}\text { Exterior } \\
\text { Equipment } \\
\text { [MMBtu] }\end{array}$ & $\begin{array}{c}\text { Fans } \\
\text { [MMBtu] }\end{array}$ & $\begin{array}{c}\text { Pumps } \\
\text { [MMBtu] }\end{array}$ & $\begin{array}{c}\text { Heat } \\
\text { Rejection } \\
{[\text { MMBtu] }}\end{array}$ & $\begin{array}{c}\text { Humidifi- } \\
\text { cation } \\
\text { [MMBtu] }\end{array}$ & $\begin{array}{c}\text { Heat } \\
\text { Recovery } \\
{[\text { MMBtu] }}\end{array}$ & $\begin{array}{c}\text { Water } \\
\text { Heater } \\
\text { [MMBtu] }\end{array}$ & $\begin{array}{c}\text { Refrigera- } \\
\text { tion } \\
\text { [MMBtu] }\end{array}$ & $\begin{array}{c}\text { Total } \\
\text { Energy } \\
\text { [MMBtu] }\end{array}$ & $\begin{array}{c}\text { EUI } \\
{[\mathrm{kBtu} / \mathrm{sf}]}\end{array}$ & $\begin{array}{c}\text { Energy } \\
\text { Savings [\%] }\end{array}$ & $\begin{array}{c}\text { Energy Savings } \\
\text { w/o } \\
\text { PlugLoad [\%] } \\
\end{array}$ \\
\hline \multirow{2}{*}{$\begin{array}{c}1 \mathrm{~A} \\
\text { Miami }\end{array}$} & $90.1-2004$ & 35 & 1,718 & 1,148 & 81 & 1,576 & 0 & 579 & 0 & 0 & 0 & 0 & 43 & 74 & 5,254 & 71.0 & \multirow{2}{*}{$22 \%$} & \multirow{2}{*}{$32 \%$} \\
\hline & $90.1-2010$ & 18 & 1,157 & 782 & 33 & 1,548 & 0 & 359 & 0 & 0 & 0 & 80 & 43 & 74 & 4,094 & 55.4 & & \\
\hline \multirow{2}{*}{$\begin{array}{c}\text { 1B } \\
\text { Riyadh }\end{array}$} & 90.1-2004 & 106 & 1,808 & 1,148 & 81 & 1,576 & 0 & 702 & 0 & 0 & 0 & 0 & 40 & 72 & 5,533 & 74.8 & \multirow{2}{*}{$21 \%$} & \multirow{2}{*}{$30 \%$} \\
\hline & $90.1-2010$ & 61 & 1,315 & 792 & 33 & 1,548 & 0 & 490 & 0 & 0 & 0 & 0 & 40 & 74 & 4,353 & 58.9 & & \\
\hline \multirow{2}{*}{$\begin{array}{l}2 \mathrm{~A} \\
\text { Houston }\end{array}$} & $90.1-2004$ & 461 & 1,377 & 1,148 & 81 & 1,576 & 0 & 544 & 1 & 0 & 0 & 0 & 57 & 73 & 5,317 & 71.9 & \multirow{2}{*}{$26 \%$} & \multirow{2}{*}{$38 \%$} \\
\hline & $90.1-2010$ & 141 & 860 & 792 & 33 & 1,548 & 0 & 341 & 0 & 0 & 0 & 66 & 57 & 74 & 3,911 & 52.9 & & \\
\hline \multirow{2}{*}{$\begin{array}{c}\text { 2B } \\
\text { Phoenix }\end{array}$} & $90.1-2004$ & 245 & 1,435 & 1,148 & 81 & 1,576 & 0 & 644 & 0 & 0 & 0 & 0 & 50 & 72 & 5,251 & 71.0 & \multirow{2}{*}{$23 \%$} & \multirow{2}{*}{$33 \%$} \\
\hline & $90.1-2010$ & 111 & 978 & 800 & 33 & 1,548 & 0 & 435 & 0 & 0 & 0 & 0 & 50 & 73 & 4,029 & 54.5 & & \\
\hline \multirow{2}{*}{$\begin{array}{c}3 \mathrm{~A} \\
\text { Memphis }\end{array}$} & $90.1-2004$ & 780 & 1,015 & 1,148 & 81 & 1,576 & 0 & 497 & 1 & 0 & 0 & 0 & 67 & 72 & 5,237 & 70.8 & \multirow{2}{*}{$31 \%$} & \multirow{2}{*}{$44 \%$} \\
\hline & $90.1-2010$ & 184 & 584 & 773 & 34 & 1,548 & 0 & 304 & 0 & 0 & 0 & 66 & 67 & 73 & 3,633 & 49.1 & & \\
\hline \multirow{2}{*}{$\begin{array}{c}\text { 3B } \\
\text { El Paso }\end{array}$} & $90.1-2004$ & 353 & 890 & 1,148 & 81 & 1,576 & 0 & 554 & 1 & 0 & 0 & 0 & 64 & 71 & 4,736 & 64.0 & \multirow{2}{*}{$24 \%$} & \multirow{2}{*}{$36 \%$} \\
\hline & $90.1-2010$ & 173 & 584 & 775 & 33 & 1,548 & 0 & 355 & 1 & 0 & 0 & 0 & 64 & 73 & 3,606 & 48.8 & & \\
\hline \multirow{2}{*}{$\begin{array}{c}\text { 3C San } \\
\text { Francisco }\end{array}$} & $90.1-2004$ & 475 & 356 & 1,148 & 81 & 1,576 & 0 & 413 & 1 & 0 & 0 & 0 & 76 & 71 & 4,195 & 56.7 & \multirow{2}{*}{$26 \%$} & \multirow{2}{*}{$41 \%$} \\
\hline & $90.1-2010$ & 165 & 169 & 779 & 33 & 1,548 & 0 & 271 & 1 & 0 & 0 & 0 & 76 & 74 & 3,115 & 42.1 & & \\
\hline \multirow{2}{*}{$\begin{array}{c}4 \mathrm{~A} \\
\text { Baltimore }\end{array}$} & $90.1-2004$ & 1,613 & 696 & 1,148 & 80 & 1,576 & 0 & 475 & 3 & 0 & 0 & 0 & 79 & 72 & 5,742 & 77.6 & $37 \%$ & $520 \%$ \\
\hline & $90.1-2010$ & 246 & 451 & 758 & 34 & 1,548 & 0 & 336 & 1 & 0 & 0 & 66 & 79 & 73 & 3,590 & 48.5 & 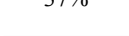 & 5270 \\
\hline $4 B$ & $90.1-2004$ & 747 & 613 & 1,148 & 81 & 1,576 & 0 & 551 & 2 & 0 & 0 & 0 & 77 & 71 & 4,865 & 65.8 & $25 \%$ & $37 \%$ \\
\hline Albuquerque & $90.1-2010$ & 385 & 402 & 757 & 33 & 1,548 & 0 & 381 & 2 & 0 & 0 & 0 & 77 & 73 & 3,658 & 49.5 & $25 \%$ & $3 / \%$ \\
\hline $4 \mathrm{C}$ & $90.1-2004$ & 1,106 & 365 & 1,148 & 80 & 1,576 & 0 & 427 & 2 & 0 & 0 & 0 & 83 & 71 & 4,857 & 65.7 & $27 \%$ & $40 \%$ \\
\hline Salem & $90.1-2010$ & 531 & 229 & 761 & 34 & 1,548 & 0 & 294 & 2 & 0 & 0 & 0 & 83 & 74 & 3,555 & 48.1 & 2710 & 4070 \\
\hline $5 \mathrm{~A}$ & $90.1-2004$ & 1,819 & 531 & 1,148 & 81 & 1,576 & 0 & 466 & 4 & 0 & 0 & 0 & 87 & 71 & 5,782 & 78.2 & $36 \%$ & $50 \%$ \\
\hline Chicago & $90.1-2010$ & 388 & 377 & 759 & 34 & 1,548 & 0 & 341 & 1 & 0 & 0 & 69 & 87 & 73 & 3,677 & 49.7 & $30 \%$ & $50 \%$ \\
\hline $5 \mathrm{~B}$ & $90.1-2004$ & 1,403 & 435 & 1,148 & 80 & 1,576 & 0 & 486 & 3 & 0 & 0 & 0 & 86 & 71 & 5,288 & 71.5 & $26 \%$ & $37 \%$ \\
\hline Boise & $90.1-2010$ & 767 & 297 & 762 & 33 & 1,548 & 0 & 339 & 3 & 0 & 0 & 0 & 86 & 73 & 3,908 & 52.8 & $20 \%$ & (1) \\
\hline $5 \mathrm{C}$ & $90.1-2004$ & 1,237 & 224 & 1,148 & 80 & 1,576 & 0 & 386 & 2 & 0 & 0 & 0 & 86 & 71 & 4,811 & 65.0 & $29 \%$ & $43 \%$ \\
\hline Vancouver & $90.1-2010$ & 533 & 126 & 779 & 34 & 1,548 & 0 & 253 & 2 & 0 & 0 & 0 & 86 & 74 & 3,435 & 46.4 & $29 \%$ & $43 \%$ \\
\hline $6 \mathrm{~A}$ & $90.1-2004$ & 2,395 & 390 & 1,148 & 80 & 1,576 & 0 & 462 & 5 & 0 & 0 & 0 & 94 & 71 & 6,221 & 84.1 & $40 \%$ & $54 \%$ \\
\hline Burlington & $90.1-2010$ & 520 & 284 & 760 & 34 & 1,548 & 0 & 340 & 2 & 0 & 0 & 72 & 94 & 72 & 3,726 & 50.4 & 4070 & $34 / 0$ \\
\hline $6 \mathrm{~B}$ & $90.1-2004$ & 1,954 & 302 & 1,148 & 80 & 1,576 & 0 & 479 & 5 & 0 & 0 & 0 & 95 & 70 & 5,710 & 77.2 & $37 \%$ & $51 \%$ \\
\hline Helena & $90.1-2010$ & 444 & 205 & 763 & 34 & 1,548 & 0 & 355 & 1 & 0 & 0 & 67 & 95 & 72 & 3,584 & 48.5 & $31 \%$ & $51 \%$ \\
\hline 7 & $90.1-2004$ & 3,295 & 260 & 1,148 & 80 & 1,576 & 0 & 503 & 7 & 0 & 0 & 0 & 106 & 71 & 7,046 & 95.3 & $43 \%$ & $56 \%$ \\
\hline Duluth & $90.1-2010$ & 860 & 173 & 757 & 34 & 1,548 & 0 & 371 & 3 & 0 & 0 & 80 & 106 & 71 & 4,001 & 54.1 & $45 \%$ & $50 \%$ \\
\hline 8 & $90.1-2004$ & 5,231 & 143 & 1,148 & 80 & 1,576 & 0 & 489 & 13 & 0 & 0 & 0 & 119 & 70 & 8,869 & 119.9 & $36 \%$ & $44 \%$ \\
\hline Fairbanks & $90.1-2010$ & 2,496 & 100 & 785 & 35 & 1,548 & 0 & 397 & 8 & 0 & 0 & 91 & 119 & 71 & 5,650 & 76.4 & $30 \%$ & $44 \%$ \\
\hline
\end{tabular}




\section{F.7 Secondary School Energy Saving Results}

\begin{tabular}{|c|c|c|c|c|c|c|c|c|c|c|c|c|c|c|c|c|c|c|}
\hline Zone & Standard & $\begin{array}{c}\text { Heating } \\
\text { [MMBtu] }\end{array}$ & $\begin{array}{c}\text { Cooling } \\
\text { [MMBtu] }\end{array}$ & $\begin{array}{c}\text { Interior } \\
\text { Lights } \\
\text { [MMBtu] }\end{array}$ & $\begin{array}{c}\text { Exterior } \\
\text { Lights } \\
\text { [MMBtu] }\end{array}$ & $\begin{array}{c}\text { Interior } \\
\text { Equipment } \\
\text { [MMBtu] }\end{array}$ & $\begin{array}{c}\text { Exterior } \\
\text { Equipment } \\
\text { [MMBtu] }\end{array}$ & $\begin{array}{c}\text { Fans } \\
{[\mathrm{MMBtu}]}\end{array}$ & $\begin{array}{c}\text { Pumps } \\
\text { [MMBtu] }\end{array}$ & $\begin{array}{c}\text { Heat } \\
\text { Rejection } \\
{[\text { MMBtu] }}\end{array}$ & $\begin{array}{c}\text { Humidifi- } \\
\text { cation } \\
\text { [MMBtu] }\end{array}$ & $\begin{array}{c}\text { Heat } \\
\text { Recovery } \\
\text { [MMBtu] }\end{array}$ & $\begin{array}{c}\text { Water } \\
\text { Heater } \\
{[\text { MMBtu] }}\end{array}$ & $\begin{array}{c}\text { Refrigera- } \\
\text { tion } \\
\text { [MMBtu] }\end{array}$ & $\begin{array}{c}\text { Total } \\
\text { Energy } \\
\text { [MMBtu] }\end{array}$ & $\begin{array}{c}\mathrm{EUI} \\
{[\mathrm{kBtu} / \mathrm{sf}]}\end{array}$ & $\begin{array}{c}\text { Energy } \\
\text { Savings [\%] }\end{array}$ & $\begin{array}{c}\text { Energy Savings } \\
\text { w/o } \\
\text { PlugLoad [\%] }\end{array}$ \\
\hline \multirow{2}{*}{$\begin{array}{c}1 \mathrm{~A} \\
\text { Miami }\end{array}$} & $90.1-2004$ & 71 & 5,593 & 3,125 & 210 & 3,041 & 0 & 1,594 & 212 & 0 & 0 & 0 & 57 & 154 & 14,057 & 66.7 & \multirow{2}{*}{$27 \%$} & \multirow{2}{*}{$34 \%$} \\
\hline & $90.1-2010$ & 38 & 3,600 & 2,066 & 84 & 2,961 & 0 & 1,013 & 64 & 0 & 0 & 268 & 57 & 154 & 10,304 & 48.9 & & \\
\hline \multirow{2}{*}{$\begin{array}{c}\text { 1B } \\
\text { Riyadh }\end{array}$} & 90.1-2004 & 195 & 5,401 & 3,125 & 210 & 3,041 & 0 & 1,856 & 187 & 0 & 0 & 0 & 53 & 152 & 14,220 & 67.4 & \multirow{2}{*}{$22 \%$} & \multirow{2}{*}{$29 \%$} \\
\hline & $90.1-2010$ & 123 & 4,159 & 2,094 & 84 & 2,963 & 0 & 1,272 & 63 & 0 & 0 & 65 & 53 & 153 & 11,029 & 52.3 & & \\
\hline \multirow{2}{*}{$\begin{array}{c}2 \mathrm{~A} \\
\text { Houston }\end{array}$} & $90.1-2004$ & 1,176 & 4,362 & 3,125 & 210 & 3,041 & 0 & 1,579 & 181 & 0 & 0 & 0 & 76 & 153 & 13,903 & 65.9 & \multirow{2}{*}{$31 \%$} & \multirow{2}{*}{$40 \%$} \\
\hline & $90.1-2010$ & 280 & 2,713 & 2,095 & 84 & 2,961 & 0 & 963 & 53 & 0 & 0 & 197 & 76 & 153 & 9,577 & 45.4 & & \\
\hline \multirow{2}{*}{$\begin{array}{c}\text { 2B } \\
\text { Phoenix }\end{array}$} & 90.1-2004 & 453 & 4,488 & 3,125 & 210 & 3,041 & 0 & 1,781 & 175 & 0 & 0 & 0 & 67 & 151 & 13,492 & 64.0 & \multirow{2}{*}{$26 \%$} & \multirow{2}{*}{$34 \%$} \\
\hline & $90.1-2010$ & 172 & 3,102 & 2,117 & 84 & 2,963 & 0 & 1,160 & 58 & 0 & 0 & 114 & 67 & 152 & 9,989 & 47.4 & & \\
\hline \multirow{2}{*}{$\begin{array}{c}3 \mathrm{~A} \\
\text { Memphis }\end{array}$} & $90.1-2004$ & 2,014 & 3,241 & 3,125 & 209 & 3,041 & 0 & 1,525 & 151 & 0 & 0 & 0 & 90 & 152 & 13,550 & 64.3 & \multirow{2}{*}{$35 \%$} & \multirow{2}{*}{$45 \%$} \\
\hline & $90.1-2010$ & 310 & 2,011 & 2,058 & 84 & 2,961 & 0 & 886 & 44 & 0 & 0 & 185 & 90 & 153 & 8,782 & 41.6 & & \\
\hline \multirow{2}{*}{$\begin{array}{c}3 \mathrm{~B} \\
\text { El Paso }\end{array}$} & $90.1-2004$ & 641 & 2,657 & 3,125 & 210 & 3,041 & 0 & 1,628 & 125 & 0 & 0 & 0 & 86 & 151 & 11,663 & 55.3 & \multirow{2}{*}{$25 \%$} & \multirow{2}{*}{$34 \%$} \\
\hline & $90.1-2010$ & 327 & 1,955 & 2,061 & 84 & 2,963 & 0 & 1,013 & 40 & 0 & 0 & 43 & 86 & 152 & 8,724 & 41.4 & & \\
\hline \multirow{2}{*}{$\begin{array}{c}\text { 3C San } \\
\text { Francisco }\end{array}$} & $90.1-2004$ & 855 & 838 & 3,125 & 209 & 3,041 & 0 & 1,375 & 79 & 0 & 0 & 0 & 102 & 151 & 9,777 & 46.4 & \multirow{2}{*}{$28 \%$} & \multirow{2}{*}{$41 \%$} \\
\hline & $90.1-2010$ & 122 & 622 & 2,074 & 84 & 2,963 & 0 & 769 & 20 & 0 & 0 & 94 & 102 & 153 & 7,003 & 33.2 & & \\
\hline \multirow{2}{*}{$\begin{array}{c}4 \mathrm{~A} \\
\text { Baltimore }\end{array}$} & $90.1-2004$ & 4,121 & 2,156 & 3,125 & 209 & 3,041 & 0 & 1,539 & 115 & 0 & 0 & 0 & 107 & 152 & 14,565 & 69.1 & $44^{\circ}$ & $55 \%$ \\
\hline & $90.1-2010$ & 388 & 1,373 & 2,013 & 84 & 2,961 & 0 & 926 & 30 & 0 & 0 & 190 & 107 & 152 & 8,224 & 39.0 & $44 \%$ & $55 \%$ \\
\hline $4 \mathrm{~B}$ & $90.1-2004$ & 1,536 & 1,727 & 3,125 & 209 & 3,041 & 0 & 1,693 & 94 & 0 & 0 & 0 & 104 & 150 & 11,681 & 55.4 & $27 \%$ & $36 \%$ \\
\hline Albuquerque & $90.1-2010$ & 710 & 1,372 & 2,008 & 84 & 2,963 & 0 & 1,093 & 32 & 0 & 0 & 41 & 104 & 152 & 8,559 & 40.6 & $21 \%$ & $30 \%$ \\
\hline $4 \mathrm{C}$ & $90.1-2004$ & 2,604 & 896 & 3,125 & 209 & 3,041 & 0 & 1,439 & 61 & 0 & 0 & 0 & 112 & 151 & 11,639 & 55.2 & 320 & 150 \\
\hline Salem & $90.1-2010$ & 722 & 737 & 2,024 & 85 & 2,963 & 0 & 861 & 20 & 0 & 0 & 104 & 112 & 153 & 7,780 & 36.9 & סונד & 0 \\
\hline $5 \mathrm{~A}$ & $90.1-2004$ & 4,900 & 1,617 & 3,125 & 209 & 3,041 & 0 & 1,589 & 88 & 0 & 0 & 0 & 118 & 151 & 14,839 & 70.4 & $44 \%$ & $55 \%$ \\
\hline Chicago & $90.1-2010$ & 677 & 1,147 & 2,015 & 85 & 2,961 & 0 & 946 & 26 & 0 & 0 & 196 & 118 & 152 & 8,323 & 39.5 & $44 \%$ & $53 \%$ \\
\hline $5 \mathrm{~B}$ & $90.1-2004$ & 3,348 & 1,307 & 3,125 & 209 & 3,041 & 0 & 1,592 & 76 & 0 & 0 & 0 & 116 & 150 & 12,966 & 61.5 & $30^{\circ}$ & 300 \\
\hline Boise & $90.1-2010$ & 1,670 & 1,017 & 2,025 & 84 & 2,963 & 0 & 1,006 & 28 & 0 & 0 & 45 & 116 & 152 & 9,106 & 43.2 & 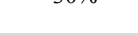 & סודנד \\
\hline $5 \mathrm{C}$ & $90.1-2004$ & 3,053 & 471 & 3,125 & 209 & 3,041 & 0 & 1,382 & 42 & 0 & 0 & 0 & 116 & 151 & 11,591 & 55.0 & $20 \%$ & $40 \%$ \\
\hline Vancouver & $90.1-2010$ & 1,513 & 440 & 2,076 & 85 & 2,963 & 0 & 810 & 16 & 0 & 0 & 40 & 116 & 153 & 8,212 & 38.9 & 2970 & $40 \%$ \\
\hline $6 \mathrm{~A}$ & $90.1-2004$ & 6,286 & 1,138 & 3,125 & 209 & 3,041 & 0 & 1,582 & 72 & 0 & 0 & 0 & 128 & 150 & 15,732 & 74.6 & $47 \%$ & $58 \%$ \\
\hline Burlington & $90.1-2010$ & 977 & 850 & 2,019 & 85 & 2,961 & 0 & 936 & 22 & 0 & 0 & 195 & 128 & 151 & 8,324 & 39.5 & 年 & 5070 \\
\hline $6 \mathrm{~B}$ & $90.1-2004$ & 5,102 & 887 & 3,125 & 209 & 3,041 & 0 & 1,621 & 64 & 0 & 0 & 0 & 129 & 150 & 14,329 & 67.9 & $43 \%$ & $55 \%$ \\
\hline Helena & $90.1-2010$ & 849 & 689 & 2,029 & 84 & 2,961 & 0 & 1,028 & 26 & 0 & 0 & 197 & 129 & 151 & 8,144 & 38.6 & $45 \%$ & 5370 \\
\hline 7 & $90.1-2004$ & 8,731 & 693 & 3,125 & 209 & 3,041 & 0 & 1,767 & 59 & 0 & 0 & 0 & 144 & 150 & 17,918 & 85.0 & $51 \%$ & $61 \%$ \\
\hline Duluth & $90.1-2010$ & 1,733 & 520 & 1,967 & 85 & 2,961 & 0 & 1,022 & 17 & 0 & 0 & 229 & 144 & 151 & 8,829 & 41.9 & & \\
\hline 8 & $90.1-2004$ & 14,746 & 376 & 3,125 & 208 & 3,041 & 0 & 1,725 & 61 & 0 & 0 & 0 & 162 & 149 & 23,594 & 111.9 & $46 \%$ & $53 \%$ \\
\hline Fairbanks & $90.1-2010$ & 5,587 & 294 & 2,101 & 87 & 2,961 & 0 & 1,093 & 25 & 0 & 0 & 263 & 162 & 150 & 12,722 & 60.3 & $40 \%$ & ש5 \\
\hline
\end{tabular}




\section{F.8 Outpatient Hourly Operation Healthcare Schedules}

\begin{tabular}{|c|c|c|c|c|c|c|c|c|c|c|c|c|c|c|c|c|c|c|}
\hline Zone & Standard & $\begin{array}{c}\text { Heating } \\
\text { [MMBtu] }\end{array}$ & $\begin{array}{c}\text { Cooling } \\
\text { [MMBtu] }\end{array}$ & $\begin{array}{c}\text { Interior } \\
\text { Lights } \\
\text { [MMBtu] }\end{array}$ & $\begin{array}{c}\text { Exterior } \\
\text { Lights } \\
\text { [MMBtu] }\end{array}$ & $\begin{array}{c}\text { Interior } \\
\text { Equipment } \\
\text { [MMBtu] }\end{array}$ & $\begin{array}{c}\text { Exterior } \\
\text { Equipment } \\
\text { [MMBtu] }\end{array}$ & $\begin{array}{c}\text { Fans } \\
{[\mathrm{MMBtu}]}\end{array}$ & $\begin{array}{c}\text { Pumps } \\
\text { [MMBtu] }\end{array}$ & $\begin{array}{c}\text { Heat } \\
\text { Rejection } \\
{[\text { MMBtu] }}\end{array}$ & $\begin{array}{c}\text { Humidifi- } \\
\text { cation } \\
\text { [MMBtu] }\end{array}$ & $\begin{array}{c}\text { Heat } \\
\text { Recovery } \\
{[\text { MMBtu] }}\end{array}$ & $\begin{array}{c}\text { Water } \\
\text { Heater } \\
{[\text { MMBtu] }}\end{array}$ & $\begin{array}{c}\text { Refrigera- } \\
\text { tion } \\
\text { [MMBtu] }\end{array}$ & $\begin{array}{c}\text { Total } \\
\text { Energy } \\
\text { [MMBtu] }\end{array}$ & $\begin{array}{c}\mathrm{EUI} \\
{[\mathrm{kBtu} / \mathrm{sf}]}\end{array}$ & $\begin{array}{c}\text { Energy } \\
\text { Savings [\%] }\end{array}$ & $\begin{array}{c}\text { Energy Savings } \\
\text { w/o } \\
\text { PlugLoad [\%] }\end{array}$ \\
\hline \multirow{2}{*}{$\begin{array}{c}1 \mathrm{~A} \\
\text { Miami }\end{array}$} & $90.1-2004$ & 1,391 & 2,051 & 580 & 215 & 1,936 & 0 & 583 & 16 & 0 & 3 & 0 & 34 & 0 & 6,807 & 166.2 & \multirow{2}{*}{$20 \%$} & \multirow{2}{*}{$27 \%$} \\
\hline & $90.1-2010$ & 837 & 1,650 & 505 & 125 & 1,902 & 0 & 400 & 16 & 0 & 1 & 0 & 34 & 0 & 5,470 & 133.6 & & \\
\hline \multirow{2}{*}{$\begin{array}{c}\text { 1B } \\
\text { Riyadh }\end{array}$} & 90.1-2004 & 1,424 & 1,716 & 580 & 215 & 1,936 & 0 & 640 & 17 & 0 & 333 & 0 & 31 & 0 & 6,892 & 168.3 & \multirow{2}{*}{$23 \%$} & \multirow{2}{*}{$32 \%$} \\
\hline & $90.1-2010$ & 730 & 1,328 & 505 & 125 & 1,902 & 0 & 445 & 16 & 0 & 206 & 0 & 31 & 0 & 5,289 & 129.2 & & \\
\hline \multirow{2}{*}{$\begin{array}{c}2 \mathrm{~A} \\
\text { Houston }\end{array}$} & $90.1-2004$ & 1,710 & 1,740 & 580 & 215 & 1,936 & 0 & 569 & 16 & 0 & 45 & 0 & 39 & 0 & 6,850 & 167.3 & \multirow{2}{*}{$22 \%$} & \multirow{2}{*}{$30 \%$} \\
\hline & $90.1-2010$ & 1,071 & 1,312 & 505 & 125 & 1,902 & 0 & 384 & 16 & 0 & 19 & 0 & 39 & 0 & 5,373 & 131.2 & & \\
\hline \multirow{2}{*}{$\begin{array}{c}\text { 2B } \\
\text { Phoenix }\end{array}$} & 90.1-2004 & 1,633 & 1,523 & 580 & 215 & 1,936 & 0 & 605 & 16 & 0 & 161 & 0 & 36 & 0 & 6,705 & 163.8 & \multirow{2}{*}{$24 \%$} & \multirow{2}{*}{$34 \%$} \\
\hline & $90.1-2010$ & 847 & 1,155 & 505 & 125 & 1,902 & 0 & 413 & 16 & 0 & 84 & 0 & 36 & 0 & 5,083 & 124.1 & & \\
\hline \multirow{2}{*}{$\begin{array}{c}3 \mathrm{~A} \\
\text { Memphis }\end{array}$} & $90.1-2004$ & 1,813 & 1,417 & 580 & 215 & 1,936 & 0 & 557 & 18 & 0 & 123 & 0 & 43 & 0 & 6,702 & 163.7 & \multirow{2}{*}{$23 \%$} & \multirow{2}{*}{$32 \%$} \\
\hline & $90.1-2010$ & 1,155 & 984 & 505 & 125 & 1,902 & 0 & 374 & 18 & 0 & 63 & 0 & 43 & 0 & 5,168 & 126.2 & & \\
\hline \multirow{2}{*}{$\begin{array}{c}3 \mathrm{~B} \\
\text { El Paso }\end{array}$} & 90.1-2004 & 1,451 & 1,093 & 580 & 215 & 1,936 & 0 & 594 & 16 & 0 & 410 & 0 & 41 & 0 & 6,337 & 154.8 & \multirow{2}{*}{$25 \%$} & \multirow{2}{*}{$36 \%$} \\
\hline & $90.1-2010$ & 723 & 796 & 505 & 125 & 1,902 & 0 & 412 & 16 & 0 & 250 & 0 & 41 & 0 & 4,770 & 116.5 & & \\
\hline \multirow{2}{*}{$\begin{array}{c}\text { 3C San } \\
\text { Francisco }\end{array}$} & $90.1-2004$ & 1,907 & 799 & 580 & 215 & 1,936 & 0 & 553 & 16 & 0 & 44 & 0 & 47 & 0 & 6,096 & 148.9 & \multirow{2}{*}{$29 \%$} & \multirow{2}{*}{$42 \%$} \\
\hline & $90.1-2010$ & 897 & 454 & 505 & 125 & 1,902 & 0 & 387 & 18 & 0 & 11 & 0 & 47 & 0 & 4,345 & 106.1 & & \\
\hline \multirow{2}{*}{$\begin{array}{c}4 \mathrm{~A} \\
\text { Baltimore }\end{array}$} & 90.1-2004 & 2,127 & 1,140 & 580 & 215 & 1,936 & 0 & 553 & 20 & 0 & 202 & 0 & 48 & 0 & 6,820 & 166.6 & $27 \%$ & 380 \\
\hline & $90.1-2010$ & 1,193 & 704 & 505 & 125 & 1,902 & 0 & 381 & 18 & 0 & 110 & 0 & 48 & 0 & 4,984 & 121.7 & $21 \%$ & $38 \%$ \\
\hline & $90.1-2004$ & 1,602 & 867 & 580 & 215 & 1,936 & 0 & 609 & 16 & 0 & 497 & 0 & 47 & 0 & 6,369 & 155.6 & 260 & 380 \\
\hline Albuquerque & $90.1-2010$ & 767 & 603 & 505 & 125 & 1,902 & 0 & 429 & 16 & 0 & 309 & 0 & 47 & 0 & 4,702 & 114.8 & $20 \%$ & $38 \%$ \\
\hline $4 \mathrm{C}$ & $90.1-2004$ & 2,111 & 667 & 580 & 215 & 1,936 & 0 & 548 & 17 & 0 & 88 & 0 & 50 & 0 & 6,212 & 151.7 & $28 \%$ & $40 \%$ \\
\hline Salem & $90.1-2010$ & 1,060 & 427 & 505 & 125 & 1,902 & 0 & 379 & 17 & 0 & 26 & 0 & 50 & 0 & 4,491 & 109.7 & $28 \%$ & $40 \%$ \\
\hline $5 \mathrm{~A}$ & $90.1-2004$ & 2,292 & 768 & 580 & 215 & 1,936 & 0 & 551 & 21 & 0 & 248 & 0 & 51 & 0 & 6,661 & 162.7 & 240 & 330 \\
\hline Chicago & $90.1-2010$ & 1,401 & 570 & 505 & 125 & 1,902 & 0 & 376 & 20 & 0 & 139 & 0 & 51 & 0 & 5,089 & 124.3 & $24 \%$ & $53 \%$ \\
\hline $5 \mathrm{~B}$ & $90.1-2004$ & 1,954 & 637 & 580 & 215 & 1,936 & 0 & 570 & 19 & 0 & 402 & 0 & 50 & 0 & 6,362 & 155.4 & 250 & 3700 \\
\hline Boise & $90.1-2010$ & 1,092 & 443 & 505 & 125 & 1,902 & 0 & 394 & 18 & 0 & 215 & 0 & 50 & 0 & 4,744 & 115.9 & $25 \%$ & $3 \%$ \\
\hline $5 \mathrm{C}$ & $90.1-2004$ & 2,068 & 570 & 580 & 215 & 1,936 & 0 & 549 & 19 & 0 & 97 & 0 & 51 & 0 & 6,084 & 148.6 & 270 & $30 \%$ \\
\hline Vancouver & $90.1-2010$ & 1,079 & 357 & 505 & 125 & 1,902 & 0 & 387 & 17 & 0 & 31 & 0 & 51 & 0 & 4,454 & 108.8 & $21 \%$ & $39 \%$ \\
\hline $6 \mathrm{~A}$ & $90.1-2004$ & 2,624 & 641 & 580 & 215 & 1,936 & 0 & 549 & 22 & 0 & 298 & 0 & 54 & 0 & 6,918 & 169.0 & 240 & 3200 \\
\hline Burlington & $90.1-2010$ & 1,639 & 459 & 505 & 125 & 1,902 & 0 & 377 & 20 & 0 & 180 & 0 & 54 & 0 & 5,260 & 128.5 & 270 & 0 \\
\hline $6 \mathrm{~B}$ & $90.1-2004$ & 2,248 & 536 & 580 & 215 & 1,936 & 0 & 578 & 21 & 0 & 500 & 0 & 54 & 0 & 6,668 & 162.8 & 260 & 360 \\
\hline Helena & $90.1-2010$ & 1,294 & 359 & 505 & 125 & 1,902 & 0 & 395 & 20 & 0 & 296 & 0 & 54 & 0 & 4,950 & 120.9 & $20 \%$ & $30 \%$ \\
\hline 7 & $90.1-2004$ & 2,980 & 466 & 580 & 215 & 1,936 & 0 & 565 & 24 & 0 & 393 & 0 & 59 & 0 & 7,217 & 176.2 & 250 & $34^{0}$ \\
\hline Duluth & $90.1-2010$ & 1,869 & 306 & 505 & 125 & 1,902 & 0 & 379 & 21 & 0 & 241 & 0 & 59 & 0 & 5,406 & 132.0 & 200 & 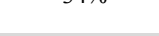 \\
\hline 8 & $90.1-2004$ & 4,284 & 334 & 580 & 213 & 1,936 & 0 & 578 & 30 & 0 & 574 & 0 & 65 & 0 & 8,594 & 209.9 & $20 \%$ & $30 \%$ \\
\hline Fairbanks & $90.1-2010$ & 3,005 & 207 & 505 & 124 & 1,902 & 0 & 376 & 26 & 0 & 371 & 0 & 65 & 0 & 6,581 & 160.7 & $25 \%$ & $50 \%$ \\
\hline
\end{tabular}




\section{F.9 Hospital Energy Saving Results}

\begin{tabular}{|c|c|c|c|c|c|c|c|c|c|c|c|c|c|c|c|c|c|c|}
\hline Zone & Standard & $\begin{array}{c}\text { Heating } \\
\text { [MMBtu] }\end{array}$ & $\begin{array}{c}\text { Cooling } \\
\text { [MMBtu] }\end{array}$ & $\begin{array}{c}\text { Interior } \\
\text { Lights } \\
\text { [MMBtu] } \\
\end{array}$ & $\begin{array}{c}\text { Exterior } \\
\text { Lights } \\
\text { [MMBtu] }\end{array}$ & $\begin{array}{c}\text { Interior } \\
\text { Equipment } \\
\text { [MMBtu] }\end{array}$ & $\begin{array}{c}\text { Exterior } \\
\text { Equipment } \\
\text { [MMBtu] }\end{array}$ & $\begin{array}{c}\text { Fans } \\
\text { [MMBtu] }\end{array}$ & $\begin{array}{c}\begin{array}{c}\text { Pumps } \\
\text { [MMBtu] }\end{array} \\
\end{array}$ & $\begin{array}{c}\text { Heat } \\
\text { Rejection } \\
{[\text { MMBtu }]}\end{array}$ & $\begin{array}{c}\text { Humidifi- } \\
\text { cation } \\
\text { [MMBtu] }\end{array}$ & $\begin{array}{c}\text { Heat } \\
\text { Recovery } \\
{[\text { MMBtu] }}\end{array}$ & $\begin{array}{c}\text { Water } \\
\text { Heater } \\
{[\text { MMBtu }]}\end{array}$ & $\begin{array}{c}\text { Refrigera- } \\
\text { tion } \\
\text { [MMBtu] }\end{array}$ & $\begin{array}{c}\text { Total } \\
\text { Energy } \\
\text { [MMBtu] } \\
\end{array}$ & $\begin{array}{c}\mathrm{EUI} \\
{[\mathrm{kBtu} / \mathrm{sf}]}\end{array}$ & $\begin{array}{c}\text { Energy } \\
\text { Savings [\%] }\end{array}$ & $\begin{array}{c}\text { Energy Savings } \\
\text { w/o } \\
\text { PlugLoad [\%] } \\
\end{array}$ \\
\hline \multirow{2}{*}{$\begin{array}{c}1 \mathrm{~A} \\
\text { Miami }\end{array}$} & $90.1-2004$ & 7,792 & 6,603 & 4,018 & 248 & 9,564 & 2,408 & 4,204 & 1,489 & 3,087 & 0 & 0 & 168 & 200 & 39,782 & 164.7 & \multirow{2}{*}{$26 \%$} & \multirow{2}{*}{$35 \%$} \\
\hline & $90.1-2010$ & 3,727 & 4,485 & 3,435 & 195 & 9,446 & 2,382 & 2,736 & 917 & 1,497 & 0 & 144 & 168 & 200 & 29,334 & 121.5 & & \\
\hline \multirow{2}{*}{$\begin{array}{c}\text { 1B } \\
\text { Riyadh }\end{array}$} & $90.1-2004$ & 7,660 & 4,979 & 4,018 & 248 & 9,564 & 2,408 & 4,476 & 1,743 & 1,303 & 12 & 0 & 149 & 196 & 36,756 & 152.2 & \multirow{2}{*}{$25 \%$} & \multirow{2}{*}{$34 \%$} \\
\hline & $90.1-2010$ & 3,601 & 3,624 & 3,435 & 195 & 9,446 & 2,382 & 2,970 & 1,063 & 460 & 11 & 0 & 149 & 197 & 27,535 & 114.0 & & \\
\hline \multirow{2}{*}{$\begin{array}{c}2 \mathrm{~A} \\
\text { Houston }\end{array}$} & $90.1-2004$ & 9,572 & 5,409 & 4,018 & 248 & 9,564 & 2,408 & 4,189 & 1,438 & 2,304 & 2 & 0 & 212 & 193 & 39,556 & 163.8 & \multirow{2}{*}{$25 \%$} & \multirow{2}{*}{$33 \%$} \\
\hline & $90.1-2010$ & 5,037 & 3,905 & 3,435 & 195 & 9,446 & 2,382 & 2,693 & 888 & 1,052 & 1 & 144 & 212 & 193 & 29,585 & 122.5 & & \\
\hline \multirow{2}{*}{$\begin{array}{c}\text { 2B } \\
\text { Phoenix }\end{array}$} & $90.1-2004$ & 8,937 & 4,159 & 4,018 & 248 & 9,564 & 2,408 & 4,384 & 1,788 & 1,424 & 7 & 0 & 187 & 192 & 37,315 & 154.5 & \multirow{2}{*}{$25 \%$} & \multirow{2}{*}{$34 \%$} \\
\hline & $90.1-2010$ & 4,432 & 3,090 & 3,436 & 195 & 9,446 & 2,382 & 2,825 & 1,115 & 635 & 6 & 0 & 187 & 193 & 27,943 & 115.7 & & \\
\hline \multirow{2}{*}{$\begin{array}{c}3 \mathrm{~A} \\
\text { Memphis }\end{array}$} & $90.1-2004$ & 10,467 & 4,308 & 4,018 & 248 & 9,564 & 2,408 & 4,122 & 1,410 & 1,608 & 4 & 0 & 246 & 188 & 38,591 & 159.8 & \multirow{2}{*}{$25 \%$} & \multirow{2}{*}{$33 \%$} \\
\hline & $90.1-2010$ & 5,682 & 2,868 & 3,434 & 195 & 9,446 & 2,382 & 2,675 & 885 & 729 & 3 & 144 & 246 & 188 & 28,879 & 119.6 & & \\
\hline \multirow{2}{*}{$\begin{array}{c}3 \mathrm{~B} \\
\text { El Paso }\end{array}$} & 90.1-2004 & 7,643 & 2,913 & 4,018 & 248 & 9,564 & 2,408 & 4,383 & 1,269 & 779 & 11 & 0 & 235 & 186 & 33,657 & 139.4 & \multirow{2}{*}{$22 \%$} & \multirow{2}{*}{$31 \%$} \\
\hline & $90.1-2010$ & 4,091 & 2,173 & 3,434 & 195 & 9,446 & 2,382 & 2,944 & 707 & 340 & 10 & 0 & 235 & 187 & 26,145 & 108.3 & & \\
\hline \multirow{2}{*}{$\begin{array}{c}\text { 3C San } \\
\text { Francisco }\end{array}$} & $90.1-2004$ & 10,730 & 2,048 & 4,018 & 248 & 9,564 & 2,408 & 4,082 & 1,384 & 183 & 2 & 0 & 283 & 181 & 35,131 & 145.5 & \multirow{2}{*}{$24 \%$} & \multirow{2}{*}{$33 \%$} \\
\hline & $90.1-2010$ & 5,577 & 1,552 & 3,434 & 195 & 9,446 & 2,382 & 2,715 & 854 & 55 & 1 & 0 & 283 & 181 & 26,676 & 110.5 & & \\
\hline \multirow{2}{*}{$\begin{array}{c}4 \mathrm{~A} \\
\text { Baltimore }\end{array}$} & $90.1-2004$ & 12,003 & 3,456 & 4,018 & 248 & 9,564 & 2,408 & 4,110 & 1,295 & 1,037 & 7 & 0 & 288 & 182 & 38,616 & 159.9 & $26 \%$ & $34 \%$ \\
\hline & $90.1-2010$ & 6,451 & 2,151 & 3,433 & 195 & 9,446 & 2,382 & 2,726 & 822 & 432 & 4 & 144 & 288 & 182 & 28,657 & 118.7 & 2010 & 3470 \\
\hline & $90.1-2004$ & 9,047 & 2,585 & 4,018 & 248 & 9,564 & 2,408 & 4,484 & 1,354 & 441 & 12 & 0 & 282 & 181 & 34,623 & 143.4 & $23 \%$ & $32 \%$ \\
\hline Albuquerque & $90.1-2010$ & 4,804 & 1,863 & 3,433 & 195 & 9,446 & 2,382 & 3,050 & 872 & 154 & 11 & 0 & 282 & 181 & 26,674 & 110.5 & $23 \%$ & $2 \%$ \\
\hline $4 \mathrm{C}$ & $90.1-2004$ & 11,475 & 1,768 & 4,018 & 248 & 9,564 & 2,408 & 4,078 & 1,010 & 294 & 3 & 0 & 306 & 178 & 35,350 & 146.4 & $23 \%$ & $32 \%$ \\
\hline Salem & $90.1-2010$ & 6,530 & 1,225 & 3,434 & 195 & 9,446 & 2,382 & 2,735 & 621 & 116 & 3 & 0 & 306 & 179 & 27,172 & 112.5 & $23 \%$ & $32 \%$ \\
\hline $5 \mathrm{~A}$ & $90.1-2004$ & 13,257 & 2,610 & 4,018 & 248 & 9,564 & 2,408 & 4,114 & 1,211 & 769 & 8 & 0 & 318 & 179 & 38,702 & 160.3 & $25 \%$ & $33 \%$ \\
\hline Chicago & $90.1-2010$ & 7,250 & 1,845 & 3,434 & 195 & 9,446 & 2,382 & 2,741 & 814 & 323 & 5 & 144 & 318 & 179 & 29,075 & 120.4 & $25 \%$ & $30 \%$ \\
\hline $5 \mathrm{~B}$ & $90.1-2004$ & 11,146 & 2,047 & 4,018 & 248 & 9,564 & 2,408 & 4,279 & 1,224 & 251 & 10 & 0 & 312 & 177 & 35,685 & 147.8 & $23 \%$ & $31 \%$ \\
\hline Boise & $90.1-2010$ & 6,408 & 1,326 & 3,434 & 195 & 9,446 & 2,382 & 2,889 & 797 & 85 & 9 & 0 & 312 & 177 & 27,461 & 113.7 & $25 \%$ & 5170 \\
\hline $5 \mathrm{C}$ & $90.1-2004$ & 11,978 & 1,560 & 4,018 & 247 & 9,564 & 2,408 & 4,042 & 936 & 215 & 4 & 0 & 318 & 177 & 35,466 & 146.9 & $23 \%$ & $32 \%$ \\
\hline Vancouver & $90.1-2010$ & 6,900 & 1,014 & 3,436 & 195 & 9,446 & 2,382 & 2,731 & 569 & 70 & 3 & 0 & 318 & 177 & 27,240 & 112.8 & $23 \%$ & $2 \%$ \\
\hline $6 \mathrm{~A}$ & $90.1-2004$ & 14,485 & 2,135 & 4,018 & 248 & 9,564 & 2,408 & 4,076 & 1,036 & 531 & 9 & 0 & 344 & 176 & 39,028 & 161.6 & $25 \%$ & $33 \%$ \\
\hline Burlington & $90.1-2010$ & 8,042 & 1,523 & 3,434 & 195 & 9,446 & 2,382 & 2,729 & 718 & 223 & 5 & 144 & 344 & 177 & 29,361 & 121.6 & 2570 & DST \\
\hline $6 \mathrm{~B}$ & $90.1-2004$ & 12,208 & 1,726 & 4,018 & 247 & 9,564 & 2,408 & 4,307 & 1,195 & 161 & 12 & 0 & 347 & 174 & 36,368 & 150.6 & $23 \%$ & $31 \%$ \\
\hline Helena & $90.1-2010$ & 6,824 & 1,279 & 3,434 & 195 & 9,446 & 2,382 & 2,933 & 859 & 53 & 8 & 144 & 347 & 175 & 28,078 & 116.3 & $23 \%$ & $31 \%$ \\
\hline 7 & $90.1-2004$ & 16,055 & 1,559 & 4,018 & 247 & 9,564 & 2,408 & 4,165 & 905 & 286 & 11 & 0 & 385 & 173 & 39,776 & 164.7 & $25 \%$ & $33 \%$ \\
\hline Duluth & $90.1-2010$ & 9,054 & 1,097 & 3,434 & 195 & 9,446 & 2,382 & 2,779 & 655 & 110 & 7 & 144 & 385 & 173 & 29,859 & 123.6 & 2570 & DST \\
\hline 8 & $90.1-2004$ & 21,767 & 1,042 & 4,018 & 246 & 9,564 & 2,408 & 4,068 & 610 & 127 & 14 & 0 & 436 & 170 & 44,470 & 184.1 & $24 \%$ & $31 \%$ \\
\hline Fairbanks & $90.1-2010$ & 13,397 & 708 & 3,436 & 193 & 9,446 & 2,382 & 2,722 & 537 & 32 & 8 & 144 & 436 & 170 & 33,613 & 139.2 & 2470 & $31 \%$ \\
\hline
\end{tabular}




\section{F.10 Small Hotel Energy Saving Results}

\begin{tabular}{|c|c|c|c|c|c|c|c|c|c|c|c|c|c|c|c|c|c|c|}
\hline Zone & Standard & $\begin{array}{c}\text { Heating } \\
\text { [MMBtu] }\end{array}$ & $\begin{array}{l}\text { Cooling } \\
\text { [MMBtu] }\end{array}$ & $\begin{array}{c}\text { Interior } \\
\text { Lights } \\
\text { [MMBtu] }\end{array}$ & $\begin{array}{c}\text { Exterior } \\
\text { Lights } \\
\text { [MMBtu] }\end{array}$ & $\begin{array}{c}\text { Interior } \\
\text { Equipment } \\
\text { [MMBtu] }\end{array}$ & $\begin{array}{c}\text { Exterior } \\
\text { Equipment } \\
{[\text { MMBtu] }}\end{array}$ & $\begin{array}{c}\text { Fans } \\
{[\mathrm{MMBtu}]}\end{array}$ & $\begin{array}{c}\text { Pumps } \\
\text { [MMBtu] }\end{array}$ & $\begin{array}{c}\text { Heat } \\
\text { Rejection } \\
{[\text { MMBtu] }}\end{array}$ & $\begin{array}{l}\text { Humidifi- } \\
\text { cation } \\
\text { [MMBtu] }\end{array}$ & $\begin{array}{c}\text { Heat } \\
\text { Recovery } \\
{[\text { MMBtu] }}\end{array}$ & $\begin{array}{c}\text { Water } \\
\text { Heater } \\
\text { [MMBtu] }\end{array}$ & $\begin{array}{c}\text { Refrigera- } \\
\text { tion } \\
{[\mathrm{MMBtu}]}\end{array}$ & $\begin{array}{c}\text { Total } \\
\text { Energy } \\
{[\mathrm{MMBtu}]}\end{array}$ & $\begin{array}{c}\text { EUI } \\
{[\mathrm{kBtu} / \mathrm{sf}]}\end{array}$ & $\begin{array}{c}\text { Energy } \\
\text { Savings [\%] }\end{array}$ & $\begin{array}{c}\text { Energy Savings } \\
\text { w/o } \\
\text { PlugLoad [\%] }\end{array}$ \\
\hline \multirow{2}{*}{$\begin{array}{c}1 \mathrm{~A} \\
\text { Miami }\end{array}$} & $90.1-2004$ & 9 & 823 & 472 & 90 & 970 & 0 & 380 & 1 & 0 & 0 & 0 & 345 & 0 & 3,090 & 71.5 & \multirow{2}{*}{$11 \%$} & \multirow{2}{*}{$16 \%$} \\
\hline & $90.1-2010$ & 5 & 634 & 391 & 62 & 960 & 0 & 343 & 1 & 0 & 0 & 0 & 345 & 0 & 2,741 & 63.5 & & \\
\hline \multirow{2}{*}{$\begin{array}{c}1 \mathrm{~B} \\
\text { Riyadh }\end{array}$} & $90.1-2004$ & 35 & 743 & 472 & 90 & 970 & 0 & 396 & 1 & 0 & 0 & 0 & 321 & 0 & 3,028 & 70.1 & \multirow{2}{*}{$11 \%$} & \multirow{2}{*}{$17 \%$} \\
\hline & $90.1-2010$ & 19 & 573 & 391 & 62 & 960 & 0 & 357 & 1 & 0 & 0 & 0 & 321 & 0 & 2,684 & 62.1 & & \\
\hline \multirow{2}{*}{$\begin{array}{c}2 \mathrm{~A} \\
\text { Houston }\end{array}$} & $90.1-2004$ & 193 & 638 & 472 & 90 & 970 & 0 & 381 & 1 & 0 & 0 & 0 & 401 & 0 & 3,146 & 72.8 & \multirow{2}{*}{$13 \%$} & \multirow{2}{*}{$19 \%$} \\
\hline & $90.1-2010$ & 94 & 485 & 391 & 62 & 960 & 0 & 344 & 1 & 0 & 0 & 0 & 401 & 0 & 2,738 & 63.4 & & \\
\hline \multirow{2}{*}{$\begin{array}{c}\text { 2B } \\
\text { Phoenix }\end{array}$} & $90.1-2004$ & 115 & 636 & 472 & 90 & 970 & 0 & 389 & 1 & 0 & 0 & 0 & 368 & 0 & 3,041 & 70.4 & \multirow{2}{*}{$13 \%$} & \multirow{2}{*}{$19 \%$} \\
\hline & $90.1-2010$ & 51 & 470 & 391 & 62 & 960 & 0 & 352 & 1 & 0 & 0 & 0 & 368 & 0 & 2,655 & 61.5 & & \\
\hline \multirow{2}{*}{$\begin{array}{c}3 \mathrm{~A} \\
\text { Memphis }\end{array}$} & $90.1-2004$ & 349 & 500 & 472 & 90 & 970 & 0 & 379 & 1 & 0 & 0 & 0 & 444 & 0 & 3,205 & 74.2 & \multirow{2}{*}{$14 \%$} & \multirow{2}{*}{$20 \%$} \\
\hline & $90.1-2010$ & 183 & 372 & 389 & 62 & 960 & 0 & 342 & 1 & 0 & 0 & 0 & 444 & 0 & 2,753 & 63.7 & & \\
\hline \multirow{2}{*}{$\begin{array}{c}3 \mathrm{~B} \\
\text { El Paso }\end{array}$} & $90.1-2004$ & 186 & 450 & 472 & 90 & 970 & 0 & 390 & 1 & 0 & 0 & 0 & 430 & 0 & 2,989 & 69.2 & \multirow{2}{*}{$12 \%$} & \multirow{2}{*}{$18 \%$} \\
\hline & $90.1-2010$ & 93 & 343 & 389 & 62 & 960 & 0 & 351 & 1 & 0 & 0 & 0 & 430 & 0 & 2,629 & 60.9 & & \\
\hline \multirow{2}{*}{$\begin{array}{c}\text { 3C San } \\
\text { Francisco }\end{array}$} & $90.1-2004$ & 208 & 247 & 472 & 90 & 970 & 0 & 378 & 1 & 0 & 0 & 0 & 491 & 0 & 2,858 & 66.2 & \multirow{2}{*}{$12 \%$} & \multirow{2}{*}{$18 \%$} \\
\hline & $90.1-2010$ & 75 & 200 & 391 & 62 & 960 & 0 & 339 & 1 & 0 & 0 & 0 & 491 & 0 & 2,520 & 58.3 & & \\
\hline \multirow{2}{*}{$\begin{array}{c}4 \mathrm{~A} \\
\text { Baltimore }\end{array}$} & $90.1-2004$ & 653 & 357 & 472 & 90 & 970 & 0 & 378 & 1 & 0 & 0 & 0 & 498 & 0 & 3,419 & 79.1 & $16 \%$ & $22 \%$ \\
\hline & $90.1-2010$ & 349 & 286 & 388 & 62 & 960 & 0 & 341 & 1 & 0 & 0 & 0 & 498 & 0 & 2,884 & 66.8 & $10 \%$ & $22 \%$ \\
\hline & $90.1-2004$ & 373 & 331 & 472 & 90 & 970 & 0 & 395 & 1 & 0 & 0 & 0 & 490 & 0 & 3,122 & 72.3 & 130 & $10 \%$ \\
\hline Albuquerque & $90.1-2010$ & 191 & 274 & 388 & 62 & 960 & 0 & 353 & 1 & 0 & 0 & 0 & 490 & 0 & 2,719 & 62.9 & $15 \%$ & $19 \%$ \\
\hline $4 \mathrm{C}$ & $90.1-2004$ & 519 & 230 & 472 & 90 & 970 & 0 & 377 & 1 & 0 & 0 & 0 & 520 & 0 & 3,179 & 73.6 & $15 \%$ & $21 \%$ \\
\hline Salem & $90.1-2010$ & 243 & 199 & 388 & 62 & 960 & 0 & 341 & 1 & 0 & 0 & 0 & 520 & 0 & 2,714 & 62.8 & $15 \%$ & $21 \%$ \\
\hline $5 \mathrm{~A}$ & $90.1-2004$ & 955 & 293 & 472 & 90 & 970 & 0 & 377 & 1 & 0 & 0 & 0 & 535 & 0 & 3,693 & 85.5 & 170 & 230 \\
\hline Chicago & $90.1-2010$ & 543 & 236 & 388 & 62 & 960 & 0 & 342 & 1 & 0 & 0 & 0 & 535 & 0 & 3,066 & 71.0 & 178 & 2570 \\
\hline $5 \mathrm{~B}$ & $90.1-2004$ & 665 & 252 & 472 & 90 & 970 & 0 & 383 & 1 & 0 & 0 & 0 & 528 & 0 & 3,362 & 77.8 & $15 \%$ & $21 \%$ \\
\hline Boise & 90.1-2010 & 356 & 209 & 389 & 62 & 960 & 0 & 348 & 1 & 0 & 0 & 0 & 528 & 0 & 2,852 & 66.0 & $15 \%$ & $21 \%$ \\
\hline $5 \mathrm{C}$ & $90.1-2004$ & 600 & 194 & 472 & 90 & 970 & 0 & 372 & 1 & 0 & 0 & 0 & 536 & 0 & 3,234 & 74.9 & $15 \%$ & $21 \%$ \\
\hline Vancouver & $90.1-2010$ & 295 & 168 & 389 & 62 & 960 & 0 & 339 & 1 & 0 & 0 & 0 & 536 & 0 & 2,750 & 63.7 & $15 \%$ & $21 \%$ \\
\hline $6 \mathrm{~A}$ & $90.1-2004$ & 1,210 & 242 & 472 & 90 & 970 & 0 & 375 & 1 & 0 & 0 & 0 & 568 & 0 & 3,928 & 90.9 & $18 \%$ & $24 \%$ \\
\hline Burlington & $90.1-2010$ & 710 & 201 & 388 & 62 & 960 & 0 & 341 & 1 & 0 & 0 & 0 & 568 & 0 & 3,230 & 74.8 & $18 \%$ & $24 \%$ \\
\hline $6 \mathrm{~B}$ & $90.1-2004$ & 945 & 206 & 472 & 90 & 970 & 0 & 385 & 1 & 0 & 0 & 0 & 573 & 0 & 3,642 & 84.3 & $16 \%$ & $22 \%$ \\
\hline Helena & $90.1-2010$ & 539 & 174 & 389 & 62 & 960 & 0 & 349 & 1 & 0 & 0 & 0 & 573 & 0 & 3,047 & 70.5 & 1070 & 2270 \\
\hline 7 & $90.1-2004$ & 1,602 & 188 & 472 & 90 & 970 & 0 & 379 & 1 & 0 & 0 & 0 & 621 & 0 & 4,323 & 100.1 & $20^{\circ}$ & 260 \\
\hline Duluth & $90.1-2010$ & 918 & 155 & 388 & 62 & 960 & 0 & 342 & 1 & 0 & 0 & 0 & 621 & 0 & 3,447 & 79.8 & 2070 & 2070 \\
\hline 8 & $90.1-2004$ & 2,383 & 138 & 472 & 90 & 970 & 0 & 375 & 1 & 0 & 0 & 0 & 686 & 0 & 5,114 & 118.4 & $20 \%$ & $24 \%$ \\
\hline Fairbanks & $90.1-2010$ & 1,552 & 117 & 389 & 62 & 960 & 0 & 342 & 1 & 0 & 0 & 0 & 686 & 0 & 4,108 & 95.1 & $20 \%$ & $24 \%$ \\
\hline
\end{tabular}




\section{F.11 Large Hotel Energy Saving Results}

\begin{tabular}{|c|c|c|c|c|c|c|c|c|c|c|c|c|c|c|c|c|c|c|}
\hline Zone & Standard & $\begin{array}{c}\text { Heating } \\
\text { [MMBtu] }\end{array}$ & $\begin{array}{c}\text { Cooling } \\
\text { [MMBtu] }\end{array}$ & $\begin{array}{c}\text { Interior } \\
\text { Lights } \\
\text { [MMBtu] }\end{array}$ & $\begin{array}{c}\text { Exterior } \\
\text { Lights } \\
\text { [MMBtu] }\end{array}$ & $\begin{array}{c}\text { Interior } \\
\text { Equipment } \\
\text { [MMBtu] }\end{array}$ & $\begin{array}{c}\text { Exterior } \\
\text { Equipment } \\
\text { [MMBtu] }\end{array}$ & $\begin{array}{c}\text { Fans } \\
\text { [MMBtu] }\end{array}$ & $\begin{array}{c}\begin{array}{c}\text { Pumps } \\
\text { [MMBtu] }\end{array} \\
\end{array}$ & $\begin{array}{c}\text { Heat } \\
\text { Rejection } \\
\text { [MMBtu] }\end{array}$ & $\begin{array}{c}\text { Humidifi- } \\
\text { cation } \\
\text { [MMBtu] }\end{array}$ & $\begin{array}{c}\text { Heat } \\
\text { Recovery } \\
{[\text { MMBtu] }}\end{array}$ & $\begin{array}{c}\text { Water } \\
\text { Heater } \\
\text { [MMBtu] }\end{array}$ & $\begin{array}{c}\text { Refrigera- } \\
\text { tion } \\
\text { [MMBtu] }\end{array}$ & $\begin{array}{c}\text { Total } \\
\text { Energy } \\
{[\mathrm{MMBtu}]}\end{array}$ & $\begin{array}{c}\text { EUI } \\
{[\mathrm{kBtu} / \mathrm{sf}]}\end{array}$ & $\begin{array}{c}\text { Energy } \\
\text { Savings [\%] }\end{array}$ & $\begin{array}{c}\text { Energy Savings } \\
\text { w/o } \\
\text { PlugLoad [\%] }\end{array}$ \\
\hline \multirow{2}{*}{$\begin{array}{c}1 \mathrm{~A} \\
\text { Miami }\end{array}$} & $90.1-2004$ & 990 & 7,408 & 1,379 & 291 & 3,397 & 927 & 1,050 & 451 & 0 & 0 & 0 & 3,699 & 70 & 19,662 & 161.0 & \multirow{2}{*}{$24 \%$} & \multirow{2}{*}{$30 \%$} \\
\hline & $90.1-2010$ & 225 & 4,055 & 1,292 & 223 & 3,373 & 903 & 620 & 109 & 0 & 0 & 286 & 3,699 & 73 & 14,858 & 121.7 & & \\
\hline \multirow{2}{*}{$\begin{array}{c}1 \mathrm{~B} \\
\text { Riyadh }\end{array}$} & $90.1-2004$ & 873 & 5,530 & 1,379 & 291 & 3,397 & 927 & 867 & 343 & 0 & 0 & 0 & 3,293 & 69 & 16,968 & 138.9 & \multirow{2}{*}{$13 \%$} & \multirow{2}{*}{$16 \%$} \\
\hline & $90.1-2010$ & 419 & 4,404 & 1,292 & 223 & 3,373 & 903 & 739 & 106 & 0 & 0 & 0 & 3,293 & 72 & 14,825 & 121.4 & & \\
\hline \multirow{2}{*}{$\begin{array}{c}2 \mathrm{~A} \\
\text { Houston }\end{array}$} & $90.1-2004$ & 2,310 & 5,074 & 1,379 & 290 & 3,397 & 927 & 750 & 374 & 0 & 0 & 0 & 4,633 & 70 & 19,204 & 157.3 & \multirow{2}{*}{$22 \%$} & \multirow{2}{*}{$26 \%$} \\
\hline & $90.1-2010$ & 563 & 3,082 & 1,293 & 223 & 3,373 & 903 & 587 & 100 & 0 & 0 & 243 & 4,633 & 73 & 15,072 & 123.4 & & \\
\hline \multirow{2}{*}{$\begin{array}{c}2 \mathrm{~B} \\
\text { Phoenix }\end{array}$} & $90.1-2004$ & 1,832 & 4,753 & 1,379 & 290 & 3,397 & 927 & 853 & 348 & 0 & 0 & 0 & 4,089 & 69 & 17,938 & 146.9 & \multirow{2}{*}{$18 \%$} & \multirow{2}{*}{$23 \%$} \\
\hline & $90.1-2010$ & 465 & 3,437 & 1,293 & 223 & 3,373 & 903 & 678 & 108 & 0 & 0 & 0 & 4,089 & 71 & 14,640 & 119.9 & & \\
\hline \multirow{2}{*}{$\begin{array}{c}3 \mathrm{~A} \\
\text { Memphis }\end{array}$} & $90.1-2004$ & 3,004 & 3,577 & 1,379 & 290 & 3,397 & 927 & 698 & 338 & 0 & 0 & 0 & 5,366 & 69 & 19,045 & 156.0 & \multirow{2}{*}{$20 \%$} & \multirow{2}{*}{$24 \%$} \\
\hline & $90.1-2010$ & 704 & 2,449 & 1,291 & 223 & 3,373 & 903 & 572 & 98 & 0 & 0 & 228 & 5,366 & 72 & 15,280 & 125.1 & & \\
\hline \multirow{2}{*}{$\begin{array}{c}3 \mathrm{~B} \\
\text { El Paso }\end{array}$} & $90.1-2004$ & 2,071 & 2,711 & 1,379 & 290 & 3,397 & 927 & 750 & 258 & 0 & 0 & 0 & 5,125 & 69 & 16,977 & 139.0 & \multirow{2}{*}{$14 \%$} & \multirow{2}{*}{$17 \%$} \\
\hline & $90.1-2010$ & 691 & 2,231 & 1,291 & 223 & 3,373 & 903 & 680 & 91 & 0 & 0 & 0 & 5,125 & 71 & 14,679 & 120.2 & & \\
\hline \multirow{2}{*}{$\begin{array}{c}\text { 3C San } \\
\text { Francisco }\end{array}$} & $90.1-2004$ & 2,214 & 1,119 & 1,379 & 290 & 3,397 & 927 & 678 & 187 & 0 & 0 & 0 & 6,160 & 70 & 16,423 & 134.5 & \multirow{2}{*}{$13 \%$} & \multirow{2}{*}{$17 \%$} \\
\hline & $90.1-2010$ & 653 & 885 & 1,292 & 223 & 3,373 & 903 & 605 & 74 & 0 & 0 & 0 & 6,160 & 72 & 14,238 & 116.6 & & \\
\hline \multirow{2}{*}{$\begin{array}{c}4 \mathrm{~A} \\
\text { Baltimore }\end{array}$} & $90.1-2004$ & 4,934 & 2,408 & 1,379 & 290 & 3,397 & 927 & 702 & 280 & 0 & 0 & 0 & 6,265 & 69 & 20,651 & 169.1 & $26 \%$ & $31 \%$ \\
\hline & $90.1-2010$ & 471 & 1,727 & 1,290 & 223 & 3,373 & 903 & 614 & 88 & 0 & 0 & 226 & 6,265 & 72 & 15,252 & 124.9 & $20 \%$ & $31 \%$ \\
\hline & $90.1-2004$ & 3,582 & 1,846 & 1,379 & 290 & 3,397 & 927 & 761 & 226 & 0 & 0 & 0 & 6,129 & 70 & 18,606 & 152.4 & $16 \%$ & $19 \%$ \\
\hline Albuquerque & $90.1-2010$ & 1,239 & 1,606 & 1,290 & 223 & 3,373 & 903 & 728 & 88 & 0 & 0 & 0 & 6,129 & 71 & 15,650 & 128.2 & $10 \%$ & $19 \%$ \\
\hline $4 \mathrm{C}$ & $90.1-2004$ & 4,518 & 1,084 & 1,379 & 290 & 3,397 & 927 & 699 & 184 & 0 & 0 & 0 & 6,645 & 69 & 19,193 & 157.2 & 17\% & $21 \%$ \\
\hline Salem & $90.1-2010$ & 1,747 & 926 & 1,290 & 223 & 3,373 & 903 & 637 & 73 & 0 & 0 & 0 & 6,645 & 71 & 15,887 & 130.1 & 1770 & $21 \%$ \\
\hline $5 \mathrm{~A}$ & $90.1-2004$ & 6,669 & 1,828 & 1,379 & 290 & 3,397 & 927 & 705 & 265 & 0 & 0 & 0 & 6,893 & 69 & 22,421 & 183.6 & $29 \%$ & $35 \%$ \\
\hline Chicago & $90.1-2010$ & 727 & 1,429 & 1,290 & 223 & 3,373 & 903 & 638 & 89 & 0 & 0 & 217 & 6,893 & 71 & 15,852 & 129.8 & $29 \%$ & $53 \%$ \\
\hline $5 \mathrm{~B}$ & $90.1-2004$ & 5,687 & 1,396 & 1,379 & 290 & 3,397 & 927 & 747 & 220 & 0 & 0 & 0 & 6,781 & 69 & 20,893 & 171.1 & $19 \%$ & $23 \%$ \\
\hline Boise & $90.1-2010$ & 2,198 & 1,202 & 1,290 & 223 & 3,373 & 903 & 692 & 91 & 0 & 0 & 0 & 6,781 & 71 & 16,823 & 137.8 & 1770 & $25 \%$ \\
\hline $5 \mathrm{C}$ & $90.1-2004$ & 4,714 & 823 & 1,379 & 290 & 3,397 & 927 & 681 & 158 & 0 & 0 & 0 & 6,900 & 69 & 19,338 & 158.4 & $22 \%$ & $26 \%$ \\
\hline Vancouver & $90.1-2010$ & 778 & 728 & 1,291 & 222 & 3,373 & 903 & 637 & 62 & 0 & 0 & 171 & 6,900 & 72 & 15,137 & 124.0 & $22 \%$ & $20 \%$ \\
\hline $6 \mathrm{~A}$ & $90.1-2004$ & 8,073 & 1,365 & 1,379 & 290 & 3,397 & 927 & 703 & 228 & 0 & 0 & 0 & 7,450 & 69 & 23,880 & 195.5 & $31 \%$ & $37 \%$ \\
\hline Burlington & $90.1-2010$ & 1,039 & 1,122 & 1,290 & 223 & 3,373 & 903 & 634 & 79 & 0 & 0 & 213 & 7,450 & 71 & 16,397 & 134.3 & 5170 & 林 \\
\hline $6 \mathrm{~B}$ & $90.1-2004$ & 7,536 & 1,037 & 1,379 & 290 & 3,397 & 927 & 757 & 206 & 0 & 0 & 0 & 7,531 & 69 & 23,130 & 189.4 & $29 \%$ & $34 \%$ \\
\hline Helena & $90.1-2010$ & 941 & 999 & 1,290 & 222 & 3,373 & 903 & 708 & 81 & 0 & 0 & 225 & 7,531 & 71 & 16,344 & 133.8 & $29 \%$ & \\
\hline 7 & $90.1-2004$ & 10,486 & 929 & 1,379 & 290 & 3,397 & 927 & 747 & 219 & 0 & 0 & 0 & 8,332 & 68 & 26,774 & 219.2 & $34 \%$ & $39 \%$ \\
\hline Duluth & $90.1-2010$ & 1,750 & 806 & 1,290 & 222 & 3,373 & 903 & 661 & 76 & 0 & 0 & 235 & 8,332 & 71 & 17,719 & 145.1 & $34 \%$ & $39 \%$ \\
\hline 8 & $90.1-2004$ & 15,940 & 634 & 1,379 & 288 & 3,397 & 927 & 774 & 225 & 0 & 0 & 0 & 9,420 & 67 & 33,051 & 270.6 & $32 \%$ & $36 \%$ \\
\hline Fairbanks & $90.1-2010$ & 5,574 & 585 & 1,290 & 221 & 3,373 & 903 & 680 & 95 & 0 & 0 & 244 & 9,420 & 70 & 22,455 & 183.9 & & \\
\hline
\end{tabular}




\section{F.12 Warehouse Energy Saving Results}

\begin{tabular}{|c|c|c|c|c|c|c|c|c|c|c|c|c|c|c|c|c|c|c|}
\hline Zone & Standard & $\begin{array}{c}\text { Heating } \\
\text { [MMBtu] }\end{array}$ & $\begin{array}{c}\text { Cooling } \\
\text { [MMBtu] }\end{array}$ & $\begin{array}{c}\text { Interior } \\
\text { Lights } \\
\text { [MMBtu] }\end{array}$ & $\begin{array}{l}\text { Exterior } \\
\text { Lights } \\
\text { [MMBtu] }\end{array}$ & $\begin{array}{c}\text { Interior } \\
\text { Equipment } \\
\text { [MMBtu] }\end{array}$ & $\begin{array}{l}\text { Exterior } \\
\text { Equipment } \\
\text { [MMBtu] }\end{array}$ & $\begin{array}{c}\text { Fans } \\
\text { [MMBtu] }\end{array}$ & $\begin{array}{c}\text { Pumps } \\
\text { [MMBtu] }\end{array}$ & $\begin{array}{c}\text { Heat } \\
\text { Rejection } \\
\text { [MMBtu] }\end{array}$ & $\begin{array}{l}\text { Humidifi- } \\
\text { cation } \\
\text { [MMBtu] }\end{array}$ & $\begin{array}{c}\text { Heat } \\
\text { Recovery } \\
{[\text { MMBtu] }}\end{array}$ & $\begin{array}{c}\text { Water } \\
\text { Heater } \\
\text { [MMBtu] }\end{array}$ & $\begin{array}{c}\text { Refrigera- } \\
\text { tion } \\
\text { [MMBtu] }\end{array}$ & $\begin{array}{c}\text { Total } \\
\text { Energy } \\
{[\text { MMBtu] }}\end{array}$ & $\begin{array}{c}\text { EUI } \\
{[\mathrm{kBtu} / \mathrm{sf}]}\end{array}$ & $\begin{array}{c}\text { Energy } \\
\text { Savings [\%] }\end{array}$ & $\begin{array}{c}\text { Energy Savings } \\
\text { w/o } \\
\text { PlugLoad [\%] }\end{array}$ \\
\hline \multirow{2}{*}{$\begin{array}{c}1 \mathrm{~A} \\
\text { Miami }\end{array}$} & $90.1-2004$ & 53 & 95 & 457 & 117 & 132 & 0 & 68 & 0 & 0 & 0 & 0 & 5 & 0 & 927 & 17.8 & \multirow{2}{*}{$33 \%$} & \multirow{2}{*}{$39 \%$} \\
\hline & $90.1-2010$ & 0 & 69 & 306 & 60 & 127 & 0 & 49 & 0 & 0 & 0 & 0 & 5 & 0 & 617 & 11.9 & & \\
\hline \multirow{2}{*}{$\begin{array}{c}\text { 1B } \\
\text { Riyadh }\end{array}$} & $90.1-2004$ & 86 & 337 & 457 & 117 & 132 & 0 & 262 & 0 & 0 & 0 & 0 & 5 & 0 & 1,396 & 26.8 & \multirow{2}{*}{$27 \%$} & \multirow{2}{*}{$30 \%$} \\
\hline & $90.1-2010$ & 17 & 277 & 319 & 60 & 127 & 0 & 210 & 0 & 0 & 0 & 0 & 5 & 0 & 1,015 & 19.5 & & \\
\hline \multirow{2}{*}{$\begin{array}{l}2 \mathrm{~A} \\
\text { Houston }\end{array}$} & $90.1-2004$ & 220 & 54 & 457 & 117 & 132 & 0 & 53 & 0 & 0 & 0 & 0 & 6 & 0 & 1,039 & 20.0 & \multirow{2}{*}{$32 \%$} & \multirow{2}{*}{$36 \%$} \\
\hline & $90.1-2010$ & 116 & 42 & 313 & 60 & 127 & 0 & 47 & 0 & 0 & 0 & 0 & 6 & 0 & 711 & 13.7 & & \\
\hline \multirow{2}{*}{$\begin{array}{c}2 \mathrm{~B} \\
\text { Phoenix }\end{array}$} & $90.1-2004$ & 125 & 164 & 457 & 117 & 132 & 0 & 169 & 0 & 0 & 0 & 0 & 6 & 0 & 1,169 & 22.5 & \multirow{2}{*}{$24 \%$} & \multirow{2}{*}{$27 \%$} \\
\hline & $90.1-2010$ & 78 & 143 & 328 & 60 & 127 & 0 & 152 & 0 & 0 & 0 & 0 & 6 & 0 & 894 & 17.2 & & \\
\hline \multirow{2}{*}{$\begin{array}{c}3 \mathrm{~A} \\
\text { Memphis }\end{array}$} & $90.1-2004$ & 423 & 38 & 457 & 117 & 132 & 0 & 47 & 0 & 0 & 0 & 0 & 7 & 0 & 1,222 & 23.5 & \multirow{2}{*}{$30 \%$} & \multirow{2}{*}{$34 \%$} \\
\hline & $90.1-2010$ & 272 & 27 & 317 & 60 & 127 & 0 & 42 & 0 & 0 & 0 & 0 & 7 & 0 & 853 & 16.4 & & \\
\hline \multirow{2}{*}{$\begin{array}{c}3 \mathrm{~B} \\
\text { El Paso }\end{array}$} & $90.1-2004$ & 259 & 40 & 457 & 117 & 132 & 0 & 64 & 0 & 0 & 0 & 0 & 7 & 0 & 1,077 & 20.7 & \multirow{2}{*}{$26 \%$} & \multirow{2}{*}{$29 \%$} \\
\hline & $90.1-2010$ & 193 & 31 & 323 & 60 & 127 & 0 & 58 & 0 & 0 & 0 & 0 & 7 & 0 & 799 & 15.4 & & \\
\hline \multirow{2}{*}{$\begin{array}{l}\text { 3C San } \\
\text { Francisco }\end{array}$} & $90.1-2004$ & 379 & 0 & 457 & 117 & 132 & 0 & 18 & 0 & 0 & 0 & 0 & 8 & 0 & 1,111 & 21.3 & \multirow{2}{*}{$23 \%$} & \multirow{2}{*}{$26 \%$} \\
\hline & $90.1-2010$ & 314 & 0 & 329 & 60 & 127 & 0 & 16 & 0 & 0 & 0 & 0 & 8 & 0 & 855 & 16.4 & & \\
\hline \multirow{2}{*}{$\begin{array}{c}4 \mathrm{~A} \\
\text { Baltimore }\end{array}$} & $90.1-2004$ & 730 & 13 & 457 & 117 & 132 & 0 & 35 & 0 & 0 & 0 & 0 & 8 & 0 & 1,492 & 28.7 & & \\
\hline & $90.1-2010$ & 516 & 8 & 316 & 60 & 127 & 0 & 30 & 0 & 0 & 0 & 0 & 8 & 0 & 1,066 & 20.5 & $29 \%$ & $31 \%$ \\
\hline & $90.1-2004$ & 513 & 13 & 457 & 117 & 132 & 0 & 41 & 0 & 0 & 0 & 0 & 8 & 0 & 1,281 & 24.6 & & \\
\hline Albuquerque & $90.1-2010$ & 386 & 9 & 319 & 60 & 127 & 0 & 36 & 0 & 0 & 0 & 0 & 8 & 0 & 945 & 18.2 & $26 \%$ & $29 \%$ \\
\hline $4 \mathrm{C}$ & $90.1-2004$ & 544 & 1 & 457 & 117 & 132 & 0 & 23 & 0 & 0 & 0 & 0 & 9 & 0 & 1,282 & 24.6 & & \\
\hline Salem & $90.1-2010$ & 437 & 0 & 321 & 60 & 127 & 0 & 21 & 0 & 0 & 0 & 0 & 9 & 0 & 976 & 18.8 & $24 \%$ & $27 \%$ \\
\hline $5 \mathrm{~A}$ & $90.1-2004$ & 1,036 & 7 & 457 & 117 & 132 & 0 & 43 & 0 & 0 & 0 & 0 & 9 & 0 & 1,800 & 34.6 & & \\
\hline Chicago & $90.1-2010$ & 791 & 4 & 314 & 61 & 127 & 0 & 34 & 0 & 0 & 0 & 0 & 9 & 0 & 1,340 & 25.8 & $26 \%$ & $28 \%$ \\
\hline $5 \mathrm{~B}$ & $90.1-2004$ & 723 & 6 & 457 & 117 & 132 & 0 & 37 & 0 & 0 & 0 & 0 & 9 & 0 & 1,481 & 28.5 & 260 & $28 \%$ \\
\hline Boise & $90.1-2010$ & 542 & 4 & 329 & 60 & 127 & 0 & 32 & 0 & 0 & 0 & 0 & 9 & 0 & 1,102 & 21.2 & $26 \%$ & $28 \%$ \\
\hline $5 \mathrm{C}$ & $90.1-2004$ & 631 & 0 & 457 & 117 & 132 & 0 & 24 & 0 & 0 & 0 & 0 & 9 & 0 & 1,371 & 26.3 & & \\
\hline Vancouver & $90.1-2010$ & 502 & 0 & 335 & 61 & 127 & 0 & 22 & 0 & 0 & 0 & 0 & 9 & 0 & 1,056 & 20.3 & $23 \%$ & $25 \%$ \\
\hline & $90.1-2004$ & 1,258 & 2 & 457 & 117 & 132 & 0 & 38 & 0 & 0 & 0 & 0 & 10 & 0 & 2,013 & 38.7 & $31 \%$ & $33 \%$ \\
\hline Burlington & $90.1-2010$ & 785 & 1 & 384 & 61 & 127 & 0 & 26 & 0 & 0 & 0 & 0 & 10 & 0 & 1,394 & 26.8 & $31 \%$ & $33 \%$ \\
\hline $6 \mathrm{~B}$ & $90.1-2004$ & 1,074 & 1 & 457 & 117 & 132 & 0 & 38 & 0 & 0 & 0 & 0 & 10 & 0 & 1,829 & 35.1 & & \\
\hline Helena & $90.1-2010$ & 660 & 1 & 386 & 60 & 127 & 0 & 28 & 0 & 0 & 0 & 0 & 10 & 0 & 1,272 & 24.4 & $30 \%$ & $33 \%$ \\
\hline 7 & $90.1-2004$ & 1,804 & 0 & 457 & 117 & 132 & 0 & 49 & 0 & 0 & 0 & 0 & 10 & 0 & 2,569 & 49.4 & & $29 \%$ \\
\hline Duluth & $90.1-2010$ & 1,255 & 0 & 377 & 60 & 127 & 0 & 35 & 0 & 0 & 0 & 0 & 10 & 0 & 1,866 & 35.9 & $27 \%$ & $29 \%$ \\
\hline 8 & $90.1-2004$ & 1,959 & 0 & 457 & 116 & 132 & 0 & 36 & 0 & 0 & 0 & 0 & 12 & 0 & 2,712 & 52.1 & & \\
\hline Fairbanks & $90.1-2010$ & 1,436 & 0 & 390 & 62 & 127 & 0 & 28 & 0 & 0 & 0 & 0 & 12 & 0 & 2,055 & 39.5 & $24 \%$ & $25 \%$ \\
\hline
\end{tabular}




\section{F.13 Quick Service Restaurant Energy Saving Results}

\begin{tabular}{|c|c|c|c|c|c|c|c|c|c|c|c|c|c|c|c|c|c|c|}
\hline Zone & Standard & $\begin{array}{l}\text { Heating } \\
\text { [MMBtu] }\end{array}$ & $\begin{array}{c}\text { Cooling } \\
\text { [MMBtu] }\end{array}$ & $\begin{array}{c}\text { Interior } \\
\text { Lights } \\
\text { [MMBtu] }\end{array}$ & $\begin{array}{l}\text { Exterior } \\
\text { Lights } \\
\text { [MMBtu] }\end{array}$ & $\begin{array}{c}\text { Interior } \\
\text { Equipment } \\
\text { [MMBtu] }\end{array}$ & $\begin{array}{l}\text { Exterior } \\
\text { Equipment } \\
\text { [MMBtu] }\end{array}$ & $\begin{array}{c}\text { Fans } \\
\text { [MMBtu] }\end{array}$ & $\begin{array}{c}\text { Pumps } \\
\text { [MMBtu] }\end{array}$ & $\begin{array}{c}\text { Heat } \\
\text { Rejection } \\
\text { [MMBtu] }\end{array}$ & $\begin{array}{l}\text { Humidifi- } \\
\text { cation } \\
\text { [MMBtu] }\end{array}$ & $\begin{array}{c}\text { Heat } \\
\text { Recovery } \\
{[\text { MMBtu] }}\end{array}$ & $\begin{array}{c}\text { Water } \\
\text { Heater } \\
\text { [MMBtu] }\end{array}$ & $\begin{array}{c}\text { Refrigera- } \\
\text { tion } \\
\text { [MMBtu] }\end{array}$ & $\begin{array}{c}\text { Total } \\
\text { Energy } \\
{[\text { MMBtu] }}\end{array}$ & $\begin{array}{c}\text { EUI } \\
{[\mathrm{kBtu} / \mathrm{sf}]}\end{array}$ & $\begin{array}{c}\text { Energy } \\
\text { Savings [\%] }\end{array}$ & $\begin{array}{c}\text { Energy Savings } \\
\text { w/o } \\
\text { PlugLoad [\%] }\end{array}$ \\
\hline \multirow{2}{*}{$\begin{array}{c}1 \mathrm{~A} \\
\text { Miami }\end{array}$} & $90.1-2004$ & 35 & 191 & 71 & 26 & 687 & 0 & 75 & 0 & 0 & 0 & 0 & 40 & 66 & 1,191 & 476.0 & \multirow{2}{*}{$7 \%$} & \multirow{2}{*}{$16 \%$} \\
\hline & $90.1-2010$ & 26 & 162 & 34 & 11 & 686 & 0 & 82 & 0 & 0 & 0 & 0 & 40 & 66 & 1,107 & 442.8 & & \\
\hline \multirow{2}{*}{$\begin{array}{c}\text { 1B } \\
\text { Riyadh }\end{array}$} & $90.1-2004$ & 33 & 189 & 71 & 26 & 687 & 0 & 110 & 0 & 0 & 0 & 0 & 37 & 63 & 1,217 & 486.6 & \multirow{2}{*}{$6 \%$} & \multirow{2}{*}{$13 \%$} \\
\hline & $90.1-2010$ & 33 & 168 & 34 & 11 & 686 & 0 & 113 & 0 & 0 & 0 & 0 & 37 & 63 & 1,146 & 458.3 & & \\
\hline \multirow{2}{*}{$\begin{array}{l}2 \mathrm{~A} \\
\text { Houston }\end{array}$} & $90.1-2004$ & 158 & 142 & 71 & 26 & 687 & 0 & 82 & 0 & 0 & 0 & 0 & 49 & 64 & 1,279 & 511.6 & \multirow{2}{*}{$8 \%$} & \multirow{2}{*}{$17 \%$} \\
\hline & $90.1-2010$ & 128 & 116 & 35 & 11 & 686 & 0 & 89 & 0 & 0 & 0 & 0 & 49 & 64 & 1,178 & 471.1 & & \\
\hline \multirow{2}{*}{$\begin{array}{c}\text { 2B } \\
\text { Phoenix }\end{array}$} & $90.1-2004$ & 91 & 151 & 71 & 26 & 687 & 0 & 107 & 0 & 0 & 0 & 0 & 44 & 63 & 1,241 & 496.0 & \multirow{2}{*}{$6 \%$} & \multirow{2}{*}{$15 \%$} \\
\hline & $90.1-2010$ & 82 & 129 & 34 & 11 & 686 & 0 & 111 & 0 & 0 & 0 & 0 & 44 & 63 & 1,160 & 463.8 & & \\
\hline \multirow{2}{*}{$\begin{array}{c}3 \mathrm{~A} \\
\text { Memphis }\end{array}$} & $90.1-2004$ & 258 & 102 & 71 & 26 & 687 & 0 & 81 & 0 & 0 & 0 & 0 & 56 & 63 & 1,344 & 537.5 & \multirow{2}{*}{$7 \%$} & \multirow{2}{*}{$14 \%$} \\
\hline & $90.1-2010$ & 231 & 83 & 34 & 11 & 686 & 0 & 87 & 0 & 0 & 0 & 0 & 56 & 62 & 1,251 & 500.2 & & \\
\hline \multirow{2}{*}{$\begin{array}{c}3 \mathrm{~B} \\
\text { El Paso }\end{array}$} & $90.1-2004$ & 156 & 82 & 71 & 26 & 687 & 0 & 96 & 0 & 0 & 0 & 0 & 54 & 62 & 1,233 & 493.2 & \multirow{2}{*}{$6 \%$} & \multirow{2}{*}{$13 \%$} \\
\hline & $90.1-2010$ & 146 & 71 & 34 & 11 & 686 & 0 & 97 & 0 & 0 & 0 & 0 & 54 & 62 & 1,161 & 464.1 & & \\
\hline \multirow{2}{*}{$\begin{array}{c}\text { 3C San } \\
\text { Francisco }\end{array}$} & $90.1-2004$ & 229 & 4 & 71 & 26 & 687 & 0 & 62 & 0 & 0 & 0 & 0 & 63 & 61 & 1,204 & 481.4 & \multirow{2}{*}{$8 \%$} & \multirow{2}{*}{$19 \%$} \\
\hline & $90.1-2010$ & 180 & 3 & 34 & 11 & 686 & 0 & 69 & 0 & 0 & 0 & 0 & 63 & 60 & 1,107 & 442.5 & & \\
\hline \multirow{2}{*}{$\begin{array}{c}4 \mathrm{~A} \\
\text { Baltimore }\end{array}$} & $90.1-2004$ & 423 & 60 & 71 & 26 & 687 & 0 & 77 & 0 & 0 & 0 & 0 & 64 & 61 & 1,470 & 587.8 & & \\
\hline & $90.1-2010$ & 353 & 45 & 34 & 11 & 686 & 0 & 74 & 0 & 0 & 0 & 0 & 64 & 61 & 1,328 & 531.1 & $10 \%$ & $18 \%$ \\
\hline & $90.1-2004$ & 277 & 48 & 71 & 26 & 687 & 0 & 91 & 0 & 0 & 0 & 0 & 63 & 61 & 1,324 & 529.6 & & \\
\hline Albuquerque & $90.1-2010$ & 237 & 37 & 33 & 11 & 686 & 0 & 82 & 0 & 0 & 0 & 0 & 63 & 61 & 1,210 & 483.9 & $9 \%$ & $18 \%$ \\
\hline $4 \mathrm{C}$ & $90.1-2004$ & 407 & 18 & 71 & 26 & 687 & 0 & 75 & 0 & 0 & 0 & 0 & 68 & 61 & 1,412 & 564.5 & & \\
\hline Salem & $90.1-2010$ & 313 & 14 & 34 & 11 & 686 & 0 & 73 & 0 & 0 & 0 & 0 & 68 & 60 & 1,258 & 503.2 & $11 \%$ & $21 \%$ \\
\hline $5 \mathrm{~A}$ & $90.1-2004$ & 589 & 42 & 71 & 26 & 687 & 0 & 75 & 0 & 0 & 0 & 0 & 70 & 61 & 1,621 & 648.0 & & \\
\hline Chicago & $90.1-2010$ & 486 & 31 & 34 & 11 & 686 & 0 & 72 & 0 & 0 & 0 & 0 & 70 & 60 & 1,451 & 580.3 & $10 \%$ & $18 \%$ \\
\hline $5 \mathrm{~B}$ & $90.1-2004$ & 461 & 34 & 71 & 26 & 687 & 0 & 87 & 0 & 0 & 0 & 0 & 69 & 60 & 1,495 & 597.8 & $10^{\circ}$ & $19 \%$ \\
\hline Boise & $90.1-2010$ & 379 & 25 & 33 & 11 & 686 & 0 & 80 & 0 & 0 & 0 & 0 & 69 & 60 & 1,343 & 537.2 & $10 \%$ & $19 \%$ \\
\hline $5 \mathrm{C}$ & $90.1-2004$ & 476 & 3 & 71 & 26 & 687 & 0 & 53 & 0 & 0 & 0 & 0 & 70 & 60 & 1,447 & 578.5 & $11^{\circ}$ & $21 \%$ \\
\hline Vancouver & $90.1-2010$ & 362 & 2 & 34 & 11 & 686 & 0 & 58 & 0 & 0 & 0 & 0 & 70 & 60 & 1,284 & 513.4 & $11 \%$ & $21 \%$ \\
\hline $6 \mathrm{~A}$ & $90.1-2004$ & 738 & 25 & 71 & 26 & 687 & 0 & 69 & 0 & 0 & 0 & 0 & 75 & 60 & 1,751 & 700.2 & $11^{1}$ & $18 \%$ \\
\hline Burlington & $90.1-2010$ & 606 & 18 & 34 & 11 & 686 & 0 & 70 & 0 & 0 & 0 & 0 & 75 & 60 & 1,560 & 623.9 & $11 \%$ & $18 \%$ \\
\hline $6 \mathrm{~B}$ & $90.1-2004$ & 608 & 18 & 71 & 26 & 687 & 0 & 79 & 0 & 0 & 0 & 0 & 76 & 60 & 1,625 & 649.8 & & \\
\hline Helena & $90.1-2010$ & 505 & 14 & 34 & 11 & 686 & 0 & 75 & 0 & 0 & 0 & 0 & 76 & 59 & 1,461 & 584.0 & $10 \%$ & $18 \%$ \\
\hline 7 & $90.1-2004$ & 934 & 13 & 71 & 26 & 687 & 0 & 67 & 0 & 0 & 0 & 0 & 84 & 59 & 1,940 & 775.7 & $11^{1}$ & 170\% \\
\hline Duluth & $90.1-2010$ & 774 & 9 & 34 & 11 & 686 & 0 & 68 & 0 & 0 & 0 & 0 & 84 & 59 & 1,724 & 689.3 & $11 \%$ & $17 \%$ \\
\hline 8 & $90.1-2004$ & 1,425 & 4 & 71 & 26 & 687 & 0 & 61 & 0 & 0 & 0 & 0 & 94 & 59 & 2,426 & 970.1 & $10^{\circ}$ & \\
\hline Fairbanks & $90.1-2010$ & 1,225 & 3 & 34 & 11 & 686 & 0 & 64 & 0 & 0 & 0 & 0 & 94 & 58 & 2,176 & 870.0 & $10 \%$ & $14 \%$ \\
\hline
\end{tabular}




\section{F.14 Full Service Restaurant Energy Saving Results}

\begin{tabular}{|c|c|c|c|c|c|c|c|c|c|c|c|c|c|c|c|c|c|c|}
\hline Zone & Standard & $\begin{array}{c}\text { Heating } \\
\text { [MMBtu] }\end{array}$ & $\begin{array}{c}\text { Cooling } \\
\text { [MMBtu] }\end{array}$ & $\begin{array}{c}\text { Interior } \\
\text { Lights } \\
\text { [MMBtu] }\end{array}$ & $\begin{array}{c}\text { Exterior } \\
\text { Lights } \\
\text { [MMBtu] }\end{array}$ & $\begin{array}{c}\text { Interior } \\
\text { Equipment } \\
\text { [MMBtu] }\end{array}$ & $\begin{array}{c}\text { Exterior } \\
\text { Equipment } \\
\text { [MMBtu] }\end{array}$ & $\begin{array}{c}\text { Fans } \\
\text { [MMBtu] }\end{array}$ & $\begin{array}{c}\begin{array}{c}\text { Pumps } \\
\text { [MMBtu] }\end{array} \\
\end{array}$ & $\begin{array}{c}\text { Heat } \\
\text { Rejection } \\
{[\text { MMBtu] }}\end{array}$ & $\begin{array}{c}\text { Humidifi- } \\
\text { cation } \\
\text { [MMBtu] }\end{array}$ & $\begin{array}{c}\text { Heat } \\
\text { Recovery } \\
\text { [MMBtu] }\end{array}$ & $\begin{array}{c}\text { Water } \\
\text { Heater } \\
\text { [MMBtu] }\end{array}$ & $\begin{array}{c}\text { Refrigera- } \\
\text { tion } \\
\text { [MMBtu }]\end{array}$ & $\begin{array}{c}\text { Total } \\
\text { Energy } \\
\text { [MMBtu] }\end{array}$ & $\begin{array}{c}\text { EUI } \\
{[\mathrm{kBtu} / \mathrm{sf}]}\end{array}$ & $\begin{array}{c}\text { Energy } \\
\text { Savings [\%] }\end{array}$ & $\begin{array}{c}\text { Energy Savings } \\
\text { w/o } \\
\text { PlugLoad [\%] } \\
\end{array}$ \\
\hline \multirow{2}{*}{$\begin{array}{c}1 \mathrm{~A} \\
\text { Miami }\end{array}$} & $90.1-2004$ & 19 & 353 & 176 & 55 & 867 & 0 & 143 & 0 & 0 & 0 & 0 & 115 & 64 & 1,792 & 325.7 & \multirow{2}{*}{$16 \%$} & \multirow{2}{*}{$31 \%$} \\
\hline & $90.1-2010$ & 25 & 251 & 75 & 23 & 864 & 0 & 85 & 0 & 0 & 0 & 0 & 115 & 64 & 1,503 & 273.2 & & \\
\hline \multirow{2}{*}{$\begin{array}{c}\text { 1B } \\
\text { Riyadh }\end{array}$} & $90.1-2004$ & 39 & 367 & 176 & 55 & 867 & 0 & 269 & 0 & 0 & 0 & 0 & 102 & 62 & 1,938 & 352.2 & \multirow{2}{*}{$19 \%$} & \multirow{2}{*}{$34 \%$} \\
\hline & $90.1-2010$ & 37 & 266 & 76 & 23 & 864 & 0 & 145 & 0 & 0 & 0 & 0 & 102 & 62 & 1,575 & 286.3 & & \\
\hline \multirow{2}{*}{$\begin{array}{c}2 \mathrm{~A} \\
\text { Houston }\end{array}$} & $90.1-2004$ & 188 & 283 & 176 & 55 & 867 & 0 & 224 & 0 & 0 & 0 & 0 & 144 & 63 & 2,000 & 363.4 & \multirow{2}{*}{$20 \%$} & \multirow{2}{*}{$35 \%$} \\
\hline & $90.1-2010$ & 160 & 182 & 76 & 23 & 864 & 0 & 88 & 0 & 0 & 0 & 0 & 144 & 62 & 1,599 & 290.7 & & \\
\hline \multirow{2}{*}{$\begin{array}{c}\text { 2B } \\
\text { Phoenix }\end{array}$} & $90.1-2004$ & 141 & 300 & 176 & 55 & 867 & 0 & 260 & 0 & 0 & 0 & 0 & 127 & 62 & 1,989 & 361.5 & \multirow{2}{*}{$20 \%$} & \multirow{2}{*}{$36 \%$} \\
\hline & $90.1-2010$ & 90 & 206 & 76 & 23 & 864 & 0 & 139 & 0 & 0 & 0 & 0 & 127 & 61 & 1,587 & 288.4 & & \\
\hline \multirow{2}{*}{$\begin{array}{c}3 \mathrm{~A} \\
\text { Memphis }\end{array}$} & $90.1-2004$ & 364 & 204 & 176 & 55 & 867 & 0 & 221 & 0 & 0 & 0 & 0 & 167 & 62 & 2,115 & 384.4 & \multirow{2}{*}{$20 \%$} & \multirow{2}{*}{$33 \%$} \\
\hline & $90.1-2010$ & 297 & 129 & 74 & 23 & 864 & 0 & 86 & 0 & 0 & 0 & 0 & 167 & 61 & 1,701 & 309.2 & & \\
\hline \multirow{2}{*}{$\begin{array}{c}\text { 3B } \\
\text { El Paso }\end{array}$} & $90.1-2004$ & 240 & 172 & 176 & 55 & 867 & 0 & 249 & 0 & 0 & 0 & 0 & 159 & 61 & 1,980 & 360.0 & \multirow{2}{*}{$19 \%$} & \multirow{2}{*}{$34 \%$} \\
\hline & $90.1-2010$ & 166 & 119 & 74 & 23 & 864 & 0 & 131 & 0 & 0 & 0 & 0 & 159 & 60 & 1,597 & 290.3 & & \\
\hline \multirow{2}{*}{$\begin{array}{c}\text { 3C San } \\
\text { Francisco }\end{array}$} & $90.1-2004$ & 395 & 10 & 176 & 55 & 867 & 0 & 124 & 0 & 0 & 0 & 0 & 191 & 61 & 1,879 & 341.5 & \multirow{2}{*}{$20 \%$} & \multirow{2}{*}{$37 \%$} \\
\hline & $90.1-2010$ & 213 & 8 & 74 & 23 & 864 & 0 & 74 & 0 & 0 & 0 & 0 & 191 & 59 & 1,508 & 274.1 & & \\
\hline \multirow{2}{*}{$\begin{array}{c}4 \mathrm{~A} \\
\text { Baltimore }\end{array}$} & $90.1-2004$ & 683 & 114 & 176 & 55 & 867 & 0 & 142 & 0 & 0 & 0 & 0 & 195 & 61 & 2,293 & 416.8 & $19 \%$ & $30 \%$ \\
\hline & $90.1-2010$ & 495 & 75 & 74 & 23 & 864 & 0 & 79 & 0 & 0 & 0 & 0 & 195 & 60 & 1,865 & 339.0 & 1970 & $30 \%$ \\
\hline & $90.1-2004$ & 427 & 99 & 176 & 55 & 867 & 0 & 248 & 0 & 0 & 0 & 0 & 190 & 61 & 2,123 & 385.8 & $21 \%$ & $36 \%$ \\
\hline Albuquerque & $90.1-2010$ & 307 & 62 & 73 & 23 & 864 & 0 & 92 & 0 & 0 & 0 & 0 & 190 & 60 & 1,671 & 303.7 & $21 \%$ & $30 \%$ \\
\hline $4 \mathrm{C}$ & $90.1-2004$ & 687 & 35 & 176 & 55 & 867 & 0 & 134 & 0 & 0 & 0 & 0 & 206 & 60 & 2,221 & 403.7 & $20 \%$ & $34 \%$ \\
\hline Salem & $90.1-2010$ & 439 & 25 & 74 & 24 & 864 & 0 & 77 & 0 & 0 & 0 & 0 & 206 & 59 & 1,767 & 321.2 & $20 \%$ & $34 \%$ \\
\hline $5 \mathrm{~A}$ & $90.1-2004$ & 949 & 78 & 176 & 55 & 867 & 0 & 139 & 0 & 0 & 0 & 0 & 214 & 60 & 2,539 & 461.5 & $19 \%$ & $29 \%$ \\
\hline Chicago & $90.1-2010$ & 695 & 53 & 74 & 24 & 864 & 0 & 79 & 0 & 0 & 0 & 0 & 214 & 59 & 2,063 & 374.9 & $19 \%$ & $29 \%$ \\
\hline $5 \mathrm{~B}$ & $90.1-2004$ & 705 & 71 & 176 & 55 & 867 & 0 & 232 & 0 & 0 & 0 & 0 & 211 & 60 & 2,376 & 431.9 & $21^{\circ}$ & $33 \%$ \\
\hline Boise & $90.1-2010$ & 526 & 41 & 73 & 23 & 864 & 0 & 86 & 0 & 0 & 0 & 0 & 211 & 59 & 1,884 & 342.3 & $21 \%$ & $33 \%$ \\
\hline $5 \mathrm{C}$ & $90.1-2004$ & 788 & 7 & 176 & 55 & 867 & 0 & 114 & 0 & 0 & 0 & 0 & 214 & 60 & 2,282 & 414.7 & $20 \%$ & $33 \%$ \\
\hline Vancouver & $90.1-2010$ & 502 & 8 & 75 & 24 & 864 & 0 & 70 & 0 & 0 & 0 & 0 & 214 & 59 & 1,816 & 330.0 & $20 \%$ & $33 \%$ \\
\hline $6 \mathrm{~A}$ & $90.1-2004$ & 1,172 & 52 & 176 & 55 & 867 & 0 & 130 & 0 & 0 & 0 & 0 & 231 & 60 & 2,744 & 498.7 & $18 \%$ & $27 \%$ \\
\hline Burlington & $90.1-2010$ & 880 & 31 & 74 & 24 & 864 & 0 & 75 & 0 & 0 & 0 & 0 & 231 & 59 & 2,238 & 406.8 & $10 \%$ & 2710 \\
\hline $6 \mathrm{~B}$ & $90.1-2004$ & 919 & 42 & 176 & 55 & 867 & 0 & 222 & 0 & 0 & 0 & 0 & 234 & 60 & 2,575 & 468.0 & $19 \%$ & $29 \%$ \\
\hline Helena & $90.1-2010$ & 711 & 25 & 73 & 23 & 864 & 0 & 85 & 0 & 0 & 0 & 0 & 234 & 58 & 2,075 & 377.1 & $19 \%$ & $29 \%$ \\
\hline 7 & $90.1-2004$ & 1,461 & 29 & 176 & 55 & 867 & 0 & 130 & 0 & 0 & 0 & 0 & 259 & 59 & 3,037 & 552.0 & $16 \%$ & $23 \%$ \\
\hline Duluth & $90.1-2010$ & 1,169 & 17 & 74 & 24 & 864 & 0 & 75 & 0 & 0 & 0 & 0 & 259 & 58 & 2,540 & 461.6 & $10 \%$ & $25 \%$ \\
\hline 8 & $90.1-2004$ & 2,220 & 12 & 176 & 55 & 867 & 0 & 122 & 0 & 0 & 0 & 0 & 293 & 58 & 3,803 & 691.2 & $16 \%$ & $21 \%$ \\
\hline Fairbanks & $90.1-2010$ & 1,800 & 7 & 75 & 24 & 864 & 0 & 72 & 0 & 0 & 0 & 0 & 293 & 57 & 3,193 & 580.3 & $10 \%$ & $21 \%$ \\
\hline
\end{tabular}




\section{F.15 Mid-Rise Apartment Energy Saving Results}

\begin{tabular}{|c|c|c|c|c|c|c|c|c|c|c|c|c|c|c|c|c|c|c|}
\hline Zone & Standard & $\begin{array}{c}\text { Heating } \\
\text { [MMBtu] }\end{array}$ & $\begin{array}{c}\text { Cooling } \\
\text { [MMBtu] }\end{array}$ & $\begin{array}{c}\text { Interior } \\
\text { Lights } \\
\text { [MMBtu] }\end{array}$ & $\begin{array}{c}\text { Exterior } \\
\text { Lights } \\
\text { [MMBtu] }\end{array}$ & $\begin{array}{c}\text { Interior } \\
\text { Equipment } \\
\text { [MMBtu] }\end{array}$ & $\begin{array}{c}\text { Exterior } \\
\text { Equipment } \\
\text { [MMBtu] }\end{array}$ & $\begin{array}{c}\text { Fans } \\
\text { [MMBtu] }\end{array}$ & $\begin{array}{c}\begin{array}{c}\text { Pumps } \\
\text { [MMBtu] }\end{array} \\
\end{array}$ & $\begin{array}{c}\text { Heat } \\
\text { Rejection } \\
{[\text { MMBtu] }}\end{array}$ & $\begin{array}{c}\text { Humidifi- } \\
\text { cation } \\
\text { [MMBtu] }\end{array}$ & $\begin{array}{c}\text { Heat } \\
\text { Recovery } \\
\text { [MMBtu] }\end{array}$ & $\begin{array}{c}\text { Water } \\
\text { Heater } \\
\text { [MMBtu] }\end{array}$ & $\begin{array}{c}\text { Refrigera- } \\
\text { tion } \\
\text { [MMBtu }]\end{array}$ & $\begin{array}{c}\text { Total } \\
\text { Energy } \\
\text { [MMBtu] }\end{array}$ & $\begin{array}{c}\text { EUI } \\
{[\mathrm{kBtu} / \mathrm{sf}]}\end{array}$ & $\begin{array}{c}\text { Energy } \\
\text { Savings [\%] }\end{array}$ & $\begin{array}{c}\text { Energy Savings } \\
\text { w/o } \\
\text { PlugLoad [\%] } \\
\end{array}$ \\
\hline \multirow{2}{*}{$\begin{array}{c}1 \mathrm{~A} \\
\text { Miami }\end{array}$} & $90.1-2004$ & 2 & 401 & 95 & 69 & 491 & 0 & 200 & 0 & 0 & 0 & 0 & 175 & 0 & 1,433 & 42.5 & \multirow{2}{*}{$10 \%$} & \multirow{2}{*}{$15 \%$} \\
\hline & $90.1-2010$ & 1 & 314 & 99 & 38 & 485 & 0 & 182 & 0 & 0 & 0 & 0 & 175 & 0 & 1,294 & 38.4 & & \\
\hline \multirow{2}{*}{$\begin{array}{c}1 \mathrm{~B} \\
\text { Riyadh }\end{array}$} & $90.1-2004$ & 6 & 430 & 95 & 69 & 491 & 0 & 290 & 0 & 0 & 0 & 0 & 161 & 0 & 1,542 & 45.7 & \multirow{2}{*}{$11 \%$} & \multirow{2}{*}{$16 \%$} \\
\hline & $90.1-2010$ & 4 & 332 & 99 & 38 & 485 & 0 & 253 & 0 & 0 & 0 & 0 & 161 & 0 & 1,373 & 40.7 & & \\
\hline \multirow{2}{*}{$\begin{array}{c}2 \mathrm{~A} \\
\text { Houston }\end{array}$} & $90.1-2004$ & 117 & 286 & 95 & 69 & 491 & 0 & 212 & 0 & 0 & 0 & 0 & 207 & 0 & 1,477 & 43.8 & \multirow{2}{*}{$14 \%$} & \multirow{2}{*}{$20 \%$} \\
\hline & $90.1-2010$ & 62 & 216 & 99 & 38 & 485 & 0 & 170 & 0 & 0 & 0 & 0 & 207 & 0 & 1,277 & 37.8 & & \\
\hline \multirow{2}{*}{$\begin{array}{c}\text { 2B } \\
\text { Phoenix }\end{array}$} & $90.1-2004$ & 44 & 346 & 95 & 69 & 491 & 0 & 264 & 0 & 0 & 0 & 0 & 188 & 0 & 1,497 & 44.4 & \multirow{2}{*}{$14 \%$} & \multirow{2}{*}{$21 \%$} \\
\hline & $90.1-2010$ & 20 & 248 & 99 & 38 & 485 & 0 & 207 & 0 & 0 & 0 & 0 & 188 & 0 & 1,286 & 38.1 & & \\
\hline \multirow{2}{*}{$\begin{array}{c}3 \mathrm{~A} \\
\text { Memphis }\end{array}$} & $90.1-2004$ & 192 & 218 & 95 & 69 & 491 & 0 & 194 & 0 & 0 & 0 & 0 & 232 & 0 & 1,491 & 44.2 & \multirow{2}{*}{$12 \%$} & \multirow{2}{*}{$18 \%$} \\
\hline & $90.1-2010$ & 134 & 161 & 99 & 38 & 485 & 0 & 160 & 0 & 0 & 0 & 0 & 232 & 0 & 1,309 & 38.8 & & \\
\hline \multirow{2}{*}{$\begin{array}{c}\text { 3B } \\
\text { El Paso }\end{array}$} & $90.1-2004$ & 72 & 214 & 95 & 69 & 491 & 0 & 218 & 0 & 0 & 0 & 0 & 223 & 0 & 1,383 & 41.0 & \multirow{2}{*}{$11 \%$} & \multirow{2}{*}{$17 \%$} \\
\hline & $90.1-2010$ & 48 & 155 & 99 & 38 & 485 & 0 & 181 & 0 & 0 & 0 & 0 & 223 & 0 & 1,229 & 36.4 & & \\
\hline \multirow{2}{*}{$\begin{array}{c}\text { 3C San } \\
\text { Francisco }\end{array}$} & $90.1-2004$ & 103 & 58 & 95 & 69 & 491 & 0 & 190 & 0 & 0 & 0 & 0 & 259 & 0 & 1,265 & 37.5 & \multirow{2}{*}{$12 \%$} & \multirow{2}{*}{$20 \%$} \\
\hline & $90.1-2010$ & 59 & 37 & 99 & 38 & 485 & 0 & 131 & 0 & 0 & 0 & 0 & 259 & 0 & 1,108 & 32.8 & & \\
\hline \multirow{2}{*}{$\begin{array}{c}4 \mathrm{~A} \\
\text { Baltimore }\end{array}$} & $90.1-2004$ & 397 & 137 & 95 & 69 & 491 & 0 & 181 & 0 & 0 & 0 & 0 & 263 & 0 & 1,632 & 48.4 & $12 \%$ & $17 \%$ \\
\hline & $90.1-2010$ & 270 & 114 & 99 & 38 & 485 & 0 & 167 & 0 & 0 & 0 & 0 & 263 & 0 & 1,435 & 42.5 & $12 \%$ & $11 \%$ \\
\hline & $90.1-2004$ & 191 & 144 & 95 & 69 & 491 & 0 & 211 & 0 & 0 & 0 & 0 & 258 & 0 & 1,458 & 43.2 & $10 \%$ & $15 \%$ \\
\hline Albuquerque & $90.1-2010$ & 119 & 121 & 99 & 38 & 485 & 0 & 194 & 0 & 0 & 0 & 0 & 258 & 0 & 1,314 & 38.9 & $10 \%$ & $15 \%$ \\
\hline $4 \mathrm{C}$ & $90.1-2004$ & 295 & 67 & 95 & 69 & 491 & 0 & 176 & 0 & 0 & 0 & 0 & 276 & 0 & 1,468 & 43.5 & $10^{\circ}$ & $15 \%$ \\
\hline Salem & $90.1-2010$ & 198 & 59 & 99 & 38 & 485 & 0 & 163 & 0 & 0 & 0 & 0 & 276 & 0 & 1,318 & 39.1 & $10 \%$ & $15 \%$ \\
\hline $5 \mathrm{~A}$ & $90.1-2004$ & 634 & 106 & 95 & 69 & 491 & 0 & 180 & 0 & 0 & 0 & 0 & 284 & 0 & 1,859 & 55.1 & $13 \%$ & $18 \%$ \\
\hline Chicago & $90.1-2010$ & 448 & 89 & 99 & 38 & 485 & 0 & 166 & 0 & 0 & 0 & 0 & 284 & 0 & 1,610 & 47.7 & $13 \%$ & $18 \%$ \\
\hline $5 \mathrm{~B}$ & $90.1-2004$ & 387 & 96 & 95 & 69 & 491 & 0 & 202 & 0 & 0 & 0 & 0 & 280 & 0 & 1,619 & 48.0 & $11^{1}$ & $16 \%$ \\
\hline Boise & $90.1-2010$ & 268 & 82 & 99 & 38 & 485 & 0 & 186 & 0 & 0 & 0 & 0 & 280 & 0 & 1,439 & 42.6 & $11 \%$ & $10 \%$ \\
\hline $5 \mathrm{C}$ & $90.1-2004$ & 388 & 43 & 95 & 69 & 491 & 0 & 155 & 0 & 0 & 0 & 0 & 284 & 0 & 1,526 & 45.2 & $11 \%$ & $16 \%$ \\
\hline Vancouver & $90.1-2010$ & 270 & 42 & 99 & 38 & 485 & 0 & 145 & 0 & 0 & 0 & 0 & 284 & 0 & 1,364 & 40.4 & $11 \%$ & $10 \%$ \\
\hline $6 \mathrm{~A}$ & $90.1-2004$ & 762 & 74 & 95 & 69 & 491 & 0 & 172 & 0 & 0 & 0 & 0 & 303 & 0 & 1,966 & 58.3 & $13 \%$ & $17 \%$ \\
\hline Burlington & $90.1-2010$ & 563 & 65 & 99 & 38 & 485 & 0 & 159 & 0 & 0 & 0 & 0 & 303 & 0 & 1,713 & 50.8 & $15 \%$ & 1770 \\
\hline $6 \mathrm{~B}$ & $90.1-2004$ & 560 & 67 & 95 & 69 & 491 & 0 & 198 & 0 & 0 & 0 & 0 & 306 & 0 & 1,785 & 52.9 & $11 \%$ & $16 \%$ \\
\hline Helena & $90.1-2010$ & 412 & 59 & 99 & 38 & 485 & 0 & 184 & 0 & 0 & 0 & 0 & 306 & 0 & 1,583 & 46.9 & $11 \%$ & $10 \%$ \\
\hline 7 & $90.1-2004$ & 1,044 & 51 & 95 & 69 & 491 & 0 & 191 & 0 & 0 & 0 & 0 & 333 & 0 & 2,273 & 67.4 & $18 \%$ & $22 \%$ \\
\hline Duluth & $90.1-2010$ & 720 & 42 & 99 & 38 & 485 & 0 & 155 & 0 & 0 & 0 & 0 & 333 & 0 & 1,873 & 55.5 & $10 \%$ & 2270 \\
\hline 8 & $90.1-2004$ & 1,276 & 38 & 95 & 69 & 491 & 0 & 187 & 0 & 0 & 0 & 0 & 370 & 0 & 2,525 & 74.8 & $11 \%$ & $13 \%$ \\
\hline Fairbanks & $90.1-2010$ & 1,069 & 32 & 99 & 38 & 485 & 0 & 159 & 0 & 0 & 0 & 0 & 370 & 0 & 2,251 & 66.7 & 1170 & $15 \%$ \\
\hline
\end{tabular}




\section{F.16 High-Rise Apartment Energy Saving Results}

\begin{tabular}{|c|c|c|c|c|c|c|c|c|c|c|c|c|c|c|c|c|c|c|}
\hline Zone & Standard & $\begin{array}{c}\text { Heating } \\
\text { [MMBtu] }\end{array}$ & $\begin{array}{c}\text { Cooling } \\
\text { [MMBtu] }\end{array}$ & $\begin{array}{c}\text { Interior } \\
\text { Lights } \\
\text { [MMBtu] }\end{array}$ & $\begin{array}{c}\text { Exterior } \\
\text { Lights } \\
\text { [MMBtu] }\end{array}$ & $\begin{array}{c}\text { Interior } \\
\text { Equipment } \\
\text { [MMBtu] }\end{array}$ & $\begin{array}{c}\text { Exterior } \\
\text { Equipment } \\
\text { [MMBtu] }\end{array}$ & $\begin{array}{c}\text { Fans } \\
\text { [MMBtu] }\end{array}$ & $\begin{array}{c}\begin{array}{c}\text { Pumps } \\
\text { [MMBtu] }\end{array} \\
\end{array}$ & $\begin{array}{c}\text { Heat } \\
\text { Rejection } \\
\text { [MMBtu] }\end{array}$ & $\begin{array}{c}\text { Humidifi- } \\
\text { cation } \\
\text { [MMBtu] }\end{array}$ & $\begin{array}{c}\text { Heat } \\
\text { Recovery } \\
{[\text { MMBtu] }}\end{array}$ & $\begin{array}{c}\text { Water } \\
\text { Heater } \\
\text { [MMBtu] }\end{array}$ & $\begin{array}{c}\text { Refrigera- } \\
\text { tion } \\
\text { [MMBtu] }\end{array}$ & $\begin{array}{c}\text { Total } \\
\text { Energy } \\
{[\mathrm{MMBtu}]}\end{array}$ & $\begin{array}{c}\text { EUI } \\
{[\mathrm{kBtu} / \mathrm{sf}]}\end{array}$ & $\begin{array}{c}\text { Energy } \\
\text { Savings [\%] }\end{array}$ & $\begin{array}{c}\text { Energy Savings } \\
\text { w/o } \\
\text { PlugLoad [\%] }\end{array}$ \\
\hline \multirow{2}{*}{$\begin{array}{c}1 \mathrm{~A} \\
\text { Miami }\end{array}$} & $90.1-2004$ & 1 & 1,455 & 222 & 193 & 1,113 & 0 & 479 & 69 & 62 & 0 & 0 & 463 & 0 & 4,057 & 48.1 & \multirow{2}{*}{$4 \%$} & \multirow{2}{*}{$5 \%$} \\
\hline & $90.1-2010$ & 0 & 1,400 & 228 & 148 & 1,093 & 0 & 450 & 54 & 60 & 0 & 0 & 463 & 0 & 3,896 & 46.2 & & \\
\hline \multirow{2}{*}{$\begin{array}{c}1 \mathrm{~B} \\
\text { Riyadh }\end{array}$} & $90.1-2004$ & 1 & 1,477 & 222 & 190 & 1,113 & 0 & 742 & 71 & 42 & 0 & 0 & 428 & 0 & 4,288 & 50.8 & \multirow{2}{*}{$6 \%$} & \multirow{2}{*}{$8 \%$} \\
\hline & $90.1-2010$ & 1 & 1,398 & 228 & 145 & 1,093 & 0 & 648 & 53 & 40 & 0 & 0 & 428 & 0 & 4,034 & 47.8 & & \\
\hline \multirow{2}{*}{$\begin{array}{c}2 \mathrm{~A} \\
\text { Houston }\end{array}$} & $90.1-2004$ & 264 & 1,009 & 222 & 192 & 1,113 & 0 & 508 & 69 & 43 & 0 & 0 & 546 & 0 & 3,965 & 47.0 & \multirow{2}{*}{$10 \%$} & \multirow{2}{*}{$14 \%$} \\
\hline & $90.1-2010$ & 110 & 948 & 228 & 146 & 1,093 & 0 & 415 & 49 & 40 & 0 & 0 & 545 & 0 & 3,574 & 42.4 & & \\
\hline \multirow{2}{*}{$\begin{array}{c}2 \mathrm{~B} \\
\text { Phoenix }\end{array}$} & $90.1-2004$ & 60 & 1,143 & 222 & 190 & 1,113 & 0 & 633 & 73 & 37 & 0 & 0 & 498 & 0 & 3,970 & 47.1 & \multirow{2}{*}{$10 \%$} & \multirow{2}{*}{$13 \%$} \\
\hline & $90.1-2010$ & 14 & 1,022 & 228 & 145 & 1,093 & 0 & 504 & 49 & 33 & 0 & 0 & 498 & 0 & 3,585 & 42.5 & & \\
\hline \multirow{2}{*}{$\begin{array}{c}3 \mathrm{~A} \\
\text { Memphis }\end{array}$} & $90.1-2004$ & 470 & 766 & 222 & 189 & 1,113 & 0 & 463 & 65 & 31 & 0 & 0 & 610 & 0 & 3,929 & 46.6 & \multirow{2}{*}{$10 \%$} & \multirow{2}{*}{$14 \%$} \\
\hline & $90.1-2010$ & 279 & 703 & 228 & 144 & 1,093 & 0 & 392 & 47 & 28 & 0 & 0 & 609 & 0 & 3,524 & 41.8 & & \\
\hline \multirow{2}{*}{$\begin{array}{c}3 \mathrm{~B} \\
\text { El Paso }\end{array}$} & $90.1-2004$ & 111 & 764 & 222 & 191 & 1,113 & 0 & 521 & 53 & 23 & 0 & 0 & 588 & 0 & 3,586 & 42.5 & \multirow{2}{*}{$8 \%$} & \multirow{2}{*}{$12 \%$} \\
\hline & $90.1-2010$ & 51 & 691 & 228 & 145 & 1,093 & 0 & 442 & 37 & 21 & 0 & 0 & 588 & 0 & 3,295 & 39.1 & & \\
\hline \multirow{2}{*}{$\begin{array}{c}\text { 3C San } \\
\text { Francisco }\end{array}$} & $90.1-2004$ & 164 & 171 & 222 & 189 & 1,113 & 0 & 467 & 47 & 6 & 0 & 0 & 679 & 0 & 3,058 & 36.2 & \multirow{2}{*}{$11 \%$} & \multirow{2}{*}{$18 \%$} \\
\hline & $90.1-2010$ & 59 & 145 & 228 & 144 & 1,093 & 0 & 329 & 27 & 5 & 0 & 0 & 678 & 0 & 2,708 & 32.1 & & \\
\hline \multirow{2}{*}{$\begin{array}{c}4 \mathrm{~A} \\
\text { Baltimore }\end{array}$} & $90.1-2004$ & 1,028 & 491 & 222 & 188 & 1,113 & 0 & 432 & 59 & 19 & 0 & 0 & 689 & 0 & 4,240 & 50.3 & $120 \%$ & $16 \%$ \\
\hline & $90.1-2010$ & 616 & 503 & 228 & 143 & 1,093 & 0 & 406 & 46 & 19 & 0 & 0 & 688 & 0 & 3,742 & 44.4 & $12 \%$ & $10 \%$ \\
\hline & $90.1-2004$ & 411 & 509 & 222 & 189 & 1,113 & 0 & 504 & 47 & 15 & 0 & 0 & 676 & 0 & 3,687 & 43.7 & $8 \%$ & $11 \%$ \\
\hline Albuquerque & $90.1-2010$ & 199 & 539 & 228 & 144 & 1,093 & 0 & 474 & 37 & 16 & 0 & 0 & 675 & 0 & 3,404 & 40.4 & $8 \%$ & $11 \%$ \\
\hline $4 \mathrm{C}$ & $90.1-2004$ & 689 & 243 & 222 & 185 & 1,113 & 0 & 424 & 49 & 8 & 0 & 0 & 722 & 0 & 3,655 & 43.3 & $10 \%$ & $14 \%$ \\
\hline Salem & $90.1-2010$ & 399 & 269 & 228 & 141 & 1,093 & 0 & 400 & 38 & 9 & 0 & 0 & 721 & 0 & 3,297 & 39.1 & 1070 & $14 \%$ \\
\hline $5 \mathrm{~A}$ & $90.1-2004$ & 1,680 & 387 & 222 & 185 & 1,113 & 0 & 445 & 60 & 14 & 0 & 0 & 743 & 0 & 4,851 & 57.5 & $14 \%$ & $19 \%$ \\
\hline Chicago & $90.1-2010$ & 1,078 & 402 & 228 & 141 & 1,093 & 0 & 408 & 46 & 15 & 0 & 0 & 743 & 0 & 4,153 & 49.2 & $14 \%$ & $19 \%$ \\
\hline $5 \mathrm{~B}$ & $90.1-2004$ & 934 & 340 & 222 & 185 & 1,113 & 0 & 484 & 49 & 10 & 0 & 0 & 733 & 0 & 4,070 & 48.3 & $11 \%$ & $15 \%$ \\
\hline Boise & $90.1-2010$ & 566 & 365 & 228 & 141 & 1,093 & 0 & 455 & 38 & 11 & 0 & 0 & 733 & 0 & 3,629 & 43.0 & $11 \%$ & $15 \%$ \\
\hline $5 \mathrm{C}$ & $90.1-2004$ & 919 & 158 & 222 & 182 & 1,113 & 0 & 383 & 43 & 5 & 0 & 0 & 744 & 0 & 3,769 & 44.7 & $11 \%$ & $15 \%$ \\
\hline Vancouver & $90.1-2010$ & 565 & 195 & 228 & 139 & 1,093 & 0 & 363 & 34 & 6 & 0 & 0 & 744 & 0 & 3,367 & 39.9 & $11 \%$ & $15 \%$ \\
\hline $6 \mathrm{~A}$ & $90.1-2004$ & 1,962 & 270 & 222 & 184 & 1,113 & 0 & 419 & 53 & 10 & 0 & 0 & 792 & 0 & 5,026 & 59.6 & $14 \%$ & $18 \%$ \\
\hline Burlington & $90.1-2010$ & 1,330 & 295 & 228 & 140 & 1,093 & 0 & 393 & 42 & 11 & 0 & 0 & 791 & 0 & 4,323 & 51.2 & $14 \%$ & $18 \%$ \\
\hline $6 \mathrm{~B}$ & $90.1-2004$ & 1,325 & 240 & 222 & 183 & 1,113 & 0 & 481 & 45 & 7 & 0 & 0 & 799 & 0 & 4,417 & 52.4 & $11 \%$ & $15 \%$ \\
\hline Helena & $90.1-2010$ & 888 & 268 & 228 & 140 & 1,093 & 0 & 454 & 35 & 8 & 0 & 0 & 798 & 0 & 3,912 & 46.4 & $11 \%$ & $15 \%$ \\
\hline 7 & $90.1-2004$ & 2,756 & 192 & 222 & 183 & 1,113 & 0 & 503 & 59 & 7 & 0 & 0 & 869 & 0 & 5,904 & 70.0 & $20 \%$ & $25 \%$ \\
\hline Duluth & $90.1-2010$ & 1,741 & 196 & 228 & 140 & 1,093 & 0 & 386 & 38 & 7 & 0 & 0 & 868 & 0 & 4,697 & 55.7 & 2010 & $25 \%$ \\
\hline 8 & $90.1-2004$ & 3,000 & 142 & 222 & 159 & 1,113 & 0 & 477 & 48 & 4 & 0 & 0 & 963 & 0 & 6,128 & 72.6 & $13 \%$ & $16 \%$ \\
\hline Fairbanks & $90.1-2010$ & 2,315 & 148 & 228 & 121 & 1,093 & 0 & 405 & 33 & 4 & 0 & 0 & 962 & 0 & 5,310 & 62.9 & & \\
\hline
\end{tabular}





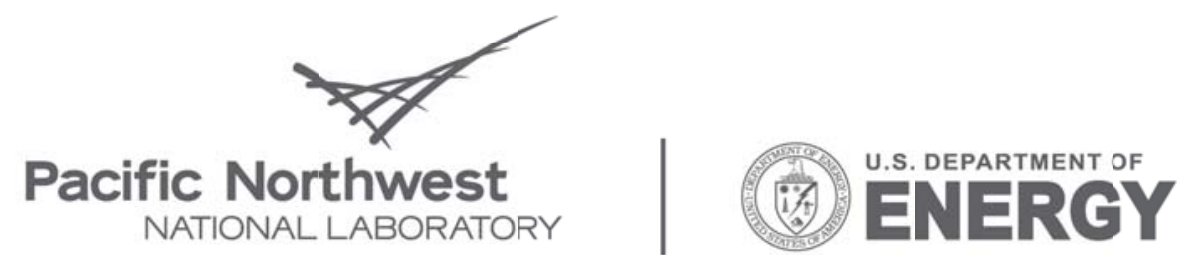

Proudly Operated by Battelle Since 1965

902 Battelle Boulevard

P.O. Box 999

Richland, WA 99352

1-888-375-PNNL (7665)

www.pnl.gov 